


\section{PRINCIPLES OF SOIL MICROBIOLOGY}





\title{
PRINCIPLES OF SOIL MICROBIOLOGY
}

\author{
BY \\ SELMAN A. WAKSMAN \\ Associate Professor of Soil Microbiology, \\ Rutgers University, and Microbiologist of the \\ New Jersey Agricultural Experiment Stations
}
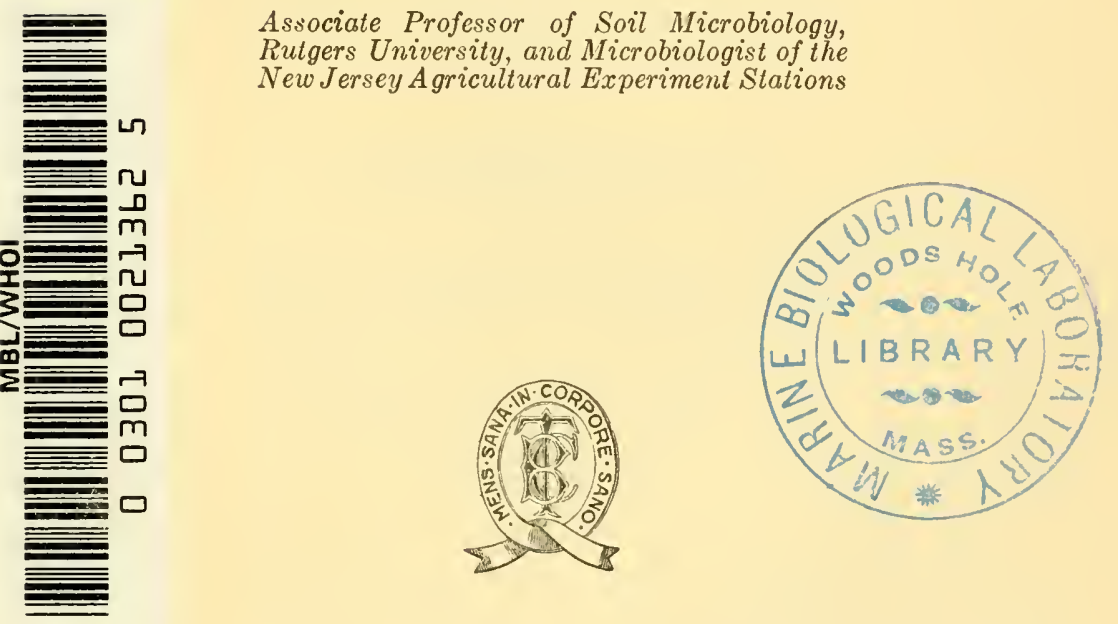

LONDON

BAILLIERE, TINDALL AND COX

8 HENRIETTA STREET, COVENT GARDEN, W. C. 2 
ALL RIGHTS RESERVED, 1927

PRINTED IN AMERICA

COMPOSED AND PRINTED AT THE

IVAVERLY PRESS

BALTIMORE, MD., C. s. A. 
In the years of their seventy-fifth and seventieth anniversaries respectively, this book is dedicated. to Professors

\section{W. BEIJERINCK}

\section{and}

\section{S. WINOGRADSKY}

the investigators who have thrown the first light upon some of the most important soil processes and whose contributions can well be considered first and foremost in the science of Soil

Microbiology

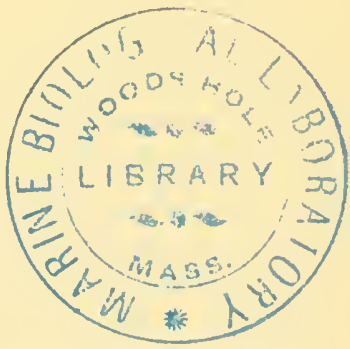





\section{PREFACE}

Although the biochemical processes in the soil as well as the nature of the microorganisms present there have received considerable attention from various points of view and although an extensive literature has accumulated, not only dealing with soil processes in general but even with certain specific activities of the organisms, our present knowledge of the soil microflora and microfauna and of the numerous transformations that they bring about has not advanced beyond a mere beginning of a systematic study. The isolation of numerous microorganisms from the soil, their identification and cultivation upon artificial media is very important but such data do not tell what rôle they play in the soil. A knowledge of the activities of certain organisms isolated from the soil is certainly necessary, but that is not a knowledge of the extent to which these processes take place in the soil itself. A book on soil microbiology should include a study of the occurrence of microorganisms in the soil, their activities and their rôle in soil processes. It is this last phase which has been studied least and where the information available is far from satisfactory in explaining what is taking place in the soil. This is due largely to the limitations of the subject which depends for its advance on botany, zoology, bacteriology, chemistry, including biological and physical, and especially upon the advance of our understanding of the physical and chemical conditions of the soil.

There are various kinds of audiences to which a book on soil microbiology may appeal. There is the scientific farmer who may search for a better understanding of the processes taking place in the soil, those processes which control the growth of his crops and indirectly influence the growth of his animals. There is the agronomist, who is interested in the fundamental reactions controlling soil fertility, by reason of the need of directing such processes towards a greater utilization of the nutrients added to the soil or stored away in the soil organic matter. There is the investigator, the soil chemist or the soil microbiologist, who, in attacking problems dealing with the occurrence of microorganisms in the soil, their activities, and especially with the relation of these activities to the physical and chemical soil conditions, seeks for specific or general information. These investigators may deal with organisms 
or processes which could be better understood when correlated with the other soil organisms and the numerous other processes. An attempt has been made to compile a book which will be of service not only to the investigators in soil science, but also to workers in allied sciences, especially botany, plant physiology, plant pathology and bacteriology, as well as to the general student in agriculture.

This book is a collection of known facts concerning microorganisms found in the soil and their activities; it is a study of the literature dealing with the science in question; it is an interpretation of the facts already presented; it indicates the various lines of investigation and notes where further information is especially wanted. Soil microbiology is a science which is at the very base of our understanding of agricultural processes and the practice of agriculture; it comprises a number of sciences. The book may, therefore, be looked upon more as an introduction to further research rather than as an ordinary text-book; as of help to those working in the allied sciences, who are desirous of obtaining some information concerning the soil population and its activities.

If this volume will help to disclose to the reader some of the numerous interrelated processes in the soil, if it will present in a clearer light to the chemist, the physiologist, the botanist, the bacteriologist and the zoologist the nature of the many scientific and practical problems awaiting the investigator, if it contributes in a small measure toward making soil science an exact science, the author will feel that he has been amply rewarded.

The author is greatly indebted to his various colleagues for reading and criticizing the different chapters of the book and for the many helpful suggestions generously offered, especially to Dr. H. J. Conn, of the New York Agricultural Experiment Station, for reading Chapters I and VI; to Dr. B. M. Bristol Roach, of the Rothamsted Experimental Station, and Dr. G. T. Moore, of the Missouri Botanical Garden, for reading the Chapter on Algae; to Dr. Ch. Thom of the Bureau of Chemistry, for reading the Chapter on Fungi; to Dr. M. C. Rayner, of Bedford College, London, for reading the section dealing with Mycorrhiza Fungi; to Dr. A. T. Henrici, of the University of Minnesota, for reading the Chapter on Actinomyces; to Dr. W. M. Gibbs, of the Idaho Agricultural Experiment Station, for reading the Chapter on Nitrifying Bacteria; to Dr. A. L. Whiting, of the University of Wisconsin and to Dr. L. T. Leonard of the Bureau of Plant Industry, for reading the Chapter on Nodule Bacteria; to Dr. R. Burri, of Liebefeld, Switzerland, and to Dr. I. C. Hall, of the Colorado Medical School, 
for reading the Chapter on Anaerobic Bacteria; to Mr. D. W. Cutler, Mr. H. Sandon, of the Rothamsted Experimental Station, and Prof. C. A. Kofoid, of the University of California, for reading the Chapter on Protozoa; to Dr. N. Cobb and Dr. Steiner, of the Bureau of Plant Industry, for reading the Chapter on Soil Invertebrates; to Dr. O. Meyerhof, of the K. Wilhelm Institute, Berlin, for reading the Chapter on Energy Transformation; to Dr. T. B. Osborne, of the Connecticut Agricultural Experiment Station, for reading the Chapter on Protein Transformation; to Mr. A. Bonazzi, of Cuba, for reading the Chapter on Non-symbiotic Nitrogen Fixation; to Dr. R. L. Jones, of the University of Wisconsin, for reading Chapter XXX; to Dr. E. B. Fred, of the University of Wisconsin, for reading the Chapter on Nitrate-reducing Bacteria; to Prof. D. R. Hoagland and Dr. W. P. Kelley, of the University of California for reading Chapters 24 and 25 respectively; to the members of the Soil Microbiology Division of the New Jersey Agricultural Experiment Station, especially to Dr. J. G. Lipman and Dr. R. L. Starkey, for reading various parts of the book, and to all those who have generously allowed the use and reproduction of the various illustrations in the text.

Selman A. Waksman.

August 25, 1926.

New Brunswick, N.J., U.S.A. 



\title{
A CLASSIFIED LIST OF BOOKS FOR REFERENCE IN SOIL MICROBIOLOGY
}

\author{
CLASSIFICATION OF ORGANISMS
}

Bacteria

Bergey, D. H. A manual of determinative bacteriology. Williams \& Wilkins Co., Baltimore. 1923.

Buchanan, R. E. General systematic bacteriology. History, nomenclature, groups of bacteria. (Monogr. on systematic bacteriology, vol. 1.) Williams \& Wilkins Co., Baltimore. 1925.

Chester, F. D. A manual of determinative bacteriology. Macmillan Co., New York and London. 1901.

FlüGGe, C. Die Mikroorganismen. 2 vols., 3rd Ed. Leipzig. 1896.

Lemmann, K. B., and Neumann, R. O. Atlas und Grundrisz der Bakteriologie. 6th Ed. Teil. I, Atlas. Teil II, Text. J. F. Lehmann. München. - 1920 .

Matzuschita, T. Bakteriologische Diagnostik. Jena. 1902.

Mrgula, W. System der Bakterien. Jena. Bd. I, 1897; Bd. II. 1900.

Winslow, C. E. A., And Winslow, A. R. The systematic relationships of the Coccaceae. J. Wiley \& Sons, New York. 1908.

\section{Fungi}

BREFELd, O. Botanische Untersuchungen über Schimmelpilze. 1872.

Clements, F. E. The genera of fungi. Minneapolis. 1909.

Coupin, H. Fungi (champignons). Album Gén. Cryptogames. 1921.

DeBary, A. Comparative morphology and biology of the fungi, mycetozoa and bacteria. (Tr. Gainey, H. E. F. and Balfour, I. B.) Clarendon Press, Oxford. 1887.

Engler, A., and Prantu, K. A. Die natürlichen Pflanzenfamilien. Teil I, Abt. I. Engelmann, Leipzig. 1900.

Fischer, E. Pilze. Handwört. Naturwiss. V. 7. Jena. 1912.

Gä́mann, E. Vergleichende Morphologie der Pilze. G. Fischer, Jena. 1926.

Lindad, G. Fungi imperfecti. Hyphomycetes. Rabenhorst's Kryptogamen Flora. Vols. 8 and 9. 1907-1910.

Lindau, G. K. Kryptogamenflora fur Anfänger. 2 (1) Die mikroskopischen Pilze (Myxomyceten, Phycomyceten und Ascomyceten). 2nd. Ed. J. Springer, Berlin. 1922.

SaCCARdo, P. A. Sylloge Fungorum. Patavia. 1882-1913.

Wettstein, R. Handbuch der systematischen Botanik. 3d Ed. Vol.1. Wien. 1923.

ZoPF, W. Die Pilze in morphologischer, physiologischer, biologischer und systematischer Beziehung. Breslau. 1890. 


\section{Algae}

Chonat, R. Monographie d'Algues en eulture pure. Bern. 1913.

Coupin, H. Les algues du globe. V. 1. Paris. 1912.

Engler, A., And Prantl, K. A. Die natürlichen Pflanzenfamilien. Teil I, Abt. 1a. Leipzig. 1897.

Heurck, H. J. Traité des Diatomées. Anvers. 1899.

LıNdaU, G. Kryptogamenflora für Anfänger. Bd. IV, 1, 2 and 3. Die Algen. J. Springer, Berlin. 1914-1916.

Oltmanns, Fr. Morphologie und Biologie der Algen. 3 vols. 2nd Ed. G. Fiseher, Jena. 1922.

Pascher, A. Die Süsswasserflora Deutsehlands, Österreichs und der Schweiz. Jena. H. 4 to H. 12. G. Fischer. 1915-1925.

Trluden, J. E. Minnesota algae. Minneapolis. 1910.

DE Toni, G. B. Sylloge algarum omnium hucus que cognitarum. 1889-1907. Padua.

West, G. S. Algae. Cambridge Botanical Handbooks. I. Cambr. Univ. Press. 1916.

\section{Yeasts}

Chapman, A. C., and Baker, F. G. C. An atlas of the saccharomycetes. London. 1906.

Jörgensen, A. Die Mikroorganismen der Gürungsgewerbe. 5th Ed.

Gulluermond, A. 'The yeasts. (Trans. F. W. Tanner.) J. Wiley \& Sons, New York. 1920.

Henneberg, W. Gürungsphysiologisches Praktikum. Berlin. 1909.

KLö̈cker, A. Die Gärungsorganismen in der Theorie und Praxis der Alkoholgärungsgewerbe. Max Waag. 2nd Ed. Stuttgart. 1906.

Kont, F. G. Die Hefepilze. Quelle und Meyer. Leipzig. 1908.

Lindner, A. Saccharomycetineae. In Kryptogamenflora der Mark Brandenburg. Bd. 7, H. 1. Leipzig. 1905.

\section{Protozoa}

Bütschil, O. Protozoa. In Bronn's Thierreich. 1882-1887.

Calkins, G. N. The Jiology of the protozoa. Lea \& Feliger, Philadelphia. 1926.

CAsн, J. The British freshwater Rhizopods and Ileliozoa. Roy. Soc. London. 1905-1921.

Doflein, F. Lehrbuch der Protozoenkunde. 4th Ed. Jena. G. Fischer. 1916.

Lister, A. A monograph of the mycetozoa. 3rd Ed. Rev. G. Lister, Brit. Museum, London. 1925.

MacBride, T. H. North American slime molds. 2nd Ed. Macmillan. 1922.

Minciin, E. A. An introduction to the study of the protozoa. E. Arnold, London. 1912.

Pascher, A., and Lemmermann, E. Die Sütsswasserflora Deutschlands, Österreichs und der Schweiz. H. 1 to H. 3. G. Fischer, Jena. 1913.

Wenyon, C. M. Protozoology. 2 vols. Baillière, Tindall and Cox. London. 1926. 
Schatffer, A. A. Taxonomy of the Amebas with description of thirty-nine new marine and fresh-water species. Vol. 24, Carnegie Inst. Wash., Dept. Marine Biol. 1926.

\section{Nematodes}

Baylis, H. A., AND Daubney, R. A synopsis of the families and genera of Nematoda. Brit. Museum, London. 1926.

De Man, J. G. Nouvelles recherches sur les nématodes libres terricoles. M. Nijhoff, Hague. 1922.

Micoletzky, H. Die freilebenden Erd-Nematoden. Arch. Naturges. 87 (Abt. A). 1922.

Yorke, W., ANd Maplestone, P. A. The nematode parasites of vertebrates. P. Blakiston's Son \& Co., Philadelphia. 1926.

Ward, H., and Whipple, G. C. Fresh Water Biology. J. Wiley \& Sons, New York. 1918.

\section{THEORETICAL AND APPLIED MICROBIOLOGY \\ General Microbiology}

BaumgäRtel, T. Grundriss der theoretischen Bakteriologie. J. Springer, Berlin. 1924.

Benecke, W. Bau und Leben der Bakterien. Teubner, Leipzig. 1912.

Conn, H. W., And Conn, H. J. Bacteriology. Williams \& Wilkins Co., Baltimore. 1923.

Ellis, D. Practical bacteriology. London. 1923.

Fischer, A. Vorlesungen über Bakterien. Jena. 1903.

Hiss, P. H., And Zinsser, H. A text book of bacteriology. 5th Ed. Appleton \& Co., New York. 1922.

Jordan, E. O. A text-book of general bacteriology. 7th Ed. Philadelphia, 1922.

Kiendalu, A. J. Bacteriology, general, pathological and intestinal. $2 \mathrm{~d}$ Ed. Philadelphia. 1921.

Kólle, W., and Wassermann, A. Mandbuch der pathogenen Mikroorganismen. 2d Ed. Jena. 1913.

Kruse, W. Allgemeine Mikrobiologie. Vogel, Leipzig. 1910.

Kruse, W. Einführung in die Bakteriologie. W. de Gruyter, Berlin. 1920.

Meyer, A. Die Zelle der Bakterien. Jena. 1912.

Omeliansky, W. L. Principles of microbiology (Russian). U. S. S. R. Leningrad. 5th Ed. 1924.

Park, W. H., Williams, A. W. And Krumwiede, C. Pathogenic microörganisms. Eighth Ed. Lea \& Febiger, Philadelphia. 1924.

\section{Agricultural Microbiology}

BaUmgärtel, T. Vorlesungen über landwirtschaftliche Mikrobiologie. P. Parey, Berlin. 1925-1926.

Buchanan, R. E. Agricultural and industrial bacteriology. New York. 1922. Chudiakov, H. H. Agricultural Microbiology (Russian). Moskau. 1926. 
Doclaux, E. Traité de Microbiologie. Masson et Cie, Paris. Vols. I-IV. 1898-1901.

Fuhrman,, F. Vorlesungen über technische Mykologie. G. Fischer, Jena. 1913.

Greaves, J. E. Agricultural bacteriology. Lea and Febiger, Philadelphia. 1922.

JANKE, A. Allgemeine technische Mikrobiologie. I. Steinkopff. Dresden and Leipzig. 1924.

Kayser, E. Microbiologie appliquée à la fertilisation du sol. J. B. Baillière, Paris. 1921.

Kiossowicz, A. Einführung in die Agrikulturmykologie. Teil I, Bodenbakteriologie. Borntraeger, Berlin. 1912.

Lafar, F. Handbuch der technischen Mykologie. 5 Vols. G. Fischer, Jena. 1904-1913.

LiPMan, J. G. Bacteria in relation to country life. The Macmillan Co., New York. 1911.

LöHNis, F. Handbuch der landwirtschaftlichen Bakteriologie. Borntraeger, Berlin. 1910.

I.öhnis, F., ANd Fred, E. B. Agricultural bacteriology. McGraw-Hill, New York. 1923.

Russell, Sir John, ANd others. The microorganisms of the soil. Longmans, Green \& Co., London. 1923.

Marshall, C. E. Microbiology. Blakiston, Philadelphia. 3rd Ed. 1922.

Russeli, H. L., and Hastings, E. G. Agricultural bacteriology. 1915.

Rossi, G. DE. Microbiologia agraria e technica. Unione Tip, Torino. 19211926.

Smitif, E. F. Bacteria in relation to plant diseases. Vol. I, 1905; vol. II, 1911; Vol. III, 1914.

Stoklasa, J., and Doereli, E. G. Handbuch der physikalischen und biochemischen Durchforschung des Bodens. P. Parey, Berlin. 1926.

TANner, F. W. Bacteriology and mycology of foods. New York. 1919.

\section{Manuals of Bacteriologic Technic}

Abderhalden, E. Handbuch der biologischen Arbeitsmethoden. Abt. XI. 2nd Ed. 1924-1926.

AвеL, R. Bakteriologisches Taschenbuch. C. Kabitzsch, Leipzig. 26th Ed. 1923.

American Public Health Association standard methods for the examination of water and sewage. 1915.

Barnard, J. E., AND Welch, F. V. Practical photo-micrography. 2nd Ed. Longmans, Green \& Co., New York. 1925.

Besson, A. Technique microbiologique et sérothérapique. 3 vol. 1921-1923.

Burgess, P. S. Soil bacteriology laboratory manual. 1914.

Exich, F. Lehbach der Mikrochemie, Munich. 1926.

Euringhaus, A. Das Mikroskop, seine wissenschaftlichen Grundlagen und seine Anwendung. Teubner, Leipzig.

Ehrlich and Weigert. Encyclopedie der mikroscopischen Technik. Vol. I \& II. 1910. 
Erre, J. W. H. Bacteriological technique. 2nd Ed. 1913.

Fred, E. B. A laboratory manual of soil bacteriology. Blakiston Co., Philadelphia. 1916.

GAGE, S. H. The microscope. 14th Ed. Comstock, Ithaca, N. Y. 1925.

Giltner, W. Laboratory manual in general microbiology. 3rd Ed. J. Wiley and Sons, New York. 1926.

HAGEr, H. Das Mikroskop und seine Anwendung. 13th Ed. by F. 'Tobler. J. Springer, Berlin. 1925.

Heinemann, P. G. A laboratory guide in bacteriology. 3rd Ed. 1915.

Hewlett, R. T. A manual of bacteriology. London. 1921.

Косн, А. Mikrobiologisches Praktikum. J. Springer, Berlin. 1922.

Kraus, R., and Uhlenhuth, P. Handbuch der mikrobiologischen Technik. 3 vols. Urban and Schwarzenberg, Berlin. 1923-1924.

Küster, E. Kultur der Mikroorganismen. 3rd Ed. Teubner, Leipzig. 1921. Langeron, M. Précis de microscopie. 4th Ed. Masson et Cie, Paris. 1925.

Ladbenheiner. Lehrbuch der Mikrophotographie. 1920.

LEe, A. B. The microtomist's Vade-Mecum. 8th Ed. Churchill, London. 1921.

Lipman, J. G., ANd Brown, P. E. Laboratory guide in soil bacteriology. 1911.

Löınıs, F. Landwirtschaftlich-bakteriologisches Praktikum. 2nd Ed. Borntraeger, Berlin. 1920.

MACE, E. Traité pratique de bactériologie. Atlas de Microbiologie. Baillière. Paris. 1913.

Meyer, A. Praktikum der botanischen Bakterienkunde. G. Fischer, Jena. 1903.

Prowazek, S. V. (V. Jollos). Taschenbuch der mikroskopischen Technik der Protistenuntersuchung. 3rd Ed. J. A. Barth, Leipzig. 1922.

Sieben, H. Einführung in die botanische Mikrotechnik. Fischer, Jena. 1913. Schneider, A. Bacteriological methods in food and drug laboratories. Blakiston, Philadelphia. 1915.

\section{SOILS AND PLANTS}

\section{The Physics and Chemistry of Soils and Manures}

Aikman, C. M. Manures and principles of manuring. London. 1910.

Cameron, F. K. The soil solution, the nutrient medium for plant growth. Easton, Pa. 1911.

Clarke, F. W. The data on geochemistry. Bul. 770, U. S. Geol. Survey. 1924.

Errenterg, P. Die Bodenkolloide. 3rd Ed. Steinkopff, Dresden and Leipzig. 1920.

Finerson, F. V. Agricultural geology. J. Wiley \& Sons, New York. 1920.

Fraps, G. S. Principles of agricultural chemistry. The Chemical Publishing Co., Easton, Pa. 1913.

Glinka, K. D. Soils of Russia and adjoining countries (Russian). Gosizdat, Moskau. 1923.

HALL, A. D. The soil, an introduction to the scientific study of the growth of crops. 3rd Ed. London. 1920.

Hinkle, S. F. Fertility and crop production. Sandusky, Ohio. 1925. 
Lyon, T. L., And Buckman, H. C. The nature and properties of soils. Macmillan, New York. 1922.

Heiden, E. Lehrbuch der Düngerlehre. 2 parts. Hannover. 1879-1887.

Hilgard, E. W. Soils, their formation, properties, composition and relations to climate and plant growth. Macmillan, New York. 1912.

Hoering, P. Moornutzung und Torfverwertung mit besonderer Berücksichtigung der Trockendestillation. J. Springer, Berlin. 1915.

Honcamp, F., and Nolte, O. Àgrikulturchemie. T. Steinkopff, Dresden and Leipzig. 1924.

Hopkins, C. G. Soil fertility and permanent agriculture. Ginn \& Co., Boston. 1910 .

Köвer, L. Der Bau der Erde. Borntraeger, Berlin. 1921.

Mayer, A. Die Düngerlehre. 7th Ed. C. Winters, Heidelberg. 1924.

Merrill, G. P. Rocks, rock weathering and soils. Macmillan, New York. 1897.

Mitscherlich, E. A. Bodenkunde für Land- und Forstwirte. 3rd Ed. P. Parey, Berlin. 1920.

Murrax, J. A. The science of soils and manures. 3rd Ed. D. VanNostrand Co. 1925.

Puchner, H. Der Torf. F. Enke, Stuttgart. 1920.

Ramann, E. Bodenkunde. 3rd Ed. J. Springer, Berlin. 1911.

Russell, J. Soil conditions and plant growth. Longmans, Green \& Co. 4th Ed. London. 1921.

VAN Slyke, L. L. Fertilizers and crops. O. Jodd Co., New York. 1912.

Warington, R. Lectures on some of the physical properties of soil. Oxford. 1900.

Wheeler, H. J. Manures and fertilizers. New York. 1913.

Wiley, H. W. Principles and practice of agricultural analysis. Vol. I. Soils. 3rd Ed. Chemical Publ. Co., Easton, Pa. 1926.

\section{The Soil Environment and Higher Plants}

Brenchley, W. E. Inorganic plant poisons and stimulants. Cambridge. 1914. Clements, F. E. Aeration and air content; the rôle of oxygen in root activity. Carnegie Inst. Wash. Publ. No. 315. 1921.

Czaper, F. Biochemie der Pflanzen. 2te Aufl. 3 vols. Jena, vol. 1, 1913; vol. 2, 1920; vol. 3, 1921.

HAHN, J. Handbuch der Klimatologie. 3 vols. Stuttgart. 1908-1911.

Jost, L. Plant physiology. Tr. R. J. H. Gibson. Oxford. 1907-1913.

Kolkwitz, R. Pflanzenphysiologie. G. Fischer, Jena. 1922.

Kostytschew, S. Pflanzenatmung. J. Springer, Berlin. 1925.

Lundegardh, H. Klima und Boden in ihrer Wirkung auf das Pflanzenleben. G. Fischer, Jena. 1925.

Palladin, V. I. Plant physiology. Trans. by B. E. Livingston. 2nd Ed. Blakiston, Philadelphia. 1923.

Pfeffer, W. The physiology of plants, a treatise upon the metabolism and sources of energy in plants. Tr. A. J. Ewart. 3 vols. Oxford. 19001906. 


\section{TREATISES IN GENERAI SCIENCES}

General Biology, Physiology and Physiological Chemistry

Abderhalden, E. Handbuch der biologischen Arbeitsmethoden. 2nd Ed.

Urban \& Schwarzenberg, Berlin. 1920-1926.

Aboerhalden, E. Biochemisches Handlexikon. 11 vols. Berlin. 1911-1924. Bayliss, W. M. Principles of general physiology. 4th Ed. London. 1924.

BAYliss, W. M. The nature of enzyme action. London. 1925.

Cohnheim, O. Enzymes. 1912.

Erfront, J. Enzymes and their applications. Trans. S. C. Prescott, New York. 1902. Biochemical catalysts in life and industry. New York. 1917.

Euler, H. Chemie der Enzyme. 2nd Ed. Bergmann, Munchen. 2 vols. 1922-1924.

Euler, H. Grundlagen und Ergehnisse der Pflanzenchemie, nach der sehwedischen Ausgabe bearbeitet. I Teil, Das chemische Material der Pflanzen. Braunschweig. 1908. II Teil, Die allgemeinen Gesetze des Pflanzenlebens. III Teil, Die chemischen Vorgänge im Pflanzenkörper. Braunschweig. 1909.

Fowler, G. J. Bacteriological and enzyme chemistry. Longmans, Green \& Co., New York. 1911.

HaAs, P., AND Hill, T. G. An introduction to the chemistry of plant products. 3rd Ed. London. 1921.

Hartmann, M. Allgemeine Biologie. Jena. 1925.

Henry, T. A. The plant alkaloids. Philadelphia. 1913.

Höвеr, R. Physikalische Chemie der Zelle und der Gewebe. 5th Ed. Leipzig and Berlin. 1924.

Loes, J. The dynamies of living matter. New York. 1906.

Lовв, J. The mechanistic conception of life: biological essays. Chicago. 1912.

Loes, J. The organism as a whole, from the physicochemical viewpoint. New York and London. 1916.

Loeb, J. Proteins and the theory of colloidal behavior. 2nd Ed. McGraw-Hill, New York. 1924.

Mathews, A. P. Physiological chemistry. 3rd Ed. New York. 1920.

Oppenheimer, C. Handbuch der Biochemie der Menschen und der Tiere. 2nd Ed., 5 vols. G. Fischer, Jena. 1924-1926.

Oppenheimer, C. Die Fermente und ihre Wirkungen. 5th Ed., 2 vols. G. Thieme, Leipzig. 1925-1926.

Robertson, T. B. Principles of biochemistry. Lea \& Febiger, Philadelphia. 1920.

Robertson, T. B. Physical chemistry of the proteins. Longmans, Green \& Co., New York and London. 1918.

Schorger, A. W. Chemistry of cellulose and wood. McGraw-Hill, New York. 1926.

Thatcher, R. W. The chemistry of plant life. McGraw-Hill, New York. 1924.

Verworn, M. Allgemeine Physiologie, ein Grundriss der Lehre vom Leben. 6th Ed. Jena. 1915. 
Wiesner, J. V. Die Rohstoffe des Pflanzenreiches. 3rd Ed., 3 vols., Engelmann, Leipzig. 1921.

Wohlgemuth, J. Grundrisz der Fermentmethoden. Berlin. 1913.

\section{Physics and Chemistry, as applied to Biology}

Bechнold, H. Colloids in Biology and Medicine. New York. 1919. (Tr. J. G. M. Bullowa.)

Clark, W.M. The determination of hydrogenions. 2nd Ed., Williams \& Wilkins Co., Baltimore. 1922.

Conen, E. Physical chemistry for physicians and biologists. (Tr. M. Fischer.) New York. 1903.

Erchwald, E., ANd Foder, A. Die physikalisch-chemischen Grundlagen der Biologie. Berlin. 1919.

Findlay, A. Osmotic pressure. 2nd Ed. London. 1919.

Fredndich, H. Kapillarchemie, eine Darstellung der Chemie der Kolloide und verwandter Gebiete. Leipzig. 1923.

Hatscher, E. An introduction to the physics and chemistry of colloids. 4th Ed., London and Philadelphia. 1922.

Hedis, S. G. Grundzüge der physikalischen Chemie in ihrer Beziehung zur Biologie. J. F. Bergmann, München. 1924.

Jellinek, K. Lehrbuch der physikalischen Chemie. 2 vols. Stuttgart. 1914 1915.

Kolthoff, I. M., and Furman, N. H. Indicators. J. Wiley \& Sons, New York. 1926.

Lewis, G. N., AND RANDAlL, M. Thermodynamics and the free energy of chemical substances. McGraw-Hill, New York. 1923.

Lewis, W. C. McC. A system of physical chemistry. 3 vols., $3 d$ and 4 th Ed. Longmans, Green \& Co., London and New York. 1920-1925.

Lotka, A. J. Elements of physical biology. Williams \& Wilkins Co., Baltimore, Md. 1926.

MicClendon, J. F., and Medes, G. Physical chemistry in medicine. W. B. Saunders Co., Philadelphia. 425 p. 1925.

Nernst, W. Theoretische Chemie vom Standpunkte der Avogadroschen Regel und der Thermodynamik. 10th Ed., Enge. Stuttgart. 1921.

Philip, J. C. Physical chemistry: its bearing on biology and medicine. Longmans, Green \& Co., New York and London. 3d Ed. 1925.

TAYLOR, W. W. The chemistry of colloids and some technical applications. 3d Ed. London. 1921.

Waksman, S. A., And Davison, W. C. Enzymes. Williams \& Wilkins Co., Baltimore. 1926.

Wasinburn, E. W. An introduction to the principles of physical chemistry from the standpoint of modern atomistics and thermodynamics. 2d Ed. New York. 1921.

Willows, R. S., AND HATChEK, E. Surface tension and surface energy and their influence on chemical phenomena. 3d Ed. London. 1923.

Zsigmondy, R., Spear, E. B., and Norton, J. F. The chemistry of colloids. New York. 1917. 


\section{Mathematics}

Davenport, C. B. Statistical methods, with special reference to biological variation. 3d Ed. New York. 1914.

Fischer, R. A. Statistical methods for research workers. Oliver and Boyd, Edinburgh. 1925.

Mellor, W. J. Higher mathematics for students of chemistry and physics, with special reference to practical work. 4th Ed. London. 1913.

Nernst, W., And Schoenflies, A. Einführung in die mathematische Behandlung der Naturwissenschaften. Berlin. 1919. 



\section{CONTENTS}

\section{PART A. OCCURRENCE AND DIFFERENTIATION OF MICRO- ORGANISMS IN THE SOIL}

\section{Chapter I}

NUMBERS OF DIFFERENT GROUPS OF MICROORGANISMS FOUND IN THE SOIL AND METHOD OF DETERMINATION

The occurrence of microorganisms in the soil. Proof of microbial activities in the soil. Methods of study. Direct microscopic method. Organisms found in the soil by the direct microscopic method. Cultural methods for demonstrating the kinds of organisms active in the soil. Cultural methods for the determination of numbers of microorganisms in the soil. Culture media. Sampling of soil. Treatment of soil samples and preparation of plates. Incubation of plates and counting of organisms. Mathematical interpretation of results. Comparison of plate and microscopic methods. Numbers of bacteria in the soil. Bacterial numbers in manure. Numbers of bacteria in the soil during different seasons of the year. Distribution of bacteria at various depths. Numbers of specific physiological groups of bacteria. Numbers of actinomyces in the soil. Numbers of fungi in the soil. Methods of counting protozoa. Numbers of protozoa in the soil....

\section{PART B. ISOLATION, IDENTIFICATION, AND CULTIVATION OF SOII, MICROORGANISMS}

\section{Chapter II}

PURE CULTURE STUDY AND CLASSIFICATION OF SOIL BACTERIA

Pure culture study. Differentiating characters of bacteria. Life cycles of bacteria. Classification of soil bacteria based upon their physiological

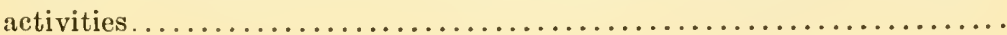

\section{Chapter III}

\section{AUTOTROPHIC BACTERIA}

The nature of autotrophic bacteria. Bacteria deriving their energy from nitrogen compounds. Solid media for the isolation and cultivation of the nitrite forming organisms. Morphology of the nitrite forming organisms. Nitrate forming organisms (Nitrobacter). Occurrence of nitrifying bacteria in the soil. Bacteria deriving their energy from the oxidation of sulfur and its compounds. Classification of sulfur bacteria. Oxidation of selenium and its compounds. Bacteria oxidizing iron compounds. Bac- 
teria obtaining their energy from the oxidation of simple carbon compounds. Methane bacteria. Bacteria oxidizing carbon monoxide. Bac-

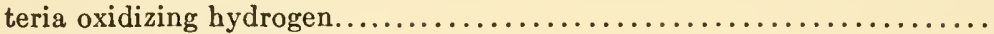

\section{Chapter IV}

\section{BACTERIA FIXING ATMOSPHERIC NITROGEN}

Nitrogen fixation in nature. Classification of nitrogen-fixing bacteria. Isolation of anaerobic bacteria. Morphology of the anaerobic bacteria. Distribution of anaerobic nitrogen-fixing bacteria in the soil. Physiology of anaerobic nitrogen-fixing bacteria. Non-symbiotic nitrogen fixing aerobic bacteria. Description of species of Azotobacter. Morphology and life cycle of Azotobacter. Physiology of Azotobacter. Other nonsymbiotic nitrogen-fixing bacteria. Symbiotic nitrogen fixation by nodule bacteria. Historical. Nomenclature. Media. Nodule formation. Isolation of organism from nodules. Isolation from soil. Colony appearance. Morphology and life cycle of organism. Motility. Physiology of nodule bacteria. Specific differentiation. Nodule formation by non-leguminous plants. Nodule formation in the leaves of some plants............. 103

\section{Chapter V}

HETEROTROPHIC, AEROBIC BACTERIA REQUIRING COMBINED NITROGEN

General classification. Spore-forming bacteria. Classification of sporeforming bacteria. Occurrence of spore-forming bacteria in the soil. Nonspore-forming bacteria. Classification. Occurrence of non-spore-forming bacteria in the soil. Thermophilic bacteria. Mycobacteria. Myxobacteria 141

\section{Chapter VI}

\section{ANAEROBIC BACTERIA}

Oxygen tension in the growth of bacteria. Methods of isolation of anaerobic bacteria from the soil. Cultivation of anaerobes. Classification of soil anaerobes. Physiological activities of anaerobic bacteria. Soil processes in which anaerobic bacteria take an active part................. 160

\section{Chapter VII}

\section{BACTERIA REDUCING NITRATES AND SULFATES}

General classification of nitrate reducing bacteria. Organisms reducing nitrates to nitrites. Organisms reducing nitrates to ammonia. Bacteria reducing nitrates to atmospheric nitrogen. Description of some typical denitrifying bacteria. Bacteria reducing sulfates to hydrogen sulfide....

\section{Chapter ViII}

BACTERIA CAPABLE OF DECOMPOSING CELLULOSES AND OTHER COMPLEX CARBOHYDRATES AND HYDROCARBONS IN THE SOIL

Microorganisms concerned in the decomposition of celluloses in nature. Anaerobic bacteria. Aerobic bacteria. Decomposition of cellulose by 
denitrifying bacteria. Thermophilic bacteria. Pectin decomposing bacteria. Bacteria decomposing hydrocarbons and benzene ring compounds. . 190

Chapter IX

BACTERIA DECOMPOSING UREA, URIC, AND HIPPURIC ACIDS

Organisms decomposing urea. Methods of isolation. Occurrence of urea bacteria. Classification and description. Bacteria decomposing calcium cyanamide. Uric and hippuric acid bacteria...................206

\section{Chapter X}

SOIL ALGAE

Introductory. Methods of isolation of impure cultures of algae. Isolation of pure cultures. Cultivation of soil algae. Distribution of algae in the soil. Occurrence of algae in the soil. Biochemical activities of algae.

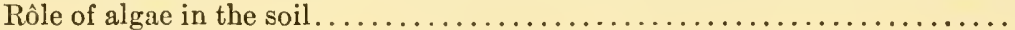

\section{Chapter XI}

SOIL FUNGI

Occurrence of fungi in the soil. Methods of demonstrating the occurrence and abundance of fungi in the soil. Methods of cultivation of soil fungi. Isolation of single spore cultures. Classification of fungi with special reference to those occurring in the soil. Occurrence of specific fungi in the soil. Activities of fungi in the soil. Influence of reaction upon the growth of fungi. Cellulose decomposition by fungi. Decomposition of nitrogenous substances (ammonia formation). Utilization of nitrogen compounds by fungi. Nitrogen fixation. Mrcorrhiza Fungr. Nature of mycorrhiza formation. Plants forming mycorrhiza. Organisms responsible for mycorrhiza formation. Rôle of mycorrhiza in the nutrition of plants....

\section{Chapter XII \\ SOIL ACTINOMYCES}

General considerations. General description of the genus Actinomyces. Terminology and systematic position. Species differentiation. Methods of study. Nature of growth on artificial media. Vegetative mycelium. Spore bearing mycelium. Utilization of carbon compounds by actinomyces as sources of energy. Nitrogen utilization. Oxygen requirement. Influence of temperature, drying and radiation. Influence of reaction and salt concentration. Influence of poisons. Reduction of nitrates and other compounds. Production of odor. Pigment formation. Variability. Species differentiation. Key to the identification of species of soil actinomyces. Importance of actinomyces in the soil............. 285 


\section{Cilapter XIII}

SOIL PROTOZOA

General morphology of protozoa. Physiology of protozoa. Media for the cultivation of protozoa. Isolation of pure cultures of protozoa. Staining of protozoa. Life history of protozoa. Occurrence of trophic and encysted protozoa in the soil. Classification and occurrence of protozoa in the soil. Importance of protozoa in the soil . . . . . . . . . . . . . . . . . . .

\section{Chapter XIV}

THE NON-PROTOZOAN FAUNA IN THE SOIL

Animal ecology as a whole and classification of soil forms. Methods of study. Flatworms. Nematoda. Rotatoria. Annelida. Tartigrada. Arthropoda. Arachnida. Myriapoda. Insecta. Mollusca. Influence of environmental conditions on the invertebrate fauna of the soil. Economic importance of the invertebrate fauna of the soil................ 34

\section{PART C. CHEMICAL ACTIVITIES OF MICROORGANISMS}

\section{Chapter XV}

\section{GENERAL PRINCIPLES OF MICROBIAL METABOLISM}

Metabolism as a whole. Chemical reactions in the microbial cell. Enzymes of microorganisms. Reaction velocity. Growth, life and death of microorganisms. Chemical composition of the microbial cell............. 367

\section{Chapter XVI}

ENERGY TRANSFORMATIONS IN THE METABOLISM OF MICROORGANISMS

Life and energy. Energy transformations by autotrophic bacteria. Energy utilization from the oxidation of nitrogen compounds. Energy utilization from the oxidation of sulfur and its compounds. Energy utilization from the oxidation of iron compounds. Energy utilization from the oxidation of hydrogen. Energy utilization from the oxidation of simple carbon compounds. Heterotrophic utilization of energy by microorganisms. Aerobic utilization of energy. Anaerobic utilization of energy. Efficiency of energy utilization by heterotrophic microorganisms. Reduction of nitrates and sulfates and energy utilization. Comparative amounts of energy liberated by microbiological processes. Energy transformation in synthetic processes. Energy transformation in the soil................

\section{Chapter XVII}

CHEMISTRY OF DECONPOSITION OF NON-NITROGENOUS ORGANIC MATTER BY SOIL MICROORGANISMS

Composition of vegetable organic matter. Chemistry of celluloses. Mechanism of decomposition of cellulose by microorganisms. Decomposition of cellulose by anaerobic bacteria. Decomposition of cellulose by aerobic 
bacteria. Decomposition of cellulose by thermophilic bacteria. Decomposition of cellulose by denitrifying bacteria. Cellulose decomposition by actinomyces. Cellulose decomposition by filamentous fungi. Cellulose lecomposition in manure. Importance of cellulose decomposition in the soil. Influence of soil conditions upon cellulose decomposition. Chemistry of hemicelluloses. Decomposition of hemicelluloses by microorganisms. Lignins, ligno-celluloses and their decomposition. Pectins, mucilages and gums and their decomposition by microorganisms. Starches and their decomposition by microorganisms. Decomposition of fats and waxes. Decomposition of paraffins, aliphatic hydrocarbons and benzene ring compounds in the soil. Decomposition of glucosides and monosac-

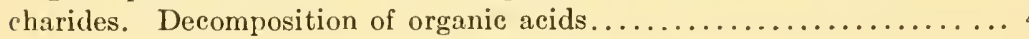

\section{Chapter XVIII}

DECOMPOSITION OF PROTEINS AND OTHER ORGANIC NITROGENOUS COMPOUNDS BY SOIL MICROORGANISMS

Physical and chemical properties of proteins. Chemistry of protein hydrolysis. Protein decomposition by microorganisms. Chemistry of ammonia formation in the decomposition of proteins by microorganisms. Decomposition of organic nitrogenous compounds of a non-protein nature. Ammonia formation by bacteria. Ammonia formation by fungi and actinomy. ces. Rate of ammonia formation by microorganisms and methods of determinination. Nitrogen transformation in the rotting of manure. Nitrogen transformation in the decomposition of organic matter in the soil. Influence of nitrogenous decomposition products on the growth of

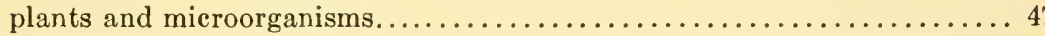

\section{Chapter XIX}

INFLUENCE OF AVAILABLE ENERGY UPON THE TRANSFORMATION OF NITROGENOUB COMPOUNDS BY MICROORGANISMS

Carbon and nitrogen transformation by microorganisms. Influence of nonnitrogenous organic compounds upon the decomposition of nitrogenous compounds and upon the amounts of ammonia liberated. Decomposition of organic substances of varying carbon-nitrogen ratio. Different groups of microorganisms as affecting the carbon nitrogen ratio in the medium. Influence of straw and plant residues upon the grow th of cultivated plants. . 504

\section{Chapter XX}

\section{OXIDATION PROCESSES-NITRATE FORMATION}

Oxidation-reduction phenomena. Oxidation processes in the soil. Source of nitrates in the soil. Mechanism of ammonia oxidation. Mechanism of nitrite oxidation. Nitrate formation from inorganic salts and from organic nitrogenous compounds. Influence of reaction on nitrate formation. Influence of organic matter upon nitrate formation. Influence of salts. Influence of soil gases. Nitrate formation in solution and in soil. Influence of soil treatment upon nitrification in the soil. Oxidation of sulfur and other minerals in the soil. Oxidation of organic compounds in the soil. 520 


\section{Chapter XXI}

\section{REDUCTION PROCESSES-NITRATE REDUCTION}

Reduction processes in the soil. Transformation of nitrates by microorganisms. Nitrate assimilation. Utilization of nitrates by microorganisms as sources of oxygen. Reduction of nitrates to gaseous nitrogen and oxides of nitrogen. Formation of nitrogen gas from organic compounds. Denitrification in the soil. Importance of nitrate-reduction in

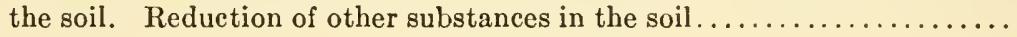

\section{Chapter XXII}

\section{FIXATION OF ATMOSPHERIC NITROGEN BY MICROORGANISMS}

Non-symbiotic fixation of nitrogen. Source of energy. Chemistry of decomposition of carbohydrates. Respiration and nitrogen fixation. Protein synthesis by Azotobacter. Chemistry of process of non-symbiotic nitrogen fixation. Influence of available nitrogen compounds upon nitrogen fixation. Influence of salts upon nitrogen fixation. Influence of organic matter upon nitrogen fixation. Influence of reaction. Influence of moisture and temperature upon nitrogen fixation. Soil cultivation and nitrogen fixation. Importance of non-symbiotic nitrogen-fixation processes in the soil. Symbiotic Nrtrogen Fixation. Relation between the bacteria and the host plant. Chemistry of nitrogen-fixation by symbiotic bacteria. Production of gum by legume bacteria. Influence of reaction on the growth of Bact. radicicola and nodule formation. Nodule formation and nitrogen fixation. Influence of environmental conditions. Importance of symbiotic nitrogen fixation in the soil. Associative action of legumes

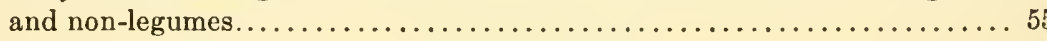

\section{Chapter XXIII}

\section{TRANSFORMATION OF SULFUR BY MICROORGANISMS}

Sources of sulfur in the soil and processes of transformation. The nature of oxidation of sulfur and its compounds in the soil. Reduction of sulfur and its compounds. Formation of $\mathrm{H}_{2} \mathrm{~S}$ in the decomposition of organic matter. Sulfur oxidation and transformation of minerals............... 600

\section{PART D. SOIL MICROBIOLOGICAL PROCESSES AND SOIL FERTILITY}

\section{Chapter XXIV}

THE SOIL AS A MEDIUM FOR THE GROWTH AND ACTIVITIES OF MICROORGANISMS

The soil as a culture medium. Soil composition and microbiological activities. The mineral composition of the soil. The physico-chemical rôle of organic matter in the soil. Colloidal condition of soils and microbiological activities. Soil solution. Soil reaction and microbiological activities. The soil atmosphere. Soil temperature. Growth of microorganisms in soil in pure and mixed culture. The idea of a soil population............6 619 


\section{Chapter XXV}

TRANSFORMATION OF MINERALS IN THE SOIL

Nature of mineral transformation by microorganisms. Decomposition of rocks and rock constituents by microorganisms. Nature of phosphorus compounds in the soil. Decomposition of organic phosphorus compounds by microorganisms. Transformation of insoluble tri-calcium phosphates into soluble forms by microorganisms. Transformation of insoluble phosphates by inorganic and organic acids formed by microorganisms. Transformation of potassium in the soil by microorganisms. Transformation of calcium in the soil. Transformation of magnesium in the soil. Transformation of manganese in the soil. Transformation of zinc. Transformation of iron. Transformation of aluminum in the soil. Rôle of minerals in

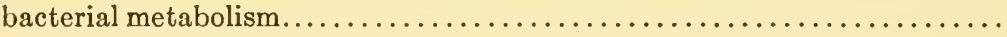

\section{Chapter XXVI}

TRANSFORMATION OF ORGANIC MATTER IN THE SOIL

Nature of soil organic matter. Decomposition of organic matter added to the soil. Transformation of the various constituents of the organic matter added to the soil. Evolution of carbon dioxide as an index of decomposition of organic matter in the soil. Formation of ammonia (and nitrate) as an index of decomposition of organic matter in the soil. Formation of "humus" as an index of decomposition of organic matter in the soil. Nature of soil "humus." Chemistry and classification of humus compounds. Soil organic matter and the activities of microorgan-

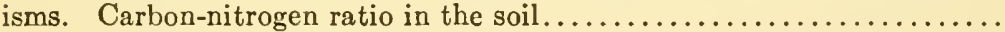

\section{Chapter XXVil}

MICROBIOLOGICAL ANALYSIS OF SOIL AS AN INDEX OF SOIL FERTILITY

Soil fertility and microbiological activities. Methods for determining the microbiological condition of the soil. Numbers of microorganisms in the soil. Nitrifying capacity of the soil. Evolution of carbon dioxide. Cellulose decomposing capacity of the soil. Nitrogen fixing and mannite decomposing capacity of the soil. The catalytic action of the soil. Oxi-

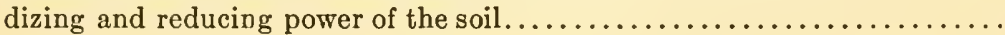

\section{Chapter XXVIII}

SOIL MICROBIOLOGICAL EQUILIBRIUM; INFLUENCE OF AIR DRYING AND PARTIAL STERILIZATION UPON THE ACTIVITIES OF MICROORGANISMS IN THE SOIL

Microbiological equilibrium in the soil. Influence of air drying of soil upon the microbiological equilibrium. Influence of caustic lime upon soil processes. Partial sterilization of soil. The use of heat as an agent of partial sterilization. Influence of volatile antiseptics upon bacterial activities in the soil. Protozoan theory. Agricere and bacteriotoxin theory. Destruction of selective groups of organisms. Interrelationships of micro-

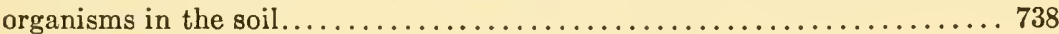




\section{Chapter XXIX}

INFLUENCE OF ENVIRONMENTAL CONDITIONS, SOIL TREATMENT, AND PLANT GROWTH UPON MICROORGANISMS AND THEIR ACTIVITIES IN THE SOIL

Influence of organic matter upon the soil population. Influence of stable manure. Influence of temperature. Influence of moisture. Influence of soil cultivation. Influence of salt concentration upon the activities of microorganisms in the soil. Influence of calcium oxide and carbonates of calcium and magnesium. Influence of growing plants upon soil microorganisms and their activities............................. 767

\section{Chapter XXX}

SOIL AS A HABITAT FOR MICROORGANISMS CAUSING PLANT AND ANIMAL DISEASES

Influence of saprophytic soil microorganisms upon plant growth. Saprophytism and parasitism among soil microorganisms. Animal and plant diseases caused by bacteria that may be found in the soil. Plant diseases caused by fungi found in the soil. Plant and animal diseases caused by species of actinomyces. Plant and animal diseases caused by invertebrate animals found in the soil. Relation of soil environment to plant infection. Influence of reaction upon the growth of plant pathogenic organisms in the soil. Methods of control.................................. 801

\section{Chapter XXXI}

SOIL INOCULATION

Beneficial and injurious microbiological processes in the soil. Introduction of certain useful microorganisms into the soil. Legume inoculation. Use of soil for inoculation of legumes. Commercial cultures and their preparation. Biological types of legume bacteria. Importance of legume inoculation. Inoculation of non-leguminous plants with nodule bacteria. Inoculation of soil with non-symbiotic nitrogen-fixing bacteria. Soil inoculation with autotrophic bacteria. Inoculation of soil with heterotrophic, non-

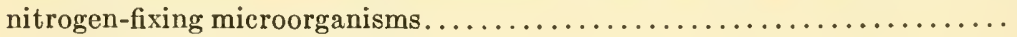

\section{Chapter XXXII}

HISTORY OF SOIL MICROBIOLOGY, ITS PAST, PRESENT AND FUTURE

Beginnings of soil microbiology. Soil microbiology as an independent science. Recent advances of the science. Present outstanding problems

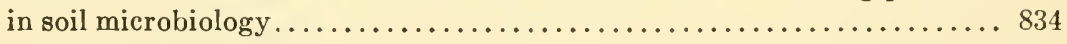




\section{PART A \\ OCCURRENCE AND DIFFEREN'TIATION \\ OF MICROORGANISMS \\ IN THE SOIL}

"... le rôle des infiniments petits m'apparaissait infiniment grand..."

-Pasteur. 



\section{CHAPTER I}

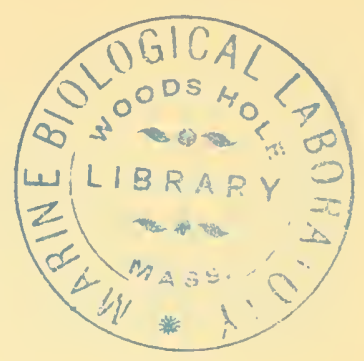

Numbers of Different Groups of Microorganisms Found in the Soll and Methods of Determination

The occurrence of microorganisms in the soil. The microorganisms present in the soil belong, in an uneven proportion, to the plant and animal kingdoms, the former including the large majority both in numbers and in kinds. Chart 1 gives a visual representation of the relationships of the various groups of soil microorganisms. The relative importance in the soil, however, both as to numbers and physiological activities, varies with the different groups.

The animal world is represented in the soil by the protozoa, nematodes, rotifers, earthworms and various other worms as well as insects. The nematodes occur abundantly in all soils, but especially in greenhouse soils and certain infested field soils. Large numbers as well as numerous species of amoebae, ciliates and flagellates represent the protozoa in the soil.

The microscopic plant world is represented in the soil by the algae, fungi and bacteria, named in the order of their increasing importance of numbers and activities. Among the algae, the Cyanophyceae and Chlorophyceae are best represented in the soil. The soil fungi can be subdivided further into three groups:

1. Yeasts and yeast-like fungi, like the Monilia and Oidia (these two groups may, however, be classed with the true fungi).

2. Molds and other true fungi. Here we find the Mucorineae represented by the extensive genera Rhizopus, Mucor, Zygorhynchus and other Phycomycetes; various Ascomycetes, including the genus Chaetomium and other genera; Hyphomycetes represented by the Mucedinaceae (Aspergillus, Penicillium, Sporotrichum, Botrytis, Trichoderma, Verticillium, etc.), Dematiaceae, Stilbaceae and Tuberculareaceae. The Basidiomycetes are probably represented abundantly in the soil by the sterile mycelium as well as by some of the mycorrhiza fungi.

3. Actinomyces. Ten to 50 per cent of the colonies developing from a soil on the common agar or gelatin plate belong to this important group of soil organisms. They are generally classified by bacteriologists with 
the bacteria; actually they belong to the fungi and are so far known to be represented in the soil by one extensive genus Actinomyces.

Bacteria predominate, in numbers and in the variety of activities, over all the other groups of microorganisms. This was the reason why the earlier microbiologists named the whole science of soil microbiology "soil bacteriology." It has long been recognized, however, that the soil population consists of various microorganisms other than bacteria, so that the more comprehensive term is fast coming into general use. Since the bacterial activities in the soil do not coincide with their taxonomic groupings, these organisms may be classified on the basis of their physiology for the sake of convenience in treatment. As a major division, the bacteria can be separated into two large groups:

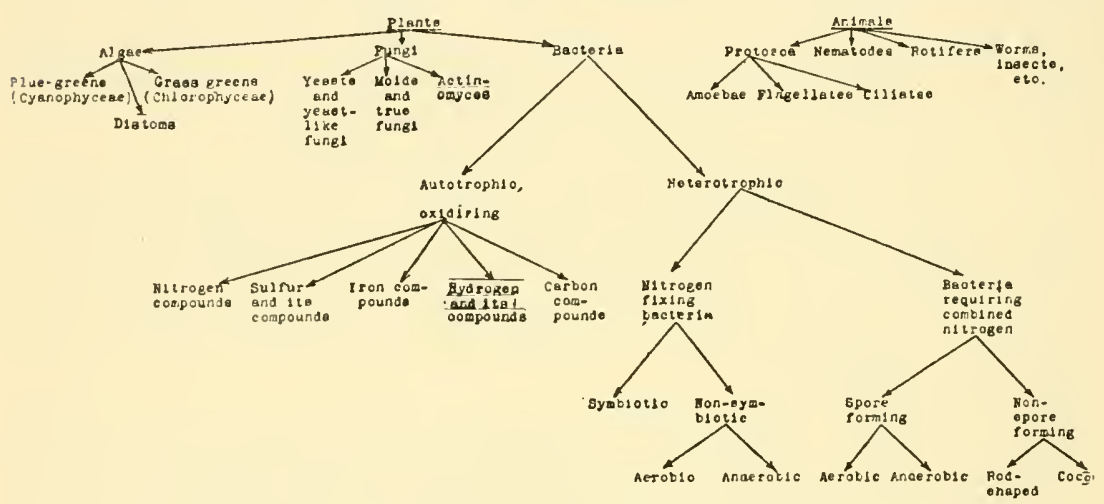

Chart I. The microflora and microfauna of the soil

(1) autotrophic, and (2) heterotrophic forms. Living organisms that require for their nutrition substances which have been built up by other organisms are called heterotrophic. The heterotrophic saprophytic bacteria consume, for their energy and for the building up of their protoplasm, the organic compounds of plant and animal bodies. Organisms like the green plants and certain bacteria that can thrive on purely inorganic substances and obtain their carbon from the carbon dioxide of the atmosphere are called autotrophic. But while the green plants derive their energy photosynthetically, the autotrophic bacteria derive their energy from the oxidation of purely inorganic substances, or chemosynthetically. The autotrophic group of bacteria is represented in the soil by smaller numbers and by much fewer species than the heterotrophic group, but it includes forms which are of greatest impor- 
tance in the physiological processes in the soil, namely the organisms which oxidize ammonium salts to nitrites, nitrites to nitrates, sulfur and sulfur compounds to sulfates, and a few other less important groups.

The heterotrophic bacteria are further subdivided on the basis of their nitrogen utilization: (1) Those bacteria that are able to fix atmospheric nitrogen in the presence of sufficient carbohydrates as sources of energy. This division is again only secondary in numbers, but its three representative groups play an important part in the soil economy, namely in the increase of the combined nitrogen of the soil. They are the symbiotic nitrogen-fixing, or nodule bacteria; the nonsymbiotic aerobic nitrogen-fixing bacteria and the non-symbiotic anaerobic nitrogen-fixing bacteria. (2) Those bacteria which depend, for their metabolism, upon the nitrogen of the soil, in organic or inorganic forms. The heterotrophic non-nitrogen-fixing bacteria can be further subdivided, using as a basis either the need of free or combined oxygen or spore formation. The heterotrophic, non-nitrogenfixing, aerobic bacteria are usually the organisms which are found on the plates, when an analysis of numbers of bacteria in the soil is made by the common agar or gelatin plate method.

In addition to the microscopic forms, ultramicroscopic microorganisms capable of passing through bacterial filters have been reported ${ }^{1}$ as present in the soil. These have been only insufficiently studied. We may be dealing here with certain stages of other organisms, as suggested by Löhnis for gonidia. A certain relation was observed between the ultrafilterable microbes and microbial enzymes and other cell constituents. Attention may be called here to the extensive literature concerning the nature of the bacteriophage; investigators do not agree as yet whether these are ultramicroscopic organisms or are of the nature of enzymes. An attempt to study the physiological activities of the invisible soil microorganisms has been made ${ }^{2}$ but without any success.

Proof of microbial activities in the soil. The food requirements of the various groups of soil microorganisms are so distinctly different that no single artificial culture medium could be devised on which all of them could be studied. A large number of microorganisms, to which some of the most important soil forms belong, will grow only under very special conditions, such as selective media or selective environments.

${ }^{1}$ Melin, E. Ultramikroskopische Mikroben im Waldboden. Ber. deut. Bot. Gesell. 40: 21-25. 1922. See also Miehe, H. Biol. Centrbl. 43: 1-15. 1923.

${ }^{2}$ Rossi, G. Preliminary note on the microbiology of the soil and the possible existence therein of invisible germs. Soil Sci. 12: 409-412. 1921. 
Various media and different methods have to be used for the study of the different groups. In some cases, special enrichment culture media favoring the development of particular organisms have to be devised, so that the growth of these will take place in preference to that of all the other organisms. We thus often create artificial conditions which are distinctly different from those of the soil and conclusions, based on the results of growth of the organisms under such artificial conditions, often do not hold true for the soil. To be able to grow the organisms in pure culture in the soil, the latter must be first sterilized. No method of sterilization has yet been devised which would not modify, in a fundamental manner, the chemical conditions of the soil. What will hold true for sterilized soil, then, may not hold true for unmodified soil. Again, the various organisms exist in the soil in large numbers, with a number of associative and antagonistic influences at work (both by living microorganisms and their products). Each organism has arlapted itself to its environmental conditions and to the other organisms and may be, so to speak, in a condition of "unstable equilibrium." When this same organism is cultivated, in pure culture, upon a favorahle nedium, its activities are very likely to be different from those in the normal soil. Before we can conclude that a microorganism is active in the soil and that certain chemical transformations are produced by this organism under ordinary soil conditions, certain requirements must be satisfied. The following postulates, applied by Koch to pathogenic bacteria, and modified by $\mathrm{Conn}^{3}$ in their application to soils should hold true for soil microorganisms: (1) The organism must be shown to be present in the soil in an active form when the chemical transformation under investigation is taking place. (2) The organism must be shown to be present in larger numbers in such soil than in similar soil in which the chemical change is not taking place. The organism must be isolated from the soil and studied in pure culture. (4) The same chemical change must be produced by the organism in experimentally inoculated soil, making the test, if possible, in unsterilized soil. (5) 'The organism must be found in the inoculated soil.

Mcthods of study. The methods generally employed for the study of soil bacteria can be divided into those of direct microscopic observation and cultural methods. The former have been suggested by Conn and firther developed by Winogradsky. The latter have been used by the

${ }^{3}$ Conn, H. J. The proof of microbial agency in the chemical transformation of soil. Science. N.S. 46: 252-255. 1917. 
great majority of other soil microbiologists. Artificial culture media are employed, or at least artificial conditions are created. In many instances, therefore, no direct evidence is furnished as to what is actually taking place in the soil, under natural conditions. The results obtained under laboratory conditions often have to be interpreted as to their bearing upon actual field results.

The information obtained from the study of soil microbiology by the use of the different methods can throw light upon three groups of phenomena: (1) the numbers and kinds of microorganisms occurring in the soil; (2) the activities of soil microorganisms; (3) the bearing of these activities upon soil fertility.

\section{Direct microscopic method.}

The method consists in preparing a suspension of coil in a dilute fixative solution, then spreading one or two drops of the suspension upon a clean slide, drying and staining with an acid dye. For qualitative purposes, about 0.5 to 1 gram of soil is placed ${ }^{4}$ in a test tube; 6 to 8 ec. of a fixing solution, eonsisting of 0.04 per cent sterile gelatin in water, are then added and the mixture well shaken. Two loopfuls of the suspension are placed upon elean slides; after drying, the slides are stained with a 1 per eent solution of rose bengal in 5 per eent phenol-water mixture. The preparation is heated on a steam bath until most of the liquid has evaporated and the excess of stain is removed by dipping the slide in water. The preparation is then dried on the steam bath and examined mierosespically. The gelatin fixative can be omitted ${ }^{5}$ and the films fixed to the slide by flouding, after drying, with a very dilute solution of eollodion in ether and alcohol.

The method was modified and improved by Winogradsky, ${ }^{6}$ who found that the presenee of large yellow grains of inorganie soil material hinders the proper examination of the field under the microseope. The soil samples are well mixed and powdered. One gram of the soil (on a dry basis) is then added to 4 ec. of distilled water and shaken vigorously for five minutes. After allowing to rest 30 seconds the suspension eovering the large sedimented inorganic particles is poured off into a small tube of a hand centrifuge. Two 3-ec. portions of distilled water are then added to the residue, shaking each time one minute, allowing to rest 30 seeonds and then pouring into the same tube of the eentrifuge. Ten units of water are thus used for one unit of soil. After these three washings the

${ }^{4}$ Conn, H. J. The microseopie study of baeteria and fungi in soil. N. Y. Agr. Exp. Sta. Tech. Bul. 64. 1918; An improved stain for baeteria in soil. Stain Teehnol. 1: 126-128. 1926.

${ }^{5}$ Whittles, C. L. The determination of the number of bacteria in soil. Jour. Agr. Sci. 13: 18-48. 1923; 14: 346-369. 1924.

${ }^{6}$ Winogradsky, S. Sur l'ćtude microscopique du sol. Compt. Rend. Acad. Sci. 179: 367-371. 1924; Etudes sur la microbiologie du sol. 1. Sur la méthode. Ann. Inst. Past. 39 : 299-354. 1925. 
first sediment suspended in distilled water settles immediately. During these manipulations, which require about 10 minutes, a second sediment is formed in the tube of the centrifuge. About half of the suspension is carefully taken out and placed in another centrifuge tube; on centrifuging, a third sediment is formed. Preparations are then made from each sediment and from the noncentrifuged and centrifuged suspensions. One drop of the various preparations is placed upon a slide covering just $1 \mathrm{sq}$. cm.; the preparations are dried in an oven and are rapidly covered with a very dilute agar solution. One per cent warm agar solution is best for the first two sediments and 0.1 per cent cold agar solution for the third sediment. For the suspensions, no fixative is necessary. When the agar is dried, several drops of absolute alcohol are used for fixing and the preparation is stained by means of a solution of an acid dye in 5 per cent phenol solution. Rose bengal may be used, but its action is prolonged, followed by a drop of acetic acid, then washed. Extra erythrosine in 5 per cent phenol solution is superior. The bacterial cells are colored, but not the capsules and mucus; this is especially true of the compact colonies as those of Nitrosomonads and other soil forms which so readily over-color with basic dyes; the colloids are only faintly colored; the agar is readily discolored by the process of washing with cold water. The dye is allowed to act 5 to 15 minutes in the cold or on slight warming, then washed a few seconds in water.

The preparations from the first sediment are usually free from bacteria, except in soils rich in organic matter, when some of the particles are not removed by three washings. The second preparation shows on examination the same mierobes, qualitatively and quantitatively, as the third sediment, where conditions for examination are most favorable. The fourth preparation made from the suspension is usually most instructive. The living cells only take the stain, while the spores stain only very faintly or not at all and can be seen only when present in large numbers. Protozoan cysts are recognized by their intense coloration and can easily be counted.

Winogradsky suggested to use always for comparison a control soil, which had no addition of fresh organic matter for a considerable period of time. A normal arable soil contains a native or autochtonous flora consisting of short bacteria with rounded ends and of cocci, 1 to $1.5 \mu$ in diameter. Often larger forms, 1 to $3 \mu$ in diameter, resembling Azotobacter are found. They group into rounded colonies consisting of about 100 cells in a compact mass with a common capsule, but occasionally with as few as a dozen individuals (Pl. I). The field between is completely devoid of microbes. The colonies are situated on the soil colloidal matter. This is the reason why the centrifuged suspension is practically free from colonies which are carried down by the flakes of organic matter. Spore-bearing bacilli, filamentous bacteria, spirals, mycelial filaments, actinomyces, and protozoan cysts are absent or are very rare. 'The presence of these indicates that the soil is in an active state of fermentation, due to recent addition of organic matter. 

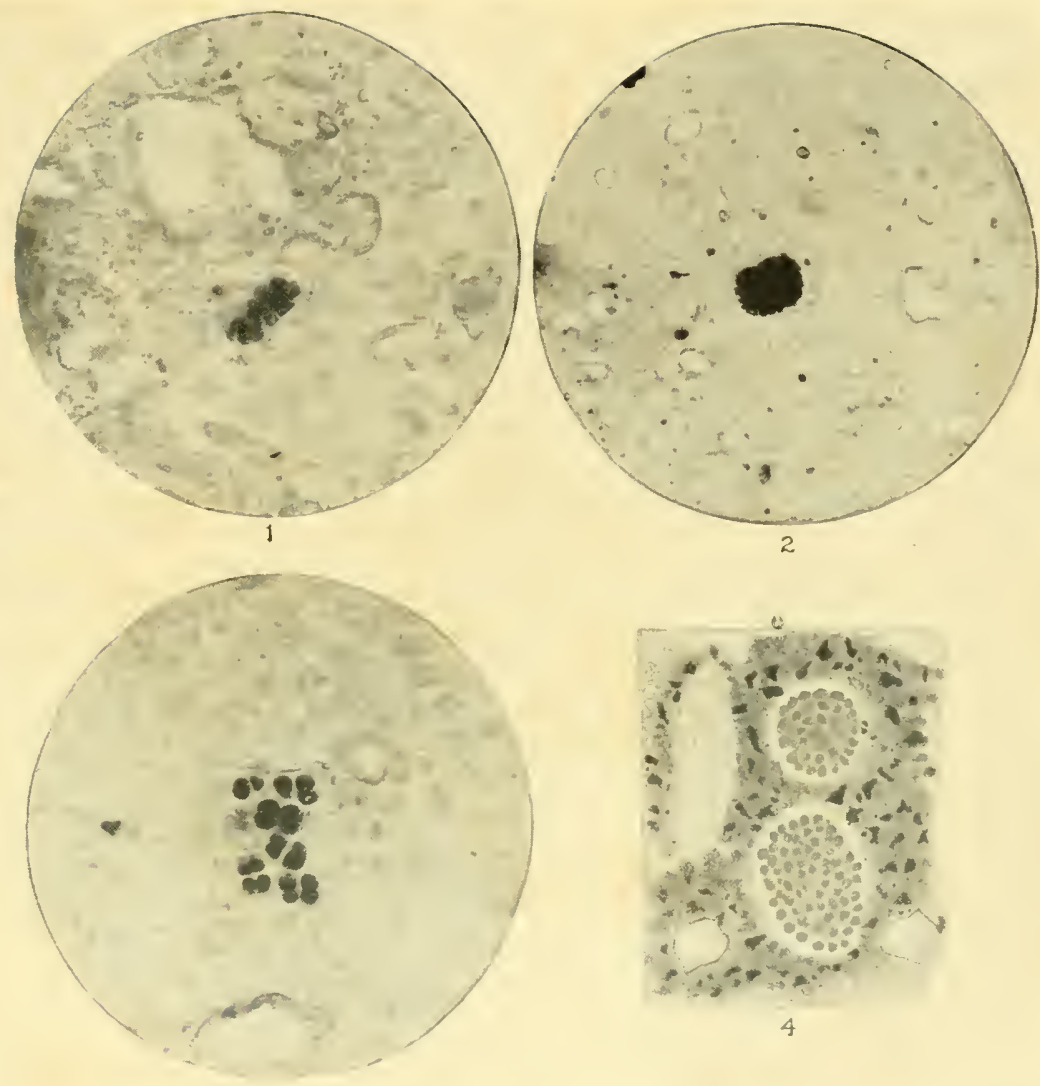

3

1. The bacteria grow in the soil, in the form of zooglea-like masses, upon the colloidal material surrounding the inorganic soil particles, as shown by the direct microscopic method, $\times 1200$ (from Winogradsky).

2. Zooglea-like mass of bacteria in soil, as shown by the direct microscopic method, $\times 1200$ (from Winogradsky).

3. Large cells of bacteria in Texas sandy soil (Azotobacter?), as shown by direct microscopic examination, $\times 1200$ (from Winogradsky).

4. The distribution of organic matter and bacteria in the soil (Russian tshernoziem) (after Winogradsky). 

The application of the direct microscopic examination to the study of occurrence and distribution of microorganisms in the soil gives more direct evidence as to the presence and relative abundance of specific groups of microorganisms. The direct microscopic examination has been used $^{7}$ for counting bacteria in animal feces; it can also be used for counting various microorganisms in culture. To determine the numbers of microorganisms quantitatively by the use of the direct microscopic method, various difficulties are encountered:

1. Some of the microorganisms, like the protozoa, will be destroyed in the process of staining.

2. Others, like the fungi, may prove too large, for the very small quantity of soil that can be used for the examination.

3. The bacteria themselves are found in clumps upon the colloidal film and not in the soil solution. Not only is it difficult to count the bacteria in the film, but the variability is so great that it would take a large number of counts to obtain reliable results

The same procedure is followed as for qualitative determinations.

The soil is diluted by means of a weak solution of gelatin ( 0.15 gram gelatin in $1000 \mathrm{cc}$. of hot water and kept sterile in a cotton plugged flask) using one part of soil to 3 to 10 parts of solution depending on the soil type, heavier soils requiring a higher dilution. The smear is prepared from $0.1 \mathrm{cc}$. of the infusion measured out from a thin graduated pipette, to cover $1 \mathrm{sq} . \mathrm{cm}$. on a clean slide, previously rinsed in alcohol; the smears are allowed to dry over a steam bath. For staining either rose bengal ( 1 gram in $100 \mathrm{cc}$. of 5 per cent phenol solution) or erythrosine can be employed. The stain is allowed to act 1 to 3 minutes, then washed and dried. With the rose bengal stain the bacteria are found deep pink or red, the mineral particles uncolored, some of the dead organic matter light pink but most of it yellow or unstained. The preparations are examined with an oil immersion objective and a high-power eye-piece. By means of a simple equation, the number of organisms can then be determined. It is advisable not to count the entire field, but to mark off the central portion. ${ }^{8}$ A disc with circles and cross lines is placed in the eye-piece. Conn suggested to use a circle of such a size as to cover an area on the slide either 80 or 113 microns in diameter. Every organism in the area will represent two and one millions respectively per cubic centimeter, using a 1.9 ( $\frac{1}{12}$ inch) fluorite objective (N.A. 1.32) with a $12.5 \times$ ocular. This quantity is multiplied by the dilution of the soil to give the number of bacteria per gram of soil.

However, the uneven distribution of the bacteria in the soil, causing great irregularities and the difficulty of distinguishing bacterial cells from

${ }^{7}$ Klein, A. Die physiologische Bakteriologie des Darm-Kanals. Arch. Hyg. 45: 117. 1902.

${ }^{8}$ Breed, R. S., and Brew, J. D. Counting bacteria by means of the microscope. N. Y. Agr. Exp. Sta., Tech. Bul, 49. 1916. 
soil particles, especially in case of clay soils, and of separating living from dead bacteria make accurate counts impossible. The method can, therefore, not be used as yet for quantitative work, but is quite applicable for qualitative purposes, to show the types of microorganisms which exist in the soil in an active form. The microscopic method may be used for counting bacteria in culture media, especially in a liquid form, but even here the total volume of microbial cells may prove ${ }^{9}$ a better index of the activities of the organisms than their numbers.

Organisms found in the soil by the direct microscopic method. Conn demonstrated that the actual number of bacteria found in the soil, by the use of the microscope, is probably five to twenty times as great as that indicated by the culture plate method. This discrepancy is due to that fact that a large number of soil bacteria do not grow on the plates. By far the greatest number of microorganisms found in the soil, by the use of the microscope, consists of the minute non-sporeforming rods and cocci. The large spore-forming bacteria (as Bac. megatherium and Bac.cereus) have been found in normal soil only in the form of spores, which make up a very small proportion of the total bacterial flora of the soil. Filaments of actinomyces have also been found, but to a lesser extent than the spores of these organisms. Fungus mycelium was not found in any soil, except when an unusual amount of organic matter is present. The spore-forming bacteria become ${ }^{10}$ active in the soil only when a great excess of 'easily decomposable organic matter has been added or when the moisture content of the soil is high. The minute non-spore-forming rods and cocci are considered ${ }^{11}$ to form the autochtonous microflora of the soil.

Other investigators found that the microscopic examination of soil bacteria allows the differentiation of three distinct groups, ${ }^{12}$ namely (a) cocci and short rods, (b) typical large cells of Azotobacter and (c) bacillary forms. The first two groups are largely connected with the

${ }^{9}$ Skar, O. Mikroskopisehe Zählung und Bestimmung des Gesamtkubikinhaltes der Mikroorganismen in festen und flüssigen Substanzen. Centrbl. Bakt., II, 57:327-344. 1922. Fries, K. A. Eine einfache Methode zur genauen Bestimmung der Bakterienmengen in Bakteriensuspensionen. Centrlbl. Bakt. I (Orig.), 86: $90-96.1921$.

10 Winogradsky, S. Sur la microflore autochtone de la terre arable. Compt. Rend. Acad. Sei. 178: 1236-39. 1924.

${ }^{11}$ Joffe, J. S., and Conn, H. J. Factors influeneing the aetivity of spore forming bacteria in soil. N. Y. Agr. Exp. Sta. Bul. 97. 1923.

12 Richter, A. A. and B. A. To the question of microscopic soil investigation. (Russian). Utehonie Zapiski, Saratov Univ. 4: No. 1. 1925. 
colloidal soil particles, in the form of zooglea, surrounded by slimy capsules; the third group is found mostly in the soil solution, but the representatives of this group occur frequently also in the form of clumps, especially on decomposing organic matter. A comparative study of the occurrence of these three groups at different depths of soil has given the following results:

\begin{tabular}{|c|c|c|c|c|c|c|}
\hline \multirow{2}{*}{ TYPE OF SOIL } & \multirow{2}{*}{ DEPTH } & \multicolumn{3}{|c|}{$\begin{array}{l}\text { NUMBERS OF BACTERIA IN } \\
\text { MILLIONS PER GRAM }\end{array}$} & \multirow{2}{*}{$\begin{array}{l}\text { YEAST } \\
\text { CELLS }\end{array}$} & \multirow{2}{*}{$\begin{array}{l}\text { PIECES OF } \\
\text { FUNGUS } \\
\text { MYCELIUM }\end{array}$} \\
\hline & & Cocei & $\begin{array}{l}\text { Azoto- } \\
\text { bacter } \\
\text { cells }\end{array}$ & Bacilli & & \\
\hline \multirow{4}{*}{ Forest soil. } & & & & & $\begin{array}{l}\text { millions } \\
\text { per gram }\end{array}$ & $\begin{array}{l}\text { millions } \\
\text { per aram }\end{array}$ \\
\hline & Surface & 1,379 & 156 & 1,212 & 1 & 47 \\
\hline & $10 \mathrm{~cm}$ & 991 & 82 & 466 & 31 & 34 \\
\hline & $20 \mathrm{~cm}$ & 281 & 188 & 169 & - & 7 \\
\hline \multirow{2}{*}{ Brown loam soil. } & Surface & 870 & 188 & 376 & 84 & 5 \\
\hline & $10 \mathrm{~cm}$ & 569 & 184 & 106 & 1 & 3 \\
\hline \multirow{3}{*}{ Sandy soil. } & Surface & 519 & 155 & 192 & 79 & 3 \\
\hline & $10 \mathrm{~cm}$ & 407 & 112 & 153 & 23 & 19 \\
\hline & $20 \mathrm{~cm}$. & 269 & 51 & 139 & 8 & 3 \\
\hline
\end{tabular}

The non-spore forming bacteria are thus found to be most abundant, the large rods or bacillary forms coming next, especially in soils rich in decomposing organic matter. Fungus mycelium is also abundant in such a soil.

Cultural methods for demonstrating the kinds of organisms active in the soil. The cultural methods for the study of soil microorganisms are divided into methods for (a) quantitative study of soil microorganisms, (b) qualitative studies, and (c) for the study of microbiological activities, both in pure culture and in the soil.

Winogradsky ${ }^{13}$ suggested to use the silica gel plate, to which a specific substance is added, for demonstrating the existence of specific organisms in the soil.

Pure, colorless potassium silicate is dissolved in water to a specific gravity of 1.06 (6 to 8 Beaumé). A dilution of $\mathrm{HCl}$ equivalent to a specific gravity of 1.10 (13 Beaumé) is also prepared. An equal volume of the silicate is poured into the

${ }^{13}$ Winogradsky, S. Sur une méthode pour apprécier le pouvoir fixateur de l'azote dans les terres. Compt. Rend. Acad. Sci. 180: 711-716. 1925. 
acid solution and both are well mixed. The mixture is then distributed into Petri dishes and these are allowed to rest over night. A firm gel is obtained. The uncovered dishes containing the gel are then placed in flowing water for at least twenty-four hours, until no reaction is given with methyl red or brom cresol purple and with $\mathrm{AgNO}_{3}$. A solution containing the minerals and specific substance, either in solution or as an insoluble suspension, may then be poured over the surface of the gel and the dishes placed in an oven at $60^{\circ}$ to $65^{\circ} \mathrm{C}$, until the excess moisture has dried off. The gel in the dish is inoculated with small particles of soil, the dish is covered and placed in an incubator. After a few days, the specific organism, if present in the soil, will develop on the gel surrounding the particles of soil. By this method the presence of Azotobacter in soil can be readily demonstrated, provided mannite and $\mathrm{CaCO}_{3}$ are employed in addition to the minerals. Nitrite-forming bacteria will develop in an ammonium salt medium, nitrate-forming organisms in a nitrite medium, etc. ${ }^{14}$

However, the cultural methods, largely the enrichment media developed by Winogradsky and Beijerinck, and the common gelatin and agar plate have been used most extensively for establishing the presence and abundance of specific organisms in the soil.

Cultural methods for the determination of numbers of microorganisms in the soil. The earliest investigations in soil bacteriology were carried out, ${ }^{15,16,17}$ by the use of methods developed in medical bacteriology. Soils were diluted with sterile soil, then plated out with gelatin and numbers determined after a certain incubation period. Later, sterile water was used for making the dilutions. In some cases small quantities of soil were weighed directly for the preparation of the plates. The method itself was imperfect and the results unrepresentative, and no relation was established between numbers and soil productivity. Hiltner and Störmer ${ }^{18}$ suggested the use of the dilution method, with the hope of doing away with the plate method, but here again the heterotrophic bacteria were determined by their growth on agar or gelatin

${ }^{14}$ The gel may also be prepared by methods described elsewhere (p. 196).

${ }^{15} \mathrm{Koch}, \mathrm{R}$. Zur Untersuchung von pathogenen Organismen: Bodenuntersuchung. Mitt. K. Gesundheitsamt. 1: 34-36. 1881.

${ }^{16}$ Proskauer, B. Über die hygienische und bautechnische Untersuchung des Bodens auf dem Grundstücke der Charité und des sogen. "Alten CharitéKirchhofes." Bakteriologisches Verhalten des Bodens. Ztschr. Hyg. 11: 22-24. 1882 .

${ }^{17}$ Fränkel, C. Untersuchungen ïber das Vorkommen von Mikroorganismen in verschiedenen Bodenschichten. Ztschr. Hyg. 2: 521-582. 1887.

${ }^{18}$ Hiltner, L., and Störmer, K. Studien über die Bakterienflora des Ackerbodens, mit besonderer Berücksichtigung ihres Verhaltens nach einer Behandlung mit Schwefelkohlenstoff und nach Brache. Arb. Biol. Abt. Land. r. Forstw., K. Gesundheitsamt. 3: 445-545. 1903. 
media, while the autotrophic and nitrogen-fixing organisms were found not to be able to develop readily in high dilutions. Each of these two methods (plate and dilution) for determining the number of microorganisms in the soil has certain advantages and disadvantages.

The plate method consists in diluting the soil with sterile tap water, making a series of dilutions, so that $1 \mathrm{cc}$. of the final dilution, when plated out with nutrient agar or gelatin, will allow 40 to 200 colonies to develop on the plate. The dilution method consists of diluting the soil first with sterile water, as with the plate method, but transferring 1 cc. of several of the final dilutions into special sterile nutrient media adapted for the growth of particular groups of microorganisms. The number of microorganisms will be found to lie between the two highest dilutions, one of which gives positive and the other negative growth. This allows us to determine approximately the number of organisms belonging to each group and present in the particular soil. ${ }^{19}$ The latter method is rather cumbersome, since it involves the preparation of a large number of media and the use of a number of containers for the development of various physiological groups of organisms for making the various dilutions, also, it involves great variability in the results. ${ }^{20}$ The plate method is convenient, but its chief limitation is the fact that it allows the development of only the heterotrophic, non-nitrogen fixing, aerobic bacteria and of yeasts, molds and actinomyces. The dilution method can be used for the study of practically all known soil forms. The two methods may then be used each for its particular purpose, particularly in view of the fact that, for those microorganisms that develop on the common culture plate, the dilution method was not found $^{18}$ to give higher results than the plate method. The latter method should, therefore, be utilized for a general study of the numbers of microorganisms in the soil, keeping in mind its limitations, while the dilution method should be used for the determination of the abundance of special groups of microorganisms which do not develop on the plate.

Culture media. With the introduction by Koch in 1881 of the gelatin plate for counting bacteria in general, an impetus was also given to the study of soil bacteria. But, unfortunately, Koch himself and practically all the bacteriologists following him for the next fifteen years were medical men interested particularly in the possible presence of patho-

${ }^{19}$ Löhnis, F. Zur Methodik der bakteriologischen Bodenuntersuchung. Centrbl. Bakt. II, 14: 1-9. 1905.

${ }^{20}$ Fischer, H. Zur Methodik der Bakterienzählung. Centrbl. Bakt. II, 25: 457-459. 1910. 
genic bacteria in the soil and their importance as carriers of infection. They quite properly, from their point of view, used the methods of medical bacteriology. But even the excellent and stimulative researches of Koch and those following him ${ }^{21}$ could not lay a proper foundation of soil microbiology, due primarily to the lack of proper methods.

The meat-extract-peptone agar or gelatin, found so valuable in pathogenic bacteriology, is entirely inappropriate for soil work, for various reasons, chief among which is the fact that the medium is not standard in composition and that it allows a rapid development of a few organisms which readily overgrow the plate and thus may prevent entirely the development of others. The distinct inferiority of bouillon agar or bouillon gelatin can be seen from the results of Engberding, ${ }^{22}$ who found that a soil giving 99 colonies with Heyden agar, gave 39 with bouillon agar and only two with bouillon gelatin. But even the Heyden agar is not definite in composition, although it is often used for counting soil bacteria.

The media used for the determination of numbers of microorganisms in the soil (those that develop on the plate) should allow the development of the greatest possible number of organisins and should be standard in composition, so that every batch made up in the same laboratory or at any other laboratory will be like every other batch. 'This means that inorganic salts should be used. If organic substances are necessary, they should be pure, stable, and standard if possible, as in the case of the carbon and nitrogen sources. Various sugars or organic acids used as sources of earbon can be obtained in a stanclard form. Nitrogen substances should also be as standard as possible and used in as small amounts as possible. Agar in itself should not serve as a nutrient and should be, therefore, as pure as possible. The objection to gelatin is that it serves also as a nitrogen source for many microorganisms, thus making the medium not standard. It should, therefore, be used only in qualitative work or in special instances, as in the study of the number of gelatin-liquefying organisms in the soil. To hold in check the development of certain rapidly growing organisms, which prevent the growth of the numerous but slow growing bacteria in the soil, the organic matter content of the media had to be reduced to a minimum.

${ }^{21}$ Houston, A. C. Chemical and bacteriological examination of soils. Local Gov't. Board, Rept. 27: 251-296. 1898.

${ }_{22}$ Engberding, D. Vergleichende Untersuchungen über die Bakterienzahl im Ackerboden in ihrer Abhängigkeit von äusscrn liinflüssen. Centrbl. Bakt. II, 23: $569-642.1909$. 
The first important modifications in the composition of the medium for a quantitative determination of soil bacteria were made by the introduction of the soil infusion agar ${ }^{23}$ and later by the elimination even of the soil extract, ${ }^{24}$ using a synthetic agar, with only 0.05 gram of peptone per liter. The soil extract media do not, however, meet the qualification of being "standard in composition," since the soil infusion varies with the soil used for making the infusion. The synthetic medium was further modified ${ }^{25}$ by the substitution of egg-albumin and casein for peptone. Among the other synthetic media suggested for the quantitative estimation of soil bacteria and actinomyces, sodium asparaginate agar, ${ }^{26}$ asparaginate-mannite agar, ${ }^{27}$ and urea nitrate agar $^{28}$ should be mentioned. For the estimation of fungi, special acid media have to be used. For the protozoa, the dilution method still remains the most reliable, and nutrient agar or special liquid media can be employed for the development of the organisms in the final dilutions.

\section{Composition of synthetic media}

I. Fischer's soil extract agar:

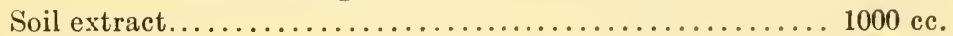

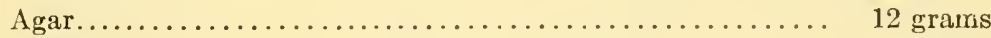

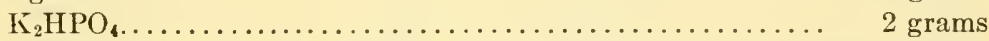

The soil extract is prepared by heating soil for half an hour at 15 pounds pressure with an equal weight of a 0.1 per cent solution of $\mathrm{Na}_{2} \mathrm{CO}_{3}$.

${ }^{23}$ Fischer, H. Bakteriologisch-chemische Untersuchungen. Bakteriologischer Teil. Landw. Jahrb. 38: 355-364. 1909.

2 Lipman, J. G., and Brown, P. E. Media for the quantitative estimation of soil bacteria. Centrbl. Bakt. II, 25: 447-454. 1910.

${ }_{25}$ Brown, P. E. Media for the quantitative determination of bacteria in soils. Centrbl. Bakt. II, 38: 499-506. 1913; also Iowa Agr. Exp. Sta., Res. Bul. 11, 396-407. 1913. Waksman, S. A. Microbiological analysis of soils as an index of soil fertility. II. Methods of the study of numbers of microorganisms in the soil. Soil Sci. 14: 283-298. 1922; Waksman, S. A., and Fred, E. B. A tentative outline of the plate method for determining the number of microorganisms in the soil. Ibid. 14: 27. 1922 .

${ }^{26}$ Conn, H. J. Culture media for use in the plate method of counting soil bacteria. N. Y. Agr. Exp. Sta. Tech. Bul. 38. 1914.

27 Thornton, H. G. On the development of a standardized agar medium for counting soil bacteria, with especial regard to the repression of spreading colonies. Ann. Appl. Biol. 9: 241-274. 1922.

${ }^{28}$ Cook, R. C. Quantitative media for the estimation of bacteria in soils. Soil Sci. 1: 153-161. 1916. 
II. Lipman and Brown's synthetic agar:

Distilled water...... 1000 cc.

Glucose.......... 10 grams

Agar............. 20 grams $\quad \mathrm{MgSO}_{4} \cdot 7 \mathrm{H}_{2} \mathrm{O} \ldots \ldots .0 .20 \mathrm{gram}$

Peptone........... 0.05 gram $\quad \mathrm{K}_{2} \mathrm{HPO}_{4} \ldots \ldots . \ldots .60 .50$ gram

III. Albumin agar:

Distilled water..... 1000 cc. $\quad \mathrm{MgSO}_{4} \cdot 7 \mathrm{H}_{2} \mathrm{O} \ldots \ldots .0 .20 \mathrm{gram}$

Agar........... 15.00 grams $\mathrm{K}_{2} \mathrm{HPO}_{4} \ldots \ldots \ldots \ldots .0 .50 \mathrm{gram}$

Powdered egg al-

$\mathrm{Fe}_{2}\left(\mathrm{SO}_{4}\right)_{3} \ldots \ldots \ldots \ldots$ trace

bumin........... 0.25 gram

Glucose........... 1.00 gram

The albumin is suspended in 5 to $10 \mathrm{ec}$. of water, then $1.0 \mathrm{cc}$. of $0.1 \mathrm{~N} \mathrm{NaOH}$ solution is added, so as to convert it into sodium albuminate; the albuminate is added only to the filtered medium.

IV. Casein agar. Same as medium III, only 1.0 gram of purified casein is used in place of the albumin. The casein is dissolved in $8 \mathrm{cc}$. of $0.1 \mathrm{~N} \mathrm{NaOH}$.

V. Asparaginate agar:

\begin{tabular}{|c|c|c|}
\hline intillotor & & \\
\hline & 12.0 & $\mathrm{CaCl}_{2}$ \\
\hline ium asparaginate. & 1.0 gram & $\mathrm{KCl} \ldots \ldots \ldots \ldots \ldots \ldots, 0.1 \mathrm{gram}$ \\
\hline
\end{tabular}

$\mathrm{MgSO}_{4} \cdot 7 \mathrm{H}_{2} \mathrm{O} \ldots \ldots . .0 .2$ gram

$10 \mathrm{ec}$. of $1.0 \mathrm{~N} \mathrm{NaOH}$ solution added per liter to bring the desired reaction.

VI. Asparagine-mannite agar:

Distiiled water...... 1000 cc.

Agar............. 15 grams

$\mathrm{K}_{2} \mathrm{HPO}_{4} \ldots \ldots \ldots \ldots, 1.0$ gram

$\mathrm{MgSO}_{4} \cdot 7 \mathrm{H}_{2} \mathrm{O} \ldots \ldots .0 .2 \mathrm{gram}$

$\mathrm{CaCl}_{2} \ldots \ldots \ldots \ldots \ldots .0 .1 \mathrm{gram}$

$\mathrm{NaCl} \ldots \ldots \ldots \ldots, 0.1 \mathrm{gram}$

$\mathrm{FeCl}_{3} \ldots \ldots \ldots \ldots .0 .002$ gram

$\mathrm{KNO}_{3} \ldots \ldots \ldots \ldots, 0.5$ gram

Asparagine........ 0.5 gram

Mannite........... 1.0 gram

The mannite is added after the agar and other constituents have been dissolved and medium filtered. The reaction is adjusted to $\mathrm{pH}$ 7.4.

VII. Urea ammonium nitrate agar:

Distilled water...... 1000 cc.

Agar............. 15.0 grams

$\mathrm{K}_{2} \mathrm{HPO}_{4} \ldots \ldots \ldots \ldots, 0.5 \mathrm{gram}$

$\mathrm{MgSO}_{4} \cdot 7 \mathrm{H}_{2} \mathrm{O} \ldots \ldots . \quad 0.2 \mathrm{gram}$

Reaction is about $\mathrm{pH}$ 7.0.

In addition to these media, soil extract and tap water gelatin recommended by Conn and used chiefly for qualitative purposes can also be mentioned:

VIII. Tap water gelatin ${ }^{29}$

Tap water.................................. 1000 cc.

Gelatin (Gold Label)........................ 200 grams

These media are about equally favorable to the development of aerobic, heterotrophic bacteria, deriving their nitrogen from inorganic

${ }^{20}$ Medium is clarified by means of white of egg; reaction is adjusted to 0.5 per cent normal acid to phenolphthalein, which requires $20-30 \mathrm{cc} .1 .0 \mathrm{~N} \mathrm{NaOH}$; when Bacto-gelatin is used, only 10 sc. of alkali is required and no clarification. 


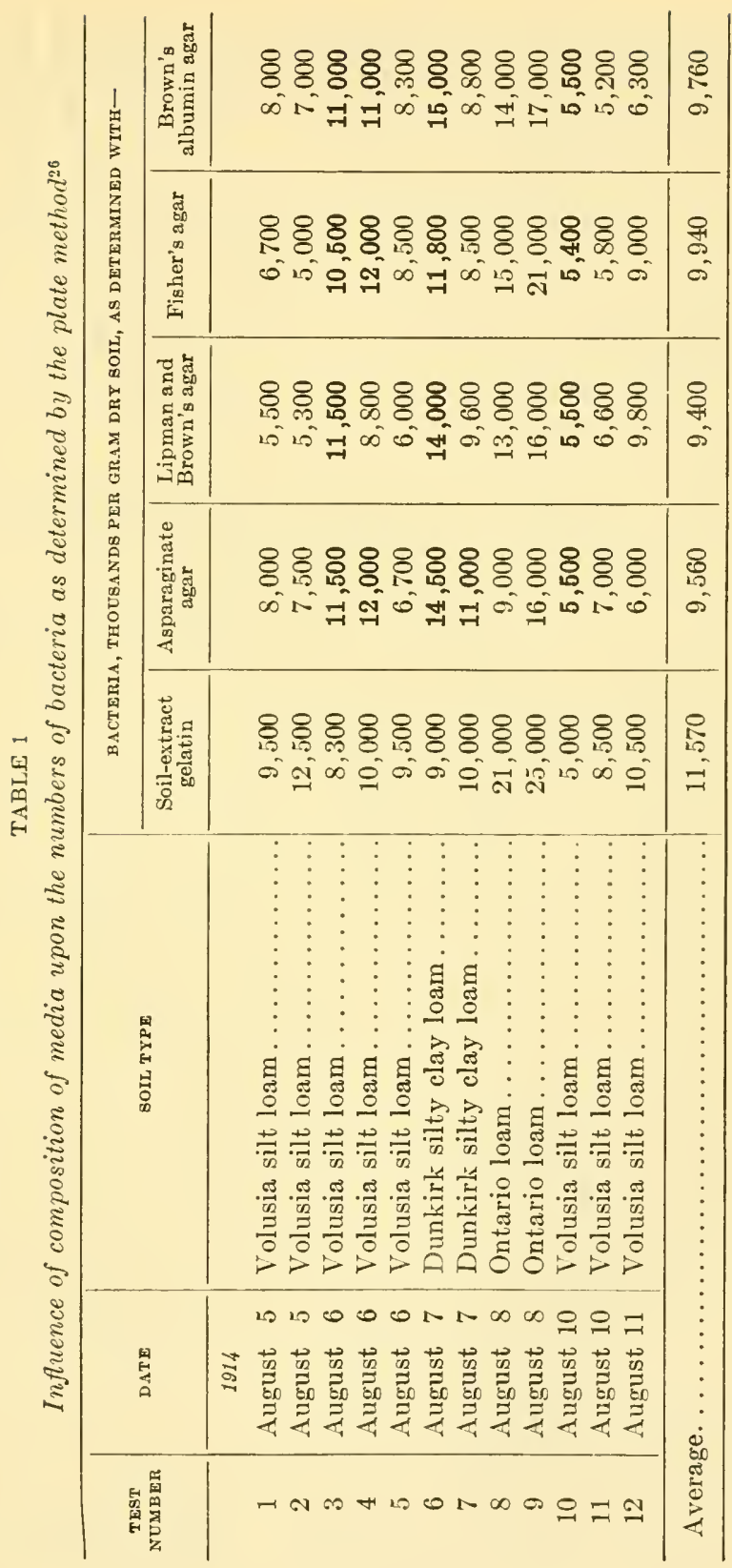


or organic compounds, and of actinomyces, but give somewhat different results for different soils, as shown by Conn. Egg-albumin agar and especially soil extract agar were found by others ${ }^{30}$ to give higher and more uniform results than other media.

In preparing the media, the constituents including the agar or gelatin are dissolved in boiling water: after filtration through cotton, the more decomposable constituents are added, as in the case of urea, ammonium nitrate and glucose in the urea nitrate agar, albumin and casein solutions and the sodium asparaginate as well as the glucose, in the corresponding media, so as to avoid any possible effect of preliminary heating on these substances.

The reaction of the media is an important factor. Its adjustment to a definite point of titration is practically valueless in media, where the buffer content is variable. ${ }^{31}$ A slight acidity has usually been found to be the most favorable reaction for the development of the majority of soil bacteria. When determined by the hydrogen-ion coneentration, colorimetrically or electrometrically, this reaction was found to be $\mathrm{pH}$ 6.5 (albumin and easein media) to $\mathrm{pH} 7.0$ (asparaginate agar media).

The media are placed in 10-ee. portions in test tubes, or in 100-ec. to 200-ec. portions in Erlenmeyer flasks. These are plugged with cotton and sterilized in the autoclave, at 15 pounds pressure, for 15 to 20 minutes. A soil may contain 5 to 30 million bacteria (including actinomyces) per gram and only 50,000 fungi or less. The final dilution used for the determination of bacteria would be 100,000 or 200,000 . Some of the plates will have no fungi at all, while others may have one, two or more colonies. In this case the proper dilution for the determination of fungi would be 1000, but there will be so many bacteria on the plate that most of the fungi misy actually fail to develop or make only a seant growth. A medium should be used which allows only the developinent of fungi. Use is made of the fact that the majority of fungi can stand greater degrees of acidity than the bacteria and actinomyces For qualitative purposes and for pure culture study, any medium favorable for the development of fungi, such as raisin extract (60 grams of raisins heated at $60^{\circ}$ to $75^{\circ} \mathrm{C}$. in $1000 \mathrm{cc}$. of tap water, filtered), which is

${ }^{30}$ Smith, N. R., and Worden, S. Plate counts of soil microorganisms. Jour. Agr. Res. 31: 501-517. 1925.

${ }^{31}$ Clark, W. MI. The "reaction" of bacteriologie culture media. Jour. Inf. Dis., 17: 109. 1915. Clark, M. W. The determination of hydrogen ions. 2d Ed. The Williams \& Wilkins Co., Baltimore. 1922; Gillespie, I. J. Colorimetric deternination of hydrogen-ion concentration without buffer mixtures, with esperial referenee to soils. Soil Sei. 9: 115-136. 1920. 
already acid in reaction, or a medium to which enough lactic acid is added to bring the reaction to $\mathrm{pH}$ 4.0. Because of the high acidity, $25 \mathrm{gm}$. of agar are required per liter. For quantitative purposes, however, a synthetic medium is always to be preferred $:^{32}$

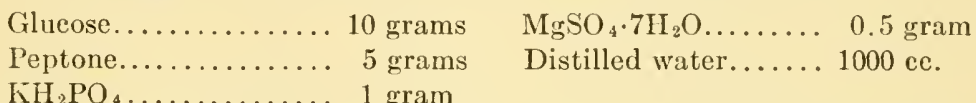

The ingredients are dissolved by boiling and enough normal acid $\left(\mathrm{H}_{2} \mathrm{SO}_{4}\right.$ or $\mathrm{H}_{3} \mathrm{PO}_{4}$ ) is added to bring the reaction to $\mathrm{pH} 3.6$ to 3.8 . This will require from 6 to 7 ce. of normal acid per liter of medium. Twenty-five to 30 grams of agar are added and dissolved by boiling; the medium is then filtered, tubed and sterilized as usual. The final reaction of the medium should be pII 4.0.

For soils to which an excess of organic matter has recently been addled, the dilution used for the determination of fungi is usually from one hundredth to one-tenth of the dilution used for the determination of numbers of bacteria.

All the necessary glassware and water blanks should be prepared and sterilized before the soil samples are taken. 'Three or four pipettes and the same number of water blanks are required for every soil sample. Ninety-nine or $90 \mathrm{cc}$. portions of tap water, depending on the fact whether 1-ec. or 10-ce. pipettes are employed for making the dilutions, are placed in the fluslis which are then plugged with cotton. The glassware (including the Petri dishes) is sterilized in the hot air sterilizer for two hours at $160^{\circ} \mathrm{C}$., while the water blinks are sterilized in the autoclave, at 15 pounds pressure for 15 or 20 minutes. The smpling bottles may be sterilized either with the other glassware or with the water blanks.

Sampling of soil. It has been shown both by cultural studies ${ }^{1 s}$ and by the use of the microscope ${ }^{33}$ that a given soil will contain at a given time, in a given soil layer, a uniform bacterial flora. Samples taken under the same experimental conditions will, therefore, be the same bacteriologically, while any change in soil type and treatment will result in a change in bacterial relations. When comparing different soils, samples taken from the same depth should be compared. The variability of a soil itself, even as to physical and chemical factors, is so great, however, that it is not surprising that such a sensitive indicator as bacterial numbers and activities should also vary. To meet the factor of variation, the common practice has been to use composite samples,

${ }^{32}$ Waksman, S. A. A method for counting the number of fungi in the soil. Jour. Bact. 7: 339-341. 1922.

${ }_{33}$ Winogradsky, 1925 (p. 7). 
taken from a thorough mixture of several representative borings to the same depth in various parts of the field. This may be sufficient, if the probable error involved in the determination is known. A study of the variability of the soil in relation to the numbers of bacteria, as determined by the plate method, was found ${ }^{34}$ to yield in one particular plot eight to twenty-five millions per gram of soil. These results were based on fifty-one samples of soil taken from one-twentieth of an acre; the samples were taken at intervals of 5 by 8 feet. The numbers of bacteria of practically a whole series of plots variously treated and where definite bacteriological differences have been established were found to fall within that range of number's. This would make any results obtained from a determination of numbers of bacteria based upon a single sample practically valueless. Before any definite conclusions can be drawn from a determination of bacterial activities in the soil, it is advisable to study the variability of the particular soil. This is done by taking a large number of samples from a particular field and working out the probable error of the particular variable which should not be greater than $\mathrm{Em}=2.5$ per cent.

For practical purposes, five composite soil samples each consisting of three to four borings taken from different parts of the field will give good results not only in the study of numbers of microorganisms but also in the study of specific physiological activities of soil bacteria.

In taking the samples, a small amount of soil $\left(\frac{1}{4} \mathrm{inch}\right)$ is scraped away from the surface by means of a spatula. The samples are taken by means of sampling tubes or augers, carefully cleaned previously, to a depth of 6 to $6 \frac{1}{2}$ inches, unless a study is made of the distribution of microorganisms at different depths. In that case a ditch may be made 3 feet long by 1 foot wide and, after scraping off the surface soil, at the desired depth, by means of a spatula, the samples are taken; small metallic sampling tubes (about 1 inch in diameter) made of iron or copper, with sharp ends may also be used for this purpose.

Care is taken not to contaminate the soil samples with other soil or by exposing them too long to the atmosphere. However, no absolute sterility in the process of sampling is required, since the numbers of microorganisms in the soil are very large in comparison with any possible contamination from a brief exposure. The samples are placed in sterile sampling bottles and brought to the laboratory as quickly as possible. A rapid change was found ${ }^{35}$ to take place in the numbers of

${ }^{84}$ Waksman, S. A. Microbiological analysis of soil as an index of soil fertility. I. The mathematical interpretation of numbers of microorganisms in the soil. Soil Sci. 14: 81-101. 1922.

${ }^{85}$ Fränkel, 1887 (p. 12). 
soil microorganisms when the soil is kept for a short time in the laboratory. Some investigators ${ }^{36}$ found a strong decrease in numbers, on keeping the soil sample for any length of time. An increase can be expected in soils, in which the activities of microorganisms have been kept in check, as in the case of dry soils moistened, soils treated with gaseous disinfectants, samples from low depths, frozen soils in the process of thawing off. In the case of normal soils, a decrease may be expected; Hiltner and Störmer recorded a change in the numbers of bacteria from $7,519,000$ to $2,087,000$ in sixteen days and from $8,280,000$ to $7,016,000$ in six days.

The bacteriological analysis should, therefore, be made at once, or as soon as the soils can be conveniently brought into the laboratory.

\section{Treatment of soil samples and preparation of plates.}

Before taking out portions of the samples for analysis, each sample is thoroughly mixed by means of a clean spatula. When many small stones are present, the sample is first sieved through a clean (sterile if possible) 2-mm. sieve. A definite portion of soil is transferred by any convenient method into an Erlenmeyer flask containing a definite quantity of sterile tap water, giving the first dilution. It is preferable to have the first dilution $1: 10$ or $1: 20$, i.e., to use ten or twenty times as much sterile water as soil taken. To give an initial dilution of 1:10, $10 \mathrm{gm}$. of soil is added to $100 \mathrm{cc}$. of water. ${ }^{37}$ If the soil contains considerable organic matter, it may be advisable to triturate it first in a mortar with a little of the diluting liquid. The weight of the soil is either included in the total volume of the first dilution ( 10 grams of soil with sterile tap water to make 100 cc.volume) or not (10 grams of soil added to $100 \mathrm{cc}$. of water).

The mixture of soil and water is shaken for five minutes. This results in maximum counts, shorter periods being insufficient to separate all the bacteria from the soil: longer periods of shaking have a destructive influence upon the bacterial numbers. The soil should not be allowed to be too long in contact with the water of dilution, otherwise an injurious effect will take place which is probably due to the plasmolytic action of the liquid. This leads to a rapid decrease in the number of microorganisms affecting the vegetative cells first. An injurious effect will occur only after $3-4$ hours. ${ }^{38}$

In preparing the further dilutions, the contents of the flask from which the suspension is withdrawn should be kept in motion. The further dilutions can be made up on the basis of $1: 10$ or to $1: 100$. It has been suggested $d^{37,39}$ to limit the further dilutions also to $1: 10$, i.e., each higher dilution should be made by

${ }^{36}$ Hiltner and Störmer, 1903 (p. 12).

${ }^{37}$ Wyant, Z. N. A comparison of the technic recommended by various authors for quantitative bacteriological analysis of soil. Soil Sci. 11: 295-303. 1921.

${ }^{38}$ Engberding, 1909 (p. 14).

${ }^{39}$ Noyes, H. A., and Voigt, E. A technic for a bacteriologicafexamination of soils. Proc. Ind. Acad. Sci. 1916, 272-301. 
taking 10 ec. of the lower dilution and 90 ee. of the sterile diluting fluid. However, even by making higher dilutions such as $1: 50$ or $1: 100$ in each ease, reliable results are obtained.

The amount of soil used in making the first dilution, and the various subsequent dilutions are not of primary importance, if care is taken in the technic and in the calculations. By using for the first dilution 0.1201 gram of soil, Hiltner and Störmer found 9,500,000 bacteria in $1 \mathrm{gram}$ of moist soil and, by using 6.7841 grams of the same soil, 9,400,000 bacteria were found in 1 gram of the same soil. In another soil, they found, by using 0.5862 and $21.1820 \mathrm{gram}$ portions of soil, counts of $7,750,000$ and $7,700,000$ respectively per $1 \mathrm{gram}$ of soil. The higher the dilution, the greater is the probable error of the results. The final dilution should be such as to allow between 40 and 200 colonies to develop on the plate, in the case of bacteria (and actinomyces). ${ }^{40}$ The number of fungus colonies allowed per plate on the special acid medium should be 20 to 100 . This will necessitate that the soil should be diluted, in the counting of fungi, only to about 500 to 2000 , so that the highest dilution is only $1^{\frac{1}{0}}$ of that employed for the total bacterial numbers for the same soil, in the case of productive soils. For soils very rich in organic matter or for highly acid soils, the ratio between the highest clilution for fungi and bacteria should be 1:50 or 1:10.

Sterile tap water should be used for making the dilutions. Distilled water has an injurious effect (plasmolysis). Salt solution or nutricnt medium have no advantage over ordinary tap water. Instead of the usual shaking methods, a method has been suggested ${ }^{41}$ for the disintegration and dispersion of the soil particles, by means of which plate counts are supposed to give results comparable with direct counts. The use of a deflocculating agent and protective colloid combined with long vibration of the suspension were recommended. However, conditions were made so as to favor bacterial development and the inethod cannot be recommended without further study.

The plates are prepared from $1 \mathrm{cc}$. of the final dilution in a regular bacteriological way. The number of plates to be used for each soil sample is important. The number of colonies varies greatly with the different plates and results based on averages of two or three plates, without allowing for variability, makes them almost worthless. Hiltner and Störmer recognized this fact and used four and sometimes

${ }_{40}$ Breed, R. S., and Dotterer, W. D. The number of colonies allowable on satisfactory agar plates. N. Y. Agr. Exp. Sta. Tech. Bul. 53. 1916.

41 Whittles, 1923-24 (p. 7). 
eight plates. The average error obtained was 8 to 10 per cent, in some cases even 15 per cent, in other words, the difference between the extreme variations was equivalent to $\frac{1}{3}$ of the mean value. Variations equal to one-third of the actual counts have been observed. ${ }^{42}$ The variability may be somewhat decreased by very careful technic, but not reduced to a small error.

Incubation of plates and counting of organisms. The plates are incubated at a constant temperature, preferably $25^{\circ}$ to $27^{\circ} \mathrm{C}$. for agar media, while gelatin media are incubated at $18^{\circ} \mathrm{C}$. The plates for the determination of fungi are incubated for 48 to 72 hours; a shorter period of time is insufficient for the development of all the colonies, while a longer period favors rapid overgrowth of some fungi. The colonies are counted after 48 and again after 72 hours. The bacterial plates are incubated for seven to twelve days. A shorter period was found ${ }^{43}$ to allow only an insufficient development of the microorganisms. When the plates are incubated only two or three days not all the organisms develop into visible colonies, especially the slow growing non-spore forming bacteria and actinomyces. Hiltner and Störmer and others also found an incubation period of seven days to be most favorable.

Lower temperatures require longer incubation periods, so that, at room temperature, the plates should be incubated for fourteen days to give the maximum development of microorganisms, while, at $25^{\circ}$, seven days are sufficient. Higher temperatures, particularly above $30^{\circ} \mathrm{C}$., have an injurious action upon the development of certain soil organisms; the medium in the plate also dries out rather rapidly.

At the end of the incubation period, all colonies on the plates are counted. Where only 40 to 200 colonies are allowed per plate, it is sufficient to make with a glass pencil two or three cross lines over the plate and count all the colonies with the naked eye. But if, for one reason or another (pure culture study, for example), a lower dilution is used and the number of colonies exceeds 200 (a shorter inculation period may then have to be employed) the counting plate has to be utilized. In that case, of course, one has to depend on the manufacturer for the accuracy of divisions on the plate. A large enough number of sections should be counted so as to reduce the error involved in the determinations to a minimum. All the colonies, except the fungi, are counted and recorded as the total number of organisms developing on the plate, where no separate count of actinomyces is desired. Otherwise, after all the colonies have been counted, the actinomyces are determined separately. It is advisable to have recourse to the microscope for the examination of all the doubtful colonies, which are then marked off with a glass pencil. The plates may also be incubated a few days (4 to 7 ) longer and actinomyces colonies counted. The number of actinomyces may then be subtracted from the "total number of organisms" to give the number of true bacteria.

${ }^{42}$ Remy, Th. Bodenbakteriologische Studien. Centrbl. Bakt. II, 8: 657-662, 72S-735. 1902.

${ }^{43}$ Conn, H. J. Soil flora studies. I. Methods best adapted to the study of the microscopic soil flora. N. Y. Agr. Exp. Sta. Tech. Bul. 57. 1917. 
The total number of organisms developing on the plate is recorded either on the basis of moist soil, giving thereby the moisture content of the soil, or on the basis of dry soil. The moisture is determined by drying 10 grams of soil (50 or 100 grams may also be used, especially in the case of non-homogeneous soil, like peat) at $100^{\circ} \mathrm{C}$. to constant weight. If $\mathrm{N}$ is the total number of organisms developing on the plate from a given soil, $a$ the average number for each plate, $u$ the amount of dilution, $x$ the moisture content of the soil, then,

$$
N=\frac{a \cdot u \cdot 100}{100-x}
$$

Mathematical interprelation of results. The determination of numbers of microorganisms by the plate method involves a number of manipulations, each of which involves a certain error. The final error is a resultant of all these errors. The constant errors should be eliminated, but the occasional errors depend on the "Law of Chance" and these tend to counterbalance one another rather than to fall in one direction. A study of the variability of the number of bacteria, actinomyces, and fungi on their respective media is given in table 2 . The results were calculated as follows:

If $n$ plates are used for making a quantitative bacteriological count of a given soil, $a$ the number of colonies developing on the plates, while $z_{n}$ is the most probable value obtained from counting $n$-plates, or the arithmetic mean value, then we have

$$
z_{n}=\frac{\Sigma a}{n}
$$

In other words, the mean $\left(z_{n}\right)$ is found by dividing the sum of all the determinations by the number of determinations.

The following formulae are commonly used for calculating the average deviation and most probable error of the determination.

$$
\begin{aligned}
& \text { Average deviation, } \sigma=\sqrt{\frac{\sum\left(Z_{n}-a\right)^{2}}{n-1}} \\
& \text { Most probable error }= \pm 0.6745 \sqrt{\frac{\sum(Z n-a)^{2}}{n(n-1)}} \\
& \text { C.V. }=\frac{\text { the average deviation } \times 100}{\text { mean }} \\
& \mathrm{Em}=\frac{\text { most probable error } \times 100}{\text { mean }}
\end{aligned}
$$


The probable error of the standard deviation is obtained from the formula $\pm 0.6745 \frac{\sigma}{\sqrt{2 n}}$. The coefficient of variability (C.V.) is the percentage ratio of the standard deviation $(\sigma)$ from the mean. The probable error of the coefficient of variability $= \pm 0.6745 \frac{\mathrm{C} . \mathrm{V}}{\sqrt{2 n}}$. By the use of formulae for the calculations of the errors of observation, the error of the mean arithmetical value of the plate counts can be determined. ${ }^{44}$

By taking several representative soil samples and by using several plates, the error can be reduced to a minimum. A combination of five soil samples and ten plates, for each soil to be tested, will reduce the error for bacterial numbers to 1.8 per cent and for actinomyces to 2.7 per cent. ${ }^{45}$ The same is true of fungi; when a low dilution (1000) is combined with an acid medium, and 5 to 10 plates are used for each sample, the error may be reduced to 2 per cent.

It is of interest to note here that in order to determine accurately the average value of hygroscopic moisture in the soil, Floess ${ }^{46}$ found that fifty soil samples, taken at definite distances in the field, are required. The probable error was calculated from the formula:

$$
r=\frac{[v] \cdot 0.845}{\sqrt{n(n-1)}}
$$

Where [v] is the sum of all individual variations from the mean and $n$ the number of observations.

Under ideal conditions, the bacterial counts on parallel plates will vary in a manner similar to samples from a Poisson series. ${ }^{47}$ The accuracy can thus be determined with precision and the mean count of a number of plates is a direct measure of the bacterial population capable of developing on the plate. Agreement with the theoretical distribution may be tested by means of the index of dispersion.

${ }^{44}$ Davenport, C. B. Statistical methods. Wiley, New York. 1914. Barlow, P. Tables of squares, cubes, square roots, cube roots, reciprocals. Spon. London. 1914.

${ }^{45}$ Waksman, 1922 (p. 20).

${ }^{46}$ Floess, R. Die Hygroskopizitätsbestimmung, ein Masstab zur Bonitierung des Ackerbodens. Landw. Jahrb. 42: 255-289. 1912.

${ }^{47}$ Fischer, R. A., Thornton, H. G., and Mackenzie, W. A. The aceuracy of the plating method of estimating the density of bacterial populations. Ann. Appl. Biol. 9 : 325 -359. 1922 . 


$$
X^{2}=\frac{1}{x} S(x-\bar{x})^{2}
$$

where $\bar{x}$ is the mean and $x$ any individual number of colonies counted on a plate; $S$ stands for summation and $X^{2}$ as the index of variability.

With a carefully improved technic, an accurate conformity with the theoretical distribution can be attained even with a mixed bacterial flora of the soil. Any significant departure from the theoretical distribution is a sign that the mean may be wholly unreliable.

Comparison of plate and microscopic methods. By comparing the results obtained by the microscopic and plate methods of determining the numbers of microorganisms in the soil, $\mathrm{Conn}^{48}$ came to the conclusion that if an organism that can grow well on the plate is present in a soil, the plate count will be nearly as high or even higher than the microscopic count. In the case of large-sized bacteria, like Bac. cereus, the microscopic count was found by Conn to be higher than the plate count; in the case of small bacteria, like Bact. fuorescens, or the orange-liquefying type, which are easily overlooked under the microscope, the plate count is considerably higher. For the determination of the aerobic, heterotrophic, non-nitrogen fixing bacteria in the soil, which develop readily on the plate, the latter method is as satisfactory as the microscopic method. A number of bacteria, like the cellulose-decomposing forms, some urea bacteria, and others, even among the aerobic heterotrophic organisms, are not capable of developing on the common plate, while some nitrogen-fixing bacteria may develop. The distinct difference between plate and microscopic counts of bacteria in normal soil is due not only to the organisms which are not capable of growing on common nutrient media, but also to the fact that a large number of cells, even of the organisms capable of growing on the common plate, do not develop into colonies. The actual number of bacteria in the soil is probably five to twenty and even more times as ligh as the counts obtained by the plate method.

For the present, however, the plate method is the most satisfactory one for determining the relative abundance of microorganisms (bacteria, actinomyces and fungi) in the soil. For determining the numbers of protozoa and specific physiological groups of bacteria, the dilution method still remains the most satisfactory. In the case of actinomyces and especially fungi, a colony on the plate represents either a spore or a piece of mycelium in the soil; since the spore is only the

${ }^{48}$ Conn, 1918 (p. 7). 
reproductive stage, while the mycelium is the active stage of the organism, and since some fungi, like the Mucoraceae, produce a mycelium which does not readily break up into fragments, the results obtained by plate count may be far from representing the actual abunlance of the particular organisms in the soil.

Numbers of bacteria in the soil. In view of the fact that the methods used in the past for the determination of numbers of bacteria in the soil varied greatly and most of the media were not synthetic in composition, the results cannot be readily compared. However, certain fundamental facts have been established, which throw interesting light upon the nature of the soil population. By the use of the microscopic method Conn found, in one gram of soil, 140 to 390 millions of small rod-shaped bacteria less than 0.5 micron in diameter, 1.5 to 12 million rods 0.5 to 0.8 micron in diameter and 500,000 to $5,000,000$ spores per 1 gram of soil. Very few of the large rods (over 1 micron in diameter) were found in all the soil samples. In manured soils, the number of bacteria were found to reach $800,000,000$ per gram, as determined microscopically. Still larger numbers were reported by others (p. 11). On the other hand, by the use of nutrient agar plate, Adametz ${ }^{49}$ found 320,000 to 500,000 bacteria per gram of sandy soil, and 360,000 to 600,000 in loamy soils. The numbers of bacteria in the soil obtained by the numerous investigators fall somewhere between these two sets of figures. These tremendous differences and variable results led Löhnis ${ }^{50}$ to the conclusion that a determination of bacterial numbers in the soil is worthless as an attempt of interpreting soil phenomena. However, when the results are considered critically and compared carefully, it is found that the information obtained from the study of numbers of microorganisms gives not only an interesting insight into the microbiological population of the soil, but also throws light on soil fertility, particularly when this information is combined with that obtained from the study of physiological activities of soil microorganisms (p. 711).

In general the numbers of bacteria, as determined by the plate method, are found to range in normal soils well supplied with organic matter from 2 to 200 millions per gram, as determined by the plate method. These numbers vary with the soil type, soil treatment, season of year, depth, moisture content and various environmental

${ }^{49}$ Adametz. Untersuchungen über die niederen Pilze der Ackerkrume. Diss. Leipzig. 1886.

${ }^{50}$ Löhnis, F. Handbuch der landwirtschaftlichen Bakteriologie. Berlin, 1910 , p. 513. 
conditions. No two soils, even from the same locality can be compared on the basis of mere bacterial numbers without a detailed knowledge of the physical and chemical condition of soil, treatment, etc. In some soils, like very poor sandy soils, very acid peat soils and abnormal acid or alkaline soils, the number of bacteria may be much below 2,000,000 per gram. The sandy soils of the Pinebarrens of New Jersey, for example, contain only 25,000 to 100,000 bacteria per gram, while certain acid peat and acid forest soils may be nearly free from bacteria capable of developing on the common agar or gelatin plate. Very heavily manured soils, such as greenhouse soils or market garden soils, particularly at the time of active decomposition of the organic matter, may contain over $200,000,000$ bacteria per gram, even as shown by the plate method.

Bacterial numbers in manure. Manure consists of (1) solid excreta, (2) straw, hay or peat litter, and (3) urine. Solid excreta are very rich in bacteria. The bacterial numbers in feces were found ${ }^{51}$ to be very variable; 1 gram of fresh human feces may contain 18,000,000,000 bacteria. Dry cow manure was shown ${ }^{52}$ to contain, by weight, 9 to 20 per cent bacteria. One gram of fresh cow manure $(17.65$ per cent dry weight) should thus contain 18 to 40 billions bacteria, the larger number of which consists of dead cells. However, by the plate method, only 40 to 70 millions bacteria per gram of cattle manure and 100 to 150 millions per gram of horse manure were obtained. By the use of the gravimetric method, Lissauer ${ }^{53}$ estimated that 4.26 to 15.67 per cent of the feces of man (on the average 9 per cent), 3.54 to 9.08 of $\mathrm{dog}, 0.41$ to 1.31 of rabbit and 14.73 to 18.75 per cent of the feces of cattle consisted of bacteria; the kind of food (vegetable or animal) influenced the numbers. Since $1 \mathrm{mgm}$. of dry bacteria contains $4,000,000,000$ cells, $1 \mathrm{mgm}$. of cow feces would contain 63 to 80 millions of bacteria. By the plate method, manure of stall-fed cattle was found ${ }^{54}$ to contain 1 to 120 million bacteria per gram, while that of cattle on pasture contained only

${ }^{51}$ Matzuschita, T. Untersuchungen über die Mikroorganismen des menschlichen Kotes. Arch. Hyg. 41: 210-255. 1901.

${ }^{52}$ Stoklasa, J. Über die Wirkung des Stallmistes. Ztschr. landw. Versuch. Österreich. 10: 440. 1907.

${ }^{53}$ Lissauer, M. Über den Bakteriengehalt menschlicher und tierischer Füces. Arch. Hyg. 58: 136-149. 1906.

${ }^{54}$ Gruber, Th. Die Bakterienflora von Runkelrüben, Steckrüben, Karotten, von Milch während der Stallfütterung und des Weideganges einschlieszlich der in Streu, Gras und Kot vorkommenden Mikroorganismen und deren Mengenvehältnisse in den 4 letzten Medien. Centrbl. Bakt. Abt. II, 22: 401-416. 1909. 
1 to 4 million. One billion bacteria were demonstrated ${ }^{55}$ in 1 ce. of the intestinal contents of the ox.

However, many of the earlier investigators recorded too low numbers, due to faulty technic. In the more recent studies ${ }^{56}$ $12,000,000,000$ living microorganisms were recorded per 1 gram of compost of manure and straw and even these figures were too low, due to the fact that not all groups of organisms were counted. The feces of white rats was sliown ${ }^{57}$ to consist of 33 to 42 per cent bacteria by weight, although no attempt was made to differentiate between the living and dead cells.

The bacterial content of straw also varies greatly. Seventy-four thousand to $11,640,000$ bacteria were found ${ }^{58}$ per gram of straw and a decrease was observed as a result of drying and preservation under clean surroundings. The numbers of bacteria per gram of hay may vary between 10 and 400 millions per gram. ${ }^{59}$ Figures varying from 3.6 to 600 millions of microorganisms per gram of straw were also reported. These organisms consist of non-spore formers (Bact. herbicola, Bact. güntheri, Bact. acidi lactici, Bact. fluorescens), spore-formers, butyric acid bacteria, cocci, actinomyces ( 2 to 83 per cent of flora) and a few fungi. ${ }^{60}$

Urine is practically sterile, when it leaves the healthy body, but, on exposure, bacteria begin to multiply very rapidly, and soon an abundant flora consisting of bacteria and protozoa may appear.

The number of bacteria in stable manure will vary greatly, depending on its composition, the amount of solid excreta, and the degree of decomposition. The numbers will also depend of course upon the method used for their estimation, plate, dilution and microscopic methods giving different results. Fresh manure is very rich in Bact. coli, which

${ }_{55}$ HÏ̈ttermann, W. Beiträge zur Kenntnis der Bakterienflora im normalen Darmtraktus des Rindes. Diss. Bern. 1905; Koch's Jahresb. Gïirungs. 16: 402. 1905.

${ }^{56}$ Löhnis, F., and Smith, J. II. Fühl. landw. Ztg. 63: 153. 1914.

57 Osborne, T. B., and Mendel, L. B. Jour. Biol. Chem. 18: 177. 1914.

${ }^{58}$ Hoffmann, F. Wie grosz is die Zahl der Mikroorganismen auf dem Cietreide unter verschiedenen Bedingungen. Woch. Brau. p. 1153; Koch's Jahresher. Gärungs. 7: 67-68. 1896. Esten, W. M., and Mason, C. J. Sources of bacteria in milk. Storrs (Conn.) Agr. Exp. Sta. Bul. 51. 1903.

${ }^{59}$ Dïggeli, M. Beitrag zur Kenntnis der Sellsterhitzung des Heues. Naturw. Ztschr. Land. Forstw. 4: 473-492. 1906.

${ }^{60}$ Kürsteiner, R. Die Bakterienflora von frischen und benutzten Streumaterialien, mit besonderer Berücksichtigung ihrer Einwirkung auf Mileh. Centrbl. Bakt. II, 47: 1-191. 1916. 
soon disappears in the composting of the manure. At first there is a multiplication of the bacteria, soon followed by a reduction in numbers, when the process of rotting of the manure is advanced. In manure fourteen years old and greatly reduced in volume, 12.5 millions of bacteria were found per gram (using manure extract-gelatin medium for counting), while manure preserved with superphosphate, gypsum and kainit contained 3.75 millions baeteria per gram. ${ }^{e 1}$

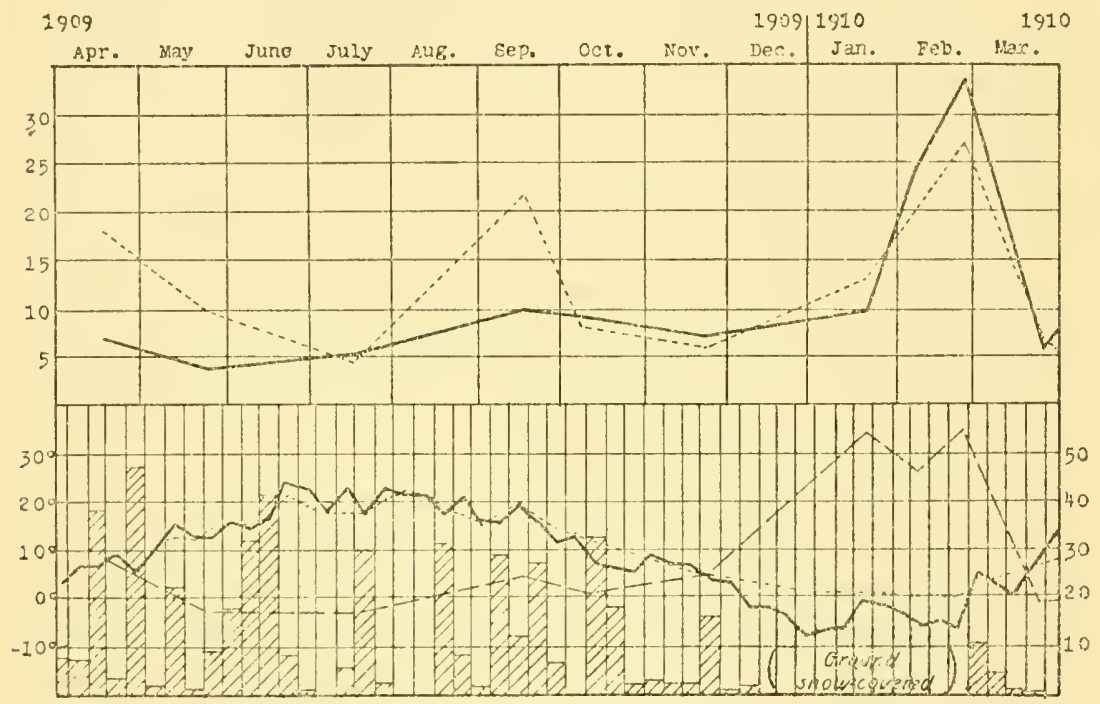

FIa. 1. Upper eurves show millions of baeteria per gram of dry soil, throughout the year:- - - good soil, ------- poor soil; lower eurves show:-- - soil moisture in per cent; —_ atmospherie temperature; ------- soil temperature; shaded eolumns represent rainfall per week, in millimeters (from Conn).

Numbers of bacteria in the soil during different scasons of the year. The season of the year cannot be considered as one single variable, so that its influence upon bacterial numbers and activities could be studied. The moisture content of the soil at the particular date of sampling, kind of erop, stage of growth of erop, previous soil treatment, and many other factors will influence the numbers and types of microorganisms found in the soil. Few bacteria may be found in the soil at the end of a long dry period. After the first rainfall, there is a rapid increase in

${ }^{61}$ Löhnis, F., and Kuntze, W. Beiträge zur Kenntnis der Mikroflora des Stalldüngers. Centrbl. Bakt. II, 20: 676-687. 1908. 
numbers, due to the fact that a continued dry period brings about a phenomenon similar to partial sterilization of the soil and with the first increase in moisture there is an increase of available organic and inorganic materials, leading to a rapid increase in bacterial numbers. Several investigators found larger bacterial numbers in the soil in summer than in winter, the maximum being reached in July and August. In the spring of the year, with the increase in soil temperature, there is a corresponding increase in bacterial numbers. ${ }^{62}$ It was suggested, ${ }^{38}$ however, that the water content of the soil is the most important factor bearing upon bacterial numbers: cultivation increases the number by increasing the water content. Engberding ${ }^{38}$ was unable to demonstrate any influence of temperature upon the numbers of bacteria in mineral soils. This difference in results may be due to the difference in the composition of the soil. The numbers of bacteria (and protozoa) were even found to fluctuate from day to day. ${ }^{63}$ Well-marked seasonal changes in the soil population are superimposed on the daily variations in numbers. These changes are not directly influenced by temperature or rainfall, but show a similarity to the seasonal fluctuations recorded for many aquatic organisms.

Conn ${ }^{64}$ after a careful comparison of baeterial numbers in frozen and unfrozen soil, came to the conclusion that the number of bacteria in frozen soil is generally larger than in unfrozen soil, which is true not only of cropped soil, but also of sod and fallow land. This increase in bacterial numbers after freezing was believed not to be due to an increase in moisture content, even though in an unfrozen condition the bacterial numbers seemed to increase and decrease parallel to the moisture content of the soil. The increase in frozen soil seemed to be a result of actual multiplication of the bacteria, rather than of a mere rise of the organisms from lower depths brought about by mechanical forces alone. Conn, therefore, suggested that there are two groups of bacteria in the soil, "summer" and "winter" bacteria, which are active in the respective periods. These results were at first confirmed. ${ }^{65}$ The

62 Remy, 1902 (p. 23).

${ }^{63}$ Cutler, D. W., Crump, L. M., and Sandon, H. A quantitative investigation of the bacterial and protozoan population of the soil, with an account of the protozoan fauna. Phil. Trans. Roy. Soc. London, B, 211: 317-350. 1922.

${ }^{64}$ Conn, H. J. Bacteria in frozen soils. Centrbl. Bakt. II, 28: 422-434. 1910; 32: 70-97. 1911; 42: 510-519. 1914; N. Y. Agr. Exp. Sta. Tech. Bul. 35. 1914.

${ }^{65}$ Brown, P. E., and Smith, R. E. Bacteria at different depths of some typical Iowa soils. Iowa Agr. Exp. Sta., Res. Bul. 8: 281-321. 1912. 
theory was suggested that surface tension exerted by the soil particles on the films of water, as well as the presence of salts in the water and the concentration of salts, which may occur when the main body of water begins to freeze, all cause the hygroscopic water in soils to remain uncongealed, and consequently bacteria may live in it and multiply to a comparatively large extent. Other result $\mathrm{s}^{66}$ also tended to indicate that low temperatures may greatly increase the numbers of bacteria. 'To explain these phenomena, the mechanical transportation of the bacteria by the moisture coming up from below during heavy frost was suggested. ${ }^{67}$ It was later found, ${ }^{68}$ however, that a slightly frozen condition of the soil allowed bacterial development, but severe frosts produced a checking action, the decrease being parallel with the depression of temperature. No change in crop and plant remains took place in Canada during the winter since the temperature of the soil goes down too low. The occurrence of two maximum counts of bacteria observed ${ }^{69}$ in Iowa soils during the year, on February 12 and June 19, with intervening minimum counts, were used to prove the theory that temperatures much below zero are necessary before the hygroscopic moisture freezes and, until that occurred, a development of bacteria might be expected. It may also be suggested that a slight freezing of the soil, in modifying the colloidal condition of the soil may have the same stimulating action as air drying, treating with disinfectants, etc., in other words, shifting the soil equilibrium, so that a more rapid multiplication of the bacteria may take place.

A more recent careful study of the influence of freezing upon soil bacteria demonstrated that the increase recorded previously is not due to an actual multiplication of the bacteria but rather to a breaking up of the clumps of bacteria in the soil resulting in a larger number of colonies developing on the plate. ${ }^{70}$ The moisture content and rate of

${ }^{66}$ Weber, G. G. A. Dic Einwirkung der Kälte auf die Mikroorganismen und ihre Tätigkeit im Boden. Diss. Jena, 88. 1912. (Centrbl. Bakt., II, 37: 113. 1912.)

${ }^{67}$ Harder, E. G. The occurrence of bacteria in frozen soil. Bot. Gaz. 61: 363. 1916.

${ }^{68}$ Vanderleck, J. Bacteria of frozen soils in Quebec. I and II. Trans. Roy. Soc. Canada (Ser. III, Sec. IV), 11: 15. 1918; 12: 1. 1918.

${ }^{69}$ Brown, P. E., and Halversen, W. V. Effect of seasonal conditions and soil treatment on bacteria and molds in the soil. Iowa Agr. Exp. Sta., Res. Bul. 56: 251-275. 1919 .

${ }^{70}$ Vass, A. F. The influence of low temperature on soil bacteria. Cornell Univ. Agr. Exp. Sta. Memoir 27. 1919. 
thaw are important factors, in determining the extent of the breaking up process. The work of Lochhead ${ }^{71}$ also tends to refute the idea that there are in the soil two groups of bacteria, winter and summer forms. Although the numbers of bacteria in frozen soil are high, there is no phenomenal increase, as a result of freezing, while thawing of the soi! brought about a great increase in numbers. A typical winter flora is absent and the bacteria are to be regarded as cold-enduring rather than psychrophilic in the true sense. There was also no indication of a rise of organisms from unfrozen levels to the frozen surface layers.

Distribution of bacteria at various soil depths. In humid soil, most of the bacteria are concentrated in the upper 2 feet of soil and the highest numbers are found just 1 to 3 inches below the surface. The germicidal effect of the rays of the sun and the rapid evaporation of the moisture tend to diminish the numbers right at the surface. Much fewer bacteria are present in the subsoil; in sandy soils, due to better aeration, the numbers do not diminish as rapidly. Since most of the earlier work was limited to the use of the plate method, the results are of necessity too low.

Proskauer ${ }^{72}$ was the first to point out the fact that the numbers of bacteria in humid soils decrease with depth: at a depth of about one meter the soil was found to be almost free from bacteria. Fränkel ${ }^{73}$ observed a decrease of bacterial numbers with depth of soil, from 90,000 to 300,000 at the surface, to 100 to 700 at a depth of 2.5 meters. The change was not gradual, but sudden and irregular. The bacteria were found to go deeper in cultivated than in uncultivated soils, but no influence of the crop upon the number of organisms could be demonstrated. A decrease from 2,564,000 bacteria at the surface to none at a depth of six feet was observed ${ }^{74}$ in a stony soil, and from 524,500 at the surface to 5,800 at a depth of 1.5 meters in a wet meadow soil. Clover soils contained $6,000,000$ bacteria at a depth of $20 \mathrm{~cm}$. and 1,500,000 at 50 cm. depth. ${ }^{75}$ A change from $8,000,000$ bacteria per gram of soil at the surface to sterility at a depth of one meter was also recorded. ${ }^{76}$ The

${ }^{71}$ Lochhead, A. G. Microbiological studies of frozen soil. Trans. Roy. Soc. Canada. 18: 75-96. 1924; Soil Sci. 21: 225-232. 1926.

${ }^{72}$ Proskauer, 1882 (p. 12).

${ }^{73}$ Fränkel, 1887 (p. 12).

${ }^{74}$ Reimers, J. Über den Gehalt des Bodens in Bacteria. Ztsehr. Hyg. 7 : 319-346. 1889.

${ }^{75}$ Caron, A. Landwirtschaftlich-bakteriologische Probleme. Landw. Vers. Sta., 45: 401-418. 1895.

${ }^{76}$ Stoklasa, J., and Earnest, A. Über den Ursprung, die Menge und die Bedeutung des Kohlendioxyds im Boden. Centrbl. Bakt. II, 14: 723-736. 1905. 
numbers of bacteria usually increase from the surface to a depth of 4 to 6 inches ${ }^{77}$ this is followed by a decrease to a depth of 24 inches in humid soils. The maximum numbers were found at six inches of depth $;^{78}$ in some $\operatorname{cases}^{79}$ the maximum was found at a depth of 4 inches, where the greatest numbers of organisms are found followed by a more or less regular drop. Soils under shade (orehard, forest, meadow) have the highest numbers of bacteria at a depth of 1 inch, then the numbers

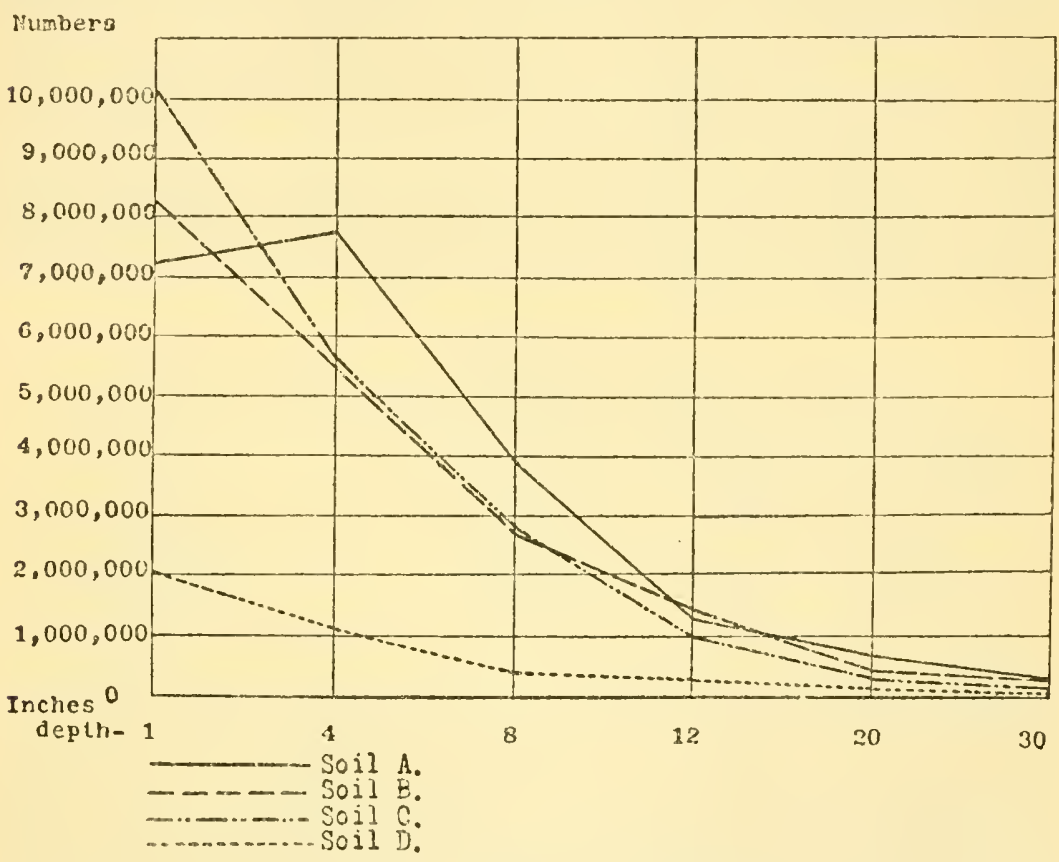

Fig. 2. Numbers of bacteria at different depths of soil, on the average of several determinations throughout the year: $A$, rich garden soil $B$, cultivated orchard soil; $C$, clay soil, under timothy; $D$, acid forest soil (from Waksman).

decrease with depth, while soils exposed to the sun have the highest numbers at a depth of 4 inehes. $^{80}$

${ }^{77}$ Chester, F. D. The bacteriological analysis of soils. Del. Agr. Exp. Sta. Bul. 65. 1904.

${ }^{78}$ King, W. E., and Doryland, C. J. T. The influence of depth of cultivation upon soil bacteria and their activities. Kans. Agr. Exp. Sta. Bul. 161: 211-242. 1909.

${ }^{79}$ Brown and Smith, 1912 (p. 32).

${ }^{80}$ Waksman, Yoil Sci., 1: 363-380. 1916. 
In the case of arid soils, the microorganisms are found to penetrate much deeper into the subsoil layers, the activities of the organisms continuing in some cases undiminished through six feet of soil. The numbers of bacteria may even be greater at a depth of 24 inches than at 6 inches $;^{81}$ a wind-blown arid soil of Arizona, of a pH 8.6 to 9.0 and with an average annual rainfall of 13 inches was found to contain 401,000 organisms at a depth of 6 inches, and 1,898,500 at a depth of 12 inches and 916,500 at a depth of 24 inches. Fifty-two per cent of the organisms developing on the plate were actinomyces. Better aeration and presence of organic matter are no doubt largely responsible for this greater distribution of microorganisms with depth of soil in arid regions. The favorable influence of irrigation upon bacterial numbers is marked not only at the surface but also at lower depths, ${ }^{82}$ as shown in table 3 . Further information on the influence of depth upon microorganisms and their activities is given elsewhere (p. 48).

TABLE 3

Distribution of soil bacteria in different depths of soil in arid regions

\begin{tabular}{c|c|c} 
DEPTH & IRRIGATED SOIL & DRY-FARM SOIL \\
\hline 1 foot & $6,240,000$ & $4,372,000$ \\
2 feet & $1,760,000$ & $1,267,000$ \\
3 feet & $1,147,0$ C0 & $1,174,000$ \\
\hline
\end{tabular}

Numbers of specific physiological groups of bacteria in the soil. In determining the numbers of specific morphological or physiological groups of bacteria in the soil, the dilution method is largely employed, as outlined above. ${ }^{83,84}$ The number obtained indicates a certain minimum of cells of the particular organism, since often many of the cells introduced into the specific medium may fail to develop. Hiltner and Störmer found that a soil, which gave by the gelatin plate $1,270,000$ bacteria, contained a much greater number of bacteria, when determined by the dilution method.

${ }^{81}$ Lipman, C. 13. The distribution and activities of bacteria in soils of the arid region. Univ. Cal. Publ. Agr. Sci. 1: 7-20. 1912;4: 113-120. 1919. Snow, L. M. A comparative study of the bacterial flora of wind-blown soil. I. Arroyo bank soil. Tueson, Arizona. Soil Sci. 21: 143-161. 1926.

${ }^{82}$ Greaves, J. E. Agricultural bacteriology. Lea and Febiger. Phila., p. 164. 1922.

${ }^{83}$ Löhnis, 1905 (p. 13).

${ }^{84}$ Millard, W. A. Bacteriological tests in soil and dung. Centrbl. Bakt. II, 31: 502-507. 1911 . 
Although by the plate method the number of Azotobacter cells present in the soil (when they are present at all) is rather small, amounting to only a few hundreds ( 800 to 1000$)^{85}$ or a few thousands ${ }^{86}$ per gram, the direct microscopic examination reveals a great abundance of these organisms in soils properly limed and buffered. Clostridium pastorianum (Bac. amylobacter A. M. et Bred.) may be found in numbers ranging from 1 to 5 millions per gram of soil. In poorly buffered and in acid soils, Azotobacter is absent altogether and its place is taken by the Clostridium, as shown later.

For the determination of the numbers of bacteria belonging to the genus Rhizobium, a medium containing 2 grams levulose, 0.06 gram asparagine, 0.1 gram sodium citrate, 0.1 gram potassium citrate and 2 grams of agar in 100 parts of tap water may be used. ${ }^{87}$ When the plates are poured, 3 to 5 drops of normal solution of sodium carbonate are

TABLE 4

Numbers of physiological groups of bacteria in 1 gram of soil

\begin{tabular}{|c|c|c|c|}
\hline & $\begin{array}{l}\text { RESULTS } \\
\text { OF HILNER AND } \\
\text { STÖRMER }\end{array}$ & $\begin{array}{l}\text { RESULTS OF } \\
\text { LÖHNIS, } 83 \text { AVER- } \\
\text { AGE OF SUMMER } \\
\text { AND WINTER } \\
\text { VALUES }\end{array}$ & $\begin{array}{c}\text { RESULTS OF } \\
\text { MILLARD, AVER- } \\
\text { AGE OF MAXIMUM } \\
\text { AND MININUM } \\
\text { VALUES }\end{array}$ \\
\hline I. Peptone decomposing........ & $3,750,000$ & $4,375,000$ & $75,000,000$ \\
\hline II. Urea decomposing.... & 50,000 & 50,000 & $27,500,000$ \\
\hline III. Nitrifying . . . . . . . & 7,000 & 5,000 & 100,000 \\
\hline IV. Denitrifying . . . . . . & 50,000 & 50,000 & 162,500 \\
\hline V. Nitrogen-fixing....... & 25 & 388 & $2,500,000$ \\
\hline
\end{tabular}

added to $10 \mathrm{cc}$. of medium. Most bacteria and molds do not develop on this medium; 50 to 86 per cent of the colonies are Rhizobia which are small or punctiform, white, somewhat stiff and gummy. To confirm the diagnosis, the colonies are transferred to plates of nutrient agar or plant extract (beans) agar. The numbers of Rhizobia in the soil were found to run parallel with its fertility, and as many as 3 to 4

${ }^{85}$ Truffaut, G., and Bezssonoff, H. Augmentation du nombre des Clostridium Pastorianum (Winogradsky) dans les terres partiellement sterilisées par le sulfure de calcium. Compt. Rend. Acad. Sci.172: 1319-1324. 1921;173: S69-870. 1921. La Science du Sol. 1: 3-61. 1922.

${ }^{86}$ Razoomov, A. S. Method of counting soil bacteria according to their physiological groups (Russian). Trans. Institute of Fertilizers, No. 28, Moscow. 1925.

${ }^{87}$ Greig-Smith, R. The determination of rhizohia in the soil. Centrbl. Bakt. II, 34: 2:7-229. 1912 . 


\begin{tabular}{|c|c|c|c|c|c|c|c|c|}
\hline & 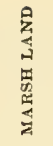 & ${ }_{\substack{0 \\
0}}^{\infty}$ & & $\begin{array}{l}8 \\
8 \\
8 \\
8 \\
-1\end{array}$ & $\begin{array}{l}8 \\
0 \\
8 \\
8\end{array}$ & 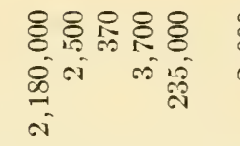 & $\begin{array}{l}8 \\
8 \\
\text { i }\end{array}$ & $\because=0 \mathrm{O}$ \\
\hline & 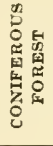 & $\frac{a}{-N}$ & & $\begin{array}{l}8 \\
8 \\
8 \\
8 \\
-10\end{array}$ & $\begin{array}{l}8 \\
8 \\
8 \\
8\end{array}$ & 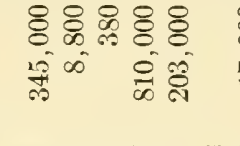 & $\begin{array}{l}8 \\
0 \\
=\end{array}$ & 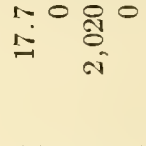 \\
\hline 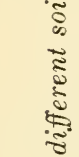 & 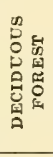 & $\begin{array}{l}0 \infty \\
\stackrel{\sim}{\sim}\end{array}$ & & $\begin{array}{l}8 \\
8 \\
8 \\
8 \\
-1\end{array}$ & $\begin{array}{l}8 \\
8 \\
8 \\
8 \\
-1\end{array}$ & 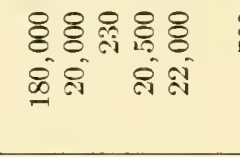 & 8 & $\infty=\frac{1}{20} 0$ \\
\hline 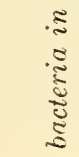 & 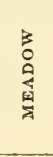 & $\begin{array}{l}0 \\
\stackrel{0}{=}=\end{array}$ & & $\begin{array}{l}8 \\
8 \\
8 \\
\infty \\
\infty\end{array}$ & $\begin{array}{l}8 \\
8 \\
8 \\
8 \\
\text { is }\end{array}$ & 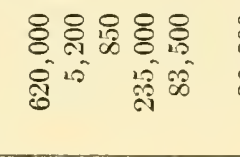 & $\begin{array}{l}8 \\
\infty \\
\infty \\
\infty\end{array}$ & 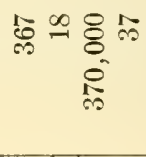 \\
\hline 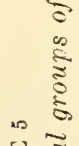 & 惫 & $\rightarrow 0$ & & $\begin{array}{l}8 \\
8 \\
8 \\
\infty \\
\infty\end{array}$ & $\begin{array}{l}8 \\
8 \\
8 \\
0 \\
0\end{array}$ & 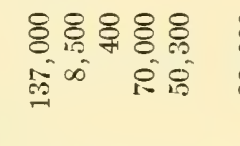 & $\begin{array}{l}8 \\
\text { हैं } \\
\text { लं }\end{array}$ & 옥 \\
\hline 离 & 总 & $\exists \because$ & & $\begin{array}{l}8 \\
8 \\
8 \\
\wp \\
-\end{array}$ & $\begin{array}{l}8 \\
8 \\
8 \\
8 \\
\text { oi }\end{array}$ & 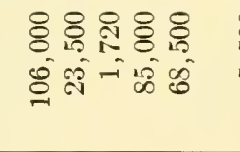 & $\begin{array}{l}8 \\
8 \\
10 \\
10\end{array}$ & 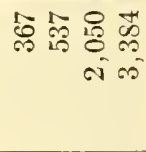 \\
\hline 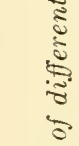 & 蛋 & & & $\begin{array}{l}8 \\
8 \\
8 \\
+1 \\
\infty\end{array}$ & $\begin{array}{l}8 \\
8 \\
8 \\
\infty \\
\infty\end{array}$ & 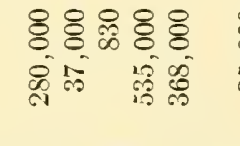 & $\begin{array}{l}8 \\
8 \\
10\end{array}$ & 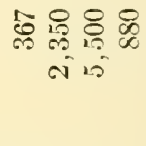 \\
\hline 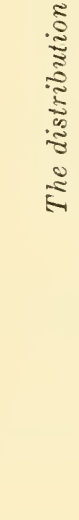 & 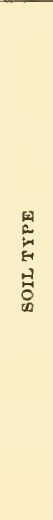 & 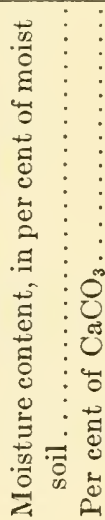 & 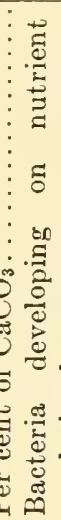 & 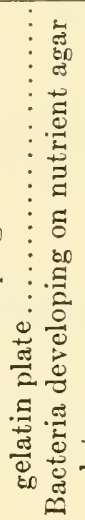 & 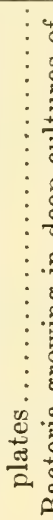 & 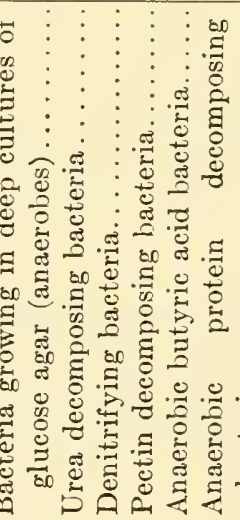 & 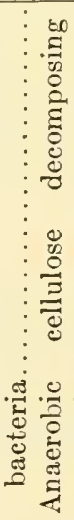 & 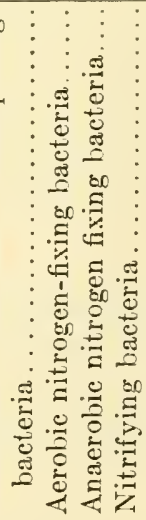 \\
\hline
\end{tabular}


million cells were found per gram of soil, comprising 0.4 to 6.75 per cent of the total flora developing on the plate. Since Rhizobium was found to fix 3 to $5.6 \mathrm{mgm}$. of nitrogen for $100 \mathrm{cc}$. of solution, it was believed to be identical with Bact. radicicola.

The use of starch agar for determining the numbers of organisms in the soil capable of utilizing starch has also been suggested. ${ }^{89}$

A detailed report of the abundance of various physiological groups of bactcria in different soils is given in table 5, based upon three determinations made by Dügelli ${ }^{88}$ in 1920 , using two samples for each determination.

Numbers of actinomyces in the soil. The synthetic media (p. 16) best adapted for the growth of bacteria are also well adapted for the growth of actinomyces, and their numbers can be determined on the same plate used for bacterial numbers. If the reaction of the media favorable for the study of numbers of the three groups of soil organisms are compared, the optimum for actinomyces is found to be $\mathrm{pH} 7.0$ to 7.5, for bacteria $\mathrm{pH} 6.5$ to 7.0, for fungi $\mathrm{pH} 4.0$. Of course, these are not the optima for the growth of the particular organisms in pure culture. The incubation period for counting actinomyces should be at least 7 days and, if possible, 14 days, at $25^{\circ}$ to $30^{\circ} \mathrm{C}$.

The actinomyces are, next to the bacteria, the most abundant group of organisms in the soil, as far as forms developing on the plate are concerned. Since a colony arises from a conidium, a chain of conidia or a piece of vegetative mycelium, larger numbers may not necessarily indicate more abundant vegetative growth, but a larger abundance of conidia.

Hiltner and Störmer observed an increase in the numbers of actinomyces in the autumn, relative to the other groups of microorganisms, due to the increase of the content in undecomposed organic matter in the soil. They were found to form in the spring 20 per cent, in the fall 30 per cent, dropping in the winter to 13 per cent, of the total soil microbial flora developing on the plate. The addition of stable manure, due to its straw content, results in an increase in the numbers of actinomyces.

${ }^{88}$ Düggeli, M. Die Bakterien des Waldbodens. Schweiz. Ztschr. f. Forstwes. 1923; Forschungen auf dem Gebiete der Bodenbakteriologie. Landw. Vorträge. Verlag Huber, Frausenfeld. 1921. H. 3.

${ }^{89}$ Hoffmann, C. A contribution to the subject of soil bacteriological analytical methods. Centrbl. Bakt. II, 34: 3S6-3Ss. 1912. 
Loam soils were found ${ }^{90}$ to contain a higher number of actinomyces than other soils, sandy soils coming last; a proportionate increase of these organisms was found in the fall (27 to 35 per cent) over the spring (18 to 23 per cent), but no reduction was observed in the winter. Cultivation of the soil effected a decrease in the numbers of actinomyces. These organisms are also found abundantly in forest soils $(24$ to 27 per cent of the flora) and on the roots of different plants, particularly grass and legume roots, the upper cell layers of which died down.

The soil microflora developing on the plate may consist of as many as 40 per cent of actinomyces; the total number of these organisms was found to be as high as 12 to 14 millions per gram of soil. ${ }^{91,92}$ Sod soils contain larger numbers of actinomyces than cultivated soils and it was

TABLE 6

Bacteria and actinomyces at various depths

Average of three New Jersey soils

\begin{tabular}{c|c|c|c|r}
\hline \multirow{2}{*}{ DEPTH } & \multicolumn{2}{|c|}{ BACTERIA } & \multicolumn{2}{c}{ Actinomyces } \\
\cline { 2 - 5 } & $\begin{array}{c}\text { Numbers in 1 } \\
\text { gram }\end{array}$ & Per cent & $\begin{array}{c}\text { Numbers in 1 } \\
\text { gram }\end{array}$ & Per cent \\
\cline { 2 - 4 } inches & & & & \\
1 & $7,340,000$ & 90.8 & 743,000 & 9.2 \\
4 & $5,300,000$ & 85.0 & 933,000 & 15.0 \\
8 & $2,710,000$ & 81.6 & 612,000 & 18.4 \\
12 & 950,000 & 79.9 & 239,000 & 20.1 \\
20 & 259,000 & 51.3 & 246,000 & 49.7 \\
30 & 124,000 & 34.6 & 240,000 & 63.6 \\
\hline
\end{tabular}

suggested, therefore, that they may play an active part in the decomposition of organic matter in the soil. ${ }^{93}$ The numbers of actinomyces decrease regularly with depth, but they increase in proportion to the other microorganisms, so that at a depth of 30 inches they form 65.6 per cent of the total microbial flora developing on the agar plate. ${ }^{94}$

90 Fousek, A. Über die Rolle der Streptotricheen im Boden. Mitt. Landw. Lchrkan. K. K. Hochschule f. Bodenk. Wien, 1: 217-244. 1913.

${ }^{91}$ Conn, H. J. Distribution of bacteria in various 'soil types. Jour. Amer. Soc. Agron. 5: 218-221. 1913.

${ }_{92}^{2}$ Krainsky, A. Die Aktinomyceten und ihre Bedeutung in der Natur. Centrbl. Bakt. II, 41: 649-688. 1914.

${ }_{93}$ Conn, H. J. A possible function of actinomycetes in soil. Jour. Bact. 1: 197-207. 1916; N. Y. State Agr. Exp. Sta. Tech. Bul. 60.

${ }_{94}$ Waksman, S. A., and Curtis, R. E. The actinomyces of the soil. Soil Sci. 1 : 99-134. 1916. 
Similar results were obtained by other investigators. ${ }^{95}$ It is not known whether this is due to the greater resistance of these organisms to the lack of oxygen, to the washing down of the conidia, or to some other cause. Since these organisms are very sensitive to acidity and to an excess of moisture, acid soils and water-logged soils contain a minimum number of actinomyces; since they play an active part in the decomposition of soil organic matter, heavy soils and soils rich in undecomposed organic matter, especially when well limed or buffered, contain

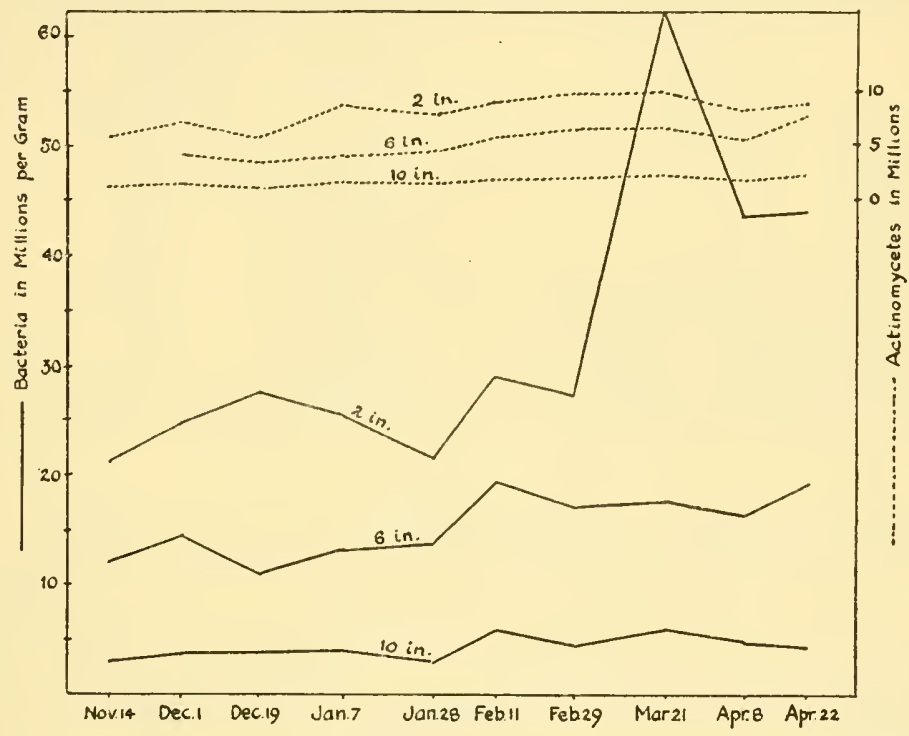

Fig. 3. Variation of numbers of bacteria and actinomyces at different seasons of the year and different depths of soil (from Lochhead).

high numbers of actinomyces, in comparison with the bacteria of the same soil.

The addition of manure ${ }^{96,97}$ as well as of different other forms of undecomposed organic matter greatly stimulates the development of actinomyces and may even result in an increase in their relative abundance, in

95 Lochhead, 1924 (p. 34).

${ }_{96}$ Hiltner, L. U̇ber neuere Ergebnisse und Probleme auf dem Gebiete der landwirtschaftlichen Bakteriologie. Jahrb. Ver. angew. Bot. for 1907, 5 : 200-222. 1908.

${ }^{97}$ Bright, J. W., and Conn, H. J. Ammonification of manure in soil. N. Y. Agr. Exp. Sta. Tech. Bul. 67. 1919. 
comparison with the other organisms developing on the plate. Among the other most important factors influencing the total and relative abundance of actinomyces in the soil is the soil reaction; the less acid the soil, the higher is the relative number of actinomyces. The influence of soil treatment upon the development of these organisms in the soil is shown in table 7 .

TABLE 7

Influence of soil treatment on the number of actinomyces in the soil

\begin{tabular}{|c|c|c|c|}
\hline TREATMENT OF SOIL & $\begin{array}{l}\text { ACTINOMYCES } \\
\text { PER GRAM }\end{array}$ & $\begin{array}{l}\text { PER CENT OF } \\
\text { FLORA } \\
\text { DEVELOPING } \\
\text { ON J'LATE }\end{array}$ & $\begin{array}{l}\text { SOIL REACTION } \\
\text { pHI }\end{array}$ \\
\hline Unfertilized . & $1,150,000$ & 27.7 & 4.6 \\
\hline Lime alone. & $2,410,000$ & 31.6 & 6.4 \\
\hline Minerals*............ & $1,520,000$ & 22.7 & 5.5 \\
\hline Manure and minerals.......... & $2,920,000$ & 24.5 & 5.4 \\
\hline Minerals and ammonium sulfate....... & 370,000 & 12.1 & 4.1 \\
\hline Minerals, ammonium sulfate and lime... & $2,520,000$ & 26.5 & 5.8 \\
\hline Minerals and sodium nitrate. .......... & $2,530,000$ & 25.0 & 5.5 \\
\hline
\end{tabular}

* 320 pounds of $\mathrm{ICl}$ and 610 pounds acid phosphate per acre every year.

TABLE 8

Influence of liming and fertilization upon the numbers of fungi in the soil

\begin{tabular}{|c|c|c|}
\hline SOIL TREATMENT & pII & $\begin{array}{l}\text { NUMBERS } \\
\text { OF FUNGI PER } \\
\text { GRAM }\end{array}$ \\
\hline Unfertilized . . . . . . . . . . & 4.8 & $6.5,500$ \\
\hline Lime alone .................. & 6.4 & 16,900 \\
\hline Minerals.................. & 5.6 & 45,600 \\
\hline Minerals + lime . . . . . . . . . . . . . & 6.4 & 26,300 \\
\hline 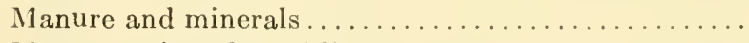 & 5.6 & 91,000 \\
\hline Manure, minerals and lime $\ldots \ldots \ldots \ldots \ldots \ldots \ldots$ & 7.0 & 29,400 \\
\hline $\mathrm{NaNO}_{3}$ and minerals . . . . . . . . . . . . & 5.8 & 45,900 \\
\hline$\left(\mathrm{NH}_{4}\right)_{2} \mathrm{SO}_{4}$ and minerals . . . . . . . . . . . . & 4.6 & 107,900 \\
\hline Manure, $\mathrm{NaNO}_{3}$ and minerals . . . . . . . . . . . & 5.8 & 87,600 \\
\hline
\end{tabular}

Numbers of fungi in the soil. Fungi also exist in the soil both in the form of vegetative mycelium and reproductive spores. Methods for demonstrating the existence of specific forms in the soil are described elsewhere (p. 239). There is no method yet devised for finding out how much of the fungus material exists in the soil as mycelium or as spores; we neither have means of determining how many of the colonies develop- 
ing on the plate are due to spores and how many to pieces of mycelium. There is also no basis for comparing the relative abundance and potential activity between the bacterial and fungus flora of the soil; for example, 1000 colonies of fungi may indicate a greater activity than $1,000,000$ colonies of bacteria, when a certain process, such as cellulose or protein decomposition is studied. However, if the 1000 fungus colonies represent inactive spores, the activity of the organism may be questioned.

With these limitations in mind and in view of the fact that most of the determinations of numbers of fungi have been made by the use of high

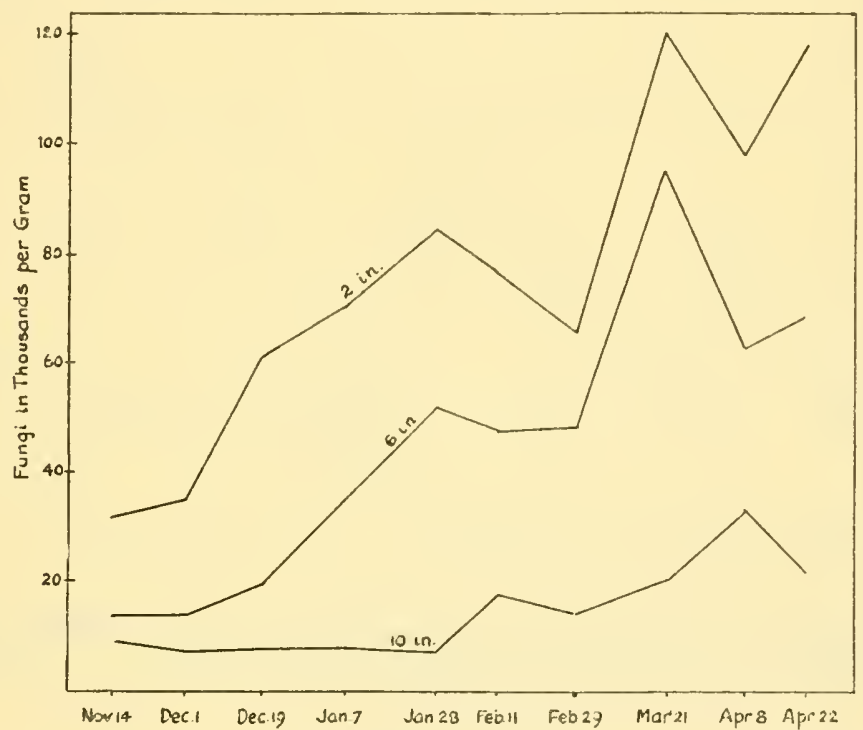

FIG. 4. Variation of numbers of fungi at different seasons of the year and different depths of soil (from Lochhead).

dilutions and of the bacterial agar plate, it is questionable to what extent many of the results obtained in the past actually represent even relative soil conditions. In general, the soil is found ${ }^{98}$ to harbor between 30,000 and 900,000 fungi (spores and pieces of mycelium) per gram, depending on the type of soil and treatment. Others ${ }^{99}$ reported a range of 42,000

98 Waksman, S. A. Soil fungi and their activities. Soil Sci. 2: 103-155. 1916; Is there any fungus flora of the soil? Ibid. 3: 565-589. 1917; Waksman, $\mathrm{S}$. A. Influence of soil reaction upon the distribution of fungi in the soil. Ecology, 5: 54-59. 1924.

${ }^{99}$ Brown and Halversen. 1919 (p. 33). 
to 131,000 fungi per gram of soil when plated out on three different media, with a ratio between the fungi and bacteria developing on the plate as 1:40 or 1:50. However, whenever possible, these results should be checked up by microscopic observations.

An acid medium similar to the one described above, combined with a low dilution allows the determination, with a fair degree of accuracy, of
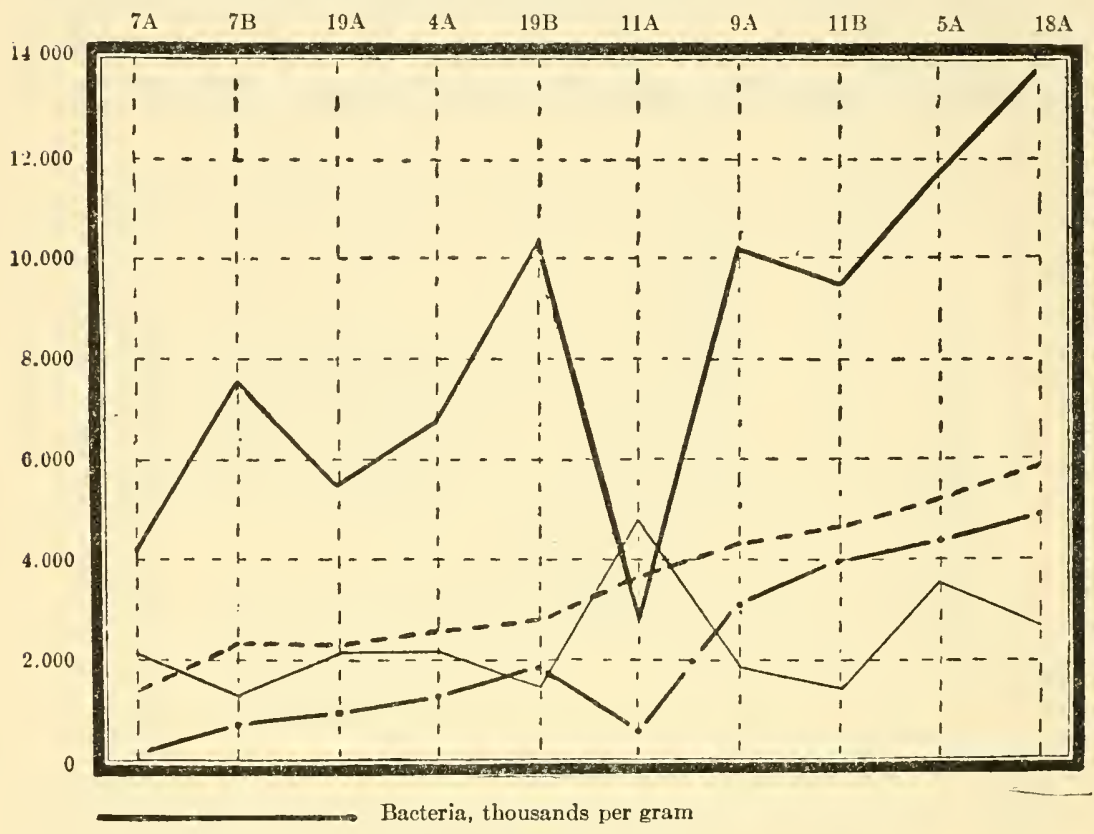

Fungi, hundreds per gram

- _ _ _ _ _ Average yield, 1908-1921

. - Yield for 1921

Fig. 5. Influenee of soil treatment upon the numbers of baeteria and fungi in the soil: $7 \mathrm{~A}$ and $7 \mathrm{~B}$, no fertilizer or manure; $4 \mathrm{~A}, 19 \mathrm{~A}, 19 \mathrm{~B}$, reeeiving only mineral fertilizers (phosphate and $\mathrm{KCl}$ ); $11 \mathrm{~A}$ and $11 \mathrm{~B}$, ammonium sulfate and minerals; $9 \mathrm{~A}$, sodium nitrate and minerals; $5 \mathrm{~A}$, stable manure and minerals; the B plots limed in 1908, 1913, 1918 (after Waksman and de Rossi).

the relative abundance of fungi in the soil. The more acid the soil is, the greater is the number of fungi relative to the number of the other soil microorganisms. Figure 4 gives the changes in the number of fungi during the year and at different depths and fig. 5 shows the influence of soil treatment upon the numbers of bacteria and fungi in the soil. 
Numbers of protozoa in the soil. The protozoa exist in the soil both in an active stage and in a cyst condition. The methods employed should give more or less accurate information concerning the numbers of protozoa in the soil in both of these two stages. It is sometimes essential to be able to count protozoa in culture solutions. This can be done in four different ways. (1) The most common method consists in placing a drop of a known volume of the protozoan suspension under the microscope and counting the number of protozoa. The use of a slimy colloidal solution for the purpose of reducing the motility of protozoa, as, for example, semen psylii, semen cydoniae or gum tragacanth has been suggested. ${ }^{100}$ Two per cent gelatin solution may also be employed for this purpose. (2) The use of a standard loop devised for bacteria may also be employed ${ }^{101,102}$ for counting of protozoa. (3) The agar plate method may be used. ${ }^{103}$ None of these three methods is very suitable for the determination of the number of protozoa in the soil itself, although the first two can be used for the examination of soil for the presence of living protozoa. For an accurate determination of the total number of protozoa in the soil, including both the active forms and the cysts, the (4) dilution method is most appropriate. ${ }^{104,105,106}$ The method consists in diluting the soil with sterile tap water, then placing 1 cc. portions of the various dilutions into sterile media, incubating, examining the cultures at periodic intervals (5, 12 and 20 days) and determining the highest dilution at which growth takes place. The number of protozoa is thus found to lie between this and the next higher dilution at which growth did not take place. If, for example, a dilution of 1:1000 gives growth, while 1:10,000 does not give any, there are between 1000 and 10,000 protozoa in a gram of soil. The

${ }^{100}$ Statkewitsch, P. Zur Methodik der biologischen Untersuchungen über die Protisten. Arch. Protistenk. 5: 17-39. 1905.

101 Müller, P. T. Über eine neue, rasch arbeitende Methode der bakteriologischen Wasseruntersuchung und ihre Anwendung auf die Prüfung von Brunnen und Filterwerken. Arch. Hyg. 75: 189-223. 1912.

102 Koch, G. P. Soil protozoa. Jour. Agr. Res. 4: 511-559. 1915; 5: 477-488. 1915; Soil Sci. 2: 163.1916.

${ }^{103}$ Killer, J. Die Zählung der Protozoen im Boden. Centrbl. Bakt. II, 37 : 521-534. 1913.

${ }^{104}$ Rahn, O. Methode zur Schätzung der Anzahl von Protozoen im Boden. Centrbl. Bakt. II, 36: 419-421. 1913.

${ }^{105}$ Cunningham, A. Studies on soil protozoa. Jour. Agr. Sci. 7: 49-74. 1915. ${ }^{106}$ Sherman, J. M. The number and growth of protozoa in soil. Centrbl. Bakt. II, 41: 625-630. 1914; also 1916 (p. 47). 
dilutions can be made narrower and the number of protozoa determined with a greater degree of accuracy. This method can also be modified so as to give not only the total number of protozoa in the soil, but also the number of active forms and cysts. ${ }^{107}$

The soil is passed through a $3 \mathrm{~mm}$. sieve and two 10 -gram samples are taken. The total number of protozoa (active forms plus cysts) is determined, in one sample, while the other sample is used for the determination of cysts. Taking eare to agitate the flask while the liquid is being transferred, the following dilutions are prepared:

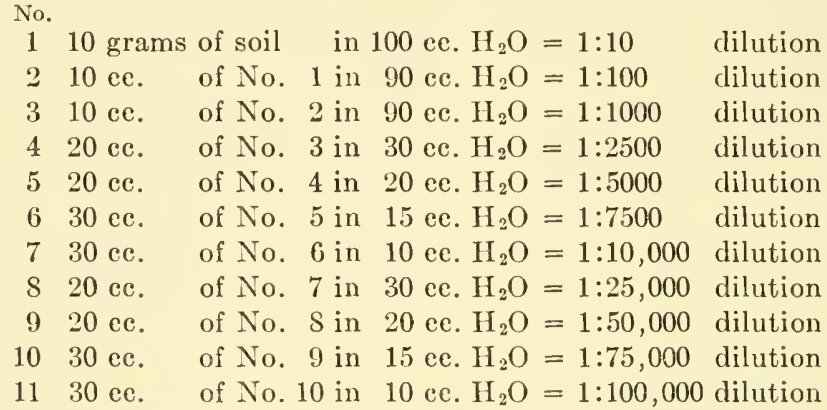

Dilutions of 25-102,400 or 50-204,800 may also be prepared.

Nutrient agar is poured into a series of sterile Petri dishes. When the medium has solidified, the dishes are inoculated in pairs with $1 \mathrm{cc}$. of each dilution. The same pipette may be used when one begins with the highest dilution and goes back to the lowest. The plates are incubated at $18^{\circ}$ to $20^{\circ}$ for 28 days and examined after $7,14,21$, and 28 days. A little sterile water is added to the plates, in case they begin to dry out. The examination is made by scraping off a little of the surface of the plate, placing on a slide under the microseope and examining with low and high power.

The second 10 -gram sample of soil is treated with sufficient 2 per cent $\mathrm{HCl}$, over night, to neutralize the carbonate present in the soil and still leave an excess of unehanged 2 per cent $\mathrm{HCl}$. This kills all the active forms leaving the cysts unharned. The number of protozoa is then determined by the same dilution method. The number of eysts subtracted from the total number of organisms, obtained in the first count, gives the number of active protozoa per gram of soil.

Fisher ${ }^{108}$ investigated the theory of estimation of microorganisms by the dilution method and found that a very high efficiency can be thus obtained ( 87.71 per cent). By the use of a special table, the number of protozoa can be calculated, when the number of negative plates is

${ }^{107}$ Cutler, D. W. A method for estimating the number of active protozoa in the soil. Jour. Agr. Sci. 10: 135-143. 1920.

108 Fischer, R. A. On the mathematieal foundations of theoretical statisties. Phil. Trans. Roy. Soc. London, Ser. A, 222: 309-368. 1922. 
known. By using 26 plates and a series of dilutions (13) ranging from $\frac{1}{25}$ to $1 \frac{1}{10}, 400$, the following results were obtained: ${ }^{109}$

\begin{tabular}{c|c||c|c}
\hline $\begin{array}{c}\text { NUMBER OF ETERILE } \\
\text { PLATES }\end{array}$ & PROTOZOA PER GRAM & $\begin{array}{c}\text { NUMBER OF STERILE } \\
\text { PLATES }\end{array}$ & PROTOZOA PER GRAM \\
\hline 1 & 110,000 & 14 & 640 \\
2 & 59,000 & 15 & 450 \\
3 & 36,000 & 16 & 320 \\
4 & 23,000 & 17 & 230 \\
5 & 16,000 & 18 & 160 \\
6 & 11,000 & 19 & 110 \\
7 & 7,600 & 20 & 79 \\
8 & 5,300 & 21 & 56 \\
9 & 3,700 & 22 & 35 \\
10 & 2,600 & 23 & 25 \\
11 & 1,800 & 24 & 15 \\
12 & 1,300 & 25 & 6.8 \\
13 & 900 & & \\
\hline
\end{tabular}

For the examination of trophic protozoa, the soil sample is moistened with some sterile water, placed on a slide and examined for a minute under the microseope.

When soil or soil suspension is placed in a medium favorable for the development of protozoa, there is found a close connection between the growth of these organisms to that of the bacteria, the former always lagging behind. There is also observed a general sequence of protozoan forms, the flagellates appearing first, followed by the ciliates and later by the amoebae. A detailed review of the media used for the cultivation of protozoa is given elsewhere (p. 317).

Garden soils contain a great number of protozoa;110 amoebae were found $^{111}$ to develop on agar plates, even when the inoculum was only $1 \mathrm{mgm}$. of soil. An average of about 100 eiliates and 1000 to 10,000 flagellates per gram of soil was reported by earlier workers. ${ }^{112}, 114$ Sherman ${ }^{113}$ compared the numbers of protozoa in sixteen soils representing various soil types under various treatments; he found that normal

109 Cutler et al., 1922 (p. 32).

110 Hiltner, 1907 (p. 47).

111 Störmer, K. Über die Wirkung des Schweffelkohlenstoffs und ähnlicher Stoffe auf den Boden. Jahresb. Ver. angew. Bot. for 1907, 5: 113-131. 1908. 112 Rahn, 1913 (p. 45).

${ }^{113}$ Sherman, J. M. Studies on soil protozoa and their relation to the bacterial flora. Jour. Bact. 1: 35-66; 165-185. 1916.

114 Waksman, S. A. Studies on soil protozoa. Soil Sei. 1: 135-152; 2: 363376. 1916. 
fertile soil has a protozoan content approximating 10,000 per gram, the flagellates constituting the greater portion; about 100 ciliates were found per gram; certain types of protozoa are active in the'soil under

TABLE 9

Influence of organic malter on numbers of protozoa in the soil (average of 10 counts) 117

\begin{tabular}{|c|c|c|c|c|c|c|}
\hline & \multicolumn{3}{|c|}{$\begin{array}{c}\text { BROADBALK MANURED } \\
\text { (10 PER CENT ORGANIC } \\
\text { MATTER) }\end{array}$} & \multicolumn{3}{|c|}{$\begin{array}{l}\text { HARPENDEN FIELD } \\
\text { (5.7 PER CENT ORGANIC } \\
\text { MATTER) }\end{array}$} \\
\hline & $C^{*}$ & $F$ & A & $\mathrm{C}$ & $\mathbf{F}$ & A \\
\hline February 1-March $5,1917 \ldots$ & 20 & 32,000 & 1500 & 10 & 13,500 & 500 \\
\hline April 17-June 6, $1917 \ldots \ldots$ & 130 & 23,000 & 1600 & 20 & 71,000 & 500 \\
\hline June 13 -September $20,1917 \ldots$ & 120 & 31,200 & 18,600 & 10 & 25,700 & 17,000 \\
\hline October 10-December 15, 1917. & 20 & 42,300 & 23,200 & 10 & 23,330 & 10,000 \\
\hline
\end{tabular}

${ }^{*} \mathrm{C}=$ ciliates, $\mathrm{F}=$ flagellates, $\mathrm{A}=$ amoebae.

TABLE 10

Influence of soil depth upon the numbers of protozoa ${ }^{\mathrm{I1}}$

\begin{tabular}{|c|c|c|c|}
\hline DEPTH & A MOEBAE PER 1 GRAM & $\begin{array}{c}\text { FLAGELLATES PER } 1 \\
\text { ORAM }\end{array}$ & CILIATES PER 1 ORAM \\
\hline inches & & & \\
\hline 6 & 1750 & 8750 & 100 \\
\hline 12 & 0 & 100 & 0 \\
\hline 18 & 0 & 100 & 0 \\
\hline
\end{tabular}

TABLE 11

Numbers of protozoa and bacteria per gram of soil from two Broadbalk plots ${ }^{119}$

\begin{tabular}{|c|c|c|c|c|c|c|}
\hline & \multicolumn{2}{|c|}{ MANURED } & \multicolumn{2}{|c|}{ UNMANURED } & \multirow{2}{*}{$\begin{array}{l}\text { ACTIVE } \\
\text { ForMS }\end{array}$} & \multirow{2}{*}{$\begin{array}{c}\text { APPROXI- } \\
\text { AIATE } \\
\text { DIAMETEY } \\
\mu\end{array}$} \\
\hline & Winter total & Summer & $\begin{array}{c}\text { Winter } \\
\text { total }\end{array}$ & $\underset{\text { total }}{\text { Summer }}$ & & \\
\hline Plagellates. & 150,000 & 600,000 & 5,500 & 15,000 & 15 to 95 & $7.5-15$ \\
\hline Amoebae... & 5,000 & 15,000 & 40 & 2,000 & per & $8-22$ \\
\hline Thecomoebae. & $\ldots \ldots$ & 1,000 & & $\ldots \ldots \ldots$ & cent & 15 \\
\hline Ciliates.... & 50 & 200 & & $\ldots \ldots \ldots$ & in all & $20-40$ \\
\hline Bacteria... & $10,000,000$ & $24,000,000$ & $4,000,000$ & $5,000,000$ & cases & $1-4$ \\
\hline
\end{tabular}

normal and even sub-normal conditions of moisture, the active forms being probably restricted to the flagellates. Although the amoebae are also widely distributed in the soil, ${ }^{115}$ their numbers have not been re-

${ }^{116}$ Martin, C. H., and Lewin, K. R. Some notes on soil protozoa. Phil. Trans. Roy. Soc. London, 205B: 77-94. 1914; Jour. Agr. Sci. 7: 106-119. 1915. 
ported in detail due to the difficulty of their development on the common media. In soils with a moisture content not in excess of the physical optimum, protozoa exist mainly in a nontrophic state. ${ }^{116}$ The protozoa become active in the soil whenever there is excessive moisture present for a period of several hours. Such conditions are common, especially in rainy seasons, in poorly drained soils, in spring, etc. The protozoa then excyst and, after a period of active growth, they reproduce. When conditions become again unfavorable, they either encyst or die. Protozoa are readily found in field ditches, furrows with standing water, etc. Since the protozoa chiefly use bacteria as their food

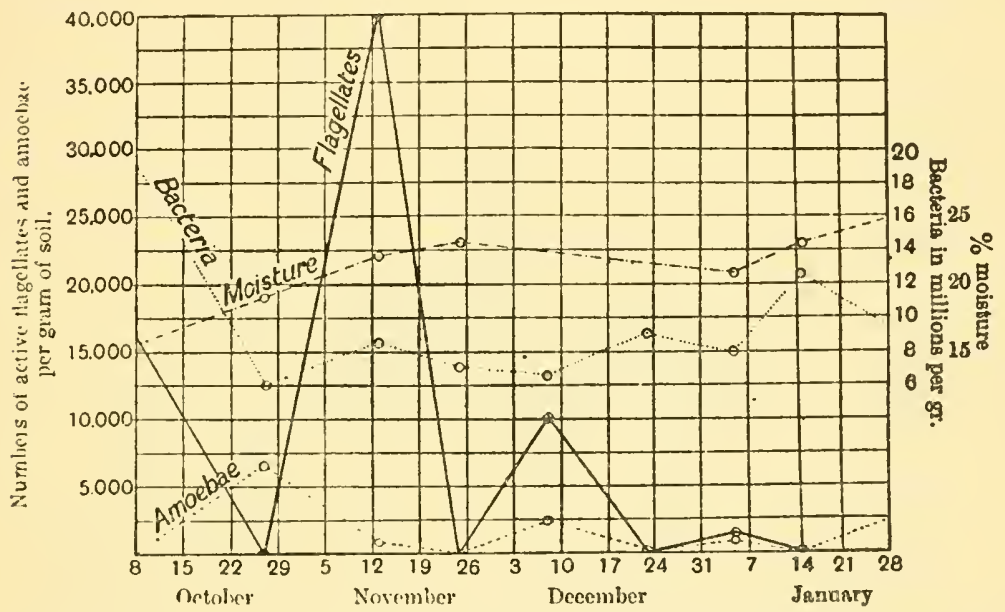

Fig. 6. Numbers of active flagellates, amoebae and bacteria in the soil, in relation to its moisture content (from Cutler and Crump).

(perhaps also organic matter and soil extracts, especially in the case of small flagellates), they are more abundant in rich fertile soils than in poor acid soils. Their greatest numbers are concentrated in the top four or six inches of soil, where the bacteria are also at a maximum, while below twelve inches the soil is practically free from protozoa. ${ }^{117}$ Isolated species may be found, usually in a cyst condition, even at very low depths. ${ }^{118}$ By the use of the method above described, Cutler and

${ }^{116}$ Fellers, C. R., and Allison, F. E. The protozoan fauna of the soils of New Jersey. Soil Sci. 9: 1-25. 1920.

${ }^{117}$ Crump, L. M. Numbers of protozoa in certain Rothamsted soils. Jour. Agr. Sci. 10: 182-198. 1920.

118 Sandon, 1927 (p. 329). 
Crump ${ }^{119}$ estimated at frequent intervals the numbers of active protozoa and cysts in Rothamsted soils and found them to be much higher on the manured than on the unmanured plot.

The numbers of protozoa and bacteria were found to vary from day to day. ${ }^{120}$ An inverse relation was found between the number of active amoebae and bacteria.

The numbers of algae in the soil can also be determined by the dilution method, using the specific media, described elsewhere (p. 221) best

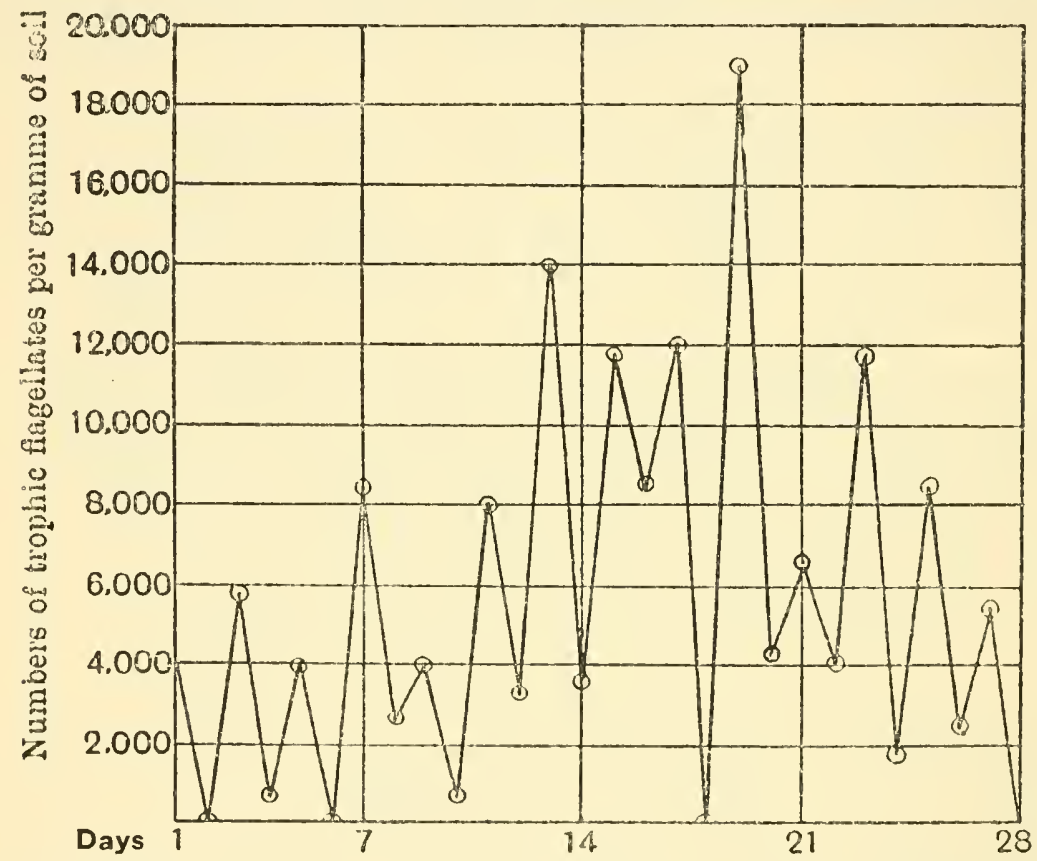

Fig. 7. Daily variation of active flagellates in the soil (from Cutler and Crump).

adapted to the development of these organisms. ${ }^{121}$ The numbers of nematodes and other worms, insects and other members of the invertebrate population of the soil, as well as methods of determination, are given elsewhere (p. 342).

119 Cutler, D. W., and Crump, L. M. Daily periodicity in the numbers of active soil flagellates: with a brief note on the relation of trophic amoebae and bacterial numbers. Ann. Appl. Biol. 7: 11-24. 1920.

${ }^{120}$ Cutler et al., 1922 (p. 32).

${ }^{121}$ Bristol-Roach, 1926 (p 225) 
PART B

ISOLATION, IDENTIFICATION, AND CULTIVATION

OF SOIL MICROORGANISMS 



\section{CHAPTER II}

\section{Pure Culture Study and Classification of Soll Bacteria}

It is almost impossible at present to make a complete study of the various types of bacteria occurring in the soil, due both to the great variety of forms and to the lack of sufficient knowledge concerning many of them. Bacteria offer but few stable characteristics which can be utilized for their separation. Classification of bacteria in general and of soil bacteria, in particular, is not fully satisfactory. The different systems of classification can, therefore, be merely tentative; they are based either on the physiological activities of the organisms, especially their carbon, nitrogen, and oxygen metabolism, or on their morphological relationships. In the general subdivision of the soil bacteria, the physiological system will be utilized for the greater convenience which it offers in the study of the rôle of these organisms in the soil; in the differentiation of the individual bacteria within the large groups morphological characters are utilized.

Pure culture study. In the case of large organisms, a pure culture corresponds to an individual. In the case of the unicellular bacteria, the transformation carried on by one cell is too small, and large numbers of organisms must take part in a reaction, before measurable changes are obtained; these individual cells, however, must be as much alike as possible. The various bacteria do not exist in the soil in pure culture, but in mixed associations; entirely different results are usually obtained under natural conditions, with the various microbiological processes completing one another, than in pure culture. This is especially true in the case of organisms which depend for their nutrients upon the activities of other organisms, as in the case of the nitrite bacteria which depend upon the various proteolytic organisms for their substrate (ammonia), and the nitrate-forming bacteria which depend upon the nitrite formers for their supply of energy source (nitrite). Antagonistic effects are often marked under natural surroundings, while they are eliminated in pure culture. Certain soil processes, such as cellulose decomposition or nitrogen-fixation, are carried on much more actively by crude than by pure cultures of the organisms concerned, due to the fact that the accompanying organisms 
either use up the deleterious waste products or in some other way contribute to the process in question.

To be able to identify the various species of bacteria and determine their specific functions upon nutritive media and in the soil, it is necessary to obtain them in pure culture. A mere microscopic examination of bacteria is usually insufficient for their identification. They should be studied on artificial culture media and records made of the cultural characteristics and biochemical changes produced. Among these characteristics, we may include size, appearance and color of colony; growth upon solid and liquid media; modification of color, consistency, reaction and chemical composition of the medium; action upon sugars and proteins and enzyme formation, and influence of oxygen tension, temperature and chemical agents. Among the morphological characteristics, we may include form, size, grouping and appearance of cells, motility, spore formation, manner of reproduction, etc.

Pure cultures of bacteria and other microorganisms are often weakened, when grown on artificial culture media, or may lose altogether their capacity of producing the change which they carry on in nature, as in the case of certain nitrogen-fixing bacteria. This leads to differences in results in the hands of different investigators. We are dealing here with organisms whose functions are changeable and which are very variable in their activities. ${ }^{1}$ It is best to work with freshly isolater organisms and it is always advisable to establish the constancy of physiological characteristics.

In obtaining pure cultures of a number of soil bacteria, especially those producing certain biochemical changes when grown in the presence of specific substances, the selective or accumulative culture method used extensively by Beijerinck, ${ }^{2}$ Winogradsky and others may be utilized. The first step made in the isolation of a particular organism consists in adding some of the material (soil or manure) to a liquid medium containing nutrients especially adapted to the growth of that particular organism. This allows the accumulation of the organism in question and eliminates largely the other accompanying forms. By transferring repeatedly to the same sterile medium, an enrichment culture is obtained. Theoretically one species is obtained under ideal enrichment

${ }^{1}$ Pringsheim, H. Die Variabilität niederer Organismen. Berlin. J. Springer. 1910.

${ }^{2}$ Richter, O. Die Bedeutung der Reinkultur. Borntraeger. Berlin. 1907; Stockhausen. Oekologie, Anhäufungen nach Beijerinck. 1907. 
conditions; actually, a number of strains may be obtained, which, on separation, may often be mistaken for different species.

The direct method of isolation suggested by Winogradsky ${ }^{3}$ may also be employed. This consists in adding a specific nutrient to a silica gel plate, containing the necessary nutrients, and inoculating with particles of soil. Only the organisms capable of acting upon the specific substrate will develop on the plate in forms readily isolated.

In the case of the majority of soil bacteria (especially the heterotrophic forms), both aerobic or anaerobic, the plate method will prove convenient for the isolation of the individual organisms from colonies. The selective culture method in most cases and the plate method in some cases yield only crude cultures of the organisms. In the majority of cases these cultures are quite satisfactory. However, for biochemical studies and especially in the study of life cycles of bacteria, it is advisable to obtain single-cell cultures of the organisms. In most instances this is accomplished by the dilution method, which may be accompanied by the transfer of a single cell by the India ink $^{5}$ method or by means of a capillary pipette. ${ }^{6}$ The first consists in mixing a highly diluted culture with sterile India or China ink, placing pin-point droplets of the mixture upon the surface of sterile agar or gelatin, covering with sterile cover slips, examining with highpower objective for the presence of a single cell, incubating, and finally transferring or lifting the cover slip with adhering bacterial cell and inoculating into sterile medium. The second method consists in

${ }^{3}$ Winogradsky, 1925 (p. 11).

${ }^{4}$ Löhnis, F. Studies upon the life cycles of the bacteria. I. Mem. Nat. Acad. Sci. 16, 1921, No. 2, p. 39.

${ }^{5}$ Burri, R. Eine einfache Methode zur Reinzüchtung von Bakterien unter mikroskopischer Kontrolle des Ausgangs von der einzelnen Zelle. Centrbl. Bakt. II, 20: 95-96. 1908; Das Tuschepunktverfahren. G. Fischer. Jena. 1909.

${ }^{6}$ Barber, M. A. On heredity in certain micro-organisms. Kansas Univ. Science Bull. 4: no. 1 48 p. 1907; Jour. Inf. Dis. 5: 379. 1908; 8: 348. 1911; The pipette method in the isolation of single microörganisms and in the inoculation of substances into living cells. Philippine Jour. Sci. B. 9: 307-360. 1914; The use of single cells method in obtaining pure cultures of anaerobes. Jour. Exp. Med. 32: 295. 1920; Shouten, S. L. Reinkulturen aus einer unter dem Mikroskop isolierten Zelle. Ztschr. Wissensch. Mikrosk. 22: 10, 1907; 24: 258. 1907; Hecker, F. A new model of double pipette holder and the technic for the isolation of living organisms. Jour. Inf. Dis. 19: 305. 1916; Hort. Jour. Hyg. 18: 361. 1920; Topley, W. W. C., Barnard, J. E., and Wilson, G. S. A new method of obtaining cultures from single bacterial cells. Jour. Hyg. 20: 221-226. 1921; Malone, R. H., A simple apparatus for isolating single microorganisms. Jour. Path. Bact. 22: 222. 1918. 
drawing up individual cells by means of the Barber capillary pipette and transferring them to specific sterile liquid media. The micromanipulator of Chambers ${ }^{7}$ may also be employed.

In view of the fact that the bacteria live and act in the soil in mixed culture, important information is obtained not only from the study of pure cultures, but also from mixed cultures, either crude or artificially prepared.

For a description of pure cultures of bacteria, the Chart of the Society of American Bacteriologists can be used..$^{3,9}$ This includes a study of the important morphological, physiological and cultural characteristics of the organisms. However, the chart can not be readily utilized in the description of most of the soil bacteria with the exception of some of the heterotrophic bacteria requiring combined nitrogen, especially the spore-forming organisms. ${ }^{10}$

Differentiating characters of bacteria. The size of the organisms is a variable factor with rather large limits of variation which depend upon the nutrient media in which the cells are grown and various environmental conditions. ${ }^{11}$ However, in the case of the spore-forming bacteria, the size of the spore is of great diagnostic value. Motility of bacteria has been utilized in the classification of Migula but the constancy and value of this character have been questioned by Lehmann and Neumann, ${ }^{12}$ who found the presence or absence of spore production by

7 Chambers, R. New micromanipulator and methods for the isolation of a single bacterium and the manipulation of living cells. Jour. Inf. Dis. 31: 334-343, 344-348. 1922.

${ }^{8}$ Harding, H. A. The constancy of certain physiological characteristies in the classification of bacteria. N. Y. Agr. Exp. Sta. Tech. Bul. 13. 1910.

${ }^{9}$ Rahn, O., and Harding, H. A. Die Bemühungen zur einheitlichen Beschriebung der Bakterien in America. Centrbl. Bakt. II, 42: 3S5-393. 1914.

10 The methods used in the description of these organisms are discussed in the various Reports of the Committee on Bacteriological Technic of the Society of American Bacteriologists. C. B. T. Methods of pure culture study. Jour. Bact. 3: 115-13S. 1918; 4: 107-132. 1919; 5: 127-143. 1920; 7: 107-132. 1919. Conn, H. J. et al. Recent work on the descriptive chart and the manual of inethods. Ibid. 10: 315-319. 1925. Also Conn, H. J. Soil flora studies. II. Methods best adapted to the study of the soil bacteria. N. Y. Agr. Exp. Sta. Tech. Bul. 57: 18-42. 1917.

${ }^{11}$ Löhnis, F., and Smith, N. R. Life cycles of bacteria. Jour. Agr. Res. 6: 676-702. 1916; 23: 401-432. 1923; also Löhnis, 1921 (p. 55); Scales, F. M. Induced morphologic variation in B. coli. Jour. Inf. Dis. 29: 591-610. 1921.

${ }^{12}$ Lehmann, K. B., and Neumann, R. O. Atlas und Grundrisz der Bakteriologie. München, Lehmann's. 1920. 
bacteria to be a more definite characteristic. The form of growth of the various organisms is also of important diagnostic value.

As to the various physiological characteristics, some, like liquefaction of gelation, nitrate reduction ${ }^{13}$ and chromogenesis, are of considerable diagnostic value; others, like diastatic power, fermentation of sugars, indol formation, action on milk, give rather inconsistant results.

Although the morphological characters of the bacteria should be utilized in a scientific system of classification, the soil bacteria lend themselves readily to a general classification based upon their physiological activities. Such a system is suggested here for the purpose of grouping the bacteria according to the important soil processes in which they take an active part, utilizing the more systematic classification for the discussion of the specific organisms.

Life cycles of bacteria. According to Löhnis, bacteria live alternately in an organized and in an amorphous or "symplastic" stage. In the latter stage the living matter which has been previously enclosed in the separate cell, undergoes a thorough mixing either by a complete disintegration of the cell wall and cell contents or by a "melting together" of the contents of many cells which leave their empty cell walls behind them; it seems to be formed both of the vegetative and reproductive cells; this process is similar to autolysis, without the destruction of the living substance. The symplasm may undergo amoeboid changes or become encapsulated, giving spherical macrocysts. In the process of formation of new individual cells from the symplasm, "regenerative units" are first visible, which increase in size becoming either directly vegetative cells or "regenerative bodies." The latter become, by germination and stretching, normal cells or return temporarily into the symplastic stage.

In addition to symplasm formation, two or more individual cells may unite directly (conjunction). All bacteria multiply not only by fission but also by the formation of gonidia, which first become regenerative bodies or exospores. The gonidia may either grow directly into full cells or enter the symplastic stage. Thread-like branching forms may also be produced from the symplasm. The life cycles of each species of bacteria is composed of several sub-cycles showing wide morphological and physiological differences. They are connected with each other by the symplastic stage (Nos. $47,48, \mathrm{Pl}$. IX). However, some investi-

${ }^{23}$ Breed, R. S. The standard method of determining nitrate reduction. Science, N. S. 41: 661. 1914. 
gators $^{14}$ deny the formation of symplasm by Azotobacter; this is looked upon as a stage of gradual autolysis of the cell membrane rather than a stage of reproduction. Henrici ${ }^{15}$ demonstrated that bacterial cells undergo metamorphosis cluring the growth of a culture, similar to that exhibited by cells of a multicellular organism; each species presents three types of cells: a young form, an adult form and a senescent form; the variations depend upon the rate of metabolism.

Classification of bacteria. This is not the place to discuss the value of the different systems of classification of bacteria. It is sufficient to call attention to the systems of Migula, Lehmann and Neumann and to that proposed by the Committee on Classification of the Society of American Bacteriologists, and incorporated in Bergey's Manual. ${ }^{16}$ One may conveniently use here Migula's classification, with slight modifications, especially in the case of the Bacteriaceae, which are more commonly divided on the basis of spore formation.

I. Simple and undifferentiated forms, not forming any threads and not branching under normal conditions. Order Eubacteria.

1. Cells mostly spherical, rarely rod-shaped, Coccaceae Zopf emend. Migula:

(a) Division in one direction, frequent formation of chains, 1. Streptococcus Billroth.

(b) Irregular division in all directions; cells occur singly, in pairs or clumps, but not in chains, 2. Micrococcus Cohn.

(c) Division in three directions leading to packet formation, 3 . Sarcina Goodsir.

Planostreptococcus, Planococcus, Planosarcina include similar but flagellated group.

2. Cells mostly rod-shaped, rarely spherical or eurved, Bacteriaceae Zopf emend. Migula:

(a) No endospores formed, 4. Baclerium Cohn.

(b) Endospores formed, 5. Bacillus Cohn.

(c) Cells with polar flagella; endospores rarely formed, 6. Pseudomonas.

3. Cells mostly curved or spiral, rarely spherical or rod-shaped, SPIrilitaCEAE Migula:

(a) Cells comma-shaped, 7. Vibrio Müller emend. Löffler.

(b) Cells rigid, spiral shaped, 8. Spirillum Ehrenberg emend Löffier.

(c) Cells flexible, spiral shaped, 9. Spirochaeta Ehrenberg.

${ }^{14}$ Beauverie, J. Le symplasme bactérien existe-t-il? Cas de l'azotobacter. Compt. Rend. Acad. Sci. 180: 1792-1794. 1925.

${ }^{15}$ Henrici, A. T. On cytomorphosis in bacteria. Science 61: 644-646. 1925.

${ }^{16}$ Winslow, C.-E. A., Broadhurst, J., Buchanan, R. E., Krumwiede, C., Rogers, L. A., and Smith, G. H. The families and genera of the bacteria. Jour. Bact. 5: 191-229. 1920; also Ibid. 2: 505. 1917; Bergey, 1924 (p. x). 
II. Growth similar to the Eubacteria, but cells containing bacteriopurpurin (and bacteriochlorin), being colored rose, red or violet. Order RHodoBACTERIA.

III. Colorless bacteria accumulating sulfur within their cells. Order ThioBACTERIA.

IV. Alga-like bacteria. Order Pнycobacteria. This order comprises the family Chlamydobacteriaceae which form sheaths; these include the iron bacteria. ${ }^{17}$

V. Fungus-like bacteria, rod-shaped, rarely filamentous. Order Mrcobacteria. The Actinomyces are frequently included in this genus.

VI. Bacterial cells enclosed in a slimy mass, forming a pseudoplasmodium-like aggregation before passing into a cyst-producing resting stage. Order MYXOBACTERIA.

\section{Clussification of soil bacteria based upon their physiological activities ${ }^{18}$}

I. Autotrophic and facultative autotrophic bacteria, deriving their carbon primarily from the $\mathrm{CO}_{2}$ of the atmosphere and their energy from the oxidation of inorganic substances or simple compounds of carbon.

1. Bacteria using nitrogen compounds as sources of energy:

(a) Nitrite forming bacteria.

(b) Nitrate forming bacteria.

2. Bacteria using sulfur and sulfur compounds as sources of energy.

3. Bacteria using iron (and manganese) compounds as sources of energy.

4. Bacteria using simple carbon compounds as sources of energy :

(a) Bacteria oxidizing carbon monoxide.

(b) Bacteria oxidizing methane.

5. Bacteria using hydrogen as a source of energy.

II. Heterotrophic bacteria deriving their carbon and energy from various organic compounds:

1. Nitrogen-fixing bacteria, deriving their nitrogen from the atmosphere, in the form of gaseous atmospheric nitrogen:

a. Non-symbiotic nitrogen-fixing bacteria:

(a) Anaerobic types: Butyric acid bacteria (Bac. amylobacter), including species of Clostridium, Granulobacter, etc.

(b) Aerobic types: Azotobacter, Radiobacter, Bact. aerogenes, Bact. pneumoniae, etc.

b. Symbiotic nitrogen-fixing (nodıle) bacteria.

${ }^{17} \mathrm{~A}$ detailed review of "The generic names of bacteria" is given by E. M. A. Enlows. Hyg. Lab. Bul. 121. Washington, D. C., 1920; Buchanan, R. E. Systematic bacteriology. 1925.

${ }_{18} \mathrm{~A}$ detailed system of bacteria based on biochemical relationships has been proposed by Orla-Jensen-Die Hauptlinien des natürlichen Bakteriensystems. Centrbl. Rakt. II, 22: 305-346. 1909. 
2. Aerobic bacteria requiring combined nitrogen:

a. Spore producing bacteria.

b. Non-spore producing bacteria.

3. Anaerobic bacteria, requiring combined nitrogen.

For the sake of convenience three other groups of bacteria may be discussed separately, due to their specific physiological activities and importance in certain soil processes; these bacteria belong, according to their morphology and general physiology, to groups 2 and 3, namely:

4. Cellulose decomposing bacteria.

5. Urea and uric acid bacteria.

6. Denitrifying bacteria. 


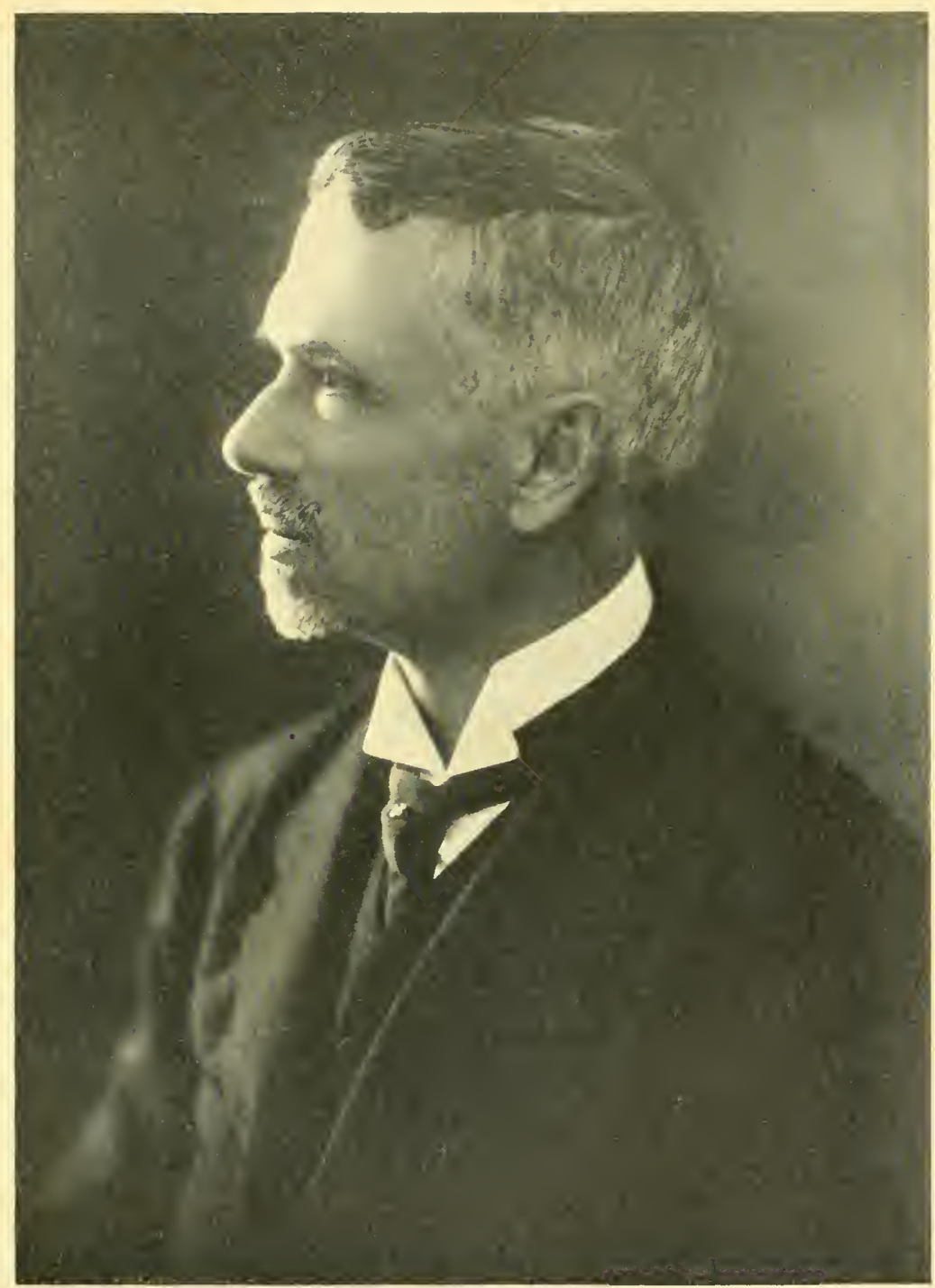

S. WIXOGRADSKY 



\section{CHAPTER III}

\section{Autotrophic Bacteria}

The nature of autotrophic bacteria. Autotrophic bacteria are organisms which are capable of obtaining their carbon from $\mathrm{CO}_{2}$ of the atmosphere and their energy from the oxidation of inorganic substances, including simple inorganic compounds (or the elementary form) of nitrogen, sulfur, iron, hydrogen and carbon. Some of these transformations, particularly those of the nitrogen and the sulfur compounds are of great importance in the soil.

Obligate autotrophic bacteria, or anorgoxydants, are characterized ${ }^{1}$ by a series of physiological properties, which differentiate them sharply from the rest of the bacteria. These properties are as follows:

1. Their development in nature takes place only in strongly elective, almost pure mineral media, which contain specific oxidizable inorganic substances.

2. Their existence is connected with the presence of these substances, which undergo oxidation as a result of the life activities of the organisms.

3. This oxidation process supplies their only source of energy.

4. The organisms do not need any organic nutrients for structure or for energy.

5. They are almost incapable of decomposing organic matter and may even be checked in their development by its presence.

6. They use, as an exclusive source of carbon, carbon dioxide, which is assimilated chemosynthetically.

These original conceptions of Winogradsky may be modified at present in two respects:

1. The presence of organic matter may not prove injurious to the activities of the autotrophic bacteria. As a matter of fact, the presence of small quantities of certain organic substances may even be stimulating to some. Furtleer, the existence of these organisms in the soil, where they carry on their life processes, takes place in the presence of soluble organic substances.

1 Winogradsky, S. Fisenbakterien als Anorgoxydanten. Centrbl. Bakt. II, 57: $1-21$. 1922 . 
2. Only few of the autotrophic bacteria are obligate, some are faeultative autotrophic. The latter, as in the case of some sulfur, hydrogen and methane bacteria, can exist both autotrophically and heterotrophically.

Bacteria deriving their energy from nitrogen compounds. The bacteria which are able to derive their energy from the oxidation of simple forms of nitrogen (nitrifying bacteria) are divided into two groups; (1) those that oxidize ammonium salts to nitrites, and (2) those that oxidize nitrites to nitrates. The latter comprise rather limited groups of microorganisms, both in their morphology and physiology. Representatives of both groups were isolated and described by Winogradsky ${ }^{2}$ in 1891 and 1892.

Various purely chemical theories were suggested at different times to explain the process of nitrification in nature. Pasteur ${ }^{3}$ was the first to suggest that the oxidation of ammonia to nitrate is accomplished by the agency of microorganisms. This view was definitely confirmed (1877) by Schlösing and Müntz ${ }^{4}$ who demonstrated that the heating of soil, otherwise capable of rapidly transforming ammonia to nitrites, to $100^{\circ} \mathrm{C}$. or treating it with antiseptics (chloroform) was sufficient to prevent nitrification; when a fresh portion of soil was added to the treated soil, the power of transforming ammonia to nitrates was restored. Aeration was found to be essential to nitrification. It was obtained either by bubbling air through the medium, or by spreading the medium in a thin layer over the bottom of the container. According to Schlösing,, oxygen is taken up during the process of nitrification and the quantity of oxygen consumed bears a constant ratio to the amount of nitrogen nitrified. A temperature of about $37^{\circ} \mathrm{C}$. and the presence of calcium carbonate or alkaline carbonates in low concentrations ( 0.2 to 0.5 per cent) were also found to be favorable. These investigations proved that the conditions commonly utilized in the saltpeter heaps were quite essential for the activities of the organisms; namely, (1) the presence of nitrogenous

2 Winogradsky, S. Recherches sur les organismes de la nitrification. Contributions à la morphologie des organismes de la nitrification. Arch. Sci. Biol., St. Petersbourg, 1: S7, 127. 1892.

${ }^{3}$ Pasteur, L. Etudes sur les mycodermes. Rôle de ces plantes dans la fermentation acétique. Compt. Rend. Acad. Sci. 54: 265-270. 1862.

${ }^{4}$ Schlösing, Th. and Müntz, A. Sur la nitrification par les ferments organisés. Compt. Rend. Acad. Sci. 84: 401. 1877; 85: 1018-1020. 1877; 86: 892. 1878; 89: 891-4, 1047-7. 1879.

${ }^{5}$ Schlösing, Th. Sur la nitrification de l'ammoniaque. Compt. Rend. Acad. Sci. 109: 423-428. 1889 . 
organic compounds thoroughly mixed with the soil, (2) a thorough aeration of all the layers of the heap, (3) a proper moisture content kept up by moistening the heap at regular intervals, (4) the presence of bases, like calcium carbonate (or soap water). The activities were found to be noticeable at $5^{\circ} \mathrm{C}$, became prominent at $12^{\circ}$ and reached a maximum at $37^{\circ}$. Higher temperatures $\left(45^{\circ}\right)$ exerted an injurious effect and at $55^{\circ} \mathrm{C}$ the process came to a standstill.

Warington ${ }^{6}$ confirmed the biological nature of nitrification not only in soil, but also in ammoniacal solutions inoculated with soil. $\mathrm{He}$ studied (1) the influence of organic substances upon nitrification, (2) the abundant production of nitrites in the process of nitrification and (3) the nitrification of organic nitrogen. Warington observed that in a liquid medium containing ammonium chloride, chalk, and sodiumpotassium tartrate, the ammonia could be acted upon only to a very limited extent; when sugar replaced the tartrate, there was a decided injurious effect upon the process of nitrification, which could not be explained, since the nature of the organism was unknown. The relative amounts of nitrite and nitrate formed in the process of nitrification presented another unexplainable difficulty. As to the nitrification of organic nitrogenous substances (urine, milk, asparagine), Warington demonstrated that this has to be preceded first by their transformation into ammonia; in other worck, only those substances can be nitrified which can first be converted into ammonia. It was soon found that nitrites arose from the oxidation of ammonia and not from the reduction of nitrates; Munro ${ }^{7}$ distinguished ammonia formation from ammonia oxidation (nitrification) and, without suspecting the existence of the different organisms, he had a rather clear idea of the two processes.

All attempts to isolate the specific organisms concerned in the process of nitrification failed, in spite of the fact that nitrification is an important biological process not only in the soil but also in sewage purification. This was chiefly due to the fact that the proper methods were lacking. Although claims have been put forth by various investigators ${ }^{8}$ that a

${ }^{6}$ Warington, R. On nitrification. Jour. Chem. Soc. (London), 33: 44-51. 187S; 35: 429-456. 1879; 45: 637-672. 1884; Chem. News. 61: 135. 1890; Trans. Chem. Soc. London, 59: 484-529. 1891.

${ }^{7}$ Munro, J. H. M. The formation and destruction of nitrates and nitrites in artificial solutions and in river and well water. Jour. Chem. Soc. 49: 632-691. 1886 .

${ }^{8}$ Heraeus, W. Über das Verhalten der Bakterien im Brunnenwasser, sowie über redueierende und oxydierende Eigensehaften der Bakterien. Ztschr. Hyg. 1: $193-235.1886$. 
number of organisms, some even pathogenic in nature, are able to produce nitrates, they were valueless due to improper interpretation. The traces of nitrates probably came from the atmosphere and the nitrites from the reduction of the nitrates present in the medium. ${ }^{9}$ The French ${ }^{4,5}$ and English ${ }^{6,10}$ investigators were primarily chemists, while the German bacteriologists ${ }^{8}$ were so much under the influence of the gelatin plate method of $\mathrm{R}$. Koch that the absence of growth on that medium was thought to indicate the entire absence of an organism.

Winogradsky started out with the idea that we were dealing here with an organism of unknown properties which does not develop on the gelatin plate. Fresh from his work on the sulfur and iron bacteria (1885-1888), whereby he recognized organisms which can derive their energy from inorganic compounds, he reasoned that a source of energy so abundant as ammonia would be likely to be utilized by microorganisms. If so, the organisms concerned might show properties similar to those of organisms oxidizing other inorganic substances. The principle of elective culture was adopted, whereby conditions are made unfavorable for the development of any other organism, except those that are able to oxidize ammonium compounds. Winogradsky used a medium of the following compositions:

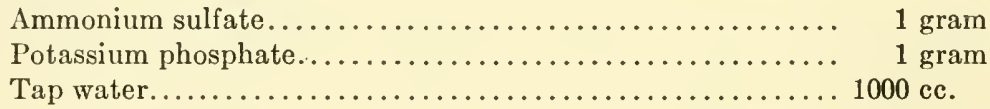

Portions of this medium (100 cc.) were placed in flasks each of which contained 0.5 to 1 gram basic magnesium carbonate. The flasks were inoculated with a little soil and, when active nitrification took place, transfers were made to fresh quantities of medium. The ammonia disappeared in two weeks, while the di-phenylamine reaction for nitrates appeared in four days and reached its maximum in another three to four days. Gelatin plates made from the flasks gave various species of bacteria and yeasts, but none of them was able to nitrify. This confirmed the idea of Winogradsky that the organism in question cannot develop on gelatin. After several transfers, the observation was made that a bacterium was present on the magnesium carbonate sediment, covering it in the form of a zooglea. Under the microscope,

${ }^{9}$ Winogradsky, S. Die Nitrifikation. Lafar's Handb. Tech. Myk. 3: 132 181. 1904 .

${ }^{10}$ Frankland, G. C., and P. F. The nitrifying process and its specific ferment. Trans. Roy. Soc. London, B, 181: 107-128. 1890. 
the bacterium from the sediment was found to be regularly oval or ellipsoidal in nature; it was also present in the medium. In order to obtain pure cultures of these organisms Winogradsky ${ }^{11}$ made use of the two facts that the bacterium did not grow on the gelatin plate and in nutrient bouillon but was found abundantly on the magnesium carbonate sediment. Some of that sediment was streaked out over a gelatin plate and those particles, which remained sterile on the plate, after a few days incubation, were transferred into fresh flasks containing the ammonium medium. The final steps in the study and isolation of the bacteria concerned in the process of nitrification were the separation

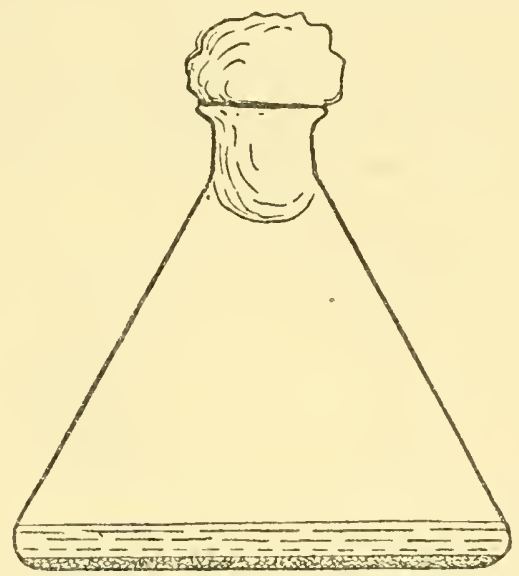

FIG. 8. Winogradsky flask for experiments on nitrification. Layer of $\mathrm{MgCO}_{3}$ on bottom of flask and mineral salt solution above it (after Omeliansky).

of the nitrite and nitrate organisms and their cultivation upon specific media.

For the growth of the nitrite and nitrate forming bacteria, a thorough aeration of the culture is essential. Winogradsky used flasks of large diameter $(12 \mathrm{~cm})$ with flat bottoms, in which the liquid formed only a shallow layer (less than $1 \mathrm{~cm}$. in height). Boulanger and Massol $^{12}$ used scoria and allowed the liquid to reach only half the height of the scoria layer, which was moistened at regular

${ }^{11}$ Winogradsky, S. Recherches sur les organismes de la nitrification. Ann. Inst. Past. 4: 213-231, 257-274. 1890; 5: 92-100. 1891.

12 Boulanger, E., and Massol, L. Etudes sur les microbes nitrificateurs. Ann. Inst. Past. 17: 492-515. 1903; 18: 181-196. 1904. Compt. Rend. Acad. Sci. 687. 1905. 
intervals, by the shaking of the flask; this hastened the process of nitrification. Still more intensive nitrification was obtained by allowing the ammoniacal solutions to flow through peat and carbon black inoculated with nitrifying organisms. ${ }^{13}$ Ignited soil placed in flat bottomel Fernbach flasks, combined with a slow rotary movement of the culture gave intensive nitrification. ${ }^{14}$

An alkaline reaction is essential for nitrite and nitrate formation. In the absence of basic carbonates, only ammonium carbonate is oxidized; in the presence of sodium, magnesium or calcium carbonate, free ammonia as well as the sulfate, phosphate and chloride of ammonium can nitrify. ${ }^{15}$ This is due to the fact that the optimum reaction for the organisms is on the alkaline side of neutrality ( $\mathrm{pH} 7.0$ to 8.0). The presence of the base in the medium is essential as a neutralizing agent to prevent the reaction of the medium from becoming too acid, due to the formation of nitric and sulfuric acids from the oxidation of the ammonium salt.

In addition to the medium given above, two other media were used:15,16

\begin{tabular}{|c|c|c|}
\hline - & MEDIUM 2 & MEDIUM 3 \\
\hline 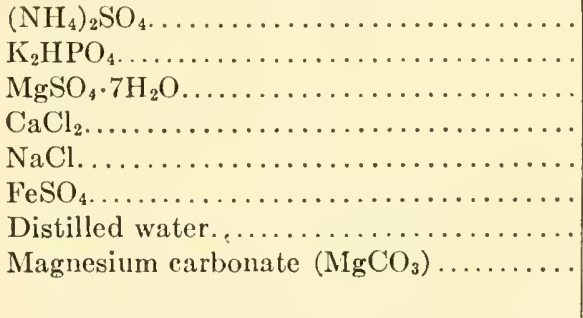 & $\begin{array}{c}2.0-2.5 \text { grams } \\
1.0 \text { grams } \\
0.5 \text { gram } \\
\text { Trace } \\
\\
1000 \mathrm{ec} . \\
\text { Excess }(0.5 \text { gram } \\
\text { per flask) }\end{array}$ & $\begin{array}{c}2.0 \text { grams } \\
1.0 \text { grams } \\
0.5 \text { gram } \\
2.0 \text { grams } \\
0.4 \text { gram } \\
1000 \mathrm{cc} . \\
\text { Excess (0.5 gram } \\
\text { per flask) }\end{array}$ \\
\hline
\end{tabular}

The medium is distributed into flasks (about 50 cc. portions), which are then plugged with cotton and sterilized at 15 pounds pressure for 15 minutes. It is best to sterilize the ammonium sulfate separately, as a 5 or 10 per cent solution, and then add it by means of a sterile pipette to the sterile flasks. Gibbs ${ }^{17} \mathrm{em}-$ ployed medium 3, but reduced the ammonium salt to one gram and substituted a trace of ferric sulfate for the ferrous salt.

${ }^{13}$ Müntz, A., and Lainé, E. Utilisation des tourbièrs dans la production intensive des nitrates. Compt. Rend. Acad. Sci. 142: 1239-1244. 1906; also Ann. Sci. Agron. Ser. 3, 2: 287-395. 1906.

${ }^{14}$ Bonazzi, A. On nitrification. Jour. Bact. 4: 43-59. 1919.

15 Winogradsky, 1904 (p. 64).

${ }_{16}$ Omeliansky, V. Úber die Isolierung der Nitrifikationsmikroben aus dem Erdboden. Centrbl. Bakt. II, 5: 537-549. 1899.

${ }^{17}$ Gibbs, M. W. The isolation and study of nitrifying bacteria. Soil Science, 8: 427-481. 1919 . 
When 1 gram of soil is inoculated into the flasks containing the culture medium, growth will usually take place at $25^{\circ}$ to $30^{\circ} \mathrm{C}$ after 4 to 5 days, but sometimes only after weeks. Some soils, however, such as acid peat and certain acid forest soils, ${ }^{18}$ may not contain the organisms in question. They are not very sensitive to drying, ${ }^{17}$ but the action of steam or volatile antiseptics is injurious and results in their destruction in the soil. Manured and cultivated soils contain the nitrifying organisms in greatest abundance, especially in the upper layers of soil. ${ }^{19}$

The appearance of growth is accompanied by the formation of nitrous acid and disappearance of ammonia. The former is demonstrated by the starch-zinc iodide reagent and the latter by Nessler's reagent. When all the ammonium is oxidized, a fresh portion of ammonium sulfate is adcled; a sterile 10 per cent solution of the salt is kept in a flask with a plugged graduated pipette: $1 \mathrm{cc}$. will be equivalent to addition of 0.2 per cent of the salt to the medium. When a second portion of the ammonium salt is added, it is oxidized much more rapidly since the specific organisms have already developed abundantly. A third portion is oxidized even more rapidly, until a certain limit of reaction is attained depending on the solution of the $\mathrm{MgCO}_{3}$ and the accumulation of nitrous acid. The culture is then transferred to a fresh flask with medium, using preferably a few drops from the bottom of the flask, since the bacteria form a sediment on the $\mathrm{MgCO}_{3}$. Oxidation sets in now more rapilly and goes on more regularly. After four or five more transfers and repeated addition of ammonium sulfate to each culture before a new transfer is made, the culture is rich enough in the specific organisms and can be used for isolation purposes.

The oxidation of nitrous to nitric acid by the nitrate-forming bacteria does not begin until the oxidation of the ammonium salt to nitrous acid by the nitrite-forming bacteria is completed; this is due to the fact that free ammonia, liberated from the interaction of the ammonium salt and carbonate, has a toxic effect upon the nitrate organism. ${ }^{\circ}$ The latter is present in crude culture together with the nitrite former and, even when the latter reaches its maximum, the former is still dormant. However, as soon as all the ammonia is transformed into nitrite, the nitrate former becomes active. When transfers are made from the crucle culture, the stage of oxidation will account for the organism which will be prevalent. If the transfer is made at an early stage

${ }^{18}$ Migula, W. Beiträge zur Kenntnis der Nitrifikation. Centrbl. Bakt. II, 6: 365-370. 1900 .

19 Warington, 1878 (p. 63). 
of oxidation, when the ammonium salt is still abundant, the nitrate former may be entirely eliminated in the process of several consecutive transfers. If nitrite is substituted in the medium, in place of the ammonium salt, and the culture is inoculated with soil or from a previous culture during the process of nitrate formation, and transfers are constantly made upon the nitrite medium, the nitrite forming organism may be entirely eliminated. The two bacteria can thus be separated by means of their characteristic metabolism.

Solid media for the isolation and cultivation of the nitrite forming organism. Silicic acid media were used first ${ }^{20}$ for the isolation of the nitrite forming bacterium.

Equal volumes of clear sodium or potassium silicate (specific gravity 1.05 to 1.06 ) and $\mathrm{HCl}$ (specific gravity 1.10 ) are mixed by pouring the first into the second; the mixture is then dialyzed in parchment paper dialyzers, for several days in clistilled water, which is repeatedly changed. ${ }^{21}$ When the dialyzate gives no further reaction, other than mere turbidity, with $\mathrm{AgNO}_{3}$, the dialysis is completed. The clear solution contains about 2 per cent silicic acid and can be preserved for three months in clean glass-stoppered bottles and readily sterilized at $115^{\circ}$ to $120^{\circ} \mathrm{C}$. In addition to the silicic acid, four liquid solutions are prepared:
1. $\left(\mathrm{NH}_{4}\right)_{2} \mathrm{SO}_{4} \ldots \ldots \ldots .3$ grams $\mathrm{K}_{2} \mathrm{HPO}_{4} \ldots \ldots \ldots \ldots \quad 1$ gram $\mathrm{MgSO}_{4} \cdot 7 \mathrm{H}_{2} \mathrm{O} \ldots \ldots .0 .5 \mathrm{gram}$ Distilled water.... $100 \mathrm{cc}$.

2. 2 per cent solution of ferrous sulfate

3. Saturated $\mathrm{NaCl}$ solution

4. Milk of magnesia, i.e., a thick suspension of finely powdered magnesium carbonate in distilled water

Fifty cubic centimeters of the silicic acid solution is placed in a flask, then $2.5 \mathrm{cc}$. of solution 1 are added and $1 \mathrm{cc}$. of solution 2. Enough milk of magnesia is added to give the mixture a milky appearance $(0.1$ per cent sodium carbonate solution may be used in place of the magnesia). The mixture is then poured, with continued stirring, into sterile, small thin-walled Petri dishes. Finally, one drop of solution 3 is placed in the center of each plate. When allowed to rest in an horizontal position, the liquid solidifies in about an hour. To get a more solid medium, it is better to allow the clishes to rest 24 hours, then dry them out in the thermostat.

The medium is inoculated either directly into the flask before the plates are poured, or by placing a drop on the surface of the plate. The drop is spread over the surface of the medium with the tip of a sterile glass rod and the same rod is used for the inoculation of a second and third plate, so as to obtain a series of dilutions.

${ }^{20}$ Winogradsky, 1891 (p. 65).

${ }^{21}$ Omeliansky, 1899 (p. 66). 
The dishes are incubated in an inverted position at $25^{\circ}$ to $30^{\circ} \mathrm{C}$. The development of an organism on the plate is first detected by chemical tests for the formation of nitrous acid and disappearance of ammonia. The tests are made by cutting a piece of the gel with a sterile loop and placing them in dishes containing the proper reagent. The culture can then be "fed" with 1 or 2 drops of a sterile 10 per cent ammonium sulfate solution to bring about further development of the organism.

The minute microscopic colonies are better studied on the clear (sodium carbonate) medium and soon after the addition of a fresh portion of ammonium sulfate. The colonies are at first colorless, then they become yellowish to brownish and finally dark brown; after a certain time (10 to 14 days), the dark colonies clear up, beginning from the edge toward the center, till finally the dark colony becomes colorless. A pure colony will show uniform fine granulation up to the edge, while contaminated colonies have an hyaline rim. A clear zone is formed around each colony on the $\mathrm{MgCO}_{3}$ medium due to the fact that the latter is gradually dissolved by the nitrous acid; it is often difficult, however, to demonstrate this zone. The plate is carefully examined with a magnification of 50 to 100 , and several clear surface colonies are selected for transfer. Winogradsky recommended the use of finely drawn sterile glass rods which are first dipped into the colony, then transferred into the flasks with sterile liquid medium and, by striking the bottom of the flask, the tip of the rod with the inoculum is broken off and left in the flask. A number of transfers are made, since, in many cases, the organism fails to develop. It is much more difficult to obtain a culture from the dark colonies (zooglea) than from the colorless colonies. To prove the purity of the culture, a few drops (about 0.5 cc.) of the liquid are inoculated into bouillon and meat peptone agar. No growth should take place after two weeks incubation; this combined with microscopic examinations indicates the absence of contaminations.

The silica gel can also be prepared by the method of Stevens and Temple, ${ }^{22}$ as modified by Doryland:23 24 grams of $\mathrm{K}_{2} \mathrm{SiO}_{3}$ and 8.4 grams of $\mathrm{Na}_{2} \mathrm{SiO}_{3}$ are dissolved in $500 \mathrm{cc}$. of water to give a concentration of 34.2732 grams of $\mathrm{H}_{2} \mathrm{SiO}_{3}$ per liter. One-half this concentration of $\mathrm{H}_{2} \mathrm{SiO}_{3}$ per liter gives a medium, which will solidify in approximately five minutes, thus making it suitable for plating. The mixture of the two salts lessens the danger of too

${ }^{22}$ Stevens, F. L., and Temple, J. C. A convenient mode of preparing silicate jelly. Centrbl. Bakt. I1, 21: 84-87. 1908.

${ }^{22}$ Doryland, C. J. T. Preliminary report on synthetic media. Jour. Bact. 1: 135-152. 1916. 
great a concentration of sodium. The detrimental influence of too great a concentration of the sodium and potassium salts can still further be lessened by using a mixture of acids, such as equivalent solutions of $\mathrm{HCl}, \mathrm{H}_{2} \mathrm{SO}_{4}$ and $\mathrm{H}_{3} \mathrm{PO}_{4}$, thus giving in the finished medium chlorides, sulfates and phosphates of both bases.

The solutions of the three acids are standardized separately against the solution of the silicates, so that $1 \mathrm{cc}$. of each acid would just neutralize $1 \mathrm{cc}$. of the silicate solution, against methyl orange. Methyl red and brom cresol purple can also be employed. Before the final standardization, 0.5 gram $\mathrm{MgSO}_{4}, 0.01$ gram $\mathrm{CaCO}_{3}$ or $\mathrm{CaO}, 0.01$ gram $\mathrm{Fe}_{2}\left(\mathrm{SO}_{4}\right)_{3}$ or $\mathrm{FeCl}_{3}, 0.01$ gram $\mathrm{MnSO}_{4}$ and 1 gram of ammonium sulfate are added to the $\mathrm{HCl}$ solution.

The three acids are then mixed, taking $153.5 \mathrm{cc}$. of $\mathrm{HCl}, 77 \mathrm{cc}$. of $\mathrm{H}_{2} \mathrm{SO}_{4}$ and $116 \mathrm{cc}$. of $\mathrm{H}_{3} \mathrm{PO}_{4}$. One cubic centimeter of this mixture will just neutralize $1 \mathrm{cc}$. of the silicate solution, using phenolphthalein as an indicator. The two solutions are placed in sterile bottles connected by siphons with automatic burettes, the overflow caps of which are plugged with cotton to prevent contamination from the air. The solutions are allowed to stand several hours, to sterilize the containers, then $5 \mathrm{cc}$. portions of the acid mixture followed by the same amounts of silicate mixture are placed in sterile Petri dishes, which are then rotated thoroughly; the jelly sets in five minutes. This medium has, however, never been tested out sufficiently; it is possible that the osmotic concentration of the salts may prove too excessive.

In addition to the silica plate method, three more methods are available for the isolation of the nitrite forming bacteria.

Method 1. Agar may be prepared according to Beijerinck, ${ }^{24}$ whereby 3 per cent agar is dissolved in distilled water, filtered and allowed to solidify in thin layers in glass containers. The solidified agar is then cut up into pieces, covered with distilled water and incubated at $37^{\circ}$ for two weeks; the soluble constituents of the agar come into solution and are decomposed; the water is changed several times. The agar is so purified that it can be used for the cultivation of the organisms. It is preserved either under water or in a dried condition. Two-tenths per cent $\mathrm{NH}_{4} \mathrm{NaHPO}_{4} \cdot 4 \mathrm{H}_{2} \mathrm{O}$ and 0.05 per cent $\mathrm{KCl}$ and chalk are then added to the agar and brought into solution. The plates have a milky appearance. The agar may be washed in distilled water for several days, then dried at $60^{\circ} \mathrm{C}$. A 2.5 per cent solution of agar is then made, tubed in $10 \mathrm{cc}$. portions and sterilized in the autoclave at 15 pounds pressure. Three solutions are then prepared and sterilized in small portions.

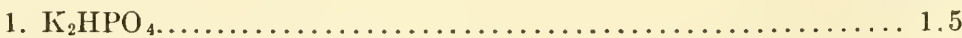

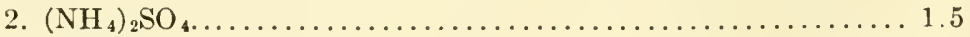

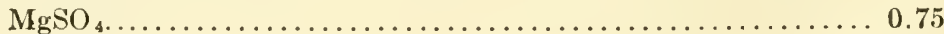

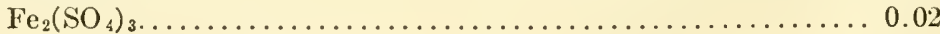

24 Beijerinck, W. M. Kulturversuche mit Amöben auf festem Substrate. Centrbl. Bakt. I, 19: 257-267. 1896. 


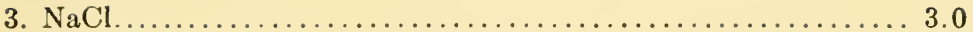

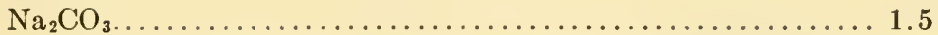

The agar is melted and cooled to $40^{\circ} \mathrm{C}$. Portions $(1 \mathrm{cc}$.) of the three solutions are placed in sterile petri-dishes, inoculum is added, then the melted agar. All the contents of the plate are properly mixed. If it is desired to use $\mathrm{MgCO}_{3}$, it should be added to the plate directly, at the time of pouring, and $\mathrm{Na}_{2} \mathrm{CO}_{3}$ omitted from solution 3 . The colonies of the bacterium develop on this medium only slowly and a prolonged incubation period ( 3 to 4 weeks) is required. Agar media are also more favorable to the development of contaminating organisms than silica gel.

Method 2. This is the magnesium carbonate-gypsum block method. ${ }^{26,26}$ A mixture is made of 300 grams gypsum $\left(\mathrm{CaSO}_{4} \cdot \mathrm{H}_{2} \mathrm{O}\right), 30$ grams $\mathrm{MgCO}_{3}$ and 3 grams $\mathrm{MgNH}_{4} \mathrm{PO}_{4}$. This is carefully made into a homogeneous putty-like mass by means of water or of a water extract of a fertile soil, using 250 grams per liter of water, then mixing 8 parts of the powder and 3 parts of the liquid. The paste is then put upon a glass plate and, by means of a knife, streaked out to a thickness of 0.5 to $0.75 \mathrm{~cm}$. Round portions are cut out for the plates and oblong for the tubes. After the material has completely solidified, it is sterilized together with the glass containers. A small amount of the sterile nutrient liquid, without the ammonium sulfate and $\mathrm{MgCO}_{3}$, is placed at the bottom of the container, and the surface of the plate is inoculated from the liquid culture. The nitrite forming bacteria develop on these blocks as yellow-brown colonies. $\mathrm{MgCO}_{3}$ alone can be used, to which the nutrient solution is added. The yellowish colonies sink into this medium due to the dissolution of the $\mathrm{MgCO}_{3}$ by the nitrous acid. The use of filter paper, partly covered with the nutrient solution, in addition to some $\mathrm{MgCO}_{3}$, has also been suggested. ${ }^{27}$ The organism forms minute yellow dots becoming gradually brown. However, even the most recent students on this subject ${ }^{28}$ found that the original silica gel method of Winogradsky is still the best for the isolation of the nitrite forming bacteria.

Method 3. Winogradsky ${ }^{29}$ recently suggested the possibility of using a direct method for the isolation of nitrite forming, as well as other bacteria. This new method promises to replace all the other methods, due to the rapidity with which the organisms can be isolated. A series of plates containing silica gel, prepared by one of the methods outlined above, and ammonium salt as the sole source of energy are inoculated by placing minute particles of soil into the gel all over the plates; these are then incubated. The nitrite-forming bacteria develop

${ }^{25}$ Omeliansky, W. L. Magnesia-Gipsplatten als neues festes Substrat für die Kultur des Nitrifikationsorganismen. Centrbl. Bakt. II, 6: 652-655. 1899.

${ }^{26}$ Makrinov, J. Magnesia-Gipsplatten und Magnesia-Platten mit organischer Substanz als sehr geeignetes festes Substrat für die Kultur der Nitrifikationsorganismen. Centrbl. Bakt., II, 24: 415-423. 1910.

${ }^{27}$ Omeliansky, W. L. Kleinere Mitteilungen über Nitrifikationsmikroben. Centrbl. Bakt., II, 8: 785-787. 1902.

${ }^{28}$ Bonazzi, A. On nitrification. III. The isolation and description of the nitrate ferment. Bot. Gaz. 68: 194-207. 1919.

${ }^{29}$ Winogradsky, 1925 (p. 7, 11). 
in the form of a zooglea-like zone around the soil particles, and can be readily isolated by transferring to sterile liquid medium.

Morphology of the nitrite forming bacterium. In the process of nitrification we are dealing not with one organism, but with a group of closely related organisms. One strain was isolated ${ }^{30}$ from soils of Western Europe and was called Nitrosomonas (Nitr. europea Winogradsky). Another strain was isolated from soils of South America (CampinasBrazil, Quito-Ecuador) and Australia (Melbourne) and was called Nitrosococcus.

When a vigorous culture of Nitrosomonas is inoculated into the sterile liquid medium, an appreciable nitrite reaction is obtained in 2 to 3 days, reaching a maximum in 5 to 6 days. When the culture is examined microscopically, very few organisms are found in the supernatant liquid, but rare, compact, variable $(10$ to $50 \mu)$ zooglea recognized with difficulty are formed in the sediment. When a drop of KI-I solution is added, the cells are easily recognized. In $S$ to 10 days, the liquid becomes opalescent and, on examination in a hanging drop, it is found to consist of swarming, ellipsoidal, motile microbes, as seen in Plate III. This shows the zooglea broken up into a swarm stage.

The cells of the Nitr. europea are always oblong, similar to a zero, never coccus-like, 1.2 to $1.8 \mu$ long by 0.9 to $1 \mu$ wide. They can be stained with all ordinary basic anilin dyes and are Gram positive. The motile cells of the swarm carry on one end a moderately long

\section{PLATE III}

\section{NitRIFying BACteria}

5. Surface colonies of Nitrosomonas on silicic acid gel; stained with carbol fuchsin, $\times 130$ (from Gibbs).

6. Surface colony of Nitrosomonas on silicic acid gel; stained with carbol fuchsin, $\times 800$ (from Gibbs).

7. Nitrosomonas europea, $\times 660$ (from Winogradsky).

8. Nitrosomonas javanensis, $\times 660$ (from Winogradsky).

9. Colonies of Nitrobacter; deep-seated colonies on washed agar, unstained, $\times 240$ (from Gibbs).

10. Nitrobacter from culture in liquid medium; stained with carbol fuchsin, $\times 1660$ (from Gibbs).

11. Nitrobacter from nitrite-agar cultures, 2 months old (from Fred and Davenport).

12. Nitrobacter from nitrite-agar cultures, 15 days old, showing polar flagella (from Fred and Davenport).

30 Winogradsky, 1892 (p. 62). 


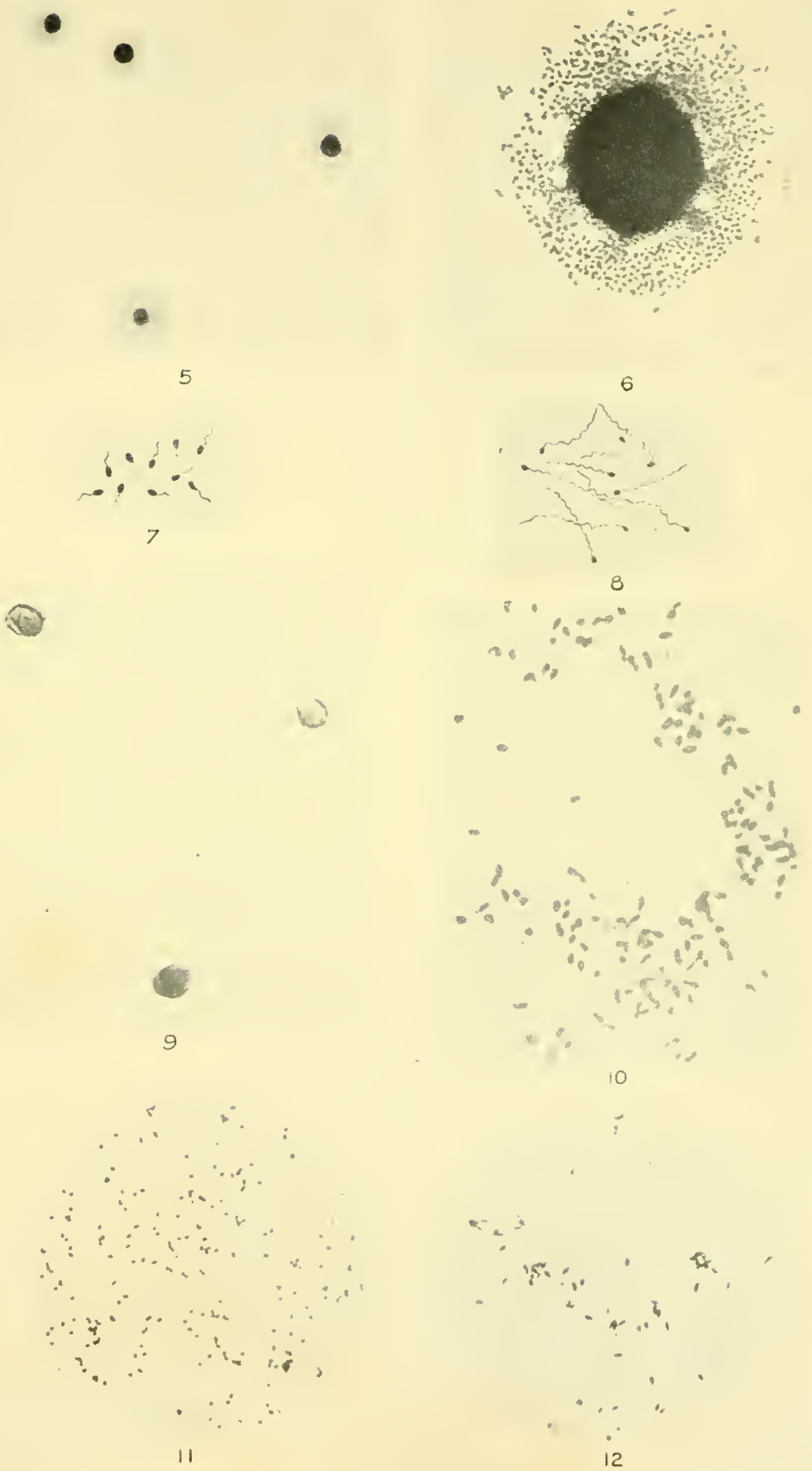



flagellum; the latter can be stained by the Loeffler method, by adding 10 to 15 drops of 1 per cent sodium carbonate solution to the ferrotannate, or by the method of Zettnow.

In some cases the motile stage may be predominant over the zooglea formation or vice versa. It is important to note that the predominance of the particular stage is characteristic of the strain, so that one might suspect that we are dealing here with two distinct races. The two stages are also distinguished by their rapidity of oxidation of ammonia, the motile stage being the stronger. Winogradsky suggested that the cause for this lies in the fact that the active stage (monas) consumes more energy and comes more readily in contact with the ammonia and oxygen than the non-motile zooglea. The zooglea are probably resting stages, being also more resistant to drying. Gibbs isolated the Nitrosomonas from soils of North America and found it to be 1.2 to 1.5 by 0.9 to $1.0 \mu$ in size, rounded or oval, which stained uniformly. The organism was found chiefly in the free cell stage. Thermal death point of the organism was between $53^{\circ}$ and $55^{\circ} \mathrm{C}$. (10 minutes).

Other organisms also capable of oxidizing ammonia to nitrite, but having different morphological characters, were isolated by Winogradsky from soils in Europe. So, for example, the form isolated from soil of St. Petersburg was a true coccus, about $1 \mu$ in diameter, sometimes forming zooglea and sometimes growing free, but never in the swarm stage. A constant property of its morphology is a central nuclcus-like body, made visible by various stains, particularly by methylene blue.

The Nitr. javanesis is a still smaller coccus $(0.5$ to $0.6 \mu)$ and has been isolated by Winogradsky from the soil of Buitenzorg, Java. This form grows both in the monas and zooglea stages, the first having very long (up to $30 \mu$ ) flagella. Free cells are present only in the swarm stage, mostly in pairs. Winogradsky also isolated from the soil of Quito, South America, a non-motile coccus (Nitrosococcus) termed by Migula Micr. nitrosus. This organism consists of large cocci 1.4 to $1.7 \mu$ in diameter, always growing as free cells and never forming zooglea, while the motile stage could never be demonstrated. It is obligate aerobic, gram-positive. It forms rather large, opaque yellowish colonies on the silica gel but the colonies are made up of free cells. The cells appear larger in the living state than in the stained preparation, probably due to a thick gelatinous membrane which does not stain or becomes invisible on desiccation. Bonazzi ${ }^{31}$ isolated the

${ }^{81}$ Bonazzi, 1919 (p. 71). 
Nitrosococcus also from the soil of North America (Ohio) : it forms small yellowish colonies (224 by $160 \mu$ on the silica gel) surrounded by a colorless halo, due to the solution of the $\mathrm{MgCO}_{3}$. Colonies of $1 \mathrm{~mm}$. in diameter have been obtained by renewing the $\left(\mathrm{NH}_{4}\right)_{2} \mathrm{SO}_{4}$ in the plates when necessary. The organism was found to be present in two stages: (1) as megalococci, $1.25 \mu$ in diameter, of a slightly irregular form, occurring in thick gelatinous masses; when the cultures are in the process of active oxidation, the megalococci give rise to small cocci; (2) a form which leaves the gelatinous mass and become free. The hanging drop cultures showed no motility.

The organism is stained as follows. The cover glass preparation is fixed in flame, treated with mordant 1 minute in the cold with a 0.25 per cent solution of malachite green in distilled water, washed with cold water, and stained cold with a 0.25 per cent water solution of gentian violet for another minute. The stain is then rapidly washed with water previously heated to 50 to $60^{\circ} \mathrm{C}$. The megalococci are stained deep purple and the small cocci purple-black.

The existence of the several forms of nitrite-forming organisms in the soils from different continents was explained by Winogradsky as due to the probability that local conditions favored the adaptation of a particular variety.

Nitrate forming bacteria (Nitrobacter). The organism that is able to oxidize nitrite to nitrate was discovered by Winogradsky ${ }^{32}$ in 1891 in the solutions where nitrate formation was taking place.

It was finally cultivated in a sodium nitrite medium to which the ordinary nutrients and magnesium carbonate or sodium carbonate have been added as follows:

\begin{tabular}{|c|c|c|}
\hline $\mathrm{NaNO}_{2} \ldots$ & 1.0 gram & $\mathrm{NaCl} \ldots \ldots \ldots \ldots$ \\
\hline $\mathrm{K}_{2} \mathrm{HPO}$ & 0.5 gram & $\mathrm{Na}_{2} \mathrm{CO}_{3}$ (anhydride) \\
\hline $\mathrm{MgSO}_{4} .$. & $0.3 \mathrm{gram}$ & $\begin{array}{l}\mathrm{FeSO}_{4} \ldots \ldots \ldots \ldots \\
\text { Distilled water...... }\end{array}$ \\
\hline
\end{tabular}

(The ferrous sulfate may be reduced to a trace and the anhydrous $\mathrm{Na}_{2} \mathrm{CO}_{3}$ to 0.5 gram.)

Fifty cubic centimeter portions of the sterile solution in flasks are inoculated with soil. The course of the reaction is followed by the disappearance of the nitrous acid and the appearance of nitric acid (using diphenylamine and concentrated sulfuric acid). When all the nitrite has been oxidized, fresh portions of the salt are added, in the form of a sterile solution as in the case of the ammonium sulfate, and the culture is studied microscopically, using carbol fuchsin for staining.

32 Winogradsky, 1904 (p. 64). 
The inoculated solutions show no turbidity or pellicle formation. It is only after repeated additions of nitrite that a bluish slime can be distinguished on the bottom and wall of the flask wherever it is in contact with liquid. When this slime is examined microscopically, it is found to consist of a layer of minute, spindle-shaped (generally) rods staining with difficulty. After several transfers into fresh flasks containing sterile liquid medium, the culture is sufficiently enriched, so that plates can be prepared.

The following agar medium is used for the isolation and cultivation of the organism:

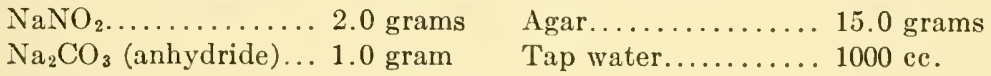

$\mathrm{K}_{2} \mathrm{HPO}_{4} \ldots \ldots \ldots \ldots .0 .5 \mathrm{gram}$

The surface of the solidified agar plate is smeared with a drop of the solution in which the organism has developed, and the plates are allowed to incubate 14 days at $30^{\circ}$. The streak then appears opaque and rounded numerous small droplets are differentiated with the naked eye. The sub-surface colonies are shining, slightly brownish, of various shapes developing in two weeks to a diameter of 30 to $50 \mu$. On the surface of the plate, the colonies appear as round homogeneous drops, reaching, in two weeks, a diameter of 100 to $180 \mu$. On slants the growth is dirty white, with a large, semi-fluid drop at the bottom. When a loop of this material is transferred into a $25 \mathrm{cc}$. portion of nitrite solution, the nitrite reaction disappears in 3 to 4 days.

Care should be taken not to mistake other bacteria for the nitrate former, since several soil bacteria grow on this medium. The smallest colonies are selected and carefully checked up with the disappearance of the nitrite reaction, combined with prolonged incubation (3 weeks at $30^{\circ} \mathrm{C}$.). Transfer is then made of characteristic colonies by means of the open capillary glass rods described above. From a series of transfers, some will be found to develop into pure cultures. To ascertain the purity of the culture, several drops of the liquid culture are added to bouillon or agar.

Nitrobacter is a non-motile, rod-shaped bacterium, obligate aerobic, non-spore forming, gram-negative. The cells are stained with carbol fuchsin, and can then be washed with dilute acidified alcohol. It is 1 by 0.3 to $0.4 \mu$ in size, with one or both ends pointed; the staining is not uniform, the central part being stained, while the pointed ends remain almost colorless. In Loeffler's alkaline methylene blue, only the nucleus-like bodies are stained well, but not the surrounding cell. By staining in warm gentian-violet, then washing with a 2 per cent $\mathrm{NaCl}$ solution, the cells are found to be 1.2 to 1.5 by 0.6 to $0.7 \mu$, surrounded by a capsule, 
commonly found in single cells or in pairs. The thermal death-point is $56^{\circ}$ to $58^{\circ} \mathrm{C}$. The colonies on agar are rounded and light-brown, in 7 to 10 clays at $25^{\circ} \mathrm{C}$. After two weeks, they are darker in color; deep colonies are 30 to $50 \mu$ in diameter and surface colonies are 50 to $150 \mu$ in diameter, with a tendency to spread. The nitrate bacteria may also be isolated directly from the silica gel plate, when nitrite is used as the only source of energy.

Beijerinck ${ }^{33}$ claimed that the nitrate-forming bacterium can grow in the presence of various organic substances but that the organism loses some of its power of oxidation after growing in the presence of soluble organic matter. Accordingly, he suggested that growth and oxidation are two distinct functions and that even if small amounts of organic substances $(0.05$ per cent) did not prevent the oxidation of nitrite to nitrate, reproduction of the organism in solutions containing large amounts of these substances caused a stable modification in their physiology.

However, Fred and Davenport ${ }^{34}$ obtained no evidence to support the statements of Beijerinck. Contrary to the general opinion, they found that certain forms of organic matter benefit rather than injure the nitrate-forming bacterium. They grew the Nitrobacter on washed nitrite agar and on slants of Nähstoff-Heyden agar with or without $\mathrm{NO}_{2}$-ion present. The organism does not reproduce in NährstoffHeyden solution, which is non-toxic, while beef-infusion and peptonebeef infusion, in higher concentrations, are toxic. The harmful material is non-volatile and can be removed by extraction with ether or alcohol. Nitrobacter will live 2 to 6 weeks in 1 per eent solutions of Nährstoff-Heyden, gelatin, peptone, easein, yeast water and milk, and also in distilled water without any further development. Gelatin, peptone, casein, skimmed milk, beef infusion and beef extract do not decrease the oxidation of nitrite by the organism; asparagine, $\left(\mathrm{NH}_{4}\right)_{2} \mathrm{SO}_{4}$, and urea retard the oxidation; Nährstoff-Heyden increases it above water controls; sealed agar slants of Nitrobacter were kept more than a year without serious injury to their power of oxidation.

Winogradsky ${ }^{35}$ definitely pointed out that growth and nitrite oxida-

${ }^{33}$ Beijerinck, M. W. Über das Nitratferment und über physiologische Artbildung. Folia Microb. 3: 91-113. 1914.

${ }^{34}$ Fred, E. B., and Davenport, A. The effect of organic nitrogenous compounds on the nitrate-forming organism. Soil Sci. 11: 389-407. 1921.

35 Winogradsky, S. Sur la prétendue transformation du ferment nitrique en espèce saprophyte. Compt. Rend. Acad. Sci. 175: 301-303. 1922. 
tion are inseparable functions; organic matter ( 1 per cent peptone) may paralyze the organism, but does not kill it and does not change it, since, when transferred upon proper media, it resumes its activities.

The respiration of the organisms, the chemistry of the processes of nitrite and nitrate formation, and their importance in soil fertility are discussed in detail elsewhere (p. 525).

Occurrence of nitrifying bacteria in the soil. All soils, not very acid in reaction, contain bacteria capable of oxidizing ammonium salts to nitrites and the latter to nitrates. The limiting acidity for the development of these bacteria in the soil is $\mathrm{pH} 4.0$ to 4.4 , while the optimum reaction is at $\mathrm{pH} 6.8$ to $7.3 .^{36}$ When a soil more acid in reaction than the minimum for their development is treated with lime, the organisms will gradually appear in the soil; however, inoculation with a good fertile soil is often practiced, so as to introduce the organisms immediately. The numbers of the nitrifying bacteria per gram of soil vary from a few to $10,000 .{ }^{37}$ The method commonly used for this determination consists in diluting the soil with sterile water, then adding $1 \mathrm{cc}$. portions of the various dilutions to the proper media. Positive growth indicates a minimum number of organisms. It is possible, however, that many cells have to be added to a liquid medium, before growth can take place, since conditions are not made as favorable for their development in artificial liquid media as in normal soil. In humid soils, the bacteria are present in the upper few inches and rapidly disappear in the subsoil. However, in arid soils, they occur to a depth of many feet. ${ }^{38}$

In addition to the typical nitrite and nitrate bacteria clescribed by Winogradsky and isolated by other investigators, various reports have been made concerning the isolation of nitrite and nitrate forming organisms, ranging from typical autotrophic forms, like the nitromicrobium of Stutzer and Hartleb, ${ }^{39}$ to forms possessing properties altogether uncharacteristic of autotrophic bacteria, such as cellulose decomposition, gelatin liquefaction, nitrate reduction, etc. $;^{40}$ however, the last investigations still remain to be verified.

${ }^{36}$ Gaarder, T., and Hagem, O. Nitrifikation in sauren Lösungen. Bergen Míuseum Aarbook. 1922-3, No. 1.

37 Düggeli, 1923 (p. 39).

38 Lipman, 1912 (p. 36).

${ }^{39}$ Stutzer, A., and Hartleb, R. Untersuchungen über die bei der Bildung von Salpeter beobachteten Mikroorganismen. Mitt. landw. Inst. Breslau, 1: 75-99, 197-232. 1901.

40 Sack, J. Nitratbildende Bakterien. CentrbI. Bakt., II, 62: 15-24. 1924; 64: $32-37,37-39.1925$. 
Bacteria deriving their energy from the oxidation of sulfur and its compounds. The sulfur bacteria do not form any uniform group of microorganisms, as in the case of the nitrifying bacteria, either morphologically or physiologically. Morphologically they are found among the Desmobacteriaceae (Thiobacteriales) and among the Bacteriaceae (Eubacteriales). Physiologically they may oxidize hydrogen sulfide and other sulfides, elementary sulfur, or thiosulfate and they may act either in an acid or in an alkaline reaction. Some are obligate autotrophic and some are facultative. The bacteria which are found in normal, fertile soils or those that become active in the soil, when introduced, are limited chiefly to the genus Thiobacillus among the Bacteriaceae.

All microorganisms require minute quantities of sulfur for the synthesis of their protoplasm. Various bacteria and even some fungi seem to be capable of oxidizing small amounts of sulfur. But only certain bacteria work over much larger quantities of sulfur than would be necessary for their body structure, since they utilize the sulfur or its conpounds as a source of energy. The sulfur is to the sulfur bacteria, as

\section{PLATE IV}

\section{Sulfulr and Iron Bacteria}

13. Beggiatoa alba, thread forming sulfur-oxidizing bacterium: $a$, in liquid culture rich in $\mathrm{H}_{2} \mathrm{~S} ; b$, culture kept 24 hours in liquid freed from $\mathrm{H}_{2} \mathrm{~S} ; c, 48$ hours later in the same liquid (sulfur droplets have disappeared, cell division takes place and protoplasmic contents are left), $\times 600$ (after Omeliansky).

14. Thread-forming, sulfur-oxidizing bacteria: ( $\mathrm{x}$ ) Beggiatoa media and (y) Beggiatoa minima, $\times 600$ (after Omeliansky).

15. Thioploca ingrica, $\times 200$ (after Wislouch and Omeliansky).

16. Young threads of Thiothrix nivea, $\times 600$ (after Omeliansky).

17. Thiophysa macrophysa, showing drops of sulfur on periphery and oxalate crystals in center, $\times 660$ (after Nadson and Omeliansky).

18. Thiospirillum winogrudskii: $a \times 100$ and $\mathrm{b} \times 660$ (from Omeliansky).

19. Chromatium olénii, $\times 660$ (after Omeliansky).

20. Achromatium oxaliferum: $A$, showing the calcium bodies, but not sulfur; $B$, without the calcium bodies, but with a number of droplets of sulfur (from Nadson and Wislouch).

21. Thiobacillus thioparus, showing drops of precipitated sulfur among the rodshaped organisms, $\times 1000$ (from Düggeli).

22. Thiobacillus thiooxidans, $\times 660$ (Original).

23. Diagrammatic sketch of several typical iron bacteria: a, Spirophyllum ferrugineum; $b$, Gallionella ferruginea; $c$, Leptothrix ochracea, $\times$ about 720 (from Harder, by courtesy of U. S. Geological Survey).

24. Cladothrix dichotoma, $\times 190$ (after Molish). 


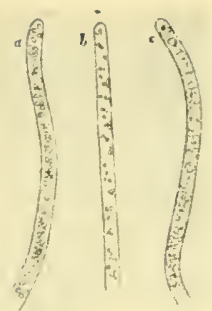

13

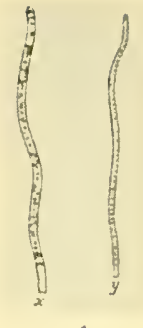

14

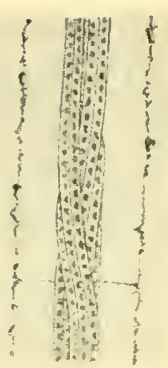

15

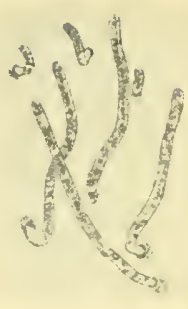

16

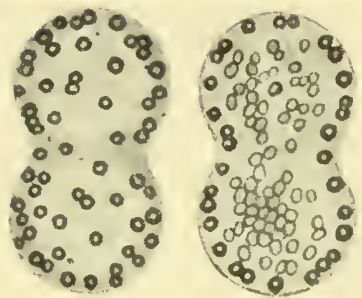

17

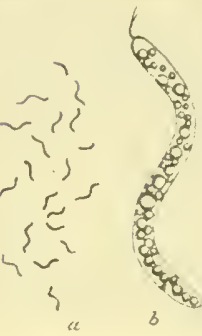

18

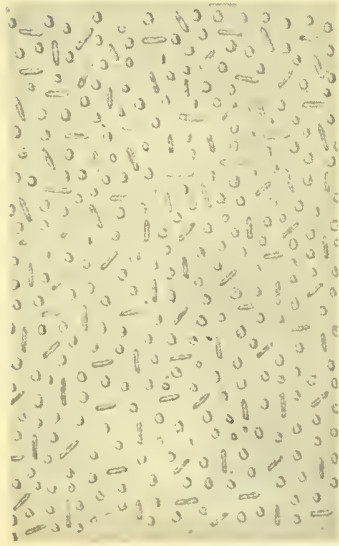

21

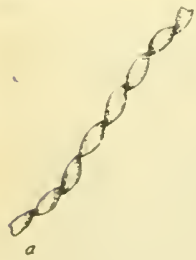

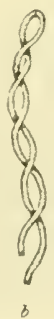
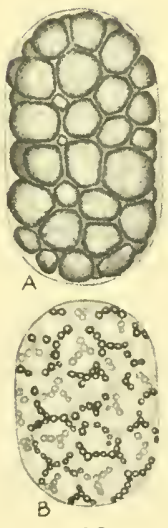

20

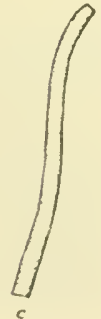

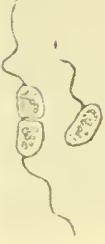

19

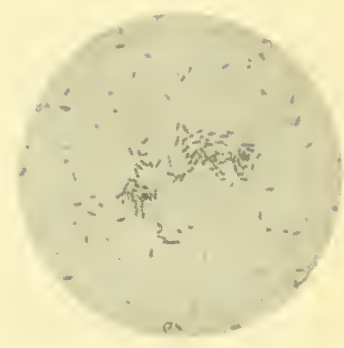

22 

the ammonium sulfate is to the Nitrosomonas and Nitrosococcus, the nitrous acid and nitrite to Nitrobacter and the carbon compounds to the heterotrophic bacteria.

The sulfur bacteria, or those bacteria which are capable of obtaining the energy necessary for their growth from the oxidation of sulfur or its compounds, should be distinguished from other bacteria taking part in the sulfur cycle, such as those liberating $\mathrm{H}_{2} \mathrm{~S}$ in the hydrolysis of proteins or in the reduction of sulfates.

Classification of sulfur bacteria. The sulfur oxidizing bacteria can be divided into five groups.

1. 'Thread-forming, colorless bacteria, accumulating sulfur within their cells; Beggiatoa and Thiothrix are representatives of this group.

2. Non-thread forming, colorless bacteria, accumulating sulfur within their cells; a number of forms (Thiospirillum, Thiovulum, Achromatium, etc.) of various sizes and shapes, the distinguishing characteristic of which is the fact that they oxidize $\mathrm{H}_{2} \mathrm{~S}$ and accumulate sulfur within their cells, are included in this group. Some of these have been isolated in pure culture.

3. Purple bacteria. Some of these seem to play a part in the sulfur cycle, although none of the sulfur forms have yet been isolated in pure culture.

4. Colorless, non-thread forming sulfur oxidizing bacteria, which do not accumulate sulfur within their cells, but which produce an abundance of sulfur (from $\mathrm{H}_{2} \mathrm{~S}$ and thiosulfates) outside of their cells. 'The two characteristic and most important forms belonging to this group are Thiobacillus denitrificans Beijerinck, an anaerobic form, deriving its oxygen from the decomposition of nitrates, and Thiobacillus thioparus Beijerinck, which oxidizes thiosulfates, $\mathrm{H}_{9} \mathrm{~S}$, and $\mathrm{S}$ and allows an extensive accumulation of sulfur from the first two.

5. The fifth group is similar to group 4 in morphology (but is less than $1 \mu$ in length) and is distinctly different physiologically. The organisms belonging to this group can act upon thiosulfates and $\mathrm{H}_{2} \mathrm{~S}$, but they oxidize elementary sulfur very rapidly, allowing the medium to become acid up to a reaction of $\mathrm{pH} 0.6$ to 1.2 . The only known representative of this group is Thiobacillus thiooxidans Waksman and Joffe.

The sulfur bacteria can also be divided into, $a$, sulfide bacteria, or those organisms which act primarily upon $\mathrm{H}_{2} \mathrm{~S}$ and sulfides and which would include the first three groups in the previous classification; $b$, thiosulfate or "thionic acid" bacteria, equivalent to group 4 ; $c$, sulfur bacteria, 
acting primarily upon elementary sulfur, equivalent to group 5 . The first four groups have their optimum on the alkaline side of neutrality, while the last group has its optimum on the acid side of neutrality. Only the last two groups (4 and 5) occur in the soil and play an active part in the oxidation of sulfur and its compounds in the soil. The first three groups do not occur to any extent in normal cultivated soils, but are mentioned here for the sake of completeness.

Group I. Colorless, thread-forming sulfur hacteria, accumulating sulfur within their cells (Nos. 13-16, Pl. IV). The representatives of this group are able to act only upon $\mathrm{H}_{2} \mathrm{~S}$. In view of the fact that these are primarily water and mud forms, only the general principles involved are discussed. This group of sulfur oxidizing bacteria consists of three genera: Beggiatoa, including motile organisms forming no sheaths; Thiothrix, fastened forms forming no sheaths; and Thioploca, threadforming bacteria, surrounded with a jelly-like sheath. The Beggiatoa were the first organisms to attract attention as having to do with the oxidation of sulfur or its derivatives. Cramer ${ }^{41}$ pointed out that the granules found within the cells of Beggiatoa consisted of sulfur. Cohn ${ }^{42}$ then proposed the theory that the Beggiatoa and the purple bacteria produce hydrogen sulfide by the reduction of sulfates. But it was Winogradsky ${ }^{43}$ who demonstrated that the hydrogen sulfide is produced by other bacteria and is oxidized by the Beggiatoa to sulfur and sulfuric acid.

This oxidation is so important for the very existence of these organisms that, when the hydrogen sulfide is taken out of the medium, they oxidize the sulfur present within their cells and, when this is used up, they die out. The energy liberated in this process is utilized by the organisms for the assimilation of carbon dioxide. For every gram of carbon, 8 to 19 grams of sulfur are consumed. If there is enough $\mathrm{H}_{2} \mathrm{~S}$, the presence of traces of organic substances and nitrates in the water is sufficient for the development of these organisms, while the presence of sugars, peptone and like nutrients will stimulate the growth of other microbes but will injure these sulfur bacteria.

${ }^{41}$ Cramer, In Mïller, C., Chemisch-physikalische Beschreibung der Thermen von Boden in der Schweiz. 1870.

${ }^{42}$ Cohn, F. Untersuchungen über Bakterien II. Beitr. Biol. Pflanz. 1: H. 3, p. 141 . 1875 .

${ }^{43}$ Winogradsky, S. Beiträge zur Morphologie und Physiologie der Bakterien. I. Schwefelbakterien. Leipzig. 1883; Ann. Inst. Past. 3: 1883, No. 2; Ùber Schwefellakterien. Bot. Ztg. 45: 4\$9, 513, 529, 545, 569, 585, 606. 1887. 
According to Winogradsky, the sulfuric acid formed is neutralized by the calcium carbonate or bicarbonate present in the water, since the reaction of the water cultures of these bacteria was not found to become acid. In reference to the physiology of these organisms, the results of Winogradsky can be summarized as follows: (1) The sulfur bacteria oxidize hydrogen sulfide and accumulate sulfur in the form of small spheres, consisting of soft amorphous sulfur which never crystallizes in the living cells. (2) They oxidize the sulfur to sulfuric acid, which is at once neutralized, by the carbonates present, into sulfates. Without sulfur, the organisms soon die off. (4) They can live and multiply in liquid containing only traces of organic substances.

This last point was refuted by Keil, ${ }^{44}$ who demonstrated that the organisms are autotrophic and do not need organic substances for their growth. Keil claims to have isolated pure cultures of Beggiatoa and Thiothrix, and found that these organisms are capable of living in media free from any traces of organic matter, although the presence of small quantities of organic substances is not detrimental to them. The raw cultures were obtained by Keil by placing a layer of black mud containing these bacteria on the bottom of a glass container, 3 to $4 \mathrm{~cm}$. high, covering it with 2 to $3 \mathrm{~cm}$. of river water and placing in the dark, at room temperature. The Beggiatoa formed a white layer over the mud. The Thiothrix could be easily distinguished by the fact that they were fastened at one end. By adding water from a sulfur spring to Petri dishes, then placing these under a bell-jar, the amount of gas necessary for the growth could readily be ascertained. Ammonium salts were found to be used as sources of nitrogen and only carbonic acid as a source of carbon. Carbon dioxide pressure may vary within the limits of 0.5 and $350 \mathrm{~mm}$. (25 mm. is the optimum); oxygen may vary within 10 to $20 \mathrm{~mm}$., and $\mathrm{H}_{2} \mathrm{~S}$ within 0.6 to $1.7 \mathrm{~mm}$. The presence of carbonates is important for the neutralization of the acids.

The pure cultures were obtained from the enriched culture by the mere mechanical process of washing out all other organisms first with ordinary water and then with sterile water. This was followed by growth under the bell-jar, at definite gas pressures and frequent changes of medium. Further information on this group of organisms is found

${ }^{44}$ Keil, F. Beiträge zur Physiologie der farblosen Schwefelbakterien. Beitr. Biol. Pflanz, II : 335-372. 1912. 
in the work of Omeliansky, ${ }^{45}$ Düggeli, ${ }^{46}$ Bavendamm, ${ }^{47}$ and others. ${ }^{48}$ The Thioploca has been studied in detail by Wislouch ${ }^{49}$ and Kolkwitz. ${ }^{50}$ Group II. The second group of the sulfur oxidizing bacteria is heterogeneous in nature and consists of all colorless organisms, which form no threads and which contain sulfur within their cells. These also act only on $\mathrm{H}_{2} \mathrm{~S}$ (Nos. 17-20, Pl. IV). This group includes organisms of various forms. They may be obtained by placing the cut rhizomes of water plants, together with the mud, into tall glass cylinders with some river or canal water and a few grams of calcium sulfate. When placed in the dark, $\mathrm{H}_{2} \mathrm{~S}$ will be produced in 5 to 10 days, and the colorless non-thread-forming sulfur bacteria are found in 3 to 6 weeks. The nature of the plant or animal material, nature of the mud and quantity of $\mathrm{H}_{2} \mathrm{~S}$ produced, determine which species will predominate. Among the organisms described at various times we might mention: Monas mülleri and Monas fallax Hinze, ${ }^{48}$ Thiophysa volutans Hinze, ${ }^{51}$ Thiospirillum winogradskii Omeliansky, ${ }^{52}$ Thiovulum Hinze, Spirillum Molisch, Bacterium bovista ( 2 to 4 by 0.6 by $1.5 \mu$ ), Bacillus thiogenes ( 2 to 6 by 0.9 to $1.34 \mu$ ), and Achromatium.53,54 Most organisms belonging to this group have been found in water and in mud; few of them have been obtained in pure cultures. They play an important part in the formation of the

${ }^{45}$ Omeliansky, W. L. Der Kreislauf des Schwefels. Lafar's Handb. techn. Mykol. 3: 214-244. 1904.

${ }^{46}$ Düggeli, M. Die Schwefelbakterien. Neujahrsbl. Naturf. Gesell. Zürich. 1919, No. 121, 43 p.

${ }^{47}$ Bavendamm, W. Die farblosen und roten Schwefelbakterien des Süsz- und Salzwassers. G. Fischer. Jena. 1924.

${ }^{48}$ Hinze, G. Beiträge zur Kenntnis der farblosen Schwefelbakterien. Ber. deut. bot. Gesell. 31: 189-202. 1913. Molisch, H. Neue farblose Schwefelbakterien. Centrbl. Bakt. II, 33: 55-62. 1912.

${ }^{49}$ Wislouch, S. M. Thioploca ingrica nov. spez. Ber. deut. bot. Gesell. 30: 470-473. 1912.

${ }^{50}$ Kolkwitz, R. Uber die Schwefelbakterie Thioploca ingrica Wislouch. Eer. deut. bot. Gesell. 30: 662-666. 1912.

"Hinze, G. Thiophysa volutans, ein neues Schwefelbakterium. Ber. deut. bot. Gesell. 21: 309-316. 1903.

${ }^{52}$ Omeliansky, W. L. Ủber eine neue Art farbloser Thiospirillen. Centrbl. Bakt. II, 14: 769-772. 1905.

${ }^{53}$ Nadson, G. A. On the sulfur bacteria of the sea of Hapsala. Bull. Jard. Bot. St. Petersburg, 13: 106-112. 1913; On the sulfur bacteria Thiophysa and Thiosphaerella. Jour. Microb. (Russian) 1: 52-72. 1914.

${ }^{54}$ West, G. S., and Griffith, B. M. The lime-sulfur bacteria of the genus Hillowia. Ann. Bot. 27: 83-91. 1913. 
curative muds. ${ }^{55}$ According to Nadson, some of these organisms, like Achromatium and Thiophysa, can accumulate in their cells sulfur as well as oxalate crystals. Jegunow described two sulfur bacteria: Thiobacterium $\alpha$, a motile, colorless, slightly curved organism, 4.5 to $9 \mu$ long and 1.4 to $2.3 \mu$ wide, containing a finely granulated plasma and large sulfur granules, and Thiobacterium $\beta$, motile, colorless, curved, 2.5 to 5 by 0.6 to $0.8 \mu$, and containing a row of shining sulfur granules. Various bacteria belonging to this group have been reported ${ }^{56}$ to occur in the soil, namely: Spirillum agilissimum filled with black sulfur granules, measuring about 6 to 10 by 1.8 to $2.0 \mu$, having rapid motility, and isolated from river mud in Gratz; Chromatium cuculliferum which is round to slightly elliptical, 6 by $4 \mu$, of a slow motility, with black, shining, sulfur drops always found in one pole, with one flagellum on the granule-free pole. This latter form was found in rotting mass of algae in the garden basin at Gratz. However, since none of the forms has been considered from the point of view of its rôle in soil transformations, their importance in the soil is doubtful. A detailed study of the morphology and biology of Achromatium oxalifcrum Schew., containing granules of a calcium salt (oxalate, carbonate or thiosulfate) and sulfur has been made by Nadson and Wislouch..$^{57}$

Group III. This group consists of the sulfur oxidizing organisms found among the purple bacteria. They are distinguished from the sulfur bacteria described above by the production of a red, red violet or red brown pigment which is unevenly distributed throughout the cell; in addition to the red pigment (bacterio-purpurin), there is also present in all these bacteria a green pigment (bacterio-chlorin). 'These bacteria are found abundantly in sulfur springs and in mud waters. Not all the purple bacteria are able to utilize hydrogen sulfide and not all of them accumulate sulfur within their cells. Molisch ${ }^{58}$ succeeded in cultivating some of them in pure culture, but not the sulfur forms. The rôle of sulfur in the metabolism of the purple bacteria is still an open question, since, according to Molisch, the hydrogen sulfide is not

${ }^{55}$ Jegunow, M. Bakterien Gesellschaften. Centrbl. Bakt. II, 2: 11-21, 441$449 ; 478-482 ; 739-752.1896$.

${ }^{56}$ Gicklehorn, J. Über neue farblose Schwefelbakterien. Centrbl. Bakt. II, E0: 415-427. 1920.

${ }^{67}$ Nadson, G. A., and Wislouch, C. M. La structure et la vie de la bactérie géante Achromatium oxaliserum Schew. Bull. Jard. Bot. Rep. Russe. 22: 1-24. 1923.

${ }^{58}$ Molisch, H. The Purpurbakterien nach neuen Untersuchungen. Jena. G. Fischer, 1907 . 
required for nutrition. These results are in direct opposition to the earlier ideas of Winogradsky and others.

Group IV. This group includes the colorless organisms that do not accumulate sulfur within their cells, but produce sulfur abundantly from thiosulfate and hydrogen sulfide outside of their cells (No. 21, Pl. IV). These were first demonstrated by Nathanson ${ }^{59}$ (1902) in sea water. They were found to be able, by means of oxidation of hydrogen sulfide or sodium thiosulfate, to reduce carbonic acid and construct organic substances from it. Nathanson used a medium of the following composition:
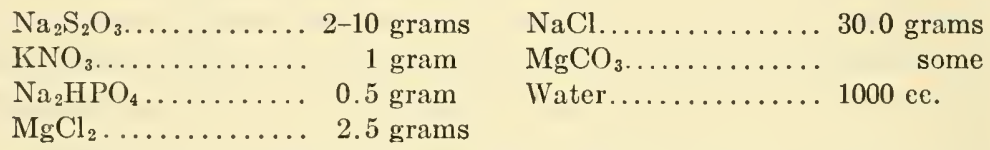

A good growth of these bacteria was obtained after 1 to 2 days, in the form of a white pellicle covering the surface; this consisted of rodshaped organisms intermixed with amorphous sulfur.

On adding agar to the above medium Nathanson has been able to isolate the organism in pure culture. In the absence of the carbonate, but in the presence of air containing carbon dioxide, the growth was much slower. In the absence of both carbonate and carbon dioxide, no growth took place, even in the presence of various organic substances. The medium did not become acid even in the absence of carbonate. While no sulfur accumulated within the cell, there was an abundant production of free sulfur outside of the cell, not in direct contact with the colony but at some distance from it. This led to the theory of extracellular oxidation. Nathanson suggested that the sulfur is produced in a secondary reaction between the undecomposed thiosulfate and the tetrathionate formed from the oxidation of the thiosulfate.

Beijerinck ${ }^{60}$ employed the following medium:

$$
\begin{aligned}
& \mathrm{Na}_{2} \mathrm{~S}_{2} \mathrm{O}_{3} \cdot 5 \mathrm{H}_{2} \mathrm{O} \ldots \ldots \ldots .0 \text { grams } \quad \mathrm{NH}_{4} \mathrm{Cl} \ldots \ldots \ldots \ldots . .6 \text { gram } \\
& \mathrm{NaHCO}_{3} \ldots \ldots \ldots \ldots, 1.0 \text { gram } \mathrm{MgCl}_{2} \ldots \ldots \ldots \ldots . . .60 .1 \mathrm{gram} \\
& \mathrm{Na}_{2} \mathrm{HPO} \text { 4......... 0.2 gram Water.......... } 1000 \text { ce. }
\end{aligned}
$$

The medium was left unsterilized and was inoculated with canal water and incubated at $28^{\circ}$ to $30^{\circ} \mathrm{C}$. In 2 to 3 days, the surface of the medium

${ }^{59}$ Nathanson, A. Über eine neue Gruppe von farblosen Sehwefelbakterien und ihren Stoffwechsel. Mitt. Zool. Station, Neapel 15: 655. 1902.

${ }^{60}$ Beijerinek, M. W. Über die Bakterien, welehe sieh im Dunkeln mit Kohlensïure als Kohlenstoffquelle ernühren können. Centrbl. Bakt. II, 11: 593-599. 1904. 
became covered with free sulfur, intermixed with bacteria. On making a transfer into a fresh flask with medium, a sulfur layer was obtained in 24 hours, originating from the thiosulfate. This reaction is exothermic and functions as a source of energy. The energy is used for the reduction of $\mathrm{NaHCO}_{3}$ and for the building of the bacterial body. Calcium sulfide, hydrogen sulfide and tetrathionate can replace the thiosulfate. The ammonium salt can be replaced by nitrates. None of the organic substances tested could replace the carbonic acid as a source of carbon. The organism, Thiobacillus thioparus Beijerinck, was reported to be a short rod, 3 by $0.5 \mu$, not forming any spores, very motile and very sensitive, so that on plates the organisms die off in a week.

By adding 2 per cent agar to the above medium the organism can be grown on the plate; transfers are then made from individual colonies into fresh lots of the liquid medium giving a pure culture of the organism. The colonies are of a pin-point form and are distinguished from contaminations by their yellow appearance, due to an abundant separation of sulfur. According to Düggeli, ${ }^{61}$ this organism is only 0.3 to $0.5 \mu$ long. Jacobsen $^{62}$ demonstrated that this organism can also oxidize sulfur to sulfuric acid, in the following medium:

\begin{tabular}{|c|c|}
\hline $\mathrm{K}_{2} \mathrm{HPO}_{4} \ldots \ldots \ldots \ldots 0.5 \mathrm{gram}$ & $\mathrm{CaCO}_{3}$ or $\mathrm{MgCO}_{3} \ldots 20.0$ grams \\
\hline $0.5 \mathrm{~g}$ & Precipitated sulfur... 10.0 grams \\
\hline $\mathrm{MgCl}_{2} \ldots \ldots \ldots \ldots 0.2$ gram & Distilled water..... $1000 \mathrm{cc}$ \\
\hline
\end{tabular}

An organism similar to the Thiobacillus thioparus was found ${ }^{63}$ to be active in the oxidation of sulfur in alkali soil, giving the gross microscopic reactions of the form studied by Nathanson and Beijerinck.

Group IV of the sulfur bacteria includes, in addition to the aerobes, anaerobic bacteria which are able to obtain their oxygen from nitrates. Beijerinck obtained an oxidation of sulfur accompanied by a reduction of the nitrate to atmospheric nitrogen by using the following medium in closed flasks and incubating at $30^{\circ} \mathrm{C}$.

\begin{tabular}{|c|c|}
\hline $\mathrm{KNO}_{3} \ldots \ldots \ldots \ldots \ldots 0.5 \mathrm{gram}$ & $\mathrm{CaCO}_{3} \ldots \ldots \ldots \ldots$ \\
\hline $\mathrm{Na}_{2} \mathrm{CO}_{3} \ldots \ldots \ldots \ldots .20 .2 \mathrm{gram}$ & Sulfur.......... 100.0 grams \\
\hline $\mathrm{K}_{2} \mathrm{HPO}_{4} \ldots \ldots \ldots \ldots$ & Canal water....... $1000.0 \mathrm{cc}$ \\
\hline
\end{tabular}

${ }^{61}$ Düggeli, 1919 (p. 82).

${ }^{62}$ Jacobsen, H. C. Die Oxidation von elementarem Schwefel durch Bakterien. Folia Microb. 1: 487-496. 1912; 3: 155-162. 1914.

${ }^{63}$ Waksman, S. A. Microorganisms concerned in the oxidation of sulfur in the soil. V. Bacteria oxidizing sulfur under acid and alkaline conditions. Jour. Bact. 7: 609-616. 1922. 
The sulfur is oxidized to sulfuric acid which acts upon the $\mathrm{CaCO}_{3}$ giving $\mathrm{CaSO}_{4}$ and $\mathrm{CO}_{2}$. Beijerinck isolated, in pure culture, an organism, Thiobacillus denitrificans, which is a very motile, short rod, hardly distinguishable microscopically from the Thiobacillus thiopurus, using the following medium:

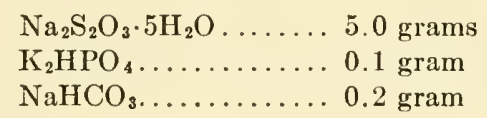

Agar............. 20.0 grams

Tap water......... 1000 cc.

On the plate, both organisms lose their ability to grow very rapidly, long before they are dead.

The denitrifying organism was studied in greater detail by Lieske, ${ }^{64}$ who used a medium having the following composition:

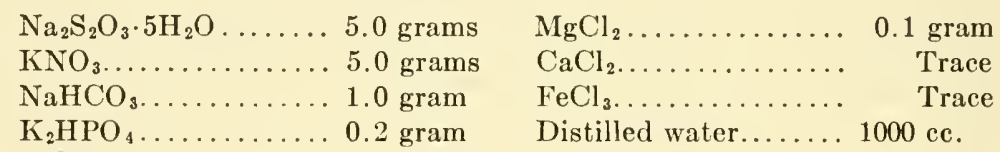

This medium is placed in tall glass cylinders and is inoculated with river mud containing $\mathrm{H}_{2} \mathrm{~S}$. In a few days, one or more opalescent zones are formed in the liquid, at some distance from the surface, containing the denitrifying bacteria in question. The culture is then transferred into an Erlenmeyer flask filled with the medium and stoppered with a rubber stopper through which a bent glass tube is passed, one end of which is dipped in mercury and the rest filled with medium. The culture is incubated at $25^{\circ}$ to $30^{\circ} \mathrm{C}$. and in a few days the active formation of nitrogen gas takes place. By inoculating the above medium, to which 1.5 per cent washed agar has been added, pure cultures are obtained. The organism can also be cultivated in dilute meat extract media to which thiosulfate has been added.

Thiobacillus denitrificans Beij. as described by Lieske is a small narrow rod, $1 \mu$ long, not producing any spores. It is not injured by sunshine or oxygen, although it thrives better in its absence. It is autotrophic, but is not injured by organic substances. Various carbonates and bicarbonates can be used as sources of carbon, but $\mathrm{CO}_{2}$ cannot be used because of the injurious effect of the free sulfuric acid formed. In the presence of nitrates, the following substances can be utilized as sources of energy: hydrogen sulfide, flowers of sulfur, sodium thio-

${ }^{64}$ Lieske, R. Untersuchungen über die Physiologie denitrifizierender Schwefelbakterien. Ber, deut. bot. Gesell. 30: 12-22. 1912. 
sulfate and sodium tetrathionate, which are completely oxidized to sulfate.

The energy liberated in the process is sufficient both for the reduction of the nitrate, which is an endothermic phenomenon, and the assimilation of $\mathrm{CO}_{2}$ from the carbonate and bicarbonate. The reason why the same organism can oxidize various compounds of sulfur, while other autotrophic soil bacteria, like those concerned in nitrification, can act only on one definite compound, is explained by Lieske to be due to the step-like oxidation of the sulfur compounds. For every $100 \mathrm{gm}$. of $\mathrm{Na}_{2} \mathrm{~S}_{2} \mathrm{O}_{3}$ oxidized to sulfate, Lieske found that $1 \mathrm{gm}$. of carbon is assimilated.

The Thiobacillus denitrificans is of universal occurrence in various soil types, the number of bacteria increasing with the increase in the carbon content of the soil. ${ }^{65}$ By adding thiosulfate and bicarbonate to the soil, intensive nitrate decomposition takes place. The organism occurring in various soils varies in activity, so that the forms from composts, forest soils and peat belong to a group which is four times as active as the form from cultivated soils. Thiobacillus denitrificans offers, according to Beijerinck, ${ }^{6}{ }^{6}$ the natural connecting link between sulfur oxidizing bacteria and denitrifying bacteria.

Trautwein ${ }^{67}$ isolated an organism from the soil which was classified with Thiobacillus denitrificans Beij.; this organism is 1 to 2 by $0.5 \mu$ in size, motile, can reduce nitrate, but can grow also under aerobic conditions; it grows well on organic media and does not precipitate any sulfur from thiosulfate. The organism is facultative autotrophic, since it can obtain its carbon both from $\mathrm{CO}_{2}$ (with thiosulfate as a source of energy) and from organic substances (in the absence of thiosulfate). It was grown on the following medium:

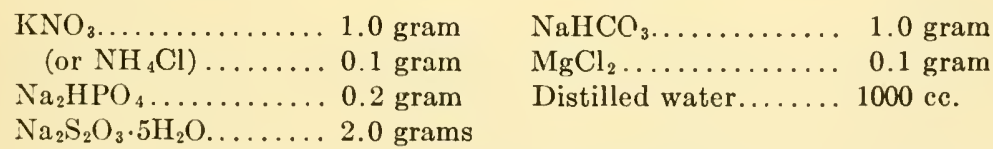

To prepare a solid medium, agar is added to the above solution. As organic media, ordinary bouillon or nutrient agar can be employed.

${ }^{65}$ Gehring, A. Beiträge zur Kenntnis der Physiologie und Verbreitung denitrifizierender Thiosulfat Bakterien. Centrbl. Bakt. II, 42: 402-438. 1915.

${ }^{66}$ Beijerinck, 1920 (p. 547).

${ }^{67}$ Trautwein, K. Beitrag zur Physiologie und Morphologie der Thionsäurebakterien (Omelianski). Centrbl. Rakt. II, 53: 513-548. 1921. 
The bacterium was found to be related ${ }^{68}$ to the fluorescens group in the Lehmann and Neumann system, especially to the Bact. denitrificans (Stutzer and Burri) L and N.

According to Klein and Limberger ${ }^{69}$ the thionic acid bacteria are capable of oxidizing all sources of sulfur found in the soil (elementary sulfur, hydrogen sulfide, other sulfides, sulfites and hydrosulfites) to sulfate and polythionate. The sulfur can also be utilized in the form of organic sulfur (cystin, albumin, nuclein, meat extract) and is oxidized, through the sulfur stage, to sulfate. The organism reduces $\mathrm{KNO}_{3}$ to nitrite and to ammonia, in the oxidation of sulfur. The claim, however, that this organism can also oxidize $\mathrm{NH}_{4} \mathrm{Cl}$ to nitrite needs further confirmation, especially since the cultivation of these organisms in pure culture may not often be a very easy matter.

In this group of thionic acid bacteria, we have another connecting link, between autotrophic and heterotrophic nutrition in nature.

Group V. Minute, colorless, aerobic, non-spore and non-thread forming bacteria, acting primarily on elementary sulfur and oxidizing it rapidly to sulfuric acid (No. 22, Pl. IV).

When sulfur is mixed with soil, it is oxidized slowly at first and then as the soil becomes acid it oxidizes rapidly. If powdered rock phosphate is added to the mixture of soil and sulfur, the rock is transformed into soluble phosphates by the acid formed from the sulfur. This process has been utilized ${ }^{70}$ in composting sulfur, rock phosphate and soil in various proportions. A direct correlation was found between the acid formed, as shown by the increase in the hydrogen-ion concentration, and the amount of phosphates going into solution. When a fresh compost is inoculated with some material from an old compost, the reaction goes on more rapidly, indicating the biological nature of the process.

By inoculating a medium free from any organic compounds and carbonates and containing sulfur as the only source of energy, in addition to minerals and tri-calcium phosphate as a neutralizing agent, the

68 Trautwein, K. Die Physiologie und Morphologie der fakultativ autotrophen Thionsäurebakterien unter heterotrophen Ernährungsbedingungen. Centrbl. Bakt. II, 61: 1-5. 1924.

${ }^{69}$ Klein, G., and Limberger, A. Zum Kreislauf des Schwefels im Boden. Biochem. Ztschr. 143: 473-483. 1923.

${ }^{70}$ Lipman, J. G., McLean, H. C., and Lint, H. C. Sulfur oxidation in soils and its effect on the availability of mineral phosphates. Soil Sci. 2: 499-538. 1916. McLean, H. C. The oxidation of sulfur by microorganisms and its relation to the availability of phosphates. Soil Sci. 5: 251-290. 1918. 
growth of a bacterium, capable of oxidizing sulfur to sulfuric acid, was obtained. ${ }^{71}$ The acid produced interacted with the tricalcium phosphate and transformed it into $\mathrm{CaSO}_{4}$ and monocalcium phosphate and finally into phosphoric acid. The bacterium was, however, accompanied by other organisms, chiefly mold spores, which persisted in the medium on repeated transfer. Repeated attempts to grow the bacterium on agar plates failed. After all the calcium of the phosphate had been transformed into calcium sulfate, the medium became very acid, as low as $\mathrm{pH} 0.58$.

In order to make use of the fact that the organism can withstand a high acid concentration, the media were prepared with an initial reaction of $\mathrm{pH}$ 2.0. This allowed only the development of the sulfuroxidizing organism. The high initial acidity accompanied by the use of high dilutions of the culture in making the transfers $(1: 100,000)$, finally resulted in obtaining the culture pure. This was demonstrated by the fact that no growth took place when inoculated on bouillon and other media, favorable for the development of bacteria and fungi, even after 10 to 14 days incubation. Microscopic examinations also demonstrated the purity of the culture. This organism was described as Thiobacillus thiooxidans. ${ }^{72}$ It is a small, non-motile organism, 0.75 to 1.0 by 0.5 to $0.75 \mu$, producing cloudiness throughout the medium but without the formation of any pellicle. The two media best adapted for the growth of this organism have the following composition:

I

\begin{tabular}{|c|c|}
\hline & $0.2 \mathrm{gra}$ \\
\hline (1) & $0.5 \mathrm{gr}$ \\
\hline $\mathrm{H}_{2} \mathrm{H}_{2} \mathrm{P}_{2} \ldots \ldots \ldots$ & $\begin{array}{l}3.0 \text { grams } \\
0.25 \text { gram }\end{array}$ \\
\hline
\end{tabular}

Elementary, powdered sulfur....... 10 grams

Distilled water...... $1000 \mathrm{cc}$.
II

$$
\begin{aligned}
& \left(\mathrm{NH}_{4}\right)_{2} \mathrm{SO}_{4} \ldots \ldots \ldots, 0.2 \text { gram } \\
& \mathrm{MgSO}_{4} \cdot 7 \mathrm{H}_{2} \mathrm{O} \ldots \ldots \ldots \quad 0.5 \mathrm{gram} \\
& \mathrm{KH}_{2} \mathrm{PO}_{4} \ldots \ldots \ldots \ldots, 1.0 \text { gram } \\
& \text { Re-precipitated } \\
& \mathrm{Ca}_{3}\left(\mathrm{PO}_{4}\right)_{2} \ldots \ldots \ldots 2.5 \text { grams } \\
& \text { Sulfur........... } 10.0 \text { grams } \\
& \mathrm{H}_{3} \mathrm{PO}_{4}\left(\frac{M}{1}\right) \text { to adjust reaction to } \\
& \mathrm{pH}=3.0
\end{aligned}
$$

Distilled water...... $1000 \mathrm{ce}$.

The sulfur in both media and the $\mathrm{Ca}_{3}\left(\mathrm{PO}_{4}\right)_{2}$ in medium II are weighed out separately in the individual flasks into which the media are distributed (100-ce. portions are usually placed in 250-cc. flasks). The media are sterilized for thirty minutes, in flowing steam, on three consecutive days.

${ }^{71}$ Lipman, J. G., Waksman, S. A., and Joffe, J. S. The oxidation of sulfur by soil microorganisms. Soil Sci. 12: 475-489. 1921.

72 Waksman, S. A., and Joffe, J. S. Thiobacillus thiooxidans, a new sulfuroxidizing organism, isolated from the soil. Jour. Bact. 7: 239-256. 1922. 
When a flask with one of these two media is inoculated from a fresh vigorous culture (seven to fourten days old) of the Th. thiooxidans, growth will be manifested by a uniform turbidity, without any pellicle formation, within four to five days, at 25 to $30^{\circ} \mathrm{C}$., the culture becoming very turbid in seven to eight days; the sulfur which has been floating on the surface begins to drop down. The same phenomenon is observed when the medium is inoculated with a little soil containing the bacterium, only the length of time required for development is sometimes a little longer, depending upon the abundance of the organism in the soil, condition of soil, etc. By using the dilution method, even the approximate number of the organisms in the soil can be estimated. The culture obtained on the two media is practically pure, due to the fact that very few other organisms would develop under these conditions.

The bacterium is strictlyaerobic and is benefited both by aeration and greater surface exposure. When a particle of sulfur from the flask is examined, it is found to be surrounded by the bacteria. At the same time there is an intense increase in acidity of the medium.

In the presence of calcium phosphate or carbonate, the sulfuric acid, as soon as formed, interacts with the calcium salt giving crystals of $\mathrm{CaSO}_{4} \cdot 2 \mathrm{H}_{2} \mathrm{O}$, which are seen in the culture hanging down from the particles of sulfur floating on the surface, till finally the bottom of the flask is covered with gypsum crystals. The organism forms no spores and is destroyed at 55 to $60^{\circ} \mathrm{C}$. in several minutes. The limiting alkaline reaction is about $\mathrm{pH} 6.0$, which is distinctly acid, while at the other extreme it will grow at $\mathrm{pH} 1.0$. The optimum lies at $\mathrm{pH} 2.0$ to 4.0. It is possible, however, to accustom the organism to a neutral and even an alkaline reaction, especially when transferred from one soil to another before the reaction becomes too acid.

The organism derives its carbon from the $\mathrm{CO}_{2}$ of the atmosphere; carbonates and bicarbonates affect it injuriously in so far as they tend to make the reaction alkaline. The presence of organic substances is not injurious. As a matter of fact, sugars, like lactose and galactose, ethyl alcohol, and glycerol may even slightly stimulate growth but without affecting sulfur oxidation and carbon assimilation. For establishing the purity of the culture, the organism can be grown on a solid medium having the following composition: $:^{73}$

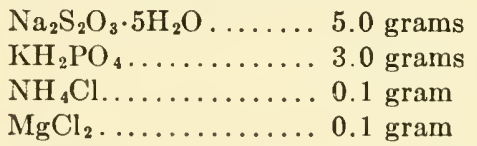

${ }^{73}$ Waksman, S. A. Microorganisms concerned in the oxidation of sulfur in the soil. IV. A solid medium for the isolation and cultivation of Thiobacillus thiooxidans. Jour. Bact. 7: 605-608. 1922. 
The medium is prepared as usual and sterilized at 15 pounds pressure for fifteen minutes. Plates and slants are inoculated from a vigorous liquid culture and incubated at $25^{\circ}$ to $30^{\circ} \mathrm{C}$. Growth appears in five to six days in the form of minute straw yellow to cream-colored colonies. Under the microscope, each colony is found to be surrounded with crystals of gypsum due to the action of the sulfuric acid, formed from the oxidation of the thiosulfate, upon the $\mathrm{CaCl}_{2}$. This phenomenon is particularly prominent in media containing tricalcium phosphate in place of the chloride; a clear zone is formed around each colony, due to the disappearance of the insoluble calcium salt. ${ }^{74}$

When, instead of an ordinary neutral or acid soil, an alkaline soil is used for composting, the sulfur is also oxidized to sulfuric acid with the result that the alkalinity of the soil is decreased. When enough sulfur is added, black alkali soil having a reaction of $\mathrm{pH} 9.8$ can be made neutral and even acid. At first it was thought that Thiobacillus thiooxidans is responsible for this oxidation, particularly since the same acid composts were employed. It is possible, however, that the organism concerned in the oxidation of elementary sulfur in alkali soil is of an entirely different nature, approaching more the Th. thioparus of Beijerinck, in its cultural and some physiological characters, rather than the Th. thiooxidans. The latter, however, is also found in alkaline composts, and it is possible that both organisms take an active part in the oxidation of the sulfur under alkaline conditions. The Th. thioparus group has its optimum on the alkaline side ( $\mathrm{pH} 7.0$ to 9.0 ), as shown by Trautwein, while the Th. thiooxidans has its optimum on the acid side. Both organisms may, therefore, act upon the sulfur under alkaline conditions. However, the phylogenetic relationship of the various species of Thiobacillus, as well as the differences in their chemical action still remain to be investigated.

Oxidation of selenium and its compounds. Brenner ${ }^{75}$ isolated from the soil an organism (Micrococcus selenicus, less than $0.5 \mu$ in size), which is capable of oxidizing selenides and using the energy obtained for its activities. Sodium selenite, sodium thiosulfate or sodium selenate, as well as litmus, methylene blue or indigo carmin, can be used as hydrogen acceptors (or sources of oxygen) but not nitrates, sulfates, sulfites or tellurites. In addition to selenide, the organism can also use various

${ }^{74}$ The occurrence of the Thiobacillus group in the soil has been further studied by Brown, H. D. Sulfofication in pure and mixed cultures, with special reference to sulfate production, hydrogen-ion concentration and nitrification. Jour. Amer. Soc. Agron. 15: 350-3S2. 1923.

${ }^{75}$ Brenner, W. Züchtungsversuche einiger in Schlamm lebenden Bakterien auf selenhaltigem Nährbodem. Jahrb. wiss. Bot. 57: 95-127. 1916. 
alcohols (ethyl-, iso-butyl) as well as asparagine and glucose as sources of energy, but not proteins. The carbon is obtained, however, only from organic substances (ethyl alcohol). The possible oxidation of elementary selenium, in the absence of organic matter, with an increase of acidity of the medium has also been suggested. ${ }^{76}$ The Th. thioparus and Th. thiooxidans were found to be inactive in both cases. The relation between the oxidation of selenium and of selenide and autotrophic processes is unknown.

Bacteria oxidizing iron compounds. The nitrifying bacteria are found to be strictly autotrophic and, in the case of the nitrite formers, are even injured by the presence of organic matter. The sulfur bacteria are not injured by the organic matter present in the medium (except $T h$. thiooxidans which is injured by nitrogenous substances above 0.2 per cent) and some of them can even utilize organic materials. The utilization of complex organic substances is true even to a greater extent in the case of iron bacteria, only one or two forms of which are known to require iron compounds as a source of energy, while the majority are able to derive their energy heterotrophically. The strictly iron bacteria, or those organisms that are capable of oxidizing ferrous to ferric iron, whereby the energy obtained is used for the chemosynthetic assimilation of carbon, should be distinguished from those organisms that can absorb or accumulate iron, when living in media containing iron. Unlike the latter process the precipitation of iron by true iron bacteria is a direct result of utilization of energy from the oxidation of iron. ${ }^{77}$

As early as 1836 , Ehrenberg, ${ }^{78}$ found that microorganisms play an important part in the formation of ochraceous deposits of bog iron ore. The iron precipitating organisms are present universally in nature, wherever iron-bearing waters occur. They belong chiefly to the threadforming bacteria, although a number of them have also been found to belong to the Eubacteria. Here again we find a similarity between the iron and sulfur bacteria, a large number of forms belonging to distinctly different morphological groups. The majority of these forms belong to the higher bacteria, according to the following classification ${ }^{88}$ :

${ }^{76}$ Lipman, J. G., and Waksman, S. A. The oxidation of selenium by a new group of autotrophic microorganisms. Science, N. S. 57: 58. 1923.

${ }_{77}$ Winogradsky, 1922 (p. 61).

78 Ehrenberg, C. G. Vorläufige Mittheilungen ïber das wirkliche Vorkommen fossiler Infucorien, und ihre grösse Verbreitung. Poggendoff's Annalen 38: 213-227. 1836. 
I. Thread-forming bacteria consisting of sheaths with included cells generally plainly visible. Reproduction by internally produced conidia or by the separation of motile and non-motile cells (Trichobacteria).
Crenothrix
Leptothrix
L. ochracea
L. trichogenes

II. True bacteria:

\section{Gallionella (Spirophyllum) \\ Siderocapsa \\ Sideromonas}

Only a few of the numerous forms described are true iron bacteria.

It was assumed that the higher bacteria present a variety of forms, such as single threads composed of cylindrical cells placed end to end and generally inclosed in sheaths; ribbon forms, twisted spirally; cylindrical threads showing false branching, or coiled threads and ribbon forms produced by the bending of the filaments in the middle and the twisting of the ends around each other like a rope. ${ }^{79}$ Gallionella (Spirophyllum) ${ }^{80}$ was considered to be the most abundant of the iron bacteria. The flat ribbon-like or tape-like threads are twisted in the form of spirals. These spiral bands may occur as single filaments or may be coiled together.

Some of the iron bacteria are also capable of oxidizing manganese salts and precipitate manganese hydrates in their cells; ${ }^{81}$ Winogradsky suggested that we may be dealing here with organisms less specialized than the other autotrophic bacteria, some being iron-bacteria in the proper sense (Gallionella, Spirophyllum, etc.), some iron-manganese bacteria (Crenothrix, Leptothrix, etc.) and some may possibly be obligate manganese-bacteria.

Winogradsky ${ }^{82}$ found in 1888 that Leptothrix will live and grow only in solutions in which iron is present in the ferrous form; where the living cells are present, a brown coloration of the sheath takes place due to the oxidation of the iron salt. The oxidation of ferrous compounds $\left(\mathrm{FeCO}_{3}\right)$

${ }^{79}$ Harder, E. C. Iron depositing bacteria and their geologic relations. Prof. paper 113, U. S. Geological Survey, Dept. of Interior, 1919.

${ }^{80}$ Ellis, D. On the discovery of a new genus of thread bacteria (Spirophyllum ferrugineum Ellis). Proc. Roy. Soc. Edinburgh, 27: 21-34. 1907. Lieske, 1911 (p. 95).

${ }^{81}$ Schorler, B. Beiträge zur Kenntnis der Eisenbakterien. Centrbl. Bakt. II, 12: 681-695. 1904; Die Rostbildung in den Wasserleitungsröhren. Ibid. 15: 564-568. 1906.

82 Winogradsky, S. Über Eisenbakterien. Bot. Ztg. 46: 262-270. 1858. 
to ferric hydroxide is necessary for the life and growth of the organisms, this process furnishing the necessary energy to the cell for the assimilation of carbon. According to Molisch, ${ }^{83}$ however, Leptothrix will grow well in iron-free media, particularly in peptone solutions, forming perfectly colorless sheaths. If iron or manganese compounds are present in the solutions, they are oxidized and taken up by the sheaths; even dead cells (killed by boiling) are able to take up ferric hydroxide in their sheaths. He, therefore, concluded that the process is merely physicochemical and the change of ferrous to ferric compounds is due to simple chemical oxidation and is not connected with the life processes of the cell. Similar observations were made by Ellis ${ }^{84}$ and others, ${ }^{85}$ who claimed that these bacteria living in iron waters have the power of attracting ferric hydroxide, which is found in quantity in such waters, the deposition of iron being merely a purely mechanical process. This was entirely due to the lack of proper differentiation between the physico-chemical absorption and chemico-biological oxidation of iron, on the one hand, and between the obligate and facultative autotrophy, on the other hand. This led to the general terminology of bacteria which accumulate iron as "iron bacteria," 86 and frequently also to absurdities, as in the case of isolation of a bacterium which can accumulate both iron and calcium (incrustations), where it has been suggested that iron can be replaced by calcium, although evidently no oxidation of calcium is possible. ${ }^{87}$ It has, however, recently, been suggested $^{8 s}$ that the cells of Gallionella (Spirophyllum) are nothing more than a product of secretion of a small bacterium, 1.2 by $0.5 \mu$, consisting of two coccus-like cells $(0.6$ by $0.5 \mu)$; the threads themselves consist only of ferric hydrate which dissolves completely in hydrochloric acid, leaving the living cells only at the end of the threads.

${ }^{83}$ Molisch, H. Die Eisenbakterien. Jena. 1910.

${ }^{84}$ Ellis, D. A contribution to the knowledge of thread bacteria. Centrbl. Bakt. II, 19: 507-518. 1907; 26: 321-329. 1910; 31: 499-504. 1911; Iron bacteria. Science Progr. 10: 374-392. 1916; Iron bacteria. Methuen \& Co., London. 1919.

${ }^{85}$ Rullman, W. Úber Eisenbakterien. Centrbl. Bakt. II, 33: 277-289. 1912. Zikes, H. Vergleichende Untersuchungen über Sphaerotilus natans (Kützing) und Cladothrix dichotoma (Cohn) auf Grund von Reinkulturen. Centrbl. Bakt. II, 43: 529-552. 1915.

${ }^{86}$ Löhnis, 1910, p. 704 (p. 28).

${ }^{87}$ Brusoff, A. Ferribacterium duplex, eine stäbchenförmige Eisenbakterie. Centrbl. Bakt. II, 45: 547-554. 1916; also 48: 193-210. 1918.

${ }^{88}$ Cholodny, N. Die Eisenbakterien. Beitrïge zu einer Monographie. G. Fischer. Jena. 1926. 
Lieske $^{89}$ working with Spirophyllum confirmed the original observations of Winogradsky. The oxidation of $\mathrm{FeCO}_{3}$ takes place according to the following equation:

$$
2 \mathrm{FeCO}_{3}+\mathrm{H}_{2} \mathrm{O}=\mathrm{Fe}_{2}(\mathrm{OH})_{6}+2 \mathrm{CO}_{2}+29 \text { calories }
$$

Lieske used a medium having the following composition:
$\left(\mathrm{NH}_{4}\right)_{2} \mathrm{SO}_{4} \ldots \ldots \ldots \ldots 1.5$ grams
$\mathrm{K}_{2} \mathrm{HPO}_{4}$
0.05 gram

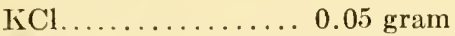
$\mathrm{Ca}\left(\mathrm{NO}_{3}\right)_{2} \ldots \ldots \ldots \ldots .0 .01 \mathrm{gram}$
$\mathrm{MgSO}_{4}$. . .
0.05 gram
Distilled water....... $1000 \mathrm{cc}$.

The medium was placed in Erlenmeyer flasks (100 cc.) to a height of $2 \mathrm{~cm}$, sterilized and allowed to stand two days. Coarse iron filings, which had been dry sterilized for one hour at $160^{\circ} \mathrm{C}$. were then added, 0.05 gram to each flask. The flasks were inoculated with a small amount of culture of iron bacteria, placed under a bell-jar in a cool place, and $\mathrm{CO}_{2}$ added up to 1 per cent. This resulted in the formation of about 0.01 per cent of $\mathrm{FeCO}_{3}$, which remained constant as long as there was metallic iron present.

Spirophyllum developed in four days in the cultures to which iron was added. Pure cultures were obtained by repeated transfers to sterile flasks. Similar results were obtained in 1888 by Winogradsky for Leptothrix ochracea, although he did not work with pure cultures. Organic matter in concentrations of over 0.01 per cent (peptone, asparagine, sugar) produced an injurious effect upon the growth of Spirophyllum. This organism can oxidize no other iron salt, except the bicarbonate, and also not $\mathrm{MnCO}_{3}$, showing it to be strictly autotrophic and highly specialized. Leptothrix ochracea was found by Lieske to be able to utilize manganese carbonate as well as iron carbonate as a source of energy and to be facultative autotrophic, capable of existing also in organic media.

The two media used by Lieske for pure culture study have the following composition:

I

Distilled water...... $1000 \mathrm{cc}$.

Agar............. 10.0 grams

Manganese acetate... 0.1 gram
Manganese car-
bonate saturated
solution...... 1:10
$\mathrm{NaHCO}_{3} \ldots \ldots \ldots 0.001$ per cent
$\left(\mathrm{NH}_{4}\right)_{2} \mathrm{SO}_{4} \ldots \ldots .0 .001$ per cent
$\mathrm{K}_{2} \mathrm{HPO}_{4}$ and
$\mathrm{MgSO}_{4} \ldots \ldots \ldots$.

One may well agree with Harder ${ }^{79}$ that certain iron-depositing organisms, such as Spirophyllum, require ferrous bicarbonate in solution and

${ }^{89}$ Lieske, R. Beiträge zur Kenntnis der Physiologie von Spirophyllum ferrugineum Ellis, einem typischen Eisenbakterium. Jahrb. wiss. Bot. 49: 91-127. 1911; Zur Ernährungsphysiologie der Eisenbakterien. Centrbl. Bakt. II, 49: 413-425. 1919. 
cannot live without it (obligate autotrophic), others, like Leptothrix, can live without any iron compounds, but, if they are present, can use either ferrous bicarbonate (or manganese bicarbonate) or soluble organic compounds (facultative autotrophic). Others, such as the various lower bacteria, will use the organic radical of certain soluble organic iron salts when present but cannot utilize any inorganic iron salts; in other words, the accumulation or incrustation of iron is purely mechanical and these bacteria should not be considered as iron bacteria at all. Among the latter organisms we would probably include the form (similar to Bac. subtilis), ${ }^{90}$ which precipitates ferric hydroxide from solutions of iron salts, then reduces the hydroxide anaerobically to bog iron.

Bacteria oblaining their energy from the oxidation of simple carbon compounds. Methane bacteria. Methane may be produced in appreciable amounts in volcanic eruptions, around oil mines and as a result of different chemical processes. It is also produced in the anaerobic decomposition of cellulose, of other carbohydrates, organic acicls and proteins. $^{91}$ Swamps, ${ }^{92}$ manure heaps and low-lying meadows also contribute large amounts of methane to the atmosphere.

Although the chemical oxidation of methane has been demonstrated in various instances, it is primarily a phenomenon accomplished by microorganisms. According to Harrison and Aiyer, ${ }^{92}$ the soil film contains bacteria and algae capable of oxidizing methane and hydrogen and assimilating methane and $\mathrm{CO}_{2}$, increasing the oxygen output. $B$. methanicus (Methanomonas methanica Orla-Jensen) was isolated from the soil by Söhngen. ${ }^{93}$ It was found to be a short, motile rod, 2 to 3 by 1.5 to $2 \mu$ in size, and could transform methane partly into organic compounds and partly into $\mathrm{CO}_{2}$. In older cultures the organism became nearly spherical.

${ }_{90}$ Mumford, E. M. A new iron bacterium. Jour. Chem. Soc. 103: 645-650. 1913

${ }^{91}$ Omeliansky, W. De la mise en liberté de méthane au cours des processus biologiques naturels. Arch. Sci. Biol. St. Petersbourg, 12: No. 2. 1906.

${ }^{92}$ Harrison, W. H., and Aiyer, P. A. S. The gases of swamp rice soils. II, Their utilization for the aeration of the roots of the crop. Mem. Dept. Agr. India, Chem. Ser. 4: 1-18. 1914.

${ }^{3}$ Söhngen, N. L. L̇ber Bakterien, welche Methan als Kohlenstoffnahrung und Energiequelle gebrauchen. Centrbl. Bakt. II, 15: 513-517. 1906. 
The medium used by Söhngen consisted of :

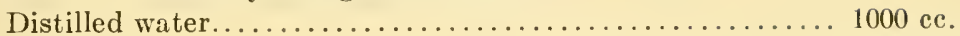

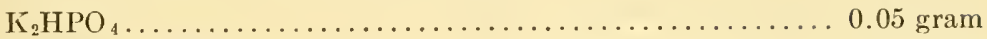

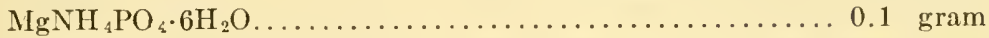

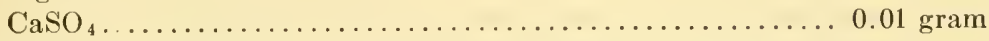

Inoculation was made with soil. The atmosphere consisted of one part $\mathrm{CH}_{4}$ and two parts air. ${ }^{94}$

Certain other common bacteria are capable of oxidizing methane, as in the case of Bact. pyocyaneum ${ }^{95}$ and Bact. Aluorescens liquefaciens. ${ }^{96}$ Mün $z^{97}$ isolated a methane oxidizing organism, not identical with that of Söhngen, which he also called Methanomonas methanica. It thrives at $18^{\circ}$ to $40^{\circ}$ with an optimum at $34^{\circ} \mathrm{C}$. This organism measured 0.9 to 2.2 by 0.3 to $0.4 \mu$ in size, was elliptical to cylindrical, non-motile. High methane and low oxygen content of atmosphere were best for its growth, although the organism was aerobic. Hydrogen and carbon monoxide could not replace methane, although alcohols, carbohydrates and salts of organic acids could. Nitrogen was utilized both in inorganic and organic forms. The organism may be considered as facultative autotrophic although the autotrophy of this organism is still questionable.

B. hexacarbovorum was found $\mathrm{d}^{98}$ to be able to utilize methane, toluol, xylol and illuminating gas as the only sources of carbon. Various other hydrocarbons can also be utilized as sources of energy by bacteria. ${ }^{99}$ In this connection mention should be made of the work of Söhngen on the Mycobacteria ( $M$. lacticola, M. phlei), which were found capable of deriving their energy from the oxidation of benzol, paraffin, petroleum, and assimilating the $\mathrm{CO}_{2}$ of the atmosphere. In regard to the oxidation

${ }^{94}$ Kaserer, H. Über die Oxydation des Wasserstoffes und des Methans durch Mlikroorganismen. Centrbl. Bakt. II, 15: 573-576. 1906.

${ }_{95}$ Söhngen, N. L. Het onstaan en verdwijnen van Waterstof en Methaan onder den invloed van het organische leven. Proefschrift. Delft. 1906 (Bot. Centrhl. 105: 371-372. 1907.)

${ }_{96}$ Aiyer, P. A. S. The gases of swamp rice soils. V. A methane-oxidizing bacterium from rice soils. Mem. Dept. Agr. India, Chem. Ser. 5: 177-180. 1920.

${ }^{97}$ Münz, E. Zur Physiologie der Methanbakterien. Diss. Halle, 1915.

${ }_{98}$ Störmer, 1907 (p. 47).

${ }_{99}$ Tausz, J., and Peter, M. Neue Methode der Kohlenwasserstoffanalyse mit Hilfe von Bakterien. Centrbl. Bakt. II, 49: 497-554. 1920. 
of pure carbon by bacteria, certain investigation $\mathrm{s}^{100}$ point to positive results and others ${ }^{101}$ to negative results.

Bacteria oxidizing carbon monoxide. Carbon monoxide is produced, in large amounts, in the incomplete combustion of carbon compounds and, in small amounts, in the decomposition of manure. ${ }^{102}$ It can be oxidized, not only chemically, but also by microorganisms. B. olligocarbophilus (Carboxydomonas oligocarbophila Orla-Jensen), isolated from the soil, could purify the laboratory air rich in CO. ${ }^{103}$ 'The organism was cultivated on simple inorganic media free from any other carbon sources. It was found to be a small rod ( 0.7 to 1.0 by $0.5 \mu)$, nonmotile, the cells being united into irregular masses by a slimy substance. The $\mathrm{CO}$ is utilized as a source of energy and is oxidized to $\mathrm{CO}_{2}{ }^{104}$ It is interesting to note that the organism developing under these conditions was later found to be an actinomyces. ${ }^{105}$

Bacteria oxidizing hydrogen. Hydrogen can be oxidized both aerobically and anaerobically. De Saussure ${ }^{106}$ demonstrated in 1838 that moist soil will transform hydrogen readily into water, while soil heated or treated with antiseptic substances is unable to do so. A number of bacteria were isolated ${ }^{104,} 107$ from soils which were able to oxidize hydrogen autotrophically with the formation of water. The organism isolated from the soil by Kaserer (Hydrogenomonas pantotropha (Kaserer) Orla Jensen) was an aerobic, short, motile rod, 1.2 to 1.5 by 0.4 to $0.5 \mu$ in size, occurring singly or in chains, encapsulated. It was motile by

100 Galle, E. Ưber Selbstentzündung der Steinkohle. Centrbl. Bakt. II, 28: 461-473. 1910.

${ }^{101}$ Schroeder, H. The bacterial content of coal. Centrbl. Bakt. II, 41: 460-469. 1914.

102 Löhnis, 1910, p. 542.

${ }^{103}$ Beijerinck, M. W., and Van Delden, A. Über eine farblose Bakterie, deren Kohlenstoffnahrung aus der atmosphärischen Luft herrührt. Centrbl. Bakt. II, 10: 33-47. 1903.

104 Kaserer, H. Die Oxydation des Wasserstoffes durch /Mikroorganismen. Centrbl. Bakt. II, 16: 681-696, 769-775. 1906.

${ }^{105}$ Lantzsch, 1923 (p. 298).

106 de Saussure, Th. Action de la fermentation sur le mélange des gaz oxygène et hydrogène. Mem. Soc. phys. Hist. Nat. Genève, 8: 163-190. 1839.

${ }^{107}$ Niklewski, B. Ein Beitrag zur Kenntnis wasserstoffoxydierenden Mikroorganismen. Centrbl. Bakt. II, 20: 469-473. 1908; Niklewski, B. Über die Wasserstoffoxydation durch Mikroorganismen. Jahrb. Wiss. Bot. 48: 113-142. 1910. Nabokich, A. J., and Lebedeff, A. F. Utber die Oxydation des Wasserstoffes durch Bakterien. Centrbl. Bakt. II, 17: 350-355. 1906; Biochem. Ztschr. 7: 1-10. 1908 . 
means of a single polar flagellum. The gelatin colonies were yellow, smooth, rarely greenish; the gelatin was not liquefied. Yellow to greenish growth on agar.

Kaserer suggested that both the methane and hydrogen oxidation phenomena are of great importance in the soil, due to the fact that these substances, which are produced in the subsoil by anaerobic processes, are thus oxidized and made available to the soil.

Kiaserer's medium consisted of :

\begin{tabular}{|c|c|}
\hline $\mathrm{K}_{2} \mathrm{HPO}_{4} \ldots \ldots \ldots \ldots .0 .5 \mathrm{gram}$ & $\mathrm{NaHCO}_{3} \ldots \ldots \ldots \ldots \ldots \quad 0.5 \mathrm{gram}$ \\
\hline $0.2 \mathrm{gram}$ & Trace \\
\hline $\mathrm{NH}_{4} \mathrm{Cl} \ldots \ldots \ldots \ldots \ldots 1.0 \mathrm{gram}$ & Water........... $1000 \mathrm{cc}$ \\
\hline
\end{tabular}

The organism growing on this medium developed poorly under autotrophic conditions, the oxidation of hydrogen becoming prominent in the presence of small amounts of soluble organic matter. ${ }^{108}$ A nonmotile bacterium, 1.4 by $0.5 \mu$ in size, was isolated, different from the $H$ pantotropha of Kaserer. The greatest amount of hydrogen was oxidized in the presence of 0.01 to 0.03 per cent peptone, nutrose or sodium asparaginate. In association with certain bacteria, the organism was much more active.

Niklewski used a medium containing:

\begin{tabular}{|c|c|}
\hline $\mathrm{NH}_{4} \mathrm{Cl} \ldots \ldots \ldots \ldots \ldots 1.0 \mathrm{gram}$ & $\ldots \ldots \ldots, 0.2$ \\
\hline $1.0 \mathrm{gram}$ & $0.0001 \mathrm{gram}$ \\
\hline $\mathrm{MgSO}_{4} \cdot 7 \mathrm{H}_{2} \mathrm{O}$ & $\ldots 15.0 \quad$ grams \\
\hline .. $1.0 \mathrm{gram}$ & Water.......... \\
\hline
\end{tabular}

The cultures were placed in a bell-jar, through which purified hydrogen was passed, at $38^{\circ}$ to $35^{\circ} \mathrm{C}$. The cultures developed in 3 to 4 days. Two organisms were isolated:

Hydrogenomonas vitrea formed a pellicle on the surface of the liquid medium. Small yellow subsurface colonies were formed on the agar. On the surface the colonies were transparent, folded. The cells are $2 \mu$ long. Obligate autotrophic. No motility observed.

Hydrogenomonas flava formed shining yellow colonies on the surface of the agar, not spreading as rapidly as the $H$. vitrea, surface smooth, edge entire; microscopically, the cells were found to be somewhat smaller $(1.5 \mu \mathrm{long})$. No pellicle formation on liquid media. Obligate autotrophic. No motility observed.

By further study, Niklewski ${ }^{109}$ isolated an organism (H. agilis) which can oxi-

${ }^{108}$ Harrison, W. H., and Aiyer, P. A. S. The gases of swamp rice soils. III. A hydrogen-oxidizing bacterium from these soils. Mem. Dept. Agr. India, Chem. Ser. 135-148. 1916.

109 Niklewski, B. Über die Wasserstoffaktivierung durch Bakterien unter besonderer Berücksichtigung der neuen Gattung Hydrogenomonas agilis. Kosmos, Lemberg. 1923. (Centrbl. Bakt. II, 40: 430-433. 1914.) 


\begin{tabular}{|c|c|c|c|c|c|c|c|c|c|c|c|}
\hline & 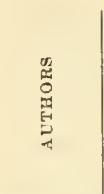 & 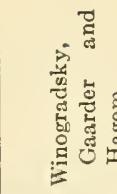 & 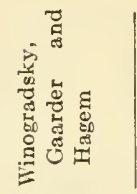 & 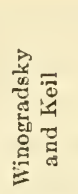 & 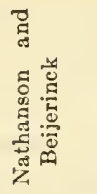 & 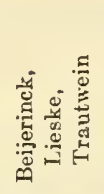 & 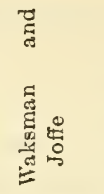 & 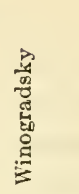 & 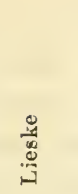 & 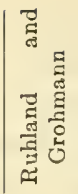 & 总 \\
\hline \multirow{9}{*}{ 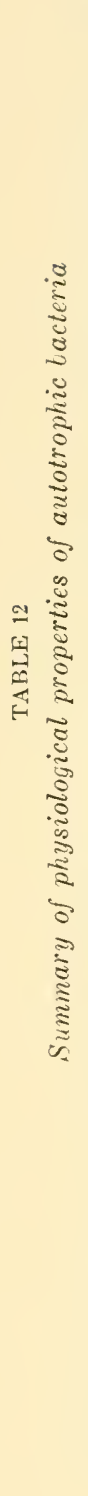 } & $\stackrel{\mathscr{A}}{\vec{u}}$ & z & & 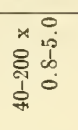 & $\begin{array}{l}0 \\
0 \\
x \\
x \\
\infty\end{array}$ & - & 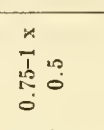 & & & $\stackrel{x}{x} 0$ & 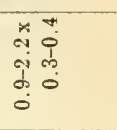 \\
\hline & 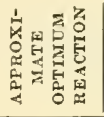 & 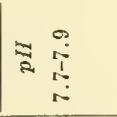 & $\begin{array}{l}m \\
0 \\
\infty \\
0 \\
0\end{array}$ & $\begin{array}{l}\widehat{\Xi} \\
0 \\
\infty\end{array}$ & $\begin{array}{l}\hat{\vdots} \\
0 \\
\infty\end{array}$ & $\begin{array}{l}0 \\
0 \\
\vdots \\
0 \\
i\end{array}$ & $\begin{array}{l}0 \\
0 \\
0 \\
0 \\
0 \\
0\end{array}$ & a. & $\therefore$ & $\begin{array}{l}1 \\
\infty \\
0 \\
0 \\
0 \\
0\end{array}$ & a. \\
\hline & 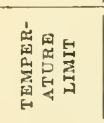 & 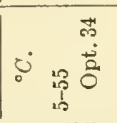 & 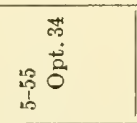 & 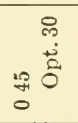 & & $\begin{array}{l}\text { 品 } \\
\text { 芯 }\end{array}$ & 号 & 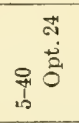 & वี & $\mid$\begin{tabular}{l}
$\stackrel{8}{8}$ \\
\multirow{3}{0}{} \\
0
\end{tabular} & 유 \\
\hline & 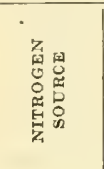 & 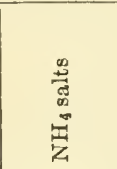 & 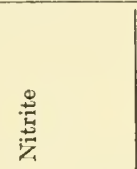 & 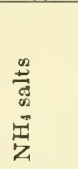 & 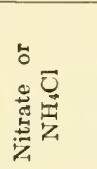 & 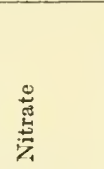 & 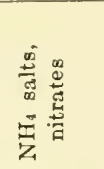 & 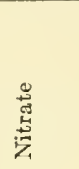 & 苋 & 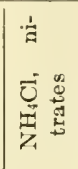 & 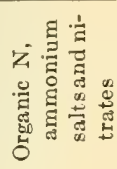 \\
\hline & 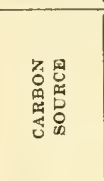 & 8 & 80 & 8 & 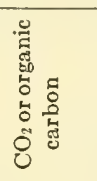 & 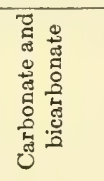 & 8 & 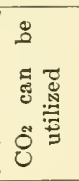 & ¿̊ & 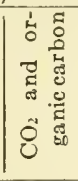 & 苞 \\
\hline & 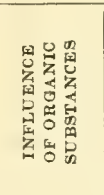 & 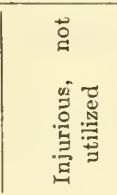 & 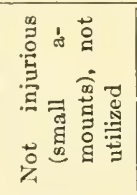 & 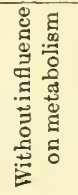 & 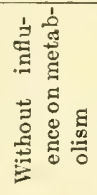 & 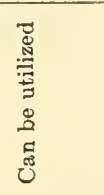 & 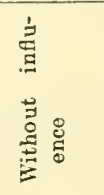 & 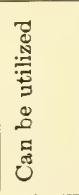 & 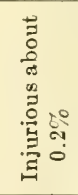 & 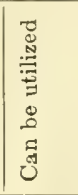 & 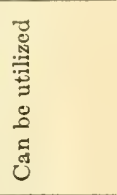 \\
\hline & 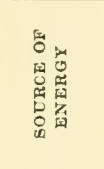 & 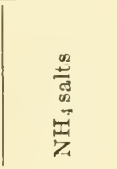 & 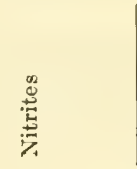 & \begin{tabular}{|l} 
: \\
|
\end{tabular} & 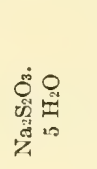 & 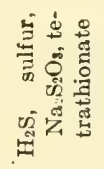 & 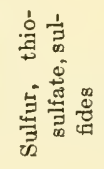 & 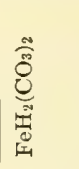 & 窎 & $\tilde{7}$ & ت्ञ \\
\hline & 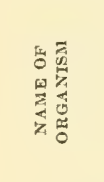 & 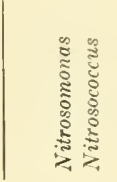 & 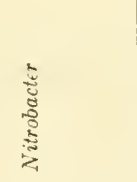 & 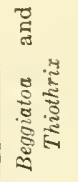 & 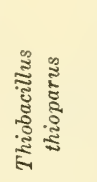 & 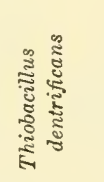 & 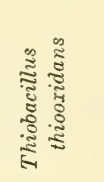 & 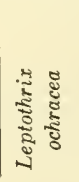 & 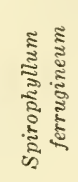 & 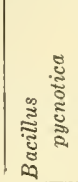 & 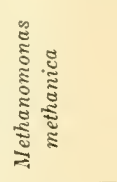 \\
\hline & & & 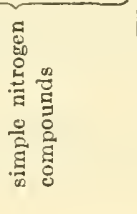 & & & 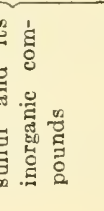 & & & & 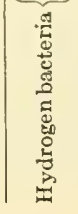 & 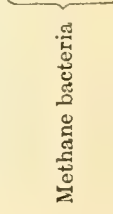 \\
\hline
\end{tabular}


dize hydrogen by using the oxygen obtained from the reduction of nitrates and sulfates and in some cases of citrate, tartrate and oxalate. The presence of nitrate enables the organism to oxidize hydrogen anaerobically. The organism can also exist aerobically using free oxygen for the autotrophic oxidation of hydrogen. It can also exist heterotrophically similar to the other organisms.

For the isolation of pure cultures of hydrogen oxidizing bacteria, Lebedeff 110 used a medium consisting of 1000 parts of water, $2.0 \mathrm{KNO}_{3}, 0.5 \mathrm{NaH}_{2} \mathrm{PO}_{4}, 0.2$ $\mathrm{MgSO}_{4}$, traces of $\mathrm{FeCl}_{3}$ and an atmosphere of hydrogen containing 5 to 15 per cent $\mathrm{CO}_{2}$. One hundred cubic centimeter portions of medium were placed in side-arm flasks, inoculated with soil; after evacuating and introducing the gas, the flasks were sealed. After 5 to 6 days of growth the organism appeared in the form of a surface pellicle. After 3 to 4 transfers, the organism was isolated on a silica gel plate, kept in an atmosphere of hydrogen containing 5 to 10 per cent $\mathrm{CO}_{2}$. After 8 to 10 days, miky-white regular colonies appeared on the plate. These consisted of rod-shaped (spore forming ?) bacteria, 1.2 to $1.5 \mu$ long, motile by means of a single flagellum. The organism was heterotrophic, forming on gelatin milky-white colonies which changed later to brownish, and was named Bac. hydrogenes. Gelatin was liquefied, various sugars, organic acids and protein derivatives were utilized as sources of carbon. Optimum temperature $26^{\circ} \mathrm{C}$.

Recent studies ${ }^{11,112}$ have shown that a number of different species of hydrogen bacteria are present in the soil. They live autotrophically with hydrogen as a source of energy and heterotrophically in the absence of hydrogen, thus being facultative autotrophic. The different species differ in their sensitiveness to oxygen pressure or in the ability to use combined oxygen for the oxidation of hydrogen. A newly found species Bacillus pycnoticus was studied in detail. It is a rod-shaped organism, 1.5 to 4 by $1.0 \mu$, every preparation containing non-motile and motile cells, with peritrichic flagellation. In addition to the rods, true cocci as well as giant cells and thick-walled, egg-shaped cells, ten times as large as the normal bacterial cell, were found in the culture. The purity of the culture was established by single-cell isolation, using Burri's India ink method. The giant cells are involution forms, produced under special environmental conditions. The spores swell up in length and width, before they can germinate, and may account for the egg-shaped figures; they also break up into true cocci.

The organism is grown in an inorganic solution containing sufficient

110 Lebedeff, A. F. Investigations of the chemosynthesis of Bacillus hydrogenes (Russian). Odessa. 1910.

111 Grohmann, G. Zur Kenntnis Wasserstoff-oxydierender Bakterien. Centrbl. Bakt. II, 61: 256-271. 1924.

${ }^{112}$ Ruhland, W. Beiträge zur Physiologie der Knallgasbakterien. Jahrb. IViss. Bot. 63: 321-389. 1924. 
iron, the latter being added to the sterilized medium, and with hydrogen in the atmosphere.

The optimum reaction is at $\mathrm{pH} 6.8$ to 8.7 , the limits being $\mathrm{pH} 5.2$ to 9.2. Growth takes place on the surface, at the boundary between the gas and the liquid; in some cases, the liquid becomes turbid. Partial pressure of the gases $\left(\mathrm{H}_{2}\right.$ and $\left.\mathrm{CO}_{2}\right)$ has an inappreciable influence upon growth. Respiration of the organism is discussed in detail elsewhere (p. 403). 


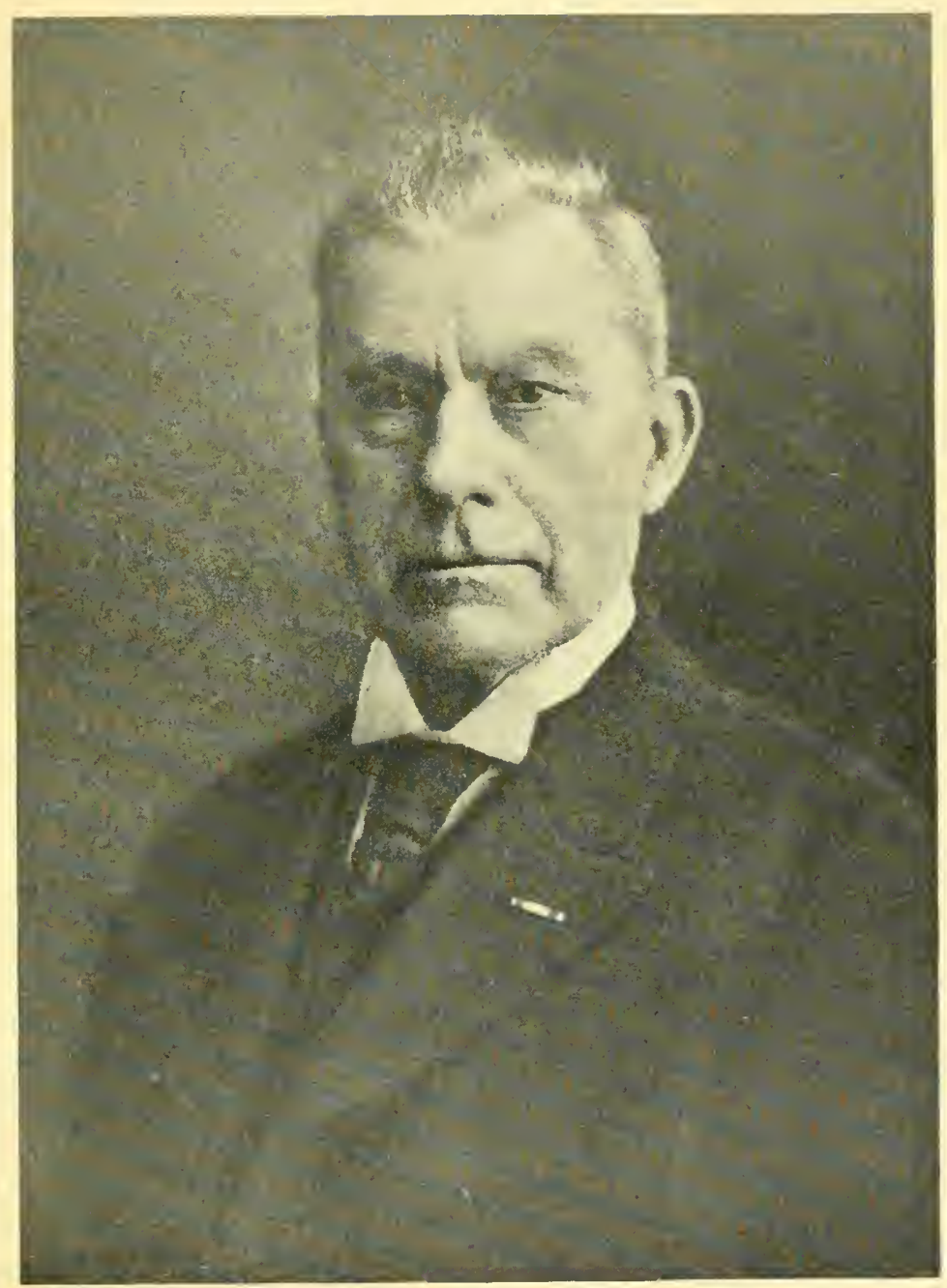

II. W. BEIJERINCK 



\section{CHAPTER IV}

\section{Bacteria Fixing Atmospheric Nitrogen}

Nitrogen fixation in nature. All higher plants, all animals and the great majority of microorganisms depend for their nutrition on combined nitrogen, whether organic or inorganic in nature, and can make no use whatsoever of the great store of gaseous nitrogen in the atmosphere. Large quantities of nitrogen, therefore, are removed every year from the soil by the growing crops. In addition to that, several groups of soil microorganisms are even capable of reducing nitrates and liberate atmospheric nitrogen. The quantities of manure returned to the soil are far from sufficient to replace the losses from the soil; the attempt to replace this loss by artificial fertilizers may be sufficient to supply the need of the growing plant but not to replenish the losses from the soil. This is accomplished through the agency of nitrogen-fixing bacteria, working alone or in symbiosis with higher plants. A small amount of combined nitrogen is formed by chemical agencies, such as electrical discharges, and is brought down with the yearly rainfalls, but this hardly amounts to more than one or two pounds of nitrogen per acre per year, while ordinary forest trees may remove in the wood and leaves over 50 pounds of nitrogen per acre per year. The rest of the nitrogen is presumably fixed in the soil by the agency of microorganisms.

The first organisms to be studied in connection with the fixation of atmospheric nitrogen were the bacteria forming nodules on the roots of leguminous plants; it was then believed that only those organisms that live symbiotically on the roots of the plants are able, during this process of symbiosis, to transform the gaseous nitrogen of the atmosphere into combined forms. It was later found $\mathrm{d}^{1-3}$ that these bacteria are also capable of fixing nitrogen in the absence of the host plant, when

${ }^{1}$ Beijerinck, M. W. Die Bakterien der Papilionaceenknöllchen. Bot. Ztg. 46: 725-735, 741-750, 758-771, 782-790, 797-803. 1888.

2 Mazé, M. Fixation de l'azote par le bacille des nodosités des Légumineuses. Ann. Inst. Past. 11: 44 54. 1898.

${ }^{3}$ Chester, F. D. Oligonitrophile Bodenbakterien. 4th Ann. Meet. Soc. Amer. Bact. Washington, D. C. 1902. (Centrbl. Bakt. II, 10: 382. 1903). 
grown in pure culture. ${ }^{4}$ But, in addition to these bacteria, the soil harbors other organisms, always living non-symbiotically, which are capable of fixing gaseous nitrogen, in the presence of a proper source of energy. Berthelot ${ }^{5}$ suggested, on the basis of numerous investigations, that the fixation of atmospheric nitrogen is well distributed among soil microorganisms. He isolated a number of bacteria from the soil and found that some of them were able to increase the amount of combined

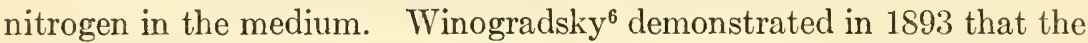
property of nitrogen-fixation is limited to certain specific soil organisms; the mere growth of an organism on nitrogen-free media was still no indication that it was capable of obtaining its nitrogen from the gaseous form of the atmosphere. An organism is considered as unable to fix nitrogen, unless an actual increase in combined nitrogen has been demonstrated by chemical analysis. However, Beijerinck ${ }^{7}$ found that the number of bacteria in the soil capable of fixing nitrogen is much larger than suspected by Winogradsky; he designated as oligonitrophilic those bacteria that were capable of developing in media containing only traces of combined nitrogen and considered them as nitrogen-fixing forms.

The first non-symbiotic nitrogen-fixing organism was isolated by Winogradsky in 1893. Clostridium pastorianum (Bac. amylobacter A.M. et Bred), an anaerobic organism, was found capable of bringing about an increase in the amount of combined nitrogen in the medium, in the presence of an available source of energy. Caron ${ }^{8}$ soon (1895) isolated a spore-forming organism, Bac. ellenbachensis $\alpha$, closely related to Bac. mycoides and Bac. megatherium, to which he ascribed the property of fixing nitrogen. This claim was confirmed by Stoklasa, ${ }^{9}$ who

${ }^{4}$ Negative results have recently been reported by Barthel, Chr. Meddel. Centralanst. forsoksv. Jordbr. Bakt. Avd. 43, 1926.

5 Berthelot, M. Fixatión de l'azote atmosphérique sur la terre végétale. Ann. chim. Phys. 13: 5-14, 15-73, 74-78, 78-92, 93-119. 1888. Nouvelles recherches sur les microorganismes du sol fixateurs de l'azote. Bull. Soc. Chim. III, 11: 781-783. 1894 .

${ }^{6}$ Winogradsky, 1893 (p. 107).

${ }^{7}$ Beijerinck, M. W. Über oligonitrophile Mikroben. Centrbl. Bakt. II, 7: 561-582. 1901 .

8 Caron, A. Landwirtschaftlich-bakteriologische Probleme. Landw. Vers. Sta. 45: 401-418. 1895 .

${ }^{9}$ Stoklasa, J. Studien über die Assimilation elementaren Stickstoffs durch die Pflanzen. Landw. Jahrb. 24: 827-863. 1893; Biologische Studien über "Alinit." Centrbl. Bakt., II, 4: 39, 78, 119, 284, 507, 535. 1898; 5: 350-359. $1899 ; 7: 257-270$. 1901 . 
reported appreciable gains in nitrogen by this organism. ${ }^{10}$ The idea then originated to utilize this organism for soil inoculation and a special preparation "alinit," in a powdered form, was placed on the market. This proved to be a failure, but aroused great interest and expectations among the farmers. Actually this organism was found to be unable to fix any nitrogen. ${ }^{11,12}$

The important contribution to the subject of non-symbiotic nitrogenfixing bacteria, next to Winogradsky's work, was the isolation of the aerobic organisms Azotobacter chroococcum and Azotobacter agile by Beijerinck. ${ }^{13}$ In addition to the Azotobacter group, Beijerinck and Van Delden ${ }^{14}$ also found that various forms of the genus Grarulobacter (which are actually varieties of Bac. asterosporus (A.M.) Mig.) are capable of fixing nitrogen. A number of other bacteria, commonly found in the soil are also able to fix small amounts of nitrogen on artificial culture media, especially when freshly isolated from the soil.

Algae, fungi and actinomyces do not fix any atmospheric nitrogen. However, symbiosis between nitrogen fixing bacteria and algae has been established..$^{15,16}$ Symbiosis is also probable between bacteria and certain non-leguminous plants, like Alnus, Eleagnus, Myrica, Coriaria, Ceanothus, the bacteria forming nodules on the roots of these plants. Symbiosis between bacteria and leaves of certain plants was observed in the case of Pavetta, ${ }^{17}$ Ardisia, ${ }^{18}$ Kraussia. ${ }^{19}$ Knots are formed at the place of

${ }^{10}$ See also Beijerinck, M. W. L'influence des microbes sur la fertilité du sol et la croissance des végétaux supérieurs. Arch. Neerl. Sci. Exact. Nat., Ser. II, 8: VIII-XXXVI. 1904.

${ }^{11}$ Stutzer, A., and Hartleb, R. Untersuchungen über das im Alinit enhaltene Bakterium. Centrbl. Bakt., II, 4: 31-39, 73-77. 1898.

${ }^{12}$ Krüger, W., and Schneidewind, W. Untersuchungen über Alinit. Landw. Jahrb. 28: 579-591. 1899.

${ }^{13}$ Beijerinck, 1901 (p. 104).

${ }^{14}$ Beijerinck, M. W., and Van Delden, A. Über die Assimilation des freien Stickstoffs durch Bakterien. Centrbl. Bakt., II, 9: 3-43. 1902.

${ }^{15}$ Reinke, J. Symbiose von Volvox und Azotobacter. Ber. deut. bot. Ges. 21: 482-484. 1903.

${ }^{16}$ Fischer, H. Über Symbiose von Azotobacter mit Oscillarien. Centrbl. Bakt. II, 12: 267-268. 1904.

${ }^{17}$ Faber, F. C. Das erbliche Zusammenleben von Bakterien und tropischen Pflanzen. Jahrb. wiss. Bot. 51: 285-375. 1912; 54: 243-264. 1914.

${ }^{18}$ Miehe, H. Die sogenannten Eiweissdrüisen an den Blättern von Ardisia crispa A. D. C. (V. M.). Ber. deut. bot. Ges., 29: 156-157. 1911; 34: 576-580. 1916. Weitere Untersuchungen über die Bakteriensymbiose bei Ardisia crispa. II. Die Pflanze ohne Bakterien. Jahrb. wiss. Bot. 58: 29. 1917.

${ }^{19}$ Georgevitch. A new case of symbiosis between a bacillus and a plant. Bull. Bot. Garden Kew, 1916, p. 105. 
penetration of the microbe into the tissues of the plant. According to Faber, the bacteria bringing about these formations can also fix nitrogen when not working symbiotically with plants. The bacteria are carried through the seed, in to which they penetrate when the plant is still alive. The amount of nitrogen thus fixed may be so considerable that in India Pavetta plants are used as green manure.

Direct nitrogen fixation by higher plants was first suggested by the early chemists, Priestly and Ingenhouse. Positive results were reported also by some recent investigators. ${ }^{20,21}$ However the work of investigators, like Boussingault, ${ }^{22}$ Lawes, Gilbert and Pugh, ${ }^{23}$ and the more recent work of Molliard ${ }^{24}$ and numerous others definitely point to the fact that non-leguminous plants are unable to fix any atmospheric nitrogen.

Classification of nitrogen-fixing bacteria. The nitrogen-fixing bacteria require organic compounds of carbon for structural and energy purposes. These organisms can be classified on the basis of their source of carbon, whether they derive it in a non-symbiotic manner or obtain it from the growing plant, with which they live symbiotically. None of these organisms are obligate, since they can also obtain their nitrogen from organic or inorganic nitrogen compounds.

I. Non-symbiotic nitrogen fixing bacteria

1. Anaerobic bacteria

Bac. amylobacter (Clostridium group, Amylobacter group, Granulobacter group)

Other butyrie acid bacteria

2. Aerobic bacteria

(a) Azotobaeter group

(b) Radiobacter group

${ }^{20}$ Mameli, E., and Pollacci, G. Sur l'assimilatione diretta dell'azoto atmosferico libero nei vegetali. Atti. Ist. Bot. Pavia, Ser. 2, 15: 159-257. 1911; Centrbl. Bakt. II, 32: 257. 1912.

${ }^{21}$ Lipman, C. B., and Taylor, J. K. Proof of the power of the wheat plant to fix atmospheric nitrogen. Seience, 56: 605-606. 1922; J. Frankl. Inst. 1924, 475506 .

${ }^{22}$ Boussingault, J. B. Recherches sur la végétation, entreprises dans le but d'examiner si les plantes fixent dans leur organisme l'azote qui est à l'état gazeux dans l'atmosphère. Ann. Chim. Phys. (3) 43: 149-223. 1855.

${ }^{23}$ Lawes, J. B., Gilbert, J. H., and Pugh, E. On the sourees of the nitrogen of vegetation, with special reference to the question whether plants assimilate free or uncombined nitrogen. Phil. Trans. Roy. Soc. London, 151: 431-577. 1861; Rothamsted Mem. 1, No. 1; 3, No. 1.

${ }^{24}$ Molliard, M. L'azote libre et les plantes supérieures. Rev. Gen. Bot. 28: 225-250. 1916. 
(c) Bact. pneumoniae, Bact. aerogenes, and other non-spore forming bacteria

(d) Bac, asterosporus group and other spore-forming bacteria.

II. Symbiotic nitrogen-fixing bacteria

1. Bacteria living in the roots of leguminous plants

2. Bacteria living on and in the roots of non-leguminous plants

3. Bacteria living in the leaves of certain plants

Isolation of anacrobic bacteria. For the isolation of bacteria capable of fixing atmospheric nitrogen, Winogradsky ${ }^{25}$ used a solution free from combined nitrogen of the following composition:

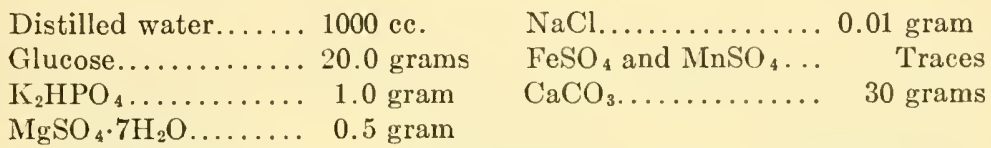

One hundred cubic centimeters of this medium is placed in a flask and 4 grams of chalk added. The medium is sterilized at $106^{\circ}$ to $110^{\circ}$ for 30 to 45 minutes. A small quantity of soil, preferably first pasteurized is used for inoculation. After a few days' incubation at $25^{\circ}$ to $30^{\circ}$, the surface of the liquid becomes covered with a thin pellicle of aerobic bacteria; gas bubbles are formed abundantly, an indication of butyric acid fermentation. Gas formation begins from the lump of soil and spreads all over the flask, so that the whole surface is soon covered with gas, while the chaik is lumped together by bacterial slime. The culture gives off an odor of butyric acid and its esters. On examining the culture microscopically, it is found that the bacteria in the film and in the residue are not alike. The film contains an aerobic organism, while the residue contains Clostridium (Bac. amylobacter) in abundance, in the characteristic forms. Transfers are made, by inoculating a piece of chalk from the bottom of the flask into fresh lots of media. When the calture is sufficiently enriched in Clostridia (after three to four transfers), attempts are made at isolation of pure cultures. Pieces of potato smeared with chalk are placed in Petri dishes and sterilized. These are inoculated with spore material and incubated, under anaerobic conditions, at $30^{\circ}$ to $35^{\circ}$, in a partial vacuum or hydrogen atmosphere. After 5 to 7 days, there appear upon the surface of the potato elevated, rounded, yellowish colonies filled with gas bubbles. On opening the apparatus, the colonies can be examined for Clostridia and transfers made into liquid media or fresh potato cultures. The organism often occurs on the potato in involution forms, which temporarily lose the capacity of spore formation. The culture can be grown under aerobic conditions in the presence of an aerobic non-spore forming organism, such as Bact. fluorescens or Azot. chroococ-

25 Winogradsky, S. Sur l'assimilation de l'azote gazeux de l'atmosphère par les microbes. Compt. Rend. Acad. Sci. 116: 1385-1388. 1893; 118: 353.1894 ; Recherches sur l'assimilation de l'azote libre de l'atmosphère par les microbes. Arch. Sci. Biol. (St. Petersburg), 3: 297. 1895; Clostridium pasteurianum, seine Morphologie und seine Eigenschaften als Buttersïureferment. Centrbl. Bakt. II, 9: 43-62. 1902. 
cum. When a pure culture is wanted, the culture is pasteurized (at $75^{\circ}$ for 10 minutes), whereby the non-spore forming aerobe is killed and the spore-forming Clostridium is obtained pure. ${ }^{26}$

Bredemann $^{27}$ used a solid medium of the following composition:

Glucose......... 1.0 gram
Witte peptone...... 1.2 grams
Liebig's meat extract.. 0.8 gram
NaCl........... 0.2 gram

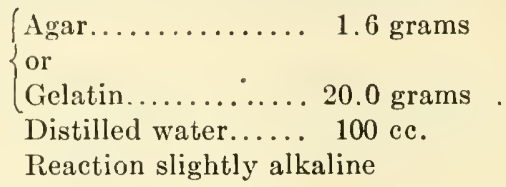

The various butyric acid bacteria, including the $C l$. pastorianum, grow very well on this medium, which can be used both for the isolation and cultivation of the organisms.

${ }^{26}$ Omeliansky, W. L., and Solounskoff, M. Sur la distribution des bacteries azotofixatrices dans les sols russes. Arch. Sci. Biol. 18: 1-24. 1915.

${ }^{27}$ 13redemann, 1909 (p. 109).

\section{PLATE VI}

\section{Non-Symbiotic Nitrogen Fixing Bacteria}

25. Clostridium pastorianum (Buc, amylobacter), stage preceding spore-formation; stained with gentian violet, $\times 660$ (from Omeliansky and Solounskoff).

26. Clostridium pastorianum (Bac. amylobacter), spore-formation, $\times 660$ (after Winogradsky and Omeliansky).

27. Clostridium pastorianum (Bac. amylobacter), large involution forms; dark color due to coloration of the glycogen with iodine (after Bredemann and Omeliansky).

28. Azotobacter chroococcum, young culture (from Krzemieniewski).

29. Az. chroococcum, resting forms of sarcina type (from Krzemieniewski).

30. Az. chroococcum, thread forms, individual cells undergoing division (from Krzenieniewski).

31. Az. chroococcum, growth on agar, showing the darkening of the culture (from Krzemieniewski).

32. Az. agile, grown on phosphate-glucose agar, 2 days old, $\times 660$ (from Beijerinck).

33. Az. agile, showing flagella, stained by method of Zettnow, $\times 660$ (from Beijerinck).

34. Bac. asterosporus, 1-5, showing different stages of development and spore formation; 6, spore with folded envelope; 7 , cross section of spore (after Bredemann and Omeliansky).

35. Az. vinelandii (from Lipman).

36. Bac. malabarensis: $A$, culture on meat extract agar; $B$, on soil infusionmannite agar; $C$, soil infusion mannite solution (from Löhnis and Pillai). 


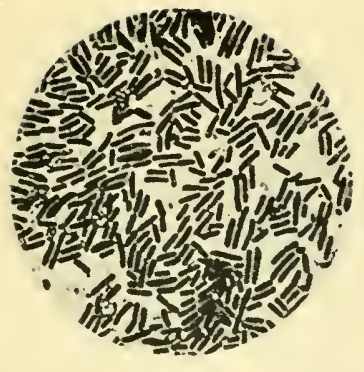

25
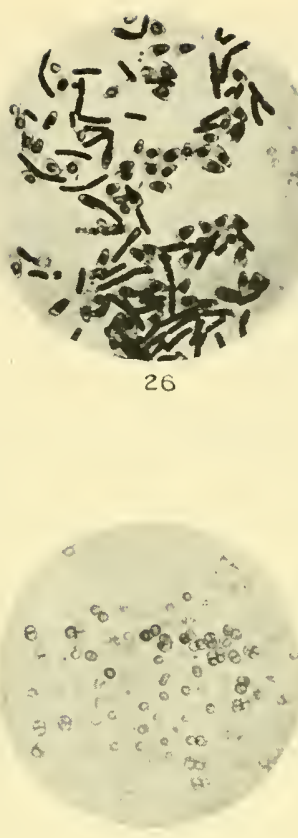

29

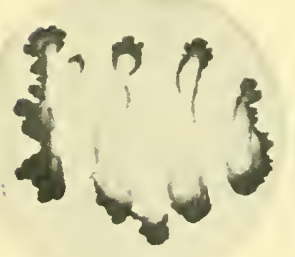

31

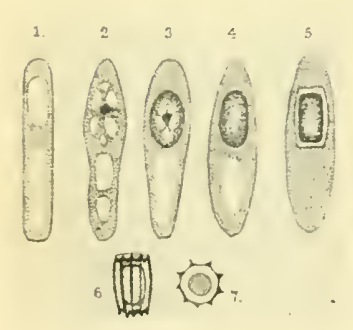

34

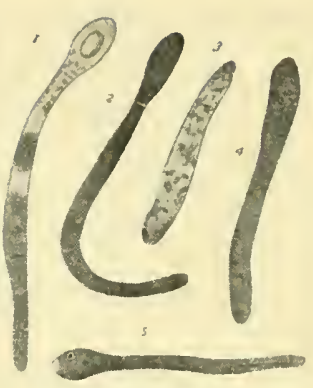

27
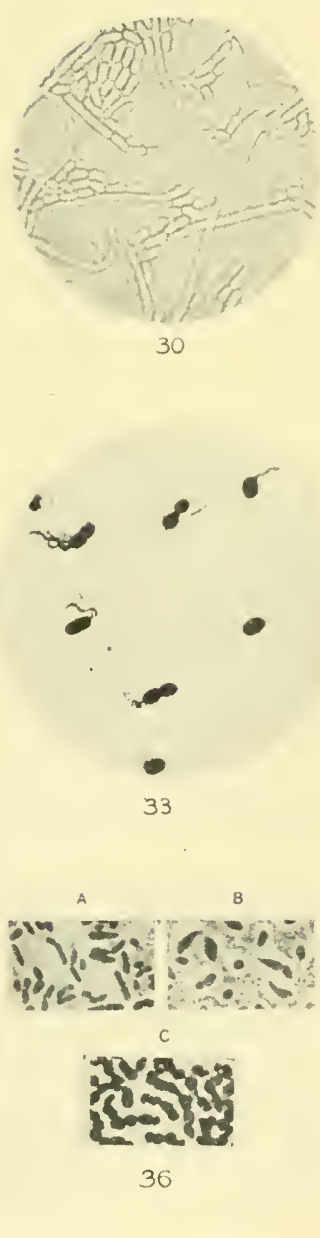



\section{Morphology of the anaerobic bacteria.}

Cl. pastorianum is an actively motile gram-positive rod, occurring singly. The straight cylindrical rods, with rounded ends, are, when young, 1.5 to $2 \mu$ long by 1.2 to $1.3 \mu$ thick. They may reach a size of 2 to 6 by 0.8 to $1.3 \mu$. The protoplasm is homogeneous, stains well with aniline dyes and gives a yellow color with iodine; older cells become spindle-shaped, coloring violet-brown with iodine. The size of the cells is greatly influenced by the composition of the medium. Both young and old cells are motile, by peritrichous flagella. When the nutrients in the medium are exhausted, spore formation takes place; the rods change into short, thick cells greatly swollen in center, with a diameter twice, or more than twice as great as the original. The cell membrane becomes sharply contoured and surrounds an hyaline substance which encloses the spore. The contents of the cell become granulated, stain with aniline dyes only with difficulty and color violet with iodine. The spore is formed in one end of the enlarged part of the cell and stains well with aniline dyes, but not with iodine; methylene blue stains the spore dark blue and the protoplasm light blue. By the swelling of the hyaline substance, the mother cell bursts open in one end: the ripe spore, 1.6 by $1.3 \mu$, is now found to lie in a rounded three cornered spore-capsule. It is characteristic of the species for the capsule to adhere to the spore for a considerable period of time. Under favorable conditions, as on fresh media, the spores swell up and the spore envelope breaks. The spore-germination takes place at one pole towards the open end of the capsule. The young cell soon divides, while the old shell may remain in the liquid for a long time. The cell also produces various involution forms, as long threads irregularly swollen and often carrying a spore at one end. Glycogen and granules accumulate in the cells of the organisms just previous to spore formation.

Bredemann ${ }^{28}$ included all the butyric acid bacteria under the name of Bac. amylobacter A. M. et Bred., since the various characteristics, such as size and shape of organism, motility, character of growth on various media, liquefaction of gelatin, carbon sources, products of metabolism, deposition of amylaceous material are all variable characteristics. The most stable characteristics are the form and size of spore as well as the polar germination. Omeliansky, ${ }^{29}$ however, did not agree with the grouping of all the Clostridia, Cranulobacter, Bac. orthobutylicus and others together, but suggested that some of the characters are sufficiently constant to be of value in classification.

The nitrogen-fixing capacity is well distributed among the butyric acid bacteria, including the $\mathrm{Cl}$. pastorianum of Winogradsky, $\mathrm{Cl}$.

${ }^{28}$ Bredemann, G. Untersuchungen über die Variation und das Stickstoffbindungsvermögen des Bacillus asterosporus A. M. Centrbl. Bakt. II, 22: 44-89. 1908; 23: 385-568. 1909; Ber. deut. bot. Gesell. 26: 362 and 795. 1908.

${ }^{29}$ Omeliansky, W. L. Morphological and cytogical investigations on nitrogenfixing bacteria (Russian). Arch. Sci. Biol., 20: 24-49. 1916. 
americanum, a facultative aerobic organism, isolated by Pringsheim, ${ }^{30}$ Granulobacter pectinovorum of Beijerinck and Van Delden, and others.

Distribution of anaerobic nitrogen-fixing bacteria in the soil. Winogradsky has already demonstrated the wide occurrence of Clostridium, which he isolated from every soil sample taken in St. Petersburg and in Paris. A larger form was found in southern Russia. More recent studies $^{31}$ demonstrated the presence of this organism in practically all the Russian soils; the various strains found in different localities vary greatly in their morphology. Similar results were obtained for German soils. ${ }^{32}$ An examination of 152 different soil samples taken in different parts of the world indicated the presence of Bac. amylobacter in 137 cases, including surface soils and subsoils, cultivated and virgin soils, except in a few acid peat soils. ${ }^{33}$ The occurrence of Bac. amylobacter in Vesuvian soils has also been pointed out. ${ }^{34}$

The number of nitrogen-fixing Clostridia in the soil was found to be over 100,000 per gram, or much more abundantly than Azotobacter. ${ }^{35}$ This led various investigators to conclude that the Clostridium rather than Azotobacter is the most important group of non-symbiotic nitrogen-fixing bacteria. Düggeli ${ }^{36}$ found 100 to $1,000,000$ anaerobic and 0 to 100,000 aerobic-nitrogen-fixing bacteria per gram of soil. Plots receiving sodium nitrate as a source of nitrogen contained 10,600 to 12,000 Bac. amylobacter and 4,900 to 6,300 Azotobacter cells; plots receiving no nitrogen, but potassium and phosphorus-fertilizers, contained 1,120,000 Bac. amylobacter and 98,700 Azotobacter cells per gram of soil.

Physiology of anacrobic nitrogen-fixing bacteria. Winogradsky found $C l$. pastorianum to be an obligate anaerobic form which can develop under aerobic conditions only in the presence of aerobic bacteria. However, the aerobic $\mathrm{Cl}$. americanum isolated by Pringsheim was very similar

${ }^{30}$ Pringsheim, H. Über ein stickstoffassimilierendes Clostridium. Centrbl. Bakt. II, 16: 795-800. 1906; 20: 248-256. 1907; 21: 673. 1908; 23: 300. 1909; 24: 488-496. 1909; 36: 468-472. 1913; 40: 21-23. 1914.

${ }^{31}$ Omeliansky and Solounskoff, 1915 (p. 108).

${ }^{32}$ Freudenreich, E. v. Ueber stickstoff bindende Bakterien. Centrbl. Bakt. 10: 514-522. 1903.

${ }^{33}$ Haselhoff, E., and Bredemann, G. Untersuchungen über anaerobe stickstoffsammelnde Bakterien. Landw. Jahrb. 35: 381-414. 1906.

${ }^{34}$ Riccardo, S. Primo contributo alla conoscenza dei Batteri fissatori di azoto nei terreni vesuviani. Ann. R. Sc. Sup. Agr. Portici, 18: 1-50. 1923.

${ }^{36}$ Truffaut, G., and Bezssonoff, N. Augmentation du nombre des Clostridium Pastorianum (Winogradsky) dans les terres partiellement sterilisées par le sulfure de calcium. Compt. Rend. Acad. Sci. 172: 1319-1322. 1921.

${ }^{36}$ Düggeli, 1921 (p. 39). 
in morphology to the other Clostridia, but was capable of fixing larger quantities of nitrogen, perhaps due to its aerobic nature. Bredemann, after examining a large number of Clostridia, came to the conclusion that they are all capable of developing more or less even in the presence of air and fix nitrogen. The presence of $30 \mathrm{mgm}$. of oxygen per 1 liter of air will still allow spore germination.

The optimum temperature for the development of the organism is $28^{\circ}$ to $30^{\circ} \mathrm{C}$. The spores are not destroyed at $75^{\circ}$ even at the end of 15 hours; at $100^{\circ} \mathrm{C}$ the spores are destroyed in five minutes.

Cl. pastorianum utilizes glucose, maltose, lactose, levulose, sucrose, galactose, maltose, raffinose, dextrin, inulin, glycerol, mannite and lactates. Winogradsky found that the nitrogen source greatly influences the nature of the carbon sources that can be utilized. The greater the concentration of sugar the lower is its economic utilization, $3.2 \mathrm{mgm}$. nitrogen being fixed per gram of glucose in 0.5 per cent solution, $2 \mathrm{mgm}$., in 2 per cent solution and $1.2 \mathrm{mgm}$. in 4 per cent solution.

In the presence of combined nitrogen, nitrogen fixation decreases and comes to a standstill, when the solution contains more than six parts of combined nitrogen in one thousand parts of solution (Winogradsky). Omeliansky, however, observed some fixation even with a concentration of 16 parts of combined nitrogen.

The optimum reaction for the growth of $C l$. pastorianum is $\mathrm{pH} 6.9$ to 7.3, but it still develops well at $\mathrm{pH}$ 5.7. It can withstand a greater acidity than proteolytic anaerobes like Bac. putrificus, from which it can be thus freed..$^{37}$ The addition of $\mathrm{CaCO}_{3}$ to the glucose medium has a favorable effect, in neutralizing the acids formed; $\mathrm{MgCO}_{3}$ is less favorable. $C l$. pastorianum can thus withstand a greater acidity than Azotobacter, whose limit is pH 6.0. In acid soils (more acid than pH 6.0) Azotobacter is inactive while the butyric acid bacteria may still be abundant.

When freshly isolated, the Clostridium fixes more nitrogen than when cultivated for a long time in artificial media. The culture can be invigorated by growing it in Winogradsky's liquid medium, to which enough ammonium sulfate is added so as to offer the organism less nitrogen than is needed for the complete decomposition of the sugar. By transferring from this culture, when gas formation ceases, normal growth and nitrogen fixation is obtained. Bredemann ${ }^{38}$ invigorated the culture by passing it through soil.

37 Dorner, 1924 (p. 165).

${ }^{38}$ Bredemann, G. Die Regeneration des Stickstoffbindungsvermögens der Bakterien. Centrbl. Bakt. II, 23: 41-47, 385-568. 1909. 
A fertile garden soil is dried, sieved and placed in a flask to a height of $5 \mathrm{~cm}$. The soil is moistened with water and sterilized in an autoclave for 45 minutes at $150^{\circ} \mathrm{C}$. When the soil is found to be sterile, it is inoculated with an emulsion of a fresh growth of the weakened culture grown on agar. The flasks are allowed to incubate, one at room temperature under aerobic conditions and one at $28^{\circ}$ under anaerobic conditions, for one month, then at room temperature under aerobic conditions. The soil has all dried out by this time. When two grams of it is inoculated into sterile liquid medium, active growth and gas formation begins in 12 hours, reaching a maximum in 36 hours.

It was found that this invigorated culture would coagulate milk with gas formation. Most strains, however, would not grow upon milk. Gelatin was not liquified and casein was not decomposed. Ammonia was not formed from peptone, nitrates were not reduced.

Non-symbiotic nitrogen-fixing aerobic bacteria. When a simple medium containing tap water, 0.02 per cent $\mathrm{K}_{2} \mathrm{HPO}_{4}$ and glucose as a source of carbon is inoculated with soil and incubated in the dark, $\mathrm{Cl}$. pastorianum, together with other bacteria, is obtained. When the glucose is replaced by mannite (2 per cent) or by propionate of potassium or sodium, another large organism predominates; Beijerinck called this organism Azotobacter chroococcum and found it in all soils and manures. ${ }^{39}$ On repeated transfer to fresh lots of sterile media, the organism was gradually purified from the majority of contaminating organisms and finally isolated on mannite agar. In addition to the above simple medium several other media are used successfully for the isolation of Azotobacter:

1. Beijerinck medium:

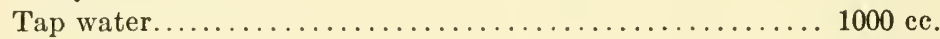

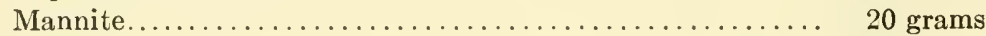

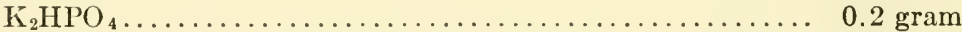

The mannite can be replaced by dextrin, glycerol, calcium malate $(0.5$ per cent) and other salts of organic acids. The water may be replaced by soil extract. ${ }^{40}$

2. Lipman's solution:41

Distilled water...... $1000 \mathrm{cc}$.

Mannite........... 15 grams

$\mathrm{K}_{2} \mathrm{HPO}_{4} \ldots \ldots \ldots \ldots, 0.2$ gram

$\mathrm{MgSO}_{4} \cdot 7 \mathrm{H}_{2} \mathrm{O} \ldots \ldots \ldots 0.2 \mathrm{gram}$

$\mathrm{CaCl}_{2} \ldots \ldots \ldots \ldots \ldots . . . . .02$ gram

$\mathrm{FeCl}_{3} 1$ drop of 10 per cent solution

${ }^{39}$ Beijerinck, 1901 (p. 104).

${ }^{40}$ Löhnis, F. Beiträge zur Kenntnis der Stickstoffbakterien. Centrbl. Bakt. II, 14: 582-604, 713-723. 1905; Landwirtschaftlich-bakteriologisches Praktikum. 1911. P. 131.

${ }^{41}$ Lipman, J. G. Further contributions to the physiology and morphology of members of the Azotobacter group. N. J. Agr. Exp. Sta. 25th Ann. Rpt. 1904, 237-289. Lipman, J. G., and Brown, P. E. A laboratory guide in soil bacteriology. 1911. 
The substances are dissolved, and enough 10 per cent $\mathrm{NaOH}$ is added to make faintly pink to phenolphthalein.

3. Ashby's solution:42
Distilled water...... $1000 \mathrm{cc}$.
$\mathrm{NaCl} \ldots \ldots \ldots \ldots \ldots . .2 \mathrm{gram}$
Mannite..................... 15 grams
$\mathrm{CaSO}_{4} \cdot 2 \mathrm{H}_{2} \mathrm{O} \ldots \ldots \ldots .0 .1 \mathrm{gram}$
$\mathrm{K}_{2} \mathrm{HPO}_{4} \ldots \ldots \ldots \ldots .0 .2$ gram
$\mathrm{CaCO}_{3} \ldots \ldots \ldots \ldots \ldots . . .6$ grams
$\mathrm{MgSO}_{4} \cdot 7 \mathrm{H}_{2} \mathrm{O} \ldots \ldots \ldots, 0.2 \mathrm{gram}$

Make neutral to phenolphthalein with $\mathrm{NaOH}$ solution.

4. Omeliansky's solution:43
Distilled water...... $1000 \mathrm{cc}$.
$\mathrm{MgSO}_{4} \cdot 7 \mathrm{H}_{2} \mathrm{O} \ldots \ldots .0 .5 \mathrm{gram}$
Dextrin........... 20 grams
$\mathrm{CaCO}_{3} \ldots \ldots \ldots \ldots \ldots$ grams
$\mathrm{K}_{2} \mathrm{HPO}_{4} \ldots \ldots \ldots \ldots, 1.0$ gram

Solid media are prepared by adding 15 or $20 \mathrm{gm}$. of agar to the above solutions. For the study of pigment formation the last medium is very appropriate. Potato and potato agar, milk, mannite-nitrate media are also employed for the study of the morphology of the organism.

A small quantity of fertile garden soil, or well limed and manured field soil is used for the inoculation of the sterile liquid medium. After a few day's incubation at $25^{\circ}$ to $30^{\circ} \mathrm{C}$., a pellicle is formed on the surface of the liquid, at first gray in color, later becoming brownish. A microscopic examination of the pellicle shows the presence of the typical Azotobacter cells with large slimy capsules. A part of the pellicle is then transferred into a fresh flask with sterile medium. After several transfers, the culture is sufficiently enriched in Azotobacter so that one can proceed to isolate it on agar media. A loopful of material from a young culture, in which no heavy pellicle has as yet been formed, is diluted in a few cubic centimeters of sterile water to separate the Azotobacter cells. A second and third dilution is made and the surfaces of a series of Petri dishes, in which liquefied mannite agar has been placed and allowed to cool, are then streaked out with the suspensions of the various dilutions. At $25^{\circ} \mathrm{C}$., pale, rounded, raised colonies are formed in a few days. In addition to these, transparent raised colonies of Radiobacter are also found. The Azotobacter colonies are carefully selected by microscopic examination and are transferred into sterile liquid media. These precautions are very important so as not to have the culture contaminated.

The silica gel plate, to which minerals and mannite have been added, inoculated with small particles of soil will give direetly a nearly pure culture of Azotobacter, as shown by Winogradsky. ${ }^{44}$

${ }^{42}$ Ashby, S. F. Some observations on the assimilation of atmospheric nitrogen by a free living soil organism, Azotobacter chroococcum of Beijerinck. Jour. Agr. Sci. 2: 35-51. 1907.

${ }^{43}$ Omeliansky, W. L., and Sseverowa, O. P. Die Pigmentbildung in Kulturen des Azotobacter chroococcum. Centrbl. Bakt. II, 29: 643-650. 1911.

${ }^{44}$ Winogradsky, 1925 (p. 11). 
Description of species of Azotobacter. Azotobacter is a bacterium, 4 to $6 \mu$ broad, forming, when young, diplococci or short rods, with hyaline contents, often containing a vacuole and forming a slimy wall. Various involution forms, as threads reaching to 60 to $80 \mu$ in length, may be formed. Formation of nuclei has been demonstrated by Prazmowski. The younger cells are motile, by means of the 4 to 10 polar flagella, which are about as long as the bacteria. The organisms are aerobic, readily killed on heating. Beijerinck, Lipman and Jones ${ }^{45}$ denied the existence of spores in Azotobacter. According to Ashby, Fischer and Krzemieniewsky, spore formation is positive, since the organism can resist drying for a long period of time. Prazmowski ${ }^{46}$ demonstrated that spore formation takes place under normal conditions, with sufficient aeration and in the presence of humates. The process of spore formation is later described in detail. ${ }^{47,48}$

Azotobacter chroococcum Beij. is universally distributed in soils having a reaction above $\mathrm{pH}$ 6.0. It produces a crude floating membrane on tap water containing 2 per cent mannite and 0.02 per cent $\mathrm{K}_{2} \mathrm{HPO}_{4}$ inoculated with garden soil. Only occasional individuals in young cultures are motile by means of a single flagellum. The size of the cell is differently reported by investigators, varying from 3 to 4 by 5 to $6 \mu$ and even 3 to 4 by 9 to $12 \mu$ to 2 to 3 by 3 to $4 \mu$ (limits 1.5 to $7 \mu$ ) and even 1 to $2 \mu$ for cocci and 1.5 to 2 by 3 to $4 \mu$ for rods. ${ }^{49}$ Old membranes consist of micrococci of various sizes united to form sarcina-like masses, possessing mucilaginous walls. The older cultures are frequently brown or black. This organism oxidizes numerous carbon compounds to $\mathrm{CO}_{2}$ and $\mathrm{H}_{2} \mathrm{O}$. According to Stoklasa, ${ }^{60}$ organic acids are also formed; however, Omeliansky suggested that Stoklasa probably worked with contaminated cultures.

Azotobacter agile Beij. was found universally distributed in canal waters of Delft; the crude and pure cultures are obtained by previous methods. The

${ }^{45}$ Jones, D. H. A morphological and cultural study of some Azotobacter. Centrbl. Bakt., II, 38: 14-21. 1913. Further studies on the growth cycle of Azotobacter. Jour. Bact. 5: 325. 1920.

${ }^{46}$ Prazmowski, A. Die Entwicklungsgeschichte, Morphologie und Cytologie des Azotobacter chroococcum Beij. Centrbl. Bakt. II, 33: 292-305. 1912; 37: 299. 1913. Azotobacter-Študien. II. Physiologie und Biologie. Ariz. Akad. Krakau. Math.-Naturw. Kl. (B), 1912, 855-950. (Centrbl. Bakt. II, 37: 299-301. 1913).

${ }^{47}$ Löhnis and Smith, 1916 (p. 56).

${ }^{48}$ Mulvania. Observations on Azotobacter. Science, 42: 463. 1915.

${ }^{49}$ Bonazzi, A. Cytological studies of Azotobacter chroococcum. Jour. Agr. Res., 4: 225-241. 1915.

${ }^{60}$ Stoklasa, J. Beitrag zur Kenntnis der chemischen Vorgänge bei der Assimilation des elementaren Stickstoffs durch Azotobacter und Radiobacter. Centrbl. Bakt. II, 21: 484-509, 620-632. 1908. 
organism is very motile by means of a bundle of polar flagella. The cells are large, transparent, resembling monads, of ten with a clearly discernible cell wall, protoplasm, nucleus, granules and vacuoles. In the presence of salts of organic acids, it produces a green or red diffusible pigment.

Azotobacter vinelandii was isolated by Lipman ${ }^{51}$ from a New Jersey soil in 1903. In four days it forms on mannite agar colonies $4 \mathrm{~mm}$. in diameter. These are round, raised, concentric and semi-transparent, with denser whitish centers; the deep colonies are white, small, hardly more than $1 \mathrm{~mm}$. in diameter, elliptical to spindle-shaped. A white thick membrane is formed on the mannite solution. When undisturbed, the liquid culture shows the formation of a bright yellow pigment, concentrated near the surface and gradually diffusing through the liquid. In older cultures the pigment gradually diffuses throughout the medium and becomes darker, until in old cultures it may become a yellowish red. At the same time the bacterial mass may also become darker. A considerable number of forms, ranging from large rods with rounded ends to spherical organisms, are found in mannite cultures. Most of the organisms are actively motile, showing progressive and at times rotatory motility. As the culture grows older, the number of shorter rods increases, and the cells begin to accumulate and store up fat, which appears in small globules throughout the bacterial body and gives it a granular appearance. Various involution forms are produced in meat extract bouillon. A temperature of $85^{\circ} \mathrm{C}$. for five minutes is sufficient to destroy all the cells. The organism stains readily with carbol fuchsin, with aqueous solutions of gentian violet, methyl violet or fuchsin and Löffer's methylene blue. The bright yellow pigment produced in mannite solution is favored by greater suriace of medium (oxygen need), is soluble in alcohol and decolorized by weak acids. The organism is very active in the fixation of atmospheric nitrogen.

Azotobacter beijerinckii was isolated by Lipman in 1904. It forms pure white, moist, soft, irregularly round, netted colonies. In mannite solution, the organism forms a turbidity, with white circular dots on surface and walls, gradually settling to the bottom. The cells are large, almost spherical, occurring singly, or in chains of two or more. This organism is much larger than $A$. chroococcum and $A$. rinclandii and does not show any motility. On solid media, a yellowish pigment is formed. Azotobacter vitreum was isolated by Löhnis and Westermann. ${ }^{52}$ It forms only round cells, is non-motile, grows as transparent, moist colonies on solid media, without any pigment. Prazmowski doubts whether this organism belongs to the genus Azotobacter.

Distribution of Azotobacter in the soil. Azotobacter is of universal occurrence in the soil, ${ }^{53}$ but not to such an extent as Clostridium. Out of one hundred and five soil samples examined, Burri ${ }^{54}$ found Azoto-

${ }^{51}$ Lipman, J. G. Experiments on the transformation and fixation of nitrogen by bacteria. N. J. Agr. Exp. Sta. Rpt. 24: 217-285. 1903. 25th Ann. Rpt. 1901, 237-289; Azotobacter studies. Ibid. 26: 254. 1905; 29: 137. 1908.

${ }^{52}$ Löhnis, F., and Westermann, T. Über stickstoffixierende Bakterien. Centrbl. Bakt. II, 22: 234-254. 1908.

${ }^{53}$ Beijerinck and Van Delden. 1902 (p. 105).

${ }^{54}$ Burri, R. Die Nutzbarmachung des Luftstickstoffs durch Bodenbakterien. Schweiz. Ztschr. Forstwesen. 55: 89. 1904. 
bacter missing in thirty-four cases, chiefly in heavy clay soils. Jones and Murdoch ${ }^{55}$ found Azotobacter in nine out of seventeen soil types examined and in twenty-two out of twenty-nine soil samples representing nine types. Eighteen was the maximum number of Azotobacter cells found per one gram of soil.

The absence of Azotobacter in the soil is probably due, in the majority of cases, to the soil reaction, since this organism cannot develop in a soil having an acidity greater than $\mathrm{pH}$ 6.0. As soon as the reaction of the soil is adjusted by means of lime so that the $\mathrm{pH}$ becomes greater than 6.0, an Azotobacter flora will develop. . $^{56-58}$

Azotobacter is widely represented in the soil by various forms, so that Löhnis and Westermann counted in 1908 as many as twenty-one forms. These were believed, however, to represent only four types. Lipman and Burgess ${ }^{59}$ isolated in 1915 a number of forms from American and foreign soil including several new species. The most conmon form, however, was in both cases $A$. chroococcum.

As a result of a study of a large number of soils, Lipman and Burgess ${ }^{59}$ came to the conclusion that, with a proper supply of energy producing materials, all agricultural soils may be made to fix atmospheric nitrogen when inoculated into a properly constituted mannite solution; however, only a fraction of these soils (one-third) contain Azotobacter organisms. Those soils that contain Azotobacter have a more vigorous nitrogen fixing power. As much as $10 \mathrm{mgm}$. of nitrogen are fixed per gram of mannite in solution and $12.6 \mathrm{mgm}$. in the soil by pure cultures of Azotobacter, which approaches that obtained from A. vinelandii. The latter is found to be the strongest nitrogen fixing organism, while $A$. chroococcum the most common.

${ }_{55}$ Jones, D. H., and Murdoch, F. G. Quantitative and qualitative bacterial analysis of soil samples taken in the fall of 1918. Soil Sci. 8: 259-267. 1919.

${ }^{56}$ Christensen, H. R. Untersuchungen über einige neuere Methoden zur Restimmung der Reaktion und des Kalkbedürfnisses des Erdbodens. Intern. Mitt. Bodenk. 13: H. 3-4. 1923.

${ }^{57}$ Gainey, P. L. A study of the effect of changing the absolute reaction of soil upon their Azotobacter content. Jour. Agr. Res. 24: 289-296, 759-767, 907938. 1923.

${ }_{58}$ Waksman, S. A. The occurrence of Azotobacter in cranberry soils. Science, 48: 653. 1918.

${ }^{59}$ Lipman, C. B., and Burgess, P. A. Studies on nitrogen fixation and Azotobacter forms in soils of foreign countries. Centrbl. Bakt. II, 44: 481-511. 1915. 
Azotobacter was found in most Javan soils, ${ }^{60}$ in all soils in India ${ }^{61}$ in a half of Polish soils ${ }^{62}$ and in about 33 per cent of the cultivated soils in Japan. ${ }^{63}$ The wide distribution of Azotobacter in Russian soils, in Utah soils $^{64}$ and in Danish soils ${ }^{65}$ has also been pointed out. However, Azotobacter is almost completely absent in Finnish soils, even those that are well buffered and supplied with $\mathrm{CaCO}_{3}{ }^{66}$

Azotobacter derived from different localities may vary greatly in the amounts of nitrogen fixed. In humid regions the nitrogen-fixing organisms are confined to the upper few inches of soil. ${ }^{67}$ However, in arid regions, they may be quite active to a depth of 3 to 4 feet. Azotobacter occurs more frequently in cultivated than in virgin soils. The number of Azotobacter in the soil is highest in spring and fall of year and lowest in summer and winter. According to Beijerinck, the number of Azotobacter in the soil runs parallel with soil fertility. It is interesting to note that Azotobacter is among the first organisms to develop in a newly formed soil, as in the case of Vesuvian soils. ${ }^{68}$

Löhnis and Smith recognized only two species of Azotobacter isolated so far: A. chroococcum and A. agile Beij. (Syn. A. vinelandii J. G. Lipman). A beijerinckii Lipman was looked upon as a variety of $A$. chroococcum and $A$. vitreum Löhnis as a variety of $A$. agile.

Morphology and life cycle of Azolobacter. The form and size of Azotobacter cells depend upon the composition of the medium and conditions of cultivation. Increased aeration brings about a lengthening of the forms and greater motility. In the presence of organic colloidal substances, especially those containing nitrogen, as well as aluminum salts, the cells remain in a young condition for a long time;

${ }^{60}$ Groenewege, J. Occurrence of Azotobacter in tropical soils. Arch. Suikinderind. 21: 790-793. 1913.

${ }^{61}$ Hutchinson, C. M. Soil bacteriology. Rpt. Agr. Res. Inst. Pusa. 1911-12, 85-90; Azotobacter and nitrogen fixation in India soils. Mem. India Agr. Exp. Sta. Bact. Ser. 1: 98-112. 1915.

${ }^{62}$ Ziemiecka, J. Présence de l'azotobacter dans les sols polonais. Rocznikow Nauk Rolniczych. 10: 1-78. 1923.

${ }^{63}$ Yamagata, U., and Itano, A. Physiological study of Azotobacter chroococcum, beijerinckii and vinelandii types. Jour. Bact. 8: 521-531. 1923.

${ }^{64}$ Greaves, J. E. Azofication. Soil Sci. 6: 163-217. 1918.

${ }^{65}$ Weis, F., and Bornebusch, C. H. On the presence of Azotobacter in Danish woods. Det. Forstlige Forsogs. Danmark, 4: 319-331. 1914.

${ }^{66}$ Brenner, W. Azotobacter in finnländischen Böden. Geolog. Konn. Finland. Agr. Geol. Meddl. 20: 1924.

${ }^{67}$ Ashby, 1907 (p. 113).

${ }^{68}$ Riccardo, 1923 (p. 110). 
alkali salts and other salts stimulate the maturity of the culture. Prazmowski also observed changes of the dark brown $A$. chroococcum into a colorless race similar to $A$. vinelandii and $A$. agile and a yellow race similar to $A$. beijerinckii; he concluded, therefore, that the various species described are merely races of one greatly variable species. These results are confirmed by Omeliansky, ${ }^{69}$ who found that pigment formation by Azotobacter depends entirely on the composition of the medium. However, this is not sufficient to deny the existence of the various species altogether, especially since the genus itself is very variable, and it is difficult to establish the limits for its systematic position. The organism most commonly studied is $A$. chroococcum. It goes through a regular life cycle. Drying stimulates spore formation. The membrane surrounding the cell becomes more compact and thinner while the cell itself changes into a spore. ${ }^{70}$ Prazmowski observed spore formation also in ordinary media, containing soil extract. Several spores were found to be produced in a cell and these are believed to be responsible for the irregular packet and sarcina forms observed in mature cultures. The latter are formed by simple fission of the cell. ${ }^{71}$ The granules arising from the splitting up of the supposed nuclear body may act as gonidia spores.

Löhnis and Smith claim that the genus Azotobacter is characterized by seven different cell types:

1. Large non-sporulating, globular, oval, or rod-like cells, with polar or peritrichous flagella.

2. Coccoid cells, the vegetative growth of the regenerative bodies, identical with Micrococcus.

3. Dwarfed cell type, the vegetative growth of the gonidia.

4. Irregular, fungoid cells, similar to Mycobacterium.

5. Small non-sporulating rods, identical either with Bact. lactis viscosum or Bact. putidum.

6. Small sporulating rods, identical either with Bac. fusiformus or Bac. pumillus A. M. et Gotteil.

7. Large sporulating cells.

${ }^{69}$ Omeliansky, 1916 (p. 109).

${ }^{70}$ Fischer, H. Ein Beitrag zur Kenntnis der Lebensbedingungen von stickstoffsammelnden Bakterien. Centrbl. Bakt. II, 14: 33-34. 1905; 15: 235-236. 1906.

${ }^{71}$ Jones, D. H. A morphological and cultural study of some Azotobacter. Centrbl. Bakt. II, 38: 14-25. 1913; 42: 68-9. 1914; Trans. Roy. Soc. Canada. Ser. 3, 7: 1913, Sect. IV. Further studies on the growth cycle of Azotobacter. Jour. Bact. 5: 325-342. 1920. 
The reproductive organs of Azotobacter are:

1. Gonidia, in part filterable, produced in the cell.

2. Regenerative bodies and exospores, either produced by the cells or growing up from the symplasm.

3. Arthrospores formed by fragmentation of the rod-like or fungoid cells.

4. Mycrocysts, globular or oval resting cells.

5. Endospores, produced singly by the rod-like cells in terminal or in central position, or in the form of two or more globular or spindle-shaped sporangia.

Gonidia form the basis for the development of regenerative bodies, arthrospores and endospores. Symplasm formation and regeneration of new cells proceeds with Azotobacter as with other bacteria. ${ }^{72}$

Physiology of Azotobacter. There is an important difference in the amount of nitrogen fixed by pure cultures of the organism and by crude cultures in the presence of other organisms, in favor of the last. This was first recognized by Beijerinck and Van Delden, who went as far as to state that $A$. chroococcum is incapable of fixing any appreciable quantities of nitrogen, when growing in pure culture, but large amounts of nitrogen are fixed in the presence of the spore bearing Granulobacter or non-spore bearing members of the $B$. aerogenes group and $B$. radiobacter. Members of the Granulobacter group were found capable of fixing nitrogen by themselves, this power becoming very pronounced in the presence of Azotobacter. On the other hand, Gerlach and Vogel ${ }^{73}$ proved conclusively that $A$. chroococcum is able to fix large quantities of atmospheric nitrogen when grown in pure culture, in the presence of salts of organic acids or sugar. This was soon confirmed by others. ${ }^{74,75}$ The presence of other organisms, however, is advantageous to the amount of nitrogen fixed and the rate of fixation, either by using up the waste products or creating otherwise favorable conditions. Young cultures will fix more nitrogen than old cultures; crude cultures more than pure cultures.

A number of hexoses (glucose best), pentoses, alcohols (mannite) and salts of organic acids, such as malate, ${ }^{76}$ lactate, butyrate, succinate,

72 On the systematic position of Azotobacter, the work of Löhnis and Hanzawa should be consulted. Löhnis, F., and Hanzawa, J. Die Stellung von Azotobacter im System. Centrbl. Bakt. II, 42: 1-8. 1914.

${ }^{73}$ Gerlach, M., and Vogel, I. Stickstoffsammelnde Bakterien. Centrbl. Bakt. 8: 669-674. 1902; 9: 817-821, 881-892. 1902; 10: 363-643. 1903.

${ }^{74}$ Freudenreich, 1903 (p. 113).

${ }^{75}$ Lipman, 1903 (p. 115).

${ }^{76}$ Beijerinck, M. W. Utber ein Spirillum, welches freien Stickstoff binden kann? Centrbl. Bakt. II, 63: 353-359. 1925. 
can be utilized as sources of energy. The available evidence seems to indicate that celluloses may be utilized as sources of energy, when cellulose decomposing bacteria are present, but not directly. ${ }^{77}$ Ammonium salts are utilized more readily than nitrates as sources of nitrogen. Only traces of minerals are required, but the organism can withstand as much as 10 per cent $\mathrm{MgSO}_{4}$. It resists drying very readlily and is sensitive to high temperatures: the cells are destroyed in a few minutes at $55^{\circ} \mathrm{C}$., but resist drying for many years. ${ }^{78}$

Other non-symbiotic nitrogen-fixing bacteria. In addition to the $\mathrm{Cl}$. pastorianum and the Azotobacter group, various other bacteria are capable of fixing appreciable quantities of nitrogen, as pointed out by Beijerinck and van Delden for a freshly isolated culture of Bacillus mesentericus, and for a number of species of the aerobic Granulobacter. The same is true of Bact. lactis viscosum, Bact. pneumoniae, Bact. radiobacter and Bact. prodigiosum. ${ }^{79}$ Bact. aerogenes, Bact. pyocyaneum and a number of other bacteria were also found capable of fixing small amounts of nitrogen, especially when freshly isolated from the soil. The claims that various spore-forming bacteria, like Bac. subtilis, Bac. megatherium, etc., are also capable of fixing nitrogen were found to be unfounded. However, two representatives of the Bac. mesentericus group, namely Bac. malabarensis and Bac. danicus, the first isolated from South Indian rice soil and the second from nodules of Vicia, were found capable of fixing nitrogen. Bact. radicicola, the legume organism, can live in the soil outside of the nodules and may fix small quantities of atmospheric nitrogen on artificial media. ${ }^{80}$ As much as $1.2 \mathrm{mgm}$. nitrogen may be fixed per $100 \mathrm{cc}$. of medium. ${ }^{81}$ Bac. asterosporus can fix 1 to $3 \mathrm{mgm}$. nitrogen for every

${ }^{77}$ Pringsheim, H. Über die Verwendung von Cellulose als Energiequelle zur Assimilation des Luftstickstoffs. Centrbl. Bakt. II, 23: 300-308. 1909; 26: 222-227. 1910; Biol. Centrbl. 31: 65. 1911; Hutchinson and Clayton, 1918 (p. 196).

${ }^{78}$ Stapp, C., and Ruschmann, G. Zur Biologie von Azotobacter. Arb. Biol. Reichsaust. Land. u. Forstw. 13: 305-368. 1924.

${ }^{79}$ Löhnis, F. Beitrïge zur Kenntnis der Stickstoffbakterien. Centrbl. Bakt. II, 14: 582-604. 1905. Löhnis, F., and Pillai, N. K. Über stickstofffixierende Bakterien. II. Centrbl. Bakt. II, 19: 87-96. 1907; 20: 781-799. 1908.

${ }^{80}$ Löhnis, 1910 (p. 28); Lipman and Fowler, 1915 (p. 129).

${ }^{81}$ Fred, E. B. The fixation of nitrogen by means of Bacillus radicicola without the presence of a legume. Va. Agr. Exp. Sta. Ann. Rpt. 1909-1910, 138-142. 
gram of glucose consumed; the organism soon loses this property, but it can regain it on passage through soil. ${ }^{82}$ Planobacillus nitrofigens, a large, rod-shaped, spore-forming bacterium, capable of fixing in three weeks in a soil extract medium containing 2 per cent of mannite, 3.57 mgm. of nitrogen in $100 \mathrm{cc}$. of solution, was described. ${ }^{83} \mathrm{~A}$ form related to $B$. vulgare was found capable of fixing 1.8 to $4.7 \mathrm{mgm}$. of nitrogen for one gram of sugar consumed. ${ }^{84}$ A nitrogen-fixing organism (Bac. azophile) was also isolated from manure. ${ }^{85}$ Certain thermophilic bacteria, growing in mixed culture at $61^{\circ} \mathrm{C}$, are capable of fixing appreciable quantities of nitrogen..$^{86}$

Azotobacter may also live symbiotically with algae ${ }^{87}$ and other bacteria. ${ }^{88}$ The quantities of nitrogen thus fixed may be considerable. ${ }^{89}$ The symbiotic action between $\mathrm{Cl}$. pastorianum and Azotobacter, whereby the second uses up the oxygen making conditions favorable for the former, has been demonstrated. ${ }^{90}$ The various acids produced by the former are neutralized by the soil bases and can be utilized by the Azotobacter as sources of energy; this symbiotic action leads to a maximum economy in the utilization of energy.

In respect to non-symbiotic nitrogen-fixation in the soil, Winogradsky ${ }^{91}$ distinguishes three catagories: 1 . Very active soils are characterized by an abundance of aerobic nitrogen-fixing bacteria and by the ability to give readily spontaneous cultures of these bacteria when enriched with an assimilable carbon source. 2. Soils only moderately

${ }^{82}$ Bredemann, G. Untersuchungen über die Variation und das Stickstoffbindungsvermögen des Bacillus asterosporus A. M. ausgeführt an 27 Stammen verschiedener Herkunft. Centrbl. Bakt. II, 22: 44-89. 1908.

${ }^{83}$ Bondorff, K. A. Planobacillus nitrofigens n. sp. Den. Kgl. Veterinaer og I andboholskr. Aarskr. 1918, 365-369.

${ }^{84}$ Truffaut, G., and Bezssonoff, N. Un nouveau bacille fixant d'azote. Compt. Rend. Acad. Sci. 175: 544. 1922.

${ }^{85}$ Fulmer, H. L., and Fred, E. B. Nitrogen-assimilating organisms in manure. Jour. Bact. 3: 422-434. 1917.

${ }^{86}$ Pringsheim, H. Ueber die Assimilation des Luftstickstoffs durch thermophile Bakterien. Centrbl. Bakt. II, 31: 23-27. 1911.

${ }^{87}$ Fischer, 1904 (p. 105); Heinze, B. Einige Beiträge zur mikrobiologischen Bodenkunde. Centrbl. Bakt. II, 16: 640-653, 703-711. 1906.

${ }^{88}$ Beijerinck and van Delden, 1902 (p. 105).

${ }^{89}$ Hutchinson, C. M. Soil biology. Agr. Res. Inst. Pusa., Sci. Rpts. 1922-23, 43-49.

${ }^{90}$ Omeliansky, 1916 (p. 109).

${ }^{21}$ Winogradsky, S. Etudes sur les microbes fixateurs d'azote. Ann. Inst. Past. 40: 455-520. 1926. 
active show less development of nitrogen-fixing bacteria and a retarded or no development of spontaneous cultures. 3. Inactive soils are free from aerobic nitrogen fixing bacteria. The methods of analyses are described elsewhere (p. 732).

Symbiotic nitrogen-fixation by nodule bacteria. Historical. Many centuries before the discovery of the nodule bacteria and their part in the enrichment of the soil with combined nitrogen, due to their symbiotic action with leguminous plants, had been established, the practical agriculturist came to consider the growth of these plants in the soil equivalent to manuring the soil for the succeeding crop. ${ }^{92}$

In the early part of the 19th century Davy"3 stated that "peas and beans seem to be well adapted to prepare the soil for wheat. Peas and beans contain a substance similar to proteins; but it seems that the nitrogen, which is one of the constituents of this substance, takes its

92 Use of legumes by Romans is found in the work of Plinius-Historia naturalis LVIII; Varro-De re rustica. Lib. I, Chap. 23; by ancient Chinese, in the book of F. H. King-Farmers of forty centuries. Madison, Wis. 1911.

${ }^{93}$ Dạvy, H. Elements of agricultural chemistry. 1814, p. 412.

\section{PLATE VII}

\section{Symbiotic Nitrogen Fixing Bacteria}

37. Types of nodules on leguminous and non-leguminous plants: A, Trifolium pratense; $B$, Garden pea; C, Cowpea; D, Soja hispida; E, Vicia faba; F, Ceanothus americanus; $G$, nodules on leaf of Pavetta indica; $H, A$ lnus. (A, after Makrinov and Omeliansky; $C, D$, after Albrecht; $E$, after Straszburger and Omeliansky; $F$, after Burrill; $G$, after Faber and Omeliansky; $I$, after de Rossi.)

38. Detailed examination of Bact. radicicola on lupines: $a$, nodule, natural size; $b$, cross section of root and nodule; $c$, cell of nodule filled with bacteria, $\times 400$; $d$, nodule bacteria, $\times 1200 ; e-f$, bacteroids, $\times 1200$ (after Woronin, Fischer and Omeliansky).

39. Nodule bacteria of Vicia sativa: $a-d$, transformation of rods into bacteroids (after Beijerinck).

40. Nodule bacteria from nodules of alfalfa, $\times 1200$ (from Edwards and Barlow).

41. Flagellation of bacteria of leguminosae: 1, Phaseolus vulgaris; 2, Cracca virginiana; 3, Vicia sativa; 4, Medicago sativa; 5, Melilotus alba; 6, Lespedeza striata (from Shunk).

42. Bact. rubiacearum of Pavetta zimmermanni: $A$, contents of nodule; $B$, preparation of colony grown on agar; $C$, various forms of different stages of development of pure culture: $A$ and $B, \times 1660 ; C, \times 1300$ (after von Faber and de Rossi). 

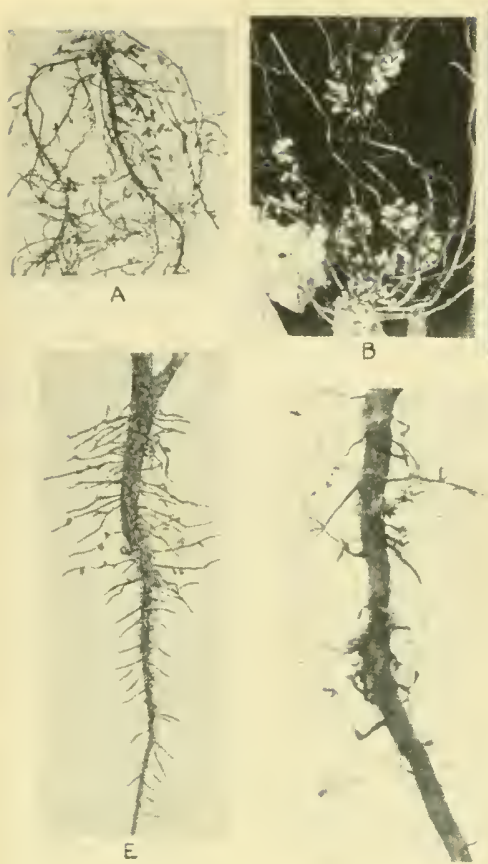

B

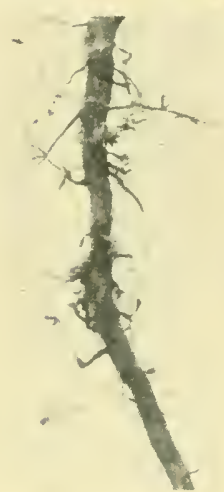

\section{din हiी}

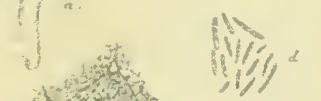

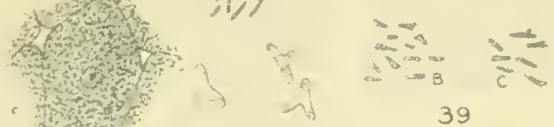

ntw
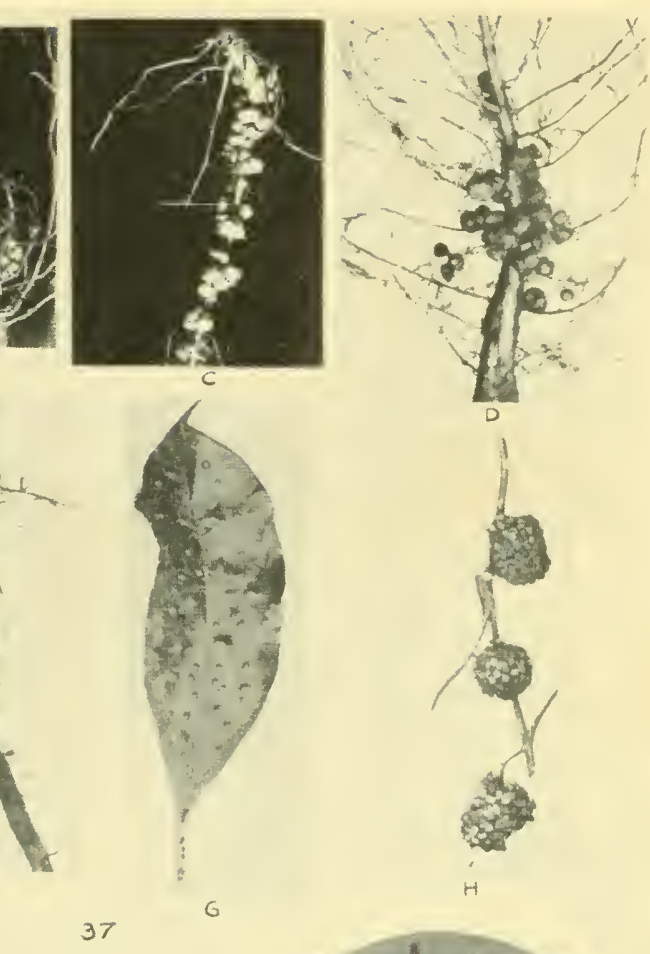

G
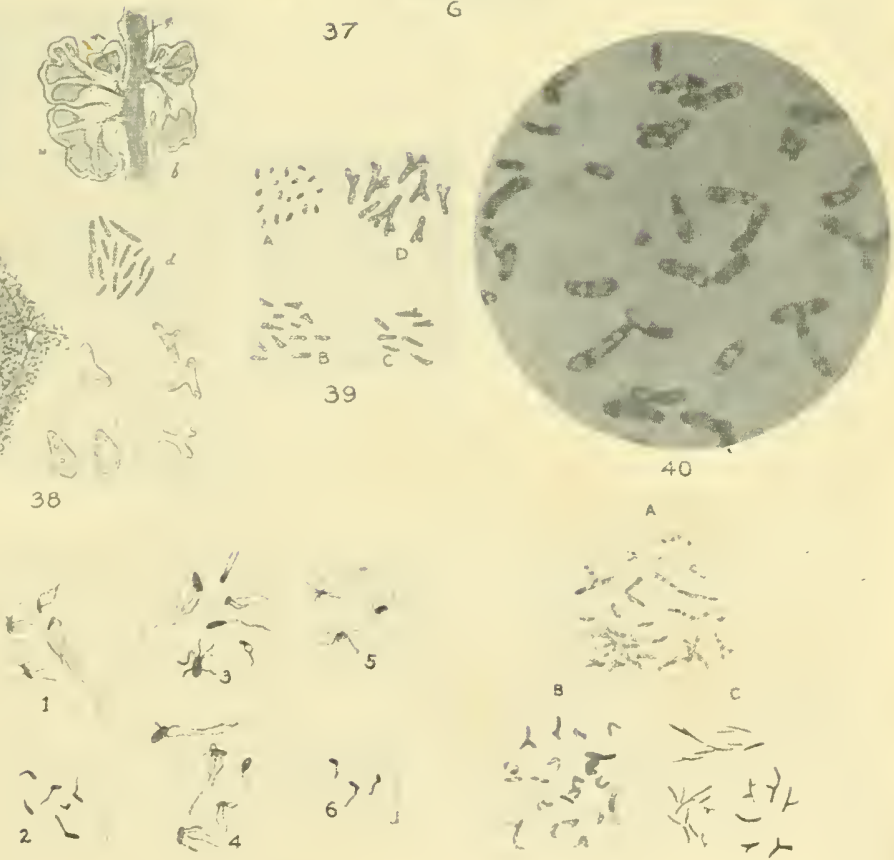

41

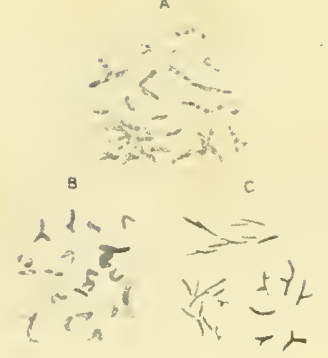



origin from the atmosphere." Boussingault ${ }^{94}$ was the first to carry out a series of systematic studies on the nitrogen nutrition of leguminous and cereal plants. He established the fact that, in the cultivation of clover in unmanured soils, there is a definite gain, not only of carbon, hydrogen and oxygen, but also of large quantities of nitrogen; wheat, however, under the same conditions shows no gain or loss in nitrogen. Boussingault definitely expressed his opinion that nitrogen belongs to those elements which leguminous plants (clover, peas) can assimilate from the atmosphere, while cereal plants (wheat, oats) cannot do so. In attempting to repeat these experiments under more carefully controlled conditions, Boussingault ignited the sand (thus killing the bacteria) and found that neither cereals nor legumes were capable of assimilating atmospheric nitrogen..$^{95}$

In an elaborate series of experiments begun in 1857 at the Rothamsted Experimental Station, Lawes, Gilbert and Pugh $^{96}$ were so careful to eliminate any possibility of the plants obtaining any combined nitrogen from the atmosphere, that they destroyed the organism fixing the nitrogen symbiotically with leguminous plants; they thus failed to become the discoverers of this symbiotic relationship, since, in the absence of the bacteria, the leguminous plants behaved like the cereals and could not utilize the atmospheric nitrogen. Breitschneider ${ }^{97}$ demonstrated in 1861 that legumes do not fix any nitrogen when the soil is ignited but do so in unignited soil. Schulz-Lupitz ${ }^{98}$ grew lupines for fifteen consecutive times, without the application of nitrogen fertilizer and without diminishing yields; cereals following lupines gave much higher yields than on the same land not preceded by the leguminous crop; the nitrogen content of the soil was actually found to increase.

The presence of nodules on the roots of leguminous plants was recorded by Malpighi ${ }^{99}$ as early as 1687 , but he, as well as others, con-

${ }^{94}$ Boussingault. Recherches chimiques sur la végétation enterprises dans le but d'examiner si les plantes prennent de l'azote de l'atmosphère. Compt. Rend. Acad. Sci. 6: 102-112. 1838; 7: 889-892; Ann. Chim. et phys. (2), 67: 1-54 1838; 69: 353-367. 1838; Compt. Rend. Acad. Sci. 38: 580-607. 1854; 39: 601-613.

${ }^{05}$ Ville. Note sur l'assimilation de l'azote de l'air par les plantes. Compt. Rend. Acad. Sci. 31: 578. 1850; 35: 464-468, 650-654. 1852; 38: 705-709, 723727. $1854 ; 43: 143-148.1856$.

${ }_{96}$ Lawes, Gilbert and Pugh, 1861 (p. 106).

${ }_{97}$ Breitschneider. Kann der freie Stickstoff zur Bildung der Leguminosen beitragen? Jahresber. Agr. Chem. 4: 123. 1861.

${ }_{98}$ Schultz, I. Reinertrüge auf leichtem Boden, ein Wort der Erfahrung, zur Abwehr der wirtschaftlichen Notlı. Landw. Jahrb. 10: 777-84S. 1 ss1. 126.

${ }^{99}$ Malpighi. Opera omnia. Anatomia plantarum, Pars II. De gallis. 1687, 
sidered them as root galls. Lachmann ${ }^{100}$ observed, in 1858, that motile bacteria cause the formation of the nodules and he suggested that the nodules are the organs of nitrogen fixation. In 1866 Woronin $^{101}$ found the nodules to consist of bacteria, but even he considered these nodules as pathological outgrowths. Frank ${ }^{102}$ demonstrated in 1879 that the formation of nodules can be prevented by the sterilization of the soil. Frank's view as well as that of other investigators ${ }^{103}$ was that the nodules are caused by outside infection. Hellriegel and Wilfarth ${ }^{104}$ and Atwater ${ }^{105,106}$ finally demonstrated in 1884-1886 that the nodules on the roots of leguminous plants are due to bacterial infection, that this is beneficial, since it is within these nodules where the bacteria fix the atmospheric nitrogen. When nodules were formed, the plants could be grown on artificial soils containing but traces of combined nitrogen, provided the mineral elements necessary for the nutrition of the plant were present. In the absence of nodules, the plants were unable to utilize the atmospheric nitrogen for its growth. When sterilized soil was treated with fresh soil infusion, nodule formation took place and the plants grew normally. The growth of the Gramineae depended, however, on the nitrate content of the soil. These results were soon confirmed by Lawes and Gilbert ${ }^{107}$ and others.

100 Lachmann. Über Knöllchen der Leguminosen. Landw. Mitt. Zeitschr• K. Lehranstalt. u. Vers. Sta. 1858, p. 37.

101 Woronin, M. Observations sur certaines excroissances que presentent les racines de l'aune et du lupin des jardins. Ann. Sci. Nat. Bot., ser. 5, 7: 73-S6. 1S67; also Mem. Acad. Imp. Sci. St. Petersberg, 7 ser., 10: 1-13. 1866.

102 Frank, B. Über die Parasiten in der Wurzelanschwellung der Papilionaceen. Bot. Ztg. 37: 377-388, 393-400. 1879.

103 Ward, M. On the tubercular swellings on the roots of Vicia faba. Phil. Trans. Roy. Soc. London 178, 1887.

104 Hellriegel, H. Welche Stickstoffquellen stehen der Pflanze zu Gebote? Tagebl. Natforsch. Vers. Berlin, 1886, p. 290; Chem. Centrbl. 1886, 871; Landw. Vers. Sta. 33: 464-465. 1886. Hellriegel, H., and Wilfarth, H. Untersuchungen über die Stickstoff-Nahrung der Gramineen und Leguminosen. Beilageheft Ztschr. Ver. Rübenzückerind. 1888, 1-234.

105 Atwater, W. O. On the assimilation of atmospheric nitrogen by plants. Rpt. Brit. Assn. Adv. Sci. 54: 685. 1884.

${ }^{106}$ Atwater, W. O., and Woods, C. D. The acquisition of atmospheric nitrogen by plants. Amer. Chem. Jour. 6: 365. 1885; also 8: 398 420. 1886; Conn. (Storrs) Agr. Exp. Sta. Bul. 5, 1889; Conn. (Storrs) Agr. Exp. Sta. Ann. Rpt. 1889, 11-51.

${ }^{107}$ Lawes, J., and Gilbert, J. New experiments on the question of fixation of free nitrogen. Proc. Roy. Soc. London 47: 85-118. 1890. 
The causative organism was isolated in 1888, in pure culture, by Beijerinck, ${ }^{108}$ who named it Bacillus radicicola. Beijerinck described three stages in the development of the organism.

1. The organism is present in the soil in the form of small rods which can penetrate the root hairs of the leguminous plants and from there it is transferred to the "infectious tissue."

2. The organism changes into a motile bacillus.

3. It changes into the bacteroid form which functions as the symbiotic organism.

The organism was soon grown, on artificial culture media, by a number of investigators. ${ }^{109}$ The mechanism of root infection by pure cultures of bacteria was worked out by Prazmowski in 1889. ${ }^{109 a}$ Schloesing and Laurent ${ }^{110}$ demonstrated that the nitrogen is actually obtained by the bacteria in the form of nitrogen gas from the atmosphere. Leguminous plants were grown in sterile glass cylinders containing sterile sand and watered with sterile water. When the composition of the gas in the cylinder was determined, it was found that, while the uninoculated plants showed a gain of only $0.6 \mathrm{mgm}$. of nitrogen and no nodule formation, inoculated plants showed a gain of 34.1 and $40.6 \mathrm{mgm}$. of nitrogen and abundant nodule formation. Nobbe and Hiltner ${ }^{111}$ concluded that the fixation of nitrogen by leguminous plants is closely related to the formation of bacteroids in the nodules.

Nomenclature. The causative organism of the nodules on the roots of leguminous plants is referred to by different names, depending on the particular system of classification. As pointed out above, the discoverer

${ }^{108}$ Beijerinck, 1888 (p. 103). See also Prazmowski. Das Wesen und die biologische Bedeutung der Wurzelknöllchen der Erbse. Bot. Centrbl. 39: 356362. 1889; Landw. Vers. Sta. 37: 161-238. 1890.

${ }^{109}$ For a review of earlier literature see Voorhees and Lipman, 1907 (p. 491). Hiltner, 1904 (p. 128). Löhnis, 1910. Burrill and Hansen, 1917 (p. 126); Müller, A., and Stapp, C. Beiträge zur Biologie der Leguminosenknöllchenbakterien mit besonderer Berücksichtigung ihrer Artverschiedenheit. Arb. Biol. Reichsanst. L. u. Forstm. 14: 455-554. 1925.

109 Prazmowski, A. Die Wurzelknöllchen der Erbse. Landw. Vers. Sta. 37: 161; 38: 5. 1890 .

110 Schloesing, Th., and Laurent, E. Recherches sur la fixation de l'azote libre par les plantes. Compt. Rend. Acad. Sci. 111: 750-754. 1890;113: 776-778, 1095-1060. 1891; 115: 1017. 1892; Ann. Inst. Past. 6: 65-115, 824-940. 1892.

${ }^{111}$ Nobbe, F., and Hiltner, L. Wodurch werden die knöllchenbesitzenden Leguminosen befähigt, den freien atmosphärischen Stickstoff für sich zu verwerten. Landw. Vers. Sta. 42: 459-478. 1893. 
of the organism, Beijerinck, termed it Bacillus radicicola. In view of the fact that this is a non-spore forming organism and it is destroyed at $60^{\circ}$ to $70^{\circ} \mathrm{C}$., Prazmowski changed its name to Bacterium radicicola. The fact that a number of races produce only a single polar flagellum led various investigators ${ }^{112,113}$ to classify the organism with the genus Pseudomonas, under the name of Pseudomonas radicicola. E. F. Smith ${ }^{114}$ and the Committee of the Society of American Bacteriologists (p. 58) decided that the organism described by Frank ${ }^{115}$ in 1879 as Schinzia leguminosarum was the nodule forming organism and deserves priority; the name of Bacterium leguminosarum or Rhizobium leguminosarum was therefore suggested. It is doubtful, however, whether Frank ever saw the nitrogen-fixing, nodule-forming organism. ${ }^{116}$ According to Löhnis and Hansen, ${ }^{117}$ the nodule bacteria do not represent a special genus Rhizobium, but are closely related to Bact. radiobacter, Bact. lactis viscosum, Bact. pneumoniae and Bact. aerogenes, the last three being immotile and the first motile. The species differ only to a slight extent, in their physiological and morphological characters; the branched cell forms (so-called "bacteroids") are common to all members of the group of capsule bacteria, when tested adequately. These closely related forms are well distributed in the soil and Bact. radiobacter may actually be present in the root nodules of leguminous plants. On account of its resemblance to Bact. radicicola, it has been mistaken for the nodule-producing organism in the cowpea-soybean group, since it grows rapidly on the plates made from the nodules; however, it can be differentiated from the latter by its brown growth on potato.

Media. A number of media have been suggested, at various times, for the cultivation of the organism causing the nodules on leguminous

112 Moore, G. T. Bacteria and the nitrogen problem. Yearb. U. S. Dept. Agr. for 1902, 333-342.

${ }^{113}$ Burrill, T. J., and Hansen, R. Is symbiosis possible between legume bacteria and non-legume plants? Ill. Agr. Exp. Sta. Bul. 202: 115-181. 1917. (Complete bibliography to 1915).

114 Smith, E. F. Bacteria in relation to plant diseases. Washington, 2: 97146. 1921 .

${ }^{115}$ Frank, B. Über den gegenwartigen Stand unserer Kenntnis der Assimilation elementaren Stickstoffs durch die Pflanze. Ber. deut. bot. Gesell. 7: 234247. 1889; Landw. Jahrb. 19: 523-640. 1890; also Frank, 1879 (p. 124).

${ }^{116}$ Kellerman, K. F. The present status of soil inoculation. Centrbl, Bakt. II, 34: 42-50. 1912.

${ }^{117}$ Löhnis, F., and Hansen, R. Nodule bacteria of leguminous plants. Jour. Agr. Res. 20: 543-556. 1921. 
plants. In addition to various organic media, extracts of carrots, of leaves and of seeds of leguminous plants, a number of inorganic media have been suggested. Of these, several may be selected:

1. Wood ash medium: ${ }^{113}$

Wood ash extract (15 grams ashes to 1 liter of tap water).. 1000 ce.

Sucrose............................. 10 grams

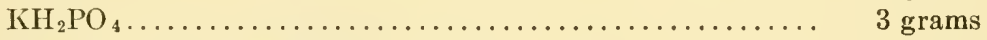

2. Ashby's mannite solution (p. 113).

3. Conn's asparaginate solution (p. 16)

4. Glucose medium:119

Distilled water. .... $1000 \mathrm{cc}$.

Glucose........... 20 grams

$\mathrm{KH}_{2} \mathrm{PO}_{4} \ldots \ldots \ldots \ldots, 1.0$ gram

$\mathrm{MgSO}_{4} \cdot 7 \mathrm{H}_{2} \mathrm{O} \ldots \ldots \ldots \quad 0.1 \mathrm{gram}$

5. Sucrose medium:
Tap water........ 1000 cc.
Sucrose.......... 10 grams
6. Mannite medium:120
Mannite........... 10 grams
$\mathrm{NaCl} \ldots \ldots \ldots \ldots \ldots .2 \mathrm{gram}$
$\mathrm{K}_{2} \mathrm{HPO}_{4} \ldots \ldots \ldots \ldots .0 .5$ gram
$\mathrm{MgSO}_{4} .7 \mathrm{H}_{2} \mathrm{O} \ldots \ldots \ldots 0.2 \mathrm{gram}$
$\mathrm{KH}_{2} \mathrm{PO}_{4} \ldots \ldots \ldots \ldots \ldots$ gram
$\mathrm{MgSO}_{4} \ldots \ldots \ldots \ldots \ldots . . .5$ gram
$\mathrm{CaCO}_{3} \ldots \ldots \ldots \ldots \ldots 1.0$ gram
Yeast water......... $100 \mathrm{cc}$.
Distilled water....... 900 cc.
Washed agar....... 15 grams

$\mathrm{CaSO}_{4} \cdot 2 \mathrm{H}_{2} \mathrm{O} \ldots \ldots . . .0 .1 \mathrm{gram}$

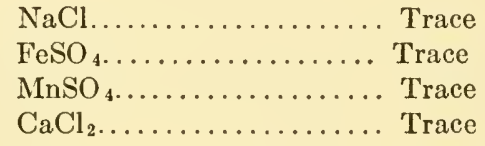

The yeast water is prepared ${ }^{121}$ by stirring starch-free yeast with ten times its weight of tap water, steaming for 1 to 2 hours, then sterilizing and, after allowing to stand 24 hours, siphoning off the clear brown liquid.

Various legume extract and tomato extract media are also employed: A decoction of 100 grams material of the green plants and roots in $1000 \mathrm{cc}$. of water, to which 1 per cent glucose is added and some $\mathrm{CaCO}_{3}$ to make the reaction neutral. ${ }^{122}$ For solid media, 1.2 to 1.5 per cent of agar is used; for gelatin media, 12 per cent of gelatin is used. When the reaction is adjusted by the hydrogen-ion concentration method, it should be brought to $\mathrm{pH} 6.8$ to 7.5 .

118 Harrison, F. C., and Barlow, B. The nodule organism of the Leguminosaeits isolation, cultivation and commercial application. Centrbl. Bakt. II, 19: 264-272, 426-441. 1907; Trans. Roy. Soc. Can. Ser. (2), 12: 157-237. 1907.

${ }^{119}$ Fred, E. B. A physiological study of the legume bacteria. Va. Agr. Exp. Sta. Ann. Rpt. 1911, 145-174.

120 Wright, W. H. The nodule bacteria of soybeans. I. Bacteriology of strains. Soil Sci. 20: 95-120. 1925.

${ }^{121}$ Fred, E. B., Peterson, W. H., and Davenport, A. Fermentation characteristics of certain pentose destroying bacteria. Jour. Biol. Chem. 42: 175.1920.

${ }^{122}$ Nobbe, F., and Hiltner, I. Künstliche Ueberführung der Knöllchenbakterien von Erbsen in solche von Bohnen (Phaseolus). Centrbl. Bakt. II, 6: 449457. 1900 . 
Nodule formation. The bacteria usually enter the plant through the root hairs, being attracted through the secretion of soluble carbohydrates or organic acids by the plant. On entering the root, the bacteria multiply forming a thread of infection, similar to a fungus hypha, which enters the root and branches out into the parenchymatous cells of the plant. In some cells, the thread breaks up into individual cells which, on multiplication, fill the whole protoplasm of the cell; the bacteria give rise at the same time to branching forms, commonly referred to as "bacteroids."

The size, form and position of nodules vary with the nature of the plant, soil in which it is grown and virulence of the bacteria, as shown by Hiltner, ${ }^{123}$ who explained nodule formation by his theory of immunity discussed elsewhere (p. 589). According to Bryan, ${ }^{24}$ nodule formation is greatly influenced by the reaction of the soil: alfalfa and clover produce maximum growth and number of nodules at $\mathrm{pH} 7.8$, alsike and red clover at $\mathrm{pH} 5.6$; the critical $\mathrm{pH}$ values for nodule formation are 4.0 and 9.0 to 10.0 . Nodules will be formed at all temperatures at which the plant can make a growth that is at all vigorous. ${ }^{125}$ The presence of nitrates or other available nitrogen compounds in the soil depresses nodule formation.

Isolation of organism from nodules. Harrison and Barlow ${ }^{126}$ describe in detail the method of isolation and cultivation of the organism.

A medium sized nodule, appearing young and sound, is selected. It is cut off so as to leave 2 to $3 \mathrm{~mm}$. of the root on both sides to permit handling it with forceps. The nodule is then washed, rinsed in distilled water and dropped into a sterilizing liquid containing 1 gram $\mathrm{HgCl}_{2}$ and $2.5 \mathrm{cc}$. c. p. $\mathrm{HCl}$ in $500 \mathrm{cc}$. of water. The nodule is well shaken in the solution for 3 to 4 minutes, then washed three times in sterile distilled water. It is then covered with about 1 ec. of sterile distilled water and crushed with a sterile, heavy glass rod. Two or three drops of the cloudy suspension are placed into a test tube of the agar medium, which has previously been liquefied and cooled to $45^{\circ} \mathrm{C}$. A second tube of agar is then inoculated with five drops from the first; a third tube is inoculated from the

${ }^{123}$ Hiltner, L. Die Bindung von freiem Stickstoff durch das Zusammenwirken von Schizomyceten und von Eumyceten mit höheren Pflanzen. Lafar's Handb. techn. Mykol. 3: 24-70. 1904.

${ }^{124}$ Bryan, O. C. Effect of reaction on growth, nodule formation and calcium content of alfalfa, alsike clover and red clover. Soil Sci. 15: 23-35. 1923.

125 Jones, F. R., and Tisdale, W. B. Effect of soil temperature upon the development of nodules on the roots of certain legumes. Jour. Agr. Res. 22: 17-31. 1921.

${ }^{126}$ Harrison and Barlow, 1907 (p. 127). 
second and a fourth tube from the third; the plates are poured and incubated at $20^{\circ}$ to $25^{\circ} \mathrm{C}$. The organism is isolated upon sterile agar slants or liquid media from a typical colony upon the plate, using the third and fourth plates and discarding the first two. The lens-shaped and pin-head colonies should be selected rather than the giant colonies. In case of questionable plates, replating may be necessary from the culture isolated. To keep the cultures in stock, one of the above agar media (ash or mannite agar) may be used.

Isolation from soil. The Bact. radicicola can readily spread through the soil ${ }^{127}$ and persist there for a long period of time. The bacteria move in the soil at a definite rate. ${ }^{128}$ Bact. radicicola can also be cultivated from the soil, although the specificity of the forms isolated by Nobbe and Hiltner and Gage ${ }^{129}$ has not been sufficiently demonstrated. The results of Greig-Smith concerning the great abundance of Bact. radicicola in the soil were not confirmed. The numbers of each strain in the soil depend upon the reaction of the soil, an acidity greater than $\mathrm{pH} 5.4$ being detrimental to the development of most strains; at a favorable reaction ( $\mathrm{pH} 5.4-6.8$, depending on strain), as many as 100,000 to $1,000,000$ cells of different strains may be found per gram of soil. ${ }^{130}$ Kellermann and Leonard ${ }^{131}$ could isolate the organism only from soils sterilized and previously inoculated. Lipman and Fowler ${ }^{132}$ isolated Bact. radicicola from soil, in which legumes have previously been grown, and demonstrated its ability to cause the formation of nodules on the roots of leguminous plants. Two media were employed: (1) 1000 grams of water, 10 grams maltose, 1 gram $\mathrm{K}_{2} \mathrm{HPO}_{4}, 1$ gram $\mathrm{MgSO}_{4}, 2$ to 3 drops each of 10 per cent solution of $\mathrm{NaCl}, \mathrm{FeCl}_{3}, \mathrm{MnSO}_{4}$, and $\mathrm{CaCl}_{2}$ and 15 grams of agar. (2) Soil extract, obtained by boiling one part of soil with three parts of water for one hour, then filtering and adding 15 grams of agar and 10 grams of maltose to 1 liter of the extract. A soil in which

${ }^{127}$ Ball, O. M. A contribution to the life history of Bacillus (Ps.) radicicola Beij. Centrbl. Bakt. II, 23: 47-59. 1909.

${ }^{128}$ Kellerman, K. F., and Fawcett, E. H. Movements of certain bacteria in soils. Science, 25: 806. 1907.

129 Nobbe, Hiltner and Schmid, 1895 (p. 134); Gage, G. E. Biological and chemical studies on nitrosobacteria. Centrbl. Bakt. II, 27: 7-48. 1910.

130 Wilson, J. K. Legume bacteria population of the soil. Jour. Amer. Soc. Agron. 18:911 -919. 1926.

131 Kellerman, K. F., and Leonard, L. T. The prevalence of Bacillus radicicola in soil. Science, n. s. 38:95-98. 1913.

${ }^{132}$ Lipman, C. B., and Fowler, L. W. Isolation of Bacillus radicola from soil. Science, N. S. 41: 256-259, 725. 1915. 
Vicia sicula has been grown a year before was used for plating out on these media. The capacity of the colonies developing on the plate to inoculate plants obtained from disinfected seed grown in sterile soil was then tested, and it was found that nearly half of the colonies were those of the organism in question.

Vogel and Zipfel ${ }^{133}$ demonstrated by agglutination tests, using highly potent immune serum, that the nodule bacteria can be readily isolated from the soil; this method is even more reliable than the clirect inoculation test, since, with the latter method, negative inoculation results are often obtained.

Colony appearance. The colonies appearing on the plate are either surface or deep colonies. The first are drop-like, watery, mucilaginous in appearance, gray-white to pearly white in color, glistening, and semitranslucent to opaque. The edges are smooth and even; they frequently attain a size of $1 \mathrm{~cm}$. or more in diameter. The deep colonies are small, lens or spindle shaped, with smooth and even edges, opaque, granular in structure, and cream colored to chalky white. They slowly increase in size, eventually appearing on the surface, when growth becomes rapid. When first isolated, colonies may not appear before 6 to 14 days. Some races grow much faster than others, as in the case of Pisum, Vicia, Lupinus, Trifolium, Melilotus, and Medicago. To the slow growers belong the Vigna (cowpea), Glycine (Soja, soybean), and others (No. 46, Pl. VIII).

Morphology and life cycle of organism. The organism varies greatly in size and shape in the nodule. Many small, oval forms, described by Beijerinck as swarmers, and normal rods are found together with a few large club-shaped or branching forms (bacteroids) in the young nodules. In the old, decomposing nodule, the branching forms are extremely vacuolated, showing small, oval, deep staining bodies within. ${ }^{134}$ These bodies may be the motile swarmers or the branching form dividing into bacilli.

In pure cultures, the organism forms minute short rods, motile when young by means of flagella. ${ }^{135}$ The bacteroids may be produced also

${ }^{133}$ Vogel, J., and Zipfel, H. Beiträge zur Frage der Verwandtschaftsverhältnisse der Leguminosenknöllchenbakterien und deren Artbestimmung mittels serologischen Untersuchungsmethoden. Centrbl. Bakt. II, 54: 13-34. 1921.

${ }^{134}$ de Rossi, G. Über die Mikroorganismen welche die Wurzelknöllchen der Leguminosen erzeugen. Centrbl. Bakt. II, 18: 289-314, 481-489. 1907.

135 Barthel, Chr. Die Giesseln des Bacterium radicicola (Beij.). Ztschr. Garungsphys. 6: 13.1917. 
on artificial culture media in the presence of acid phosphate, ${ }^{136}$ sodium succinate and glycerol, ${ }^{137}$ caffeine ${ }^{138}$ and cumarine. ${ }^{139}$ According to Barthel, ${ }^{140}$ caffeine and other vegetable alkaloids, like guanidine, pyridine and chinoline, will stimulate the formation of involution forms in pure culture; he suggested, therefore, that the formation of these so-called bacteroids in root nodules is due to the presence of alkaloids in the plant. The bacteroids are never so large and numerous on the artificial culture media as in a young nodule; they are produced, either in the medium, or in the nodule due to specific nutrition or to unfavorable conditions; in that stage they are hardy and multiply rapidly. According to Zipfel, the branching forms are not degeneration forms, but may be looked upon as a normal and necessary stage in the life of the organism with specific biological functions; they are formed from rods and change again into rods when inoculated into proper media.

Five stages in the life cycle of the Bact. radicicola, through which it passes under cultural conditions, were recognized. ${ }^{141}$

1. Non motile, pre-swarmer form, obtained in 4 to 5 days when a culture of the organism is placed in a neutral soil solution.

2. Larger, non-motile coccus. The pre-swarmer coccoid changes in the presence of saccharose, certain other carbohydrates and phosphates, by increasing in size until the diameter has doubled.

3. Motile, swarmer stage, when the cell becomes ellipsoidal and develops high motility.

4. Rod-form, as a result of the further elongation of the swarmer, with decreasing motility.

5. Vacuolated stage. When available carbohydrates become exhausted or the organism is placed in a neutral soil extract, the cell becomes highly vacuolated and the chromatin divides into a number of bands. Finally these bands become rounded off and escape from the rod as the coccoid pre-swarmer. The preswarmer stage is usually formed from normal rods in calcareous soils, when

136 Stutzer, A. Die Bildung von Bakteroiden in künstlichen Nährboden. Centrbl. Bakt. II, 7: 897-912. 1901.

${ }^{137}$ Buchanan, R. E. The bacteroids of Bacillus radicicola. Centrbl. Bakt. II, 23: 59 91. 1909.

138 Zipfel, H. Beiträge zur Morphologie und Biologie der Knnöllchenbakterien der Leguminosen. Centrbl. Bakt. II, 32: 97-137. 1912.

${ }^{139}$ Fred, 1911 (p. 127).

${ }^{140}$ Barthel, C. Contribution à la recherche des causes de la formation des bactéroides chez les bacteries des Legumineuses. Ann. Inst. Past. 35: 634-647. 1921.

141 Bewley, W. F., and Hutchinson, H. B. On the changes through which the nodule organism (Ps. radicicola) passes under cultural conditions I Iotur. Agr. Sci. 10: 144-162. 1920. 
calcium or magnesium carbonates are added to the medium, or under anaerobic conditions. Acid soils cause the production of highly vacuolated cells and eventually kill the organism. These studies need further confirmation.

Motility. In young agar slants, the organisms are found to be very motile. Owing to the slime produced by the organism, the demonstration of flagella is very difficult; this was the reason for considerable disagreement among the different investigators. It has come to be recognized, ${ }^{142}$ however, that the nodule bacteria possess two types of flagellation: peritrichous and monotrichous. Differences, however, have been reported even for a single strain. The soybean organism was reported ${ }^{143}$ by some as possessing peritrichic flagellation, but by most other workers ${ }^{144}$ as monotrichous. The differences thus obtained were due either to the fact that cultures of various ages were employed or different types of bacteria exist, even for the same plant (as Soja $\max )$, in different parts of the world. ${ }^{145,146}$

For staining of flagella, the following modification of the Loeffler's stain may be used:

\section{Solution $A$}

Ferric chloride $(1: 20$ a parts

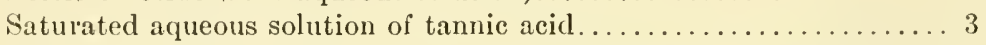

This solution improves with age; it should be at least a week or two old and should be filtered before using.

Solution B

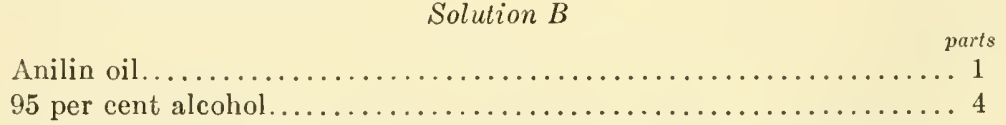

The bacterial suspension is allowed to air-dry on a clean cover glass. About 5 drops of solution $\mathrm{A}$ are then placed on the cover glass, followed immediately by 1 to 2 drops of solution B. The combination is allowed to act at room temperature for 2 minutes and is then washed in distilled water. The stain (30 parts of saturated alcoholic solution of methylene blue, 13 parts of solution B as mordant and 100 parts of $1: 10,000 \mathrm{KOH}$ solution) is applied for 2 minutes.

${ }_{142}$ Hansen, R. Note on the flagellation of the nodule organisms of the Teguminosae. Science. N. S. 50: 565-569. 1919.

${ }^{143}$ Wilson, J. K. Physiological studies of Bacillus radicicola of soybean (Soja max Piper) and of factors influencing nodule production. Cornell Univ. Exp. Sta. Bul. 386. 1917.

${ }_{144}$ Wright, 1925 (p. 127).

145 Shunk, I. V. Notes on the flagellation of nodule bacteria of leguminosae. Jour. Bact. 6: 239-246. 1921; Ibid. 5 : 181-1S7. 1920.

140 Fred and Davenport, 1918 (p. 582). 
Löhnis and Hansen and Shunk observed the two distinct types of flagellation referred to above. In the single flagellate types (monotrichous), the flagellum is not strictly polar but is usually attached to the corner. However, organisms obtained from nodules of different species of plants belonging to one genus have the same type of flagellation.

Physiology of nodule bacteria. The different strains of Bact. radicicola are strictly aerobic.

Maltose, sucrose, glucose and mannite offer the best sources of carbon; lactose, dextrin and glycerol can also be utilized. According to Beijerinck, separate carbon and nitrogen sources (asparagine, ammonium sulfate, sodium or potassium nitrate) are required. Lauren $t^{147}$ first showed that the organism can be cultivated on nitrogenfree media, containing 0.1 per cent $\mathrm{KH}_{2} \mathrm{PO}_{4}, 0.01$ per cent $\mathrm{MgSO}_{4}$ and 5 to 10 per cent of an available energy source. When grown on such a medium, it will fix atmospheric nitrogen. ${ }^{148}$

The presence of nitrates in the medium and in the soil diminishes nitrogen-fixation by the organism. This has been demonstrated by Nobbe and Richter ${ }^{149}$ and others, and it was found to be due not to any injurious influence of the nitrate but to the fact that the plant, capable of obtaining its nitrogen from the soil, represses the development of the nodules.

A condition is found here very similar to the influence of nitrates upon nitrogen fixation by non-symbiotic bacteria. Prucha ${ }^{150}$ found that the addition of $\mathrm{KNO}_{3}, \mathrm{Ca}\left(\mathrm{NO}_{3}\right)_{2}, \mathrm{NH}_{4} \mathrm{Cl}$, or peptone to sandy soil, at the rate of 0.25 gram of the salts to 300 grams air-dry soil, had an inhibiting effect on nodule development of Canada field pea, while $\mathrm{MgSO}_{4}, \mathrm{KH}_{2} \mathrm{PO}_{4}, \mathrm{Ca}\left(\mathrm{H}_{2} \mathrm{PO}_{4}\right)_{2}$ and tannic acid, especially in low concentrations, had a beneficial effect.

The optimum reaction for the growth of the bacteria is $\mathrm{pH} 5.5$ to 7.0 , depending on the nature of the plant, with limiting reactions of $\mathrm{pH}$ 3.2 to 5.0 on the acid side, and $\mathrm{pH} 9.0$ to 10.0 on the alkaline. The optimum temperature is $25^{\circ}$ to $28^{\circ} \mathrm{C}$. with $0^{\circ}$ and $50^{\circ}$ as the limits.

${ }^{147}$ Laurent, E. Sur le microbe des nodosités des Légumineuses. Compt. Rend. Acad. Sci. 111: 754. 1890; Ann. Inst. Past. 4: 722. 1890; 5: 105-139. 1891.

${ }^{148}$ Fred, 1910 (p. 120).

${ }^{149}$ Nobbe, F., and Richter, L. Über den Einfluss des Nitratstickstoffs und der Humussubstanzen auf den Impfungserfolg bei Leguminosen. Landw. Vers. 56: 441-448. 1902; 59: 167-174. 1904.

${ }^{150}$ Prucha, M. J. Physiological studies of Bacillus radicicola of Canada field pea. Cornell Univ. Agr. Exp. Sta. Mem. 5, 1915. 
The nodule bacteria can be modified in their ability to grow under unfavorable conditions; a character, such as tolerance to dyes, may be modified relatively quickly (Burke and Burkey).1.51 However, the character which has been lost as a result of cultivation on artificial media is quickly regained when the culture is returned to the soil.

Specific differentiation. Three groups of methods are usually employed for the specific differentiation of the nodule bacteria: (1) plant inoculation, (2) morphological and cultural studies, (3) serological and immunological reactions. Although Nobbe, Hiltner and Schmid ${ }^{152}$ came to the conclusion that the bacteria in the nodules of all legumes are strains of the same organism, the fact was soon brought to light that not all the bacteria obtained from the nodules of various plants can cross-inoculate and produce nodules on the roots of other leguminous plants. These plants could readily be divided into several closely related groups, the plants belonging to each group having their own specific organism, with cross inoculation taking place only by the members of each group.

Hiltner and Störmer ${ }^{153}$ came to recognize, on the basis of morphological and cultural studies, two groups of nodule bacteria: (1) Bact. radicicola on Pisum, Vicia, Lathyrus, Phaseolus, Trifolium, etc., and (2) Bact. beijerinckii on Lupinus, Ornithopus, Glycine. The former grows well on certain gelatin media and readily produces branching forms, while the latter grows poorly on gelatin media. It was soon found that a further subdivision would have to be made, Pisum, Trifolium, Medicago and Lupinus bacteria being taken as representative types.

Zipfel ${ }^{154,155}$ made use of agglutination tests and concluded that nodule bacteria were not varieties of the same species, but that distinct species existed. Six groups were thus distinguished: (1) Lupinus, (2) Trifolium, (3) Medicago, (4) Pisum, (5) Faba, and (6) Phaseolus.

${ }^{151}$ Burke, V., and Burkey, I. Modifying Rhizobium radicicolum. Soil Sci. 20: $143-146.1925$.

${ }_{152}$ Nobbe, F., Hiltner, L., and Schmid, E. Versuche über die Biologie der Knnöllchenbakterien der Leguminosen, insbesondere über die Frage der Arteinheit derselben. Landw. Vers. Sta. 45: 1 27. 1895.

${ }^{153}$ Hiltner, L., and Störmer, K. Neue Untersuchungen über die Wurzelknöllchen der Leguminosen und deren Erreger. Arb. k. Gesundhtsamt., Biol. Abt. 3: 151-307. 1903

${ }_{154}$ Zipfel, 1912 (p. 131).

${ }^{155}$ Vogel and Zipfel, 1921 (p. 130). 
On the basis of serological investigation, Klimmer and Krüger ${ }^{156}$ formed nine groups of legume bacteria: (1) Lupinus and Ornithopus, (2) Melilotus, Medicago, and Trigonella, (3) Vicia (V. sativa), (4) Pisum, (5) Vicia faba, (6) Trifolium pratense, (7) Phaseolus vulgaris, (8) Soja hispida, and (9) Onobrychis sativa.157 Other serological studies ${ }^{158}$ confirmed the general conclusion that the nodule bacteria include more than one organism.

The agar test-tube method may be used for the study of nodule formation on the roots of legumes by different strains of bacteria. ${ }^{159}$ On the basis of the cultural method, the nodule bacteria were divided into the following groups: (1) alfalfa organism inoculating also Medicago lupulina, M. denticulata and Melilotus, (2) clover organism inoculating all species of Trifolium, (3) vetch and garden pea, (4) cowpea, (5) soybean, (6) garden bean. Burrill and Hansen ${ }^{160}$ demonstrated, by cross-inoculation studies, eleven kinds of bacteria divided into three groups, namely: (1) thin, scant, slow growth on ash-agar slant; little gum formed, flagella easily demonstrated-Vigna, Cassia, Acacia, Glycine, etc.; (2) more rapid and more abundant growth; glistening, opaque and pearly white; considerable gum formed which interferes with attempt of staining flagella-Melilotus, Medicago, Trigonella; (3) very fast, spreading growth; watery and semi-translucent; very slimy and sticky, due to excess of gum-Vicia, Pisum, Lens, Lathyrus, Trifolium, Phaseolus and Strophostyles.

Löhnis and Hansen ${ }^{161}$ divided the bacteria of the leguminous plants into two groups, the representatives of which differ both morphologically and physiologically. The first group shows all the features of Bact. radicicola; it is peritrichic, grows relatively fast on agar plates and

${ }^{156}$ Klimmer, M., and Krüger, R. Sind die bei den verschiedenen Leguminosen gefundenen Knöllchenbakterien artverschieden? Centrbl. Bakt. II, 40: 256-265. 1914; Klimmer, M. Zur Artverschiedenheit der Leguminosen-Knöllchenbakterien festgestellt auf Grund serologischer Untersuchungen. Centrbl. Bakt. II, 55: 281-283. 1922.

${ }^{157}$ Simon, J. Über die Verwandtschaftsverhältnisse der Leguminosen-Wurzelbakterien. Centrbl. Bakt. II, 41: 470-479. 1914.

${ }^{158}$ Stevens, J. W. Can all strains of a specific organism be recognized by agglutination? Jour. Inf. Dis. 33: 557. 1923; A study of various strains of Bacillus radicicola from nodules of alfalfa and sweet clover. Soil Sci. 20: 45-66. 1925.

${ }^{159}$ Garman, H., and Didlake, M. Six different species of nodule bacteria. Ky. Agr. Exp. Sta., Bul. 184: 343-363. 1914.

${ }_{160}$ Burrill and Hansen, 1917 (p. 126).

${ }^{161}$ Löhnis and Hansen, 1921 (p. 126). 
changes milk characteristically; it produces nodules on the roots of clover, sweet clover, alfalfa, vetch, pea, navy bean, lupine, black locust, Amorpha and Strophostyles. The second group is characterized by monotrichic flagellation, comparatively slow growth on agar plates, and inability to cause a marked change in milk. It has been isolated from the soybean, cowpea, lima bean, peanut, beggarweed, Acacia, Genista Cassia and Amphicarpa. However, they do not suggest separating the organism into two new species before the complete life history of the two groups is known.

Bergey, ${ }^{162}$ following the system proposed by the Society of American Bacteriologists placed the Bact. radicicola in a separate genus "Rhizobium," and separated the different forms into two species: (1) Rh. leguminosum Frank, inoculating Pisum, Vicia, Lathyrus, etc., (2) Rh. radicicolum Beij. of Trifolium, Phaseolus, etc.

The following is a list of leguminous plants, divided on the basis of interinoculation. ${ }^{163}$ The different members in any one group are those which can be inoculated by the strain of the Bact. radicicola specific for that group.

\section{Group I:}

Trifolium pratense, red clover

Trifolium hybridum, alsike clover

Trifolium alexandrinum, bersem clover

Trifolium incarnatum, crimson clover

Trifolium repens, white clover

Trifolium medium, zigzag, or cow clover

Group II:

Melilotus alba, white sweet clover

Melilotus officinalis, yellow sweet clover

Mcdicago sativa, alfalfa

Medicago hispida, bur clover

Mcdicago lupulina, black medick, or yellow trefoil

Trigonclla foenum-graceum, fenugreek
Group III:

Vigna sinensis, cowpea

Cassia chamaecrista, partridge pea

Arachis hypogoea, peanut

Lespedeza striata, japan clover

Muenna utilis, velvet bean

Baptisia tinctoria, wild indigo

Desmodium eaneseens, tick trefoil

Acacia armata, acacia

Genista tinetoria, dyer's greenwood

Phascolus lunatus, lima bean

Group IV:

Pisum sativum arvense, Canada field pea

Vicia villosa, hairy vetch

Vicia sativa, spring vetch

Vicia faba, broad bean

Lens esculenta, lentil

Lathyrus latifolius, sweet pea

162 Bergey, 1923 (p. x).

${ }^{163}$ Hansen, R. Symbiotic nitrogen-fixation by leguminous plants with special reference to the bacteria concerned. Scientific Agriculture (Canada) 1: 59-62. 1921; Whiting, A. L., Fred, E. B., and Helz, G. E. A study of the root nodule bacteria of wood's clover (Dalea alopecuroides). Soil Sci. 22:467-476. 1926. 
Group V:

Glycine hispida (Soja max), soybean

Group VI:

Phaseolus vulgaris, garden bean

Phaseolus multiflorus, scarlet runner bean

Group VII:

Lupinus percnnis, lupine

Ornithopus sativa, seradella

Group VIII :

Amphicarpa monoica, hog peanut
Group IX:

Amorpha canescens, lead plant

Group X:

Strophostylcs helvola, trailing wild bean

Group XI:

Robinia pseudo-acacia, black or common locust

Group XII:

Dalea alopecuroides, wood's clover

An interchangeability between the soy bean and cowpea has been demonstrated $^{164}$ in the laboratory, however. Field tests from other sources do not indicate such relationship. Various explanations for the specificity, based on soil reaction, climate, etc., have been proposed. Burrill and Hansen properly suggested that it may be a case of specific enzymes produced by the bacteria or of differences in the root-sap, which cannot be detected by chemical methods. So far we have to depend on cross inoculation and serological tests for the specific separation. No morphological differences have yet been established, except the division into two groups suggested by Löhnis and Hansen; we do not know whether we are dealing here with different species or mere biological races.

The application of serological reactions has brought out the fact that various strains of bacteria may form nodules on the same plant, but only one serological type is found in the same nodule. ${ }^{165}$ Other investigators ${ }^{166,167}$ also found that not all strains of Bact. radicicola of one leguminous plant are identical. This suggested the existence of various biotypes even for the same plant. The existence of two general types of the organism which can form nodules on the soy bean, identical morphologically but different physiologically and especially serologically, has been demonstrated. ${ }^{167}$

These results are probably due to the fact that a bacterial culture is actually a population in which the different cells have variable properties. Although morphology may not be sufficient to demonstrate any

${ }^{164}$ Leonard, L. T. Nodule production kinship between the soybean and cowpea. Soil Sci. 15: 277-283. 1923.

${ }^{165}$ Bialosuknia, W., and Klott, C. Badania nad Bakterium radicicola. Roczn. Nauk. Rolniczych. 9: 288-335. 1923.

${ }_{168}$ Stevens, 1923-25 (p. 135).

${ }^{167}$ Wright, 1925 (p. 127). 
differences between the members of the population, physiological reactions and the even more sensitive serological reactions can bring out these variations. This explains the modification of a strain when grown on artificial culture media or as a result of repeated passage through the host plant. It also suggests the possibility of improving or deteriorating a strain by the proper selection of the types of cell. This phenomenon explains the increase in activity and fixation of nitrogen by repeated passage through plants. ${ }^{168}$ The process of adaptation to a particular host plant is longer in case of vegetatively weak organisms than for vegetatively strong organisms.

A detailed study of the chemistry of nitrogen fixation by nodule bacteria (588) and the artificial inoculation of soil with bacterial cultures (817) will be discussed elsewhere.

Nodule formation by non-leguminous plants. In addition to the legumes, a number of non-legumes are found possessing nodules on their roots. Of these, most attention has been paid to Ceanothus (red-root), Elaeagnus (silver berry), Alnus (alder), Podocarpus, Cycas and Myrica (sweet gale).

At first these nodules were thought to be of fungus origin. The nodules of Alnus, Elaeagnus and Ceanothus were found $d^{169-171}$ to be caused by bacteria belonging to the Bact. radicicola group and capable of fixing nitrogen. In some plants at least (Myrica) the organism is of the nature of an Actinomyces. ${ }^{172}$ Coriaria japonica produces nodules similar to those produced by the Alder, due probably to an Actinomyces (Act. myricae according to Peklo) in both cases. ${ }^{173}$ In the roots of cycads, Bact. radicicola, Azotobacter and an alga (Anabaena) were demon-

${ }^{168}$ Wunschik, H. Erhöhung der Wirksamkeit der Knöllchenerreger unserer Schmetterlingsblütler durch Passieren der Wirtpflanze. Centrbl. Bakt. II, 64: 395-445. 1925.

${ }^{169}$ Hiltner, L. Über die Bedeutung der Wurzelknöllchen von Alnus glutinosa für die Stickstoffernährung dieser Pflanze. Landw. Vers. Sta. 46: 153-161. 1896.

${ }_{170}$ Kellerman, K. F. Nitrogen-gathering plants. Yearb. Dept. Agr. U. S. A., 1910, 213-218.

171 Bottomley, W. B. The root nodules of Ceanothus americanus. Ann. Bot. 29: 605-610. 1915 .

${ }_{172}$ Arzberger, E. G. The fungous root-tubercles of Ceanothus americanus, Elaeagnus argentea, and Myrica cerifera. Mo. Bot. Gard. 21 Ann. Rpt.: 60-103, 1910.

${ }^{173}$ Shibata, K., and Tahara, M. Studien über die Wurzelknöllchen. Bot. Mag. Tokyo, 31: 157-182. 1917. 
strated. ${ }^{174}$ Burrill and Hansen ${ }^{175}$ came to the conclusion that the root-nodules of Ceanothus (C. americanus), Alnus, Cycas revoluta, and Myrica are not caused by Bact. radicicola. The evidence that Elaeagnus and Podocarpus nodules are caused by $B$. radicicola is not conclusive. It is still questionable whether nitrogen fixation by any of these plants takes place, ${ }^{176}$ although it is claimed ${ }^{176 a}$ that some plants (like Casuarina) are thus able to grow readily in very poor sandy soil. The question of symbiosis with fungi (mycorrhiza formation) is discussed elsewhere.

It is of interest to point out, in this connection, that there are leguminous plants, which do not form any nodules. These include Gymnocladus, Carcis, Gleditsia and the Cassias of the subfamily Caesalpinaceae.

Nodule formation in the leaves of some plants. A condition similar to nodule formation by bacteria on the roots of leguminous plants has been observed on the leaves of certain tropical plants, namely the Myrsinaceae, such as Ardisia, certain Rubiaceae, such as Pavetta and Grumilea. Koorders ${ }^{177}$ demonstrated the presence of either bacteria or fungi in the bloom bud hydathodes of nineteen species of tropical plants, representing six genera; a symbiotic relation was found to exist between the host plant and the microorganisms. Zimmermann ${ }^{173}$ was the first to show that the nodules on the leaves of the Rubiaceae (four species examined) are filled with bacteria. He also found nodules on the upper side of the leaf of Pavetta lanceolota and on the under side of $P$. angustifolia. The bacteria were present in chains and as longer forms. $P$. indica had even a greater number of nodules scattered over the whole surface of both sides of the leaf and formed dark green spots. The bacteria do not penetrate the cell but are found in the intra-cellular

${ }^{174}$ Spratt, E. R. The formation and physiological significance of root nodules in the Podocarpineae. Ann. Bot. 26: 801-814. 1912; The root nodules of the Cycadaceae. Ibid. 29: 619-626. 1915.

175 Burrill and Hansen, 1917 (p. 126).

${ }^{176}$ Miehe, H. Anatomische Untersuchung der Pilzsymbiose bei Casuarina equisetifolia nebst einigen Bemerkungen über das Mykorhizenproblem. Flora, 111-112: 431-449. 1918.

${ }_{176 a}$ Rao, R. A. Casuarina root nodules and nitrogen fixation. Madras Agr. Dept. Yearbook, 1923, 60-67.

${ }_{177}$ Koorders, S. H. Über die Blüthenknospen Hydathoden einiger tropischen Pflanzen. Ann. Jard. Bot. Buitenzorg, 14: 354-477. 1897.

178 Zimmermann, A. Über Bakterienknoten in den Blättern einiger Rubiaceen. Jahrb. wiss. Bot. 37: 1-11. 1902. 
spaces. An organism belonging to the mycobacteria (Mycob. rubiacearum) was isolated ${ }^{179}$ from the leaf nodules. The same organism was also isolated from Pavetta and other plants. Miehe ${ }^{180}$ isolated a rodshaped organism, Bac. foliicola, active in forming nodules on the leaves of Ardisia. It is a motile rod ( $1-2.5$ by $0.4-0.5 \mu)$ with peritrichic flagella and later changes into a branching form. These "bacteroids" may be foumd in the cells of the leaves and also on special media. The bacteria are already present in the seeds, between the embryo and the endosperm, so that the plants do not have to be inoculated anew with each new growth. In this respect they are similar to the endotrophic myeorrhiza of the Ericaceae which are considered elsewhere. When the young plants grow, the bacteria follow the growing tip to the new parts of the plant, as they develop. The bacteria are eventually found in the entire plant, where they develop in masses in the intracellular spaces. With the development of the fruit, the bacteria are enclosed in the embryo sack and remain with the seed. Miehe concluded that Bac. foliicola fixed nitrogen; he recognized this phenomenon as one of hereditary symbiosis. The bacteria forming nodules on the leaves of Pavetta indica and Chomelia asiatica enter the stomata of the leaf, live there and fix the nitrogen from the air. The bacteria are found at all the life stages of the plant, symbiosis being developed to a much greater extent than in the Leguminosae and being hereditary in nature. Plants freed from bacteria, by warming the seed for 25 minutes at $50^{\circ} \mathrm{C}$, develop very slowly and suffer from lack of nitrogen. The bacteria are aerobic, rod-shaped cells. ${ }^{181}$

The presence of nitrogen-fixing bacteria in the swollen glands on the points of the leaves of Dioscorea macroura has also been demonstrated. ${ }^{182}$

${ }^{179}$ von Faber, F. C. Die Bakteriensymbiose der Rubiaceen. Jahrb. wiss. Bot. 54: 243-264. 1914; also Ibid. 51: 285-295. 1912.

${ }^{180}$ Miehe, H. Weitere Untersuchungen über die Bakteriensymbiose bei Ardisia crispa. Jahrb. wiss. Bot. 53: 1-54. 1913; 58: 29. 1917. Ber. Bot. Gesell. 29: 156. 1911;34: 576. 1916.

181 Rao, K. A. A preliminary account of symbiotic nitrogen fixation in nonleguminous plants, with special reference to Chomelia asiatica. Agr. Jour. India, 18: 132-143. 1923.

${ }^{182}$ Orr, M. V. Nitrogen fixation in leaf glands. Notes from the Roy. Bot. Gard., Edinburgh, 14: 57-72. 1924. 


\section{CHAPTER V}

Heterotrophic, Aerobic Bacteria Requiring Combined Nitrogen

General classification. The heterotrophic bacteria requiring combined nitrogen comprise the large numbers of organisms developing on the common plate used for counting bacteria and probably a still greater number of organisms, which develop very slowly or do not develop upon the plate at all. Morphologically they consist of spore-forming and non-spore forming rods, cocci and spirilli. Physiologically they take part in numerous soil processes, especially in the decomposition of both simple and complex organic substances in the soil including proteins, their derivatives, and other nitrogen compounds; celluloses, pentosans, and other complex and simple carbohydrates; fats and various other ingredients of natural organic matter. Morphology alone is an insufficient basis for the classification of these organisms. Just as in the general classification, one must consider the various physiological processes in which these bacteria are concerned. The system used here is far from satisfactory, due to insufficient lnowledge concerning the organisms themselves. This system is bound to change with the advance of our knowledge.

The cellulose-decomposing bacteria, the nitrate and sulfate-reducing bacteria, and the urea-decomposing organisms are treated separately, because of their specific physiology and the special methods which are essential for their isolation, cultivation and study. Some of these, especially some of the urea-decomposing forms and nitrate-reducing bacteria, are no doubt modifications of the more general groups considered here. As a general basis of classification, the following one may be used conveniently:

I. Aerobic bacteria:

1. Spore-forming rods

2. Non-spore forming rods

3. Cocci

4. Spirilli

II. Anaerobic bacteria

The difference between the aerobism and anaerobism of soil bacteria is largely one of degree and not of kind, as will be shown later. The 
anaerobic bacteria, especially the obligate forms, will be treated separately because of their peculiar physiology. Of the two groups of aerobic rod-shaped bacteria, the non-spore formers are more numerous than the spore-formers. The latter usually become very active when fresh organic matter, rich in proteins, is added to the soil but they soon sporulate and generally remain in the soil in that condition until another favorable period arrives. The non-spore forming bacteria and cocci, living upon the colloidal film surrounding the inorganic soil particles, make up the bulk of the numbers of the soil population. Most of these organisms have not yet been described at all or only very insufficiently. Their physiological activities are also insufficiently studied and their rôle in soil processes is little understood.

Spore-forming bacteria. The spore-forming, aerobic, heterotrophic bacteria have been studied more completely than the non-spore formers or the anacrobic bacteria. This is due to the fact that they readily develop on the common gelatin and agar media, forming large characteristic colonies. When a short period of incubation is used, they are found to be among the most numerous organisms developing on the plate. Houston ${ }^{1}$ found in 1898 four common spore-forming bacteria in the soil: Bac. mycoides, Bac. subtilis (which was, according to Conn, ${ }^{1}$ Bac. cereus), a "granular bacillus," equivalent to Bac. megatherium, and Bac. mesentericus representing a group composed of a number of illdefined, small spore-forming organisms. ${ }^{2}$ Houston states that Bac. mycoides is present in the vegetative stage and as spores. Others ${ }^{3}$ found the spore-forming bacteria to be present in the soil only in the

1 Houston, 1898 (p. 14).

${ }^{2}$ Conn, H. J. Soil flora studies. IIl. Spore-forming bacteria in soil. N. Y. Agr. Exp. Sta. Tech. Bul. 58. 1917.

${ }^{3}$ Conn, H. J. Are spore-forming bacteria of any significance in soil under normal conditions? N. Y. Agr. Exp. Sta. Tech. Bul. 51. 1916.

\section{PLATE VIII}

43. Bacterium phlë: A, colony of organism on washed agar containing inorganic salts, with petroleum vapor as the only source of energy; $B$, colony on agar with inorganic salts and 1 per cent glycerol (after Söhngen and de Rossi).

44. Deep agar colonies of anaerobic bacteria: colonies of Bac. perfringens in nitrate glucose agar (from Weinberg and Seguin).

45. Deep agar colonies of anaerobic bacteria: Bac. putrificus in glucose agar, 48 hours old (from Weinberg and Seguin).

46. Ash-agar plate showing the organism forming nodules on the roots of $a$, Genista tinctoria, 25 days old; $b$, Pisum sativum, 7 days old (from Burrill and Hansen). 


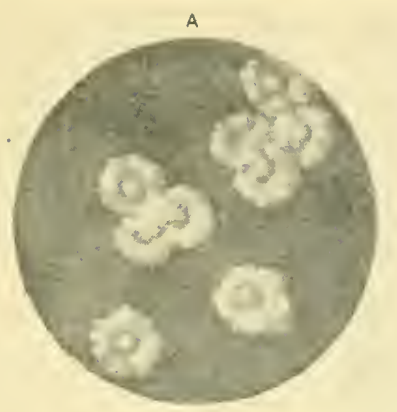

B

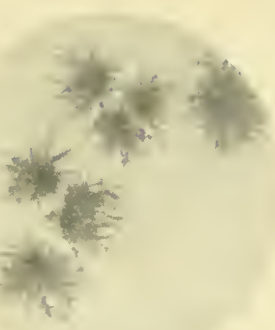

43
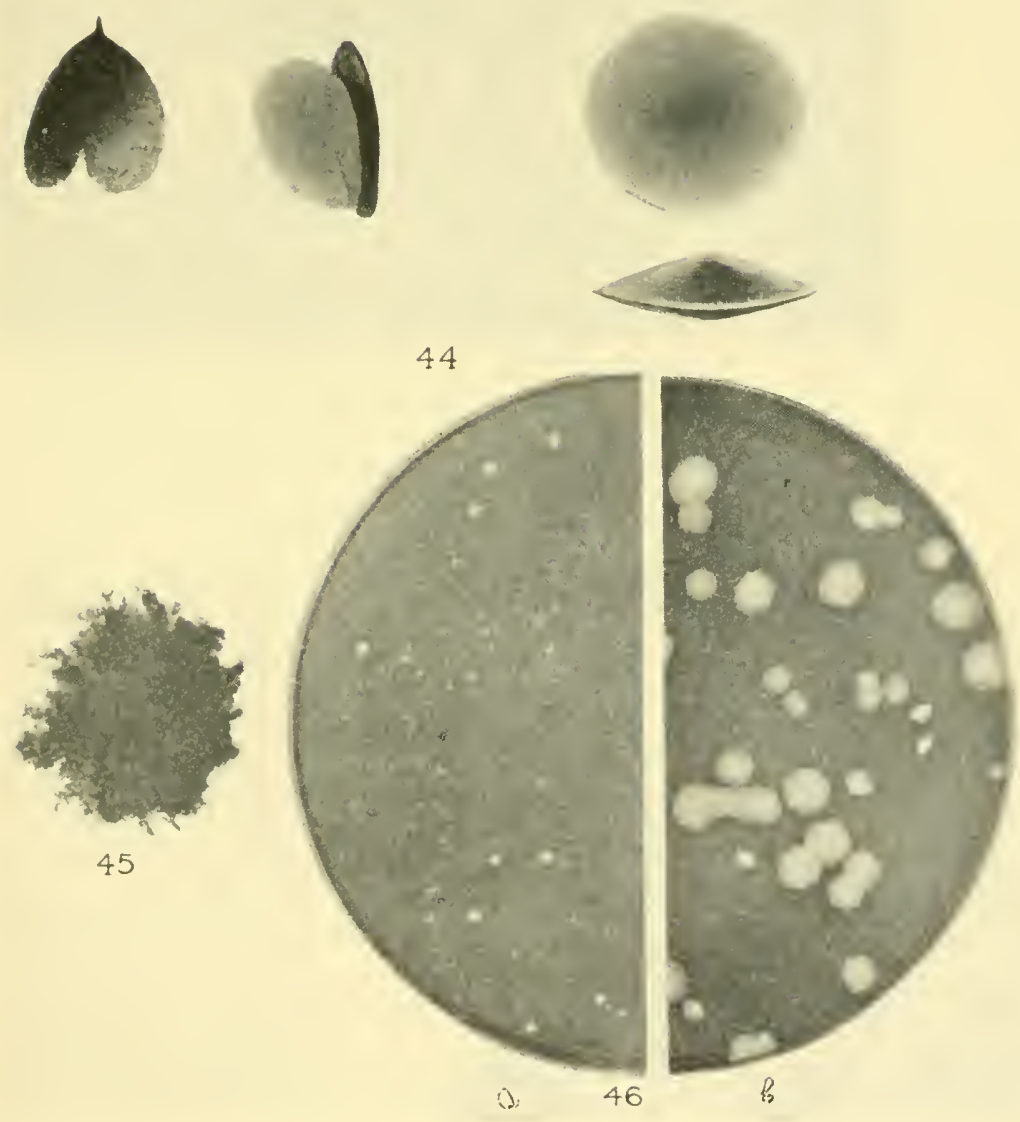

form of spores. The spores vegetate in the presence of a large amount of organic matter and an excess of moisture. ${ }^{4}$

A detailed study of the spore-forming bacteria has been made by various investigators ${ }^{5-8}$ and recently by Ford $^{9}$ and associates, whose work is used as a basis for the following classification.

\section{Classification of Spore-forming Bacteria ${ }^{9}$}

\section{Group I. Subtilis group}

Small, homogeneous, sluggishly motile organisms measuring 0.4 by 1.5 to $2.5 \mu$. No threads on glucose agar. Central or excentric spores, oval, measuring 0.5 by 0.75 to $0.88 \mu$, often retaining terminal tags of protoplasm. Growth on solid media hard and penetrating, with tenacious scums on fluid media.

Bacillus subtilis Cohn

Bacillus subtilis-viscosus Chester

(Characterized by viscosity)

\section{Group 11. Mesenlericus group}

Small, homogeneous, actively motile organisms measuring 0.5 by 2 to $4 \mu$. They often produce long threads on glucose agar. The spores measure 0.5 by 1 to $1.12 \mu$, oval and retaining terminal tags of protoplasm. The growth on solid media is a soft pultaceous mass with tendency to wrinkle; on fluid media, growth is in the form of a friable easily-broken scum.

Bacillus vulgatus (Flügge) Trevisan

(Bacillus mesentericus vulgatus Flügge)

Bacillus mesentericus (Flügge) Migula

(Bacillus mesentericus fuscus Flügge)

Bacillus aterrimus Lehmann \& Neumann

(Bacillus mesentericus niger Lunt)

Bacillus globigii Migula

(Bacillus mesentericus ruber Globig)

${ }^{4}$ Winogradsky, 1924 (p. 542).

${ }^{5}$ Gottheil, O. Botanische Beschreibung einiger Bodenbakterien. Centrbl. Bakt. II, 7: $430-435,449-465,481-497,529-544,582-591,627-637,680-691,717-730$. 1901 .

${ }^{6}$ Neide, E. Botanische Beschreibung einiger sporenbildenden Bakterien. Centrbl. Bkt. II, 12: 1-32, 161-176, 337-352, 539-554. 1904.

${ }^{7}$ Chester, F. D. Observations on an important group of soil bacteria. Organisms related to Bacillus subtilis. Del. Agr. Exp. Sta., Rept. 15: 42-96. 1904. A review of the Bacillus subtilis group of bacteria. Centrbl. Bakt. II, 13: 737752. 1904.

${ }^{8}$ Holzmüller, K. Die Gruppe des Bacillus mycoides Flügge. Centrbl. Bakt. II, 23: 304-354. 1909.

${ }^{9}$ Ford, W. W., Lawrence, J. S., Laubach, C. A., and Rice, J. L. Studies on aerobic spore-bearing non-pathogenic bacteria. Jour. Bact. 1: 273-320, 493-534. 1916. 
Bacillus niger Migula

(Bacillus lactis niger Gorini)

Bacillus mesentericus var. flavus

Bacillus panis Migula

(Bacillus mesentericus panis viscosus Vogel)

(Motility lost by capsule formation)

\section{Group III. Cohaerens-simplex group}

Motile organisms somewhat larger than either Bacillus subtilis or Bacillus mesentericus, measuring 0.37 to 0.75 by 0.75 to $3 \mu$. Thicker and longer forms on glucose agar. Involution and shadow forms are common and appear early. The spores are cylindrical, measuring 0.56 to 0.75 by 1 to $1.5 \mu$. A soft mass is formed on solid media; turbidity with little or no seum on liquid media.

Bacillus cohaerens Gottheil

Bacillus simplex Gottheil

Bacillus agri Ford and associates

Bac. asterosporus and Bac. teres A. M. and Neide belong also to this group.

\section{Group IV. Mycoides group}

Large organisms with square ends growing in long chains. Single cells measure 0.5 by 3 to $6 \mu$. On glucose agar, the organisms are thicker and longer and are made up of globular bodies. Tendency for the organisms to grow in curves or spirals. The spores are central or excentric, round or oval to cylindrical, measuring 0.75 to 1 by 1 to $2 \mu$. Dry and penetrating growth on solid media; firm tenacious scum on liquid media.

Bacillus mycoides Flügge

Bacillus prausnitzii Trevisan

(Bacillus ramosus liquefaciens Prausnitz)

Bacillus adhaerens Ford and associates

(No motility)

\section{Group V. Cereus group}

Large, motile organisms with rounded ends, measuring 0.75 by 2.25 to $4 \mu$. Tend to grow in short chains. Thicker and longer on glucose agar, where protoplasm is converted into globular bodies. Central or excentric spores, cylindrical, measuring 0.5 to 0.75 by 1.12 to $1.5 \mu$. Spores retain protoplasm at one or both ends, often resembling enlarged subtilis or mesentericus spores. A soft pultaceous mass is formed on solid media, with tendency to fold or wrinkle; thick friable scum on liquid media.

Bacillus cereus Frankland (The Bac. ellenbachensis often referred to as an important soil organism belongs here).

Bacillus albolactus Migula

Bacillus cereus var. fluorescens Ford and associates

\section{Group VI. Megatherium group}

Very large, actively motile organisms, measuring 0.75 to 1.25 by 3 to $9 \mu$. Long forms are of ten produced; these spread out, lose their cytoplasm and show peculiar 
aggregations of protoplasm at the periphery. The protoplasm is rapidly converted into peculiar globular, highly refractile bodies, particularly on glucose agar. Shadow and transparent forms appear early. The spores are central, excentric or sub-terminal, oval to cylindrical, measuring usually 0.75 to 1.12 by 1.5 to $2 \mu$. Spores vary greatly in shape, being sometimes round, sometimes rectangular, often reniform. Growth on solid media as thick pultaccous mass, on liquid media as turbidity with little or no scum formation.

Bacillus megatherium De Bary

Bacillus petasites Gottheil

Bacillus ruminatus Gottheil

\section{Group VII. Round terminal spored group}

Small, actively motile organisms, measuring 0.5 to 0.75 by 1.5 to $3 \mu$, often forming long threads in old cultures. Protoplasm homogeneous. Spores subterminal or terminal, round, thicker than the organisms from which they spring, measuring 1 to $1.5 \mu$ in diameter.

Bacillus pseudotetanicus (Kruse) Migula

(Bacillus pseudotetanicus var. aerobius Kruse)

Bacillus fusiformis Gottheil

\section{Group VIII. Cylindrical terminal spored group}

Small, thin, actively motile organisms, measuring 0.37 to 0.5 by 2.5 to $4 \mu$. Slightly larger on glucose agar but no change in character of protoplasm. Spores terminal, cylindrical, measuring usually 0.75 by 1.12 to $1.5 \mu$.

Bacillus circulans Jordan

Bacillus brevis Migula

Bacillus terminalis Migula

\section{Group IX. Central spored group}

Lung, actively motile organisms with pointed ends, measuring 0.37 to 0.5 by 1.12 to $4 \mu$. Slightly larger on glucose agar, but no change in character of protoplasm. The spores develop in the middle of the rods, which become spindleshaped. The spores are large, cylindrical, measuring 0.6 to 0.8 by 1.12 to $1.5 \mu$.

Bacillus centrosporus Ford and associates

Bacillus laterosporus Ford and associates

A summary of the characteristic points of the spore-forming bacteria, recognized by A. Meyer and his associates is given in table $13{ }^{10}$

Occurrence of aerobic, spore-forming bacteria in the soil. By the use of gelatin plates the three most common spore-forming bacteria in the soil can be readily recognized by speed of gelatin liquefaction and type of colony. Except for the non-spore forming Bact. fluorescens, Bac. mycoides is the most rapid liquefier; it produces large filamentous to rhizoid colonies. Bac. cereus liquefies gelatin almost as rapidly as Bac.

${ }^{10}$ Stapp, 1920 (p. 213). 


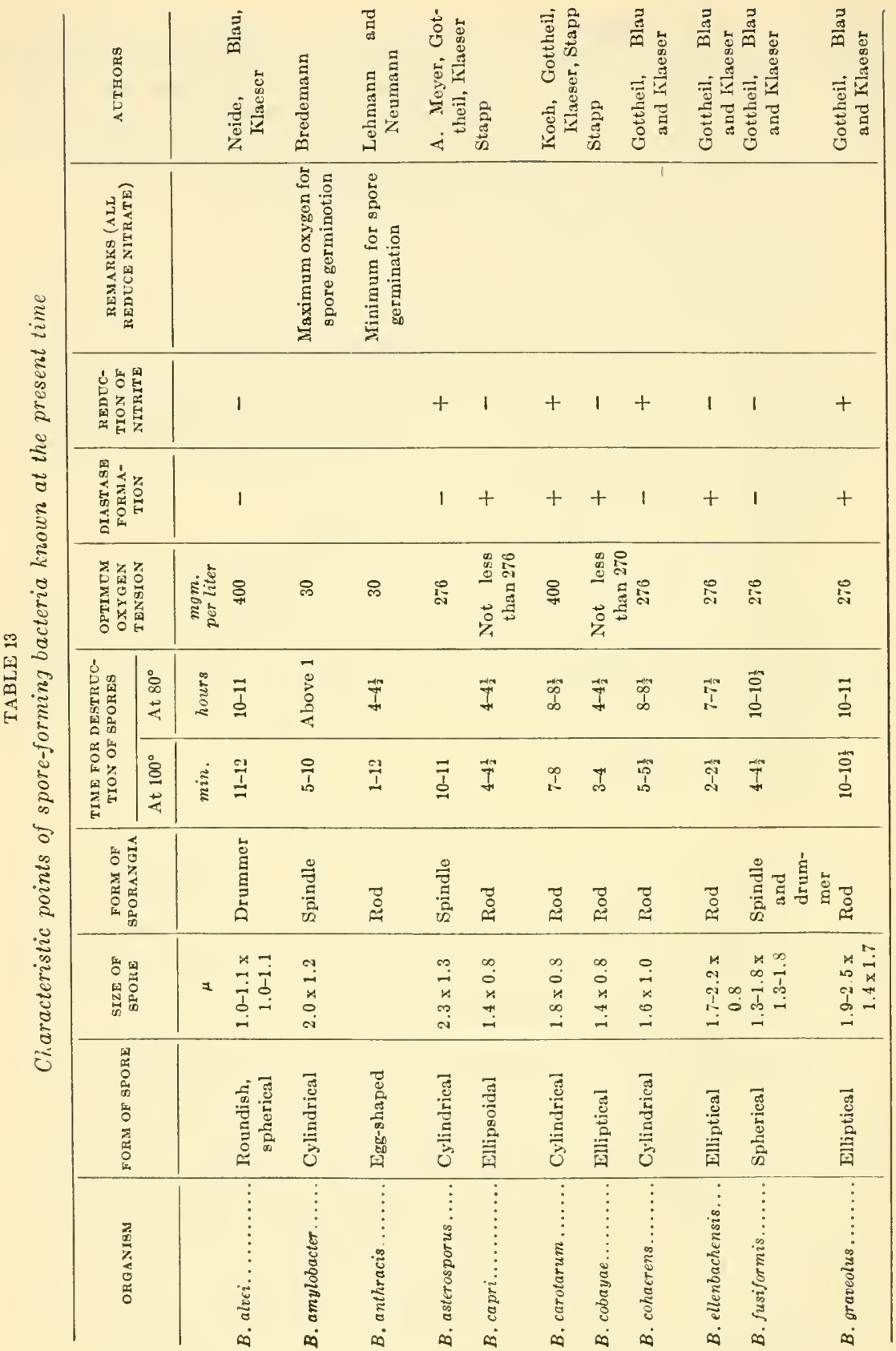


HETEROTROPHIC BACTERIA REQUIRING COMBINED NITROGEN 147

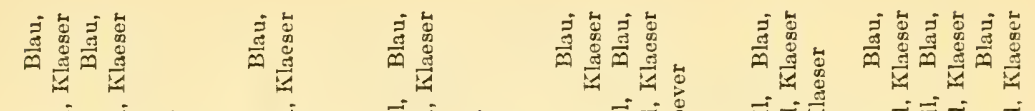

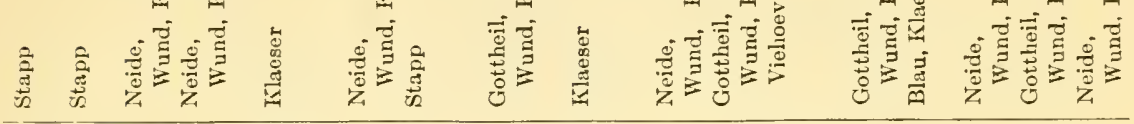

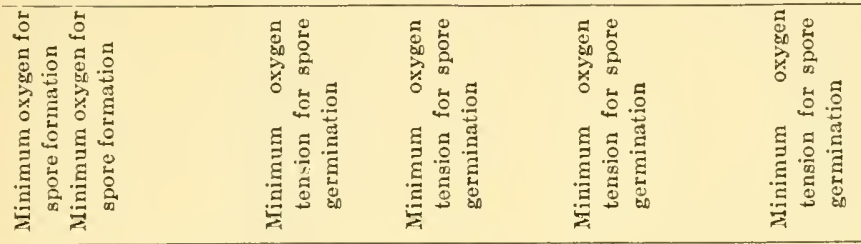

$1111+1+1+1+1+1$ 윰 임

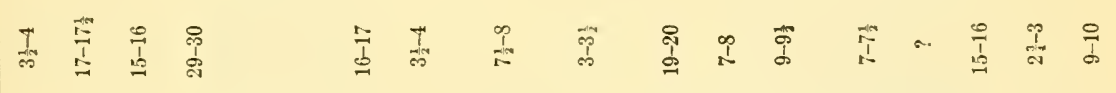

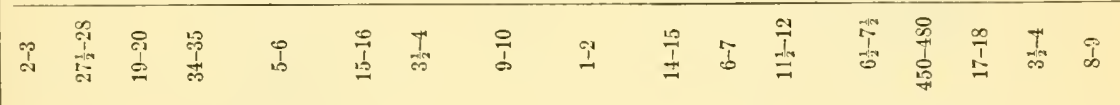

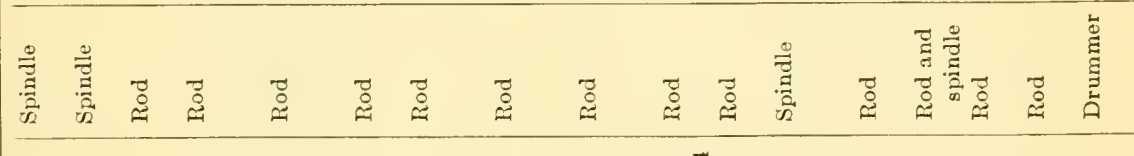

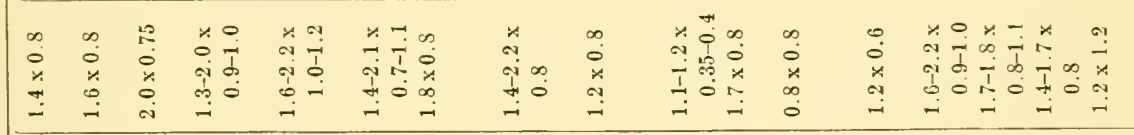

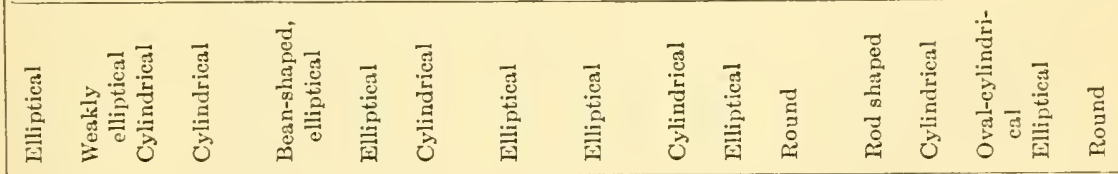

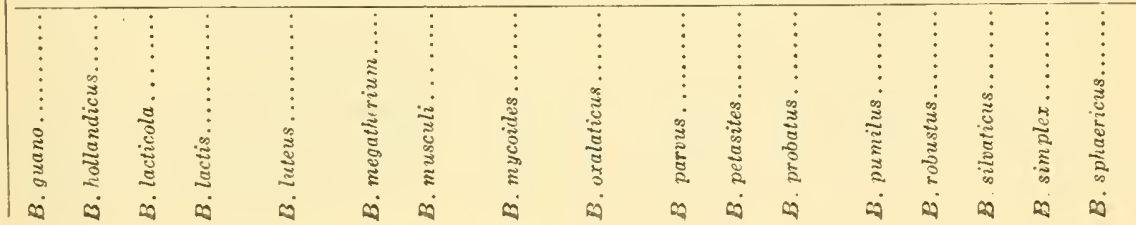




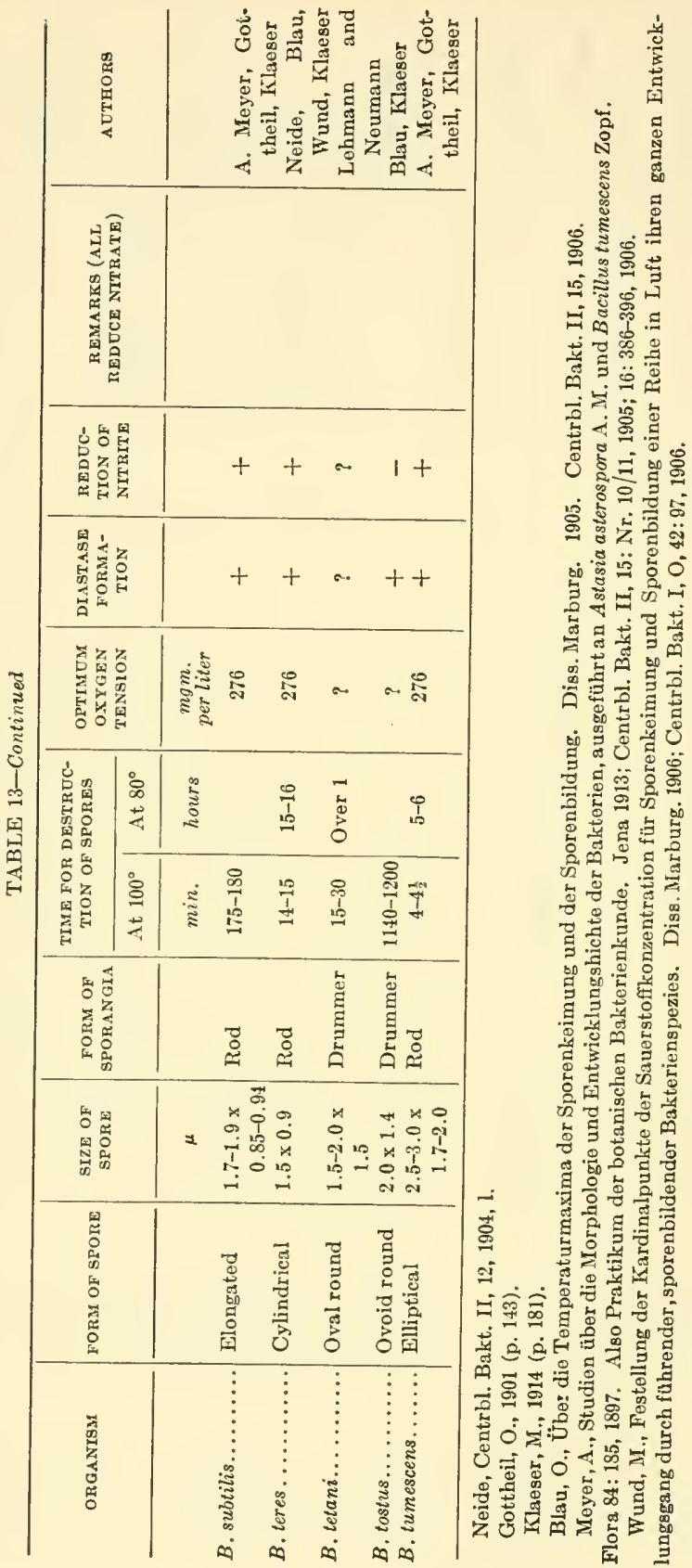


mycoides and usually forms round colonies with entire edges; the surface membrane contains granules which tend to be arranged concentrically. Bac. megatherium liquefies gelatin more slowly; its colonies are seldom over $1 \mathrm{~cm}$. in diameter and are characterized by a flocculent center composed of white opaque granules, surrounded by a zone of clear liquefied gelatin; the smaller colonies have no surrounding zone and are recognized only by their granular structure. ${ }^{11}$

These organisms as well as various other spore-forming bacteria are of universal occurrence in the soil. The following forms were demonstrated $^{12}$ in the soil of Northern Greenland: Bac. subtilis, Bac. mesentericus, Bac. asterosporus, and Bac. malaberensis. According to Flügge ${ }^{13}$ Bac. mycoides is present in almost every soil examined. Holzmüller ${ }^{14}$ also found one form or another of Bac. mycoides in every soil. Gottheil found Bac. asterosporus very abundantly in the soil as well as Bac. ellenbachensis, and to a less extent Bac. cohaerens, Bac. fusiformis, Bac. petasites, Bac. graveolus, Bac. pumilus, Bac. ruminatus, Bac. subtilis and Bac.tumescens. Bac. simplex was found only once, while the presence of Bac. mycoides and Bac. carotarum could not be established

According to Ford and associates Bac. cereus is very predominant in Maryland soils, followed by Bac. subtilis; Bac. mesentericus was more abundant than Bac. vulgatus, while Bac. megatherium, Bac. petasites and Bac. mycoides were found only rarely. Five hundred and twenty cultures were isolated from eight soils (five near Baltimore and three from Nazareth, Pa.). All soil samples were boiled in water for 20 minutes just before plating, to kill all the vegetative cells of bacteria as well as the other soil organisms and leave only the spores of the spore-forming bacteria. (See tabulation on p. 150.)

The three most common types of spore-forming bacteria found in the soil by Conn were: Bac. megatherium (averaging about 375,000 per gram), Bac. mycoides (225,000 per gram) and Bac. cereus $(180,000$ per gram).

The relative number of spore-forming bacteria in the soil depend on the length of the incubation period. When a short incubation period is used, nearly half of the colonies on the plate may be found to consist

11 Conn, 1917 (p. 142).

12 Barthel, Ch. Recherches bactériologiques sur le sol et sur les matières fécales des animaux polaires du Groenland septentrional. Saertryk Meddel. Groenland 64, Kopenhagen. 1922.

${ }^{13}$ Flügge, 1896 (p. x).

14 Holzmüller, 1909 (p. 143). 


\begin{tabular}{|c|c|c|}
\hline \multirow{2}{*}{ ORGANISM } & \multicolumn{2}{|c|}{$\begin{array}{l}\text { PRESENCE IN NUMBER } \\
\text { OF SOIL SAMPLES }\end{array}$} \\
\hline & $\begin{array}{l}\text { Baltimore } \\
\text { soil }\end{array}$ & $\begin{array}{l}\text { Nazareth } \\
\text { soil }\end{array}$ \\
\hline 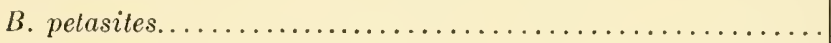 & 73 & 116 \\
\hline 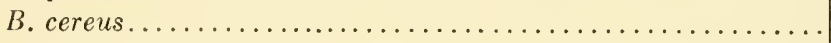 & 134 & 41 \\
\hline 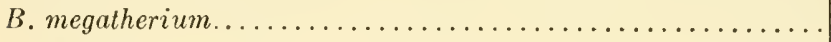 & 29 & 13 \\
\hline 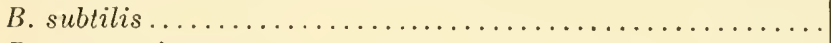 & 24 & 9 \\
\hline 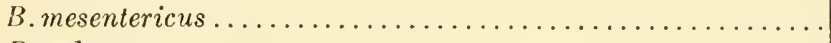 & 9 & 11 \\
\hline 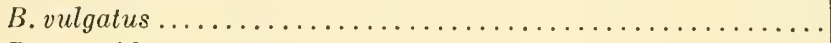 & 12 & 6 \\
\hline 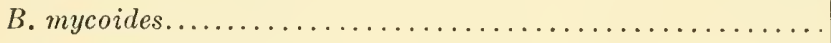 & 15 & 2 \\
\hline 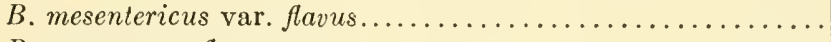 & & 9 \\
\hline 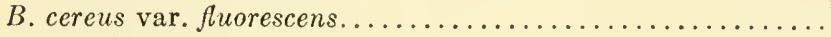 & 3 & \\
\hline 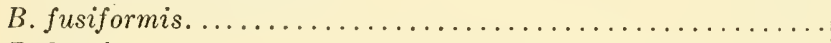 & 3 & 2 \\
\hline 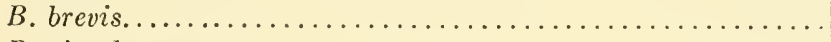 & & 3 \\
\hline 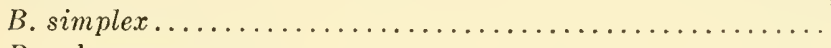 & 1 & \\
\hline 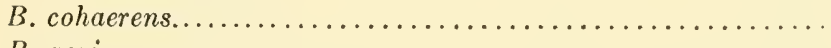 & 1 & 2 \\
\hline 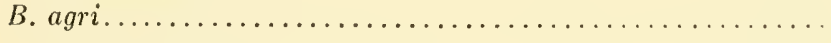 & 2 & \\
\hline Total i & 306 & 214 \\
\hline
\end{tabular}

of spore-forming organisms. ${ }^{15}$ When a long incubation period is used they are found to form only about 5 per cent of the colonies. ${ }^{16,17}$ The presence of spore-forming bacteria, which are destroyed with difficulty by partial sterilization, varies with the soil. ${ }^{18}$ Here belong Bac. mycoides, Bac. mesentericus and Bac. mesentericus ruber. The simplest way of destroying these is to heat the soil for 30 minutes at $100^{\circ} \mathrm{C}$. on seven consecutive days and then to incubate the soil, between successive sterilizations, at room temperature.

Non-spore forming bacteria. Although the heterotrophic non-spore forming bacteria include the most predominant group of soil organisms developing on the plate and even more so in the microscopic examination of the soil, very little attention has been paid to their identification. This has been due, probably, to the fact that these organisms grow poorly and only very slowly on laboratory culture media. The inappreciable results obtained by the ordinary chemical tests led to the general assumption that they are of little importance in the soil. The fact must also be kept in mind that certain very important physiological

${ }^{15}$ Chester, F. D. Study of the predominating bacteria in a soil sample. Del. Agr. Exp. Sta., Rept. 14: 52-63. 1903.

${ }^{16}$ Hiltner and Störmer, 1903 (p. 12).

${ }^{17}$ Conn, 1917 (p. 142).

${ }_{18}$ Eckelmann, 1918 (p. 641). 
groups of soil organisms, such as the Thiobacillus group of sulfur bacteria, the nitrite, nitrate forming and other autotrophic bacteria, as well as various heterotrophic bacteria, such as many of the aerobic cellulose decomposing bacteria, certain urea bacteria, etc., belong to this group of organisms.

Except for the physiological groups just mentioned, the study of the heterotrophic, non-spore-forming bacteria, which do or do not develop on the common synthetic and nutrient media, has been neglected. This has been largely a result of the lack of proper methods of study. Organisms have been looked for which take part in the various known processes, largely in the nitrogen transformation in the soil. If an organism did not take part in the processes of nitrification or sulfuroxidation, nitrogen-fixation or cellulose decomposition, and if it did not produce ammonia rapidly from proteins, it was assumed to be unimportant in the soil.

We must assume from the meager information available that the non-spore-forming bacteria take part in the slow but constant decomposition of the soil organic matter. Winogradsky considers them as the native (autochtonous) population of the soil. When fresh organic matter is added to the soil, the fungi and the spore-forming bacteria at once become active, until the organic matter is reduced to a certain consistency (so-called "humus"). These organisms then become inactive again until a fresh supply of energy is introduced into the soil. The "humus" left is constantly acted upon by the non-spore-forming bacteria (and actinomyces), which mineralize it, liberating the nitrogen and other mineral elements into available forms.

Classification. The heterotrophic, non-spore-forming aerobic bacteria usually produce punctiform colonies on agar and gelatin, are chromogenic or non-chromogenic, motile or non-motile, some liquefy gelatin rapidly, while others only slowly or not at all. The non-sporeforming bacteria, which form the most abundant group of soil organisms, as shown both by microscopic and cultural methods, can be divided into (1) the forms that liquefy gelatin rapidly and (2) the forms that liquefy gelatin slowly.

The most important representatives of the group of rapid liquefying organisms is the Bact. fluorescens or Pseud. fluorescens. The whole group is often spoken of as the fluorescens group, although many of the organisms never produce any fluorescens.

The representatives of the second group comprising the bacteria which form pin-point colonies on the agar and gelatin plate and which 
liquefy gelatin only very slowly, are characterized by poor growth in all liquid media and by the formation of punctiform colonies on gelatin. These organisms are usually less than one micron in length and less than half a micron in diameter, being short rods or cocci; growth on agar streaks is fair, soft, smooth, glistening, slimy to watery. Due to the fact that they grow only poorly in liquid media, they do not lend themselves readily to physiological studies. They also appear much the same morphologically. The silica gel plate with soil extract as the nutritive ingredient presents a new and promising method for their study.

Conn $^{19}$ divided these organisms into five groups on the basis of their growth upon a synthetic medium $\left(1.0\right.$ gram $\mathrm{NH}_{4} \mathrm{H}_{2} \mathrm{PO}_{4}, 0.2$ gram $\mathrm{KCl}, 0.2$ gram $\mathrm{MgSO}_{4}, 10.0$ sugar in 1000 cc. of water, adjusted to $\mathrm{pH}$ 7.0):

1. Organisms forming small short rods, usually under $0.5 \mathrm{mi}-$ cron in diameter, non-motile or having one or possibly two polar flagella; no tendency to change in morphology but very variable in their physiology.

2. Organisms that appear for a day or two after inoculation on a new medium as small short rods, less than $0.5 \mu$ in diameter, then shorten and appear like micrococci. All liquefy gelatin, slowly however, and can be separated on the basis of physiological characteristics.

3. Small short rods, with a tendency to produce long filaments, usually unbranched, but frequently branched.

4. Organisms consisting, in young cultures, mostly of branching forms, apparently produced by the germination of small spherical arthrospores. The branching forms disappear in a few days, leaving the coccoid forms.

5. Organisms occurring normally as cocci, but with a tendency to produce rods and filaments after a few days of growth on ordinary media. This group is more abundant in manure than in soil.

The first two groups are most numerous in the soil. According to Winogradsky ${ }^{20}$ the cocci predominate, as shown by the direct microscopic method (including probably also the short rods). These organisms were found to grow in groups (masses, zooglea) imbedded in the colloids which cover the soil particles.

${ }^{19}$ Conn, H. J. Soil flora studies. VI. The punctiform-colony-forming bacteria in the soil. N. Y. Agr. Exp. Sta. Tech. Bul. 115. 1925.

20 Winogradsky, 1925 (p. 7). 
The term "Micrococcus" was applied ${ }^{21}$ to designate the genus of irregular mass-forming cocci. Sixteen species were separated on the basis of gelatin liquefaction, nitrate reduction and ability to utilize certain ammonium salts as the only source of nitrogen.

The fact must also be mentioned that a few spore-forming organisms are found to form punctiform colonies. They are not related to the other spore-forming bacteria in their general physiology and stand also apart from the "slow growers." Except the Bact. fluorescens and Bact. caudatum, the other non-spore-forming bacteria cannot be readily recognized by their colonies on gelatin or agar. The rapid liquefaction of the gelatin by the former and the orange color of the latter allow a ready recognition of these two types. Bact. aerogenes and Bact. coli isolated from the soil can be readily distinguished from Bact. coli of fecal origin by the fact that the former use citrates as a source of carbon and the latter do not;22 also by the production of a red iron rust growth on Harder's medium. ${ }^{23}$

Occurrence of non-spore-forming bacteria in the soil. The non-sporeforming bacteria are numerically the largest group of soil microorganisms. It still remains to be demonstrated, however, what bulk they occupy in the soil population and what relative importance may be ascribed to them in transformations in the soil. Seventy-five per cent of the total number of colonies developing on the plate are non-spore-forming bacteria and cocci, the other 25 per cent include the spore-forming organisms and actinomyces. The seventy-five per cent of the colonies is made up largely of the slow growing organisms; between 2 to 60 millions of these organisms, as determined by the plate method, are found per 1 gram of soil. The non-spore-forming bacteria are believed to be very active in the soil (Conn, Winogradsky), particularly in view of their great variability as affected by the soil treatment. Conn found that a certain soil contained 350,000 rapid-liquefying colonies, 11,000,000 punctiform colonies and 4,700,000 spore-formers and actinomyces, before aeration; after aeration for one day these numbers changed to

${ }^{21}$ Hucker, G. J. Studies on the coccaceae. I. Previous taxonomic studies concerning the genera of the coccaceae. N. Y. Agr. Exp. Sta. Tech. Bul. 99. 1924; II. A study of the general characters of the micrococci. Ibid. 100. 1924; III. The nitrogen metabolism of the micrococci. Ibid. 101. 1924; IV. The classification of the genus micrococcus Cohn. Ibid. 102, 1924.

${ }^{22} \mathrm{Koser}, \mathrm{S}$. A. Utilization of the salts of organic acids by the colon-aerogenes group. Jour. Bact. 8: 493-520. 1923; 9: 59-77. 1924.

${ }^{23}$ Murray, T. J., and Skinner, C. E. Differentiation of B. aerogenes and B. coli of fecal origin. Proc. Soc. Exp. Biol. Med. 23: 104-106. 1925. 
$1,500,000$ of the first, $22,500,000$ of the second, and 4,000,000 of the third. Aeration of soil and the addition of organic matter bring about the greatest numerical increase in the group of non-spore-forming bacteria in the soil. The above numbers as determined by the plate method represent only a fraction of the actual abundance of these organisms in the soil, since they live in zooglea-like masses imbedded in the soil colloids and cannot be readily separated into individual cells.

Of the non-spore-forming bacteria and cocci, some are especially abundant in the soil. The available information on this subject is very meager due largely to the difficulty of studying some of the slow growing organisms on artificial media. The Bact. fluorescens is especially abundant, having been found in soils all over the world. The same is true of certain cocci or very short rods.

Severin ${ }^{24}$ found rods to predominate in freshly plowed manured soil as well as in manure itself; however, in two weeks cocci predominated According to Houston, ${ }^{25}$ Bact. vulgare (Proteus vulgaris), Bact. prodigiosum and various Sarcinae are less abundant in the soil than the spore-forming bacteria, actinomyces, and the Bact. fiuorescens. When inoculated into soil, Bact. prodigiosum persisted only when the soil was previously sterilized and kept moist; when the soil was air dried or when the inoculation took place into non-sterile soil, the organism was rapidly destroyed. The occurrence of brown fluorescent bacteria in the soil was pointed out by Bazarewski.. ${ }^{26}$ Barthel $^{27}$ found in a North Greenland soil Bact. fluorescens, Bact. caudatum, Bact. punctatum, Bact. violaceum, Bact. lactis viscosum, Bact. umbilicatum, Bact. ochraceum and Bact. zopfii. Among the cocci, Barthel found Tetracoccus and Sarcina flava. In addition to these organisms, various other bacteria, like those forming a blue pigment, those accompanying the nitrogenfixing organisms, various spirilli, vibrios, and cocci have been reported to be found in the soil by different investigators. Certain organisms, like Bact.vulgare, Bact.coli and others, present abundantly in manure and feces, are thus abundantly introduced into the soil and may survive there for a long time, some of which, such as various proteolytic and cellulose-decomposing bacteria, may even become active there.

24 Severin, S. A. Die im Miste vorkommenden Bakterien und deren physiologische Rolle bei der Zersetzung desselben. Centrbl. Bakt. II, 1: 100-104. 1895; Zhur. Opit. Agron. 1: 463-489. 1900.

25 Houston, 1898 (p. 14).

${ }^{26}$ Bazarewski, S. v. Über zwei neue farbstoffbildenden Bakterien. Centrbl. Bakt. II, 15: 1-7. 1905.

27 Barthel, 1922 (p. 149). 
The bacteria of the so-called colon group found abundantly in the feces of warm blooded animals differ, in certain cultural characteristics, ${ }^{28}$ from those found in the soil, the former being largely Bact. coli and the latter belonging to the Bact. aerogenes group, which is even capable of fixing small amounts of nitrogen. Out of 467 strains of bacteria isolated from various soils by Chen and Rettger, 430 were identified as Bact. acrogenes, 17 as Bact. cloacae and only 20 as Bact. coli; the sources of the Bact. coli strain were shown by a sanitary survey to be not entirely free from animal pollution. However, all of 173 organisms found in the feces of various animals were typical Bact. coli. When Bact. coli and even Bact. aerogenes are added to the soil in considerable numbers, they rapidly die out, ${ }^{29}$ since conditions are not very favorable for their development, although Bact. coli was found ${ }^{30}$ to survive in the soil for 4 years.

It is of interest to note here that Stoklasa ${ }^{31}$ found the following organisms in the "rhizosphere" or in close proximity to the root system of plants, consisting largely of non-spore-forming bacteria:

Bact. acidi lactici $\alpha$ and $\beta$
Bact. pneumoniae
Bact. coli group
Bact. proteus vulgaris
Bact. ochraceum
Bact. fulvum
Bact. punctatum
Bact. putidum
Bact. fluorescens liquefaciens

Bact. anthracoides

Azotobacter chroococcum

Butyric acid bacteria

Bac. mycoides

Bac. mesentericus

Mycoderma

Cladosporium herbarum

Fusarium

Thermophitic bacteria. It has been known since the work of Globig, ${ }^{32}$

${ }^{28}$ Chen, C. C., and Rettger, L. F. A correlation study of the colon-aerogenes group of bacteria, with special reference to the organisms occurring in the soil. Jour. Bact. 5: 253-29S. 1920; Levine, M. Bacteria fermenting lactose and their significance in water analysis. Iowa Engin. Fxp. Sta. Bul. 62. 1921.

${ }^{29}$ Skinner, C. E., and Murray, T. J. The viability of B. coli and B. aerogenes in soil. Jour. Inf. Dis. 38: 37-41. 1926.

${ }^{30}$ Young, C. C., and Greenfield, M. Observation on the variability of the Bacterium coli group under natural and artificial conditions. Amer. Jour. Publ. Health, 13: 270-273. 1923. See also Koser, S. A. Coli-aerogenes group in soil. Jour. Amer. Water Works Assn. 15: 641-646. 1926.

31 Stoklasa, 1926 (p. xiii).

${ }^{32}$ Globig. Über Bakterienwachstum bei 50-70 Ztschr. Hyg. 3: 294-321. 1888. 
Macfayden and Blaxall ${ }^{33}$ in 1888 , and other workers soon following ${ }^{34,35}$ that there are bacteria in the soil which are capable of growing at high temperatures, namely at $50^{\circ}$ to $70^{\circ} \mathrm{C}$., and which refuse to grow in the laboratory at room temperature. Various investigators ${ }^{36-38}$ found in stable manure organisms capable of growing at temperatures up $79.5^{\circ} \mathrm{C}$. Schloesing ${ }^{39}$ demonstrated in 1892 that the self-heating and burning of hay, cotton, manure, etc., is caused by microorganisms which he called therhogenic bacteria. It may be here largely a question of thermotolerant organisms rather than strict thermophiles. ${ }^{40}$ Thermophilic bacteria were found in sands of the Sahara Desert, ${ }^{41}$ but are absent in forest soils. The distribution of these organisms in the soil seems to depend on the manure used. Garden soils heavily manured may contain 1 to 10 per cent of the flora developing on the plate as thermophilic forms, while field soils contain only 0.25 to 0 per cent. Uncultivated

${ }^{33}$ Macfayden, A., and Blaxall, F. R. Thermophilic bacteria. Jour. Path. Bact. 3: 87-99. 1894.

${ }^{34}$ Rabinowitsch, L. Über die thermophilen Bakterien. Ztschr. Hyg. 20: 154. 1895. Oprescu, V. Studien über thermophile Bakterien. Arch. Hyg. 33: 164. 1898. Schillinger, A. Über die thermophilen Bakterien. Hyg. Rundsch. 1898, p. 568. Tsiklinsky, P. On microorganisms living at high temperatures. Russ. Arch. Pathol. 5, 1898 (Ambroz, A. Über das Phänomen der Thermobiose bei den Mikroorganismen. Centrbl. Bakt. I, Ref. 48: 257-279, 289-312. 1910). Sames, T. Zur Kenntnis der bei höheren Temperaturen wachsenden Bakterien und Streptothrixarten. Ztschr. Hyg. 33: 313. 1910.

${ }^{35}$ Blau, O. Ueber die Temperaturmaxima der Sporenkeimung und der Sporenbildung, sowie die supramaximalen Tötungszeiten der Sporen der Bakterien, auch derjenigen mit hohen Temperaturminima. Centrbl. Bakt. II, 15: 97-143. 1906.

${ }^{36}$ Burrill, T. J. The biology of silage. Ill. Agr. Exp. Sta. Bul. 7. 1889.

${ }^{37}$ Schloesing, Th. Sur la fermentation forménique du fumier. Compt. Rend. Acad. Sci. 109: 835-840. 1889.

${ }^{38}$ Dupont, C. Sur les fermentations aérobies du fumier de ferme.". Ann. Agron. 28: 289. 1902.

${ }^{39}$ Schlocsing, T. Contribution à l'étude des fermentations du fumier. Ann. Agron. 18: 5. 1892 .

${ }^{40}$ Miehe, H. Die Selbsterhitzung des Heus. G. Fischer. Jena 1907. Schütze, H. Beiträge zur Kenntnis der thermophilen Actinomyceten und ihrer Sporenbildung. Arch. Hyg. 67: 35-56. 1908.

${ }^{41}$ Nègre, L. Bactéries thermophiles des sables du Sahara. Compt. Rend. Soc. Biol. 74: 814-816. 1913. 
soils may be entirely free from thermophilic organisms ${ }^{42}$ the geographic condition has no influence..$^{43}$

Globig ${ }^{32}$ isolated a number of thermophilic bacteria from the soil and believed that, because most of them were isolated from the surface layers, the rays of the sun supply the heat necessary to obtain the high temperatures. Rabinowitsch ${ }^{34}$ isolated eight species of thermophilic bacteria from soil and feces, varying in morphology (rod shaped to comma shaped), size of spores, color of colony on agar and potato. A number of other bacteria were isolated ${ }^{35}$ which had an optimum at $60^{\circ}$ to $65^{\circ} \mathrm{C}$. and were killed by heating at $100^{\circ} \mathrm{C}$. for 8 to 20 hours. A variety of $B$. coli and a spore-bearing organism, Bac. calfactor, as well as several fungi and actinomyces, were found capable of growing at high temperatures and taking an active part in the decomposition of hay. ${ }^{40}$ The size of Bac. calfactor changes with temperature at which it is grown (on hay infusion agar at $70^{\circ} \mathrm{C}$. it is 5 by $0.4 \mu$; at $56^{\circ} \mathrm{C} .-5$ by $0.7 \mu$; at $30^{\circ} \mathrm{C} .-3$ by $0.8 \mu$ ). The rods occur singly, not in chains, and are motile at favorable temperatures (above $30^{\circ}$ ). The spores are 1.5 by $0.8 \mu$. Spore germination takes place in 60 minutes at $60^{\circ} \mathrm{C}$; in 85 minutes, 2 cells are already formed. This rapid multiplication accounts for the fact that at $50^{\circ} \mathrm{C}$., turbidity is definite in liquid decoctions within six hours and an abundant growth is produced on agar.

de Kruyff ${ }^{44}$ isolated from the soil ten species of rod shaped, thermophilic bacteria, most of them being long rods, forming oval to round spores; most of them produce proteolytic enzymes and do not grow on potato. He suggested that with a rise in temperature in tropical soil they take the place of the ordinary bacteria. It has been established that there occur in soils thermophilic nitrogen-fixing bacteria, ${ }^{45}$ thermophilic cellulose decomposing bacteria $a^{46-48}$ and thermophilic denitri-

${ }^{42}$ Migula, W. Über die Tätigkeit der Bakterien im Waldboden. Forstwissensch. Zentrbl. 57 (Neue Folge 35): 161-169. 1913.

${ }^{43}$ Mischustin, E. Untersuchungen über die Temperaturbedingungen für bakterielle Prozesse im Boden in Verbindung mit der Anpassungsfähigkeit der Bakterien an das Klima. Centrbl. Bakt. II, 66: 328-344. 1926.

${ }^{44}$ de Kruyff, E. Les bactéries thermophiles dans les Tropiques. Centrbl. Bakt. II, 26: 65-74. 1910.

${ }^{45}$ Pringsheim, 1911 (p. 121).

${ }^{46}$ Pringsheim, 1913 (p. 202).

${ }^{47}$ Kroulik, A. Über thermophile Zellulosevergärer'. Centrbl. Bakt. II, 36: 339-346. 1912.

18 Viljoen, Fred and Peterson, 1926 (p. 202). 
fying bacteria. ${ }^{49}$ The nature of the medium was found ${ }^{50}$ to have an important influence upon the temperature optimum of the organism. Two per cent of glucose is added to soil either alone or with 2 per cent $\mathrm{CaCO}_{3}$; this is then steamed at $100^{\circ}$ for 20 minutes, to kill the non-spore-forming organisms. Water is added to bring the moisture to 16 per cent and the soils are incubated at $52^{\circ} \mathrm{C}$. for 4 to 6 days, at which time the bacteria are isolated. These bacteria grow in media at $52^{\circ} \mathrm{C}$., but not at $28^{\circ}$ to $30^{\circ}$; when reinoculated into soil, they may grow well even at $15^{\circ}$ to $20^{\circ}$ although not so abundantly. Miehe assumed that these organisms can develop only in manure heaps where a great deal of heat is generated. However, others ${ }^{50}$ suggested that they do not always lead a latent life in the soil, but find in summer a suitable temperature for their development. ${ }^{51}$ Among the activities of the thermophilic bacteria, the decomposition of organic matter, especially the decomposition of celluloses in manure, occupies the first place. Many of the bacteria are strongly proteolytic. Most of them are strictly aerobic and form spores. Some organisms are facultative thermophilic, since they can grow at $20^{\circ}$, have their optimum at $50^{\circ} \mathrm{C}$. and maximum at about $60^{\circ} \mathrm{C} .{ }^{52}$

Mycobacteria. The Mycobacteria are a group of organisms which differ from true bacteria by the formation of more or less long monopodially branched threads under normal conditions of growth. They are largely acid fast and represent botanically a well clefined group of organisms, standing midway between the true bacteria and the actinomyces group, which should be already more properly classified with the fungi. A number of these organisms were isolated from manure ${ }^{53}$ and from soil. ${ }^{54,55}$ A selective development of these organisms will take place upon agar plates, containing the necessary minerals, an

${ }^{49}$ Ambroz, A. Dinitrobacterium thermophilum spec. nova, ein Beitrag zur Biologie der thermophilen Bakterien. Centrbl. Bakt. II, 37: 3-16. 1913.

${ }^{50}$ Koch, A., and Hoffmann, C. Über die Verschiedenheit der Temperaturansprüche thermophiler Bakterien im Boden und in künstlichen Nährsubstraten. Centrbl. Bakt. II, 31: 433-436. 1911.

${ }^{51}$ Krohn, V. Studien über thermophile Schizomyceten. Ann. Acad. Sci. Fennicae, Ser. A. 21: 1-125. 1923. Helsingfors.

${ }^{52}$ Bergey, D. H. Thermophilic bacteria. Jour. Bact. 4: 301-306. 1919.

${ }^{53}$ Moëller, A. Ein neuer säure- und alkoholfester Bacillus aus der Tuberkelbacillengruppe, welcher echte Verzweigungsformen bildet. Centrbl. Bakt. 25: 369-373. 1899.

${ }^{54}$ Söhngen, 1913 (p. 204).

s5 Vierling, K. Morphologische und physiologische Untersuchungen über bodenbewohnende Mykobakterien. Diss. Univ. Heidelberg. 1921. 

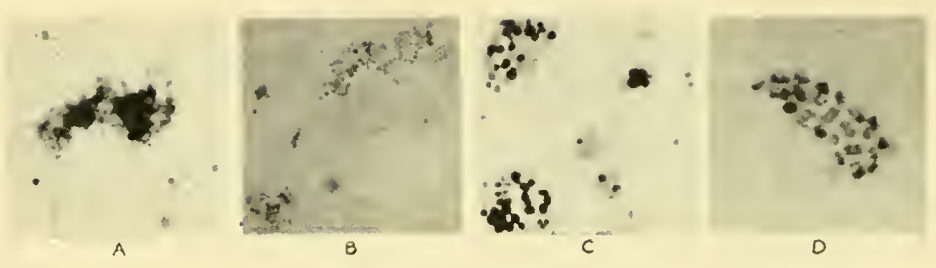

47
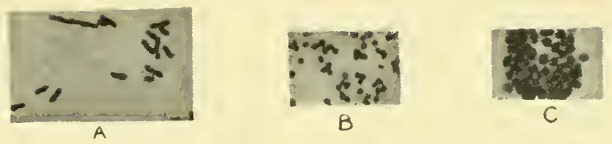

48

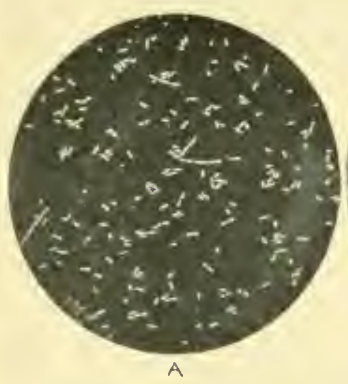

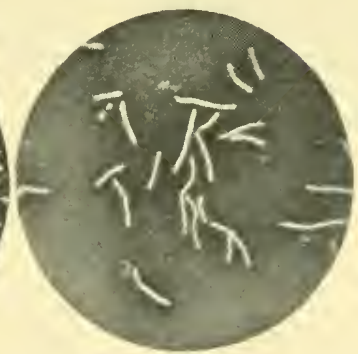

B

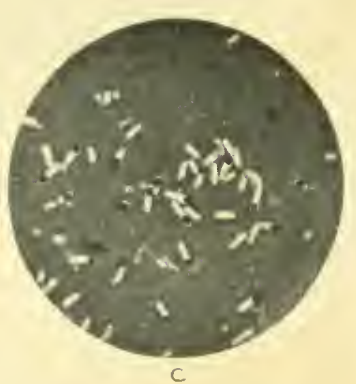

49

47. Life cycle of Azotobacter chroococcum: a, formation of symplasm by regenerative bodies on potato, in 9 days; $b$, regenerative units starting to grow, on beef gelatin, in 4 weeks; c, regenerative bodies growing from symplasm, on beef agar, in 4 weeks; $d$, formation of new cells by agglomeration of regenerative units on mannite soil extract, in 4 days; $\times 600$ (from Löhnis and Smith).

45. Influence of composition of medium upon the morphology of Bact. pneumoniae: $A$, on beef agar, 1 day at $37^{\circ} \mathrm{C}$; $B$, on egg agar, 1 day at $19^{\circ} \mathrm{C}$; $C$, on starch agar, 1 day at $19^{\circ} \mathrm{C}$.; $\times 660$ (from sicales).

49. Some typical soil bacteria, as shown by the India Ink method. A, short non-spore forming rods (bacteria); $B$, long, non-spore forming rods (bacteria); $C$, spore-forming rods (bacilli) (from Kiirsteiner). 

inorganic source of nitrogen and inoculated with a soil suspension, if the cultures are placed under a bell jar together with a dish of benzene or petroleum, and incubated at $30^{\circ} \mathrm{C}$. The final isolation and purification of the organisms can be accomplished by means of ordinary bacteriological methods. Spore formation takes place by contraction of the cell contents, in a manner similar to that of the actinomyces (p. 294), giving coccus-like fragments. The colonies on solid substrates have a certain thread-like structure (No. 13, Pl. VIII).

The organisms readily utilize various hydrocarbons as sources of energy. ${ }^{54}$ They do not form any ammonia from proteins $;{ }^{55}$ most of them reduce nitrates to nitrites (similar to actinomyces). Their rôle in the soil seems to consist largely in the decomposition of certain organic compounds.

Myxobacteria. Myxobacteria occur abundantly in manure and probably take a part in the decomposition of certain constituents of natural organic materials. To demonstrate the presence of Myxobacteria in the soil, balls of rabbit manure, previously moistened with water and sterilized in the autoclave, are placed on the surface of the particular layer of soil. Frequently $7-10$ species are thus obtained from one soil sample. ${ }^{56}$

${ }^{66}$ Krzemieniewsky, H. and S. Die Myxobakterien von Polen. Acta Soc. Bot. Poloniae. 4: 1-54. 1926. 


\section{CHAPTER VI}

\section{Anaerobic Bacteria}

Oxygen tension in the growth of bacteria. Pasteur ${ }^{1}$ was the first to demonstrate that there are organisms, among them yeasts, which can live in the presence of only small traces of oxygen. Since the growth of the microorganisms is so abundant that the small amount of oxygen present is rapidly used up, it can be assumed that the greater part of their development takes place in the absence of free oxygen. Pasteur has further shown that, in the case of yeasts, growth in the absence of oxygen takes place only in the presence of sugar utilizable by these organisms. Those organisms which are able to grow both in the pres-

1 Pasteur, L. Animalcules infusoires vivant sans gaz oxygène libre et déterminant des fermentations. Compt. Rend. Acad. Sci. 52: 360. 1S61; Expériences et vues nouvelles sur la nature des fermentations. Ibid., 1260; $56: 416,1189$. $1863 ; 75: 784$. $1872 ; 80: 1875$.

\section{PLATE X}

\section{Heterotrophic Aerobic and Anaerobic Bacteria}

50. Bac. mycoides, $\times 660$ (from Conn).

51. Bac. cereus, $\times 660$ (from Conn).

52. Bac. megatherium, $\times 660$ (from Conn).

53. Bac. simplex, $\times 660$ (from Conn).

54. Bact. vulgare, $\times 660$ (after Omeliansky).

55. Bact. pyocyaneum, $\times 660$ (after Omeliansky).

56. Bact. fluorescens, $\times 600$ (after de Rossi).

57. Bac. butyricus: $a$, non-spore forming; $b$, spore forming, $\times 660$ (from Omeliansky).

58. Bac.sporogencs: $a, 24$ hour culture upon glucose bouillon; $b$, flagella, stained by Loeffler's method (from Weinberg and Seguin).

59. Bac. putrificus, 48 hour old colony in deep glucose agar (from Weinberg and Seguin).

60. Bac. probatus: $A$, non-sporulating bacilli of a fresh agar culture; $B$, sporulating bacilli of an agar culture 4-8 days old; $C$, spores with adhering membrane of a 2 to 3 week old culture upon potato, $\times 1300$ (after Viehoever and de Rossi).

61. Sarcina ureae, $\times 660$ (after Omeliansky).

62. Bac. nitroxus, 3-day old culture, grown at $30^{\circ}, \times 480$ (after Beijerinck and Minkmann and de Rossi).

63. Spirillum desulfuricans, $\times 660$ (after Beijerinck and Omeliansky). 


ence and absence of free oxygen were termed by Liborius" "facultative anaerobes." It has also been observed by Pasteur that certain butyric acid bacteria grow abundantly in the liquid medium, through which a current of carbon dioxide is passed, but are destroyed, when a current of air is passed for 2 hours through the liquid. Those organisms, which are unable to thrive under partial oxygen pressure and cannot withstand even small amounts of oxygen, were termed by Liborius "obligate anaerobes." Beijerinck ${ }^{3}$ divided the bacteria into two groups, according to their oxygen need: (1) "aerophile," or those requiring a high oxygen tension, including the aerobes and facultative anaerobes, which can grow in ordinary atmosphere; and (2) "microaerophile," or those organisms that require a more or less low oxygen tension and do not grow readily in ordinary atmosphere. The influence of oxygen on some bacteria was illustrated by the accumulation of the cells in a hanging drop preparation; the aerophiles gathered in the outer zone, while the microaerophiles massed together where the oxygen tension was least. The spirillum type was intermediate. Burri ${ }^{4}$ could not agree with this division and suggested that the terminology of Liborius is much more appropriate. Not only obligate anaerobic bacteria, but also the facultative forms were able to live in the complete absence of oxygen for a number of generations without being injured.

No general minimum oxygen tension could be found for all obligate anaerobic bacteria, but the various anaerobic forms varied in the limit of this tension: ${ }^{5}$ the oxygen limit for the blackleg bacillus (Bac. chauvoei) is 1.04 per cent oxygen in the atmosphere, 0.65 per cent for Bac. tetani, 0.27 per cent for Clostridium butyricum and 0.13 per cent for Bactridium butyricum; the obligate anaerobic bacteria could be so adapted as to withstand some amounts of oxygen. Even many species which usually grow in the complete absence of oxygen, such as Bac. amylobacter, can thrive in the presence of oxygen. A typical obligate anaerobe has no minimum oxygen tension limit, it is characterized by the existence of a very low maximum oxygen tension and it can grow in the total absence

${ }^{2}$ Liborius, P. Beiträge zur Kenntnis des Sauerstoffbedürfnisses der Bakterien. Ztschr. Hyg. 1: 115. 1886.

${ }^{3}$ Beijerinck, M. W. Ueber Atmungsfiguren beweglicher Bakterien. Centrbl. Bakt. 14: 827-845. 1893; also Arch. Neerland., Ser. II, 2: 397. 1899; Phénomènes de reduction produits par les microbes. Ibid. 9: 131. 1904.

${ }^{4}$ Burri, R. Intramolekulare Atmung, Anaërobiose und Mikroaërophilie. Centrbl. Bakt., II, 17: 804 . 1907.

${ }^{5}$ Chudiakow, N. Zur Lehre von der Anaërobiose. Moskau. 1896 (Centrbl. Bakt. II, 4: 389-394. 1898). 
of oxygen. We do not know of any true anaerobes which grow only in the complete absence of oxygen. Small quantities of free oxygen will even act as stimuli to obligate anaerobes.

The oxygen need of an organism was characterized" by the "cardinal points" for growth and spore formation, namely: minimum, optimum, and maximum, so that there is a gradual transition between aerobes and anaerobes. The following cardinal points for spore formation characterize a series of typical bacteria, atmospheric air at $18^{\circ}$ and $750 \mathrm{~mm}$. pressure containing $276 \mathrm{mgm}$. of oxygen per liter:

\begin{tabular}{|c|c|c|c|}
\hline & MINLMUM & OPTIMUM & MaXIMUM \\
\hline & mgm. & $m g m$. & $m g m$. \\
\hline Bac, amylobacter.................... & 0 & $10(?)$ & About 2.5 \\
\hline Bac. asterosporus................ & 0 & 100 & 5,600 \\
\hline Bac. fusiformis................... & 6.8 & 70 & 1,061 \\
\hline 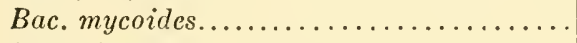 & 4.3 & 70 & 1,336 \\
\hline Bac. simplex...................... & 6.8 & 276 & 1,263 \\
\hline Bac. subtilis....................... & 4.3 & 400 & 4,317 \\
\hline 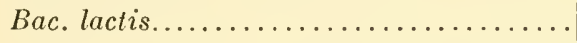 & 20.0 & 400 & 1,336 \\
\hline
\end{tabular}

A high maximum does not necessarily correspond to a high minimum. The first generation of anaerobes is more sensitive to oxygen than the following generations, which may even thrive better in the presence of a limited oxygen supply than in its complete absence. ${ }^{7}$ This points to adaptation in course of time. Even in the case of a single generation, the organism can withstand greater concentrations of oxygen after the growth of the culture has somewhat advanced than in the beginning. It has been claimed ${ }^{8}$ that the growth of even obligate anaerobic bacteria

${ }^{B}$ Meyer, A. Apparat für die Kultur von anaëroben Bakterien und für die Bestimmung der Sauerstoffminima für Keimung, Wachstum und Sporenbildung der Bakterienspeeies. Centrbl. Bakt., II, 15: 337. 1906. Bemerkungen über Aërobiose und Anaërobiose. Centrbl. Bakt. I, 49: 305-316. 1909; also Ibid. II, 15: $1905 ; 16$ : 386, 481-488, 577-588, 673-687. 1906. Wund, M. Feststellung der Kardinalpunkte der Sauerstoffkonzentration. Centrbl. Bakt. 42: 97-101, 193202, 289-296, 385-393. 1906.

' Burri, 1907 (p. 161); Kürsteiner, J. Beiträge zur Untersuehungstechnik obligat anaërober Bakterien, sowie zur Lehre vón der Anaërobiose überhaupt. Centrbl. Bakt. II, 19: 1-26, 97-115, 202-220, 3S5-399. 1907; Burri, R. and Kürsteiner, J. Ein experimentaler Beitrag zur Kenntnis der Bedeutung des Sauerstoffentzugs für die Entwicklung obligat anaërober Bakterien. Ibid. 21: 2\$9 307. 1908; Landw. Jahrb. d. Sehweiz. 1909, 422.

${ }^{8}$ Fermi, C., and Bassu, E. Untersuehungen über die Anaërobiosis. Centrbl. Bakt. I, 35: 563-568, 714-722. 1905; 38: 138-145, 241-248, 369-380. 1905. 
is greatly injured in the complete absence of oxygen; however, Kürsteiner ${ }^{7}$ demonstrated that both obligate and facultative anaerobes will thrive well for a number of generations in atmospheres free from oxygen. Free oxygen exerts an injurious effect upon obligate anaerobic bacteria, as pointed out already by Pasteur, the degree of injury depending on temperature, age and abundance of cells. ${ }^{9}$ In the following pages, the term "anaerobe" will be applied only to the so-called "obligate anaerobes."

The presence of suspended particles, especially in case of colloidal suspensions, favors the growth of anaerobic bacteria possibly through their oxygen absorption. ${ }^{10}$

The more recent studies on oxidation-reduction processes in the growth of microorganisms have brought out the fact that only those bacteria are capable of growing anaerobically, which are capable of activating some constituent of the medium as a hydrogen acceptor. Some bacteria, like B. vulgare, can activate nitrate and can, therefore, grow anaerobically in the presence of nitrate and certain hydrogen donators; Bact. coli and Bact. prodigiosum can activate nitrate, fumarate, malate and aspartate and can grow anaerobically, in the presence of any of these substances, and with glycerol as a hydrogen donator. ${ }^{11}$ Recent important contributions point to the lack of catalase formation by anaerobic bacteria. ${ }^{12}$ Peroxides are formed in the aerobic growth of bacteria and these peroxides would become injurious to the organisms if not for the catalase which is formed and which rapidly breaks up the peroxide into inactive oxygen and water. The anaerobic bacteria, which are unable to form catalase are thus subject to the destructive action of the peroxide when grown under aerobic conditions.

A number of indicators are employed for measuring anaerobiosis or

${ }^{9}$ Bachmann, 1912 (p. 164).

${ }^{10} \mathrm{Hata}, \mathrm{S}$. Über eine einfache Methode zur aerobischen Kultivierung der Anaëroben mit besonderer Berücksichtigung ihrer Toxinproduktion. Centrbl. Bakt. I, 46: 539-554. 1908; v. Lennep, R. Folia Microb. 1: No. 3. 1913.

${ }_{11}$ Quastel, 1925 (p. 469).

${ }^{12}$ McLeod, J. M., and Gordon, J. Catalase production and sensitiveness to $\mathrm{H}_{2} \mathrm{O}_{2}$ among bacteria; with a scheme of classification based on these properties. Jour. Path. Bact. 26: 326-331, 332-343. 1923; The relation between the reducing powers of bacteria and their capacity for forming peroxide. Ibid. 28: 155-164, 147-153. 1925. 
determining the end point of free oxygen.13 However, various difficulties are found in an attempt to use indicators, such as methylene blue, as criteria in anaerobiosis.

For the existence of even obligate anaerobes in the soil we need not imagine a soil atmosphere free from atmospheric oxygen, but simply that anaerobic conditions, favorable for the activities of these organisms, are produced due to the active utilization of the oxygen and production of $\mathrm{CO}_{2}$ by aerobic organisms, which results in a reduction of the oxygen tension. This can be imitated artificially in the laboratory, when anaerobes are grown readily under ordinary conditions, in the presence of rapidly growing aerobic bacteria, like Bac. subtilis. Another illustration of this phenomenon is the growth of the two nitrogenfixing organisms, the anaerobic Bac. amylobacter and the aerobic, rapidly growing Azotobacter. Exposure to oxygen has, however, an injurious effect upon anaerobic organisms, vegetative cells being destroyed in 10 minutes and spores in 8 days; ${ }^{14}$ in the case of Bac. amylobacter; the injurious effect of air exposure upon the vegetative cells sets in only after 40 minutes, while the spores are not injured even after 3 hour exposure..$^{15}$

Methods of isolation of anaerobic bacteria from the soil. There are a number of methods available for the isolation of anaerobic bacteria. ${ }^{16}$ These bacteria have to be separated not only from aerobic organisms, but often also from other facultative or obligate anaerobic bacteria. The anaerobes, just as the aerobic bacteria, vary greatly in their food requirements and manner of growth, and the methods of isolation have to be adapted to the particular organism in question. There is a large number of species of anaerobes in the soil and it is insufficient to depend on microscopic examinations alone for demonstrating the existence of specific forms. In all cases, the isolation and demonstration of the different species must be undertaken. In case the nature of an organism that is looked for is known, the development of a proper culture

${ }^{13} \mathrm{Hall}$, I. C. Chemical criteria of anaerobiosis with special reference to methylene blue. Jour. Bact. 6: 1-42. 1921. Kadisch, E. Centrbl. Bakt. I, Orig. 90:462-46S. 1923. Clark, W. M., Cohen, B., and Gibbs, H. D. Studies on oxidation-reduction. VIII. Methylene blue. U. S. Publ. Health Serv. Publ. Health Repts. Repr. no. 1017. 1925.

${ }^{14}$ Bachmann, F. Beitrag zur Kenntnis obligat anaërober Bakterien. Centrbl. Bakt. II, 36: 1-41. 1912.

15 Dorner, 1924 (p. 165).

${ }^{16}$ Heller, H. H. Principles concerning the isolation of anaerobes. Jour. Bact. 6: $445-470.1921$. 
medium is simplified. An enriched culture is first prepared either by adding some soil to a specific medium kept under specific conditions, or the specific substance is added to the soil itself. An attempt is then made to obtain a culture of the specific bacterium free from accompanying non-spore-forming and spore-forming aerobic and anaerobic organisms.

For the separation of spore-forming organisms from non-sporeformers, whether aerobes or anaerobes, the soil is heated at $75^{\circ}$ to $80^{\circ} \mathrm{C}$., by placing 2 grams of soil in 10 ec. of sterile water and keeping in a water bath for 10 minutes. This leads to the destruction of all the vegetative cells, while bacterial spores are not injured. The soil is then inoculated into a proper medium, favorable for the development of the specific organism, which will develop under proper eultural eonditions; the culture is then transferred repeatedly upon the selective medium and grown uncler striet anaerobic conditions. To purify anaerobes from aerobes, the method of Dorner ${ }^{17}$ can be used. The deep agar tube, inoculated with the organisms, is allowed to eool and the agar to solidify. Two cubic centimeters of melted agar containing 0.2 per cent of mercury bichloride is then poured on the surface of the cooled agar and the tubes are closed with rubber stoppers. The aerobes are thus completely eliminated. However, neither of these methods will separate the facultative anaerobes from the obligate anaerobes.

To separate anaerobes from spore-forming aerobes, use is made of three procedures: (1) Strict anaerobic methods of eultivation. The inhibitive aetion of gentian-violet on aerobic growth; $;{ }^{18,19}$ a $1: 100,000$ to $1: 400,000$ dilution of the dye in the agar medium is sufficient to render cultures of anaerobic bacteria free from spore-forming aerobes. (3) Anaerobic organisms are less sensitive than aerobes to pyrocatechin, chinon, sodium formate, and sodium sulphindigotate. ${ }^{20,21}$

The most difficult process, of ten involving a complicated technic, is

${ }^{17}$ Dorner, W. Beobachtungen über das Verhalten der Sporen und vegetativen Formen von Bac. amylobacter A. M. et Bredemann bei Nachweis- und Reinzuchtversuchen. Landw. Jahrb. Schweiz. 1924, 1-28.

${ }_{18}$ Churchman. The selective bactericidal action of gentian violet. Jour. Exper. Med. 16: 2, 221, 1912.

${ }^{19}$ Hall, I. C. Practical methods in the purification of obligate anaerobes. Jour. Inf. Dis. 27: 576-590. 1920.

${ }^{20}$ Kitasato, S., and Weyl, Th. Zur Kenntniss der Anaeroben. Zeitschr. Hyg. 8: 41, 404. 1890 .

${ }^{21}$ Rivas, D. Ein Beitrag zur Anaërobenzüchtung. Centrbl. Bakt. 32: 831842. 1902 . 
the separation of spore-forming anaerobes from other spore-forming anaerobes. The improper separation has led to exaggerated claims for the nature and activities of the organisms. All or some of the following procedures are utilized for this separation:

1. Heating the soil so as to kill the vegetative forms, then introducing various diutions of the heated soil suspension into the proper medium and making transfers from the culture at different stages of development (heating the culture every time a new transfer is made). The various spore-forming anaerobes sporulate at different periods of their development: some, like the saccharolytic bacteria, sporulate early; others, like most proteolytic forms, sporulating late.

2. Use of selective media stimulating the predominant development of the organism sought. This method has been of great help in the isolation of some important soil anaerobes. It is sufficient to mention that by the use of selective media and proper environmental conditions, such organisms as the anaerobic nitrogen-fixing forms, thermophilic and cellulose-decomposing forms and others were isolated. The specific medium is inoculated with an infusion of soil or manure, which may be previously heated, if the organism in question forms spores, and incubated at the desired temperature. The adjustment of the medium to specific reactions may often be sufficient to separate one group of organisms from another, often even anaerobic forms from one another. For instance, the adjustment of the nitrogen-free glucose media to a $\mathrm{pH}$ of 5.5 will not only favor the development of the nitrogen-fixing Clostridium pastorianum, but will also prevent the development of the proteolytic organisms, which usually accompany it.22 For the enrichment of cellulose decomposing anaerobic organisms, the use of a specific liquid medium or of a silica gel plate with cellulose as the only source of energy is recommended (p. 196). For the decomposisition of hemicellulose, physiological salt solution containing cubes of potato has been used, ${ }^{23}$ while, for starch splitting organisms, media containing 1 per cent peptone broth and 5 per cent starch have been suggested. ${ }^{24}$

3. The use of aniline dyes for the elimination of certain species of organisms.

4. Selective temperatures for the enrichment of various organisms,

22 Dorner, 1924 (p. 165).

${ }^{23}$ Ankersmit, P. Untersuchungen über die Bakterien im Verdauungskanal des Rindes. Centrbl. Bakt. I, Orig, 39: 359-574, 687. 1905; 40: 100-118.

${ }^{24}$ Choukevitch, J. Etude de la flore bactérienne du gros intestin du cheval. Ann. Inst. Past, 25: 247. 1911. 
developing preferably at the different temperatures, as in the case of thermophilic bacteria.

5. Use of high dilutions for the separation of organisms before plating. ${ }^{25}$

6. Isolation of the individual colony. This can be accomplished either $(a)$ by the picking of surface colonies from agar or gelatin plates or slants in large tubes, kept under anaerobic conditions; (b) by picking colonies from deep agar tubes, ${ }^{26}$ the last procedure being the easiest and most reliable in the process of separation of pure cultures of anaerobic bacteria from all accompanying forms.

7. Finally the isolation of single cells either by the India ink method, ${ }^{27}$ by the method of Barber, or by one of the microscopic methods. ${ }^{28}$

A detailed study of the various methods used for the isolation from surface colonies is given elsewhere. ${ }^{29,30}$

In general, plates or large agar slants containing the proper culture media are streaked out and placed either in vacuo, in hydrogen, carbon dioxide, or in an atmosphere from which the oxygen is removed by means of sodium pyrogallate. ${ }^{31}$ To produce discreet colonies, the agar plates or slants must be dried before inoculating, but too much drying of the medium is injurious. The slants or plates are streaked out with a loopful of the material taken from the enriched culture or using a dilution of it. The plates are immediately placed in the atmosphere of the neutral gas; the agar may also be placed into the upper part of a Petri dish, which is then covered directly with the sterile inverted lower half of the dish and the whole covered with a larger Petri dish. ${ }^{32}$

${ }^{26}$ Stoddard, J. L. Points in the technic of separating anaerobes. Jour. Am. Med. Assn. 79: 906. 1918.

${ }^{25}$ Burri, R. Zur Isolierung der Anaëroben. Centrbl. Bakt. II, 8: 533-537. 1902.

${ }^{27}$ Burri, 1909 (p. 55); also in Krause-Uhlenhut's Handbuch der mikrobiologischer Technik. 2: 329. 1923.

${ }^{28}$ Barber, 1911-1920 (p. 56). Kendall, A. I., Cook, M., and Ryan, M. Methods of isolation and cultivation of anaerobic bacteria. Jour. Inf. Dis. 29: 227-234. 1921. Holker, J. Micro- and Macro-methods of cultivating anaerobic organisms. Jour. Path. Bact. 22: 28. 1919; 23: 192-195. 1920.

${ }^{29}$ von Hibler, E. Untersuchungen über die pathogenen Anaeroben. Jena. 1908.

${ }^{30}$ Besson, A. Practical bacteriology, microbiology and serum therapy. London, 1913.

${ }^{31}$ Lentz, O. In Friedberger und Pfeiffer's Lehrbuch der Mikrobiologie. Jena, 1919, p. 370 .

${ }^{32}$ Marino, F. Méthode pour isoler les anaérobes. Ann. Inst. Past. 21: 1005. 1907; also Ogata, M., and Takenouchi, M. Einfache Plattenkulturmethode der anaëroben Bakterien. CentrbI. Bakt. I, 73: 75-77. 1914. 
However, the deep colony procedure, used first by Liborius for the isolation of anaerobic bacteria, has been preferred by a number of workers. The selection of a suitable medium for this purpose is essential; the medium should be clear and transparent and enough dilution tubes should be used. Some actively growing anaerobes will grow through the agar as if it was a broth; this "permeat-

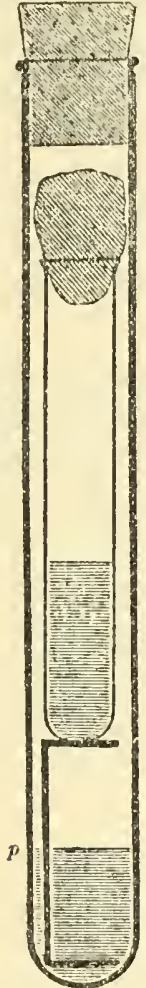

Fig. 9. Buchner tube for the anaerobic cultivation of bacteria: $p$, the alkaline pyrogallol solution; inner tube contains culture of organism (after Omeliansky). ing growth" will contaminate the other colonies. The deep tubes of sterile agar are placed in boiling water till the agar is melted, tubes are shaken to remove air, and agar cooled down to $45^{\circ}$. Long boiling is inadvisable, since the cotton becomes saturated with moisture. Three tubes are employed for ordinary purposes of dilution, but for new material or for weakly growing organisms among rapidly growing forms, more tubes may be used. Tube 1 is inoculated with one loopful of the enriched culture or soil suspension. The tube is then shaken, and transfer is made by means of a sterile pipette (a Pasteur pipette may be used), previously flamed, into tube 2 . The inoculum is placed throughout the length of the agar, while withdrawing the pipette, taking care not to blow air into the agar in the tube, the latter being then shaken. The pipette is flamed and, by means of it, some of the agar from tube 2 is transferred to tube 3 , which is also shaken. The tubes are plugged with cotton, as ordinary aerobic tubes, and incubated aerobically at $25^{\circ}$ to $28^{\circ}$. For actively growing species, 12 to 24 hours' incubation are sufficient; for slow growing forms, such as Bac. amylobacter, 4 to 8 days may be required. The colonies are examined, by means of a hand lens, for permeating growth and aerobic organisms. Final isolation is made from the colonies of the mixed culture. The tube and colonies to be transferred are selected. A plain glass or metal rod, sterilized in the flame and cooled, may be used to pierce the agar to the bottom of the tube, so as to admit air and allow the expulsion of the unbroken agar from the tube upon a sterile half of a Petri dish. The agar tube may also be placed for a second or two into warm water so as to separate the agar from the walls of the tube. The 
agar cylinder is then cut up into fine slices by means of a sterile scalpel; the desired colony is selected, either with the naked eye or using the microscope, and the agar is carefully cut away from it. A transfer is then made by pricking the colony with a fine sterile platinum needle and inoculating deep tubes with sterile agar or slants and liquid media, which are then incubated in an oxygen-free atmosphere.

When single cells are separated from one another to obtain pure cultures, it is better to isolate the spores rather than vegetative cells, since these give a much larger number of successful cultures (Barber). A medium somewhat more acid than the optimum (as $\mathrm{pH} 6.0$ ) is more favorable for the germination of the spores. Semi fluid media (containing 0.1 to 0.2 per cent agar) are preferable to liquid media, since the presence of a colloid greatly hastens the germination of the bacterial spores. ${ }^{33}$

Further information on the isolation of anaerobic bacteria is given clsewhere. ${ }^{34-39}$

Cultivation of anaerobes. 'There are a number of methods available for the cultivation of anaerobes, these methods being largely concerned with the reduction of the oxygen tension; some of these have been referred to already previously.

I. Cultivation in the absence of oxygen:

1. Mechanical protection against the atmospheric oxygen. The use of large volumes of freshly-boiled liquid media placed at a high level; also the process of covering the media with a layer of liquid petrolatum or other inert oil has been known since Pasteur. A layer of solid medium can be placed in a Petri dish, then inoculated with anaerobic bacteria and covered with a solution of agar (1.2 to 1.5 per cent) in distilled water. This layer of agar, in covering the medium, prevents sufficiently the admission of oxygen. The solid medium may also be

${ }^{33}$ Lantzsch, 1921 (p. 620).

${ }^{34}$ Kürsteiner, 1907 (p. 162).

${ }^{35}$ Veillon, A., and Mazé, P. De l'emploi des nitrates pour la culture et l'isolement des microbes anaérobies. Compt. Rend. Soc. Biol., 68: 112. 1910.

${ }^{36}$ Northrup, Z. A simple apparatus for isolating anaerobes. Jour. Bact. 1: 90-91. 1916.

${ }^{37}$ Hort, E. C. The cultivation of anaerobic bacteria from single cells. Jour. Hyg. 18: 361. 1920.

${ }^{38}$ Fuhrmann, F., and Pribram, E. Die wichtigsten Methoden beim Arbeiten mit Bakterien. Abderhalden's Handb. biol. Arb. Methoden. XII: 483-702. 1924.

${ }^{39}$ Löwi, E. Zur Technik der Anaerobenkultur mittels des Pyrogallolverfahrens. Centrbl. Bakt. I, Orig., 82: 493-496. 1919. 
placed in the upper part of a Petri dish, then covered with the lower part, placed into the upper part. Solid medium may also be placed in deep layers in ordinary containers, then inoculated with a long platinum loop reaching to the bottom of the container (Liborius). The agar can be taken out from the deep tube, by stabbing to the bottom a sterile glass or metallic tube, $2 \mathrm{~mm}$. in diameter, so as to admit air. ${ }^{40}$

2. Cultivation of anaerobes in vacuo. This method was also proposed by Pasteur and consists in placing the medium in a tube with a capillary end, inoculating, pumping out the air, then sealing the end. Petri dishes can also be placed in an ordinary desiccator, from which the atmosphere is then pumped out. The method described by Meyer ${ }^{41}$ can be used for the cultivation of bacteria at different partial oxygen tensions.

3. Absorption of oxygen from the atmosphere. The most common method of absorption of oxygen from the atmosphere is carried out by means of alkaline pyrogallate solution introduced by Buchner. ${ }^{42}$ A mixture of equal portions oi 10 per cent solutions of pyrogallol and $\mathrm{KOH}$ are often used, or 5 per cent solution of the first and 12.5 per cent of the second. Buchner used 1 gram of pyrogallic acid and $10 \mathrm{cc}$. of 10 per cent solution of $\mathrm{KOH}$ for every $100 \mathrm{cc}$. of air space. ${ }^{42}$ The method of Buchner was modified for liquid media:44 the sterile cotton plug is pushed into the tube; 1 ce. of 20 per cent pyrogallic acid and 1 cc. of 20 per cent $\mathrm{KOH}$ are placed upon it, the tube is then closed with a rubber stopper. An alkaline pyrocatechin $\mathrm{FeSO}_{4}$ solution to be used as a sensitive reagent for determining traces of oxygen has been suggested.45 The following method is very convenient: ${ }^{46}$ About 15 to $20 \mathrm{cc}$. of agar medium is placed in a large tube, about 1 inch in diameter, the tube is plugged with cotton and sterilized, then slanted. Immediately after inoculation, the cotton plug is pressed deeply into the tube, about 1 to 2 inches above the tip of slant. One eubic centimeter of a 20 per cent solution of pyrogallic acid (or a tabloid containing $0.13 \mathrm{gram}$ of the acid) and $0.25 \mathrm{cc}$. of a 40 per cent solution of $\mathrm{KOH}$ are poured upon the plug, the tube closed with a rubber stopper, turned upside down and placed in the incubator.

In the case of Petri dishes, Omeliansky used a combination of evacuation and absorption of oxygen. ${ }^{43}$ Ten per cent solution of $\mathrm{KOH}$ is poured upon the bottom of a desiccator and an open Petri dish containing dry pyrogallol is placed in it. The dishes containing fresh medium and inoculated are then placed into the

${ }^{40}$ Burri, R., Staub, W., and Hohl, J. Süssgrünfutter und Buttersäurebazillen. Schweiz. Milchztg. 45: nos. 78, 83. 1919.

${ }^{41}$ Meyer, 1905 (p. 162).

${ }^{42}$ Buchner, H. Eine neue Methode zur Kultur anaerober Mikroorganismen. Centrbl. Bakt. 4: 149. 1888.

${ }^{43}$ Omeliansky, W. L. Ein einfacher Apparat zur Kultur von Anaëroben in Reagenzglase. Centrbl. Bakt. II, 8: 711-714. 1902.

${ }^{44}$ Wright, J.H. A method for the cultivation of anaërobic bacteria. Centrbl. Bakt. I, 29: 61. 1901 .

${ }_{45}$ Binder, K., and Weinland, R. F. Über eine neue scharfe Reaktion auf elementaren Sauerstoff. Ber. deut. chem. Gesell. 46: 255-259. 1913.

${ }^{46}$ Buchanan, R. M. An inset absorption appliance for the test-tube culture of Anaerobes. Centrbl. Bakt. I, Orig., 74: 526-527. 1914. 
desiccator. The latter is covered and evacuated. The desiccator is then carefully turned so as to mix the alkali with the pyrogallol. Since this takes place in the presence of traces of oxygen it browns only slightly. If the cover is not tight, the admission of oxygen is readily indicated by the rapid browning of the mixture. A beaker with water may be placed in the desiccator to prevent the rapid drying out of the media. ${ }^{47}$

Various other methods for the physical or chemical absorption of the oxygen from the atmosphere have been used; they are based upon the addition of organic or inorganic substances, possessing a strong reducing power, to the medium or outside of the medium in a gas-tight vessel. These include ferrous sulfate, sodium sulfide, ammonium sulf-hydrate, sodium sulfite, ferro-ammonium sulfate, phosphorus; glucose, sodium formate, pyrocatechin, indigo-carmin; metallic iron and zinc; various tissues, pieces of potato, carrot, fresh yeast, etc. These treatments are often accompanied by a partial vacuum. The plates or tubes may be placed in a container to which a quantity of freshly cut potatoes is added, then covered with a bell jar.

4. Replacement of air by an indifferent gas. Hydrogen, carbon dioxide, nitrogen, and other inert gases may be used for this purpose. A tube, ${ }^{48,49}$ flask or desiccator ${ }^{50,51}$ supplied with a two-holed rubber stopper can be used for this purpose. When all the air is replaced by the inert gas, the tubes are sealed. ${ }^{62}$

\section{Cultivation in the presence of oxygen:}

5. Cultivation of anaerobes in the presence of aerobic organisms. This method approaches nearest to what takes place in nature than any of the other methods. By cultivating an anaerobic spore forming organism with an aerobic non-spore former, like Bact.prodigiosum, it is easy to obtain a pure culture of the former by pasteurization. This method has only a limited application in the study of pure cultures. Beijerinck ${ }^{53}$ employed obligate aerobic bacteria to eliminate the last traces of oxygen from the atmosphere. A combination of two of the above processes may be used.

The media used for the isolation and cultivation of anaerobic bacteria depend

47 Rockwell, G. E. An improved method for anaerobic cultures. Jour. Inf. Dis. 35: $581-486.1924$.

48 Fraendel, C. Über die Kultur anaërober Mikroorganismen. Centrbl. Bakt. 3: 735, 763. 1888.

${ }^{49}$ Petri, R. J., and Maaszen, A. Ein bequemes Verfahren für die anaërobe Züchtung in Flüssigkeiten. Arb. K. Ges. Amt. 8: 314. 1893.

${ }^{50}$ Botkin, S. Eine einfache Methode zur Isolierung anaërober Bakterien. Ztschr. Hyg. 9: 383.1890.

51 Novy, F. G. Die Plattenkultur anaërober Bakterien. Centrbl. Bakt. 16: 566. 1894 .

${ }^{52}$ Richardson, A. C., and Dozler, C. C. A safe method for securing anaerobiosis with hydrogen. Jour. Inf. Dis. 31: 617-621. 1922.

${ }^{63}$ Beijerinck, M. W. Oidium lactis, the milk mould, and a simple method to obtain pure cultures of anaerobes by means of it. Proc. Sec. Sci. K. Akad. Wettensch. Amsterdam, 21: 1219-1226. 1919. 
upon the specific organisms. Certain special methods may also be used. Among these, gelatin and milk have played an important part. By inoculating milk with a small quantity of soil, a certain type of butyric acid bacteria can be readily demonstrated. This is not a medium for enrichment of anaerobes, as for differential purposes. Various protein (egg-albumin) and glucose media can be used. The medical bacteriologists have made extensive use of brain and blood agar media. To demonstrate the presence of certain organisms, specific media may have to be used. To demonstrate the presence of Bac, amylobacter, nitrogen-free g'ucose (2 per cent) agar placed in a deep tube is inoculated with a soil suspension; if quantitative results are wanted, various dilutions are employed (the soil suspension may be previously heated, in a water bath, at $80^{\circ}$ for 10 minutes, whereby only the number of spores is obtained). The tubes are closed with rubber stoppers (when the culture is to be isolated, a surface layer of sublimate agar is used) and incubated at $30^{\circ}$. Gas formation will take place on the second day, breaking up the medium. This and the production of butyric acid will indicate the presence of the organism; the colonies are lens-shaped. Microscopic examination of the culture can be made by staining with Lugol's reagent. The method of Burri can be used for determining the number of anaerobic bacteria in the soil, not only by establishing the presence of growth in the final dilution, but by actually counting the colonies in the deep tube.

Classification of soil anaerobes. Various systems for the classification of anaerobic bacteria and their relation to aerobes have been proposed at different times. ${ }^{54,55}$ But even at the present time, a proper classification of anaerobes, especially of soil forms is lacking. The idea that anaeobic bacteria vary greatly has served further to increase the existing confusion. This led to various exaggerations, such as the existence of only a few anaerobic forms which change into one another, or the making of new genera on the basis of minor physiological differences. ${ }^{56}$

The following system of classification of soil anaerobes may be suggested here merely as a tentative working basis:

I. Bacteria acting primarily upon carbohydrates:

1. Bacteria utilizing largely simple carbohydrates and starches as sources of energy, of ten referred to as saccharolytic. Here belong the butyric acid bacteria, often classified as one species, Bac. amylobacter A. M. et Bred. These decompose sugars with the formation of butyric acid and gas:

(a) Nitrogen-fixing bacteria-Clostridium pastorianum Winogradsky (Bac, amylobacter von Tieghem, Bac. amylocyme Perdrix, Bac. butyricus Botkin, Granulobacter saccarobutyricum Beij., Bac. orthobutylicus Grimbert, Clostridium americanum Pring-

${ }^{64}$ Hibler, 190 (p. 167); Bredemann, 1909 (p. 109).

65 Jungano, M., and Distaso, A. Les anaérobies. Paris. 1910.

${ }^{6} \mathrm{Heller}, \mathrm{H}$. H. Classification of the anaerobic bacteria. Bot. Gaz. 73: 70-79. 1922; Jour. Bact. 7: 1-3S. 1922. 
sheim, Bac. amylobacter A. M. Bred.) and allied forms found in great abundance in practically all soils. This organism or group was classified by Bergey as $C l$. butyricum Prazmowski and by Lehman and Neumann as Bac. pastorianus (Winogradsky). ${ }^{57}$ Its physiology and occurrence in the soil is discussed elsewhere (p. 110).

(b) Bac. welchii Migula (Bac. aerogenes capsulatus Welch and Nutall, Bac. perfringens Veillon and Zuber, Bac.enteritidis sporogenes Klein), a short rod 4 to 8 by 1 to $1.5 \mu$, single or in pairs; nonmotile, forming oval, central or excentric spores; encapsulated (No. 44, Pl. IX). Found repeatedly in the soil and in sewage. 58

2. Bacteria decomposing pectins.

(a) Bac. amylobacter group, which includes the Clostridium pastorianum (same as 1a). The forms causing the retting of flax have been described under various names. Here belong the Plectridium of Fribes and Winogradsky, the Clostridium of Behrens, the Plectridium pectinovorum of Störmer, the Granulobacter pectinovorum of Beijerinck and van Delden."s

(b) Bac. fclsineus Carbone.

3. Bacteria decomposing celluloses:

(a) Anacrobic bacteria decomposing celluloses at ordinary temperatures. Here belong the hydrogen and methane organisms of Omeliansky and the Bac. cellulosae dissolvens Khouvine.

(b) Thermophilic cellulose decomposing bacteria-Clostridium thermocellum Viljoen, Fred and Peterson. The occurrence and isolation of these organisms is described elsewhere (p. 202).

II. Bacteria acting primarily upon proteins:

1. Strongly proteolytic forms:

(a) Bac.sporogenes Metchnikoff (No. 58, Pl, X), a motile, flagellated, gram positive bacillus, with rounded ends, 3 to 7 by 0.6 to $0.8 \mu$; one of the strongest proteolytic bacteria known; it decomposes proteins with the formation of gas, a darkening of the medium and production of a pronounced odor; the subterminal spores are formed readily. Found abundantly in the soil, manure, street dust and sewage.

57 Further information on the classification of the anaerobic bacteria acting primarily upon carbohydrates is given by Donker, H. J L. Bijdrage tot de kennis der Baterzuur-, Butylalcohol-en Acetongistingen. Delft. 1926.

${ }^{58}$ Klein and Houston. Rept. Med. Officer, Local Govt. Board, London, 1898 1899, 318; Greer, F. E. Anaerobes in sewage. Amer. J. Publ. Health, 15: 860-867. 1925.

${ }^{59}$ Ruschmann, G., and Ravendamm, W. Zur Kenntnis der Rösterreger Bacillus felsineus Carbone und Plectridium pectinovorum (Bac. amylobacter A. M. et Bredemann). Centrbl. Bakt. II, 64: 340-394. 1925. 
(b) Bac. oedematis maligni Koch (Vibrion septique Pasteur), found in the intestines of man and in the soil. ${ }^{60}$

(c) Bac. putrificus Bienstock, a motile, flagellated bacillus, forms terminal oval spores and has weak saccharolytic and strong proteolytic properties. Milk is gradually digested, without rapid coagulation (No. $45, \mathrm{Pl}$. IX).

(d) Bac. histalyticus Weinberg and Seguin, 3.0 to 5.0 by 0.5 to $0.7 \mu$, occurring singly or in pairs, motile by peritrichous flagella; spores oval excentric. This organism has been isolated from the soil by Peterson and Hall. ${ }^{61}$

(e) Bac. balulinus van Ermengem, large rods with rounded ends; oval, subterminal spores. The natural habitat of this organism has been found in virgin and cultivated soils, mountain and forest soils, ${ }^{62-64}$ throughout the world.

2. Weakly proteolytic organisms:

(a) Bac. bifermentans Tissier and Martelly, non-motile bacillus, with large central, oblong to oval spores.

(b) Bac. Ictani Nicolaier; 4 to 8 by 0.4 to $0.6 \mu$; motile by means of peritrichic flagella; unable to utilize carbohydrates, introduced into the soil with the manure. ${ }^{65}$ Its occurrence in the soil has been demonstrated ${ }^{64,66}$ in many of the samples examined.

Various other anaerobic bacteria which are weakly proteolytic, but are capable of attacking different carbohydrates, with the formation of gas have been isolated either directly from the soil or from other sources, which may indicate a soil habitat, such as Bac. chauvoei. A detailed study of the various anaerobic bacteria, including Bac. sporogenes, Bac. histolyticus and others, secured from wound infections and

${ }^{60}$ Gt. Britain National Health Ins. Joint Comm., Medical Research Committee. Special Reports, Series No. 39. Reports of the Committee upon anaerobic bacteria and infections. 1919.

${ }^{61}$ Peterson, E. C., and Hall, I. C. The isolation of Bacıllus histolyticus from soil in California. Proc. Soc. Exp. Biol. Med. 20: 502-503. 1923.

62 Tanner, F. W., and Dack, G. M. Clostridium botulinum. Jour. Inf. Dis. 31: 92-100. 1922 .

${ }_{63}$ Dubovsky, B. J., and Meyer, K. F. An experimental study of the methods available for the enrichment, demonstration of $B$. botulinus in specimens of soil, etc. Jour. Inf. Dis. 31: 501-540, 541-555, 556-558, 559-594, 595-599, 600-609, 610-613. 1922 .

${ }^{64}$ Hall, I. C., and Peterson, E. C. The detection of Bacillus botulinus and Bacillus tetani in soil samples by the constricted tube method. Jour. Bact. 9: 201-209. 1924.

${ }^{65}$ Noble, W. Experimental study of the distribution and habitat of the tetanus bacillus. Jour. Inf. Dis. 16: 132-141. 1915.

${ }^{66}$ Dubovsky, S. J., and Meyer, K. F. The occurrence of B. tetani in soil and on vegetables. Jour. Inf. Dis. 31: 614-616. 1922. 
probably coming in most cases originally from the soil has been made by Weinberg and Seguin. ${ }^{67}$

III. Bacteria obtaining their oxygen from inorganic salts:

1. Bacteria reducing nitrates.

2. Bacteria reducing sulfates.

Both of these groups are described in detail elsewhere (p. 180).

Anaerobic organisms may occur in the soil in great abundance; $\mathrm{Ucke}^{68}$ found a garden soil to contain $13 \frac{1}{2}$ million cells of anaerobic bacteria and 500,000 spores per 1 gram of soil. In some cases individual species are found in the soil in great abundance. Kürsteiner, for example, found as many as 1 million and more cells of Bac. putrificus per 1 gram of soil. Bac. amylobacter was found by Bredemann to be present in practically every soil examined, both in the surface layer and in the subsoil, in cultivated soils, in primeval forests and in pure sand; the organism occurred only irregularly in acid peat soil. Out of 200 samples of Swiss soils examined, only seven clid not contain this organism. ${ }^{69}$ The number of colonies formed on artificial media are considerably less than the actual number of organisms actually present in the soil; this is brought out by the results of Dorner, ${ }^{69}$ who found that out of 1000 spores present in a medium, only 3 germinated and developed into colonies, while out of 1000 vegetative cells, 45.1 produced colonies.

By the use of the dilution and selective culture method, Dïggeliro found 1000 to $1,000,000$ anaerobic butyric acid bacteria per gram of soil, 0 to 1000 anaerobic cellulose-decomposing bacteria, 100 to 1,000,000 anaerobic nitrogen-fixing bacteria, from 100 to $1,000,000$ anaerobic protein-decomposing bacteria and 100 to 1,000,000 pectin-decomposing bacteria. By the deep tube method, only between 19,000 and 900,000 anaerobic bacteria were found per gram of soil. This is due to the fact that no single solid medium can be devised which would be favorable for the development of all anaerobic bacteria.

Various anaerobic bacteria take an active part in the composting of manure in the heap, whenever there is an insufficiency of aeration. The so-called phenomenon of "putrefaction" is chiefly a result of the decomposition of protein substances under anaerobic conditions, due to

${ }^{67}$ Weinberg, M., and Seguin, P. La gangrène gazeuse. Masson \& Cie. Paris. 1918.

${ }^{68}$ Ucke, A. Ein Beitrag zur Kenntnis der Anaeroben. Centrbl. Bakt. I, 23: $996-1001.1898$.

${ }^{69}$ Dorner, 1924 (p. 165).

${ }^{70}$ Düggeli, 1921 (p. 39). 
incomplete oxidation as a result of insufficient aeration. The absence of air in the deeper piles of manure, the slightly alkaline reaction and the presence of large amounts of undecomposed substances make conditions favorable for the development of anaerobic bacteria. ${ }^{71}$ Various anaerobic urea bacteria ${ }^{72}$ and thermophilic organisms ${ }^{73}$ also find conditions in the composting manure heap favorable for their development. Well rotted horse manure contains spore-forming, anaerobic thermophilic bacteria $7^{74}$ the limiting temperature for their growth was found to be $60^{\circ}$ to $65^{\circ} \mathrm{C}$. and the thermal death point $110^{\circ}$ to $120^{\circ} \mathrm{C}$. Some of these organisms were found to be actively proteolytic. No growth took place at room temperature. Various anaerobic spore-bearing bacteria are no doubt brought into the soil with the feces in great abundance; a number of these organisms have actually been demonstrated in intestinal secreta. ${ }^{75}$

Physiological activities of anaerobic bacteria. It is impossible to discuss the physiological activities of the various obligate anaerobic bacteria, since they differ greatly in the nature of their metabolism. Those that obtain their energy from cellulose, those that can obtain their nitrogen from the elementary form, those that can utilize nitrate or sulfate oxygen, and those that produce foul odors from complex proteins have a distinct physiology from one another and cannot be considered under one heading, merely because they are similar in their requirements of oxygen tension. They usually have an optimum range of hydrogenion concentration at $\mathrm{pH} 6.0$ to 8.2 with a limiting range of $\mathrm{pH} 5.0$ to 9.0 ; the spores germinate better at a higher acidity, with an optimum at pH 6.0 to $7.2 .^{76}$

While aerobic bacteria produce largely carbon dioxide among the volatile gases, the anaerobic bacteria are characterized by the production

71 Severin, S. A. Die im Miste vorkommende Bakterien und deren physiologische Rolle bei der Zersetzung derselben. Centrbl. Bakt. II, 1: 799-817. 1895; 3: 628-633, 708. 1897. Zhur. Opit. Agron. (Russian), 1: 463-489. 1920.

72 Geilinger, 1917 (p. 210).

${ }^{73}$ Veillon, R. Sur quelques microbes thermophiles strictement anaérobies. Ann. Inst. Past. 36: 422-438. 1922.

74 Damon, S. R., and Feiber, W. A. Anaerobic sporulating thermophiles. Jour. Bact. 10: 37-46. 1925.

${ }^{75} \mathrm{Kahn}, \mathrm{M}$. C. Anaerobic spore-bearing bacteria of the human intestine in health and in certain diseases. Jour. Inf. Dis. 35: 423-478. 1924.

${ }^{76}$ Dozier, C. C. Optimum and limiting hydrogen-ion concentrations for B. botulinus and quantitative estimation of its growth. Jour. Inf. Dis. 35: 105133. 1924 . 
of a number of other gases. It is sufficient to mention hydrogen and methane, as a result of decomposition of carbohydrates, hydrogen sulfide as a result of reduction of sulfates, elementary nitrogen and oxides of nitrogen as a result of reduction of nitrates, and various amines, elementary nitrogen and oxides of nitrogen, hydrogen sulfide, mercaptans and thioether as a result of decomposition of proteins. It is necessary to be able to measure these and determine them quantitatively, especially since they are often of great economic importance when a soil is water-logged for a longer or shorter period of time. The bacteria are grown on suitable media (specific for the various organisms) under anaerobic conditions, in tubes or bottles connected with a manometer. The tubes may also be placed in a Novy jar used as a respiratory chamber. ${ }^{77}$ The growth may be carried on in an atmosphere of pure gas, such as $\mathrm{N}_{2}, \mathrm{H}_{2}, \mathrm{CO}_{2}$. By using a compensation manometer, the pressure changes taking place within the culture tube or jar can be observed constantly, these changes indicating the periods of active growth followed by the cessation of growth and respiration. The samples of gas are withdrawn directly into a burette or first into a sampler, then into a modified Henderson-Haldane or other suitable apparatus.

The volume of the gas to be analyzed is first measured; the gas is then passed back and forth into 10 per cent $\mathrm{KOH}$ solution to absorb the $\mathrm{CO}_{2}$, which is determined by difference in the volume of gas. The latter, freed from $\mathrm{CO}_{2}$, is passed into an alkaline pyrogallate solution (or sticks of yellow phosphorus in water) to absorb the oxygen; the latter is determined also by the difference in volume of the gases. The estimation of hydrogen, methane and other combustible gases is carried on in a combustion chamber over heated platinum, in the presence of oxygen (or air as a source of oxygen). By measuring the amount of $\mathrm{CO}_{2}$ formed in combustion, it is possible to calculate the amount of methane and other hydrocarbons present in the gas mixture; the amount of hydrogen is then determined by the difference between the loss due to combustion and the methane present. The amount of oxygen absorbed in the combustion is obtained by calculation or by the difference between the oxygen added and that remaining, as determined by absorption in the pyrogallate solution. The $\mathrm{CO}_{2}$ present in the medium (liquid) is aerated into standard $\mathrm{Ba}(\mathrm{OH})_{2}$ solution, then titrated.

${ }^{77}$ Novy, F. G., Roehm, H. R., and Soule, M. H. Microbic respiration. I. The compensation manometer and other means for the study of microbic respiration. Jour. Inf. Dis. 36: 109-167. 1925. 
Oxides of nitrogen are determined by combustion in the platinum spiral before oxygen (or air) is admitted, in the presence of hydrogen. The contraction in volume serves as an index of $\mathrm{N}_{2} \mathrm{O}\left(\mathrm{N}_{2} \mathrm{O}+\mathrm{H}_{2} \rightarrow\right.$ $\mathrm{H}_{2} \mathrm{O}+\mathrm{N}_{2}$ ). The oxides of nitrogen may be absorbed from 100 cc. sample of gas in $200 \mathrm{cc} . \mathrm{M} / 50 \mathrm{KOH}$ solution, then oxidized to nitrate by adding $5 \mathrm{cc}$. of 30 per cent hydrogen peroxide. The solution is evaporated to dryness on a water bath and nitrates determined by the phenoldisulphonic acid method. ${ }^{78}$ Volatile amines and mercaptans do not occur in great abundance among the decomposition products in the soil, but are found largely in the anaerobic decomposition of manure: ${ }^{79,80}$ $\mathrm{H}_{2} \mathrm{~S}$ gas can be determined by absorption with acetates of lead and cad mium, or ammoniacal cadmium chloride solution, then titrating the CaS with iodine in acid solutions. ${ }^{81}$

Among the gases formed by the proteolytic bacteria, like Bac. sporogenes, we find largely $\mathrm{CO}_{2}$ and some hydrogen; the odoriferous gases consist largely of $\mathrm{H}_{2} \mathrm{~S}$; some elementary nitrogen and $\mathrm{N}_{2} \mathrm{O}$ are also formed. The saccharolytic organisms, like Bac. welchii, produce a large amount of hydrogen, often as much as 50 per cent of the gases. ${ }^{81}$ The ratio between the $\mathrm{CO}_{2}$ and hydrogen depends largely upon the environmental conditions of growth.

Anaerobic bacteria form various acids (acetic, butyric, lactic), alcohols (ethyl, butyl), and in some cases acetone. Often closely related organisms vary greatly in their metabolic products. For example, while different members of the Bac. amylobacter group (Clostridia, Plectridia, Granulobacter) produce butyric acid, the closely related Bac. felsineus does not do so.

Soil processes in which anaerobic bacteria take an active part. Attention has already been called to a number of important physiological processes in the soil, in which anaerobic bacteria take an active part. It is sufficient to indicate that such processes as decomposition of celluloses, pectins and proteins, and the fixation of nitrogen non-symbiotically are as active anaerobically as aerobically. Ammonia formation

${ }^{78}$ Allison, V. C., Parker, W. L., and Jones, J. W. Determination of oxides of nitrogen. Tech. Paper No. 249, U. S. Bureau of Mines. 1921.

${ }^{79}$ Guggenheim, M. Die biogenen Amine. 1920.

${ }^{80}$ Hirsh, P. Die Einwirkung von Mikroorganismen auf die Eiweisskörper. Lorntraeger. Berlin. 1918.

${ }^{81}$ Anderson, B. G. Gaseous metabolism of some anaerobic bacteria. XIX. Methods. Jour. Inf. Dis. 35: 213-243. 1924. 
from proteins is very active under anaerobic conditions. ${ }^{82-84}$ Two maxima were found for nitrogen-fixation in the soil, one under aerobic and another under anaerobic conditions; ${ }^{85,86}$ a higher fixation may actually be obtained anaerobically. ${ }^{87}$ The decomposition of cellulose under anaerobic conditions is carried on entirely by bacteria. The phenomena of reduction under anaerobic conditions, especially that of nitrates, may become an important economic factor.

It is important to point out, in this connection, the active rôle which anaerobic bacteria play in the rotting of manure. As a matter of fact, the lowest loss of nitrogen and the most efficient conservation of the important elements of the manure is accomplished by keeping it compact and moist, so as to prevent the action of aerobic fungi and bacteria and stimulate the action of anaerobic bacteria. As far back as 1889, Schloesing ${ }^{88}$ pointed out that under anaerobic conditions there is no loss of nitrogen. The gases were found to consist of equal volumes of methane and carbon dioxide, when the manure is incubated at $52^{\circ} \mathrm{C}$. Water takes part in the reaction supplying some oxygen for the formation of $\mathrm{CO}_{2}$ and some hydrogen for the methane. The amount of gas procluced per hour rapidly increases until it reaches a maximum on the 6th day, when it begins to diminish. At $42^{\circ} \mathrm{C}$., $850 \mathrm{cc}$. of gas collected from the decomposition of $100 \mathrm{gm}$. of manure consisted of $713.6 \mathrm{cc}$. $\mathrm{CO}_{2}, 97.6$ cc. methane and 38.8 cc. hydrogen.

Further information on the decomposition of proteins and carbohydrates under anaerobic conditions and on the nature of soil gases is given elsewhere (p.638).

${ }^{2}$ Löhnis, 1905 (p. 120).

${ }^{83}$ Traaen, A. E. Ủber den Einfluss der Feuchtigkeit auf die Stickstoffumsetzungen im Erdboden. Centrbl. Bakt. II, 45: 115. 1916.

${ }^{84}$ Murray, T. J. The oxygen requirements of biological soil processes. Jour. Bact. 1: 597-614. 1916.

${ }^{85}$ Greaves, J. E. Azofication. Soil Sci. 6:163-218. 1918.

${ }^{86}$ Lipman and Sharp, 1915 (p. 584).

${ }^{87}$ Panganiban, E. H. Rate of decomposition of organic nitrogen in rice paddy soils. Phillip. Agriculturist, 12: 63. 1923; Temperature as a factor in nitrogen changes in the soil. Jour. Amer. Soc. Agron. 17: 1-31. 1925.

88 Schloesing, 1889 (p. 62). 


\section{CHAPTER VII}

\section{Bacteria Reducing Nitrates and Sulfates}

General classification of nitrate reducing bacteria. A large number of organisms, including numerous bacteria and actinomyces, fungi, yeasts and higher plants, but especially the first two groups, are capable of reducing nitrates to nitrites; this often serves as the first step in the process of assimilation of nitrate nitrogen. Some organisms, chiefly fungi and certain bacteria, but also higher plants, are capable of reducing the nitrate to ammonia. However, only specific bacteria are capable, under certain conditions, of reducing the nitrate and the nitrite to elementary nitrogen and oxides of nitrogen, in which form the nitrogen escapes into the atmosphere. Under anaerobic conditions, the nitrate and nitrite may serve as sources of oxygen for these bacteria, which enables them to oxidize the available sources of energy. ${ }^{1}$ The last process is usually referred to as complete or direct denitrification and the bacteria concerned in this process are spoken of as denitrifying bacteria. These bacteria can be further subdivided into $(a)$ those which use as a source of energy inorganic substances, notably sulfur, and (b) those that use organic carbon compounds as sources of energy. Complete denitrification is generally favored by the presence of nitrate, suitable sources of energy (usually carbon compounds), absence of free oxygen and proper reaction.

The bacteria, which reduce nitrates only to nitrites or to ammonia, but not to nitrogen gas (elementary form and oxides), may be best spoken of as nitrate reducing bacteria, reserving the term denitrifying bacteria for the other organisms.

Organisms reducing nitrates to nitrites. The reduction of nitrates in the soil has been demonstrated in the first part of the 19th century.

${ }^{1}$ Weissenberg, H. Studien über Denitrifikation. Arch. Hyg. 30: 279-290. 1897; Jensen, H. Das Verhältnis der denitrifizierenden Bakterien zu einigen Kohlenstoff verbindungen. Centrbl. Bakt. II, 3: 622-627, 689-698. 1897; Beiträge zur Morphologie und Biologie der Denitrifikationsbakterien. Ibid. 4: 401-411, 449-460. 1898; Pakes, W. C. C., and Jollyman, W. H. The collection and examination of the gases produced by bacteria from certain media. Jour. Chem. Soc. I, 79: 322-329. 1901. 
This process was found to be brought about by various groups of microorganisms, capable of reducing nitrates to nitrites, first by Schönbein ${ }^{2}$ in 1868 , then by others, especially by Gayon and Dupetit. ${ }^{3}$ In addition to various bacteria, ${ }^{4}$ certain yeasts, filamentous fungi, ${ }^{5}$ and actinomyces ${ }^{6}$ are capable of reducing nitrates to nitrites. The composition of the medium is important in this respect, particularly the nature of other sources of nitrogen and of the energy source. The presence of carbohydrates, glycerol and organic acids, in addition to peptone, was found to stimulate the reduction of nitrate to nitrite, while an abundance of oxygen injured it.

Frankland ${ }^{7}$ called attention to the fact that certain bacteria (Bac. ramosus and Bac. pestifer) are specifically concerned in this process. The reduction was favorably influenced by increasing the organic matter content of the solution, especially the peptone. Anaerobiosis or lack of sufficient aeration greatly favors nitrite formation. ${ }^{8-10}$ Nitrite-forming bacteria are well distributed in the soil. ${ }^{11,12}$ Such soil forms as Bac. megatherium ${ }^{13}$ and Bact. vulgare $^{14}$ are found among the

2 Schönbein, C. F. Über die Umwandlung der Nitrate in Nitrite durch Conferven und andere organische Gebilde. Jour. prakt. Chem. 105: 208-214. 1868.

${ }^{3}$ Gayon, U., and Dupetit, G. Sur les fermentations des nitrates. Compt. Rend. Acad. Sci. 95: 644-646. 1882; Sur la transformation des nitrates en nitrites. Ibid., 1365-1367; Recherches sur la réduction des nitrates par les infiniments petits. Nancy. 1886; Mem. Soc. Sci. phys. Nat. Bordeaux. 1886; Ann. Sci. Agron. 1: 226-325. (1885) 1886.

${ }^{4}$ Maassen, A. Die Zersetzung der Nitrate und Nitrite durch die Bakterien. Arb. K. Gesundheitsamt, 18: 21-77. 1901.

${ }^{5}$ Wolff, K. Denitrifikation und Gärung. Hyg. Rundschau, 91: 538. 1899.

${ }^{6}$ Waksman, 1919 (p. 299).

${ }^{7}$ Frankland, P. J. The action of some specific microorganisms on nitric acid. Chem. News, 57: 89. 1888; Über einige typische Mikroorganismen im Wasser und im Boden. Ztschr. Hyg. 6: 373. 1899.

${ }^{8}$ Laurent, E. Experiences sur la réduction des nitrates par les végétaux. Ann. Inst. Past. 4: 722-744. 1890.

${ }^{9}$ Kühl, H. Beitrag zur Kenntnis des Denitrifikationsprozesses. Centrbl. Bakt. II, 20: 258-261. 1908.

${ }^{10}$ Caron, H. V. Untersuchungen über die Physiologie denitrifizierender Bakterien. Centrbl. Bakt. II, 33: 62-116. 1912.

11 Jensen, 1897 (p. 180).

${ }_{12}$ Klaeser, M. Die Reduktion von Nitraten zu Nitriten und Ammoniak durch Bakterien. Centrbl. Bakt. II, 41: 365-430. 1914: Ber. deut. bot. Gesell. 32: 58. 1914.

${ }^{13}$ Stoklasa, 1898 (p. 104).

${ }^{14}$ Horowitz, A. Contribution à l'étude du genre Proteus vulgaris. Ann. Inst. Past. 20: 307-318. 1916. 
nitrite formers. Out of 109 species of bacteria tested by Maassen, ${ }^{15}$ in a solution containing 5 per cent peptone and 0.5 per cent sodium nitrate, 85 were found capable of reducing nitrates to nitrites, especially Bact. pyocyaneum; 46 reduced the nitrite to ammonia and 4 liberated atmospheric nitrogen. Out of 28 species of bacteria studied by Klaeser, ${ }^{12}$ all but one were found capable of reducing nitrates. Many strict aerobic bacteria are capable of acting anaerobically in the presence of nitrates. Intensive aeration inhibits the process of nitrate reduction. The reaction of the medium has an important influence in determining whether nitrates are reduced to nitrites or ammonia; an alkaline reaction favors the first process and an acid reaction the second.

Klaeser used a medium having the following composition:

\begin{tabular}{|c|c|c|}
\hline & 2 grams & $\mathrm{NaCl}, \ldots . . . \ldots . .$. \\
\hline & & 0.3 \\
\hline & $1 \mathrm{gram}$ & $\mathrm{FeCl}_{3}$ \\
\hline
\end{tabular}

$\mathrm{CaCl}_{2} \ldots \ldots \ldots \ldots . . .1$ gram

Other media, with and without peptone, but containing nitrates, can also be used for demonstrating nitrate reduction by bacteria. The formation of nitrites from nitrates has been suggested as a test in characterizing bacteria. ${ }^{16}$

The following organisms can be recorded as capable of reducing nitrates to nitrites: Bact. coli, Bact. vulgare and allied species, Bact. prodigiosum, Bact. putidum, Bact. Auorescens, Bact. pyocyaneum, Bact. herbicola, Bac. subtitis and allied species, Bac. vulgatus, Bac. mycoides, Micr. pyogenes, Mycobact. phlei and other mycobacteria, B. porticensis and others. Some of these organisms, such as Bact. coli, are also capable of forming hydrogen. ${ }^{17}$ The products formed from the reduction of the nitrate depend largely upon the composition of the medium and oxygen tension.

Organisms reducing nitrates to ammonia. Marchal ${ }^{18}$ was one of the first to demonstrate that certain bacteria (Bac. mycoides) are capable of reducing nitrates to ammonia, with the intermediate formation of ni-

15 Maassen, 1901 (p. 181).

${ }^{16}$ Conn, H. J., and Breed, R. S. The use of the nitrate-reduction test in characterizing bacteria. Jour. Bact. 4: 267-290. 1919.

${ }^{17}$ Mazé, P. Les phénomènes de fermentation sont les actes de digestion nouvelle demonstration apportée par l'étude de la dénitrification dans le regne végétal. Ann. Inst. Past. 25: 289-312, 369-391. 1911.

${ }_{18}$ Marchal, E. The production of ammonia in the soil by microbes. Agr. Sci. 8: 574. 1894; Centrbl. Bakt. II, 1: 75\&. 1895. 
trites. Beijerinck and van Delden ${ }^{19}$ found that various bacteria, like Bac. subtilis and Bac. mesentericus vulgatus, are capable of producing both ammonia and nitrite from nitrates, but no ammonia from nitrites; Azotobacter chroococcum, however, produced ammonia from nitrates and nitrites. The reduction process takes place in the presence of carbohydrates and organic acids as sources of carbon. ${ }^{20}$ These bacteria undoubtedly include the "protein-forming bacteria" described by Gerlach and Vogel, ${ }^{21}$ capable of transforming nitrate into protein nitrogen with an intermediate reduction to ammonia nitrogen.

Kruse $^{22}$ called attention to the fact that those microorganisms, which cannot bring about "fermentation of the nitrate" (complete reduction to nitrogen), are capable of reducing it to ammonia. This seems to be the natural process, when microorganisms are assimilating nitrates and nitrites, to reduce them first to ammonia, as shown for a number of bacteria and fungi. ${ }^{23}$

Bacteria reducing nitrates to atmospheric nitrogen. The formation of gaseous nitrogen in the process of decomposition of organic matter in the soil was first observed by Davy. ${ }^{24}$ This was ascribed to a chemical interaction between nitrites and amino acids in the soil, resulting in the formation of gaseous nitrogen. ${ }^{25}$ Gayon and Dupetit ${ }^{26}$ pointed out in 1882 that bacteria were responsible for this process and that the free nitrogen originated from the nitrates. Dehérain and Maquenne ${ }^{27}$ demonstrated that nitrate decomposition in the soil takes place only in the absence of atmospheric oxygen and in the presence of an abundance

${ }^{19}$ Beijerinck, M. W., and van Delden, A. Über die Assimilation des freien Stickstoffs durch Bakterien. Centrbl. Bakt. II, 9: 3-43. 1902.

${ }^{20}$ Stoklasa, J., and Vitek, E. Beiträge zur Erkenntnis des Einflusses verschiedener Kohlenhydrate und organischer Säuren auf die Metamorphose des Nitrats durch Bakterien. Centrbl. Bakt. II, 14: 102-118. 1905.

${ }^{21}$ Gerlach and Vogel. Utber eiweissbildende Bakterien. Centrbl. Bakt. II, 7: 609-623. 1901 .

${ }^{22}$ Kruse, 1910 (p. xii).

${ }^{23}$ Kostyschew, S., and Tswetkowa, E. Úber die Verarbeitung der Nitrate in organische Stickstoff verbindungen durch Schimmelpilze. Ztschr. physiol. chem. 111: 171-200. 1921.

${ }^{24}$ Davy, 1814 (p. 122).

${ }^{25}$ Dietzell, B. E. Ueber die Entbindung von freien Stickstoff bei der Fäulnis. Ztschr. Landw. Ver. Bayern. 72: 186-201. 1882. (Biederm. Centrbl. Agrik. Chem. 11: 417-420. 1882).

${ }^{26}$ Gayon and Dupetit, 1882 (p. 181).

${ }^{27}$ Dehérain, P. P., and Maquenne. Sur la réduction des nitrates dans la terre arable. Compt. Rend. Acad. Sci. 95: 691-693, 732-734, 854-856. 1882. 
of organic matter. The process is checked by heating the soil or treating it with chloroform, which results in the destruction of the bacteria responsible for the reduction of the nitrates. ${ }^{28}$ In the decomposition of organic nitrogenous compounds, free from nitrates, both in the presence and absence of oxygen, nitrogen gas is not produced; when nitrates are present, an active reduction takes place in the absence of oxygen, with the formation of gaseous nitrogen and various oxides of nitrogen. ${ }^{29}$ This reduction diminishes with an increase in the amount of oxygen present but does not stop entirely. Even those investigators who believed at first that denitrification is a purely chemical process, carried out by means of the soil colloids, were convinced by later studies that nitrate reduction is not of a chemical nature. ${ }^{30}$

Bacteria may bring about the formation of nitrogen gas from nitrates in two different ways: (a) indirectly and (b) directly. The nitrite which is formed in the process of reduction of nitrate by Bact. coli, Bact. vulgare, Bact. prodigiosum, Bac.vulgatus, may interact chemically with the amino nitrogen of the peptone molecule or the various amino acids formed from the decomposition of peptone, liberating gaseous nitrogen. The various oxides of nitrogen formed from the reduction of nitrate may also interact with the ammonia nitrogen formed from the peptone and result in free nitrogen gas:

$$
\mathrm{NH}_{4} \mathrm{NO}_{2}=2 \mathrm{H}_{2} \mathrm{O}+\mathrm{N}_{2}
$$

These indirect processes play only a questionable rôle in the soil. However, in addition to these bacteria, which in themselves are unable to produce nitrogen gas directly from nitrates, the soil harbors various specific bacteria capable of reducing the nitrate molecule directly to atmospheric nitrogen. Breal ${ }^{31}$ found that a nitrate solution to which straw is added liberates a great deal of gaseous nitrogen. Similar results have been obtained on inoculating a nitrate solution with horse

${ }^{28}$ Ehrenberg, A. Experimentaluntersuchungen über die Frage nach dem Freiwerden von gasformigen Stickstoff bei Fäulnissprocessen. Ztschr. physiol. Chem. 11: 145-178, 438-471. 1886.

${ }^{29}$ Tacke, Br. Über die Entwicklung von Stickstoff bei Fäulniss. Landw. Jahrb. 16: 917-939. 1888.

${ }^{30}$ Vogel, J. Über das Verhalten von Nitrat im Ackerboden. Centrbl. Bakt. II, 34: 540. 1912; Landw. Vers. Sta. 78: 265-301. 1912; 82: 159-160. 1913.

${ }^{31}$ Bréal, E. De la présence dans la paille d'un ferment aérobie réducteur de l'acide nitrique. Ann. Agron. 18: 181-195. 1892. Compt. Rend. Acad. Sci. 114: 681-684. 1892 . 
manure. Wagner ${ }^{32}$ then attempted to draw, on insufficient ground, broad generalizations concerning the reduction of nitrates to gaseous nitrogen by denitrifying bacteria in manure, even when added to the soil.

Gayon and Dupetit ${ }^{33}$ isolated from the soil, in 1886, two anaerobic bacteria ( $B$. denitrificans $\alpha$ and $\beta$ ) capable of reducing nitrates to gaseous nitrogen. The two organisms were cultivated upon a medium having the following composition: ${ }^{34}$

1. Distilled water.... $250 \mathrm{cc}$. $\mathrm{KNO}_{3} \ldots \ldots \ldots \ldots \ldots 2$ grams Asparagine....... 1 gram
2. Distilled water.... $500 \mathrm{cc}$.

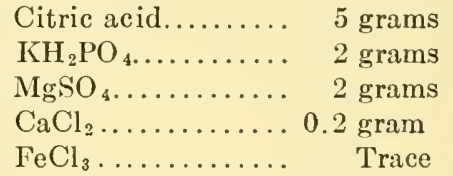

Solution 2 is neutralized with a 10 per cent solution of $\mathrm{NaOH}$ or $\mathrm{KOH}$, with phenolphthalein as an indicator. The two solutions are mixed and made up to $1000 \mathrm{cc}$. with distilled water.

For the isolation of denitrifying organisms, various other media can be used: (1) 1000 cc. water, 10 grams glucose, 6 grams $\mathrm{NaNO}_{3}, 6$ grams $\mathrm{NaCl}, 0.02$ gram $\mathrm{Ca}_{3}\left(\mathrm{PO}_{4}\right)_{2} \cdot{ }^{35}$ (2) 100 cc. water, 0.5 to 1.5 grams $\mathrm{NaNO}_{3}, 20$ to 50 grams glycerol, 7 grams malic acid (neutralized with sodium carbonate), 0.5 gram sodium phosphate, 0.5 gram $\mathrm{NaCl}, 0.5$ gram $\mathrm{Na}_{2} \mathrm{CO}_{3}, 0.1$ gram $\mathrm{MgSO}_{4} \cdot{ }^{36}$ (3) 1000 ec. water, 20 grams of calcium tartrate, citrate or malate, 10 to 20 grams $\mathrm{KNO}_{3}, 0.5$ gram $\mathrm{K}_{2} \mathrm{HPO}_{4}$.

Under anaerobic conditions, practically all the nitrate nitrogen can be transformed into gaseous nitrogen. When asparagine is replaced by sugar, the ammonia otherwise produced from the asparagine is not formed. In the reduction of nitrate to gaseous nitrogen (so-called "nitrate fermentation"), there is an abundant accumulation of alkali, till the process is stopped when the alkali concentration is equivalent to 1 per cent sodium carbonate. ${ }^{37}$ When the alkali is neutralized by means

32 Aeby, J., Dorsch, R., and Matz, Fr., and Wagner, P. Forschungen über den relativen Düngewart und die Konservierung des Stallmistsickstoffs. Landw. Vers. Sta. 48: 247-360. 1897.

${ }^{33}$ Gayon and Dupetit, 1886 (p. 181).

${ }^{34}$ Giltay, E., and Aberson, G. Denitrifizierende Organismen im Boden. Arch. Neerland. 25: 341. 1892.

${ }^{35}$ Ampola and Ulpiani. Gazz. chim. ital. 1898, 410.

${ }^{36}$ Maassen, 1901 (p. 181).

${ }^{37}$ Burri, R., and Stutzer, A. Über Nitrat zerstörende Bakterien und den durch dieselben bedingten Stickstoffverlust. Centrbl. Bakt. II, 1: 257-265, 350-364, 392-398, 422-432. 1895; 2: 473-474. 1896. 
of an acid, nitrate reduction continues further, until all the nitrate has disappeared. ${ }^{38}$ The organisms are very sensitive to free acids. The optimum reaction for the reduction of nitrates is $\mathrm{pH} 7.0$ to 8.2 ; the limiting reactions are $\mathrm{pH} 5.5$ and $\mathrm{pH} 9.8$. The optimum reaction for the reduction of nitrites is $\mathrm{pH} 5.5$ to 7.0 .

The reduction of nitrates to atmospheric nitrogen may be a result of associative action of two bacteria, one (Bact. coli) reducing the nitrate to nitrite and the other (Bact. denitrificans I) reducing the nitrite to atmospheric nitrogen. ${ }^{37}$ In case of associative growth, the aerobic form removes the free oxygen, thus enabling the other organism to become the denitrifier. Some organisms reduce only nitrates to nitrogen. The four species found by Maaszen capable of reducing nitrate to gaseousnitrogen were Bact. fluorescens liquefaciens, Bact. fluorescens from blood, Bact. pyocyaneum and Bact. praepollens. These results were confirmed by other investigators, ${ }^{39-41}$ who found Bact. pyocyaneum, Bact. hartlebii and fluorescent bacteria among the most active denitrifying organisms.

Among the forms capable of reducing nitrates completely to gaseousnitrogen, we may also include various organisms isolated from horse manure, ${ }^{42}$ from cattle excreta (Bact. denitrificans agilis) ${ }^{43}$ and from the soil. ${ }^{44-46}$ Van Iterson ${ }^{47}$ demonstrated the presence in the soil of various bacteria, namely Bact. stutzeri, Bact. denitrofluorescens and Bact. vul-

${ }^{38}$ Zacharowa, T. M. Process of denitrification as dependent upon the reaction of the medium. Trans. Institute of Fertilizers, No. 15, 1923, Moskau.

${ }^{39}$ Sewerin, S. A. Zur Frage über die Zersetzung von salpetersauren Salzen durch Bakterien. Centrbl. Bakt. II, 3: 504-517, 554-563. 1897; 22: 348-370. $1909 ; 25$ : 479-492. 1909.

${ }^{40}$ Christensen, H. R. Zwei neue fluoreszierende Denitrifikationsbakterien. Centrbl. Bakt. II, 11: 190-194. 1904.

${ }^{41}$ Fred, E. B. Eine physiologische Studie über die nitratereduzierenden Bakterien. Centrbl. Bakt. II, 32: 421-449. 1911.

42 Schirokikh, J. Über einen neuen Salpeter zerstörenden Bacillus. Centrbl. Bakt. II, 2: 204-207. 1896.

${ }^{43}$ Ampola, G., and Garino, E. Ueber die Denitrifikation. Centrbl. Bakt. II, 2: 670-676. 1896;3: 309-310. 1897.

44 Jensen, 1897-8 (p. 180).

${ }^{45}$ Höflich, C. Vergleichende Untersuchungen über die Denitrifikationsbakterien des Mistes, des Strohes und der Erde. Centrbl. Bakt. II, 8: 245-248, 273-278, 305-308, 336-339, 361-367, 398-406. 1902.

${ }^{46}$ Cingolani, M. Recherche intorno al processo della denitrificazione. Staz. Sper. Agr. ital. 41: 521-538. 1908; Ann. Staz. Chim. Agr. Spes. Roma (2), 2: 274. 1908. (Centrbl. Bakt. II, 23: 238. 1909.)

${ }^{47}$ van Iterson, C. Anhäufungsversuche mit denitrifizierenden Bakterien. Centrbl. Bakt. II, 12: 106-116. 1904. 
pinus, which reduce nitrates to gaseous nitrogen, in the presence of small quantities of organic matter. In the same soil, where nitrification takes place under aerobic conditions, denitrification will take place in the absence of free oxygen.

The following authentic organisms capable of reducing nitrates to atmospheric nitrogen have been isolated and described (some of these are probably only varieties of other species which do not denitrify):

Bact. denitrificans ( $=$ Bact. denitrificans I Burri and Stutzer, Pseud. stutzeri Mig.) L and $N$ (1.5 to 3 by $0.7 \mu$ ), a motile, non-spore forming, aerobic organism.

Bact. stutseri (= Bact. denitrificans II Burri and Stutzer, Bact.nitrogenes Mig.) $\mathrm{L}$ and $\mathrm{N}$ ( 2 to 4 by 0.7 to $0.8 \mu$ ), a motile, non-spore forming, facultative anaerobic organism, isolated from straw and horse manure..$^{48}$

Bact. künnemanni (= Bac. denitrificans III Künnemann), a motile, non-spore forming organism.

Bact. denitrificans agilis ${ }^{49}$ ( 1 to 1.5 by 0.1 to $0.3 \mu$ ), a motile, peritrichic, nonspore forming organism; gram-negative, facultative anacrobic, granulated and developing slow; according to Löhnis this is a denitrifying variety of Bact. radiobacter.

Bact. ulpiani (= Bac. denitrificans VI Ampola et Ulpiani), a motile, non-spore forming, gram-negative organism.

Vibrio denitrificans ${ }^{50}$ ( 2 to 4 by $0.5 \mu$ ), a motile, non-spore forming organism.

Bac. schirokikhi, ${ }^{51}$ a motile, spore-forming, proteolytic, aerobic organism.

Bact. praepollens, ${ }^{52}$ a small, non-motile, obligate aerobic organism, reducing only nitrites.

Bac. nitroxus ${ }^{53}$ (No. 62, Pl. X) comprising bacilli of variable dimensions, globous, pyriform, filiform; they take the form of Clostridia at the time of spore formation, giving an intense glycogen reaction; facultative anaerobic; on repeated transfer under aerobie conditions may lose faculty of reproduction; gelatin is liquefied.

In addition to these and the above mentioned bacteria, we may also call attention to a few other denitrifying forms which were isolated, such as Bact. $f u l$ vum, ${ }^{54}$ Bact. hartlebii, ${ }^{55}$ Bact. centropunctatum, Bact. nitrovorum, B. porticensis, ete. Most of these organisms are strict aerobes, some being eapable of decomposing proteins actively. Most of them grow on nitrate (0.2 to 1.0 per cent) media, with

${ }^{48}$ Künnemann, O. Über denitrifizierende Mikroorganismen: Landw. V ersuchsta. 50: 65-113. 1898.

${ }^{49}$ Ampola and Garino, 1896-1897 (p. 186); Kuntze, W. Beiträge zur Morphologie und Physiologie der Bakterien. Centrbl. Bakt. II, 13: 1-12. 1904.

${ }^{50}$ Sewerin, 1897 (p. 186).

${ }^{51}$ Jensen, 1898 (p. 180).

${ }^{62}$ Maassen, 1899 (p. 181).

${ }^{53}$ Beijerinck and Minkman, 1910 (p. 546).

${ }^{54}$ Bierema, S. Die Assimilation von Ammon-, Nitrat- und Amidstickstoff durch Mikroorganismen. CentrbI. Bakt. II, 23: 672-726. 1909.

${ }^{65}$ Jensen, 1898 (p. 180). 
the formation of a gas (largely $\mathrm{N}$, some $\mathrm{CO}_{2}$ ) and nitrite. In the absence of free oxygen, these organisms can exist anaerobically in the presence of nitrate.

A thermophilic denitrifying baeillus ( 3.5 to 7 by 1 to $1.8 \mu$ ), facultative anaerobic, reducing nitrates with the formation of gas and growing at high temperatures $\left(52^{\circ} \mathrm{C}\right.$.) has also been deseribed. ${ }^{56}$

Several organisms reducing nitrates are capable of obtaining their energy from inorganic compounds. Thiob. denitrificans Beij. oxidizes sulfur and reduces nitrates to nitrogen gas. This organism, or rather group of organisms, is widely distributed in the soil..$^{57,58}$ Thiosulfate ean be oxidized by the organism under anaerobic conditions only in the presenee of nitrate as a source of oxygen. ${ }^{59}$ The utilization of the energy obtained by the oxidation of hydrogen gas for the reduction of nitrates has been pointed out by Niklewski ${ }^{60}$ for $H$. agilis.

The decomposition of cellulose in the soil may be carried on by the symbiotic action of two bacteria, one redueing nitrate to atmospheric nitrogen and the other decomposing the cellulose; the decomposition products of the cellulose are used by the nitrate reducing organism as a source of energy, which enables it to reduee the nitrate, while the oxygen thus liberted is utilized by the cellulose decomposing organism, under anaerobic conditions. ${ }^{61}$

Bacteria reducing sulfates to $\mathrm{H}_{2} \mathrm{~S}$. A detailed study of the formation of hydrogen sulfide in nature is given elsewhere (p. 600). It is sufficient to call attention here to the bacteria capable of producing this substanee as a result of reduction of sulfates and other oxygen-rich sulfur compounds (like thiosulfates). Microspira desulfuricans (No. 63, Pl. $\mathrm{X}$ ), capable of bringing about this reduction, was first studied by Beijerinek, ${ }^{62}$ then obtained in pure culture by Van Delden. ${ }^{63}$ It was isolated on the following mediun:
$\mathrm{K}_{2} \mathrm{HPO}_{4} \ldots \ldots \ldots \ldots 0.5$ gram
Sodium lactate...... 5.0 grams
$\mathrm{MgSO}_{4}$ or $\mathrm{CaSO}_{4} \ldots \ldots \quad 1.0$ gram
$\mathrm{FeSO}_{4} \ldots \ldots \ldots \ldots \ldots$ Trace
Asparagine......... 1.0 gram
Tap water......... $1000 \mathrm{cc}$.

\footnotetext{
${ }^{66}$ Ambroz, 1913 (p. 15s).

57 Lieske, 1912 (p. 86).

${ }^{58}$ Gehring, 1914 (p. 87).

${ }_{69}$ Trautwein, 1921 (p. 87).

${ }^{60}$ Niklewski, 1914 (p. 99).

${ }^{61}$ Gerretsen, 1921 (p. 736).

${ }^{62}$ Beijerinck, M. W. Über Spirillum desulfuricans als Ursache von Sulfatreduktion. Centrbl. Bakt. II, 1: 1-9, 4S-59, 104-114. 1895.

${ }^{63}$ Van Delden, A. Beitrag zur Kenntnis der Sulfatreduktion durch Bakterien. Centrbl. Bakt. II, 11: 81-94, 113-118. 1904.
} 
The medium is filled to the neek of the bottles, then inoculated and incubated at $25^{\circ} \mathrm{C}$. Sulfur reduction becomes evident by a ehange in color due to formation of $\mathrm{H}_{2} \mathrm{~S}$. The bacterium can be isolated from the soil when some sodium sulfite is added to the medium. The presence of organic substances as sources of energy and anaerobic conditions are required for the action of the organism. For the isolation of pure cultures, 10 per cent gelatin or 2 per cent agar is added to the above medium; in place of $\mathrm{FeSO}_{4}$ a trace of $\mathrm{FeSO}_{4} \cdot\left(\mathrm{NH}_{4}\right)_{2} \mathrm{SO}_{4} \cdot 6 \mathrm{H}_{2} \mathrm{O}$ together with some sodium carbonate is used. In 3 to 6 days small black colonies appear. Sulfur is deposited in the colony, on the solid medium, among the baeterial cells, clue to the incomplete reduction of the sulfate. The organism is a very motile spirillum, 4 by $1 \mu$ in size and is strictly anaerobic.

Another organism (Microspira aestuarii) was isolated from sea water. Various thermophilic bacteria (Vibrio thermo desulfuricans) are capable of reducing sulfates. ${ }^{64}$ These three forms are closely related to one another and have the ability, apart from all other bacteria, to utilize sulfates and thiosulfates as sources of oxygen under anaerobic conditions.

An actinomyces ( $A$. pelogenes) capable of reducing sulfates to sulfides and forming iron sulfide was also isolated. ${ }^{65}$ These organisms occur in great abundance in certain lakes and seas, and especially in the black eurative muds; their reducing properties under these conditions keep the sulfur in the process of constant transformation, ${ }^{66}$ as discussed in detail elsewhere (p. 611).

${ }^{64}$ Elion, L. A thermophilic sulfur-reducing bacterium. Centrbl. Bakt. II, 63: 58-67. 1924.

${ }^{65}$ Sawyalow, W. Über Schwefelwasserstoffgärung im schwarzen Heilschlamme. Centrbl. Bakt. II, 39: 440-447. 1913.

${ }^{66}$ Nadson, G. A. On the hydrogen sulfide fermentation in the Weissovo Lake and the participation of microbes in the formation of the black mud. 1903. St. Petersburg. (Russian.) 


\section{CHAPTER VIII}

\section{Bacteria Capable of Decomposing Celluloses and Other Complex Carbohydrates and Hydrocarbons}

IN THE SOIL

Microorganisms concerned in the decomposition of celluloses in nature Among the microorganisms concerned in the decomposition of different constituents of plant and animal tissues, those capable of breaking down celluloses have attracted considerable attention, due to the fact that these materials make up a large part of the bulk of the organic matter added to the soil, but chiefly because the organisms concerned are more or less specific in nature. Many bacteria are capable of existing only with celluloses as a source of energy and some cannot even utilize any other source of energy. Organisms capable of decomposing celluloses are found among various groups of fungi, among the actinomyces and among the bacteria. However, under anaerobic conditions, the fungi and actinomyces do not thrive and bacteria alone are entirely concerned in the process.

The cellulose-decomposing bacteria can be divided into two groups, (1) the aerobic and (2) the anaerobic forms. Certain special groups of these forms may be concerned in the process, namely (3) the thermophilic bacteria, probably active in the decomposition of celluloses in manure and also in the soil under certain conditions, and (4) the denitrifying bacteria, active only in the presence of nitrates and under certain specific conditions. ${ }^{1}$

Anaerobic bacteria. Mitscherlich ${ }^{2}$ observed in 1850 that, in the rotting of potatoes in water, the cell walls are destroyed while the starch accumulates at the bottom of the container. He ascribed this action to

${ }^{1}$ See Pringsheim, H. Die Polysaccharide. 2 Auf. Springer. Berlin. 1923; Karrer, P. Einführung in die Chemie der polymeren Kohlenhydrate. Akad. Verlagsges. Leipzig. 1926. 'Rippel, A. Der biologische Abbau der pflanz-, lichen Zellmembrannen. Ztschr. angew. Bot. 1: 78-97. 1919; Waksman, S. A. and Skinner, C. E. The microorganisms concerned in the decomposition of celluloses in the soil. Jour. Bact. 12: 57-84. 1926.

${ }^{2}$ Mitscherlich. Zusammensetzung der Wand der Pflanzenzelle. Monatschr. K. Akad. Wiss. Berlin. 1850, 102-110. 
vibrios which were present in abundance in the water. Van Tieghem ${ }^{3}$ described in detail a species of Amylobacter previously found to occur in decomposing plant tissues and staining blue with iodine; it decomposed young plant tissues with the formation of butyric acid, carbon dioxide and hydrogen. However, this organism was not a species in the true sense of the word, but a collective form; it is doubtful whether it decomposed pure cellulose at all, so that it could hardly deserve the term "cellulose organism." Since cellulose forms an important constituent of manure, attention has been directed chiefly towards cellulose decomposition in the rotting of manure. It has been found, for example that the atmosphere at different depths of the manure pile consists of various gases. The content of carbon dioxicle and especially of methane increases and the nitrogen content decreases with depth. Oxygen is entirely absent at the lower depths of the pile.

Omeliansky ${ }^{5}$ was the first to establish definitely the connection between the activities of microorganisms and the decomposition of cellulose.

The following medium was employed:

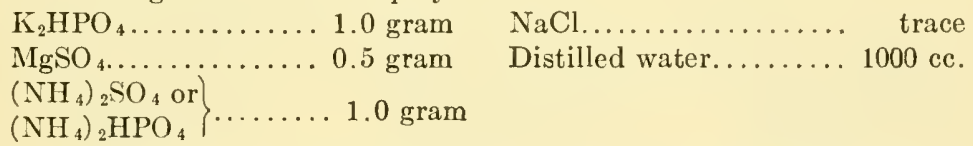

The ammonium salt may be replaced by 0.5 per cent asparagine or 0.1 per cent peptone. Some chalk and pure filter paper were placed in long-necked bottles, which were then filled with the medium to the stopper. The flasks were inoculated with horse manure or river mud and incubated at $34^{\circ}$ to $35^{\circ}$. After a considerable period of incubation (usually more than a week), gas production set in. The paper became covered with specks; these were the places where the decomposition of the cellulose began. At the end of the growth period (active fermentation), which is accompanied by abundant gas formation, there remained only a part of the paper, half rotted and entirely changed in appearance. This residue fell apart at the slightest touch. The white color of the paper had changed into yellow-brown, the medium also was colored, and the odor of the medium was that of rotten cheese. When precipitated cellulose was used in place of filter paper, the reaction was more rapid.

${ }^{3}$ Van Tieghem, P. E. L. Sur le Bacillus amylobacier et son rôle dans la putréfaction des tissus végétaux. Compt. Rend. Acad. Sci. 68: 205-210; 89: 5-8, 1102-1104. 1879; Bull. Soc. Bot. France, 24: 128-135. 1877; 26: 25. 1879; 28 : 243-245. 1887.

${ }^{4}$ Omeliansky, W. L. Die Cellulosegärung. Lafar's Handb. tech. Mykol. 3: $245 \rightarrow 268.1904$.

5 Omeliansky, W. Ueber die Gärung der Cellulose. Centrbl. Bakt. II, 8: 193-201, 225-231, 257-263, 2S9-294, 321-326, 353-361, 355-391, 1902; 11: 369-377, $1904 ; 36: 472-473.1913$. 
Omeliansky found that the mixture of gases contained hydrogen or methane, these two gases being produced by two different organisms. When the inoculum was added without preliminary heating, methane formation took place; when the inoculum was heated for 15 minutes at $75^{\circ}$, conditions favored the development of the bacteria which produced hydrogen in the decomposition of cellulose. The spore of the methaneforming organism was found to germinate earlier than that of the hydrogen form. When the culture was transferred, the former organism predominated and the latter could be finally entirely eliminated. By heating the inoculum or a young culture, the vegetative cells produced from the spores of the methane form, which had already germinated, were killed, while the ungerminated spores of the hydrogen form survived and proceeded to develop. If this process of heating the culture at an early stage of development was repeated several times, the hydrogen form could be obtained free from the methane form.

\section{PLATE XI}

Cellulose and Pectin-decomposing Bacteria

64. (x), Bac. cellulosae hydrogenicus syn Bac. fossicularum L \& N, and $(y)$, Bac. cellulosae methanicus syn Bac. methanigenes L \& N: $a$, young cells; $b$, spore formation; $c$, ripe spores, $\times 660$ (from Omeliansky).

65. Bac. cellulosae dissolvens, showing bacteria attached to the cellulose fiber, by their non-sporulating extremities (from Khouvine).

66. Holes in paper produced by Spirochaeta cytophaga, grown in Petri dish culture upon $\mathrm{NaNO}_{3}$-mineral salt agar with filter paper superimposed, natural size (from Hutchinson and Clayton).

67. Spirochaeta cytophaga, young culture on filter paper placed in tube; typical incurvation of thread forms (from Hutchinson and Clayton).

68. Sp. cytophaga, formation of pre-sporoid stage with double granules (from Hutchinson and Clayton).

69. Bact. fimi, 15-day old colonies on cellulose agar plate, at $30^{\circ} \mathrm{C}$. (from MeBeth and Scales).

70. Bact. fimi, vegetative cells from 24-hour culture on nutrient agar, stained with carbol-fuchsin, $\times 660$ (from McBeth and Scales).

71. Bac. cytaseus, 15 -day old colonies on cellulose agar plate, at $30^{\circ} \mathrm{C}$. (from McBeth and Scales).

72. Bac. cytascus, nine day old culture at $30^{\circ} \mathrm{C}$., showing spore formation; aqueous fuchsin stain, $\times 660$ (from McBeth and Scales).

73. Clostridium thermocellum, a thermophilic cellulose decomposing bacillus. A 48 starch-hgar culture at $65^{\circ} \mathrm{C}$. stained with carbol fuchsin for 5 minutes, at $100^{\circ} \mathrm{C}$., showing free spores, sporangia and vegetative rods (from Viljoen, Fred and Peterson).

74. Granulobacter pectinovorum (after Beijerinck). 


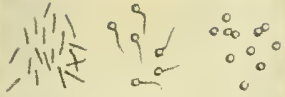

$64 x$

$64 Y$

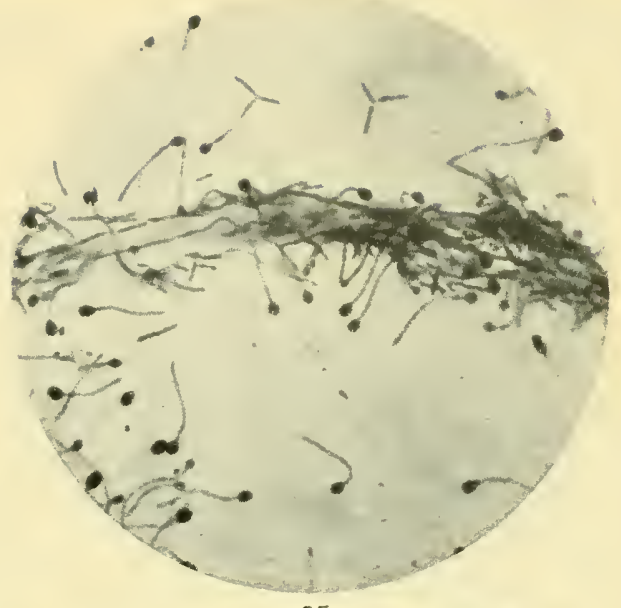

65

- : - id -

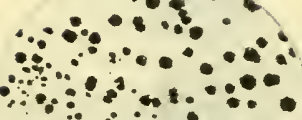

$\because \because \because \because \cdots * \bullet$

$\because \because \because \because \because \div$

$\because \div-0^{\circ}$

66

$\circ$

○

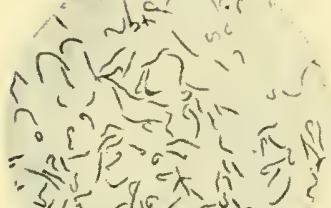

- Sili

,

- , 然然。

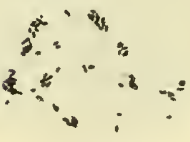

70
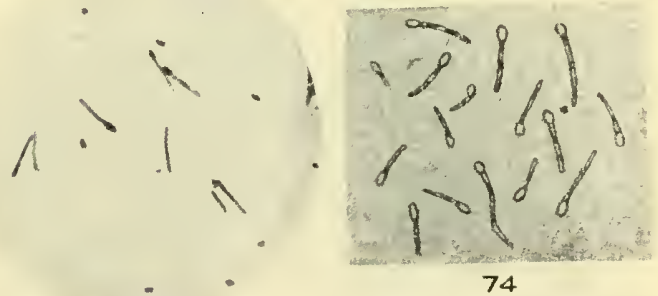

The hydrogen organism (Bac. fossicularum L. et N.) was found to form thin, straight rods ( 4 to 8 by $0.5 \mu$ ) in young cultures. With age of culture the cells become longer until they reach a length of 10 to $15 \mu$, without increasing in thickness and without forming chains. The cells are often slightly curved, sometimes even spiral-like, especially on precipitated cellulose. At a later stage, one end of the cell swells up gradually and takes the appearance of an oblong and then of a round body. A perfectly round spore develops in this swelling, fills all the space, and has a diameter not exceeding $1.5 \mu$ when ripe. After some time, the spore is liberated by the breaking up of the mother cell. Old cultures, in which the decomposition of the paper is well advanced, show only spores with a slight admixture of vegetative forms which are usually in the stage of forming spores. The spore-containing cultures may be stained with a double stain of carbol fuchsin and methylene blue. The organism is never colored blue with iodine and, therefore, lacks the important characteristics of Amylobacter. By repeated transfers on enrichment culture media, a microscopically pure culture of the organism can be obtained, especially if the inoculum is heated for 20 minutes at $90^{\circ} \mathrm{C}$. to kill all non-spore forming contaminations. But all repeated attempts to cultivate the organism on solid media failed. This prevented a detailed study of its metabolism.

The methane organism (Bac. methanigenes L. et N.) is quite similar to the hydrogen organism, but is even thinner and more gently contoured. By several transfers and on heating the inoculum, a culture is obtained which seems microscopically pure. Chains are never formed in a young stage and the cells have a tendency to curve slightly. The spores are smaller than those of the hydrogen form, being $1 \mu$ in diameter. Iodine does not give a blue color. Morphologically both organisms may be elassified as one species, while, physiologically, they are distinctly different. Attempts to cultivate this organism on solid media and obtain a pure culture also failed.

Kellerman and associates ${ }^{6}$ could not confirm the results of Omeliansky. They even succeeded in isolating from Omeliansky's cultures an aerobic cellulose-decomposing organism. They suggested, therefore, that the cellulose was decomposed by aerobic bacteria in Omeliansky's cultures, while the accompanying anacrobic forms produced gas from the products of decomposition of the cellulose by the former. However, Khouvine ${ }^{7}$

${ }^{6}$ Kellerman et al., 1912-1914 (p. 197).

${ }^{7}$ Khouvine, Mme. Y. Digestion de la cellulose par la flore intestinale de l'homme. Cour D'Appel. Paris. 1923. 
succeeded in isolating from the intestine of man an obligate anaerobic organism, Bac. cellulosae dissolvens, capable of decomposing cellulose very vigorously, especially in mixed culture. The organism was 2.5 to $12.5 \mu$ long, and did not form any flagella; the spores were 2.5 by $2 \mu$ in size. It was cultivated upon a medium containing fecal matter as a source of nitrogen. The spores were killed only on boiling for 45 to 50 minutes. The organism decomposed cellulose at $38^{\circ}$ to $51^{\circ} \mathrm{C}$., without any distinct optimum. When the oxygen tension of the atmosphere was above $12 \mathrm{~mm}$. mercury, no growth took place. The organism clung to the paper, so that the contaminating forms could be removed by washing the paper with sterile salt solution. Sixty per cent of the cel-

TABLE 14

Summary of characteristics of two anaerobic cellulose decomposing bacteria

\begin{tabular}{|c|c|c|}
\hline & $\begin{array}{l}\text { BACILLUS CELLULOSAE } \\
\text { DISSOLVENS- } \\
\text { KHOUVINE }\end{array}$ & $\begin{array}{l}\text { CLOSTRIDYM THERMOCELLUM- } \\
\text { V, F AND P }\end{array}$ \\
\hline Size of rods . . . . . . . . . . & $2.0 \times 2$ to $12 \mu$ & $5.0 \times 0.4 \mu$ \\
\hline Size of spore . . . . . . . . . & $2.0 \times 2.5 \mu$ & $0.9 \times 0.6 \mu$ \\
\hline Flagella............... & Absent & Peritrichous \\
\hline $\begin{array}{l}\text { Nutrient broth with or with- } \\
\text { out glucose.............. }\end{array}$ & No growth & $\begin{array}{l}\text { Ring, pellicle and sediment; } \\
\text { acid and gas with glucose }\end{array}$ \\
\hline Nutrient agar........... & No growth & $\begin{array}{l}\text { Small surface and subsurface } \\
\text { colonies on starch agar }\end{array}$ \\
\hline Potato slant. & No growth & Yellow growth, potato browned \\
\hline Milk................ & No growth & Acid curd in three days \\
\hline Carbohydrates decomposed.. & Only cellulose & $\begin{array}{l}\text { Hemicellulose, starch, various } \\
\text { hexoses and pentoses }\end{array}$ \\
\hline
\end{tabular}

lulose decomposed was accounted for by the carbon dioxide, hydrogen, ethyl alcohol, acetic and butyric acids, and a brown pigment. The presence of other bacteria greatly stimulated the power of this organism to decompose cellulose. The organism was found to be also abundantly distributed in the soil, occurring in all soil types, under various conditions.

The results of other investigators ${ }^{8}$ also point to the anaerobic nature of cellulose decomposing bacteria in the digestive tract of horses. Under anaerobic conditions, cellulose decomposition is carried out entirely by bacteria; the nature of the processes involved being different

${ }^{8}$ Hösslin, A., and Lesser. Über die Zersetzung der Zellulose durch den Inhalt des Coecums des Pferdes. Ztschr. Biol. 54: 47. 1910. 
from that of cellulose decomposition under aerobic conditions. ${ }^{9}$ The thermophilic Clostridium thermocellum Vil., Fred and Peterson, described later, is also an anaerobic organism, decomposing cellulose very actively. Aerobic bacteria. The first attempt to study cellulose decomposition under aerobic conditions was made by Van Iterson, ${ }^{10}$ who described a non-spore-forming organism, Bacillus ferrugineus, which decomposed cellulose under aerobic conditions, in symbiosis with a yellow micrococcus, the latter not decomposing any cellulose when alone.

The following medium was used:

Tap water.......... $100 \mathrm{cc}$.

Filter paper......... 2 grams

$\mathrm{K}_{2} \mathrm{HPO}_{\$} \ldots \ldots \ldots \ldots . .0 .05$ gram

$\mathrm{NH}_{4} \mathrm{Cl}$ (or $\mathrm{KNO}_{3}, \mathrm{KNO}_{2}$,

$\mathrm{MgNH}{ }_{4} \mathrm{PO}_{4}$, pep-

tone)............ $0.1 \mathrm{gram}$

The medium was placed in Erlenmeyer flasks to a depth of 0.5 to $1 \mathrm{~cm}$, inoculated and incubated at $28^{\circ}$ to $35^{\circ}$. Cellulose decomposition was also demonstrated by placing two pieces of filter paper and some powdered ammonium magnesium phosphate in a dish, moistening with a 0.05 per cent solution of $\mathrm{K}_{2} \mathrm{HPO}_{4}$ and inoculating with some soil. Yellowish brown spots were produced on the paper in 4 to 5 days; the paper soon became pulpy, and the individual fibers became enveloped in a "micrococcus mucilage." Pure cultures of the organism could never decompose the paper.

Merker" described two bacteria, Micrococcus cytophagus and $M$. melanocyclus, neither of which was isolated in pure culture, but which were found to be accompanied by a rod-like organism; they decomposed paper partly immersed in the medium with the formation of transparent yellowish spots. A similar organism was studied by Bojanovsky ${ }^{12}$ on silica gel media, but he also failed to separate the coccus-like form from the rod-shaped form.

The organism (Spirochaeta cytophaga) isolated from the soil by Hutchinson and Clayton ${ }^{13}$ was found to develop first as a sinuous

9 Waksman and Skinner, 1926 (p. 190).

${ }^{10}$ Van Iterson, C. Die Zersetzung von Cellulose durch aerobe Mikroorganismen. Centrbl. Bakt. II, 11: 689-698. 1904.

${ }^{11}$ Merker, E. Parasitische Bakterien auf Blättern von Elodea. Centrbl. Bakt. II, 31: 578. 1912.

${ }^{12}$ Bojanowsky, R. Zweckmäszige Neuerungen für die Herstellung eines Kieselsäure Nährbodens und einige Beiträge zur Physiologie aerober Zelluloselöser. Centrbl. Bakt. II, 64: 222-233. 1925.

${ }^{13}$ Hutchinson, H. B., and Clayton, J. On the decomposition of cellulose by an aerobic organism (Spirochaeta cytophaga n. sp.). Jour. Agr. Sci. 9: 143-173. 1918. 
filamentous cell ( 3 to 10 by 0.3 to $0.4 \mu$ ), which appears to go through a number of phases terminating in the production of a spherical body (sporoid). This differs in a number of respects from the true spores of bacteria; germination of the sporoid again gives rise to the filamentous form which possesses perfect flexibility and is feebly motile although no flagella were observed.

The organism is aerobic, with an optimum at $30^{\circ} \mathrm{C}$, and is destroyed when kept at $60^{\circ} \mathrm{C}$. for ten minutes. It does not grow in nutrient agar or gelatin, and is injuriously affected by concentrations of peptone above 0.025 per cent. As sources of nitrogen, ammonium salts, nitrates, amides and amino acids can be used, while cellulose is the only source of earbon. The soluble carbohydrates are more or less toxic. The following medium was used for the isolation and cultivation of the organism:

\begin{tabular}{|c|c|}
\hline $\mathrm{K}_{2} \mathrm{HPO}_{4} \ldots \ldots \ldots \ldots \ldots 1.0 \mathrm{gra}$ & $\ldots 0.01$ gram \\
\hline 0.1 & $\mathrm{NaNO}_{3} \ldots \ldots \ldots \ldots$ \\
\hline $\mathrm{MgSO}_{4} \ldots \ldots \ldots \ldots \ldots, 0.3 \mathrm{gram}$ & Cellulose............ \\
\hline
\end{tabular}

The same organism was found to occur in the soil and to decompose cellulose readily. ${ }^{14}$ By the use of the silica gel method suggested by Winogradsky, the Sp. cytophaga can be shown to be very abundant in the soil, especially soils receiving applications of farmyard manure and straw. ${ }^{15}$

The gel is prepared by placing a mixture of equal parts of a normal solution of $\mathrm{HCl}$ and its equivalent of potassium silicate solution into Petri dishes. After the gel has formed, the dishes are placed in running tap water for 24 hours, then several times in boiled distilled water until free from chlorides. Five grams of ground filter paper are then suspended in $100 \mathrm{cc}$. of medium containing 5 grams $\left(\mathrm{NH}_{4}\right)_{2} \mathrm{HPO}_{4}, 1$ gram $\mathrm{MgSO}_{4}, 1$ gram KCl, 0.02 gram $\mathrm{FeSO}_{4}$, in 1000 ec. distilled water; about $2 \mathrm{cc}$. portions of the suspension are spread over the surface of each plate and a small amount of $\mathrm{CaCO}_{3}$ is dusted on. The plates are then placed in the thermostat at $60^{\circ} \mathrm{C}$., until the surface of the gel becomes free from excess of liquid. Small particles of soil can then be inoculated directly upon the plate which is then covered and incubated. After 2 to 4 days, yellow and orange growth will be found to develop from the soil into the medium. Transfers are then made into flasks containing $1 \mathrm{gm}$. of filter paper and $25 \mathrm{cc}$. of above solution. The organisms will begin to develop in the form of yellow specks, forming a yellow slimy mass all over the paper in 2 to 4 days. By repeated dilutions, the organism can be isolated pure.

${ }^{14}$ Löhnis, F., and Lochhead, G. Experiments on the decomposition of cellulose by aerobic bacteria. Centrbl. Bakt. II, 58: 430-434. 1923.

15 Waksman, S. A., and Carey, C. On the use of the silica gel plate for the isolation of cellulose-decomposing bacteria. Jour. Bact. 12: 87-95. 1926. 
The abundant distribution in the soil and the rapid decomposition of cellulose by this organism is thus established and can be demonstrated without difficulty. In addition to the $S p$. cytophaga, however, there are other bacteria found in the soil which are capable of decomposing cellulose under aerobic conditions.

Extensive work has been carried out, in this connection, by Kellerman and associates.16 A special culture medium was developed, for which the cellulose was prepared in the following manner:

One liter of ammonium hydroxide, specific gravity 0.90 , is poured into a glassstoppered bottle; $250 \mathrm{cc}$. of distilled water and $75 \mathrm{grams}$ of pure copper carbonate are added: the solution is shaken vigorously until all the copper is dissolved (from 10 to 15 minutes is ordinarily required). Fifteen grams of high grade, sheet filter paper is then added to the copper-ammonium solution and mixture is shaken vigorously, at intervals of 10 minutes, for one-half hour. The solution is examined carefully to see that the paper is completely dissolved. If any particles of paper remain in the solution, the shaking must be continued until the solution is perfectly clear.

The ammonium-copper-cellulose solution $(250 \mathrm{cc}$.) is diluted to 10 liters with tap water; a weak hydrochloric acid solution prepared by adding $500 \mathrm{cc}$. of concentrated acid to 10 liters of tap water is slowly added, with frequent shaking. The addition of the acid is continued until the blue color disappears: a slight excess of acid is added. The mixture is shaken vigorously and allowed to stand a few minutes. The finely precipitated cellulose will rise to the top, due to the large quantity of free hydrogen liberated in the precipitation process. The solution is shaken vigorousiy, at intervals of a few minutes, to dislodge the hydrogen. As soon as the free hydrogen has escaped, the cellulose will settle rapidly.

The cellulose is washed through repeated changes of water until free from copper and chlorine. After the washing is complete, the cellulose in the solution is brought up to 0.5 per cent, by allowing to settle a few days and siphoning off the clear solution or by evaporation. The nutrient salts together with 1 per cent of thoroughly washed agar are then added and heated in autoclave or boiled, until the agar is dissolved. The medium is then tubed and sterilized in the usual way.

Another method for the preparation of cellulose has been suggested by Scales: ${ }^{17}$

Concentrated sulfuric acid $(100 \mathrm{cc}$.) is diluted with $60 \mathrm{cc}$. of distilled water in a 2-liter Erlenmeyer flask and cooled to $60^{\circ}$ or $65^{\circ} \mathrm{C}$. Five grams of filter paper,

${ }^{16}$ Kellerman, K. F., and McBeth, I. G. The fermentation of cellulose. Centrbl. Bakt. II, 34: 485-494. 1912; Kellerman, K. F., McBeth, I. G., Scales, F. M., and Smith, N. R. Identification and classification of cellulose dissolving bacteria. Ibid. 39 : 502-522. 1914. McBeth, I. G., and Scales, F. M. The destruction of cellulose by bacteria and filamentous fungi. U. S. Dept. Agr., Bur. Pl. Ind., Bul. 266, 1913. McBeth, I. G. Studies on the decomposition of cellulose in soils. Soil Sci. 1: 437-4S7. 1916.

17 Scales, F. M. A new method of precipitating cellulose for cellulose agar. Centrbl. Bakt. II, 44: 661-663. 1915. 
sufficient for one liter of cellulose agar, is moistened with water and added to the acid which is then vigorously agitated till the cellulose is dissolved. The flask is then quickly filled with cold tap water. The whole process of dissolving the paper and filling the flask requires about one minute. The precipitate is now filtered through paper and washed until the filtrate no longer gives any test for sulfuric acid. When the volume of the suspension is drained to about $200 \mathrm{cc}$, a hole is punched in the bottom of the filter and the whole precipitate washed out and made up to $500 \mathrm{cc}$.

The cellulose may also be obtained from plant tissues by extracting well ground material with 2 per cent $\mathrm{KOH}$ solution, washing, chlorinating, extracting again with boiling 2 per cent $\mathrm{NaOH}$ for 30 minutes and washing.

Cellulose suspension (500 ce.) prepared by any of the above methods is now added to $500 \mathrm{cc}$. of a solution containing 0.5 gram $\mathrm{K}_{2} \mathrm{HPO}_{4}, 0.5 \mathrm{gram} \mathrm{MgSO}_{4}$, 0.5 gram NaCl, 1 gram $\left(\mathrm{NH}_{4}\right)_{2} \mathrm{SO}_{4}, 1$ gram $\mathrm{CaCO}_{3}$ and 500 cc. of tap water. Ten grams of agar are dissolved in the mixed solutions and medium tubed and sterilized as usual.

When soil suspensions are direetly inoculated upon poured plates with cellulose agar, filamentous fungi will develop and tend to overgrow the plate, making difficult the isolation of the bacteria. The sample of soil or manure is added to sterile flasks containing the eellulose broth or peptone cellulose broth and, as soon as the cellulose shows signs of disintegration, transfers are made upon fresh sterile flasks. This avoids the development of fungi. After several preliminary eultivations upon the liquid enrichment media, the eultures are plated out on the cellulose agar.

The colonies of cellulose-decomposing organisms developing on the plates show a translucent area due to the decomposition of the cellulose in the agar, as well as neutralization of the $\mathrm{CaCO}_{3}$ by the acids formed from the ammonium sulfate and cellulose decomposition. Starch agar and finally nutrient agar may be used for the final cultivation of the organisms. The cellulose-destroying bacteria studied by Kellerman and associates were found to grow more rapidly under aerobic conditions, although some anaerobic development has also been observed. They show a more vigorous growth on media containing organic nitrogen (peptone) than inorganic nitrogen. They usually reduce nitrates to nitrites, attack various carbohydrates, and do not form any gaseous products from eellulose or the lower carbohydrates. The paper is disintegrated into fine fibres and a small amount of organic acids is formed.

The following liquid medium was used for demonstrating the dissolution of the filter paper:

Soil extract.........500 cc.

Peptone........... 2.0 grams

Distilled water....... 500 cc.

$\mathrm{CaCO}_{3} \ldots \ldots \ldots \ldots \ldots$ excess

$\mathrm{K}_{2} \mathrm{HPO}_{4} \ldots \ldots \ldots \ldots \ldots .6 \mathrm{gram}$

Reaction $\mathrm{pH} \ldots \ldots \ldots 7.0$

$\left(\mathrm{NH}_{4}\right)_{2} \mathrm{SO}_{4} \ldots \ldots \ldots \ldots 1.0$ gram

All the forms studied were rod-shaped organisms varying in length from 0.8 to $3.5 \mu$. Only in three species were involution forms observed. Five species produced spores. Twenty-seven of the thirty-six species isolated were motile. 
These organisms are widely distributed in the soil. When kept under laboratory conditions, for any length of time, especially on nutrient agar media, they undergo marked physiological changes which may include loss of cellulose-decomposing power. Transfers made from the clear zone around the colony of the cellulose-decomposing bacterium growing on the plate decomposed cellulose readily; when the culture was transferred upon nutrient agar, the organism lost its cellulosedecomposing power. Löhnis and Lochhead ${ }^{18}$ suggested that the threadlike organism, described above, plays a prominent rôle in the aerobic decomposition of cellulose and is accompanied by numerous other cellulose-decomposing bacteria of lower efficiency. This led Omeliansky $^{19}$ and Pringsheim ${ }^{20}$ to suggest that the organisms isolated by Kellerman, McBeth and Scales were not in themselves cellulose decomposing forms but were present as contaminations. When isolations were attempted on the agar plate, it was these contaminations that were isolated, while the true cellulose decomposing forms were lost.

In general, a large number of aerobic bacteria capable of decomposing cellulose have been isolated from the soil, but the identity of many of them is doubtful. ${ }^{21-24,26}$

Gray and Chalmers ${ }^{25}$ isolated from the soil an aerobic organism capable of decomposing cellulose and liquefying agar (Microspira agar-liquefaciens); this

${ }^{18}$ Löhnis and Lochhead, 1923 (p. 196).

${ }^{19}$ Omeliansky, 1913 (p. 191).

${ }^{20}$ Pringsheim, H., and Lichtenstein, S. Zur vermeintlichen Reinkultur der Zellulosebakterien. Centrbl. Bakt. II, 60: 309-311. 1923.

21 Sack, J. Zellulose-angreifende Bakterien. Centrbl. Bakt. II, 62: 77-80. 1924

${ }^{22}$ Epstein, A. Un nouvel agent destructeur des polysaccharides complexes, Pseudomonas polysaccharidarum n. sp. Bull. Soc. Bot. Genève (2), 11: 191-195. 1920.

${ }^{23}$ Distaso, A. Sur un microbe qui désagrège la cellulose (Bacillus cellulosae desagregans n. sp.). Compt. Rend. Soc. Biol. 70: 995-996. 1911.

${ }^{24}$ Hopfe, A. Bakteriologische Untersuchungen über die Celluloseverdauung. Centrbl. Bakt. I, 83: 374-386. 1919.

${ }^{25}$ Gray, P. H. H., and Chalmers, C. H. On the stimulating action of certain organic compounds on cellulose decomposition by means of a new aerobic microorganism that attacks both cellulose and agar. Ann. Appl. Biol. 11: 324-338. 1924.

${ }^{26}$ Gescher, N. Über cellulosezersetzende Bakterien. Faserforschung, 2: 28-40. 1922. 
bacterium is 2 by 0.5 to $0.7 \mu$ with coccoid forms of 0.5 to $0.7 \mu$, motile with a single flagellum. The addition of dextrin, lignin, xylose and certain sugars stimulated cell development. ${ }^{26}$

Decomposition of cellulose by denitrifying bacteria. Certain bacteria are able to decompose cellulose and utilize the energy for the reduction of nitrates to nitrites. A medium containing 0.25 gram $\mathrm{KNO}_{3}, 0.05$ gram $\mathrm{K}_{2} \mathrm{HPO}_{4}$ and 2 grams of cellulose in the form of filter paper in 100 cc. of tap water can be used. ${ }^{27}$ This medium is placed in a glass stoppered flask up to the neck, inoculated with canal slime and incubated anaerobically at $35^{\circ}$. Cellulose decomposition begins in a week and is accompanied by reduction of nitrate to nitrite. The nitrite also disappears in 15 days. On renewing the medium, the process of nitrate reduction is greatly hastened. The cellulose becomes orange yellow and of a slimy consistency. It is broken down into fibers which finally disappear. The gases consist of a mixture of nitrogen and carbon dioxide. No organism responsible for the process of cellulose-decomposition could be isolated from the mixture of various bacteria and protozoa.

Groenewege, ${ }^{28}$ using a medium which consisted of 20 grams filter paper, 2.5 grams $\mathrm{KNO}_{3}$ and 0.5 gram $\mathrm{K}_{2} \mathrm{HPO}_{4}$ in 1000 cc. water and inoculated with soil, found that the process of cellulose decomposition by denitrifying bacteria is carried on by the symbiotic action of two groups of organisms, one of which decomposes the cellulose and the other of which uses the products formed as a source of energy for the reduction of nitrates. By the symbiotic action of the two organisms the cellulose disappears much more rapidly than by the action of the cellulose organism alone. Gas formation began to take place on the second day, accompanied by a reduction of nitrate to nitrite and $\mathrm{NO}$ with a gradual dissolution of the paper. The process was especially active when the culture solution was renewed by decantation.

To stimulate the development of cellulose-decomposing organisms, Van Iterson buried filter paper in the soil and after four weeks found that it became almost entirely decomposed and covered with orange and black spots. The black spots consisted of fungi. Using this material for inoculation, a complete reduction of 0.6 per cent $\mathrm{KNO}_{3}$ took place in three days. On replacing the solution by decantation, complete denitrification may take place in twenty-four hours. The organisms responsible for the process were obtained in pure cultures by the use of

${ }^{27}$ Van Iterson, 1904 (p. 195).

${ }^{28}$ Groenewege, J. Untersuchungen über die Zersetzung der Zellulose durch aerobe Bakterien. Bull. Jard. Bot. Buitenzorg. 2, f. 3: 261-345. 1920. 
nutrient agar plates. A small piece of the decomposing cellulose is thoroughly disintegrated on the plate, by means of a sterile spatula. If a large piece of paper is used, it should be previously washed in salt solution, to wash off the rapidly growing organisms not taking part in the processes of cellulose decomposition and nitrate reduction. These organisms develop only slowly as minute colonies and the plates have to be incubated for four to six days at room temperature, before transfers can be made. In the presence of rapidly growing organisms the minute colonies usually fail to develop.

The bacteria isolated in the processes of cellulose decomposition and nitrate reduction were divided ${ }^{28}$ into three groups: (1) those which effected denitrification in nitrate bouillon but not in the cellulose- $\mathrm{KNO}_{3}(0.1$ per cent) medium; (2) those which did not reduce nitrates in the nitrate bouillon but eaused reduction in the cellulose nitrate medium; (3) those which did not reduce nitrate in either medium. A combination of the first two groups or of all three brought about active reduction of nitrate and decomposition of cellulose. Group 1 was found to consist of two bacteria, namely Bact. opalescens and Bact.viscosum; group 2 consisted of three strains of Bact.cellaresolvens (a very fine, aerobic, rodshaped organism), all of which grew very slowly and formed minute colonies on nutrient agar. The cellulose decomposing organism was obligate aerobic. $B$. cellaresolvens attacked cellulose; the products of the decomposition (acetic, butyric and lactic acids) could serve as food for the denitrifying organisms, $B$. opalescens and B. viscosum. The complete process is one of symbiosis.

For a quantitative study of cellulose decomposition, Groenewege used a medium consisting of :

Filter paper.......... $200 \mathrm{mgm}$.

$\mathrm{NH}_{4} \mathrm{Cl} \ldots \ldots \ldots \ldots, 40 \mathrm{mgm}$.

$\mathrm{K}_{2} \mathrm{HPO}_{4} \ldots \ldots \ldots \ldots, 20 \mathrm{mgm}$.

$\mathrm{CaCO}_{3} \ldots \ldots . . . .4 .400 \mathrm{mgm}$.

Tap water.......... 40 cc.

The medium was inoculated with pure cultures of the organisms and mixtures of the cellulose decomposing and denitrifying forms. After three weeks, $10 \mathrm{ec}$. of 10 per cent $\mathrm{HCl}$ was added, flasks filled to half with water and after the cellulose settled, the liquid was taken off. This was repeated until the liquid was free from acid. The residuc was then centrifuged, dried and weighed. The cellulose decomposing bacteria alone decomposed 17 to $135 \mathrm{mgm}$. of the cellulose (depending on strain) and 22 to $151 \mathrm{mgm}$. in the presence of the denitrifying bacteria. Similar results were obtained with asparagine as a souree of nitrogen, indicating that the favorable influence of the $B$. opalescens on $B$. cellaresolvens is due to a symbiotic action.

Thermophilic bacteria. MacFayden and Blaxall ${ }^{29}$ were the first to demonstrate the presence in the soil of organisms which are able to decompose cellulose at $60^{\circ}$ to $65^{\circ} \mathrm{C}$. The process was accelerated under

${ }^{29}$ Macfayden, A., and Blaxall, F. R. Thermophilie bacteria. Trans. Jenner. Inst. Prevent. Med. Ser. 2: 162-187. 1899. 
anaerobic conditions. They believed that the process is carried out by the combined action of several organisms. Kroulik ${ }^{30}$ used a medium, similar to that employed by Omeliansky, consisting of 1 gram $\left(\mathrm{NH}_{4}\right)_{3} \mathrm{PO}_{4}$, 1 gram $\mathrm{K}_{2} \mathrm{HPO}_{4}, 0.5$ gram $\mathrm{MgSO}_{4}$, trace of $\mathrm{NaCl}, 1000$ ec. distilled water, 1 to 2 per cent cellulose and 0.5 to 1 per cent $\mathrm{MgCO}_{3}$. He demonstrated the common occurrence of bacteria able to decompose cellulose at $60^{\circ}$ to $65^{\circ} \mathrm{C}$., particularly in places where cellulose is present in abundance. Both aerobic and anaerobic forms have been demonstrated. Two aerobic forms were found in great abundance during the early stages of decomposition, but when isolated on nutrient agar media, they did not decompose cellulose further. Two anaerobic bacteria were isolated which did not grow upon agar. ${ }^{31}$ Various other thermophilic cellulosedecomposing bacteria have also been isolated from the soil. ${ }^{32-34}$ For this purpose a medium consisting of 2 grams $\mathrm{NaNH}_{4} \mathrm{HPO}_{4} \cdot \mathrm{H}_{2} \mathrm{O}, 1 \mathrm{gram}$ $\mathrm{KH}_{2} \mathrm{PO}_{4}, 0.3$ gram $\mathrm{CaCl}_{2}, 5$ grams peptone, 15 grams cellulose, 1000 cc. of tap water and excess of $\mathrm{CaCO}_{3}$ is inoculated with infusions of rapidly decomposing manure and the cultures are incubated at $65^{\circ} \mathrm{C}$. Gas bubbles begin to rise after 18 to 24 hours and the formation of $\mathrm{H}_{2} \mathrm{~S}$ becomes evident. $^{34}$ After 30 to 36 hours, the cellulose pulp is raised to the surface, loses its fibrous structure, and turns brownish-yellow in color. Further transfers do not form any more $\mathrm{H}_{2} \mathrm{~S}$. The cellulose begins to decompose after 18 hours and the process is completed after 6 to 8 days. When inoculations from individual colonies are made upon glucose agar, the isolated cultures do not decompose cellulose. Pure cultures are obtained by means of deep agar-cellulose tubes. The organism does not grow at 28 to $37^{\circ} \mathrm{C}$., makes some growth at $43^{\circ}$ to $50^{\circ} \mathrm{C}$, grows best at $65^{\circ} \mathrm{C}$. The spores are destroyed at $115^{\circ}$ in 37 minutes. When grown on common agar media, the power of cellulose decomposition is lost. This is probably clue to the loss of some highly oxidizable component, during the process of plating, which is needed to initiate the process of decomposition.

A comparative summary of this thermophilic organism (Clostridium

${ }^{30}$ Kroulik, 1913 (p. 157).

${ }^{31}$ See also Noack, 1912 (p. 300).

32 Pringsheim, H. Über die Vergärung der Zellulose durch thermoplite Bakterien. Centrbl. Bakt. II, 38: 513-516. 1913.

${ }^{33}$ Langwell, H., and Lymn, A. Discussion on the action of bacteria on cellulosic materials. Jour. Soc. Chem. Ind. 42T: 2s0-2s7. 1923.

${ }^{34}$ Viljoen, J. A., Fred, E. B., and Peterson, W. H. The fermentation of cellulose by thermophilic bacteria. Jour. Agr. Sci. 16: 1-17. 1926. 
thermocellum V.F. and P) and the anaerobic organism of Khouvine is given in table 14. The Bac. cellulosae dissolvens approaches the Spirochaeta cytophaga in its cellulose-decomposing capacity, in being unable to grow on any media except those containing cellulose. $\mathrm{Cl}$. thermocellum can grow with other sources of energy. One must keep in mind, however, the fact that when this organism is grown on other sources of energy it looses its power to decompose cellulose.

Pectin decomposing bacteria. Pectins, like celluloses, are decomposed by (1) fungi, ${ }^{35}$ (2) aerobic bacteria, and (3) anaerobic bacteria. The aerobic bacteria capable of decomposing pectins include Bac. asterosporus and Bac. mesentericus. ${ }^{36}$ In addition to these organisms, there are various other aerobic bacteria, such as Bac. subtilis, Bact. fluorescens, ${ }^{35}$ Bac. macerans ${ }^{37}$ and Pectinobacter amylophilum ${ }^{38}$ which were found to be able to decompose pectins. The Bac. comesii and Bac. lramerii of Rossi ${ }^{39}$ are merely species of Bac. mesentericus or Bac. asterosporus. ${ }^{40}$ Mention should also be made of the bacteria causing soft rots of vegetables, especially Bac. carotovorus, ${ }^{41}$ which are capable of breaking down pectins readily.

The anaerobic bacteria capable of decomposing pectins include two organisms: (a) Bac. amylobacter and (b) Bac. felsineus. The former ${ }^{42}$

${ }^{35}$ Hauman, L. Etude microbiologique et chimique du rouissage aérobic du lin. Ann. Inst. Past. 16: 379-385. 1902; Behrens, J. Über die Taurotte von Flachs und Hanf. Centrbl. Bakt. II, 10: 524-530. 1903; Die Pektingärung. Lafar's Handb. techn. Mykol. 3: 269-286. 1904.

${ }^{36}$ Beijerinck, M. W., and van Delden, A. Over de bacterien, welke bij het roten van vlas werdzaam zijn. Kon. Akad. Wetensch. te Amsterdam. Dec. 19: 673. 1903.

${ }^{37}$ Schardinger, F. Ueber die Bildung kristallisierter, Fehlingsche Lösung nicht reduzierender Körper (Polysaccharide) aus Stärke durch mikrobielle Tätigkeit. Centrbl. Bakt. II, 22: 98-103. 1909.

${ }^{38}$ Makrinov, I. A. Sur un nouveau microorganisme provoquant la fermentation de l'amidon et des matières pectiques. Arch. Sci. Biol. 18: No. 5. 1915.

${ }^{39}$ Rossi, G., and Guarnieri, G. Il bacillus comesii e le sue proprieta. Primi tentativi di macerazione di fibre tessili con fermenti selezionati. R. Sc. Agr. Portici. 1906; Industrial retting of textile plants by microbiological action. Inter. Inst. Agr. Bur. Intel. Pl. Dis. 7: 635. 1916.

${ }^{40}$ Ruschmann, G., and Ravendamm, W. Die Flachsröste mit Plectridium pectinovorum (Bac. amylobacter A. M. Bredemann) und Bacillus felsineus Carbone. Centrbl. Bakt. II, 65: 43-58. 1925.

${ }^{41}$ Jones, L. R. Pectinase, the eytolytic enzyme produced by Bacillus carotovorus and certain other soft-rot organisms. N. Y. Agr. Exp. Sta. Tech. Bul. 11, 289-368. 1909.

42 Bredemann, 1909 (p. 109). 
comprises a variety of forms described under different names, including Plectridium, ${ }^{43}$ Clostridium $^{44}$ and Cranulobacter. ${ }^{45}$ However, not all forms of Bac. amylobacter are capable of retting flax. Bac. felsineus Carbone $^{46}$ is 3 to 5 by 0.3 to $0.4 \mu$ and forms free spores 3 by 1.5 to $2 \mu$ in size. It is similar in morphology and general physiology to Bac. amylobacter A. M. et Bred., but varies from the latter by being unable to produce butyric acid. ${ }^{40}$

Bacteria decomposing hydrocarbons and benzene ring compounds. Petroleum, paraffin oil and other hydrocarbons can be readily used by a number of soil bacteria as sources of energy. ${ }^{47}$

To obtain an enriched culture, the following medium was used:

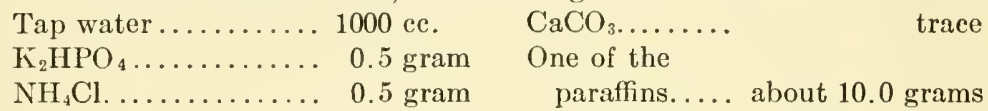
Petroleum, benzin and paraffin oil can be used directly. The paraffin is first melted by warming and the solution is then vigorously shaken. The medium is inoeulated with soil and incubated. At $20^{\circ}$, fluorescent and fat-splitting organisms develop; at $38^{\circ}$, Mycobacteria ( 4 to 10 by 0.5 to $1.5 \mu$ ) and Micr. paraffinae develop. Söhngen found that 4 to $8 \mathrm{mgm}$. of petroleum were oxidized in 24 hours at $28^{\circ} \mathrm{C}$. for every square centimeter of surface of solution. Pure cultures of the organisms were obtained on a medium consisting of :

Washed agar........ 20 grams Distilled water........ 1000 ce.

$\mathrm{K}_{2} \mathrm{HPO}_{4} \ldots \ldots \ldots \ldots, 0.5 \mathrm{gram}$ Paraffin vapor

$\mathrm{MgSO}_{4} \ldots \ldots \ldots \ldots \ldots . .5 \mathrm{gram}$

The number of bacteria capable of oxidizing paraffin in the soil are very large, reaching 50,000 to 200,000 per gram of garden soil. Among the species isolated we find Bact. fluorescens liquefaciens and non-liquefaciens, Bact. pyocyaneum, B. stutzeri, B. lipolyticum $\alpha, \beta, \gamma$ and $\delta$, Micr. paraffinae, and all fat-splitting forms. Tausz and Peter $^{48}$ isolated three organisms from the soil capable of decomposing hydrocarbons: Bact. aliphaticum, Bact. aliph. liquefaciens and Paraffinbacterium. The first was isolated

${ }^{43}$ Winogradsky, S., and Friebes, V. Sur le rouissage du lin et son agent nicrobien. Compt. Rend. Acad. Sci. 121: 242. 1895.

${ }^{44}$ Störmer, K. Ueber die Wasserröste des Flaches. Mitt. deut. Landw. Gesell. 18: 193. 1903; Chem. Centrbl. 76: 41. 1905.

${ }^{45}$ Beijerinck and Van Delden, 1902 (p. 183).

${ }^{46}$ Carbone, D., and Tobler, F. Die Röste mit Bacillus felsineus. Faserforsch.

2: 163-184. 1923.

${ }^{47}$ Söhngen, N. L. Benzin, Petroleum, Paraffinol und Paraffin als Kohlenstoff- und Energiequelle für Mikroben. Centrl,l. Bakt. II, 37: 595-609. 1913.

${ }^{48}$ Tausz, J., and Peter, M. Neue Methode der Kohlenwasserstoffanalyse mit Hilfe von Bakterien. Centrbl. Bakt. II, 49: 497-554. 1919. 
on inorganic and organic media to which a few drops of $n$-hexan was added; it is 2 by $1.5 \mu$ in size, motile by means of peritrichic flagella, Gram-negative and grows well with aliphatic hydrocarbons as the only source of carbon and energy. The second organism was isolated on media containing naphthenes as cyclohexan and 1-3 dimethylcyclohexan. It is similar to the first organism, but is strongly proteolytic. The third organism was isolated on selective media consisting of inorganic solutions and paraffin oil. In liquid media, the organism forms motile rods, 4 to 6 by $2 \mu$, developing into long chains. Rapid spore formation is characteristic and it is, therefore, related to $B$. subtilis.

Various bacteria capable of oxidizing phenol to $\mathrm{CO}_{2}$, pyrocatechin to oxychinon, benzol to fatty acids and $\mathrm{CO}_{2}$, and capable of decomposing toluol, xylol and guajacol were isolated from the soil. ${ }^{49}$

Aerobic clostridia, Bact. fluorescens group and Mycobacteria, are also concerned in the decomposition of phenols, cresols and related compounds in the soil.

'Wagner, R. Über Benzol-Bakterien. Ztschr. Gärungsphysiol. 4: 289-319. 1914. 


\section{CHAPTER IX}

\section{Bacteria Decomposing Urea, Utric and Hippuric Acids}

Urea, uric and hippuric acids are the products of protein decomposition in the animal organism and form the most important nitrogen constituents of the liquid part of the manure. These compounds are not directly available as sources of nitrogen to higher plants. They have to be first decomposed by various groups of microorganisms existing in manure and in the soil and transformed into ammonia and other compounds. The chemical processes concerned are discussed in detail elsewhere (p. 486).

Organisms decomposing urea. Pasteur ${ }^{1}$ was the first to recognize in 1860 that ammonia formation from urea is brought about by a living organism, namely Torula ammoniacale. It was later found that organisms capable of decomposing urea are found in most families of bacteria, actinomyces and fungi, but certain specific bacteria, whose metabolism is closely connected with the transformation of this substance, are termed urea bacteria. These are divided into cocci and bacilli. 'The former are usually destroyed at $60^{\circ}$ to $70^{\circ}$, while the latter, due to their ability to form endospores, can withstand heating at $90^{\circ}$ to $95^{\circ}$ for several hours. The optimum temperature for the action of these organisms is about $30^{\circ} \mathrm{C}$. They usually thrive best in media containing urea ( 2 per cent), particularly when made alkaline with ammonium carbonate ( 2 to 3 grams per liter). The accumulation of ammonium carbonate from the hydrolysis of the urea is so great, in many instances, as to kill the organisms themselves. A rapid urea decomposition does not necessarily accompany a rapid growth. The urea bacteria differ in their oxygen tension; most of them are aerobic, although the amount of oxygen required may be rather small. Many of these organisms are probably varieties of some of the common soil bacteria. The urea splitting bacteria are commonly found in great abundance in soil, manure, dust and water. Miquel $^{2}$ found urea organisms in the canal

${ }^{1}$ Pasteur, L. De l'origine des ferments. Nouvelles expériences relatives aux générations dites spontanées. Compt. Rend. Acad. Sci. 50: 849-854. 1860.

${ }^{2}$ Miquel, P. Die Vergärung des Harnstoffes, der Harnsäure und der Hippursäure. Lafar's Handb. techn. Mykol. 3: 71-85. 1904. (References to earlier work.) 
waters of Paris, fifty-two forms in the sewage waters and sixty-six in the drainage of the privy closets. The urea bacteria of the surface soil were found to form 1 to 2 per cent of the total number of bacteria. Manure and urine contained 10 per cent of their flora as urea bacteria. The air in Paris was found to contain one urea splitting organism for every sixty-seven other forms.

Urea bacteria are very abundant in the soil (p. 37). Frequently the urea is so rapidly decomposed as to lead to actual losses of ammonia. This can be prevented, however, by a proper mixture of the urea in the soil. ${ }^{3}$

Methods of isolation. The isolation and cultivation of the urea bacteria does not present great difficulty. The selective and enrichment cultivation ${ }^{4}$ can be readily utilized for this purpose.

For the purposes of isolation, two solutions have been suggested: ${ }^{5}$
1. Tap water....... $1000 \mathrm{ec}$.
$\mathrm{K}_{2} \mathrm{HPO}_{4} \ldots \ldots \ldots \ldots .0 .5 \mathrm{gram}$
2. Tap water....... 1000 cc.
Calcium citrate or
$\mathrm{K}_{2} \mathrm{HPO}_{4} \ldots \ldots \ldots \ldots \quad 0.5$ gram
tartrate....... 10.0 grams
Ammonium
malate....... 10.0 grams
Urea............ 30.0 grams
Urea .......... 50.0 grams

One hundred cubic centimeters of either solution is inoculated with 2 grams of soil and incubated at $23^{\circ}$ or $33^{\circ}$; in 36 to 48 hours, the medium becomes well inoculated with urea bacteria. After two or three transfers, the organisms are readily obtained in pure culture. A medium consisting of 50 grams of urea, 0.5 gram $\mathrm{K}_{2} \mathrm{HPO}_{4}, 100$ cc. of soil extract and $900 \mathrm{cc}$. of tap water may be used. ${ }^{6}$ Peptone gelatin containing 2 to 5 per cent of urea was found to be a very good solid medium. ${ }^{7}$ A few days after inoculation, often only after twenty-four hours, most of the visible colonies will be found surrounded with a halo. This is composed of dumb-bell shaped crystals insoluble in water and consisting of carbonate and phosphate of calcium which were precipitated from the medium as a result of the formation of ammonium carbonate from the urea. The stronger the action of the bacteria, the wider is the zone. The halo of crystals either surrounds the colony to a width of several millimeters or rapidly covers, in 24 hours, the whole plate. The urea organisms are thus readily recognized and are then transferred upon the specific media.

${ }^{3}$ Littauer, F. Zersetzung des Harnstoffs im Boden. Ztschr. Pflanzenernähr. Düng. 3A: 65. 1925.

${ }^{4}$ Beijerinck, M. W. Anhäufungsversuche mit Ureumbakterien. Ureumspaltıug durch Urease und durch Katabolismus. Centrbl. Bakt. II, 7: 33-60. 1901. Düggeli. Naturw. Wochschr. 14: 305. 1915.

5 Söhngen, N. L. Ureumspaltung bei Nichtvorhandesein von Eisweisz. Centrbl. Bakt. II, 23: 91-98. 1909.

${ }^{6}$ Löhnis, 1905 (p. 120).

${ }^{7}$ Miquel, 1904 (p. 206). 
Ordinary bouillon, with or without peptone, yeast water, peptone solution, which have been marle alkaline and to which 0.1 to 0.2 per cent of urea has been added are quite suitable for the cultivation of the organisms. To study the urea splitting power of the organisms, various quantities of urea may be employed (usually 2 per cent), but the greater the amount of urea, the greater is the danger of the destructive action of the ammonium carbonate. Viehoever ${ }^{8}$ used, for the isolation of Bac. probatus and other urea bacteria, a medium consisting of :
Water.............. 1000 ce.
$\mathrm{NaCl} . . . . . . . . . . .0 .0 .1 \mathrm{gram}$
$\mathrm{K}_{2} \mathrm{HPO}{ }_{4} \ldots \ldots \ldots \ldots . \quad 1 \mathrm{gram}$
$\mathrm{I}_{\mathrm{eCl}} \ldots \ldots \ldots \ldots \ldots .0 .01 \mathrm{gram}$
$\mathrm{CaCl}_{2} \ldots \ldots \ldots \ldots \ldots .0 .1$ gram
Urea........... 20.0 grams
$\mathrm{MgSO}_{4} \ldots \ldots \ldots \ldots \ldots .0 .3 \mathrm{gram}$
Liebig's beef ex-
tract.......... 5.0 grams

Agar is added to this solution when a solid medium is wanted for the isolation of the bacteria from colonies. Ammonium earbonate or urea agar are prepared by adding 3 grams of the first or 3 to 30 grams of urea to a medium consisting, of 1500 parts of water +30 agar +6 peptone +4 Liebig's beef extract $+1 \mathrm{NaCl}$ $+5 \mathrm{glucose}$.

Classification and description. The urea bacteria include both anaerobic and aerobic forms. Miquel divided all these bacteria into two general groups: (1) Urococci and (2) Urobacilli. Among the cocci he observed as many as thirty different species representing four genera: Urococcus, Urosarcina, Micrococcus and Planosarcina, while the Urobacilli were also divided into various genera.

The urea decomposing organisms can thus be divided into four groups:

I. Spore-bearing cocci. Planosarcina ureae Beij. forms packets on solid and liquid media, of 4 to $S$ eells $(0.7$ to $1.2 \mu)$, and is motile by means of long flagella. The spherical endospores $(0.6 \mu)$ can withstand $80^{\circ} \mathrm{C}$. for ten minutes.

II. Non-spore bearing cocei. Urococcus van tieghemi Miquel (Syn. Torula ammoniacale Pasteur, Mic. urcac Cohn), 1 to $1.5 \mu$ in diameter, occurring in twos, often in chains; Mic. ureae liquefaciens Flügge, Uros. hansenii Miquel and a number of other Urosarcinae and Micrococci deseribed by Miquel, Rochaix and Dufourt, ${ }^{9}$ as well as the eommon species Micr. pyogenes and Strept. pyogenes.

III. Spore-bearing bacilli. These include the Urobacillus pasteurii (Miquel) Beij., 1 to 1.2 by $2.5 \mu$, single or short chains, motile, forming egg-shaped endospores, persisting in dry soil for many years, decomposing urea very aetively; Urob. duclauxii, Urob. freudenreichii, Urob. maddoxii and other species described by Miquel; Urob. leubii Beij., Bac. probatus Vieh., Bac, ureae II and III Burri. According to Löhnis, Bac. mycoides and Bac. megatherium, which decompose urea,

${ }^{8}$ Viehoever, A. B. Botanische Untersuchung harnstoffspaltender Bakterien mit besonderer Berücksichtigung der Spezies diagnostisch verwertbaren Merkmale und des Vermögens der Harnstoffspaltung. Centrbl. Bakt. 39: 209-359. 1913.

${ }^{9}$ Rochaix and Dufourt. Contribution a l'étude des urobactéries. Compt. Rend. Soc. Biol. 69: 312-314. 1910. 
belong here, as well as other spore-bearing bacteria (so-called putrefactive forms), such as the anaerobic Bac. putrificus, and Bac. perfringeus.

IV. Non-spore bearing bacteria. Bact. ureae Leube, Brct. ureae I Burri, Urobact. schutzenbergii Miquel, Urobact. miquelii Beij., Urobact. jackshii Söhngen, Urobact. beijerinckii Christ., as well as a number of common bacteria like Bact. coli, Bact. prodigiosum, Ps. fluorescens, Bact. vulgare, etc.

A large number of spore-forming and non-spore-forming bacteria were isolated from manure. ${ }^{10}$ According to Löhnis, the urea-decomposing power of the various urea bacteria quickly ceases when these organisms are kopt in culture. They cannot, therefore, be considered as representatives of separate genera, but merely as varieties of common species, like Bact. vulgare, Bact. coli, Bact. prodigiosum, Bact. fluorescens, Bact. erythrogenes. Most of the Urococcus species, which are distinguished only by degree of pigment formation and gelatin liquefaction, belong chiefly to the Microc. pyogenes Rosenb. The same may be true of Microc. urcae Cohn. Bact. ureae Leube, named by Miquel Urobacillus leubii, belongs to the Bact. vulgare group; the same is true of Urob. miquelli Beij. and other Urobacilli (like Urob. jakschii Söhngen).

This assumption is justified in view of the fact that a number of common soil bacteria, including various cocci, non-spore-forming and spore-forming bacteria, are capable of decomposing urea.

Söhngen ${ }^{11}$ described two new non-spore-forming bacteria decomposing urea in the absence of proteins. An aerobic non-spore-forming, rod-shaped organism (Urob. beijerinckii), $1 \frac{1}{4}$ by $\frac{3}{4}$ to $1 \mu$ in size, was found to utilize urea both as a source of carbon and nitrogen, in the complete absence of other organic substances. ${ }^{12}$ Glucose cannot be utilized and may even injure the urea-splitting power of the organism. Humic acid was found to have a favorable influence upon the decomposition of urea.

Viehoever ${ }^{13}$ found that most of the common urea bacteria, such as Urobacillus pasteurii, Urob. leubii and probably also Urob. maddoxii, Bac. ureae II and III, Bact. ureae could be combined into one species, Bac. probatus (No. 60, Pl. X).

This organism was obtained by heating some soil at $100^{\circ} \mathrm{C}$., then inoculating into a medium containing 1 gram $\mathrm{K}_{2} \mathrm{HPO}_{4}, 0.1 \mathrm{gram} \mathrm{CaCl}_{2}, 0.3$ gram $\mathrm{MgSO}_{4}$,

${ }^{10}$ Löhnis and Kuntze, 1908 (p. 32).

11 Söhngen, 1909 (p. 207).

${ }^{12}$ Christensen, H. R. Ưber den Einflusz der Humustoffe auf die Ureumspaltung. Centrbl. Bakt. II, 27: 337-362. 1910.

${ }^{13}$ Viehoever, 1913 (p. 208). 
0.1 gram $\mathrm{NaCl}, 0.01$ gram $\mathrm{FeCl}_{3}, 20$ grams urea and 5 grams Liebig's beef extract per liter. On incubating for three weeks at $28^{\circ}$, the culture was found to contain rod-shaped organisms $10 \mu$ long which formed spores $1 \mu$ in size. A small amount of the culture was boiled for one minute at $100^{\circ}$ and the organism was obtained in pure culture by the dilution method, using the above medium with the addition of agar. The maximum acid tolerance was found to be two drops $\mathrm{N} \mathrm{H}_{2} \mathrm{SO}_{4}$ per 5 ec. of agar medium ( $\frac{1}{3}$ concentration of nutrients). The maximum alkalinity was expressed by 2 per cent dehydrated $\mathrm{Na}_{2} \mathrm{CO}_{3}$ (optimum 0.2 per cent) or 22 to 25 per cent of ammonium carbonate (optimum 0.3 per cent). The maximum concentration of urea tolerated by the organism was 30 to 40 per cent, the optimum was 3 per cent.

Bacillus probatus A. M. et Viehoever is motile, with peritrichic flagella and rounded ends; forming on ammonium carbonate or urea agar chains of 2 to 3 cells. The cells vary greatly in size, usually 1 by 0.4 to $0.8 \mu$, reaching on some media a size of 3 to 10 by $0.7 \mu$. The organism is gram-positive, spore-forming, aerobic. The size of the spores on the ammonium carbonate agar ranges from 0.5 to 1 by 0.6 to $1.2 \mu$ to almost spherical, 0.8 to $0.9 \mu$ in diameter. The spores appear in 3 to 4 days on the ammonium carbonate agar at $28^{\circ} \mathrm{C}$, more or less at the end of the cell, as drum-shaped or spindle-shaped, swollen sporangia (Pl. X). Development is weak on common nutrient and nutrient-glucose agar. White to grayish-opalescent. Colonies are formed in three days on the carlonate or urea agar. In peptone broth containing 0.2 per cent ammonium carbonate, indol, $\mathrm{H}_{2} \mathrm{~S}$ and trimethylamine are formed. No gas is formed from sugars, acid only from glucose. Ammonia is formed from nitrites. Crystals of (alcium carbonate and phosphate are formed on urea agar. The enzymes catalase, urease, reductase are formed, but not oxidase or amylase. The minimum temperature for growth is $3^{\circ}$ to $5^{\circ}$, optimum $28^{\circ}$ to $35^{\circ}$, maximum for sporeformation $42^{\circ}$ to $43^{\circ}$, for spore germination $45^{\circ}$ to $47^{\circ}$, for growth $44^{\circ}$ to $45^{\circ}$. Minimum oxygen tension per liter for spore germination and growth is $4 \mathrm{mgm}$., for spore formation $10 \mathrm{mgm}$. Maximum oxygen tension for spore germination is about 10 atmospheres, for growth 5 atmospheres, and for spore formation 1 to 5 atmospheres. The spores are killed in 11.5 to 12.5 minutes at $100^{\circ} \mathrm{C}$, , in 9 to 10 hours at $80^{\circ} \mathrm{C}$.

Geilinger ${ }^{14}$ made a detailed study of the biology of urea-decomposing bacteria, with a view of preventing the rapid loss of nitrogen due to the decomposition of urea in the manure pile. Only 5.6 per eent of the urea organisms isolated from soil and manure were able to live and decompose urea in the absence of oxygen. Some organisms were found to be obligate anaerobes and were able to thrive in the presence of a mere trace of residual oxygen. A series of bacteria capable of decomposing

${ }^{14}$ Geilinger, H. Beitrag zur Biologie der Harnstoff vergärenden Mikroorganismen, mit besonderer Berïcksichtung der Anäerobiose. Centrbl. Bakt. II, 47: 245-301. 1917. 
urea at low temperatures, even below $0^{\circ} \mathrm{C}$., were isolated from water and curative muds. ${ }^{15}$

Bacteria decomposing calcium cyanamide. Calcium cyanamide is decomposed with the formation of ammonia by Bact. erythrogencs, Bact. kirchneri as well as other non-spore-forming bacteria present in the soil. ${ }^{16}$ For the isolation of the organisms, the following media can be used: meat peptone gelatin, soil extract gelatin (10 per cent gelatin, reaction alkaline) or cyanamide solution with the addition of 10 per cent gelatin, then made alkaline after boiling. Certain bacteria can use dicyandiamide as a source of nitrogen, in the presence of glucose. The anide, however, is decomposed to a very inappreciable extent and no ammonia is formed. ${ }^{17}$

Uric and hippuric acid bacteria. Uric acid, which is an important constituent of the manure of birds and snakes and is also present to a slight extent in the urine of mammals, is also decomposed by bacteria, urea being the chief product. ${ }^{18}$ A solution of uric acid inoculated with putrid urine was found to be completely decomposed in a few days to ammonium carbonate with the formation of $\mathrm{CO}_{2} \cdot{ }^{19}$ When the process was interrupted before the uric acid was completely decomposed, urea could be demonstrated. Bact. ureae and Bact. fluorescens were found to be responsible for the process. Gérard ${ }^{20}$ found that the decomposition of uric acid goes on in two stages. The uric acid is first decomposed into urea and tartronic acid, the urea is then hydrolized to ammonium carbonate. Ulpiani and Cingolani ${ }^{21}$ isolated from chicken excreta an aerobic, motile, slime-forming streptococcus, not producing any spores

${ }^{15}$ Rubentschik, L. Über die Lebenstätigkeit der Urobakterien bei einer Temperatur unter $0^{\circ} \mathrm{C}$. Centrbl. Bakt. II, 64: 116-174. 1925; 66: 161-180. 1926.

${ }^{16}$ Löhnis, F., and Sabashnikoff, A. Ueber die Zersetzung von Kalkstickstoff und Stickstoffkalk. II. Centrbl. Bakt. II, 20: 322-332. 1908.

${ }_{17}$ Perotti, R. Über die Dicyandiamidbakterien. Centrbl. Bakt. II, 21: 200-231. 1908.

${ }^{18}$ Lex, R. UUber Fermentwirkungen der Bakterien. Centrbl. Med. Wiss. 10: 292, 513. 1872 .

${ }^{19}$ Sestini, F. and L. Über die ammoniakalische Gärung der Harnsäure. Landw. Vers. Sta. 38: 157-164. 1890.

${ }^{20}$ Gerard, E. Fermentation de l'acide urique par les microorganismes. Compt. Rend. Acad. Sci. 122: 1019-1022. 1896; 123: 185-187.

${ }^{21}$ Ulpiani, C. Über das Bakterium der Harnsäure. Cingolani, M. Chemische Gleichung der Gärung der Harnsäure. Ref. Chem. Centrbl. 2: 1287. 1903; Gaz. Chim. Ital. II, 33: 93-98, 98-124. 1903; Atti Roy. Accad. Lincei, Roma, (5) II, 12: 236-240. 1903. 
and hydrolizing uric acid into ammonium carbonate and carbon dioxide. The optimum temperature was $29^{\circ}$ to $42^{\circ}$ and at $50^{\circ}$ the organism was killed. Bact. vulgare can also decompose uric acid. ${ }^{22}$

Liebert ${ }^{23}$ isolated from the soil Bact. acidi urici, an incompletely described species, 5 by $0.7 \mu$ in size, spore forming and anaerobic. It decomposed uric acid, under anaerobic conditions, with the formation of $\mathrm{CO}_{2}$, ammonia and acetic acid.

The aerobic decomposition of uric acid is also carried out by Bact. fluorescens liquefaciens and non-liquefaciens, by Bact. calco-aceticum and Bact. pyocyaneum in neutral and acid media, and by Bact. odoratum in alkaline media. These transform uric acid into $\mathrm{CO}_{2}$ and $\mathrm{NH}_{3}$ with the intermediate production of allantoin, urea, and oxalic acid. On a medium consisting of 2000 parts of water, 6 parts uric acid, 1 part $\mathrm{K}_{2} \mathrm{HPO}_{4}$, various organisms (aerobic and anaerobic) capable of utilizing uric acid both as a source of nitrogen and carbon can be isolated from the soil. Bacl. stutzeri and Bact. pyocyaneum were found capable of utilizing uric acid as a source of carbon for denitrification. Various Radiol)acter strains are able to decompose uric acid with the formation of ammonia. ${ }^{24}$

By using a medium consisting of five grams $\mathrm{NaCl}, 0.2$ gram $\mathrm{MgSO}_{4}, 0.1$ gram $\mathrm{CaCl}_{2}, 1.0$ gram $\mathrm{K}_{2} \mathrm{HPO}_{4}, 30.0$ grams of glycerol and 0.2 gram of uric acid in $1000 \mathrm{cc}$. of distilled water, an organism, Aerobacter aerogenes, capable of decomposing uric acid was isolated. ${ }^{25}$ In addition to bacteria, certain fungi and yeasts also decompose uric acid. ${ }^{26}$

Hippuric acid abundantly produced by herbivorous animals is transformed by bacteria into glycocoll and benzoic acid. ${ }^{27}$ It can be used by a large number of bacteria both as a source of nitrogen and carbon, with the formation of ammonia and carbon dioxide. Among the bacteria described by the earlier investigators, we may mention: Microc. ureae, Microc. pyogenes, Bact. prodigiosum, ${ }^{28}$ Bact. erythrogenes, Bact freudenreichii, Bac. vulgatus, Bac. mesentericus, etc. A medium containing 1 per cent sodium hippurate, 0.2 per cent $\mathrm{K}_{2} \mathrm{HPO}_{4}$ and 0.1 per

${ }_{22}^{2}$ Nawiasky, P. Über die Umsetzung von Aminosauren durch Bac, protcus vulgaris. Arch. Hyg. 66: 241. 1908.

${ }^{23}$ Liebert, F. The decomposition of uric acid by bacteria. Akad. Wetenschap. Amsterdam. May 6, p. 61. 1909.

${ }^{24}$ Bierema, 1909 (p. 187).

${ }^{25}$ Morris, J. L., and Ecker, E. E. Destruction of uric acid by bacteria and molds. Jour. Inf. Dis. 34: 592-598. 1924.

${ }^{26}$ Kíossowicz, A. Die Zersetzung von Harnstoff, Harnsäure, Hippursäure und Glykokoll durch Schimmelpilze. Ztschr. Gärungsphysiol. 1: 60-62. 1912.

${ }^{27}$ Van Tieghem. Recherches sur la fermentation de l'urée et de l'acide liippurique. Compt. Rend. Acad. Sci. 58: 210-264. 1 S64.

28 Crisafulli, G. La reazione rossa del legno di pino per la ricerca dello indolo nelle culture in brodo dei microorganismi. Roma. 1905. 
cent $\mathrm{MgSO}_{4}$ was used to demonstrate that microorganisms, capable of transforming hippuric acid, are present in the surface layer of the soil in larger numbers and are more active than in the subsoil. ${ }^{29} \mathrm{~A}$ medium containing $1500 \mathrm{cc}$. water, 5 grams hippuric acid, 2 grams $\mathrm{K}_{2} \mathrm{HPO}_{4}$ and 1 gram $\mathrm{MgSO}_{4}$, neutralized with sodium carbonate, was also used $^{30}$ for the study of hippuric acid bacteria. Thirty-four species were isolated from soil, manure, urine, etc.; of these, twenty-eight decomposed hippuric acid and the others decomposed urea and uric acid. All those bacteria that decomposed urea also decomposed uric acid and vice versa; but those that decomposed hippuric acid did not necessarily decompose urea and uric acid, and vice versa.

Stapp ${ }^{31}$ employed, for the isolation of uric and hippuric acid bacteria, the following two media:
I. Uric acid........ 0.5 gram
$\mathrm{Na}_{2} \mathrm{HPO}_{4} \ldots \ldots \ldots, 3.0$ grams
Mineral solution.... $50 \mathrm{cc}$.
Water.......... 450 cc.
II. $\mathrm{KH}_{2} \mathrm{PO}_{4} \ldots \ldots \ldots 0.50$ gram $\mathrm{MgSO}_{4} \ldots \ldots \ldots . .25$ gram
Sodium hippurate 1.25 grams
Water.......... $500 \mathrm{cc}$.
The mineral solution used in Medium I was that of A. Meyer:
$\mathrm{KH}_{2} \mathrm{PO}_{4} \ldots \ldots \ldots \ldots \ldots 1.0 \mathrm{gram}$
$\mathrm{CaCl}_{2} \ldots \ldots \ldots \ldots \ldots . .1 \mathrm{gram}$
$\mathrm{NaCl} \ldots \ldots \ldots \ldots \ldots .0 .1 \mathrm{gram}$
$\mathrm{MgSO}_{4} \cdot 7 \mathrm{H}_{2} \mathrm{O} \ldots \ldots \ldots, 0.3 \mathrm{gram}$
$\mathrm{Fe}_{2} \mathrm{Cl}_{6} \ldots \ldots \ldots \ldots \ldots 0.01$ gram
$\mathrm{H}_{2} \mathrm{O} \ldots \ldots \ldots \ldots \ldots$...... 1000 ce.

Portions of the solutions (50 cc.) were placed into $200 \mathrm{cc}$. Erlenmeyer flasks and inoculated with soil or feces of various animals. Six species of bacilli were carefully described.

1. Bac. cobayae A. M. \& S. a non-motile, spore-forming organism. The eells attain a size up to $5.5 \mu$ long (usually $4 \mu$ ) and 1 to $1.2 \mu$ in diameter. The ellipsoidal to cylindrical spores, usually with convex poles, are 1.4 by $0 . s_{\mu}$. The organism forms diastase, protease, also $\mathrm{H}_{2} \mathrm{~S}$, tryptophane and skatol; nitrates are reduced.

2. Bac. capri A. M. \& S. is without flagella, up to $6.2 \mu$ long and 1 to $1.1 \mu$ in dianeter; ellipsoidal or egg shaped spores are 1.4 by $0.8 \mu$; reduces nitrates and forms diastase.

3. Bac.guano A. M. \& S. is a motile rod, with peritrichic flagellation, up to $5.4 \mu$ long and $0.7 \mu$ in diameter (2.8 to 3.4 by 0.6 to $0.7 \mu$ ); the ellipsoidal spores are 1.4 by $0.8 \mu$; weak reducing power, no diastase formation; gelatin is liquefied.

4. Bac. musculi A. M. \& S., with peritrichic flagellation, is 4.5 to 5 by 1 to $1.2 \mu$;

${ }^{29}$ Yoshimura, K. Note on the behavior of hippuric acid in soils. Bull. Coll. Agr. Tokyo. Imp. Univ. 2: 221-223. 1895.

${ }^{30}$ Schnellmann, H. Über die hippursäure-vergärenden Bakterien. Diss. Göttingen. 1912.

${ }^{31}$ Stapp, C. Botanische Untersuchungen einiger neuer Bakterienspezies, welche mit reiner Harnsäure order Hippursäure als alleinigem organischen Nahrstoff alıkommen. Centrbl, Bakt, II, 51: 1-71. 1920. 
spores 1 to 2.2 by 0.6 to $1.2 \mu$ (1.8 by $0.8 \mu$ ); weak reducing power; diastase is formed; gelatin is liquefied.

5. Bac. hollandicus A. M. \& S., with peritrichic flagellation, is 6 by 0.7 to $0.8 \mu$; spores $1.6 \times 0.8 \mu$; weak reducing power; diastase not formed, gelatin is liquefied. 6. Bac. carotarum Koch.

Ulpiani and Cinglani ${ }^{32}$ isolated from pigeon manure a bacterium capable of decomposing guanin and guanidin, but not uric acid.

The chemical processes involved in the transformation of urea, uric and hippuric acids are discussed elsewhere (p. 487).

${ }^{32}$ Ulpiani, C., and Cingolani, M. Sulla fermentazione della guanina. Atti R. Accad. Linc. Rend. CI. Sci. fis. Mat. et Nat. (5), 14, pt. 2: 596-600. 1905. 


\section{CHAPTER $\mathrm{X}$}

\section{Soll Algae and Their Activities}

Introductory. The microscopic chlorophyll-containing forms of the great plant division Thallophyta, the Algae, are represented in the soil by three large groups: the Cyanophyceae, Chlorophyceae and Bacillariaceae. The first contain, in addition to chlorophyll, also the pigments phycocyanin and carotin and are, therefore, blue-green to violet or brown in color; the second usually contain only chlorophyll, but sometimes also xanthophyll, and are, therefore, grass-green or yellow-green; the third contain, in addition to chlorophyll, also carotin and xanthophyll, and are golden brown in color. The chlorophyll-bearing microscopic forms of life are also represented in the soil by the Eugleneaccae and the Cryptomonadaceac (or Flagellata and Dinoflagellata), commonly classified with the Protozoa (Flagellata), and by the filamentous moss protonema, which belongs to the higher group of plants, the Bryophyta.

Algae and the autotrophic groups of bacteria are the only microorganisms in the soil that can synthesize organic matter from inorganic materials, the fungi and the heterotrophic bacteria depend for their energy upon organic matter synthesized by other forms of life. The autotrophic bacteria obtain their energy chemosynthetically, using inorganic substances as a source of energy; the algae obtain their energy photosynthetically, using the energy of the rays of the sun.

Algae are universally distributed on the surface of the soil, wherever moisture and light are available. It is sufficient to moisten the soil with water and expose it to the light to obtain in a short time an abundant vegetation. However, algae may also be living below the surface of the soil, not exposed to the direct rays of the sun and under more uniform temperature and moisture conditions. The algae, as well as the other groups of soil mieroorganisms grow in the soil in mixture and, for purposes of identification and particularly for physiological investigations, they have to be isolated and cultivated upon artificially prepared media.

Some of the algae are isolated readily from the soil and others only with difficulty. For morphological studies and classification, it is suffi- 
cicnt to separate the various forms and to cultivate them under artificial conditions, even if they are contaminated with fungi or bacteria; but for physiological studies, especially in the assimilation and transformation of various elements, as in organic matter decomposition, nitrogen fixation and symbiotic action, it is important to obtain them free from any contaminating organisms.

Mcthods of isolation of impure cultures of algae. The methods of isolation of algae from the soil fall into enrichment culture and pure culture methods. The enrichment culture methods consist in making conditions favorable for an abundant development of algae, for identification purposes; the pure culture methods deal with the processes of obtaining the organisms free not only from fungi and bacteria, but also from other algae, for physiological studies as well as for a more careful study of their morphological characteristics. ${ }^{1}$ The enrichment culture is also the preliminary step in the isolation of the pure culture. Since these organisms require light for the autotrophic assimilation of carbon dioxide (photosynthetically), this need of light is utilized for enrichment purposes. A small quantity of soil added to a large flask containing 0.02 per cent $\mathrm{K}_{2} \mathrm{HPO}_{4}$ in tap water and exposed to light will soon allow

${ }^{1}$ Wettstein, F. von. Zur Bedeutung und Teehnik der Reinkultur für die Systematik und Floristik der Algen. Österreich Bot. Ztg. 70: 23-28. 1921.

\section{PLATE XII}

Soll Algae

75. Pleurococcus (from Robbins).

76.'Mostoc commune (from Robbins).

77. Microcoleus vaginatus (from Robbins).

78. Phormidium species (from Robbins).

79. Anabaena sp. (from Robbins).

80. Nodularia sp. (from Robbins).

81. Chlumydomonas communis: $1-3$, motile vegetative cells; 4 , resting cell in which division is about to take place; 5-6, longitudinal fission into four zoogonidia ; 7 , oblique fission, $\times 960$ (from Bristol).

82. Ulothrix tenuissima $\times 550$ (from Bristol).

83. Bumillaria exilis: $a$ and $b$, vegetative filaments showing variable number of chloroplasts, $\times 550 ; c$ and $d$, filaments showing stages in formation of zoogonidia, $\times 960$ (from Bristol).

84. Cylindrospermum muscicola: a, typieal filament in different stages of spore-formation; $b$, spre formed in an irregular position, $\times 550$ (from Bristol).

85. Some typical soil diatoms: $1-2$, Navicula borealis; $3-5, N$. balfouriana; $6-9$, N. intermedia; 10-12, N. brebissonii, var. diminuta; 13, N. clliptica, var. oblongella; 14, N. elliptica, var. minima; 15-17, N. terricola, $\times$ 960-1150 (from Bristol). 


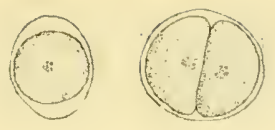

75

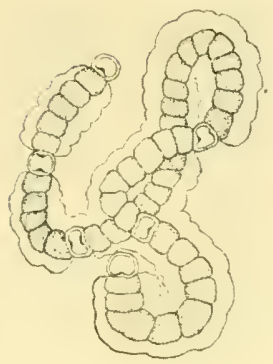

76

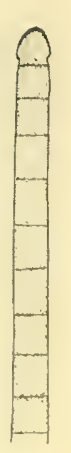

77

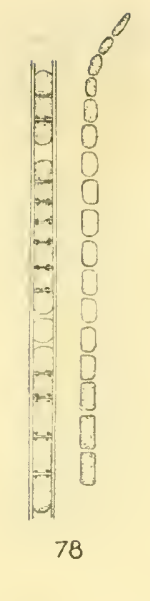

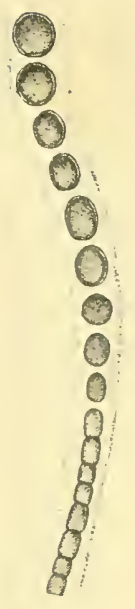

79
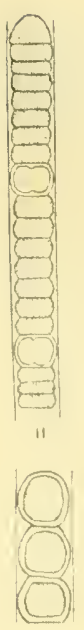

80

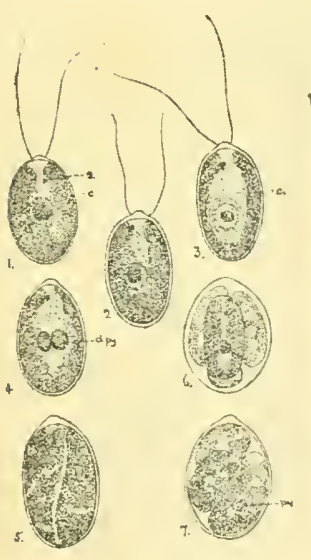

81

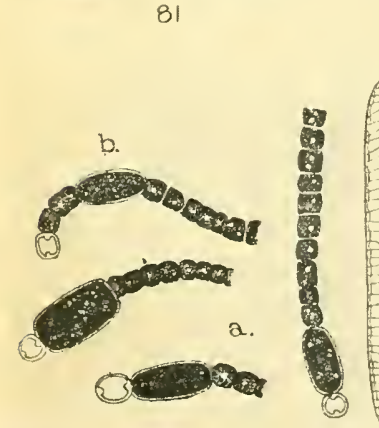

84
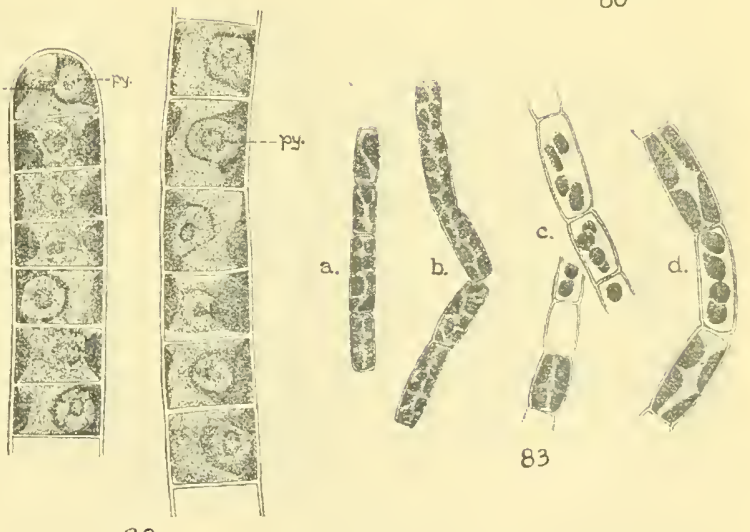

82

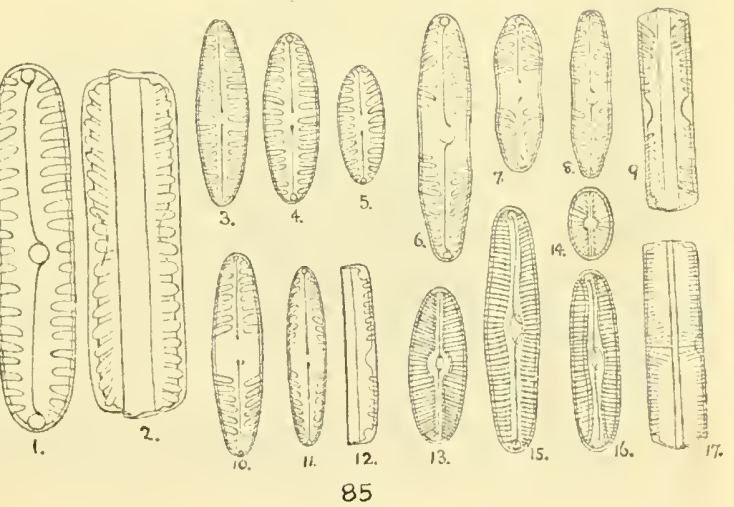



the development of various blue-green algae; dry soil will give the spore-forming Nostococaceae, such as Anabaena and Cylindrospermum. ${ }^{2}$ When a large quantity of soil is placed in tap water, various small diatoms will always develop. When proteins are added to the soil and covered with water, various Volvocineae, such as Chlamydomonas, Karteria, Chlorogonium, Spondylomorum are obtained. ${ }^{3}$ For the purpose of isolating the algae, Robbins ${ }^{4}$ used 500 ec. Florence flasks filled, to their greatest diameter, with ground quartz, previously washed free from all suspended matter. The flasks are plugged with eotton and sterilized at $120^{\circ} \mathrm{C}$. for 30 minutes. The soil is then shaken, for 5 minutes, with sterile water; an amount ( $25 \mathrm{cc}$.) equivalent to $10 \mathrm{grams}$ of soil is evenly distributed, with a sterile pipette, over the ground quartz surface. The flasks are tipped to one side so as to offer both a moist sand and a free water surface for the algae to grow on. The flasks are kept in the greenhouse in a sunny place, then in a shady place. After growth of algae has taken place, they are transferred to 1 per cent agar medium with soil extract as a base. Some of the algal material is shaken up in a test tube with a few cubic centimeters of sterile water, then transfers are made, with a platinum loop, to tubes of liquefied agar cooled to $42^{\circ} \mathrm{C}$. The tubes are shaken and the agar is poured into sterile Petri dishes. Growth of algae will appear in 2 or 3 weeks. The cultures may then be transferred to insure purity.

Moore and Karrer ${ }^{5}$ placed about $1 \frac{1}{2}$ inches of sand in pint milk bottles, to which 150 ec. of a culture solution had been added. The bottles were plugged with cotton and sterilized at 8 to 10 pounds pressure for one-half hour. Because of the soluble material present in the sand, the culture solution was one-half the strength of a modified Beijerinck solution used by Moore. ${ }^{6}$

${ }^{2}$ Beijerinck, M. W. Über oligonitrophile Mikroben. Centrbl. Bakt. II, 7: 561-582. 1901 .

${ }^{3}$ Jacobsen, H. C. Kulturversuche mit einigen niederen Volvocacecn. Ztschr. Bot. 2: 145-188. 1910.

${ }^{4}$ Robbins, W. W. Algac in some Colorado soils. Colorado Agr. Exp. Sta. Bul. 1S4. 1912.

${ }^{5}$ Moore, G. T., and Karrer, J. L. $\Lambda$ subterranean algal flora. Ann. Mo. Bot. Gard. 6: 281-307. 1919.

${ }^{6}$ Moore, G. T. Methods for growing pure cultures of algae. Jour. Appl. Microsc. 6: 2309-2314. 1903. 
The composition of the undiluted solution is as follows:
$\mathrm{NH}_{4} \mathrm{NO}_{3} \ldots \ldots \ldots \ldots .0 .5$ gram
$\mathrm{KH}_{2} \mathrm{PO}_{4} \ldots \ldots \ldots \ldots, 0.2 \mathrm{gram}$
$\mathrm{CaCl}_{2}$
0.1 gram
$\mathrm{FeSO}_{4}$
trace
$\mathrm{MgSO}_{4} \cdot 7 \mathrm{H}_{2} \mathrm{O} \ldots \ldots \ldots .0 .2 \mathrm{gram}$ Distilled water...... $1000 \mathrm{cc}$.

The bottles are inoculated with about 10 grams of soil taken at the desired depth. To lessen the amount of evaporation, waxed paper covers are placed over the cotton plugs. The sand is slanted in the bottle so as not to be wholly submerged, giving various moisture conditions. The bottles are placed so as to get good light for at least part of the day. The water lost by evaporation is replaced from time to time with sterile water.

The following two media are also recommended for the isolation of algae:

Bristol's solution 7

\begin{tabular}{|c|c|}
\hline $\mathrm{NaNO}_{3} \ldots \ldots \ldots \ldots \ldots$ & 0.5 \\
\hline $\mathrm{KH}_{2} \mathrm{PO}_{4} \ldots \ldots \ldots \ldots$ & 0.5 \\
\hline $\mathrm{MgSO}_{4} \cdot 7 \mathrm{H}_{2} \mathrm{O} \ldots$ & 0.15 \\
\hline $\mathrm{CaCl}_{2} \ldots \ldots \ldots$ & 0.05 \\
\hline $\mathrm{NaCl} \ldots$ & 0.05 \\
\hline $\mathrm{FeCl}_{3} \ldots$ & 0.005 \\
\hline
\end{tabular}

Detmer's solution

Distilled water...... $1000 \mathrm{cc}$.

Detmer's medium is diluted to one-third of its strength and 0.01 per cent $\mathrm{FeCl}_{3}$ is added. Distilled water is always prepared in a silver or glass still. Sand is placed into wide-mouth culture bottles to a depth of about 1.5 inches and moistened with one of the above media; the bottles are plugged and sterilized, then inoculated with a suspension of the soil in a sterile mineral salt solution.

The soil may also be packed in a Petri dish to a depth of about $1 \mathrm{~cm}$., well moistened with sterile distilled water, and the surface covered with a piece of pure filter paper. The cultures are kept in diffuse light, preferably at a temperature of $20^{\circ}$ to $25^{\circ} \mathrm{C}$. The paper is moistened from time to time with sterile distilled water. After 2 to 60 days, various blue-green algae are found to grow through the pores of the paper to the light. ${ }^{8}$ The mixed cultures are transferred to sterile culture solutions or proper agar media for the isolation of the individual species.

Isolation of pure cultures. The separation of various species of algae can be done either mechanically by the use of a loop and the mieroseope, or culturally by the use of solid media. ${ }^{9}$ The Barber pipette can also be employed as a mechanical means of separation.

7 Bristol, B. M. On the algal-flora of some desiccated English soils: an important factor in soil biology. Anu. Bot 34: 35-79. 1920.

${ }^{8}$ Esmarch, F. Untersuchungen über dic Verbreitung der Cyanophyceen auf und in verschiedenen Böden. Hedwigia, 55: 224-273. 1914; Diss. Kiiel. 1914.

${ }^{9}$ Pringsheim, E. G. Algenkultur. Abderhald. Handb. biol. Arbeitsmeth. Abt. XI, T. 2, 377-406. 1924. 
Beijerinck $^{10}$ was the first to isolate algae in pure culture, using a medium consisting of ditch water, to which 10 per cent gelatin had been added. The liquid media given above are well suitable for the cultivation of algae. An alkaline reaction is most favorable, since algae are usually injured in acid media.

The agar plate method for the isolation of pure cultures of algae has been successfully employed..112 The broken-up mass of algal material can be streaked out several times upon the surface of a solidified agar plate, so that each streak carries less of the inoculum than the preceding one. The inoculum may also be placed in a tube of molted and cooled agar; then a series of successive transfers are made into other tubes, so as to obtain a series of dilutions. These agar tubes inoculated with successively decreasing portions of material are poured into sterile Petri dishes. T'he streak method allows the development of surface colonies and the tube method of deep colonies. The plates are then exposed to light, so as to stimulate the development of the algae and to prevent the growth of other organisms. When the colonies have developed sufficiently they are transferred into liquid media. Algae are usually provided with a more or less highly devveloped exterior mucilaginous investment, either in the form of a sheath or of a mere gelatinization. They also develop much more slowly than fungi. Both of these factors contribute to the difficulties encountered in pure culture work with algae. ${ }^{13}$ When the life-history of the organism is known, the best period for obtaining it free from bacteria can be readily determined.

Schramm ${ }^{13}$ used, for the isolation of algac, the medium recommended by Moore. with the addition of $10 \mathrm{gm}$. of agar. The latter is carefully washed first in tap water, then in distilled water, ${ }^{14}$ so that the medium can be cooled down to about

${ }^{10}$ Beijerinck, M. W. Kulturversuche mit Zoochlorellen, Lichengonidien, und anderen niederen Algen. Bot. Ztg. 48: 725-785. 1890; Also Centrbl. Bakt., 13: $368-373.1893$.

11 Tischutkin, N. Ueber Agar-Agarkulturen einiger Algen und Amöben. Centrbl. Bakt. II, 3: 183-188. 1897.

12 Ward, H. M. Some methods for use in the culture of algae. Ann. Bot. 13: 563-566. 1899.

${ }^{13}$ Schramm, J. R. Some pure culture methods in the algae. Ann. Mo. Bot. Gard. 1: 23-45. 1914.

${ }^{14}$ Richter, O. Reinkulturen von Diatomeen. Ber. deut. bot. Gesell. 21: 493-506. 1903; Die Ernährung der Algen. Monograph, Abhandl. Int. Rev. Hydrobiol. Hydrogr. 2: 31. 1911. 
$34.5^{\circ}$ to $35^{\circ} \mathrm{C}$., without solidification. Six to eight cubic centimeters of agar are placed in a Petri dish $10 \mathrm{ec}$. in diameter. If the alga is filamentous, it is first washed in sterilized nutrient solution; if it is a unicellular form, it is diluted, the extent of dilution depending on the abundance of organisms. The material is added to the tube of liquid agar, which is then vigorously shaken so as to separate the adhering bacteria, and the contents are poured into a Petri dish. The plates are allowed to cool, then they are turned upside down, so as to prevent the moisture from spreading bacteria over the surface, and are placed in the light of a north window, preferably in a glass ease. The plates are examined frequently and, if rapidly spreading bacteria and fungi are found, they are dissected out. The algal colonies usually appear in from three to four weeks. If the inverted plates are examined from time to time with the compound microscope $(12 \mathrm{~m}$. objective), the algal colonies may be located in the very early stages of development. The colonies are marked with a glass pencil and are transferred, by means of a platinum loop, to sterile agar slants. The purity of the culture may be further tested by transferring it to media suitable for bacterial growth.

This method may have to be modified for particular forms of algae: in some instances the method of Barber is used $;^{15}$ in other cases the fact is utilized that eertain species readily produce zoospores or other free endogenous spores; in some speeies the vegetative cells are either free from bacteria or ean be rendered so by mechanical means. Pure cultures of various algae, particularly of Chlorophyceae, were thus isolated. The Cyanophyceae presented more difficult problems of isolation, since the gelatinous investments are all impregnated with bacteria, which cannot be removed even by most vigorous washing. By the use of silicic acid gel, one species of Oscillatoria and one Microcoleus were isolated. However, as soon as these two organisms are completely separated from bacteria, the media, otherwise favorable, seem to become unfavorable and the organisms eventually die.

By repeated transfer to sterile silicic acid gel plates, a species of Nostoc was isolated ${ }^{16}$ in pure culture. Another method ${ }^{17}$ consists in growing the organisms in a dilute mineral salt solution (Detmer's), either placed in flasks or impregnated in silica gel. Subcultures are made for enrichment purposes. Dilute suspensions of the algae, well shaken for the separation of the cells, are then inoculated into flasks

${ }^{15}$ Barber, 1907 (p. 55).

${ }^{16}$ Pringsheim, E. G. Kulturversuche mit Chlorophyllführenden Mikroorganismen. I. Die Kultur von Algen auf Agar. III. Zur Physiologie der Schizophyceen. Beitr. Biol Pflanz. 11. 1912; 12: 49-108. 1913.

17 Chodat, R. Etude critique et expérimentale zur le polymorphisme des algues. Genève. 1909; Monographie d'algues en culture pure. Matériaux pour la flore cryptogamique suisse. Vol. IV, Fasc. 2, 1913. Berne. 
contaning melted and cooled $\left(42^{\circ} \mathrm{C}\right.$.) agar that has been well shaken. The colonies are allowed to develop in the solid agar in bright sunlight, and are then cut out asceptically and transferred to fresh media. The process may have to be repeated. ${ }^{18}$

Cultivation of soil algae. For the cultivation of soil algae, the above three solutions, either in liquid form or with 1.5 per cent agar, can be used. A medium containing $1.475 \mathrm{gram}$ of $\mathrm{Ca}\left(\mathrm{NO}_{3}\right)_{2} \cdot 4 \mathrm{H}_{4} \mathrm{O}$, in place of 0.5 gram $\mathrm{NH}_{4} \mathrm{NO}_{3}$, per liter has been used ${ }^{19}$ with good results. For the cultivation of diatoms, a modification of Miquel's ${ }^{20}$ medium, consisting of the following two solutions has been found ${ }^{21}$ to give satisfactory results.

A. 20.2 grams $\mathrm{KNO}_{3}$ in 100 ce. of distilled water.

B. 4 grams $\mathrm{Na}_{2} \mathrm{HPO}_{4}$ in 40 ec. water +2 ec. concentrated $\mathrm{HCl}+2$ ec. $\mathrm{FeCl}_{3}$ (melted at $45^{\circ} \mathrm{C}$.) +4 grams $\mathrm{CaCl}_{2}$ dissolved in 40 cc. water.

Forty drops of $\mathrm{A}$ and 10 to 20 drops of $\mathrm{B}$ are added to 1 liter of distilled water.

In addition to the above media, the following two solutions are very favorable for the growth of algae: ${ }^{22}$

Pringsheim solution

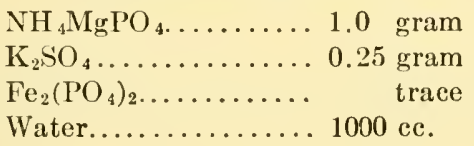

\section{Benecke $e^{23}$ solution}

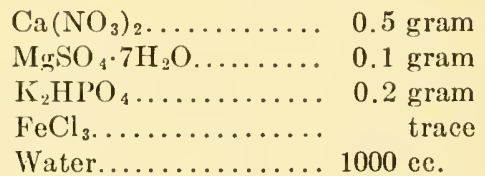

The following solid medium can be used for the cultivation of algac: Chodat ${ }^{24}$ medium

\begin{tabular}{|c|c|}
\hline $\mathrm{Ca}\left(\mathrm{NO}_{3}\right)_{2} \ldots \ldots \ldots \ldots 1.0$ gram & $\mathrm{FeSO}_{4} \ldots \ldots \ldots \ldots$ \\
\hline$\ldots 0.25 \mathrm{gram}$ & Distilled water...... $1000 \mathrm{ec}$ \\
\hline $\operatorname{lgSO}_{4} \cdot 7 \mathrm{H}_{2} \mathrm{O}$ & Washed agar.... \\
\hline 0.10 & $5.3-5.5$ \\
\hline
\end{tabular}

18 See also Bristol Roach, 1926 (p. 225).

${ }^{19}$ Wann, F. B. The fixation of nitrogen by green plants. Jour. Bot. 8: 1-29. 1921.

${ }^{20}$ Miquel, P. De la culture artificielle deз diatomées. Ch. I, Le Diatomiste. 1: 93-99. 1890.

${ }^{21}$ Ailen, E. J., and Nelson, E. W. On the artificial culture of marine plankton organisms. Jour. Marine Biol. Assoc. 8: No. 5. 1900.

22 Pringsheim, 1924 (p. 218).

${ }^{23}$ Benecke, W. Über Kulturbedingungen einiger Algen. Bot. Ztg. 56: 8397. 1898.

${ }^{24}$ Chodat, R., and Grintzesco, J. Sur les méthodes de culture pure des algues vertes. Actes Congr. Intern. Bot. Paris. 1910, 157. 
The $\mathrm{KCl}$ may be replaced by $\mathrm{CaCl}_{2}$ and the reaction adjusted to pH 7.3.25 Organic media may also be cmployed. Various proteins, including peptone, can be used as sources of nitrogen; sugar's (glucose, fructose), higher alcohols (mannite, glycerol), and organic acids (in the form of neutral salts) can be used as sources of carbon. Various decoctions of hay, manure, peas and soil cxtracts can also be used, especially when the $\mathrm{N}$ and $\mathrm{P}$ eontent of the latter is increased by the addition of inorganic salts. Of the various organic media suggested, mention may be made here of two: ${ }^{26}$
(a) Cane sugar...... 10 grams Asparagine...... 2 grams
Feptone........ 8 grams
Gelatin........ 80 grams
Water.......... $900 \mathrm{cc}$.

(b) Malt extract.... $\$ 90$ grams Glucose........ 29 grams Peptone........ 0.5 gram Asparagine...... 0.5 gram Gelatin........ 80 grams

To obtain inorganic solid media, add 15 to 20 grams of washed agar to one of the above solutions. In addition, soil, part, sand and gypsum blocks can be used very readily, the last two moistened with a nutrient solution. To eliminate all traces of organic matter silica gel can be employed.

Distribution of algae in the soil. The soil is a favorable medium for the growth of algae, which require only a relatively small amount of moisture to replace that lost by the protoplast in drying. ${ }^{27}$ In view of the fact that algae can develop on organic media also in the dark, their existence in the soil even below the sufacee is made possible.

The occurrence of algae in the soil, particularly that of diatoms, has been referred to by a number of earlier writers. ${ }^{28,29}$ Esmarch $^{30}$ attempted to determine the distribution of algae on the surface of the soil, their presence in the subsurface, and whether cultivation influenced their distribution. Four types of uncultivated soils were used: sandy

25 Fred and Peterson, 1925 (p. 378).

${ }^{26}$ Beijerinck, M. W. Over gelatine culturen van eencellige groenwieren. Verh. Prov. Utrechtsch. Genootsch. Kunst en Wetensch. 1889, 35-52. (Centrbl. Eakt. 8: 460-462. 1890.)

27 Fritsch, F. E., and Haines, F. M. The moisture relations of terrestrial algae. Ann. Bot. 148: 683-728. 1923.

28 Ehrenberg, 1837 (p. 92).

${ }^{29}$ Gregory, IW. On the presence of Diatomaceae, Philolithoria, and sponge spicules in soils which support vegetation. Amer. Jour. Sci. Arts, II, 21: 434437. 1856 .

so Esmarch, 1914 (p. 218); see also Esmarch, F. Beitrag zur Cyanophyceen. flora unserer Kíolonien. Hamburg. wiss. Anst. 28: 63-82. 1910. 
heathland containing only traces of organic matter, marshy bog, forest humus, and moist sand. The various samples were often taken from quite different localities having the same type of soil. Only 3 out of 34 samples of the sandy heathland showed the presence of Cyanophyceae on the surface. Thirty-five samples of the marshy bog soil showed no blue green algae, but contained a few diatoms and grass-green algae. Only 5 samples out of 40 of the forest humus soil contained blue green algae and only 5 species were obtained altogether from soils of this type. The moist sandy soils indicated numerous blue-green algae on the surface. Subsurface samples from below the uncultivated soils were destitute of algae except in the moist sandy soils where they were fairly extensive in distribution. A larger number of blue-green algae was found in cultivated soils. A clay soil, for example, contained 23 species of blue-green algae in 35 out of 37 samples and 29 out of 45 samples of sandy soil contained 12 different kinds of algac. In gencral, cultivated soils were found to contain a greater number of blue-green algae than uncultivated, possibly because of the difference in moisture and mineral content. Grass land was richer in species than arable land. Subsurface samples were obtained at a depth of 10 to $25 \mathrm{~cm}$. and, in some cases, at 30 to $50 \mathrm{~cm}$., in a manner to prevent surface contamination. Only a few of the samples, coming from soils where there were no surface forms, contained no blue-green algae. Eighteen separate species were isolated, the number of algae decreasing with depth. In all, 45 species were described, of which 34 belonged to the Oscillatoriaceae and Nostococaceae.

Esmarch ascribed the occurrence of subsurface forms to their being carried down by soil cultivation and by seepage of surface waters, as well as by earthworms and other soil organisms. By growing bluegreen algae in the dark, or burying algae in the soil, then examining microscopically at various intervals of time, the filaments were found to become discolored, finally changing to a yellow color; the filaments disintegrated leaving only spores and heterocysts behind. On moistening and exposing these to light, blue-green growth again appeared. The conclusion was reached, therefore, that blue-green algae cannot persist beneath the surface for any length of time, because of the absence of light and the destructive influence of the soil itself.

Acid soils were reported ${ }^{31}$ to contain a different algal flora from that commonly found in alkaline or neutral soils. Twenty-four species

${ }^{31}$ Petersen, J. B. Danske aerofile alger. Danske Vidensk. Selsk. Skrifter. 7 Raekke, Naturv og Mathem. Afd. 12: 7. 1915. 
and varieties of diatoms were found in field and garden soils, 5 in marshy soils, and comparatively few or none at all in forest and heathland soils.

Robbins $^{32}$ sampled several Colorado soils which were very rich in nitrate, by removing first the loose debris on the surface, then taking samples from the upper 3 to 4 inches. Out of 21 different species recorded, there were 18 Cyanophyceae, 1 diatom, and only 1 unicellular organism belonging to the Chlorophyceae. The Nostococaceae were best represented. The most prevalent species were Phormidium tenue, Nostoc sp., Anabaena sp., Nodularia harveyana, and Stigonema sp.

A distinct subterranean algal flora independent of the nature of the soil and the locality was found by Moore and Karrer. ${ }^{33}$ Some species multiplied even when buried at a depth of one meter. In view of the fact that these algae were found in compact undisturbed soil, the possibility suggested itself that algae are present in the soil in a vegetative condition and actually grow there and play a definite function in soil transformations.

The following list contains the algae found in the soil by Moore and Karre $r$ and the greatest depth at which they occurred:

Chlorococcum humicola (Näg.) Rab................... $100 \mathrm{~cm}$.

II antzschia amphioxys (Ehr.) Grun................. $100 \mathrm{~cm}$.

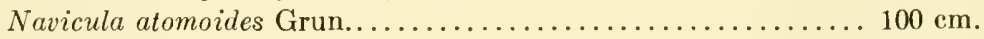

Trochiscia

Stichococcus bacillaris Näg. ................... $70 \mathrm{~cm}$.

Oscillatoria amphibia Agardh .................... $70 \mathrm{~cm}$.

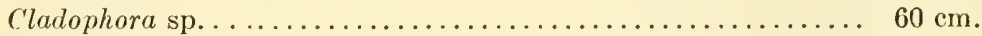

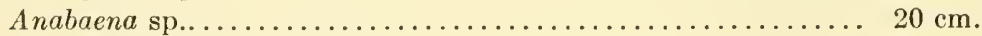

Nitzschia kutzingiana Hilse .................... $20 \mathrm{~cm}$.

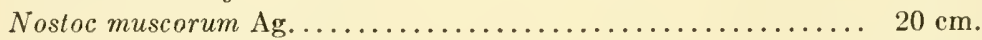

Oscillatoria chlorina Kütz.................... $20 \mathrm{~cm}$.

Oscillatoria subtilissima Kütz. .................. $20 \mathrm{~cm}$.

Scytonema hofmanni Ag...................... 20 cur.

Oscillatoria anoema (Kütz) Gomont.................... surface

Oscillatoria formosa Bory ......................... surface

Oscillatoria splendida Greville ................... surface

An extensive study of the algal flora of desiccated soils has been made

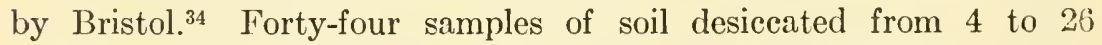
wecks and from widely separated localities were examined; a wiclely distributed ecological plant formation consisting of moss protonema

${ }^{32}$ Rolbbins, 1912 (p. 217).

${ }^{73}$ Moore and Karrer, 1919 (p. 217).

${ }^{34}$ Bristol, 1920 (p. 218). 
and algae was present in cultivated soils. In these soils, 64 species and varieties of algae consisting of 24 species of Cyanophyceae, 20 Chlorophyceae and 20 Bacillarieae (diatoms) were found. The most important species in the plant-formation are Hantzschia amphioxys, Trochiscia aspera, Chlorococcum humicola, Bumilleria exilis and, to a less degree, Ulothrix subtilis var. variabilis; moss protonema was universally present.

There seemed to be an association between three blue-greens; namely, Phormidium tenue, Ph. autumnale and Plectonema battersii, two of which were found together in 16 of the samples and all three in 7 samples. Soils rich in blue-greens contained only a few species of diatoms, and vice versa; the first occurred more frequently in arable soils and the seeond in old garden soils. The resting forms could survive desiccation for a long period of time; 35 species of blue-green algae, 4 grass-greens and 1 diatom were isolated from soils stored for about 40 years; the Nostoc muscorum and Nodularia harveyana retained vitality for the longest period of time.

Most of the algae, except a few diatoms, are severely affected by frost, so that their numbers and activities usually reach a minimum in February. As soon as the snow melts a rapid development takes place, followed again by a minimum growth in the late summer. ${ }^{36}$ With an increase in moisture, there is an increase in the numbers and activities. However, this phenomenon is not absolute. Observations by West and others indicate that different species of fresh water algae attain their maximal growth at different periods in the year. Soil algae show a sinilar variability.

The determination of numbers of algae in the soil is even less accurate than in the case of bacteria, fungi and protozoa, largely because of the layer of mucilage with which the cells of various species are surrounded. The dilution method may be used, in a manner similar to the determination of numbers of protozoa; ${ }^{37}$ a nutrient solution (p. 221) is used for the preparation of the different dilutions, and 5-ce. portions of the final dilutions are added to test-tubes containing 15-gram portions of

${ }^{35}$ Bristol, B. M. On the retention of vitality of algae from old stored soils. New Phyt. 18, 1919, Nos. 3 and 4; 1920 (p. 92-107).

${ }^{36}$ Francé, 1921 (p. 642). Magedeburg, P. Vergleichende Untersuchung der Hochmoor-Algenflora zweier deutseher Mittelgebirge. Hedwigia. 66: 1-26. 1926.

${ }^{37}$ Bristol Roach, B. M. Methods for studying soil algae. Abderhald. Handl). Biochem. Arb. Meth. Abt. XI, T. 3. 1926. 


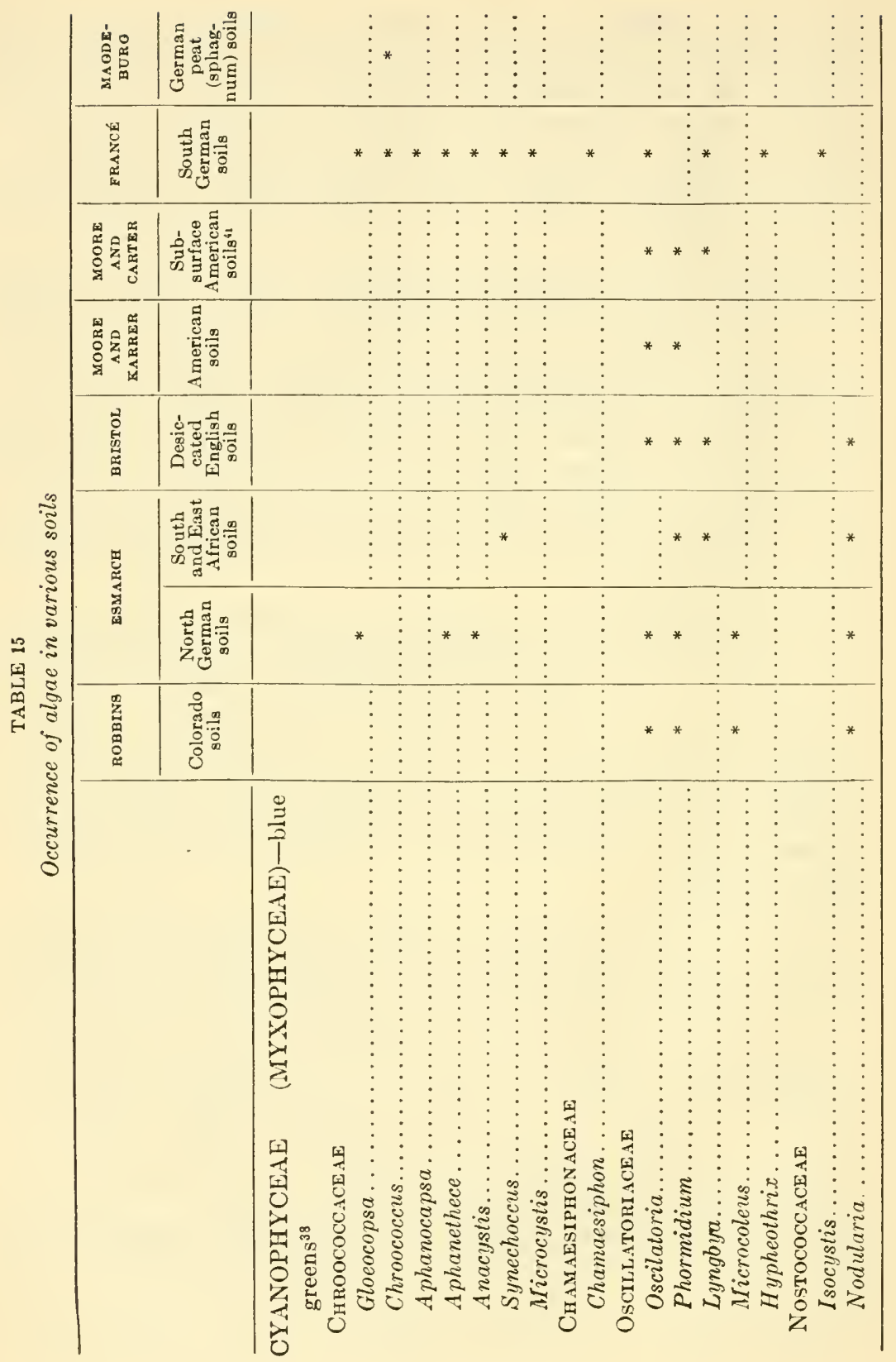




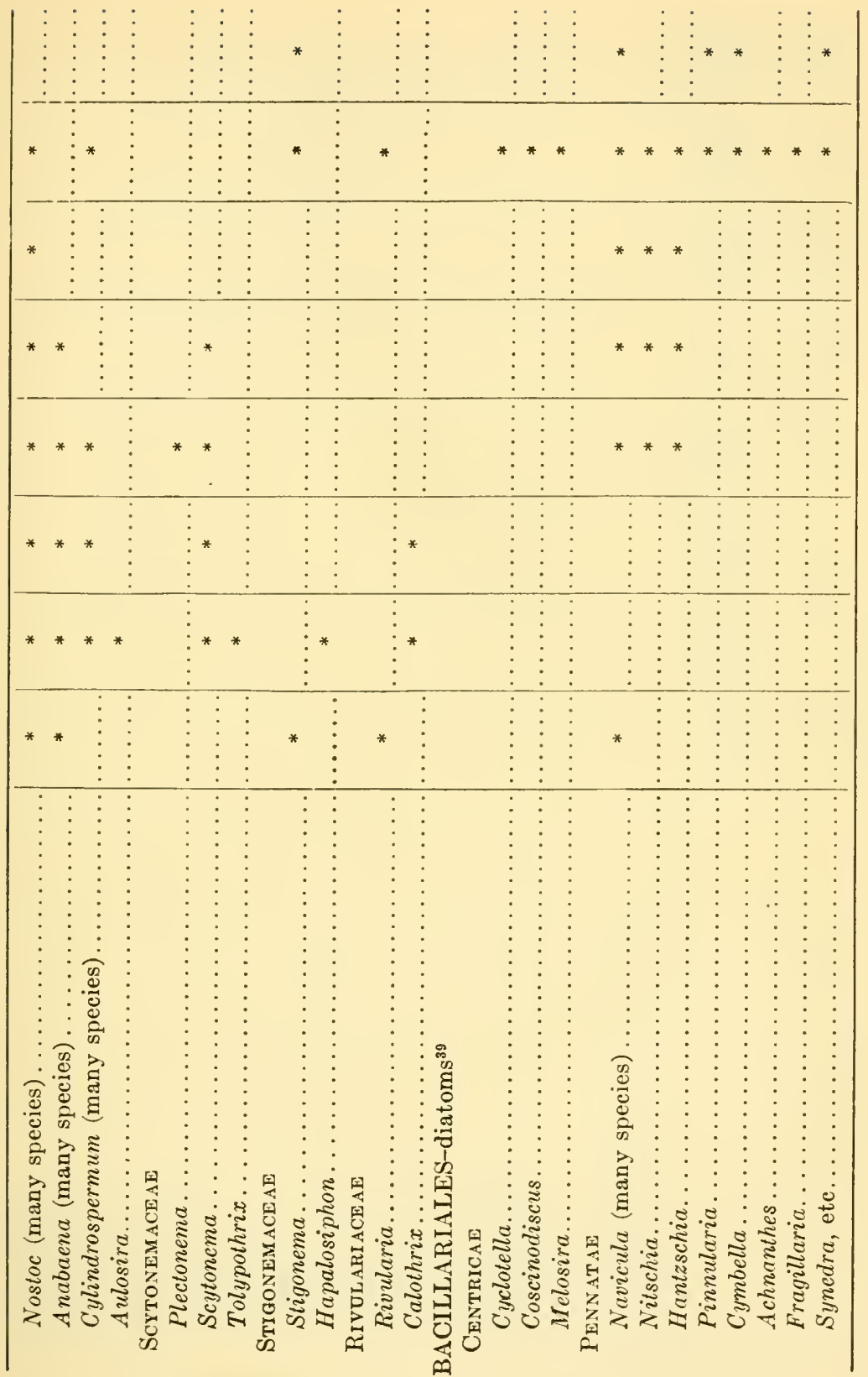




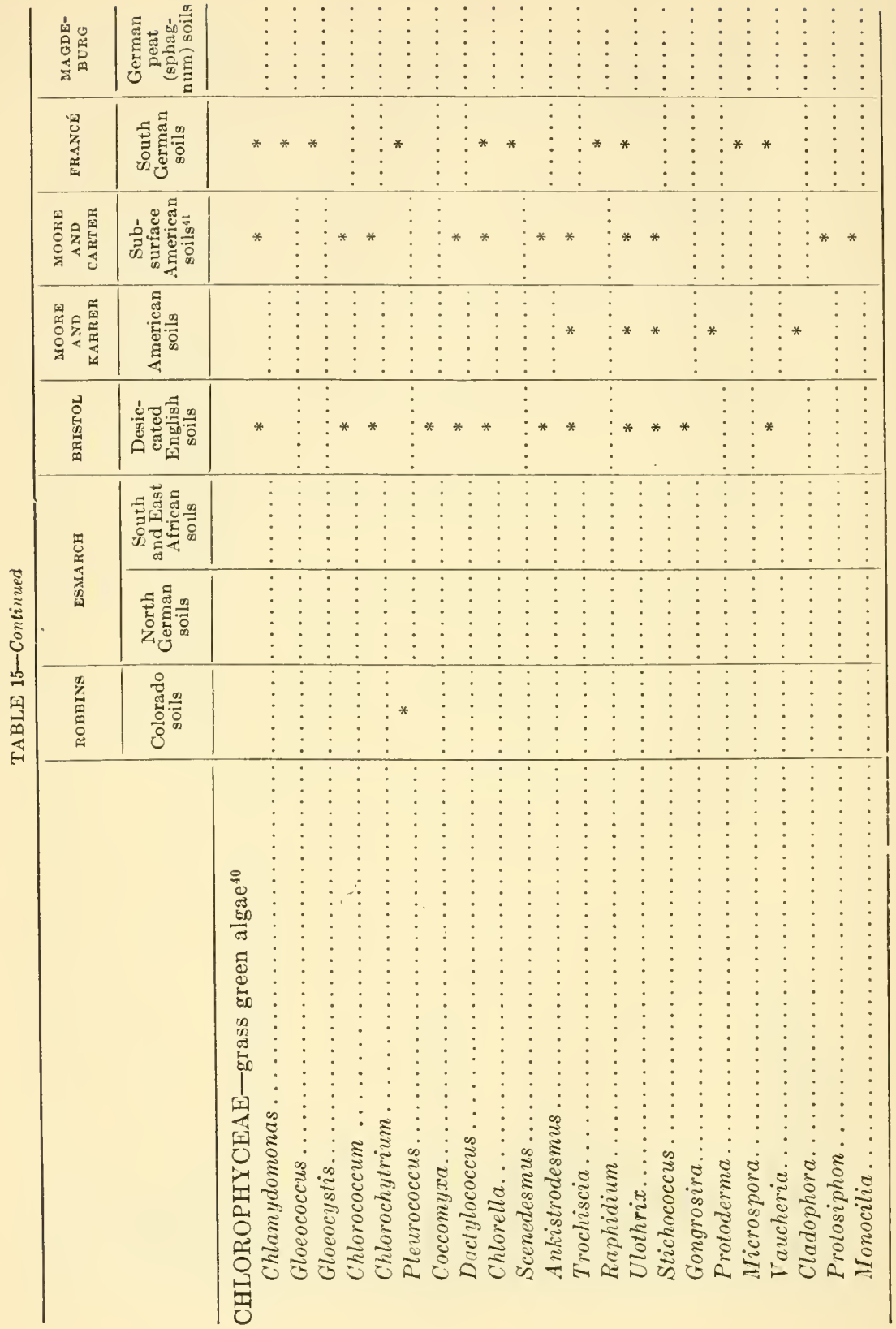




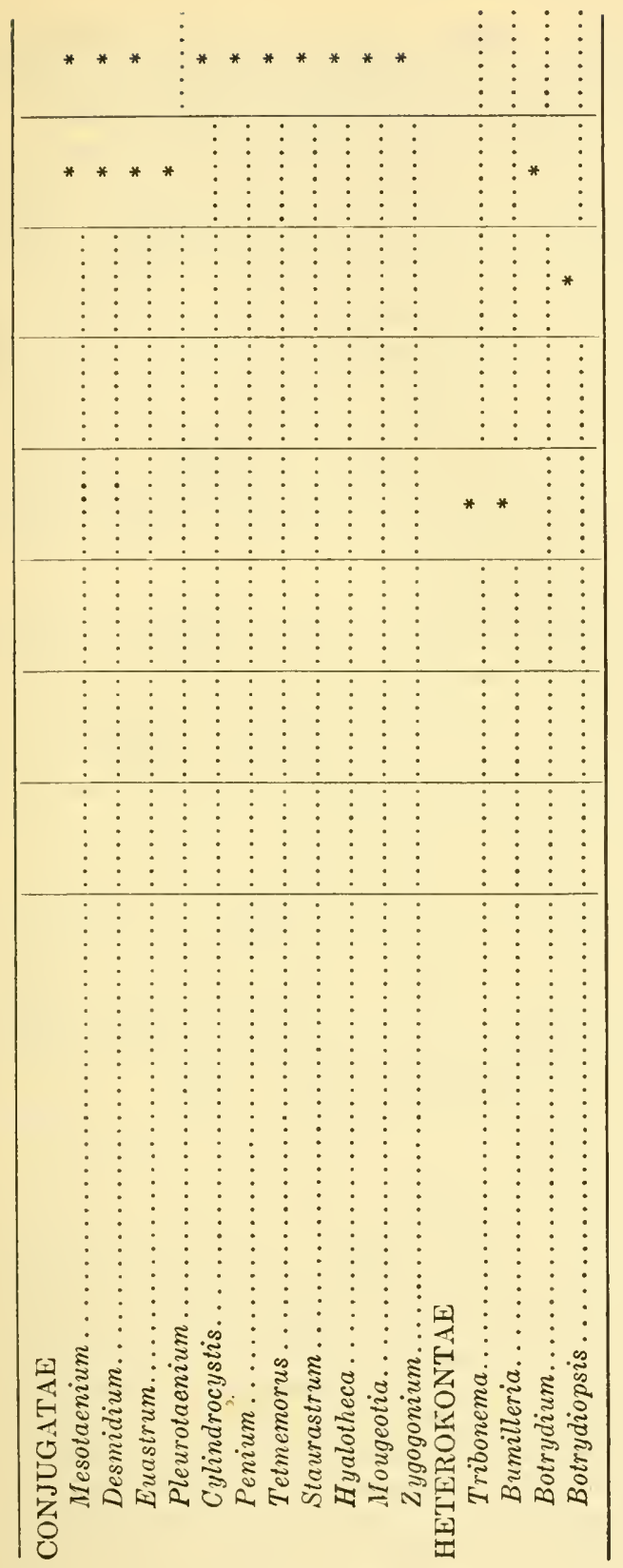


cleaned; sterilized sand. The inoculated tubes are placed in closed glass vessels and exposed to sunlight. The presence and type of growth are determined at the end of a month by microscopic examination.

Occurrence of algae in the soil. Several heterogeneous groups of Thallophytes are commonly included among the algae; they all contain chlorophyll, which is often accompanied by other pigments. Phylogenetically, the algae belong to different groups of organisms: the Cyanophyceae (Myxophyceae) or blue-green algae are related to the bacteria or Schizomycetes. F. Cohn united both of these groups into the Schizophyta, characterized by lack of a nucleus. The Flagellata and Dinoflagellata (forming thick-walled resting cysts) are related to the protozoa and are often included with these organisms. The Bacillariales, characterized by their shells and auxospore formation, stand apart also. It is also difficult to establish the relationship of the Charophyta, Phaeophyceae, and Rhodophyceae.

Without going into a detailed discussion of the classification of algae, it is sufficient to indicate that comparatively little work-a few isolated investigations-has been done on their occurrence in the soil. To indicate the very incomplete nature of the records, it is sufficient to call attention merely to the representatives of each group which have been demonstrated to be present in the soil (Table 15).

Biochemical activities of algae. ${ }^{42}$ Algae are able, in the light, to

${ }^{38}$ For a classification of the blue-green algae, see Tilden, J. E. Minnesota algae. I. Myxophyceae. Minn. Bot. Survey. 1910; Tilden, J. E. Synopsis of the blue-green algae-Myxophyceae. Trans. Amer. Microscop. Soc. 36, 1917, 179-266; Forti-Sylloge Myxophycearum. See also the general texts of de Toni, Engler and Prantl, and West; Collins, F. S. A working key to the genera of North American Algae. Tufts College Studies, 4: No. 8. 1918.

${ }^{39}$ For a classification of diatoms see vol. x by Schonfeldt of Pascher's series, and van Heurck, Traité des Diatomées.

${ }^{40}$ For a classification of the grass-green algae see West, Pascher, De Toni and Collins.

${ }^{41}$ Moore, G. T., and Carter, N. Further studies on the subterranean algal flora of the Missouri Botanical Garden. Ann. Mo. Bot. Gard. 13: 101-140. 1926.

${ }^{42}$ The following contributions should also be consulted on the carbon utilization of algae: Artari, A. Zur Ernährungsphysiologie der grünen Algen. Ber. deut. bot. Gesell. 19: 7. 1901; Jahrb. wiss. Bot. 52: 410-466. 1913; 53: 527-535. 1914 ; Chodat, 1913 (p. 220); Bokorny, Th. Zur Kenntnis der physiologischen Fähigkeiten der Algengattung Spriogyra und einiger anderen Algen. Vergleich mit Pilzen. Hedwigia, 59: 340-393. 1918; Dangeard, P. A. Observation sur une algue cultivée à l'obscurité depuis huit ans. Compt. Rend. Acad. Sci. 172: 254260. 1921; Grintzesco, J. Contribution à l'étude des Protococcoidées: Chlorella vulgaris Beijerinck, Rev. Gen. Bot. 15: 5-19, 67-82. 1903; Ternetz, C. Beiträge 
synthesize their protoplasm from $\mathrm{CO}_{2}$ and from water containing inorganic nitrogenous and mineral compounds. Some algae, however, can also utilize organic materials, the extent depending on the species; some may thus develop in the complete absence of light, leading a heterotrophic existence. Under those conditions, the chlorophyll may be either completely lost or retained. Some species can even utilize organic nitrogenous compounds, and may bring about decomposition of proteins (Chodat). In general, however, algae prefer nitrates as a source of nitrogen; ammonium salts are less favorable. Of the nitrates, $\mathrm{Ca}\left(\mathrm{NO}_{3}\right)_{2}$ is best, followed by $\mathrm{KNO}_{3}$ and $\mathrm{NaNO}_{3}$. The secondary ammonium phosphate is preferable to the other salts of ammonium, for, when the ammonium is used up, the secondary phosphate will be changed to the primary, which is only slightly acid, but the sulfate and chloride will leave the reaction of the medium acid. The preferential utilization of certain nitrogen sources may be due to a large extent to secondary reactions brought about by the residual ions. As different species behave differently toward the different sources of nitrogen, until further work has been done with a large number of species, no general conclusions can be drawn. Nitrites are not favorable, but can be utilized under proper conditions of reaction and concentration (Pringsheim). In addition to water, carbon dioxide and nitrogen source, algae require for nutrition $\mathrm{K}, \mathrm{Fe}, \mathrm{Mg}, \mathrm{P}, \mathrm{S}$, and in most cases also Ca. These are best added in the form of potassium phosphate and magnesium sulfate; a trace of iron is added in the form of chloride; and calcium, as sulfate, if it is not used as nitrate. The salts are used only in very dilute solutions ${ }^{43}$ : $\mathrm{Ca}\left(\mathrm{NO}_{3}\right)_{2}$ as 0.1 per cent, $\mathrm{MgSO}_{4}$ as 0.01 per cent and $\mathrm{K}_{2} \mathrm{HPO}_{4}$ as 0.02 per cent. A faintly alkaline reaction, as given by secondary phosphate and alkali bicarbonate, is best.

A biochemical process believed to be carried out by algae, namely, their ability to fix atmospheric nitrogen attracted considerable attention. As most of the earlier work in this connection has been carried out with impure cultures eontaminated with various bacteria, results obtained under these conditions were not reliable. The negative results could be depended upon more than the positive results. Frank ${ }^{44}$ suggested in

zur Morphologie und Physiologie der Euglena gracilis Klebs. Jahrb. wiss. Bot. 51: 435-514. 1912; Bristol Roach, B. M. On the relation of certain soil algae to some soluble carbon compounds. Ann. Bot. 40: 149-201. 1926.

${ }^{43}$ Richter, 1911 (p. 219).

${ }^{4}$ Yrank, B. Ueber den experimentallen Nachweis der Assimilation freien Stickstoffs durch erdbewohnende, Algen. Ber, deut. Bot. Gesell. 7: 34-42. 1889. Untersuchungen über die Ernährung der Pflanze mit Stickstoff und über den Kreislauf desselben in der Landwirtschaft. Landw. Jahrb. 17: 421-453. 1888. 
1889 that algae are able to fix atmospheric nitrogen; his results were substantiated by other workers, who used impure eultures of algae, Kossowitch, ${ }^{45}$ however, who was the first to use pure cultures of algae, namely a species of Cystococcus (Nägeli) and Chlorclla vulgaris Beij., demonstrated that algae do not fix any atmospherie nitrogen, and that some of the bacteria are the only organisms capable of doing that. In general, whenever pure cultures of algae were employed, nitrogen fixation was found to be negative. ${ }^{43,46}$

But even if algae do not fix any nitrogen by themselves, they were found to exert a favorable effect on the process of nitrogen-fixation by non-symbiotic bacteria. Kossowitsch, therefore, suggested that the algae work in a manner symbiotically with nitrogen-fixing bacteria, furnishing them, through photosynthetic activity, with carbohydrates. These results were confirmed by other investigators, ${ }^{47}$ especially in the case of Azotobacter and algae. ${ }^{48-51}$

Beijerinck considered those organisms that can live on media to which no nitrogen has been added (without being, however, free from combined nitrogen), to be able to fix atmospheric nitrogen; he concluded, therefore, that various Cyanophyceae are able to fix atmospheric nitrogen, since they grew in media almost free from combined nitrogen. These media were not free from nitrogen-fixing bacteria, however, and no analytical data were presented. In a series of carefully controlled experiments with pure cultures of several grass-green algac, Schramm ${ }^{52}$

${ }^{45}$ Kossowitsch, P. Untersuchungen über die Frage, ob die Algen freien Stickstoff fixieren. Bot. Ztg. 52: 97-116. 1894.

${ }^{46}$ Charpentier, P. G. Alimentation azotée d'une algue, le Cystococcus humicola. Ann. Inst. Past. 17: 321-334, 369-420. 1903.

${ }^{47}$ Krüger, W., and Schneidewind, W. Sind niedere chlorophyllgrüne Algen imstande den freien Stickstoff der Atmosphaere zu assimilieren und den Boden an Stickstoff zu bereichern? Landw. Jahrb. 29: 776-S04. 1900.

${ }^{48}$ Reinke, J. Symbiose von Volvox and Azotobaeter. Ber. deut. bot. Gesell. 21: 481. 1903. Fiseher, H. Über Symbiose von Azotobaeter mit Oseillarien. Centrbl. Bakt. II, 12: 267-268. 1904.

${ }^{49}$ Heinze, B. Einige Beiträge zur mikrobiologisehen Bodenkunde. Centrbl. Bakt. II, 16: 640-663, 703-711. 1906; Úber die Stickstoffassimilation dureh niedere Organismen. Landw. Jahrb. 35: 889-910. 1906.

${ }^{50}$ Nakano, H. Untersuchungen über die Entwicklungs- und Ernährungsphysiologie einiger Chlorophyceen. Jour. Coll. Sei., Tokyo Univ. 40:66. 1917.

${ }^{61}$ Pringsheim, 1913 (p. 220).

${ }^{62}$ Sehramm, J. R. A contribution to our knowledge of the relation of certain species of grass-green algae to elementary nitrogen. Ann. Mo. Bot. Gard. 1: 157-184. 1914. 
came to the conclusion that Chlamydomonas pisiformis Dill. forma minor Spargo, Protosiphon botryoides (Kütz) Kklebs, Chlorococcum humicola (Nägeli) Rabenh., Chlorclla vulgaris Beij., Stichococcus bacillaris Näg., Chlorella sp. and Kirchneriella sp. are unable to fix free atmospheric nitrogen in the complete absence of combined nitrogen. Wann, ${ }^{53}$ however, working in Schramm's laboratory claims to have found that seven species of algac exhibited the ability to fix atmospheric nitrogen, when grown in pure cultures on mineral nutrient agar media containing either ammonium nitrate or calcium nitrate, as a source of nitrogen, and a small amount of glucose. A gain of 1 to $12.5 \mathrm{mgm}$. of nitrogen per flask was obtained. In the absence of glucose, growth and nitrogenfixation were only slight. When urea, glycocoll, asparagine or ammonium sulfate was supplied as a source of nitrogen, either with or without glucose or mannite, no fixation took place; one species caused a loss of nitrogen. Positive nitrogen-fixation by algae has also been claimed recently by Moore and Webster. ${ }^{54}$ The fact, however, that bacteria were present in the cultures and that these were exposed to the air, from which traces of ammonia could be absorbed, would tend to invalidate these results. Bristol and Page, ${ }^{55}$ in a series of carefully controlled experiments, repeated Wann's work, using four different species of algae, each growing on six different media selected from among those used by Wann. They found no evidence to indicate any fixation of atmospheric nitrogen. In the presence of combined nitrogen, good growth was obtained, but only the original nitrogen was recovered even where it had originally been present in the form of nitrate. Bristul and Page pointed out a serious source of error in the chemical method used by Wann for the determination of the initial nitrogen content of media containing nitrates and suggested that his apparent fixation of nitrogen was probably the outcome of a faulty chemical technic since they completely failed to corroborate his results. They also suggested that the results of Moore and co-workers was of doubtful validity, since their cultures of algae were probably not free from bacteria. Bacteria can develop in the gelatinous sheaths of algae and need, therefore, not cause any turbidity of the medium.

53 Wann, 1921 (p. 221).

${ }^{54}$ Moore, B., and Webster, T. A. Studies of photosynthesis in fresh-water algae. I. The fixation of both carbon and nitrogen from the atmosphere to form organic tissue by the green plant cell. Proc. Roy. Soc. B. 91: 201-215. 1920; also 92: 51-60. 1921.

${ }_{55}$ Bristol, B. M., and Page, H. J. A critical inquiry into the alleged fixation of nitrogen by green algae. Ann. Appl. Biol. 10: 378-408. 1923. 
Rôle of algae in the soil. It is impossible to generalize concerning the rôle that algae may play in soil processes. Although it seems to be definitely established that algae are unable to fix atmospheric nitrogen, they may be able to do so by living symbiotically with nitrogen-fixing bacteria. They may also accumulate organic matter in the soil, but since they need available nitrogen, they may compete with higher plants for the soluble minerals and available nitrogen compounds in the soil. Gautier and Drouin ${ }^{56}$ exposed samples of artificial soil, free from organic material and containing only ammoniacal nitrogen, in a sheltered position for a considerable period of time. The soil became, in course of time, covered with algae (Pleurococcus vulgaris, Protococcus viridis, etc.). This resulted in a loss in total nitrogen, a still greater loss in ammonia nitrogen, and a gain in organic nitrogen. The ammonia nitrogen was converted into organic nitrogen by the algae; with an increase in growth, there was a decrease in the loss of the total nitrogen. The algae thus play also a part in preventing the loss of ammonia nitrogen, as well as the leaching out of nitrates from the soil. The probable rôle of algae may thus consist in accumulating organic matter in newly formed soils. ${ }^{57,58}$ It has been suggested ${ }^{59}$ that algae, by taking in $\mathrm{CO}_{2}$ and giving off oxygen, make swamp soils suitable for the growth of the rice plant. The roots of rice plants are typical land roots and possess no special adaptations to growth under swamp conditions. The large supply of dissolved oxygen in the swamp water produced by the photosynthetic activity of the algae enables the rice plants to grow under these artificial conditions. ${ }^{60}$

The fact that algae are present in the soil in considerable numbers, that they can grow even in the subsoil and in the dark, that they retain their vitality for very long periods, even after prolonged drought, that they can store large quantities of energy thus making them available for other organisms, all point to their probable importance in

${ }^{66}$ Gautier, A., and Drouin, R. Recherches sur la fixation de l'azote par le sol et les végétaux. Compt. Rend. Acad. Sci. 106: 754-7, 863-6, 944-7, 1098-1101, 1174-6, 1232-4. 1888; 113: 820-825. 1891.

${ }^{67}$ Treub, M. Notice sur la nouvelle flore de Krakateu. Ann. Jard. Buitenzorg. 7: 213-223. 1888.

s8 Fritsch, F. E. The rôle of algal growth in the colonization of new ground and in the determination of scenery. Geogr. Jour. 30: 531-548. 1907.

${ }^{6}$ Harrison, W. H., and Aiyer, S. Gases of swamp rice soils. Pusa Mem., Chem. Series, 3: 65-106. 1913; 4: 1-17. 1914.

so Brizi, U. Richerche sulla malattia del Rizo detta "Bruzone." Ann. dell Instit. Agr. Dott, A. Buti. 5: 79-95. 1904; 6: 61-103. 1905; 7: 104-174. 1908. 
the soil. Algae also exert a solvent action upon insoluble calcareous materials (Chodat). In this respect, algae together with certain autotrophic bacteria play an important rôle in the disintegration of rocks and in the formation of soils. The possible rôle of algae in the deposition of limonite has also been suggested. ${ }^{61}$

${ }^{61}$ Steinecke, F. Limonitbildende Algen der Heide-Flachmoore. Bot. Archiv, 4: 403-405. 1923. 


\section{CHAPTER XI}

\section{Soll FungI}

Occurrence of fungi in the soil. The chlorophyll-free microscopic plants are divided into slime-molds (Myxomycetes), bacteria (Schizomycetes or fission fungi) and true fungi (Eumycetes). The slime-molds are characterized by the formation of a plasmodium, as a result of fusion of separate individuals. They have been studied only to a very limited extent from the point of view of their occurrence and activities in the soil. All the available information is either limited to the forms occurring on decomposing wood or to those causing plant diseases. Forms like potato wart (Synchitrium endobioticum) or the club-root of cabbage and other cruciferae (Plasmodiophora brassicae) once introduced into the soil persist there for a considerable period of time. However, little is known concerning their rôle in soil processes.

The Eumycetes or true fungi cannot derive their energy from the oxidation of inorganic substances; they are heterotrophic, depending for their energy supply on the decomposition of plant and animal substances; their existence in the soil is thus closely connected with the decomposition of the organic matter added to the soil. Two distinct groups of fungi are found in the soil: (1) the ordinary filamentous fungi or molds, living freely in the soil, and (2) those capable of forming mycorrhiza with higher plants. The higher or mushroom fungi are found both among the free living forms and among those forming mycorrhiza. The soil also harbors various fungi capable of causing plant diseases, which are considered in detail elsewhere (p. 801).

It has been known for some time that fungi occur abundantly in the soil, particularly in soils rich in organic matter and acid in reaction. But in view of the fact that fungi are present in the soil both in the form of vegetative mycelium and as reproductive spores, it is rather difficult to estimate their abundance; it is even less possible to find a basis for comparing the relative abundance of fungi and bacteria in the soil and their capacity for causing a certain amount of transformation in the soil. It has been recognized ${ }^{1}$ that, under certain condi-

${ }^{1}$ Moore, G. J. Microorganisms of the soil. Science, 36: 609-615. 1912. 
tions, particularly in uncultivated soils and below the layer containing humus, fungi may be as abundant as, if not more so than, bacteria. The earlier workers ${ }^{2}$ emphasized the fact that fungi predominate in acid soils, and bacteria in neutral soils. This is true only to a certain extent. Fungi can, as a rule, withstand greater concentrations of acidity than bacteria and actinomyces, so that, at a $\mathrm{pH}$ of 4.0 , the soil may contain only small numbers of the last two groups of organisms, while the fungi may still be present in abundance. Such a reaction is also inhibitive to the growth of most higher plants. At less acid reactions, when conditions are favorable for cultivated plants $(\mathrm{pH} 4.6$ to $6.5)$, bacteria occur most abundantly, whereas the numbers of fungi will depend on the soil reaction, on the amount of organic matter, and on the abundance of water in the soil.

As far back as $1886,{ }^{3}$ attempts were made to isolate fungi from the soil and to give them names and descriptions; it is only since 1902, however, that the subject began to be treated in a systematic manner. Oudemans and Köning ${ }^{4}$ published a paper in 1902, which was the first real attempt made at a systematic study of the occurrence of fungi in the soil and their proper classification. In 1908 appeared the excellent contributions of Hagem $^{5}$ and Lendner ${ }^{6}$, on the Mucorales of the soil. These contributions were soon followed by those of other investigators ${ }^{7-9}$ who made extensive studies of the occurrence of fungi in various types of soil, under different climatic and other environmental conditions. In addition to these, a number of other contributions have been made dealing in one way or another with one or more groups of soil fungi.

${ }^{2}$ Ramann, E. Bodenkunde. Berlin, Springer. 1920.

${ }^{3}$ Adametz, L. Untersuchungen über die niederen Pilze der Ackerkrume. Inaug. Diss. Leipzig, 1886, 78 p., 2 pl.

${ }^{4}$ Oudemans, C. A. J. A., and Koning, C. J. Prodrome d'une flore mycologique, obtenue par la culture sur gelatin préparée de la terre humeuse du Spanderswoud près de Russum. Arch. Neerland. Sci. Exact. et Nat. (2), 7: 266-298. 1902.

${ }^{5}$ Hagem, O. Untersuchungen über norwegische Mucorineen, Vidensk. Selsk., I Math. Naturw. Klasse, 7: 1-50. 1907; 10: 1-52. 1910; Ann. Mycol. 8: 265286.1910.

${ }^{6}$ Lendner, A. Les Mucorinées de la Suisse. Bern, 1908.

${ }^{7}$ Jensen, C. N. Fungus flora of the soil. Cornell Univ. Agr. Exp. Sta. Bul. 315,1912 .

${ }^{8}$ Dale, E. On the fungi of the soil. Ann. Mycol. 10:452-477. 1912; 12: 33-62. 1914.

${ }^{9}$ Waksman, S. A. Soil fungi and their activities. Soil Sci. 2: 103-155. 1916; 3: 565-589. 1917. 
These were either limited to the isolation of a few forms for biochemical purposes, or they dealt with an important group of soil organisms like the Mucors, ${ }^{10}$ or with representatives of various groups in the study of one important soil process, like nitrogen fixation ${ }^{11}$ or cellulose decomposition. ${ }^{12,13}$ A number of papers and monographs are available which are devoted to certain groups of fungi, some of which were not isolated from the soil although they are of common occurrence in the soil. These contributions are of much assistance in the study and identification of the soil forms. Reference must be made here to the work of Wehmer ${ }^{14}$ and Thom ${ }^{15}$ on the genus Aspergillus; of Thom, ${ }^{16}$ Westling, ${ }^{17}$ Sopp ${ }^{18}$ and Biourge ${ }^{19}$ on Penicillium; of Hanzawa ${ }^{20}$ on Rhizopus; of Butler $^{21}$ on Pythium; of Chivers ${ }^{22}$ on Chaetomium; of Sherbakoff ${ }^{23}$ on Fusarium; and of Berkhout ${ }^{24}$ on Monilia and allied forms.

The composition of the fungus flora of the soil changes with a change in the nature of the soil, both quantitatively and qualitatively. Hagem,

${ }^{10}$ Povah, A. H. W. A critical study of certain species of Mucor. Bull. Torrey. Bot. Club, 44: 241-259, 287-313. 1917.

${ }^{11}$ Goddard, 1913 (p. 259).

${ }_{12}$ Daszewska, 1913 (p. 265).

${ }_{13}$ Traaen, A. E. Untersuchungen über Bodenpilze aus Norwegen. Nyt. Magaz. Naturw. Christiania, 62: 21-121. 1914.

14 Wehmer, C. Die Pilzgattung Aspergillus. Genève. 1901; Morphologie und Systematik der Familie der Aspergillaceen. Lafar's Handb. Techn. Mykol. 4: 192-238. 1905-7.

15 Thom, C. and Church, M. B. The Aspergilli. The Williams \& Wilkins Co., Baltimore, Md. 1926.

${ }^{16}$ Thom, C. Cultural studies of species of Penicillium. U. S. Dept. Agr. Bur. Anim. Indus. Bul. 118, 1910; also Mycologia, 7: 134-142. 1915.

${ }^{17}$ Westling, R. Über die grünen Species der Gattung Penicillium. Inaug. Dissert. Upssala. Ark. Bot., 11: 1-156. 1911.

${ }^{18}$ Sopp, J. O. Monographie der Pilzgruppe Penicillium. Vidensk. Selskr.

I. Mat. Naturv. Kl., No. 11, Kristiania. 1912.

${ }^{19}$ Biourge, Ph. Les moississures du groupe Penicillium Link. La cellule. 33: 1st. fasc. 1923. Louvain.

${ }^{20}$ Hanzawa, J. Studien über einige Rhizopus Arten. Mycol. Centrbl., 1: 406-409. 1912; 5: 230. 1915.

${ }^{21}$ Butler, E. J. An account of the genus Pythium and some Chytridiaceac. Mem. Dept. Agr. India, Bot. Ser. 5, 1: 1-160. 1907.

${ }^{22}$ Chivers, A. H. A monograph on the genera Chaetomium and Ascotricha. Mem. Torrey Bot. Club, 14: 155-240. 1915.

${ }^{23}$ Sherbakoff, C. D. Fusaria of potatoes. Cornell Univ. Agr. Exp. Sta. Mem. 6: $85-270.1915$.

${ }^{24}$ Berkhout, C. M. De Schimmelgeslachten Monilia, Oidium, Oospora en Torula. Diss. Univ. Utrecht. 1923. 
for example, has shown that cultivated soils have a distinctly different population of Mucorales than pine forest soils. The influence of reaction on the fungus population of the soil can be seen from the following example:

A soil receiving manure year after year, in addition to minerals ( $\mathrm{pH} 5.5$ ), had 79,000 fungi; the same soil receiving lime in addition to manure ( $\mathrm{pH} 6.7$ ) had only 10,000 fungi per gram. The soil receiving no manure or fertilizer ( $\mathrm{pH}$ 5.1 ), had 87,000 fungi; the same soil limed ( $\mathrm{pH} 7.0$ ) had only 16,000 fungi. The soil receiving ammonium sulfate and mineral $(\mathrm{pH} 4.2)$ had 129,000 fungi; the same soil limed ( $\mathrm{pH} \mathrm{5.2)} \mathrm{had} \mathrm{32,000.}$

Methods of demonstrating the occurrence and abundance of fungi in the soil. The methods of studying the occurrence of fungi in the soil can be divided into two groups; (1) Those methods which demonstrate the presence of particular fungi in the soil, without any reference to the question whether these occur there only in the form of spores or also in the form of vegetative mycelium. (2) Those methods which tend to demonstrate the occurrence of fungi in the soil in the form of vegetative mycelium. The first method is usually carried out as follows:

Soil samples are taken under aseptic conditions into sterile containers. There is greater danger of exposing the soil to air contamination, in the study of fungi than of bacteria. Various fungus spores are very abundaut in the ordinary bacteriological laboratory, and because of the smaller number of fungi than bacteria in the soil (or cells developing into colonies) this error introduced will be greater in the case of fungi. The presence of dust fungi will lead also to misstatements in reference to the types of fungi present in the soil.

A definite amount of soil is diluted with a definite amount of sterile tap water, and sufficiently stirred to separate the spores and pieces of mycelium from the soil particles. One-cubic-centimeter portions of the desired dilutions are then plated out with agar of definite composition and the plates are allowed to incubate for 48 to 72 hours at $25^{\circ}$ to $30^{\circ} \mathrm{C}$. Ordinary bacteriological media can be used for this purpose but acid media, having a reaction of $\mathrm{pH}=4.0$, are preferable for this first step of the isolation of fungi. The acidity prevents the bacteria from developing and the fungi can be isolated free from bacterial contaminations. A lower dilution can be employed, than would be the case with media upon which bacteria are able to develop; this allows the development of greater numbers and, therefore, of a greater variety of fungi. The medium described above (p. 19) can be used for this purpose. Any other sugar medium well adapted for the growth of fungi, to which some citric acid is added (about 1 per cent) can be used. ${ }^{25}$ For the isolation of yeast, a medium containing saccharose and 1.2 to 1.5 per cent citric acid is of ten recommended. Lactic acid can also be

${ }^{25}$ Piettre, M., and de Souza, G. Milieux acides pour l'isolement des champignons. Compt. Rend. Soc. Biol. 86: 336-337. 1922; Isolement des levures en milieux acides. Ibid., 338-340. 
used. When fruit extracts, like raisin or plum extracts, are used as a base for the medium, no acid is required, since the natural acidity of the fruit is sufficient to prevent the development of bacteria. After the organism has been isolated, it is often necessary to obtain a single spore culture; especially when the organism is wanted for the study of hereditary characteristics or for physiological investigations.

For the demonstration of fungi present in the soil in the form of vegetative mycelium, the direct inoculation method ${ }^{26}$ and the direct microscopic method ${ }^{27}$ are available. According to the first method, lumps of soil, about $1 \mathrm{cc}$. in diameter, are placed, with a sterile forceps, into a sterile plate containing $10 \mathrm{cc}$. of sterile solidified agar medium. The plates are allowed to incubate for 24 hours at $22^{\circ} \mathrm{C}$. This period of time is not sufficient for spores of the majority of soil fungi to germinate and form a mycelium visible to the naked eye, whereas the organisms actually living in the soil and forming a mycelium develop at once from the soil, so that the mycelium becomes visible earlier. After 24 hours' incubation the mycelium is transferred from the plates into sterile slants of fresh agar medium (Czapek's), care being taken to isolate the mycelium, which has grown away from the soil. The organisms thus isolated can now be cultivated, purified if necessary, and identified.

According to the second method, a small crumb (10 mgm. or less) of soil is placed upon a microscopic slide and mixed with two or three drops of water. A drop of methylene blue solution (saturated aqueous or Loeffler solution) is then added by means of a glass rod, well mixed with the soil suspension and covered with a cover slip. The preparation appears blue to the naked eye. If too much stain has been added, it is diluted by a drop of water. Examination is made with a dry lens and a highpower eye piece. By this method, fungus filaments can be demonstrated in all the soils examined. Some soils contain only 4 to 5 filaments in a preparation (comprising 5 to $10 \mathrm{mgm}$. of soil), while others, especially soils rich in undecomposed organic matter, contain fungus mycelium in great abundance.

The microseopic method, however, gives no means of identifying the particular species of fungi present in the soil as vegetative mycelium. This would be rather difficult, since the very nature of the growth of

${ }^{26}$ Waksman, S. A. Do fungi actually live in the soil and produce mycelium? Science, N. S., 44: 320-322. 1916; The growth of fungi in the soil. Soil Sci., 14: $153-158.1922$.

27 Conn, H. J. A microscopic method for demonstrating fungi and actinomycetes in soil. Soil Sci., 14: 149-152, 1922. 
fungi in the soil and on culture media is different. ${ }^{28}$ The first method is also not without fault, since some fungi, especially those forming a long mycelium, like the Mucorales, make a more extensive growth upon the plate, than other fungi. Not only are the morphological characters of the organisms different in the soil and on culture media, but they may vary with different media. ${ }^{29}$ The same is true of course of the physiological activities of the fungi; freshly isolated organisms behave differently from those kept in culture on artificial media; young cultures from spores act differently from fully developed mycelium.

Methods of cultivation of soil fungi. ${ }^{30}$ Fungi are cultivated to facilitate the study of their morphology, their reaction to environmental conditions, and their general physiology. The organisms, therefore, must be first isolated from the plate and grown in pure culture. This can be accomplished much more readily than in the case of algae or bacteria, since fungi grow rapidly, are aerobic, produce aerial spores abundantly, and can withstand comparatively large concentrations of acid.

The media for the cultivation of fungi may be designated as natural and artificial.

Among the natural media, solid substrates including soil, hay, manure, fruits, bread, and branches are largely used for the growth of fungi. These are either kept at an optimum moisture or are previously sterilized, then inoculated with the organism. In the case of acid media, heating at $100^{\circ}$ for 20 minutes may be sufficient for purposes of sterilization, but in the case of soil or hay, $1 \frac{1}{2}$ hours at 15 pounds pressure or 30 minutes at $100^{\circ}$ on seven consecutive days is required. Fruit extracts, as well as manure extracts, can also be used as nutrient solutions.

In the preparation of artificial media a nitrogen source, a carbon source, and minerals must be provided. Ammonium salts, nitrates and organic nitrogen compounds can be used as sources of nitrogen. ${ }^{31}$

${ }^{28}$ Church, M. B., and Thom, C. Mold hyphae in sugar and soil compared with root hairs. Science, N. S., 64: 470-471. 1921.

${ }^{29}$ Brierly, W. B. Some concepts in mycology-an attempt at synthesis. Trans. Brit. Mycol. Soc., 6: pt. 2. 1919.

${ }^{30}$ The cultivation of fungi is described in detail by $\mathrm{O}$. Brefeld-Untersuchungen auf dem Gesamtgebiete der Mykologie, H. 14: 60. 1908; Küster, E. Kultur der Microorganismen. 3d Ed., 1921; Lafar's Handb. d. tech. Mykol. 1, 1904 1907; E. G. Pringsheim-Pilzkultur. Abder. Handb. Biochem. Arb. Meth. Abt. XI, T. 2: 407-444. 1921; E. Pribram. Die wichtigsten Methoden beim Arbeiten mit Pilzen. Ibid. XII, H. 3: 461-482. 1924.

${ }^{31}$ Brenner, W. Die Stickstoffnahrung der Schimmelpilze. Centrbl. Bakt., II, 40: 555-647. 1914. 
The ammonium salts can be used in the form of phosphate, sulfate, chloride and salts of organic acids, like acetic, tartaric and citric, in concentrations of 0.1 to 0.5 per cent. $\mathrm{Ca}, \mathrm{K}$, and $\mathrm{Na}$ nitrates can be used by almost all Aspergillaceae and various other fungi. ${ }^{32}$ Among the organic nitrogenous compounds, peptone and amino acids (asparagine, leucine, etc.), followed by amides, amines, and alkaloids, ${ }^{33}$ are found to be favorable sources of nitrogen.

Carbohydrates and higher alcohols are the best sources of carbon; of these, glucose comes first, followed by other hexoses and pentoses. ${ }^{34}$ Sucrose is utilized only by fungi which can produce invertase; when added to an acid medium, it is inverted in the process of heating. Starch is utilized only by fungi which can produce diastase. It is employed either in the form of a paste or as soluble starch. Pectins are also used as sources of energy by various fungi. ${ }^{35}$ Celluloses can be lecomposed by certain fungi, hence mold activity is of great importance in the decomposition of organic matter in the soil. Of the alcohols, glycerol and mannite are used most readily; the lower alcohols only in dilute solutions. Of the organic acids, those having more carbon atoms, like tartaric, citric, and malic, are best. Some fungi can utilize fats as sources of energy. ${ }^{36}$

Of the mineral elements, $\mathrm{K}, \mathrm{Mg}, \mathrm{S}$, and $\mathrm{P}$ are necessary and cannot be replaced by others. If required $\mathrm{Ca}, \mathrm{Na}, \mathrm{Cl}$ need be present only in traces; $\mathrm{Fe}$ as well is sufficient in mere traces, when needed. $\mathrm{Cu}, \mathrm{Zn}$ and $\mathrm{Fe}$ can act as stimulants.

The following media can be used for the cultivation of the great majority of soil fungi:

32 Blochwitz, A. Vergleichende Physiologie der Gattung Aspergillus. Centrbl. Bakt. II, 39: 499-502. 1913; Kossowitz. Biochem. Ztschr., 67: 400. 1914.

${ }^{33}$ Ehrlich, F. Ưber einige chemische Reaktionen der Mikroorganismen und ihre Bedeutung für chemische und biologisehe Probleme. Mitt. landw. Inst. Breslau, 6: 705-713. 1912; (Centrbl. Bakt. II, 41: 245-246. 1914).

${ }^{34}$ Peterson, W. H., Fred, E. B., and Schmidt, E. G. The fermentation of pentoses by molds. Jour. Biol. Chem., 55: 19-34. 1922.

${ }^{35}$ Hauman, 1902 (p. 203); Behrens, 1903 (p. 203).

${ }^{36}$ Spieckermann, A. Mykologie der Kraftfuttermittel. Lafar's Handb. teehn. Mykol., 2: 361-385. 1907; Ztschr. Unters. Nahr. Genuszm., 27: 83. 1914; Rahn, O. Die Zersetzung der Fette. Centrbl. Bakt, II, 15: 422-429. 1906. 
Czapek's solution consisting of :

Distilled water...... $1000 \mathrm{cc}$.

Cane sugar.......... 30.0 grams

$\mathrm{NaNO} \mathrm{NO}_{3} \ldots \ldots \ldots \ldots 2.0$ grams

$\mathrm{K}_{2} \mathrm{HPO}_{4} \ldots \ldots \ldots \ldots .1 .0$ gram

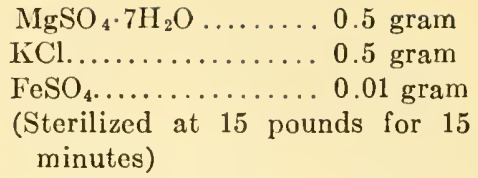

Since this medium contains cane sugar as a source of energy, and this is unfavorable for the development of the majority of Mucorales, another medium containing glucose as a source of energy should be employed for the isolation and cultivation of these forms. This medium has the following composition:

Cook's No. II medium: $:^{37}$

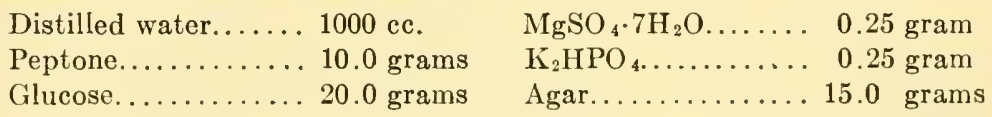

Povah ${ }^{38}$ employed the following medium for the isolation of Mucors:

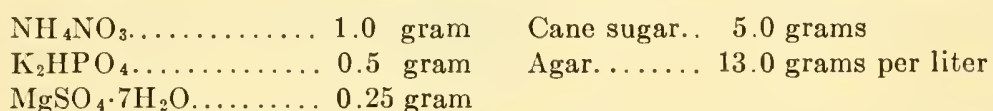

To prepare solid media, 10 or more per cent of gelatin or 1.5 to 2.0 per cent of agar is added to the above solutions. In the case of acid media (at pH 4.0), 3 per cent agar is required. In addition to the media mentioned above, Povah used another medium for stock cultures of Mucors:

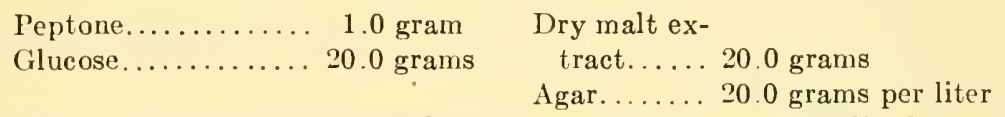

For the cultivation of the wood-destroying Basidiomycete, Merulius lacrymans, the following medium may be used:39

\begin{tabular}{|c|c|c|}
\hline & $10.0 \mathrm{grams}$ & Lactic acid......... \\
\hline $\mathrm{K}_{2} \mathrm{H}$ & 5.0 grams & Water........... 1000 grams \\
\hline $\operatorname{lgSO}_{4} \cdot 7 \mathrm{H}_{2} \mathrm{O} \ldots \ldots \ldots$ & 1.0 gram & \\
\hline
\end{tabular}

$50 \mathrm{cc}$. of this solution is added to $10 \mathrm{gm}$. of filter paper, the latter being used as a source of energy. Species of Coprinus can be cultivated upon sterile horse manure or manure decoction agar. Agaricus may be grown upon bread or bread mixed with sawdust.

Fungi will tolerate rather high concentrations of nutrients. Asp. niger has its optimum at 20 to 30 per cent cane sugar, its maximum

${ }^{37}$ Cook, M. T. The relation of parasitic fungi to the contents of the cells of the host plants. Del. Agr. Exp. Sta. Bul. 91, 1911.

${ }^{38}$ Povah, 1917 (p. 238).

${ }^{39}$ Tubeuf, C. V. Beiträge zur Kenntnis des Hausschwammes Merulius lacrymans. Centrbl. Bakt. II, 9: 127-135. 1902; Wehmer, C. Hausschwammgutachten. Jahresb. Ver. angew. Bot., 8: 178-198. 1911. 
in a solution containing 53 per cent glucose. The limiting osmotic pressure, when salts are used, is 17 to 21 atmospheres for Asp. niger and for certain green Penicillia. ${ }^{40}$ Fungi grow readily, in pure culture, at a wide range of reaction (see p. 261) and are not injured by high acidity as readily as bacteria; acid reactions, including acid soils, will, therefore, favor the development of fungi, in crude culture. With carbohydrates as sources of energy, the reaction of the medium becomes acid as a result of the growth of many fungi. With proteins and nitrates, however, the reaction will tend to become alkaline. ${ }^{41}$ Fungi, with the exception of certain yeasts and certain Mucorales and Dematium, are strictly aerobic; certain Mucors are capable of developing anaerobically, especially in the presence of available carbohydrates. Aeration will greatly stimulate the activities of most fungi, because of their strict aerobiosis. The optimum temperature lies at 20 to $30^{\circ}$ for the majority of species, in some cases (Asp. niger, Mucor. pusillus) going up to $37^{\circ}$. Some fungi (Penicillium expansum, Botrytis cinerea, Alternaria sp.) germinate slowly at $0^{\circ}$, others (Fusarium radicicola, Cephalothecium roseum) germinate slowly only at $5^{\circ}$, whereas $A$ spergillus niger will germinate only above $10^{\circ}{ }^{42,43}$ In the case of certain

${ }^{40}$ Pringsheim, E. G. Über den Einflusz der Nährstoffmenge auf die Entwicklung der Pilze. Ztschr. Bot., 6: 577-624. 1914.

${ }^{41}$ Bach, M. Variations de la concentration en ions hydrogenes sous l'influenee de l'assimilation des nitrates par l'Aspergillus repens DeBary. Compt. Rend. Acad. Sci., 178: 520-522. 1924.

${ }^{42}$ Brooks, S., and Cooley, J. S. Temperature relations of apple rot fungi. Jour. Agr. Res., 8: 139-164. 1917.

${ }^{43}$ Brown, W. The germination and growth of fungi in various temperatures and in various concentrations of oxygen and $\mathrm{CO}_{2}$. Ann. Bot., 36: 257-283. 1922.

\section{PLATE XIII}

\section{Soll FungI-Mucorales}

86. Absidia glauca, showing the runners with sporangiophores, $\times 3.5$ (from Hagem).

87. Absidia glauca, columellae, $\times 200$ (from Hagem).

88. Rhizopus nigricans, showing sporangiophores, rhizoids, and columellae, $\times 40$; spores $\times 360$ (from Jensen).

89. Rhizopu; arrhizus: 1 , runners with sporangiophores, $\times 35$; 2, swollen sporangiophore, $\times 35 ; 3$, abnormally divided sporangiophores, $\times 35$; 4 , collumellae, $\times 120 ; 5$, spores, $\times 660$ (from Hagem).

90. Zygorhynchus mölleri, showing zygospore formation, $\times 200$ (from Hagem).

91. Different forms of branching of Mucors (from Lendner).

92. Different forms of columellae of Mucors: $a$, spherical; $e$, spherical with persisting collarette; $c$, oval; $d$, oval depressed; $e$, pyriform; $f$, panduriform; $g$, conical; $h$, eylindro-conical; $i$, manniform; $k$ and $l$, spinescent (from Lendner).

93. Cunninghamella echinulata (from Lendner). 

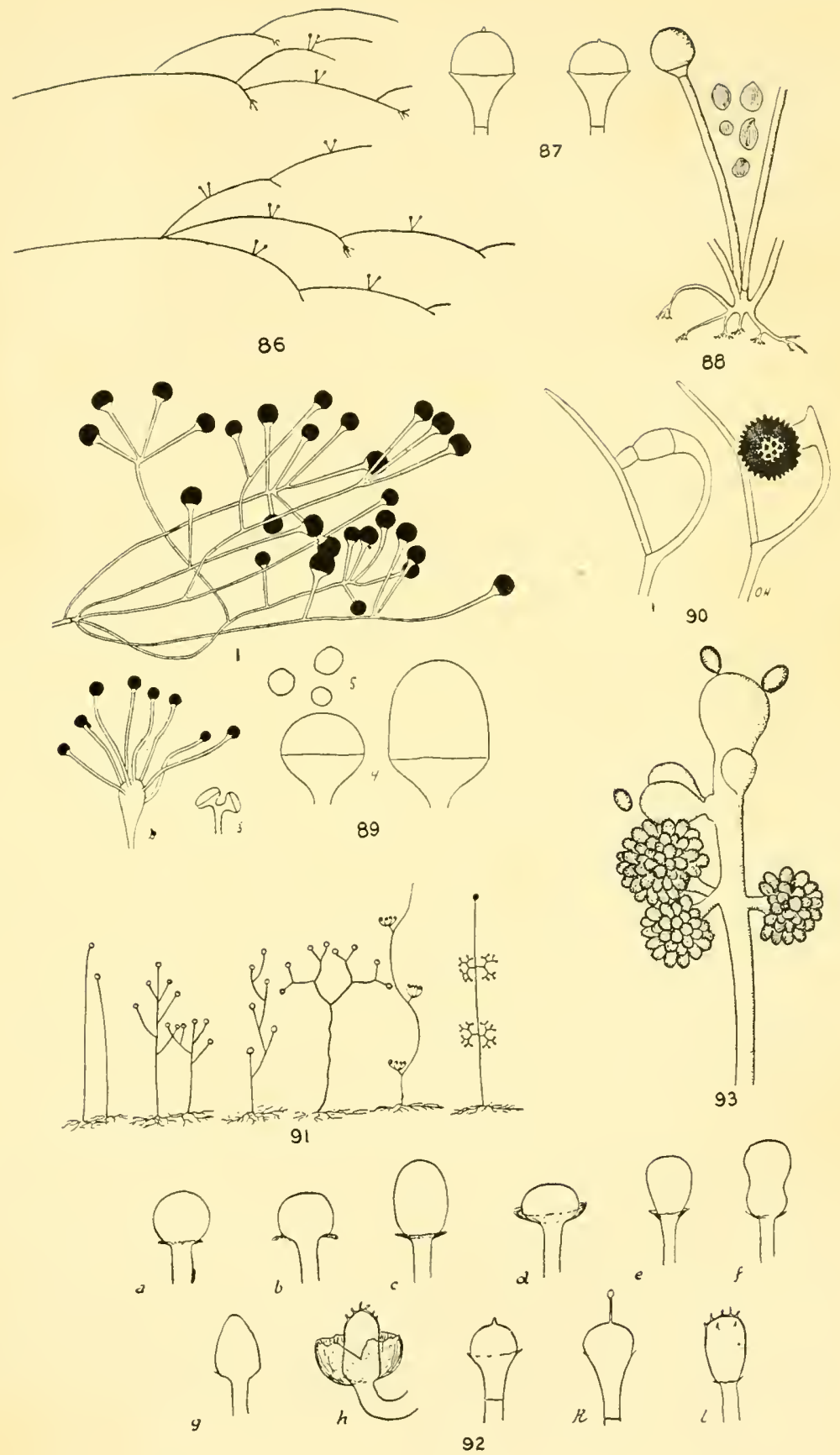

fungi, like Pen.expansum, once growth has started at ordinary temperatures, the mycelium will continue to develop at $0^{\circ}$. Oxygen pressure has little effect upon the germination and growth of various fungi. Increased carbon dioxide pressure has a retarding effect, especially at low temperatures. ${ }^{44}$ Heat has a destructive effect upon fungi; the spores of Botrytis cinerea are destroyed in ten minutes at $50.3^{\circ} ; 5$ the spores are, however, rather resistant to the action of sunlight. ${ }^{46}$ Heating for thirty minutes at $62.8^{\circ} \mathrm{C}$. is sufficient to destroy the conidia of most fungi, except certain species of Aspergillus. ${ }^{47}$ The morphology of the fungi is appreciably affected by the composition of the medium. The nature of the mycelium, the rapidity of spore formation and the color of the culture will often depend, to a greater or less extent, upon the different constituents of the medium, its concentration, and the environmental conditions, such as temperature or aeration. For this reason, synthetic media and standard conditions should be used in the study of the morphology and classification of such fungi as will thrive upon them. (The same is true, of course, of other microorganisms as well.)

Isolation of single spore cultures. In the study of fungi, especially their physiology, pure cultures from a single spore are prerequisites for any investigation. This was pointed out by Hagem and others. Some spore material is transferred by means of a platinum needle, to a flask containing about $30 \mathrm{cc}$. of sterile water. After vigorous shaking to separate the spores, a few cubic centimeters of the suspension is poured into a second flask containing sterile water. This is repeated once more, and $2 \mathrm{cc}$. of the final dilution is poured into a Petri dish containing solid nutrient material, moistening the whole surface of the plate; the excess water is then poured off. The plates are allowed to incubate for 2 to 3 days and are examined under the microscope for isolated growth derived from a single spore. This examination can be carried out by removing the cover from the Petri dish; also by

${ }^{44}$ Kostytschew, S., and Afanassiewa, M. Die Verarbeitung verschiedener organischer Verbindungen durch Schimmelpilze bei Sauerstoffmangel. Jahrb. Wiss. Bot., 60: 628-650. 1921.

${ }^{45} \mathrm{Smith}$, J. H. The killing of Botrytis cinerea by heat, with a note on the determination of temperature coefficients. Ann. Appl. Biol., 10: 335-347. 1923.

${ }_{46}$ Weinzirl, J. The resistance of mold spores to the action of sunlight. Univ. Wis. Studies in Science. 1921, No. 2, 55-59.

47 Thom, C. T., and Ayers, S. H. Effect of pasteurization on mold spores. Jour. Agr. Res., 6: 153-166. 1916. 
examining the inverted dish under the microscope, using the low power and marking with a colored pencil the spot where an individual spore has germinated. If such a growth is found, it is transferred with a small amount of substrate, by means of a sterile platinum loop, to a new dish or sterile agar slant. Povah sprayed a spore dilution upon a poured plate by means of capillary pipettes, then proceeded as before. Within twenty-four hours, after the spore was removed, transfers were made from the edge of the growth to a fresh tube; the possibility of contamination through a neighboring spore delayed in germination was thus avoided.

The following procedure may also be followed:

A small amount of the spore material is well shaken in 50 to $100 \mathrm{cc}$. of sterile water in an Erlenmeyer flask; a sterile platinum loop is then dipped into this suspension and carefully streaked out 3 or 4 times over the solidified agar in a Petri dish. The spores drop heavily at first, then singly, so that the third or fourth streak will have only single spores separated from one another. The plate is incubated for 36 to 48 hours, then examined in an inverted condition with the low power of the microscope. The streaks make easier the location of the spores. Where single spores have been dropped, they can be readily recognized, marked, and transferred with small blocks of agar into fresh dishes with agar or slants. By transferring again, within 24 hours, from the edge of the colony, and repeating the whole process when spore development takes place, single spore cultures can be assured. Of course, when the Barber ${ }^{48}$ pipette can be employed, there is greater certainty of obtaining single spore cultures. This is, however, not so necessary, in the case of fungi, as in the case of bacteria. ${ }^{49}$

Blakeslee $^{50}$ devised a procedure for the isolation of two strains of Mucorineae, plus and minus strains. This consisted in teasing out an immature zygospore and placing it in a nutrient medium favorable for growth. In some cases, growth occurred from both suspensors in sufficient amount so that they could both be transferred to a fresh culture.

\section{CLASSIFICATION OF FUNGI, WITH SPECIAL REFERENCE TO THOSE} OCCURRING IN THE SOIL

EUMYCETES. Vegetative tissues deprived of chlorophyll, unicellular or multicellular, with a typical apical growth and formation of ramified mycelium. Reproduction sexual and asexual. No locomotion in developed cells.

\footnotetext{
${ }^{48}$ Barber, 1907 (p. 55).

${ }^{49}$ Roberts, J. W. A method of isolating single spores. Phytopathol., 13: 558-560. 1923.

${ }_{50}$ Blakeslee, A. F. Sexual reproduction in the Mucorineae. Proc. Amer. Acad. Arts. Sci., 40: 205-315. 1904.
} 
A. PHYCOMYCETES ${ }^{51}$ (algal fungi). Mycelium unicellular, unseptated, branched profusely, sexual reproduction by zygospore or oospore.

I. Oonycetes. Conjugating cells differing in appearance and function and consisting of a large oogonium and small antheridium.

1. Saprolegniales (water fungi), unicellular, abundantly branched vegetative mycelium, asexual reproduction by means of conidia or swarm spores, produced in separate sporangia; sexual reproduction by means of an oogonium. A phanomyces laevis has been found to live saprophytically in the soil ;2 the same is true of Pythium de baryanum.

2. Peronosporales (downy mildews): Species of Pythium are found abundantly on rotting manure at the first stages of decomposition of organic matter. Butler ${ }^{53}$ isolated 6 species of Pythium from the soil, including $P$. de baryanum and $P$. intermedium. Various species of Phytophthora can live in the soil saprophytically.

II. ZyGomycetes: Sexual reproduction by fusion of terminal cells of branches of mycelium similar in appearance but different in sex. The most important group is the order Mucorales.

1. Reproduction asexually by spores contained in sporangia, suborder SPORANGIOPHORAE:

$1^{\prime}$. Sporangia generally only of one kind, spherical or pyriform with a membrane that dissolves or fractures easily. The septum separating the sporangiophore from the sporangium curves into the interior of the latter to form a columella. Sporangioles with persistent membranes occur very rarely and in such cases are disposed without order along the principal sporangiophore. Zygospores naked or surrounded by appendages, but never with a complete envelope. Mucoraceas.

$1^{\prime \prime}$. Sporangiophores arising from stolons (runners):

(a) Sporangiophores produced from the nodes of the stolons; spores often striated longitudinally; sporangia globose. Rhizopus. This genus is represented in the soil by five or more species, only three of which $(R h$. nigricans (88, $\mathrm{Pl}$. XIII), Rh. nodosus and $R h$. arrhizus (S9, Pl. XIII)) have been isolated in different parts of the world by Hagem, Lendner, Dale and others.

(b) Sporangiophores produced from the internode of the stolon, sporangia pyriform.

${ }^{51}$ Fischer, A. Pilze. In Rabenhorst's Kryptogamen Flora. I, 4: 1, 5. 1892 ; Lendner, 1908 (p. 237); Hagem, 1908 (p. 237).

${ }_{52}$ Busse, W., Peters, I., and Ulrich, P. Utber das Vorkommen von Wurzelbranderregern im Boden. Arb. K. Biol. Anst. Land- u. Forstw., 8: 260-302. 1911. ${ }^{53}$ Butler, 1907 (p. 238). 
Absidia (Nos. 86-87, Pl. XIII). This genus is fairly well represented in the soil, although not very common; 12 species of Absidia have been described by Lendner. A number of species have been isolated by Hagem (A. orchidis, A. glauca, A. spinosa). Other species have been isolated by Oudemans and Koning, Dale, Waksman and others.

$2^{\prime \prime}$. No stolons are formed by the mycelium.

(a) Heterothallic, occasionally homothallic, but, in the latter case, the zygophores generally arise from comparatively distant parts of the mycelium, never formed between branches of a single aerial hypha, and are usually equal. Mucor (Nos. 91-92, Pl. XIII). This genus is one of the most common in the soil and is the largest in the number of species found in the soil. It has been studied in detail by Lendner, Hagem, Povah, Jensen and others, several of whom having isolated some $25-30$ species from different soils, in different parts of the world.

(b) Homothallic zygospores produced early and abundantly. Zygophores arise close together, always originating from a single aerial hypha; they are usually unequal. Zygorhynchus (No. 90, Pl. XIII). This genus is represented in the soil only by two species, ${ }^{54}$ but these are among the very few most common soil fungi. They have been isolated by Hagem, Namyslowski, Jensen, and have been found in every soil examined from all parts of the world. They are found especially in sandy subsoils poor in organic matter.

$2^{\prime}$. Sporangia similar to those of the Mucoraceae, but of two kinds: one kind is multispored, the membrane breaking up, leaving only a naked columella; the other kind of sporangia (sporangioles) contains few spores, which have persistent membranes and are often without columellae. They are disposed at the extremity of branched sporangiophores, which are themselves arranged at regular intervals on the principal sporangiophore.

${ }^{54}$ Namyslowski, B. Zygorrhynchus Vuilleminii, une nouvelle Mucorinée isolée du sol et cultivée. Ann. Mycol., 8: 152-155. 1910. 
Thamnidiaceae. Species of Thamnidium (T. elegans) have been isolated from the soil by Jensen, Dale, Pratt and others.

$3^{\prime}$. Sporangia of one kind only, multispored; the membrane is for the major part solid, persistent, of a very dark blackish color, or is swelling only toward the base. Sometimes the sporangium dissolves simply, leaving the columella, while at other times it is thrown off at the same time as the columella and opens only after swelling of the membrane. Pilobolaceae. Species of Pilobolus have been isolated by Oudemans and Koning from soil and Povah from horse manure.

$4^{\prime}$. Sporangia without a columella, with a diffluent disappearing membrane, as in the case of the Mucoraceae. Zygospores enclosed singly in a carposporium. MonTIERELLACEAE. Several species of Mortierella have been found in the soil by Oudemans and Koning.

The last 3 genera are not of common occurrence in the soil; however, they are found abundantly on rotting manure and are thus readily introduced into the soil.

2. Reproduction asexually by conidia produced either solitary or in chains, sporangia not produced, suborder ConidioPHORAE.

1'. Conidia solitary, spherical or oval, borne on conidiophores swollen in the middle or at the extremity. Chaetocladiaceae.

(a) Conidiophores branched dichotomously in bunches or arranged irregularly. Round or oval conidia are borne around a spherical head. Cunninghamella (No. 93, Pl. XIII). C. elegans has been isolated from the soil by Lendner, Povah, and others.

(b) Conidiophores verticiliately branched, swollen into small heads furnished with sterile threads. Chaetocladium.

$2^{\prime}$. Conidia in chains:

(a) Conidiophores not swollen at tip. Piptocephalis.

(b) Conidiophores swollen at apex:

$\left(a^{\prime}\right)$ Conidiophores not branched. Syncephalis.

$\left(b^{\prime}\right)$ Conidiophores branched. Syncephalastrum.

The last 4 genera are only rarely found in the soil.

B. ASCOMYCETES. Mycelium multicellular. The group is characterized by the formation of an ascus or sac which usually contains eight spores; these asci are assumed to represent a "perfect" stage, in some cases certainly developed subsequent to fertilization; the fruiting masses containing the asci are very variable. 
I. PROTOASCI, without ascogenic hyphae. This group includes the yeasts, which reproduce vegetatively by budding: ${ }^{55}$

${ }^{55}$ A detailed study of the classification of yeasts and yeast-like fungi is given by Guilliermond-Tanner. The Yeasts; by Anderson, H. W. Yeast-like fungi of the human intestinal tract. Jour. Inf. Dis., 21: 341-381. 1917; Kohl, F. G. Die Hefepilze. 1908.

\section{PLATE XIV}

\section{Soll Fungi-Ascomycetes and Hyphomycetes}

94. Chaetomium olivaceum: $A$, perithecium, $\times 40 ; B$, mature and immature asci, $\times 160 ; C$, ascospores, $\times 360$ (from Jensen).

95. Trichoderma lignorum (f rom Jensen).

96. Trichoderma koningi: $a$, hyphae with conidiophores, $\times 56 ; b-c$, conidiophores with sterigmata; $e$, conidia, $\times 250$ (from Goddard).

97. Sporotrichum poae (from Schwartze).

98. Acrostalagmus cinnabarinus: $a-b$, hyphae bearing conidiophores $\times 56$; $c$, conidiophore with sterigmata; $d$, conidia, $\times 250$ (from Goddard).

99. Monilia koningi: $b$, conidial fructification, $\times 56 ; d$, same, $\times 100 ; f$, sterigmata, $\times 250$ (from Goddard).

100. Cladosporium herbarum: a, portion of colony grown in a hanging drop, showing mode of branching; $b$, part of the same to show arrangement of spores, $\times 270$ (from Dale).

101. Fusarium oxysporum: showing conidia $(A, B, C, D)$, chamydospores $(E, F, I)$ and conidiophores $(G, H, J)$ (from Sherbakoff).

102. Typical green Penicillium, Pen.chrysogenum: $c, d$, branching of conidial fructification, $\times 600 ; k, j, m$, sketches of conidial fructifications, $\times 90$ (from Thom).

103. Penicillium purpurogenum: $b$, typically verticilliate branching at the apex of the conidiophore; $e$, conidia bearing cell or sterigmae; $g$, diagrammatic representation of the entire conidial apparatus (from Thom).

104. Penicillium, soil series: colonies pale green, velvety at border, but more or less floccose in center with under side of mycelium rose to dark-red, conidia becoming glubose, 2 to $3 \mu$ in diameter (from Thom).

105. Asp.terreus: $a$, semidiagrammatic sketch of vesicle and sterigmata: $b, c, d$, primary and secondary sterigmata, $\times 1000 ; e$, conidia, $\times 1000 ; f$, diagram of stalk and base of calyptrate conidial mass (from Thom and Church).

106. Asp. nidulans: $a$, diagrammatic section of vesicle with two sterigmata; $b, c$, primary and secondary sterigmata, $\times 1000 ; d$, conidia $\times 1000 ; e, f, g, h, j$, diagrams of stalks and heads; $k$, perithecium surrounded by sterile hyphae; $m$, group of ascospores (from Thom and Church).

107. Alternaria humicola, showing a portion of branching chains of spores, $X$ 150 (from Dale).

108. Cephalothecium roseum, showing conidiophore and conidia (from Schwartze).

109. Botrytis vulgaris (from Schwartze).

110. Dematium: $a$, showing intercalary dark cells; $b$, Torula-like type showing terminaldark cells on lateral branches, $\times 270$ (from Dale). 


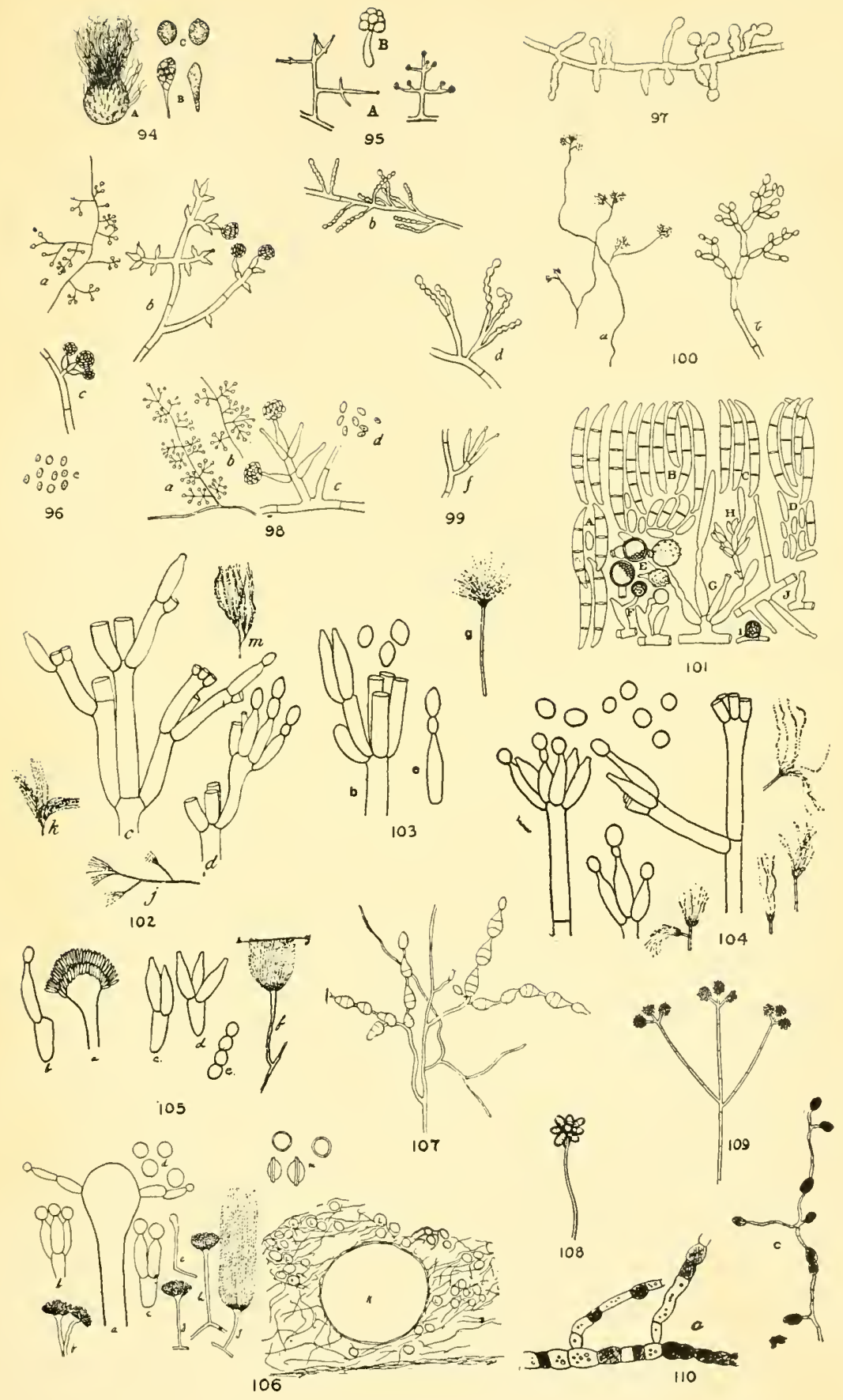



1. Cells not forming at once a surface membrane on sugar media:

(a) Ascospores having a single membrane, cells not fusing in pairs before formation, spore germination by ordinary budding. Saccharomyces.

(b) Ascospores having two membranes. Saccharomycopsis.

2. Cells forming a surface membrane at once on sugar media: Ascospores lemon shaped or with pointed ends. Willia.

The presence of yeasts in the soils of orchards and vineyards has been established by Hansen ${ }^{56}$ and others. Wine yeasts have been found in such soils even at a depth of 20 to $30 \mathrm{~cm}$. below the surface, but not at $40 \mathrm{~cm}$. depth. ${ }^{57}$ Soils rich in humus, such as peat soils, offer a favorable habitat for these organisms. ${ }^{58}$ The greatest number of yeasts isolated from the soil ${ }^{59}$ are wild yeasts, including also white and red species of Torula. An examination of eighty-seven soils from different parts of the United States revealed the presence of yeasts only in forty-five per cent of the soils; only two soil samples gave more than one species. ${ }^{50}$

II. EUASCI, with ascogenic hyphae. This group is divided into a number of subgroups, some of which contain some important soil forms. It is sufficient to mention:

1. Discomycetes,

2. Plectoascineae, containing the genera Aspergillus and Penicillium.

3. Pyrenomycetineae. These contain the following 2 common soil genera:

(a) Chactomium51 (No. 94, Pl. XIV). Various species of this genus have been isolated from the soil by Jensen, Traaen, Waksman and others.

(b) Sordaria and various other ascomycetes (Sporormia) have frequently been isolated from the soil.

${ }^{55}$ Hansen, E. C. Experimental studies on the variation of yeast cells. Ann. Bot., 9: 549-560. 1895. Neue Untersuchungen über den Kreislauf der Hefenarten in der Natur. Centrbl. Bakt. II, 10: 1-8. 1903; 14: 545-550. 1905. Compt. Rend. Trav. Lab. Carlsberg., 9: 61-69. 1911.

${ }_{57}$ Müller-Thurgau, H. Nachweis von Saccharomyces cllipsoidcs im Weinbergsboden. Centrbl. Bakt. II, 14: 296-297. 1905.

${ }^{58}$ Lemmermann, Fischer, et al., 1909 (p. 260).

${ }^{59}$ Irlöcker, A. Deux nouveaux genres de la famille des saccharomycetes. Compt. Rend. Lab. Carlsberg., 7: 273-278. 1909. De Kruyff, E. Untersuchungen über auf Java einheimische Hefearten. Centrbl. Bakt. II, 21: 616619. 1908.

${ }^{50}$ Starkey, R. L., and Henrici, A. T. The occurrence of yeast in soil. Soil Sci., 23: 33-46. 1927.

61 Chivers, 1915 (p. 251). 
C. FUNGI IMPERFECTI, no sexual spore formation known.

I. HYPHOMYCETES. ${ }^{62}$ Hyphae septate, hyaline or dark colored, separated from one another or united into coremia. Conidia formed either as oidia, by the breaking up of hyphae, or are formed on little differentiated branches of the mycelium or on special conidiophores. The latter are simple or much branched. The order is divided into 4 families, according to shape of conidiophore and structure of mycelium.

1. Conidia produced on single conidiophores, more seldom in the form of oidia. Vegetative hyphae as well as conidia and conidophores hyaline, pale or light colored, not dark, Muced1NACEAE Link:

1'. Spores one-celled:

$1^{\prime \prime}$. Conidiophores never sharply differentiated from mycelium, sometimes lacking; conidia may develop by the breaking up of hyphae into oidia:

$1^{\prime \prime \prime}$. Conidia oval or spherical, never spindleshaped:

(a) Conidiophores very short, hardly distinguished from the mycelium:

(a') Conidia produced on short side branches singly or one after another, Myceliophthora. Isolated from the soil by Goddard.

(b') Conidia large, with a thick membrane, Coccospora. Isolated from the soil by Goddard.

(b) Conidia developing as oidia lyy the breaking up of hyphae or as clains on short, not sharply differentiated branches, Oidium (Oospora). Isolated frequently from the soil.

(c) Conidia on definite branches; mycelium usually well developed and eompact, Monitia (No. 99, Pl. XIV). Various species of Monilia have been isolated from the soil.

$2^{\prime \prime \prime}$. Conidiophores well defined, erect, short; conidia in chains, short cylindrical, truncate at both ends, Geotrichum. Seldom found in the soil.

$2^{\prime \prime}$. Conidiophores sharply differentiated from the mycelium:

${ }^{62}$ In the study of this group of fungi the system used by Lindau (Fungi inperfecti: Hyphomycetes. Rabenhorst's Krypt. Flora, Abt. S and 9. 19071910) has been followed. This work as well as that of Engler, A., and Prantl, K. (Die natürlichen Pflanzenfamilien. Leipzig. 1597-1907) will be found to be of great assistance in the identification of most representatives of the Hyphomycetes, except in the case of the genera Aspergillus, Penicillium and Fusarium, where special monographs are available. 
$1^{\prime \prime \prime}$. Conidiophores unbranehed, or slightly branched, forming a head of branches and conidia:

$1^{\prime \prime \prime \prime}$. Conidia single, not in chains:

(a) Conidiophores unbranched, with swollen tip:

(a') Surface of terminal swelling definitely divided into hexagonal areas, Rhopalomyces. Found in the soil by Beekwith.

(b') Surface of terminal swelling not so divided, Oedocephalum. Rarely found in the soil.

(b) Conidiophores simple, but not with swollen tip, or branched:

(a') Conidiophores unbranched, seldom divided, conidia adjoined at tip, one after another, but all remaining united into a head:

$\left(\mathrm{a}^{\prime \prime}\right)$ Conidia embedded in slime, Iyyalopus. Rarely found in soil.

$\left(b^{\prime \prime}\right)$ Conidia not embedded in slime, Cephalosporium. Frequently found in the soil.

$\left(b^{\prime}\right)$ Conidiophores branched:

$\left(a^{\prime \prime}\right)$ Conidiophores tapering to a point bearing a head, Trichoderma (Nos. 95-96, Pl. XIV). One of the most common groups of soil fungi. Very active in the decomposition of celluloses in the soil. Species of this organism have been isolated from the soil in different parts of the world.

$\left(b^{\prime \prime}\right)$ Conidiophores with three or more fine spines, each of which bears a head, Botryosporium. Rarely found in the soil.

$2^{\prime \prime \prime \prime}$. Conidia born in chains:

(a) Conidiophores swollen at apex, Aspergillus (Nos. 105-106, Pl. XIV). Common in the soil, represented by several species.

(b) Conidiophores not swollen at apex:

$\left(a^{\prime}\right)$ Conidiophores branched, branches more or less unequal and not radiating:

$\left(a^{\prime \prime}\right)$ Conidia not embedded in slime, Penicillium (Nos. 102-104, Pl. XIV). One of the few most eommon genera in the soil; represented by many species, some of which are specifically soil forms.

$\left(b^{\prime \prime}\right)$ Conidia embedded in slime, Gliocladium. Isolated from the soil by Dale.

(b') Branches of conidiophore terminal, approximately equal and radiating, Amblyosporium. Rarely found in the soil. 
$2^{\prime \prime \prime}$. Conidiophores unbranched or branched, but branches and conidia not forming a terminal head:

$1^{\prime \prime \prime \prime}$. Conidia born on simple or branched, but not whorled hyphae:

(a) Conidia produced irregularly on the mycelium, or on short lateral branches, Sporotrichum (No.97, Pl. XIV). Commonly found in the soil, but insufficiently studied.

(b) Conidia produced on definitely differentiated erect conidiophores, which are usually much branched:

(a') Conidia single, terminal, Monosporium. Isolated from the soil by Koning, Dale and others.

(b') Conidia are usually loosely grouped at tip, Botrytis (No. 109, Pl. XIV). Represented in the soil by a number of species, some of which (B. cinerea) are cosmopolitan.

$2^{\prime \prime \prime \prime}$. Conidiophores branched in whorls:

(a) Conidia-bearing branches thick and flaskshaped; conidiophores with long sterile tips, Pachybasium. Isolated from the soil by Goddard.

(b) Conidiophores without sterile tip, conidia not produced on flask-shaped branches:

$\left(a^{\prime}\right)$ Conidia not forming chains:

$\left(a^{\prime \prime}\right)$ Conidia not embedded in slime, Verticillium. Represented in the soil by various species, some of which possess a strong cellulose decomposing power. Species of Geomyces, related to Verticillium, have been isolated from the soil by Traaen.

$\left(b^{\prime \prime}\right)$ Conidia embedded in slime, Acrostalagmus (No. 98, Pl. XIV). Frequently found in the soil.

(b') Conidia in terminal chains, Spicaria. Various species of this genus were isolated from the soil.

$3^{\prime \prime}$. Conidia born on differentiated intercalary cells of the conidiophore:

(a) Cells, bearing conidia, with raised points for attachment of conidia, Gonatobotrys. Rarely found in the soil.

(b) Cells, bearing conidia, smooth, Nematogonium. Isolated from the soil by Koning and Dale. 
$2^{\prime}$. Spores two-celled, conidia solitary:

(a) Conidia with both cells smooth:

(a') Conidia born on sides of conidiophores usually on inflated cells, not terminal, Arthobotrys. Rarely found in the soil.

$\left(b^{\prime}\right)$ Conidia produced at tips of conidiophores, not lateral, conidia solitary or in heads, pear shaped, Trichothecium. Isolated frequently from the soil.

(b) Terminal cell of conidium enlarged and roughened, Mycogone. Isolated frequently from the soil.

2. Vegetative hyphae either short, almost unnoticeable, of ten breaking up into spores, or as abundant moldy growth, septated, usually dark, seldom light colored (with dark spores). Conidiophores short, upright, simple or branched, dark colored. Conidia unseptated or variously septated, always dark colored, light only in exceptional cases (the mycelium and conidiophores are then dark). Dematiaceae.

$1^{\prime}$. Conidia unicellular:

$1^{\prime \prime}$. Mycelium little developed and breaking up into oidia, or conidia formed on short lateral hyphae that are not well differentiated from the remainder of the mycelium; conidia in chains easily broken up, Torula. Various spccies of Torula were found in the soil by Koning, Dale, Pratt and others.

$2^{\prime \prime}$. Mycelium definitely developed, with well differentiated conidiophores:

(a) Conidia not in chains:

(a') Conidia in terminal heads:

$\left(a^{\prime \prime}\right)$ Conidia developing directly from conidiophore or with very short sterigmata, Synsporium. Isolated from the soil by Dale.

$\left(b^{\prime \prime}\right)$ Conidia on thick, long sterigmata, Stachybotrys. Two species isolated from the soil by Jensen.

$\left(b^{\prime}\right)$ Conidia not in terminal heads; conidia prickly, Zygodesmus. Isolated from the soil only rarely.

$\left(c^{\prime}\right)$ Single conidia produced on branches, irregularly produced on the sides of the mycclium, Acremoniella. Rarely found in the soil.

(b) Conidia in chains:

(a') Conidiophores unbranched, lateral, with terminal chain of spores, Dema- 
2 '. Conidia two-celled:

tium (No. 110, Pl. XIV). Frequently found in the soil.

$\left(b^{\prime}\right)$ Conidiophores with branched chains of conidia, Cladosporium (Hormodendrum). Common in the soil, various species having been isolated by a number of investigators (No. 100, Pl XIV).

(a) Conidiophores short, not well differentiated from the mycelium:

(a') Conidia solitary, Dicoccum. Rarely found in the soil.

(b') Conidia in chains, Bispora. Rarely found in the soil.

$3^{\prime}$. Conidia more than two-celled:

(a) Septa of conidia perpendicular to long axis of spore, all parallel; conidia not in chains, $I I_{\ell} l$ minthosporium. Frequently found in the soil.

(b) Septa of conidia both longitudinal and crosswise; conidiophores well differentiated:

$\left(a^{\prime}\right)$ Conidia solitary and apical:

$\left(a^{\prime \prime}\right)$ Conidiophores decumbent, formed in lateral branches of mycelium, Stemphylium. Various species have been isolated from the soil.

$\left(b^{\prime \prime}\right)$ Conidiophores straight, more erect, conidium terminal, Macrosporium. Found in the soil by Dale and Pratt.

(b') Conidia in chains, Alternaria (No. 107, Pl. XIV). Represented in the soil by several species.

3. Vegetative hyphae mostly invisible, septated, branched, hyaline or dark colored. Conidiophores uniting in parallel strands to form upright coremia. From the separation of hyphae, at the top of the coremium, the conidiophores either form a head or are slightly radiating, Stilbaceac:

1'. Hyphae, coremium, and comidia hyaline or light colored; conidia one-celled; coremium with a more or less definite head, conidia not born along entire side:

(a) Conidiophores scarcely diverging at top, Ciliciopodium. Rarely found in the soil.

(b) Conidiophores divergent at top; each coremiun with lateral heads as well as terminal, Tilaehlidium. Found in the soil by Koning.

$2^{\prime}$. Hyphae, coremium and conidia usually all dark:

(a) Conidia not in chains, ovoid to oblong, hyaline, Graphium. Rarely found in the soil. 
(b) Conidia in chains, Stysanus. Found in the soil by Koning, Goddard and others.

4. Mycelium consists of branched, septated hyphae, growing in or on the medium; characteristic fructification; growth mostly of a waxy or slimy constituency, often quite tough, Tuberculariaceae Ehrenberg.

(a) Conidia and hyphae hyaline and light colored; sickle shaped conidia, both ends more or less pointed, $F u$ sarium (No. 101, Pl. XIV).

One of the most common groups of soil fungi; very active in cellulose decomposition. ${ }^{63}$ Various species of Fusarium were isolated from soils of different parts of the world.

(b) Conidia or hyphae dark or gray; conidiophores very short, conidia netted or prickly, Epicoccum. Rarely found in the soil.

II. Melanconiales, Melanconium ${ }^{64}$ is rarely found in the soil.

III. Sphaeropsidales:

1. Chaetomella. Found in the soil by Koning and Pratt.

2. Sphaeronema. Rarely found in the soil.

IV. Sterile mycelium:

1. Sclerotia formed:

(a) Sclerotia abundant, mycelium occupies secondary place, Sclerotium. Frequently found in the soil.

(b) Sclerotia seldom formed, Rhizoctonia. Various Rhizoctonia, especially $R h$. solani, are frequently found in the soil.

2. No sclerotia formed; hyphae united in strands, Ozonium. Often found in the soil (Dale).

D. BASIDIOMYCETES, characterized by the formation of a basidium, producing four sterigmata, each bearing a single spore. Among the various subgroups it is sufficient to mention the

I. Ustillaginales

II. URedinales

III. HYMENomycetes and other groups of mushroom fungi. These include various organisms (Mcrulius, Bolclus, Russula, etc.) which form mycorrhiza with higher plants ${ }^{65}$ and other forms, like Psilocybe, which may become agents in the decomposition of organic matter in the soil. ${ }^{66}$

${ }^{63}$ Sherbakoff, 1915 (p. 238); Pratt, O. A. Soil fungi in relation to diseases of the Irish potato in Southern Idaho. Jour. Agr. Res., 13: 73-99. 1918; Taylor, 1917 (p. 259).

${ }^{64}$ Edgerton, C. W. The Melanconiales. Jour. Amer. Microscop. Soc., 31: No. 4. 1912.

${ }^{65}$ Peyronel, B. Nuovi casi di rapporti micorizici tra Basidiomiceti e Fanerogame arboree. Bull. Soc. Bot. Ital., No. 1, p. 3-10. 1922.

${ }^{66}$ Thom, C., and Lathrop, E. C. Psilocybe as a fermenting agent in organic debris. Jour. Agr. Res., 30: 625-628. 1925. 


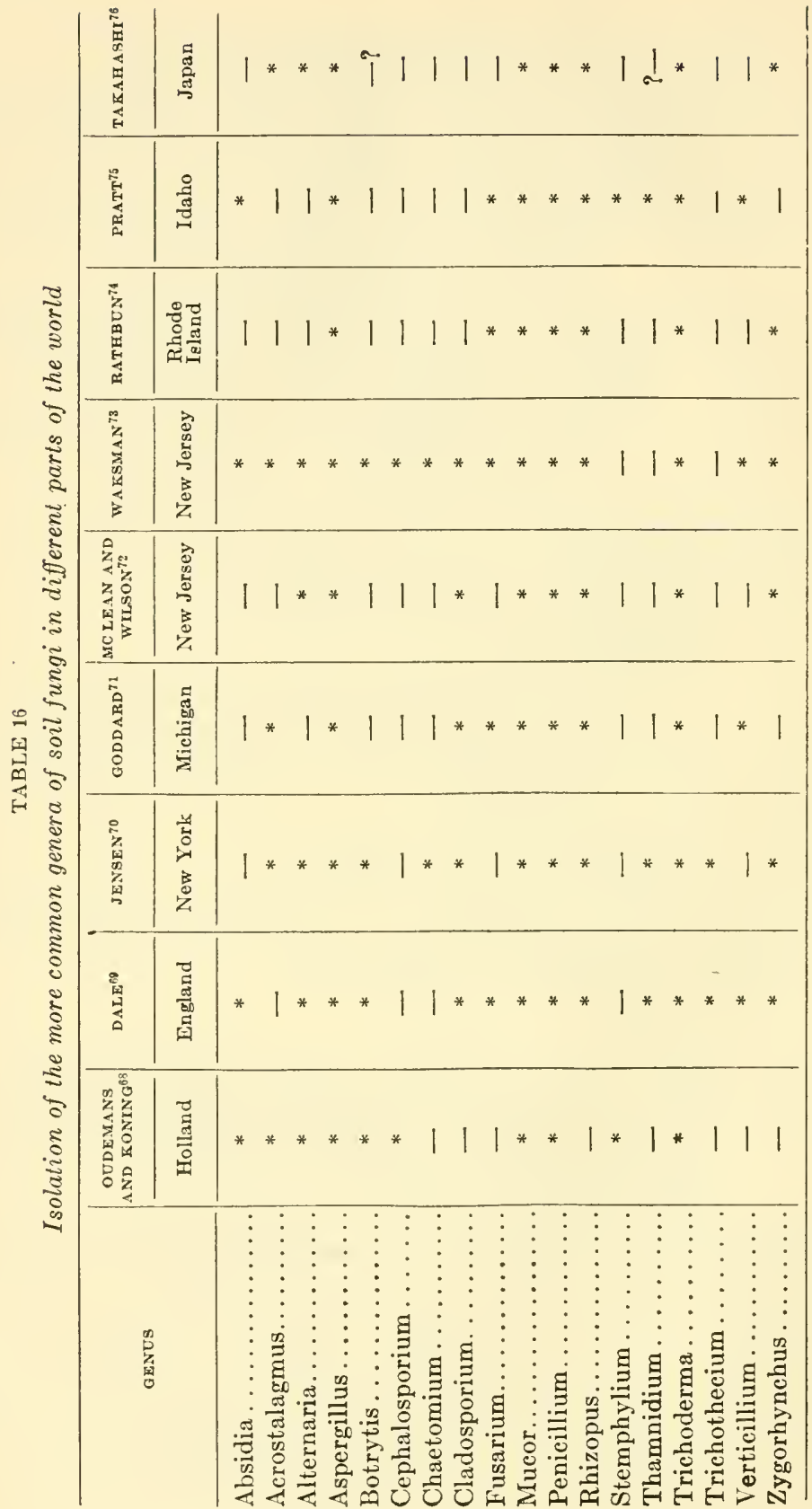


Occurrence of specific fungi in the soil. Of the various genera of fungi found in the soil, the most common, both in number of species and in frequency of occurrence, are Zygorhynchus, Penicillium, Trichoderma, Fusarium, Mucor, Aspergillus and Rhizopus. This is clearly demonstrated in table 16, where an asterisk designates that a particular genus is represented by one or more species in one or more soils. Brierly ${ }^{67}$ tabulated systematically all the fungi which have been recorded and described in soil investigations and found 56 species of Phycomycetes belonging to 11 genera; 12 species of Ascomycetes belonging to 8 genera; 197 species of Fungi imperfecti including Actinomyces, but not sterile mycelia, belonging to 62 genera.

Fungi are not limited in the soil to any particular depth, but occur at all depths, at least to a depth of four feet or more even in soils in humid regions. The numbers usually drop below the surface (upper six inches), but in the subsoil there does not seem to be a rapid diminution with greater depth. Some genera, like Zygorhynchus, occur abundantly in the subsurface soils. The distribution of fungi in the soil is believed to depend upon the amount of moisture and the character of the soil. ${ }^{77}$ The distribution of certain organisms in the soil, like Fusarium, has been ascribed to earthworms. ${ }^{78}$ Various fungi are found in the soil at a depth of 1 to 44 inches (Trichoderma köningi most abundantly); practically the same species were isolated from the intestinal canals of grubs and worms picked out from the soil and properly washed;

${ }^{67}$ Brierly, W. B. The occurrence of fungi in the soil. In The microorganisms of the soil, by Sir John Russell. 1923, 118-130.

${ }^{68}$ Oudemans and Köning, 1902 (p. 237).

${ }^{6}$ Dale, 1912 (p. 237).

70 Jensen, 1912 (p. 237).

${ }^{71}$ Goddard, H. M. Can fungi living in agricultural soil assimilate free nitrogen? Bot. Gaz., 56: 249 305. 1913.

${ }^{72}$ McLean, H. C., and Wilson, G. W. Ammonification studies with soil fungi. N. J. Agr. Exp. Sta. Bul., 270: 39. 1914.

73 Waksman, 1916 (p. 240).

${ }^{74}$ Rathbun, A. E. The fungus flora of pine seed beds. Phytopathol., 8: 469-483. 1918.

${ }^{76}$ Pratt, 1918 (p. 257).

${ }^{76}$ Takahashi, R. On the fungus flora of the soil. Ann. Phytopathol. Soc. Japan, 12: 17-22. 1919 (Bot. Abstr. 5: 92. 1920).

${ }^{77}$ Beckwith, T. D. Foot and culm infections of wheat by soil fungi in North Dakota. Phytopathol., 1: 169-176. 1911.

${ }^{78}$ Taylor, M. W. Preliminary note on the vertical distribution of Fusarium. Phytopathol., 7: 374-378. 1917. 
it was, therefore, concluded that the grubs and earthworms are the carriers of spores of soil fungi. ${ }^{79}$ It is interesting to note that Takahashi isolated the species Zygorhynchus mölleri and Trichoderma köningi in Japan at lower depths, while just below the surface he found Aspergilli, Penicillia, and other organisms, like Mucor racemosus, Stemphylium, and Chactomium.

In addition to the more than 60 genera of fungi reported to be found in the soil, probably as many more could be demonstrated, but to a comparatively more limited extent. Our methods are not sufficiently developed as yet as to allow the direct isolation of certain organisins like the Basidiomycetes. The presence of a certain organism in large numbers need not indicate its great abundance in the soil, but may be due to abundant spore formation or to local development. Repeated isolation of an organism from different soils and from various parts of the same soil is essential, before any claim can be laid to its active part in soil transformations.

Activities of fungi in the soil. Fungi require for their development the following elements: C, H, O, N, K, P, Mg, S, Fe. They obtain these either from organic or from imorganic (outside of carbon) sources. This points to their rôle in the soil, where they take part in at least two important processes: (1) rapid decomposition of complex organic substances; (2) assimilation of soluble inorganic nitrogen compounds and minerals, especially in the presence of available energy, thus removing them temporarily from the soil solution. The addition of fresh stable manure rich in straw, of green manures, and of other plant residues to the soil greatly stimulates the development of fungi; the nature of the organisms developing most abundantly depends to a large extent upon the constituents of the organic matter added. The addition of stable manure was found to stimulate the development of Penicillia and especially of Mucorales and of actinomyces. ${ }^{80}$ The addition of pure cellulose, especially in the presence of available nitrogen, brings about an extensive development of various fungi, such as Trichoderma, Fusaria, Verticillia, Monosporia, certain Penicillia, and other cellulose decomposing organisms. The reaction of the soil, the moisture content, and the nature and amount of the available nitrogen greatly modify the types of fungi developing in the soil as a result of the addition of celluloses or cellulose-rich materials. Plant substances are commonly added to the

${ }^{79}$ Rathbun, 1918 (p. 259).

${ }^{80}$ Lemmermann, O., and Fischer, H., Kappen, H., and Blanck, E. Bacteriologisch chemische Untersuchungen. Landw. Jahrb., 38: 319-364. 1909. 
soil in the form of residues or green manures, which contain only a very small amount of nitrogen ( 0.3 to 2.0 per cent). Fungi rapidly decompose practically all the constituents of the organic matter added to the soil, with the possible exception of the lignins. The fungi are very economical in this process, assimilating as much as 30 to 50 per cent of the carbon for the synthesis of cell substance. ${ }^{81}$ The latter contains 3.5 to 8.0 per cent of nitrogen. In other words the minimum nitrogen content of the fungus mycelium is twice as much as the maximum nitrogen content of green manure. If one part of fungus mycelium is synthesized for every three parts of green manure and plant stubble decomposed, and if the former contains three or more times as much nitrogen as the latter, this element will be completely reassimilated by the fungi; they may even assimilate, under certain conditions (when the

TABLE 17

Influence of reaction upon the growth of fungi

\begin{tabular}{|c|c|}
\hline ORGANISM & critical pH values \\
\hline Hucor gitwintulte. & $3.2-3.4$ to $8.7-9.2$ \\
\hline Asp. oryzae...... & $1.6-1.8$ to $9.0-9.3$ \\
\hline Asp.terriculu..... & $1.6-1.8$ to $9.0-9.3$ \\
\hline Pen. italicum. . & $1.9-2.2$ to $9.1-9.3$ \\
\hline Pen. variabile.. & $1.6-1.8$ to $10.1-11.1$ \\
\hline Fus. bullatum... & $2.0-2.2$ to $9.2-11.2$ \\
\hline Fus. oxysporum. . & $1.8-2.0$ to $9.2-11.1$ \\
\hline
\end{tabular}

plant material is low in nitrogen), the available nitrogen compounds in the soil (p. 515).

The rôle of fungi in the growth of higher plants may thus be both beneficial and injurious, depending upon conditions. This can be illustrated well by the phenomenon of formation of "fairy rings." When the spores of Agaricus germinate in the soil, small circular areas are formed and the native grasses are stimulated. The mycelium begins to spread in all directions as fungi usually do in culture media. The outward growth is slow--about $12 \mathrm{~cm}$. a year. The sod is at first stimulated by an increase in the available nitrogen resulting from the decomposition of the organic matter in the soil, then killed by insufficient soil moisture in the area of dense mycelium. When the mycelium in its

81 Waksman and Heukelekian, 1924 (p. 443); Waksman and Skinner, 1926 (p. 190). 
turn begins to decompose, the native grasses again invade the soil and develop luxuriantly, because of the abundant supply of readily available nitrogenous materials. ${ }^{82}$

Influence of reaction upon the growth of fungi. A detailed discussion of the various phases of the physiology of the fungi is out of place here, since it is given in the standard texts on plant physiology. Attention may be called to only some physiological properties of fungi which are important from the point of view of the growth and activities of these organisms in the soil.

It has been pointed out above that acid soil conditions favor the development of fungi. It need not, however, be construed that fungi grow only under acid conditions or even that they have their optimum growth at distinctly acid reactions; they have a rather wide range of reaction optimum, as shown in table $17 .{ }^{83}$

Fungi are thus shown to be much more resistant to acidity than the other groups of soil microorganisms. On the alkaline side, however, they are not more resistant than the bacteria. On the acid side there will, therefore, be no competition for the available plant food.

The reaction of the medium has an important influence upon the germination of fungus spores ${ }^{84}$ and upon the respiration of the organisms. ${ }^{85}$ Increasing acidity favorably influences the germination of the spores; a maximum of germination is exhibited by the majority of the spores tested at a $\mathrm{pH}$ of 3.0 to 4.0 . Inhibition of germination is evidenced only at $\mathrm{pH} 1.5$ to 2.5 ; the alkaline limits vary with the organism and with the medium.

Fungi as a rule modify greatly the reaction of the medium, by the production of organic acids from available carbohydrates, by the consumption of organic acids (leaving the medium less acid), or by the formation of ammonia from proteins. ${ }^{86}$

${ }^{82}$ Shanz and Piemeisel, 1917 (p. 282).

${ }^{83}$ Johnson, H. W. Relationships between hydrogen ion, hydroxyl ion and salt concentrations and the growth of seven soil molds. Iowa Agr. Exp. Sta. Res. Bul. 76. 1923.

${ }^{84} \mathrm{Webb}, \mathrm{R}$. W. Germination of the spores of certain fungi in relation to hydrogen-ion concentration. Ann. Mo. Bot. Gard., 8: 283-341. 1921.

${ }^{85}$ Molliard, M. Influence de la réaction du milieu sur la respiration du Sterigmatocystis nigra. Compt. Rend. Soc. Biol., 83: 50-51. 1920.

${ }^{86}$ Butkewitsch, Wl. Umwandlung der Eiweisstoffe dureh die niedere Pilze. Jahrb. wiss. Bot., 38: 147-240. 1903. 
Cellulose decomposition by fungi. Koning ${ }^{87}$ was the first to point out the great abundance of fungi in forest soils, where colorless and brown, septated and non-septated mycelia are found to penetrate the whole mass of organic matter. Koning suggested that fungi play an important rôle in the soil in decomposing the organic matter and in transforming it into humus. That under favorable conditions and in the presence of available energy, fungi grow very rapidly in the soil and produce a greater amount of $\mathrm{CO}_{2}$ than do bacteria, ${ }^{88,89}$ indicates a greater energy utilization. This led Neller to assume that fungi exist in the soil not merely in the form of spores, but are active there, since the $\mathrm{CO}_{2}$ production by pure cultures of fungi approached more that of a normal soil than the $\mathrm{CO}_{2}$ produced under similar conditions by bacteria. The decomposition of celluloses and of allied compounds in the soil by fungi is of great importance in soil fertility. This accounts for the abundance of fungi in soils rich in organic matter and for the great increase in numbers when stable manure and green manure are added to the soil. It has been found, ${ }^{90}$ for example, that the addition of 1 per cent of cellulose to the soil in the form of pure filter paper resulted, in two weeks, in an increase in the number of fungi from 50,000 to $1,250,000$ per gram. It has been further found that when a soil to which cellulose is added is treated with a volatile antiseptic, in sufficient amounts to kill the fungi, cellulose decomposition is greatly reduced. This process was found to take place under aerobic conditions, parallel with the development of fungi; in other words, these organisms were found to be important agents in the breaking down of the most abundant constituent of natural organic matter.

Students of plant diseases observed in the sixties of the nineteenth century that fungus hyphae grow in plant tissues, thereby penetrating cell walls. Hartig ${ }^{91}$ found that, in trees affected by fungi, all tissues

${ }^{87}$ Koning, C. J. Contributions à la connaissance de la vie des champignons humicoles et des phénomènes chimiques qui constituent l'humification. Arch. neerland. Sci. Exact. Nat., Ser. II, 9: 34-107. 1904.

${ }^{88}$ Neller, J. R. Studies on the correlation between the production of carbon dioxide and accumulation of ammonia by soil organisms. Soil Sci., 5: 225-241. 1918.

${ }^{89}$ Potter, R. S., and Snyder, R. S. The production of carbon dioxide by molds inoculated into sterile soil. Soil Sci., 5: 359-377. 1918.

${ }^{90}$ McBeth and Scales, 1912-1915 (p. 197); Waksman and Starkey, 1924 (p. 770).

${ }^{91}$ Hartig. Untersuchungen über die Zersetzungserscheinungen des Holzes. Berlin, 1878. 
disappear partly or entirely. De Bary ${ }^{92}$ was the first, however, to demonstrate that Botrytis vulgaris can decompose cellulose; actually he established that this organism can dissolve the middle lamella, which was not distinguisherl from cellulose by the older anatomists. Behrens ${ }^{93}$ first used filter paper as a nutrient for fungi and established the fact that Botrytis cinerea, Sclerotinia libertiana, Botrytis vulgaris, and a pseudo-Dematophora were able to derive their energy from pure cellulose. However, only about 10 per cent of the paper was decomposed, which led Schellenberg ${ }^{94}$ to suggest that only the impurities or hemicellulose-like compounds were decomposed.

Van Iterson ${ }^{95}$ inoculated, with soil or humus, filter paper moistened with a solution of 0.05 per cent ammonium nitrate and 0.5 per cent of $\mathrm{KH}_{2} \mathrm{PO}_{4}$ in tap water. He isolated 35 fungi including the genera Sporotrichum, Chaetomium, Botrytis, Stachobotrys, Cladosporium, Trichocladium, Mycogone, which are capable of decomposing cellulose. Not more than 4 to 14 per cent of the paper was decomposed. These results were subject to criticism, since tap water, which may contain various impurities, was used. The comparatively small loss in the weight of the cellulose was ascribed to the hemicelluloses present in the cellulose source used. Fusarium vasinfectum and other species of Fusarium were found ${ }^{96}$ to transform as much as 50 to 80 per cent of the cellulose, in the form of filter paper, into soluble forms; the medium used consisted of $10 \mathrm{gm}$. of paper and $50 \mathrm{cc}$. of a synthetic solution $\left(\mathrm{KNO}_{3}\right.$, $\mathrm{KH}_{2} \mathrm{PO}_{4}, \mathrm{MgSO}_{4}$ ) placed in Erlenmeyer flasks. As late as 1908, however, both Schellenberg and Froehlich ${ }^{97}$ claimed that, with the possible exception of Botrytis, Fusarium and wood destroying fungi, it has not been demonstrated as yet that fungi are capable of decom-

${ }^{92}$ de Bary, A. Ưber einige Sclerotinien und Sclerotinienkrankheiten. Bot. Ztg., 44: 377, 420. 1886.

${ }^{93}$ Behrens, J. Untersuchungen über den Wurzelschimmel der Reben. Centrbl. Bakt. II, 3: 584, 639, 743. 1897; also Ibid., 4: 514, 547, 577, 635, 700, $739,770.1898$.

${ }^{94}$ Schellenberg, H. C. Untersuchungen über das Verhalten einiger Pilze gegen Hemizellulosen. Flora, 98: 257-308. 1908.

${ }^{95}$ van Iterson, C. Die Zersetzung von Cellulose durch aerobe Mikroorganismen. Verslagen d. k. Akad. Wetensch., 9: 807-820. 1903; Centrbl. Bakt. II, 11: 689-698. 1904; van Iterson, C. J. and Koning, C. J. La connaissance de la vie des champignons humicoles. Arch. neerland. 2 ser. 1904, 34.

${ }^{96}$ Appel, O. and Schikhorra. Beiträge zur Kenntnis der Fusarien und der von ihnen hervorgerufenen Pflanzenkrankheiten. Arb. K. biol. Anst. Land. u. Forstw., 5: 155-188. 1906.

${ }^{97}$ Froehlich, H. Stickstoffbindung durch einige auf abgestorbenen Pflanzen häufige Hyphomyceten. Jahrb. wiss. Bot., 45: 256-302. 1908. 
posing cellulose. It remained for the more recent investigators ${ }^{98-101}$ to demonstrate definitely that not only do fungi decompose cellulose, but that pure cultures of fungi will decompose quantitatively within 3 to 4 weeks 50 per cent or more of the cellulose added in the form of filter paper. The addition of cellulose to the soil brings about an extensive development of fungi, most of which possess a very strong cellulose decomposing power. These include various species of Penicillium, Aspergillus, Trichoderma, Sporotrichum, Fusarium, and other forms which were found to be able to decompose cellulose. McBeth ${ }^{102}$ suggested that, in moist soils, particularly in humus soils, the fungi play a much more important part than in dry soils. Daszewska ${ }^{99}$ found Verticillium cellulosae, V. glaucum, Sporotrichum olivaceum and various other Sporotricha, Fusaria, Monosporia, Alternaria and Monilia among the strongest cellulose decomposing fungi in the soil. She also concluded that the Hyphomycetes play a much more important part than the bacteria in the decomposition of cellulose in the soil, the color of the humus being due to the color of the mycelium and the spores of fungi. Sugars and alcohols were formed as intermediary products.

Otto ${ }^{101}$ investigated a series of soil fungi and found the following to be able to decompose true celluloses actively: Stemphylium, Mycogone, Strachybotrys, Trichoderma, Cladosporium (Hormodendrum), and certain species of Penicillia. The cellulose was decomposed by the fungi by means of hydrolytic enzymes, which are produced only in the presence of cellulose in the medium. None of the Phycomycetes investigated could decompose cellulose. Further information on cellulose decomposition by fungi is given elsewhere. ${ }^{103-105}$

${ }^{98}$ Koning, C. J. Beijdrage tot de kennis van het leven der humicole fungi en van de scheidkundige Processen, welche bijd. humificatie hebben. Verlesungen v. de gewone Vergad. d. Wis. e. nat. Afdelling. November, 1912.

${ }^{99}$ Daszewska, W. Étude sur la désagregation de la cellulose dans la terre de bruyère et la tourbe. Bull. Soc. Bot. Genève., ser. 8, fas. 8, 255-316. 1913. ${ }^{100}$ McBeth, I. G., and Scales, F. M. The destruction of cellulose by bacteria and filamentous fungi. U. S. Dept. Agr. Bur. Plant Indus. Bul. 266, 1913; Scales, F. M. Some filamentous fungi tested for cellulose destroying power. Bot. Gaz., 60: 149-153. 1915.

${ }^{101}$ Otto, H. Untersuchungen über die Auflösung von Zellulosen und Zellwänden durch Pilze. Inaug. Diss. Berlin. Borntraeger. 1916.

${ }^{102}$ McBeth, 1916 (p. 197).

${ }^{103}$ Heller, F. Die Zersetzung der Zellulosen durch Pilze. Inaug. Diss. Rostock. 1917.

${ }^{104}$ Hopfe, A. Bacteriologische Untersuchungen über die Celluloseverdauung. Centrbl. Bakt. I, 83: 374-386, 531-537. 1919.

105 Traaen, 1914 (p. 238). 
The Mucorales are unable to decompose celluloses and most hemicelluloses. ${ }^{106}$ The ability of fungi to decompose different celluloses does not depend on the solubility of the latter in acids, but on the chemical composition of the substances in question. ${ }^{107}$ Certain Mucorales, like Rhizopus and Mucor stolonifer, are able to decompose pectins but not celluloses, whereas Botrytis and other fungi decompose the fiber itself. ${ }^{108}$

According to the earlier investigators fungi are the proper humus builders in the soil. The fallen leaves, at the end of the vegetative period in the fall, are found to be penetrated with fungus mycelium, which decomposes the leaves readily, with the production of humic substances. These accumulate, because they cannot serve as a source both of carbon and of nitrogen ${ }^{109,110}$ but, in the presence of available sources of carbon, they can be used as sources of nitrogen by fungi. More recent information tends to show that, although fungi decompose most of plant residues (with the exception of lignins) completely, they synthesize cxtensive protoplasm, which is an important part of the soil organic matter.

Decomposition of nitrogenous substances by fungi (ammonia formation). Just as in the decomposition of celluloses and allied compounds, fungi play an important rôle in the decomposition of organic nitrogenous compounds. In the presence of available carbohydrates, the fungi utilize the nitrogen compounds only as sources of nitrogen; in the complete or relative absence of available carbohydrates, they utilize the nitrogenous substances as sources of carbon and of nitrogen. In view of the fact that the energy requirements of the fungi are greater than their nitrogen requirements, a great deal more of the protein molecule will be broken down to supply the necessary carbon. The excess of nitrogen present in the protein molecule over that required by the fungus for the building up of its own proteins will be left as a waste product, in the

106 van Iterson, 1904 (p. 264); Hagem, 1910 (p. 237); Waksman and Heukelekian, 1924 (p. 443); Waksman and Skinner, 1926 (p. 190).

${ }^{107}$ Schellenberg, 1908 (p. 264).

108 Behrens, J. Taurote von Flachs und Hanf. Centrbl. Bakt. II, 10: 524530. 1903.

${ }^{109}$ Reinitzer, F. Ueber die Fignung der Huminsubstanzen zur Ernährung von Pilzen. Bot. Ztg., 58: 59-73. 1900.

110 Nikitinsky, J. Über die Zersetzung der Huminsüure durch physikalischchemische Agentien und durch Mikroorganismen. Jahrb. Wiss. Bot., 37: 365420. 1902 . 
form of ammonia.111 In general, fungi play an important part in the mineralization of the organic matter, whereby the nitrogen compounds and minerals are liberated in inorganic forms; a part of these is used by the fungi for the synthesis of fungus proteins.

Müntz and Coudon ${ }^{112}$ and Marchal ${ }^{113}$ pointed out, in 1893, the abundant formation of ammonia by fungi, the latter even ascribed the ammonia production in soils (particularly acid soils) chiefly to the action of fungi. The decomposition of proteins with the formation of amino acids and ammonia has been pointed out by Kosyachenko and others. ${ }^{114}$ Cyanamide is decomposed, with the formation of ammonia, ${ }^{115}$ as are urea, uric acid, and glycocoll. ${ }^{116}$ According to McLean and Wilson, ${ }^{117}$ filamentous fungi are capable of producing a greater accumulation of ammonia from proteins than bacteria. All the organisms studied, including representatives of the families of Mucoraceae, Aspergillaceae, Moniliaceae and Dematiaceae, were found to be capable of producing ammonia from dried blood and from cottonseed meal. The Moniliaceae were most active. In 8 to 10 days, Trichoderma koningi liberated as ammonia over half of the nitrogen in dried blood ( 1 per cent in sterile soil). The Aspergillaceae formed the least amounts of ammonia from proteins. The addition of soluble phosphate stimulated in most cases the amount of ammonia accumulated. Most fungi were capable of allowing greater accumulations of ammonia from dried blood than from cottonseed meal. This is probably due to the fact that the latter is richer in available carbon compounds, which will allow a greater synthesis of fungus proteins with the decomposition of proportionally less protein of the cottonseed meal.

Utilization of nitrogen compounds by fungi. Soil fungi may assimilate

111 Waksman, S. A. The influence of available carbohydrates upon ammonia accumulation by microorganisms. Jour. Amer. Chem. Soc., 39: 1503-1512. 1917.

112 Müntz, A., and Coudon, H. La fermentation ammoniacale de la terre. Compt. Rend. Acad. Sci., 116: 395-398. 1893.

${ }^{113}$ Marchal, E. Sur la production de l'ammoniaque dans le sol par les microbes. Bul. Acad. Roy. Sci. Belg., 25: 727-771. 1893.

${ }^{114}$ Kosyachenko, I. S. The influence of $A$. niger on the transformation of albuminoids in peas. Zhur. Opitn. Agron., 4: 439-449. 1903.

115 Kappen, H. Úber die Zersetzung des Cyanamids durch Pilze. Centrbl. Bakt. II, 26: 633-643. 1910.

${ }^{116}$ Kossovicz, A. Die Zersetzung von Harnstoff, Harnsäure, Hippursäure und Glykokoll durch Schimmelpilze. Ztschr. Garungsphysiol., 1: 60. 1912. ${ }^{117}$ McLean and Wilson, 1914 (p. 259). 
the readily available nitrogen compounds of the soil, in the presence of favorable sources of energy, thus exerting a very unfavorable action upon the growth of higher plants. Rothe ${ }^{118}$ stated that the fungi exceed the bacteria and actinomyces, in acid as well as in neutral media, in the assimilation of available nitrogen and in storing it away as microbial organic matter; in the presence of $\mathrm{CaCO}_{3}$, large quantities of nitrogen added to the soil in the form of ammonium salts are transformed by these organisms into very insoluble nitrogen compounds. The competition between fungi and higher plants for the available nitrogen, under certain conditions, was also pointed out by Hall and associates. ${ }^{119}$ Hagem $^{120}$ found that Mucorales will readily assimilate ammonium salts and transform them into microbial proteins. As pointed out above, with cellulose or other carbohydrates as sources of energy, the fungi may reassimilate 30 to 40 per cent of the carbon of the substrate decomposed. This necessitates a parallel assimilation of nitrogen; about one unit of available nitrogen is transformed into microbial protein for every 30 units of cellulose decomposed. This leads to a considerable reduction of the available nitrogen in the soil.

Ehrenberg'21 stated that fungus protein is much less available for further decomposition than bacterial protein, the fungus spores containing a large quantity of nitrogen stored away in an unavailable form, to some extent in the form of chitin, not readily subject to decomposition. ${ }^{122}$ Other investigations seem to point, however, that a large part at least of the cell substance syntherized by fungi is as rapidly decomposed as organic substances of animal origin. ${ }^{122 a}$ The disappearance of the available nitrogen added to the soil in the form of ammonium salts and nitrates is to be looked for more in the development of fungi than of bacteria. Particularly is that true when these nitro-

${ }^{118}$ Rothe. Untersuchungen über das Verhalten einiger Mikroorganismen des Bodens zu Ammonium Salze und Natriumnitrat. Inaug. Diss. Königsberg. 1904.

${ }^{119}$ Hall, A. D., Miller, N. H., and Gimmingham, C. T. Nitrification in acid soil. Proc. Roy. Soc. (London), B, 80: 196-211. 1908.

120 Hagem, 1908 (p. 237).

${ }^{21}$ Ehrenberg, P. Die Bewegung des Ammoniakstickstoffs in der Natur. Mitt. Landw. Inst. Breslau, 4: 47-300. 1907.

122 Wettstein, F. Das Vorkommen von Chitin und seine Verwertung als systematisch-phylogenetisches Merkmal im Pflanzenreiche. Sitz. Ber. Akad. Wiss. Wien, Math. Nat. Kl. (I), 130: 3-20. 1921 (Centrbl. Bakt. II, 58: 329. 1923).

1228 Starkey, 1924 (p. 684). 
genous fertilizers are added together with large quantities of manure or straw, since the available energy introduced into the soil will allow a rapid growth of the fungi, with the result that available nitrogen compounds are used up by them, to the detriment of the growth of higher plants. This action of the soil fungi has also a favorable side, namely the temporary storing of the available nitrogen salts in an insoluble form, thus preventing their leaching by drainage and irrigation. The favorable and unfavorable actions depend upon the presence or absence of higher plants.

The nutritive value of nitrogen compounds for fungi depends on the rapidity with which they can be transformed into amino acids, according to some investigators..$^{123,124}$ Other investigator ${ }^{125-127}$ are, however, of the opinion that the amino acids and nitrates are reduced to ammonium salts before they are assimilated by fungi. The ability of an organism to assimilate ammonium salts is in direct relation to its ability to withstand the mineral acid liberated. ${ }^{128}$ Assimilation of nitrates by fungi goes through the reduction of nitrates to nitrites and ammonia. Organisms, like certain Mucorales, that are incapable of reducing the nitrate molecule cannot assimilate this source of nitrogen. ${ }^{129}$

${ }^{123}$ Czapek, 1901-1902 (p. 502).

124 Puriewitsch, K. Untersuchungen über die Eiweisssynthese bei niederen Pflanzen. Biochem. Ztschr., 38: 1-13. 1912.

${ }^{125}$ Raciborski, M. I. Über die Assimilation der Stickstoffverbindungen durch Pilze. Anz. Akad. Wiss. Krakau, Math. Naturw. Kl., p. 733.1906.

${ }^{126}$ Hagem, 1910 (p. 237).

${ }^{127}$ Abderhalden, E., and Rona, P. Die Zusammensetzung des "Eiweiss" von Aspergillus niger bei verschiedener Stickstoffquelle. Ztschr. physiol. Chem., 46: 179-186. 1910.

${ }^{128}$ Ritter, G. Ammoniak und Nitrate als Stickstoffquelle für Schimmelpilze. Ber. deut. bot. Gesell., 25: 255; 27: 582-58s; 29: 570-577. 1908-1911.

${ }^{129}$ A detailed study of the nitrogen utilization by fungi is found in a paper by Brenner, while the influence of environmental conditions on the activities of soil fungi has been reviewed by Coleman. Further information on the physiology of fungi including curves of growth, influence of temperature, reaction and concentration is given by Müller. The antagonistic action of fungi to one another was studied by Nadson and Zolkiewicz and Porter. Brenner, 1914 (p. 241); Coleman, D. A. Environmental factors influencing the activity of soil fungi. Soil Sci., 2: 1-66. 1916; Müller, K. O. Untersuchungen zur Entwicklungsphysiologie des Pilzmycels. Beitr. Allg. Bot. 2: 276-322. 1922; Nadson, G. A., and Zolkiewicz, A. I. Spicaria purporogenes n. sp. On the question of antagonism among microbes. Bull. Jard. Bot. Rep. Russe., 21: suppl. 1. 1921; Porter, C. L. Concerning the characters of certain fungi as exhibited by their growth in the presence of other fungi. Amer. Jour. Bot., 11: 168-188. 1924. 
Nitrogen-fixation. Various claims have been put forth, at different times, that fungi are able to assimilate atmospheric nitrogen. In most cases the quantities fixed were very small, amounting to a few milligrams, so that cioubt might arise whether this was not due merely to experimental errors. In some cases the mere fact that fungi grew on agar free from nitrogen compounds was taken as an index of positive nitrogenfixation, the fact being overlooked thereby that some of these organisms can readily assimilate traces of ammonia present in the atmosphere and that various chemicals may contain, as impurities, small amounts of nitrogen. The more careful studies of recent investigators ${ }^{130-132}$ have definitely established the fact that common soil fungi are unable to fix atmospheric nitrogen. The only possible exceptions to this rule may be in the case of certain mycorrhiza fungi, ${ }^{133}$ especially organisms belong-

${ }^{130}$ Goddard, 1913 (p. 259).

${ }^{131}$ Chambers, C. O. The fixation of free nitrogen by certain fungi. Plant World, 19: 175-194. 1916.

${ }^{132}$ Duggar, B. M., and Davis, A. R. Studies in the physiology of the fungi. I. Nitrogen fixation. Ann. Mo. Bot. Gard., 3: 413-437. 1916.

${ }^{133}$ Peklo, J. Neue Beiträge zur Lösung des Mykorrhizaproblems. Z $Z$ tschr. Garungsphysiol., 2: 275-289. 1913.

\section{PLATE XV}

\section{Mrcorrhiza Fungi}

111. Apparatus for rooting cuttings under controlled conditions: $w$, cotton; $c$, cutting; $s$, sand; $r$, glass rod; $h$, rain water; $p$, potash tube (from Rayner).

112. Vessel for study of mycorrhiza formation in pure culture (from Melin).

113. Hyphae of Tricholoma favobrunnea, grown in pure culture in symbiosis with birch tree, $\times 50$ (from Melin).

114. Oblong section of hyphae radiating from mycorrhiza-root, $\times 500$ (from Melin).

115. Beginning of infection of epidermis of young wheat root by phycomycoid endophyte; $p$, points of entrance of mycelium into the root; attention is called to the growth of the mycelium between the cells, $\times 130$ (from Peyronel).

116. Stages of evolution, showing the process of tuber formation as a result of symbiosis: $A$, Solanum tuberosum; B, Orobus tuberosus; $C$, Ficaria ranunculoides; $D$, plantlet of Bletitta hyacinthina inoculated with attenuated Rhizoctonia repens; $E$, plantlet of $B l$. hyacinthina inoculated with an active $R h$. repens; $F$, embryo tuber of Cattleya; $t=$ tubers (after N. Bernard and Magrou).

117. Longitudinal section of a potato root, showing an early stage of fungus infection; $m$, coiled mycelium; $n$, cellular nuclei $n^{\prime}$, fungus nuclei (from Magrou).

118. Two infected cells of a potato root, the lower cell showing large bodies resulting from disintegration by phagocytosis and the upper cell showing nondisintegrated mycelium which attacks the cell (f rom Magrou).

119. Mycorrhiza cells from young root of seedling of Calluna vulgaris showing, at right, "clumping" at early stage of digestion and, at left, digestion process (from Rayner). 
PLATE XV
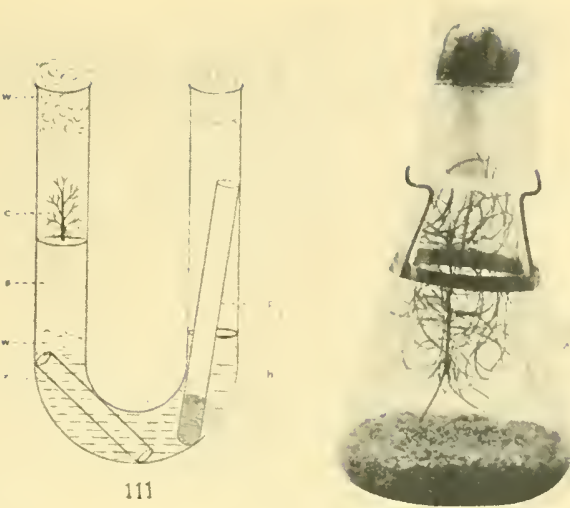

112

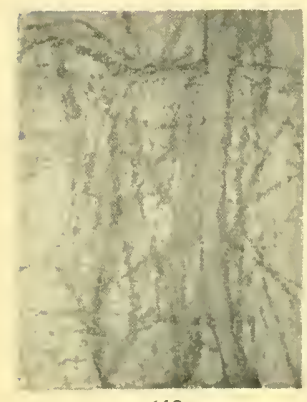

113

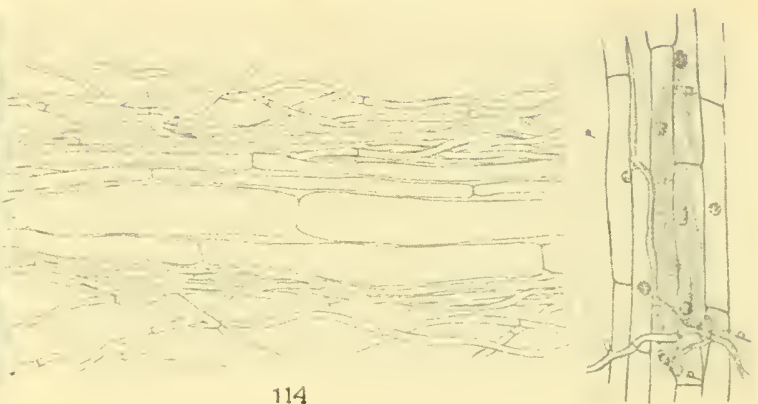

115

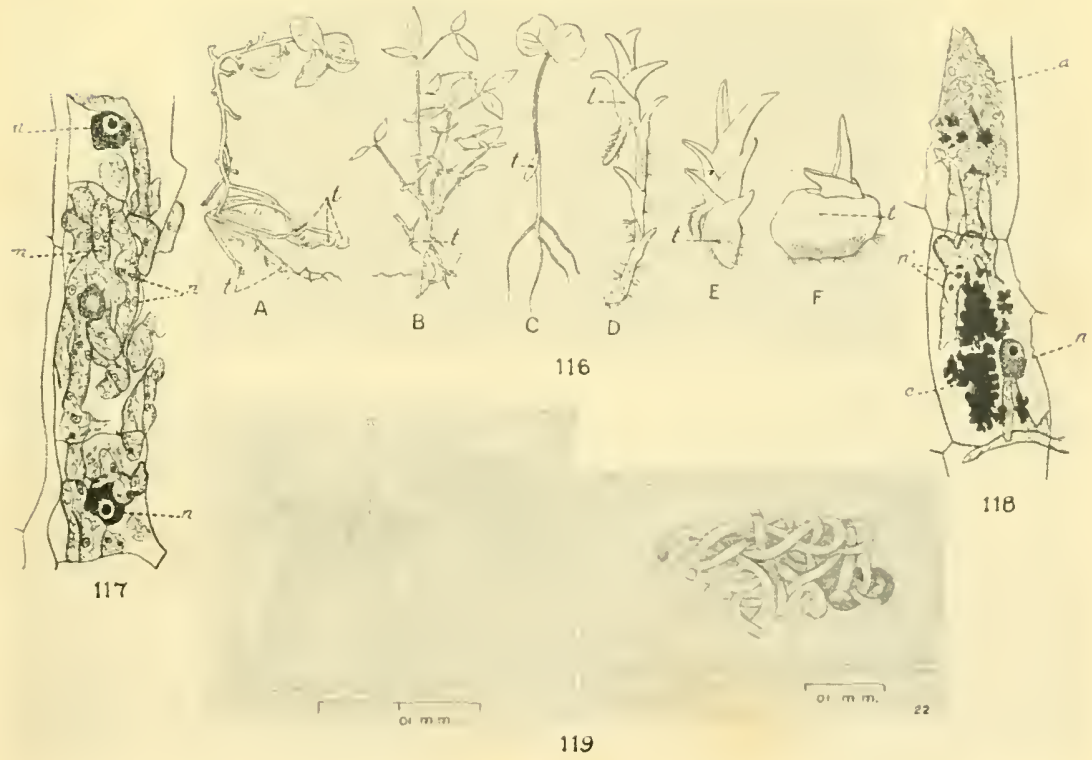



ing to the genus Phoma ( $P$. beta ${ }^{132}$ and $P$. radicis $\left.{ }^{134}\right)$, where positive nitrogen fixation has been demonstrated. Nitrogen fixation by yeasts was also found to be negative. ${ }^{135}$ A detailed review of the literature on nitrogen fixation by fungi (and algae) is given by Czapek. ${ }^{136}$ The possibility that certain fungi, like Pen. luteum, are capable of oxidizing sulfur has also been suggested. ${ }^{137,133}$

\section{MYCORRHIZA FUNGI}

Nalure of mycorrhiza formation. Pfeffer ${ }^{139}$ was the first to call attention to the possible symbiotic action between the roots of plants and fungi. The roots of higher plants, especially trees, were found to be commonly interwoven with fungus mycelium to form a symbiotic growth, to which the term "mycorrhiza" was applied.140 These formations were found to be abundant in humus or other soils containing undecomposed plant residues. Frank divided the mycorrhiza into two groups: 1. Ectotrophic mycorrhiza, when the fungus produces an external investment of the root, in the form of a crown of hyphae, without penetrating into cells other than those of the epiclermis. There is an extensive intercellular development between the cortical cells of the root. This is especially characteristic of forest trees. 2. Endotrophic mycorrhiza, in which the hyphae of the fungus penetrate to the inner parts of the roots, into definite root layers and into the cells. This is true of the Orchidaceae, Ericaceae and Eparidaceae; however,

${ }^{134}$ Ternetz, C. Úber die Assimilation des atmospherischen Stickstoffs durch Pilze. Jahrb. wiss. Bot., 44: 353-408. 1907.

${ }^{135}$ Kossowicz, A. Zur Frage der Assimilation des elementarem Stickstoffs durch Hefen und Schimmelpilzen. Biochem. Ztschr., 64: 82. 1914.

${ }^{136}$ Czapek, 2: 192-198, 1920 (p. xv).

137 Abbott, E. V. The occurrence and action of fungi in the soil. Soil Sci., 16: $207-216.1923$.

${ }^{138}$ Rippel, A. Über einige Fragen der Oxydation des elementaren Schwefels. Centrbl. Bakt. II, 62: 290-295. 1924.

${ }^{139}$ Pfeffer, W. Über fleischfressende Pflanzen und über die Ernährung durch Aufnahme organischer Stoffe überhaupt. Landw. Jahrb., 6: 969-998. 18 77.

${ }^{140}$ Frank, B. Über die auf Wurzelsymbiose beruhende Ernährung gewisser Bäume durch untererdische Pilze, und neue Mitteilungen über die Mykorrhiza der Bäume und der Monolropha hypopitys. Ber. deut. bot. Gesell., 3: 143, XXVII. 18s5; Über neue Mykorrhiza Formen. Ibid., 5: 395-40s. 1887; Utber die Verdauung von Pilzen abzielende Symbiose der mit endotrophen $\mathrm{My}$ korrhizen begatteten Pflanzen. Ibid., 9: 244. 1891. 
it is now known also for many other plants. Root hairs were found to be frequently absent in ectotrophic mycorrhiza and are replaced by hyphae of fungi. Frank formulated the theory that these absorb the mineral salts and organic nitrogen compounds for the plant, whereas the latter supplies the fungus with synthesized carbohydrates. In the case of the endotrophic mycorrhiza the plant obtains the nitrogen from the fungus in the process of digestion of the mycelium.

Frank's theories were not generally accepted, especially when endotrophic mycorrhiza were also found on forest trees and ectotrophic mycorrhiza in soils poor in organic matter. Various other theories have been put forth concerning the nature of mycorrhiza formations and their rôle in plant nutrition. Some of them were directly conflicting, largely because of the fact that the causative organisms could not be isolated and cultivated in pure culture and the mycorrhiza produced artificially. It is necessary, however, to differentiate between theories of nutrition based on observation only, and those deduced from pure culture experiments, as those of Bernard and Burgeff on orchids, Melin on Conifers and other trees, Rayner on the Ericaceae and Peyronel's recent work on endotrophic mycorrhiza. ${ }^{141}$

The penetration of the hyphae of the fungus into the root, which results in the formation of an endotrophic mycorrhiza can take place (as described for Lolium temulentum ${ }^{142}$ ) in two different ways: 1. If the hypha reaches the root hair, it may penetrate through its wall and grow through the eavity until it reaches the corresponding epidermal cell; sometimes the hypha may twist round the hair in one or two close loops before penetrating. 2. The filament may enter the root by piercing the epidermis directly. Having reached the interior of the root, the filament twists in a loose spiral-like fashion in the lumen of the epidermal cell. Growth takes place at right angles to the root surface and the next layer of root cells is infected before there is a considerable horizontal extension of the mycelium in the root. The

${ }^{141} \mathrm{~A}$ detailed review of the earlier literature on mycorrhiza is given by Bernard, Gallaud, Janse and Rayner. Bernard, N. L'évolution dans la symbiose des orchidées et leurs champignons commensaux. Ann. Sci. Nat. Bot. (9), 9: 1-186. 1909; Gallaud, I. Etudes sur les mycorhizes endotrophes. Rev. gen. Bot., 17. 1905; Janse, J. M. Les endophytes radicaux de quelques plantes javanaises. Ann. Jard. Bot. Buitenzorg., 14. 1897. Rayner, M. C. Mycorrhiza. New Phytolog., 25: 1-50, 65-108, 177-190. 1926.

${ }_{162}$ McLennan, E. I. The endophytic fungus of Lolium. II. The mycorrhiza on the roots of Lolium temulentum L., with a discussion of the physiological relationships of the organism concerned. Ann. Bot., 40: 43-68. 1926. 
hyphae in the epidermis and in the outer cortical layers are intracellular in nature, but, with horizontal spreading of the mycelium in the second root layer, branching takes place, some of the branches penetrating the cell wall into the intracellular spaces. Vesicles are formed in the second region; they are looked upon as arrested sporangial developinents or as spore bearing bodies which may function as temporary reserve organs during the early stages of the invasion of the fungus. Arbuscles and sporangioles are formed in clusters in the third region, the middle cortex.

Plants forming mycorrhiza. A large number of plants, including perennials and annuals, are capable of forming mycorrhiza with different fungi. Wild plants and fruit trees form mycorrhiza more readily than cultivated plants. Some fungi can attack a large number of plants, whereas some plants can form mycorrhiza with different fungi. This phenomenon is especially highly developed in certain cases, as in the orchids and Ericaceae; in other words, there is no direct specificity between the plant and the infecting fungus. Stahl ${ }^{143}$ and others demonstrated that most higher plants, with the exception of submerged water plants and certain specific large families of plants (Cruciferae, Cyperaceae and Polypodiaceae), possess always or occasionally mycorrhiza formations. Plants with rapid transpiration can absorb their mineral food material without the fungi, whereas plants with weak transpiration can obtain a sufficient supply of minerals only by the assistance of the symbiotic fungi. Stahl's theories, however, were not based on experimental evidence.

Bernard ${ }^{141}$ observed a series of transition stages in the degree of dependence of the plant upon the fungus. In case of a few species of orchids, as Bletitta, the seeds germinate but are unable to form roots, without infection; in the majority of other orchids, the embryo is arrested at a much earlier stage. The degree of specificity between plant and fungus varies, as does the resistance of the plant to the fungus invasion. Bernard demonstrated experimentally that symbiosis between the plant and fungus is obligate. The results obtained by practical orchid growers confirmed these facts. N. Bernard and Magrou ${ }^{144}$ developed a theory of tuber formation, in the evolution of plants, based on the

${ }^{143}$ Stahl, E. Der Sinn der Mykorrhizenbildung. Jahrb. wiss. Bot., 34: 539668. 1900; Stickstoffbindung durch Pilze bei gleichzeitiger Ernährung mit gebundenen Stickstoff. Jahrb. wiss. Bot., 49: 579-615. 1911.

${ }^{144}$ Magrou, J. Symbiose et tubérisation. Ann. Sci. Nat. (10), 3: 1S1-275. 1921; La symbiose chez les hépatiques le Pellia epiphylla et son champignon commensal. Ibid. (10), 7: 725-278. 
symbiotic action of the plants with the fungi. The establishment of symbiosis in potatoes and Orobus tuberosus germinating from seed brings about the formation of tubers out of the buds at the base of the stem. When the plants are kept from becoming infected with the symbiotic fungi or do not establish the usual symbiotic relation, without otherwise changing the conditions of growth, the same buds change into thin stems, without the formation of tubers (No. 116, Pl. XV). This theory, lowever, is still in the theoretical stage, since the evidence is incomplete.

A relation between plant and fungus resembling that found in orchids was also observed in Ericaceae, namely a complete dependence of the seedling plant upon infection by the endophyte at a critical stage, differing, however, in the mode of infection. ${ }^{145}$ In the absence of infection, root formation is arrested and growth is finally inhibited. Infection of the primary root takes place soon after germination of the seed, which is infected while still in the ovary. The formation by Arbutus unedo of root tubercles, which are arrested secondary and successive laterals of the season's growth, is due to the invasion by a fungus, which at first acts ectotrophically, then as an endotroph of the peripheral cells. ${ }^{146}$ For the development of various forest trees, such as firs and spruces, mycorrhiza are absolutely essential $;^{147}$ without them the plant development will not be normal. A large number of annual and perennial plants were also found ${ }^{148}$ to form mycorrhiza; here are included various plants among the Graminaceae (Zea mays, Triticum sativum, Hordeum vulgare, Avena sativa), Araceae, Liliaceae, Amaryllidaceae, Iridaceae, Juglandaceae, Urticaceae, Lauraceae, Polygonaceae, Chenopodiaceae (Beta vulgaris), Portulacaceae, Violaceae, Cruciferae, Ranunculaceae, Saxifragaceae, Rosaceae, Leguminaceae (Genista tinctoria, Medicago sativa, Melilotus officinalis, Trifolium pratense, Trifolium repens, Ornithopus compressus), Umbelliferae, Geraniaceae, Rutaceae,

${ }^{145}$ Rayner, M. C. Preliminary observations on the ecology of Calluna vulgaris on the Wiltshire and Berkshire downs. The New Phytol., 10: 227-240. 1911; Obligate symbiosis in Calluna vulgaris. Ann. Bot., 29: 97-133; 1915; Mycorrhiza in the Ericaceae. Brit. Mycol. Soc., 8: 61-66. 1922.

${ }^{146}$ Rivett, M. F. The root tubercles of Arbutus unedo. Ann. Bot., 38: 661677. 1924.

${ }^{147}$ Melin, E. Experimentelle Untersuchungen ïber die Konstitution und Ökologie der Mykorrhizen von Pinus silvestris L. und Picea abies (L.). Karst. Mykol. Unters. u. Ber., 2: 73-335. 1923.

${ }^{148}$ Peyronel, B. Prime ricerche sulle micorize endotrofiche e sulla mycoflora radicicola normale delle fanerogame. Riv. Biol., 5: 463-485. 1923; 6: 17-53. 1924 . 
Primulaceae, Solanaceae (Nicotiana tobaccum, Solanum tuberosum, Solanum nigrum), Scrophulariaceae, Compositae, Orchidaceae, etc. The roots of various legumes are extensively invaded by a characteristic fungus belonging to the mycorrhiza type. ${ }^{149}$ The fungus is found in the primary cortex and forms a coarse, nonseptate mycelium in the roots and sends out haustoria into the deeper cells, often filling more than half of the lumen of the cell. The fungus is well distributed in the soil, and can infect most legumes (except Lupinus perennis and two other plants) and various nonleguminous plants (Zea mays, Allium cepa, Ipomoca purpurea, Verbascum thapsus, etc.).

According to Melin, the fungus infection of the roots leads to their shortening and development into mycorrhiza. The short roots are branched in a characteristic manner, usually forklike. Mycorrhiza formation takes place best in humus soils.

Organisms responsible for mycorrhiza formation. Various species of fungi have been reported to be able to live symbiotically with higher plants. In the case of endotrophic mycorrhiza, mostly higher fungi have been found. In many cases various Phycomycetes, including the Mucorales, have been reported. In a few cases actinomyces and a species of Penicillium were believed to be involved ${ }^{150}$ although this has not been established experimentally. According to Hagem, certain Mucorales, especially Zygorhynchus mölleri, Mucor ramannianus, certain species of Absidia (A. orchidis) and a green Penicillium may form mycorrhiza with forest trees. Möller ${ }^{151}$ also suggested the possibility of formation of mycorrhiza by Zygorhynchus, an organism found to form an abundant growth in sandy soils, especially in certain pine barrens of New Jersey so as to practically hold the sand together in one mass. MacDougal ${ }^{152}$ believed that fungi belonging to Oomycetes, Gasteromycetes, Hymenomycetes, and Pyrenomycetes can form mycorrhiza, but no experimental evidence was supplied. One must discriminate carefully between attributions based merely on isolations of species of fungi from mycorrhiza plants and those in which the mycorrhiza has been produced again experimentally by pure cultures of the organisms. Positive proof of identity can only be supplied by inocu-

149 Jones, F. R. A mycorrhizal fungus in the roots of legumes and some other plants. Jour. Agr. Res., 29: 459-470. 1924.

${ }^{150}$ Peklo, 1913 (p. 270).

${ }^{151}$ Möller, A. Untersuchungen über ein und zweijährige Kiefern im märkischen Sandboden. Ztschr. Forst. u. Jagdwesen. 1903, H. 5-6.

162 MacDougal, D. 'T. Symbiotic saprophytism. Ann. Bot., 13: 1-48. 1899. 
lation into a pure culture seedling growing under controlled conditions with subsequent production of mycorrhiza. In the extensive literature on mycorrhiza formation, very few attempts which have been made to isolate the causative organism and cultivate it in pure culture, or to produce mycorrhiza artificially, have proved successful. This has been accomplished in the case of various orchids, ${ }^{153}$ in Calluna vulgaris, ${ }^{154}$ and especially by Melin for various pine trees. Bernard ${ }^{155}$ classified the fungus of orchids with Rhizoctonia, on the basis of sclerotia formation. Burgeff, however, later termed this organism Orcheomyces.

The organism isolated from Calluna vulgaris was placed by Rayner in the genus Phoma among the Sphaeropsidales. Various members of the genera Cortinarius (between C. rubipes, on the one hand, and Quercus rubra, Picea rubra, or Acer saccharum on the other), Russula (between $R$. emetica and Quercus rubra), Tricholoma (B. speciosus or T. transmutans and Quercus nigra), Armillaria (A. mellea and the orchid Gastrodia elata), Boletus (Boletus species and pine trees) were found ${ }^{157-160}$ to be the causative agents of mycorrhiza formation.

The true mycorrhiza fungi of forest trees should be looked for largely among the Hymenomycetes, given above. ${ }^{156}$ Mycorrhiza formation by Gasteromycetes is still questionable; the same is true of the ascomycetes, although Rhizoctonia belongs to this group. A number of Hyphomycetes are capable of entering the roots, where they seem to grow more or less parasitically. Some of the Hymenomycetes, such as Boletus elegans, are highly specialized upon certain host plants, whereas some are less specialized, such as Amanita muscaria, which are capable of forming mycorrhiza with species belonging to various genera.

${ }^{163}$ Bernard, 1909 (p. 272); Burgeff, H. Die Anzucht tropischer Orchideen aus Samen. Jena. 1911; Die Wurzelpilze der Orchideen. Jena. 1909; Schatz. Beiträge zur Biologie der Mykorrhizen. Inaug. Diss. Jena. 1910.

${ }^{154}$ Rayner, 1915 (p. 274).

${ }^{155}$ Bernard, 1909 (p. 272).

${ }^{156}$ Melin, E. Untersuchungen über die Bedeutung der Baummykorrhiza. Langmenska Kulturf. G. Fischer. 1925. Jena.

${ }^{167}$ Kauffman, C. H. Cortinarius as a mycorrhiza-producing fungus. Bot. Gaz., 42: 208-214. 1906.

${ }_{158}$ Pennington, L. H. Mycorrhiza-producing Basidiomycetes. Rpt. Mich. Acad. Sci., 10: 47. 1910.

${ }_{159}$ Rommel, L. G. Parallelvorkommen gewisser Boleten und Nadelbäume. Svensk. Bot. Tidskr., 15: 204-213. 1921.

${ }^{160}$ Melin, E. Über die Mykorrhizenpilze von Pinus silvestris L. und Picea abies (L.). Karst. Svensk. Bot. Tidskr., 15: 192-203. 1921; Jour. Ecol., 9: 254-257. 1922. 
Christoph ${ }^{161}$ obtained from Calluna vulgaris a Cephalosporium and claimed to have produced the mycorrhiza synthetically; however, his experimental work is open to criticism (Rayner). ${ }^{162}$ Ridler ${ }^{163}$ isolated from Pellia epiphylla a fungus which also belonged to the genus Phoma. Huber ${ }^{164}$ isolated from Liparis laeselii a Rhizoctonia (R. repens). A species of Rhizoctonia ( $R$. apocyanacearum) was also isolated from Vinca minor by Detemar. ${ }^{165}$ The fungus grows in the root in all directions, except the endodermis, both inter- and intra-cellularly. When the fungus penetrates into the cells, the starch content even of the neighboring cells begins to decrease. Infection of the plant can take place all the year around, but especially in March to May.

The organism studied by Detemar forms a special type of endotrophic mycorrhiza, termed "plasmoptic-mycorrhiza." This is due to the fact that some of the fungus cells undergo plasmoptysis as a result of certain antibody formation by the plants following the infection by the foreign fungus. This process is a step towards the assimilation of the fungus plasma by the plant. Vinca minor is obligately mycotrophic, two-thirds of the root system being infected with the fungus. The fungus can be readily grown on peptone and starch media.

According to Peyronel ${ }^{166}$ the organisms responsible in most instances $f_{0 r}$ thc formation of endotrophic mycorrhiza in phaenerogams, except in the case of the Orchidaceae, form branched or swollen haustoria and are considered to be true Phycomycetes (No. 115, Plate XV). Theoretical considerations led him to consider these organisms as belonging to a primitive group, which gave rise to the two divergent series, the Phycomycetes and Mycomycetes (Ascomycetes and Basidiomycetes). That group would also include Endogone, which may represent one of the phases of the biological cycles of the mycorrhizal endophyte. The vesicles of the phycomycetoid endophyte are very likely provisional stores for reserve material. Some of them may change afterward into

${ }^{161}$ Christoph, H. Untersuchungen über die mykotrophen Verhältnisse der Ericales und die Keimung von Pirolaceae. Beih. Bot. Centrbl., 32: H. 2, 115. 1921.

162 Rayner, 1922 (p. 274).

${ }^{163}$ Ridler, W. F. F. The fungus present in Pcllia epiphylla. Ann. Bot., 36: 193-208. 1922; 37: 483-488, 1923.

${ }^{164}$ Huber, B. Zur Biologie der Torfmoosorchidee Liparis Loeselii Rirh. Sitz. Ber. Ak. Wiss. Wien. (1), 130 (Ref. Detemar).

${ }^{165}$ Detemar, K. Über "Plasmoptysen" Mykorrhiza. Flora, 115: 406-456. 1923.

${ }^{166}$ Peyronel, 1924 (p. 274). 
apogamous oospores or sporangia, which remain latent for a long time and mature their spores only when environmental conditions are favorable. By means of these spores the organism spreads through the soil. The mycelium forms a network in the soil, surrounding the root system of the plant and growing from one plant to another. The phycomycete leads both a saprophytic and endophytic existence. The endophytes of orchids have no similarity to these endophytic phycomycetes, but are true Mycomycetes, perhaps Basidiomycetes. In addition to the endophytic phycomycete, most plants show that the mycelium of the latter is overgrown with the endophyte of the orchid mycorrhiza fungus. This form belongs to Rhizoctonia solani Kühn or Moniliopsis aderholdi Rühl, among the primitive basidiomycetes (Hypochnus group). Peyronel also found, in addition to these two endophytes, a certain number of saprophytic fungi living at the expense of weak or dead tissues in nearly all plants studied; these fungi belong to the genera Pythium, Fusarium, Dydymopsis and Rhizomyxa. Asterocystis radicis was found not only on the dying roots, but also regularly on those having a normal appearance, and can also be classed as a mycorrhiza fungus. Out of 150 species of phaenerogams growing in different localities and under different environmental conditions, Peyronel found the Rhizoctonia type in 135 . The phycomycetic mycelium, with which the Rhizoctonia is usually associated, develops before the Rhizoctonia, thus facilitating the penetration of the latter and making the host plant more receptive.

Melin ${ }^{167}$ differentiated between true mycorrhiza and pseudo-mycorrhiza in forest trees. The fungi of the former belong to the Hymenomycetes, including various species of Boletus, Amanita and Tricholoma, Lactarius, Cortinarius, Russula, some being more specialized than others. These form mycorrhiza with pine trees, birches, poplars, and other forest trees. Pseudo-mycorrhizas are formed by a number of common soil fungi (Mucor, Verticillium), which can penetrate the roots, when they are not infected by the true mycorrhiza; Mycelium radicis atrovirens (probably Cladosporium humifaciens) belongs to the latter group. Penicillia are indifferent to the roots. There is a competition in forest soils between the different fungi, in attacking the roots of the trees; the true mycorrhiza formers, when present, will enter the root first. The true mycorrhiza fungi (species of Boletus) grow best at pII

${ }^{167}$ Melin, E. Experimentelle Untersuchungen über die Birken und Espenmykorrhizen und ihre Pilzsymbionten. Svensk. Bot. Tidskr., 17: 479-520. 1923. 
5.0 and only poorly at $\mathrm{pH} 7.0$ and $\mathrm{pH} 3.5$; $^{168}$ this has an important bearing upon mycorrhiza formation. In neutral or slightly acid soils, these fungi are not virulent and either cannot form at all or form only with difficulty endo-and ecto- trophic mycorrhiza. The most abundant mycorrhiza of evergreens are found in soils of $\mathrm{pH} 4.0$ to 5.0. Rhizoctonia silvestris and Mycelium radicis atrovirens grow well in neutral or slightly alkaline media. When the reaction of the soil is near neutrality, pseudo-mycorrhiza will be formed. Melin succeeded in isolating a series of fungi and demonstrated that the same types of mycorrhiza are produced in pure culture as in the soil; these facts established experimentally allow a better insight into the rôle of mycorrhiza in plant nutrition and plant distribution.

For establishing whether a certain organism forms a mycorrhiza with a given plant, sand or forest humus can be used as a substrate. ${ }^{169}$ In the first case, 150 -gm. portions of pure, washed, dry sand are placed in 300-cc. Erlenmeyer flasks. Forty-nine cubic centimeters of the following medium is then added to each flask:

\begin{tabular}{|c|c|c|}
\hline $\begin{array}{l}\mathrm{NH}_{4} \mathrm{Cl} \ldots \\
\text { or }\end{array}$ & $0.50 \mathrm{gram}$ & 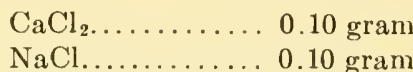 \\
\hline $\mathrm{KNO}_{3}$. & $0.95 \mathrm{gram}$ & $\mathrm{MgSO}_{4} \cdot 7 \mathrm{H}_{2} \mathrm{O} \ldots \ldots$ \\
\hline Glucose. & $0.50 \mathrm{gram}$ & $0.01 \mathrm{gram}$ \\
\hline $\mathrm{KH}_{2} \mathrm{PO}$ & $1.00 \mathrm{gram}$ & Distilled water. \\
\hline
\end{tabular}

The flasks are plugged with cotton and sterilized in flowing steam for 25 minutes on 3 consecutive days. The humus medium is prepared by saturating with water 70 grams of mixed forest humus material (upper part of slightly decomposed layer). The flasks are steriiized in steam three times, and washed twice with sterile distilled water by adding $50 \mathrm{cc}$. of water to each flask, shaking, and allowing it to rest for 24 hours, then pouring off the excess of water. This process is repeated. The contaminated cultures (examined after 14 days) are discarded.

The seeds are sterilized by moistening with water, keeping one minute in 1:1000 mercury bichloride solution, then washing in sterile water. They are then allowed to germinate upon sterile agar (1.2 per cent agar in distilled water), the individual seeds being removed from one another so that the infected seed do not infect the sterile ones. After 10 to 15 days, the germinated seeds remaining sterile are transferred by means of a sterile platinum needle to the flasks. Contaminated flasks (as shown microscopically and culturally) are discarded. The flasks are then inoculated with the cultures of the fungi in question.

${ }^{168}$ Melin, E. Über den Einflusz der Wasserstoffionenkonzentration auf die Virulenz von Kiefer und Fichte. Bot. Notiser, 1924, 38-48.

${ }^{169}$ Melin, E. Untersuchungen über die Larix-Mykorrhiza. Synthese der Mykorrhiza in Reinkultur. Svensk. Bot. Tidskr., 16: 1922. 
For the study of the rôle of fungi in the germination of seed, Knudson used a different method: 1.5 per cent of agar was added to one of the following nutrient solutions:

\begin{tabular}{|c|c|c|}
\hline & $\begin{array}{l}\text { PFEFFER'S } \\
\text { SOLUTION }\end{array}$ & SOLUTIONB \\
\hline 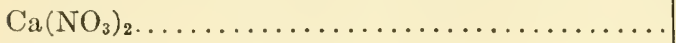 & $1.0 \mathrm{gram}$ & 1.0 gram \\
\hline $\mathrm{K}_{2} \mathrm{HPO}_{4} \ldots \ldots \ldots \ldots \ldots \ldots \ldots \ldots \ldots \ldots \ldots \ldots \ldots \ldots \ldots \ldots \ldots \ldots \ldots$ & $0.25 \mathrm{gram}$ & $0.25 \mathrm{gram}$ \\
\hline 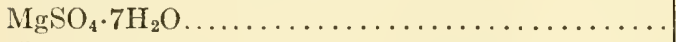 & $0.25 \mathrm{gram}$ & $0.25 \mathrm{gram}$ \\
\hline $\mathrm{KNO}_{3} \ldots \ldots \ldots \ldots \ldots \ldots \ldots \ldots \ldots \ldots \ldots$ & 0.25 gram & \\
\hline $\mathrm{KCl} \ldots \ldots \ldots \ldots \ldots \ldots \ldots \ldots \ldots$ & 0.12 gram & \\
\hline $\mathrm{FeCl}_{3} \ldots \ldots \ldots \ldots \ldots \ldots \ldots \ldots$ & $0.01 \mathrm{gram}$ & \\
\hline $\mathrm{Fe}_{2}\left(\mathrm{PO}_{4}\right)_{2} \ldots \ldots \ldots \ldots \ldots \ldots \ldots \ldots \ldots \ldots \ldots \ldots \ldots \ldots \ldots \ldots \ldots \ldots$ & & 0.05 gram \\
\hline$\left(\mathrm{NH}_{4}\right)_{2} \mathrm{SO}_{4} \ldots \ldots \ldots \ldots \ldots \ldots \ldots \ldots \ldots \ldots \ldots \ldots \ldots \ldots \ldots \ldots \ldots$ & & $0.50 \mathrm{gram}$ \\
\hline 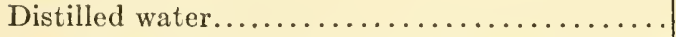 & $1000 \mathrm{cc}$. & 1000 cс. \\
\hline
\end{tabular}

The medium is placed in tubes, $180 \mathrm{~mm}$. by $18 \mathrm{~mm}$.; the tubes are plugged with cotton, autoclaved and slanted; the cotton plug is covered with a cap to prevent contamination. The seeds are sterilized in calcium hypochlorite solution (10 grams in $140 \mathrm{cc}$. distilled water, shaking well and filtering), by covering them several times in a test tube with the clear solution, for about 15 minutes. By means of a sterile platinum needle the seeds are transferred upon the surface of the sterile agar slope. The cultures are kept in moist chambers in the greenhouse shaded by cheesecloth from direct sunlight.

Rôle of mycorrhiza in the nutrition of plants. Various theories have been suggested by different investigators in an attempt to explain the rôle of the fungi in the nutrition of plants forming mycorrhiza.

1. Symbiotic action between the hyphae of the fungus and the root cells of the higher plants. Frank's ${ }^{170}$ theory was that in ectotrophic mycorrhiza the mycelial mantle takes the place and functions of the root hairs; the fungus absorbs the mineral salts and nitrogenous materials from the soil organic matter, while the host plant supplies the fungus with carbohydrates. At first, Frank claimed a similar rôle for the endotrophic mycorrhiza, but since the endophyte has little connection with the exterior of the plant, the above theory was modified to state that the plant procures the nitrogen by digesting the fungus. Stahl ${ }^{171}$ also suggested that there is a relation between the low transpiring powers of the plant and the presence of the mycorrhiza fungi in the roots, the latter supplying the former with mincral salts obtained

${ }^{170}$ Frank, 1885 (p. 271).

171 Stahl, 1900 (p. 273). 
from the soil. ${ }^{172}$ The symbiotic saprophytism was believed to be a result of the supplemental capacities of two organisms brought into nutritive contact chemotropically. ${ }^{173}$ The cells of the higher plants harboring the fungus generally show a decrease in carbohydrate and an increase in protein content. According to Bernard and Burgeff, seed infection of the embryo by the appropriate fungus is essential for the germination of orchid seeds. Knudson ${ }^{174}$ suggested, however, that the rôle of the fungus may consist merely in supplying organic matter, since the germination of the orchid seeds depends on an available supply of organic matter. When this is added in the form of certain sugars or plant extracts, germination is made possible without the aid of any fungus. The action of the fungus is ascribed to its production of enzymes which liberate products utilized by the embryo.

2. The fixation of atmospheric nitrogen by the fungi bringing about the formation of mycorrhiza. This subject has received considerable attention ${ }^{175}$ because of the important practical application of the phenomenon. Much of the earlier work, however, is largely speculative and is of little practical value. According to Rayner, ${ }^{176}$ nitrogen fixation by the endophyte of Ericaceae is demonstrated by the fact that these plants grow on poor soils deficient in available nitrogen and that pure culture seedlings of Calluna grow with marked vigor on media free from combined nitrogen. This is especially interesting, since the endophyte belongs to the genus Phoma ( $P$. radicis), which is known to be capable of fixing atmospheric nitrogen. ${ }^{177}$ Möller ${ }^{178}$ found, however, that ectotrophic mycorrhiza are mostly unable to fix any atmospheric nitrogen. The inability to fix nitrogen was also definitely established for forest trees by Melin. ${ }^{179}$

172 See also Shibata, K. Cytologische Studien über die endotrophen Mykorrhizen. Jahrb. wiss. Bot., 37: 613-684. 1902; Rexhausen, L. Die Bedeutung der exotrophen Mykorrhiza für die hoheren Pflanzen. Beitr. Biol. Pflanz., 14: 18-59. 1920; Magrou, J. La symbiose chez les plantes. Bull. Inst. Past., 20: 169-183, 217-231. 1922.

${ }^{173}$ MacDougal, D. T., 1899 (p. 275).

${ }^{174}$ Knudson, L. Non-symbiotic germination of orchid seeds. Bot. Gaz., 73: 1-25. 1922; 77: 212-219. 1924; 79: 345-379. 1925.

175 Ternetz, C. Assimilation des atmospherischen Stickstofis durch einen torf́beiwohnenden Pilz. Ber. deut. bot. Gesell., 22: $267.1904 ; 1907$ (p. 270).

${ }^{176}$ Rayner, M. C. Nitrogen-fixation in Ericaceae. Bot. Gaz., 73: 226-235. 1922.

${ }^{177}$ Duggar and Davis, 1916 (p. 270).

178 Möller, A. Mykorrhizen und Stickstoffernährung. Ber. deut. bot. Gesell., 24: 230-234. 1906.

179 Melin, 1925 (p. 276). 
3. The fungi may take an active part in the decomposition of the organic matter in the soil, thus making the nitrogen available for the growth of higher plants, first suggested by Frank and later by Shanz and Piemeisel, ${ }^{180}$ who made a detailed study of the phenomenon of fungus fairy rings. This is borne out particularly by the fact that mycorrhiza are abundant in soils rich in organic matter; many of the fungi, as the Basidiomycetes, found to be the causative agents of the true mycorrhiza are capable of decomposing difficultly soluble organic substances, such as woody tissues. They need not necessarily absorb the organic matter but merely decompose it, liberating the minerals and nitrogen, which are absorbed by the plant. According to Melin, the rôle of mycorrhiza in the nutrition of trees and other plants growing in peat (raw-humus), and similar soils, consists in obtaining the nutrients from the soil organic matter and supplying it to the plants. In soils with active nitrification, mycorrhiza formation is not essential for the forest trees. Czapek was also of the opinion that the fungus obtains, at least partly, its nutrients from the soil and not from the plant. Burgeff found that plants infected with fungi were favorably influenced in their ability to assimilate carbohydrates from the soil, when the atmosphere was free from $\mathrm{CO}_{2}$. It thus became the general opinion of the investigators ${ }^{181}$ that the fungus provides the plant with nitrogen. The fungus obtains its nitrogen from the soil organic matter, or it synthesizes its proteins from the inorganic salts of the soil. The plant is known to digest the fungus, just as in the case of insectivorous plants. This intracellular digestion, which is conspicuous in the case of many plants, may be merely a measure of resistance on the part of the vascular plants, but since the products of digestion disappear, it may be assumed that the plants absorb them (Nos. 118, 119, Pl. XV).

4. A certain amount of evidence has been submitted to indicate that the fungus may sometimes be injurious to the host plant. Gallaud considered the fungus to lead an independent existence in the root tissues, deriving all its food from the host plant and being an "internal saprophyte." Bernard actually considered the fungus to be a parasite which is subsequently checked in its development by the action of the root cells; this confers a certain immunity upon the infected plant, the process being one of phagocytosis. According to Detemer, the root

${ }^{180}$ Shanz, H. L., and Piemeisel, H. L. Fungus fairy rings in Eastern Colorado and their effect on vegetation. Jour. Agr. Res., 11: 191-246. 1917.

${ }^{181}$ Weyland, H. Zur Ernährungsphysiologie mykotropher Pflanzen. Jahrb. Wiss. Bot., 51: 1-80. 1912. 
growth of the plant is influenced injuriously by the infection of the fungus. The fungus decomposes starch readily and its growth is dependent on the presence of the roots of the plant. When the plant is grown in culture, uninfected by the fungus, it will thrive better than when grown under equal conditions in the presence of the fungus. Boulet ${ }^{182}$ found endotrophic mycorrhiza on the roots of various fruit trees and suggested that the fungus appears to live as a parasite on the host; this was believed to have generally a beneficial effect on the host, except when the essential organs of the roots are attacked. The possible parasitism of mycorrhiza (to Picea), under certain conditions, has been suggested also by Rexhausen. W. B. McDougal ${ }^{183}$ found that the fungi (belonging to the genus Cortinarius) which form ectotrophic mycorrhiza on the roots of Picea rubra are of no benefit to the trees concerned; they form no symbiotic associations with the trees, but are instances of parasitism of fungi on the roots of the trees; no harm, however, may be caused by this parasitism. This is of course merely a theoretical consideration.

This obligate relation between mycorrhiza and host plant is certain for such plants as orchids and Ericaceae. The mycorrhiza are considered in this case to be not parasitic forms but true mutualistic symbionts. The trees are not injured, whereas the fungi develop better than in pure culture, and are finally digested by the active juices of the plant. Dufrenoy ${ }^{184}$ suggested that symbiosis is a form of parasitism, in which equilibrium exists between the invading power of the fungus and the resisting power of the host; this is profitable to both, so long as it is maintained, but eventually it is a disadvantage or death to either one, if sufficient advantage is gained by the other symbiont. Rayner ${ }^{185}$ also considered that an equilibrium becomes established between the attacking mechanism of the fungus and the protective mechanism of the plant. When this equilibrium is broken down, as in the growth of the plant under unfavorable conditions (Calluna vulgaris

182 Boulet, V. Sur les mycorrhizes endotrophes de quelques arbres fruitiers. Compt. Rend. Acad. Sci., 150: 1190-1192. 1910.

${ }_{183}$ MeDougal, W. B. On the mycorrhizas of forest trees. Amer. J. Bot., 1: 51-74. 1914. Mycorrhizas of coniferous trees. Jour. Forestry, 20: 255-260. 1922 .

${ }^{184}$ Dufrenoy, J. The endotrophic mycorrhiza of Ericaceae. New Phytol., 16: 222-22s. 1917.

${ }^{185}$ Rayner, M. C. The biology of Calluna vulgaris. II. The calcifuge habit. J. Fcol., 9:60-74. 1921; The nutrition of mycorrhiza plants: Calluna vulgaris. Brit. Jour. Exp. Biol., 2: 265-292. 1925. 
growing in a calcareous soil), symbiosis changes to parasitism of the fungus upon the plant tissues. Under these conditions, the fungus, which never forms pycnidia in nature when associated with healthy plants, produces these bodies freely in the stomata which invest the roots of the unhealthy seedlings. A case of symbiosis whereby the higher plant depends completely upon the presence of the endophytic fungus has been recorded for Gastrodia elata among the orchids. ${ }^{186}$ This non-chlorophyllous plant is parasitic upon the fungus Armillaria mellea, by digestion of the mycelium by the cells of the root, the relation being obligate for the full development of the plant; the fungus itself is parastitic in habit and at first invades the tuber of the orchid. According to Rayner symbiosis in the case of mycorrhiza is considered to imply not a reciprocal relation involving mutual benefit to the participants, but, as defined by de Bary, the living together of dissimilar organisms. According to Peyronel, the phycomycetoid endophyte grows as vigorously under saprophytic conditions as in symbiosis with the plant; it continues its development, after the death of the plant, at the expense of the dead cortical tissues of the roots or organic matter in the soil.

${ }^{186}$ Kusano, S. Preliminary note on Gastrodia elata and its mycorrhiza. Ann. Bot., 25: 521-524. 1911; Jour. Coll. Agr. Tokyo, 4: 1-66. 1911. 


\section{CHAPTER XII}

\section{Soll Actinomyces}

General considerations. The actinomyces, or ray fungi, are a group of organisms present in great abundance in nature, particularly in the soil. In the case of some soils, as many as 40 to 60 per cent of the colonies developing on the common agar or gelatin plate are actinomyces. Their abundance and importance in the soil was rather overlooked until the early part of this century (Hiltner and Störmer, Beijerinck), while a systematic study of their occurrence and rôle in the soil appeared only with the work of various investigators begun about 1913 . This was due primarily to the fact that these organisms grow only slowly on the agar plate or on other common nutritive media. They form colonies which are, at early periods of incubation, hardly distinguishable from bacterial colonies. The fine mycelium, which breaks up readily into a number of fragments during the process of staining, has also contributed to the failure of a proper study of the morphology of this group of organisms and their classification. The actinomyces are characterized by extreme uniformity of growth on complex organic media and extreme variability of growth on synthetic media. On nutrient agar, potato agar and other organic media, various organisms which are otherwise distinctly different will look alike, as indicated by pigment production, intensity of pigmentation, etc. When synthetic or other specific media are used for purposes of differentiation, organisms closely related show distinctive cultural differences. Early workers in soil bacteriology grouped all the actinomyces into two or more large classes, characterized by pigment formation (chromogenic species) or formation of white aerial mycelium on nutrient agar. Hundreds of new species can be described and differentiated by minor cultural differences, such as intensity of pigmentation, rapidity of liquefaction of gelatin or starch, formation of zones on specific media, etc. It is only very recently that an attempt has been made to separate the actinomyces group into definite species and even genera, on the basis of morphological characters.

General description of the genus Actinomyces. Actinomyces Harz can be readily recognized and easily differentiated from the bacteria and other fungi. The genus is characterized by the formation of a 
monocellular mycelium, composed of hyphae, which show true branching, like that of higher fungi. The hyphae are rather long and 0.5 to $0.8 \mu$ in diameter (limits 0.3 to $1.2 \mu$ ). The mycelium develops either in the substrate or on the surface, in the form of an aerial growth. The aerial mycelium readily breaks up into short fragments, which may look like bacterial rods and also resemble true bacteria in their protoplasmic properties. When examined directly upon the agar or in a hanging drop, or when properly fixed before staining, the aerial mycelium will be found to consist of very fine, characteristic, long or short branching hyphae with the distinct spore bearing hyphae (only the closely related Mycobacteria may give a somewhat similar picture).

The spores, or reproductive conidia, are produced by a simultaneous division of the protoplasm in the sporogenous hyphae, progressing from the tip towards the base. They possess a greater power of resistance

\section{PLATE XVI}

\section{Soil Actinomyces}

120. Cross section of a young Actinomyces "colony" upon agar, $\times 65$ (from Lieske).

121. Spore germination and consecutive stages of mycelial development of an Actinomyces (from Lieske).

122. Young mycelium of an Actinomyces, growing 5 days at room temperature, $\times 400$ (from Lieske).

123. Actinomyces (XIII), with a straight type mycelium; long mycelium, little branching: $a$ and $b$, long, unbranched hyphae, showing very slight spiral tendency; $c$, chain of spores; $d, e$, portions of aerial mycelium showing branching (from Drechsler).

124. Actinomyces griseus, with a short mycelium and abundant branching: $a, b, c$, portions of aerial mycelium; $d, e$, spores germinating with one and two germ tubes respectively (from Drechsler).

125. Actinomyces reticuli, showing the formation of sporogenous hyphae in knot-like groups: $a$, formation of septa in lower sporogenous branches; $d$, formation of secondary branches (from Waksman).

126. Actinomyces (IX), showing the narrow closed fist type: $a, b$, portions of aerial mycelium, the spiral termination of which are converted into chains of uninucleated spores; $c$, portion of aerial mycelium with septa in axial filament above insertions of some sporogenous branches; $d$, sporogenous branch; $e, f$, germinating spores (from Drechsler).

127. Actinomyces scabies, showing open spiral type: $a, b$, portions of aerial mycelium, some lateral elements bearing secondary branches, developed successively; $c$, successive stages in development of the sporogenous branch, $c^{1} x$ and $c^{1} y$ representing either alternative or probably successive stages (from Drechsler). 
PI.ATE XVI

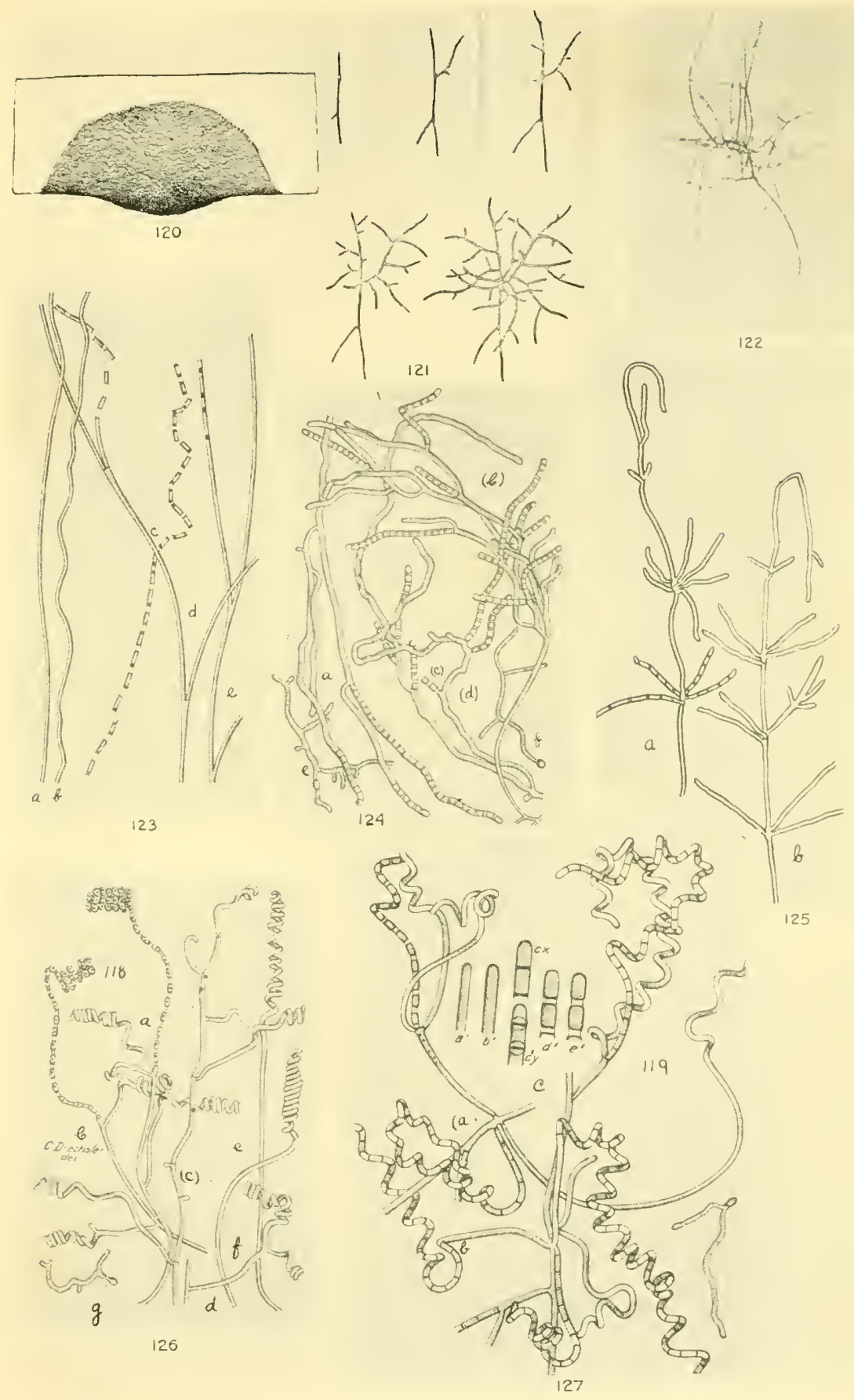



than the mycelial filaments. They resemble bacteria in size, shape and staining properties, are 0.5 to 1.5 microns in diameter, 1 to 2 microns long, oval to rod-shaped. All actinomyces, particularly in young preparations, are gram-positive. In liquid media, they never cause a turbidity, but grow either on the surface of the medium or in the form of flakes or small colonies throughout the medium; they may sink, especially the flakes, to the bottom of the container or adhere to the glass of the tube. The surface colonies may grow together to form a smooth or wrinkled membrane. The colonies on solid media are tough, leathery, smooth or wrinkled, often growing high above the surface of the medium, and are broken up only when appreciable effort is applied. When transferred to suitable media, almost all the spores germinate, while only a small part of the fragments of mycelium do so. The older the mycelium, the more reduced is the germinating power of the individual fragments. ${ }^{1}$

The aerial mycelium may be white, grey, red, yellow, brown, etc. The aerial hyphae may be short, giving the growth a chalky appearance, long and forming a thick mat over the surface of the growth, or in the form of a fine network. The colonies are often brilliantly colored; some species produce soluble pigments which vary in color and intensity in accordance with the effect of the composition of the medium. Most species are characterized by the production of a sharp peculiar odor characteristic of the soil (earthy odor). All soil species liquefy gelatin; the rapidity of liquefaction depends upon the nature of the organism and previous cultivation. Most of them produce active diastatic enzymes; fewer produce invertase; still fewer produce tyrosinase which enables them to convert the tyrosin of the protein molecule into dark colorerl melanins.

Terminology and systematic position. More names have been applied to this genus than to any other group of microorganisms. Among these, in addition to the proper designation "Actinomyces," the terms Leptothrix, Cladothrix, Oospora, Oidium, Discomyces, Nocardia, Streptothrix and Microsiphonales have been used. The terms Leptothrix and Cladothrix designate two groups of higher bacteria, having nothing in common with the Actinomyces. Leptothrix consists of chains of rodshaped bacteria surrounded by a thick gelatinous sheath, which gives them the appearance of threads, not forming any true or false branching. Cladothrix is similar to Leptothrix, forming somewhat thicker threads

1 Orskov, J. Investigations into the morphology of the ras fungl. Aevin and Munksgaard. Copenhagen. 1923. 
and possessing false branching. The individual cells may, in the case of both Leptothrix and Cladothrix, leave the sheath and take the form of swarmers possessing flagella. When a swarmer attaches itself to an old thread and develops into a new thread, false branching arises. Oospora and Oidium are names of true fungi, which have nothing in common with the actinomyces. The term Discomyces was used in 1875 in an imperfect description of actinomycosis of cattle. Nocardia was used in 1889, long after the term Actinomyces had been introduced by Harz in an accurate description of the cattle disease; that term is, therefore, without any scientific foundation. A number of investigators still adhere to these terms, especially to that of Discomyces ${ }^{2}$ and Nocardia. ${ }^{3}$ The term Streptothrix, which has been used very often in designating true actinomyces, is invalid due to the fact that it was preempted by Corda, in 1839, for a true fungus.

The term Actinomyces was used first by $\mathrm{Harz}^{4}$ in 1878 in describing the actinomycotic disease of cattle. He applied this term, which means "ray-fungus," because of the formation of bottle-shaped and ray-like swellings of the threads of the Actinomyces granules in the actinomycotic disease of cattle. This term has been accepted in all the leading recent important investigations on this group of organisms, both pathogenic and saprophytic forms. ${ }^{5-10} \mathrm{~A}$ detailed discussion of the terminology of this genus is found elsewhere. ${ }^{11-13}$

${ }^{2}$ Merrill, E. D., and Wade, H. W. The validity of the name Discomyces for the genus of fungi variously called Actinomyces, Streptothrix and Nocardia. Phillip, Jour. Sci., 14: 55-69. 1919.

${ }^{3}$ Mello, F. de, and Fernandes, J. F. S. A. Révision des champignons appartenant au genre Nocardia. Mem. Asiatic Soc. Bengal, 7: 103-138. 1919.

${ }^{4}$ Harz, C. O. Actinomyces bovis, ein neuer Schimmel in den Geweben des Rindes. Jahresber. Tierarzneischule, München, 1877-78, 125-140.

${ }^{5}$ Krainsky, A. Die Aktinomyceten und ihre Bedeutung in der Natur. Centrbl. Bakt. II, 41: 639-688. 1914.

${ }^{6}$ Waksman, S. A. Cultural studies of species of Actinomyces. Soil Sci., 8: 71-215. 1919.

${ }^{7}$ Conn, H. J. Soil flora studies. V. Actinomycetes in soil. N. Y. Agr. Exp. Sta. Tech. Bul. 60, 1917.

${ }^{8}$ Drechsler, C. Morphology of the genus Actinomyces. Bot. Gaz., 67: 65-83, 147-168. 1919.

${ }^{9}$ Lieske, R. Morphologie und Biologie der Strahlenpilze. Leipzig. 1921.

${ }^{10}$ Orskov, 1923 (p. 287).

${ }^{11}$ Lehmann and Neumann, 1921 (p. x).

${ }^{12}$ Lachner-Sandoval, V. Über Strahlenpilzc. Strassburg, Diss. 1898.

${ }^{13}$ Breed, R. S., and Conn, H. J. The nomenclature of the Actinomycetaceae. Jour. Bact., \&: 5\$5-602. 1919; 5: 489-490. 1920. 
The systematic position of actinomyces has not been satisfactorily defined. These organisms are classified more often with bacteria, ${ }^{14}$ in some cases with the fungi (among the Hyphomycetes, under Oospora, ${ }^{15}$ or as a Mucedineous group with tendencies towards an erect Isariod habit ${ }^{8}$ ) and in some cases as a separate group forming the connecting link between the bacteria and the fungi..$^{9,11,16}$ The actinomyces may look like true bacteria in ordinary stained preparations, due to the fact that the mycelium is very fine and is readily broken up into various fragments, and the conidia look very much like bacterial cells. In unstained preparations, however, such as are used for the direct examination of the colony, or when stained by some special method, ${ }^{8,17}$ the branching and manner of spore formation can be seen to resemble that of a true fungus.

Physiologically, the actinomyces are differentiated from both fungi and bacteria. The fungi are characterized, as a rule, by having greater resistance to acids than the bacteria. The actinomyces, with some few exceptions, are even more sensitive to acids than the majority of the bacteria developing on the common plate. A large number of bacteria are characterized by the formation of various gases from carbohydrates; the actinomyces are not known to form any gas from carbohydrates except $\mathrm{CO}_{2}$, which is a product of the energy metabolism of most living forms; in this respect they behave like the fungi. The apparently close relationships which the actinomyces have with both bacteria and fungi led to the assumption that the actinomyces should be looked upon as the ancestral form of both bacteria and fungi, according to the following scheme:

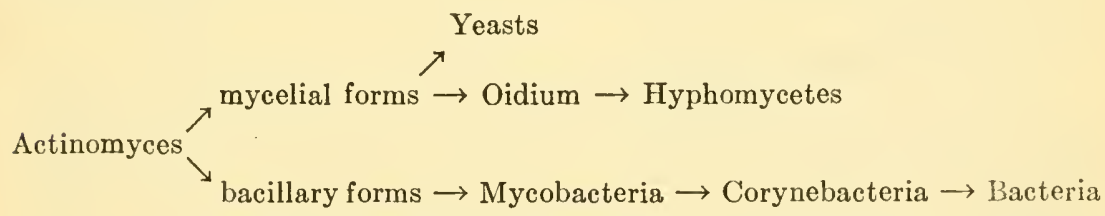

The fact seems to be definitely established that the actinomyces are not bacteria. But they cannot be classified unreservedly with the fungi,

${ }^{14}$ Bergey, 1923 (p. x).

${ }^{15}$ Savageau and Radais. Sur les genres Cladothrix, Streptothrix, Actinomyces. Ann. Inst. Past., 6: 242-273. 1892.

${ }^{16}$ Claypole, E. On the classification of the streptothrices, particularly in their relation to bacteria. Jour. Exp. Med., 17: 99-116. 1913.

${ }_{17}$ Waksman, S. A., and Curtis, R. E. The actinomyees of the soil. Soil Sci., 1: 99-134. 1916; also Waksman, 1919 (p. 288). 
particularly with the Hyphomycetes which is a rather loose conglomerate of various forms. They should be looked upon as a group of fungi, to be classified separately from the other groups, till their exact systematic position has been definitely established. However, the property of acid-fastness correlated with a certain type of pathogenicity (formation of tubercles) and with cross immunity reactions with the acid fast bacteria, points to a certain relation, of at least some pathogenic forms, to the bacteria.

Species differentiation. Large numbers of actinomyces have been described by various investigators. ${ }^{9,17}$ The larger the number of forms collected, the more difficult is the division into species. The variability of these organisms is such that out of a dozen isolations from a plate not more than two or three may be alike. Even forms recognized to be alike on one medium will be found to be different when grown on another medium. Sometimes two forms found to be alike on several media, will be found to show distinctive characters on further study. ${ }^{18}$ This is especially true of the cultural and biochemical characters and to some extent even of the morphology of the organisms.

It is important first to obtain an absolutely pure culture of the organism. Even then, an attempt to designate a species of actinomyces by the sum total of its morphological and physiological characters may not give very satisfactory results. It is best to classify the organisms into groups, defined by a sum total of certain definite morphological and physiological characters. The amount of variability within the group and the amount of overlapping between two groups is something that cannot be definitely established and must be left to the judgment of the investigator.

The species differ primarily in the length of the mycelium, type of aerial mycelium, absence or presence of spores, method of spore formation, shape and color of colony, formation of soluble pigment, oxygen requirement, production of diastatic and proteolytic enzymes and a number of other morphological and physiological characters. These vary in quantity as well as quality, not only under the influence of various environmental conditions but even on continued cultivation under the same conditions. Not only the soluble pigment may be lost or changed in color, but the color of the aerial mycelium may change and even the very property of forming aerial mycelium may be lost.

An important advance in the study of this group has been the introduction of synthetic media. A great deal of the variability mentioned

${ }^{18}$ Conn, H. J. The use of various culture media in characterizing actinomycetes. N. Y. Agr. Exp. Sta. Tech. Bul. 83, 1921. 
by Lieske was due to the use of non-synthetic nutrient agar, which is variable in composition. Two media made up exactly alike, but differing merely in the amount of boiling, period of sterilization, a slight change in ratio between the carbon and nitrogen sources, or in reaction and concentration of nutrients, will show distinctive differences for the various organisms. By growing these on synthetic media, with due allowance to variability, certain definite characters may be established.

Methods of study. For determining the abundance of actinomyces in the soil, the general media used for the determination of numbers of bacteria can be employed (p. 16). For the study of cultural and morphological characters, several media have been suggested:

1. Glucose agar: 5

10 grams glucose

0.5 gram $\mathrm{K}_{2} \mathrm{HPO}_{4}$

0.5 gram asparagine

15 grams agar

$1000 \mathrm{cc}$. distilled water

2. Malate-glycerin agar: $:^{5,7}$

10 grams calcium malate

0.5 gram $\mathrm{NH}_{4} \mathrm{Cl}$

0.5 gram $\mathrm{K}_{2} \mathrm{HPO}_{4}$

10 grams glycerin

15 grams agar

1000 cc. distilled water

Reaction adjusted by means of

$\mathrm{NaOH}$ to $\mathrm{pH}=7.0$

3. Citrate-glycerin agar: ${ }^{7}$

Same as 2, except that calcium citrate is used in place of malate
4. Czapek's agar: ${ }^{6}$

2 grains $\mathrm{NaNO}_{3}$

$1 \mathrm{gram} \mathrm{K}_{2} \mathrm{HPO}_{4}$

0.5 gram $\mathrm{MgSO}_{4}$

0.5 gram $\mathrm{KCl}$

0.01 gram $\mathrm{FeSO}_{4}$

30 grams sucrose

15 grams agar

1000 ce. distilled water

5. Starch agar: ${ }^{6}$

10 grams starch is suspended in 800 cc. of water and boiled down to 500 ec. 500 cc. water to which are added 1 gram $\mathrm{K}_{2} \mathrm{HPO}_{4}, 1$ gram $\mathrm{MgSO}_{4}, 1$ gram $\mathrm{NaCl}, 2$ grams $\left(\mathrm{NH}_{4}\right)_{2} \mathrm{SO}_{4}, 3$ grams $\mathrm{CaCO}_{3}$,

10 grams agar. The two solutions are mixed and tubed.

6. Gelatin:

15 per cent Gold Label gelatin in distilled water.

The first four media are used for the study of general cultural characters of the organisms and are well suited for morphological studies; the starch and gelatin media supply information on two of the most important physiological properties of the organisms, namely the diastatic and proteolytic.

For microscopic examinations, one of the two following methods may be used:

1. Method of Henrici: ${ }^{19}$ Melted and cooled agar is inoculated with the specific organism and spread in a thin film on flamed slides, which are then incubated in

${ }^{19}$ Personal communication. 
a sterile moist chamber. After growth has taken place, the slides are dried, fixed in alcohol and stained. 'The entire colony, with both vegetative and aerial mycelium, ean thus be examined in an undisturbed condition.

2. Method of Drechsler: The organism is grown on a synthetic medium and, when the culture is fully developed, the whole colony is cut from the agar and removed, as carefully as possible, from the tube or plate. A slide smeared with albumin fixative is now brought into firm contact with the surface mycelium and then separated from it, precautions being taken to avoid any sliding of the two surfaces on each other. If the growth is not too young, the upper portions of the aerial mycelium will be left adhering to the slide without any series disarrangement; killing and fixation may be effected at once. The material is then stained and mounted in balsam. Preparations, in which the spore chains have commenced to disintegrate, are impaired by the large masses of free spores. The most convenient fixative agent is 95 per cent alcohol. As a stain, Maidenhain's iron-alum haemotoxylin is good for protoplasmic structures. Delafictds haemotoxylin, allowed to act for 24 hours with the proper degree of decolorization, yields deeply stained, clear preparations showing distinctly the vacuoles, metachromatic and nuclear structures, and septa.

Nature of growth on artificial media. The term colony is used incorrectly in designating a mass of growth of an actinomyces, since it is merely a mass of mycelium developing out of a single spore, and not a colony in the sense of bacterial growth. Each spore or piece of mycelium separated from the colony is capable of individual existence, developing into a new colony. The single-celled colony of an actinomyces is characteristic and is easily distinguished from that of bacteria or fungi. It is usually round and develops in the form of a semi-circle into the medium (No.120, Pl.XVII). The colonies are mostly compact, leathery, adhering to the medium, the surface being either flat or elevated; the outer zone is smooth, round as seen with the naked eye, and has a fringe of minute hyphae projecting for a short distance into the medium when observed under the low power. The surface is usually dry and often presents a conical appearance; it is either free from any aerial mycelium, or covered with a chalky (mealy, mildewy) white, drab or grey aerial mycelium, or with an abundant cottony, fuzzy, white, red or grey aerial mycelium.

The subsurface growth of different organisms is little differentiated from one another, being usually of white-greyish or yellowish color; but the surface growth and the subsurface growth which may develop up to the surface, have a characteristic appearance on synthetic media. The growth of some organisms presents a smooth surface, while others have a much folded, or lichnoid surface; still others form a fine network on the surface. These characters are not constant but change with the composition of the medium and age of culture even on artificial culture media. 
Another characteristic of the growth of some species is the formation of "fairy rings" consisting of concentric spore-bearing rings and sporefree rings disposed in zones; the zones are also formed in the spore-free colony. It has been suggested ${ }^{20}$ that ring formation by fungi is a result of diffusion of injurious substances present or formed in the medium or due to the action of light, which produces a change in transpiration and temperature. No ring formation by actinomyces could take place as a result of changing periodically the environmental conditions.

Vegetative mycelium. The vegetative growth consists of a mycelium composed of profusely branching hyphae (Nos. 121-122, Pl. XVI), the terminal growing portions of which are densely filled with protoplasm. The vacuoles increase in size towards the center of the thallus. They are possibly associated with the presence of metachromatic granules which are often mistaken for micrococci or bacterial endospores. The actinomyces may be divided into two groups on the basis of the length of the hyphae: (1) those forming long, abundantly branching hyphae and (2) those which show on the slide only short unbranching pieces of mycelium or rods. According to Lieske, the aerobic forms, both spore-forming and non-spore forming, growing fast into the substratum, belong to the first group, while the anaerobic pathogenic forms are included in the second. The composition of the medium greatly influences the length of the hyphae so that, with 20 per cent of cane sugar in the medium or in strongly alkaline media, a long mycelial species was found to form a very short mycelium.

The vegetative mycelium is usually infrequently and irregularly septated. While in some forms transverse walls appear with somewhat greater frequency, there are none in which septation approaches any pronounced degree of regularity or closeness. The branches are formed by the elongation of lateral buds arising some distance back from the growing point of an axial filament. The branch thus produced gives rise to secondary branches by lateral proliferation. ${ }^{21}$ In addition to the typical monopodial branching, true dichotomy may occasionally occur. ${ }^{22}$ In old cultures, certain swellings of the terminal ends of the hyphae are observed; these may also be formed under abnormal growth conditions, as in concentrated media or in the presence of substances like caffeine.

${ }^{20}$ Munk, M. Bedingungen der Hexenringbildung bei Schimmelpilzen. Centrbl. Bakt. II, 32: 353-375. 1912. Biol. Centrbl., 34: 621. 1914.

${ }^{21}$ Macé, E. Sur les caractères de culture du Cladothrix dichotoma. Compt. Rend. Acad. Sci., 106: 1622. 1888.

${ }^{22}$ Neukirch, H. Über Strahlenpilze. II, 1902. 
These swellings are to a degree similar to the tubercles formed by pathogenic actinomyces in the animal body. These formations (so-called involution forms) cannot serve as a criterion for the separation of the organisms.

The acid-fast staining reaction cannot serve for the differentiation of soil actinomyces. In the case of pathogenic forms, the property seems to be quite constant as long as the organisms are growing in the tissues of the infected animals.

Spore bearing mycelium. Most actinomyces produce an aerial mycelium on suitable substrates either in the form of a mat of fructifications or numerous erect sporodochia (coremia). In any case each individual fructification represents a well characterized sporogenous apparatus, consisting of a sterile axial filament bearing branches in an open racemose or dense capitate arrangement. The primary branches may function directly as sporogenous hyphae, or may produce branches of the second and higher orders. In the latter case sporogenesis is confined to the terminal elements and the hyphal portions below the points of attachment of branches remain sterile.

The morphology of the spore-bearing hyphae of the various actinomyces exhibits distinct individuality and can readily serve as a basis for specific differentiation. The specialized, sporogenous hyphae are distinguished from the sterile hyphae of the aerial mycelium at an early stage of their development. While the diameter of the sterile mycelium which arises through the elongation of the growing filament tip shows very little subsequent increase in thickness, the sporogenous hyphae are in the beginning thinner than the axial hyphae from which they are derived. Increase in thickness of the sporogenous hyphae follows after the final linear extension has been attained. The final diameter of the sporogenous hyphae may be less or appreciably more than that of the vegetative hyphae.

Orskov suggested the division of actinomyces into three groups.

1. Sporogenie fungi. The spores develop into a unicellular substrate mycelium that does not divide spontaneously. Out of this mycelium arises an aerial myeelium which later divides by the breaking up of the protoplasm into regularly sized parts. These are separated from one another by constriction of the thread membrane between the individual elements. They grow in the form of fiakes in liquid media, usually at the bottom. The name Cohnistreptothrix was suggested for this group.

2. An initially undivided substrate mycelium is formed with an early development of aerial hyphae. Both substrate and aerial mycelia divide spontaneously into segments. There is early surface growth on liquid media. It is suggested to reserve the name Actinomyces for this group. 
3. A unicellular delicate branching mycelium, at the extreme tips of which single oval spores are formed. There is growth in liquid media in the form of small firm grains at the bottom and along the glass. The name Micromonospora is suggested for this group.

A classification found very convenient for the study of soil actionmyces is tentatively suggested here. It is based on the formation of sporogenous hyphae.

1. Presence of substrate mycelium alone and no aerial mycelium formed on synthetic or organic media.

2. The aerial mycelium consisting of very long filaments, rarely branching and mostly sporogenous almost to the point of origin in the nutritive mycelium, without any coiling. This group can be subdivided into two sub-groups: (a) long mycelium and little branching (No. 123, Pl. XVI); (b) short mycelium and abundant branching (No. 124, Pl. XVI).

3. Maturation of the sporogenous hyphae associated with the formation of characteristic spirals. A flexuous habit of the young filament early manifesting the tendency towards the coiling condition which becomes more definite with continued elongation. This group can be also divided into sub-groups on the basis of the obliquity of the spiral, diameter of turns, construction with reference to the dextrorse and sinistrorse condition (constant characters, according to Drechsler). The spirals range from open (No. 127, Pl. XVI), barely perceptible turns to strongly compressed spirals (No. 126), so that the adjacent turns are in continuous contact. The number of turns ranges from two or three to twenty or more.

4. Sporogenous hyphae formed in knot-like groups of three or four along a central hypha (No. 125, Pl. XVI).

Group 3 is most abundant in the soil and is, therefore, described in most detail. The representatives of this group form sporogenous hyphae ranging from the straight mycelium with a barely perceptible waviness of group 2 to the strongly compressed spirals, resembling a closed fist. The diameter of the spirals is usually somewhat in an inverse ratio to the number of turns characteristic of the species. It must be noted here, however, that the nature and composition of the medium greatly influence the morphology of the organisms. Species belonging to group 4 (Act. reticuli) when grown on Czapek's agar, are found in group 3 when grown on nutrient agar or even certain inorganic media.

By comparing the relation of the sporogenous branches to each other and the axial filaments, Drechsler noted two main types approaching each other in apparently intermediate forms, but quite distinct at the extremes: (a) erect dendroidic type in which the sequence of development of the sporogenous hyphae is successive; fructification starts from a single erect hypha with a spiral termination; sporogenesis commences 
at the tip by the insertion of regularly spaced septa, and proceeds downward toward the base of the filament; (b) prostate, racemose type in which development of fructifications is more nearly simultaneous. In most species, however, both types are combined.

The various species are usually characterized by clearly defined septation and have been separated by Drechsler into three different groups, on the basis of the disposition of their septa and development of their spores.

In the first group, the cross walls in the sporogenous hyphae remain without any very pronounced change and continue to separate the adjacent cells until they have developed into a chain of mature contiguous spores. The insertion of these septa progresses from the tip toward the base and does not break the physiological continuity of the hyphae. Food material is, apparently, readily transported through these septa to the young spores at the termination, since the spores increase in size and may deposit a wall of measurable thickness.

In the second group the septa apparently split into halves, which are then drawn apart by the longitudinal contraction of the individual protoplasts.

In the third group the cross-walls first undergo a decp constriction which, by involving the ends of the young cylindrical spores, gives to the latter an elongated ellipsoidal shape. The constricted septum now gradually loses its staining properties, and appears to become slightly drawn out in a longitudinal direction. A preparation stained with Delafield's haematoxylin usually shows many old spore chains in which the individual spores are thus connected by hyaline isthmuses. Occasionally an isthmus may be found with a remnant of the old deep staining septum still unchanged in its center.

Beyond these three types of sporulation another must at least be provisionally recognized, in which septa are either absent from the developing sporogenous hyphae or are not demonstrated by the use of ordinary stains. The protoplast appears to contract at regular intervals, yielding a series of non-contiguous spores, held together for a time by the connecting segments of evacuated filament wall.

The germination of the spores takes place in dilute nutrient solutions. The spore first swells, then one to four germ tubes are produced. The number of germ tubes is more or less characteristic of the species.

Utilization of carbon compounds by actinomyces as sources of energy. Various species of actinomyces utilize a number of sugars and higher alcohols as sources of energy, with inorganic sources of nitrogen, especially glucose, starch, maltose and glycerol. Lactose, sucrose and inulin are utilized to a less extent, depending upon the ability of the organism to form the corresponding enzyme. Arabinose, mannite 
and cellulose ${ }^{26}$ serve as good sources of carbon only for certain species. ${ }^{23}$ Various organic acids, such as succinic, malic, tartaric and citric, are well utilized, but formic, acetic, propionic, butyric, valerianic, lactic, benzoic and oxalic are not well utilized. ${ }^{24}$ Proteins and amino acids can readily be used as sources of carbon. ${ }^{25}$ Lieske $^{27}$ employed a solution of 1 per cent urea, traces of $\mathrm{K}_{2} \mathrm{HPO}_{4}$ and $\mathrm{MgSO}_{4}$ and 2 per cent of the corresponding carbon source in distilled water. He found that the aerobic, saprophytic strains utilized maltose, lactose, levulose, dextrin, glucose, glycerin, glycogen, inulin, mannite, asparagine, human blood serum, and sucrose with decreasing efficiency in the order named. Only one of the two strains utilized starch and none utilized cellulose. Failure to obtain growth with cellulose is more often due to the fact that the proper method has not been employed. Utilization of cellulose should be tested on the agar plate ${ }^{28}$ with reprecipitated cellulose or by adding cellulose to sterile soil. The same is true, to a less extent, of the utilization of starch which was found to be one of the best sources of energy for the majority of actinomyces (except a few human pathogenes). Some strains utilize ethyl and methyl alcohol and, to a small extent, tannin. Amygdalin, caffeine, sodium soap and potassium acetate may also be assimilated. ${ }^{27}$

Actinomyces can multiply in sterile butter fat; growth is accompanied by a definite increase in acidity. ${ }^{29}$ By the use of a modification of Eijkman's method, it was demonstrated that a large number of actinomyces are able to produce fat splitting enzymes. ${ }^{27}$ This was accomplished by adding 1-3 per cent of the fat to the molten agar, shaking well, pouring plates, then inoculating. On adding an indicator, such as litmus or brom phenol blue, no acidity could be indicated. The fatty acids are neutralized as can be reaclily demonstrated by the formation of crystals

${ }^{23}$ Waksman, S. A. Studies in the metabolism of actinomycetes. II. Carbon metabolism. Jour. Bact., 4: 307-330. 1919.

${ }^{24}$ Salzmann, P. Chemisch-physiologische Untersuchungen über die Lebensbedingungen von zwei Arten denitrifizierender Bakterien und der Streptothrix odorifera. Diss. Königsberg. 1901.

${ }^{25}$ Münter, F. Über Aktinomyeeten des Bodens. Centrbl. Bakt. II, 36: 365-3S1. 1913.

${ }^{26}$ Krainsky, A., 1914 (p. 288). On the decomposition of cellulose by microorganisms. Zhur. Opit. Agron., 14: 255-261. 1913.

${ }^{27}$ Licske, 1921 (p. 288).

${ }^{28}$ Scales, 1915 (p. 265).

${ }^{29}$ Jensen, O. Studien über das Ranzigwerden der Butter. Centrbl. Bakt. II, 8: 171 . 1902. 
on the plate; the form of the crystals depends on the nature of the fat used. Some actinomyces can utilize rubber as a source of carbon. ${ }^{30}$ Lantzsch ${ }^{31}$ isolated an Actinomyces growing in distilled water containing quartz or in a medium very poor in organic matter; this organism was found to be identical with Bac. oligocarbophilus of Beijerinck and it could assimilate $\mathrm{CO}$ as well as the higher aliphatic hydrocarbons, except benzol and xylol.

Actinomyces are among the very few organisms in nature which are capable of utilizing lignins and soil "humus" as sources of carbon. This can be readily demonstrated both in liquid media and by the use of silica gel plates. ${ }^{32}$

Nitrogen utilization. Proteins form good sources of nitrogen, the same is true of peptones and various amino acids. Gelatin (15 per cent in distilled water, neutralized or reaction unadjusted) is liquefied in 3 to 5 days, at $18^{\circ}$ to $20^{\circ} \mathrm{C}$, but some species will produce only a very narrow liquefied zone after 30 to 40 days. Some do not form any pigment, others form a brown to purple-brown soluble pigment on the gelatin. A number of species can also hemolyze red blood cells and produce a clear zone around the colony when grown on blood agar. The actinomyees can be divided into several groups on the basis of milk coagulation..$^{33}$

1. Rapid coagulation of milk, followed by rapid liquefaction of the coagulum, so that the tube of milk becomes clear in 6 to 7 days.

2. Rapid coagulation of the milk followed by slow liquefaction.

3. Slow coagulation followed by a rapid liquefaction.

4. Digestion of the milk proteins without any previous coagulation. This tends to indicate that the rennet-like and proteolytic enzymes are distinct.

Among the inorganic compounds, ammonium salts are utilized well, especially in the presence of sufficient buffer, especially silicates. ${ }^{34}$ The same is true of nitrates; they are reduced first to nitrites before they are assimilated. Nitrites themselves, when used in very low concen-

${ }^{30}$ Söhngen, N. L., and Fol, J. G. Die Zersetzung des Kautschuks durch Mikroben. Centrbl. Bakt. II, 40: 87-98. 1914.

${ }^{31}$ Lantzsch, K. Actinomyces oligocarbophilus (Bacillus oligocarbophilus Beij.), sein Formwechsel und seine Physiologie. Centrbl. Bakt. II, 57: 309-319. 1922 .

32 Unpublished data.

${ }^{33}$ Waksman, S. A. Studies in the metabolism of actinomycetes. I. Jour. Bact., 4 : 189-216. 1919.

${ }^{34}$ Münter, F. Über Stickstoffumsetzungen einiger Aktinomyceten. Centrbl. Bakt. II, 39: 561-583. 1914. 
trations (0.01 per cent), are also utilized. Creatinine is readily utilized; urea and acetamide are assimilated only to a limited extent by the majority of organisms, while a few forms may utilize the substances readily. ${ }^{35}$ Lieske found that urea forms an excellent source of nitrogen, while asparagine was only scantily utilized; uric and hippuric acids were not assimilated.

The proteins are decomposed, with the formation of ammonia, even in the presence of available carbohydrates, such as glucose. In other words, we do not observe here that sharp sparing action of the carbohydrate upon the decomposition of proteins, as in the case of fungi or bacteria. Guittonneau ${ }^{36}$ demonstrated that certain actinomyces are capable of producing urea from proteins, both in the presence and absence of glucose, in addition to ammonia.

Oxygen requirement. The influence of oxygen tension on actinomyces is still an undecided question. There is no doubt that the majority of soil actinomyces are aerobic. The fact that some are able to grow deep into the medium would indicate ability to grow under semi-anaerobic conditions. Beijerinck ${ }^{37}$ classified the actinomyces as facultative anaerobes. Lieske, among others, found that the actinomyces acting as animal pathogenes are anaerobic, while the saprophytic forms are chiefly aerobic. A. scabies will not germinate in the absence of oxygen; the amount of available oxygen is the limiting factor both for germination and growth.37a Other investigators ${ }^{38}$ pointed out that the recognition of strict aerobes or anaerobes is based upon errors of technic, since in no instance could a strict aerobe or anaerobe be obtained.

Influence of temperature, drying and radiation. Some actinomyces grow slowly at temperatures of $3^{\circ}$ to $6^{\circ}$. Good growth of most species is obtained at $6^{\circ}$ to $38^{\circ}, 13^{\circ}$ to $32^{\circ} \mathrm{C}$. being the optimum for the majority of soil forms. Few organisms can thrive at $40-42^{\circ}$ and none will grow at temperatures above $46^{\circ} \mathrm{C}$. except the thermophilic forms. The temperature limits may be raised a few degrees by gradual adaptation.

${ }^{35}$ Waksman, S. A. Studies in the metabolism of actinomycetes. III. Nitrogen metabolism. Jour. Bact., 5: 1-30. 1920.

${ }^{36}$ Guittonneau, G. Sur la production de l'urée au cours de l'ammonification par les Microsiphonées. Compt. Rend. Acad. Sci., 178: 1383-1385. 1924.

${ }^{37}$ Beijerinck, M. W. Úber Chinonbildung durch Streptothrix chromogena und Lebensweise dieses Mikroben. Centrbl. Bakt. II, 6:2-12. 1900.

37. Sanford, G. B. Some factors affecting the pathogenicity of Actinomyces scabies. Phytopath., 16: 525-548. 1926.

${ }^{38}$ Musgrave, W. E., Clegg, M. T., and Polk, M. Streptothricosis with special reference to the etiology and classification of Mycetoma. Philip. Jour. Sci., B., Med. Sci., 3: 447-544. 1908. 
Low temperatures (even $8^{\circ}$ to $10^{\circ} \mathrm{C}$.) do not injure the majority of actinomyces. ${ }^{27}$ High temperatures are very injurious. Some species are killed at $45^{\circ} .3^{39}$ The thermal death point of most actinomyces is $75^{\circ}$. The mycelium of some organisms may survive at $60^{\circ}$, but is killed in 20 minutes at $70^{\circ}$; the spores may survive $75^{\circ}$ for 20 minutes but are killed in 30 minutes. Some soil organisms may be able to withstand even somewhat higher temperatures.

The actinomyces spores resemble in this respect the spores of other fungi in that they do not possess the degree of resistance of the bacterial spores and are readily destroyed at temperatures a few degrees (about $5^{\circ}$ ) above the destructive tempcrature of the mycelium. Some species are thermophilic in nature and have their optimum at much higher temperature than the majority of actinomyces. The existence of actinomyces in the soil which can grow readily at $60^{\circ}$ is established. ${ }^{40,41}$ These forms are especially abundant in the upper layers of forest and garden soils; they are also found abundantly in dry peat, grass, hay and straw. The thermophilic forms do not represent one species, but several distinctly different forms. Various investigator ${ }^{42,43}$ suggested that in the selfheating of straw and other plant materials, the thermophilic forms have a chance to develop and that the addition of straw or manure to the soil helps to spread the organisms. The thermophilic actinomyces multiply rapidly in the soil when the soil is warmed during the hot summer months by the direct rays of the sun. The fact that they are found in cold places where the minimum temperature $\left(40^{\circ}\right)$ for growth of thermophilic forms is never reached, such as forest soils, deep subsoils, and frozen soil, led Lieske to conclude that some of the common forms give out mutants which develop at the higher temperatures. This whole subject deserves careful study.

All actinomyces are very resistant to drying, as indicated by the fact that they are found abundantly on dry straw, hay and soil. Berestneff $^{44}$ inoculated some ears of grain with a pure culture of $A$. violaceus

${ }^{39}$ Foulerton, A. G. R., and Jones, C. B. On the general characteristics and pathogenic action of the genus streptothrix. Trans. Path. Soc. London, 53: 56-127. 1902.

${ }^{40}$ Globig. Über Bakterienwachstum bei 50-70. Ztschr. Hyg., 3: $294.18 s 8$.

${ }^{41}$ Gilbert. Über Actinomyces thermophilus und andere Aktinomyceten. Ztschr. Hyg., 47: 383-406. 1904.

${ }^{42}$ Miehe, H. Die Selbsterhitzung des Heus. G. Fischer. Jena. 1907.

${ }^{43}$ Noack, K. Beiträge zur Biologie der thermophilen Organismen. Jahrb. wiss. Bot., 51: 593-648. 1912.

" Berestneff, N. M. Über die Lebensfähigkeit der Sporen von Strahlenpilzen. Centrbl. Bakt. I, Ref., 40: 298. 1907. 
and found that he could obtain a pure culture of the organism from the dry material after preserving it for ten years. Lieske found that only the saprophytic spores and mycelium were viable after they had been preserved on filter paper in a desiccator for eighteen months. This would point to the fact that the pathogenic actinomyces are not carried over for any long time in dry soil or straw, as is often assumed.

Direct sunlight does not exert any injurious effect upon the actinomyces and does not modify their growth. Exposure to ultraviolet rays for 10 minutes does not affect them; after one hour, the organism is definitely affected but not destroyed. Röntgen rays have no influence. ${ }^{27}$

Influence of reaction and salt concentration. It has been generally observed that alkalies and alkali substances favor the development of actinomyces, while acids and acid substances injure their activities. This is particularly true of inorganic acids, since the organic acids are utilized to some extent by the organisms and are thus broken down. The limiting acid reaction for the majority of soil actinomyces is pII 4.8 to 5.0, although some species may grow at as high an acidity as pH 3.0 to 4.0 . The optimum is $\mathrm{pH} 7.0$ to 8.5. On the alkaline side, the majority of organisms will still grow at $\mathrm{pH} 8.6$ to 9.0 , while some will grow even at more alkaline reactions. This fact can be utilized in adjusting the reaction of the soil so as to prevent the development of $A$. scabies causing potato scab.

Gillespie ${ }^{45}$ was the first to point out the fact that soils having a reaction of $\mathrm{pH} 4.8$ or less are free from scab, while those having a reaction more alkaline than $\mathrm{pH} 4.8$ are apt to have scab. Various strains of $A$. scabies may behave somewhat differently: some may be inhibited in their development at pH 5.0, while others only at pH 4.6. The organisms are also able to withstand a somewhat greater acidity in the soil than in solution. ${ }^{46}$ The reaction of the medium is usually changed by the growing organism to less acid or more alkaline; ${ }^{47}$ this is true of media containing proteins, amino acids and $\mathrm{NaNO}_{3}$. The proteins and amino acid are decomposed with abundant formation of ammonia. With ammonium salts, the ammonium radical is rapidly used up, thus allow-

${ }^{45}$ Gillespie, L. J. The growth of the potato scab organism at various hydrogen-ion concentrations as related to the comparative freedom of acid soils from the potato scab. Phytopath., 8: 257-269. 1918.

${ }^{46} \mathrm{~W}$ aksman, S. A. The influence of reaction upon the growth of actinomyces causing potato scab. Soil Sci., 14: 61-79. 1922.

${ }^{47}$ Näslund, C., and Dernby, K. G. Untersuchungen über einige physiologische Eigenschaften der Strahlenpilze. Biochem. Ztschr., 138: 477. 1923. 
ing the medium to become acid. No acids are formed from carbohydrates. Certain actinomyces will grow in media containing 12 per cent glycerol or 7 per cent $\mathrm{NaCl}^{48}$ In the presence of 18 per cent glycerol and 9 per cent $\mathrm{NaCl}$, no growth was observed. Actinomyces were found ${ }^{49}$ to grow in the presence of 5 per cent of $\mathrm{KCl}, \mathrm{NaCl}, \mathrm{KNO}_{3}$, $\mathrm{NaNO}_{3}$, as well as mixtures of these, but spore formation is depressed. Ten per cent of the salts repressed the growth of all forms except one. Magnesium salts proved much more injurious. Small quantities of alkali earths stimulated, while larger quantities injured growth and spore formation. Difficultly soluble carbonates have little effect. $\mathrm{AgNO}_{3}$ inhibited growth completely; 0.1 per cent $\mathrm{Cu}$ as $\mathrm{CuSO}_{4}$ or $\mathrm{CuCl}_{2}$ was injurious, $\mathrm{HgCl}_{2}$ was less injurious. Lead nitrate and iron salts were least injurious. Lieske could not observe any diminution in growth of various actinomyces when 15 per cent cane sugar was added to nutrient bouillon. Slight growth was obtained in the presence of 20 per cent cane sugar; no further growth was observed in the presence of 30 per cent sugar. Actinomyces are found abundantly in nature on substances containing very little water and are very active in the soil in dry seasons.

Influence of poisons. The addition of benzol to the soil was found to stimulate the development of actinomyces but they are injured by the application of carbon bisulfide. ${ }^{50}$ These organisms are not very sensitive towards chemical poisons but cannot resist the action of metallic salts. The limit of the action of a poison can be changed by gradual adaptation. Of the dyes, methylene blue, methyl violet and gentian violet are most toxic, preventing growth in 1:500,000 dilution in nutrient bouillon. ${ }^{27}$

Reduction of nitrates and other compounds. The majority of actinomyces species are able to reduce nitrates to nitrites, but not to ammonia nor to atmospheric nitrogen. ${ }^{51}$ By using the ordinary Czapek's solution, nitrite formation can be demonstrated to run parallel to the growth of the organism. Some starch solution and 0.5 per cent $\mathrm{KNO}_{3}$ may be added to ordinary nutrient agar, which is then placed in Petri dishes,

${ }^{48}$ Neukirch, 1902 (p. 293).

${ }^{49}$ Münter, F. Über den Einflusz anorganischer Salze auf das Wachstum der Aktinomyceten. Centrbl. Bakt. II, 44:673-695. 1916.

${ }^{5} 0$ Störmer, K. Über die Wirkung des Schwefelkohlenstoffs und ähnlicher Stoffe auf den Boden. Centrbl. Bakt. II, 20: 282-286. 1908.

${ }^{51}$ Fousek, A. Die Streptothricheen und ihre Bedeutung in der Natur. Mitt. landw. Lehrkanz. K. K. Hochsch. Bodenk. Vienna, 1: 217-244. 1912. 
cooled and inoculated with the organism in question. After the organism has developed for a few days, the plates are covered with a dilute solution of potassium iodide, to which some hydrochloric acid is added. The plates, in which the nitrate is reduced to nitrite, are colored blue since the nitrite liberates the iodine from the potassium iodide. ${ }^{27}$ This method, however, is not so reliable as the common method ( $\alpha$ naphthalamine + sulfonilic acid) of nitrite estimation, since the starch may be decomposed by the diastatic enzymes.

Selenium and tellurium salts ( 0.01 per cent concentration) are reduced by numerous actinomyces to elementary selenium and tellurium; the colonies are colored deep red and deep black respectively, due to the fact that the metals are deposited within the mycelium. The phenomenon is intracellular. According to Husz, ${ }^{52}$ various actinomyces isolated from the soil can reduce organic arsenic compounds, similar to Pen. brevicaule, with the production of the characteristic garlic odor. These results could not be confirmed by Lieske. This may be due either to the difference in the organisms employed or difference in methods.

Production of odor. Most actinomyces grown on organic or synthetic media produce a characterictic odor of freshly plowed soil. This is particularly true of the organisms possessing a mildewy aerial mycelium. The odor varies from earthy to musty. It was thought at first ${ }^{53}$ that this odor was formed by a specific organism. It was soon found that this is the property of a large number of species and the odor production is in itself a variable factor. The non-spore-forming organisms usually do not produce any odor. The intensity of the odor depends on the composition of the medium. Carbohydrates, particularly glycerol, stimulate the odor formation. The odoriferous substance has not been isolated yet.

A few actinomyces, particularly thermophilic forms, produce a pleasant fruity odor.

Pigment formation. The property of pigment formation is widespread amrag the actinomyces. No culture can be considered nonchromogenic until it has been studied on protein media and a variety of protein-free media. Three different kinds of pigment should be considered: that of the vegetative mycelium, of the aerial mycelium, and

${ }^{62}$ Husz, H. Zur Kenntnis der biologischen Zersetzung von Arsenverbindungen. Ztschr. Hyg., 76: 361. 1914.

${ }^{53}$ Rullmann. Chemisch-bakteriologische Untersuchungen von Zwischendecken-fühlungen mit besonderer Berücksichtigung von Cladothrix odorifera Diss. München. 1895 . 
pigment dissolved out into the medium. The aerial mycelium is usually colored white, gray or buff, sometimes red, yellow, brown, light green or bluish-green. The vegetative or substrate growth is usually colored gray, red, yellow, orange, brown or black. Among the soluble pigments, purple, brown, black and yellow are predominant; red, blue and green are also formed by some species. Soluble brown to purple pigments are very common on protein media. A slight difference in the composition of the medium has an important influence upon the pigment formation by actinomyces. ${ }^{54}$

Various attempts have been made to explain the nature of the dark brown pigments produced on organic media. Beijerinck ${ }^{55}$ suggested that the brown pigment is a result of quinone-formation, as shown by the fact that ferri-salts color the brown-colored gelatin black and the gelatin itself is made insoluble due to the action of the pigment. In the presence of $\mathrm{HCl}$, iodine is liberated from potassium iodide. The formation of the pigment has also been ascribed $^{56}$ to the action of an enzyme, as in the case of tyrosine media coloring black. But the organisms must be able to synthesize their own tyrosine and produce a brown or dark pigment since the pigment is produced also on tyrosine-free media. Someactinomyces form blue or green pigments, particularly when freshly isolated. The rapidity of gelatin liquefaction and pigment formation are utilized for diagnostic purposes. The characterization of an organism by the nature of the pigments formed has sometimes led to duplications, as in the naming of one organism, on the basis of formation of a red and blue pigment, $A$. violaceus ruber ${ }^{57}$ and $A$. tricolor. ${ }^{58}$ The pigment acts as a natural indicator. On media which are slightly acid ( $\mathrm{pH} 6.0)$, the pigment is at first red, then, with a change of reaction of the medium to alkaline, the pigment becomes blue. The chemical nature of this pigment is yet to be investigated.

Variability. The actinomyces show, in their morphological and physiological characteristics, greater variability than any other group of organisms. Size, shape and color of colonies, length of mycelium, abundance of mycelium and spore formation are determined largely

${ }^{54}$ Conn, 1921 (p. 290).

${ }_{55}$ Beijerinck, 1900 (p. 299).

${ }^{56}$ Sano, K. Beiträge zur Kenntnis der Oxydasen, insbesondere bei Bakterien. Diss. Würzburg. 1902.

57 Waksman and Curtis, 1916 (p. 290).

${ }_{68}$ Wollenweber, H. W. Der Kartoffelsehorf. Arb. d. Forsschungsinst. f. Kartoffelhau. H. 2, Berlin. 1920. 
by the composition of the medium and age of culture. When organisms are named merely on the basis of pigment production on complex media (A. chromagenus, A. sulfureus, etc.), or on the basis of color of aerial mycelium (A. albus, $A$. niger), on the basis of ring formation in aerial mycelium (A. annulatus), we are merely utilizing variable properties of the organisms as some distinguishing characters. When the organisms are transferred to other media, or even when cultivated continuously on the same medium, the pigment may change and rings may no longer be formed. The species thus lose their distinguishing characteristics and become other species. In addition to using a group of morphological and physiological characteristics which are commonly employed for the species determination, one must also allow for the variability of the organisms. Observations should be made of the morphological and physiological characteristics on synthetic media for a large number of generations. Such characters as pigment production may change. A. verne produced, when originally isolated from the soil, a beautiful green pigment on Czapek's agar, but lost the property in a few months when grown on synthetic media; after several years, it gained the property of producing a brownish-purple pigment on the same medium. The property of producing aerial mycelium may be lost and the character of growth changed. A. halstedii, when freshly isolated from the soil, produced a dark growth with a mouse-gray aerial mycelium on Czapek's agar; on continued cultivation on artificial media, the property of forming an aerial mycelium was lost altogether, and the growth became dark brown and lichnoid in appearance. In some instances, organisms that lost the power of forming aerial mycelium regained it after cultivation in sterile soil.

Similar variability is found in the rapidity of gelatin liquefaction, production of soluble pigment, action on milk, oxygen requirement, and odor production. One can readily observe in some actinomyces cultures the formation of sectors, differing in one respect or another from the rest of the growth. On transferring from such a sector to a fresh medium, an organism may be obtained which differs from the mother culture in some character such as color, presence of aerial mycelium, zone formation, pigment, etc. Lieske has thus isolated five new forms, in addition to the original, which were distinguished from one another by at least one character. Although the claim is put forth that purc spore cultures were used, no mention is made of the use of such a procedure as the Barber pipette, which would absolutely insure a singlespore culture. 
Species differentiation. For a study of cultural and biochemical characteristics of the organisms, a group of media may be recommended, which will help to bring out the salient features.

1. Synthetic media, as described above:
(a) Modified Czapek's agar
(b) Krainsky's glucose agar
(c) Malate-glycerin agar (Conn)
(d) Citrate-glycerin agar (Conn)

Temperature of incubation $25^{\circ}$, period of incubation 7 to 15 days.

2. Gelatin, 15 per cent in distilled water, reaction unadjusted; temperature of incubation $16^{\circ}$ to $18^{\circ}$; period of incubation 30 days.

3. Sterile skimmed milk; temperature of incubation $25^{\circ}$ and $37^{\circ}$; observations made daily.

4. Potato plug, $25^{\circ}$, for 7 days.

5. Starch agar, $25^{\circ}, 10$ to 15 days (test for diastatic strength).

6. Nutrient peptone agar, $25^{\circ}, 7$ to 15 days.

General morphology to be studied by direct examination of colony on plate by means of low power. For detailed study, the method of Drechsler to be used, magnification 1000 to 1200 .

The cultural characteristics of actinomyces in these media make possible the suggestion of the following tentative key for their differentiation, until a more permanent one based on morphological studies can take its place.

\section{KEY TO THE IDENTIFICATION OF SPECIES OF SOIL ACTINOMYCES}

\section{(Based chiefly on physiological characteristics)}

A. Formation of a soluble pigment on all media containing protein substances:

I. Pigment deep brown (chromogenus types):

1. A brown pigment is produced on tyrosine agar:

(a) Pigment dark brown; white to cream-colored growth on synthetic media; soluble brown pigment on synthetic media containing arabinose, glucose or lactose

\section{A. scabies}

A number of strains of Actinomyces were isolated from potato scab lesions; it was suggested that there is no justification for including all these organisms in one species. $^{58 a}$

(b) Pigment faint brown; sulfur-yellow soluble pigment on creatinine solution; aerial mycelium on glucose agar is ocher to reddish ocher colored.....A. olivochromogenus

${ }^{58 \mathrm{a}}$ Millard, W. A., and Burr, S. A study of twenty-four strains of Actinomyces and their relation to types of common scab of potato. Ann. Appl. Biol., 13:580-644. 1926 . 
2. Growth and aerial mycelium on synthetic agar green to darkgreen; soluble brown pigment on synthetic media with most carbohydrates...................... viridochromogenus

3. Deep brown to black pigment on synthetic agar:

(a) Weakly growing organisms; orange-red growth on potato plug; no visible aerial mycelium on synthetic agar

A. purpeochromogenus

(b) Vigorously growing organisms; brown to black growth on potato plug; abundant cottony aerial mycelium on synthetic agar................... pheochromogenus

4. Usually no action on milk $\left(37^{\circ}\right)$, accompanied by the darkening of the milk; mouse-gray aerial mycelium on synthetic agar; ammonium salts used readily with different sources of carbon................................... aureus

5. Brown pigment never produced on synthetic media:

(a) Aerial mycelium on synthetic media has lavender shade

A. lavendulae

(b) Aerial mycelium on synthetic agar is abundant, of a water green color...................Actinomyces 218

(c) Whirl formation in aerial mycelium on synthetic agar:

$\left(a^{\prime}\right)$ Growth colorless and aerial mycelium white

A. reticuli

(b') Growth pink, aerial mycelium rose colored; nitrate reduction very abundant; fewer whirls

A. reticulus-ruber

(d) Growth on synthetic agar sulfur-yellow, with yellow aerial mycelium; barnacle-like, greenish-yellow growth on potato plug........................... Havus

(e) Growth on synthetic agar red colored, aerial mycelium abundant, orange colored; aerial hyphae usually do not form spirals.......................... ruber

II. Soluble pigment on organic media faint brown, golden, yellow or blue:

1. Pigment blue, not always definite; soluble red pigment turning blue on synthetic agar................... violaceus-ruber

2. Pigment at first green on organic media and synthetic agar, property lost on continued cultivation, becoming brown on synthetic agar; aerial mycelium not produced on most media

A. verne

3. Soluble pigment at first brown, property lost entirely on continued cultivation; growth and aerial mycelium on synthetic agar abundant, white........................ albus

4. Soluble pigment yellowish green; growth on synthetic agar penetrating into the medium is pink............ californicus

5. Brown pigment produced only on certain protein media (usually gelatin and glucose broth, not nutrient agar):

(a) Growth on synthetic agar red to pink; no differentiated aerial mycelium or only scant white.......... bobili 
(b) Growth on synthetic agar colorless; aerial mycelium thin, rose-colored..................... roseus

(c) Growth on carrot and potato rapidly spreading, enveloping the whole plug and destroying it rápidly, plug becoming colored deeply brown............. griseolus

(d) Red (vinaceous) soluble pigment on synthetic agar, often turning red-brown; white aerial mycelium

A. erythreus

B. No soluble pigment produced on gelatin or other protein media:

I. Species strongly proteolytic; gelatin liquefied rapidly, milk clotted and peptonized rapidly.

2. Brown soluble pigment on synthetic agar; diastatic action very

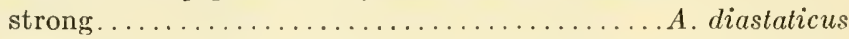

2. Rapid liquefaction of coagulated blood serum, strong hemolysis of blood $\left(37^{\circ}\right)$; aerial mycelium on synthetic agar has a tea-

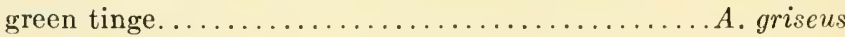

3. Yellowish green growth on starch plate with pinkish aerial mycelium; citron-yellow growth on synthetic agar.....A. citreus

4. Greenish-yellow growth on synthetic agar, gray powdery aerial mycelium, greenish-yellow soluble pigment......A. flavovircns

5. Colorless growth on synthetic agar, white to grayish aerial mycelium, no spiral formation; thin reddish-brown growth on potato plug (purplish zone on plug); faint yellow pigment may develop on gelatin, blood and egg-media.......... poolensis

6. Buff colored growth on glucose agar, violet-gray aerial mycelium; yellow growth on synthetic agar with light drab aerial mycelium; rapid destruction of potato plug

A. olivaceus

7. Very scant colorless growth with scant white aerial mycelium on synthetic agar and on synthetic media containing $\mathrm{NaNO}_{3}$ as a source of nitrogen; abundant brown growth with white acrial mycelium and soluble brown pigment on glucose agar; growth on potato plug greenish turning black...A. gelaticus

II. Proteolytic action weak:

1. Soluble pigment produced on synthetic agar:

(a) Pigment blue or blue-black.......... violaceus-caesari

(b) Pigment brown to almost black on all synthetic media with $\mathrm{NaNO}_{3}$ as a source of nitrogen.....A. exfoliatus

2. No soluble pigment on synthetic agar, although growth is colored:

(a) Growth turning black, diastatic action very strong:

$\left(a^{\prime}\right)$ Growth on synthetic agar scant with abundant spirals in aerial mycelium, no invertase pro-

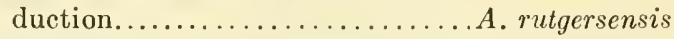

$\left(b^{\prime}\right)$ No spirals on synthetic agar, characteristic green colored growth on protein-glycerin media

A. lipmanii

(c') None or scant aerial mycelium on all media; growth abundant on synthetic agar (invertase positive); 
none or scant growth on blood agar and eggmedia..................................

(b) Growth orange colored on most synthetic and organic media; aerial mycelium pink.............. fradii

(c) Growth yellowish on synthetic and glucose agars; pinkish to cinnamon-colored on calcium malate agar; no growth on blood serum and egg media; none or only very scant and late aerial mycelium on most media..A. alboflavus

(d) Growth on synthetic media rose to red colored, aerial mycelium white, no visible action on milk. .A. albosporeus

Over fifty species of actinomyces have been isolated from the soil and described. $^{59}$ A much larger number, however, can readily be obtained from the soil. Some of them are of wide occurrence, as the A. chromogenus types (A. viridochromogenus, A. pheochromogenus, etc.), A. aureus, $A$. rutgersensis, $A$. violaceus ruber ${ }^{60}$

Importance of actinomyces in the soil. Actinomyces take an active part in the decomposition of organic matter in the soil, both of a nitrogenous and non-nitrogenous nature. Some species are capable of decomposing celluloses very rapidly and there is no doubt that under' conditions favoring their development, as in neutral or alkaline and arid soils or with insufficient moisture, actinomyces play an important part in this process. Krainsky even divided all the actinomyces into two groups: (1) the macro-actinomyces, forming oval spores and large colonies on agar and not decomposing cellulose or only to a very limited extent; and (2) the micro-actinomyces, forming spherical spores and minute colonies on agar and decomposing cellulose rapidly with the formation of pigments. Macé ${ }^{61}$ pointed out that actinomyces decompose proteins into amino acids and ammonia; he suggested that they may bring about the formation of humus (ulmic acids) in the soil. Active protein decomposition by actinomyces has also been recorded. ${ }^{62-64}$ In view of the fact that the amount of mycelium synthetized by this group of organisms is considerably smaller than that of fungi, only small amounts of nitrogen are assimilated and most of it is liberated free in

${ }^{59}$ Krainsky, 1914 (p. 288). Waksman and Curtis, 1916 (p. 290). Conn, 1917 (p. 288).

${ }^{60}$ A detailed description of various actinomyces found in the soil is given by Waksman, 1919 (p. 288) and Bergey, 1923 (p. x).

${ }^{61}$ Macé, E. De la décomposition des albuminoides par les Cladothrix (Actinomyces). Compt. Rend. Acad. Sci., 141: 147. 1905.

62 Fousek, 1913 (p. 40).

${ }^{63}$ Münter, 1914 (p. 298).

${ }^{64}$ Waksman, 1919 (p. 288). 
the form of ammonia. Non-nitrogenous organic matter does not exert such a depressing effect upon ammonia accumulation as in the case of bacteria and other fungi; as a matter of fact, ammonia formation from proteins will take place even in the presence of available carbohydrates, as pointed out above.

The accumulation of "humus" in the soil is an index of the great resistance of this group of organic substances to decomposition by microorganisms. Since this substance contains the larger part of the soil nitrogen, its decomposition is of great importance to soil fertility. Actinomyces seem to be among the very few organisms capable of attacking this resistant material and bring about its decomposition. Liming of soil and draining of swampy soil favors the development of actinomyces and also the decomposition of the soil organic matter. It is possible that a definite connection exists between these two phenomena. According to Fousek an increase in plant growth is obtained by adding actinomyces mycelium to soil, due to the increased decomposition of the organic matter thus brought about.

We find, among the actinomyces, organisms causing important plant diseases, of which potato scab and sugar beet $\mathrm{scab}^{65}$ are known. There is considerable evidence that actinomyces may enter into certain associations with plants, as pointed out by Peklo, ${ }^{66}$ who cultivated an organism, named $A$. alni, out of the nodules on the roots of Alnus and Myrica. Similar results were obtained by Lieske. In view of the fact that it has not as yet been possible to obtain the nodules by artificial inoculation, these results cannot be accepted as positive.

${ }^{65}$ Krüger, F. Untersuchungen über den Gürtelschorf der Zuckerrüben. Arb. Biol. Anst. L. Forstwirt., 4: 254-318. 1905.

${ }^{66}$ Peklo, J. Die pflanzlichen Aktinomykosen. Centrbl. Bakt. II, 27: 451479. 1910 . 


\section{CHAPTER XIII}

\section{Soll ProtozoA}

The protozoa form numerically the most abundant group of the animal population of the soil. It has been known since the work of Ehrenberg that the soil harbors a number of different protozoa, but the investigation of this subject has been greatly stimulated by the contributions of Russell and Hutchinson, ${ }^{1}$ who suggested that the limitation of bacterial activities in the soil is due to a factor of biological origin, probably the protozoa; this factor is less resistant than the soil bacteria and is readily destroyed by the treatment of soil with heat or disinfectants. This brings about a rapid development of the bacteria and the liberation of the combined nitrogen in a form available for plant growth, namely ammonia. The inference was that the soil protozoa, using the bacteria as food, limit the bacterial activities in the soil and, as a result of that, also limit soil fertility. On treating the soil with heat and disinfectants, the protozoa are destroyed, while the bacteria remain alive and begin to multiply very rapidly, their increased activities resulting in the liberation of the nitrogen and an increase of plant growth.

Additional plausibility was given to this theory by suggestions made a few years previously and supported by a number of observations, ${ }^{2}$ that a similar function is performed by protozoa during the self-purification of water (i.e., the disappearance of pathogenic bacteria during storage). In fact, in view of the close similarity between many of the biochemical problems of water and sewage purification and those of the soil, the extensive investigations that have been made in the former fields are well worth careful consideration by the soil microbiologist. ${ }^{3}$

General morphology of protozoa. A detailed study of the morphology,

${ }^{1}$ Russell, E. J., and Hutchinson, H. B. The effect of partial sterilization of soil on the production of plant food. Jour. Agr. Sci., 3: 111-144. 1909; 5: 152-221. 1913; Russell, E. J. Soil protozoa and soil bacteria. Proc. Roy. Soc. B., 89: 76-82. 1915.

${ }^{2}$ Fehrs. Die Beeinflussung der Lebensdauer von Krankheitskeimen im Wasser durch Protozoen. Hyg. Rundsch., 16: 113-121. 1906.

s Buswell and Long. Activated sludge experiments. Illinois State water supply, Bul. 18, 1923. 
classification, and physiology of protozoa is found elsewhere. ${ }^{4-8}$ Some of the information, necessary for a knowledge of the identification and study of activities of soil protozoa, is given here.

Protozoa are unicellular organisms, varying in size from a few microns to 4 to $5 \mathrm{~cm}$. Some protozoa may also form colonies consisting of numerous individuals. The majority of species, particularly the soil

${ }^{4}$ Bütschli, O. Protozoa. In Bronn's Kklassen und Ordnungen des Thierreichs. 1,1883 .

${ }^{5}$ Doflein, F. Lehrbuch der Protozoenkunde. 4th Ed., Jena, 1916.

${ }^{6}$ Minchin, E. A. An introduction to the study of protozoa. Arnold, London. 1912.

${ }^{7}$ Edmondson, C. H. The protozoa of Iowa. Proc. Davenport Acad. Sci., 12: 1-124. 1906. Schaeffer A. A. Taxonomy of the amebas, with descriptions of thirty-nine new marine and freshwater species. Dept. Marine Biol. Carnegie Inst., Washington, 24. 1926.

${ }^{8}$ Calkins, G. N. The biology of the protozoa. Lea \& Febiger, Philadelphia. 1925.

\section{PLATE XVII}

\section{Soll Protozoa}

128. Naegleria gruberi: a, small organism $(8$ to $30 \mu$ ) with one broad blunt pseudopodium or sometimes several blunt ones, and one subcentral nucleus. When it enflagellates the karyosome sends out a chromatic process $b$, which traverses the nuclear membrane, forms a marginal blepharoplast, and emerges as two long flagella $(c, d)$. The body assumes a rigid asymmetrically curved shape and the organism swims away in the typical spiral course. When it exflagellates the flagella shorten, thicken and retreat into the cytoplasm and the blepharoplast returns to the karysome within the nucleus (from Kofoid).

129. Vahlkampfia soli, a limax amoeba, from fresh fixed film (from Martin and Lewin).

130. Amoeba cucumis, a lamellipodian amoeba (from Martin and Lewin).

131. Euglypha sp., a thecamoeba (from Martin and Lewin).

132. Cyst of Amoeba cucumis (from Martin and Lewin).

133. Colpoda sleinii, $\times 800$ (from Goodey).

134. Balantiophorus elongatus, $\times 800$ (from Goodey).

135. Pleurotricha grandis (?), $\times 410$ (from Goodey).

136. Gonostomum affine, $\times 510$ (from Goodey).

137. Vorticella microstoma, living stalked form, $\times 410$ (from Goodey).

138. V. microstoma, free swimming, recently excysted form with aboral ciliary ring, $\times 510$ (from Goodey).

139. Bodo caudatus (from Martin and Lewin).

140. Monas guttula (from Fellers and Allison).

141. Cercomonas crassicauda (from Fellers and Allison).

142. Bodo ovalus (from Fellers and Allison).

143. Pleuromonas jaculans (from Fellers and Allison). 


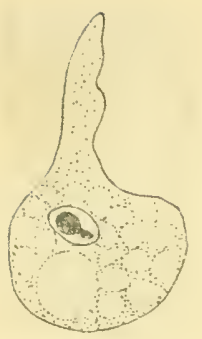

A

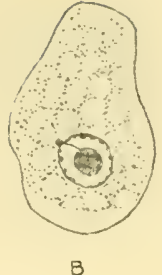

8

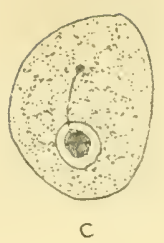

128
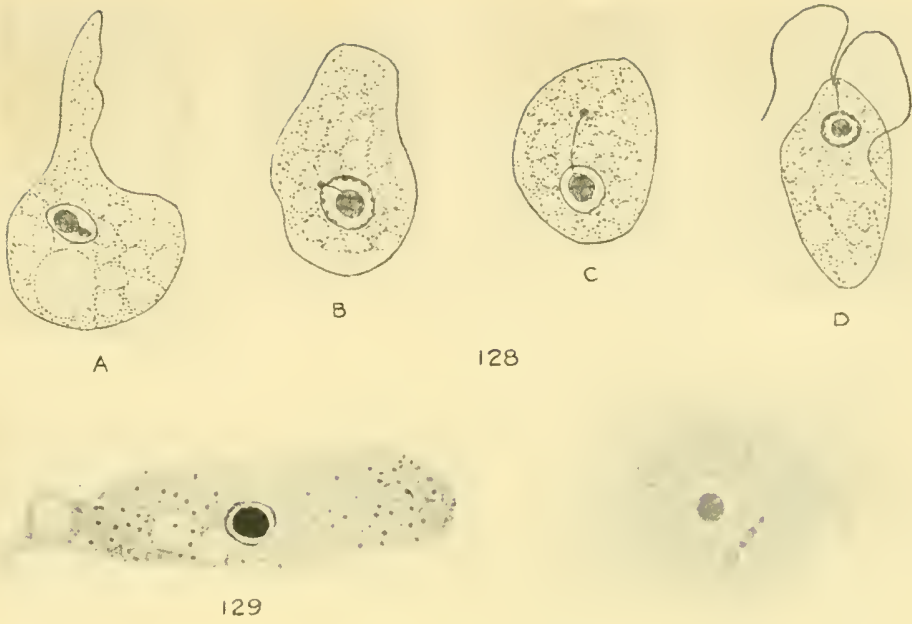

130
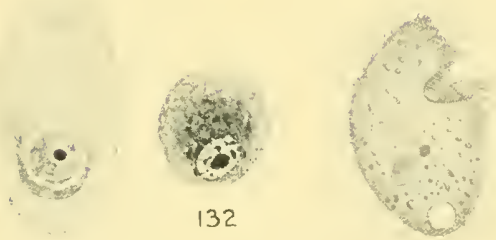

133

131
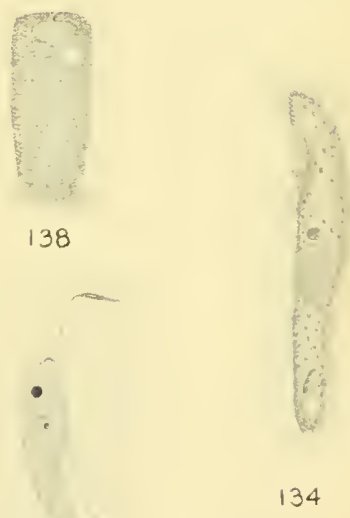

139

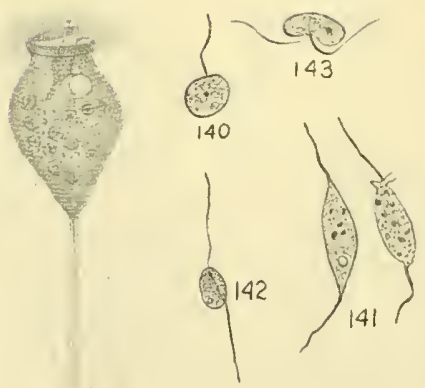



forms, are microscopic and can be studied in detail only with the highest magnifications. The protoplasm is a colloidal liquid containing chromatic or nuclear substance, generally forming nuclei readily distinguishable from the protoplasmic body, which is either naked at the surface or enclosed by a cell membrane. Usually one or two nuclei are present, in some cases several of them; most infusoria contain a large macronucleus (vegetative functions and asexual division) and a small micronucleus (sexual reproduction). Contractile vacuoles, when present, are for the elimination of waste fluids or possibly for the adjustment of the osmotic pressure of the protoplasm (absent in marine forms). Green, yellow or brown chromatophores are present in the endoplasm of some Mastigophora. The most important constituents of the cell are the complex proteins, particularly nucleins and nucleo-proteins. In addition to these, there are always present in the living cell carbohydrates, lipoids and enzymes. There are also found in the protozoa undigested food particles, waste materials or foreign elements, which take no part in the physiology of the organism; algae and bacteria may often be present in the endoplasm, possibly as a result of symbiotic relationship. Many species are subject to the attacks of minute parasitic organisms, either in the nucleus or in the cytoplasm.

Reproduction is usually effected by fission, and, in the great majority of protozoa, a process of conjugation occurs at some stage in the lifecycle, the essential part in the process being fusion of the nuclear matter from distinct individuals. Locomotion is accomplished either by cilia, flagella, pseudopodia, or may be absent entirely, this serving as a basis for classification. Organs for the capture and assimilation of food may be present or entirely absent. The protozoa are classified on the basis of locomotion into:

1. Sarcodina or Rhizopoda, motility by means of pseudopodia, i.e., extensions (usually temporary) of the protoplasm of the cell body. The pseudopodia are either broad, blunt, finger-like or filiform, simple or branched. In some (Heliozoa), the ray-like pseudopodia are usually supported by axial filaments. Some Sareodina are naked, while others form shells; these are composed of materials secreted by the animals themselves, as chitin, silica, calcium carbonate, or are constructed from foreign particles, as diatoms, sand grains, clay particles, ete. Some shells (ehitinous) are delicate, transparent, while others are composed of distinet plates, arranged more or less regularly.

2. Mastigophora or Flagellata, motility by means of flagella. These flexible, whip-like processes are usually attached at one end of the body. Either one or more flagella may be present; when single the flagellum is usually directed forward and draws the body forward by its movement. When more than one 
flagellum is present, one or more may be directed backward. Some low flagellates can form pseudopodia.

3. Ciliata or Infusoria, motility by means of numerous cilia or short hair-like processes present during the entire existence of the protozoa or during their embryonic stage only. The cilia are either evenly distributed over the surface of the organisms or are restricted to certain regions. Large spine-like cirri or setae, or vibrating membranelles may be formed from fusion of cilia. Most are free swimming, some are attached by rigid or flexible stalks or pedicels.

4. Sporozoa, motility reduced by parasitism.

The soil forms are found among the first 3 general groups.

Physiology of protozoa. The physiology of the protozoa cannot be studied adequately, in a manner similar to higher organism or to microscopic plant organisms, as fungi, bacteria and algae. This is due largely to the fact that they cannot be cultivated yet in pure cultures, free from bacteria. An approach in this direction has been made by the cultivation of protozoa with single species of bacteria.

Most of the protozoa are aerobic, obtaining their oxygen, necessary for oxidation purposes, from the air by absorbing it through the permeable membrane, without the aid of specialized respiratory organs. A few forms are anaerobic, obtaining the oxygen by reduction of oxygen rich substances. Oxidation is closely associated with nutrition and is followed by the excretion of the waste products, such as $\mathrm{CO}_{2}$, urea and other products of metabolism.

'The optimum temperature for the development of protozoa is 18$22^{\circ} \mathrm{C}$. Excessive heat kills the protozoa, but excessive cold does not injure them beyond retarding their vital activities.

The optimum reaction for the activities of protozoa was at first believed to be at the neutral point. Good growth was also obtained in acid media. ${ }^{9}$ The limiting acid and alkaline reaction values for the growth of Paramoecium caudatum were found to be at $\mathrm{pH} 5.0$ and $9.0 ;^{10}$ in other experiments Paramoecium was reported to develop normally at pH 6.4 to 8.0 ; beyond these limits, development is restricted and encystment may take place. Various soil ciliates, flagellates and amoebae were found to be able to live and reproduce in artificial media even at

${ }^{9}$ Vahlkampf. Beiträge zur Entwicklungsgeschichte von Amoeba limax, einschliesslich der Züchtung auf künstlichen Nährböden. Arch. Protistenk., 5: 167.1905.

${ }^{10}$ Dale, D. On the action of electrolytes on Paramoecium. Jour. Physiol., 46: 129-140. 1913; Koffman, M. Über die Bedeutung der Wasserstoffionenkonzentration für die Encystierung bei einigen Ciliatenarten. Arch. mikrosp. Anat. Entwicklungs., 103: 168-181. 1924. 
$\mathrm{pH} 3.5-3.9$ on the one hand and 9.75 on the other. ${ }^{11}$ Testaceous rhizopods are most numerous in acid peat soils and are very scarce in alkaline soils.

Many of the common protozoa can tolerate semi-anaerobic conditions. Aeration of soil has, therefore, little direct influence upon their development.

On the basis of their nutrition, the protozoa are divided into autotrophic (or holophytic forms which synthesize food using the energy of sunlight) and heterotrophic forms; these are subdivided into holozoic, when solid food particles are taken in, and saprophytic, when nourishment is absorbed from soluble organic substances by diffusion through the body surface. The great majority of protozoa are holozoic in their nutrition.

The autotrophic protozoa are usually found among the flagellates; they obtain their nutrition entirely from inorganic substances and the $\mathrm{CO}_{2}$ from the atmosphere; they are often spoken of as Phytoflagellates and may even be considered with the algae. They contain colored substances (chromophyll), which enables them to utilize the energy of light, similarly to higher plants. These colored substances are seldom diffused throughout the cell, but are usually present in special bodies, termed chromatophores. The most common representative of this group is the genus Euglena. In some cases, protozoa are found to live symbiotically with green algae. Such protozoa have been demonstrated among the amoebae and flagellates.

The holozoic protozoa, to which the majority of ciliates belong, use as food the various complex materials which form the constituents of living organisms (bacteria, algae). Some protozoa, like various amoebae, can feed on other protozoa, even on the larger ciliates. ${ }^{12}$ The whole organism or part of it is taken into the body of the protozoan, where it is subjected to the chemical action of digestion, with the production of organic substances utilized by the protozoan as food. The process of nutrition takes place in three stages, the taking in of the food, its decomposition, and the excretion of the unutilizable part. Digestion in all free-living protozoa is intracellular, by means of diastatic, proteo-

${ }^{11}$ Nasir cited by Sandon, 1927 (p. 329); Fine, M. S. Chemical properties of hay infusions. Jour. Exp. Zool., 12. 1912.

12 Beers, C. D. The clearing of ciliates by amoeba. Science, 64: 90. 1926; Brit. Jour. Exp. Biol., 1: 325-341. 1924; Mast, S. O., and Root, F. M. Jour. Exp. Zool., 21: 33-49. 1916; Schaeffer, A. A. Quart. Rev. Biol., 1: 95-118. 1926. 
lytic and other enzymes. ${ }^{13}$ In some, if not in the majority of protozoa, there seems to exist a certain selection for the food, some species of bacteria being preferred to others. This may be due to the fact that some bacteria are digested more readily than others by the specific enzymes of the protozoan or to the formation by the particular bacteria of substances which are injurious to the protozoan. ${ }^{14}$ Some protozoa, especially certain amoebae and flagellates, are capable of digesting complex proteins, starches and in some cases even celluloses..$^{15}$

The autotrophic protozoa have no apparent relation to the bacteria in the soil; the heterotrophic forms may play an important part in the soil by using the bacteria as food. The latter utilize the soluble inorganic and organic compounds and serve, in their turn, as food for many rhizopods and ciliates. Many of the latter are specifically adapted to the feeding on bacteria. Some protozoa also feed on fungi, algae and smaller protozoa. Doflein divides the protozoa, which require complex organic substances as food, into 4 groups: those that feed on (1) bacteria, (2) on waste products, (3) on plants (diatoms and other algae), and (4) on small animals. Most forms take in mixed food, feeding on bacteria and waste products, but the fact that the different protozoa differ from one another in their feeding habits and that some species have considerable power of selecting their food, makes a more detailed knowledge of their food requirements a necessity for the satisfactory elueidation of their rôle in the soil economy.

When an infusion of hay, straw, or moss is prepared and allowed to incubate, bacterial development takes place immediately. This is soon followed by abundant growth of various species of protozoa, including the flagellates and amoebae, later followed by the ciliates; these feed on the bacteria in the infusion. The protozoa come into the infusions from the air, where they are present in the form of eysts; as many as 13

${ }^{13}$ Mouton, H. Recherches sur la digestion chez les amibes et sur leur diastase intracellulaire. Thèse. Paris, 1902, Charaire; Compt. Rend. Acad. Sci., 133: 244. 1901. Ann. Inst. Past., 16: 457-509. 1902.

${ }^{14}$ Hargitt, G. T., and Fray, W. W. The growth of Paramecium in pure cultures of bacteria. Jour. Exp. Zool., 22: 421-455. 1917; Phillips, R. L. The growth of Paramecium in infusions of known bacterial content. Ibid., 36: 135183. 1922 .

${ }^{15}$ Stole, A. Beobachtungen und Versuche über die Verdauung und Bildung der Kohlenhydrate bei einem amöbenartigen organismus-Pelomyxa palustris Greeff. Ztschr. wiss. Zool., 68: 625-658. 1900; Clevelend, L. R. The method by which Trichonympha campanula, a protozoön in the intestine of termites, ingests solid particles of wood for food. Biol. Bul., 48: 282-287. 1925. 
species of protozoa have been demonstrated in the air in the form of eysts. $^{16}$

The soil amoebac and closely related forms select their food instead of ingesting all smaller organisms indiscriminately. Micrococci and bacteria are caten most readily, bacilli less readily, while yeasts

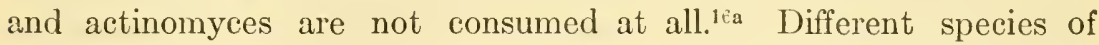
amoebae may prefer different organisms, Gram-negative forms being consumed more readily than Gram-positive forms, young cells more rearlily than old cells (Ochler). When an amoeba is once accustomed to feed on a certain bacterium, it will continue to select the particular organism in preference to others.

Facts are on record concerning the ability of various protozoa to utilize various soluble organic substances formed in the soil by bacterial action. ${ }^{17}$ This is true of flagellates and even of certain ciliates, which are said to have been cultivated free from bacteria, and to be able to derive their nutrients from various soluble organic and inorganic materials. ${ }^{18}$ Under natural conditions, however, Colpidium colpoda may feed entirely by phagocytosis, although, under artificial conditions, they may be able to obtain their food from solution. ${ }^{19}$ These results need further confirmation, the evidence submitted being insufficient to be accepted.

Media for the cultivation of protozoa. The media commonly employed in the cultivation of protozoa consist of complex organic substances. For the cultivation of chlorophyll-bearing protozoa, as well as many heterotrophic forms, purely synthetic media can be used.

For the growth of Euglena, a medium consisting of 0.5 gram peptone, 0.5 gram glucose, 0.2 gram eitric acid, 0.2 gram $\mathrm{MgSO}_{4} \cdot 7 \mathrm{H}_{2} \mathrm{O}, 0.05$ gram $\mathrm{K}_{2} \mathrm{HPO}_{4}$ in 100 parts of water has been suggested. ${ }^{20}$ The concentration of citric acid and peptone may be doubled and 0.05 per cent $\mathrm{NH}_{4} \mathrm{NO}_{3}$ may be added.

${ }^{16}$ Puschkarew, B. M. Über die Verbreitung der Süszwasserprotozoen durch die Luft. Arch. Protistend., 28: 323. 1913.

16a Severtzoff, L. B. Method of counting, culture medium and pure cultures of soil amoebae. Centrbl. Bakt. I, Orig., 92: 151-158. 1924.

17 Thornton, H. G., and Smith, G. On certain soil flagellates. Proc. Roy. Soc. B., 88: 151-165. 1914; Alexeiev, A. G. Protistic Coprology, as a special branch of protistology, and a description of several new species of protists"coprocolae." Russ. Jour. Microl., 4: 97-134. 1917.

${ }^{18}$ Peters, R. A. The substance needed for the growth of a pure culture of Colpidium colpoda. Jour. Physiol., 55: 7-32. 1917.

${ }^{19}$ Lwoff, A. Sur la nutrition des infusoires. Compt. Rend. Acad. Sci., 176: 928-930. 1923.

${ }^{20}$ Zumstein. Zur Morphologie und Physiologie der Euglena gracilis Kílebs. Jahrb. wiss. Bot., 34: 149. 1900. 
The green Paramoecium bursaria was cultivated ${ }^{21}$ on a medium consisting of:

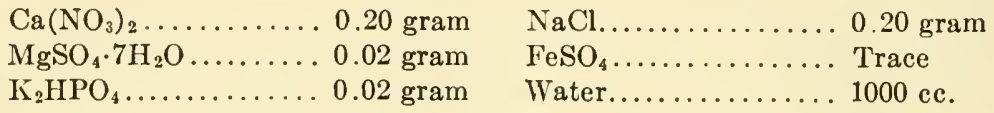

Peters' glycerophosphate medium, described below, has been used successfully for the cultivation of ciliates. Colpidium and Oicomonas were grown on the following medium:22

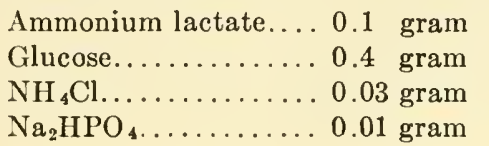

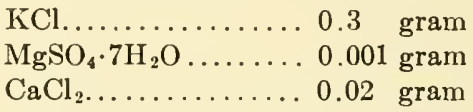

The reaction is adjusted to pH 7.0-7.4. Phenol red may be added to the cultures to follow changes in the acidity and alkalinity during the growth of the culture. Giltay solution and a synthetic glycerin medium may also be employed. ${ }^{23}$

However, the majority of the media used for the isolation of protozoa are based upon a previous development of bacteria, which, either alive or dead, may serve as food for the protozoa. Such substances as soil, straw, hay, grass, lettuce, leaves, etc. cooked in water are favorable.

Thirty to 40 grams of hay are cooked in one liter of water for thirty minutes $;^{24}$ solution is filtered, made up to volume; to prepare a solid medium 15 grams of agar are added. 0.025 per cent meat extract in distilled water was found ${ }^{25}$ to be favorable for Paramoecium aurelia. Other media containing one to two per cent of nutrose, somatose, or peptone and 1.5 per cent agar are also favorable. Martin and Lewin ${ }^{26}$ used a medium prepared by boiling three lumps of horse dung in 500 cc. water for $1 \frac{1}{2}$ hours, filtering through cloth and adding 6 grams of agar. A small amount of water or dilute albumin added to the culture plates to a depth

${ }_{21}$ Pringsheim, E. G. Die Kultur von Paramoecium bursaria. Biol. Centrbl. 35: 375. 1915; Zur Physiologie saprophytischer Flagellaten (Polytoma, Astasia, and Chilomonas). Beitr. Allg. Bot., 2: 88-137. 1921.

${ }^{22}$ Cutler, D. W., and Crump, L. M. The rate of reproduction in artificial culture of Colpidium colpoda. Biochem. Jour., 17: 174-186, 878-886. 1923.

${ }^{23}$ Cutler, D. W. Methods for the study of soil protozoa. Abderhald. Handb. biol. Arb. Method. Abt. XI, T. 3. 1926.

${ }^{24}$ Further information on hay infusions is given by Woodruff, L. L. Observations on the origin and sequence of the protozoan fauna of hay infusions. Jour. Exp. Zool., 12: 206-264. 1912; Fine, M. S. Chemical properties of hay infusions with special reference to the titratable acidity and its relation to protozoan sequence. Ibid., 12: 265-289. 1912.

${ }^{25}$ Woodruff, L. L. Jour. Exp. Zool., 12: 205. 1912; 14: 575. 1913.

${ }_{26}$ Martin, C. H., and Lewin, K. B. Some notes on soil protozoa. Phil. Trans. Roy. Soc. B, 205: 77-94. 1914; Jour. Agr. Sci., 7: 106-119. 1915. 
of $2 \mathrm{~mm}$. favored the growth of protozoa. Meat extract agar may also be used. Bacterial growth takes place from those cells which are transferred with the protozoa. In some cases, special bacterial cultures are inoculated. To prevent the accumulation of injurious by-products, the protozoan culture must be frequently transferred. A rapid development of bacteria may lead to the destruction of protozoa or may prevent their growth. ${ }^{27}$ Media containing 0.3 to 0.5 gram Liebig's beef extract, 0.3 to 0.5 gram NaCl and 20 grams of agar in 1000 cc. of water have commonly been employed. Beijerinck ${ }^{28}$ used yeasts for the cultivation of amoebae and ciliates. As a solid medium for the cultivation of amoebae, a mixture of 20 parts of agar, 100 parts of beef bouilion and 900 parts distilled water of a neutral or slightly alkaline reaction may be employed. ${ }^{29}$

The use of dead bacteria for the cultivation of amoebae has been suggested. ${ }^{30}$ Amoebae and ciliates were found ${ }^{31}$ capable of assimilating pure cultures of bacteria, utilizing dead cells as well as small particles of protein material. Gram negative bacteria were preferred to gram-positive forms; young bacterial cultures in many cases were more assimilable than old cells. Successful cultures were obtained on bacteria smeared on the plate, then autoclaved at $130^{\circ}$, for 1 hour. Azotobacter was found ${ }^{32}$ to offer good food for amoebae, on a medium containing 10 grams of dextrin, 2 grams $\mathrm{K}_{2} \mathrm{HPO}_{4}, 0.2$ gram $\mathrm{MgSO}_{4}$, 0.2 gram $\mathrm{CaCO}_{3}, 10$ grams agar in 1000 cc. water. Paramoecium was also grown in pure cultures of bacteria. ${ }^{33}$ Severtzoff $^{34}$ cultivated an amoeba on a pure culture of Bact. coli; she found that the bacterium was destroyed by a small quantity of chlorine, while the protozoan cysts

${ }^{27}$ Oehler, R. Wirkungen von Bakteriengiften auf Ciliaten. Centrbl. Bakt. I, Orig., 86: 494-500. 1921.

${ }^{28}$ Beijerinck, M. W. Kulturversuche mit Amöben auf festem Substrat. Centrbl. Bakt. I, 19: 257-267. 1896; 21: 101-102. 1878. See also Mouton, 1902 (p. 316).

${ }^{29}$ Wasielewski, T. V., and Kühn. Untersuchungen über Bau und Teilung des Amöbenkerns. Zool. Jahrb. Anat., 38: 253. 1914; also Heidelberg. Akad. Wiss Math. u. Naturw., 1: 1-31. 1913.

${ }^{30}$ Tsujitani, J. Úber die Reinkultur der Amoebae. Centrbl. Bakt. I, 24: 666-670. 1898 .

${ }^{31}$ Oehler, R. Amöbenzucht auf reinem Boden. Arch. Protistenk., 37: 175190. 1916; Flagellaten und Ziliatenzucht auf reinem Boden. Ibid., 40: 16 . 1919 ; 41: 34. 1920; 49: 112-134. 1924; Gozony, L. Kultur von Flagellaten in festen Nährböden. Centrbl. Bakt. I, Orig., 84: 565-566. 1920.

${ }^{32}$ Welch, M. W. The growth of amoeba on a solid medium for class use. Trans. Amer. Micr. Soc., 36: 21-25. 1917.

${ }^{33}$ Hargitt, F. T., and Fray, W. W. Paramoecium grown in pure cultures of bacteria. Anat. Rec., Philadelphia, 11: 516. 1916; Jour. Exp. Zool., 22: 421. 1917.

${ }^{34}$ Severtzoff, 1924. 
were left unaffected. As soon as the chlorine was removed, the amoebae excysted and began to feed rapidly on the rlead bacterial cells; when the food supply became exhausted, the protozoa encysted again. ${ }^{35}$

Robertson ${ }^{36}$ ascribed the autocatalytic phenomenon observed in the growth of protozoa to an accessory foodstuff, a soluble product of bacterial metabolism. According to Cutler it seems very uncertain that autocatalysis occurs in protozoal growth, but, if the curve is autocatalytic in nature, this is due to an increased food supply (bacteria) and not to an accessory food as Robertson suggested. Certain species of bacteria, like Bact. fuorescens and Bact. coli, may produce substances injurious to the development of the protozoa. This injurious effect may be due to the consumption of oxygen by the bacteria, or to a change in reaction brought about by bacterial growth. ${ }^{37}$

Isolation of pure cultures of protozoa. By examining crude cultures of protozoa from time to time, it is found that there is usually in any given culture a more or less definite succession of animal forms. By selecting the time and method of culture, it is possible to isolate pure protozoan cultures. Several methods have been utilized ${ }^{38}$ for isolation of amoebae, the simplest of which consists in destroying the bacteria by means of heat or disinfectants (also 2 per cent $\mathrm{HCl}$ over night or 20 per cent $\mathrm{Na}_{2} \mathrm{CO}_{3}$ for 3 days) in encysted protozoan cultures; the more resistant cysts survive. The use of the Barber pipette or Chambers' apparatus has also been suggested. Oehler inoculated first a dish containing agar or gelatin medium with a pure culture of a certain bacterium, then a mixed protozoan culture was inoculated into the center of the dish.

${ }^{35}$ Further information on the eultivation of amoebae is given by Schaeffer, A. A. Chnice of food in amoeba. Jour. Anim. Behavior, Cambridge, 7: 22025S. 1917; Arndt, A. Zur Technik der Amöbenzüchtung. Centrbl. Bakt. I, Orig., 88: 417. 1922. The influenee of baeteria upon the growth of protozoa is diseussed by Chatton, E., and Chatton, M. L'influenee des faeteurs baetériens sur la nutrition, la multiplieation et la sexualité des infusoires. Compt. Rend. Aead. Sei., 176: 1262-1265. 1923. The use of baeterial solutions for the eultivation of protozoa was reviewed by Cunningham, A., and Löhnis, F. Studies on soil protozoa: I. 'The growth of protozoa on various media and the effect of heat on aetive and eneysted forms. Centrbl. Bakt. II, 39: 596-610. 1914. Killer, J. Die Zählung der Protozoen im Boden. Centrbl. Bakt. II, 37: 521534. 1913. A detailed review of the earlier literature on the eultivation of protozoa is given by Kopeloff, Lint and Coleman, 1917 (p. 328).

${ }^{36}$ Robertson, T. B. The multiplieation of isolated infusoria. Bioehem. Jour., 15: 595-611, 612-619. 1921.

37 Oehler, 1921 (p. 319).

${ }^{38}$ Gordon, C. E. A method for obtaining amoeba. Scienee, 46: 212. 1917. 
After three days, the protozoa reached the edge of the dish. The process was repeated until finally a culture of protozoa was obtained free from any bacteria except the species inoculated into the dish.

A sample of the liquid containing the protozoa may be brought into a fine capillary tube, from which a single drop is ejected on a counting chamber (haemocytometer pattern) and immediately examined under the microscope. When a drop is obtained which contains a single organism, a drop of sterile medium or a culture of the specific bacterium is placed upon a clean cover slip which is then put on the chamber so that both drops coalesce. The chamber is then placed in a Petri dish lined with moist filter paper, and incubated. By projecting the inage of the drop upon a screen, the multiplication of the protozoan can be followed. ${ }^{39}$

It is sometimes essential to obtain cultures of protozoa free from living bacteria. This has been done by Peters, ${ }^{40}$ who isolated Colpidium colpoda from a hay infusion culture, in a drop of sterile medium, upon a sterile microscope slide.

By the use of a capillary pipette made of drawn-out glass tubing and fitted with a rubber bulb the organism was transferred, through several changes of sterile medium, upon sterile microscope slides. After about six washings, the organism was transferred to a fresh drop of sterile medium, which was placed in a two inch depression block and covered with a small sterile cover-glass, both of which had been previously sterilized by heat. By a process of trial and error, organisms were finally obtained which divided well in the sterile medium. The culture was then transferred to a sterile tube plugged with cotton.

Two media were used for the isolation and cultivation of the organism:

\begin{tabular}{|c|c|c|}
\hline I. $\mathrm{NaCl}$. & $\begin{array}{l}\text { per cent } \\
0.06\end{array}$ & $\begin{array}{c}\text { per cent } \\
0.03\end{array}$ \\
\hline $\mathrm{KCl} .$. & 0.0014 & Histidine. \\
\hline $\mathrm{CaCl}_{2}$. & 0.0012 & Arginine.... \\
\hline $\mathrm{Na}_{2} \mathrm{HPO}_{4}$. & 0.0001 & Ammonium lactate. \\
\hline $\mathrm{KH}_{2} \mathrm{PO}_{4} \ldots$ & 0.0001 & $\mathrm{FeCl}_{3} \ldots \ldots \ldots \ldots$ \\
\hline $\mathrm{MgSO}_{4}$. & 0.001 & Trace \\
\hline $\mathrm{NaHCO}_{3}$. . & 0.002 & $\mathrm{MnCl}_{2} \ldots \ldots \ldots$ \\
\hline Phenol red & Trace & Glass-distilled water \\
\hline
\end{tabular}

${ }^{39}$ Cutler and Crump, 1923 (p. 318).

${ }^{40}$ Peters, (p. 317). The results need confirmation and should not be considered as conclusive evidence. 
The constituents are sterilized separately and the final mixture sterilized at $80^{\circ} \mathrm{C}$. on three consecutive days. The reaction of the medium is adjusted to $\mathrm{pH} 7.4$.
$\mathrm{KCl} \ldots \ldots \ldots \ldots \ldots \ldots . \ldots . \ldots 01$

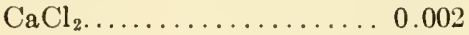

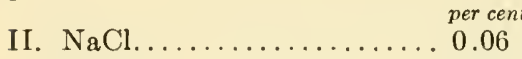
per cent
0.001
phate.............. 0.06
Phenol red............. Trace
$\mathrm{MgSO}_{4} \ldots \ldots \ldots \ldots \ldots \ldots$
Ammonium glycerophos-

As a result of a series of studies, Peters demonstrated that glucose and ammonium lactate can serve as good sources of carbon and nitrogen for Colpidium. In addition to these, phosphates and chlorides, as well as potassium and magnesium are required. Amino acids can take the place of ammonium salts as sources of nitrogen. Carbon sources containing less than three carbon atoms in the molecule are not utilized; glycerate is used, but not lactate or citrate. Purdy and Butterfield ${ }^{41}$ found, however, by the use of pure, bacteria-free cultures of protozoa, that the latter cannot exist in culture solutions containing organic matter, but free from bacteria; these form the main food of the protozoa, which develop at the expense of the bacteria.

The concentration of the medium, reaction and temperature are of great importance in the cultivation of protozoa. A ciliate and a bacterium were cultivated ${ }^{42}$ in a 0.1 per cent peptone solution, adjusted to $\mathrm{pH}$ 6.8 , at $22^{\circ}$ to $25^{\circ}$. At 24 hours, bacterial growth took place followed by that of protozoa. The protozoa could be separated from the bacteria electrolytically. Under the influence of the fall of potential, the protozoa travel to the cathode and the bacteria to the anode. This has to be repeated 6 times before cultures of protozoa free from bacteria are obtained. This procedure combined with the destruction of bacterial cells by heat were utilized by Oehler ${ }^{43}$ for the purification of amoebae and ciliates. By keeping dry cultures of protozoan cysts at $37^{\circ}$ for 6 weeks, the bacterial vegetative cells were destroyed. Water and a culture of Saccharomyces were then added to the culture and the protozoa excysted. The yeasts can be killed at $60^{\circ}$ for 24 hours. By the use of a cataphoresis apparatus and unpolarized electrodes in 0.65 per cent $\mathrm{NaCl}$ solution, the ciliates were found to travel to the cathode. However, the plate method was found to be best and the fact that protozoa

${ }^{41}$ Purdy, W. C., and Butterfield, C. T. The effect of plankton animals upon bacterial death-rates. Amer. Jour. Public Health, 8: 499-505. 1918.

42 Amster. Ein neues Züchtungsverfahren fïr Protozoen. Centrbl. Bakt.

I, Orig., 89: 166-168. 1922.

${ }^{43}$ Oehler, 1924 (p. 319). 
travel faster than bacteria is utilized in the making of transfers. Bact. fuorescens was used to repress the accompanying bacteria.

Staining of protozoa. ${ }^{44}$ Whenever possible, protozoa should be examined in a living condition, by suspending a drop of the medium or a suspension in water in a hanging drop. The motility of protozoa can be reduced as pointed out elsewhere (p. 45); various colloids (e.g. 5 per cent gelatin solution), narcotics (e. g. cocaine) or other poisons in subletal concentrations (e.g. tannic acid) can be used, varying with the species. Among the vital stains, 1 to $800-10,000$ neutral red, 1 to 10,000 $-100,000$ Bismark brown, nigrosin, methylene blue, malachite green or 1 to 500,000 cyanin may be used.

For the examination of finer structure, the protozoa are first fixed, while moist, then stained and finally dehydrated without allowing the preparation to dry. Mayer's albumin ( $50 \mathrm{cc}$. filtered egg-white +50 cc. glycerol, +1 gram sodium salicilate) may be first spread over the slide to prevent the washing away of the protozoa. A number of fixative agents have been suggested; of these a few may be mentioned:

$a$. Sublimate fixative (Schaudinn's): 2 parts of a concentrated aqueous solution of sublimate +1 part of 96 per cent alcohol +5 per cent acetic acid. Fix 10 to 30 minutes, wash in 60 per cent alcohol containing some iodine and potassium iodide, then in 70 per cent solution.

$b$. Picric acetic acid: $95 \mathrm{cc}$. of concentrated aqueous solution of picric acid +5 cc. of acetic acid. Fix for 10 minutes, then wash with 50 per cent alcohol, then in 70 per cent alcohol.

c. Chromo-aceto-osmic acid (Flemming's): $15 \mathrm{cc}$ of 1 per cent chromic acid, $4 \mathrm{cc}$. of 2 per cent osmic acid, and $1 \mathrm{cc}$. of acetic acid. Fix for 30 minutes and wash with water.

$d$. Picro-formol: 75 parts of an aqueous saturated picric acid solution, 25 parts of formaldehyde, 5 parts of acetic acid.

For staining purposes a number of dyes have been recommended, a few of which are given here:

$a$. Heidenhain's iron haemotoxylin. The preparation is first treated with 3 per cent solution of ferric alum $\left(\mathrm{NH}_{4}\right)_{2} \mathrm{Fe}_{2}\left(\mathrm{SO}_{4}\right)_{4}$, for 30 minutes, then washed with water and placed in a 0.5 per cent aqueous solution of haemotoxylin for 1 to 14 hours, then washed with water and treated with 1.5 per cent solution of ferric alum. As soon as a satisfactory differentiation has been obtained, the preparation is washed for 30 minutes in flowing water.

44 A detailed review of the fixing and staining or protozoa is given by Hargitt, Doflein and von Prowazek, while the staining of soil protozoa is given by Goodey. Hargitt, G. W. Methods of studying and mounting protozoa. Jour. Appl. Micros., 385-388. 1899; Goodey, T. A contribution to our knowledge of the protozoa of the soil. Proc. Roy. Soc. (London) B, 84: 165-180. 1911; 88: 437456. 1915; 89: 297-314. 1916. See also Bolles Lee. The microtomist's Vade mecum, and N. Hartmann. Praktikum der Protozoologie. Fischer. Jena. 
b. Delafield's haemotoxylin: 4 grams of haemotoxylin crystals are dissolved in $20 \mathrm{cc}$. of 95 per cent aleohol and added to $400 \mathrm{ce}$. of a saturated solution of ammonia alum. The mixture is exposed for a few days, filtered, and 100 ce. of glyeerol and 100 ee. of methyl aleohol are added. Solution is allowed to stand until dark, then filtered. The preparation is placed in a dilute solution of the stain in water for 30 minutes or more. When overstained, acid alcohol may be used to remove excess.

$c$. Safranin light green. The preparation is plaeed for 1 to 24 hours in a concentrated aqueous safranin solution, then washed in alcohol and placed in an alcoholic light green solution.

Among the other stains, the Giensa stain, Mann's methylene blue-eosin stain, gentian-violet and safranin may also be mentioned, while for eiliates simple staining in borax earmine is usually suffieient.

After staining, the preparation is dehydrated by passing through increasing strengths of alcohol (after washing with water, a low concentration of alcohol is used at first) to 90 per cent, then in a mixture of 1 part of absolute alcohol + 1 part xylol, then in pure xylol. The preparation is then mounted in Canada balsam.

Martin and Lewin ${ }^{45}$ examined the active soil fauna in fresh films by using pieric alcohol (50 per cent saturated solution picric acid in water +50 per cent pure alcohol), or corrosive alcohol (50 per cent saturated solution of corrosive sublimate in water +50 per cent pure aleohol). The soil is placed in a porcelain dish and enough of the fixative is poured through a funnel to the bottom of the soil layer until the soil is just covered: the dish is then slightly shaken. A film is formed which contains protozoa in a fixed and stained condition. By floating eoverslips on the surface of the liquid, the protozoa are removed and can be examined mieroscopically.

Life history of protozoa. 'The life history of a protozoan in the soil consists of a period of activity, when the animal moves, feeds and reproduces, and a period of rest, when a thick wall is secreted around the body and the cell (or cyst) becomes capable of resisting adverse conditions; the animal is distributed from place to place in the cyst state. When conditions become favorable, the wall is ruptured and the animal again becomes active. Sometimes, actual reproduction takes place within the cyst, as in Colpoda steinii. More seldom the eyst results from conjugation of two similar animals forming a large body known as the zygote. ${ }^{46}$ The physiology of encystment and excystation are obscure points concerning which a considerable literature is growing up. Earlier writers regarded cyst formation as a direct response to unfavorable external conditions and excystation as occurring whenever a cyst found itself again in an environment suitable for active life. Experi-

${ }^{45}$ Martin and Lewin, 1914-15 (p. 318).

${ }^{46}$ Martin, C. H. A note on the protozoa from siek soils, with some account of the life history of a flagellate monad. Proc. Roy. Soc. B, 85: 393-400. 1912. 
mental work has however failed to support this attractive theory and it appears that internal causes may play at least as great a part as external factors. ${ }^{47}$

Cysts are more resistant than active protozoa to the action of enzymes; also to chemicals, ${ }^{48}$ the toxic order being $\mathrm{CS}_{2}>$ alcohol $>$ acetone $>$ benzol $>$ ether $>$ xylol $>$ chloroform $>$ carbon tetrachloride. The relative toxic effect of acids upon excystation is salicylic $>$ butyric $>$ oxalic $>$ phosphoric $>$ hydrochloric $>$ sulfuric $>$ acetic. Cysts and active organisms acclimatize to higher temperatures. The greater the degree of desiccation, the higher the resistance of cysts to higher temperatures and chemicals. The cyst of Colpoda was found ${ }^{49}$ to consist of a carbohydrate, which is digested by an enzyme secreted by the enclosed organism during the process of excystation. In other protozoa the structure of the cyst wall is different being siliceous in Monas and related flagellates. Excystation may take place by digestion of the wall or by its rupture or by the emergence of the organism through a preformed pore which is a very characteristic structure in some forms.

Certain soil amoebae have also flagellate stages. ${ }^{50}$ Naegleria gruberi (No. 128, Pl. XVII) is a soil amoeba found in California soils to a depth of over 20 feet. This amoeba has a biflagellate phase, enflagellates and exflagellates rather quickly on slight provocation under the conditions of laboratory culture. It takes about 70 minutes for a culture of amoebae to change into the flagellate stage, while the reverse process is somewhat more prolonged and less uniform. The addition of water, of fresh culture medium (filtered and sterilized soil and manure infusions) or an excess of air tend to induce enflagellation, but exflagellation is less definite in response to opposite factors. ${ }^{51}$

Occurrence of trophic and encysted protozoa in the soil. The first detailed careful examination of the occurrence of active and inactive

${ }^{47}$ Kofoid, C. A. The life cycle of the protozoa. Science, N. S., 67: 397408. 1923.

${ }^{48}$ Bodine, J. H. Excystation of Colpoda cucullis. Some factors affecting excystation of C. cucullis from its resting cysts. Jour. Exp. Zool., 37: 115-125. 1923.

${ }^{49}$ Goodey, T. The excystation of Colpoda cucullis from its resting cysts, and the nature and properties of the eyst membranes. Proc. Roy. Soc. B, 86: 427439. 1913.

${ }^{50}$ Wilson, C. W. On the life-history of a soil amoeba. Univ. Cal. Publ. Zool., 16: 241-292. 1915. Kofoid, C. A. On the relative numbers of rhizopods and flagellates in the fauna of soils. Science, N. S., 42: 937-940. 1915.

${ }^{61}$ A cletailed discussion of natural history of protozoa is given by Dofflcin, $\mathrm{F}$. Studien zur Naturgeschichte der Protozoen. Zool. Jahrb., 41: 1-112. 1919. 
protozoa in the soil was carried out by Goodey ${ }^{52}$ who concluded that ciliates are present in the soil only in an encysted condition and can, therefore, not function as a factor limiting bacterial activity in the soil. Martin $^{53}$ found that smaller amoebae and flagellates play the most important part in the phenomena of sick soils, while the limiting factor as regards the activity of protozoa in the soil is the average quantity of water. Subsequent investigations ${ }^{54}$ demonstrated that a protozoan fauna normally occurs in the soil in a trophic state; this trophic fauna is most readily demonstrated in moist soil well supplied with organic matter, like heavily manured soils, sewage soils and especially greenlouse "sick" soils; the forms predominating in the soil are not necessarily the same as those that develop on artificial media (hay infusions) inoculated with soil.

A series of preparations of trophic amoebae, thecamoebae and flagellates were made ${ }^{54}$ by the methods described above. Flagellates were found ${ }^{55}$ to be the most numerous and the only active forms in moist soils; however, amoebae were not looked for. According to Crump and Cutler, ${ }^{56}$ flagellates, amoebae and thecamoebae are present in large numbers in a trophic condition in the soil; the fauna increasing with an increase in the content of organic matter in the soil.

Various American investigators ${ }^{57}$ believed that the protozoa exist in the soil mainly in a non-trophic state. Koch concluded that protozoa do not exist in normal field soils or even in soils where the moisture content is somewhat above normal; in greenhouse soils containing much organic matter and with a high moisture content, a few living protozoa were present. The protozoa were found to become active in the soil, whenever the moisture content rises considerably above the normal; both moisture and organic matter were found to be the principal limit-

${ }^{62}$ Goodey, 1911-1915 (p. 323).

${ }^{53}$ Martin, C. H. The presence of protozoa in soils. Nature (London). $1913,111$.

${ }^{64}$ Martin and Lewin, 1914-1915 (p. 318); Goodey, 1916 (p. 323).

${ }_{55}$ Waksman, S. A. Studies on soil protozoa. Soil Sci., 1, 1916, 135-152; 2: 363. 1916.

${ }^{56}$ Crump, 1920 (p. 328); Cutler, D. W. Observations on soil protozoa. Jour. Agr. Sci., 9: 430-444. 1919.

${ }^{57}$ Sherman, J. M. Studies on soil protozoa and their relation to the bacterial flora. Jour. Bact., 1: 35, 165. 1916; Koch, G. P. Soil protozoa. Jour. Agr. Res., 4: 511-559. 1915; 5: 477-4S8. 1915; Soil Sci., 2: 163. 1916; Fellers, C. R., and Allison, F. E. The protozoan fauna of the soils of New Jersey. Soil Sci., 9: 1-25. 1920. 
ing factors in the development of protozoa in the soil. According to Cutler, ${ }^{56}$ there is an intimate mechanical association between the protozoa and the soil particles which depends on a mutual surface action, and the capacity of various substances, such as sand, soil and clay, for retaining these organisms is specific and constant. The difficulty of seeing living protozoa in the soil is, therefore, due to the fact that the organisms rigidly adhere to the soil particles, and, up to a certain limit, they can be completely removed from a suspension by shaking for a few minutes with soil. Only in exceptional cases can organisms be dislodged sufficiently as to be recognized under the microscope. This is probably the reason why some investigators failed to observe living protozoa in the soil. It is beyond any doubt that protozoa lead a trophic existence in the soil; this is especially true of the small flagellates. Even if most of them encyst after a continuous dry period, the first rain that brings the moisture content of the soil to optimum will lead to a rapid excystation of the protozoa and to a longer or shorter period of activity.

A method was described by which it is possible to estimate the number of protozoa present in the soil both in a trophic and in a cyst condition. ${ }^{58}$ The total number is first determined by the dilution method. A fresh portion of the soil is then treated with 2 per cent $\mathrm{HCl}$ (specific gravity 1.15) over night, whereby all active forms are killed. A second count by the dilution method gives the number of protozoa present in the soil in the form of cysts. The difference between the first and second counts gives the number of active protozoa. In this connection reference may be made to the work of Cunningham and Löhnis, ${ }^{59}$ who found $60^{\circ} \mathrm{C}$. to be the themal death point of active protozoa $\left(44^{\circ}\right.$ for flagellates, $48^{\circ}$ for amoebae and $54^{\circ}$ for ciliates), while $72^{\circ} \mathrm{C}$. was found to kill the cysts. However, the temperature destructive to protozoa in the soil would be different from that of culture solutions. A temperature of $58^{\circ} \mathrm{C}$. was used $^{60}$ for distinguishing between cysts and active forms, but it was soon found that many cysts are also killed at that temperature. Drying reduced the number of protozoa, particularly ciliates and flagellates, amoebae preferring a somewhat drier soil.

The protozoa are widely distributed in the soil, comprising ciliates, flagellates, amoebae and thecamoebae. Some investigators reported

${ }_{58}$ Cutler, D. W. A method for estimating the number of active protozoa in the soil. Jour. Agr. Sci., 10: 135-143. 1920.

${ }^{59}$ Cunningham and Löhnis, 1914 (p. 320).

${ }^{60}$ Cunningham, A. Studies on soil protozoa. Jour. Agr. Sci., 7: 49-74. 1915 . 
an abundance of ciliates and flagellates and few amoebae, ${ }^{61}$ others ${ }^{62}$ found amocbae and thecamocbae most prevalent. The discrepancy may be due to the difference in methods used, especially in view of the sensitiveness of the latter two groups to the composition of the medium. Water appears to be the most important controlling factor, favoring the development of the soil fauna. ${ }^{63}$ The largest numbers of protozoa are found in the soil in spring, after the thawing of snow or in summer, after heavy rainfall: only cysts are found in dry and semi moist soils. ${ }^{64}$ According to Crump, the protozoan fauna is largely confined to the top six inches of soil. The amoebae are influenced by variations in the water content and temperature of the soil and by the rainfall. The richer the soil is in organic matter the richer it is in protozoa, especially in amoebae and thecamoebae. A detailed study has been made of the presence of protozoa in peat soils, ${ }^{65}$ in Egyptian soils, ${ }^{66}$ in Italian soils, ${ }^{67}$ in German soils, ${ }^{68}$ in the soils of the United States, ${ }^{69}$ in Russian soils, ${ }^{70}$ and in English soils $;^{71}$ an abundant fauna was found in various samples of moss and soil from Spitzbergen and in soils of various South Sea and Atlantic islands (Tristan da Cunha, Gough Islands, etc.). ${ }^{72}$ Most

${ }^{61}$ Feuilletau and de Bruyn, W. K. H. Über die Verbreitung von Bodenprotozoen in den Alpen. Centrbl. Bakt. II, 56: 12-13. 1922.

${ }^{62}$ Crump, L. M. Numbers of protozoa in certain Rothamsted soils. Jour. Agr. Sci., 10: 182-198. 1920.

${ }^{63}$ Coppa, A. Ricerche sui protozoi dei terreni delle acque ticinesit. Staz. sper. Agrar. ital., 54: 181-213. 1921.

${ }^{64}$ Nowikoff, M. Die Bodenprotozoen und ihre Bedeutung für die Bodenkultur. Heidelberg. 1923. C. Winter.

${ }^{65}$ Scheffelt, E. Die Einzeller der süddeutschen Moore. Mikrokosmos, 15 : 113-118. 1922.

${ }^{66}$ Ross, R., and Thomson, D. Egyptian sand amocbac. Proc. Soc. Med., Sect. Epiden., 9: 33. 1916.

${ }^{67}$ Cauda, A., and Sangiorgi, G. Untersuchungen über die Mikrofauna der Boden aus Reisgegenden. Centrbl. Bakt. II, 42: 393-398. 1914.

${ }^{68}$ Wolff, 1912 (p. 329); Oehler, 1916-1919 (p. 319).

${ }^{69}$ Kopeloff, N., Lint, C., and Coleman, D. A. A review of investigations in soil protozoa and soil sterilization (complete bibliography up to 1917). Soil Sci., 3: 197-269. 1917. Fellers and Allison, 1918 (p. 326).

${ }^{70}$ Yakimoff, M. L., and Zérèn, S. Contribution à l'étude des protozoaires des sols de Russie. Centrbl. Bakt. II, 63: 33-57. 1924; Nowikoff, 1923.

${ }^{71}$ Goodey, 1911-1915 (p. 323); Martin and Lewin, 1914-1915 (p. 318); Cutler and Crump, 1920 (p. 50); Sandon, 1927 (p. 329).

${ }^{72}$ Sandon, H. Some protozoa from the soils and mosses of Spitzbergen. Linn. Soc. Jour., 35: 449-475. 1924; Sandon, H., and Cutler, D. W. Some protozoa from the soils collected by the "Quest" Expedition. Linn. Soc. Jour., 36: $1-12$. 1924 . 
of the protozoa found in these far-away soils were identical with those found in soils in temperate climates such as English soils. A detailed study of numbers of protozoa in the soil is given elsewhere (p. 45).

Classification and occurrence of protozoa in the soil. The majority of soil protozoa are cosmopolitan, since the species found throughout the world are, with some exceptions, identical, although not all the species are found in every soil. Protozoa were demonstrated in large numbers in the soil by Ehrenberg, ${ }^{73}$ Greef, ${ }^{74}$ and Rosenberg-Lipinsky ${ }^{75}$ who considered them to be of importance in soil fertility. In the more recent contributions to the subject, a study has been made of the occurrence of protozoa in the soil and of the influence of environmental conditions upon their distribution. ${ }^{76-81}$

Fellers and Allison ${ }^{78}$ found 17 species of rhizopods, thirty-four flagellates, and fifty-one ciliates in New Jersey soils, fertile soils containing more species and greater numbers of protozoa than unfertile soils. They conclucled that the soil microfauna consists principally of small, hardy protozoa able to withstand, by means of encystation or otherwise, such extremes of heat and cold, desiccation, aeration, etc., as are natural to their life in the soil. Practically all species identified from the soil have also been found in fresh water lakes, ponds, pools and streams of New Jersey, but not in the same relative abundance, while several of the most common plankton organisms are rarely found in the soil.

Cutler and associates ${ }^{79}$ found six species of protozoa occurring con-

${ }^{73}$ Ehrenberg, C. G. Dic fossilen Infusorien und lebendige Dammerde. 1837. Berlin; Die Infusoriensthierchen als volkommene Organismen. 1839.

${ }^{74}$ Greef, R. Über einige in der Erde lebende Amöben und andere Rhizopoden. Arch. micros. Anat., 2: 299-311. 1866.

${ }^{75}$ Rosenberg-Lipinsky, Alb. v. Der praktische Ackerbau (etc.), 2: 27. 1869, Breslau.

${ }^{76}$ Wolff, Max. Der Einfluss der Bewässerung auf die Fauna der Ackerkrume mit besonderer Berücksichtigung der Bodenprotozoen. Mitt. Kaiser Wilhelm Inst. Landw. Bromberg., I: 382-401. 1909; Centrbl. Bakt. II, 33: 314-320. 1912.

${ }^{77}$ Martin and Lewin, 1914-1915 (p. 318).

${ }^{78}$ Fellers and Allison, 1920 (p. 326).

${ }^{79}$ Cutler, Crump and Sandon, 1922 (p. 32).

${ }^{80}$ Fantham, H. B., and Taylor, E. Some protozoa found in certain South African soils. So. African Jour. Sci., 18: 373-393. 1922; 19: 340-371. 1922; 20: 437-492. 1923; $21: 445-479$. 1924.

${ }^{81}$ Sandon, 1924 (p. 328); Sandon and Cutler, 1924 (p. 328); Sandon, H. The composition and distribution of the protozoan fauna of the soil. Oliver and Boyd. Edinburgh and London. 1927. 
stantly in the soil in sufficient numbers to admit the application of statistical methods to the results. These are: (1) Dimastigamoeba gruberi, (2) a small limax amoeba, (3) Heteromita sp. resembling Bodo repens, (4) a small soil flagellate, 3 to 6 by 2 to $3 \mu$; (5) Cercomonas sp. and (6) Oicomonas termo. Sandon found the following average number of species of protozoa in 107 soils examined: 7.2 flagellates, 3.4 ciliates, 2.45 amoebae and 2.0 testaceous rhizopods. While some species develop in all media employed, other forms develop only upon certain specific media.

In all Sandon ${ }^{81}$ recorded 250 species of protozoa, a small number of which were found in every soil, often in very large numbers. The flagellates Hetcromita globosus, Oicomonas termo and Cercomonas sp., the ciliates Colpoda cucullus and $C$. steinii, and the limax amoebae Näegleria gruberi and Hartmanella hyalina were most common and most abundant. While most protozoa found in the soil are also found in various other habitats, such as standing and flowing fresh waters, sea water, plankton, ete., a few are found only in the soil.

The genera and species of protozoa vary with locality and degree of soil cultivation. Fantham and Taylor ${ }^{80}$ found 1 to 22 species in each of a series of South African soils; the flagellates were largest in total number's, while the ciliates showed the largest number of species; the amount of organic matter being the limiting factor; dark, heavy, humus rich soils contained more protozoa than sandy soils; the reaction of the soil was not found to have any effect upon the protozoan fauna. Sandon has shown that the extreme climate of arctic land is not in itself an obstacle to the abundant development of protozoa, provided the soil is well manured and in good condition; however, peat soils are decidedly unfavorable for the development of protozoa except for the testaceous forms. A close positive connection has also been observed ${ }^{78,81}$ between the numbers of protozoan species and bacteria in the soil.

The protozoa reported to have been found in the soil can be classified as follows: ${ }^{82}$

82 The following letters ean be used to designate the names of the investigators, who have demonstrated the presence of the specifie protozoa in the soil: A-Wolff in Germany, B-Franeé in Germany, C-Goodey in England, D-Martin or Martin and Lewin in England, E-Waksman in New Jersey, U. S. A., FFellers and Allison in New Jersey, U. S. A., G-Cutler, Sandon and Crump in England, H-Cutler and Sandon in Spitzbergen soils, ete., I-Fantham and associates in South African soils, J-Sandon working with soils collected throughout the world, $\mathrm{K}$-Yakimoff and Zérèn in Russia, L-Perey ${ }^{87}$ in France, MAllison ${ }^{88}$ in England using Ameriean soils, $\mathrm{N}-$ Nowikoff in Russia. 


\section{A. SARCOLINA ${ }^{83}$}

I. ACTINOPODA, pseudopodia with axial filaments.

Heliozoa, spherical, with fine radiating pseudopodia, with stiff axial rods; endoplasm surrounded by vacuolated ectoplasm. The following representatives of this group have been found in the soil: Actinophrys sol (F, I, K, J), Raphidiophrys (F), Acanthocystis aculeata (I), Clathrulina elegans (F).

II. Rnzopoda, pseudopodia without axial filaments.

1. Proteomyxa, pseudopodia fine and radiating, often anastomising or forming a net-work. Among the soil forms belonging to this group are Biomyxa vagans (J), Nuclearia simplex (A, I, J, L, M), Gephyramoeba delicatula (C and J), Leptomyxa reticulata and 1 . flabellata(c), Vampyrella lalerita (F).

2. A

(a) Amocbida, naked rhizopoda, without any shells or supporting structures; pseudopodia blunt or pointed but never filamentous; may be reduced to wave-like expansions of protoplasm.

(a') Amoeba limax group. Sinall amoebae with single rounded pseudopodium; sometimes several finger-like pseudopodia formed simultaneously.

Naegleria gruberi, one of most common soil protozoa recorded by Wilson, F and G. IIartmanclla hyalina is also very abundant in the soil. Amoeba (Hyalodiscus) gutulla was found by A, B, F, I, J and IS.

(b') A. verrucosa group. Pseudopodia in the form of ridges or folds of the ectoplasmal pellicle. A. verrucosa (A.terricola?) was found in the soil by $\mathrm{A}, \mathrm{B}, \mathrm{C}, \mathrm{I}, \mathrm{J}, \mathrm{K}$ and $\mathrm{N}$. A. diploidea by $\mathrm{D}$ and $\mathrm{J}, A$. striata by $\mathrm{B}$ and $\mathrm{J}$.

( $\left.{ }^{\prime}\right)$ A. lamellipodia group, similar to previous group, with less strongly developed pellicle, including: A. glebae (J), A. actinophora (J), A. gobanniensis (D).

$\left(d^{\prime}\right)$ A. proteus group. Large amoebae, changeable in shape, with numerous long, cylindrical pseudo-

${ }^{83}$ For the identification of this group, consult, in addition to the general treatises and papers, also Edmondson, C. H. Amoeboid protozoa (Sarcodinia), in Ward and Whipple's Fresh-water biology. 1918, p. 210; Leidy, J. Fresh water rhizopods of North America, U. S. Geol. Surg., 12: 324. 1879; Cash, J., and Wailes, C. H. The British freshwater rhizopoda and heliozoa. Vols. 1-5, 1905-1921. Roy. Soc. London; Penard, E. La faune rhizopodique du bassin de Léman. Genève. 1902; Poche, F. Arch. Protistenk., 30: 251-310. 1913; Ghosh, E. A new general classification of protozoa. Jour. Roy. Micr. Soc., 272: 327-329. 1925; Sandon, 1927 (p. 329). 
podia. Representatives of this group were found in a number of soils by B, I and J.

$\left(\mathrm{e}^{\prime}\right)$ Various other amoebae have been found in the soil by different investigators, such as $A$. radiosa $(\mathrm{F}, \mathrm{J}, \mathrm{K})$ and $A$. albida $(\mathrm{J})$.

(b) Testacea, rhizopods with shells (tests), into which the whole body ean be withdrawn.

(a') Arcellidae, shells chitinous, pseudopodia lobose or simply branched. Arcella vulgaris was found in the soil by A, B, C, F, I, J and N. A. discoides by $\mathrm{A}$ and J, Pseudochlamys patella by $\mathrm{B}$, Corycia flava by B, Diflugiella by B and J, IIyalosphenia elegans, H. cuneata, II. pupilis and $H$. tincta by B, H. minuta by $\mathrm{J}$.

(b') Difflugidac, ehitinous shells covered by foreign bodies. Representatives of this group found in the soil are Diflugia pyriformis (B, F, I, J), D. globulus (B, C, F, I, J), D. pcnardi (D. fallax) (J), D. lucida and D. craterella (B), D. urceolata $(\mathrm{J}), D$. lobostoma and $D$. arcula (B and J), D. constricta (B and J), Centropyxis aculeata and C. laevigata (J), Phryganella acropodia and $P$. nidulus (B), Heleopera petricola, H. picta, H. rosea and H. sylvatica (B).

(c') Euglyphidae, chitinous shells with plates made by organism, including Euglypha tuberculata (J), E. mucronata (B), E. bryophila (J), E. strigosa (B and $\mathrm{J}), E$. rolunda (J), E. laevus, E. ciliata (B and J), Placocysta spinosa (B), Nebela collaris and $N$. lageniformis (B and J), Quadrula symmetrica and Q. globulosa (B), Q. irrcgularis (J), Assulina muscorum (B and J), A. seminulum (B), Sphenoderia lenta (B), S. fissirostris (J), $S$. denlata (B and J), Campascus sp. (B), Trinema enchclys (A, B, C, J), T. lineare and $T$. complanalum (B and $\mathrm{J}$ ), Corythion dubium (B and $\mathrm{J}$ ).

$\left(d^{\prime}\right)$ Gromiilae, membranous shells, pseudopodiareticulate, forming a network, ineluding Lecythium (Pamphagus) hyalinum (Syn. Chlamydophrys stercorea) found by A, B, C, D, F, J, $\mathrm{K}$ and L, L. mulabile by $\mathrm{B}$ and $\mathrm{F}$, Pseudodiflugia gracilis by B, Allogromia fluialis (Gromia terricola) by Müller, ${ }^{84} \mathrm{~A}$ and J, Microgromia socialis by $\mathrm{F}, \mathrm{J}$ and $\mathrm{K}$, Diplophrys archeri by $\mathrm{F}$.

${ }^{84}$ Müller, P. E. Studien über die natürlichen Humusformen. Berlin. 1857. 
B. MASTIGOPHORA. ${ }^{85}$ The soil flagellates are found largely in the following groups.

I. Pantostomatinae. Flagellates naked, colorless; food ingested, usually by means of pseudopodia, at all points of their surface; the organisms in this group possess one or more flagella and are usually more or less amoeboid.

Actinomonas miralilis was found by $\mathrm{J}$ in 11 soils collected from various parts of the world. Cercomonas crassicauda and C. longicauda are very common soil protozoa (F, G, J, K). Cercobodo was found by $\mathrm{J}$ to be represented in the soil by several species. Mastigamocba and Mastigella, comprising organisms which closely resemble amoebae but possess a single flagellum, directed forward; the flagellum is connected with the nucleus in the case of the former, but not of the latter. Mastigamoebae have been found in the soil by $\mathrm{F}, \mathrm{I}, \mathrm{J}, \mathrm{L}$ and $\mathrm{N}$.

II. Protomastiginae. Small flagellates, usually more or less amoeboid and having a fine periplast. Food taken in at one point, no chromatophores. Pseudopodia when present never acting as organs of locomotion. These include Codonosiga botrytis (C), Monosiga orata (F and J), Salpingoeca convallaria (A), Phalansterium solitarium ( $\mathrm{J}$ in 56 out of 148 soils examined), Bollo (Prowazekia) caudatus (A, D, J), B. cdax (Kühn, ${ }^{86} \mathrm{G}, \mathrm{J}, \mathrm{K}, \mathrm{N}$ ), B. saltans (A, C, F, J, N), Bodo terricola (D and others). A few other species of Bodo were reported in the soil by F, J and K. Colponema symmetrica (J), Dinomonas vorax (D), Heteromita compressus $(\mathrm{J}), H$. globosa and $H$. lens are among the most common soil protozoa: these and $H$. obovata, $H$. ovata, $H$. repens were found in the difierent soils by $\mathrm{H}$ and $\mathrm{J}$; some species of this genus were also recorded by A, E, F. Phyllomitus undulans by A, E and J, P. amylophagus found by F, G and J, Pleuromonas jaculans by A, E, F and I. Sainouron mikroteron was found to be common in Rothamsted soils by $\mathrm{J}$ and also in 45 other soils, found also by L and M. Allantoin tachyploon was found in the soil by J and M. Phyllomonas contorta by A. Proleptomonas

${ }^{85}$ Klebs, G. Flagellatenstudien. Ztschr. wissensch. Zool., 55, 1893; Lemmermann's Algen I. Flagellaten. In Kryptogamenflora der Mark Brandenberg und angrenz. Gebiete. v. 3; Pascher, A., and Lemmermann, E. Flagellatae in "Die Süsswasserflora und Fauna Deutschlands." H. 12, Jena. 1913-1914; Senn, G. Flagellata, in Engler and Prantl's "Die natürlichen Pflanzenfamilien." Bd. I, T. I, 1900; Conn, H. W., and Edmondson, C. H. Flagellate and ciliate protozoa, in Ward and Whipple's Fresh-water biology. 1918, p. 238. Keys for identification of soil flagellates. Sandon, 1927 (p. 329).

${ }^{86} \mathrm{Kühn,} \mathrm{A}$. Über Bau, Teilung und Encystierung von Bodo edax Klebs. Arch. Prot., 35: 212-254. 1915.

${ }^{87}$ Perey, J. F. Les protozoaires du sol. Ann. Sci. Agron., 39: 333-352. 1923.

${ }^{88}$ Allison, R. V. A note on the protozoan fauna of the soils of the United States. Soil Sci., 18: 339-352. 1924. 
faccicola is the only member of the Trypanosomaceae found by $\mathrm{J}$ as free-living in the soil. Spiromonas angusta was found by $A, E, G, J$ and Cunningham and Löhnis. Spongomonas is common in the soil $(J)$, while Cladomonas was found in a Spitzbergen soil by J. Tetramitus rostratus was found by J and M, T. spiralis by $\mathrm{C}, \mathrm{J}, \mathrm{L}$ and $\mathrm{M}, T$. pyriformis by $\mathrm{J}$. $\mathrm{F}$ and $\mathrm{K}$ also recorded the presence of species of Tetramitus in the soil. Hexamitus inflatus was found by F, Spironema multiciliatum by C and J.

III. Chrysomonadinae. Small flagellates; when not possessing chromatophores, resemble the Protomastiginae. Cutiele generally present, but is thin and does not prevent them from becoming amoeboid; 1 or 2 flagella. Cysts endogenous, wall being more or less impregnated with silica. This group includes the following forms found in the soil: Oicomonas termo (D, F, G, J, K), $O$. granulata (K), Chrysamocba radians (I), Mallomonas (E), Monas guttula (A, E, F, J, K, N, Koch, Cunningham and Löhnis), $M$. vivipara $(\mathrm{E}, \mathrm{F}, \mathrm{N})$, Cephalothamnion cyclopum (J), Physomonas elongata (F), Polypseudopodius bacterioides (D).

IV. Cryptomonadinae. Small forms, with two flagella, usually equal, arising behind the anterior end in a hollow which is usually the opening of a funnel running deep into the interior of the cell. Egg-shaped and more or less flattened; body enelosed in membrane and not amoeboid. One or two simple contractile vacuoles at anterior end. These include Chilomonas paramoccium (A, F, I, J, K), Cryptomonas (F, J, K), Cyathomonas truncata (Cunningham and Löhnis), Rhodomonas (I).

V. Euglinidae, characterized by a complicated vacuole system situated at anterior end and consisting of one or more accessory vacuoles which, in eontracting, empty their contents into a large main vacuole or reservoir, which communicates with the cytopharynx. Mostly with green chromatophores, enclosed in a membrane and with 1 or 2 flagella. Euglcna acus was found in the soil by $\mathrm{F}$ and K, E. deses, E. oxyuris and E. spirogyra by I, E. velata by B, E. viridis by A, E, F, I, N, Eutreptia vividis by F, Phacus longicauda by $\mathrm{F}$ and $\mathrm{I}, \mathrm{Ph}$. pyrum by $\mathrm{F}$ and $\mathrm{K}$, Trachelomonas volvocina and Cryptoglena pigra by F. Species of Astasia were found in the soil by D, F, N. Distigma (Astasia) proteus by B and K. Clostenema (Sphenomonas) socialis by F, Menoidium by J, Petalomonas angusta by $\mathrm{J}, P$. mediocanellata by $\mathrm{B}$ and $\mathrm{F}, P$. pleurosigma by $\mathrm{I}$, Scytomonas pusilla by D, L and J, Peranema trichorophorum by B, F, I, K, Urceolus cyclostomus by K, Anisonema minus by J, Entosiphon suleatum by C, I and J, Iteteronema acus by $\mathrm{I}$ and N.

VI. Phytomonadinae, Solitary or in colonies, enelosed in a cellulose wall; chlorophyll and stigma nearly always present; 1 or more simple contractile vacuoles at anterior end. Chlamydomonas sp. was found eommonly in the soil by A, E, F, K, Polytoma uvella by $\mathrm{A}, \mathrm{K}$ and $\mathrm{J}$, Chlorogonium euchlorum by $\mathrm{J}$ and $\mathrm{K}$, Pandorina morum by $\mathrm{A}$. 
VII. Dinoflagellata are enclosed in a rigid lorica and possess 2 flagella, one of which lies in a transverse groove and moves with an undulating motion and the other lies in a longitudinal groove and is trailed behind. Only one form, Glenodinium pulvisculus, has been found in the soil by $\mathrm{I}$.

The last 5 orders are among the Phytofiagellata, the typical members of which possess chromatophores; colorless species are also found in all orders and it is these which are largely found in the soil.

C. INFUSORIA (CILIATA). ${ }^{89}$ The common soil eiliates are found in the following groups:

I. HOLOTRICHA, body uniformly covered with cilia; these are similar or slightly lengthened about the mouth; no adoral spiral zone.

Various species of Holophrya were found in a number of soils by $A$, B, F, J, K. Urotricha farcta by N, U. agile by F; Enchelys is common in the soil, having been found by A, C, E, C, J, K, Koch, Cumningham and Lëhnis. Spathidium spatula by $\mathrm{C}$ and $\mathrm{K}$, Lacrymaria sp. by $\mathrm{I}$ and $\mathrm{N}$, Prorodon teres by A, F and $\mathrm{K}, P$. voum by A, E, I and Koch, Choenia sp. by J, Coleps hirtus by $\mathrm{I}$ and $\mathrm{K}$, Mesodinium sp. by F, Amphileptus cygnus and A. gigas by I, Lionotus fascicola by F and I, Loxophyllum flexilis and $L$. rostratum by I, Dileptus by F, J and $\mathrm{K}$, Nassula clegans by A, E and I, Chilodon cucullulus by F and I, C. megalotrocha by F, C. uncinatas by $\mathrm{J}$ and $\mathrm{K}$ and Trochilia palustris by $\mathrm{A}$ and $\mathrm{J}$.

Uronema marina was found in the soil by A, F, J and K. Glaucoma scintillans, $G$. pyriformis by A, Colpidium colpoda by A, E and $\mathrm{K}$ and others, this being one of the most common soil ciliates. $C$. striatum was found bv F and I. Colpoda cucullus and C. steinii, two of the most comnion soil ciliates, were recorded by most investigators on soil protozoa. C. maupasii was found in the soil by $\mathrm{F}$ and $\mathrm{J}$. F also recorded the presence in the soil of $C$. campyla, C. flavicans, C. helia and C. saprophila. Various species of Paramoecium have been found in the soil, although Sandon records the complete absence of this group in English and foreign soils. $P$. aurelia was found by $I$ and N, $P$. bursaria by I, $P$. caudatum by $\mathrm{F}$, I and $\mathrm{N}, P$. putrinum by $\mathrm{A}$ and $\mathrm{I}, P$. trichium by F, etc., Pleuronema chrysalis by A, F and I. Other species of Pleuronema were found by E, J and $\mathrm{K}$. Cyclidium glaucoma was found by $\mathrm{F}, \mathrm{J}$ and $\mathrm{K}$, Balantiophorus elongatus by $\mathrm{C}, \mathrm{J}$ and others, B. minutus by A, C and J, Lembus pusillus by F.

II. Heterotricha. Body uniformly covered with cilia, forming cirri or stout cilia in spiral adoral zone; undulating membrane often

${ }^{89}$ Conn and Edmondson, in Ward and Whipple's "Fresh-water biology"; Stokes, A. C. A preliminary contribution toward a history of the fresh water infusoria of the United States. Jour. Trenton Nat. Hist. Soc., 1: 71-344. 1858; Roux, J. Faune infusorienne des l'eaux stagnantes des environs de Genève. Genève, 1901. 
inside mouth. The following organisms belonging to this group were found in the soil: Blepharisma ovata by F, B. laterita by J, Metopus sigmoides and Metapides acuminata by F, Spirostomum ambiguum by I, Condylostoma sp. by Koch.

III. Oligotricha. Spherical or conical, with adoral zone often forming a closed ring; cilia usually absent from other parts of body. The following forms were recorded as present in the soil: Strombidium sp. by E, F and I, Halteria grandinella by A, F, I and $\mathrm{K}$. Other species of Halteria were found by B, E, J and $\mathrm{N}$.

IV. Hypotricha. Body flattened dorso-ventrically; cilia often fused to form larger appendages or cirri, usually limited to ventral surface; adoral zone of membranellae. This group is represented in the soil by Urostyla grandis (C, K), Stichotricha secunda (F), Uroleptus musculus (A, F, K and Koch), U. mobilis (J), U. piscis $(\mathrm{I}, \mathrm{J}), U$. dispar (F, I, N), Onychodromus grandis ( $\mathrm{J}$ and other investigators), Gastrostyla steinii (C, J), Gonostomum (Plagiotricha) affine (C, J, K, L, M), Oxytricha fallax (J), O. bifaria (F), O. pellionella (Cunningham and Löhnis, F, I, J); other species of Oxytricha were also found by different investigators of soil protozoa. Pleurotricha lanceolata and P. grandis (C, J), Stylonychia mytilus (B, F, I), S. pustulata (F, K), Euplotes carinata (F, J), E. charon (A, F, J), E. harpa and E. patella (I), Aspidisca costata $(\mathrm{F}, \mathrm{I}, \mathrm{K})$ and $A$. lyncaster $(\mathrm{K})$.

V. Peritricha. Body cup-like or cylindrical, often stalked, of a sedentary habit; cilia usually limited to adoral zone, the membranellae leading down to a vestibule, into which pharynx and contractile vacuoles open; a posteriol ring of cilia may be temporarily present. This group is represented in the soil by Vorticella microstoma (C, F, J, K, N), V. citrina and $V$. globularia (F), V. nebulifera $(\mathrm{K}, \mathrm{N}), V$. putrina $(\mathrm{A}, \mathrm{F})$; other species of Vorticella have also been found by different other investigators. Epistylis coarctata (C), Cothurnia doliolum (B), Vaginicola terricola (B).

Importance of protozoa in the soil. No definite evidence has as yet been submitted as to the actual rôle of protozoa in the soil. We know, on the one hand, that certain groups of protozoa at least, particularly the ciliates and amoebae, are not only capable of ingesting bacteria, but some actually use this sort of food exclusively. ${ }^{90,91}$ By determining the number of amoebae and bacteria in the soil, at daily intervals, an inverse relationship has been obtained between these two groups of organisms.

${ }^{90}$ Huntemüller, O. Vernichtung von Bakterien im Wasser durch Protozoen. Arch. Hyg., 54: 89-100. 1905; Calkins, 1926 (p. 312); Purdy and Butterfield, 1918 (p. 322); Cunningham, A. Studies on soil protozoa. Tour. Agr. Sci., 7: 4974. 1915.

${ }^{91}$ Cutler and Crump, 1920 (p. 50). 
Cutler ${ }^{92}$ purified cultures of an amoeba and a flagellate, so that they contained only three species of common soil bacteria. These were isolated free from protozoa, and suspensions were prepared of the bacteria alone and bacteria + protozoa, the latter in an encysted condition. These suspensions were sprayed on by a fine nozzle upon 100 grams of sterile soil in large sterile Petri dishes. The protozoa added per 1 gram of soil were: 25,000 for the Dimastigamoeba gruberi, 20,000 for Cercomonas crassicauda and 11 to 13 millions of bacteria. At the end of 15 days, the numbers of protozoa were: 230,000 amoebae and 420,000 flagellates per gram. The bacteria, in the protozoa free culture, reached a maximum of 214.4 millions in 6 days, then diminished to 169.2 millions in 15 days (21 per cent decrease); in the presence of the amoebae, the maximum of bacteria (178.4 millions) was attained in 3 to 5 days, then the decrease was more rapid, falling down to 72.8 millions in 15 days (59 per cent decrease); in the presence of flagellates the maximum of 103 millions was reached in 7 days, dropping to 88 millions in 15 days (14.5 per cent decrease).

Goodley ${ }^{93}$ has previously shown that amoebae of the limax group and other larger forms can lead an active existence in the soil and exert a depressing effect upon bacterial numbers. He suggested the probability that a certain point must be reached in protozoan development before the depression in bacterial numbers is caused; this number seems to be about 30,000 cells of Amoeba limax per gram of soil.

On the other hand, certain suggestions have been made that protozoa can live in the absence of bacteria. Breal ${ }^{94}$ (1896) believed that Colpoda is active in the decomposition of plant constituents of the soil with the production of ammonia. Other investigators ${ }^{95,96}$ claimed that the protozoa play an important rôle in the decomposition of organic matter in the soil. A number of protozoa are found ${ }^{97}$ to be saprophytic in nature and capable of obtaining their food by absorption. The same may be true of the soil flagellates, as evidenced by the work of Thornton and

${ }_{92}$ Cutler, D. W. The action of protozoa on bacteria when inoculated into sterile soil. Ann. Appl. Biol., 10: 137-141. 1923.

${ }_{93}$ Goodey, T. Further observations on protozoa in relation to soil bacteria. Proc. Roy. Soc., 89: 297-314. 1916.

94 Breal, E. Ann. Agron. 22: 362-375. 1896.

${ }_{95}^{95}$ Müller, 1887 (p. 332), p. 15, 56, 167.

${ }_{96}$ Hiltner, L. Über neuere Ergebnisse und Probleme auf dem Gebiete der landwirtschaftlichen Bakteriologie. Jahresb. Ver. angew. Bot. for 1907, 5: 200-222. 1908.

87 Minchin, 1912 (p. 312). 
Smith and Alekseiev, and even ciliates, as shown by Peters. In most instances, of course, no direct evidence has been submitted to show that the protozoa took an active part in the decomposition of the organic matter; the statements were often based upon the fact that protozoa were found to occur in soils in which decomposition was taking place. Goodey has also shown that when various protozoa are added to the soil, bacterial activity has not been limited, as seen in table 18 . This seems to be contrary to the latter results of Goodey ${ }^{98}$ mentioned previously; however, they are explained by the fact that soil treated with an antiseptic does not afford a suitable medium for the development of protozoa. The drop in the numbers of bacteria follows the exhaustion of available plant food in the soil.

TABLE 18

Bacteria in millions per gram

\begin{tabular}{|c|c|c|c|c|c|c|c|}
\hline & \multicolumn{7}{|c|}{ INCUBATION, DATS } \\
\hline & Start & 32 & 60 & 93 & 151 & 208 & 487 \\
\hline Untreated..... & 14.4 & 10.3 & 13 & 11.4 & 12 & 8 & 12 \\
\hline Toluene treated........ & 9.2 & 73.0 & 60 & 61.0 & 40 & 49 & 56 \\
\hline Toluene + untreated soil.. & 11.3 & 49.0 & 61 & 43.0 & 19 & 45 & 48 \\
\hline Toluene + ciliates . . . . . . & 4.5 & 371.0 & 292 & 296.0 & 56 & 64 & 73 \\
\hline Toluene + amoebae..... & 3.0 & 285.0 & 185 & 141.0 & 74 & 90 & 57 \\
\hline Toluene + flagellates... & 27.0 & 247.0 & 214 & 227.0 & 196 & 104 & 113 \\
\hline Toluene + bacteria..... & 2.3 & 500.0 & 341 & 311.0 & 181 & 151 & 150 \\
\hline
\end{tabular}

Few attempts were made to demonstrate whether protozoa actually injure important soil biological processes. Nasir ${ }^{99}$ determined the influence of the presence of protozoa (Colpidium colpoda) upon the fixation of nitrogen by Azotobacter in mannite cultures, both in solution and in sand. In 31 experiments out of 36 , the presence of protozoa resulted in an increase in the amount of nitrogen fixed by Azotobacter. The feeding action of protozoa upon Azotobacter seems to stimulate the further dievelopment of the latter and thus maintain its nitrogen-fixing efficiency for a longer period. ${ }^{99 a}$ Very little soluble nitrogen was

${ }^{98}$ Goodey, 1915 (p. 323).

${ }^{99}$ Nasir, S. M. Some preliminary investigations on the relationship of protozoa to soil fertility with special reference to nitrogen fixation. Ann. Appl. Biol., 10: 122-123. 1923.

${ }_{99 a}$ Cutler, D. W., and Bal, D. V. Influence of protozoa on the process of nitrogen fixation by Azotobacter chroococcum. Ann. Appl. Biol. 13: 516-534. 1926. 
found $^{100}$ in pure cultures of Azotobacter; this nitrogen would be produced as a result of autolysis. However, in impure cultures of Azotobacter, considerable quantities of soluble nitrogen were found; this phenomenon was ascribed to the action of amoebae.

While the results of Cutler and associates seem to demonstrate definitely that protozoa are capable of reducing the number of bacteria in the soil, due to their phagocytic action (as determined by the plate method), there is very little information available concerning their influence upon the activities of microorganisms in the soil and upon soil processes in general. The activities of bacteria decomposing organic nitrogenous compounds may not be influenced injuriously by the presence of protozoa and may even be favored, as indicated by an increase in the amount of ammonia liberated (Hill, Waksman) or nitrogen fixed by Azotobacter (Nasir). Excessive development of bacteria may become harmful to the growth of protozoa in artificial culture media, although it remains to be seen to what extent this may take place in the soil.

The fact that the protozoa destroy some soil bacteria need not indicate that they exert an injurious influence, but may result in a decided benefit to soil biological processes. Decomposition of organic matter as well as other biological activities are resultants of the multiplication and growth of the bacterial cells. By destroying the excess of bacteria, the protozoa may stimulate further bacterial development and, therefore, further biological transformations in the soil. The protozoa themselves may become later a source of energy for bacteria. The phenomena observed by Russell and Hutchinson as a result of partial sterilization of soil may not be due at all to the destruction of protozoa, but to other factors, as shown elsewhere (p. 757).

The protozoa may also take a part in some definite soil processes, such as the decomposition of certain organic substances. Cleveland ${ }^{102}$ found that protozoa living in the intestinal tract of termites feed on wood cellulose. When the protozoa are killed, the termites die on a wood

${ }^{100}$ Molér, T. Ein Beitrag zur Kenntnis der Entbindung des dureh Azotobacter fixierten Stickstoffes. Bot. Notiser. 1915, 163-175. (Centrbl. Bact. II, 47 : 635-636. 1917.)

${ }^{101}$ Hill, T. L. The relation of protozoa to certain groups of soil bacteria. Jour. Bact., 1: 423-433. 1916.

${ }^{102}$ Cleveland, L. R. The physiological and symbiotic relationships between the intestinal protozoa of termites and their host, with special reference to Reticulitermes flavipes Kollar. Biol. Bull., 46: 177-225. 1924. 
diet, since they themselves cannot utilize the cellulose, unless it has been previously decomposed by fungi. This symbiotic relationship exists for at least some protozoa. We do not know as yet whether some soil protozoa may be able to decompose complex organic substances; it is known, however, that they can readily assimilate such soluble organic and inorganic constituents as found in manure. ${ }^{103}$

${ }^{103}$ Alexeiev, 1917 (p. 317). The relation of protozoa to reducion phenomena in the soil is discussed by von Wolzogen Kühr, C. A. H. Protozoa and the phenomena of reduction in soil. Arch. voor de Suikerind. nederland. Indie., No. 27, 1125-1182. 1917. (Int. Rev. Sci. Pract. Agr., Agr. Int. and Pl. Dis., 9: 788. 1918.) 


\section{CHAPTER XIV}

\section{The Non-Protozoan Fauna of the Soll}

Animal ecology as a whole and classification of soil forms. In arldition to protozoa, other groups of invertebrate animals inhabit the soil, namely, the rotifers, nematodes, annelid-worms, insects and others. Such animals which live in the soil can be generally divided into three groups:

1. Those that spend all their life in the soil, coming to the surface only occasionally or not at all. These include various worms and rotifers.

2. Those that spend only a part of their life cycle in the soil or on its surface, as in the case of various insects.

3. Those that find only their habitat in the soil, while they may spend a large part of their time on the surface of the soil. These include ants, termites and many insects.

These organisms influence directly or indirectly various soil processes and plant growth:

1. They cause a change in the physical condition of the soil, by modifying the mechanical structure of the soil, through their continued motion or by passing the soil through their bodies as in the case of earth worms.

2. They cause various chemical changes in the soil, either directly, in their digestive processes, or indirectly, by influencing the activities of the soil fungi and bacteria.

3. They bring about a more uniform distribution of various soil bacteria and other organisms.

4. They may devour other members of the soil flora and fauna, like algae, fungi and protozoa. In this way, the higher fauna also contributes to the complex system of numerous activities going on in the soil.

5. Damage may be done to crops by eertain representatives of these groups, particularly by some of the nematodes, earthworms, insects, etc.

The soil or terrestrial fauna, outside of the protozoa, includes members from the following systematic groups:

I. Plathelminthes or Flatworms, represented in the soil, in moist environments, by the (1) Turbellaria or flatworms and (2) Trematoda or flukes.

II. Nemathelminthes or Roundworms, represented in the soil by the Nematoda or true roundworms. 
III. Trochelminthes or Trochalworms, represented in the soil by the Rotatoria or wheel animalcules.

IV. Coelhelminthes (Annelida) or Segmented Worms are represented in the soil by the Oligochaeta, including the earthworms or Terricolae and the Enchytraeids or Limicolae, and the Tardigrada.

V. Arthropoda are represented in the soil by (1) Crustaceae, especially Copepoda and Isopoda; (2) Arachnida, including the mites, ticks and spiders; (3) Myriapoda; and (4) Insecta.

VI. Mollusca, including the Gastropoda.

VII. Chordata. The vertebrates are represented in the soil by the mice, moles, marmots, etc., but these a re beyond our field of discussion.

Methods of study. For the investigation of the soil fauna, Morris ${ }^{1}$ devised an apparatus, which consists of four iron plates, two 12 by 10 inches, one 12 by 9 and one 4 by 9 inches. Each plate has an iron bar

1 Morris, H. Observations on the insect fauna of permanent pasture in Cheshire. Ann. App. Biol., $7:$ 141-155. 1921; On a method of separating insects and other arthropods from soil. Bull. Entom. Res., 13: 197. 1922; The insect and other invertebrate fauna of arable land at Rothamsted. Ann. App. Biol., 9: 282-305. 1922.

\section{PLATE XVIII}

\section{Soll Nematodes}

144. The relative abundance of nematodes in each successive two inches of upper foot of soil; derived from a low-lying alluvial soil containing about $3,000,000,000$ nematodes to the acre, most of which are in the upper 3 inches, around the plant roots (from Cobb).

145. Beneficial soil nematode, Mononchus papillatus Bastion: it feeds on other nematodes, showing remnants of several Tylenchuli $(j, t)$ (from Cobb.)

146. Assymetrical nematode Bunonema, found in decomposing organic matter (from Cobb).

147. Iota, or scaly nematode, common in the soil; head and tail end of male and female (from Cobb).

148. Male and female parasitic nematode, very simple in structure in comparison with free living nematodes (from Cobb).

149. Tylenchus devastatrix infecting onions and other bulbous plants (from Cobb).

150. Mononchus attacking Anguillula aceti (from Steiner and Heinly).

151. Sketch of the head-end of Mononchus attacking a larval Rhabditis (from Steiner and Heinly).

152. Schematic representation of the behavior of two different populations of Tylenchus dipsaci. The one population lived on Hyacinths, the other on Narcissus. Therefore, if left to choose, the first population will ignore the Narcissus, the second the Hyacinth, for each will attack only the host of its ancestors. (Slogterem, after Steiner). 

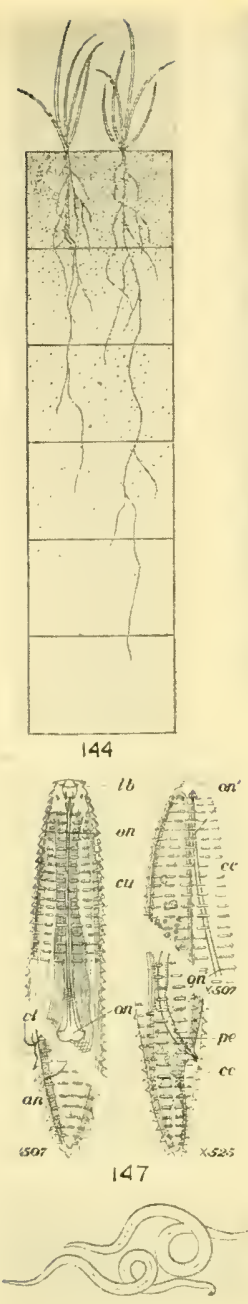

148
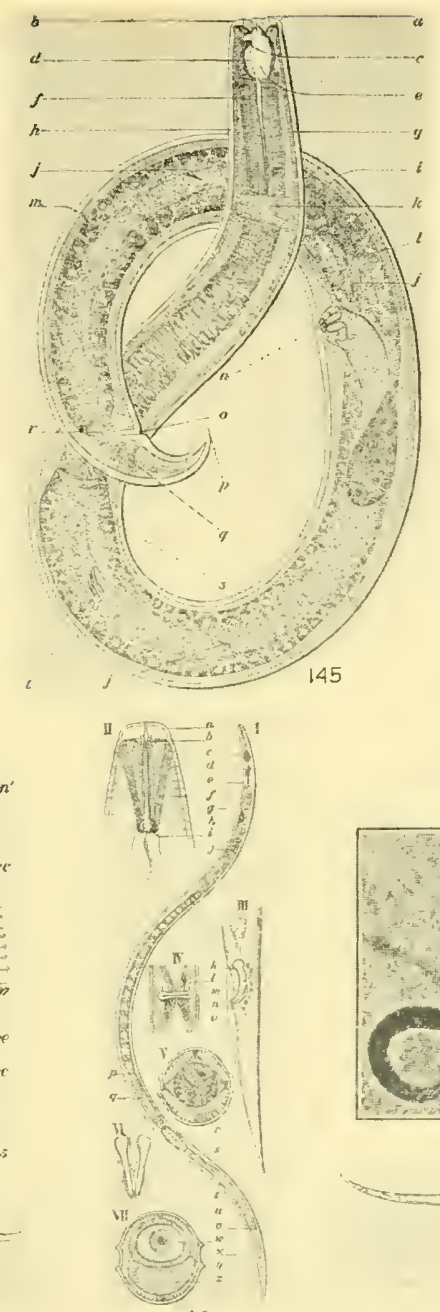

149
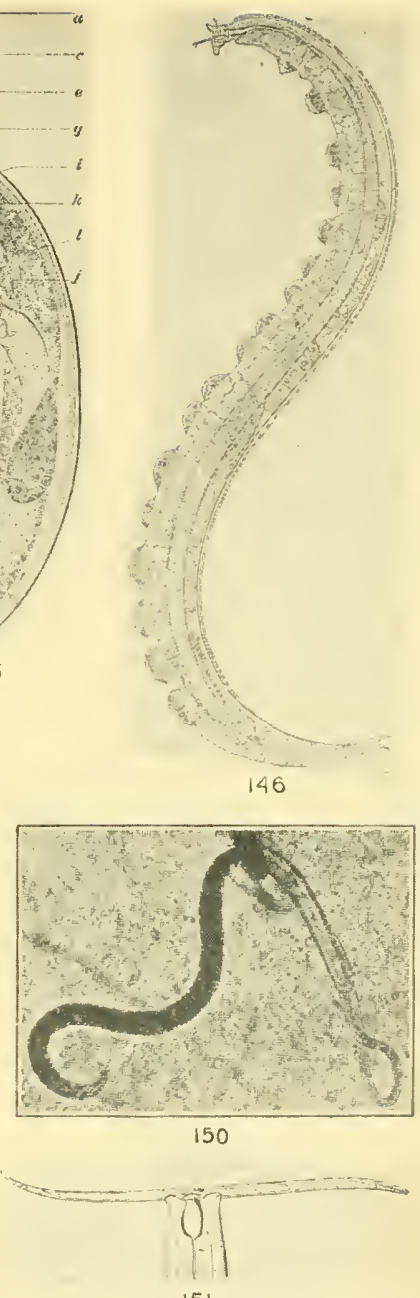

151

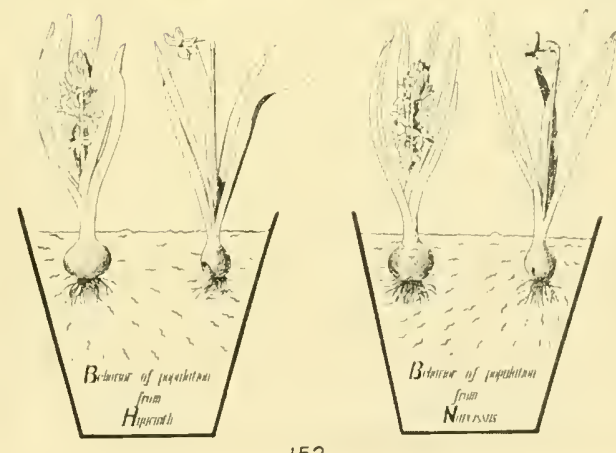

152 

fastened to it at the top, and each of the three larger plates has two projecting teeth at the bottom. The plates are driven into the ground down to the required depth to form a box 9 inches square, the smallest plate being on the side towards the outside of the plot. The plates enclose a cube of soil, with a side dimension of 9 inches, giving a total of 729 cubic inches. The soil is removed from the cube, in layers: the first sample contains only the upper inch of soil, the second and succecding samples taken at a depth of 2 inches at a time, giving in all five samples for each cube.

For making a census of the soil population, Cobb ${ }^{2}$ devised soil sampling tubes, which are open cylinders of thin metal (tin or galvanized iron) with an internal diameter of $72.1 \mathrm{~mm}$. The rim of one end is reinforced and the other sharpened. The area of the internal cross. section of the tube is one-millionth of an acre. The tubes may be of any length; for counting nematodes, 6 to 9 inch lengths are sufficient; below that depth, only few nematodes occur in the soil. Since the animal population is unevenly distributed in the soil, a number of samples are required, with a minimum of five. The various samples for one plot can be mixed and the census made. After the sampling tube is forced into the soil, enough earth is dug away to enable one to introduce a knife or saw-blade beneath the lower end of tube. The tube is then removed full of soil and capped at both ends. The samples of soil from one field are sifted and thoroughly mixed; wire sieves of $\frac{1}{2}$ to $\frac{1}{6}$ inch mesh may be used. Various methods of mixing and sampling of the soil are described by Cobb.

An aliquot portion of soil is placed in an abundance of animal-free water, usually 10 to 20 times its volume. The soil is well suspended in the water by proper stirring with compressed air, carried on fast enough not to allow the particles to settle. The heavy particles are allowed to settle for about five seconds and the supernatant liquid is rapidly poured into another vessel. The residue is washed several times with clean water, so as to remove all adhering animals, the washings being added to the original liquid. The sand and gravel are discarded. The process may be repeated so as to remove another portion of the heavy inorganic material, being sure that it is free from animals. The liquid is then allowed to run through a series of superimposed sieves, ranging from 16 to 200 meshes per inch; the sieves, especially the finer ones, are agitated when the liquid is passed through them. The finer sieves may be made of millers bolting silk. The nematodes will all pass through the 16 mesh sieve; the residual particles should be washed so as to remove the animals. Beginning

${ }^{2}$ Cobb, N. A. Estimating the nema population of soil. Bur. Pl. Ind., U. S. Dept. Agr., Agr. Tech. Circ. 1. 1918. 
with the 20-mesh, the residual material should be examined earefully. To make sure that no animals remain in the liquid, the latter is passed several times (5 to 10 ) throngh the finest sieve. When a portion of the final liquid is examined and no nematodes are found, the liquid is finally discarded. The larvae of

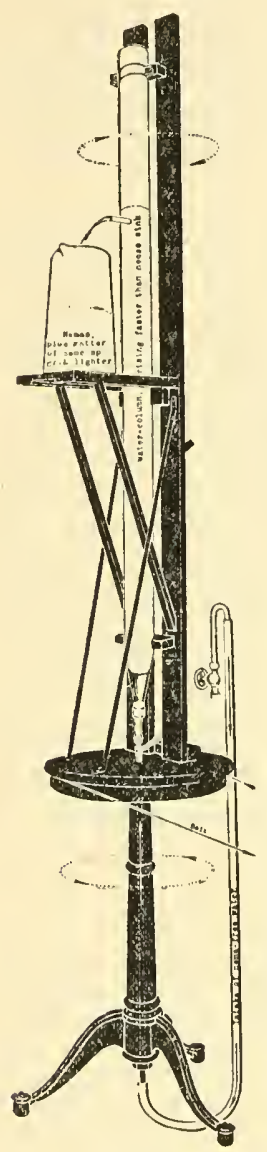

Fig. 10. Apparatus for the separation of nematodes from the soil (after Cobb). some animals, like those of Heterodera, are eaught on the finest sieves. The animals are then washed away from the sieves (kept at a slightly inelined position) by a small amount of water. The washings with the animals are either mixed or kept in separate vessels. ${ }^{3}$

The separation of the animals from the clay portion of the soil which is kept in suspension, is based upon the fact that they will settle quicker than the elay. Care should be taken that no animals are floating on the surface of the liquid. After the latter is allowed to stand for 30 minutes, it is poured off and replaced by clean water. The floating animals ean be made to sink by adding some alcohol to the run-off material (so as to make 20 to 30 per cent aleohol), shaking well and adding water inmediately (fig. 10). This process ean be modified greatly depending on nature of soil.

The mixture of inorganic soil particles and organisms, lying in clear water, are then examined by using an ordinary dissecting microscope. Nematodes are fished out by slender, tapering, sharp needles free from grease. A small portion of the debris is placed in a wateh glass, in clear water, about $\frac{1}{8}$ inch in depth. When a nematode is located, the point of the needle is brought under it and it is floated to the surface, lifted on the point of the needle and transferred to a watch glass containing a few drops of clean water. The final suspension may be well mixed and only an aliquot portion examined in a graduated watch glass. Examination should be made soon after washing is completed.

Certain members of the animal, non-protozoan population can also be isolated by the use of agar media. Small worms can be isolated ${ }^{4}$ by the following method:

${ }^{3}$ See also Baunacke, W. Untersuchungen zur Biologie und Bekämpfung des Rübennematoden Heterodera schachtii Schmidt. Arb. Biol. Reichsanst. Land. u. Forst, 11: 185-28s. 1922.

${ }^{4}$ Shaw, C. Zijehtungsversuehe zur Gewinnung von Reinkulturen kleiner Wurmarten der Garten- und Ackererde. Centrbl. Bakt. II, 64: 41-45. 1925. 
Finely eut agar (3.5 grams) is soaked over night in tap water; exeess of water is poured off and agar is dissolved in $200 \mathrm{cc}$. of tap water eontaining 1.3 grams of $\mathrm{NaCl}$. The agar is neutralized and filtered; 1.6 grams of powdered brown sugar or malt sugar is then added, the agar is sterilized and distributed into sterile Petri dishes. The soil is inoculated, in the form of a fine layer, over the eentre of the plate. The living worms will move away from the soil and, after 24 hours, they will be found on the elear agar about $0.5 \mathrm{em}$. away. These worms, espeeially those bearing eggs, ean be transferred to fresh agar plates, for the preparation of pure cultures.

\section{FLATWORMS (PLATHELMINTHES)}

The Turbellaria or free living flatworms are represented in the soil by various species of Rhabdocoelae, Allocoelae and land Planarians. Over thirty species of Rhabdocoelae were isolated from the soil. ${ }^{5}$ Among the various genera found in the soil, it is sufficient to mention Archivortex, Adenoplea, Acrochordonoposita, Geocentrophora, Prorhynchus ( $P$. stagnalis) and Planaria. The soil forms feed largely on diatoms, rotatorians, tardigrads, oligochaetes, upon one another and especially upon soil nematodes.

The Trematoda are represented in the soil by the larvae of different river flukes.

\section{NEMATODA}

Adult nematodes are usually cylindrical or spindle shaped, the posterior end being often acutely pointed or modified in form. They are transparent, non-segmented organisms, 20 to 100 times or more as long as wide. When alive and active, they thrash about in pure liquid without making much progress. They do not change their length appreciably, being thus distinguished from earthworms and other elongated small organisms, which change their length while moving. Dead nematodes lie outstretched or in a slightly curved condition.

Nematodes are found in all soils under different conditions, largely in the upper 6-8 inches, although they are often abunclant even at lower depths ${ }^{6}$ (No. 144, Pl. XVIII). They can adjust themselves to

Further information on the artificial eultivation of free-living nematodes is given by H. Metcalf in Trans. Amer. Mier. Soe., 24: 89-102. 1903; and A. C. Chandler in Seience, N. S., 60: August 29, 1924.

' Reisinger, E. Turbellaria. Strudelwïrmer. L. 6, T. 4, Sehulze's Biologie der Tiere Deutchlands. Borntraeger. 1923.

${ }^{6}$ Godfrey, G. H. The depth distribution of the root-knot nematode, Heterodera radicicola, in Florida soils. Jour. Agr. Res., 29: 93-98. 1924. 
various habitats. They are distributed by the wind, by water, by moving animals, by various plant products, implements, etc. The eggs and larvae are sometimes very resistant to drying and other adverse conditions, and can survive for many years. Large numbers of parasitic, saprophytic, and free-living species inhabit the soil, making up a large numerical proportion of its population. The number of species alone reaches many thousands. Some of these are of wide distribution.

The identification of soil nematodes may be carried out by using fixed material. Fleming's solution (p. 323) can be employed for this purpose. The organisms are placed in the solution from a few minutes to one or two hours. Should the cells become darkened, they can be bleached with $\mathrm{H}_{2} \mathrm{O}_{2}$. When the nematodes are dead and fixed, they are mounted, counted and identified, or are placed in a mixture of 5 per cent glycerol and 95 per cent water. After the water has evaporated, the animals remain in the glycerol. For careful identification and detailed study of morphology, the nematodes are placed in the middle of a glass slide in a small drop of water and covered with a cover glass. The edge of the cover glass can then be sealed to the slide by means of hot wax-paraffin which contains a certain proportion of beeswax. The slides are now examined with the compound microscope, very high power lenses being necessary. deMan ${ }^{7}$ (1884) was the first to make a careful study of the soil nematodes. He divided the organisms into three groups: (1) omnivagous species not bound to any particular soil (Dorylaimus obtusicaudatus, Monohystera filiformis, etc.); (2) meadow and field soil nematodes (Plectus cirratus, etc.); (3) sand nematodes (Mononchus parvus, etc.).

Nematodes are generally found to be abundant in forest humus as well as in cultivated soils. They are parasitic on animals and plants, or are saprophytic and free living. Even the parasites may lead an independent existence in the soil at certain stages of their development. According to Steiner, ${ }^{8}$ the nematodes are represented in Swiss soils by 139 known species, but there might be still many more. Cobb ${ }^{9}$ found nematodes to occur in large numbers in every cultivated and uncultivated soil, including forms which are parasitic on plants or

${ }^{7}$ de Man, 1922 (p. 348).

8 Steiner, G. Freilebende Nematoden aus der Schweiz. Arch. Hydrobiol. Planktonk., 9: 259-276. 1913; Zool. Anz., 46: 336-368. 1916.

${ }^{9} \mathrm{Cobb}$, N. A. Nematodes and their relationships. U. S. Dept. Agr. Yearbook, 1914, 457-490. 
animals and those that are entirely saprophytic. Different soils may be found to contain large and varying numbers of nematodes as shown in the following summary: ${ }^{10}$

\begin{tabular}{|c|c|}
\hline CORN FIELD SOILS & $\begin{array}{l}\text { MINIMUM NUMBER OF } \\
\text { NEMATODES PER ACRE, } \\
\text { TOP } 6 \text { INCHES ( } 15.2 \text { CM.) }\end{array}$ \\
\hline Missouri. ................ & $648,000,000$ \\
\hline North Carolina............. & $242,400,000$ \\
\hline New Jersey................ & $129,600,000$ \\
\hline Rhode Island........... & $610,800,000$ \\
\hline New Hampshire......... & $99,600,000$ \\
\hline 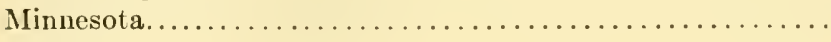 & $121,200,000$ \\
\hline 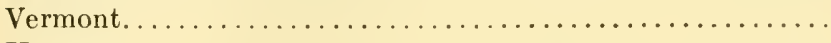 & $580,000,000$ \\
\hline 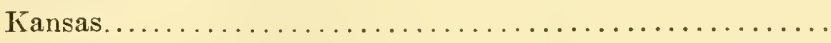 & $278,400,000$ \\
\hline
\end{tabular}

Morris ${ }^{11}$ also found large numbers of nematodes in the soil, the greatest number occurring at a depth of two to three inches in manured soil and four to five in unmanured soil. Four to five times as many nematodes were found in the manured as in the unmanured soil. According to Micoletzky, ${ }^{12}$ the soil and fresh water nematodes embrace 75 genera and 525 species. Half as many nematodes were found in the winter as in the summer. The abundance of these organisms in the soil is determined by moisture, abundance of plant life and plant residues, and other microorganisms. The different nematodes vary in their nutrition:

1. Some, like Rhabditis, Diplogaster, Cephalobus, feed at least partly on decomposing organic matter which results from the activities of the bacteria, as well as upon the bacteria themselves, and also upon fungi and algae; this is also true of such forms as Monohystera and Bunonema (No. 146, Pl. XVIII).

${ }^{10}$ Steiner, G., and Heinley, H. The possibility of control of Heterodera radicicola and other plant injurious nemas by means of predatory nemas, especially by Mononchus papillatus Bastian. Jour. Wash. Acad. Sci., 12: 367-386. 1922.

II Morris, 1922 (p. 342).

12 Micoletzky, H. Die freilebenden Erdnematoden mit besonderer Berücksichtigung der Steiermark und der Bukowina, zugleich eine Revision sämtlicher nicht mariner, freilebender Nematoden in Form von Genus-Besehreibung und Bestimmungsschlüsseln. Arch. Naturg., 87: 1-650. 1921. Zur Kenntnis tropischer, freilebender Nematoden aus Surinam, Trinidad und Ostafrika. Zool. Anz., 64: 1-28. 1925. Die freilebenden Süszwasser- und Moornematoden Dïnemarks. D. Kgl. Danske Vidensk. Selsk. Skr. Afd. 8 R., x, 2. Köbenhavn. 1925 . 
2. Some feed on the tissues and fluids of healthy or injured plants, thus becoming injurious to higher plants; these include Tylenchus, Heterodera, Aphelenchus (Nos. 14S-149, Pl. XVIII), some of which are truly parasitic and others are semi-parasitic (like Hoplolaimus) or facultative parasitic.

3. Some are parasitic on animals, especially invertebrate soil forms.

4. Some feed both on plants and animals, like Dorylaimus.

5. Some are carnivorous and predatory, feeding on other nematodes, like Ironus, Tripyla, and especially the numerous species of Mononchus. Mononchus papillatus, for example, can feed readily upon Hetervdera radicicola ${ }^{10}$ (Nos. 150151, PI. XVIII).

The maximum number of nematodes was found ${ }^{13}$ in Tyrol soils in August, reaching 320 per $10 \mathrm{cc}$. of soil; the number then dropped rapidly and reached the lowest point in November, with 23 animals per $10 \mathrm{cc}$. It remained at a low level during the winter months and began to increase again in February. On the average, 120 nematodes were found per $10 \mathrm{cc}$. of soil throughout the year. The different spccies do not reach their maximum and minimum at the same time, depending on the moisture and the temperature resistance of the organism. The genera Dorylaimus, Tylenchorhynchus, Mononchus and Hoplolaimus are almost the only organisms found during the winter months.

The class Nematoda consists of numerous small forms which are usually free-living and non-parasitic. Among the free-living forms in the soil, the genus Mononchus composed of numerous species ${ }^{14}$ is particularly abundant. Many of these species are cosmopolitan. The Mononchs occur in all kinds of arable soil, sometimes in hundreds of millions per acre. They feed on living microzoa, including other nematodes. ${ }^{14-16}$

Among the nematodes attacking the roots of various plants, causing the formation of galls, we find the sugar-beet nematode Heterodera schachtii, ${ }^{17}$ the root-knot nematode Caconema radicicola, the wheat

${ }^{13}$ Seidenschwartz, L. Jahreszyklus freilebender Erdnematoden einer Tiroler Alpenwiese. Arb. Zool. Inst. Univ. Innsbruck, 1: 37-71. 1923.

${ }^{14}$ Cobb, N. A. The Mononchs, a genus of free-living predatory nematodes. Soil Sei., 3: 431-486. 1917.

${ }^{15}$ De Man, J. G. Nouvelles recherches sur les nématodes libres terricoles. M. Njhoff. Hague. 1922.

${ }^{16}$ See also Wülker, G. Nematodes. Fadenwürmer. L. 11, T. 8, Schulze's Biologie der Tiere Deutchlands. Borntraeger. 1924.

17 Shaw, H. B. Control of the sugar-beet nematodes. Bur. Pl. Ind., U. S. Dept. Agr. Farm. Bul. 772. 1916. Baunacke, 1922 (p. 344). 
nematode Tylenchus tritici, and various others. ${ }^{18}$ Some of them attack a great variety of plants. C. radicicola, for example, attacks about five hundred kinds of plants. This organism flourishes best in highsandy soils, which are moist and warm. It attacks cotton, beans, celery, eggplants, potatoes, lettuce, peas, tomatoes, cowpeas, soybeans, nursery stock, weeds, ornamental plants and various field crops. Some plants, however, are not attacked. Heterodera schachtii attacks potatoes, sugar beets, etc., and may prove to be very injurious. ${ }^{19}$ Tylenchus dipsaci attacks clover, alfalfa, and other crops, ornamental plants, etc. ${ }^{20}$

The nematodes are represented in the soil by a large number of genera. ${ }^{21}$ It is sufficient only to enumerate some of the most common:

Iota (syn. Hoplolaimus) found in swamp and acid soils, on the roots of trees. Tylenchus, found in peat and moist soils, on plant roots; many parasitic species.

A phelenchus, found in various soils, many species parasitic.

Isonchus, found on the roots of the cotton plant.

Dorylaimus, omnivagus, very abundant in the soil.

Actinolaimus, found in peat bogs and marshy soils.

Ironus, occurs to a limited extent in very moist soil.

Mononchus, predacious nematode, represented in the soil by many species, cosmopolitan.

Diplogaster, found in moist soils.

Cyatholaimus, found in moist soils.

Plectus, omnivagous, well distributed in the soil.

Rhabditis, cosmopolitan, some species microbivorous, well distributed in the soil.

${ }^{18}$ Marcinowski, K. Parasitisch und semi-parasitisch an Pflanzen lebende Nematoden. Arl. Biol. Anst. Land. u. Forst., 7: 1-192. 1909.

${ }^{19}$ Zimmermann, H. Nematodenbefall (Heterodera) an Kartoffeln. Ztschr. Pflanzenkrank., 30: 139-145. 1920.

${ }^{20}$ Goodey, T. On the susceptibility of clover and some other legumes to stem-disease caused by the eelworm, Tylenchus dipsaci, syn. devastatrix Kuhn. Jour. Agr. Sci., 12: 20-30. 1922. Ritzema-Bas, J. Les nematodes parasites des plantes cultivées. VI. Int. Congr. Inst. Agr., Paris, 2: 306-312. 1900. The cultivation of plant pathogenic nematodes is discussed by Byars, L. P. Preliminary notes on the cultivation of the plant parasitic nematode, Heterodera radicicola. Phytopath., 4: 323-326. 1914; Hilgermann and Weissenberg, R. Nematodenzüchtung auf Agarplatten. Centrbl. Bakt., I, Orig., 80: 467-472. 1918; Berliner, E., and Busch, K. Über die Züchtung des Rübennematoden (Heterodera schachtii Schmidt) auf Agar. Biol. Centrbl., 34: 349. 1914.

${ }^{21}$ A detailed elassification of nematodes is given by Cobb, N. A. Free-living nematodes. Fresh-water Biology by Ward and Whipple, 1918, p. 459-505. Micoletzky, 1921 (p. 347) and De Man, 1922 (p. 348). 
Rhabdolaimus, found in moist soil.

Cephalobus, commonly found in the soil, can be grown on decomposing organic matter.

Teratocephalous, omnivagous, found in moist soil.

Bastiana, largely soil forms.

Tripyla, found in soils rich in undecomposed organic matter, not very abundant.

Alaimus, well distributed in the soil, especially in moist and forest soils.

Prismatolaimus, represented in the soil by some species.

Monohystera, omnivagous, found in moist soils, some feed on diatoms.

Trilobus, seldom found in moist soils, feeds on diatoms and rotatorians.

Various Mermithidae are also found in the soil.

A number of other genera, like Bunonema, Tylopharynx, Archionchus, Eutylenchus, etc., are found in the soil less abundantly.

What is known of the nutrition of free-living soil nematodes has been reviewed in detail by Menzel. ${ }^{22}$ He found that Mononchus papillatus, when brought together with Tylenchus sp., Plectus auriculatus, Tripyla media and Anguillula aceti, killed these forms either by swallowing them completely or by sucking out their contents. Steiner and Heinley grew the Mononchus papillatus in water containing some soil and placed in concave slides. It is important to use a small amount of soil free from excess of organic matter so as to prevent the rapid development of bacteria. The medium should be frequently renewed. Heterodera, Rhabditis and Anguillula were used for food. As many as 83 Heterodera radicicola were killed in one day by one Mononch; during a life time of about 12 weeks, one animal killed 1332 nematodes. It is possible that this number may be much larger under natural conditions (No. 151, Pl. XVIII).

Steiner and Heinley, therefore, brought further weight to the suggestion of Cobb that the predatory Mononchs could be used to control the plant parasitic forms, when the latter are still free in the soil. However, we must keep in mind that the mere introduction of an organism into the soil is not sufficient to insure its development; the soil should be treated in such a manner as to favor the development of the beneficial organism and discourage the development of the injurious forms. ${ }^{23}$

The rôle of nematodes in the soil may, therefore, consist of the following processes:

1. Consuming and destroying cultivated plants, often causing considerable damage.

${ }^{22}$ Menzel, R. Über die Nahrung der freilebenden Nematoden und die Art ihrer Aufnahme. Ein Beitrag zur Kenntnis der Ernährung der Würmer. Verhandl. Naturf. Gesell. Basel., 36: 153-188. 1920.

${ }^{23}$ Baunacke, 1922 (p. 344). 
2. Consuming soil bacteria and fungi.

3. Consuming soil protozoa.

4. Destroying other nematodes (predatory forms).

5. Distributing bacteria and fungi throughout the soil.

6. Taking an active part in the transformation of the soil organic matter.

7. Improving soil aeration.

\section{ROTATORIA 24}

Rotatoria or Rotifera, commonly known as wheel animalcules, are minute, chiefly microscopic, animals. They are mostly characterized by the presence of a ciliated area, or corona, at or near the anterior end of the body, which serves both for locomotion and for bringing food to the mouth. Cilia are lacking on other parts of the body; in exceptional cases, they may be present at the posterior end. The corona may, in a few cases, be lacking. The body is usually somewhat elongated, with the corona at the anterior end and a tail-like appendage at the posterior end beyond the cloacal opening. The sexes are separate, the male being a minute, degenerate form, without an alimentary canal.

They are commonly found in swamps and marshes, as well as in moss and forest leaves. Francé found the following species in the soil:

Rotifer tartigradus
Rotifer vulgaris
Philodina erythrophthalma
Philodina aculeata
Philodina vorax
Adineta vaga

Rotifer tartigradus

Rotifer vulgaris

Philodina erythrophthalma

Philodina aculeata

Adineta vaga
Callidina papillosa
Callidina ehrenbergii
Callidina multispinosa
Habrotrocha angusticollis
Diaschiza semiaperta
Chaetonotus macrotrichus

A number of other forms may occur, but they have not yet been made the subject of special study.

\section{ANNELIDA}

The annelids are represented in the soil by the earthworms (Oligochaeta-Terricolae), whose whole life cycle is passed in the soil, and by the white worms or Enchytraeids (Oligochaeta-Limicolae), which are usually abundant in moist soils, especially those rich in organic matter.

Oligochaeta-Terricolae. ${ }^{25}$ The earthworms are characterized by their flexible segmented bodies, with four rows of bristles or setae. They

${ }^{24}$ Harring, H. K. Synopsis of the rotatoria. U. S. Natl. Museum, Bul. 81, 1913; Harring, H. K., and Myers, F. J. Rotifer fauna of Wisconsin. Trans. Wiscon. Acad. Sci., 21: 415-549. 1924.

${ }^{26}$ Michaelsen, W. Oligochaeta. Das Tierreich. No. 10, 1900. 
have a well-defined body cavity and are hermaphroditic. The setae aid in locomotion. Various families are found in the soil.

The occurrence of earthworms in the soil has been of common knowledge since the work of Darwin and Hensen. ${ }^{26}$ They are especially abundant in forest soils and soils rich in organic matter ${ }^{27}$ while they are almost absent in sandy soils. Heimburger ${ }^{28}$ suggested that a correlation exists between the degree of moisture of the soil and species of earthworms inhabiting it. The worms react definitely to atmospheric moisture but less sharply than to contact with moist substrate.

To determine the numbers of earthworms in the soil, a certain volume of it is spread in a thin layer on a flat surface; when the soil begins to dry, the animals begin to move rapidly and can be counted. Moist soil may also be covered with a solution of sugar or powdered $\mathrm{KHSO}_{4}$, which will bring the worms to the surface. Morris ${ }^{29}$ found 1,010,101 earthworms per acre of manured soil and 457,912 per acre of unmanured soil. The greatest numbers occurred at a depth of two and three inches. The following species of earthworms were found in the soil by Francé: Eisenia rosea, Lumbricus terrestris, Lumbricus rubellus, Allolobophora aporata, Helodrillus ociaëdrus. It was estimated that between 200 and 1000 pounds of earthworms are present in an acre of soil. Thompson ${ }^{30}$ found eighteen individuals in a nine inch cube of the upper three inches of a pasture soil.

Soil reaction has an influence upon the development of earthworms. ${ }^{31}$ The worms feed not only upon plant residues, but also on soil organisms. Francé found various algae, fungus mycelium, protozoa and yeasts in the excreta of earthworms.

The animals pass earth through their bodies, grinding it in the

${ }^{26}$ Darwin, Ch. Vegetable mould and earthworms. London. J. Murray. 1881 ; D. Appleton, 1900. Hensen, V. Über die Fruchtbarkeit des Erdbodens in ihrer Abhängigkeit von den Leistungen der in der Erdrinde lebenden Würmer. Landw. Jahrb., 11: 661-698. 1882.

${ }^{27}$ Remelé, E., Schellhorn, and Krause, M. Anzahl und Bedeutung der niederen Organismen in Wald und Moorböden. Ztsehr. Forst. u. Jagdwes., 31: 575-606. 1899.

${ }^{28}$ Heimburger, H. V. Reactions of earthworms to temperature and atmospheric humidity. Ecology, 5: 276-282. 1924.

${ }^{29}$ Morris, H. M. Rothamsted Station Rept. for 1918-1920, p. 20.

${ }^{30}$ Thompson, M. The soil population. An investigation of the biology of the soil in certain districts of Aberystwyth. Ann. Appl. Biol., 11: 349-394. 1924.

${ }^{31}$ Arrhenius, O. Influence of soil reaction on earthworms. Ecology, 2: 255-262. 1921. 
gizzard into fine particles and decomposing some of the organic matter which may be present. The earth is then passed out of the body and deposited as castings at the surface of the burrows. The soil is thus well mixed with the organic matter and brought from the lower layers to the surface. According to Darwin, ten tons of earth for each acre of land are passed through the bodies of the earthworms every year in some cases. This mechanical action of the worms upon the structure of the soil is of great importance. Wollny $y^{32}$ considered that the worms were concerned with the decomposition of the nitrogenous compounds in the soil; a soil containing worms was found to have a higher ammonium content than the same soil free from worms. Soils containing earthworms and upon which grass was growing was found to contain more ammonia, nitrate and total nitrogen than soils without worms and grass, but this is probably due more to the grass than to the worms. ${ }^{33}$

It was suggested ${ }^{34}$ that earthworms increase plant growth by increasing the surface of soil due to excreta, thus affecting the water-holding capacity of the soil and movement of water. These organisms are commonly considered to exert an important influence upon the mechanical transformation in soil as well as soil productivity as a result of their effect upon nitrogen transformation. ${ }^{35}$ Russell, ${ }^{36}$ however, pointed out that earthworms do not appear to have any marked effect on the production of plant food; their chief work is to act as cultivators, loosening and mulching the soil, facilitating aeration and drainage by their borrows.

Oligochaeta-Limicolae or Enchytraeidae. This family is characterized by their whitish appearance and presence of more than two straight setae in some of the bundles. Moist soils, especially those rich in organic matter, will contain large numbers of these organisms. 'Thompson found as many as 86 forms in a 9-inch cube of the upper 3 inches of

32 Wollny, E. Die Zersetzung der organischen Stoffe. 1897, p. 39.

${ }^{33}$ Blanck, E., and Giesecke, F. Über den Einfluss der Regenwürmer auf die physikalischen und biologischen Eigenschaften des Bodens. Ztschr. Pflanzenernähr. Düng., 3B: 198-210. 1924.

${ }^{34}$ Kohswitz, H. G. Untersuchungen über den Einfluss der Regenwürmer auf Boden und Pflanze. Bot. Archiv., 1: 315-331. 1922.

${ }^{35}$ Aichberger, R. V. Untersuchungen über die Ernährung des Regenwurmes. Arb. Biol. Inst. München. No. 4, Kleinwelt. 1914; Heymons, R. Der Einflusz der Regenwürmer auf Beschaffenheit und Ertragsfähigkeit des Bodens. Ztschr. Pflanzenernähr. Düng., 2A: 97-129. 1923.

${ }^{36}$ Russell, E. J. The effect of earthworms upon soil productiveness. Jour. Agr. Sci., 3: 346.1910. 
pasture soil, including several species of Fredericia and Enchytraeus (E. albidus). Francé found species of Enchytraeus, Fredericia and Anachacta in the soil. According to Jegen, ${ }^{37}$ these are capable of neutralizing the injurious effect of certain nematodes in the soil; he also claimed that they play a rôle in the formation of humus in the upper soil layers. They are very sensitive to drying and to lack of oxygen. Their relative abundance is indicated by the following numbers found in one square meter of different soils, at different seasons of the year. They were practically absent in heavy clay soils, as shown in the following summary:

\begin{tabular}{|c|c|c|c|}
\hline SOIL TYPE & LOAM & SANDY SOIL & HUMOS SOHL \\
\hline Spring....... & $60-100$ & $6,900-9,000$ & $30,000-70,000$ \\
\hline Summer (dry). & $28-75$ & $2,600-4,900$ & $11,800-16,000$ \\
\hline Summer (moist). & $70-300$ & $6,500-8,500$ & $28,000-50,000$ \\
\hline Autumn......... & $100-450$ & $7,000-11,000$ & $60,000-150,000$ \\
\hline Winter.... & $800-1600$ & $6,800-9,400$ & $50,000-120,000$ \\
\hline
\end{tabular}

Tardigrada. The tardigrads are a group of Annelids, although they are often wrongly classified with the Arachnids and Arthropoda. ${ }^{38}$ The organs of locomotion are unarticulated, with more or less retractible parapodia. The body is 1 to $10 \mathrm{~mm}$. long, cylindrical, often almost worm-like. Some are without eyes, some have compound eyes in the form of black or red spots. The sexes are separate. During a period of dryness, they hibernate. Hibernation my last for years without injury to the organism. The tardigrads can withstand considerable heat and cold. Under unfavorable conditions, they encyst; regeneration of the organs follows this stage. Various species are found in the soil. Francé found this group represented by the genera Macrobiotus and Milnesium.

\section{ARTHROPODA}

Crustacea. The crustaceans are represented in the soil by the Copepoda ${ }^{39}$ (family Harpacticidae) and the Isopoda, ${ }^{40}$ or higher crus-

${ }^{37}$ Jegen, G. Bedeutung der Enchytraeiden für die Humusbildung. Landw. Jahrb. Schweiz, 34: 55-71. 1920.

${ }^{38}$ Richters, F. Tardigrada. Handwörterluch der Naturwissenschaften., 9. 1913 .

${ }^{39}$ Van Douwe, C., and Neresheiner, E. Copepoda. Die Süsswasserfauna Deutschlands. H. 11, 1909.

${ }^{40}$ Richardson. H. A monograph on the Isopods of North America. U. S. Nat. Mus. Bul. 54. 1905. 
taceans. The Harpacticidae do not have the cephalothorax and abdomen distinctly separated, so that the body is worm-like. Francé found in the soil one species of Moraria and six species of Canthocamptus. 33,700 to 80,000 Isopods were recorded per acre of soil by Morris. The presence of crustaceans in the soil was also reported by Thompson.

\section{ARACHNIDA}

The Arachnids are represented in the soil by the mites and ticks (Acarina ${ }^{41}$ ), which are chiefly carnivorous, free-living or parasitic, and by the carnivorous spiders (Areinida). Morris found the Acarina represented in the soil by the Amystidae, Tarsonemidae and Tyroglyphidae. The presence of various members of the Trombidiidac and Oribatidae in the soil was also reported by Thompson. Porrhomma, Robertus, Oedothorax, Linyphia, and others are the genera of Areinida found in the soil by Morris. The greatest numbers of Acarina were found in the upper one inch of soil, the total number being 531,986 per acre of manured soil and 215,48s per acre of unmanured soil.

\section{MYRIAPODA}

Among the myriapods present in the soil, are the millipedes (Diplopoda) which attack various crops, the centipedes (Chilopoda), which are carnivorous, and the Symphyla.

The following species of myriapods were found in the soil:42 Clomeris hexasticha, G. frausalpina, Polydesmus sp., Craspedosoma rawlinsii, C. canestrinii, Chordeuma nodulosum, Ch. silvestre, Julus nigrofuscus, C. verhoeffi, Schizophyllum sabulosum and Lithobius forficatus. Morris found 1,781,143 myriapods in the upper nine inches of an acre of manured soil and 878,787 in the corresponding unmanured soil. They were distributed more or less uniformly with depth. The Diplopoda were represented by species of Brachydesmus, Cylindroiulus, Blaniulus and Archiboreoiulus; the Chilopoda by Lithobius, Geophitis and Geophilomorph. Symphyla were also found in both soils.

${ }^{41}$ Wolcott, R. H. A review of the genera of the water mites. Trans. Amer. Micr. Soc., 26: 161-243. 1905.

42 Diem, K. Untersuchungen über die Bodenfauna in den Alpen. Jahrb. St. Gall. Naturw. Gesell. Vereinsjahr. 1901-1902. 


\section{INSECTA}

The term "soil insect" comprises all insects which, at one time or another in the course of development from the egg to the imago, spend some stage or stages of their life-histories either on or beneath the surface of the soil. ${ }^{43}$ A great many species of insects, found in most orders, are associated with the soil in one or more stages of their development. As a matter of fact, it has been stated that as many as 95 per cent of all insect species invade the soil at some stage of their development. Millions of insects are found in every acre of arable land.

On the basis of their feeding habits, the soil insects can be divided into six groups:44

1. Those feeding on subterraneous parts of plants, as the larvae of Melolontha, Agriotes and Tipula.

2. Those living saprophytically in the soil, as Collembolla and larvae of Diptera and Coleoptera.

3. Those living on other members of the soil fauna, or predaceous species, as the Carabidae and many larvae of Diptera.

4. Parasitic species, as the Hymenoptera and the Tachinidae, which pass their larval stages on or within the bodies of other organisms.

5. Insects which find their habitat in the soil, without seeking a food supply there, as in the case of ants.

6. Insects which only undergo pupation in the soil, as in the case of the Lepidoptera.

A survey of the insect fauna in cultivated and pasture lands revealed the fact that the distribution and numbers of the soil fauna are more stable on grass than on arable land. ${ }^{45}$ This is due to the fact that grassland bears a vegetative covering all the time, which offers food for the fauna. In grass land, hibernation can proceed normally. Cultivation of land brings the fauna to the surface exposing it to harsh climatic conditions and to bird attack. As vegetative growth increases, there is a corresponding increase in the fauna in both arable and grass land. Conditions in winter and early spring are detrimental to the soil fauna.

The fauna of arable land consists of species which have passed the winter in the soil and those which have migrated or are introduced

${ }^{43}$ Cameron, A. E. Soil insects. Science Progress, No. 77: 92-108. 1925.

${ }^{44} \mathrm{Imms}, \mathrm{A}$. D. The invertebrate fauna of the soil (other than protozoa). In book by Sir E. John Russell et al. The microorganisms of the soil. Longmans, Green \& Co. 1923.

${ }^{45}$ Buckle, P. A preliminary survey of the soil fauna of agrieultural land. Ann. Appl. Biol., 8: 135-145. 1921. 
during the growing season. There is no characteristic fauna in cultivated land. Buckle isolated from the soil one species of Collembola, 35 species of Coleoptera, 6 Diptera, 2 Hymenoptora, 4 Chilopoda and Diplopoda.

A detailed study of the insect fauna of the soil has also been made by Cameron, Morris and Thompson. ${ }^{46}$ Morris found 2,475,000

TABLE 19

Distribution of the invertebrate soil fauna in two plots of arable land at Rothamsted ${ }^{1}$

\begin{tabular}{|c|c|c|}
\hline & \multicolumn{2}{|c|}{$\begin{array}{l}\text { NUMBERS OF ORGANISMS PER ACRE } \\
\text { OF SOIL }\end{array}$} \\
\hline & Unmanured plot & Manured plot \\
\hline Insecta . . . . . . . . . . . . . . & $2,474,700$ & $7,727,300$ \\
\hline 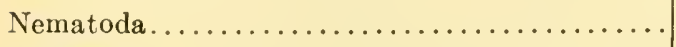 & 794,600 & $3,600,400$ \\
\hline \multicolumn{3}{|l|}{ Myriapoda: } \\
\hline Diplopoda . . . . . . . . . . . . . . . . . & 596,000 & $1,367,000$ \\
\hline 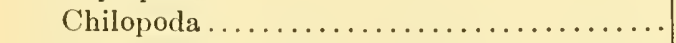 & 215,400 & 208,700 \\
\hline 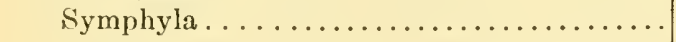 & 64,000 & 215,500 \\
\hline Total $\ldots \ldots \ldots \ldots \ldots \ldots \ldots \ldots \ldots$ & $\overline{875,400}$ & $\overline{1,791,200}$ \\
\hline Oligochaeta (Terricolae)................. & 457,900 & $1,010,100$ \\
\hline \multicolumn{3}{|l|}{ Arachnida: } \\
\hline Acarina..$\ldots \ldots \ldots \ldots \ldots \ldots \ldots \ldots \ldots \ldots \ldots \ldots \ldots \ldots \ldots$ & 215,400 & 531,900 \\
\hline Areinida $\ldots \ldots \ldots \ldots \ldots \ldots \ldots \ldots \ldots$ & 20,200 & 20,200 \\
\hline Total . . . . . . . . . . . . . . . . . . . & $\overrightarrow{235,600}$ & $\overline{552,100}$ \\
\hline Crustacea (Isopoda). . . . . . . . . . . . . & 33,700 & 80,800 \\
\hline Mollusca (Pulmonata).............. & 13,500 & 33,700 \\
\hline Total invertebrata. & $4,885,400$ & $14,795,600$ \\
\hline
\end{tabular}

${ }^{46}$ Cameron, A. E. General survey of the insect fauna of the soil within a limited area near Manchester. A consideration of the relationships between soil insects and the physical conditions of their habitat. Jour. Econ. Biol., 8: 1913, No. 3; The insect association of a local environmental complex in the district of Holmes Chapel, Cheshire. Trans. Roy. Soc. Edin., 52: pt. 1, No. 2. 1917; Morris, 1920 (p. 352); Thompson, 1924 (p. 352); See also Diem, 1901-1902; Holthaus, K. Die Siebetechnik zum Aufsammeln der Terricolfauna nebst Bemerkungen über die Oekologie der im Erdboden lebenden Tierwelt. Ztschr. 
insects in the upper nine inches of an acre of unmanured plot and $7,727,000$ in a manured plot. The dominant groups in both plots were the Collembola and Formicidae; the Chironomidae larvae and Trichocera larvae were much more abundant in the manured plot. The Collembola were represented by 14 species: the Thysanura by 3 species, the Orthoptera and Thysanoptera by one each; the Hemiptera by 4 ; the Lepidoptera by unidentified larvae; the Coleoptera by 30 species; the Diptera by 7 species and various unidentified larvae; the Hymenoptera by 10 species. The greatest majority of the organisms were found in the upper three inches of soil. The wireworms attain a maximum at a depth of 5 to 7 inches. Manuring increases the total number of soil organisms about 200 per cent, but has no appreciable influence on the number of wireworms.

Morris also found 3,586,088 insects in an acre of permanent pasture, the numbers of the different orders being Collembola-566,680, Rhynchota-15,140, Thysanoptera-43,258, Lepidoptera-15,140, Coleoptera-744,038, Diptera-2,193,180, Hymenoptera-8652. Among the injurious insects, the following were found per acre: Agriotes114,643 larvae and 8652 adults, Triphaena pronuba-4326 larvae and pupae, Tipula oleracea and T. paludosa 19,466 larvae. The family most represented was the Bibionidae, the species of this family making up 32.4 per cent of the total number of soil insects; Mycetophilidae was represented by 16.7 per cent and Staphyinidae by 12.2 per cent. The Coleoptera were represented by 29 species. According to Thompson, the orders Collembola and Acarina determine the trend of the total fauna curve, since they are the dominant groups. They persist throughout the year, while other groups like the Nematoda and Oligochaeta may be entirely missing for varying lengths of time. Cultivated land contains a considerably smaller population than pasture or grass land; the maximum population was found to occur in the winter months, due to sufficient moisture in the soil. Peat soils also contain a definite fauna of insects, as represented by the Collembola. ${ }^{47}$ $\mathrm{M}^{\prime} \mathrm{Atce}^{48}$ reported the presence of $1,216,880$ animals belonging to In-

wiss. Insektenbiol., 6: 1-4, 44-57. 1910; Adams, C. C. An ecological study of prairie and forest invertebrates. Ill. State Lab. Nat. Hist. Bul. 11: Art. 2. 1915; Shelford, V. E. Animal communities in temperate America. Geogr. Soc. Chicago, Bul. No. 5; Univ. Chicago Press. 1913; Vestal, A. G An associational study of Illinois sand prairie. Ill. State Lab. Nat. Hist. Bul. 10: Art. 1. 1913.

${ }^{47}$ Handschin, E. Beiträge zur Kenntnis der Collembolefauna der Hoch moore Estlands. Beitr. Kunde Estlands., 10: 167-176. 1924.

${ }^{8}$ M'Atee, W. L. Census of four square feet. Science, N. S., 26: 447-449. 1907. 
secta, Arachnida and other Arthropoda, Annelida and Gastropoda in an acre of forest soil.

A detailed study of the subterranean aphids has been made by Cutright. ${ }^{49}$

\section{MOLLUSCA}

The molluses possess a soft body encased in a hard shell consisting either of one part (Gastropoda snails) or two parts (Lamellibranchiata). The soil molluses include the snails and the slugs, which frequently leave the soil which they inhabit for feeding purposes in the presence of sufficient moisture. Most of these forms usually consume vegetable matter, while some (Testacella) are carnivorous. France found in the soil the genera Carychium and Helix. ${ }^{50}$

Influence of environmental conditions on the invertebrate fauna of the soil. Larvae of soil insects are very sensitive to evaporation of moisture, especially at $20^{\circ} \mathrm{C}$. or over. ${ }^{51}$ They do not occur in dry exposed soils, but rather in most soils where the humidity is not far below saturation and the temperature seldom goes above $20^{\circ}$ to $23^{\circ} \mathrm{C}$. Below $8^{\circ} \mathrm{C}$., most soil insects become inactive. Hibernating soil insects possess a great capacity of resisting freezing temperatures. They migrate vertically, according to season, especially in cold climates. ${ }^{52}$ The invertebrate fauna of the soil is generally much more abundant in heavy than in light sandy soils because of the moisture conditions. ${ }^{53}$ According to Morris, the depth to which insects penetrate into the soil is due to depth of food, aeration, moisture and soil temperature; insects are found, therefore, at greater depths in arable soil than in pasture land.

The addition of organic matter to the soil increases the moisture holding capacity of the soil and offers food material for many species. Different soil insects respond differently to varying degrees of humidity,

${ }^{49}$ Cutright, C. R. Subterranean aphids of Ohio. Ohio Agr. Exp. Sta. Bul. 387: 175-238. 1925.

${ }^{50}$ The influence of soil reaction upon snail development is discussed by Atkins, W. R. G., and Lebour, M. V. Soil reaction, water snails, and river flukes. Nature, 11: 83.1923.

${ }^{51}$ Hamilton, C. C. The behavior of some soil insects in gradients of evaporating power of air, carbon dioxide and ammonia. Biol. Bull. 32: 159-182. 1917.

${ }^{52}$ Griddle, N. The habits and control of white grubs in Manitoba. Agr. Gaz. Canada, 5: No. 5. 1918.

${ }^{53}$ Ramann, E. Regenwïrmer und Kleintiere im deutschen Waldboden. Int. Mitt. Bodenk., 1: 138-164. 1911. 
some selecting light, sandy soils and others living only in soils saturated with water. The optimum soil habitat is determined by the ratio or balance between the amount of available oxygen and the amount of carbon dioxide which can be endured without injury. ${ }^{54}$ Loam soils have a more abundant insect fauna than clay and sandy soils. ${ }^{51}$

Table 19 shows the influence of manuring of soil upon the distribution of the invertebrate fauna; these are not maximum numbers, but are in many cases, especially in the case of nematodes, far too low, as can be seen from the data recorded previously (p. 347). The distribution of the organisms with depth of soil is greatly influenced by manuring and plowing of the soil, the greatest number of insects and most other invertebrates occurring within the upper 3 inches of soil.

The great majority of free-living soil nematodes are "world wide" or are found everywhere when conditions are favorable for their development. To what extent this is true of the other members of the invertebrate fauna of the soil still remains to be investigated.

Economic importance of the invertebrate fauna of the soil. The treble rôle of the invertebrate fauna in the soil may be included under the heads of (1) mechanical effect upon the soil, as discussed above; (2) a relation to the transformation of organic substances in the soil; (3) a relation to the growth of higher plants. The influence of the invertebrate fauna upon the bacteria, fungi, actinomyces and algae of the soil is still a matter of speculation. There is no doubt that the fauna feeds to some extent upon the soil microflora and thus influences its activities. The earlier idea of Pasteur that the distribution of anthrax bacteria in the soil is brought about by worms inhabiting the soil may hold true also for the true soil microflora.

McColloch ${ }^{55}$ suggested that there is a reciprocal relation between the soil and its insect population: these utilize the soil for shelter, protection, as an avenue for travel, and find there their food, moisture and atmosphere. The soil is benefited, on the other hand, by being well mixed by the mechanical separation of particles, improvement of aeration and drainage, and addition of organic matter. The mechanical effect may be injurious as a result of the fact that the soil may become porous leading to an increase in evaporation and plant injury. Morris found that the nitrogen content of the invertebrate fauna

${ }^{54}$ Adams, 1915 (p. 358). See also Hesse, R. Tiergeographie auf ökologischer Grundlage. Jena. 1924.

${ }^{55} \mathrm{McColloch}, \mathrm{J}$. W. The rôle of insects in soil deterioration. Jour. Amer. Soc. Agr., 18: 143-159. 1926. 
varied from 4.88 per cent for the Myriapoda to 11.18 per cent for the Collembola, making a total nitrogen content of the fauna of an acre of manured ground 16.2 pounds and 7.5 pounds for unmanured ground. More than half of this nitrogen was in the bodies of the earthworms. The action of worms and insects in assisting the breaking down of vegetable matter, with the formation of amorphous "humus," was considered" of importance. The soil insects are frequently classified ${ }^{57}$ into three groups: beneficial, noxious and innocuous. The first include such forms as species of Ichneumonidae and Braconidae, which are parasitic on cutworms, predatory Carabidae and scavenging Scarabaeidae. The noxious insects are found among the Elatericlae, Noctuidae, some Scarabaeidae, Curculionidae and Tipulidae. The innocuous forms are those which find in the soil a temporary retreat for pupation; even injurious species, like the potato-beetle, may be harmless during the soil phases.

Among the most important insects whose larvae may become of great economic importance in the soil in injuring field crops, are the wireworms, white grubs and cutworms. ${ }^{58}$ The parents of the wireworms are the so-called "click," "jumping" or "snapping" beetles. The adults deposit their eggs chiefly in grass land. The small wireworms which hatch out feed on the roots of various plants or seeds before they are sprouted, especially when the crop is planted after sod. This continues until the insects are fully mature, which requires three to five years. The damage is usually most severe in spring. An abundance of wireworms in sandy soil frequently makes it necessary to abandon or "rest" the land.

The parents of the white grubs are the June bugs (beetles) which also lay their eggs principally in sod land during June. The eggs hatch in about two weeks. The grubs feed on any plants available and go down seven to fourteen inches below the surface when cold weather approaches. With the coming of warm weather the following spring, they come up again towards the surface where they feed on plants throughout the

${ }^{6}$ Kostytschew, P. Russian tschernoziems. Petrograd. 1886, p. 165-191. Ann. Sci. Agr., 2: 1887; Recherches sur la formation et les qualités de l'humus. Ann. Agron., 17: 17-38. 1891.

s7 Cameron, 1925 (p. 356).

${ }^{6}$ Headlee, T. J. Soil-infesting insects. N. J. Agr. Exp. Sta. Cir. 26; Anderson, G. M. The slender wireworm; its relation to soils. S. C. Agr. Exp. Sta. Bul. 204. 1920; Thomas, W. A. Corn and cotton wireworms. S. C. Agr. Exp. Sta. Bul. 155. 1911. 
season. ${ }^{59}$ This is twice repeated; the common cycle being three years. This white grub may become a limiting factor in continuous wheat production in certain sections; the infestation usually increasing with each generation, so that it becomes necessary to rotate with a cultivated crop. The green June beetle and muck beetle also (McCulloch) prefer soils receiving heavy applications of animal manures.

The cutworms hatch in September or October and become very active during the following spring. They cut off young plants near the surface of the soil and lap up the exuding sap. This is usually done at night.

Crop rotation, use of artificial fertilizers, fall plowing, ${ }^{60}$ the use of poisoned and other baits, ${ }^{61}$ soil fumigants $\left(\mathrm{CS}_{2}\right)$ and insecticicles (Paris green), ${ }^{62}$ as well as the direct mechanical protection of plants, are among the remedies suggested for these three pests.

Insects may also inhibit the activities of certain specific soil organisms, such as legume bacteria, by feeding on the nodules. This was pointed ${ }^{63}$ out for the beet leaf larva Ceratoma trifurcata, and for the mealy bugs Pseudococcus maratinus. ${ }^{64}$ As many as fifteen bugs were seen on one soybean nodule.

In addition to the invertebrate, there exists also a vertebrate fauna in the soil, including moles, blind mice, field micc, marmots, etc. Francé suggests that there exists an association in soil (Edaphon) consisting of bacteria, algae, fungi, diatoms, protozoa, rotatoria, nematodes, worms, myriapods and insects. The bacteria and fungi liberate

${ }^{59}$ McColloch, J. W., and Hayes, W. P. Soil temperature and its influence on white grub activities. Ecology, 4: 29-36. 1923; Osborn, H. The problem of permanent pasture with special reference to the biological factors. Proc. 39th Ann. Meet. Soc. Prom. Agr. Sci., 7-18. 1919.

${ }^{60}$ Hyslop, J. A. Wireworms attacking ccreal and forage crops. U. S. Dept. Agr. Bul. 156. 1915; Hunter, W. D. Relation between rotation systems and insect injury in the south. U. S. Dept. Agr. Yearbook, 1911: 201-210. 1912.

${ }^{61}$ Treherne, R. C. Wireworm control. Entom. Branch, Dept. Agr., Canada, Pamphl. 33. 1920.

${ }^{62}$ Davis, J. J. Miscellaneous soil insecticide tests. Soil Sci., 10: 61-76.

${ }^{63}$ McConnell, W. R. A unique type of insect injury. Jour. Econ. Entom., 8: 261-267. 1915; Another nodule destroying beetle. Ibid., 8: 551. 1915; Leonard, L. T., and Turner, C. F. Influence of Ceratoma trifurcata on the nitrogen-gathering functions of the cowpea. Jour. Amer. Soc. Agr., 10: 256261. 1918 .

${ }^{64}$ Leonard, L. T. Mcaly bugs on the roots and nodules of legumes growing in the ficld. Science, N. S., 57: 671-672. 1923. See also Folsom, J. W. The insect pests of clover and alfalfa. Ill. Agr. Exp. Sta. Bul. 134. 1909. 
nitrogen for the algae; all three forms serve as food for rhizopods and together with these they serve as food for rotatoria and nematodes; the latter are eaten by amoebae, myriapodes, insects, etc.; these are, in turn, decomposed by the fungi and bacteria.

It is sufficient to call attention to the rôle of termites (Hodotermes) in certain soils, to obtain an idea as to the probable importance of the animal population in soil processes. Termites live in tropical and subtropical countries, not only in wooden structures, in which they cause active decomposition of organic matter of living and dead plants, but also in the soil itself. The underground termites are found in great abundance in dry countries and in deserts. They form a great abundance of nests, which are connected by a net of underground passages. These termite nests make the soil very porous, with the result that there is a great increase in the amount of water required for saturation of the soil. The activities of the termites in the soil result in increases in the concentration of salts. These increases may be from 0.06 to 1.3 per cent. The termites, as a result of the numerous passages formed in the soil, appreciably improve soil drainage. ${ }^{65}$

${ }_{65}$ Dimo, N. A. The rôle and importance of termites in the life of soils and subsoils of Turkestan (Russian). In Soil and Bot. Geogr. Investig. of the basins of Amu-Daria and Sir-Daria. Moskau, 2: 1-38. 1916. 



\section{PART C \\ CHEMICAL ACTIVITIES OF MICROORGANISMS}

"Für alle Lebewesen ist ein nie fehlendes Kennzeichen der Energiestrom. Meist bezeichnet man den hier staltfindenden Vorgang mit dem Namen Stoffwechsel. Dieses Wort trifft aber nicht die Hauptsache."WI. OsTWALD. 



\section{CHAPTER XV}

\section{General Principles of Microbial Metabolism}

Metabolism as a whole. To be able to understand the chemical processes taking place in the soil as a result of the activities of microorganisms and to learn how to control these processes so as to produce conditions which make a soil productive and thus benefit the growth of higher plants, we must understand the metabolism of the various groups of soil microorganisms. The biological changes produced in the soil fall under the class of chemical reactions. However, the biologist is dealing with dynamic phenomena, while the chemist considers chiefly static phenomena. This is the reason why a chemical analysis of a soil is far from sufficient to give us information as to productivity of the soil, or the rapidity with which the nutrients necessary for the growth of higher plants become available. We must consider not only chemical changes as such, but also the course or rate of change. This ean be done and the information, subject to a host of variable factors, can be properly interpreted only when the metabolism of the organisms concerned is taken into consideration.

The metabolism of the leading groups of soil microorganisms can be considered under the transformation of carbon, of nitrogen and of mineral compounds. From the point of view of soil productivity, various groups of soil microorganisms may be considered to play important rôles in certain specific transformations, depending on the nature of the organism and nature of the medium. The various transformations in the soil dovetail and, for a proper understanding of the resulting phenomena, metabolism should always be considered as a whole.

The carbon source is used by the heterotrophic microorganisms as a source of energy and as a source of carbon for structural purposes, namely, for the building up of the microbial cell. In both cases the carbon is required in the form of complex organic compounds, such as carbohydrates, hydrocarbons, fats, fatty acids, proteins and their split products including amino acids and acid amides. Some organisms prefer one group of compounds and some another, while some can utilize a variety of substances as sources of carbon. A great many 
of the known soil bacteria are more or less selective in their action (when grown, of course, upon artificial culture media); many soil fungi and actinomyces and a number of bacteria can derive their carbon, both for energy and structural purposes, from a great variety of substances. Bact. pyocyaneum, for example, can obtain its carbon not only from carbohydrates, but also from lactic and acetic acids, glycerol, ethyl and methyl alcohols, and other substances. ${ }^{1}$ Other bacteria like the cellulose decomposing Spirochaeta cytophaga require only very specific compounds, namely celluloses, as sources of energy.

The autotrophic bacteria need no complex carbon compounds as sources of energy or for structural purposes. They can derive their carbon for the synthesis of their protoplasm from the carbon dioxide of the atmosphere or in solution. The facultative autotrophic bacteria can obtain their carbon either from $\mathrm{CO}_{2}$ or from organic compounds. There is some evidence, however, that growth of heterotrophic organisms is also favorably affected by the presence of $\mathrm{CO}_{2}$, as in the case of Bac. subtilis and Bact. vulgare, which could not grow when both oxygen and carbon dioxide were removed. ${ }^{2}$ The presence of carbon dioxide is essential not only for the growth of aerobic bacteria but also for the development of the anaerobic forms.

In view of the fact that the microbial cells contain between 3 and 15 per cent of nitrogen, large quantities of this element have to be assimilated, particularly by organisms producing an extensive growth. Nitrogen is obtained from proteins and their degradation products or simple inorganic nitrogenous compounds, including the ammonium salts of organic and inorganic acids and nitrates. Some organisms, especially the heterotrophic bacteria, prefer and many even require complex proteins, albumoses or peptones as a source of nitrogen (and energy), while other microorganisms, especially the fungi and autotrophic bacteria, will thrive just as well and sometimes even better upon simple compounds of nitrogen. Bact. pyocyaneum can obtain its nitrogen from amino compounds, amides, nitrates and nitrites, but these substances must be changed, either by hydrolysis or by reduction, to ammonia before they are assimilated. The nitrogen-fixing

${ }^{1}$ Supniewski, J. Untersuchungen über den Stoffwechsel der Kohlenstoffverbindungen bei Bacillus pyocyaneus. Biochem. Ztschr., 154: 90-97, 9S-103. 1924.

${ }^{2}$ Rockwell, G. E. The influence of $\mathrm{CO}_{2}$ on the growth of bacteria. Jour. Infec. Dis., 32: 98-104. 1923; 35: No. 6. 1924; 38: 92-100. 1926; Valley G., and Rettger, L. F. Preliminary report on the influence of carbon dioxide on bacterial growth. Abstr. Bact. (Proc.), 9: 344-345. 1925. 
microorganisms, capable of utilizing free nitrogen gas, in the absence of available compounds of this element, stand as a group by themselves.

The minerals, chiefly phosphates and potassium salts, but also iron, magnesium, sulfur, calcium and traces of other elements, are utilized by all microorganisms either in the form of simple inorganic compounds or are obtained from complex organic substances in the process of their decomposition. The minerals may often be obtained from insoluble inorganic materials, especially if the organism produces acids which tend to make them soluble.

In the utilization of nutrients by heterotrophic microorganisms, two general stages are observed. (1) The dissimilation or decomposition stage, in which organic matter is broken down by the agencies of hydrolysis, oxidation and reduction. (2) Assimilation stage, or synthesis, whereby the cells of microorganisms are built up out of the substances previously broken down.

The metabolism of autotrophic bacteria consists only of the synthesizing stage so far as organic substances are concerned. The autotrophic microorganisms utilize for their synthesis the products of dissimilation of the heterotrophic organisms, such as the various minerals, nitrogen compounds and even energy sources such as ammonia, hydrogen sulfide, etc. The heterotrophic microorganisms utilize for their dissimilation stage the products of assimilation of the autotrophic forms, namely the complex organic substances synthesized by these cells.

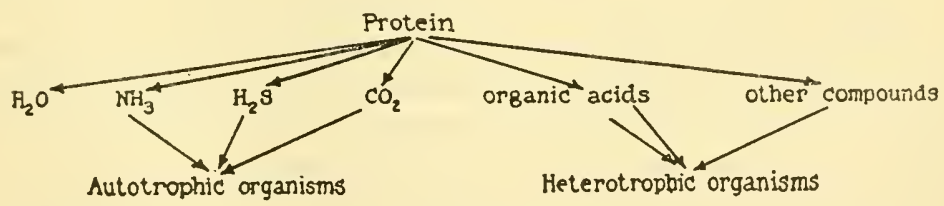

Only the autotrophic organisms actually produce work, in the true thermodynamic sense, as shown later, while the heterotrophic forms may simply build up the new protoplasm out of the constituents of the medium. This explains the considerably greater assimilation and the more extensive protoplasm produced for the same amount of energy available.

Chemical reactions in the microbial cell. The microbial cell may be considered as an osmotic system. The absorption and liberation of substances by microorganisms leads to a series of ehemical reactions 
necessary for the continuation of life and characteristic of the living cell. Most of these reactions are carried on in the cell by the agency of organic catalysts or enzymes, which may also be secreted outside of the cell; this allows certain chemical reactions to take place outside of the cell.

The chemical reactions depend on the presence of specific substances or substrates, the chemical and physical condition in which these substances are present, temperature, reaction, etc. The activities of the microorganisms will result in a change both in nature of the substrate as well as in the condition of the medium in which they work. Celluloses and proteins, substances of high molecular weight and low osmotic pressure, will be changed by processes of hydrolysis, to sugars and organic acids or to peptides and amino acids, substances of low molecular weight and high osmotic pressure. On the other hand, the absorption of soluble nitrogen salts and minerals and their synthesis into microbial protoplasm will bring about a reverse condition. The ionic exchange in the living cell, as the absorption of the base in the case of ammonium salts or absorption of the acid in the case of nitrates, will tend to leave the medium more acid or more alkaline respectively. The formation of organic acids, such as gluconic, citric, oxalic and fumaric by fungi, lactic, formic, propionic and acetic by bacteria, and inorganic acids, such as carbonic, nitrous, nitric and sulfuric, will also lead to a change in the hydrogen-ion concentration of the medium. These acids will combine with the insoluble and soluble bases forming new salts. Some of these, such as the salts of organic acids, may be used as sources of carbon, liberating the bases which will combine with the carbon dioxide of the atmosphere to form carbonates, and again change the reaction of the medium from acid to alkaline. Others, like the nitrates and sulfates, may be again assimilated by microorganisms and higher plants. These may be washed from the soil in the drainage waters, they may be absorbed by the soil colloids, or they may form simple or complex salts with the various inorganic or organic soil constituents.

All of these reactions bring about constant ehanges in the osmotic concentration and the reaction of the medium. This is further accentuated by the formation of electrolytes from non-electrolytes (ammonia and nitrates from proteins and amino acids, phosphates and sulfates from complex protoplasm) and vice versa. It is important, tl.erefore, to gain knowledge of the osmotic concentration of the soil 
solution, as determined by the lowering of the freezing point, ${ }^{3}$ change in conductivity, ${ }^{4}$ or other convenient method; also of the hydrogen-ion concentration, as determined by the electrometric or colorimetric method, ${ }^{5}$ and of the buffer content of the soil, as determined by the curves which show the relation between addition of acid and alkali and change in reaction.

Enzymes of microorganisms. A large number of chemical reactions are carried on by the microbial cell by means of enzymes. These are either secreted outside of the cell (exo-enzymes) or remain within the cell and can be separated from it only with great difficulty (endoenzymes). Among the different reactions, in which enzymes take an active part, we need mention but four: (1) Hydrolysis. This involves the transformation of various polysaccharides into sugars, of proteins into amino acids, of amino acids into ammonia and oxy-acids; the transformation of insoluble organic substances (starch, fibrin) into soluble forms, and finally glycolytic decompositions, as the transformation of sugar into lactic acid $\left(\mathrm{C}_{6} \mathrm{H}_{12} \mathrm{O}_{6}=2 \mathrm{C}_{3} \mathrm{H}_{6} \mathrm{O}_{3}\right)$. (2) Oxidation, resulting in the liberation of energy. Some of the oxidation processes, such as the formation of acetic acid from alcohol, citric and oxalic acids from glucose, are frequently referred to as fermentations. These are distinguished from true fermentations, which result in the liberation of energy by the decomposition of complex organic compounds into simpler forms, without the intervention of free oxygen, as in alcoholic and butyric acid fermentations. (3). Reduction. Substances rich in oxygen are reduced to substances poor in oxygen, such as the reduction of nitrates, nitrites and sulfates, and the oxygen may be used for purposes of oxidation. The coupled reactions of oxidation and reduction, whereby the one substance is oxidized and the other reduced at the same time are common in microbiological reactions. (4) Synthetic reaction, including anhydride formation and condensation.

${ }^{3}$ Bouyoucos, G. J., and McCool, M. M. The freezing point method as a new means of measuring the concentration of the soil solution directly in the soil. Mich. Agr. Exp. Sta., Tech. Bul. 24, 1915; 27, 1916; 31, 1916; 37, 1917; 43, 1918. Hoagland, D. R. The freezing point method as an index of variation in the soil solution due to season and erop growth. Jour. Agr. Res., 12: 369.1918.

${ }^{4}$ Hibbard, R. P., and Chapman, C. W. A simplified apparatus for measuring the conductivity of electrolytes. Mich. Agr. Exp. Sta., Tech. Bul. 23, 1915.

${ }^{5}$ Clark, W. M. The determination of hydrogen ions. The Williams \& Wilkins Co., Baltimore. 1922. 
Reaction velocity. Reactions between ions take place in homogeneous media with great velocity. In colloidal media, such as the living cell or the soil, the time factor is of great importance. The reactions between molecules is much slower than between ions even in homogeneous media, but more so in such an heterogeneous medium as the soil. The kinetics of chemical reactions, which includes the decomposition of fats, carbohydrates, glucosides, proteins, as well as the various oxidation and reduction phenomena, is of prime importance in soil microbiology. The course of change is determined by measuring at definite intervals of time the amount of change that has taken place and the results are calculated on a definite basis, such as moles per liter. The law of Wilhelmy, ${ }^{6}$ that the reaction velocity is at any given time proportional to the amount of unchanged substrate, applies to monomolecular reactions, or where only one substance changes in concentration. The hydrolysis of sugars and glucosides belongs to this type of reaction, while saponification of esters is already bimolecular.

The fundamental equation of the monomolecular reaction is

$$
\frac{d x}{d t}=K(a-x),
$$

It becomes, on integration,

$$
K=\frac{1}{t} \ln \frac{a}{a-x},
$$

where $a$ is amount of undecomposed substrate, $x$ the amount decomposed in $t$ minutes. An understanding of the temperature coefficient is also important. In most reactions, with every increase in $10^{\circ} \mathrm{C}$. temperature, the velocity is increased two to three times. ${ }^{7}$ This usually holds true at temperatures ranging from 0 to $35^{\circ}$. Above that temperature, the destructive effect of heat is greater than the stimulating action. The thermophilic bacteria will exist even at $55^{\circ}$ to $65^{\circ} \mathrm{C}$. and carry on their activities at such temperatures.

Grouth, life and death of microorganisms. The numbers of bacteria and other microorganisms in the soil vary greatly not only from day to day, but even within brief periods of time, as a result of the changes in the environmental conditions. The age of the bacteria may be only a few days, while they reproduce within twenty to thirty minutes.

'Wilhelmy, L. Über das Gesetz, nach welchem die Einwirkung der Säuren auf Rohrzucker stattfindet. Pogg. Ann., 81: 413-499. 1850.

${ }^{7}$ van't Hoff, J. H. Chemische Dynamik. 1898, p. 224. 
Growth of an organism can be continued indefinitely, when repeatedly transferred upon fresh media. In the same medium, however, there is at first a decided increase in the numbers and activities of a microorganism, soon coming to a maximum and this is followed by a rapid decrease. The limitations to further growth are the lack of nutrients and the formation of injurious waste products.

Kruse reports that, after two days of growth on agar cultures, certain bacteria are reduced to 10 per cent of the maximum; in three days, to 1 per cent and, in seven days, they are all dead. The curve shown in fig. $11^{8}$ illustrates this process.

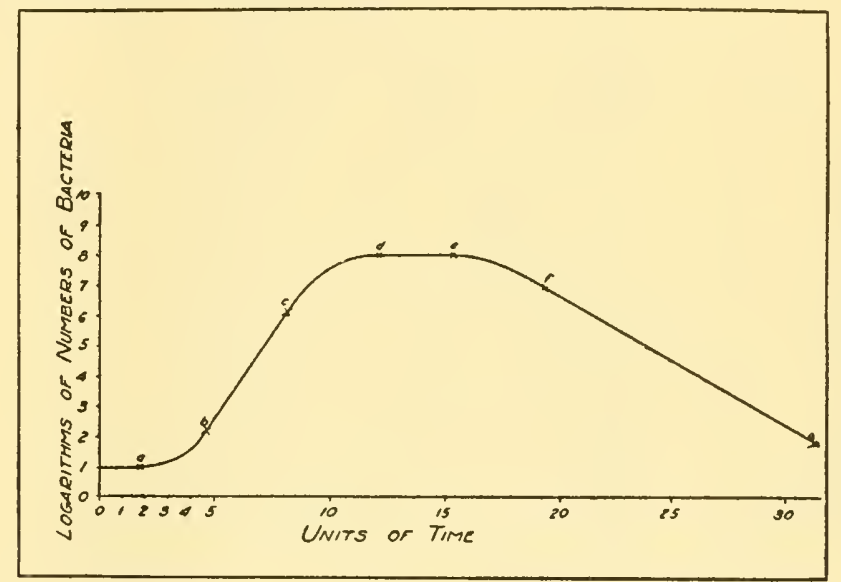

FiG. 11. Rate of increase in numbers of a bacterium (from Buchanan)

Different organisms grow at a different rate of rapidity and also disintegrate at a different rate. Growth of microorganisms in a limited amount of medium soon reaches a maximum due to the exhaustion of one or more nutrients in the medium or to the formation of injurious by-products, such as acids, alkalies or some toxic substances. ${ }^{9}$ While the older parts die off, the younger may still continue to grow and these may use the nutrients made available by the decomposition (autolysis) of the older parts.

A microbial cell thus passes through a period of youth, full development and old age. These stages can be expressed by the autocatalytic

${ }^{8}$ Buchanan, R. E. Life phases in a bacterial culture. Jour. Inf. Dis., 23 : 109-125. 1918.

- Chambers, W. H. Studies in the physiology of the fungi. XI. Bacterial inhibition by metabolic products. Ann. Mo, Bot. Gard., 7: 249-289. 1920. 
curve, suggested by Robertson. ${ }^{10}$ A difference exists in the physiological activities and in the physico-chemical condition of young and mature cells. ${ }^{11}$ A medium, in which growth of a certain organism has ceased as a result of accumulation of an injurious substance, may be treated so as to neutralize the accumulated acid or alkali, the limiting nutrient may be added, or finally the toxic substance may be destroyed by means of heat. ${ }^{12}$ The organism will then begin to grow again and

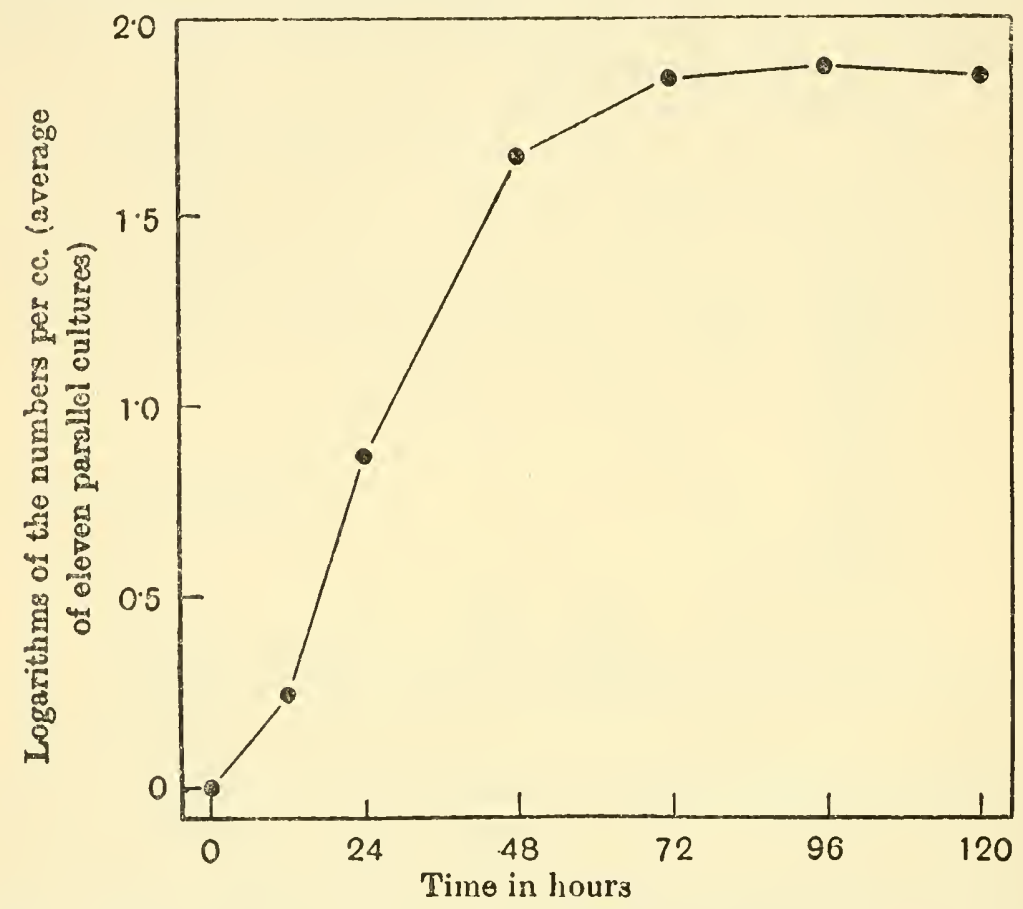

FIG. 12. Rate of increase in numbers of a protozoan (after Cutler and Crump)

pass through another cycle of activities. Limitations of growth and formation of certain substances (ammonia, nitrate) may thus be due

${ }^{10}$ Robertson, T. B. On the nature of the autocatalyst of growth. Arch. Entw. Mech., 37:497-508. 1913; Tables for the computation of curves of autocatalysis, with especial reference to curves of growth. Univ. Cal. Publ. Physiology, 4:211-228. 1915.

11 Sherman, J. M., and Albus, W. B. Physiological youth of bacteria. Jour. Bact., 8: 127-138. 1923.

${ }^{12}$ Rahn, O. Über den Einflusz der Stoffwechselprodukte auf das Wachstum der Bakterien. Centrbl. Bakt. II, 16: 417-429, 609-617. 1906. 
either to reactions of autocatalysis, as 'suggested by Robertson, or perhaps more likely to the development of a certain balance between the reproduction of the cells and the accumulation of injurious products of metabolism. ${ }^{13}$ Miyake, ${ }^{14}$ using the results of Lipman and associates $^{15}$ on ammonia accumulation and of Warington on nitrate accumulation in the soil, calculated that these processes are autocatalytic chemical reactions. The maximum rate occurs when the total amount

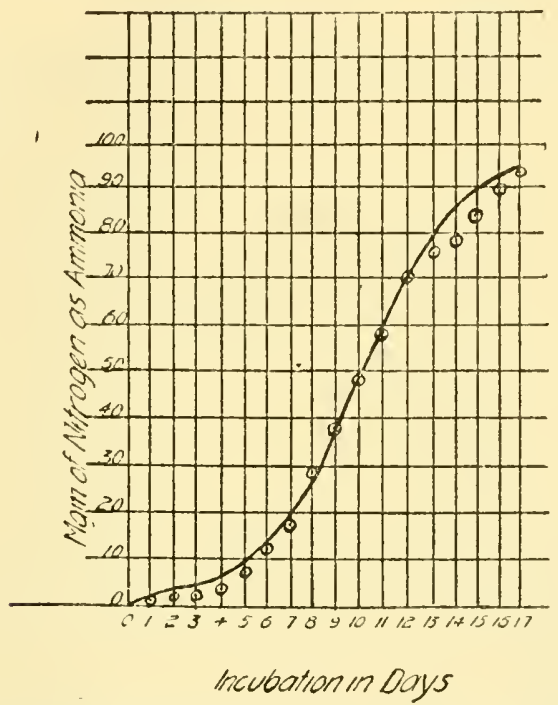

FId. 13. Rate of ammonia formation from peptone by Asp. niger (after Waksman).

of production is half completed. The amount of ammonia or nitrate increases according to the formula:

$$
\frac{d x}{d t}=K x(A-x)
$$

${ }^{13}$ Meller, R. Utber den Verlauf des Wachstums bei Bacillus (Proteus) vulgaris in seiner Abhängigkeit von einigen Stoffwechselprodukten. Centrbl. Bakt., I, 64: 1-32. 1925.

${ }^{14}$ Miyake, K. On the nature of ammonification and nitrification. Soil Sci., 2: 4S1-492. 1916. Jour. Biochem. Tokyo, 1: 123-130. 1922.

${ }^{15}$ Lipman, J. G., Blair, A. W., Owen, I. L., and McLean, H. C. Experiments on ammonia formation in the presence of carbohydrates and other non-nitrogenous organic matter. N. J. Agr. Exp. Sta. Bul. 247, 1912. 
in which $A$ is the initial quantity of material subject to transformation, $x$ is the amount transformed in time $t$, and $K$ is a constant. On integration, the equation becomes

$$
\log \frac{x}{A-x}=K\left(t-t_{1}\right)
$$

in which $t_{1}$ is the time at which the reaction has proceeded half way to equilibrium, that is when $x=\frac{A}{2}$ and $K=k A$.

Similar results have been obtained ${ }^{16}$ for ammonia formation from peptone by $A$. niger and for $\mathrm{CO}_{2}$ evolution by fungi in the decomposition

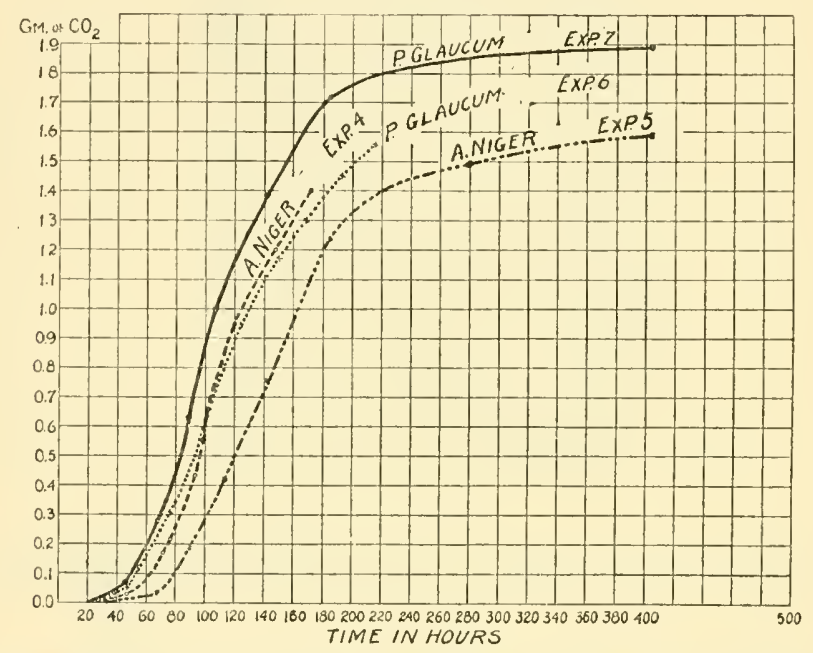

Fia. 14. Rate of $\mathrm{CO}_{2}$ production from xylose by two fungi (after Peterson, Fred and Schmidt).

of pentoses. The formation by the microbial cell of toxic substances which are selectively adsorbed on its surface has been demonstrated by Rideal. ${ }^{17}$

The different microorganisms are not growing in the soil in pure culture. In the presence of a great number of various other organisms,

${ }^{16}$ Waksman, S. A. Studies on proteolytic activities of soil microorganisms, with special reference to fungi. Jour. Bact., 3: 475-492. 1918.

${ }_{17}$ Rideal, E. K. Colloid phenomena in bacteriology. Brit. Assn. Adv. Sci. 1923, 31-38. 
stimulative and injurious substances may be formed constantly. ${ }^{18}$ It has even been claimed that soil microorganisms produce substances (nucleic acids) which stimulate the growth of cultivated plants. ${ }^{19}$

Chemical composition of the microbial cell. The presence of a certain number of organisms in a given soil and at a given time is not due to a mere accident, but because a definite amount of energy, nitrogen and minerals are made available for their growth and reproduction in a given period of time, and as a result of definite environmental conditions. A change in the energy supply and in the environment will change not

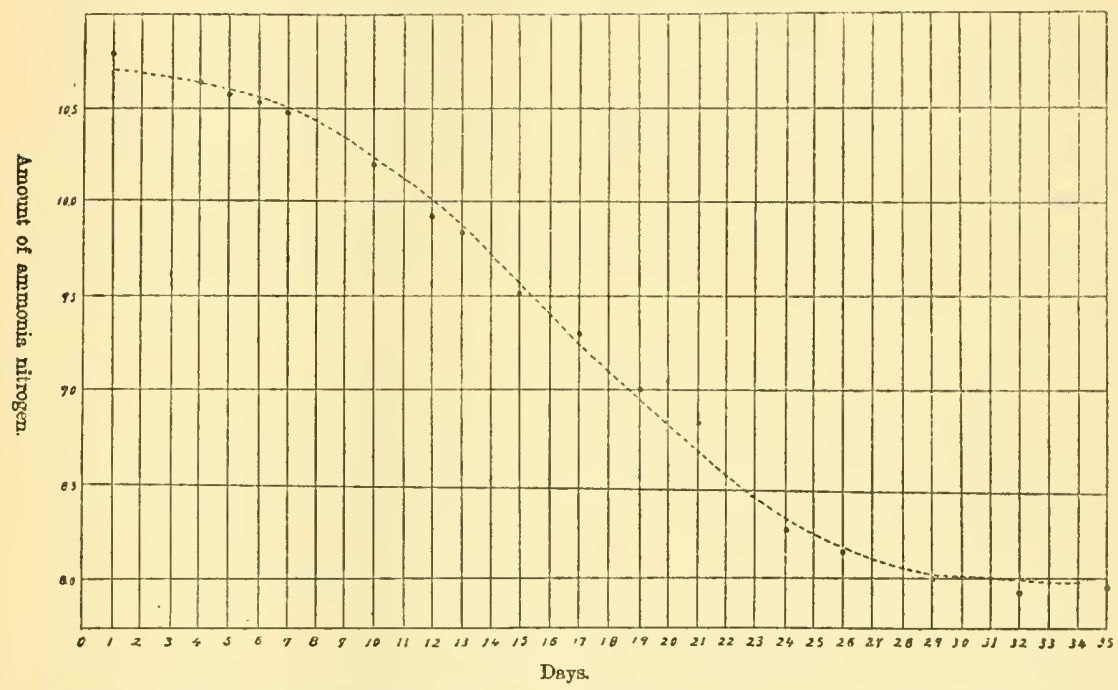

Frg. 15. Rate of oxidation of ammonia to nitrate, as shown by disappearance of ammonia in soil (after Miyake and Soma).

only the numbers of microorganisms, but also the nature of the soil population. Different numbers and different kinds of microorganisms will be found in a given soil, at different periods, because varying quantities of nutrients are made available. When a soil is air-dried and again moistened, there is an increase in the numbers and activities of microorganisms, because the process of drying results in rendering a greater amount of the inorganic and organic matter available.

${ }^{18}$ Pringsheim, E. G. Utber die gegenseitige Schädigung und Förderung von Bakterien. Centrbl. Bakt. II, 51: 72-85. 1920.

${ }^{19}$ Mockeridge, F. A. The formation of plant growth-promoting substances by microorganisms. Ann. Bot., 38: 723-734. 1924. 
When a fresh amount of undecomposed organic matter is added to the soil, a rapid increase in numbers of microorganisms takes place because a large amount of the energy added is readily available.

Microorganisms are not, however, constant in composition. They vary with the composition of the medium and adapt themselves to the available nutrients. Cramer ${ }^{20}$ found that the average water content of bacteria grown on agar media was 87.71 per cent. The dry material consisted of 50.47 to 51.81 per cent carbon, 6.59 to 7.49 per cent hydrogen, 12.32 to 13.46 per cent nitrogen and 7.79 to 10.36 per cent ash. On media rich in carbohydrate the nitrogen content was often less than 10 per cent. The alcohol ether extract varied from 9.06 to 24.0 per cent, depending on the organisms and the composition of the medium.

According to Nicolle and Alilaire, ${ }^{21}$ bacteria contain, on the basis of dry weight of cells, 8.3 to 10.8 per cent of nitrogen. The moisture content of the cells varied from 73.4 to 85.5 per cent; acetone extracted 6.3 to 15.6 per cent of the dry material and chloroform 1.5 to 11.8 per cent. The phosphorus content of the chloroform extract varied from 0.2 to 2.5 per cent. ${ }^{22}$

Algae grown on synthetic nutrient agar media with $\mathrm{Ca}\left(\mathrm{NO}_{3}\right)_{2}$ as the only source of nitrogen were found ${ }^{23}$ to contain 7.4 per cent nitrogen, on an ash-free basis. About 25 per cent of this nitrogen could be extracted with water and consisted of proteins, amino acids and peptides. The nitrogen content of fungi was found ${ }^{24}$ to vary between 2.3 and 6.6 per cent, depending on the nature of substrate. Soon after the spores germinate and active cell formation talies place, the nitrogen content of the fungi may be much higher. ${ }^{25}$ A study of the nitrogen content of bacteria, fungi and actinomyces, grown on media containing an amino acid as the only source of carbon and nitrogen,

${ }^{20}$ Cramer, E. Die Zusammensetzung der Bakterien in ihrer Abhängigkeit von dem Nährmaterial. Areh. Hyg., 16: 151-195. 1893.

21 Nicolle, M., and Alilaire, E. Note sur la production en grand des corps bactériens et sur leur composition chimique. Ann. Inst. Past., 23: 547-557. 1909.

${ }^{22}$ Further information on the composition of the bacterial cells is given by Kruse, 1910 (p. xii).

${ }^{23}$ Fred, E. B., and Peterson, W. H. Forms of nitrogen in pure cultures of algae. Bot. Gaz., 79: 324 328. 1925.

${ }^{24}$ Mazé, P. Recherches sur les modes d'utilisation du earbone ternaire par les végétaux et les microbes. Ann. Inst. Past., 16: 346-378. 1902.

${ }_{25}$ Nikolsky, M. Über den Einfluss der Nahrung von verschiedenen Kohlehydraten auf die Entwicklung der Schimmelpilze. Centrbl. Bakt. II, 12: 554$559,656-675.1904$. 
shows ${ }^{26}$ that both the nature of the organism and the presence of nonnitrogeneous substances are of great importance in this connection.

The nitrogen content of some fungi may be as low as 1 per cent, ${ }^{27}$ in the absence of available nitrogen and in the presence of an excess of energy compounds. It may be as high as $8-11$ per cent, ${ }^{28}$ in the absence of sufficient energy and in the presence of an excess of nitrogen. The wide variation is due to the adaptation of the organisms to the

TABLE 20

Nitrogen content of some typical soil organisms

\begin{tabular}{|c|c|c|}
\hline NAME OF ORGANISM & $\begin{array}{c}1 \text { PER CENT } \\
\text { GLUTAMIC ACID }\end{array}$ & $\begin{array}{c}1 \text { PER CENT } \\
\text { GLUTAMIC ACID }+ \\
2 \text { PER CENT } \\
\text { GLUCOSE }\end{array}$ \\
\hline & per cent & per cent \\
\hline 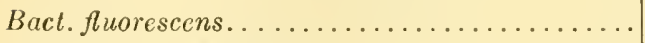 & 10.0 & 10.0 \\
\hline Act. viridochromogenus................ & 8.0 & 8.0 \\
\hline Zygorhynchus mölleri.................. & 6.8 & 4. 6 \\
\hline Trichoderma koningi................... & 6.9 & 5.3 \\
\hline
\end{tabular}

TABLE 21

Influence of age of culturc upon the nitrogen content of a fungus ${ }^{25}$

\begin{tabular}{c|c|c|c}
\hline \multirow{2}{*}{ AGE, DAYS } & TOTAL DRY MYCELIUM & NITROGEN PRESENT & NITROGEN \\
\cline { 2 - 4 } 4 & gram & gram & per cent \\
6 & 0.46 & 0.075 & 16.2 \\
8 & 0.51 & 0.043 & 7.1 \\
10 & 1.12 & 0.062 & 5.6 \\
12 & 1.67 & 0.104 & 6.2 \\
14 & 1.72 & 0.090 & 5.2 \\
\hline
\end{tabular}

media. Nikolsky ${ }^{25}$ demonstrated that the age of the organism (Mucor amylomyces), even grown on the same medium, influences its eomposition.

The nature of the organism itself, even among related forms, is of great importance, as shown ${ }^{29}$ for two organisms grown in a synthetic medium, with 2 per cent xylose as the source of energy (table 22).

${ }^{26}$ Waksman, S. A., and Lomanitz, S. Contribution to the chemistry of decomposition of proteins and amino acids by various groups of microorganisms. Jour. Agr. Res., 30: 263-281. 1924.

${ }^{27}$ Gerlach, M., and Vogel, I. Weitere Versuche mit stickstoffbindenden Bakterien. Centrbl. Bakt. II, 10:636-643. 1903.

${ }^{28}$ Czapek, 1902 (p. 502).

${ }^{29}$ Peterson, W. H., Fred, E. B., and Schmidt, E. G. The fermentation of pentoses by molds. Jour. Biol. Chem., 54: 19-34. 1922. 
The concentration of nutrients is also of great importance in determining the composition of fungus mycelium, as shown by Raulin ${ }^{30}$ (table 23).

In general, the nitrogen content of bacteria and yeasts is found to be about 10 per cent or more, indicating that their cells consist largely of proteins. The nitrogen content of fungi is much lower showing that the nitrogen-free substances predominate in the mycelium. The same is true of higher fungi, Zopf ${ }^{31}$ having found that the dry weight of these consists of $11-51$ per cent protein, 2.15 per cent ash, 1 to 10 per cent fat and 37 to 82 per cent carbohydrate. The nitrogen con-

TABLE 22

Influence of nature of fungus upon its composition

\begin{tabular}{|c|c|c|c|c|c|}
\hline CULTURE & $A G \mathbb{E}$ & CARBON & HYDROGEN & NITROGEN & A9H \\
\hline & days & per cent & per cent & per cent & percent \\
\hline Asp. niger. . . . & $7-14$ & $44.5-47.3$ & $6.97-8.0$ & $4.2-4.7$ & $4.0-6.4$ \\
\hline Pcn. glaucum... & $9-14$ & $46.3-50.7$ & $7.44-8.03$ & $5.0-5.9$ & $4.5-7.5$ \\
\hline
\end{tabular}

TABLE 23

Influence of concentration of minerals in solution upon the nitrogen content of fungi

\begin{tabular}{c|c}
\hline MINERAL CONTENT OF MEDIUM & NITROGEN CONTENT OF DRY MYCELIUM \\
\hline per cent & per cent \\
0.2 & 2.0 \\
1.7 & 5.7 \\
2.7 & 6.4 \\
\hline
\end{tabular}

tent of invertebrates has been reported ${ }^{32}$ as 10.65 to 11.2 per cent for insects and insect larvae, 9.4 per cent for earthworms, and 4.9 per cent for myriapods.

The mineral composition of microorganisms depends also on the mineral composition of the medium. It has been shown ${ }^{33}$ in the case of cholera bacteria cultivated in nutrient bouillon, that, with an ash content of 2.1 per cent $\mathrm{P}_{2} \mathrm{O}_{5}$ in the medium, the ash of the bacterial

${ }^{30}$ Raulin, 1869 (p. 415).

${ }^{31}$ Zopf. Pilze. Breslau. 1890, p. 119-121.

32 Morris, 1922 (p. 342).

${ }^{33}$ Cramer, E. Die Aschenbestandtheile der Cholerabacillen. Arch. Hyg., 28: 1-15. 1897. 
cells consisted of 10.9 per cent $\mathrm{P}_{2} \mathrm{O}_{5}$; with 7.9 per cent $\mathrm{P}_{2} \mathrm{O}_{5}$ in the medium, the ash of the bacteria contained 28.7 per cent $\mathrm{P}_{2} \mathrm{O}_{5}$; with 39.8 per cent $\mathrm{P}_{2} \mathrm{O}_{5}$ of the ash in the medium, the ash of the bacteria consisted of 38.4 per cent $\mathrm{P}_{2} \mathrm{O}_{5}{ }^{34}$ The same is not true, however, of the other ash constituents. Among these, we find $\mathrm{K}, \mathrm{Na}, \mathrm{Mg}, \mathrm{Ca}, \mathrm{Fe}$, $\mathrm{Si}, \mathrm{S}$ and $\mathrm{Cl}^{35}$ as shown in table 24 .

Some organisms (Aspergillus, Penicillium, Mucor and other fungi) can thrive without calcium, while others (Azotobacter) do not develop in the absence of this mineral element. ${ }^{36}$

According to Stoklasa, ${ }^{37}$ Azot. chroococcum consists of 11.3 per cent nitrogen (see p. 570) and 9.60 per cent ash. The latter is made up of

TABLE 24

Mineral composition of microorganisms

\begin{tabular}{|c|c|c|c|c|c|}
\hline & \multicolumn{5}{|c|}{ MINIMUM AND MAXIMUM FIGURES ON BASIS OF ASH CONTENT } \\
\hline & Bacteria ${ }^{34}$ & Fungi ${ }^{34}$ & $\begin{array}{l}\text { Spores of } \\
\text { fungi } 34\end{array}$ & Yeasts ${ }^{35}$ & Higher fungi ${ }^{3}$ \\
\hline & per cent & per cent & per cent & per cent & per cent \\
\hline $\mathrm{P}_{2} \mathrm{O}_{5} \ldots \ldots$ & $10.0-55.2$ & $44.8-59.4$ & 39.6 & $51.0-590$ & 40.0 \\
\hline $\mathrm{SO}_{3} \ldots$ & $1.0-8.0$ & $\operatorname{Tr}-2.1$ & 2.0 & $0.6-6.0$ & 8.0 \\
\hline $\mathrm{SiO}_{2} \ldots$ & $0.5-7.8 ?$ & $\operatorname{Tr}-2.0$ & $\ldots$ & $0-1.6$ & 1.0 \\
\hline $\mathrm{Cl} \ldots$ & $2.3-44.0$ & 0.3 & $\ldots$ & $0.03-1.0$ & $\ldots$ \\
\hline $\mathrm{K}_{2} \mathrm{O} \ldots$ & $4.0-25.6$ & $8.7-39.5$ & 46.0 & $28.0-40.0$ & 45.0 \\
\hline $\mathrm{Na}_{2} \mathrm{O} \ldots$ & $13.6-34.0$ & $0.2-19.0$ & $\ldots$ & $0.5-1.9$ & 1.4 \\
\hline $\mathrm{MgO} . \ldots$. & $0.1-11.5$ & $3.8-8.1$ & 4.3 & $4.0-8.1$ & 2.0 \\
\hline $\mathrm{CaO} \ldots \ldots \ldots$ & $0.3-14.0$ & $1.0-13.8$ & $\ldots$ & $1.0-4.5$ & 1.5 \\
\hline $\mathrm{Fe}_{2} \mathrm{O}_{3} \ldots \ldots \ldots$ & 8.1 & $0.1-0.7$ & 5.0 & $0.1-7.3$ & 1.0 \\
\hline
\end{tabular}

4.93 per cent $\mathrm{P}_{2} \mathrm{O}_{5}, 0.29$ per cent $\mathrm{SO}_{3}, 2.41$ per cent $\mathrm{K}_{2} \mathrm{O}, 0.07$ per cent $\mathrm{Na}_{2} \mathrm{O}, 0.82$ per cent $\mathrm{MgO}, 0.34$ per cent $\mathrm{CaO}$ and 0.08 per cent $\mathrm{Fe}_{2} \mathrm{O}_{3}$.

The non-nitrogenous portion of the microbial cell consists chiefly of fats, gums and various hemicelluloses, chitin and frequently glycogen. Winterstein and Reuter ${ }^{38}$ reported that ether extracted from higher fungi

${ }^{34}$ See also de Rossi, 1925 (p. xiii).

${ }^{35}$ See also Mayer, A. Gärungschemie. 5 Aufl. 1902, p. 118 (cited by Kruse).

${ }^{36}$ Loew, O. Über das Kalkbedürfnis von Algen und Pilzen. Biol. Centrbl., 45: $122-125.1925$.

${ }^{37}$ Stoklasa, 1908 (p. 114). It will be shown later (p. 570) that analyses of Azotobacter cells made by different investigators do not agree.

${ }^{38}$ Winterstein, E., and Reuter, C. Úber die stickstoffhaltigen Bestandteile der Pilze. Centrbl. Bakt. II, 34: 566-572. 1912. See also N. L. Iwanow. Uber die Natur des Eiweisstoffes der Pilze. Biochem. Ztschr., 137: 331-340. 
4.0 per cent of material ( 3.3 per cent fat and 0.5 per cent cholesterol); alcohol extracted 12 per cent (sugars, lecithin, bases, amino acids, purine bodies); water soluble portion, 28 per cent (sugars, glycogen, amino acids, purine bases, etc.); and residue was made up of 30 per cent protein, 10 per cent amorphous carbohydrate (para-iso-dextrin) and 6 per cent chitin. Lower fungi are also capable of synthesizing soluble phosphatides. ${ }^{39}$

The lipoids in the cell wall are primarily responsible for the difficulty with which bacterial proteins are digested. When gram-negative bactcria are treated with flowing steam or with lipoid soluble substances, the digestibility is greatly increased. ${ }^{40}$ Gram-positive bacteria (Bac. cereus, Bac. subtilis) are more easily oxidizable (isoelectric point at $\mathrm{pH} 2.0$ to 3.0 ) than gram-negative bacteria (Bact. coli, Bact. aerogenes, isoelectric point at $\mathrm{pH} 5.0$ ). Bacteria are also found to possess a distinct amphoteric character. ${ }^{41}$ The place of glycogen may be taken by other reserve carbohydrates, as mycodextran and mycogalactan found in young cultures of Pen. expansum and Asp. niger. ${ }^{42}$ The starch content of fungi was found ${ }^{43}$ to be influenced by the nitrogencarbohydrate ratio of the medium: the lower the ratio, the greater is the starch formation in the cells of the fungi. Cramer ${ }^{44}$ previously obtained from the spores of Pen. glaucum 17 per cent of "spore starch." This was, probably, an impure preparation of mycodextran contaminated by some other carbohydrate, giving the iodine reaction. Galactans have been reported in bacterial slime by Schardinger. ${ }^{45}$ A number

${ }^{39}$ Grafe, V., and Magistris, H. Zur Chemie und Physiologie der Pflanzenphosphatide. II. Die wasserlöslichen Phosphatide aus Aspergillus oryzae. Biochem. Ztschr., 162: 366-398. 1925.

${ }^{40}$ Dukes, C. E. The digestibility of bacteria. Brit. Med. Jour. I, 430-432. 1922.

${ }^{41}$ Stearn, E. W., and Stearn, A. E. A study of the chemical differentiation of bacteria. Jour. Bact., 10: 13-23. 1925.

${ }_{42}$ Dox, A. W., and Neidig, R. E. The soluble polysaccharides of lower fungi. I. Mycodextran, a new polysaccharide in Penicillium expansum. Jour. Biol. Chem., 18: 167-175. 1914; 19: 235-237. 1914; 20: 83-85. 1915.

${ }_{43}$ Schmidt, D. Úber die Pilzstärke (Amylose) bei Aspergillus niger v. Tgh. und einige Bemerkungen über ihren diastatischen Abbau. Biochem. Ztschr. 158: 223-252. 1925 .

${ }^{44}$ Cramer, E. Die Zusammensetzung der Sporen von Penicillium glaucum und ihre Beziehung zu der Widerstandsfähigkeit derselben gegen äussere Einflüsse. Arch. Hyg., 20: 197-210. 1894.

${ }^{45}$ Schardinger, F. Über die Gärprodukte eines schleimbildenden Bacillus in Rohrzuckerlösungen und die Zusammensetzung eines aus dem Schleime isolierten Kohlehydrates. Centrbl. Bakt. II, 8: 144-147, 175-180. 1902. 
of hexosans, including cellulans, related to celluloses and produced by Bac. astcrosporus and Bact. prodigiosum, levulans, formed by bacteria belonging to the Bac. subtilis group, and dextrans produced by Bact. radicicola, have been reported in bacterial slime. Galactans were found in the capsules of bacteria. ${ }^{46}$

${ }^{46}$ Beijerinck, M. W. Die durch Bakterien aus Rohrzucker erzeugten schleimigen Wandstoffe. Folia Microbiol., 1: 377-408. 1912: Kramer, E. Centrbl. Bakt. 1, 87: 401-406. 1921. 


\section{CHAPTER XVI}

Energy Transformation in the Metabolism of Microorganisms

Life and energy. Life involves the transformation of energy. A perfectly resting organism changes a certain amount of potential energy from a chemical form into heat energy; an active organism will, in addition to that, also transform a certain amount of that potential energy into kinetic energy; while a growing organism will also consume energy for growth or for synthetic purposes and change it into another form of potential energy. The amount of energy transformed by a microorganism and the amount utilized by the same organism for growth purposes depend on the nature of the organism, the source of energy, the extent of the chemical transformation of this source of energy and various environmental conditions. Respiration is the process whereby energy is generated in the cell. Energy originates in the cell, as a result of chemical changes in the compounds within the cell. With each chemical reaction, a series of energy transformations takes place, whereby the chemical energy is partly transformed into chemical energy of a lower potential and partly into other forms of encrgy The presence of free oxygen is not required for the release of energy, since the anaerobic bacteria derive their energy from the decomposition of organic compounds rich in oxygen by a process of oxidation-reduction, whereby one substance is oxidized and another is reduced.

The autotrophic groups of microorganisms obtain their energy either chemosynthetically, by the oxidation of inorganic substances (including simple compounds of carbon), or photosynthetically, as in the case of the algae. The heterotrophic groups of microorganisms obtain both the energy and carbon source from organic substances, such as carbohydrates, proteins and other complex carbon compounds, either by oxidation or by intramolecular structural changes.

Since the energy utilized by autotrophic and hetcrotrophic bacteria is derived by two different processes, these will be considered separately. Some organisms which belong to the autotrophic group can also grow readily under heterotrophic conditions, as the hydrogen bac- 
teria, ${ }^{1}$ some thiosulfate bacteria ${ }^{2,3}$ and some iron bacteria. ${ }^{4}$ These are the facultative autotrophic organisms.

With the exception of the chlorophyll-containing plants, all organisms derive their energy from the substances (nutrients) used for their metabolism. There is a definite relation between the energy transformation and the synthesis by the organism, depending upon the nature of the nutrients and nature of the organisms.

Lavoisier was the first to suggest that metabolism consists in the oxidation of carbon compounds. This idea was further developed, in two distinctly different directions, by Pasteur ${ }^{5}$ who discovered the true or anaerobic fermentations and by Winogradsky who discovered the oxidation of inorganic substances. The earlier idea of Pasteur on the intramolecular shift of oxygen, or as it would be termed today "oxidation-reduction process," has found recently further confirmation in the work of Neuberg and others on the formation of pyruvic acid in alcoholic fermentation. It can be generally stated that the displacement of oxygen within the molecule is the cause of considerable generation of heat of reaction. Fats cannot be, therefore, decomposed under anaerobic conditions, because they contain insufficient oxygen.

In the case of autotrophic bacteria there is a lack of correlation between the oxidation of nutrients, oxygen intake and carbon dioxide production. These organisms utilize inorganic substances exclusively for the construction of their body tissues. This points to the fact that the problem of energy transformation in microorganisms is a different. problem from that of the transformation of nutrients in synthesis. While an autotrophic organism may obtain its nutrients (minerals, nitrogen source) from the same materials as an heterotrophic organism, the energy and the carbon are obtained from two distinctly different sources. ${ }^{6}$

The transformations of energy are based upon the fundamental laws of thermodynamics. Energy cannot be destroyed, nor can it be created. This law formulated by J. R. Mayer and H. Helmholz desig-

${ }^{1}$ Niklewski, B. Über die Wasserstoffoxydation durch Mikroorganismen. Jahrb. wiss. Bot., 47: 113-142. 1910.

${ }^{2}$ Trautwein, 1921 (p. 87).

${ }^{3}$ Beijerinck, M. W. Chemosynthesis at denitrification with sulfur as sourec of energy. K. Akad. v. Wetenschapen, Amsterdam, 22: 899-908. 1920.

${ }^{4}$ Molish, H. Die Pflanzen in ihren Beziehungen zum Eisen. Jena. 1892; Die Eisenbakterien. Jena. 1910; Cholodny, 1926 (p. 94).

${ }^{5}$ Pasteur, L. Etudes sur la bière. Paris. 1876.

${ }^{6}$ Meyerhof, O. Zur Energetik der Zellvorgänge. Göttingen. 1913. 
nates that, in all physical and chemical processes, the sum of energy remains unchanged, while the form and distribution are changed. In other words, according to the law of conservation of energy, any system in a given condition contains a definite quantity of energy; when this system undergoes change, any gain or loss in its content of energy is equal to the loss or gain of the energy in the surrounding systems. ${ }^{7}$

According to the second law of thermodynamics, every process that occurs spontaneously is capable of doing work; to reverse any such process requires the expenditure of work from outside (Lewis). While all forms of energy can be completely transformed into heat, heat energy can never be completely transformed into other forms of energy; this leads to a decrease in the convertible or free energy. Each transformation of energy involving heat formation leads, therefore, to a dissipation of energy and to a diminution of the amount of frec energy. This law formulated by Carnot and Clausius is also designated as the law of entropy. Under "entropy" we understand the part of heat energy which, at a given temperature, cannot be further converted into other forms of energy. All processes in nature lead to an increase in entropy. ${ }^{8}$ The supply of energy in nature is constantly replenished by the green plants, utilizing the free energy of the sun. In the combustion of coal, in the decomposition of complex carbon compounds, heat is liberated; in the building up of organic compounds from earbon dioxide, heat is stored as potential energy. In the course of life processes, cell growth and cell activities, a part of the energy is either used up for the activities of the cell or is stored away in the process of building up the more complex cell constituents; the remainder, after a series of transformations (overcoming resistance, etc.), is transformed into heat and dissipated into space.

Only "free energy" may be transformed into mechanical work. ${ }^{9}$ The maximum of work which can be obtained from a given process, at constant temperature and pressure, is designated as $\Delta F, F$ being the free encrgy. This is related to the total external work done by a system as a heat of reaction is related to the total energy content. A change in the condition of the substrate can be characterized by a change in free energy, or better, by the maximum of work which can

${ }^{7}$ Lewis, G. N. The free energy of ehemical substances. Jour. Amer. Chem. Soc., 35: 1-30. 1913.

${ }^{8}$ Tangl, F. Energie, Leben und Tod. Springer. Berlin. 1914.

${ }^{9}$ Lewis, G. N., and Randall, M. Thermodynamics and the free energy of chemical substances. MIcGraw-Hill, New York. 1923. 
be obtained from the process; this is a better measure than the heat of reaction, which includes also the diffused energy which serves to increase the entropy of the system.

The figures given in the following pages refer to the heat of reaction and are based upon one mol of the reacting substances. It would be more correct and would present a truer picture of the process if the free energy values were utilized, considering also the heat of solution and heat of dilution, especially in the oxidation of substances in a solid phase; by considering the energy of ionization, the values will frequently be distinctly different, as in the case of oxidation of free ammonia or of the ammonium ion. Unfortunately practically all the data recorded in the literature dealing with the transformation of energy by microorganisms are calculated on the basis of heat of reaction and may be thus provisionally recorded..$^{9 a}$ These data are based upon the work of Thomsen, Berthelot, Ostwald and others.

The thermochemical results are usually presented as follows:

$$
\mathrm{H}_{2}(\mathrm{~g})+\frac{1}{2} \mathrm{O}_{2}(g)=\mathrm{H}_{2} \mathrm{O}(l)+68.4 \text { Cal. }
$$

The last figure indicates the heat of reaction per mol of the reacting substances.

On the basis of energy utilization, the soil microorganisms can be divided into four distinct groups:

I. Microorganisms obtaining their energy autotrophically:

1. Photosynthetic utilization of energy-algae.

2. Chemosynthetic utilization of energy-autotrophic bacteria.

II. Microorganisms obtaining their energy heterotrophically; or from the decomposition and transformation of orgănic matter:

3. Organisms which utilize atmospheric oxygen and obtain their energy by oxidations-aerobic bacteria, fungi, actinomyces, etc.

4. Organisms which obtain their energy without the intervention of atmospheric oxygen, or by true "fermentation? prosesses-anaerobic bacteria.

Energy transformations by autotrophic bacteria. Since autotrophic bacteria are capable of assimilating carbon from $\mathrm{CO}_{2}$ and of deriving their necessary energy from the oxidation of simple substances, accurate information can be obtained on the amount of chemical energy required to build up complex organic substances from minerals and carbon dioxide. The simple composition of the nutrients helps to differentiate between structural and functional energy required in the metabolism; it also throws light on the influence of concentration of

$$
\text { 9 a See Baas4Bcking and Parks. Physiol. Rev., 7: 85-106. } 1927 .
$$


nutrients, neutralization of waste products and amount of total available energy utilized by the organism in connection with carbon assimilation. These are the only microorganisms (except the algae), which are capable of doing work in the true sense. The autotrophic bacteria can be classified on the basis of the elements and compounds from which they are able to obtain energy:

1. Nitrogen and its compounds. We do not as yet know whether the nitrogen-fixing bacteria are capable of utilizing any energy which may be liberated in the process of transformation of the elementary nitrogen into the first compound of nitrogen. Only two groups of organisms, which are capable of obtaining energy from the oxidation of nitrogen compounds are known: $(a)$ those that oxidize ammonia or ammonium ion to nitrite, and (b) those that oxidize nitrite to nitrate; both of these are usually classified together under the term "nitrifying" bacteria.

2. Sulfur and its compounds. The latter include the reduced and partially oxidized compounds of sulfur, $\mathrm{H}_{2} \mathrm{~S}$, sulfides, thiosulfates and, perhaps, sulfites and hyposulfites. The organisms obtaining their energy from the oxidation of sulfur and its compounds, especially the sulfides, belong to morphologically different groups.

3. Selenium and its compounds. Our information as to the energy utilization in the oxidation of these substances is rather indefinite.

4. Iron compounds. The most important of these is ferrous carbonate. As shown elsewhere, not all organisms which are capable of precipitating ferric hydroxide are autotrophic bacteria. ${ }^{10}$

5. Hydrogen and simple hydrocarbons.

6. Carbon and its compounds. These include carbon monoxide, methane, higher hydrocarbons, and alcohol. The autotrophic nature of these is questionable; they may even be considered as heterotrophic. It is not definitely known whether any organisms are capable of obtaining energy from the oxidation of elementary carbon.

Energy utilization from the oxidation of nitrogen compounds. Energy is obtained by certain well defined groups of microorganisms from the oxidation of ammonium salts to nitrites (nitrite formers) or from the oxidation of nitrites to nitrates (nitrate formers). In the case of these

${ }^{10}$ Various organisms are capable of accumulating metals within their cells, without the metal taking part in the chemical processes of the organism; this has been demonstrated for gold by Plotho: O. von Plotho.-Der Einfluss kolloidaler Metallosungen und seine Ursachen. Biochem. Ztschr., 110: 1-32. 1920. 
bacteria, there is no ordinary respiration from organic substances, as shown by Meyerhof:

\begin{tabular}{c|c}
\hline O2 ACTUALIY A BSORBED FroM ATMOSPHERE & $\begin{array}{c}\text { O2 REQUIRED FOR THE OXIDATION OF NITRITE, } \\
\text { ACCORDING TO THE REACTION }\end{array}$ \\
\hline$c c$. & $c c$. \\
0.270 & 0.273 \\
0.392 & 0.396 \\
0.277 & 0.290 \\
0.293 & 0.295 \\
0.244 & 0.240 \\
\hline
\end{tabular}

The whole process of respiration can thus be presented by the following reactions: ${ }^{11}$

$$
\left(\mathrm{NH}_{4}\right)_{2} \mathrm{CO}_{3}+3 \mathrm{O}_{2}=2 \mathrm{HNO}_{2}+\mathrm{CO}_{2}+3 \mathrm{H}_{2} \mathrm{O}+147.2 \mathrm{Cal} .
$$

or

$2 \mathrm{NH}_{3}$ (acq.) $+3 \mathrm{O}_{2}=2 \mathrm{HNO}_{2}+2 \mathrm{H}_{2} \mathrm{O}+156.8 \mathrm{Cal}$.

78.4 calories are liberated per $1 \mathrm{~mol}$ of ammonia oxidized $2 \mathrm{HNO}_{2}+\mathrm{O}_{2}=2 \mathrm{HNO}_{3}+37.6 \mathrm{Cal}$.

18.8 calories are liberated per $1 \mathrm{~mol}$ of nitrite oxidized.

For the synthesis of its protoplasm, the organism obtains its carbon from the $\mathrm{CO}_{2}$ of the atmosphere:

$$
\mathrm{CO}_{2}+\mathrm{H}_{2} \mathrm{O}=\frac{1}{6}\left(\mathrm{C}_{6} \mathrm{H}_{12} \mathrm{O}_{6}\right)+\mathrm{O}_{2}-113 \mathrm{Cal} .
$$

Winogradsky, ${ }^{12}$ however, suggested that no oxygen is separated in the respiration of the nitrite forming bacteria and no carbohydrates are formed; the ammonia may react directly with $\mathrm{CO}_{2}$ giving urea:

$$
\mathrm{H}_{2} \mathrm{CO}_{3}+2 \mathrm{NH}_{3}=\mathrm{CO}\left\langle\sum_{\mathrm{NH}_{2}}^{\mathrm{NH}_{2}}+2 \mathrm{H}_{2} \mathrm{O}\right.
$$

The urea can be used directly for the synthesis of proteins; the carbohydrate required for the synthesis of amino acids may be formed

11 The heats of reaction in all autotrophic and a few heterotrophic processes have been recalculated, using Landolt-Börnstein's Physikalisch-chemische Tabellen. 5te Auf. Berlin. 1923; the data for the greater part of the heterotrophic processes have been taken from Kruse's book.

12 Winogradsky, S. Sur les organismes de la nitrification. Compt. Rend. Acad. Sei., 110: 1013-1016. 1890. 
in a manner similar to that suggested ${ }^{13}$ for plants, whereby formaldehyde is synthesized from $\mathrm{CO}_{2}$ and gives rise to sugar:

$$
\begin{aligned}
& 2 \mathrm{NH}_{3}+2 \mathrm{O}_{2}=2 \mathrm{HNO}_{2}+2 \mathrm{H}_{2} \\
& \mathrm{CO}_{2}+2 \mathrm{H}_{2}=\mathrm{HCOH}+\mathrm{H}_{2} \mathrm{O}
\end{aligned}
$$

No oxygen is liberated in this reaction and no carbohydrate from the outside is required.

It has also been suggested that chemosynthesis takes place in a manner similar to photosynthesis:

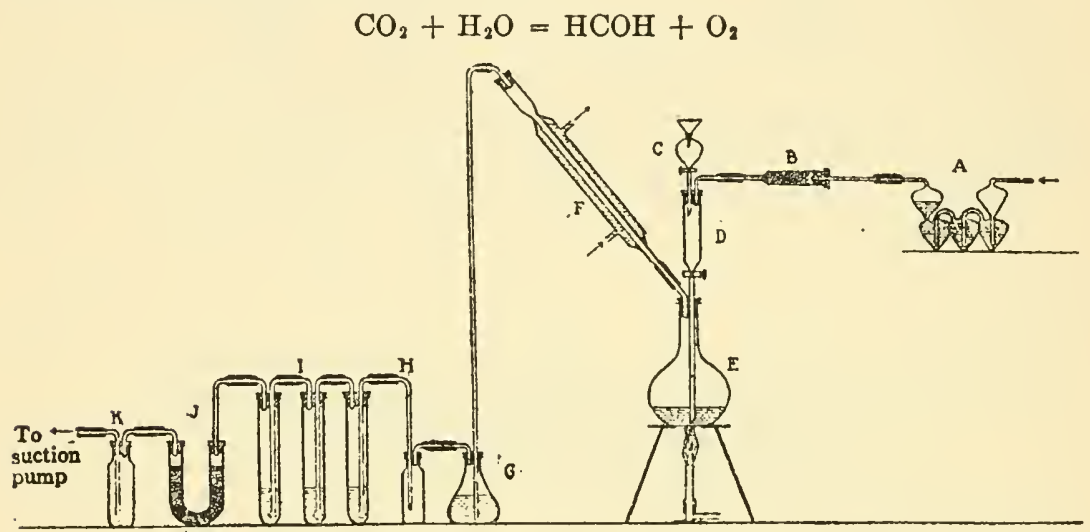

Fra. 16. Apparatus for carbon determination in solution cultures (after Waksman and Starkey).

By whatever mechanism the protoplasm is synthesized from $\mathrm{CO}_{2}$, energy is required to enable the organism to carry out this work. The energy is obtained from the oxidation of the inorganic substrate, according to the work of Meyerhof ${ }^{14}$ with the nitrate forming organism:

Nitrogen oxidized (from $\mathrm{NO}_{2}^{-}$to $\mathrm{NO}_{3}^{-}$),

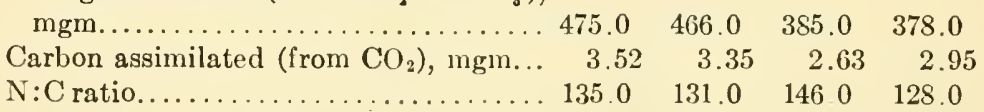

Accordingly, 135 parts of nitrogen are changed from the nitrite to the nitrate form for one part of carbon assimilated from the $\mathrm{CO}_{2}$ of the

${ }^{13}$ Loew, O. Ueber die Ernährungsweise des nitrifizierenden Spaltpilzes Nitromonas. Bot. Centrbl., 46: 222-223. 1891.

${ }^{14}$ Meyerhof, O. Untersuchungen über den Atnungsvorgang nitrifizierender Bakterien, Pflug. Arch. Ges. Physiol., 164: 353-427. 1916; 165: 229-284. $1916 ; 166: 240-280.1917$. 
atmosphere. These results allow the calculation of the amount of energy actually utilized by the organism for synthetic purposes. As pointed out above, $18.8 \mathrm{Cal}$. are formed in the oxidation of $1 \mathrm{~mol}$ (14 grams) of nitrogen in the nitrite form. The heat of combustion of $1 \mathrm{~mol}$ (12 grams) of pure carbon to carbon dioxide in solution is 103 Cal. If the calculation is based on the formation of a carbohydrate, the energy required is even larger (113 Cal.) because of the addition of water. To gain this number of calories, 135 times as much nitrate nitrogen is formed as there is carbon assimilated and changed into an organic form, or

$$
\frac{\text { Milligrams of nitrogen oxidized }\left(\mathrm{NO}_{2}^{-}\right)}{\text {Milligrams of carbon assimilated }\left(\mathrm{CO}_{2}\right)}=135
$$

One can thus calculate that for 12 grams of carbon (mol of $\mathrm{CO}_{2}$ ), 1620 grams of nitrogen (135 by 12 grams) are transformed. This corresponds to 115.7 mols of $\mathrm{NO}_{2}(1620: 14)$. Since 18.8 Cal. of heat are liberated per mol of $\mathrm{NO}_{2}^{-}$oxidized to $\mathrm{NO}_{3}^{-}$, the total will be equivalent to 2175 Cal. (115.7 by 18.8). Out of this number of calories liberated, only $113 \mathrm{Cal}$. are gained in the synthetic process (assimilation of one mol of carbon as $\mathrm{CO}_{2}$ ); this means that only about 5.2 per cent of the energy liberated in the oxidation process is utilized for doing work, in the synthesis of protoplasm out of $\mathrm{CO}_{2}$ and inorganic nitrogen and minerals.

The observations of Coleman $^{15}$ that the nitrate bacteria require carbon dioxide only at the start of the growth period but do not require it for further development, as well as the remarks of Beijerinck ${ }^{16}$ that nitrate forming bacteria do not show any definite proof for chemosynthesis of carbon dioxide, were based on inaccuracies in the determinations. The earlier observation of Winogradsky that the nitrate bacteria can build up their body substance without the aid of foreign organic matter has been confirmed.

In carrying out these experiments, Meyerhof used 50-cc. portions of nutrient solution consisting of chemically pure salts in water distilled over sulfuric acid. The solution was placed in clean flasks, and inoculated with a fresh culture of the organism. The air passing through the cultures was first passed through four per cent $\mathrm{KMnO}_{4}$ solution, pure concentrated $\mathrm{H}_{2} \mathrm{SO}_{4}$ and $\mathrm{N} \mathrm{NaHCO}$. The growth of the culture was

${ }^{15}$ Coleman, L. C. Untersuchungen über Nitrifikation. Centrbl. Bakt. II, 20: 401-420, 4S4-514. 1908 .

16 Beijerinck, 1914 (p. 76). 
normal and the carbon was derived from the $\mathrm{NaHCO}_{3}$ in the medium. In the presence of $\mathrm{CO}_{2}$ in the atmosphere, the bicarbonate was found to serve as a buffering agent in the medium keeping the reaction at pH 8.8 which is optimum for the activities of these bacteria. When phosphates were used as buffering agents the organism was found to make a normal growth, using the $\mathrm{CO}_{2}$ coming into solution from the atmosphere. No growth took place in the total absence of $\mathrm{CO}_{2}$.

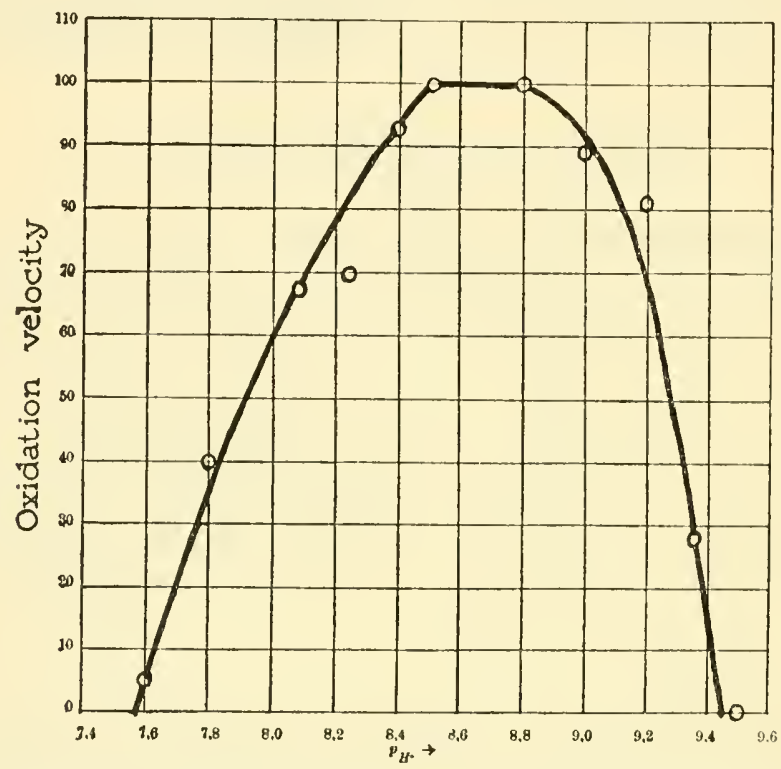

F1G. 17. Influence of reaction upon the respiration of nitrite-forming bacteria (after Meyerhof).

For the study of respiration, Meyerhof grew the organism in the general medium till a good growth had taken place. A certain concentration of the nitrite was introduced into a definite volume of culture and the flask placed in thermostat. The change produced in a definite period of time (usually 4 to 6 hours) was taken as a measure of the respiratory power of the culture. Meyerhof demonstrated that, outside of the nitrite oxidation and carbon assimilation, no other reaction takes place in the process of energy transformation. The nitrate organism utilizes only the nitrite-ion as a source of energy and no other substance.

With an increasing nitrate content, growth and respiration are 
lessened (fig. 19). This injury is caused also by other salts in similar osmotic concentrations. A decrease in the concentration of oxygen lessens both growth and respiration, so that at $\frac{7}{10}$ atmosphere pressure, respiration is decreased by 66 per cent (fig. 20). This injury is reversible. Growth may be even more injuriously affected than respiration. The optimum and minimum reaction points for respiration lie at $\mathrm{pH} 5.6$ and 10.3 respectively, with an optimum pH 8.3 to 9.3 (fig. 17). ${ }^{17}$ For growth and respiration definite concentrations of $\mathrm{O}_{2}, \mathrm{NO}_{2}, \mathrm{NO}_{3}, \mathrm{OH}^{-}$ and traces of $\mathrm{H}_{2} \mathrm{CO}_{3}$ are required. The other salts and nutrients play only the part of buffering agents.

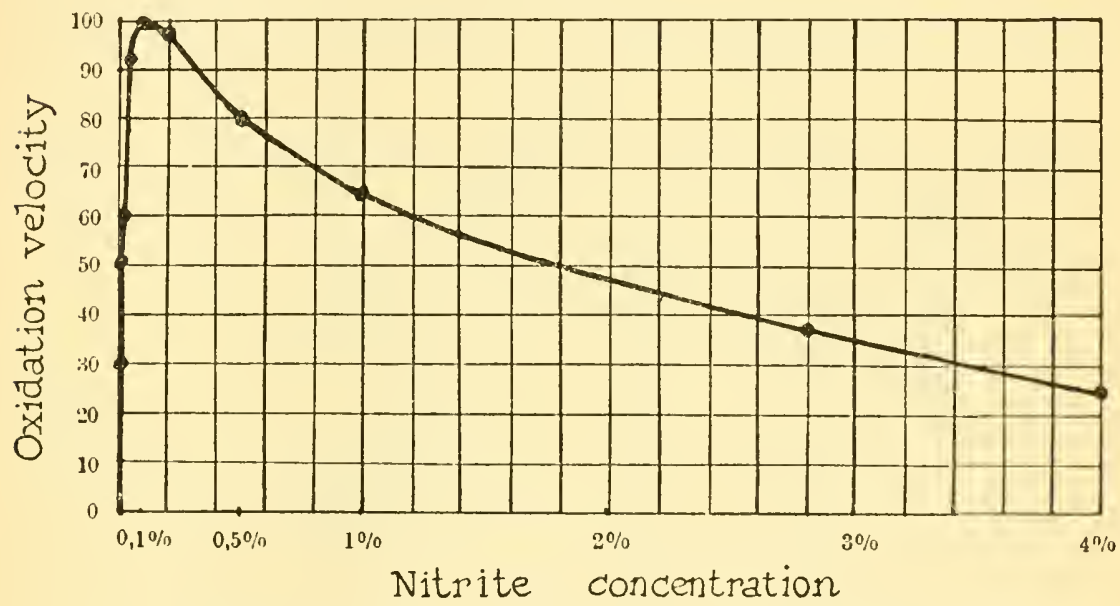

FIG. 18. Influence of nitrite concentration upon the oxidation velocity of nitrate forming bacteria (from Meyerhof).

Winogradsky observed the interesting phenomenon that ammonium salts injuriously affect the growth of nitrate bacteria. 'This seemed rather strange in view of the fact that the nitrate bacteria are active side by side with the nitrite bacteria which use the ammonium salt as a source of energy. It was then ${ }^{18}$ suggested that the two processes follow in two successive periods in the soil, nitrate formation beginning only after all the ammonium salt is converted into nitrite. On de-

17 As shown clsewhere (p. 529), the limiting and optimum reactions for the growth of the nitrate-forming organism are different from the optima of respiration.

${ }^{18}$ Omelianski, W. Über die Nitrifikation des organischen Stickstoffes. Centrbl. Bakt. II, 5: 473-490. 1899. 
creasing the amount of $\mathrm{Na}_{2} \mathrm{CO}_{3}$, which would lead to a lower alkalinity, Boulanger and Massol $^{19}$ found that the injurious effect of ammonium salt is less and concluded, therefore, that the growth of nitrate bacteria is not injured by the salt but by free ammonia. This was confirmed by Meyerhof who found that the injurious influence of ammonia and its derivatives (aliphatic amines) consists in the penetration of the base into the cell (which does not take place in the case of ammonium salt) and in a specific action of the $\mathrm{NH}_{3}$ and $\mathrm{NH}_{2}$ group. Lipoid in-

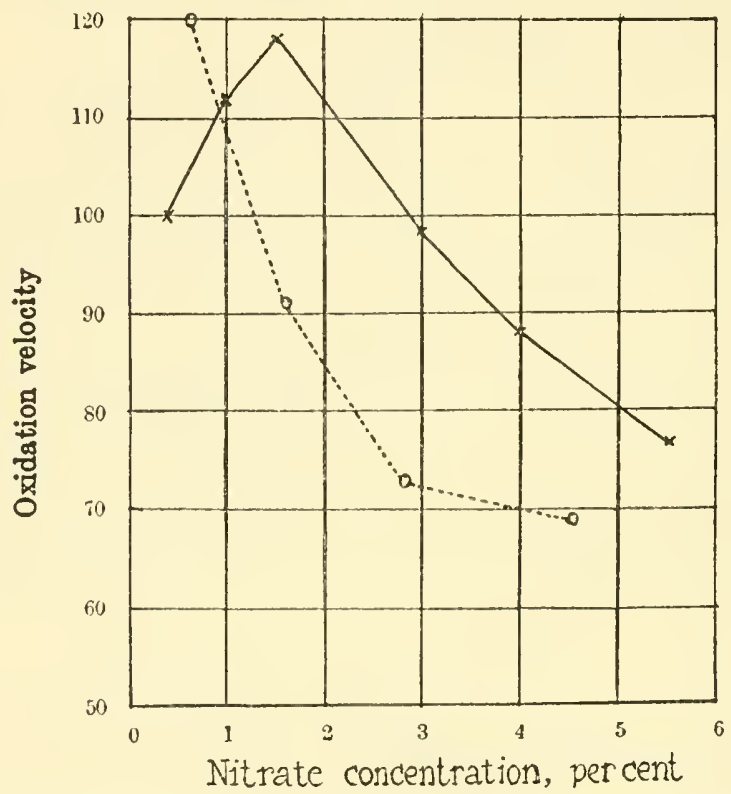

FIG. 19. Influence of nitrate concentration upon the growth (-------) and respiration (--) of nitrate forming bacteria (from Meyerhof).

soluble amines, like the diamines, are not injurious. The injurious effect of amines and cations depends upon their ability to penetrate into the cell and upon the reaction of the media; respiration is usually less affected than growth. Iron salts are taken out by the organism from iron poor media. Whether or not iron plays the part of a catalyzer is still undecided. According to Ashby, ${ }^{20}$ nitrification takes place in the

19 Boulanger and Massol, 1905 (p. 65).

${ }^{20}$ Ashby, S. F. Some observations on nitrification. Jour. Agr. Sci., 2: 5267. $1907-8$. 
presence of ferric hydroxide to a considerable extent. The important rôle of iron was also established for the growth and respiration of various other bacteria.

As to the energy utilization of the bacteria oxidizing ammonium salts, the following results of Winogradsky are illuminating:

\begin{tabular}{|c|c|c|c|c|}
\hline $\operatorname{mgm} \ldots \ldots \ldots \ldots \ldots \ldots \ldots \ldots \ldots \ldots \ldots \ldots$ & 722.0 & 506.1 & 928.3 & 815.4 \\
\hline $\mathrm{C}$ assimilated (from $\mathrm{CO}_{2}$ ), mgm. . & 19.7 & 15.2 & 26.4 & 22.4 \\
\hline $\mathrm{N}: \mathrm{C}$ ratio............... & 36.8 & 33.3 & 35.2 & 36.4 \\
\hline
\end{tabular}

About 35 parts of nitrogen were thus found to be changed from ammonia to nitrite for every part of carbon assimilated from the $\mathrm{CO}_{2}$ of

TABLE 25

Influence of organic matter upon the growth of nitrite and nitrate-forming bacteria

\begin{tabular}{|c|c|c|c|c|}
\hline \multirow{2}{*}{ SUBSTANCE } & \multicolumn{2}{|c|}{ N1TRITE ORGANISM } & \multicolumn{2}{|c|}{ NITRATE ORGANISM } \\
\hline & Growth checked & Growth stopped & $\begin{array}{l}\text { Growth } \\
\text { checked }\end{array}$ & $\begin{array}{l}\text { Growth } \\
\text { stopped }\end{array}$ \\
\hline & per cent & per cent & per cent & per cent \\
\hline Glucose...... & 0.025 & 0.05 & 0.05 & 0.2 \\
\hline Peptone..... . & 0.025 & 0.2 & 0.8 & 1.25 \\
\hline Asparagine... & 0.025 & 0.3 & 0.05 & 0.5 \\
\hline Glycerol.... & More than 0.2 & $\ldots$ & 0.05 & 4.0 \\
\hline Urea ............. & More than 0.2 & $\ldots$ & 0.5 & 4.0 \\
\hline Sodium acetate.... & 0.5 & More than 1.5 & 1.5 & 3.0 \\
\hline Ammonia.......... & $\ldots \ldots$ & $\ldots$ & 0.0005 & 0.015 \\
\hline
\end{tabular}

the atmosphere. Similar results were obtained by Meyerhof. In the process of oxidation of ammonia to nitrite four times as much energy (78.4 Calories per mol) is liberated as in the process of oxidation of nitrite to nitrate (18.8 Calories per mol). But four times as much nitrogen is transformed in the latter processes $(\mathrm{N}: \mathrm{C}=135)$. The utilization of energy for chemosynthesis of carbon is, therefore, almost identical and is equivalent to about 5 per cent.

With an active culture under proper conditions, the process of oxidation of ammonium salts is very rapid. Meyerhof found that, with a maximum aeration, 4 grams of ammonium sulfate are oxidized to nitrite in one liter of medium in 24 hours. Respiration decreases with a decrease in oxygen concentration, the reaction being reversible. The reaction optimum for respiration is at a $\mathrm{pH} 8.4$ to 8.8 , with mini- 
mum points at 9.4 and 7.6. Warington ${ }^{21}$ believed that nitrification of ammonia could take place only with ammonium carbonate and that the function of carbonates in solution was to supply the ammonium carbonate by interaction with the other ammonium salts. This was, however, found to be incorrect by Bonazzi, ${ }^{22}$ and others. According to Bonazzi, the oxidation of ammonia can be considered to take place in two steps: (a) respiration, with resultant gain in energy and synchronous nitrogen absorption; (b) nitrogen assimilation (nitrification

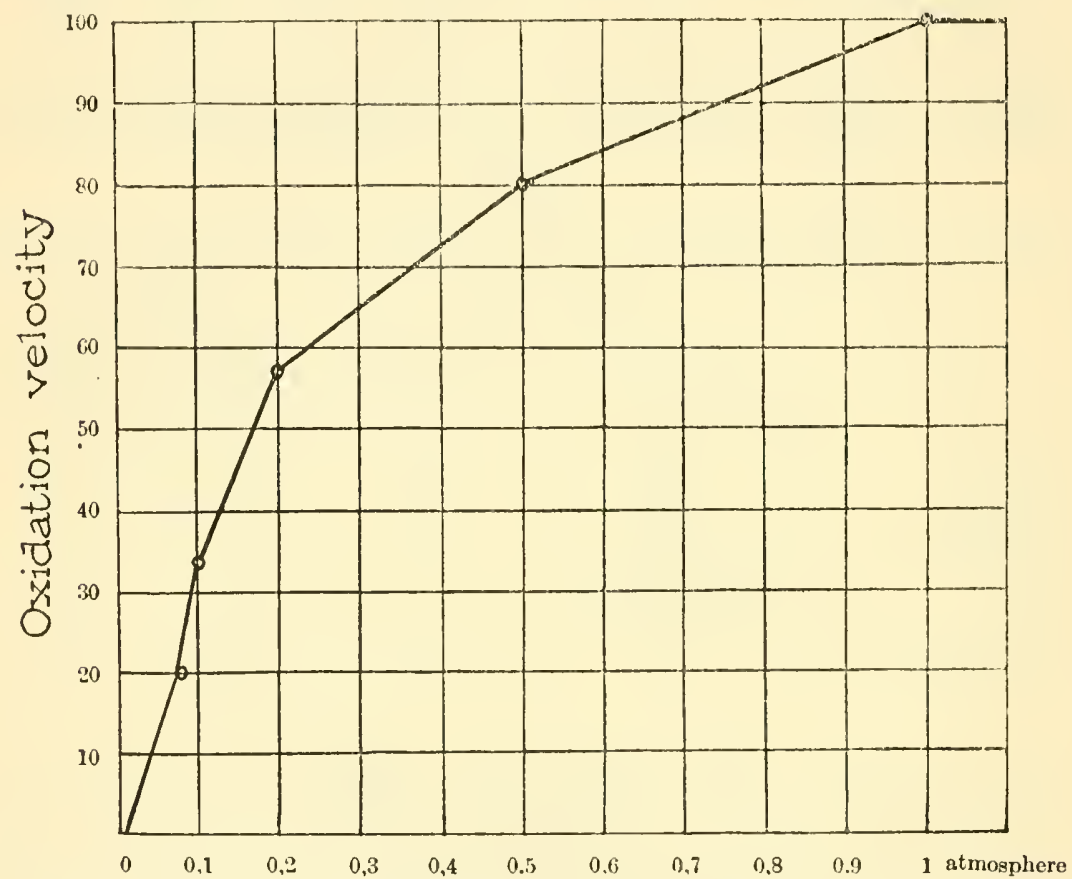

FIG. 20. Influence of oxygen pressure upon the oxidation of nitrite to nitrate (from Meyerhof).

proper) whereby oxidation of the absorbed nitrogen takes place, the utilized portion goes to make up the following cell generations, nitrous acid is split off and excreted as a non-utilizable product, and energy is liberated.

${ }^{21}$ Warington, 1878-1891 (p. 63).

${ }^{22}$ Bonazzi, A. On nitrification. IV. The carbon and nitrogen relations of the nitrite ferment. Jour. Bact., 6: 479-499. 1921. 
The influence of organic matter on nitrite and nitrate-forming bacteria has been studied in detail by Winogradsky and Meyerhof. These results indicate that soluble organic substances have a distinct injurious effect upon the respiration and growth of both the nitrite and nitrate-forming bacteria. The injurious effect of amines was found to be parallel to their "lipoid solubility." The importance of this phenomenon in soil processes is discussed elsewhere. A detailed study of the influence of various ions and ion antagonism upon the respiration of these two groups of organisms has been made by Meyerhof.

Energy utilization from the oxidation of sulfur and its compounds. Winogradsky ${ }^{23}$ was the first to demonstrate that certain bacteria living in sulfur springs, like Beggiatoa, Thiothrix and others, use $\mathrm{H}_{2} \mathrm{~S}$ as a source of energy. This is first oxidized to sulfur and water:

$$
\mathrm{H}_{2} \mathrm{~S}+\frac{1}{2}(\mathrm{O})_{2}=\mathrm{H}_{2} \mathrm{O}+\mathrm{S}+61.1 \mathrm{Cal} \text {. }
$$

The reaction $\mathrm{H}_{2} \mathrm{~S}=\mathrm{H}_{2}+\mathrm{S}$ is endothermic, but the simultaneous oxidation of the hydrogen makes the process exothermic. The sulfur accumulates within the cells and is further oxidized, in the presence of carbonates $\left(\mathrm{CaCO}_{3}\right)$.

$$
\text { (S) } \mathrm{rh}+1 \frac{1}{2}\left(\mathrm{O}_{2}\right)+\mathrm{H}_{2} \mathrm{O}=\mathrm{H}_{2} \mathrm{SO}_{4}+142.2 \mathrm{Cal} \text {. }
$$

$\mathrm{H}_{2} \mathrm{~S}$ is a weak acid and undergoes hydrolytic dissociation, which increases with a decrease in the hydrogen-ion concentration:

$$
\mathrm{K}_{1}\left[\mathrm{H}_{2} \mathrm{~S}\right]=\left[\mathrm{H}^{+}\right]\left[\mathrm{HS}^{-}\right]
$$

in which

$$
\begin{aligned}
& \mathrm{K}_{1}=0.91 \times 10^{-7}, \text { at } 18^{\circ} \mathrm{C} . \\
& \mathrm{K}_{2}\left[\mathrm{HS}^{-}\right]=\left[\mathrm{H}^{+}\right]\left[\mathrm{S}^{--}\right] \\
& \mathrm{K}_{2} \text { is very small, about } 10^{-15}
\end{aligned}
$$

Baas-Becking ${ }^{24}$ assumed that not the $\mathrm{H}_{2} \mathrm{~S}$ as such, but rather the hydrosulfide is used by the sulfur bacteria as a souree of energy, since the $\mathrm{H}_{2} \mathrm{~S}$ has a lower energy value. This is seen by arranging the sulfur compounds according to their free energy levels.

${ }^{23}$ Winogradsky, 1887 (p. 80).

${ }^{24}$ Baas-Becking, L. G. M. The source of energy of the sulfur bacteria. Proc. Soc. Exp. Biol. Med., 22: 127-130. 1924; Studies on the sulfur bacteria. Ann. Bot., 39: 613-650. 1925. 


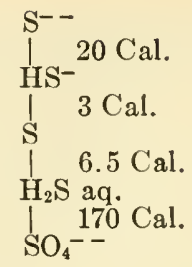

$\mathrm{H}_{2} \mathrm{~S}$ itself is probably poisonous to Beggiatoa as it is to other bacteria. The hydrogen sulfide is produced by bacteria from the decomposition of organic matter, from the reduction of sulfates and other compounds of sulfur and by inorganic agencies (p. 600), and is used as a source of energy.

The sulfur bacteria can be divided into three physiological groups on the basis of the sulfur compounds from which they derive their energy:

1. Sulfide bacteria. These organisms obtain their energy chiefly from the oxidation of hydrogen sulfide and other sulfides. They include the thread-forming, purple, and other bacteria accumulating sulfur within their cells. According to Keil, ${ }^{25}$ only Beggiatoa and Thiothrix are autotrophic bacteria, while the purple bacteria are not autotrophic. ${ }^{26}$

2. Thiosulfate or thionic acid bacteria. These obtain their energy primarily from the oxidation of thiosulfates. Some seem to be also capable of oxidation of elementary sulfur. They include Thiobacillus thioparus Beij. and the various strains of Th. denitrificans Beij. The first is obligate autotrophic while the second, at least some strains of it, is facultative autotrophic. According to Lieske, ${ }^{27} \mathrm{Th}$. denitrificans assimilated $10.9 \mathrm{mgm}$. of carbon for every gram of thiosulfate oxidized. One gram of thiosulfate is equivalent to $405 \mathrm{mgm}$. of sulfur. Therefore, thirty-seven parts of sulfur are oxidized to two parts of carbon assimilated chemosynthetically.

Nathanson first suggested the following reaction for the process of transformation of thiosuliate, which results in the accumulation of sulfur in the medium:

$$
3 \mathrm{Na}_{2} \mathrm{~S}_{2} \mathrm{O}_{3}+2 \frac{1}{2}\left(\mathrm{O}_{2}\right)=2 \mathrm{Na}_{2} \mathrm{SO}_{4}+\mathrm{Na}_{2} \mathrm{~S}_{4} \mathrm{O}_{6}
$$

The free sulfur, which was formed in the medium, was believed to originate by the chemical interaction of the tetrathionate with some of the thiosulfate. However Beijerinck believed the sulfur to be produced directly from the thiosulfate:

$$
\mathrm{Na}_{2} \mathrm{~S}_{2} \mathrm{O}_{3}+\frac{1}{2}\left(\mathrm{O}_{2}\right)=\mathrm{Na}_{2} \mathrm{SO}_{4}+(\mathrm{S})
$$

\footnotetext{
${ }^{25}$ Keil, 1912 (p. 81).

${ }^{26}$ Molish, 1907 (p. 83).

${ }^{27}$ Lieske, 1912 (p. 86).
} 
The organism isolated by Trautwein oxidized thiosulfate without the formation of free sulfur. The results obtained tend to sustain the reaction suggested by Nathanson:

$$
\begin{aligned}
& 4 \mathrm{Na}_{3} \mathrm{~S}_{2} \mathrm{O}_{3}+6 \mathrm{O}_{2}=4 \mathrm{Na}_{2} \mathrm{~S}_{2} \mathrm{O}_{5} \\
& 3 \mathrm{Na}_{2} \mathrm{~S}_{2} \mathrm{O}_{3}+2 \frac{1}{2}\left(\mathrm{O}_{2}\right)=\mathrm{Na}_{2} \mathrm{~S}_{4} \mathrm{O}_{6}+2 \mathrm{Na}_{2} \mathrm{SO}_{4}
\end{aligned}
$$

Sulfate, dithionate and tetrathionate are formed, but no free sulfur and no sulfuric acid.

In the oxidation of sulfur and reduction of nitrates by $T h$. denitrificans, the following reactions have been suggested:

$5(\mathrm{~S}) \mathrm{rh}+6 \mathrm{KNO}_{3}+2 \mathrm{H}_{2} \mathrm{O}=\mathrm{K}_{2} \mathrm{SO}_{4}+4 \mathrm{KHSO}_{4}+3 \mathrm{~N}_{2}$

$5(\mathrm{~S}) \mathrm{rh}+6 \mathrm{KNO}_{3}+2 \mathrm{CaCO}_{3}=3 \mathrm{~K}_{2} \mathrm{SO}_{4}+2 \mathrm{CaSO}_{4}+2 \mathrm{CO}_{2}+3 \mathrm{~N}_{2}$

$5 \mathrm{Na}_{2} \mathrm{~S}_{2} \mathrm{O}_{3}+8 \mathrm{KNO}_{3}+2 \mathrm{NaHCO}_{3}=6 \mathrm{Na}_{2} \mathrm{SO}_{4}+4 \mathrm{~K}_{2} \mathrm{SO}_{4}+2 \mathrm{CO}_{2}+4 \mathrm{~N}_{2}+\mathrm{H}_{2} \mathrm{O}$

3. Sulfur bacteria. These organisms derive their energy primarily from the oxidation of elementary sulfur. They include Th. thiooxidans Waksman and Joffe. The oxidation takes place according to the reaction given above ( $p$. 397). One mol of rhombic sulfur will thus liberate 142.2 Cal. Thiosulfate is oxidized by this organism to sulfate and sulfuric acid.

Thiobacillus thioparus was found to derive its carbon only from the $\mathrm{CO}_{2}$ of the atmosphere or from bicarbonates and carbonates in solution. ${ }^{28,30}$ Organic materials do not exert any injurious influence, nor stimulate growth, since they cannot take the place of $\mathrm{CO}_{2}$. Th. denitrificans is capable also of developing readily on organic media, assimilating organic carbon; $;^{29,31}$ in other words, this organism is facultative autotrophic. On thiosulfate media the carbon is derived either from $\mathrm{CO}_{2}$ or bicarbonates but not from carbonates. Lieske, ${ }^{32}$ however, could not find any injurious or stimulating action due to organic matter, Th. denitrificans deriving its carbon only chemosynthetically. Although small quantities of glucose are used up by Th. thiooxidans, neither the growth of the organism nor the sulfur-carbon ratio $\left(\frac{\text { sulfur oxidized }}{\mathrm{CO}_{2} \text { assimilated from atmosphere }}\right)$ are appreciably affected. ${ }^{33}$ It remains to be found, therefore, in what connection the glucose is used.

${ }^{28}$ Nathanson, 1902 (p. 84).

${ }^{29}$ Beijerinck, 1904 (p. 84).

so Jacobsen, 1912 (p. 85).

31 Trautwein, 1921 (p. 87).

${ }^{32}$ Lieske, 1912 (p. 86).

${ }^{33}$ Starkey, R. L. Concerning the physiology of Thiobacillus thiooxidans, an autotrophic bacterium oxidizing sulfur under acid conditions. Jour. Bact., 135-164, 165-195. 1925. 
According to Trautwein respiration does not depend on the oxygen tension; oxidation is not affected even at a pressure of $\frac{1}{8}$ atmosphere. At ${ }_{1}^{\frac{1}{1}}$ atmosphere, however, respiration completely ceases. Th. denitrificans can grow in the complete absence of oxygen when nitrates are present. The latter are reduced to atmospheric nitrogen and the oxygen is used for the purpose of oxidation.

Sulfates, even up to 5.0 per cent concentration, do not injure sulfur oxidation. In this respect the thiosulfate bacteria behave differently from the Nitrosomonas and Nitrobacter, since the sulfur organisms are not injured by the oxidation products while the nitrite and nitrate bacteria are. The chlorine ion exerts, however, an injurious influence: oxidation of sulfur is reduced by 38 per cent at $0.3 \mathrm{~N}$ concentration of $\mathrm{NaCl}$.

The optimum reaction for the activities of $T h$. denitrificans lies at a pH 7.9 to 9.1 , with a minimum of $\mathrm{pH} 3.5$. In acid media the reaction tends to become more alkaline as a result of the activities of the organism, since no free acid is formed.

The most extensive work on the respiration of sulfur-oxidizing bacteria has been done with Th. thiooxidans. This organism is capable of utilizing elementary sulfur, sulfide and thiosulfate as sources of energy. The carbon is derived only from carbon dioxide. The presence of glucose is not injurious to the growth and sulfur oxidizing capacity of the organism but it cannot serve either as a source of energy or as a source of carbon. No growth takes place when the cultures are placed in a $\mathrm{CO}_{2}$-free atmosphere. ${ }^{34}$ Bicarbonates, particularly when the proper reaction of the medium is obtained by means of an acid, may take the place of $\mathrm{CO}_{2}$ only to a small extent, as seen from table 26. The slight increase in acidity in the cultures of the ordinary medium and glucose medium grown in the $\mathrm{CO}_{2}$-free atmosphere is due to the acidity introduced with the inoculum (3 drops per $100 \mathrm{cc}$. of culture medium). It may be of interest to point out, in this connection, that the optimum reaction for the growth of the organism is pH 1.0 to 5.0 .

A modified medium may be used for this purpose, namely 0.2 gram $\left(\mathrm{NH}_{4}\right)_{2} \mathrm{SO}_{4}, 0.1$ gram $\mathrm{MgSO}_{4}, 0.01$ gram $\mathrm{FeSO}_{4}, 0.25$ gram $\mathrm{CaCl}_{2}, 3.0$ grams $\mathrm{K}_{2} \mathrm{HPO}_{4}, 10$ grams sulfur in 1000 ce. water. The water is distilled twice, the second time using glass containers only and pre-

${ }^{34}$ Waksman, S. A., and Starkey, R. L. Carbon assimilation and respiration of autotrophic bacteria. Proc. Soc. Exp. Biol. Med., 20: 9-14. 1922. 
viously treating the water with $\mathrm{KMnO}_{4}$. The ratio between the sulfur oxidized and earbon assimilated from $\mathrm{CO}_{2}$ of the atmosphere (S:C) was found to be about 32 . With thiosulfate as a source of energy the ratio was found to be about 64 . The apparatus used for carbon determination is given in figure 16 .

About six and two-thirds per cent of the heat liberated in the oxidation of elementary sulfur is utilized for the chemosynthetic assimilation of carbon. ${ }^{35}$ However, when conditions are unfavorable for the development of the organism, the sulfur-carbon ratio may increase. For example, the presenee of nitrates in the medium, which exerts a toxic effect upon the respiration of the organism, resulted in a wider sulfur-

Influence of carbon source upon the growth and sulfur oxidation of Thiobacillus thiooxidans

\begin{tabular}{|c|c|c|c|c|}
\hline \multirow{3}{*}{ TREATMENT } & \multicolumn{4}{|c|}{ ATMOSPHERE } \\
\hline & \multicolumn{2}{|c|}{ Ordinary } & \multicolumn{2}{|c|}{$\mathrm{CO}_{2}$-free } \\
\hline & Final $\mathrm{pH}$ & Titre* $^{*}$ & $\mathrm{pH}$ & Titre* \\
\hline Regular medium, control............... & 4.2 & 2.20 & 4.2 & 2.20 \\
\hline Inoculated $\ldots \ldots \ldots \ldots \ldots \ldots \ldots \ldots \ldots \ldots$ & 1.2 & 12.15 & 3.8 & 2.25 \\
\hline 1 per cent glucose, control................ & 3.0 & 2.20 & 3.0 & 2.2 \\
\hline Inoculated. . . . . . . . . . . . . . . & $1.2(-)$ & 13.15 & 2.8 & 2.3 \\
\hline 0.1 per cent $\mathrm{NaHCO}_{3}$, control . ....... & 6.6 & 1.3 & 6.6 & 1.3 \\
\hline 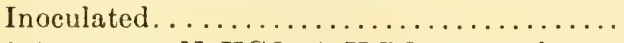 & 5.4 & 2.0 & 6.0 & 1.75 \\
\hline 0.1 per cent $\mathrm{NaHCO}_{3}+\mathrm{H}_{3} \mathrm{PO}_{4}$, control.... & 6.2 & 2.2 & 6.2 & 2.2 \\
\hline 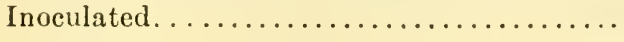 & 1.5 & 9.3 & 5.3 & 2.5 \\
\hline
\end{tabular}

* 'Titre = cubic centimeter of $0.1 N \mathrm{NaOH}$ necessary to neutralize $10 \mathrm{cc}$. of medium, with phenolphthalein as indicator.

carbon ratio. The sulfates were found to have no effect on the respiration of the sulfur oxidizing bacteria, exeept in very high concentrations. Nitrates are very toxic, especially in concentrations above 0.2 molar. Phosphates proved to be more toxic than sulfates, but less toxic than nitrates. As stated above, glueose was not found to be toxic, but peptone became toxic in eoneentrations of 0.05 per cent. The concentration of sulfur in the medium did not exert any important influence on sulfur oxidation; an increase in the quantity of sulfur led to an increase in oxidation. As to the influence of sulfuric acid or the prod-

${ }^{35}$ Waksman, S. A., and Starkey, R. L. On the growth and respiration of sulfur oxidizing bacteria. Jour. Gen. Physiol., 5: 285-310. 1923. 
uct of the reaction, it was found that normal growth took place even in concentrations of 0.25 molar, while 0.5 molar did not completely prevent growth. In general, the metabolism of the Thiobacillus thiooxidans approached, in its energy utilization, very closely that of Nitrosomonas and Nitrobacter.

Energy utilization from the oxidation of iron compounds. Certain bacteria are able to utilize the energy obtained from the oxidation of certain iron compounds and live autotrophically. According to Lieske, ${ }^{36}$ Spirophyllum ferrugineum can grow in inorganic media free from organic matter and oxidize ferrous carbonate to ferric hydroxide. The process supplies the organism with the necessary energy for the chemosynthetic assimilation of $\mathrm{CO}_{2}$ :

$$
2 \mathrm{Fe} \mathrm{CO}_{3}+3 \mathrm{H}_{2} \mathrm{O}+\frac{1}{2}\left(\mathrm{O}_{2}\right)=\mathrm{Fe}_{2}(\mathrm{OH})_{6}+2 \mathrm{CO}_{2}+29.8 \mathrm{CaI} .
$$

One mol of ferrous carbonate thus liberates only about 15 Calories; and 1 gram of the substance oxidized liberates $0.12 \mathrm{Cal}$. The amount of energy obtained is small in comparison with that liberated in the processes of oxidation of the nitrogen and sulfur compounds. The organism has to oxidize, therefore, large quantities of iron to obtain enough energy to assimilate the necessary carbon chemosynthetically. This results in the accumulation of large quantities of iron hydrate in the bacterial bodies; to assimilate one part of carbon, about 750 parts of hydrate must be formed. This figure is, however, far from accurate, as stated by Lieske. Other ferrous salts will not take the place of the carbonate. Much organic matter impairs growth and may finally stop it altogether.

Some organisms, like species of Leptothrix, can live without iron compounds, but can utilize them either in the form of ferrous carbonate or as soluble organic iron salts. Other bacteria will use certain soluble organic iron compounds, but cannot utilize inorganic iron salts. We have here a series of transition stages from pure autotrophy to pure heterotrophy. Harder ${ }^{37}$ divides the iron bacteria, as regards their physiological activities, into three groups:

1. Those that precipitate ferric hydroxide from solutions of ferrous bicarbonate and use the carbon dioxide liberated and the energy produced during oxidation for their life activities (autotrophic).

${ }^{36}$ Lieske, 1911 (p. 95).

${ }^{37}$ Harder, E. C. Iron depositing bacteria and their geologic relations. Prof. Paper 113, U. S. Geological Survey, Washington. 1919. 
2. Those which do not require ferrous bicarbonate for their life processes but which deposit ferric hydroxide when either inorganic or organic iron salts are present (facultative autotrophic).

3. Those which attack organic iron salts, using the organic acid radical as a nutrient and precipitating ferric hydroxide or basic ferric salts which are gradually changed to ferric hydroxide. Inorganic iron salts, however, are not utilized as sources of energy and this group is heterotrophic.

Energy utilization from the oxidation of hydrogen. The oxidation of hydrogen by bacteria is accompanied by the liberation of large quantities of heat, according to the following reaction:

$$
\mathrm{H}_{2}+\frac{1}{2}\left(\mathrm{O}_{2}\right)=\mathrm{H}_{2} \mathrm{O}+68.4 \mathrm{Cal} \text {. }
$$

Thus 1 gram of hydrogen gives more than eight times as much heat of combustion (34.2 Cal.) as 1 gram of starch (4.1 Cal.). Some of the hydrogen bacteria (Hydrogenomonas pantotropha) can grow on purrely inorganic media, utilizing the energy obtained from the oxidation of hydrogen for the assimilation of carbon chemosynthetically from the $\mathrm{CO}_{2}$ of the atmosphere. ${ }^{38}$ Kaserer suggested that the mechanism of hydrogen transformation will depend on the nature of the organism.

Hydrog. pantotropha changes the hydrogen and carbon dioxide directly into the first substance necessary for the synthesis of organic matter, namely to formaldehyde.

$$
\mathrm{H}_{2} \mathrm{CO}_{3}+2 \mathrm{H}_{2}=\mathrm{CH}_{2} \mathrm{O}+2 \mathrm{H}_{2} \mathrm{O} ; \mathrm{CH}_{2} \mathrm{O}+\mathrm{O}_{2}=\mathrm{H}_{2} \mathrm{CO}_{3}
$$

The oxidation of hydrogen is thus found to lead to two processes, assimilation of carbon dioxide and oxidation of the hydrogen. For every volume of $\mathrm{CO}_{2}$ assimilated, two volumes of hydrogen gas are oxidized. For every two volumes of hydrogen oxidized one volume of oxygen disappears. The formation of formaldehyde as an intermediary product was not confirmed by Lebedeff. The bacteria ( Hydrog. vitrea and Hydrog. fiava) isolated by Niklewski ${ }^{39}$ also grew in an inorganic solution with an atmosphere of $\mathrm{H}_{2}, \mathrm{O}_{2}$, and $\mathrm{CO}_{2}$. Organic compounds were formed from the hydrogen and carbon dioxide; those were then oxidized to carbon dioxide and water during respiration. The autotrophic nature of the process has been definitely established by Lebe-

${ }^{38}$ Kaserer, 1906 (p. 97). See Klein and Svolba, Ztschr. Bot. 19: 65. 1926.

${ }^{39}$ Niklewski, 1910 (p. 98).

${ }^{10}$ Lebedeff, A. F. Über die Assimilation des Kohlenstoffes bei wasserstoffoxydierenden Bakterien. Ber. deut. bot. Gesell., 27: 595-602. 1909. Nabokich and Lebedeff, 1907 (p. 98). 
deff, ${ }^{40}$ who found that the growth of Bac. hydrogenes in an inorganic medium resulted in an exchange of gases (reduced to $0^{\circ}$ and $760 \mathrm{~mm}$.) with the $\mathrm{H}_{2}: \mathrm{O}_{2}$ varying from 2.00 to 2.62 . 588 to 1860 cc. $\mathrm{H}_{2}$ are oxi. dized for every $100 \mathrm{cc} . \mathrm{CO}_{2}$ assimilated. The oxidation of $\mathrm{H}_{2}$ is not necessarily connected with the reduction of $\mathrm{CO}_{2}$. The ratio $\mathrm{H}_{2}: \mathrm{CO}_{2}$ depends upon the age of the culture. Since the organisms utilize the

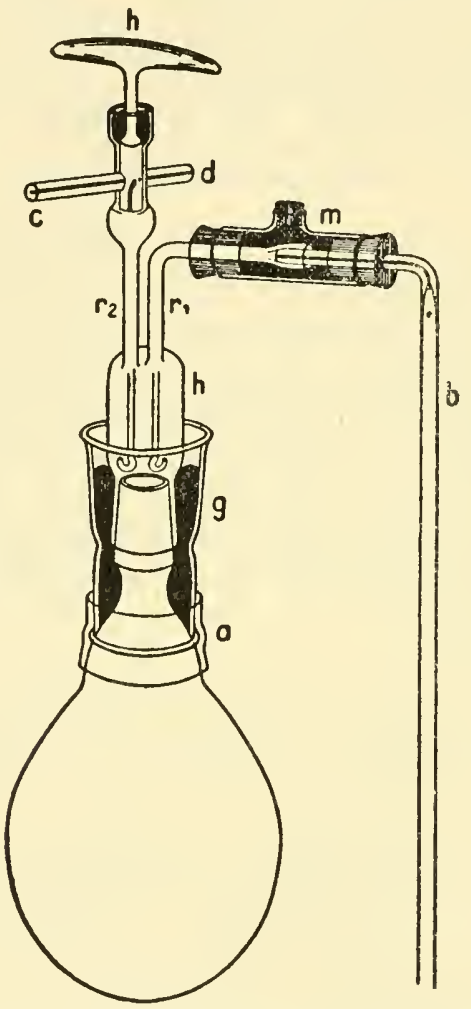

Fig. 21. Culture vessel for study of hydrogen utilization by bacteria (from Ruhland).

energy obtained from the oxidation of the $\mathrm{H}_{2}$ for the reduction of $\mathrm{CO}_{2}$, the $\mathrm{H}_{2}: \mathrm{CO}_{2}$ ratio is wider in older than in younger cultures. The energy process was believed to be independent of the process of assimilation of carbon and could be expressed by the equation:

$$
2 \mathrm{H}_{2}+\mathrm{O}_{2}=2 \mathrm{H}_{2} \mathrm{O}
$$


The gas exchange in the autotrophic assimilation of carbon by nonchlorophyll-containing bacteria is thus similar to the gas exchange of green plants. On organic media, the organism grows in a manner similar to heterotrophic bacteria. In the presence of organic matter the organism oxidizes $\mathrm{H}_{2}$ considerably less than in its absence.

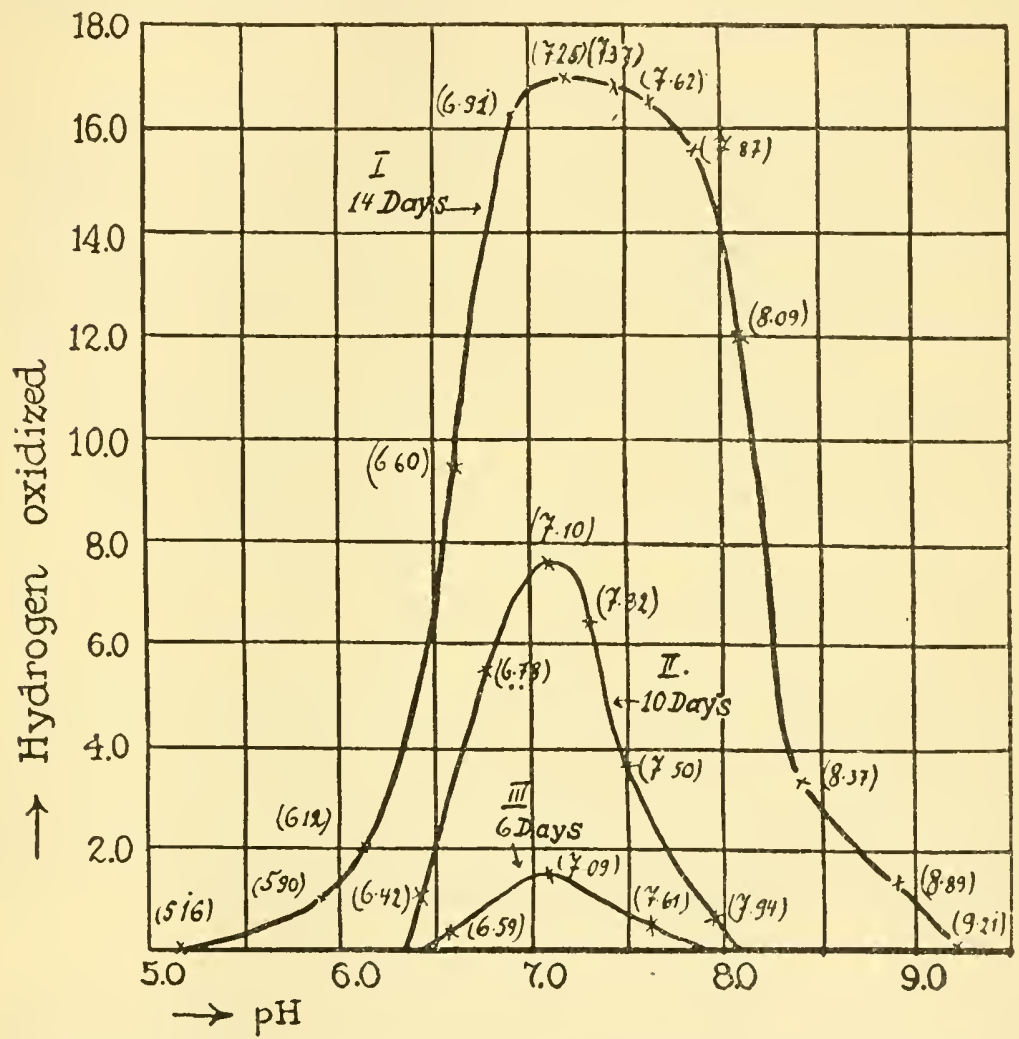

FIG. 22. Reaction of medium and oxidation of hydrogen by bacteria (Ruhland)

The organisms oxidizing hydrogen are thus found to be facultative autotrophic, i.e., they are able to develop heterotrophically in the absence of hydrogen. Whenever hydrogen is present, however, they are capable of developing autotrophically. The presence of iron (when only $2.4 \times 10^{-5} \mathrm{mgm}$. Fe are present in $50 \mathrm{cc}$. no growth or hydrogen oxidation takes place) and a proper $\mathrm{pH}$ value (6.8 to 8.7 opt.) were found to be essential for the respiration of organisms oxidizing hydro- 
gen. ${ }^{41}$ On the acid side, growth diminishes due to the disappearance of $\mathrm{HCO}_{3}{ }^{-}$(in favor of $\mathrm{CO}_{2}$ ) and to the direct action of the hydrogen-ion on the hydrogen oxidation. On the alkaline side, growth diminishes due to an increasing diminution of the iron. Organic carbon sources exert a certain protective action upon the oxidation of the hydrogen due to the production of organic acids and, therefore, a reaction unfavorable to the bacteria. Organic substances, which do not result in formation of acid, as well as small amounts of sugar, tend to slow down the oxidation of hydrogen at first, but then accelerate it. The reaction is carried on to completion, so long as there are any traces of $\mathrm{H}_{2}$ and $\mathrm{O}_{2}$ in the atmosphere. Different $\mathrm{CO}_{2}$ pressures influence growth by influencing the reaction. The hydrogen-oxygen (elemental) ratio is usually greater than two to one, reaching 2.78 because of the formation of free oxygen in the reduction of $\mathrm{CO}_{2}$. The most efficient utilization of the energy of the reaction for chemosynthetic purposes is at a neutral reaction when $1 \mathrm{cc} . \mathrm{CO}_{2}$ is assimilated for $8 \mathrm{cc} . \mathrm{H}_{2}$ oxidized. The utilization quotient $Q n=\frac{\mathrm{CO}_{2} \text { assimilated }}{\mathrm{H}_{2} \text { oxidized }}$ lies between 0.01 and 0.148 . As much as 20 per cent of the energy liberated may be used for the chemosynthetic assimilation of $\mathrm{CO}_{2}$. Partial pressure of $\mathrm{H}_{2}$ has no influence on the energy utilization and $\mathrm{CO}_{2}$ assimilation. Nitrate is reduced to nitrite (not to atmospheric nitrogen), but the oxygen cannot be used for the anaerobic oxidation of hydrogen. Narcotics (urethane, HCN) exert an injurious effect upon oxidation.

Energy utilization from the oxidation of simple carbon compounds. Methane is oxidized by certain bacteria which use the energy thus obtained for the cliemosynthetic utilization of $\mathrm{CO}_{2}$.

$$
\mathrm{CH}_{4}+2 \mathrm{O}_{2}=\mathrm{CO}_{2}+2 \mathrm{H}_{2} \mathrm{O}+218 \mathrm{Cal} \text {. }
$$

This process is carried out, under autotrophic conditions, by Methanomonas methanica. ${ }^{42} \mathrm{Mün}^{43}$ found these bacteria developing readily in an atmosphere rich in methane with an optimum concentration of oxygen at 2 per cent. Nitrogen is utilized in inorganic and organic forms. The organism is facultative autotrophic, being

${ }^{41}$ Ruhland, W. Aktivierung von Wasserstoff und Kohlensäureassimilation durch Bakterien. Ber. deut. Bot. Gesell., 40: 180-184. 1920-1922; also Ruhland, 1924 (p. 101).

${ }^{42}$ Sohngen, 1906 (p. 96).

${ }^{43}$ Münz, E. Zur Physiologie der Methanbakterien. Diss. Halle. 1915. 
able to develop heterotrophically. The methane cannot be replaced by hydrogen or carbon monoxide, but can be replaced by various organic compounds, such as alcohols, carbohydrates, and salts of organic acids.

The utilization of carbon monoxide as a source of energy by bacteria was demonstrated by Kaserer:

$$
\mathrm{CO}+\frac{1}{2}\left(\mathrm{O}_{2}\right)=\mathrm{CO}_{2}+74 \mathrm{Cal} \text {. }
$$

Closely related processes to the autotrophic utilization of inorganic compounds are the oxidation of simple organic compounds, of which we need mention only the oxidation of alcohol to acetic acid, and the utilization of hydrocarbons as sources of energy. The $\mathrm{CO}_{2}$ assimilation of these as well as of the methane bacteria is not established. The physiology of these organisms is little understood.

The acetic acid bacteria are divided, ${ }^{44}$ on the basis of their carbon and nitrogen utilization, into two groups: (1) haplotrophic, those which obtain their energy from the oxidation of alcohol, and (2) symplotrophic, or those which require organic compounds. The energy utilization of the former is of interest here:

$$
\mathrm{CH}_{3} \cdot \mathrm{CH}_{2} \cdot \mathrm{OH}+\mathrm{O}_{2}=\mathrm{CH}_{3} \mathrm{COOH}+\mathrm{H}_{2} \mathrm{O}+112 \mathrm{Cal} \text {. }
$$

1.47 Cal. are thus liberated for every gram of alcohol oxidized. These bacteria do not need any other organic matter, either as sources of energy or carbon. The tendency was, therefore, to classify these organisms with the autotrophic bacteria. According to Neuberg, ${ }^{45}$ however, in the case of the acetic acid bacteria the ethyl alcohol is first oxidized to acetaldehyde; this is either further oxidized to acetic acid or is used for the synthesis of the microbial protoplasm. These organisms, therefore, are not autotrophic since they do not derive their carbon from carbon dioxide and, in regard to energy and carbon utilization, may both be classified with the heterotrophic organisms.

$$
\mathrm{CH}_{3} \cdot \mathrm{CH}_{2} \cdot \mathrm{OH} \rightarrow \mathrm{CH}_{3} \cdot \mathrm{CHO} \nearrow_{\mathrm{CH}_{3} \cdot \mathrm{COOH}}^{\mathrm{CH}_{3} \cdot \mathrm{CH}_{2} \cdot \mathrm{OH}}{ }_{\mathrm{CH}_{3} \cdot \mathrm{CHO}}^{\nearrow}{ }_{\mathrm{CH}_{3} \cdot \mathrm{COOH}}^{\mathrm{CH}_{3} \cdot \mathrm{CH}_{2} \mathrm{OH}}
$$

44 Janke, A. Forschungsergebnisse auf dem Gebiete der Essigbakteriologie und Fortschritt der Gärungsessigindustrie. Centrbl. Bakt. II, 53: 81-124. 1921.

${ }^{45}$ Neuberg, C., and Windisch, F. Vom Wesen der Essiggärung und von verwandten Erscheinungen. Die Naturwiss., 13: 993-996. 1925; Biochem. Ztschr., 166: 454-481. 1925.! 
Energy is liberated in the oxidation of the ethyl alcohol to acetaldehyde, but only one-third of that energy is liberated in the oxidation-reduction of the acetaldehyde. The nature of energy utilization by bacteria capable of oxidizing hydrocarbons and amorphous carbon ${ }^{46}$ still remains to be studied.

Heterotrophic utilization of energy by microorganisms. The great majority of soil microorganisms, both in respect to numbers and species, have to depend for their energy supply upon complex organic or carbonaceous substances. These may be simple or complex carbohydrates, fats, or proteins and their derivatives. The carbohydrates contain about 40 to 45 per cent carbon, the proteins about 50, the lignins about 60 , and the fats about 75 per cent. In the combustion of the carbon and the hydrogen, energy is liberated.

The nutrient consumption by heterotrophic microorganisms follows three courses; viz., energy, structural or reserve purposes and residual substances. The energy goes to produce work against the exterior and to elevate the chemical potential of the substances formed. ${ }^{47}$ The organism may derive its energy and material needed for the synthesis of the protoplasm from the same nutrient or from two different nutrients. Fats form only a rather small part of the constituents of the plant residues and manures added to the soil. Our chief attention may, therefore, be devoted to the other two groups of substances. Both carbohydrates and proteins may be utilized as sources of energy by most of the aerobic and anaerobic heterotrophic microorganisms. The decomposition products will differ. Under aerobic conditions a carbohydrate is usually decomposed to $\mathrm{CO}_{2}$ and $\mathrm{H}_{2} \mathrm{O}$ or to various organic acids, $\mathrm{CO}_{2}$ and $\mathrm{H}_{2} \mathrm{O}$. Under anaerobic conditions, it is decomposed into $\mathrm{H}_{2}$ or $\mathrm{CH}_{4}$, or both, and into different acids, $\mathrm{CO}_{2}$ and $\mathrm{H}_{2} \mathrm{O}$. The amount of energy made available depends upon the nature of the decomposition taking place. Under aerobic conditions the proteins are decomposed to amino acids, $\mathrm{NH}_{3}, \mathrm{CO}_{2}$, and $\mathrm{H}_{2} \mathrm{O}$; under anaerobic conditions, to different products of putrefaction, such as various amines, mercaptans, etc., $\mathrm{NH}_{3}$ and $\mathrm{CO}_{2}$.

${ }_{46}$ Tausz, J., and Peter, M. Neue Methode der Kohlenwasserstoffanalyse mit Hilfe von Bakterien. Centrls. Bakt. II, 49: 497-554. 1920. Any possible action of bacteria upon amorphous carbon is still a matter of eonjecture. See Potter, M. C. Bacteria as agents in the oxidation of amorphous carbon. Proe. Roy. Soc. B, 80: 239-259. 1908.

${ }_{47}$ Terroine, E. F., and Wurmser, R. L'énergie de eroissance. I. Le développement de l'Aspergillus niger. Bull. Soc. Chim. Biol., 4: 519-567. 1922; Wurmser, R. Ibid., 5: 506-528. 1923. 
When carbohydrates are used as sources of energy, the organisms have to obtain their nitrogen from another source, either inorganic or organic. In the case of proteins, both the energy and nitrogen are obtained from the same source. In view of the fact that the protoplasm synthesized by microorganisms has about the same carbon content as the original protein and usually a lower nitrogen content and since only a part of the energy liberated is utilized by the organism and often a larger part converted into kinetic energy, the use of proteins as sources of energy results in a liberation of inorganic nitrogen, usually in the form of ammonia.

Two methods are commonly employed for determining the energy transformation of microorganisms, (1) the differential method which determines the heat of combustion of a medium before and after the growth of microorganisms; (2) the direct method which measures the heat formed during the life processes of the microorganisms. Rubner ${ }^{48}$ found that both of these methods gave comparable results. A third method is also possible. It is based upon indirect calorimetry or the calculation of energy utilization from the chemical changes produced in the metabolism. This method has been used largely in the study of energy changes by autotrophic bacteria where the chemical substances involved are relatively simple in composition. In the case of the reactions brought about by heterotrophic bacteria, we are still in the dark as to a number of chemical and thermochemical reactions involved.

Most nutrients are richer in oxygen than the microbial protoplasm. This is particularly true when nitrate forms the nitrogen source. Synthesis of protoplasm can, therefore, be looked upon in heterotrophic processes more as a process of reduction rather than of oxidation. The intake of oxygen, or respiration, serves the purpose of energy transformation, rather than for synthetic purposes. Oxygen oxidizes the nutrients available, the degree of oxidation determining the final products. The complete oxidation of carbohydrates gives carbon dioxide and water; in the case of nitrogenous substances ammonia (or nitrate) and sulfuric acid are also produced. In the case of substances low in oxygen (hydrogen-oxygen ratio more than 1), such as fats, fatty acids and alcohols, the amount of oxygen necessary for oxidation is so great that only aerobic organisms, such as fungi, are capable of using them as sources of energy. It must be emphasized

\footnotetext{
${ }^{48}$ Rubner, 1903 (p. 419).
} 
in this connection that there is a distinct difference in the usage of the terms "supply, expenditure, utilization and transformation" of energy in the case of autotrophic bacteria on the one hand, and heterotrophic on the other. In the case of the autotrophic organisms, a part of the energy goes to produce work in the true thermodynamic sense. In the case of the heterotrophic organisms, we can speak of a "supply and exchange of energy" only in specific cases, as in the synthesis of fats from carbohydrates, where thermodynamic work takes place. When bacteria or fungi growing in carbohydrate media, store away carbohydrates (hemicelluloses, cellulose or chitin), this is not work in the thermodynamic sense and is carried out with practically no energy transformation. One should differentiate between true syntheses which are also reductions and a mere assimilation of nutrients. However, the formation of carbohydrates by microorganisms involves only a small loss of energy when carbohydrates are used as a substrate; a greater loss of energy with fats and a very considerable loss of encrgy when carbohydrates are formed from proteins as a substrate. ${ }^{49}$

Aerobic utilization of energy. Taking glucose as a starting point, the following products of oxidation are produced, depending on the degree of oxidation: $:^{50}$

$$
\begin{aligned}
& \mathrm{C}_{6} \mathrm{H}_{12} \mathrm{O}_{6}+\frac{1}{2} \mathrm{O}_{2}=\mathrm{C}_{6} \mathrm{H}_{12} \mathrm{O}_{7}+\text { ? Cal. } \\
& \text { Gluconic } \\
& \text { acid } \\
& \mathrm{C}_{6} \mathrm{H}_{12} \mathrm{O}_{6}+\mathrm{O}_{2}=\mathrm{C}_{6} \mathrm{H}_{10} \mathrm{O}_{7}+\mathrm{H}_{2} \mathrm{O}+\text { ? Cal. } \\
& \text { Glucuronic } \\
& \text { acid } \\
& \mathrm{C}_{6} \mathrm{H}_{12} \mathrm{O}_{6}+1 \frac{1}{2} \mathrm{O}_{2}=\mathrm{C}_{6} \mathrm{H}_{8} \mathrm{O}_{7}+2 \mathrm{H}_{2} \mathrm{O}+199 \text { Cal. } \\
& \text { Citric } \\
& \text { acid } \\
& \mathrm{C}_{6} \mathrm{H}_{12} \mathrm{O}_{6}+3 \mathrm{O}_{2}=\mathrm{C}_{3} \mathrm{H}_{6} \mathrm{O}_{3}+3 \mathrm{CO}_{2}+3 \mathrm{H}_{2} \mathrm{O} \\
& \text { Lactic } \\
& \text { acid } \\
& \mathrm{C}_{6} \mathrm{H}_{12} \mathrm{O}_{6}+4 \frac{1}{2} \mathrm{O}_{2}=3 \mathrm{C}_{2} \mathrm{H}_{2} \mathrm{O}_{4}+3 \mathrm{H}_{2} \mathrm{O}+493 \mathrm{Cal} \text {. } \\
& \text { Oxalic acid } \\
& \mathrm{C}_{6} \mathrm{H}_{12} \mathrm{O}_{6}+6 \mathrm{O}_{2}=6 \mathrm{CO}_{2}+6 \mathrm{H}_{2} \mathrm{O}+676 \text { Cal. }
\end{aligned}
$$

${ }^{49}$ Terroine, E. F., Bonnet, R., Jacquot, R., and Vincent, G. Rendements énergétiques comparés dans le développement de moissures aux dépens d'hydrates de carbone ou de protéiques et action dynamique spécifique. Compt. Rend. Acad. Sci., 177: 900-902, 1923. 178: 869, 1488. 1924.

${ }^{60}$ Kruse, 1910 (p. xii). 
All reactions, except the fourth one, actually take place and the products of oxidation can be determined from the amount of sugar and oxygen consumed. The ratio of $\mathrm{CO}_{2}$ to $\mathrm{O}_{2}$, or the respiratory quotient, is equal to zero in most of the above equations. When the quotient is less than 1, the oxidation is incomplete. With complete oxidation, $\mathrm{CO}_{2}: \mathrm{O}_{2}=1$.

In the oxidation of alcohol to acetic acid, $\mathrm{CO}_{2}: \mathrm{O}_{2}=0$, but with complete combustion, $\mathrm{CO}_{2}: \mathrm{O}_{2}=0.67$,

$$
\mathrm{C}_{2} \mathrm{H}_{6} \mathrm{OH}+3 \mathrm{O}_{2}=2 \mathrm{CO}_{2}+3 \mathrm{H}_{2} \mathrm{O}+326 \text { Cal. }
$$

In the oxidation of tartaric acid, the $\mathrm{CO}_{2}: \mathrm{O}_{2}=1.6$,

$$
\mathrm{C}_{4} \mathrm{H}_{6} \mathrm{O}_{6}+2 \frac{1}{2} \mathrm{O}_{2}=4 \mathrm{CO}_{2}+3 \mathrm{H}_{2} \mathrm{O}+262 \mathrm{Cal} \text {. }
$$

In the oxidation of palmitic acid, the $\mathrm{CO}_{2}: \mathrm{O}_{2}=0.7$,

$$
\mathrm{C}_{16} \mathrm{H}_{32} \mathrm{O}_{2}+23 \mathrm{O}_{2}=16 \mathrm{CO}_{2}+16 \mathrm{H}_{2} \mathrm{O}+236 \mathrm{Cal} \text {. }
$$

The oxidation of nitrogen compounds gives quotients smaller or greater than 1.

$$
\begin{aligned}
& \mathrm{C}_{6} \mathrm{H}_{13} \mathrm{NO}_{2}+7 \frac{1}{2} \mathrm{O}_{2}=6 \mathrm{CO}_{2}+5 \mathrm{H}_{2} \mathrm{O}+\mathrm{NH}_{3}+775 \mathrm{Cal} . \\
& \text { Leucine } \\
& \mathrm{CO}_{2}: \mathrm{O}_{2}=0.8 \\
& \mathrm{C}_{2} \mathrm{H}_{5} \mathrm{NO}_{2}+1 \frac{1}{2} \mathrm{O}_{2}=2 \mathrm{CO}_{2}+\mathrm{H}_{2} \mathrm{O}+\mathrm{NH}_{3}+152 \mathrm{Cal} . \\
& \text { Glycocoll } \\
& \mathrm{CO}_{2}: \mathrm{O}_{2}=1.33
\end{aligned}
$$

The oxidation of proteins, which consist of the different amino acids, will, therefore, give a quotient falling between the two above equations, becoming 1 with complete oxidation. Usually, it is less than 1 and

\begin{tabular}{|c|c|c|}
\hline \multirow{2}{*}{ SUBGTANCE OXIDIZED } & \multicolumn{2}{|c|}{ RESPIRATORY QUOTIENT } \\
\hline & $\begin{array}{l}\text { Calculated accord- } \\
\text { ing to formula for } \\
\text { chemical oxidation }\end{array}$ & $\begin{array}{l}\text { Found on analyz- } \\
\text { ing the gas formed }\end{array}$ \\
\hline Tartaric acid. & 1.60 & 1.62 \\
\hline Glucose........ & 1.00 & 0.95 \\
\hline Lactic acid.... & 1.00 & 0.85 \\
\hline Glycerol.............. & 0.85 & 0.75 \\
\hline Mannite .............. & 0.92 & 0.65 \\
\hline
\end{tabular}
may even be 0 when oxidation stops at the oxalic acid stage. Some of the oxygen may be used up for the oxidation of nitrogen and sulfur compounds, as in the case of the action of the autotrophic bacteria when the respiratory quotient equals 0 .

Puriewitsch ${ }^{5 l}$ calculated the respiratory quotient for Asp. niger, using different sources of energy:

${ }^{51}$ Puriewitsch, K. Physiologische Untersuchungen über Pflanzenatmung. Jahrb. wiss. Bot., 35: 572-610. 1900. 
In this particular case, tartaric acid and glucose have undergone complete oxidation while for the other three substances it is only partial. For a quantitative determination of respiration of microorganisms the methods suggested by Bieling, ${ }^{52}$ Warburg, ${ }^{53}$ and Osterhaut ${ }^{54}$ can be used. The last is based upon the time required to produce definite changes in the acidity. The hydrogen-ion concentration has no in fluence upon the absolute respiration of fungi or upon the ratio betweer: growth and respiration, as shown by Gustafson ${ }^{55}$ for Pen. chrysogenum and Lundegardh ${ }^{56}$ for Fusaria. Phosphate was found to have a favorable effect on respiration. It is of interest to note that phosphate has a specific action in bringing about the auto-oxidation of fructose. ${ }^{53}$

Anaerobic utilization of energy. According to Pasteur, ${ }^{57}$ fermentation is the activity of cells in the absence of air or free oxygen, which results in the liberation of energy necessary for the growth and other vital activities of the cells in a manner similar to aerobic respiration in the presence of oxygen. In the absence of air, cells obtain the oxygen from the carbohydrate itself, whereby one half of the carbohydrate molecule is reduced and the other oxiclized. In the case of alcoholic fermentation by yeast, alcohol is the reduction product and $\mathrm{CO}_{2}$ the oxidation product.

$$
\begin{aligned}
& \mathrm{C}_{6} \mathrm{H}_{12} \mathrm{O}_{6}=2 \mathrm{CH}_{3} \cdot \mathrm{CHOH} \cdot \mathrm{COOH}+25 \mathrm{Cal} \text {. } \\
& \text { Lactic acid } \\
& \mathrm{C}_{6} \mathrm{H}_{12} \mathrm{O}_{6}=2 \mathrm{CH}_{3} \cdot \mathrm{CH}_{2} \cdot \mathrm{OH}+2 \mathrm{CO}_{2}+27 \text { Cal. } \\
& \text { Alcohol } \\
& \mathrm{C}_{6} \mathrm{H}_{12} \mathrm{O}_{6}=\mathrm{CH}_{3} \cdot \mathrm{CH}_{2} \cdot \mathrm{CH}_{2} \cdot \mathrm{COOH}+2 \mathrm{CO}_{2}+2 \mathrm{H}_{2}+15 \text { Cal. } \\
& \text { Butyric acid }
\end{aligned}
$$

${ }^{52}$ Beiling, R. Eine Methode zur quantitativen Bestimmung der Atmung von Mikroorganismen und Zellen. Centrbl. Bakt. I, O, 90: 49-52. 1923.

${ }^{63}$ Warburg, O., and Negelein, E. Über die Reduktion des Salpetersäure in grünen Zellen. Biochem. Ztsehr., 110: 66-115. 1920; 142: 317-333. 1923; Warburg, O., and Yabusoe, M. Über die Oxydation von Fructose in Phosphatlösungen. Biochem. Ztschr., 146: 380-386. 1924.

${ }^{54}$ Osterhaut, W. J. V. Comparative studies on respiration. Jour. Gen. Physiol., 1: 171-179. 1918.

${ }^{65}$ Gustafson, F. G. The effect of hydrogen ion concentration on the respiration of Penicillium chrysogenum. Jour. Gen. Physiol., 2: 617-626. 1920.

${ }^{56}$ Lundegardh, H. Der Einflusz der Wasserstoffionenkonzentration in Gegenwart von Salzen auf das Wachstum von Gibberella saubinetii. Biochem. Ztsehr., 146: 564-572. 1924.

${ }^{57}$ Pasteur, L. Etudes sur la bière. Paris. 1876. 
The heat liberated in the fermentation reactions is calculated as follows:

Heat of combustion of glueose................

Heat of combustion of alcohol .................

Heat of solution of glucose.................... 2.1 Cal.

Heat of solution of alcohol................. $2.25 \mathrm{Cal}$.

$$
\begin{array}{cc}
(674+2.1) & -2(326.2-2.25) \\
\text { glucose } & \text { alcohol }
\end{array}
$$

alcohol

Since in the reaction of alcoholic fermentation, some other reaction products are formed, the amount of heat produced by a mol of sugar converted into alcohol is about 27 cal. Rubner found that actually $24 \mathrm{cal}$. were liberated in this reaction.

Some of the anaerobic fermentations are not accompanied by the production of $\mathrm{CO}_{2}$, as in the lactic and acetic acid fermentations.

$$
\mathrm{C}_{6} \mathrm{H}_{12} \mathrm{O}_{6}=3 \mathrm{CH}_{3} \mathrm{COOH}+44 \mathrm{Cal} \text {. }
$$

In the anaerobic decomposition of cellulose, whereby hydrogen and methane are formed (whether by pure cultures or mixed cultures) the following reactions may be suggested:

$$
3 \mathrm{C}_{6} \mathrm{H}_{12} \mathrm{O}_{6}=\underset{\text { butyric acid }}{3 \mathrm{CH}_{3}} \cdot \mathrm{CH}_{2} \cdot \mathrm{CH}_{2} \cdot \mathrm{COOH}+\underset{\text { acetic acid }}{\mathrm{CH}_{3} \cdot \mathrm{COOH}}+4 \mathrm{CO}_{2}+2 \mathrm{H}_{2} \mathrm{O}+2 \mathrm{H}_{2}
$$

$3 \mathrm{C}_{6} \mathrm{H}_{12} \mathrm{O}_{6}=2 \mathrm{CH}_{3} \cdot \mathrm{CH}_{2} \cdot \mathrm{CH}_{2} \cdot \mathrm{COOH}+2 \mathrm{CH}_{3} \cdot \mathrm{COOH}+4 \mathrm{CO}_{2}+2 \mathrm{H}_{2} \mathrm{O}+2 \mathrm{CH}_{4}$

When the heat of reaction of oxidation is compared with that of "fermentation," the former is found to be much greater than the latter: $1 \mathrm{~mol}$ of sugar liberates $676 \mathrm{Cal}$. when it is completely oxidized (to $\mathrm{CO}_{2}$ and $\mathrm{H}_{2} \mathrm{O}$ ) and only about $25 \mathrm{Cal}$. in the alcoholic or lactic acid "fermentation," and even less in the butyric acid fermentation. Since the amount of growth of the cells of microorganisms is in direct proportion to the production of energy, much larger quantities of substrate have to be decomposed in the "fermentations" than in the oxidations by free oxygen in order to liberate the same amount of heat and allow the same amount of work or equal growth of the cells to take place. Some of the products of the "fermentation" processes may be used for the synthesis of the cellular substance. This is particularly true in the decomposition of proteins and carbohydrates. ${ }^{58}$

When organic acids, hydrogen and methane are the products of decomposition they may be used as sources of energy by other micro-

${ }^{58}$ See Meyerhof, O. Über den Einflusz des Sauerstoffs auf die alkoholisehe Gärung der Hefe. Biochem. Ztsehr., 162: 43-\$6. 1925. 
organisms, if conditions are made favorable, as by the addition of free oxygen.

$2 \mathrm{CH}_{3} \cdot \mathrm{CHOH} \cdot \mathrm{COOH}+2 \mathrm{O}_{2}=2 \mathrm{CH}_{3} \mathrm{COOH}+2 \mathrm{CO}_{2}+2 \mathrm{H}_{2} \mathrm{O}+240 \mathrm{Cal}$. Lactic acid acetic acid

$2 \mathrm{CH}_{3} \mathrm{COOH}+3 \mathrm{O}_{2}=2 \mathrm{HCOOH}+2 \mathrm{CO}_{2}+2 \mathrm{H}_{2} \mathrm{O}+294 \mathrm{Cal}$. Formic acid

$$
2 \mathrm{HCOOH}+\mathrm{O}_{2}=2 \mathrm{CO}_{2}+2 \mathrm{H}_{2} \mathrm{O}+126 \mathrm{Cal} \text {. }
$$

The more recent conceptions of oxidation-reduction processes (p. 520), tend to explain the mechanism of energy utilization under "anaerobic" conditions. Quastel and associates ${ }^{59}$ have shown that anaerobic growth of an organism can be expected to take place when a pair of organic compounds, neither of which supports anaerobic growth, fulfill the following conditions: (1) both are "activated" by the organism so that simultaneous oxidation and reduction may occur; (2) energy necessary for growth is liberated in the interaction; (3) as a result of such an interaction some substance is produced which is capable of entering into the synthetic processes of the cell. These conditions are fulfilled for Bact. coli by lactic acid or glycerol, on the one hand, and nitrate or fumerate, on the other, the former contributing hydrogen and the latter utilizing it.

$\mathrm{CH}_{2} \mathrm{OH} \cdot \mathrm{CH} \mathrm{OH} \cdot \mathrm{CH}_{2} \mathrm{OH}+\mathrm{COOH} \cdot \mathrm{CH}: \mathrm{CH} \cdot \mathrm{COOH}=\mathrm{CH}_{2} \cdot \mathrm{CH} \mathrm{OH} \cdot \mathrm{COOH}+$ glycerol Fumaric acid $\mathrm{COOH} \cdot \mathrm{CH}_{2} \cdot \mathrm{CH}_{2} \cdot \mathrm{COOH}+33 \mathrm{Cal}$.

$\mathrm{CH}_{2} \mathrm{OH} \cdot \mathrm{CH}_{2} \mathrm{OH}+2 \mathrm{COOH} \cdot \mathrm{CH}: \mathrm{CH} \cdot \mathrm{COOH}=\mathrm{CH}_{3} \cdot \mathrm{CO} \cdot \mathrm{COOH}+$ $2 \mathrm{COOH} \cdot \mathrm{CH}_{2} \cdot \mathrm{CH}_{2} \cdot \mathrm{COOH}+50 \mathrm{Cal}$.

Malic and aspartic acids can also serve as weak hydrogen acceptors for Bact. coli. In some cases, the same substance can serve both as the hydrogen donator and acceptor, as brought out by the Cannizzaro reaction, especially in the case of pyruvic acid:

$$
\begin{aligned}
& \mathrm{CH}_{3} \cdot \mathrm{CO} \cdot \mathrm{COOH}+\mathrm{H}_{2} \mathrm{O}+\mathrm{CH}_{3} \cdot \mathrm{CO} \cdot \mathrm{COOH}= \\
& \text { pyruvic acid pyruvic acid } \\
& \mathrm{CH}_{3} \cdot \mathrm{CHOH} \cdot \mathrm{COOH}+\mathrm{CH}_{3} \cdot \mathrm{COOH}+\mathrm{CO}_{2}+15 \mathrm{Cal} \text {. } \\
& \text { lactic acid } \\
& \text { acetic acid }
\end{aligned}
$$

${ }^{59}$ Quastel, H., Stephenson, M., and Whetham, M. D. Some reactions of resting bacteria in relation to anaerobic growth Biochem. Jour., 19: 304-317. 1925; Quastel, J. H., and Stephenson, M. Further observations on the anaerobic growth of bacteria. Ibid., 660-666. 
According to Aubel, ${ }^{60}$ glucose is decomposed under anaerobic conditions by Bact. coli by a reaction of internal coupling, one half molecule (lactic acid) giving an exothermic reaction and the other half molecule (pyruvic acid, used as a starting point for synthetic processes) giving an endothermic reaction:

$$
\mathrm{C}_{6} \mathrm{H}_{12} \mathrm{O}_{6}=\mathrm{CH}_{3} \cdot \mathrm{CHOH} \cdot \mathrm{COOH}+\mathrm{CH}_{3} \cdot \mathrm{CO} \cdot \mathrm{COOH}+\mathrm{H}_{2}
$$

0.48 gram of carbon of the sugar decomposed gave 0.216 gram as lactic acid, 0.081 gram as pyruvic acid, 0.042 gram as acetic acid, 0.044 gram as alcohol, and 0.052 gram as $\mathrm{CO}_{2}$. From the point of view of energy utilization, "acrobiosis" and "anaerobiosis" mean simply the liberation of energy by free oxygen or by an intramolecular rearrangement.

The transformation of urea into ammonium carbonate is a purely hydrolytic process, which yields a small amount of energy. ${ }^{61}$

$$
\mathrm{NH}_{2} \cdot \mathrm{CO} \cdot \mathrm{NH}_{2}+2 \mathrm{H}_{2} \mathrm{O}=\left(\mathrm{NH}_{4}\right)_{2} \mathrm{CO}_{3}+7 \mathrm{Cal} \text {. }
$$

Efficiency of energy utilization by heterotrophic microorganisms. When the various microorganisms are compared in the amount of nutrients transformed and in the synthesis of cellular material, fungi are found to consume, under favorable conditions, $1 \frac{1}{2}$ to 2 times as much nutrient as is necessary for the building of the cells. Raulin, ${ }^{62}$ for example, found that $A$. niger will synthesize 1 gram of mycelium for every 2.30 grams of sugar decomposed, i.e., the coefficient of utilization of sugar by this organism was 44 per cent. According to Wehmer, ${ }^{63}$ the growth of $A$. niger (weight of mycelium) is parallel to the energy value of the nutrient. This is clearly illustrated in table $27 .{ }^{64}$ Peptone is the exception. This is probably due to the fact that a large part of the energy was left unutilized in the form of protein-split products. Terroine $^{65}$ has also shown that while $100 \mathrm{Cal}$. in the form of glucose will

${ }^{60}$ Aubel, E. Sur l'origine de l'énergie permettant au Bacterium coli, de se développer aux dépens du glucose. Compt. Rend. Acad. Sci., 181: 571-573. 1925.

${ }^{61}$ Berthelot, M., and Petit, P. Sur la chaleur animale et sur les chaleurs de formation et de combustion de l'urée. Ann. chim. Phys. (6), 20: 13-20. 1890.

${ }^{62}$ Raulin, J. Êtudes chimiques sur la végétation. Ann. Sci. Nat. Bot. (5), 11: 93.1869 .

${ }^{83}$ Wehmer, C. Entstehung und physiologische Bedeutung der Oxalsïure im Stoffwechsel einiger Pilze. Bot. Ztg., 41: 337. 1891.

${ }^{64}$ Kruse, 1910 (p. xii).

${ }_{65}$ Terroine, Bonnet, Jacquot, and Vincent. 1923-1924 (p. 410). Bull. Soc. Chim. Biol., 7: 351-379. 1925; Terroine, E. F., and Wurmser, P. L'utilisation des substances ternaires dans la croissances de l'Aspergillus niger. Compt. Rend. Acad. Sci., 174: 1435-7. 1922; 175: 228-230. 
allow the synthesis of 58 Cal. of fungus mycelium, 100 Cal. in the form of protein will allow the synthesis of only $39 \mathrm{Cal}$. of fungus mycelium. There is also a large loss of energy in the process of deaminization.

Fungi generally waste (give out) about as much energy as they assimilate in their bodies. Under unfavorable conditions, the amount of energy assimilated by the body is much smaller in comparison with that utilized. The coefficient of utilization was found to decrease with age of culture, due to the fact that, after the nutrients have been used up, the cells of the organism begin to undergo autolysis and its constituents are used as sources of energy

Terroine and Wurmser determined, for Asp. niger, "the utilization quotient" of sugars by comparing the dry weight of the mycelium produced with the weight of the sugar consumed. It was found to be

TABLE 27

Influence of energy source upon the growth of fungi

\begin{tabular}{|c|c|c|}
\hline SOURCE OF ENERGY & $\begin{array}{c}\text { ENERGY } \\
\text { EQUIVALENT OF } \\
1.5 \text { GRAMS } \\
\text { OF MATERIAL }\end{array}$ & FUNGUS MYCELIUM \\
\hline & calories & gram \\
\hline Tartaric acid $\ldots \ldots \ldots \ldots \ldots \ldots \ldots \ldots \ldots \ldots \ldots \ldots$ & 2.6 & 0.155 \\
\hline Citric acid $\ldots \ldots \ldots \ldots \ldots \ldots \ldots \ldots \ldots \ldots \ldots \ldots \ldots \ldots$ & 3.7 & 0.240 \\
\hline 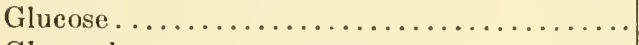 & 5.6 & 0.278 \\
\hline 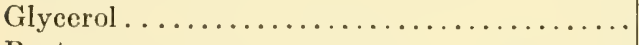 & 6.5 & 0.475 \\
\hline 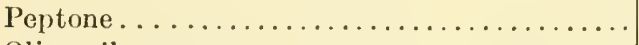 & 6.8 & 0.162 \\
\hline 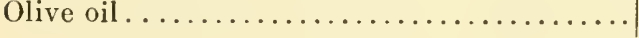 & 14.0 & 0.810 \\
\hline
\end{tabular}

43 to 44 per cent for glucose, levulose, saccharose, maltose, arabinose xylose. The concentration of the nitrogenous substance, varying from 0.5 to 4 per cent, does not influence the quotient of utilization, which was found to be lower with sodium and aluminum nitrate as a source of nitrogen ( 0.34 to 0.35 ) than with ammonium sulfate or nitrate, urea or guanidine (0.42). The addition of sulfuric acid to the sodium nitrate medium resulted in an increase in the quotient. The utilization of an energy source by $A$. niger was calculated as follows.

The heat of combustion of mycelium was 4.8 Cal. per gram and that of glueose $3.76 \mathrm{Cal}$. The energy utilization is, therefore, (44 parts of myeelium $\times 4.8$ ) $\div(100$ parts of sugar $\times 3.76)=56$ per cent. The combustion of glucose in the culture medium was, however, not complete. A combustion of the medium, made before and after the cultivation of $A$. niger, gave 6.46 and 0.51 respectively. The difference of these figures, 5.95, represents the metabolizable energy $U$ for 
the particular culture. The mycelium from this eulture gave on combustion $3.55 \mathrm{Cal}$. $=U^{\prime}$. The ratio of the energy stored in the mycelium to the metabolizable energy $U$ is thus found to be $3.55 \div 5.95=59.6$ per cent, or very near the above figure, caleulated from other data.

When fully developed mycelium is placed in Czapek's solution, it does not grow further but forms $\mathrm{CO}_{2}$; this permits the calculation of a minimum value for maintenance energy. The consumption of glucose by Asp. niger is at any instant the sum of two terms: (1) a term proportional to the rate of growth, which represents the amount of glucose which should disappear to form the substance of the mycelium

TABLE 28

Relation of metabolic products of fungi to one another and to sugar consumed (pentoses)

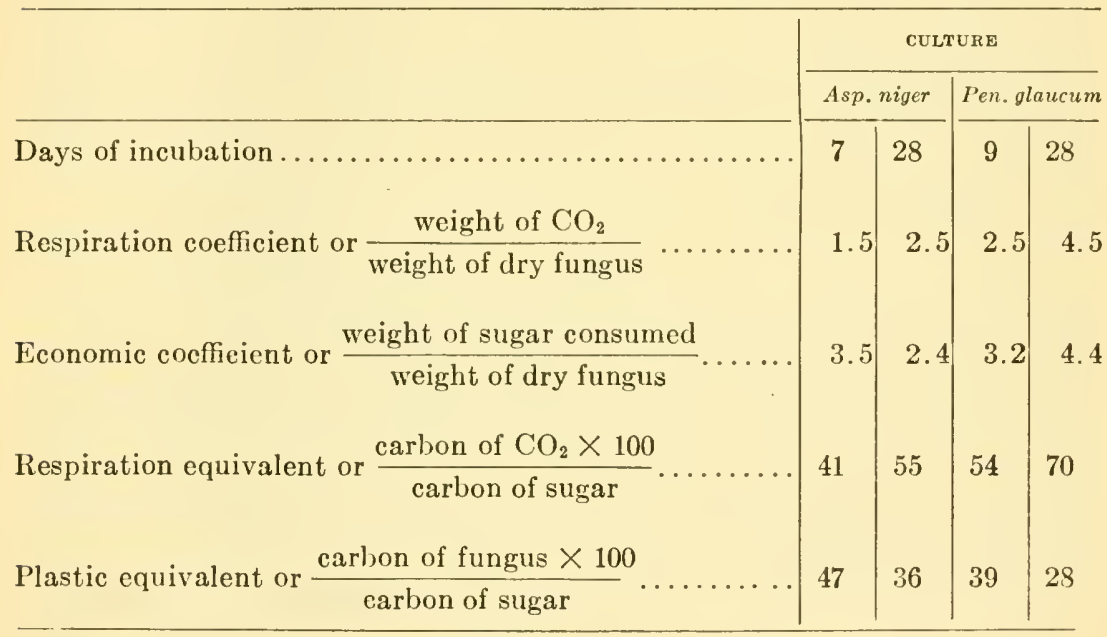

and (2) a term proportional to the weight of mycelium already formed at that instant, which represents the consumption of sugar for maintenance. ${ }^{66}$

There is a definite relation between utilization of sugar, growth of fungi and evolution of $\mathrm{CO}_{2}$, as shown in table $28 .{ }^{67}$ The "economic

${ }^{66}$ Further information on energy utilization by fungi and yeasts, in the absence of an excess of oxygen, is given by Kostytsehew, S., and Afanasjeva, M. Die Verarbeitung verschiedener organiseher Verbindungen durch Schimmelpilze bei Sauerstoffmangel. Jahrb. wiss. Bot., 60:628-650. 1921; Rona, P., and Grassheim, K. Studien zur Zellatmung. I. Beitrïge zur Atmung der Hefezcllen. Biochem. Ztschr., 134: 146-162. 1922; Meyerhof, 1925 (p. 413).

${ }^{87}$ Peterson, Fred and Schmidt, 1922 (p. 242). 
coefficient" of storage-rot fungi was found ${ }^{68}$ to vary from 3.86 to 22.86 , while the respiration coefficient varied from 2.9 to 11.4. The respiration of thermophilic fungi is less than that of common fungi. Penicillium sp. produces at $15^{\circ}$ in 24 hours enough $\mathrm{CO}_{2}$ to correspond to 67 per cent of dry weight; at $25^{\circ}, 133$ per cent. By applying the van't Hoff formula for the temperature coefficient, Noack ${ }^{69}$ calculated that, at $45^{\circ}, 532$ per cent $\mathrm{CO}_{2}$ would be produced by Penicillium, while the thermophilic Thermoascus produced only 310 per cent $\mathrm{CO}_{2}$ at $45^{\circ}$. The temperature quotient is 1.7-1.9 for $10^{\circ}$ temperature difference for Thermoascus and 2-3 for common fungi. ${ }^{70}$

Bacteria utilize for synthetic purposes a smaller amount of the energy made available than do fungi. The utilization is largest with aerobic bacteria. This is further accentuated by the fact that bacteria usually form a larger quantity of intermediary products than fungi. The energy utilization by the various bacteria depends upon the nature of the organism and mechanism of decomposition of substrate, ranging from 37 to 38 per cent of the energy made available in the case of $\mathrm{Bac}$. subtilis and aerobic yeasts to only 0.5 to 7.0 per cent of the energy for urea, acetic, and nitrite bacteria. The lower the relative amount of energy made available the greater is the transformation of matter and energy for the same amount of cell-protoplasm synthesized. The fact that heterotrophic bacteria are capable of synthesizing a large part of the cell constituents by merely assimilating the constituents of the substrate without producing much work, while the urea and autotrophic bacteria have to do work, also explains the lower energy utilization and, therefore, the larger amount of matter and energy transformation in the case of the last group.

Arnaud and Charrin ${ }^{71}$ cultivated Bact. pyocyaneum on a medium

${ }^{68}$ Harter, L. L., and Weimer, J. L. Respiration of sweet potato storage rot fungi when grown on a nutrient solution. Jour. Agr. Res., 21: 211-226. 1921.

${ }^{69}$ Noack, K. Der Betriebstoffwochsel der thermophilen Pilze. Jahrb. wiss. Bot., 59: 413-466. 1920.

${ }^{70}$ Further information on the influence of temperature upon life processes is given by Kanitz, A. Temperature und Lebensvorgänge. Borntraeger. Berlin. 1915; Arrhenius, S. Quantitative laws in physical chemistry, 1915; Crozier, W. J., On biological oxidations as function of temperature. Jour. Gen. Physiol., 7: 189-216. 1924.

${ }^{71}$ Arnaud, A., and Charrin, A. Recherches chimiques sur les secrétions microbiennes. Compt. Rend. Acad. Sci., 112: 755-758, 1157-1160. 1891. 
containing 0.5 per cent asparagine, as a source of carbon and nitrogen. These two elements were accounted for as follows:

\begin{tabular}{|c|c|c|}
\hline & CARBON & NITROGEN \\
\hline & per cent & percent \\
\hline Assimilated by the bacteria........ & 13.8 & 4.66 \\
\hline Given off as $\mathrm{CO}_{2}$ or $\mathrm{NH}_{3} \ldots \ldots \ldots \ldots \ldots$ & 72.5 & 91.0 \\
\hline 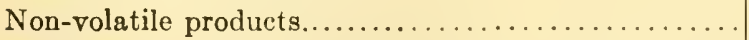 & 13.5 & 4.04 \\
\hline
\end{tabular}

Kruse calculated from these data that 19 per cent of the energy that was made available from the decomposition of the asparagine had been utilized by the bacteria for the synthesis of bacterial protoplasm. According to Rubner, ${ }^{72}$ the relative energy utilization of bacteria is independent of temperature. The total amount of energy transformed depends, however, largely on the temperature of growth, as shown in table 29. The clata were obtained by growing Bact. vulgare in 500 cc. portions of 6 per cent meat extract solution. Rubner found that aerobic bacteria are capable of utilizing 30.8 to 11.6 per cent of the energy transformed, pathogenic bacteria the least. The thermophilic bacteria utilized 24.9 per cent of the energy.

Linhart ${ }^{73}$ calculated that only about 1 per cent of the total available energy in mannite is utilized by Azotobacter for the fixation of nitrogen. This was based upon the assumption that Azotobacter fixes 10 grams of nitrogen for every gram of mannite decomposed and that all the mannite is converted into $\mathrm{CO}_{2}$. No allowance was made for the formation of intermediary products or the synthesis of microbial protoplasm.

When amino acids are used as sources of energy, the process of synthesizing microbial protoplasm is a very economical one in which little energy is wasted. This is true for fungi ${ }^{74}$ and bacteria. Bact. coli was found ${ }^{75}$ to be able to utilize the energy of amino acids three to eight times more effectively than that of glucose. According to Czapek

72 Rubner, M. Energieverbrauch im Leben der Mikroorganismen. Arch. Hyg., 48: 260-311. 1903; Die Beziehungen zwischen Bakterienwachstum und Konzentration der Nahrung (Stickstoff und Schwefelumsatz). Ibid., 57: 161192. 1906; Energieumsatz im Leben einiger Spaltpilze. Ibid., 57: 193-243.

${ }^{73}$ Linhart, G. A. The free energy of biological processes. Jour. Gen. Physiol., 2: 247-251. 1920.

74 Czapek, 1902 (p. 502).

${ }^{75}$ Shearer, C. On the amount of heat liberated by $B$. coli when grown in the presence of free amino acids. Jour. Physiol., 55: 50-60. 1921. 
this may be due to the direct assimilation of the amino acids for the synthesis of microbial protoplasm.

In summarizing the energy utilization by different groups of microorganisms, it may be said that fungi transform usually 30 to 60 per cent of the substrate into mycelium, aerobic bacteria 10 to 20 per cent, while anaerobic bacteria may transform only 1 per cent or less of the nutrients into synthesized cells.

Reduction of nitrates and sulfates and energy utilization. In addition to respiration by the agency of free oxygen (autotrophic and heterotrophic) and intramolecular respiration or "fermentation," there is another form of respiration whereby the oxygen in certain inorganic compounds, namely nitrates and sulfates, is utilized. Just as the oxidation phenomena are accompanied by the liberation of

TABLE 29

Infuence of temperature upon growth and energy utilization of Bact. vulgare

\begin{tabular}{|c|c|c|c|c|c|c|c|c|}
\hline \multirow{2}{*}{$\begin{array}{l}\text { INCUBA- } \\
\text { TION }\end{array}$} & \multirow{2}{*}{$\begin{array}{l}\text { TEMPER- } \\
\text { ATURE }\end{array}$} & \multirow{2}{*}{$\begin{array}{c}\text { NITROGEN } \\
\text { CONTENT OF } \\
\text { BACTERIAL } \\
\text { GROWTH }\end{array}$} & \multirow{2}{*}{$\begin{array}{l}\text { CALORIFIC } \\
\text { VALUE OF } \\
\text { DRY CELLS }\end{array}$} & \multicolumn{2}{|c|}{ ENERGY OF MEDIUM } & \multirow{2}{*}{$\begin{array}{l}\text { METABO- } \\
\text { LIZABLE } \\
\text { FNERGY }\end{array}$} & \multirow{2}{*}{$\begin{array}{l}\text { TOTAL } \\
\text { ENERGYY } \\
\text { TRANS- } \\
\text { FORMED }\end{array}$} & \multirow{2}{*}{$\begin{array}{l}\text { ENERGY } \\
\text { UTILIZA- } \\
\text { TION }\end{array}$} \\
\hline & & & & $\begin{array}{l}\text { Before } \\
\text { growth }\end{array}$ & $\begin{array}{c}\text { After } \\
\text { growth }\end{array}$ & & & \\
\hline days & $C^{\circ}$ & gram & & & & & & per cent \\
\hline 7 & 36.0 & 0.135 & 4.00 & 84.22 & 69.28 & 14.94 & 18.94 & 21.2 \\
\hline 14 & 14.5 & 0.037 & 1.72 & 84.22 & 79.32 & 4.90 & 6.62 & 25.9 \\
\hline 21 & 14.5 & 0.032 & 1.44 & 84.22 & 78.38 & 5.84 & 7.28 & 19.9 \\
\hline 30 & 14.5 & 0.045 & 2.06 & $\$ 4.22$ & 77.73 & 6.49 & 8.55 & 24.1 \\
\hline 37 & 14.5 & 0.067 & 2.82 & 84.22 & 72.44 & 11.78 & 14.60 & 20.5 \\
\hline
\end{tabular}

energy, so are the reduction phenomena accompanied by the consumption of energy. This energy is, however, returned even to a greater extent in the accompanying oxidation. The oxygen rich compounds are reduced and the oxygen is utilized for the oxidation of other substances, the latter process supplying the energy for the former. Nitrification, which is an oxidation process, is accompanied by the reduction of $\mathrm{CO}_{2}$, which is used as a source of carbon; denitrification, which is a reduction process, is accompanied by oxidation phenomena (oxidation of carbohydrates, etc.), in which the combined oxygen is used to produce energy.

The oxygen obtained from the nitrate or the sulfate is utilized for the oxidation of carbohydrates, organic acids or certain inorganic substances. This may be accomplished by one organism, as in the case of the denitrifying sulfur-oxidizing organism, or by the symbiotic 
action of two organisms, as in the case of cellulose oxidation and denitrification. ${ }^{76}$ Trautwein $^{77}$ pointed out that Thiob. denitrificans, which oxidizes thiosulfate aerobically, can carry on this process in the absence of atmospheric oxygen but in the presence of nitrates. When tartaric acid is oxidized by atmospheric oxygen or by reduction of nitrates, nearly equal amounts of energy are liberated, since the reduction of nitrates to atmospheric nitrogen does not consume a large amount of energy.

$$
\begin{aligned}
& \mathrm{C}_{4} \mathrm{H}_{6} \mathrm{O}_{6}+2 \frac{1}{2}\left(\mathrm{O}_{2}\right)=4 \mathrm{CO}_{2}+3 \mathrm{H}_{2} \mathrm{O}+282 \mathrm{Cal} . \\
& \text { Tartaric acid } \\
& \quad \mathrm{C}_{4} \mathrm{H}_{6} \mathrm{O}_{6}+2 \mathrm{HNO}_{3}=4 \mathrm{CO}_{2}+4 \mathrm{H}_{2} \mathrm{O}+\mathrm{N}_{2}+253.4 \text { Cal. }
\end{aligned}
$$

Attention should also be called to the reduction of nitrate in the assimilation of nitrate by the chlorophyll-bearing algae ${ }^{78}$ and to the rôle of nitrate as hydrogen acceptor in the growth of certain anaerobic bacteria. The first is carried through the following series of reactions:

$$
\begin{aligned}
& \mathrm{NO}_{3}^{-}+\mathrm{H}_{2} \mathrm{O}+2 \mathrm{H}^{+}=\mathrm{NH}_{4}^{+}+2 \mathrm{O}_{2}-68 \mathrm{Cal} . \\
& 2 \mathrm{O}_{2}+2 \mathrm{C}=2 \mathrm{CO}_{2}+230 \mathrm{Cal} .
\end{aligned}
$$

or

$$
\mathrm{NO}_{3}^{-}+\mathrm{H}_{2} \mathrm{O}+2 \mathrm{H}^{+}+2 \mathrm{C}=\mathrm{NH}_{4}^{+}+2 \mathrm{CO}_{2}+162 \mathrm{Cal} \text {. of free energy }
$$

Out of a total of 230 Cal. liberated, only 68 Cal. or about 30 per cent is utilized for the reduction of the nitrate. The question of nitrate reduction by bacteria will be discussed in detail elsewhere (p. 545). ${ }^{79}$

The reduction of sulfate to sulfide requires a large expenditure of energy and accounts for the distinct difference in energy gain when oxidation takes place by means of atmospheric oxygen or when the oxygen is derived from the reduction of sulfates.

$$
\begin{aligned}
& \mathrm{H}_{2} \mathrm{SO}_{4}=\mathrm{H}_{2} \mathrm{~S}+2 \mathrm{O}_{2}-135 \mathrm{Cal} \text {. } \\
& 2 \mathrm{C}_{3} \mathrm{H}_{6} \mathrm{O}_{3}+6 \mathrm{O}_{2}=6 \mathrm{CO}_{2}+6 \mathrm{H}_{2} \mathrm{O}+659 \mathrm{Cal} . \\
& \text { lactic acid } \\
& 2 \mathrm{C}_{3} \mathrm{H}_{6} \mathrm{O}_{3}+3 \mathrm{H}_{2} \mathrm{SO}_{4}=6 \mathrm{CO}_{2}+6 \mathrm{H}_{2} \mathrm{O}+3 \mathrm{H}_{2} \mathrm{~S}+254 \mathrm{Cal} .
\end{aligned}
$$

${ }^{76}$ Groenewege, 1920 (p. 200).

77 Trautwein, 1921 (p. 87).

${ }_{78}$ Warburg, O., and Negelein, E. Über den Energieumsatz bei der Kohlensäureassimilation. Ztschr. physik. Chem., 102: 235-266. 1922.

${ }^{79}$ Jensen, Orla. Die Hauptlinien des natürlichen Bakteriensystems. Centrbl. Bakt. II, 22: 97-98, 305-346. 1909. 
The amount of energy thus liberated is only about 38 per cent of the energy liberated in oxidation of lactic acid by free oxygen.

Comparative amounts of energy liberated in microbiological processes. The different nutrients develop the following number of calories as listed here. The final products, when not $\mathrm{CO}_{2}$, are given in parenthesis.

I. Oxidation by means of free oxygen (Kruse)

\begin{tabular}{|c|c|c|}
\hline & $\begin{array}{l}1 \text { ORAM OF } \\
\text { NUTRIENT }\end{array}$ & $\begin{array}{l}1 \text { MOL. OF } \\
\text { NUTRIENT }\end{array}$ \\
\hline & Calories & C'alories \\
\hline Nitrous acid (nitric acid) $\ldots \ldots \ldots \ldots \ldots \ldots \ldots$ & 0.4 & \\
\hline 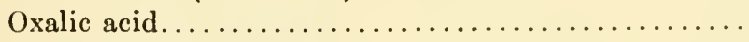 & 0.68 & 61.0 \\
\hline Glucose (to citric acid) $\ldots \ldots \ldots \ldots \ldots \ldots \ldots \ldots \ldots$ & 1.4 & \\
\hline 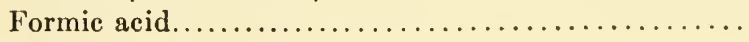 & 1.37 & 62.9 \\
\hline 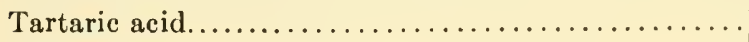 & 1.88 & 280.0 \\
\hline 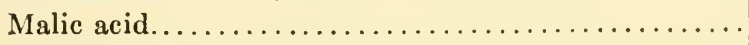 & 2.39 & 320.0 \\
\hline 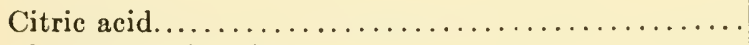 & 2.48 & 475.0 \\
\hline 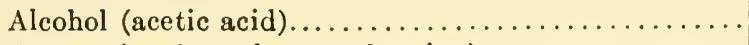 & 2.5 & \\
\hline 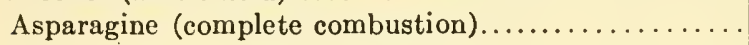 & 3.51 & 464.1 \\
\hline 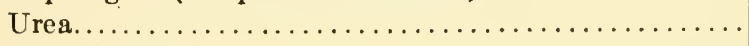 & 2.54 & 153.0 \\
\hline 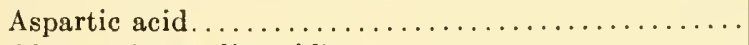 & 2.90 & 386.0 \\
\hline 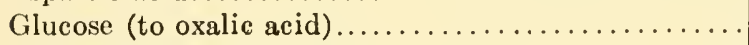 & 2.8 & \\
\hline 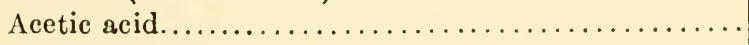 & 3.49 & 209.6 \\
\hline 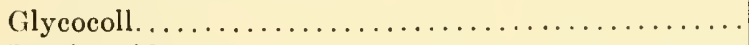 & 3.13 & 235.0 \\
\hline 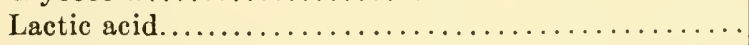 & 3.66 & 326.0 \\
\hline 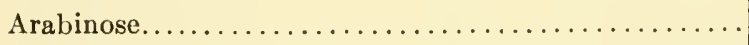 & 3.72 & 588.0 \\
\hline 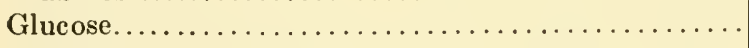 & 3.74 & 674.0 \\
\hline 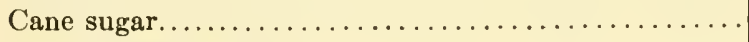 & 3.96 & $1,354.0$ \\
\hline 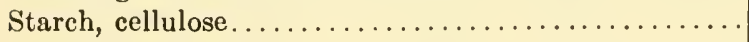 & 4.18 & \\
\hline 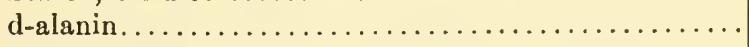 & 4.37 & 388.0 \\
\hline 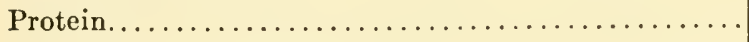 & $4.5-5.0$ & \\
\hline Ammonia (to nitrous acid) $\ldots \ldots \ldots \ldots \ldots \ldots \ldots$ & 4.6 & \\
\hline 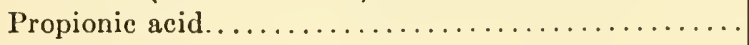 & 4.96 & 367.0 \\
\hline 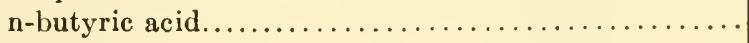 & 5.96 & 525.0 \\
\hline 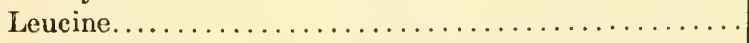 & 6.53 & 856.0 \\
\hline 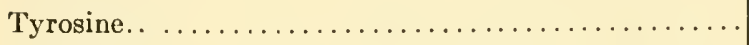 & 5.92 & $1,072.0$ \\
\hline 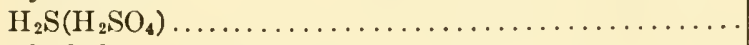 & 6.4 & \\
\hline 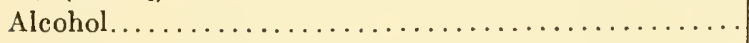 & 7.1 & \\
\hline 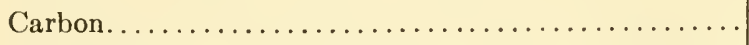 & 8.0 & \\
\hline 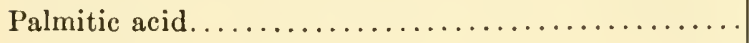 & 9.2 & \\
\hline 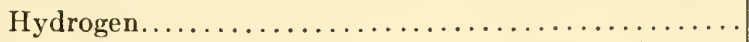 & 34.6 & \\
\hline
\end{tabular}

II. Oxidation by means of oxygen from oxygen-rich compounds (Kruse)

\begin{tabular}{l|l|l}
\hline Tartaric acid by means of denitrifying bacteria.................. & 1.6
\end{tabular}

Lactic acid by means of Spir. desulfuricans.......... 1.0 
III. Intramolecular respiration "fermentation"

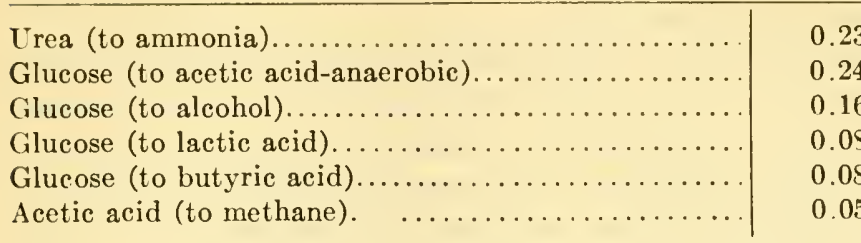

Energy transformation in synthetic processes. The energy transformation in the synthetic action of microorganisms depends upon the nature of the organism and of the substances present as nutrients. The autotrophic bacteria and algae build up their carbohydrates from the $\mathrm{CO}_{2}$; this phenomenon is one of reduction and involves, therefore, a great expenditure of energy.

$$
6 \mathrm{CO}_{2}+6 \mathrm{H}_{2} \mathrm{O}=\mathrm{C}_{6} \mathrm{H}_{12} \mathrm{O}_{6}+6 \mathrm{O}_{2}-676 \mathrm{Cal} .
$$

This energy is obtained from the oxidation of ammonia, nitrous acid, thiosulfate, sulfur, etc. (and, in the case of algae, photosynthetically). Because of the large amount of energy required for synthetic purposes and since work in the true sense is to be produced, large quantities of these substances have to be oxidized.

When carbohydrates are synthesized from organic compounds or, in general, when an organism grows in a medium containing organic substances as sources of energy, much less energy is consumed in the synthesis of the protoplasm, as seen by reversing several of the above reactions.

$$
\begin{aligned}
& 3 \mathrm{C}_{2} \mathrm{H}_{4} \mathrm{O}_{2}=\mathrm{C}_{6} \mathrm{H}_{12} \mathrm{O}_{6}-44 \mathrm{Cal} . \\
& 2 \mathrm{C}_{3} \mathrm{H}_{6} \mathrm{O}_{3}=\mathrm{C}_{6} \mathrm{H}_{12} \mathrm{O}_{6}-28 \mathrm{Cal} .
\end{aligned}
$$

The energy required in this case is obtained by aerobic microorganisms from oxidation processes and by anaerobic bacteria by means of "fermentations" or reactions of oxidation-reduction. The production of polysaccharides from the monosaccharide requires only a small expenditure of energy.

$$
\begin{aligned}
& 2 \mathrm{C}_{6} \mathrm{H}_{12} \mathrm{O}_{6}-\mathrm{H}_{2} \mathrm{O}=\mathrm{C}_{12} \mathrm{H}_{22} \mathrm{O}_{11}-3.3 \mathrm{Cal} . \\
& n\left(\mathrm{C}_{6} \mathrm{H}_{12} \mathrm{O}_{6}\right)-\mathrm{H}_{2} \mathrm{O}=\left(\mathrm{C}_{6} \mathrm{H}_{10} \mathrm{O}_{3}\right) n-(4.3 \mathrm{Cal} .) n
\end{aligned}
$$

The building up of fats from carbohydrates or glycerol is a reduction phenomenon, it involves work in the thermodynamic sense and requires a large expenditure of energy. This can, therefore, take 
place only when accompanied by active oxidation whereby a large amount of energy is made available.

In the synthesis of protein compounds by microorganisms, nitrates are first reduced to ammonia and, if proteins or amino acids form the nitrogen source, they are hydrolized to ammonia and the corresponding oxy-acids. The combination of the ammonia with the various oxyacids, either synthesized by the autotrophic organisms from $\mathrm{CO}_{2}$ or produced by the heterotrophic organisms from the complex organic substances in the medium, results in the formation of amino acids, from which the microbial proteins can be formed:

$$
\underset{\text { Propionic acid }}{\mathrm{C}_{3} \mathrm{H}_{6} \mathrm{O}_{2}}+\mathrm{NH}_{3}=\mathrm{C}_{3} \mathrm{H}_{7} \mathrm{NO}_{2}+\mathrm{H}_{2} .
$$

The propionic acid is derived from lactic acid or from glucose, so that glucose and ammonia can be used directly for the synthesis of alanine: $:^{80}$

$$
\begin{aligned}
& \mathrm{C}_{6} \mathrm{H}_{12} \mathrm{O}_{6}+2 \mathrm{NH}_{3}=2 \mathrm{C}_{3} \mathrm{H}_{7} \mathrm{NO}_{2}+2 \mathrm{H}_{2} \mathrm{O}+63 \text { Cal. } \\
& \text { Alanine } \\
& \mathrm{C}_{6} \mathrm{H}_{12} \mathrm{O}_{6}+\mathrm{NH}_{3}=\mathrm{C}_{6} \mathrm{H}_{13} \mathrm{NO}_{2}+\mathrm{H}_{2} \mathrm{O}+3 \mathrm{O}-101 \mathrm{Cal} \text {. } \\
& \text { Leucine } \\
& \mathrm{C}_{6} \mathrm{H}_{12} \mathrm{O}_{6}+3 \mathrm{NH}_{3}=\underset{\text { Glycocoll }}{3 \mathrm{C}_{2} \mathrm{H}_{5} \mathrm{NO}_{2}+3 \mathrm{H}_{2}+11 \text { Cal. }} \\
& 2 \mathrm{C}_{6} \mathrm{H}_{12} \mathrm{O}_{6}+3 \mathrm{NH}_{3}=3 \mathrm{C}_{4} \mathrm{H}_{7} \mathrm{NO}_{4}+6 \mathrm{H}_{2}+31 \mathrm{Cal} \text {. } \\
& \text { Asparagine }
\end{aligned}
$$

When proteins or amino acids form the only sources of both carbon and nitrogen, the oxy-acids produced from the amino acids may be utilized for the building of the protein molecule. ${ }^{81}$ In the case of carbohydrates, pyruvic acid and acetaldehyde are important substances in the synthesizing activities of microorganisms (Neuberg).

Once the amino acids are synthesized, the protein molecule is formed from them by the union of a carboxyl and an amino group with the elimination of a molecule of water. The amount of energy required is much smaller in comparison with that necessary for the synthesis of the amino acids. ${ }^{82}$

${ }^{80}$ Kruse, 1910 (p. xii).

${ }^{81}$ Czapek, 1902 (p. 502).

82 Further information on the transformation of energy in synthetic processes is given by Nathanson, A. Úber kapillarelektrische Vorgänge in der lebenden Zelle. Kolloid-chem. Beihefte., 11: H. 10-12. 1919. 
Energy transformation in the soil. The microbiological processes in the soil can be considered from the point of view of energy transformation, ${ }^{83}$ by determining the calorific value of the organic matter present in the soil. When organic matter is added to the soil, in the form of manures, green manures, plant stubble, etc., a certain amount of potential energy is introduced. A part of this is liberated as heat and dissipated into space as a result of the activities of microorganisms, a part is stored in the microbial cells, and a part is left in the form of undecomposed organic matter or various intermediary products. The energy stored away in the microbial cells and that left in the undecomposed or partially decomposed organic matter go to increase the energy content of the soil. This energy is only gradually liberated as a result of the activities of microorganisms.

TABLE 30

Relation between $\mathrm{CO}_{2}$ and energy liberation in some typical microbiological processes

\begin{tabular}{|c|c|c|}
\hline 1 GRAM OF $\mathrm{CO}_{2}$ LIBERATES IN & CALORIES & RATIO \\
\hline Butyric acid "fermentation"..... & 0.29 & 1 \\
\hline Oxidation of sugar to oxalic acid.... & 0.69 & 2.3 \\
\hline Complete oxidation of sugar ....... & 2.55 & 8.5 \\
\hline Alcoholic "fermentation" ............. & 3.71 & 12.3 \\
\hline Methane fermentation ............... & 4.80 & 16.5 \\
\hline
\end{tabular}

The calorific value of the soil organic matter represents the minimum energy available for the activities of microorganisms, since the autotrophic bacteria can obtain their energy also from inorganic substances in the soil.

Since the organic matter added to the soil has a calorific value of 4.6 to 5.0 Cal. per gram, the addition of 3 tons of dry ash-free organic matter, in the form of manure or green manure, per acre of soil, introduces 13,000,000 Cal. available for the activities of microorganisms. Considering the average content of organic matter in the soil as 2 to 3 per cent, the potential energy available in one acre of soil (12 inches deep) is about 200,000,000 Cal., equivalent to about twenty-four tons of anthracite coal. The freshly introduced organic matter begins to decompose immediately in the soil, at first rapidly, then more and more slowly, until a certain equilibrium is established, as shown by the

${ }^{83}$ van Suchtelen, F. H. H. Energetic und die Mikrobiologie des Bodens. Centrbl. Bakt. II, 58: 413-430. 1923. 
evolution of carbon dioxicle. A part of the energy is stored away in the cells of the microorganisms, while a larger part is dispersed into space.

The amount of $\mathrm{CO}_{2}$ produced from the soil, as well as in an artificial culture, can be used as an index of the activities of soil microorganisms. There is no close correlation, however, between the amount of $\mathrm{CO}_{2}$ formed and the energy liberated by microorganisms, since energy may be liberated without the production of $\mathrm{CO}_{2}$ (oxidationreduction processes) and $\mathrm{CO}_{2}$ may be formed as a result of chemical interaction between acids and carbonates, without energy liberation. Different microorganisms bring about different reactions, each of which involves a different transformation of energy. The different amounts of energy liberated in different microbiological reactions are given in table $30 .{ }^{83}$

The production of heat serves as a more reliable index of the energy transformation by microorganisms, since the latter are chiefly responsible for the exothermic processes in the soil. However, most of our information on the decomposition of organic matter in the soil is limited to the determination of $\mathrm{CO}_{2}$ as an index, as shown elsewhere (p. 681). 


\section{CHAPTER XVII}

\section{Chemistry of Decomposition of Non-nitrogenous Organic Matter By SoIl Microorganisus}

Composition of vegetable organic matter. Vegetable organic matter is added to the soil in the form of green manure, stable manure, plant residues and roots of cultivated and wild plants. This organic matter consists largely of celluloses, hemicelluloses and pentosans, starches and other complex carbohydrates; lignins and compounds of these with carbohydrates; simple carbohydrates; complex proteins, protein degradation products and purine bases; fats, waxes, glucosides, tannins, pigments and mineral matter. A typical analysis of a series of native vegetable substances is given in table 31 , in per cent of water-free substance. ${ }^{1}$

However, the composition of the organic materials varies with the degree of ripening of the plant, as shown ${ }^{2}$ in table 32 for oat straw. A decrease in nitrogen content and an increase in content of lignocelluloses depresses the rapidity of decomposition of the plant materials in the soil, as shown later (p. 459). The elementary composition of some typical plant products, on the basis of several analyses is given in tables 33 and 34 .

The difference in analysis reported by different investigators is due to differences in the plant varieties, in the composition of the soil, age of plant, error of manipulation, etc.

Chemistry of celluloses. The constituents of cell membranes can be generally classified into five groups: $:^{3,4}$

1. True celluloses, or the condensation products of glucose, not acted upon by dilute acids.

${ }^{1}$ Pringsheim, H. Die Polysaccharide. 2nd Ed. 1923, Berlin.

${ }^{2}$ Berry, R. A. Composition and properties of oat grain and straw. Jour. Agr. Sci., 10: 358. 1920.

${ }_{3}^{3}$ Tollens, B. Über Cellulose, Oxycellulose, Hydrocellulose, die Pektinkörper, sowie Traganth. Ber. deut. chem. Gesell., 34: 1434-1441. 1901.

${ }^{4}$ Heuser, F. I ehrbuch der Cellulosechemie. 2 Aufl. Berlin, Borntraeger. 1923. 
TABLE 31

The composition of a few natural organic materials

\begin{tabular}{|c|c|c|c|c|c|c|}
\hline & $\begin{array}{c}\text { CELLU. } \\
\text { LOSE }\end{array}$ & $\begin{array}{l}\text { PENTO- } \\
\text { SANS }\end{array}$ & LIGNIN & $\begin{array}{c}\text { CRUDE } \\
\text { PROTEIN }\end{array}$ & $\begin{array}{l}\text { GUMS } \\
\text { AND } \\
\text { WAXES }\end{array}$ & $\mathrm{ASH}$ \\
\hline Hay ............. & 28.50 & 13.52 & 28.25 & 9.31 & 2.00 & 6.05 \\
\hline Oats straw.. & 35.43 & 21.33 & 20.40 & 4.70 & 2.02 & 4.81 \\
\hline Barley straw . . & 32.92 & 21.45 & 18.66 & 3.20 & 1.40 & 5.56 \\
\hline Corn cobs..... & 37.66 & 31.50 & 14.70 & 2.11 & 1.37 & 1.80 \\
\hline Corn fodder.... & 30.56 & 23.54 & 15.13 & 3.50 & 0.77 & 6.15 \\
\hline Rice straw . . . . . . . . & 31.99 & 27.67 & 18.48 & 5.33 & 0.51 & 5.43 \\
\hline Straw of winter cereals... & 34.27 & 21.67 & 21.21 & 3.00 & 0.67 & 4.33 \\
\hline
\end{tabular}

TABLE 32

Influence of age on the composition of oat straw

\begin{tabular}{|c|c|c|c|c|c|c|}
\hline & JUNE 7 & JUNE 21 & JULY 5 & JULY 19 & AUGUST 3 & AUOUST 16 \\
\hline Crude protein. & 16.5 & 10.6 & 7.0 & 4.7 & 2.8 & 1.4 \\
\hline Crude fiber....... & 14.1 & 21.6 & 24.7 & 24.7 & 24.8 & 28.3 \\
\hline Cellulose........ & 12.4 & 19.0 & 20.8 & 21.1 & 21.4 & 23.6 \\
\hline Total nitrogen. & $\ldots$ & $\ldots$ & $\ldots$ & 0.515 & $\ldots$ & 0.200 \\
\hline Ash . . . . . . . . & $\ldots$ & $\ldots$ & $\ldots$ & 5.5 & $\ldots$ & 6.6 \\
\hline $\mathrm{P}_{2} \mathrm{O}_{5} \ldots \ldots \ldots \ldots \ldots$ & $\cdots$ & $\cdots$ & $\cdots$ & 0.296 & $\cdots$ & 0.164 \\
\hline $\mathrm{K}_{2} \mathrm{O} \ldots \ldots \ldots \ldots \ldots$ & $\cdots$ & $\ldots$ & $\ldots$ & 1.03 & & 0.98 \\
\hline
\end{tabular}

TABLE 33

Elementary composition of a few plant products ${ }^{5}$

\begin{tabular}{|c|c|c|c|c|c|}
\hline & $\mathrm{C}$ & $\mathrm{H}$ & $\mathrm{N}$ & $\mathrm{O}$ & ASH \\
\hline Dry pine needles............ & 41.96 & 3.98 & 1.42 & 21.07 & 31.57 \\
\hline Oak leaves ................ & 49.11 & 6.12 & 1.71 & 29.38 & 13.68 \\
\hline Maple leaves........... & 44.61 & 5.01 & 1.89 & 29.18 & 19.31 \\
\hline Wheat straw . . . . & 47.01 & 5.66 & 0.82 & 38.61 & 7.90 \\
\hline Corn stover. . ......... & 43.30 & 5.75 & 1.69 & 37.58 & 11.68 \\
\hline Grain stubble and roots... & 32.81 & 4.62 & 1.63 & 28.82 & 32.12 \\
\hline Lupine................ & 44.12 & 6.03 & 3.19 & 33.67 & 12.99 \\
\hline Luzerne. . . . . . ........ & 43.28 & 5.86 & 1.95 & 38.54 & 10.37 \\
\hline Clover.................. & 44.31 & 5.91 & 2.98 & 36.01 & 10.29 \\
\hline
\end{tabular}

- Dvořák, J. Studien über die Stickstoffanäufung im Boden durch Mikroorganismen. Ztschr. landw. Vers. Sta. Oesterreich., 15: 1077-1121. 1912. 
2. Hemicelluloses, or the condensation products of hexoses (galactose, mannose) and of pentoses (arabinose, xylose), readily hydrolyzed by dilute mineral acids.

3. Pectins, different in composition, but related to the hemicelluloses. ${ }^{7}$

4. Lignins, forming complex physical, absorption compounds or mechanical incrustations with celluloses, known as ligno-celluloses, which constitute the woody tissues of plants. ${ }^{8}$

5 . Corky or cutinized lamellae, identified microscopically by the Sudanglycerol reaction and not well defined chemically.

The woody parts of plants or the plant cell membranes are usually referred to as "crude fiber." This is made up of cell walls composed principally of celluloses; they are accompanied by various other substances, depending upon the nature of the plant; even the carbon content of celluloses of different origin varies. ${ }^{9}$ This is probably due, not to differences in the constitution of the celluloses, but to the differences

TABLE 34

Mineral composition of a few plant products ${ }^{6}$

\begin{tabular}{|c|c|c|c|}
\hline & $\mathrm{N}$ & $\mathbf{P}$ & $\mathrm{K}$ \\
\hline 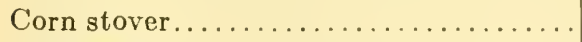 & 0.81 & 0.07 & 0.78 \\
\hline 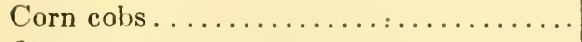 & 0.50 & 0.03 & 0.64 \\
\hline 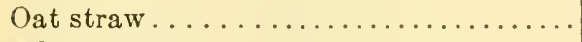 & 0.58 & 0.09 & 1.09 \\
\hline Wheat straw . . . . . . . . . . . . & 0.53 & 0.09 & 0.83 \\
\hline Clover hay . . . . . . . . . . . . . . & 2.17 & 0.18 & 1.12 \\
\hline Timothy hay . . . . . . . . . . . . . & 0.84 & 0.13 & 1.34 \\
\hline
\end{tabular}

in the amount and kind of impurities present. In the case of cotton, flax and hemp, pectin forms the chief impurity. In the case of straw, wood and jute, lignin is the impurity. This gave rise to the terms pecto-celluloses and lignocelluloses. Celluloses of different origin are decomposed with different rapidity, ${ }^{10}$ probably as a result of differences in the physical condition as well as impurities present.

${ }^{6}$ Thorne, C. E. Farm manures. O. Judd. New York. 1914.

${ }^{7}$ Ehrlich, F. Die Pektinstoffe, ihre Konstitution und Bedeutung. Chem. Ztg., 41: 197-200. 1917 .

${ }^{8}$ Riefenstahl, R. Der gegenwärtige Stand der Ligninchemie. Ztschr. angew. Chem., 37: 169-177. 1924.

${ }^{9}$ König, J. Bestimmung der Cellulose, des Lignins und Kutins in der Rohfaser. Z. Unters. Nahrungs u. Genussm., 12: 388. 1906; Ber. deut. chem. Gesell., 39: 3564-3570. 1906.

${ }^{10}$ Ernest, A. Beitrag zur Kenntnis einiger Cellulosen. Ber. deut. chem. Gesell., 39: 1947-1951. 1906. 
Chemically, the true celluloses are non-nitrogenous, amorphous polysaccharicles, exhibiting a characteristic fibrous structure. They are insoluble in simple solvents and soluble in ammoniacal copper solution, in $\mathrm{ZnCl}_{2}$ and strong acids $\left(\mathrm{H}_{2} \mathrm{SO}_{4}\right)$, giving a dark brown to violet color with chlor-zinc iodide. They are very resistant to the action of plants, animals and majority of microorganisms, but they can be hydrolized by strong acids and certain specific microorganisms. They occur only in a natural state (plant tissues) and have not as yet been synthesized in the laboratory. Cotton contains 87 to 91 per cent celulose; wood of evergreens, 60 per cent; and cereal straw, 35 per cent. The empirical formula for cellulose is that of polysaccharides, namely $\left(\mathrm{C}_{6} \mathrm{H}_{10} \mathrm{O}_{5}\right)_{n}$, the same as that of starch. It contains 44.42 per cent carbon and 6.22 per cent hydrogen. The ratio of oxygen to hydrogen is $8: 1$. On hydrolysis of cellulose, substances with an aldehyde (d-glucose united by cellobiose linkages) grouping are obtained.

Various formulae have been suggested to account for the chemical structure of the cellulose molecule. This is looked upon either as a polymerized molecule of cellobiose held together by strictly primary valencies or as a colloid molecule held together by secondary or residual valencies.

When hydrolyzed by means of acetic acid anhydride and sulfuric acid, the cellulose swells and gocs into solution in the form of a colloidal cellulose slime. On further hydrolysis, the disaccharide cellobiose is obtained (only about 36 per cent):

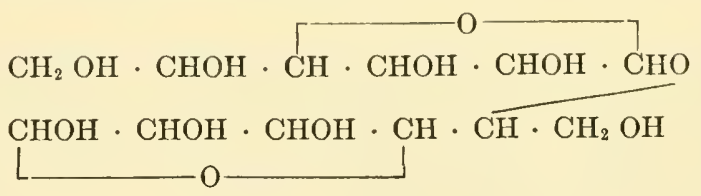

This consists of two molecules of d-glucose and differentiates cellulose from starch, which on hydrolysis gives first maltose, then glucose. ${ }^{11}$

$$
\begin{aligned}
& 2\left(\mathrm{C}_{6} \mathrm{H}_{10} \mathrm{O}_{5}\right)_{n}+n \mathrm{H}_{2} \mathrm{O}=n \mathrm{C}_{12} \mathrm{H}_{22} \mathrm{O}_{11} \\
& \mathrm{C}_{12} \mathrm{H}_{22} \mathrm{O}_{11}+\mathrm{H}_{2} \mathrm{O}=2 \mathrm{C}_{6} \mathrm{H}_{12} \mathrm{O}_{6} \\
& \text { cellobiose } \\
& \text { glucose }
\end{aligned}
$$

The existence of a reducing trisaccharide (procellose) as a possible intermediary product of hydrolysis between cellulose and cellobiose

"Skraup, Z. H., and König, J. Über Cellose, eine Biose aus Cellulose. Ber. deut. chem. Gesell., 34: 1115-1118. 1901. 
has been suggested.12 On hydrolysis, it gives a molecule of glucose and one of cellobiose, the latter breaking down to two molecules of glucose. ${ }^{13}$

In the earlier literature, especially on the transformation of plant materials in the composting of manure and in soil, the conception of cellulose has frequently been confused with that of "crude fiber." However, the two are not identical, and it is essential to know how to measure quantitatively the well defined chemical complex, namely, the cellulose. For this purpose, the method of Charpentier ${ }^{14}$ is most suitable.

Schweitzer's reagent is prepared by dissolving 200 grams $\mathrm{CuSO}_{4}$ in hot water, then precipitating with a calculated amount of ammonia (23 grams $\mathrm{NH}_{3}$ or $99 \mathrm{cc}$. of ammonia water, specific gravity 0.90 ). The excess of ammonia is neutralized with sulfuric acid. The precipitate is washed 3-4 times by decantation, then filtered on a Buchner funnel through a hardened filter paper. The hardened precipitate is dissolved in sufficient ammonia water (specific gravity 0.91 ), by shaking for 4 to 5 hours, so that $100 \mathrm{cc}$. of reagent contains 1.5 grams Cu $(5 \mathrm{cc}$. of reagent is evaporated over sulfuric acid under a bell-jar, dried and heated to constant weight and weighed as $\mathrm{CuO}$ ).

Twenty grams of soil previously treated with finely divided cellulose are placed in a cylinder of $150 \mathrm{ec}$. capacity with $100 \mathrm{cc}$. of the Schweitzer reagent. The cylinder is closed and shaken, in a special shaking machine, for 30 minutes: the suspension is then allowed to settle. The solution is filtered through asbestos in a Gooch crucible and $50 \mathrm{cc}$. of the filtrate are precipitated with $200 \mathrm{cc}$. of $\delta 0$ per cent alcohol. The precipitate is filtered through a Gooch crucible and

12 Bertrand, G., and Benoist, S. Sur un nouveau sucre, le procellose, obtenu à partir de la cellulose. Compt. Rend. Acad. Sci., 176: 1583-1587. 1923.

${ }^{13}$ Further information on the chemistry of celluloses is given by Schwalbe, C. G. Die Chemie der Cellulose unter besonderer Berücksichtigung der Textilund Zellstoffindustrien. Berlin, Borntraeger. 1911; Czapek, F. Biochemie der Pflanzen. Bd. 1, p. 645. Heuser, 1923 (p. 427). Pringsheim, 1923 (p. 427). Euler, A. C. Úber die Konstitution der Zellulose und der Zellobiose. Chem. Ztg., 45: 977-998. 1921. Hibbert, H. Studies on the chemistry of cellulose. I. The constitution of cellulose. Jour. Ind. Engin. Chem., 13: 256-260; 334 342. 1921; Cross, C. F., and Bevan, E. J. Cellulose. Longmans, Green \& Co., London. 1916; Karrer, P. Einführung in die Chemie der polymeren Kohlenhydrate. Akad. Verlagsgesellsch. Leipzig. 1925.

${ }^{14}$ Charpentier, C. A. G. Studien über den Einfluss des Rindvieh- und Pferdestallmistes auf die Zersetzung der Zellulose in der Ackererde. Thesis. Univ. Helsingfors. 1921. Also Meddel. No. 205 Centralanst. forsoksv. jordbruck. Bakteriol. Avdel. No. 22, Stockholm. 1920. On the preparation of Schweitzer's reagent, see Dischendorfer, O. Über das Zellulosereagens Ku upferoxydammoniak. Ztschr. wiss. Mikrosk., 39: 97. 1922. General methods of cellulose determination are given by Cross and Bevan. 
is then washed with (1) dilute (1 per cent) hydrochloric acid, (2) distilled water, (3) dilute (2 per cent) $\mathrm{KOH}$ solution, (4) distilled water, (5) dilute $\mathrm{HCl}$ solution, (6) distilled water, (7) alcohol, and finally (8) ether. The cellulose is then dried at $100^{\circ}$ to $110^{\circ}$ to constant weight, burnt off and the crucible is reweighed. The difference obtained gives the amount of cellulose in 10 grams of soil.

Soils rich in organic matter (so-called "humus soils") have to be treated first with 10 per cent $\mathrm{CaO}$, so as to neutralize the humus substances, which would prevent the solution of the cellulose, ${ }^{15}$ or extracted with 2 per cent solution of sodium hydroxide, then washed with water, dilute acetic acid and water. To determine cellulose in straw, wood or other natural products added to the soil, the latter is first treated with sodium acid sulfite, and then extracted with Schweitzer's reagent;16 the natural plant material may also be extracted with 2 per cent sodium hydroxide solution, at 15 pounds pressure, for 30 to 60 minutes, then washed and boiled with 2 per cent solution of sulfuric acid and washed, and only then extracted with Schweitzer's reagent; the precipitation of the cellulose, filtering, washing and igniting is carried out as in the case of pure cellulose.

Mechanism of decomposition of cellulose by microorganisms. Mitscherlich $^{17}$ was the first (1850) to attribute the fermentation of cellulose to the activities of microorganisms. Popoff ${ }^{18}$ demonstrated in 1875 the connection between cellulose decomposition and methane formation; in the anaerobic decomposition of organic matter, the $\mathrm{CO}_{2}: \mathrm{CH}_{4}$ ratio was found to be $1: 1$. Tappeiner ${ }^{19}$ established conclusively that microorganisms are concerned in the decomposition of cellulose.

In studying the bacterial changes which take place normally in the intestinal canal, Tappeiner introduced finely divided cotton or paper into flasks containing a 1 per cent neutral solution of beef extract. The flasks and contents were sterilized and then inoculated with small quantities of pancreatic juice and incubated at $35^{\circ} \mathrm{C}$. They were so arranged that the gases could be collected and analyzed. The resulting product consisted of acetic acid, isobutyric acid,

15 Dmochowski, R., and Tollens, B. Über eine neue Methode der quantitativen Zellulosebestimmung. Jour. Landw., 58: 1-20. 1910.

${ }^{16}$ Bengtsson, 1925 (p. 680).

${ }_{17}$ Mitscherlich, F. Über die Zusammensetzung der Wand der Pflanzenzelle. Ber. Bekanntmach. Verhandl. Königl. Preuss. Akad. Wissensch. Berlin, 1850, 102-110.

18 Popoff, L. Über die Sumpfgasgärung. Arch. Ges. Physiol., 10: 113-146. 1875.

${ }_{19}$ Tappeiner, H. Utber Celluloseverdauung. Ber. deut. chem. Gesell., 15: 999-1002. 1882; Ztschr. Biol., 20: 52-134. 1884. 
acetaldehyde, methane and carbon dioxide. The last two were in the ratio of 1:7.2 at the beginning of the experiment and 1:3.4 at the close. In another set of experiments, an alkaline medium was used; the same qualitative but different quantitative results were obtained, there being a large amount of hydrogen evolved in the alkaline medium.

Hoppe-Seyler ${ }^{20}$ placed 25.773 grams of filter paper into $1000 \mathrm{cc}$. flasks containing $700 \mathrm{cc}$. of water; this was inoculated with sewage and the gaseous products collected over mercury. The cultures were incubated at room temperature for four years. During the first year there was considerable gas evolved, but the evolution gradually became slower until, at the end of four years, the evolution of gas had practically ceased. The analysis showed that 15 grams of the cellulose had been decomposed with the formation of carbon dioxide and methane. Hoppe-Seyler was unable to find any of the true sugars, although he thought it possible that there were some dextrin compounds in solution. When air was excluded, there was a greater production of methane and to a less extent carbon dioxide. Hoppe-Seyler suggested that the process of cellulose decomposition proceeds in two stages: the cellulose is first hydrated with the formation of glucose, according to the equation:

$$
\left(\mathrm{C}_{6} \mathrm{H}_{10} \mathrm{O}_{5}\right)_{n}+n \mathrm{H}_{2} \mathrm{O}=n \mathrm{C}_{6} \mathrm{H}_{12} \mathrm{O}_{6}
$$

The glucose is then broken down to carbon dioxide and methane:

$$
\mathrm{C}_{6} \mathrm{H}_{12} \mathrm{O}_{6}=3 \mathrm{C}_{2} \mathrm{H}_{4} \mathrm{O}_{2}=3 \mathrm{CO}_{2}+3 \mathrm{CH}_{4}
$$

This reaction depended on the supply of oxygen; the greater the amount of available oxygen the less $\mathrm{CH}_{4}$ and the more $\mathrm{CO}_{2}$ was formed in the process. However, neither was glucose demonstrated as an intermediary product nor was there any evidence submitted that only $\mathrm{CO}_{2}$ and $\mathrm{CH}_{4}$ are formed.

Omeliansky ${ }^{21}$ distinguished methane and hydrogen fermentations of cellulose, both processes being anaerobic in nature; organic acids, alcohols and gases were also formed. Van Iterson ${ }^{22}$ was the first to demonstrate that cellulose decomposition may also take place under aerobic conditions. Aerobic and anaerobic decomposition of cellulose

${ }^{20}$ Hoppe-Seyler, F. Über Gärung der Cellulose mit Bildung von Methan und Kohlensäure. Ztschr. physiol. Chem., 10: 201-217; 401-440. 1886.

${ }^{21}$ Omeliansky, 1902 (p. 191).

${ }^{22}$ Iterson, G. van. Die Zersetzung von Cellulose durch aerobe Mikroorganismen. Centrbl. Bakt. II, 11: 689-698. 1904. 
were two distinct processes, carried on by different organisms and under distinctly different conditions.

The anaerobic processes of cellulose decomposition may be conveniently divided into two groups. (1) In the absence of nitrate, the cellulose may undergo a hydrogen or methane fermentation by anaerobic bacteria. (2) In the presence of nitrates, the cellulose is clestroyed by aerobic denitrifying bacteria.

Under aerobic conditions cellulose decomposition was found to take place in two ways. (1) If the medium is slightly alkaline, certain aerobic bacteria and actinomyces will be most active. (2) If the medium is acid, fungi are active in the decomposition of the cellulose.

The microorganisms capable of decomposing cellulose can be divided into seven general groups: (1) anaerobic bacteria, (2) aerobic bacteria, (3) thermophilic bacteria, (4) denitrifying bacteria, (5) actinomyces, (6) fungi, and (7) possibly also invertebrate animals. ${ }^{23}$ In normal cultivated soils, the aerobic bacteria, fungi, and actinomyces are largely concerned with the decomposition of celluloses. ${ }^{24,25}$ Under anaerobic conditions, as in peat and cranberry bogs, anaerobic bacteria are responsible for the decomposition of celluloses; while, in the manure heap, thermophilic bacteria may be largely active.

The true celluloses are digested by the herbivorous animals by means of the bacteria present in their intestinal tract. ${ }^{26}$ When stable manure is added to the soil, large quantities of cellulose decomposing bacteria are introduced. This has led to the claim that the addition of stable manure is equivalent to inoculations of soil with strong cellulose decomposing bacteria. It is doubtful, however, whether these organisms could become active in the soil, even if all normal soils were not already abundantly supplied with various types of organisms capable of decomposing celluloses.

To be able to demonstrate the nature of the decomposition of cellulose by microorganisms, enzymes had to be obtained so as to allow the investigation of the hydrolytic nature of the phenomenon. Some

${ }^{23}$ Younge, C. M. The digestion of cellulose by invertebrates. Sci. Progr. No. 78: 242-248. 1925.

${ }^{24}$ Mütterlein, C. Studien über die Zersetzung der Cellulose im Dünger und im Boden. Inaug. Diss. Leipzig. 1913; Waksman and Skinner, 1926 (p. 190).

${ }^{25}$ Pringsheim, H. Die Beziehungen der Zellulosezersetzung zum Stickstoffhaushalt im der Natur. Centrbl. Bakt. II, 37: 111-112. 1913.

${ }^{26}$ Scheunert, A. Beiträge zur Kenntnis des Cellulosverdauung im Blindarm und des Enzymgehaltes des Coecalsecretes. Ztschr. physiol. Chem., 48: 926. 1908. 
bacteria decompose celluloses with the formation of a clear zone around the colony, indicating the formation of an cxo-cellular enzyme; ${ }^{27}$ other microorganisms, especially certain fungi and bacteria, can utilize cellulose without the production of a clear zone on the cellulose plate, indicating the endo-nature of the corresponding enzyme.

Pringsheim ${ }^{28}$ allowed the decomposition of cellulose to proceed till a maximum has been reached, as indicated by gas formation. Bacterial action was then quickly brought to a standstill by the introduction of a proper antiseptic, which prevented the further development of the bacteria without injuring the enzyme cellulase. The products of hydrolysis (sugars) will then accumulate, due to the fact that the sudden stop of bacterial action does not prevent the hydrolytic enzyme (cellulase) from breaking down the cellulose. The hydrolytic products cellobiose and glucose are demonstrated by the reduction of Fehling's solution, and formation of corresponding osazones.

Since the decomposition of cellulose is a comparatively slow process, especially at normal temperatures, the hydrolytic action of the enzyme is also very slow and does not lead to any abundant accumulation of products of hydrolysis. This, as well as the destruction of the hydrolytic enzymes by proteolysis, suggested the use of large quantities of media which are concentrated in vacuo, at a low temperature, so as to obtain a solution with a sugar concentration sufficient for identification. In the methane, hydrogen, and denitrifying proccsses, it takes two to seven days before reducing sugar can be demonstrated. The thermophilic bacteria, which are much more active, give a strong reduction of Fehling solution in 24 hours.

Just as starch is hydrolyzed by amylase at first to the disaccharide maltose and then by a separate enzyme (maltase) to glucose, so is cellulose first hydrolyzed by the cellulase of bacteria to the disaccharide cellobiose, then by the enzyme cellobiase to glucose. The latter enzyme has also been demonstrated in cellulose decomposing bacteria and fungi. ${ }^{29}$

${ }^{27}$ Kellerman and McBeth, 1912 (p. 197). Löhnis, F., and Lochhead, G. Experiments on the decomposition of cellulose by aerobic bacteria. Centrbl. Bakt. II, 58: 430-434. 1923.

${ }_{28}$ Pringsheim, H. Utber den fermentativen Abbau der Zellulose. Ztschr. physiol. Chem., 78: 266-291. 1912.

${ }^{29}$ Fischer, E., and Zemplen, G. Verhalten der Cellobiose und ihres Osons gegen einige Enzyme. Liebig's Ann. Chem., 335: 1-6. 1909: 372: 254-256. 1910; Bertrand, G., and Holderer, M. La cellase et le dédoublement diastatique du cellose. Compt. Rend. Acad. Sci., 149: 1385. 1909; 150: 230. 1910. 
Cellulase acts at temperatures of $20^{\circ}$ to $70^{\circ}$. When a culture of thermophilic bacteria acting at $55^{\circ}$ is brought to room temperature, the action of the living bacterial cells upon cellulose and the production of gas stop but the enzyme action continues even at $20^{\circ}$. By a mere change in temperature, active growth accompanied by gas formation is discontinued; under these conditions enzyme action results in an accumulation of sugar, as indicated by reduction of Fehling's solution and osazone formation. The cellulose is transformed into cellobiose and the latter partly to glucose by the enzyme cellobiase, which is still active at $20^{\circ}$. By raising the temperature to $67^{\circ}$, Pringsheim succeeded in repressing both the growth of bacteria and the action of cellobiase, leaving only cellulase active; this resulted in the accumulation of only cellobiose. Groenewege ${ }^{30}$ also demonstrated that bacteria hydrolyze cellulose, by means of an enzyme cellulase, into cellobiose and the latter is then hydrolyzed to glucose. In an alkaline medium, cellobiose is formed faster than it is hydrolyzed. It is much easier to demonstrate the formation of an enzyme decomposing celluloses by fungi. ${ }^{31}$

The glucose formed from cellulose by the action of the bacterial enzymes is rapidly broken down by the same organisms or by accompanying forms to various organic acids, such as acetic, butyric and lactic or formic, acetic and valeric (Groenewege). These acids are decomposed, either by the same bacteria or by a secondary flora, to carbon dioxide and water. In the decomposition of sugars by the anaerobic bacteria, methane, hydrogen and carbon dioxide are formed directly. In some cases, the transformation of the cellulose leads to the formation of mucilages consisting of hemicelluloses. According to Neuberg and Cohn, ${ }^{32}$ acetaldehyde is formed as an intermediary product in the decomposition of cellulose by thermophilic bacteria. It is this acetaldehyde which may serve as the building stone for the synthesis of the microbial protoplasm. The formation of pigments in the decomposition of cellulose is more characteristic of the organism than of the cellulose.

${ }^{30}$ Groenewege, J. Untersuchungen über die Zersetzung der Zellulose durch aerobe Bakterien. Bull. Jard. Bot. Buitenzorg (3), 2: 287. 1920; Meddel. Alg. Proefsta. Landbr. Dept. Nijv. Handel., 13: 1-23. 1923.

${ }^{31}$ Kellerman, K. F. Formation of cytase by Penicillium pinophilum. U. S. Dept. Agr., Bur. Pl. Ind. Circ. 113, 1912; Ellenberger, W. Zur Frage der Cellulosverdauung. Ztschr. physiol. Chem., 96: 236-254. 1915; Kosin, N. I. On the aerobic decomposition of cellulose by fungi. Rpt. of the Physico-Chem. Lomonossov Soc., Moskau, 2: 57-98. 1921.

${ }^{32}$ Neuberg, C., and Cohn, R. Über Zwischenprodukte des bakteriellen Abbaues von Cellulose. Biochem. Ztschr., 139: 527-544. 1923. 
In view of the fact that certain aerobic bacteria cannot utilize sugars as sources of energy, it still remains to be demonstrated just how the cellulose molecule is decomposed by these organisms.

Decomposition of cellulose by anaerobic bacteria. The anaerobic decomposition of cellulose results in the formation of organic acids and gases consisting of carbon dioxide and methane or hydrogen. As pointed out above, Omeliansky ${ }^{36}$ found that the formation of methane or hydrogen in the anaerobic process is due to the fact that different organisms are active in either case. When cellulose was decomposed by the methane organism 50 per cent of the substrate was changed to gas (6.5 per cent methane and 43.5 per cent $\mathrm{CO}_{2}$ ), and 50 per cent into fatty acids (acetic and butyric). When cellulose was decomposed by the hydrogen organism, about 33 per cent of the substrate was changed into gases ( 4 per cent hydrogen and 29 per cent $\mathrm{CO}_{2}$ ) and 67 per cent into fatty acids (acetic, butyric, and small quantities of valerianic acid). The decomposition of cellulose is soon stopped by the rapid accumulation of acids unless $\mathrm{CaCO}_{3}$ is added to keep the medium neutral. Even then the process of cellulose decomposition is very slow and it may take months before 5 to 10 grams of filter paper suspended in a liter of medium are fully dissolved. Omeliansky showed that it took the hydrogen organism thirteen months to form the following products from 3.347 grams of cellulose:

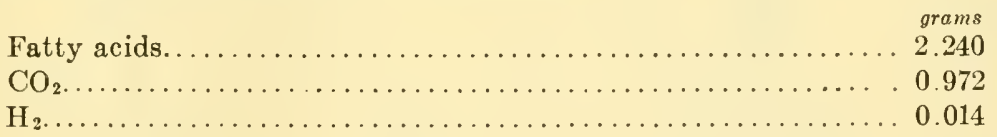

The loss of 0.121 gram was believed to be due to substances not determined, including valerianic acid, higher alcohols, aromatic substances and dissolved hydrogen.

The methane organism formed, out of 2 grams of cellulose decomposed:

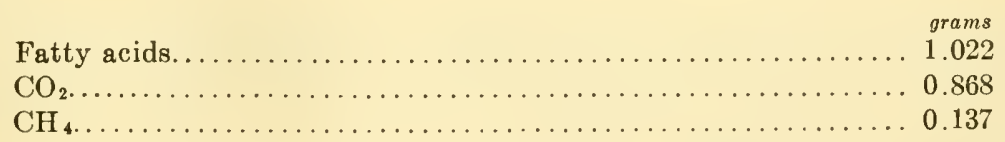

The methane and hydrogen processes go on simultaneously in mixed culture. A convenient apparatus for the study of cellulose decomposition under anaerobic conditions is shown in fig. 23.

${ }^{33}$ Omeliansky, 1904 (p. 191). 
The anaerobic bacillus isolated by Khouvine ${ }^{34}$ from the human intestinal tract was found to be capable of using cellulose as the only source of energy; sugars could not be utilized. One gram of cellulose was decomposed in 16 days; but, in the presence of other bacteria, five

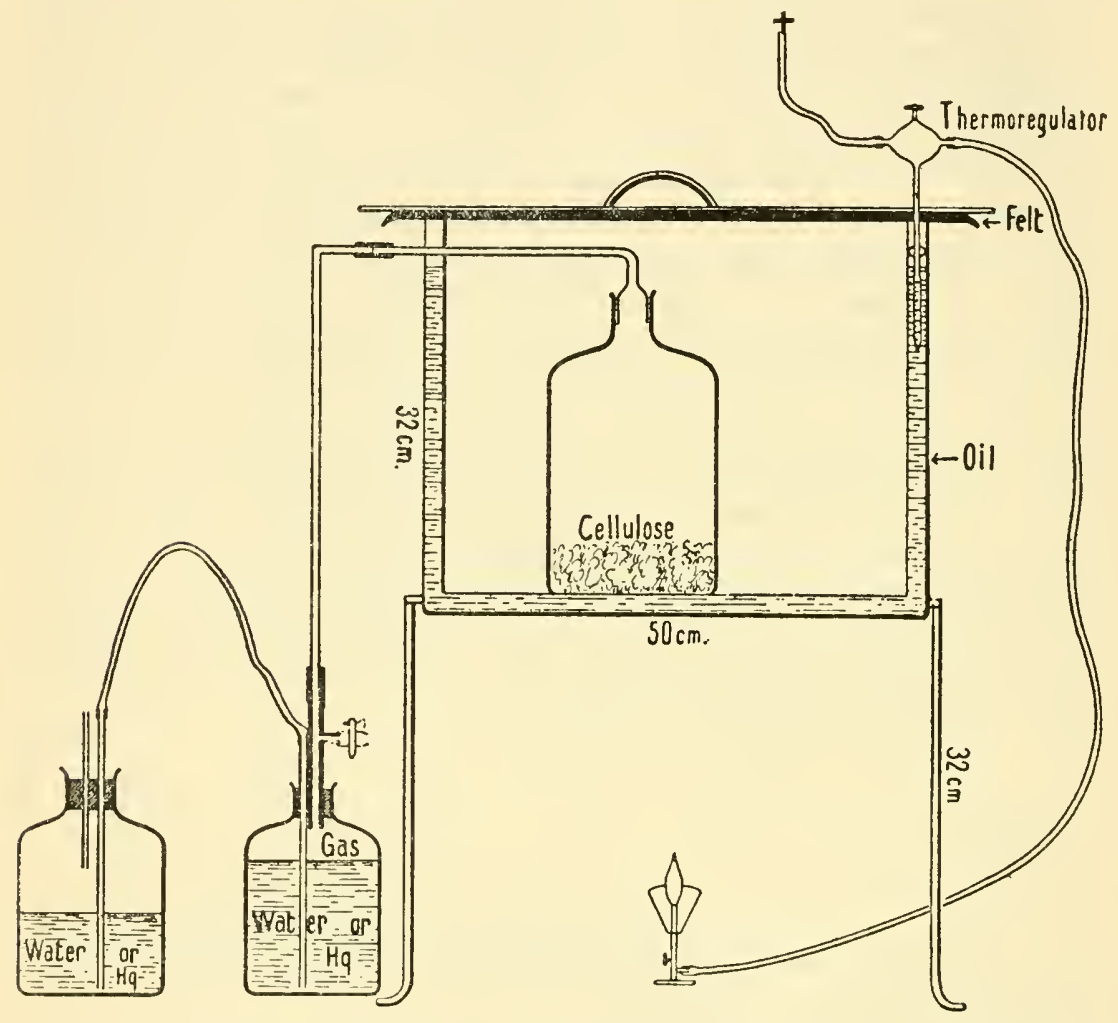

FIG. 23. Apparatus for study of cellulose decomposition, under anaerobic conditions (after Pringsheim).

times as much cellulose was decomposed. Among the decomposition products, $\mathrm{CO}_{2}, \mathrm{H}_{2}$, ethyl alcohol, acetic and butyric acids, traces of lactic acid, products precipitated by alcohol and a yellow pigment could be demonstrated.

${ }^{34}$ Khouvine, 1923 (p. 193). 
The following equations were suggested ${ }^{35}$ to explain the anaerobic decomposition of celluloses:

$$
\begin{aligned}
& \mathrm{C}_{6} \mathrm{H}_{10} \mathrm{O}_{6}+\mathrm{H}_{2} \mathrm{O} \rightarrow \underset{2}{2} \mathrm{CH}_{3} \cdot \mathrm{CO} \cdot \mathrm{COOH}+2 \mathrm{H}_{2} \\
& \text { Pyruvic acid } \\
& \mathrm{CH}_{3} \cdot \mathrm{CO} \cdot \mathrm{COOH}+\mathrm{H}_{2} \rightarrow \mathrm{CH}_{3} \cdot \mathrm{CHOH} \cdot \mathrm{COOH} \\
& \text { Lactic acid } \\
& \mathrm{CH}_{3} \cdot \mathrm{CO} \cdot \mathrm{COOH} \rightarrow \\
& \quad \mathrm{CH}_{3} \cdot \mathrm{CHO}+\mathrm{CO}_{2} \\
& \text { acetaldehyde } \\
& 2 \mathrm{CH}_{3} \cdot \mathrm{CHO}+\mathrm{H}_{2} \mathrm{O} \rightarrow \mathrm{CH}_{3} \cdot \mathrm{CH}_{2} \cdot \mathrm{OH}+\mathrm{CH}_{3} \cdot \mathrm{COOH} \\
& 2 \mathrm{CH}_{3} \cdot \mathrm{CH}_{2} \cdot \mathrm{OH} \rightarrow \mathrm{CH}_{3} \cdot \mathrm{COOH}+2 \mathrm{CH}_{4}
\end{aligned}
$$

Lactic acid may also break down to give butyric acid

$2 \mathrm{CH}_{3} \cdot \mathrm{CHOH} \cdot \mathrm{COOH} \rightarrow \mathrm{CH}_{3} \cdot \mathrm{CH}_{2} \cdot \mathrm{CH}_{2} \cdot \mathrm{COOH}+2 \mathrm{CO}_{2}+2 \mathrm{H}_{2}$

Decomposition of cellulose by aerobic bacteria. Cellulose decomposition by aerobic bacteria can be studied by suspending filter paper in a shallow layer of a medium containing an appropriate nitrogen source and the necessary minerals and inoculated with a pure or crude culture of bacteria, or with soil or manure. At room temperature, the cellulose will be found to be rapidly decomposed with the formation of a slime or mucilage which may be colored yellow or red. Carbon dioxide is formed abundantly but no other gas, so that no visible "fermentation" is found to take place; small quantities of acids are formed in the medium. The cellulose is largely macerated and the fibers separated from one another and gradually reduced to a pulp. Some organisms are very active and others are very slow. With some species isolated by Kellerman and associates, ${ }^{36}$ the principal by-products were found to consist of formic and acetic acids, while others gave rise only to traces of fatty acids; no aldehydes, ketones or alcohols were formed. The aerobic bacterium Spirochaeta cytophaga uses cellulose as the only source of carbon and produces a pigment related to the carotin group, also some mucilage, which does not give rise to optically active compounds on hydrolysis, and small quantities of fatty acids, chiefly butyric. The mucilage is extracted in the crude "humus" fraction in soil analysis. ${ }^{37}$

Decomposition of cellulose by thermophilic bacteria. Thermophilic bacteria destroy cellulose very actively. A nutrient solution contain-

${ }^{35}$ Langwell and Lymn, 1923 (p. 202).

${ }^{36}$ Kellerman et al., 1914-1916 (p. 197).

${ }^{37}$ Hutchinson and Clayton, 1919 (p. 195). 
ing pure filter paper, inoculated with a small quantity of soil and incubated at $60^{\circ} \mathrm{C}$, produces gas and a distinct odor. The filter paper is all broken up in 10 to 14 days, with the formation of $\mathrm{CO}_{2}$ and $\mathrm{CH}_{4}$; formic and acetic acids are also demonstrated among the decomposition products. ${ }^{38}$ Kroulik $^{39}$ obtained cellulose decomposition at $60^{\circ} \mathrm{C}$, under aerobic and anaerobic conditions: When cellulose was decomposed aerobically, only $\mathrm{CO}_{2}$ was formed; under anaerobic conditions, the cellulose was decomposed more completely, with the formation of $\mathrm{H}_{2}, \mathrm{CO}_{2}$ and even $\mathrm{H}_{2} \mathrm{~S}$. Among the decomposition products, considerable quantities of acetic acid, some butyric, formic and acetic acids were demonstrated. Organic nitrogen was found to be the best source of nitrogen. Pringsheim ${ }^{40}$ obtained, under anaerobic conditions, out of 3 grams of cellulose decomposed, $0.2125 \mathrm{gram}$ formic acid, 1.15 gram acetic acid and a small quantity of lactic acid. Carbon dioxide made up 21.9 to 49.1 per cent of the gases, the rest was hydrogen Ethyl alcohol, acetic, butyric and lactic acids, hydrogen and methane result from the decomposition of cellulose at higher temperatures. By changing the conditions of growth, the relative amounts of the products may be changed. Viljoen, Fred and Peterson ${ }^{41}$ found that, out of 60 grams of cellulose added to 4 liters of medium containing 20 grams of peptone, 42 grams were decomposed by thermophilic (anaerobic bacteria) with the formation of the following products:

\begin{tabular}{|c|c|c|}
\hline & YIELD & $\begin{array}{l}\text { CARBON } \\
\text { CONTENT }\end{array}$ \\
\hline & grams & grams \\
\hline Acetic acid................... & 21.6 & 8.6 \\
\hline Alcohol.................... & 10.3 & 5.4 \\
\hline 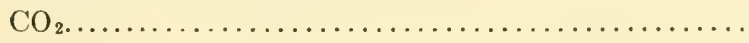 & 11.94 & 3.0 \\
\hline
\end{tabular}

Carbon of cellulose decomposed. 18.6 grams

Carbon of products accounted for 17.0 grams

Among the gases, hydrogen was formed in considerable quantities, but no methane.

The rapid heating of hay results from transformation of cellulose and other carbohydrates in the hay by microorganisms. ${ }^{42}$ Bact. coli,

${ }^{38}$ MacFayden and Blaxall, 1899 (p. 201).

${ }^{39}$ Kroulik, 1913 (p. 157).

${ }^{40}$ Pringsheim, 1913 (p. 202).

${ }^{41}$ Viljoen, Fred and Peterson, 1926 (p. 202).

${ }^{42}$ Miehe, 1907 (p. 300); Utber die Selbsterhiztung des Heues. Arb. deut. landw. Gesell. H 196, 36 p. 1911; (CentrbI. Bakt. II, 34: 281-282. 1912). 
Oidium lactis and Bac. calfactor were found capable of heating up well packed hay and a mixture of two of these organisms could bring about a normal heating of moist hay. In addition to these, Miche ${ }^{42}$ isolated an actinomyces and various fungi from the piles of heated hay. However, the actual rôle of these organisms in the heating of hay is still unclear. It has been suggested that either inflammable products are formed or that the initial reaction of raising the temperature is biological, followed by chemical processes.

Decomposition of cellulose by denilrifying bacteria. In the decomposition of cellulose by denitrifying bacteria, the energy liberated is used for the reduction of nitrates to atmospheric nitrogen; the oxygen thus obtained is utilized for the oxidation of the cellulose. Carbon dioxide and water are the chicf products formed in the decomposition of cellulose, while nitrogen gas is a product of the reduction of nitrates. The formation of carbonates, due to the reduction of the nitrates, leads to the alkalinization of the medium:

$$
\begin{gathered}
5 \mathrm{C}_{6} \mathrm{H}_{10} \mathrm{O}_{5}+24 \mathrm{KNO}_{3}=24 \mathrm{KHCO}_{3}+12 \mathrm{~N}_{2}+6 \mathrm{CO}_{2}+13 \mathrm{H}_{2} \mathrm{O} \\
\mathrm{C}_{6} \mathrm{H}_{10} \mathrm{O}_{5}+8 \mathrm{KNO}_{3}=4 \mathrm{KHCO}_{3}+2 \mathrm{~K}_{2} \mathrm{CO}_{3}+4 \mathrm{~N}_{2}+3 \mathrm{H}_{2} \mathrm{O}
\end{gathered}
$$

Groenewege $e^{43}$ demonstrated that this process of cellulose decomposition is a result of the symbiotic action of two groups of bacteria, one of which decomposes the cellulose and the other reduces the nitrate utilizing the energy liberated by the former. By the combination of these two processes the cellulose is decomposed much more readily than by the cellulose bacteria alone. Under acrobic conditions, cellulose decomposition takes place readily with other sources of nitrogen, as seen from table 35 .

The cellulose decomposing organism produces an enzyme which hydrolyzes the cellulose into sugars. The latter are transformed by the organism into organic acids (acetic, butyric and lactic). The sugars and the acids are used as sources of energy by the denitrifying bacteria which decompose them into $\mathrm{CO}_{2}$ and water. The intermediary products of cellulose decomposition can also be used as a source of energy by $A z$. chroococcum which is enabled thereby to fix nitrogen and form dark brown pigments in the soil.

Cellulose decomposition by actinomyces. The capacity of decomposing cellulose and using it as a source of energy is well distributed among the actinomyces. ${ }^{44}$ This can be readily demonstrated either by the

${ }^{43}$ Groenewege, 1920-1923 (p. 436).

"Fousek, 1913 (p. 302). 
cellulose-plate method or by adding cellulose, in the form of filter paper, to a medium containing the necessary inorganic salts and a source of nitrogen. Krainsk $y^{45}$ found that certain pigment-producing species, forming small, spherical spores (Act. melanocyclus and Act. melanosporeus) are particularly active in this connection, forming black or red rings on the paper and causing a decomposition of the cellulose. On the agar plate, clear rings are formed around the colony, due to the decomposition of the cellulose by an exo-enzyme. To study the process quantitatively, a definite amount of filter paper is placed in flasks containing a synthetic nutrient medium, with ammonium salt (using in the case of chloride or sulfate also calcium carbonate so as not to allow the reaction to become too acid, which would prevent the development of the organism) or nitrate as a source of nitrogen. The paper

TABLE 35

Cellulose decomposed in 28 days by a mixture of a cellulose-decomposing and denitrifying organism

\begin{tabular}{|c|c|c|}
\hline NITROGEN SOURCE & FILTER PAPER ADDED & $\begin{array}{l}\text { FILTER PAPER } \\
\text { DECOMPOSED }\end{array}$ \\
\hline & $\begin{array}{l}m g m . \\
2310\end{array}$ & $\begin{array}{l}\text { mgm. } \\
1910\end{array}$ \\
\hline $\begin{array}{l}\mathrm{NH}_{4} \mathrm{NO}_{3}, 0.1 \text { per cent......... } \\
\mathrm{KNO}_{3}, 0.1 \text { per cent. } \ldots \ldots \ldots \ldots \ldots \ldots \ldots \ldots\end{array}$ & $\begin{array}{l}231.0 \\
225.8\end{array}$ & $\begin{array}{l}191.0 \\
107.3\end{array}$ \\
\hline 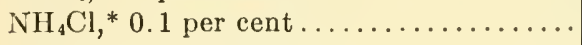 & 231.5 & 209.5 \\
\hline Asparagine, 0.2 per cent. . . . . . . . . . & 226.5 & 198.0 \\
\hline
\end{tabular}

* $\mathrm{CaCO}_{3}$ was added with the ammonium chloride so as to keep the reaction alkaline.

is allowed to dip partly in the medium, since the actinomyces are aerobic organisms and do not develop readily below the surface of the medium. After a definite period of incubation, the culture is filtered and residual paper washed and weighed. It is necessary to determine the nitrogen content of the washed paper, due to the presence of some of the mycelium of the organism. By allowing 10 per cent as the nitrogen content of the mycelium, the residual cellulose can be readily calculated. The liquid medium is analyzed for the residual inorganic nitrogen and various organic acids. It is found that a definite ratio exists between the amount of cellulose decomposed and nitrogen assimilated by the organism. Some of the organisms will decompose the paper to such an extent as to leave transparent mucilaginous strands

45 Krainsky, 1913-1914 (p. 297). 
which fall to pieces when an attempt is made to lift them out of the medium. Some actinomyces produce red and black pigments through the paper. However, when compared with the bacteria and fungi capable of decomposing celluloses, the action of most of the actinomyces upon cellulose is only slow and limited.

Cellulose decomposition by filamentous fungi. The destruction of hemicellulose in plant tissues is to be sharply differentiated from that of cellulose. Fungi act differently upon hemicelluloses of different plants, due probably to the difference in chemical composition of the plant tissues rather than to differences in solubility of the hemicelluloses. ${ }^{46}$ It has been shown elsewhere (p. 263) that fungi possess a strong cellulose-decemposing power, especially certain Fusaria, Aspergilli, Penicillia, Trichodermae and various Dematiaceae. It has even been suggested that in normal cultivated soils, these organisms play the most important rôle in this connection. The following method can be used for comparing the cellulose decomposing power of different microorganisms:

Finely ground filter paper (1 gram) and $20 \mathrm{cc}$. of a nutrient solution [10 grams $\left(\mathrm{NH}_{4}\right)_{2} \mathrm{SO}_{4},\left(\mathrm{NH}_{4}\right)_{2} \mathrm{HPO}_{4}$ or $\mathrm{NH}_{4} \mathrm{NO}_{3}, 3$ grams $\mathrm{K}_{2} \mathrm{HPO}_{4}, 2$ grams $\mathrm{MgSO}_{4}, 1$ gram $\mathrm{NaCl}, 1000 \mathrm{cc}$. of tap water, with or without 5 grams $\mathrm{CaCO}_{3}$ ] are added to 100 grams portions of sand or soil, placed in flasks, sterilized (for 2 hours at 15 pounds pressure) and inoculated. If possible, it is advisable to connect the flasks with an aeration apparatus and determine the evolution of $\mathrm{CO}_{2}$. When soil is used as a medium, a control without cellulose, sterilized and inoculated should also be employed. When $\mathrm{CaCO}_{3}$ is added, allowance should be made for the $\mathrm{CO}_{2}$ given off by the interaction of organic acids with the carbonate. The cultures are incubated for 3 to 6 weeks at $25^{\circ}$ to $28^{\circ} \mathrm{C}$. At the end of the incubation period, the amount of cellulose left in the 20 grams of the moist culture (allowing for the moisture content) is determined by the quantitative method of Charpentier. A series of results ${ }^{47}$ obtained by this procedure, with sand as a medium, are presented in table 36 .

When cellulose is the only source of energy available, one part of nitrogen is assimilated by fungi from inorganic sources added to the medium for every thirty parts of cellulose decomposed. ${ }^{48}$ This fact

${ }^{46}$ Schellenberg, 1908 (p. 261).

47 Waksman, S. A., and Heukelekian, H. Cellulose decomposition by various groups of soil microorganisms. 4th Int. Cong. Pedology. Rome. 3: 216-22s. 1924.

${ }^{48}$ Heukelekian, O., and Waksman, S. A. Carbon and nitrogen transformations in the decomposition of cellulose by filamentous fungi. Jour. Biol.Chem., 66: $323-342$. 1925 . 
permits the measurement of nitrogen transformation as an index of cellulose decomposition, since they run parallel.

There is good evidence that fungi are chiefly responsible for the decomposition of celluloses in acid, humid soils under acrobic conditions. When the soil is partially sterilized to eliminate the fungi, cellulose decomposition comes practically to a standstill. When cellulose is added to the soil, especially in the presence of an available source of nitrogen, the fungi develop much more abundantly than

TABLE 36

Decomposition of cellulose by pure cultures of microorganisms

\begin{tabular}{|c|c|c|}
\hline ORGANISM & INCUBATION & $\begin{array}{l}\text { CELLULOSE } \\
\text { DECOMPOSED }\end{array}$ \\
\hline & days & per cent \\
\hline 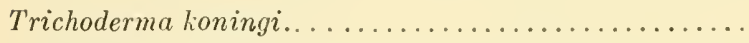 & 21 & 46.8 \\
\hline 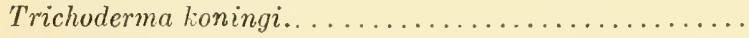 & 42 & 95.0 \\
\hline 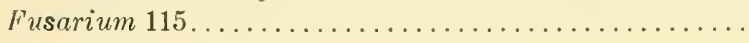 & 21 & 36.8 \\
\hline 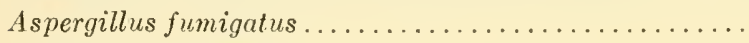 & 21 & 93.0 \\
\hline 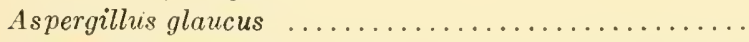 & 21 & 49.0 \\
\hline 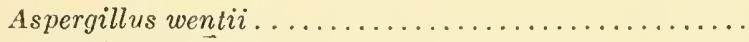 & 21 & 0 \\
\hline 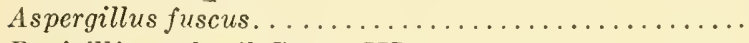 & 21 & 0 \\
\hline 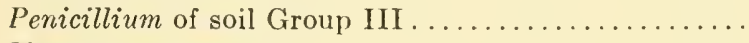 & 21 & 8.5 \\
\hline 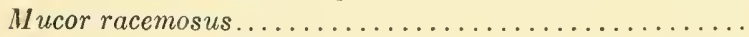 & 21 & 0 \\
\hline 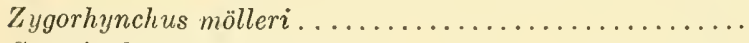 & 21 & 0 \\
\hline 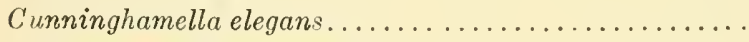 & 21 & 0 \\
\hline 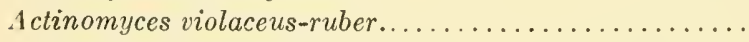 & 21 & 6.8 \\
\hline 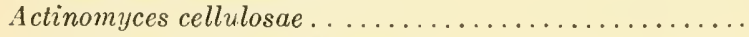 & 42 & 12.76 \\
\hline Actinomyces viridochromogenus. ................ & 42 & 0 \\
\hline 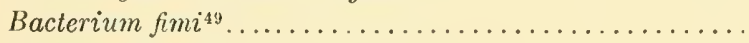 & 42 & 29.0 \\
\hline 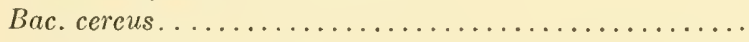 & 42 & 0 \\
\hline 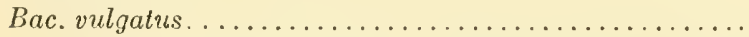 & 42 & 0 \\
\hline
\end{tabular}

either the bacteria or actinomyces; ${ }^{50}$ this can be readily demonstrated both by the plate and direct microscopic methods.

Cellulose decomposition in manure. Thirty to forty per cent of the diry weight of manure consists of cellulose and 20 to 30 per cent of pentosans. ${ }^{51}$ When manure undergoes decomposition, whether in the

${ }^{49}$ This organism of Kellerman et al., was from stock culture; Spirochaeta cyiophaga studied later was found to be much more active and decomposed almost as much cellulose as the fungi themselves.

${ }^{50}$ Waksman and Skinner, 1926 (p. 190).

${ }^{51}$ Stoklasa, J. Über die Wirkung des Stallmistes. Ztschr. landw. Versuchsw. Oesterr., 10: 440. 1907; Fuhling's landw. Ztg., 56: 411. 1907. 
compost heap or in the field, the celluloses and the pentosans are the first to disappear (following of course the immediate decomposition of the small amounts of sugars and starches that may be present in the manure). Dehérain ${ }^{52}$ distinguished two processes of manure decomposition: (1) aerobic, when the temperature goes up to $65^{\circ}$ to $70^{\circ}$; (2) anaerobic, at $30^{\circ}$ to $35^{\circ}$. The composition of the gases given off in the decomposition of manure is given in table 37 .

Deherain believed that a large part of the cellulose of the straw is decomposed, with the formation of $\mathrm{CH}_{4}$ and $\mathrm{CO}_{2}$. The residue left, after a part of the nitrogenous substances and the cellulose have been decomposed, forms the black matter of the manure. This is accompanied by the transformation of ammonia (urea) nitrogen into protein nitrogen. A spore bearing bacillus was found to decompose the cellulose actively under anaerobic conditions with the formation of methane,

TABLE 37

Composition of gases in different parts of the manure heap

\begin{tabular}{|c|c|c|c|}
\hline & $\begin{array}{c}\text { TOP LAYER OF } \\
\text { HEAP }\end{array}$ & $\begin{array}{c}\text { MIDDLE LAYER } \\
\text { OF HEAP }\end{array}$ & $\begin{array}{l}\text { BOTTOM LAYER } \\
\text { OF HEAP }\end{array}$ \\
\hline & per cent & per cent & per cent \\
\hline Carbon dioxide......... & 21.6 & 31.0 & 37.1 \\
\hline Oxygen ................. & 0.0 & 0.0 & 0.0 \\
\hline 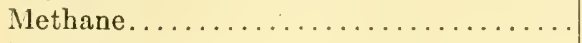 & 0.0 & 33.3 & 58.0 \\
\hline Nitrogen...................... & 78.4 & 35.5 & 4.9 \\
\hline
\end{tabular}

when a small amount of manure was inoculated into a synthetic medium. Omeliansky succeeded in demonstrating that both methane and hydrogen-cellulose fermentations take place in manure. In view of the fact that the decomposition of the organic matter in manure and in soil leads to a marrowing of the carbon-nitrogen ratio and formation of dark-colored substances, Omeliansky ${ }^{53}$ suggested that the cellulose decomposition takes place according to the reaction:

$$
2\left(\mathrm{C}_{6} \mathrm{H}_{10} \mathrm{O}_{5}\right)=5 \mathrm{CO}_{2}+5 \mathrm{CH}_{4}+2 \mathrm{C} .
$$

He states "It is possible that a general reaction of this sort forms the basis of the universal processes of humification, that is, the gradual

52 Dehérain, P. P. Ann. Agron., 14: 97-133. 1888. (Dehérain, 1902 (p. 793).)

${ }^{53}$ Omeliansky, 1926, (p. xii) p. 309. No experimental evidence was submitted to justify this equation and it is doubtful whether it ever takes place in nature. Cellulose decomposition never results in the direct formation of "humus." 
transformation of organic substances into a mixture of brown and black substances with a high content of carbon such as is characteristic of fossil coals. But whatever the mechanism of these transformations, the active participation of microorganisms in the latter cannot be clenied." According to Pringsheim, ${ }^{54}$ thermophilic bacteria are also active in the decomposition of cellulose in manure, with the formation of acetic and formic acids, $\mathrm{CO}_{2}$, hydrogen and methane.

The pentosans may be acted upon even before the celluloses are decomposed. When fresh manure is allowed to compost, the bacteria and fungi transform the celluloses, pentosans and pectins of the straw into various organic substances and carbon dioxide. The organisms thereby absorb a great deal of the available nitrogen present in the urine for the synthesis of their protoplasm. When fresh manure is applied to the soil directly, it may not stimulate and may even injure plant growth. This is due to the assimilation of the available nitrogen in the manure and in the soil by the microorganisms which use the carbohydrates of the manure as sources of energy. The composting of the manure brings about a great reduction in the nitrogen-free compounds and the transformation of the available nitrogen into microbial proteins. ${ }^{55}$

Importance of cellulose decomposition in the soil. According to Mütterlein's ${ }^{56}$ calculation, 1 acre of soil in Cermany receives yearly about $200 \mathrm{kgm}$. of cellulose in the form of manure. When we add to that the amount introduced by green manuring, plant stubble, root residues, weeds, etc., quite appreciable quantities are obtained. Some of the plant constituents are attacked more readily than others. The sugars and starches and, to a more limited extent, the proteins are acted upon first, then the pentosans and celluloses; then the oils, fats and lignins; and finally the waxes which may persist in the soil for a long time unaltered.

Cellulose was considered by older investigators and even some recent ones ${ }^{57}$ to be the mother substance of soil "humus." On the other hand, Hoppe-Seyler ${ }^{53}$ and others have demonstrated that since

${ }^{54}$ Pringsheim, 1913 (p. 202).

${ }^{65}$ Heinze, B. Úber die Verrottung des Stalldüngers. Centrbl. Bakt. II, 25: 503-504. 1910.

${ }^{56}$ Mütterlein, 1913 (p. 434).

${ }^{57}$ Marcusson, J. Torfzusammensetzung und Lignintheorie. Ztschr. angew. Chem., 38: 339. 1925.

${ }^{63}$ Hoppc-Seyler, 1889 (p. 700). 
no dark colored substances are formed directly from the decomposition of celluloses in the soil, the sources of "humus" are to be looked for in the other plant constituents besides the celluloses (p. 691). However, indirectly cellulose may contribute to the soil organic matter or "humus", due to the fact that it is a readily available source of energy and is decomposed in aerated soils largely through the activities of fungi and bacteria, resulting in the synthesis of an extensive microbial protoplasm. ${ }^{59}$

Although celluloses cannot be used directly as sources of energy for nitrogen-fixing bacteria, they may form products which are available sources of energy for these organisms. Beijerinck ${ }^{60}$ found that a medium consisting of two parts of paper, two parts of chalk and 0.05 per cent $\mathrm{K}_{2} \mathrm{HPO}_{4}$ in 100 cc. of tap water was a favorable medium for nitrogen-fixation. At $25^{\circ}$ to $30^{\circ}$, there developed chiefly the hydrogenforming organism together with Bact.radiobacter and Azotobacter. For every gram of cellulose decomposed, 8 to $9 \mathrm{mgm}$. of nitrogen were fixed. Bac. amylobacter ${ }^{\text {fl }}$ and Azotobacter ${ }^{62}$ are unable to attack cellulose in pure culture. Only in mixture with cellulose decomposing organisms, are they able to fix nitrogen, at the expense of the cellobiose, the glucose or the fatty acids formed from the decomposition of the celiulose. In a mixture of the methane-forming organism and Clostridium americanum, Pringsheim ${ }^{61}$ obtained $12.1 \mathrm{mgm}$. nitrogen fixed for $1 \mathrm{gram}$ of cellulose decomposed. The methane bacterium produced 10 grams fatty acid out of 20 grams cellulose; but in the presence of nitrogen-fixing organisms, only 0.064 gram fatty acid accumulated. Azotobacter fixed $4.5 \mathrm{mgm}$. of nitrogen out of 1 gram of cellulose, in symbiosis with the methane organism; this is probably due to the fact that Azotobacter does not thrive well under semi-anaerobic conditions.

${ }^{53}$ Waksman, S. A. Soil Sci., 22: 123-162, 221-232, 323-333, 395-406. 1926.

${ }^{60}$ Beijerinck, M. IV. L'influence des microbes sur la fertilité du sol et la croissance des végétaux supérieurs. Arch. Neerland. Sci. Ex. Nat. Ser. II, 9: 8-36. 1904.

61 Pringsheim, H. Ueber die Verwendung von Cellulose als Energiequelle zur Assimilation des Luftstickstoffs. Centrbl. Bakt. II, 23: 300-304. 1909; 26: 222-227. 1910. Die Beziehungen der Zellulosezersetzung zum Stickstoffgehalt in der Natur. Mitt. deut. landw. Gesell., 1912, 1913, p. 26, 43 (Centrbl. Bakt. II, 37: 111. 1913).

${ }^{52}$ Koch, A., and Seydel, S. Über die Verwertung der Zellobiose als Energiequelle bei der Stickstoffbindung durch Azotobacter. Centrbl. Bakt. II, 31: 567-577. 1911 . 
Under aerobic conditions, Koch ${ }^{63}$ obtained a more favorable nitrogen fixation by Azotobacter.

Koch found stronger cellulose-decomposing bacteria in manure than in normal soil and, therefore, suggested that the beneficial effect of stable manure is due to the introduction of strong cellulose decomposing bacteria, as shown by the increased action of green manure when it is inoculated with a small amount of stable manure. The more rapid decomposition of the green manure results in an increased nitrogen fixation. Similar ideas on the favorable influence of small amounts of stable manure have been expressed by Lipman and associates. ${ }^{64}$ Their ideas were not confirmed by a careful analysis of the processes of cellulose decomposition. It was found ${ }^{65}$ that the favorable addition of small amounts of stable manure is due to the nutrients, especially the nitrogen that it contains.

Nitrogen-fixation as a result of symbiotic action of nitrogen-fixing and cellulose-decomposing bacteria, with cellulose as the only source of energy, has also been demonstrated by other investigators. ${ }^{66}$ Peat is very resistant to the action of cellulose decomposing bacteria, but this resistance can be overcome by preliminary treatment of the peat, as boiling, steaming, or grinding. It is claimed that it may then become a source of energy for nitrogen fixing microorganisms. ${ }^{67}$ The importance of this process in increasing the supply of soil nitrogen is, however, still questionable.

Influence of soil conditions upon cellulose decomposition. The existence of thermophilic bacteria in the soil indicates that a high temperature is not injurious to cellulose decomposition but may even be highly beneficial. According to Bertrand and Compton, ${ }^{68} 46^{\circ}$ is the

${ }^{63}$ Koch, A. Die Luftstickstoffbindung im Boden mit Hilfe von Cellulose als Energiematerial. Centrbl. Bakt. II, 27: 1-7. 1910; Jour. Landw., 55: 355416. 1907.

${ }^{64}$ Lipman, J. G., Blair, A. W., Owen, I. L., and MeLean, H. C. The influence of bacteria supplied in manure on the decomposition of green manure (legume and non-legume). N. J. Agr. Exp. Sta. 25th. Ann. Rpt.: 245-260. 1912; 26th: 47.1-478. 1913; 27th: 223-226. 1914.

${ }^{65}$ Barthel, Chr., and Bengtsson, N. Action of stable manure in the decomposition of cellulose in tilled soil. Soil Sci., 18: 185-200. 1924; Medd. No. 300, Centralanst. forsoks. jordbruks. Bakt. avd. 40. Stockholm. 1926.

${ }^{66}$ Hutchinson and Clayton, 1918 (p. 195). Groenewege, 1920 (p. 436).

${ }^{67}$ Schınidt, F. W. Torf als Energiequelle für die stickstoffassimilierende Bakterien. Centrbl. Bakt. II, 52: 281-289. 1920.

${ }^{68}$ Bertrand, G., and Compton, A. Influence de la température sur l'activité de la cellase. Bull. Soc, chim. France, (4), 9: 100. 1911. 
optimum temperature for the action of cellobiase, while Pringsheim found that cellulose decomposition will take place at temperatures of $20^{\circ}$ to $70^{\circ}$.

As to the influence of soil reaction, Hellström ${ }^{69}$ demonstrated in 1899 that the action of lime on peat soils is not so much to serve as a nutrient for plants as to stimulate the decomposition of the organic substances in the peat and neutralize the acid products formed. Christensen ${ }^{70}$ also found that a basic soil shows a much higher cellulose decomposition than a base-free soil. The results of Charpentier and Barthel ${ }^{65}$ seem to prove that liming of soil has no favorable action at all upon cellulos

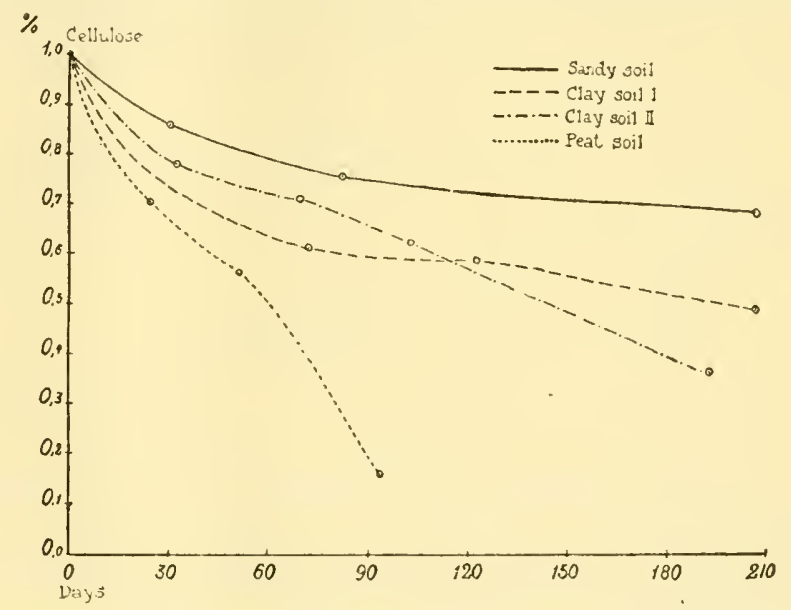

Fig. 24. Influence of soil type upon the decomposition of cellulose (after Charpentier).

decomposition. This is due largely to the fact that the process is carried out both by fungi and bacteria. The reaction of the soil no doubt influences the type of organisms taking an active part in cellulose decomposition, but not the process itself. Since various fungi and various bacteria decompose cellulose actively, a change in reaction will favor the development of either one group or another, while the actual amount of cellulose decomposed may be influenced only inappreciably. However, the decomposition of the organic matter of the soil itself, such as "humus" of mineral soils or peat and other decomposed or semi-decomposed organic materials may be greatly stimulated by the

${ }^{69}$ Hellström, P. 1909. Ref. Charpentier, 1921 (p. 431).

${ }^{70}$ Christensen, 1915 (p. 578). 
addition of lime. Using $\mathrm{CO}_{2}$ evolution as an index of decomposition of organic matter, Potter and Snyder ${ }^{71}$ found that $\mathrm{CaCO}_{3}$ accelerates the rate of decomposition of the organic matter present in the soil or added in the form of stable manure (10 to 50 tons per acre). Similar results were previously obtained by Lemmermann and associates. ${ }^{72}$

To stimulate cellulose decomposition in the soil, it may be sufficient to add the proper nutrients, such as phosphoric acid or nitrogen substances. Charpentier ${ }^{73}$ found that the addition of 2 per cent of cow or horse manure will greatly stimulate cellulose-decomposition in the soil. The influence of the manure depends on the content of nutrients in the manure and in the soil. With a sufficient amount of moisture and a favorable reaction, the action of the manure is greater with a higher content

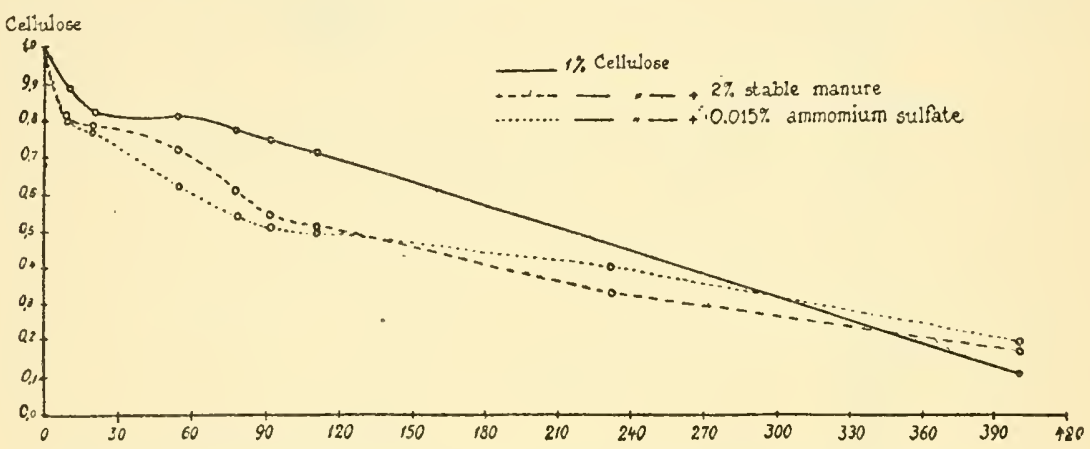

FIG. 25. Influence of nitrogen source upon the decomposition of cellulose in the soil (after Charpentier).

of nutrients in the manure and a lower content in the soil. 'The greater the moisture content of the soil, the quicker will the cellulose be decomposed. Cellulose decomposition is active both in acid and alkaline soils, and lime merely plays the part of a regulator of soil reaction. The addition of equal amounts of nitrogen in the form of ammonium sulfate and cow manure brings about an equal stimulation of cellulose

${ }^{1}$ Potter, R. S., and Snyder, R. S. Carbon dioxide production in soils and carbon and nitrogen changes in soils variously treated. Iowa Agr. Exp. Sta. Res. Bul. 39: 255-309. 1917.

${ }^{72}$ Lemmermann, O., Aso, K., Fischer, H., and Fresenius, L. Untersuchungen über die Zersetzung der Kohlenstoff verbindungen verschiedener organischer Substanzen im Boden, speziell unter dem Einfluss von Kalk. Landw. Jahrb., 41: 217-256. 1911.

${ }^{73}$ Charpentier, 1921 (p. 431). 
decomposition in the soil. This points conclusively to the fact that the stimulating influence of cow and horse manure is due to its nitrogen content. Tables 38 and 39 and figures 24 and 25 show the influence of manure, soil reaction and nitrogen source on cellulose decomposition in various soils, as determined by Charpentier.

The content of available nitrogen in the soil is thus found to be the most important factor controlling cellulose decomposition. 'The ratio between the cellulose decomposed and nitrogen required by the organisms is about $30-35$ to $1 .^{74}$ This ratio will depend of course upon the amount of available nitrogen. When the latter is in excess and is,

TABLE 38

Composition of soils used for study of cellulose decomposition

\begin{tabular}{|c|c|c|c|c|}
\hline SOIL TYPE & $\begin{array}{l}\text { DRY MATTER } \\
\text { PER CENT }\end{array}$ & $\begin{array}{c}\text { A\&H } \\
\text { PER CENT OF } \\
\text { DRY } \triangle A T T E R\end{array}$ & $\begin{array}{l}\text { CELLULOSE } \\
\text { PER CENT OF } \\
\text { DRY MATTER }\end{array}$ & $\mathrm{pH}$ \\
\hline Clay soil I. & 82.0 & 94.8 & 0.06 & 6.12 \\
\hline Clay soil II . . . . & 82.0 & 93.5 & 0.01 & 7.08 \\
\hline Sandy soil..... & 92.0 & 97.8 & 0.04 & 6.56 \\
\hline Peat soil...... & 40.0 & 19.9 & 0.03 & 5.44 \\
\hline
\end{tabular}

TABLE 39

Influence of cellulose (1 per cent) upon soil reaction (using clay soil $I$ )

\begin{tabular}{|c|c|c|c|c|}
\hline & \multicolumn{2}{|c|}{ No LIME } & \multicolumn{2}{|c|}{$\begin{array}{l}\text { WITH LIME }(0.5 \text { PER CENT } \\
\mathrm{CaCO}_{3}\end{array}$} \\
\hline & $\underset{\text { beginning }}{\mathrm{pH} \text { at }}$ & $\mathrm{pH}$ at end & $\underset{\text { beginning }}{\mathrm{pH} \text { at }}$ & $\mathrm{pH}$ at end \\
\hline Unmanured soil. . . . . . . . . & 6.12 & 5.54 & 7.73 & 7.37 \\
\hline 2 per cent cow manure..... & 6.12 & 6.30 & 7.73 & 7.77 \\
\hline
\end{tabular}

therefore, not the limiting factor, the above ratio will hold true. When the amount of available nitrogen is low, it will be utilized by the organisms over and over again, i.e., a part of the synthesized protoplasm of the microorganisms will be decomposed, liberating some of the nitrogen which is immediately again assimilated thus enabling the organisms to decompose more cellulose. The process will be continuous, tending to give a higher ratio between the cellulose decomposition and apparent nitrogen assimilation.

i4 Waksman and Heukelekian, 1924 (p. 443). Anderson, J. A. The influence of available nitrogen on the fermentation of cellulose in the soil. Soil Sci., 21: 115-126. 1926. 
Chemistry of hemicelluloses. The hemicelluloses are amorphous polysaccharides, but are distinguished from the celluloses by their easy solubility in dilute alkalies and in hot dilute acids, such as 1 per cent $\mathrm{HCl}$. Some give the brown to black iodine reaction like true celluloses. On hydrolysis hemicelluloses give glucose, mannose, galactose, or mixtures of these, xylose and arabinose; the hemicelluloses are thus termed dextrans, mannans, galactans, mannogalactans, pentosans (xylans, arabinans), according to the constituent monosaccharides. Hemicelluloses are present not only in higher plants, but also in algae, fungi and lichens (lichenin). Hemicelluloses of plant seeds are insoluble in water, diastase solution (differentiating them from starches), cold dilute $\mathrm{KOH}$, but are more readily hydrolized by acids into sugars than the celluloses. In relation to their rôle in the plant tissues, celluloses are commonly believed to serve as protective substances in plants and are unaffected by plant metabolism, while hemicelluloses are reserve materials in the plants, which must be brought into a soluble form by means of enzymes, before they can be utilized in plant nutrition; in some plants they serve for structural purposes holding the fibers together. The hemicelluloses thus comprise two different groups of substances: (1) the reserve celluloses (mostly mannans) of seed, and to some extent of grasses; (2) supporting substances, mostly galactans and pentosans, having a mechanical function. The reserve hemicelluloses and starches can take the place of one another, so that seeds poor in starch are rich in reserve celluloses and vice versa.

The pentosans are present in the cell walls of all green plants, in the bark and woody fiber of trees, in mosses, fungi, seeds and fruits. They occur very abundantly in straw which usually contains 23 to 29 per cent pentosan. Corn cobs contain 32 per cent pentosan; pine needles 6.8 per cent, oak leaves 10.3 per cent. Older tissues contain larger quantities of pentosans than younger ones. According to Van Hulst, Peterson and Fred, ${ }^{75}$ the pentosan content of the corn plant increases from 7.4 per cent in the kernel to 31.8 per cent in the cob at maturity. ${ }^{76}$ The pentosans are probably not reserve materials but

${ }^{75}$ Van Hulst, J. H., Peterson, W. H., and Fred, E. B. Distribution of pentosans in the corn plant at various stages of growth. Jour. Agr. Res., 23: 655663. 1923.

${ }^{76}$ The method of determination of pentosans is given by Pervier, N. C., and Gortner, R. A. The estimation of pentoses and pentosans. Jour. Ind. Engin. Chem., 15: 1167, 1255. 1923. 
are of importance in the formation of wood and skeletal structure of various plants. The formula for pentosans is $\left(\mathrm{C}_{5} \mathrm{H}_{8} \mathrm{O}_{4}\right)_{n}$, yielding, on hydrolysis, $\mathrm{C}_{5} \mathrm{H}_{10} \mathrm{O}_{5}$ or pentoses. The quantitative method of determining pentosan is based on the formation of a pentose from the pentosan, and of furfural from the pentose on further heating with acid. Pentosans are determined quantitatively by (1) the phloroglucinol method, ${ }^{77}(2)$ the bromine titration method, ${ }^{78}$ or (3) by the colorimetric estimation of furfural. ${ }^{79}$

A weighed quantity of material (also soil or culture medium) is distilled with 12 per cent $\mathrm{HCl}$ until the distillate gives no further coloration with aniline acetate. All connections in the distilling apparatus should be of glass. The distillate is made up to $500 \mathrm{cc}$. with 12 per cent $\mathrm{HCl}$. Standard, approximately $0.1 \mathrm{~N}$ sodium bromide-bromate solution $(25 \mathrm{cc}$.) is pipetted into each of four well-stoppered bottles, $200 \mathrm{cc}$. of the distillate is added to each of two bottles and $200 \mathrm{cc}$. of 12 per cent $\mathrm{HCl}$ to the two other bottles. These are allowed to stand in the dark for one hour, and, after the addition of $10 \mathrm{cc}$. of 10 per cent KI solution, the liberated iodine is determined by titration with $0.1 \mathrm{~N}$ sodium thiosulfate solution. The number of cubic centimeters required by the sample is subtracted from the number required by the blank, the difference being a measure of the furfural present. One cubic centimeter of $0.1 \mathrm{~N}$ sodium thiosulfate $=2.4$ $\mathrm{mgm}$. furfural.

Humus soils are rich in pentosans or substances which yield furfural on boiling with $\mathrm{HCl}^{80}$ Forest soil, with 23.42 per cent humus, was found to contain 0.75 per cent pentosan; garden soil, with 9.85 per cent humus, contained 0.39 per cent pentosan; sandy soil, with 2.68 humus, contained only 0.04 per cent pentosan. Shorey and Lathrop ${ }^{81}$ found pentosans universally distributed in the soil, the pentosan carbon ranging from 1.3 to 28.53 per cent of the total carbon. As much as 2.75 per cent pentosan was found in a North Dakota soil in which flax had been grown for a number of years. The presence of pentosans

${ }^{77}$ Kröber, E. Untersuchungen über die Pentosanbestimmungen mittelst der Salzsäure-Phloroglucinmethode nebst einigen Anwendungen. Jour. Landw., 48: 357-384. 1900.

${ }^{78}$ Powell, W. J., and Whittaker, H. The determination of pentosans in wood cellulose. Jour. Soc. Chem. Ind. Trans., 43: 35-36. 1924.

${ }^{79}$ Youngburg, G. E., and Pucher, G. W. Studies on pentosan metabolism. I. A colorimetric method for the estimation of furfural. Jour. Biol. Chem., 61: 741-746. 1924.

${ }^{80}$ Chalmot, G. de. Pentosans in plants. Amer. Chem. Jour., 16: 218-223. 1894; Note on pentosans in soils. Ibid., 229.

${ }^{81}$ Shorey, E. C., and Lathrop, E. C. Pentosans in soils. Jour. Amer. Chem. Soc., 32: 1680-1683. 1910. 
in the soil is a result of addition of plant residues, which have resisted decomposition, such as a part of the ligno-cellulose or is a product of the decomposition of complex compounds, such as nucleo-proteins. Fungus mycelium will contain about 1 per cent pentosan even when grown on a pentose-free medium.

Decomposition of hemicelluloses by microorganisms. Many fungi are capable of decomposing hemicelluloses. These include various species of Aspergillus and other organisms. ${ }^{82}$ Ccrtain lower animals are also capable of assimilating hemicelluloses. ${ }^{83}$ The hydrolysis of these polysaccharides is carried on by means of an enzyme cytase. ${ }^{84}$

TABLE 40

Decomposition of pentosans by fungi and by a mixed flora ${ }^{85}$

\begin{tabular}{|c|c|c|}
\hline OROANISM & $\begin{array}{l}\text { CORN STOVER } \\
\text { PENTOSAN } \\
\text { DERTROYED IN } \\
\text { 142 DAYS }\end{array}$ & $\begin{array}{l}\text { RYE STRAW } \\
\text { PENTOSAN } \\
\text { DESTROYED IN } \\
\text { 300 DAYS }\end{array}$ \\
\hline & percent & per cent \\
\hline Asp. flavus. . . . . . . . . . . & 40.1 & 38.1 \\
\hline 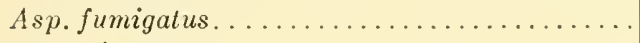 & 53.0 & 35.1 \\
\hline 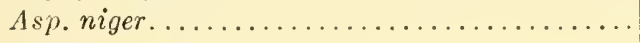 & 44.5 & 33.9 \\
\hline 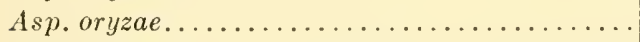 & 38.0 & \\
\hline 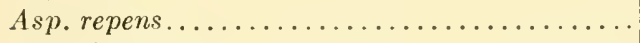 & 31.0 & \\
\hline Pen. glaucum......................... & 33.0 & 36.6 \\
\hline 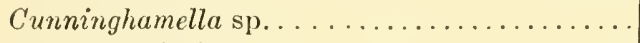 & 42.5 & \\
\hline 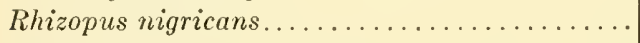 & 29.5 & \\
\hline 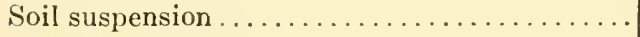 & & 35.1 \\
\hline 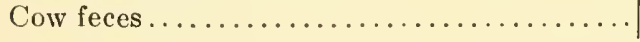 & & 33.2 \\
\hline
\end{tabular}

Schmidt, Peterson and Fred ${ }^{85}$ tested the pentosan decomposing power of a number of different fungi, by adding 1 gram of corn stover or rye straw to $25 \mathrm{cc}$. of a nutrient mineral solution containing $\mathrm{NH}_{4} \mathrm{NO}_{3}$ as the only source of nitrogen. Different organisms were found to vary in their ability to decompose pentosans. It is interesting to note

${ }^{82}$ Hérissey, H. Recherches chimiques et physiologiques sur la digestion des mannanes et des galactanes par le seminase chez les végétaux. Thèse. Paris. 1903. Schellenberg, 1908 (p. 264). Otto, 1916 (p. 265).

${ }^{83}$ Bierry, H., and Giaja, J. Untersuchungen über die Mannane, Galaktine und Zellulosen-angreifenden Enzyme. Biochem. Ztschr., 40: 370. 1912.

${ }^{84}$ Newcombe, F. C. Cellulose-enzymes. Ann. Bot., 13: 49-81. 1899.

${ }^{85}$ Schmidt, E. G., Peterson, W. H., and Fred, E. B. The destruction of pentosans by molds and other microorganisms. Soil Sci., 15: 479-4S8. 1923. Ver Hulst, Peterson and Fred, 1923 (p. 452). 
that a suspension of soil or of cow feces, containing a mixed flora, did not decompose any more pentosan than pure cultures of fungi. Wood pentosan (alder, poplar, birch) was not destroyed in solution, due to the presence of a substance inhibiting the growth of the fungi. When added to the soil, 37 to 72 per cent of the wood pentosan was decomposed. Pure cultures of bacteria were also found capable of decomposing pentosans in the corn, varying from 1.7 to 12.8 per cent. The maximum destruction of the pentosan (12.8 per cent) was made by Bac. Alavigena, a cellulose decomposing organism. Among the other hemicelluloses decomposed by bacteria, we find also agar-agar. ${ }^{86}$ Pringsheim ${ }^{87}$ demonstrated that a trisaccharide is formed as an intermediary product of the decomposition of mannans by bacteria. ${ }^{88}$

It should be noted here that, in the transformation of organic matter added to the soil, the pentosans are decomposed more rapidly than the celluloses and both much more rapidly than the lignins (p. 460).

Lignins, ligno-celluloses and their decomposition. Lignin, or the noncarbohydrate portion of the lignified tissues after it has been freed from fats, waxes, resins and tannins, is, next to celluloses and hemicelluloses, the most abundant constituent of plant tissues. Sphagnum moss contains 9 to 13 per cent lignin, cereal straw 18 to 22 per cent, saw grass, reeds and wood 28 to 37 per cent and nut shells up to 47 per cent. In the plant tissues, lignin is present in a free state only to a very inconsiderable extent, but largely in the form of compounds with celluloses. Ligno-celluloses are considered by some to be chemical complexes in the form of esters, by others as physical (incrustants) or adsorption compounds. These have a higher carbon content ( 47 to 50 per cent) than pure celluloses, due to the presence of the lignins, which contain 62 to 64 per cent carbon. The exact chemical nature of the lignin itself is still a matter of dispute.

The cell wall of plants consists of practically pure cellulose in the carly stages of growth, but this is changed into ligno-cellulose with advancing growth; the lignin is formed from carbohydrates originally

${ }^{86} \mathrm{Gran}, \mathrm{H}$. H. Studien über Meeresbakterien. II. Über die Hydrolyse des Agar-agars dureh ein neues Enzym, die Gelase. Bergens Mus. Aarborg, 1902, H. I. Biernaeki, W. Bacterium nenckii Biern., ein neuer den Agar verflüssigender Mikroorganismus. Centrbl. Bakt. II, 29: 166-169. 1911. Gray and Chalmers, 1925 (p. 199).

${ }^{87}$ Pringsheim, H. Über den fermentativen Abbau der Hemicellulosen. Ztschr. physiol. Chem., 80: 376-382. 1912.

${ }^{88}$ See also Cramer. Inaug. Diss. Halle. 1910. 
present in the cell wall. Pentosans are considered ${ }^{89}$ as intermediate products in the formation of lignin. The latter is believed to be made up of hydrosols of high molecular weight which are adsorbed from the sap by the cellulose fibers. ${ }^{90}$ Maximum lignification corresponds with maximum percentage of adsorbed material; this may be followed by chemical reactions, such as dehydration. The lignin content of rye straw was found ${ }^{91}$ to increase with age, the greatest increase occurring during the period preceding ear formation. In the ligno-cellulose complex the cellulose is linked with two non-cellulose substances one of which contains an aromatic nucleus, while the other is presumed to be a pentosan since it yields furfural on distillation with $\mathrm{HCl}$.

Two different processes are available for the preparation of lignin, based upon the fact that it is insoluble in concentrated acids and is soluble in alkalies, when heated under pressure; acid or alkali lignin are thus obtained. To prepare acid lignin, finely ground straw or wood is extracted with ether and then treated with a concentrated acid, using either 72 per cent $\mathrm{H}_{2} \mathrm{SO}_{4}$, or fuming $\mathrm{HCl}$ solution (specific gravity 1.21), or a mixture of $1 \mathrm{vol}$. $\mathrm{HCl}$, specific gravity 1.07 , and 6 vol. 72 per cent $\mathrm{H}_{2} \mathrm{SO}_{4} \cdot{ }^{2}$

Alkali lignin can be prepared by extracting the plant material with $\mathrm{NaOH}$. The actual amount of lignin thus obtained will depend on the concentration of the alkali used, temperature and period of extraction. The following method may be used: $:^{93}$ Ten parts of a 10 per cent $\mathrm{NaOH}$ solution are added to one part of finely ground straw, wood, or soil containing these materials, and the mixture is heated at $130^{\circ}$ under

${ }^{89}$ Rassow, B., and Zschenderlein, A. Über die Natur des Holzes des Hanfes. Ztschr. Angew. Bot., 34: 204-206. 1921.

${ }^{90}$ Esselen, G. J. A few high spots in the chemistry of cellulose. Jour. Ind. Engin. Chem., 15: 306-307. 1923.

${ }^{01}$ Beckmann, E., Liesche, D., and Lehmann, F. Lignin als Winterrogenstroh. Ztschr. Angew. Bot., 34: 285-288. 1921; Biochem. Ztschr., 139: 491508. 1923.

${ }^{92}$ Klason. Beiträge zur Kenntnis der chemischen Zusammensetzung des Fichtenholzes. Berlin. 1911; Willstätter, R., and Zeichmeister, L. Zur Kenntnis der Hydrolyse von Cellulose. I. Ber. deut. chem. Gesell., 46: 2401-2412. 1913; Hägglund, E., and Bjorkman, C. B. Untersuchungen über das SalzsäureLignin. Biochem. Ztschr., 147: 74-80. 1924; Cellulosechemie, 4: 74-77. 1923; Schwalbe, H. Eine neue Methode zur Bestimmung des Lignins. Papierfabr., 23: 174-177. 1925; Wenzl, H. Papierfabr., 23: 305-306. 1925; Schorger, 1926 (p. xvi).

${ }^{93}$ Powell, W. J., and Whittaker, H. The chemistry of lignin. I. Flax lignins and some derivatives. Jour. Chem. Soc. Trans., 125: 35-36. 1924. 
pressure, for one hour or more. Two volumes of water are then added to the digested mixture and the dark-colored solution containing the lignin is filtered off. The warm filtrate is acidified with hot hydrochloric acid, brought to boiling and the precipitated lignin is centrifuged or filtered off. To obtain pure lignin, this preparation is washed with hot dilute hydrochloric acid, dried, redissolved in a mixture of acetone and water, and reprecipitated by pouring into a mixture of hot hydrochloric acid (20 per cent) solution. The lignin is now filtered off, washed with hot water and dried at $40^{\circ} \mathrm{C}$. The yield of lignin by alkali extraction is considerably lower than that obtained by treatment with strong acids. By raising the temperature of extraction to $180^{\circ} \mathrm{C}$., a yield almost equivalent to that of acid lignin may be obtained. ${ }^{94}$

It is doubtful whether lignin is a single chemical compound, Ritter ${ }^{95}$ having shown that it can be separated even by mechanical means into two forms, one of which is located in the middle lamella of the tree and has a methoxyl content of 10.8 to 13.6 per cent and the other is cell wall lignin with a methoxyl content of 4.3 to 4.8 per cent. By treatment with alcohol or with $\beta$ naphthol, lignin can also be separated into two fractions, one soluble and the other insoluble. A close relationship was found to exist between certain alcohol-soluble resins, tannins, and lignin.

Various formulae have been suggested to account for the chemical composition of lignin. It is sufficient to give the formula of Klason:

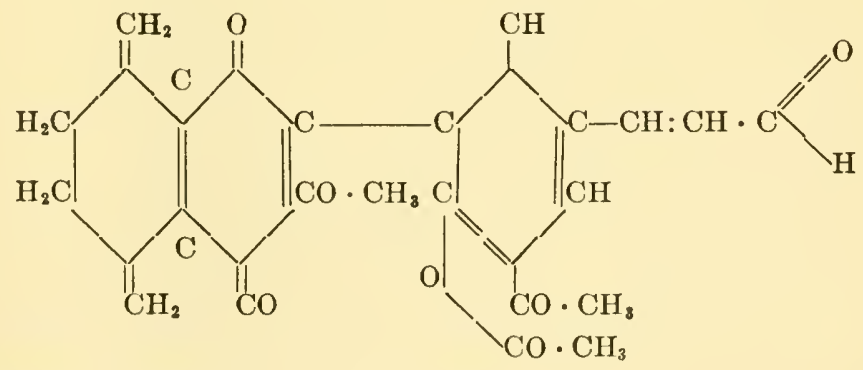

${ }^{94}$ Mehta, M. M. Biochemical and histological studies on lignification. I. The nature of lignin: its physiological significance and its estimation in timbers. Biochem. Jour., 19: 958-978. 1925.

${ }^{95}$ Ritter, G. J. Distribution of lignin in wood. Jour. Ind. Engin. Chem., 17: 1194-1197. 1925. 
Powell and Whittaker suggested the following formula for flax lignin:

$$
\mathrm{C}_{40} \mathrm{H}_{30} \mathrm{O}_{6}\left(\mathrm{OCH}_{3}\right)_{4}(\mathrm{OH})_{5} \cdot \mathrm{CHO}
$$

For rye lignin the formula $\mathrm{C}_{40} \mathrm{H}_{44} \mathrm{O}_{15}$ has been suggested. The carbon content of lignin is thus found to be about 63.0 per cent.

The methods of determination of lignin in natural organic substances are based either upon the destruction of all the carbohydrates with concentrated acids, or upon the oxidation of lignin with chlorine clioxide or other oxidizing agent, or upon the determination of some chemical constituent of lignin, such as the methoxyl groups. ${ }^{95 a}$ However, none of these methods are very accurate. Alkalies extract, under pressure, only a part of the lignin; but this method can be applied most readily to soils.

For the study of its decomposition by microorganisms, lignin can be added, either in crude or pure form, to soil or to a solution containing a source of nitrogen and the necessary minerals. The growth of the organisms, the evolution of $\mathrm{CO}_{2}$, or the disappearance of the lignin added can be taken as quantitative indices of decomposition.

Pringsheim and Fuchs ${ }^{96}$ dissolved 10 grams of lignin (obtained by treating spruce wood with 11.5 per cent $\mathrm{NaOH}$ under pressure, then precipitating the lignin with $\mathrm{HCl}$ and heating in the presence of an excess of 2 per cent acid) in $\mathrm{NH}_{4} \mathrm{OH}$ and then warmed the solution to drive off the excess of ammonia. The solution thus obtained was added to 5 liters of a nutrient medium containing 20 grams $\left(\mathrm{NH}_{4}\right)_{2} \mathrm{SO}_{4}$, 3 grams $\mathrm{K}_{2} \mathrm{HPO}_{4}, 2.5$ grams $\mathrm{MgSO}_{4}$ and 2 grams $\mathrm{CaCO}_{3}$. The medium was inoculated with soil and incubated at $37^{\circ}$; decomposition was found to take place. It resulted in the complete disappearance of the pentosan content and in the reduction of the methoxyl content of the lignin. The ability of certain bacteria to decompose lignins has also been pointed out by Schrader. ${ }^{97}$ Attention must be called here to the fact that alkali lignin usually contains some pentosans and probably some proteins; it is these substances which frequently undergo decomposition

96a Schorger, 1926 (p. xvi); Schwalbe, C. G., Die chemische Untersuchung pflanzlicher Rohstoffe und der daraus abgeschiedenen Zellstoffe. Papier. Ztg. Bd. 13. 1920.

${ }_{96}$ Pringsheim, H., and Fuchs, W. Ửber den bakteriellen Abbau von Ligninsäure. Ber. deut. chem. Gesell., 56: 2095-2097. 1923.

${ }^{97}$ Schrader, H. Über das VerhaIten von Cellulose, Lignin, Holz und Torf gegen Bakterien. Ges. Abh. Chem. der Kohle., 5: 553; Chem. Centrbl., 4: 1044. $1922 ; 3-4: 1649.1923$. 
and not the lignin itself, the latter being very resistant to the action of microorganisms. ${ }^{98}$ Very few organisms (largely actinomyces and certain bacteria) are capable of attacking lignins and use them as sources of energy.

Celluloses and other carbohydrate constituents of straw, such as the pentosans, are completely digested by animals. However, the presence of lignins which thoroughly impregnate the cellulose make the process of digestion more difficult. When the lignins are made soluble or removed by alkaline treatment, the straw becomes a more available source of energy and its digestibility is greatly increased. This removal of the lignin can be accomplished by treating the straw with various concentrations of $\mathrm{NaOH}$ or $\mathrm{Ca}(\mathrm{OH})_{2}$ at different temperatures and pressures. In the soil the celluloses and hemicelluloses are decomposed by microorganisms long before the lignins are appreciably acted upon. The very organisms concerned are different.

Crude plant materials undergo in the soil a series of chemical transformations carried out by a number of different organisms; the sugars, starches and proteins are decomposed by some, the celluloses and pentosans by others and the lignins by still others. Conditions favorable and uninjurious to the decomposition of celluloses (such as acidity of medium) may be unfavorable or distinctly injurious to the decomposition of lignins.

In addition to certain actinomyces and bacteria, higher fungi are capable of decomposing lignins to a limited extent, much less so than celluloses, and it is these organisms which are concerned largely with the rotting of wood. The mycelial filaments penetrate into the woody tissues and cause their decomposition. Most of these fungi belong to the Basidiomycetes, chiefly Hymenomycetes. ${ }^{99}$ Czapek $^{100}$ suggested that two enzymes (hydromase and cellulase) are active in the reaction. Certain filamentous fungi seem to exert some action upon lignocelluloses, as shown by Otto, ${ }^{101}$ who found that Trichothecium, Aspergillus and Mucor can dissolve out certain substances from

${ }^{98}$ Fischer, 1923 (p. 693); Waksman, 1926 (p. 447).

${ }^{99}$ Rudan, B. Vergleichende Untersuchungen über die Biologie holzerstörender Pilze. Beitr. Biol. Pflanz., 13: 375. 1917; Hubert, E. E. Jour. Agr. Res., 29: 526. 1924.

${ }^{100}$ Czapek, F. Zur Biologie holzbewohnender Pilze. Ber. deut. bot. Gesell. 1899; Ueber die sogenannten Ligninreaktionen des Holzes. Ztschr. physiol. Chem., 27: 141-166. 1899.

101 Otto, 1916 (p. 265). 
the organic complexes. ${ }^{102}$ Among the higher fungi Merulius lacrimans occupies the leading place. The course of decomposition is as follows: The fungi first assimilate the sugars, then the dextrins and gums, later the hemicelluloses, and finally the celluloses are acted upon. The physical properties are changed at the same time. The formation of socalled "humus" in the soil, especially in forest soils, is in close connection with the decomposition of wood; the organic substance is first attacked by fungi; a mixed flora of bacteria and fungi then follows, finally a rich fauna of lower animals. Among the residual substances, which go to form the so-called humus and humic acids, lignin occupies a leading place.

It may be added here that, as far as our present information is concerned, corky and cutinized lamellae are not acted upon to any extent by microorganisms. ${ }^{104}$

Pectins, mucilages and gums, and their decomposition by microorganisms. A number of constituents of the vegetable organic matter are characterized by a colloidal slimy constituency; they are usually amorphous in nature and soluble in water. Some are of a pentosan nature, like the pectins; others are of a hexosan nature, like the levulosans. They can thus be classified with the hemicelluloses. A number of substances synthesized by microorganisms belong here, namely the slime of cellulose-decomposing bacteria, of nitrogen-fixing and other bacteria, the mycodextrans and mycogalactans of fungi, etc.

The intracellular substance (middle lamella) of parenchymatous tissues of plants consists of pectic substances, or pectose, insoluble in cold water. Heating for a few minutes in an acid solution transforms the insoluble pectoses into soluble pectins; these change into pectic acid on heating with alkali. ${ }^{105}$ As pointed out above, pectins are readily

${ }_{102}$ Schellenberg, H. C. Die Holzersetzung als biologisches Problem. Vierteljahrschr. Naturf. Gesell. Zürich, 65: 30-31. 1920. (Centrbl. Bakt. II, 55: 351. 1922); Ward, H. M. Ann. Bot. 12: 565. 1898.

${ }^{103}$ Further information on the decomposition of wood and the organisms concerned is given by Tubeuf, C. F. V. Holzzerstörende Pilze und Haltbarmachung des Holzes. Lafar's Handb. techn. Mykol., 3: 286-333. 1904; Thaysen, A. C. The action of bacteria on cellulose and lignified vegetable tissues. Fuel., 2: 274-276. 1923. (Chem. Abstr., 18: 700. 1924.)

${ }^{104}$ Miyoshi, M. Die Durchbohrung von Membranen durch Pilzfäden. Jahrl). Wiss. Bot., 28: 269-289. 1895; Otto, 1916 (p. 265).

${ }^{105}$ Devaux, H. Sur la nature de la lamelle moyenne dans les tissus moux. Mem. Soc. Sci. phys. Nat. Bordeaux (6), 3: 89. 1903. (Bot. Centrbl., 96: 1. 1904); Compt. Rend. Acad. Sci., 162: 561-563. 1916; Conrad, C. M. A biochemical study of the insoluble pectic substances in regetables. Amer. Jour. Bot. 13: 531-547. 1926. 
decomposed by various aerobic and anaerobic bacteria and fungi. Sugars are claimed to be the primary products formed from the hydrolysis of pectins. Among the secondary products, we find volatile acids (acetic and butyric), hydrogen and carbon dioxide. Some organisms produce formic, lactic and succinic acids, in addition to $\mathrm{CO}_{2}, \mathrm{H}_{2}$ and acetic acid. In the process of retting of flax and hemp, especially under anaerobic conditions, alcohols and acetone are also formed, in addition to the above products.

Different species of fungi, like Rhizopus, both parasitic and nonparasitic forms, secrete an enzyme pectinase which dissolves the middle lamella of potatoes and of other plants. ${ }^{106}$

A similar enzyme is formed by Bac. carotovorus in the rotting of carrots. ${ }^{107}$ Microorganisms capable of decomposing pectins do not usually possess the ability of attacking celluloses, otherwise the retting process would be accompanied by the destruction of the cclluloses of the fibers. Certain levulosans are not readily acted upon by microorganisms. ${ }^{108}$

Starches and their decomposition by microorganisms. Starches are predominantly reserve materials, forming 60 to 70 per cent of the dry weight of cereal grain. They are complex carbohydrates of the formula $\left(\mathrm{C}_{6} \mathrm{H}_{10} \mathrm{O}_{5}\right)_{n} \cdot \mathrm{H}_{2} \mathrm{O}$ but are more readily soluble than celluloses and give the characteristic blue color with iodine. They swell in hot water. They are much more readily acted upon by microorganisms than the celluloses, due to the fact that a large number of soil forms, including the bacteria, actinomyces and fungi, produce very active diastatic enzymes which hydrolyze the starches first into dextrins of different complexity, then into sugars (maltose and glucose).

$$
\begin{aligned}
& 2\left(\mathrm{C}_{6} \mathrm{H}_{10} \mathrm{O}_{5}\right)_{n}+n \mathrm{H}_{2} \mathrm{O}=n \mathrm{C}_{12} \mathrm{H}_{22} \mathrm{O}_{11} \\
& \text { starch maltose } \\
& \mathrm{C}_{12} \mathrm{H}_{22} \mathrm{O}_{11}+\mathrm{H}_{2} \mathrm{O}=2 \mathrm{C}_{6} \mathrm{H}_{12} \mathrm{O}_{6} \\
& \text { maltose glucose }
\end{aligned}
$$

The ability of certain bacteria and fungi to produce enzymes hydrolyzing starch is so great that the processes have been utilized for various commercial purposes where diastatic enzymes are required. Certain bacteria, however, are capable of breaking down starches with the

${ }^{106}$ Harter, L. L., and Weimer, J. L. A comparison of the pectinase produced by different species of Rhizopus. Jour. Agr. Res., 22: 371-377. 1921; Amer. Jour. Bot., 10: 127-132, 167-169. 1895.

107 Jones, 1909 (p. 203).

${ }^{108}$ Colin, H, and Estienne, V. Utilisation de lévulosanes par les organismes. Bull. Soc. Chim. Biol., 6: 431-435. 1924. 
formation of acids, alcohols and acetone. ${ }^{109}$ In this, the action of bacteria upon starch may be distinct from that of diastatic enzymes, which give 100 per cent maltose, and from the acid hydrolysis of starch, which results in the formation of glucose.

The number of organisms in the soil capable of hydrolyzing starch can be readily determined. The soil is diluted 1:1000 to 1:200,000. The final dilution is plated out on a medium which consists of 15 grams potato starch, 1 gram of an organic or inorganic source of nitrogen, 0.5 gram $\mathrm{K}_{2} \mathrm{HPO}_{4}, 15$ grams of agar and traces of $\mathrm{MgSO}_{4}$ and $\mathrm{FeCl}_{3}$ in 1000 cc. of water. After a few days incubation (3 to 7), the plates are covered with a dilute solution of iodine and potassium iodide. The colonies of the microorganisms producing diastase will be surrounded with a clear zone; these colonies may then be counted. A number of bacteria are capable of decomposing starch, including various spore forming organisms, such as Bac. subtilis, Bac. mesentericus, Bac. cereus and other common soil bacteria, and also various species of Bac. amylobacter. Certain non-spore bearing bacteria, such as certain cellulose-decomposing organisms and others, are also capable of decomposing starch. The ability to hydrolyze starch is widely distributed among fungi, such as Asp. oryzae, Asp. niger and Amylomyces boidin.

Formic, acetic and butyric acids, traces of lactic and succinic acids, various alcohols (ethyl and butyl), aldehydes and acetone, hydrogen and carbon dioxide have been obtained among the products of decomposition of starches by microorganisms. Bac. mesentericus, for example, breaks down starches into carbon dioxide, formic and valerianic acids. Bac. granulobacter pectinovorum growing in media rich in starch changes the starch into glucose by means of enzymes; the sugar passes into the cell and is oxidized to acetic and butyric acids, a part of which is reduced to the corresponding alcohols. ${ }^{110}$

Inulin, similar in its properties to starch, but giving levulose on hydrolysis, can also be decomposed by various bacteria and fungi. ${ }^{11}$

${ }^{109}$ Schardinger, F. Bacillus macerans, ein Aceton-bildender Rottebacillus. Centrbl. Bakt. II, 14: 772-781. 1905; Zur Biochemie des Bacillus maccrans. Ibid., 19: 161-163. 1907; 22: 9S-103. 1909; 18S-197. 1911. For further information on this subject, consult Pringsheim, 1923 (p. 427).

${ }^{110}$ Speakman, H. B. Biochemistry of the acetone and butyl alcohol fermentation of starch by Bacillus granulobacter pectinovorum. Jour. Biol. Chem., 41: 319-343. 1920.

${ }^{111}$ Grafe, V., and Vouk, V. Das Verhalten einiger Saccharomyzeten (Hefen) zu Inulin. Ztschr. Garungsphys., 3: 327-333. 1913; Kiesel, A. L'influence de la rćaction du milieu sur l'action de l'inulase de l'Aspergillus niger. Ann. Inst. Past., 28: 747-757. 1914. 
Decomposition of fats and waxes. Fats are widely distributed in the plant and animal residues added to the soil. They are also synthesized by the different groups of soil microorganisms. The amount of fat synthesized and the nature of the fat will depend upon the type of organisms and stage of growth. The fat is a reserve substance and is readily utilized by the organisms in the absence of other available sources of energy. ${ }^{112}$

Fats decompose only slowly in moist soils, and almost not at all in dry soils. According to Rubner, ${ }^{113}$ only 22.9 per cent of butterfat added to soil (4.5 grams of fat to 200 grams of soil) was decomposed cluring a period of one year and 38.1 per cent in twelve years; other fats were decomposed at a different rate. The fats are first hydrolyzed, according to the general reaction:

$$
\mathrm{C}_{3} \mathrm{H}_{5} \mathrm{O}_{3} \cdot \mathrm{R}_{3}+3 \mathrm{H}_{2} \mathrm{O}=\mathrm{C}_{3} \mathrm{H}_{8} \mathrm{O}_{3}+3 \mathrm{R} \cdot \mathrm{OH}
$$

The glycerol or corresponding alcohols are readily utilized by various groups of microorganisms as sources of energy, while the fatty acids are decomposed further. A typical fat is decomposed in the soil as follows:

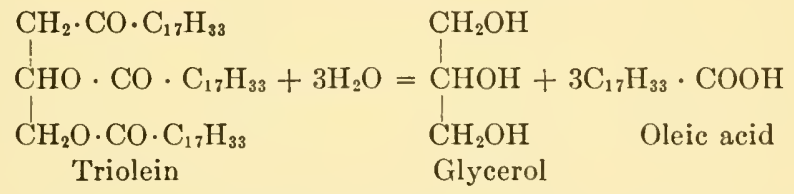

$$
\begin{aligned}
& \mathrm{CH}_{3}\left(\mathrm{CH}_{2}\right)_{7} \mathrm{CH}=\mathrm{CH}\left(\mathrm{CH}_{2}\right)_{7} \mathrm{CO}_{2} \mathrm{H}+\mathrm{H}_{2} \mathrm{O}+\frac{1}{2}\left(\mathrm{O}_{2}\right) \rightarrow \\
& \text { Oleic acid }
\end{aligned}
$$$$
\mathrm{CH}_{3}\left(\mathrm{CH}_{2}\right)_{7} \cdot \mathrm{CHOH} \cdot \mathrm{CHOH}\left(\mathrm{CH}_{2}\right)_{7} \mathrm{CO}_{2} \mathrm{H}
$$

Dioxystearic acid

This last substance has been demonstrated in the soill14 and was also found in the cells of fungi. Fats are decomposed chiefly by fungi, with the possible formation of ketones, and by a number of aerobic

112 Dubaquié. Recherches sur les matières grasses des végétaux inférieurs. Mem. Soc. Sci. Phys. Nat. Bordeaux (6). 1910.

${ }^{113}$ Rubner, N. Notiz über die Zersetzung von Fetten im Boden. Arch. Hyg., 91: 290. 1922 .

114 Schreiner, O., and Shorey, E. The isolation of harmful organic substances from soils. Bur. Soils, U. S. Dept. of Agr. Bul. 53. 1909. 
bacteria, including Staph. pyogenes aureus, Bact. prodigiosum, Bact. pyocyaneum, Bact. fluorescens, Bact. lipolyticum. ${ }^{115}$

It is possible, however, that some fat may also be decomposed under anaerobic conditions. The chemical processes involved may be different, Bach and Sierp ${ }^{116}$ having shown that, under anaerobic conditions, $\mathrm{CO}_{2}$ is split off and the fatty acids change into hydrocarbons. This results in the formation of products of a lower saponification and higher iodine number than the original fat.

Waxes are chemically related to the fats, being esters of higher alcohols and fatty acids. For example, flax wax consists of phytosterol and ceryl alcohol, as well as of palmitic-, stearic-, oleic-, linolic-, and linoleic acids. These substances are even more resistant to decomposi-

TABLE 41

Influence of age of cult're upon the fat content of Asp. niger 112 350 cc. Raulin's solution containing 4.7 per cent invert sugar

\begin{tabular}{c|c|c|c}
\hline AGE OF CULTURE & RESIDUAL SUGA & $\begin{array}{c}\text { DRY WEIGHT OF } \\
\text { MYCELIUM }\end{array}$ & FAT CONTENT \\
\hline days & $g m$. & $m g m$. & per cent \\
1 & 8.6 & 0.29 & 2.11 \\
2 & 1.9 & 5.10 & 12.0 \\
3 & 0 & 6.30 & 7.5 \\
4 & 0 & 4.1 & 4.0 \\
7 & 0 & 1.7 & 1.6 \\
12 & 0 & 1.3 & 0.6 \\
\hline
\end{tabular}

${ }^{115}$ Schenker, R. Zur Kenntniss der Lipase von Aspergillus niger (van Tiegh). Biochem. Ztschr., 120: 164-196. 1921; Derx, H. G. Der oxydative Abbau der Fette durch Schimmel. Konigl. Akad. Wiss. Amsterdam, 33: 545-558. 1924; Söhngen, N. L. Lipase production of microbes. Konink. Acad. Wetenschap. Amsterdam., 19: 698. 1910; 20: 126. 1911; Eijkman, C. Über Enzyme bei Bakterien und Schimmelpilzen. Centrbl. Bakt. I, 29: 841-848. 1901; de Kruyff, E. Les bactéries hydrolysant et oxydant les graisses. Bull. dept. agr. Ind. néerland. IX. Buitenzorg. 1907. (Centrbl. Bakt. II, 20:610-611. 1908); Huss, H. Eine fettspaltende Bakterie (Bactridium lipolyticum n. sp.). Centrbl. Bakt. II, 20: 474-484. 1908; Stephenson, M., and Whetham, M. D. Fat metabolism of the timothy hay bacillus. Proc. Roy. Soc. B., 93: 262-280. 1922; Shibata, N. Zur Frage der Fettzersetzung einiger Saprophyten. Jour. Biochem. Tokyo, 1: 249-260. 1922.

${ }^{116}$ Bach and Sierp. Untersuchungen über den anaëroben Abbau organischer Stoffe durch Bakterien des Klärschlammes. Centrbl. Bakt. II, 62: 24-76. 1924. A detailed review of the formation and decomposition of fats by microorganisms is given by Seliber, G. The formation and decomposition of fats by microorganisms. Glavnauka. Leningrad. 1926. 
tion than the fats; they are acted upon under completely aerobic conditions by soil fungi and certain bacteria. It may be of interest to mention here that Greig-Smith ${ }^{117}$ attempted to explain soil exhaustion as a result of an accumulation of fats and waxes ("agricere"); when these are partly removed by the action of volatile antiseptics, further decomposition of the soil organic matter sets in (see p. 759).

Decomposition of paraffins, aliphatic hydrocarbons and benzene ring compounds in the soil. According to Söhngen, ${ }^{118}$ various non-spore forming bacteria and Mycobacteria are capable of oxidizing paraffin, benzin, petroleum and paraffin oil. On adding 2 grams of paraffin to the medium, incubating one month at $28^{\circ}$, then extracting the remaining paraffin with petroleum ether, it was found that the following amounts were decomposed:

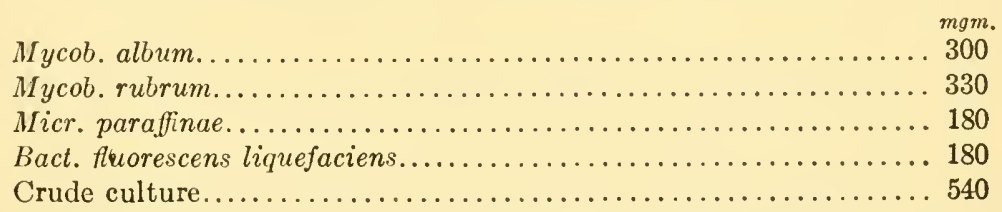

In addition to the bacteria, certain fungi are also capable of utilizing paraffins as sources of energy. Tausson ${ }^{119}$ found that Asp. flavus decomposed paraffin of a high melting point $\left(+78^{\circ}\right)$, with an economic coefficient of 53 to 66.5 per cent. A white Penicillium has been found ${ }^{120}$ to be capable of using paraffin as the only source of energy.

Bact. aliphaticum isolated from the soil is capable of decomposing quantitatively benzol, $n$-hexan $\left(\mathrm{CH}_{3}\left(\mathrm{CH}_{2}\right)_{4} \mathrm{CH}_{3}\right)$, n-octan $\left(\mathrm{CH}_{3}\left(\mathrm{CH}_{2}\right)_{6^{-}}\right.$ $\left.\mathrm{CH}_{3}\right)$, (di-iso-amyl $\left(\left(\mathrm{CH}_{3}\right)_{2} \mathrm{CH}\left(\mathrm{CH}_{2}\right)_{4} \cdot \mathrm{CH}\left(\mathrm{CH}_{3}\right)_{2}\right)$, $n$-hexadecan $\left(\mathrm{CH}_{3}\right.$ $\left.\left(\mathrm{CH}_{2}\right)_{14} \mathrm{CH}_{3}\right)$, triocontan $\left(\mathrm{C}_{30} \mathrm{H}_{62}\right)$ and tetratriocontan $\left(\mathrm{C}_{34} \mathrm{H}_{70}\right)$, but not naphthenes. ${ }^{121}$ Bact. aliphaticum liquefaciens decomposes small quantities of naphthenes; the physical constants of the corresponding hydrocarbon change thereby giving higher values. The organism can be used for testing the purity of naphthene hydrocarbons and for the separation of aliphatic hydrocarbons from naphthenes, since the former are decomposed quantitatively.

${ }^{117}$ Greig-Smith, 1912 (p. 760).

${ }^{118}$ Söhngen, N. L. Benzin, Petroleum, Paraffinöl und Paraffin als Kohlenstoffund Energiequelle für Mikroben. Centrbl. Bakt. II, 37: 595-609. 1913.

${ }^{119}$ Tausson, W. O. Zur Frage über Assimilation des Paraffins durch Mikroorganismen. Biochem. Ztschr., 155: 356-368. 1925.

${ }_{120}$ Rahn, O. Ein Paraffin zersetzender Schimmelpilz. Centrbl. Bakt., 16: 382-384. 1906.

121 Tausz and Peter, 1920 (p. 408). 
Benzene ring compounds, including phenol, cresol and naphthalene disappear rapidly in the soil, due largely to the action of various bacteria (Mycobacteria; large, sporangia-producing rods, and short, oval pseudomonads). ${ }^{122}$ However, Sen Gupta ${ }^{123}$ found that the disappearance of phenol in the soil is caused largely by the catalytic action of manganese oxide.

Decomposition of glucosides and monosaccharides. Glucosides are widely distributed in the plant kingdom and are, therefore, introduced into the soil by various bacteria and fungi. The first products of hydrolysis are glucose and aromatic compounds, as shown in the case of amygdalin:

$$
\underset{\text { Amygdalin }}{\mathrm{C}_{20} \mathrm{H}_{27} \mathrm{NO}_{11}}+2 \mathrm{H}_{2} \mathrm{O}=2 \mathrm{C}_{6} \mathrm{H}_{12} \mathrm{O}_{6}+\underset{\begin{array}{c}
\text { Benzal- } \\
\text { dehyde }
\end{array}}{\mathrm{C}_{7} \mathrm{H}_{6} \mathrm{O}}+\mathrm{HCN}
$$

Salicin is decomposed into glucose and saligenin:

$$
\mathrm{C}_{13} \mathrm{H}_{18} \mathrm{O}_{7}=\mathrm{C}_{6} \mathrm{H}_{12} \mathrm{O}_{6}+\mathrm{C}_{7} \mathrm{H}_{8} \mathrm{O}_{2}
$$

The hydrolysis of indican $\left(\mathrm{C}_{14} \mathrm{H}_{17} \mathrm{NO}_{6}\right)$ with the formation of glucose and indoxyl $\left(\mathrm{C}_{8} \mathrm{H}_{6} \mathrm{NO}\right)$, which changes in the air to indigo blue $\left(\mathrm{C}_{16} \mathrm{H}_{10} \mathrm{~N}_{2} \mathrm{O}_{2}\right)$ belongs also to this type of reaction. ${ }^{124}$ The glucose is used by a great variety of microorganisms, benzaldehyde or the other benzol ring compounds are decomposed sooner or later, as well as hydrocyanic acid.

Monosaccharides are decomposed by the great majority of heterotrophic microorganisms inhabiting the soil. The nature of the reaction depends upon the organism concerned and environmental conditions. Under certain conclitions, the sugar is broken up to $\mathrm{CO}_{2}$ and $\mathrm{H}_{2} \mathrm{O}$, liberating the maximum amount of energy; under other conditions, acids, alcohols or both, with or without gases $\left(\mathrm{H}_{2}, \mathrm{CH}_{4}, \mathrm{CO}_{2}\right)$ are formed. The organic acids commonly formed by fungi are gluconic, citric, oxalic and fumaric; by bacteria: butyric, lactic, acetic, propionic, valerianic, formic, etc. Among the other products formed, largely by bacteria, we find alcohols, including ethyl-, methyl- and butyl-, and acetone. These substances are usually oxidized further or are resynthesized, with the result that complex products are formed again.

122 Thornton, H. The destruction of aromatic antiseptics by soil bacteria. Nature, 111: 347. 1923.

${ }^{123}$ Sen Gupta, N. N. Dephenolisation in soil. Jour. Agr. Sci., 11: 136-158 $1921 ; 15: 497-515.1925$.

12:4 Behrens, J. Glycosidspaltungen und Oxydasenwirkungen. Lafar's Handb. techn. Mykol., 1: 641-695. 1904. 
Just as glucuronic acid in the animal body, gluconic acid is the first product in the decomposition of glucose by fungi. ${ }^{125} \mathrm{Asp}$. niger produced both gluconic $\left(\mathrm{C}_{6} \mathrm{H}_{12} \mathrm{O}_{7}\right)$ and citric acids $\left(\mathrm{C}_{6} \mathrm{H}_{8} \mathrm{O}_{7}\right)$ from glucose, the latter being formed in more acid and the former in less acid media; neither is intermediary to the formation of the other; both are decomposed further to oxalic acid $\left(\mathrm{C}_{2} \mathrm{H}_{2} \mathrm{O}_{4} \cdot 2 \mathrm{H}_{2} \mathrm{O}\right)$. The presence of $\mathrm{CaCO}_{3}$ in the medium will favor the formation of gluconic acid; its absence or a high acidity of the medium will favor the formation of citric acid. Out of $215 \mathrm{gm}$. of sugar decomposed (in $1200 \mathrm{cc}$. of medium containing 0.15 per cent $\mathrm{NH}_{4} \mathrm{NO}_{3}$ ), there were formed 19 grams of fungus mycelium, 63.7 grams gluconic acid, 57.3 grams citric acid and 24.2 grams oxalic acid. ${ }^{26}$

According to Aubel, ${ }^{127}$ hexoses are acted upon by Bact. pyocyaneum in the following manner:

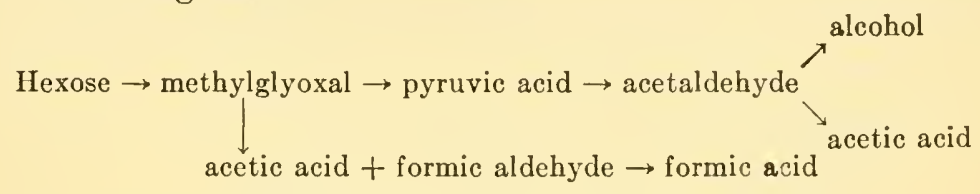

Bact. coli changes glucose to ethyl alcohol, lactic and acetic acids, $\mathrm{CO}_{2}$ and $\mathrm{H}_{2}$.

$$
2 \mathrm{C}_{6} \mathrm{H}_{12} \mathrm{O}_{6}+\mathrm{H}_{2} \mathrm{O}=2 \mathrm{C}_{3} \mathrm{H}_{6} \mathrm{O}_{3}+\mathrm{C}_{2} \mathrm{H}_{4} \mathrm{O}_{2}+\mathrm{C}_{2} \mathrm{H}_{5} \mathrm{OH}+\mathrm{H}_{2}+2 \mathrm{CO}_{2}
$$

As an instance of the chemistry of decomposition of starch or sugar under anaerobic conditions, it is sufficient to illustrate the action of Bac. acetoethylicum. ${ }^{128}$

$$
\mathrm{H}_{2}+\mathrm{CO}_{2}+\left.\mathrm{CH}_{\mathrm{CH}_{3} \cdot \mathrm{CH}_{2} \cdot \mathrm{OH}}\right|_{\mathrm{CH}_{3}} \cdot \mathrm{COOH} \leftarrow \mathrm{H}_{2}+\mathrm{CH}_{3} \cdot \mathrm{CO} \cdot \mathrm{COOH}+\mathrm{H}_{2} \rightarrow \mathrm{CH}_{3} \cdot \mathrm{CHOH} \cdot \mathrm{COOH}
$$

${ }^{125}$ Falck, R., and Kiuyma, B. Methodisches und Prinzipielles zur Darstellung organischer Säuren auf biologischen Wege mit Hilfe von Fadenpilzen. Ber. deut. chem. Gesell., 57: 915-920, 920-923. 1924.

${ }^{126}$ Butkewitsch, W. Úber die Bildung der Glukon-und Citronsäure in den Pilzkulturen auf Zucker. Biochem. Ztschr., 154: 177-190. 1924; Jahrb. wiss. Bot., 64: 636-650. 1925. See also Berhauer, K. Zum Problem der Säurebildung durch Aspergillus niger. Ibid., 153: 517-521. 1924.

${ }^{127}$ Aubel, E. Attaque du glucose et du lévulose par le bacille pyocyanique. Compt. Rend. Acad. Sci., 175: 1493-1495. 1921.

${ }^{128}$ Northrop, J. H., Ashe, L. H., and Senior, J. K. Biochemistry of Bacillus acetoethylicum with reference to the formation of acetone. Jour. Biol. Chem., 
The action of Bac. granulobacter pectinovorum upon starch, pentoses and hexoses results ${ }^{129}$ in the formation of acetone, butyl alcohol, hydrogen and carbon dioxide, with various acids (butyric, acetic, lactic) as intermediary products. When aliphatic compounds with carboxyl groups are acted upon by Bact. pyocyaneum, they become alkaline as a result of the oxidation of the carboxyl groups. Compounds containing $-\mathrm{CHO}$ or $-\mathrm{OH}=\mathrm{CO}-$ groups become acid as a result of oxidation. ${ }^{130}$

The formation of butyric acid by the various butyric acid bacteria under anaerobic conditions can be represented as follows:

$$
\mathrm{C}_{6} \mathrm{H}_{12} \mathrm{O}_{6}=\mathrm{C}_{4} \mathrm{H}_{8} \mathrm{O}_{2}+2 \mathrm{CO}_{2}+2 \mathrm{H}_{2}
$$

This process is much more complex than represented by the above reaction, since other acids and various alcohols are also formed. The acid itself may be formed as a result of the synthetic processes rather than by direct decomposition. ${ }^{131}$

$$
\begin{aligned}
& \mathrm{C}_{6} \mathrm{H}_{12} \mathrm{O}_{6}=2 \mathrm{CH}_{3} \cdot \mathrm{CO} \cdot \mathrm{COOH}+2 \mathrm{H}_{2} \cdot \\
& 2 \mathrm{CH}_{3} \cdot \mathrm{CO} \cdot \mathrm{COOH}=\mathrm{CH}_{3} \cdot \mathrm{COH} \cdot \mathrm{COOH} \\
& \quad \begin{array}{c}
\mathrm{CH}_{2} \\
\text { Aldole }
\end{array} \\
& \mathrm{C}_{6} \mathrm{H}_{8} \mathrm{O}_{6}=2 \mathrm{CO}_{2}+\mathrm{C}_{4} \mathrm{H}_{8} \mathrm{O}_{2} \cdot \\
& 2 \mathrm{CH}_{3} \cdot \mathrm{CO} \cdot \mathrm{COOH} \rightarrow \mathrm{CH}_{3} \cdot \mathrm{CHO}+\mathrm{CO}_{2} \\
& 2 \mathrm{CH}_{3} \cdot \mathrm{CHO}+\mathrm{H}_{2} \mathrm{O}=\mathrm{CH}_{3} \cdot \mathrm{COOH}+\mathrm{CH}_{3} \cdot \mathrm{CH}_{2} \cdot \mathrm{OH} .
\end{aligned}
$$

Decomposition of organic acids. Fatty-acids are thus formed from poly- and mono-saccharides, from proteins and their derivatives. When neutralized, these acids serve as good sources of energy for various bacteria and fungi. The great majority of heterotrophic bacteria can utilize malic, citric, fumaric, glyceric, succinic, formic, lactic, mucic, and tartaric acids; a small number utilize acetic, propionic, quinonic

39: 1-21. 1919; Speakman, H. B. The biochemistry of acetone formation from sugars by Bacillus acetoethylicum. Jour. Biol. Chem., 64: 41-52. 1921.

${ }^{129}$ Speakman, H. B. Molecular configuration in the sugars and acid production by Bacillus granulobacter pectinovorum. Jour. Biol. Chem., 58: 395-413. 1923.

${ }^{1 s 0}$ Supniewski, J. Recherches sur la transformation des combinaisons carbonés par le Bacille pyocyanique. Compt. Rend. Soc. Biol., 89: 1377-1379. 1923.

181 Neuberg, C., and Arinstein, B. Vom Wesen der Buttersäure und Butylalkoholgärung. Biochem. Ztschr., 117: 269-314. 1921. 
acids. Maleic, $\beta$-oxy-butyric, $\alpha$-oxy-butyric and oxalic acids are utilized only to a very limited extent. The decomposition of these acids results in the formation of alkali carbonates, which lead to an alkaline reaction of the medium:

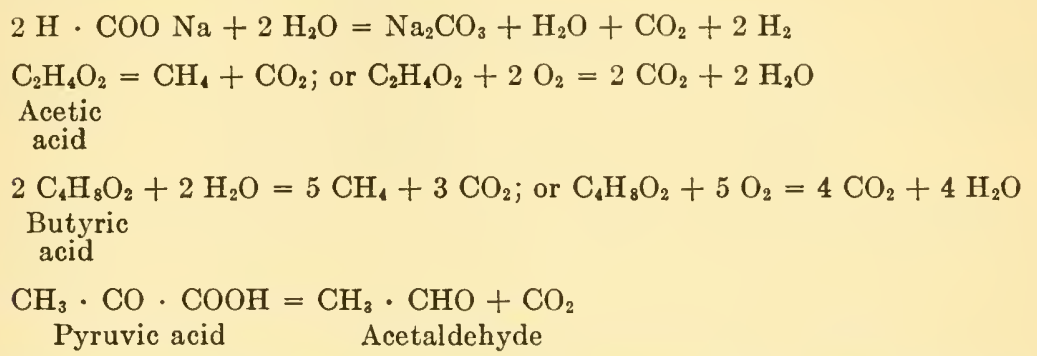

Fumaric acid is decomposed by Bact. pyocyaneum ${ }^{132}$ to the lower fatty acids, chiefly acetic; pyruvic acid may also be isolated.

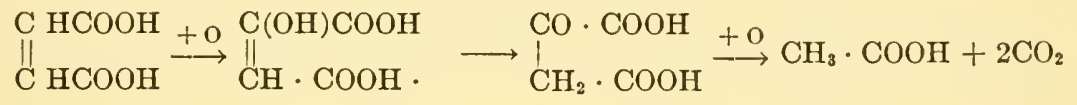

The rôle of pyruvic acid in fermentation processes (anaerobic utilization of energy) suggested by Neuberg and associates found support in various investigations on the nutrition of bacteria. ${ }^{133}$

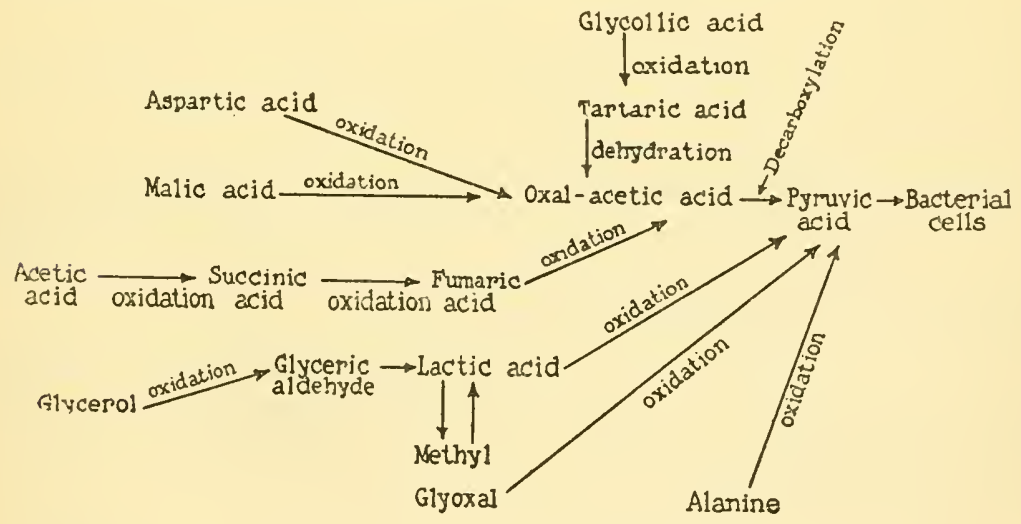

${ }^{132}$ Quastel, J. H. The fermentation of the unsaturated dicarboxylic acids. I. Fumaric acid. Biochem. Jour., 18: 365-380. 1924.

${ }^{133}$ Quastel, J. H. On a possible rôle of pyruvic acid in bacterial growth. Biochem. Jour., 19: 641-644, 645-651, 652-659, 660-666. 1925. A detailed review of the subject of the transformation of the sugar molecule by bacteria is given by Schoen, M. Le problème des fermentations. Masson et Cie. Paris. 1926. 


\section{CHAPTER XIIII}

Decomposition of Proteins and Other Organic Nitrogenous Compounds by Soll Microorganisms

Most of the nitrogen added to the soil by the plowing under of sod, plant stubble, green and stable manures, is in the form of proteins and their derivatives. The same is true of the organic nitrogenous fertilizers of plant and animal origin, such as dried blood, tankage, fish scraps and cottonseed meal. These substances cannot be assimilated by higher plants as such but have to be first broken down into simple compounds. This process is carried out in the soil by the agency of microorganisms, the final product of hydrolysis being chiefly ammonia. The latter is either used by the plants as such or is oxidized further to nitrates. Nitrates are either assimilated by plants or by microorganisms, reduced by denitrifying bacteria, or washed out in the drainage waters.

The nitrogen content of cereal straw, corn cobs and leaves of trees varies from 0.40 to 0.80 per cent; of legume hay from 2 to 3 per cent; of cow manure, free from straw, about 3.5 per cent; horse manure, about 1.5 per cent; chicken manure, 2.1 per cent, on an air dry basis. ${ }^{1}$ When these substances are added to the soil they undergo a series of transformations, largely biological in nature, involving processes of hydrolysis, oxidation, reduction and synthesis. These transformations result in the liberation of nitrogen in an available form which may again be wholly or partly reassimilated by soil microorganisms, in the presence of available energy material.

Physical and chemical properties of proteins. Proteins are complex substances, consisting of carbon, hydrogen, oxygen, nitrogen, sulfur, and in some cases of phosphorus and iron. The average composition of a typical protein is as follows:
C. $\begin{gathered}\text { per cent } \\ 50,6-55 . \ldots \ldots \ldots \ldots\end{gathered}$
percent
H......... $6.5-7.3$
$15.0-19.3$
O............... 21.5-23.5

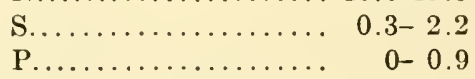

1 Thorne, C. E. Farm manures. O. Judd Co., New York. 1914. 
No molecular formula can be ascribed to the proteins and their molecular weight is still a subject of study.

Structurally, the proteins are characterized as condensation products of amino acids which are united chiefly by the peptide linkage $(\mathrm{R}-\mathrm{CO}$. $\mathrm{NH}-\mathrm{R}$ ), similar to the polypeptides. On hydrolysis by acids, alkalies, or specific enzymes, the proteins break up into the constituent amino acids. From 10 to 25 per cent of the nitrogen is present in the proteins in the unstable form of the amide linkage $\left(\mathrm{R}-\mathrm{CONH}_{2}\right)$. About 60 per cent of the nitrogen is assumed to be in the peptide linkage.

The physical properties of the proteins vary very widely. When dried in the presence of moisture, when boiled with acids and alkalies, and when acted upon by some microorganisms, the proteins show a tendency to coloration. This is due to the formation of insoluble pigmented substances, called melanins, probably related to the so-called "humins." Most proteins are soluble in water or in dilute acids or alkalies; a few, like keratin from horn, are insoluble in water and require strong acids and alkalies to bring them into solution. The proteins are amphoteric substances, being capable of combining with both acids and alkalies, neutralizing them, and causing a decrease in the hydrogenor hydroxyl-ion concentration. Coagulation, precipitation and color reactions vary with the different proteins, depending on their constitution and state of purity.

On hydrolysis by acids or enzymes, the proteins are broken down to proteoses, then to peptones and finally to amino acids, which are simple crystallizable substances. Some amino acids, like tyrosine, may appear in the early stages of hydrolysis. The proteoses and peptones consist of several groups of amino acids, these groups being smaller than the original protein. The majority of amino acids in the protein molecule are characterized by the fact that one hydrogen in the $\alpha$ position is replaced by $\mathrm{NH}_{2}$. In the case of two of the basic amino acids, viz., arginine and lysine, a second amino group is present. A third amino acid, histidine, contains an imidazol nucleus and is basic. Acetic acid, $\mathrm{CH}_{3} \mathrm{COOH}$, gives amino-acetic acid, glycocoll or glycine, $\mathrm{CH}_{2} \mathrm{NH}_{2} \mathrm{COOH}$. The general formula of a mono-amino-monocarboxylic acid is $\mathrm{R}-\mathrm{CH}\left(\mathrm{NH}_{2}\right) \mathrm{COOH}$. When two hydrogens are replaced by amino groups, we have di-amino acids.

Due to the presence of amino groups, the amino acids possess both acid and basic properties, so that glycocoll can form salts both with bases $\left(\mathrm{CH}_{2} \mathrm{NH}_{2} \mathrm{COOK}\right)$ and acids $\left(\mathrm{CH}_{2} \mathrm{NH}_{2} \mathrm{COOH} \cdot \mathrm{HCl}\right)$ under proper conditions of hydrogen-ion concentration. The dicarboxylic acids, 
the general formula of which is $\mathrm{H}_{2} \mathrm{~N} \cdot \mathrm{R}>_{\mathrm{COOH}}^{\mathrm{COOH}}$, like aspartic acid $\left(\mathrm{COOH} \cdot \mathrm{CH}_{2} \cdot \mathrm{CHNH}_{2} \cdot \mathrm{COOH}\right)$ and glutamic acid, possess properties of stronger acids than the mono-carboxylic acids. One of the carboxyls in the dibasic acids is relatively strong, the other is of about the same strength as the carboxyl groups of the ordinary mono amino acids. The three basic amino acids, arginine, histidine and lysine, are fairly strong bases and only show acid properties at extremely small hydrogen-ion concentrations, i.e., $\mathrm{pH} 12.0$ to 14.0 . When the hydroxyl group of a carboxylic acid is replaced by an amino group, an acidamide, like $\mathrm{CH}_{3} \mathrm{CONH}_{2}$ (acetamide) is formed.

A mixture of amino acids obtained by the hydrolysis of proteins can be analyzed according to Fischer's method. The diamino-acids are first separated from the mono-amino acids, by precipitation with phosphotungstic acid. Excess of $\mathrm{HCl}$ is added and the mixture of mono-amino acids is then evaporated to a sirup in vacuo and dissolved in ethyl alcohol; dry hydrochloric acid gas is passed into the solution to form the chlorides of the amino-acid esters. The esters must then be set free by neutralization of the $\mathrm{HCl}$, and extracted with ether or chloroform. The esters are separated by fractional distillation in vacuo. When a knowledge of the total proportion of the various groups of amino acids is sufficient, the method of Van Slyke affords a good procedure.

Fischer ${ }^{2}$ succeeded in combining amino acids into complex groups known as peptides, thus obtaining dipeptides $\left(\mathrm{CH}_{2} \mathrm{NH}_{2} \mathrm{CO} \cdot \mathrm{NHCH}_{2}\right.$ $\mathrm{COOH}$ or glycyl-glycine) and other polypeptides, the more complex ones approaching native proteins, in their general properties. The investigations of Fischer and associates gave strong evidence supporting the view that the protein molecule is built up of amino acids according to the following structure: $\mathrm{NH}_{2} \cdot \mathrm{CHR} \cdot \mathrm{CO}-(\mathrm{NH} \cdot \mathrm{CHR}$. $\mathrm{CO})_{\mathrm{x}}-\mathrm{NH} \cdot \mathrm{CHR} \cdot \mathrm{COOH}$. The albumins, globulins, glutelins and gliadins (or prolamins) are the most important vegetable proteins. ${ }^{3}$ The chemical nature of the different proteins is determined by the quantitative relationship of the various amino acids and their arrangement in the molecule.

${ }^{2}$ Fischer, E. Untersuchungen über Aminosïuren, Polypeptide und Proteine. Berlin. 1906.

${ }^{3}$ Osborne, T. B. The vegetable proteins. Longmans Green \& Co. 2nd ed. 1924 . 
Chemistry of protein hydrolysis. Protein decomposition by microorganisms includes a group of processes; namely, (1) hydrolysis of proteins to albumoses, peptones and amino acids, (2) deaminization resulting in the formation of ammonia, (3) formation of secondary decomposition products, such as amines, (4) completion of decomposition of proteins involving phenomena of oxidation and reduction with the formation of $\mathrm{CO}_{2}, \mathrm{H}_{2} \mathrm{O}, \mathrm{H}_{2} \mathrm{~S}$ and $\mathrm{NH}_{3}$.

When the proteins are hydrolyzed by acids and alkalies, the resulting products are amino acids and some ammonia. The latter is probably liberated as a result of the action of the acid or alkali on the amide union $\left(\mathrm{CO} \cdot \mathrm{NH}_{2}\right)$ in the protein molecule, and in the case of the alkali treatment as a result of the destruction of arginine. The larger portion of the nitrogen is present, after hydrolysis, in the form of amino groups. However, in the protein molecule, the greater portion of the nitrogen is present in imino groups (NH), with the exception of one of the two amino groups of lysine ( $\omega$ group) which exists $\mathrm{f}_{\mathrm{r}} \mathrm{ee}^{4}$ This is also true of a part of the nitrogen in histidine, arginine and tryptophane. This $\omega$ group of lysine accounts for the entire amount of amino nitrogen found in the native protein molecule on treating with nitrous acid. ${ }^{5}$ The $\alpha$-amino groups, which constitute the larger portion of the protein nitrogen, are present only condensed into peptide linkages. On hydrolysis, the free amino nitrogen increases and the peptide linkages $(\mathrm{R}-\mathrm{CO} \cdot \mathrm{NH}-\mathrm{R})$ become separated into amino and carboxyl groups. The measure of this increase in amino nitrogen can serve as an index of the process of protein hydrolysis.

Some proteins are easily hydrolyzed, while others are acted upon with great difficulty. This is very important from the point of view of the availability of nitrogen for plant growth. The action of chemical reagents and moist heat will bring about a complete hydrolysis of the proteins to amino acids and ammonia. Proteolytic enzymes usually do not break down the protein molecule completely. Some, like pepsin, split up the protein chain at one or more junctures, with-

${ }^{4}$ Van Slyke, D. D., and Birchard, F. J. The nature of the free amino groups in proteins. Jour. Biol. Chem., 16: 539-547. 1913.

'Van Slyke, D. D. The analysis of proteins by determination of the chemical groups characteristic of the different amino acids. Jour. Biol. Chem., 10: 15-55. 1911; Quantitative determination of alipathic amino groups, Ibid., 12 : 275-2S4. 1912; Improvement in the method for analysis of proteins by determination of the chemical groups characteristic of the different amino acids. Ibid., 16: 539-547. 1913; 22: 281-285. 1915. 
out forming free amino acids, but form groups (albumoses, peptones, peptides) of lower amino acid content. Other enzymes, like trypsin and erepsin, split the protein molecule more completely, bringing about the formation of free amino acids. Still other enzymes (desamidases, deaminases) act upon the amino acids and acid amides liberating ammonia.

The degradation of proteins by microorganisms proceeds along the general lines of that produced by acids or proteolytic enzymes. A further transformation of the protein derivatives takes place, however, with the production of various secondary decomposition products, such as ammonia and carbon dioxide, as well as amines, fatty acids, alcohols, aldehydes, methane, phenol, indol, skatol, hydrogen sulfide, etc. Ammonia which is so important, both from the point of view of the metabolism of microorganisms and soil fertility, is usually formed as a secondary decomposition product of the proteins; usually the amino acid is used thereby as a source of energy.

In some cases proteins form compounds with nucleic acids, giving nucleo-proteins (or protein nucleates). These compounds are present to a limited extent in all plants, animals and microorganisms, and are thus introduced into the soil. On hydrolysis, a nucleo-protein is transformed into an albumin (histone) and nuclein; the nuclein is further hydrolyzed to albumin and nucleic acid. The protein, or albumin, is decomposed by the microorganisms into albumoses, peptones, amino acids and ammonia. The presence of these substances in the soil has actually been demonstrated. ${ }^{6}$ Often several groups of organisms take part in the process; some break down the protein to amino compounds and others utilize the latter and form ammonia, as shown later. This is again comparable to the action of the different groups of enzymes.

The nucleic acids consist of $\mathrm{C}, \mathrm{H}, \mathrm{O}, \mathrm{N}$ and $\mathrm{P}$, in various proportions, depending on the source of the acids. The composition of nucleic acid from wheat is given as $\mathrm{C}_{41} \mathrm{H}_{61} \mathrm{O}_{31} \mathrm{~N}_{16} \mathrm{P}_{4}$; that of yeast, $\mathrm{C}_{36} \mathrm{H}_{48} \mathrm{O}_{30} \mathrm{~N}_{14} \mathrm{P}_{4}$. The dissociation products vary with the source of the acid; those of plant origin are phosphoric acid, guanine, adenine, cyto-

- Walters, E. H. The presence of proteoses and peptones in soils. Jour. Ind. Eng. Chem., 7: S60. 1915; Lathrop, E. C. The organic nitrogen compounds of soils and fertilizers. Jour. Frankl. Inst., 183: 169-206, 303-321, 465498. 1917; Shorey, E. C. The isolation of creatinine from soils. Jour. Amer. Chem. Soc., 34: 99-107. 1912; Nucleic aeids in soils. Science, 35: 390. 1912; Some organic soil constituents. Bur. Soils, U. S. Dept. Agr. Bul. 88. 1912. 
sine, thymine and laevulinic acid. Laevulinic acid is formed from a hexose group in the molecule of the nucleic acid. The decomposition of the nucleic acids takes place as follows: ${ }^{7}$

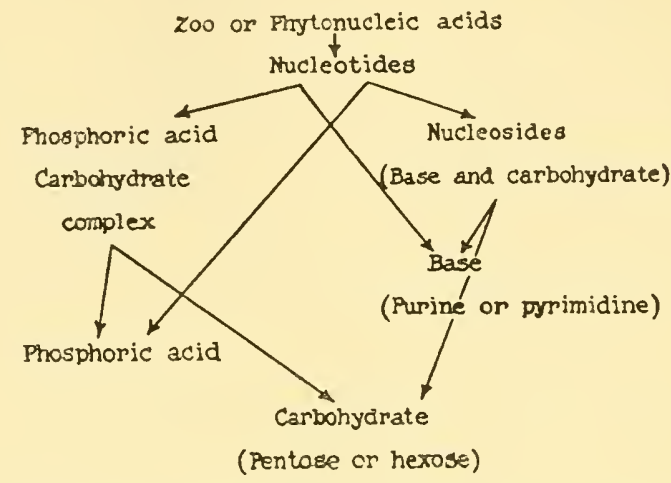

Protein decomposition by microorganisms. The course of protein decomposition by microorganisms can be followed in three different ways.

1. The disappearance of the protein. The residual protein is precipitated by means of an acid or alkali, by alcohol or other precipitating agents or by heat. The protein is determined either by weighing the dry precipitate or determining the total nitrogen in it. In the case of peptone, the biuret test may be $u^{8} d^{8}$ as a measure of its decomposition.

2. The formation of intermediary products, such as peptones or amino compounds. The first can be determined quantitatively by the biuret reaction and the second by the Van Slyke method, ${ }^{9}$ the formol titration method, ${ }^{10}$ or the Folin method. ${ }^{11}$

3. The formation of ammonia as the final product of protein decomposition.

Each of these three methods has its advantages and disadvantages. By the first method, we determine the absolute amount of protein decomposed, but we do not know how far the decomposition has pro-

${ }^{7}$ Levene, P. A. Partielle Hydrolyse der Nucleinsäuren. Abderhald. Handb. Biochem. Arbeitsm., 2: 605-609. 1911; 5: 499-499. 1911.

${ }^{8}$ Berman, N., and Rettger, L. F. The influence of carbohydrates on the nitrogen metabolism of bacteria. Jour. Bact., 3: 359-402. 1918.

${ }^{9}$ Van Slyke, 1913-14 (p. 473).

${ }^{10}$ Sörensen, S. P. L. Enzymstudien. I. Biochem. Ztschr., 7: 45. 1907.

11 Folin, O. A new colorimetric method for the determination of amino acid nitrogen in blood. Jour. Biol. Chem., 51: 377-391. 1922. 
ceded, whether to soluble polypeptide molecules or to amino acids and ammonia. The methods of precipitation are also different for the various proteins and involve differences in procedure.

The second method enables one to follow the course of protein decomposition by the increase in the amino nitrogen. ${ }^{12}$ The great disadvantage of this method is that the various microorganisms will show different increases of amino nitrogen with the same amount of protein decomposed. This is due to the fact that the different organisms, even decomposing equal amounts of proteins, will transform the intermediary products with different rapidity. The fungi, for example, will hardly allow any great increase in amino nitrogen, but will rapidly transform the intermediary products to ammonia, especially in the absence of available carbohydrate. In the presence of carbohydrate, the protein will be decomposed only to a limited extent. The bacteria and actinomyces, however, will allow a much greater accumulation of amino-nitrogen and a correspondingly lower accumulation of ammonia. The fact that the amino compounds are only intermediate products and that their accumulation depends on the presence of carbohydrates indicates that, at best, this index can be only approximate.

The third method has the advantage of measuring a final product and not an intermediate one. The fact that various organisms form ammonia from proteins with various speeds, some breaking down the protein completely and others incompletely, is an outstanding disadvantage of this method. In the presence of available carbohydrates, the ammonia may also be reassimilated by the organism as a source of nitrogen for the synthesis of its protoplasm, so that a mistaken impression may be had that no protein is decomposed.

The study of protein decomposition would be incomplete without mentioning the so-called processes of putrefaction, or decomposition of proteins in the absence of oxygen or in the presence of a limited amount of it, with the production of evil smelling gaseous products. ${ }^{13}$ This subject has been least studied from the point of view of transformation in the soil; most of the work was done in connection with pathogenic anaerobic bacteria. Putrefaction was often differentiated

12 Sears, H. J. Studies in the nitrogen metabolism of bacteria. Jour. Inf. Dis., 19: 105-137. 1916; Itano, A. The relation of hydrogen ion concentration of media to the proteolytic activity of Bacillus subtilis. Mass. Agr. Exp. Sta. Bul. 167. 1916; Waksman, $191 \mathrm{~S}$ (p. 495); Debord, J. J. Certain phases of nitrogenous metabolism in bacterial eultures. Jour. Bact., 8: 7-45. 1923.

${ }^{13}$ Flügge. Die Mikroorganismen. Leipzig. Vogel. 1S96. v. I, p. 254. 
from "decay;" the latter (often referred to as "eremacausis") was used to designate the decomposition of nitrogenous organic substances in the presence of oxygen, marked by the volatilization of organic constituents while the non-volatile mineral constituents are left behind..$^{14}$

However, both of these phenomena (putrefaction and decay) were not sufficiently understood by the old chemists and bacteriologists and did not have a proper biological or chemical basis. With the advance of our knowledge of the chemistry of proteins, particularly when it was found that ammonia and the "ill-smelling gaseous products" were by-products of secondary reactions of protein hyclrolysis, the difference between "decay" and "putrefaction," as indicating activities of special groups of bacteria, disappeared. Both of these terms may just as well be dropped from the bacteriological vocabulary, since they do not designate definite chemical processes. Like all chemical reactions brought about by biological agencies, the final products of protein decomposition are a result not only of specific microorganisms, but of various environmental conditions, such as oxygen supply and presence of non-nitrogenous substances, which determine the secondary reactions involved after the hydrolysis of the proteins has taken place. The designation of a process by the nature of these secondary reactions, as a result of environmental conditions, led to a great deal of confusion and a lack of proper understanding of the processes involved.

The first systematic study of the chemical reactions accompanying the decomposition of proteins by bacteria (in the so-called process of putrefaction) was made by Nencki. ${ }^{15}$ He found that, in the decomposition of fibrin, albumin and gelatin by bacteria, various decomposition products are formed, including leucine, tyrosine, glycocoll and indol. When gelatin was decomposed for four days at $40^{\circ} \mathrm{C}$. there were formed, for every 100 parts of gelatin, 9.5 parts of ammonia, 24.2 volatile fatty acids, 12.2 glycocoll, 19.4 peptone and 6.5 carbon dioxide, 71.8 per cent in all. Quantities of gas were also produced in the process. Nencki concluded that the decomposition of proteins takes place in two stages; viz., processes of hydrolysis and reduction and

14 Wollny, E. Die Zersetzung der organischen Stoffe. Heidelberg, Winter. 1897.

${ }_{15}$ Nencki, M. Úber die Harnfarbstoffe aus der Indigogruppe und über die Pankreasverdauung. Ber. deut. Chem. Gesell., 7: 1593-1600. 1874; 8: 336338. 1875. 
oxidation. Jeannert, ${ }^{16}$ studying the decomposition of proteins under anaerobic conditions, demonstrated among the decomposition products of gelatin, $\mathrm{CO}_{2}, \mathrm{NH}_{3}, \mathrm{H}_{2} \mathrm{~S}$, acetic-, butyric-, and valeric acids, glycocoll and leucine. These substances, except glycocoll, were also formed from albumin, in addition to hydrogen, hydrogen sulfide, tyrosine and amido-valeric acicl.

These investigations were followed by numerous others with crude and pure cultures of bacteria, whereby amino acids, fatty acids and certain gases, including $\mathrm{NH}_{3}, \mathrm{CO}_{2}$ and $\mathrm{H}_{2} \mathrm{~S}$, were demonstrated as products of hydrolysis. In the case of the so-called putrefactive organisms, indol, skatol, phenol, and other substances were also demonstrated. Bac. subtilis was found ${ }^{17}$ to produce from cotton-seed meal in five weeks: albumoses, peptones, phenyl-acetic and phenyl-propionic acids, ammonia, mercaptan, basic amines, $\mathrm{H}_{2} \mathrm{~S}$, and $\mathrm{CO}_{2}$; after three months, valerianic and indol-acetic acids, indol, skatol, and phenol were also demonstrated in the culture.

The presence of specific amino acids in the protein molecule is necessary for the formation of some of the final products. It is sufficient to mention tryptophane as a source of indol, cysteine and other sulfur compounds as a source of $\mathrm{H}_{2} \mathrm{~S}$, and tyrosine as a source of cresol and phenol.

A number of bacteria are unable to attack pure proteins; only the degradation products are acted upon. The presence of simple nitrogen compounds may be required to start the development of the organism. ${ }^{18}$ In many instances, however, even native proteins will be acted upon after the organism starts to grow and the proper enzymes are formed. Under natural conditions, the proteins are usually always accompanied by small amounts of their derivatives or by simple nitrogen compounds, especially when added to the soil.

The nature of the products formed will depend not only upon the

16 Jeannert, J. Untersuchungen über Zersetzung von Gelatine und Eiweiss durch die geformten Pankreasfermente bei Luftausschluss. Jour. prakt. Chem. N. F., 15: 353-389. 1877.

${ }^{17}$ Köönig, J., Spieckermann, A., and Olig, A. Die Zersetzung pflanzlicher Futtermittel durch Bakterien. Centrbl. Bakt. II, 10: 535-549. 1903.

${ }^{18}$ Bainbridge, F. A. The action of certain bacteria on proteins. Jour. Hyg., 11: 341-355. 1911; Sperry, J. A., and Rettger, S. F. The behavior of bacteria towards purified animal and vegetable proteins. Jour. Biol. Chem., 20: 445-459. 1915; Berman, N., and Rettger, L. F. Bacterial nutrition: further studies on the utilization of protein and non-protein nitrogen. Jour. Bact., 3: 367-388. 1918. 
environmental conditions but also upon the organisms concerned. In the great majority of cases, especially in the study of the activities of soil microorganisms, the measurement of ammonia was used as an index of protein decomposition. ${ }^{19}$

But even in the case of protein decomposition in soil, where one group of organisms readily acts upon the products formed by another, various protein derivatives are found, in addition to ammonia.

Lathrop, ${ }^{20}$ for example, found that histidine, hypoxanthine, cytosine, xanthine, nucleic acid, creatinine, cyanuric acid are of common occurrence in the soil; arginine, lysine, adenine, choline, trimethylamine occur only infrequently in the soil. This leads to the assumption that a part of the proteins and other organic nitrogenous compounds are accumulating in the soil, originating from plant residues, stable manure, green manure, organic fertilizers and the bodies of microorganisms. Lathrop analyzed, by the Van Slyke method, soils to which proteins (dried blood) had been added, at the beginning of the experiment and at the end of various periods of incubation. Even after a 240-day period of decomposition of dried blood in the soil, proteins, or proteinlike complexes, insoluble in distilled water, but extractable by dilute alkaline solution, were found to be present in the soil. It is not known, however, whether these proteins are residues from the dried blood which have resisted decomposition by the soil microorganisms, or whether they are synthesized materials or constituents of the bodies of the latter. Evidence was obtained to indicate that a formation of new protein material takes place in the soil in the course of decomposition of proteins and this new protein is perhaps somewhat resistant to decomposition. Protein-like bodies giving reactions for proteoses and peptones have also been isolated from the soil. ${ }^{21}$

Miyake ${ }^{22}$ found that fatty amino compounds seem to be transformed into ammonia more easily than aromatic compounds; aromatic imino compounds are decomposed with greater difficulty than the aromatic amino compounds. The nature of the other group in the molecule

${ }^{19}$ A detailed review of the extensive literature on ammonia formation in the decomposition of organic matter, up to 1910, is given by Voorhees and Lipman, 1907 (p. 491) and Lohnis, 1910 (p. xiii).

${ }^{20}$ Lathrop, 1917 (p. 474).

${ }^{21}$ Walters, 1915 (p. 474).

${ }^{22}$ Miyake, $\mathrm{K}$. Influence of the chemical structure of the compounds to be ammonified upon the rate of ammonification. Jour. Amer. Chem. Soc., 39: 2378-2382. 1917. 
does not seem to have any influence upon the rate of transformation of imino nitrogen into ammonia nitrogen.

These results tend to indicate that a simple observation of the amount and rate of ammonia formation need not necessarily indicate the course of protein decomposition. A certain set of conditions will lead to the formation of one group of compounds by bacteria from a certain protein, while another group of compounds will be formed from the same protein under different conditions. It was also generally assumed ${ }^{23}$ that the rapid oxidation of proteins may result in the liberation of elementary nitrogen, according to the reaction:

$$
4 \mathrm{NH}_{3}+3 \mathrm{O}_{2}=6 \mathrm{H}_{2} \mathrm{O}+2 \mathrm{~N}_{2}
$$

However, the work of Ehrenberg ${ }^{24}$ pointed to the negligible loss of nitrogen from this source. Appreciable losses may occur either through direct volatilization of ammonia or by leaching of nitrates.

Chemistry of ammonia formation in the decomposition of proteins by microorganisms. Müntz ${ }^{25}$ was the first to demonstrate in 1890 that organic matter is decomposed by organisms with the formation of ammonia, which is only then nitrified. In soils in which nitrification has been stopped by the use of heat or disinfectants, ammonia accumulates, indicating that this treatment was sufficient to kill the organisms oxidizing ammonia to nitrate, but not those that produce ammonia from proteins. Müntz and Coudon ${ }^{26}$ have further shown that no ammonia was formed during two and one-half years in sterilized soil, while the unsterilized soil produced, in sixty-seven days, 41 to 100 mgm. of ammonia per 100 grams of soil. These investigations were followed by those of $\mathrm{Marchal}^{27}$ and numerous others which pointed to the importance of ammonia formation in the soil and the rôle of microorganisms in its formation from proteins. This was found to be not a specific property of certain bacteria, but a function of a large number of microorganisms.

23 Voorhees and Lipman, 1907 (p. 491), p. 49.

24 Ehrenberg, 1907 (p. 268).

${ }^{25}$ Müntz, A. Sur la décomposition des engrais organiques dans le sol. Compt. Rend. Acad. Sci., 110: 1206-1209. 1890.

${ }^{26}$ Müntz, A., and Coudon, H. La fermentation ammoniacale de la terre. Compt. Rend. Acad. Sci., 116: 395-398. 1893.

${ }^{27}$ Marchal, E. Sur la production de l'ammoniaque dans le sol par les microbes. Bull. Acad. Roy. Sci. Belg., (3), 25: 728-738; 27: 71-103. 1895; Centrbl. Bakt. II, 1: 753-758. 1895. 
When proteins are hydrolyzed by means of acids or enzymes, only 10 per cent of the total nitrogen in casein and 25 per cent in gliadin is liberated as ammonia, as a result of the breaking of the acid amide $\left(-\mathrm{CO} \cdot \mathrm{NH}_{2}\right)$ linkages. When proteins are acted upon by microorganisms, especially when those are used as sources of energy, large quantities of ammonia will be produced as a waste product. Seventyfive per cent or more of the protein-nitrogen can be found to accumulate in the soil in the form of ammonia within a few days, with proteins as the only source of energy. The ammonia is produced by a series of chemical changes which depend upon the nature of the organism, presence of nutrients other than amino acids (such as available carbohydrates), oxygen tension, and other conditions under which the reactions take place.

Ammonia formation from amino acids may involve processes of hydrolysis, oxidation or reduction, or a combination of two or all, resulting in the splitting of the amino group or the carboxyl group or both. The various reactions may be summarized, as follows:

1. Hydrolytic decomposition:

$$
\begin{aligned}
& \mathrm{NH} \cdot \mathrm{C}\left(\mathrm{NH}_{2}\right) \cdot \mathrm{NH} \cdot\left(\mathrm{CH}_{2}\right)_{3} \cdot \mathrm{CH}\left(\mathrm{NH}_{2}\right) \cdot \mathrm{COOH}+\mathrm{H}_{2} \mathrm{O}= \\
& \text { arginine } \\
& \mathrm{CH}_{2}\left(\mathrm{NH}_{2}\right) \cdot \mathrm{CH}_{2} \cdot \mathrm{CH}_{2} \cdot \mathrm{CH}\left(\mathrm{NH}_{2}\right) \cdot \mathrm{COOH}+\mathrm{CO}\left(\mathrm{NH}_{2}\right)_{2} \\
& \text { ornithine } \\
& \text { urea }
\end{aligned}
$$

The hydrolysis of an amino acid may result in the formation of a lower fatty acid and ammonia, of an alcohol, $\mathrm{CO}_{2}$ and ammonia, or of an aldehyde, lower acid and ammonia, as shown by the general formulae:

$$
\begin{aligned}
& \mathrm{R} \cdot \mathrm{CH} \cdot \mathrm{NH}_{2} \cdot \mathrm{COOH}+\mathrm{H}_{2} \mathrm{O}=\mathrm{R} \cdot \mathrm{CHOH} \cdot \mathrm{COOH}+\mathrm{NH}_{3} \\
& \mathrm{R} \cdot \mathrm{CH} \cdot \mathrm{NH}_{2} \cdot \mathrm{COOH}+\mathrm{H}_{2} \mathrm{O}=\mathrm{R} \cdot \mathrm{CH}_{2} \mathrm{OH}+\mathrm{CO}_{2}+\mathrm{NH}_{3} \\
& \mathrm{R} \cdot \mathrm{CH} \cdot \mathrm{NH}_{2} \cdot \mathrm{COOH}+\mathrm{H}_{2} \mathrm{O}=\mathrm{R} \cdot \mathrm{CHO}+\mathrm{H} \cdot \mathrm{COOH}+\mathrm{NH}_{3}
\end{aligned}
$$

These processes are carried out by various aerobic organisms. ${ }^{28}$ Formula (2) is of common occurrence among bacteria, ${ }^{29}$ fungi and yeasts, ${ }^{30}$ as in the case of formation of isoamyl alcohol from leucine.

${ }^{28}$ Dakin, H. D. The oxidation of leucin and amido-isovaleric acid and of amido- $n$ valeric acid with hydrogen peroxide. Jour. Biol. Chem., 4: 63-76. 1908; Ehrlich, F., and Jacobsen, A. Über die Umwandlung von Aminosïuren in Oxysäuren durch Schimmelpilze. Ber. deut. Chem. Gesell., 44: 888. 1911; (Centrbl. Bakt. II, 33: 346-347. 1912).

${ }^{29}$ Nawiasky, P. Úber die Umsetzung von Aminosïuren durch Bac. proteus vulgaris. Arch. Hyg., 66: 209-243. 1908; also 64: 33-61. 1908.

${ }^{30}$ Ehrlich, F. Ueber die Entstehung des Fuselöls. Ztschr. Ver. Deut. Zuckerind. Tech. T. N. S., 42: 539-567. 1905. 
According to Ehrlich, ${ }^{30}$ the reaction takes place as follows:

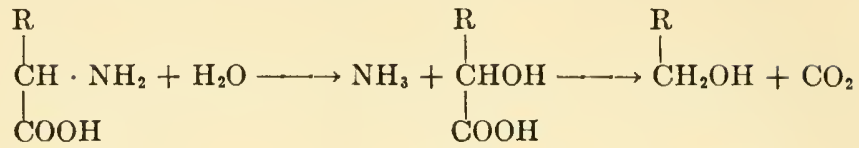

$$
\begin{aligned}
& \text { Amino acid Hydroxy- Alcohol } \\
& \text { fatty acid } \\
& \mathrm{CH}_{3} \cdot \mathrm{CHNH}_{2} \cdot \mathrm{COOH}+\mathrm{H}_{2} \mathrm{O}=\mathrm{CH}_{3} \cdot \mathrm{CH}_{2} \mathrm{OH}+\mathrm{NH}_{3}+\mathrm{CO}_{2} \\
& \text { Alanine } \\
& \begin{array}{l}
\mathrm{CH}_{3} \\
\mathrm{CH}_{3}
\end{array}>\mathrm{CH} \cdot \mathrm{CH}_{2} \cdot \mathrm{CH} \cdot \mathrm{NH}_{2} \cdot \mathrm{COOH}+\mathrm{H}_{2} \mathrm{O}=\mathrm{NH}_{3}+ \\
& \text { Leucine } \\
& \stackrel{\mathrm{CH}_{3}}{\mathrm{CH}_{3}}>\mathrm{CH} \cdot \mathrm{CH}_{2} \cdot \mathrm{CHOH} \cdot \mathrm{COOH} \stackrel{+\mathrm{H}_{2}}{\longrightarrow}
\end{aligned}
$$

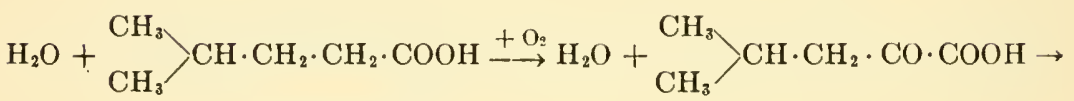

$$
\begin{aligned}
& \text { Caproic acid } \\
& \mathrm{CO}_{2}+\underset{\mathrm{CH}_{3}}{\stackrel{\mathrm{CH}_{3}}{>}}>\mathrm{CH} \cdot \mathrm{CH}_{2} \cdot \mathrm{CHO} \stackrel{+\mathrm{H}_{2}}{\longrightarrow} \underset{\mathrm{CH}_{3}}{\mathrm{CH}_{3}}>\mathrm{CH} \cdot \mathrm{CH}_{2} \cdot \mathrm{CH}_{2} \mathrm{OH} \rightarrow \\
& \stackrel{+\mathrm{O}_{2}}{\longrightarrow} \mathrm{H}_{2} \mathrm{O}+\underset{\substack{\mathrm{CH}_{3} \\
\text { iso-valerianic acid. }}}{\stackrel{\mathrm{CH}_{3}}{>}}>\mathrm{CH} \cdot \mathrm{CH}_{2} \cdot \mathrm{COOH}
\end{aligned}
$$

2. Decarboxylation:

$$
\begin{aligned}
& \mathrm{R} \cdot \mathrm{CH} \cdot \mathrm{NH}_{2} \cdot \mathrm{COOH}=\mathrm{R} \cdot \mathrm{CH}_{2} \cdot \mathrm{NH}_{2}+\mathrm{CO}_{2} \\
& \mathrm{R} \cdot \mathrm{CH}_{2} \cdot \mathrm{NH}_{2}+\mathrm{H}_{2} \mathrm{O}=\mathrm{R} \cdot \mathrm{CH}_{2} \cdot \mathrm{OH}+\mathrm{NH}_{3}
\end{aligned}
$$

This process of amino acid dccomposition through the amine stage, with the formation of alcohol and ammonia, has been described for yeasts and fungi. ${ }^{31}$ The first part of the process, namely the formation of amines, is characteristic of the so-called putrefaction processes. ${ }^{32}$ The transformation of amino acids into nitrogen bases is found to take place in the formation of para-oxy-phenyl-ethylamine from tyrosine, of pentamethyl-diamine (cadaverine) from lysine, of tetramethylenediamine (putrescin) from ornithine, etc.

${ }^{31}$ Ehrlich, F., and Pistchimuka, P. Überführung von Aminen in Alkohole durch Hefe und Schimmelpilze. Ber. deut. chem. Gesell., 45: 1006-1012. 1912.

3" Rettger, L. F. Studies on putrefaction. Jour. Biol. Chem., 2: 71-96. $1906 ; 4: 45-55.1907 ; 13: 341-346.1912$. 
$\mathrm{OH} \cdot \mathrm{C}_{6} \mathrm{H}_{4} \mathrm{CH}_{2} \cdot \mathrm{CH} \cdot \mathrm{NH}_{2} \cdot \mathrm{COOH}=\mathrm{OH} \cdot \mathrm{C}_{6} \mathrm{H}_{4} \cdot \mathrm{CH}_{2} \cdot \mathrm{CH}_{2} \cdot \mathrm{NH}_{2}+\mathrm{CO}_{2}$ tyrosine

A mono-amino di-carboxylic acid may lose a $\mathrm{CO}_{2}$ group, with the formation of a mono-carboxylic acid:

$$
\underset{\text { Aspartic acid }}{\mathrm{HOOC}} \cdot \mathrm{CH}_{2} \cdot \mathrm{CH} \cdot \mathrm{NH}_{2} \mathrm{COOH}=\underset{\beta \text {-alanine }}{\mathrm{CH}_{2}} \cdot \underset{\mathrm{CH}_{2}}{\mathrm{NH}_{2}} \cdot \mathrm{COOH}+\mathrm{CO}_{2}
$$

3. Reductive deaminization:

$$
\mathrm{R} \cdot \mathrm{CH} \cdot \mathrm{NH}_{2} \cdot \mathrm{COOH}+\mathrm{H}_{2}=\mathrm{R} \cdot \mathrm{CH}_{2} \cdot \mathrm{COOH}+\mathrm{NH}_{8}
$$

or

$$
\mathrm{R} \cdot \mathrm{CH} \cdot \mathrm{NH}_{2} \cdot \mathrm{COOH}+\mathrm{H}_{2}=\mathrm{R} \cdot \mathrm{CH}_{3}+\mathrm{NH}_{3}+\mathrm{CO}_{2}
$$

This process of reduction is carried on by anaerobic bacteria, which reduce the $\alpha$-amino acids, with the formation of saturated fatty acids and ammonia. As instances, one may cite the formation of acetic acid and ammonia, or methane, $\mathrm{CO}_{2}$ and ammonia, from glycocoll, as well as the following reactions:

$$
\begin{aligned}
& \mathrm{C}_{6} \mathrm{H}_{5} \cdot \mathrm{CH}_{2} \cdot \mathrm{CH} \cdot \mathrm{NH}_{2} \cdot \mathrm{COOH}+\mathrm{H}_{2}=\mathrm{C}_{6} \mathrm{H}_{6} \cdot \mathrm{CH}_{2} \cdot \mathrm{CH}_{2} \cdot \mathrm{COOH}+\mathrm{NH}_{3} \\
& \text { Phenyl-alanine Phenyl-propionic acid } \\
& \mathrm{COOH} \cdot \mathrm{CH}_{2} \cdot \mathrm{CH} \cdot \mathrm{NH}_{2} \cdot \mathrm{COOH}+\mathrm{H}_{2}=\left(\mathrm{CH}_{2}\right)_{2} \cdot(\mathrm{COOH})_{2}+\mathrm{NH}_{3} \\
& \text { aspartic acid succinic acid }
\end{aligned}
$$

The formation of butyric acid takes place according to the same reaction:

$$
\begin{gathered}
\mathrm{COOH} \cdot \mathrm{CH}_{2} \cdot \underset{\text { glutamic acid }}{\mathrm{CH}_{2} \cdot \mathrm{CH} \cdot \mathrm{NH}_{2} \cdot \mathrm{COOH}+\mathrm{H}_{2}=} \\
\underset{\text { butyric acid }}{\mathrm{CH}_{3}} \cdot \underset{\mathrm{CH}_{2}}{\mathrm{CH}_{2}} \cdot \mathrm{COOH}+\mathrm{NH}_{3}+\mathrm{CO}_{2}
\end{gathered}
$$

4. Anaerobic bacteria may produce ammonia from amino acids, without reduction. ${ }^{33}$

$$
\mathrm{R} \cdot \mathrm{CH}_{2} \cdot \mathrm{CH} \cdot \mathrm{NH}_{2} \cdot \mathrm{COOH}=\mathrm{R} \cdot \mathrm{CH}: \mathrm{CH} \cdot \mathrm{COOH}+\mathrm{NH}_{3}
$$

5. Oxidative deaminization:

$$
\mathrm{R} \cdot \mathrm{CH} \cdot \mathrm{NH}_{2} \cdot \mathrm{COOH}+\mathrm{O}_{2}=\mathrm{R} \cdot \mathrm{COOH}+\mathrm{NH}_{3}+\mathrm{CO}_{2}
$$

This process is carried out by aerobic organisms, especially by fungi. ${ }^{34}$ As

${ }^{33}$ Raistrick, H. Studies on the eycloclastic power of bacteria. I. A quantitative study of the aerobic decomposition of histidine by bacteria. Biochem. Jour., 13: 446-458. 1919.

${ }^{34}$ Dakin, H. D. Oxidations and reductions in the animal body. 2nd ed., Longmans, Green \& Co. 1922; Ehrlich and Jacobsen, 1912 (p. 481 ). 
examples of this reaction, the transformation of leucine into isovaleric acid, ${ }^{35}$ as shown above, of glutamic acid into succinic acid may be cited:

IIOOC $\cdot \mathrm{CH}_{2} \cdot \mathrm{CH}_{2} \cdot \mathrm{CH} \cdot \mathrm{NH}_{2} \cdot \mathrm{COOH}+\mathrm{O}_{2}=\mathrm{HOOC} \cdot \mathrm{CH}_{2} \cdot \mathrm{CH}_{2} \cdot \mathrm{COOH}+\mathrm{NH}_{3}+\mathrm{CO}_{2}$ glutamic acid

The decomposition of one amino acid may involve the reactions of oxidation, deaminization, decarboxylation and reduction. The same organism may bring about a series of these reactions, while different results may be obtained by the same organism under different conditions.

The transformation of tyrosine takes place according to the following reactions:
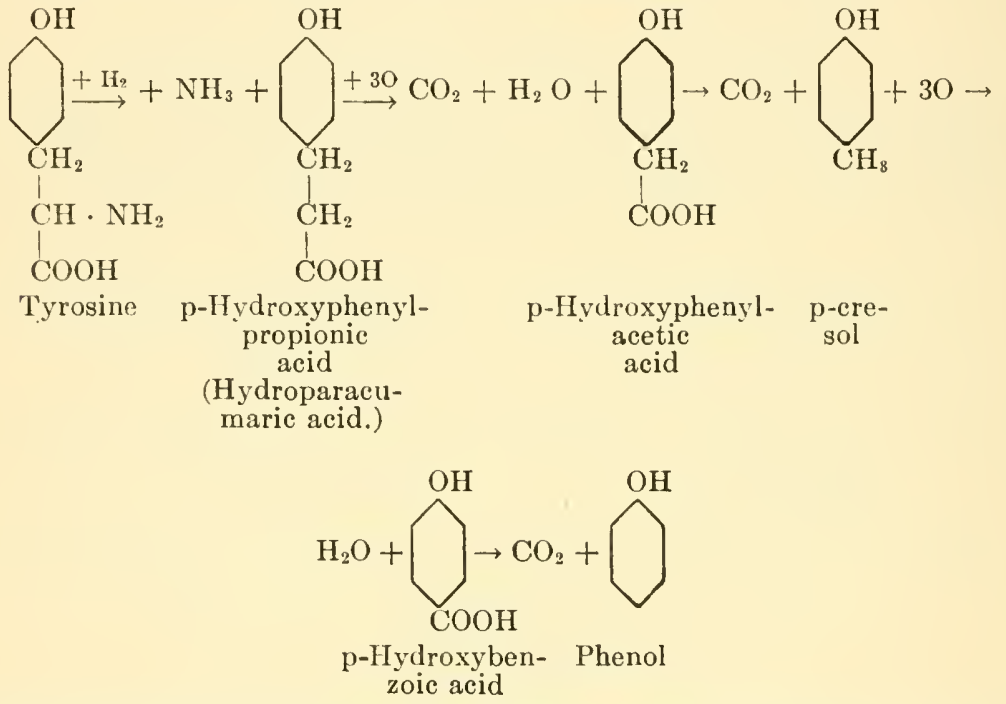

Tyrosine may also be decomposed to homogentisic acid, ammonia and carbon dioxide, as shown by Beijerinck ${ }^{36}$ for an actinomyces.

Aeration conditions have an important influence upon the nature of the products formed from the decomposition of the amino acids. Products formed under aerobic conditions, such as hydroxy acids, may prove unstable under anaerobic conditions, and vice versa. P-hydroxy-phenyl-propionic acid is formed from tyrosine under anaerobic conditions; it is oxidized to p-cresol and phenol when air is admitted.

The acids formed in the process of deaminization give rise to calcium salts. These are broken down to carbonates and the ammonia is oxidized to nitrates. The amines formed from decarboxylation are, however, more resistant to bacterial action. In the case of optically

${ }^{35}$ Nencki, M. Über den chemischen Mechanismus der Fäulniss. Jour. prakt. Chem., 17: 105-124. 1878.

${ }^{36}$ Beijerinck, M. W. On the composition of tyrosinase from two enzymes. K. Akad. Wetenschappen Amsterdam., 15: 932-937. 1913. 
active amino acids, both forms are attacked, at equal or unequal rates. In the case of glutamic acid, the rate is the same. ${ }^{37}$

The amides are also readily broken down by various microorganisms, especially in the presence of available energy. Bact. vulgare will almost completely hydrolyze asparagine to ammonia and aspartic acid in twenty-four hours. The acid is changed, at the same time, to succinic acid, or acetic acid and ammonia. Bact. pyocyaneum ${ }^{38}$ attacks readily aliphatic and cyclic amino acids as sources of energy, but not benzene derivatives ( $\mathrm{p}$ - or $\mathrm{m}$-amino-benzene). It decomposes tyrosine completely; tryptophane is broken down to $\left(\mathrm{NH}_{4}\right)_{2} \mathrm{CO}_{3}$ and indol; the indol is converted to anthranilic acid. In the decomposition of amino acids by Bact. pyocyaneum, the carboxyl group is first removed and ammonia is then formed. ${ }^{39}$

Decomposition of organic nitrogenous compounds of a non-protein nature. In addition to proteins, other organic nitrogen compounds, like lecithine, methylated amines, purine bases and other substances present in plant or animal tissues and found in the soil ${ }^{40}$ are acted upon by microorganisms with the formation of simpler compounds; ammonia is one of these.

Lecithine is first split to choline, glycerophosphoric acid and fatty acids:<smiles>CCOCC(CO)OCO</smiles>

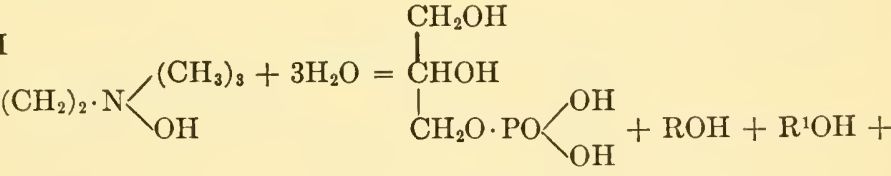

$$
\begin{aligned}
& \text { Glycerophospho- Fatty acids } \\
& \text { ric acid } \\
& \left(\mathrm{CH}_{2}\right)_{2} \mathrm{OH} \cdot \mathrm{N}\left\langle\frac{\mathrm{OH}}{\left(\mathrm{CH}_{3}\right)_{3}}\right.
\end{aligned}
$$

Choline

${ }^{37}$ Neuberg, C. Verhalten von racemischer Glutaminsäure bei der Fäulins. Biochem. Ztschr., 18: 431-434. 1909.

${ }^{38}$ Supniewski, J. Der Stoffwechsel der zyklischen Verbindungen bei Bacillus pyocyaneus. Biochem. Ztschr., 146: 522-535. 1924; Compt. Rend. Acad. Sci. Biol., 89: 1379. 1923.

${ }^{39}$ Further information on bacterial decomposition of amino acids is given by Brasch, W. Über den bakteriellen Abbau primärer Eiweiszspaltprodukte. Biochem. Ztschr., 18: 380-390. 1909; 22: 403. 1909; Ackermann, D. Über die Entstehung von Fäulnisbasen. Ztschr. physiol. Chem., 60:482-501. 1909; 65: 504-510. 1910; Ellinger, A. Über die Entstehung von Fäulnisbasen. Ztschr. physiol. Chem., 65: 394-396. 1910.

${ }^{40}$ Potter, R. S., and Snyder, R. S. Soluble non-protein nitrogen of the soil. Jour. Agr. Res., 6: 61-65. 1916; Lathrop, 1917 (p. 474). 
The choline is decomposed into ammonia, trimethylamine, carbon dioxide and methane. Betaine $\left(\left(\mathrm{CH}_{3}\right)_{3} \equiv \mathrm{N}_{\mathrm{O}}^{-\mathrm{CH}_{2} \cdot \mathrm{CO}}\right)$, creatinine, guanidine ${ }^{41}$ and purine bases, like uric acid, also undergo decomposition by microorganisms:

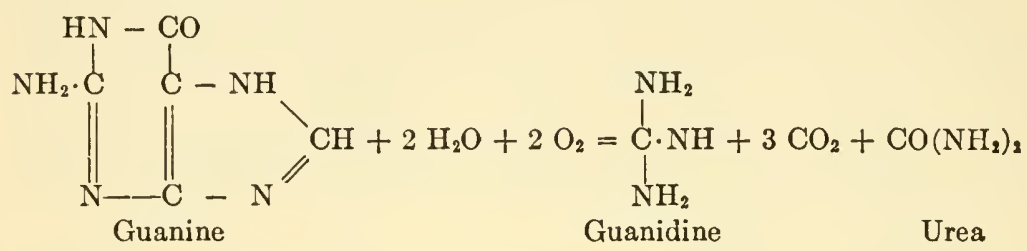

Uric acid undergoes a series of transformations before ammonia is produced, both in animal metabolism, and in its decomposition by bacteria. ${ }^{42}$

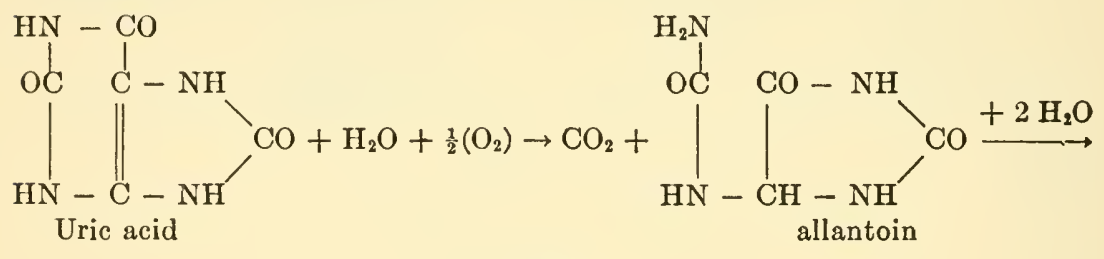

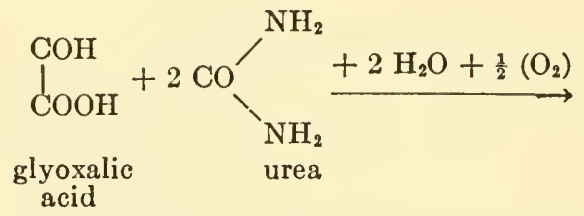

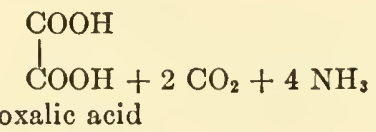

${ }^{41}$ Bierema, S. Die Assimilation von Ammon-, Nitrat- and Amidostickstoff durch Mikroorganismen. Centralb. Bakt. II, 23: 672-726. 1909.

${ }^{42}$ Wiechowski, W. Das Schicksal intermediärer Harnsäure beim Menschen und der Allantoingehalt des menschlichen Harns, nebst Bemerkungen über Nachweis und Zersetzbarkeit des Allantoins. Biochem. Ztschr., 25: 431-459. 1910; Liebert, F. The decomposition of uric acid by bacteria. K. Akad. Wetensch. Amsterdam. Proc. Sect. Sci., 12: 54-64. 1909. 
Uric acid can also be decomposed by various bacteria according to the following reactions:

$$
\begin{gathered}
\mathrm{C}_{6} \mathrm{H}_{4} \mathrm{~N}_{4} \mathrm{O}_{3}+8 \mathrm{H}_{2} \mathrm{O}+1 \frac{1}{2}\left(\mathrm{O}_{2}\right)=4 \mathrm{NH}_{4} \mathrm{HCO}_{3}+\mathrm{CO}_{2} \\
\mathrm{C}_{5} \mathrm{H}_{4} \mathrm{~N}_{4} \mathrm{O}_{3}+4 \mathrm{H}_{2} \mathrm{O}=\mathrm{C}_{3} \mathrm{H}_{4} \mathrm{O}_{5}+2 \mathrm{CO}\left(\mathrm{NH}_{2}\right)_{2} \\
\text { tartronic } \\
\text { acid } \\
\mathrm{C}_{5} \mathrm{H}_{4} \mathrm{~N}_{4} \mathrm{O}_{3}+2 \mathrm{H}_{2} \mathrm{O}+1 \frac{1}{2}\left(\mathrm{O}_{2}\right)=2 \mathrm{CO}\left(\mathrm{NH}_{2}\right)_{2}+3 \mathrm{CO}_{2}
\end{gathered}
$$

Hippuric acid is first hydrolyzed by an enzyme produced by certain fungi:
$\mathrm{C}_{6} \mathrm{H}_{5} \cdot \mathrm{CO} \cdot \mathrm{NH} \cdot \mathrm{CH}_{2} \cdot \mathrm{COOH}+\mathrm{H}_{2} \mathrm{O}=\mathrm{C}_{6} \mathrm{H}_{5} \cdot \mathrm{COOH}+\mathrm{NH}_{2} \cdot \mathrm{CH}_{2} \cdot \mathrm{COOH}$ Hippuric acid Benzoic
Glycocoll$$
\text { acid }
$$

Among the other nitrogenous substances which have to be first decomposed by microorganisms before they can be assimilated by plants, we find urea ${ }^{43}$ and cyanamide. Urea is hydrolized, with the formation of ammonia, by a large number of soil microorganisms as well as by specific groups of bacteria, which utilize the energy liberated in the process.

$$
\mathrm{CO}\langle\overbrace{\mathrm{NH}_{2}}^{\mathrm{NH}_{2}}+2 \mathrm{H}_{2} \mathrm{O}=\left(\mathrm{NH}_{4}\right)_{2} \mathrm{CO}_{3}=\mathrm{CO}_{2}+2 \mathrm{NH}_{3}+\mathrm{H}_{2} \mathrm{O}
$$

According to Yamazaki, ${ }^{44}$ the decomposition of urea takes place in two definite stages with the formation of ammonium carbonate as the intermediary product.

Fearon ${ }^{45}$ maintains that the enzyme urease decomposes urea first into cyanic acid and ammonia:

$$
\begin{aligned}
& \mathrm{HN}: \mathrm{NH}_{3}^{\mathrm{C}}-\mathrm{O} \rightarrow \mathrm{HN}: \mathrm{C}: \mathrm{O}+\mathrm{NH}_{2} \\
& \text { Urea (cylic) Cyanic acid } \\
& \text { form) }
\end{aligned}
$$

Cyanic acid is hydrolyzed, in the presence of water:

$$
\mathrm{HN}: \mathrm{C}: \mathrm{O}+\mathrm{H}_{2} \mathrm{O}=\mathrm{NH}_{3}+\mathrm{CO}_{2} \text {. }
$$

43 A detailed study of the chemistry of urea is given by E. A. Warner. The Chemistry of Urea. Longmans, Green \& Co., New York. 1923.

44 Yamazaki, E. Chemical reaction of the system urease-urea. Jour. Tokyo Chem. Soc., 39: 125-184. 1918; Sci. Rept. Tokoku Imp. Univ., 9: 97, 136. 1920.

${ }^{45}$ Fearon, W. R. Urease. I. The chemical changes involved in the zymolysis of urea. Biochem. Jour., 17: 84-93. 1923; Physiol. Rev., 6: 399-439. 1926. 
However, this still remains to be confirmed. According to Söhngen ${ }^{46}$ urea offers an exclusive source of energy to the urea bacteria but not a source of carbon, so that a carbohydrate is also necessary to insure a growth of the organisms. The maximum hydrolysis of urea, however, accompanies a minimum oxidation of organic compounds. B. erythrogenes, for example, hydrolyzes $500 \mathrm{mgm}$. urea for every $20 \mathrm{mgm}$. of carbon assimilated, while Urobac. jakschii hydrolyzes $1800 \mathrm{mgm}$. of urea for $10 \mathrm{mgm}$. of carbon assimilated.

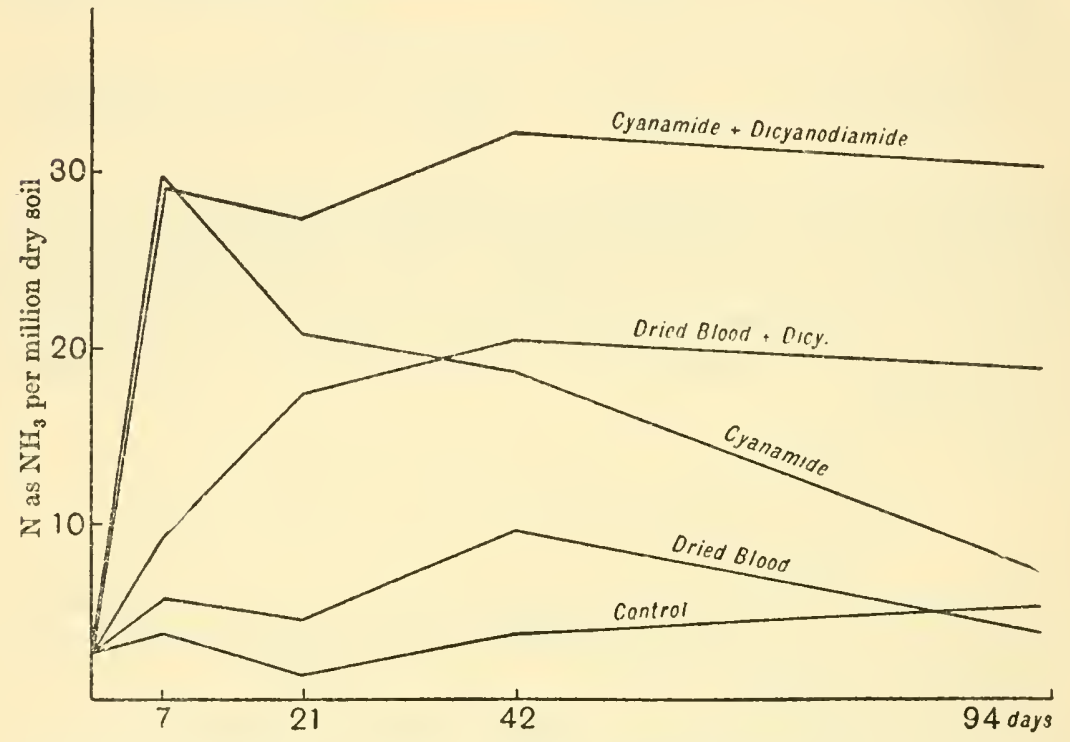

Fig. 26. Accumulation of ammonia from cyanamide and dried blood, as influenced by the presence of diacyanodiamide (from Cowie).

Cyanamide readily breaks down in the soil yielding ammonia which is then nitrified practically quantitatively. Cyanamide may first be decomposed in the soil into urea by a purely chemical process, ${ }^{47}$ under the influence of catalyzers, or it may polymerize into dicyanodiamide (especially in the presence of catalyzers such as $\mathrm{ZnCl}_{2}$ ). Dicyanodiamide does not nitrify and is even toxic to nitrifying bacteria, but is

${ }^{46}$ Söhngen, N. L. Ureumspaltung bei Nichtvorhandensein von Eiweiss. Centrbl. Bakt. II, 23: 91-9S. 1909.

${ }^{47}$ Cowie, G. A. Decomposition of cyanamide and dicyanodiamide in the soil. Jour. Agr. Sci., 9: 113-136. 1919; 10: 163-176. 1920. 
not toxic to ammonia forming organisms. ${ }^{48}$ No ammonia is formed from cyanamide in sterile soil, but considerable amounts of ammonia are produced on the addition of urease; this indicates the presence of urea. The urea is, of course, decomposed in the soil by various organisms. ${ }^{49}$

Among the other nitrogenous substances which are gradually decomposed in the soil by microorganisms, we find various alkaloids, such as cocaine, strychnine, morphine, etc..$^{50}$

Chitin is found among the synthesized constituents of the cells of microorganisms, especially fungi, and is constantly added to the store of soil organic matter. It is a polymer of mono-acetyl-glucosamine $\left(\mathrm{C}_{14} \mathrm{H}_{26} \mathrm{~N}_{2} \mathrm{O}_{10}\right)_{n}$, giving acetic acid and glucosamine upon hydrolysis. It gives a violet color with chlor-zinc iodide and a brown-red color with a solution of iodine and potassium iodide. Certain bacteria and actinomyces decompose chitin in the soil by means of an enzyme chitinase. $^{51}$ Chitin can be used by these organisms both as a sourcc of carbon and nitrogen, in the presence of $\mathrm{K}_{2} \mathrm{HPO}_{4}$ and $\mathrm{MgSO}_{4}$.

To be able to understand, how the decomposition of proteins and other nitrogenous substances by microorganisms in the soil results in the formation of ammonia, how different organisms bring about differences in the accumulation of the ammonia and how the latter is influenced by the soil environmental conditions, a knowledge of the action of the different organisms upon proteins, under different conditions, is essential.

A mmonia formation by bacteria. The earlier investigators of bacterial metabolism, like Hoppe-Seyler, Bienstock, Hauser and others, found that mixtures and pure cultures of bacteria, like Bact. vulgare, Bac. sub-

${ }^{48}$ Norris, R. V., Vismanath, B., and Aiyer, C. V. R. A preliminary note on the decomposition of calcium cyanamide in South Indian soils. Mem. Dept. Agr. India, Pusa., 7: 55-75. 1923; Ulpiani, C. Evoluzione chimica e biochimica della calciocianamide nel terreno agrario. Gaz. Chim. Ital., 40: 613-666. 1910.

${ }^{49}$ Further information on ammonia formation from cyanamide is given by Perotti, R. Über den mikrobiochemischen Prozess der Ammonization im Ackerboden. Centrbl. Bakt. II, 20: 514-518. 1908; Über die Stickstoffernährung der Pflanzen durch Amidsubstanzen. Ibid., 24: 373-382. 1909; Löhnis, 1910 (p. xiii), p. 590 .

${ }^{50}$ Lavialle, P. Destruction of alkaloids in the soil. Bull. Sci. pharmacol., 30: 321-325. 1923; (Chem. Abstr., 17: 2732).

${ }^{51}$ Benecke, W. Über Bacillus chitinovorus, einen Chitin zersetzenden Spaltpilz. Bot. Ztg., 63: 227-272. 1905; Folpmers, T. Die Zersetzung des Chitins und des Spaltungsproduktes desselben, des Glucosamins, durch Bakterien. Chem. Weekbl., 18: 249. 1921; (Centrbl. Bakt. II, 57: 97-98. 1922). 
tilis, Bact. prodigiosum, Bac. putrificus, Bact. fuorescens liquefaciens, are capable of breaking down proteins with the formation of various end products, one of which was ammonia. Proteins of both plant and animal origin were found to be decomposed by a number of bacteria giving a great variety of products. ${ }^{52}$

The investigations of Müntz and Coudon and Marchal ${ }^{53}$ called attention to the existence of large numbers of bacteria and fungi in the soil, capable of decomposing proteins with the formation of ammonia. A solution containing 1.5 per cent nitrogen, in the form of egg albumin made insoluble by means of 0.01 per cent ferric sulfate, was inoculated with various bacteria; ammonia was determined after 20 days' incubation at $30^{\circ}$ by distilling with $\mathrm{MgO}$.

TABLE 42

Protcin nitrogen transformed into ammonia

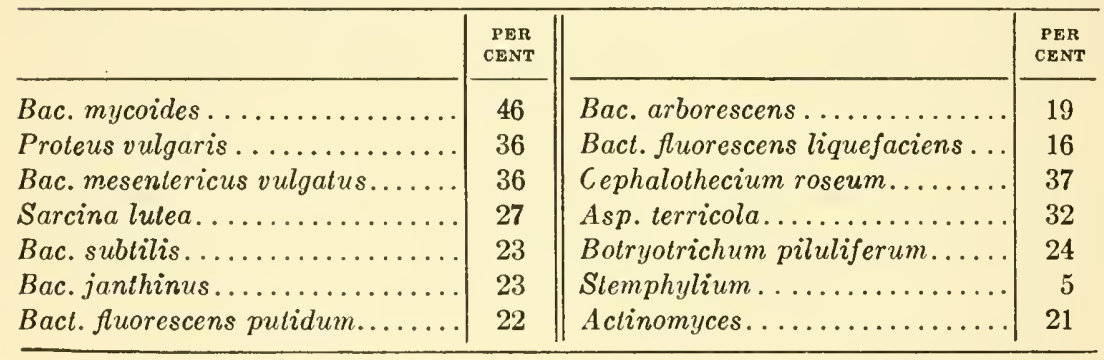

The various strains of Bac. mycoides derived from different sources varied in their power to produce ammonia from proteins. In the case of one strain of Bac. mycoides, Marchal obtained a transformation of 58 per cent of egg-albumin nitrogen into ammonia, accompanied by a marked change of the reaction of the medium to alkaline. The more dilute the solution of the protein the greater was the transformation. Of the individual amino acids, 66 per cent of the nitrogen of tyrosine in a 0.4 per cent solution, in the presence of some sugar and salts, was transformed into ammonia, with 40 per cent of the leucine and 37 per cent of asparagine in a 1 per cent solution. Only 9 per cent of the creatine was transformed into ammonia. In addition to $\mathrm{CO}_{2}$ and ammonia, peptone, leucine, tyrosine, some formic, propionic and butyric acids were demonstrated among the products of the digestion of albumin by

${ }^{52}$ Olig. Die Zersetzung pflanzlicher Futter und Nahrungsmittel durch Bakterien. Diss. Münster (Berlin. Springer). 1903.

${ }^{63}$ Müntz and Coudon, 1890-1893 (p. 267); Marchal, 1893 (p. 267). 
bacteria. For every milligram of ammonia formed $8.9 \mathrm{mgm} . \mathrm{CO}_{2}$ were liberated. Marchal concluded that Bac. mycoides is one of the most common soil organisms and one that attacks proteins most energetically. It is favored by a temperature of $30^{\circ}$, complete aeration, slightly alkaline medium and a slight concentration of nitrogenous substance in solution.

The work of Marchal was confirmed and further extended by numerous investigators. ${ }^{54}$ The great majority of soil organisms developing on the plate were found to produce ammonia from proteins. The gelatin-liquefying bacteria were found to be capable of inducing a greater protein decomposition with a more abundant ammonia formation. ${ }^{55}$ Since these organisms form at times more than 15 per cent of the total number of soil bacteria (developing on the plate), they were believed to do the initial work in rendering soluble the protein nitrogen in the soil, so that it might be further decomposed by the same or other soil organisms. ${ }^{56}$ Lipman and Burgess ${ }^{57}$ tested a series of pure cultures of bacteria for their ammonia-producing power, using various nitrogenous substances in various soils. Bac. tumescens was found to be the most efficient organism of all tested, although in some cases greater efficiency was obtained for Bac. mycoides and Sarcina lutea. Usually 20 to 30 per cent of the protein nitrogen was transformed into ammonia in twelve days.

Conn, ${ }^{58}$ however, found that, in manured soil, the non-spore forming bacteria are much more active than the spore forming organisms. According to Waksman and Lomanitz, ${ }^{59}$ Bac. cereus rapidly decomposes proteins to amino acids while Bact. fluorescens acts largely upon amino

"Severin, S. A. Die im Miste vorkommenden Bakterien und deren physiologische Rolle bei der Zersetzung derselben. Centrbl. Bakt. II, 1: 97-104, 160-168, 799-817. 1895; 628-633. 1897; 7: 369-386. 1901; 13: 616-631. 1904; Chester, F. D. The bacteriological analysis of soils. Delaware Sta. Bul. 65 . 1904; Löhnis, 1905 (p. 120); Lipman, J. G. Chemical and bacteriological factors in the ammonification of soil nitrogen. N. J. Agr. Exp. Sta. 19th Ann. Rpt. 1906, 119-188.

${ }^{15}$ Gage, S. D. Contribution to the biochemistry of sewage purification; the bacteriolysis of peptones and nitrate. Jour. Amer. Chem. Soc., 27: 327-363. 1905.

${ }^{66}$ Voorhees, E. B., and Lipman, J. G. A review of investigations in soil bacteriology. Bul. 194, Office Exp. Sta., U. S. Dept. Agr. 1907.

${ }^{67}$ Lipman, C. B., and Burgess, P. S. Studies on ammonification in soils by pure cultures. Univ. Cal. Publ. Agr. Sci., 1: 141-172. 1914.

${ }^{88}$ Conn and Bright, 1919 (p. 41).

19 Waksman and Lomanitz, 1925 (p. 379). 
acids. In the presence of a mixture of the two organisms, the protein is rapidly changed to ammonia. 'Thus there is a possibility that various organisms take an active part in the various stages of the process; organisms like Bac. cereus may be active in the first stages of hydrolysis and organisms like Bact. fluorescens, in the latter stages leading to the formation of ammonia (fig. 27). This confirmed the earlier investigations of Tissier and Martelly, ${ }^{60}$ who found that the action of Bact. coli, various micrococci and Bact. filiformis aerobius upon natural proteins was nil, or almost nil; but they acted very readily

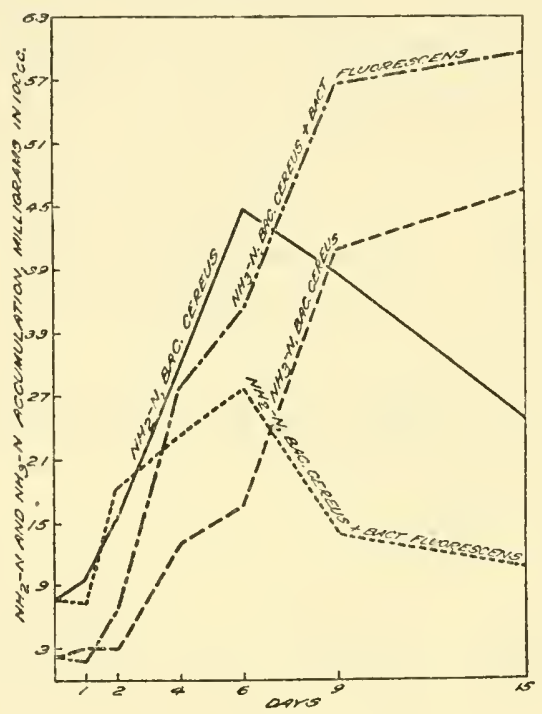

FIG. 27. Course of accumulation of amino- and ammonia-nitrogen from casein by Bac. cereus and Bact. fluorescens (from Waksman and Lomanitz).

upon the hydrolytic products of proteins. The same was true of certain anaerobic bacteria and even the action of Bact. vulgare upon pure proteins has been doubted. However, various spore-forming bacteria, especially anaerobes, like Bac. gracilis putidus, Bac. putrificus and also Bac. perfringens, Bac. bifermentans and Bac. sporogenes rapidly attacked native proteins. They suggested, therefore, to divide the bacteria into two groups, on this basis.

The number of soil bacteria capable of forming ammonia from pro-

${ }^{60}$ Tissier, H., and Martelly. Recherches sur la putréfaction de la viande de boucherie. Ann. Inst. Past., 16: 865-903. 1902. 
teins is very large; when tested in pure culture upon native proteins, the spore-forming bacteria are most active. When protein derivatives, like peptone, amino acids, and urea, are used, various non-spore forming bacteria will be found to play an important rôle in the process. In the soil itself, all of those organisms probably contribute to a greater or less extent to this process, depending upon the nutrients available and environmental conditions.

The rapidity of ammonia formation from proteins by bacteria depends not only upon the nature of the organism but also upon the kind of protein. The process of ammonia formation is completed in a few days in the case of casein, while it continues, even after a month, from gliadin. ${ }^{61}$ The amino-nitrogen content of the gliadin and casein media was 0.57 and $0.68 \mathrm{mgm}$. before hydrolysis; 42.56 and $99.31 \mathrm{mgm}$. after acid hydrolysis, and 17.03 and 46.00 after hydrolysis with Bac. subtilis. All the nitrogen forms of the protein molecule are changed more or less by the action of bacteria, the end product being ammonia; in no case, however, is one form of nitrogen completely destroyed. A similarity was found in the chemical change produced by acid hydrolysis and bacteria.

Ammonia formation by fungi and actinomyces. The actinomyces develop on artificial culture media and in the soil slower than the fungi and, when a short period of incubation is used, their intense activity in breaking down proteins and forming ammonia may be overlooked. When a long period of incubation (30 days or more) is used, they are found to be very active in this respect. ${ }^{62}$ The important point in this connection is that these organisms are capable of allowing a large accumulation of ammonia even in the presence of available carbohydrates; in other words, they prefer proteins to carbohydrates as sources of energy. According to Guittonneau, ${ }^{63}$ actinomyces produce, from proteins, not only ammonia, but also urea, both in the presence and absence of dextrose.

Fungi can decompose proteins very vigorously. Different species vary greatly in this respect, and the nature of the protein, reaction of .

${ }^{61}$ Robinson, R. H., and Tartar, H. V. The decomposition of protein substances through the action of bacteria. Jour. Biol. Chem., 30: 135-144. 1917.

${ }^{62}$ Fousek, 1912 (p. 302); Macé, E. De la décomposition des albuminoides par les Cladothrix (actinomyces). Compt. Rend. Acad. Sci., 14: 147-148. 1905; Waksman, 1920 (p. 299).

${ }^{63}$ Guittonneau, G. Sur la production de l'urée au cours de l'ammonification par les Microsiphonées. Compt. Rend. Acad. Sci., 178: 1383-5. 1924. 
medium and presence of available carbohydrates also affect the process. A large part of the nitrogen may be left in the form of intermediary products. Organisms like $A s p$. niger, which produce large amounts of acid (oxalic and citric) from carbohydrates and even from proteins and which are thus enabled to neutralize the ammonia, accumulate only very small amounts of amino acids in artificial cultures; at the same time appreciable quantities of ammonia are formed in the medium. But when the oxalic acid is neutralized with $\mathrm{CaCO}_{3}$, or when the formation of both oxalic acid and ammonia is prevented by means of insufficient aeration, an accumulation of amino acids will take place, as with the other fungi. ${ }^{64}$

When the protein is the only source of carbon during the development of fungi on the protein media, a definite parallelism is found between the growth of the mycelium and the production of ammonia. Different protein derivatives are not utilized alike and their nitrogen is not liberated alike in the form of ammonia. Asp. niger, for example, grows best with leucine, followed by peptone, asparagine and glycocoll. The difference in the nature of the carbon compounds either accompanying the proteins or the protein carbon itself accounts for the difference in the amount of fungus growth and ammonia formation. This is due to the fact that, in the absence of available carbohydrates, the organism uses the protein both as a source of energy and as a source of nitrogen; the amount of nitrogen liberated as ammonia will depend not only upon the nitrogen content of the protein, but largely upon the availability of the carbon; the nitrogen is then either liberated as a waste product, ammonia, or is reassimilated and changed into microbial protein.

McLean and Wilson ${ }^{65}$ concluded that fungi, rather than bacteria, are responsible for the large accumulations of ammonia in soil rich in organic nitrogenous substances and that this depends upon the chemical and physical composition of the soil, quality of the organic matter present and presence of soluble phosphates. The period of maximum formation and accumulation of ammonia from protein substances by

6utkewitsch, W. Umwandlung der Eiweissstoffe durch die niederen Pilze im Zusammenhange mit einigen Bedingungen ihrer Entwicklung. Jahrb. wiss. Bot., 38: 147-240. 1903. Ammonia as a product of protein transformation by fungi and conditions of its formation (Russian). Rec. d'articles dedies au Prof. C. Timiriazeff. $1916,457-499$.

${ }^{65}$ McLean, H. C., and Wilson, G. W. Ammonification studies with soil fungi. N. J. Agr. Exp. Sta., Bul. 270. 1914. 
pure cultures of various fungi was found ${ }^{66}$ to depend on the type of organism used; Monilia sitophila reached its maximum in 3 to 4 days, Mucor plumbeus reached it in 6 to 10 days.

Rate of ammonia formation by microorganisms and methods of determination. In the decomposition of proteins by pure cultures of bacteria

TABLE 43

Ammonia formation by soil fungi

\begin{tabular}{|c|c|c|}
\hline OROANISM & SOURCE OF NITROGEN* & MILLIGRAMS OF $\mathrm{NH}_{3} \mathrm{~N}$ \\
\hline 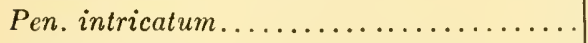 & D. B. & $20.45-11.26$ \\
\hline 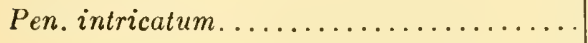 & C. S. M. & $4.65-3.85$ \\
\hline Pen. chrysogenum.................... & D. B. & 21.81 \\
\hline 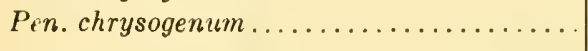 & C.S.M. & 16.82 \\
\hline Asp. fumigatus ...... & D. B. & 12.16 \\
\hline Asp. fumigatus... & C.S. M. & 7.91 \\
\hline Mucor hiemalis..... & D. B. & $12.75-29.94$ \\
\hline Mucor hiemalis. . .................... & C.S.M. & $18.09-25.89$ \\
\hline Rhiz. nigricans... & D. B. & 12.65 \\
\hline 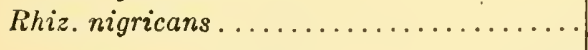 & C.S.M. & 25.40 \\
\hline Zyg. vuilleminii.... & D. B. & 28.73 \\
\hline 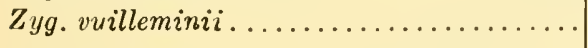 & C. S. M. & 31.43 \\
\hline Monilia sitophila................... & D. B. & 19.51 \\
\hline Monilia sitophila ................... & C.S.M. & 40.23 \\
\hline Trich. koningi..... & D. B. & $76.48-66.16$ \\
\hline 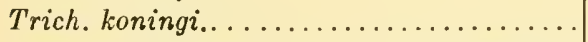 & C. S. M. & $42.60-30.63$ \\
\hline
\end{tabular}

* To 100 grams of soil were added $155 \mathrm{mgm}$. of nitrogen in the form of D. B. = Dried blood or of C.S. M. = cottonseed meal.

or fungi, as well as in the soil itself, the rate of ammonia accumulation is that of an autocatalytic chemical reaction. ${ }^{67}$ However, the nature of the protein and the presence of non-nitrogenous organic matter

${ }^{66}$ Waksman, S. A., and Cook, R. C. Incubation studies with soil fungi. Soil Sci., 1: 375-384. 1916.

${ }^{67}$ Miyake, 1916 (p. 375); Waksman, S. A. Studies on proteolytic activities of soil microorganisms with special reference to fungi. Jour. Bact., 3: 475-492. 1918. 
will influence greatly the rate of the reaction. Cainey ${ }^{68}$ observed a remarkable similarity in the rates of formation of ammonia and carbon dioxide from dried blood and cotton seed meal. At first there was a rapid increase which soon reached a maximum and then decreased rapidly. Insufficient aeration and moisture resulted in a decrease in ammonia formation. Unfavorable conditions had a more detrimental effect on the latter than on $\mathrm{CO}_{2}$ evolution (fig. 28). An interesting correlation was found ${ }^{69}$ between the amounts of ammonia

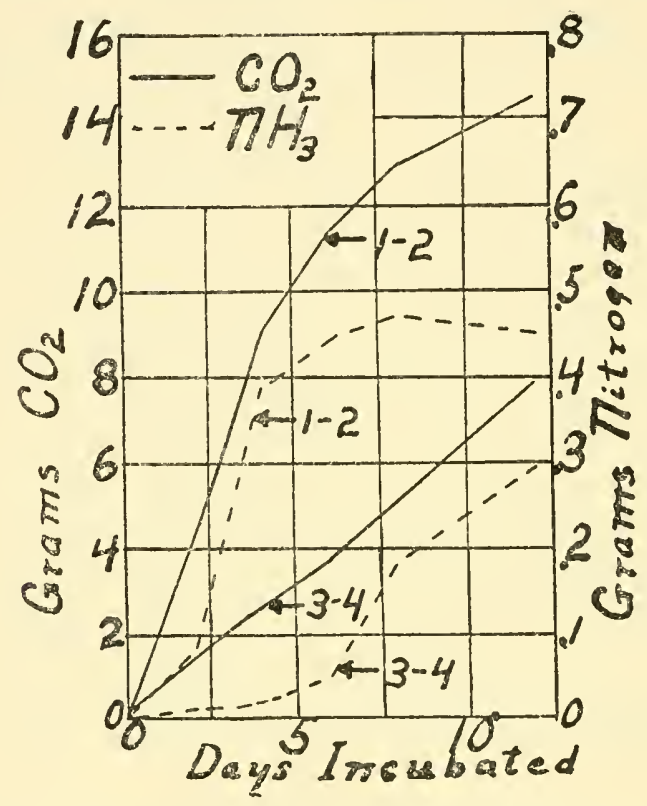

FIG. 28. Rate of decomposition of cottonseed meal in soil, as shown by the evolution of $\mathrm{CO}_{2}$ and accumulation of $\mathrm{NH}_{3} ; 1$ and 2 were aerated continuously, $s$ and 4 were aerated 30 minutes daily (from Gainey).

formed and the numbers of bacteria, as a result of addition of organic matter to the soil.

The literature on the subject of ammonia formation from the decomposition of nitrogenous organic substances added to the soil is very extensive. Unsuccessful attempts were even made to determine

${ }^{68}$ Gainey, 1919 (p. 685).

69 Beckwith, 'T. D., Vass, A. F., and Robinson, R. H. Ammonification and nitrification studies of certain types of Oregon soils. Ore. Agr. Exp. Sta. Bul.118. 1914. 
the productive capacity of a soil by its ammonia producing power, as will be shown later.

Among the methods used for determining ammonia in the soil and in solution, only three need be mentioned: (1) the direct distillation of the soil or solution with magnesium oxide; (2) the aeration method; (3) the extraction of ammonia with $\mathrm{KCl}$ solution (followed by distilling the ammonia with magnesium oxide).

The first is more rapid, but may bring about the liberation of some ammonia from amides and perhaps from other simple nitrogenous substances.

The aeration method can be used in determining ammonia in liquid culture, but requires a long time for a complete extraction of the ammonia from soils. ${ }^{70}$ It consists in placing 25 to $50 \mathrm{cc}$. of the culture or soil suspension in large heavy glass tubes or flasks, adding some heavy oil, 2 to 3 grams of $\mathrm{NaCl}$ and 2 grams of $\mathrm{Na}_{2} \mathrm{CO}_{3}$, then aerating for 2 to 3 hours. The ammonia is absorbed in a standard solution of sulfuric acid to which a proper indicator has been added (like sodium alizarine sulfonate). On placing the tubes in a water bath, at 55 to $60^{\circ} \mathrm{C}$., the process is carried out more rapidly and completely. Where heat is used, there is, of course, always some danger of hydrolysis of undecomposed proteins or their derivatives.

The extraction of the ammonia from soil by a $\mathrm{KCl}$ solution is based upon the fact that the ammonium base is replaced in its adsorbed condition in the soil by another base when added in excess to the soil (in this case by the potassium of the $\mathrm{KCl}$ solution). The process is usually carried out by extracting 25 grams of the soil successively with five to seven 100-cc. portions of approximately 4 per cent potassium chloride solution (or until the filtrate gives no test for ammonia with Nessler's reagent). Peat soils should be extracted two or three times more. Alkaline soils should be first neutralized with ammonia-free hydrochloric acid. The combined filtrates are then distilled with $\mathrm{MgO}$ into standard $0.1 \mathrm{~N} \mathrm{H}_{2} \mathrm{SO}_{4}$. When distillation is finished, the carbon dioxide is removed from the distillate by boiling, before the acid is titrated back with a standard alkali. ${ }^{71}$

${ }^{70}$ Potter, R. S., and Snyder, R. S. The determination of ammonia in soils. Jour. Ind. Engin. Chem., 7: 221. 1915; Gibbs, W. M., Neidig, R. E., and Batchelor, H. W. Aeration method for determining ammonia in alkali soils. Soil Sci., 15: 260-268. 1923.

71 Tarassoff, B. On the methods of determining ammonia in the soil (Ru;sian). Zhur. Opit. Agron., 15: 118-138. 1914; Bengtsson, N. The determination of ammonia in soil. Soil Sci., 18: 255-278. 1924. 
Nitrogen transformation in the rotting of manure. About half of the nitrogen in manure is in the form of ammonia (and urea) and half is in the form of proteins and other complex nitrogen compounds. The first part of the nitrogen rapidly changes into nitrates before the microorganisms, using the constituents of the straw and other undecomposed materials, have a chance to absorb it and change it into organic complexes. The second part has to be gradually decomposed before the nitrogen can be made available; for this a considerable period of time is required. ${ }^{72}$ The final product in the decomposition of the proteins, of the urea and of the other nitrogen compounds of the manure is chiefly ammonia. A small part of it may be lost to the atmosphere

TABLE 44

Transformation of nitrogen in the composting of manure under aerobic and anaerobic conditions ${ }^{75}$

\begin{tabular}{l|l|l|l|l|l|l}
\hline $\mathrm{NH}_{3}-\mathrm{N}$ & $\mathrm{NO}_{3}-\mathrm{N}$ & $\mathrm{NO}_{2}-\mathrm{N}$ & AMIDE-N & $\begin{array}{c}\text { OTHER } \mathrm{N} \\
\text { COM- } \\
\text { POUNDS } \\
\text { (PROTEINS) }\end{array}$ & TOTAL \\
\hline
\end{tabular}

Anaerobic conditions

\begin{tabular}{|c|c|c|c|c|c|c|}
\hline & per cent & per cent & per cent & per cent & per cent & per cent \\
\hline 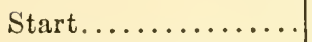 & 28 & .. & .. & 8 & 64 & 100 \\
\hline $6^{\circ} \mathrm{C}$ for 50 days... . & 29 & .. & .. & 9 & 57 & 95 \\
\hline $26^{\circ} \mathrm{C}$ for 50 days.... & 44 & .. & .. & 7 & 47 & 98 \\
\hline
\end{tabular}

Aerobic conditions

\begin{tabular}{l|r|r|r|r|r|r}
\hline Start............. & 33 & $\ldots$ & $\ldots$ & 8 & 59 & 100 \\
$15^{\circ} \mathrm{C} \ldots \ldots \ldots \ldots \ldots$ & 11 & 11 & 8 & $\ldots$ & 42 & 72 \\
$26^{\circ} \mathrm{C} \ldots \ldots \ldots \ldots \ldots$ & 5 & 2 & 7 & $\ldots$ & 55 & 69 \\
\hline
\end{tabular}

through volatilization ${ }^{73}$ but a much greater part is retained in the manure, as such, by physical or chemical agencies. A part of the ammonia is nitrified and a part is reabsorbed by the bacteria and fungi in the manure in the process of their metabolism for which the straw of the manure is used as a source of energy. Another source of loss, in the decomposition of manure, is the evolution of gaseous nitrogen, either through denitrification or through the chemical interaction of

72 Barthel, Chr. Neuere Untersuchungen über die Ausnützung des Stallmiststickstoffs im Ackerboden. Fortschr. der Landwirtsch., 1: H. 2. 1926.

${ }^{73}$ Ehrenberg, P. Die Bewegung des Ammoniakstickstoffs in der Natur. P. Parey. Berlin. 1907. 
amino acids with nitrous acid, but this loss is comparatively small. Niklewski ${ }^{74}$ found that the greatest loss of nitrogen from the stable manure is a result of the action of the nitrifying bacteria. Only about 3 per cent of the nitrogen was lost, largely as ammonia, when manure was kept for 255 days free from nitrifying bacteria. In the presence of a large amount of urine, 5 to 12 per cent of the nitrogen was lost. Manure inoculated with nitrifying bacteria lost about 20 to 24 per cent of its nitrogen. This is due chiefly to the fact that the nitrates are reduced rapidly as soon as formed and elementary nitrogen is lost into the atmosphere.

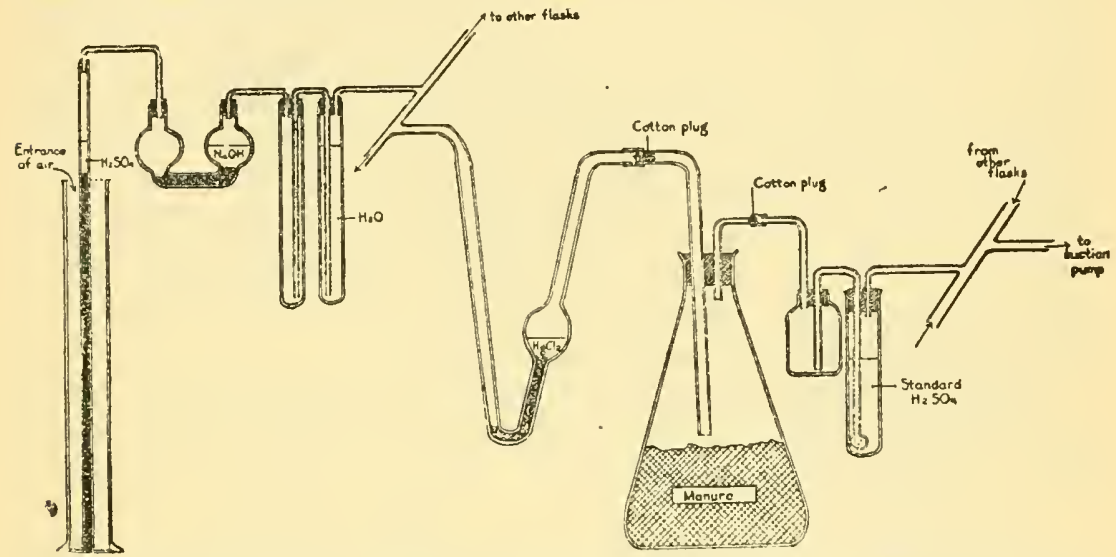

FIg. 29. Apparatus for study of ammonia formation in the decomposition of manure (from Conn and Collison).

According to Russell and Richards, ${ }^{75}$ there is a distinct difference in the transformation of nitrogen compounds in the manure when stored under anaerobic or aerobic conditions. There was practically no loss of nitrogen under anaerobic conditions; the proteins were decomposed with the formation of ammonia, particularly at the higher temperature. Under aerobic conditions, there was a great loss of nitrogen, the amide form practically disappeared, while most of the ammonia was transformed into nitrites or nitrates. In general, under anaerobic conditions, the loss of dry matter and nitrogen is at a mini-

${ }^{74}$ Niklewski, B. Utber die Bedingungen der Nitrifikation im Stallmist. Centrbl. Bakt. II, 26: 3S5-442. 1910; Rocznikow Nauk Rolniczych, 9: 1-18. 1923.

${ }^{75}$ Russell, E. J., and Richards, E. R. The changes taking place during the storage of farmyard manure. Jour. Agr. Res., 8: 495-563. 1917. 
mum; the gases formed consist of $\mathrm{CO}_{2}, \mathrm{CH}_{4}, \mathrm{H}_{2}$ and $\mathrm{NH}_{3}$. Under aerobic conditions, there is a much greater loss of dry matter with a much greater decomposition of the nitrogenous compounds. Hydrogen and methane are not found in the gases. There is no ammonia accumulation, but nitrates are formed in the outer layers; with incomplete aeration, gaseous nitrogen is formed. Various groups of bacteria and fungi are active in the process of formation of ammonia in manure, but not with equal rapidity. According to Conn and Collison, ${ }^{76}$ the strong proteolytic and gelatin liquefying organisms, like Bac. cereus and Bact. fluorescens, are not able to give off ammonia in quantities comparable to those given off from unsterilized manure. Conn found that a minute, gram-negative, non-motile, non-spore forming rod, Bact. parvulum was able to give off from manure, in pure culture in the laboratory, amounts of ammonia, equal to or greater than those obtained from unsterilized manure. The decomposition of manure in the pile may not necessarily be carried on by the same organisms as in the soil. Bact. fluorescens, which was found to be relatively less active in the manure pile, was very active in the formation of ammonia from manure in the soil. ${ }^{77,78}$

Nitrogen transformation in the decomposition of organic matter in the soil. When nitrogenous organic substances are added to the soil, a group of complex reactions will result as far as the nitrogen is concerned:

(1) The hydrolysis of the proteins into polypeptides and amino acids, with the liberation of some ammonia. (2) This is followed by the decomposition of the amino acids and other products of protein hydrolysis, with a further liberation of ammonia. (3) Synthesis of microbial protoplasm, which will lead to a storing away of a part or the whole of the ammonia nitrogen; the greater the quantity of available non-nitrogenous organic matter accompanying the nitrogenous substances, the greater will be the synthesis of microbial protoplasm, leading to a greater assimilation of the nitrogen and to a smaller accumulation of ammonia. (4) Various soil conditions, as well as differences in the composition of

${ }^{76}$ Conn, H. J., and Collison, R. C. A study of certain bacteria involved in the ammonification of manure. N. Y. Agr. Exp. Sta. Bul. 494. 1922.

${ }^{77}$ Conn, H. J., and Bright, J. W. Ammonification of manure in soil. N. Y. Agr. Exp. Sta. Tech. Bul, 67. 1919.

${ }^{78}$ Further information on the conservation of manure and the changes taking place in manure during storage is given by Löhnis, F., and Smith, J. H. Die Veränderungen des Stalldüngers während der Lagerung und seine Wirkung im Boden. Fühling's landw. Ztg. 1914, 153-167; Lemmermann, O., and Weissmann, H. Untersuchungen über die Konservierung der Jauche durch verschiedene Zusatzmittel. Landw. Jahrb., 52: 297-341. 1918. 
the nitrogenous and the accompanying non-nitrogenous organic substances, will lead to the development of different microorganisms capable of decomposing the nitrogenous materials; the carbon-nitrogen metabolism of these microorganisms is different; this leads, therefore, to differences in the amounts of ammonia liberated in a free state.

These various reactions lead to a transformation of a larger or smaller part of the nitrogen of the organic complexes into ammonia, which, either as such or after it has been oxidized to nitrates, is available as a source of nitrogen for the growth of cultivated plants. In view of the fact that the liberation of this ammonia is of such great economic importance, numerous contributions have been made to the subject, known as "ammonification." These studies were chiefly limited to adding about 1 gram of the nitrogencus organic material to 120 grams of soil, mixing, placing in tumblers, then l,ringing the moisture content of the soil to optimum (ce per cent saturation), incubating for 4 to 14 (usually 7) days, then measuring the amount of ammonia present in the soil by distilling with $\mathrm{MgO}$.

These studies resulted in a most extensive literature. It was found, ${ }^{79}$ for example, that organic nitrogenous materials of different origin liberated ammonia with a different degree of rapidity as follows:

NATURE OF MATERIAL

AMMONIA FORMED,

PER CENT OF NITROGEN ADDED

\begin{tabular}{c|c}
\hline 4 days & 7 days \\
\hline 18.24 & 32.28 \\
32.35 & 38.52 \\
49.07 & 55.39
\end{tabular}

The difference in rapidity of decomposition of the organic nitrogen compounds with the liberation of ammonia is due to the nature of the nitrogen complex, ${ }^{80}$ accompanying non-nitrogenous substances (see p. 505) and environmental conditions, which favor the development of specific organisms and, therefore, specific processes.

Influence of nitrogenous decomposition products on the growth of plants

${ }^{79}$ Lipman, J. G., Blair, A. W., Owen, I. L., and McLean, H. C. The availability of nitrogenous materials as measured by ammonification. N. J. Agr Exp. Sta. Bul. 246. 1912.

${ }^{80}$ Jodidi, S. L. Amino acids and acid amides as sources of ammonia in soils. Iowa Agr. Exp. Sta. Res. Bul. 9. 1912; Lathrop, E. C. Protein decomposition in soils. Soil Sci., 1: 509-532. 1916. 
and microorganisms. As a result of the activities of microorganisms, a large number of substances are formed from the decomposition of proteins. The most important of these is ammonia. This is either assimilated without change by plants or microorganisms or is first converted into nitrates by the nitrifying bacteria. In addition to ammonia, other nitrogenous compounds formed from the decomposition of proteins by microorganisms are beneficial to the growth of higher plants. ${ }^{81}$ It has even been suggested that substances such as nucleic acid, hypoxanthine, guanine, histidine, arginine and creatinine, are absorbed directly by the plant, without first being transformed into ammonia and nitrates. Collectively these compounds were found to be more beneficial than when used singly. ${ }^{82}$ It is possible that these substances, especially the nucleic 'acids, are not used as nutrients directly, but play a rôle in the growth of plants and microorganisms similar to that played by vitamines in the growth of higher plants.

Some of the decomposition products may have a harmful effect upon plant growth, ${ }^{83}$ as in the case of the various nitrogenous and non-nitrogenous substances that can be isolated from the soil, including pyridine and its derivatives, dihydroxystearic acid, etc.

Bacteria utilize a wide range of substances as sources of nitrogen, including proteins and their derivatives which they tend to break down further with the liberation of ammonia. ${ }^{84}$ The same is true of fungi ${ }^{85}$ According to Emmerling, fungi utilize the $\alpha$-amino acids quite

${ }^{81}$ Schreiner, O., Reed, H. S., and Skinner, J. J. Certain organic constituents of soils in relation to soil fertility. Bur. Soils, U. S. Dept. Agr. Bul, 47. 1909; Schreiner, O., and Lathrop, E. C. The chemistry of steam heated soils. Jour. Amer. Chem. Soc., 34: 1242-1259; Skinner, J. J. Effects of creatinine on growth and absorption. Bur. Soils, U. S. Dept. of Agr. Bul. 83. 1911; Hutchinson, H. B., and Miller, N. H. J. The direct assimilation of inorganic and organic forms of nitrogen by higher plants. Centrbl. Bakt. II, 30: 513-547. 1911.

${ }^{82}$ Schreiner, O., and Skinner, J. J. Nitrogenous constituents and their bearing on soil fertility. Bur. Soils, U. S. Dept. Agr. Bul. 87. 1912.

${ }^{83}$ Schreiner, O., and Shorey, E. C. 1909. The isolation of harmful organic substances from soils. Bur. Soils, U. S. Dept. of Agr. Bul. 53. 1909; Chemical nature of soil organic matter. Ibid., Bul. 74. 1910.

${ }^{84}$ Bierema, S. Die Assimilation von Ammon-Nitrat und Amidstickstoff durch Mikroorganismen. Centrbl. Bakt. II, 23: 672-726. 1909; Nawiasky, P. Ueber die Ernährung einiger Spaltpilze in peptonhaltigen Nährböden. Arch. Hyg., 64: 33-61. 1908; Ưber die Umsetzung von Aminosäuren durch Bac. proteus vulgaris. Arch. Hyg., 66: 209-243. 1908.

${ }^{85}$ Czapek, F. Untersuchungen über die Stickstoffgewinnung und Eiweissbildung der Pflanzen. Beitr. Chem. Physiol. Path., 1: 538-560. 1902; 2: 557590. 1902; 3: 47-66. 1902; Emmerling, O. Aminosäuren als Nährstoff für 
readily, but seem to be unable to attack the $\beta$-amino acids. Czapek found that $A s p$. niger could not utilize all the various nitrogenous compounds tested but grew very well on a large number of them. Amino acids were used most economically, which led Czapek to suggest that the fungi assimilate the nitrogen in that form and are spared the trouble of synthesizing the amino acids needed for their protoplasm. Hagem ${ }^{86}$ however, maintains that ammonia is the starting point in the synthesis of protoplasm by microorganisms. Fungi can utilize urea, uric acid, glycocoll, guanidine, guanine, nitrates, nitrites and ammonium salts as sources of their nitrogen, while uric acid, gycocoll and hippuric acid may serve as a source of carbon as well. ${ }^{87}$

The whole process of protein transformation and protein synthesis in the soil is very complex and is constantly in a dynamic condition. The net result is fertility or infertility, depending on which set of factors predominates in the soil at any one time. A mere determination of the amount of ammonia formed after adding to the soil a definite amount of a certain organic fertilizer, like dried blood or cottonseed meal, cannot solve the question of the availability of the nitrogen in the particular fertilizer; it does not indicate the amount of intermediate compounds formed by the decomposition of the organic matter or fertilizer in the soil and the character of the action of these compounds on plant growth.

niedere Pflanzen. Ber. deut. chem. Gesell., 35: 2289-2290. 1902; Butkewitsch, 1903 (p. 494); Brenner, W. Die Stickstoffnahrung der Schimmelpilze. Centrbl. Bakt. II, 40: 555-640. 1914.

${ }^{86}$ Hagem, 1910 (p. 237).

${ }^{87}$ Kossowicz. (Rev. Lathrop, 1917 (p. 474).) 


\section{CHAPTER XIX}

Influence of Available Energy upon the Transformation of Nitrogenous Compounds by Microorganisms

Carbon and nitrogen transformation by microorganisms. All microorganisms require a certain amount of energy for the building up of their protoplasm as well as a certain minimum of nitrogen, phosphorus and other minerals. In the case of heterotrophic, non-nitrogen-fixing microorganisms, the energy is obtained either from nitrogen-free organic compounds or from proteins and their derivatives. The nitrogen is obtained from inorganic nitrogenous salts, such as ammonium conpounds and nitrates, or from complex organic compounds, such as proteins and their derivatives. Phosphates and other minerals are obtained from the inorganic or organic compounds present.

When an organism has to derive both its carbon and nitrogen from proteins, only a small part of the nitrogen is reassimilated, while a larger part will remain as a waste product (ammonia). Several factors contribute to this phenomenon:

1. Only 10 to 40 per cent of the carbon is reassimilated by the organism and synthesized into protoplasm; a larger part is given off as $\mathrm{CO}_{2}$ (in the process of energy utilization) or is left in the form of undecomposed material or in the form of intermediary products. The smaller the amount of carbon assimilated by the organism, the less is the amount of protoplasm synthesized and, therefore, the less is the amount of nitrogen assimilated and the more of it is left in the medium as a waste product (largely $\mathrm{NH}_{3}$ ).

2. The microbial protoplasm may contain a lower per cent of nitrogen than the original protein. This will tend further to diminish the amount of reassimilated nitrogen. The excess nitrogen will be liberated as ammonia or left in the form of various protein degradation products.

In the presence of available carbohydrates, however, the microorganisms will assimilate the available ammonia nitrogen and convert it into microbial protoplasm. The greater the quantity of carbohydrate present for a given amount of protein or its derivatives the more of the nitrogen will be reassimilated by microorganisms and the less of it will be left as ammonia. The larger the ratio of the protein-free 
substances to the protein, the smaller is the amount of ammonia liberated. This has an important bearing upon the liberation of ammonia in the soil, since the great mass of organic matter usually added to the soil, in the form of manures and plant residues, contains a low per cent of nitrogen and a high per cent of energy-yielding material. The available nitrogenous plant food in the soil is also greatly affected by the conditions under which decomposition takes place, since, under different conditions, different organisms will take part in the process and will, therefore, bring about different sets of reactions. Microorganisms vary in the amount of carbon reassimilated, in the relative nitrogen content, and in the nature of decomposition that they bring about.

Influence of non-nitrogenous organic matter upon the decomposition of nitrogenous compounds and upon the amounts of ammonia liberated. The presence of non-clecomposed or only partly decomposed nonnitrogenous organic matter in the soil modifies in various ways the decomposition of nitrogenous compounds by microorganisms, by influencing the amount and the nature of decomposition.

Hirschler ${ }^{1}$ was the first to point out that the decomposition of proteins by microorganisms is modified by the presence of carbohydrates which prevent the formation of aromatic products of putrefaction. Indol, phenol, and oxy-acids were not formed in the decomposition of proteins by bacteria when sucrose, starch, dextrin, glycerol or lactic acid are present; i.e., the presence of an available source of energy modified the decomposition processes. It was later ${ }^{2}$ demonstrated conclusively that bacteria do not decompose large amounts of proteins in the presence of available carbohydrates; the amount of ammonia formed may also be greatly diminished. This is due to the fact that the organisms derive their energy preferably from carbohydrates and act upon the proteins only to an extent sufficient to obtain the nitrogen required for the synthesis of their protoplasm. Any ammonia that is produced, in this connection, may be reassimilated. In the absence of available carbohydrates, proteins are used also as sources of energy and large amounts of nitrogen are liberated as waste products in the

${ }^{1}$ Hirschler, A. Über den Einflusz der Kohlehydrate und einiger anderer Körper der Fettsäurereihe auf die Eiweissf ̈̈ulniss. Ztschr. physiol. Chem., 10: 306-317. 1886 .

2 Kendall, A.I. The significance and quantitative measurement of the nitrogenous metabolism of bacteria. Jour. Inf. Dis., 30: 211. 1922; also Ibid., 17: 442-453. 1915; Jour. Amer. Chem. Soc., 35: 1201-1249. 1913; 36: 1937-1962. 1914. 
form of ammonia. The presence of an available carbohydrate does not inhibit, but rather stimulates the multiplication of the bacteria; it lessens, however, the amount of protein to be utilized, and, therefore, the amount of ammonia accumulated. Doryland ${ }^{3}$ explained this by the fact that the organisms utilize the ammonia as a source of nitrogen and the carbohydrates as a source of energy. Thus, in the presence of available carbohydrates, two factors are at work: (1) less of the protein is decomposed since the bacteria and fungi may prefer the carbohydrate to the protein as a source of energy, (2) the ammonia that has been formed from the decomposition of proteins may be reassimilated by the microorganisms which utilize the carbohydrate as a source of energy. These organisms are, therefore, competing with higher plants, for the available nitrogen compounds in the soil. As a result of these studies, Doryland defined ammonification as "an expression of an unbalanced ratio for microorganisms, in which the nitrogen is in excess of the energy-nitrogen ratio." If the available energy material is equal to or is in excess of the energy-nitrogen ratio required by the flora, the coefficient of ammonia formation tends to approach zero; it tends to approach a maximum, if the available energy material is less than the energy-nitrogen ratio. Depending on the proportion of energy material to nitrogenous substances, "beneficial" bacteria may become "harmful." This is brought out in table 45 .

Bac. subtilis produced, in the absence of glucose, $1 \mathrm{mgm}$. of $\mathrm{NH}_{3}$ for every $49 \mathrm{mgm}$. casein decomposed. In the presence of glucose, $1874.1 \mathrm{mgm}$. of casein was decomposed; this should have produced $38.2 \mathrm{mgm} . \mathrm{NH}_{3}$, whereas only $11.9 \mathrm{mgm}$. were found. The difference between the actual amount of ammonia present in the glucose medium and the amount that would have accumulated, had the glucose been left out, is $26.3 \mathrm{mgm}$.; this quantity of ammonia must have been assimilated by the bacteria. At the same time, 1934 mgm. of glucose has disappeared or about $13 \mathrm{mgm}$. of $\mathrm{NH}_{3}$ for every 1 gram of glucose. 'The amount of nitrogen utilization by Bac. subtilis, with casein as a source of nitrogen, was found to be considerably greater than the nitrogen assimilated by this organism from inorganic salts in synthetic media, with glucose as a source of energy. This is due not only to the actually greater assimilation of nitrogen, but also because the organisms had at their disposal the energy that was made

${ }^{3}$ Doryland, C. J. T. The influence of energy material upon the relation of soil microorganisms to soluble plant food. N. D. Agr. Exp. Sta. Bul. 116. 1916. 
available from that part of the casein which has undergone decomposition. ${ }^{4}$

The various other bacteria behaved in a similar manner, differing, however, not only in the absolute amount of ammonia liberated, but also in the ratio between the glucose consumed, casein decomposed and ammonia liberated. Bac. mycoides liberated not only the largest absolute amount of ammonia, but consumed a smaller amount of

TABLE 45

Influence of glucose on ammonia accumulation from casein in $400 \mathrm{cc}$. of synthetic solution in six days at room temperature

\begin{tabular}{|c|c|c|c|c|c|c|c|}
\hline \multirow{2}{*}{ OROANISM } & & \multirow{2}{*}{$\begin{array}{c}\mathrm{NH}_{8} \\
\text { ACCUMU } \\
\text { LATED }\end{array}$} & \multirow{2}{*}{$\begin{array}{l}\text { DIFFER- } \\
\text { ENCE } \\
\text { DUETO } \\
\text { GLU- } \\
\text { COSE }\end{array}$} & \multicolumn{2}{|c|}{$\begin{array}{l}\text { CASEIN CON- } \\
\text { SUMED }\end{array}$} & \multirow{2}{*}{$\begin{array}{l}\text { GLU- } \\
\text { COSE } \\
\text { CON- } \\
\text { SUMED }\end{array}$} & \multirow{2}{*}{$\begin{array}{l}\text { BAC- } \\
\text { TERIA }\end{array}$} \\
\hline & & & & Total & $\mid \begin{array}{c}\text { Per 1 } \\
\text { mgm.of } \\
\mathrm{NH}_{3}\end{array}$ & & \\
\hline \multirow{3}{*}{ B. subtilis. . } & & $m g m$. & mgm. & $m g m$. & $m g m$. & $m g m$. & millions \\
\hline & Casein & 43.0 & & 2109.1 & 49.0 & & 28.8 \\
\hline & Casein + glucose & 11.9 & 31.1 & 1874.1 & & 1934 & 42.6 \\
\hline \multirow{2}{*}{ B. proteus } & Casein & 13.6 & & 2054.4 & 151.0 & & 62.4 \\
\hline & Casein + glucose & 2.6 & 11.0 & 1716.4 & & 1771 & 67.7 \\
\hline \multirow{2}{*}{ B. mycoides.... } & Casein & 64.9 & & 1459.0 & 22.4 & & 50.2 \\
\hline & Casein + glucose & 14.3 & 50.6 & 1001.0 & & 1885 & 61.0 \\
\hline \multirow{2}{*}{ B.megatherium... } & Casein & 20.8 & & 2055.2 & 98.8 & & 57.8 \\
\hline & Casein + glucose & 10.5 & 10.3 & 2086.5 & & 1864 & 87.9 \\
\hline \multirow{2}{*}{ B. vulgatus..... } & Casein & 32.0 & & 1734.9 & 54.2 & & 91.4 \\
\hline & Casein + glucose & 16.7 & 15.3 & 1773.1 & & 1988 & 111.2 \\
\hline \multirow{2}{*}{ Sarcina lutea.... } & Casein & 28.4 & & 829.5 & \begin{tabular}{|l}
59.2 \\
29.2
\end{tabular} & & 14.7 \\
\hline & Casein + glucose & 9.2 & 19.2 & 900.0 & & 1565 & 15.6 \\
\hline
\end{tabular}

casein for a unit of ammonia liberated. Glucose brought about in all cases an increase in the numbers of bacteria, but a decrease in the amount of casein decomposed.

4 It can be easily demonstrated in the case of fungi that the nitrogen content of the organism is higher when the energy is obtained from proteins than when it is obtained from carbohydrates. Further information on the influence of the carbon source on nitrogen utilization by Bac. subtilis is found in a paper by Aubel: E. A. Aubel. Influence de la nature de l'aliment carboné sur l'utilisation de l'azote par le Bacillus subtilis. Compt. Rend. Acad. Sci., 171: 478-479. 1920. 
A small amount of sugar ( 0.05 per cent) may even have a stimulating effect on the formation of ammonia from casein by causing an increase in the numbers of bacteria. After the sugar has all been decomposed, the increased numbers of bacteria will bring about a greater consumption of energy and, therefore, a greater decomposition of the protein and liberation of ammonia. A change from a depressing to a stimulating effect by the addition of a small amount of available carbohydrate upon the accumulation of ammonia from dried blood is

TABLE 46

Influence of various concentrations of glucose on the formation of ammonia from casein ${ }^{3}$

\begin{tabular}{|c|c|c|c|c|c|c|c|c|c|}
\hline & \multirow{2}{*}{$\begin{array}{l}\text { INCUBA- } \\
\text { TION }\end{array}$} & \multicolumn{2}{|c|}{$\mathrm{C}^{*}$} & \multicolumn{2}{|c|}{$\begin{array}{c}\mathrm{C}+0.05 \\
\text { PER CENT G }\end{array}$} & \multicolumn{2}{|c|}{$\begin{array}{c}\mathrm{C}+0.1 \\
\text { PER CENT } \mathrm{G}\end{array}$} & \multicolumn{2}{|c|}{$\begin{array}{c}\mathrm{C}+0.2 \\
\text { PER CENT } \mathrm{G}\end{array}$} \\
\hline & & $\mathrm{NH}_{3}$ & Bact. & $\mathrm{NH}_{3}$ & Bact. & $\mathrm{NH}_{3}$ & Bact. & $\mathrm{NH}_{3}$ & Bact. \\
\hline \multirow{4}{*}{ B. subtilis.. } & days & mom. & mill. & $m g m$. & mill. & $m g m$. & mill. & $m g m$. & mill. \\
\hline & 2 & 15.7 & 2.9 & 13.0 & 4.6 & 12.0 & 4.9 & 13.2 & 4.0 \\
\hline & 4 & 25.1 & 11.4 & 20.0 & 22.8 & 15.9 & 30.9 & 13.0 & 33.0 \\
\hline & 6 & 49.5 & 49.0 & 55.0 & 54.7 & 48.7 & 54.3 & 17.0 & 59.0 \\
\hline \multirow{3}{*}{ B. proteus..... } & 2 & 13.8 & 5.1 & 10.9 & 6.0 & 11.8 & 6.8 & 10.9 & 6.8 \\
\hline & 4 & 20.2 & 21.1 & 22.0 & 39.2 & 13.7 & 48.3 & 15.0 & 50.1 \\
\hline & 6 & 30.3 & 86.6 & 32.0 & 80.1 & 30.1 & 89.1 & 15.7 & 92.2 \\
\hline \multirow{3}{*}{ B. mycoides. } & 2 & 22.6 & 4.7 & 14.8 & 4.4 & 13.9 & 3.8 & 14.0 & 4.8 \\
\hline & 4 & 64.0 & 25.9 & 20.1 & 32.1 & 14.4 & 33.0 & 15.0 & 37.0 \\
\hline & 6 & 69.6 & 63.2 & 60.0 & 65.9 & 52.0 & 66.7 & 11.9 & 66.1 \\
\hline \multirow{3}{*}{ Sarcina lutea. . } & 2 & 12.9 & 1.9 & 11.2 & 2.0 & 11.9 & 2.8 & 10.8 & 3.1 \\
\hline & 4 & 22.4 & 5.9 & 10.2 & 7.6 & 11.9 & 6.1 & 12.0 & 7.4 \\
\hline & 6 & 26.1 & 7.9 & 20.0 & 19.0 & 11.3 & 10.7 & 11.0 & 8.9 \\
\hline
\end{tabular}

* $\mathrm{C}=$ casein, $\mathrm{G}=$ glucose; Bact. = bacteria in millions.

illustrated in fig. 30. In the presence of undecomposed organic matter, the soluble nitrogen salts are transformed into insoluble proteins; these compounds will be decomposed later and make the nitrogen compounds available again. ${ }^{5}$

Since the formation of ammonia is a prerequisite to nitrate formation, one would expect from these results that an excess of available energy

${ }^{5}$ Gerlach and Deusch. Über den Einflusz organischer Substanzen auf die Umsetzung und Wirkung stickstoffhaltiger Verbindungen. Mitt. Kais. Wilh. Inst. Landw. Bromberg, 4: 259. 1912; (Centrbl. Bakt. II, 37: 296. 1913). 
would repress nitrate formation in the soil. Nitrification was found ${ }^{6}$ to be checked when the carbon-nitrogen ratio in the soil is $13-15$ to 1 , but not when the ratio is 11-11.6 to 1 . When molasses was added to the soil, nitrification was stopped when the ratio was about 11:1, but was not injured when the ratio was less. However, the addition of carbon sources not readily available, such as butyric acid and alcohol, did not injure nitrification at a ratio of $14: 1$, but did injure it at a higher ratio. This phenomenon is brought out clearly when cellulose is added to the soil. The organisms using the cellulose as a source of energy assimilate the soil nitrates, without injuring, however, the activities

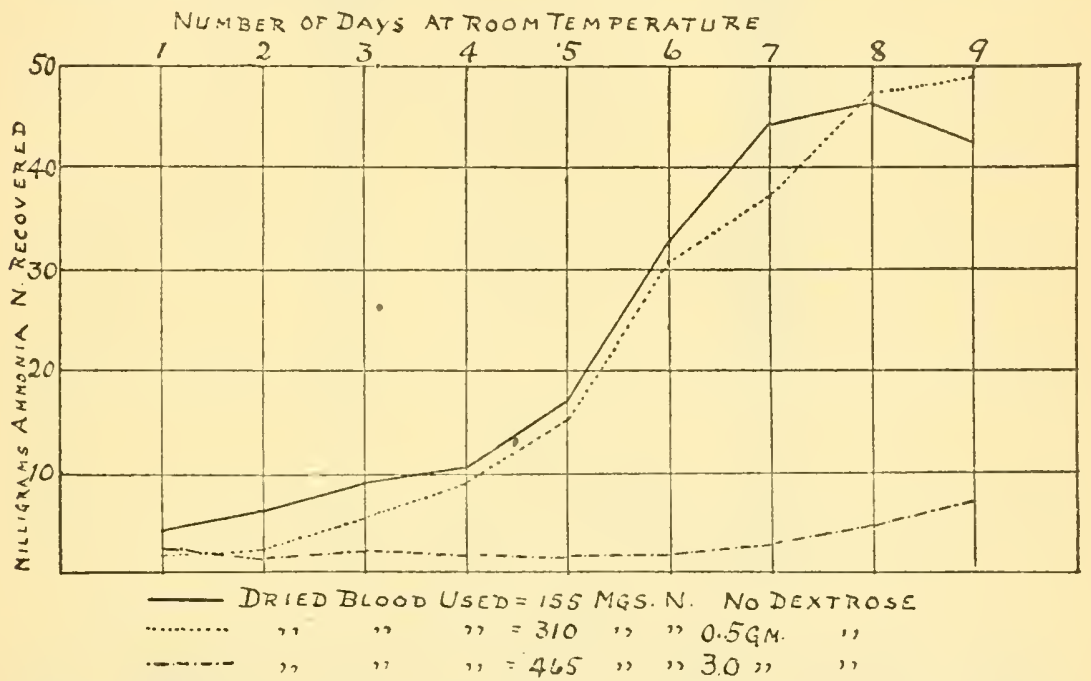

FIG. 30. Influence of glucose on ammonia accumulation from dried blood added to soil (after Lipman and associates).

of the nitrifying bacteria. Only after all the celluloses have decomposed, do nitrates begin to accumulate again, as shown in fig. 31 .

As long as there is free available energy, in excess of the available nutrients, there will be only a minimum accumulation of available plant food. When the energy approaches exhaustion the nutrients begin to accumulate, as shown in table $47 .^{7}$

${ }^{6}$ Clark, H. W., and Adams, G. O. The influence of carbon upon nitrification. Jour. Ind. Engin. Chem., 4: 272-274. 1912.

${ }^{7}$ Waksman, S. A. The influence of available carbohydrates upon ammonia accumulation by microorganisms. Jour. Amer. Chem. Soc., 39: 1503-1512. 1917. 
In sufficient time, however, there is a narrowing of the energy-nutrient ratio in the soil organic matter, and an ultimate liberation of plant food takes place. The death of large numbers of microorganisms with a low energy-nutrient ratio leads to the same end. Succeeding generations of microorganisms have at their disposal the energy material of the decomposition products from the original organic matter, the dead cells of microorganisms and the original compounds which decompose only very slowly; all of these have a narrower energy-nu-

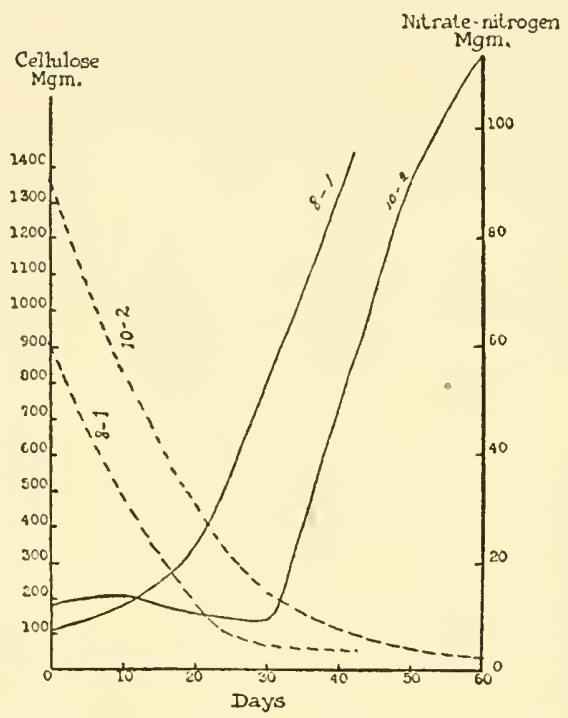

Fig. 31. Influence of cellulose on nitrate accumulation in the soil. cellulose; - - nitrate nitrogen. $8-1$ and $10-2$ are the experiment numbers (from Anderson).

trient ratio than the original organic matter added to the soil. A gradual accumulation of plant food takes place, which the microorganisms are unable to assimilate and which is left for the use of higher plants.

Decomposition of organic substances of varying carbon-nitrogen ratio. The nature and composition of the organic matter greatly influence its decomposition. The ratio between the carbon and nitrogen of the material used is of especial importance in this connection. The same is true of the nature of the non-nitrogenous organic materials introduced into the soil in addition to the nitrogenous substances. 
Table 48 has been compiled from the results of Lipman and associates, ${ }^{8}$ who added different organic nitrogenous materials to 100 gram portions of soil; the moisture content was brought to an optimum and the soils incubated for 7 days, when the ammonia was determined by

TABLE 47

Influcnce of concentration of sugar upon the accumulation of ammonia from $2 \%$ peptone solution by Asp. niger

\begin{tabular}{c|c|c|c|c}
\hline INCUBATION & SUGAR ADDED & NH $_{3}$-N IN $100 \mathrm{cC}$. & $\begin{array}{c}\text { WEIGHT OF } \\
\text { MYCELIUM }\end{array}$ & $\begin{array}{c}\text { SUGAR LEFT IN } \\
\text { MEDICM }\end{array}$ \\
\cline { 2 - 3 } days & per cent & $m g m$. & mgm. & \\
5 & 0 & 44.80 & 200 & 0 \\
5 & 1 & 40.74 & 280 & + \\
5 & 3 & 14.14 & 1,304 & ++ \\
5 & 5 & 1.26 & 1,500 & +++ \\
5 & 20 & 0 & 1,620 & ++++ \\
15 & 0 & 73.08 & 360 & 0 \\
15 & 1 & 50.68 & 930 & 0 \\
15 & 3 & 36.54 & 3,270 & 0 \\
15 & 5 & 33.04 & 5,220 & + \\
15 & 20 & 0 & 11,210 & ++ \\
\hline
\end{tabular}

TABLE 48

Influence of carbohydrates upon the accumulation of ammonia from nitrogenous organic materials

\begin{tabular}{|c|c|c|c|c|c|}
\hline \multirow{2}{*}{ NITROGENOUS BUBSTANCE } & \multirow{2}{*}{$\begin{array}{l}\text { TOTAL } \\
\text { NITROGEN IN } \\
\text { MATERIAL }\end{array}$} & \multicolumn{4}{|c|}{ AMMONIA FORMED, MILLIGRAMS } \\
\hline & & $\begin{array}{l}\text { No carbo- } \\
\text { hydrate }\end{array}$ & Glucose & Sucrose & Starch \\
\hline 4 grams & $m g m$. & & 2 grams & 2 grams & 2 grams \\
\hline Rice flour....... & 46.4 & 1.26 & 1.30 & 1.48 & 0.87 \\
\hline Corn meal.... & 51.2 & 1.18 & 1.30 & 1.04 & 0.69 \\
\hline Wheat flour.... & 94.8 & 5.14 & 3.66 & 5.84 & 1.56 \\
\hline Cowpea meal. . & 156.8 & 50.88 & 31.71 & 28.57 & 23.70 \\
\hline Linseed meal. . . . . . . & 247.0 & 110.69 & 96.01 & 60.73 & 63.34 \\
\hline Soybean meal........ & 245.6 & 129.64 & 108.03 & 94.88 & 54.36 \\
\hline Cottonseed meal...... & 246.1 & 123.63 & 99.67 & 97.23 & 54.54 \\
\hline
\end{tabular}

distilling with $\mathrm{MgO}$. Rice flour and corn meal, with a wide carbonnitrogen ratio allowed no accumulation of ammonia at all either with or

${ }^{8}$ Lipman, J. G., Blair, A. W., Owen, I. L., and McLean, H. C. Experiments on ammonia formation in the presence of earbohydrates and other non-nitrogenous organic matter. N. J. Agr. Exp. Sta. Bul. 247. 1912. 
without any additional carbohydrate. The substances rich in nitrogen allowed an accumulation of almost 50 per cent of the nitrogen as ammonia, but this was considerably reduced when additional available energy in the form of carbohydrates was added.

Table 49 illustrates the formation of ammonia from different organic materials when sufficient non-nitrogenous organic matter (starch) is added so as to introduce the same amount of fresh undecomposed organic matter. In these studies, the various amounts of the organic materials were added to $100 \mathrm{gram}$ portions of soil and the ammonia determined after 9 days. ${ }^{9}$ When the accumulation of ammonia from the various nitrogenous substances is compared, it is found to be, with the exception of casein, in direct relation to the nitrogen content of

TABLE 49

Per cent of organic nitrogen transformed into ammonia in soil

\begin{tabular}{|c|c|c|c|c|c|}
\hline \multirow{3}{*}{ SOURCE OF NITROGEN } & \multirow{3}{*}{$\begin{array}{l}\text { NITROGEN } \\
\text { CONTENT }\end{array}$} & \multirow{2}{*}{$\begin{array}{l}1 \text { GRAM OF } \\
\text { EACH ORGANIC } \\
\text { MATERIAL } \\
\text { ADDED TO } 100 \\
\text { GRANS SOIL }\end{array}$} & \multicolumn{2}{|c|}{$\begin{array}{l}132.9 \text { MGM. OF ORGANIC } \\
\text { NITROGEN ADDED } \\
\text { TO } 100 \text { GRAMS SOIL }\end{array}$} & \multirow{2}{*}{$\begin{array}{l}132.9 \text { MGM. } \\
\text { ORGANIC NITRO- } \\
\text { GEN PLUS } \\
\text { ENOUGH STARCH } \\
\text { TO MAKE } \\
\text { EQUIVALENT } \\
\text { AMOUNTS OF } \\
\text { CARBON }\end{array}$} \\
\hline & & & \multirow{2}{*}{$\begin{array}{c}\text { Aerobic } \\
\text { conditions } \\
\mathrm{NH}_{3}-\mathrm{N}\end{array}$} & \multirow{2}{*}{$\begin{array}{l}\text { Anaerobic } \\
\text { conditions } \\
\mathrm{NH}_{3}-\mathrm{N}\end{array}$} & \\
\hline & & $\mathrm{NH}_{3}-\mathrm{N}$ & & & $\mathrm{NH}_{3}-\mathrm{N}$ \\
\hline & per cent & $m g m$. & $m g m$. & mgm. & $m g m$. \\
\hline Casein ........ & 12.40 & 50.2 & 56.9 & 53.2 & 31.4 \\
\hline Dried blood........... & 13.29 & 42.4 & 49.3 & 12.3 & 18.9 \\
\hline Soybean cake........ & 8.28 & 40.9 & 48.7 & 14.0 & 34.1 \\
\hline Cottonseed meal. . & 5.10 & 27.1 & 32.0 & 8.5 & 34.0 \\
\hline Linseed meal . . . . & 5.00 & 26.0 & 34.6 & 6.9 & 34.1 \\
\hline
\end{tabular}

the materials. When the same amount of nitrogen is added to the soil, the amount of ammonia accumulated depends upon the concentration of carbonaceous substances present. These may serve as sources of energy for the microorganisms, so that less of the protein is decomposed and more of the nitrogen used up by the organisms for the synthesis of their protoplasm. When enough starch is added to make the amount of carbon equal in all cases, the amount of ammonia accumulated will generally be constant. When the amount of nitrogen is very high as in the case of dried blood, the amount of starch added was very large; since this is a very readily available source of carbon,

${ }^{9}$ Kelley, W. P. The biochemical decomposition of nitrogenous substances in soils. Hawaii Agr. Exp. Sta. Bul. 39. 1915. 
its rapid decomposition is accompanied by a greater disappearance of the ammonia nitrogen. Casein contains more nitrogen in eomparison to the earbon; therefore, the amount of nitrogen liberated as the waste product (ammonia) from the casein will be greater. When sufficient carbon is added to the casein, the amount of ammonia is the same as that of the cottonseed meal and linseed meal.

The influence of the carbon content of the nitrogenous material itself upon ammonia formation can be readily studied with simple amino acids. According to Jodidi, ${ }^{10}$ the formation of ammonia from various amino acids differs with the composition of the amino-acid molecule. In the case of glycocoll, 80 per eent of the nitrogen was transformed into ammonia, while in the ease of leucine only 49 per cent nitrogen was changed to ammonia, under the same conditions. This difference was ascribed to the inert paraffin character of the comparatively long chain of the leucine molecule. However, the results presented $^{11}$ in table 50 show that the greater the earbon content of the acid the more abundant is the growth of the organism and the less is the relative amount of nitrogen liberated as ammonia, i.e., the ammonia liberated from the decomposition of a definite amount of amino acid does not depend upon the absolute amount of nitrogen of the material decomposed, but upon the relative carbon-nitrogen content. The lower the ratio of carbon to nitrogen, the greater is the amount of ammonia liberated per unit of material decomposed.

Different groups of microorganisms as affecting the carbon-nitrogen ratio in the medium. Fungi, as a rule, can readily obtain their energy from carbohydrates, using inorganic salts as sources of nitrogen, as well as from proteins and may even prefer the former. Actinomyces and heterotrophic bacteria, however, prefer as sources of energy proteins, peptones and certain peptides to carbohydrates, especially to the polysaccharides. This accounts for the difference in behavior of these organisms towards various organic compounds added to the soil. When ground alfalfa, which contains about 2.5 to 3.0 per cent nitrogen, is added to the soil, sterilized and inoculated with fungi, only a slight accumulation of ammonia takes place, while the alfalfa is rapidly decomposed as indicated by the abundant $\mathrm{CO}_{2}$ production. This is due to the fact that the fungi produce an abundant growth and use as much as 50 to 60 per cent of the earbon for structural purposes. Since the fungi contain about 4 to 5 per eent nitrogen in

10 Jodidi, 1912 (р. 501).

11 Waksman and Lomanitz, 1925 (p. 379). 
their protoplasm ( 3 to 9 per cent as extremes), the nitrogen made available from the decomposition of the alfalfa may be just sufficient for the synthesis of the fungus protoplasm, without any excess left as ammonia.

When the same amount of alfalfa ( 0.5 to 2 per cent) is added to soil, sterilized and then inoculated with actinomyces or bacteria, some ammonia will be readily formed. This is due to the fact that these organisms synthesize a considerably smaller amount of protoplasm than do the fungi. The nitrogen content of those organisms is higher than that of fungi, viz., 7 to 12 per cent, but because of the considerably lower carbon assimilation, a great deal of the nitrogen is liberated as ammonia. In a series of detailed studies on the decomposition of organic matter by pure cultures of microorganisms, Neller ${ }^{12}$ (figs. 32-33) found

TABLE 50

Influence of composition of amino acid upon ammonia production by microorganisms

\begin{tabular}{|c|c|c|c|c|c|}
\hline AMINO ACID & $\mathrm{C} / \mathrm{N}$ & OROANISM & $\begin{array}{c}\text { DRY } \\
\text { GROWTH } \\
\text { OP CELLS }\end{array}$ & $\mathrm{NH}_{3}-\mathrm{N}$ & $\frac{\text { GROWTH }}{\mathrm{NH}_{3}-\mathrm{N}}$ \\
\hline Glycocoll . . & 1.7 & Trichoderma & $\begin{array}{c}\text { mgm. } \\
50\end{array}$ & $\begin{array}{l}m g m . \\
24.28\end{array}$ & 2.0 \\
\hline Glycocoll.......... & 1.7 & Actinomyces & 59 & 30.46 & 2.0 \\
\hline Alanine ... & 2.57 & Trichoderma & 80 & 21.98 & 3,6 \\
\hline Alanine......... & 2.57 & Actinomyces & 126 & 39.17 & 3.2 \\
\hline Glutamic acid... & 4.28 & Trichoderma & 218 & 29.12 & 7.5 \\
\hline Glutamic acid ...... & 4.28 & Actinomyces & 169 & 28.36 & 5.9 \\
\hline Glutamic acid ...... & 4.28 & Bact. fluorescens & 128 & 28.50 & 4.5 \\
\hline
\end{tabular}

that, under sterile conditions, the fungi bring about a much greater evolution of $\mathrm{CO}_{2}$ than bacteria, the action of the pure cultures of fungi approaching that of the complex mixture of organisms found in a soil suspension. The amount of ammonia liberated by the fungi, particularly by the rapidly growing forms ( $A s p$. niger), was negligible in comparison with that liberated by the bacteria. In 12 days Trichoderma and $A s p$. niger liberated, from 1 per cent alfalfa, about 21 per cent of the carbon as $\mathrm{CO}_{2}$ and a mere trace of the nitrogen as ammonia. Bac. subtilis liberated, in 8 days, from 2 per cent alfalfa, only 8.9 per cent of the carbon as $\mathrm{CO}_{2}$, but 10.4 per cent of the nitrogen was

${ }_{12}$ Neller, J. R. Studies on the correlation between the production of carbon dioxide and the accumulation of ammonia by soil organisms. Soil Sci., 5: 225241. 1918. 
changed to ammonia. This tends to demonstrate that, with a substance that has a $\mathrm{C}: \mathrm{N}$ ratio of 16 (alfalfa meal), fungi require all the nitrogen for synthetic purposes while bacteria can liberate, as ammonia, an amount of nitrogen equivalent to the amount of carbon decomposed. Since fungi produced as great an amount of $\mathrm{CO}_{2}$ as the complex soil suspension, Neller suggested that the fungi can be looked upon as organisms active in normal soil. However, if fungi were the predominating or only organisms in the soil, this state of affairs could hardly be considered beneficial to higher plants. The rapid decomposition of the organic matter by the fungi with a lack of ammonia

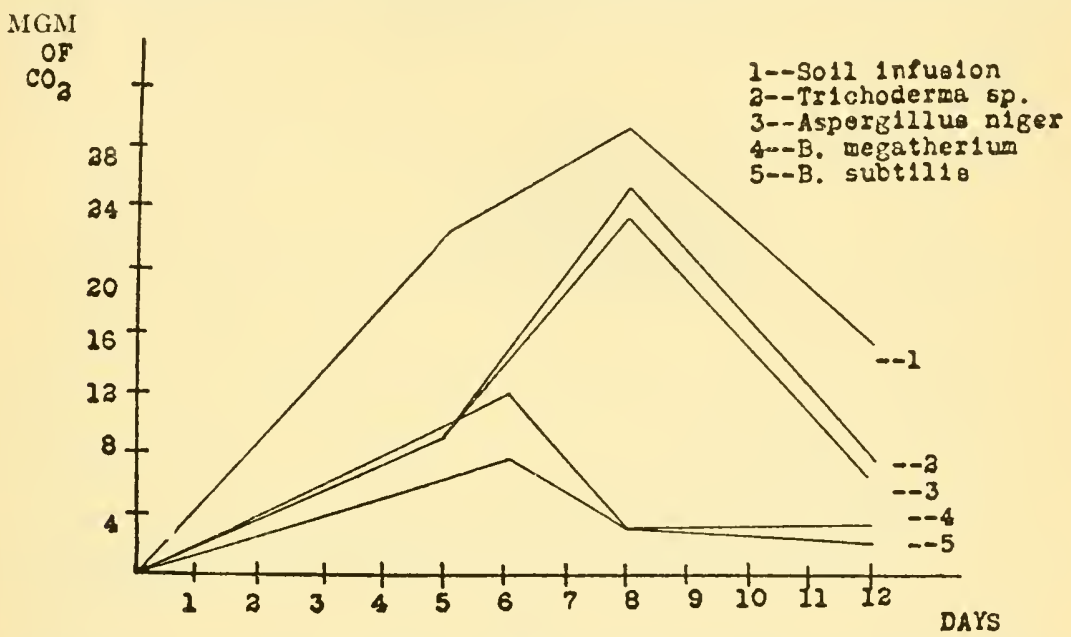

Fro. 32. Rate of decomposition of alfalfa meal by pure cultures of microorganisms and by the mixed soil flora, as indicated by the daily evolution of $\mathrm{CO}_{2}$ (from Neller).

accumulation is true only of substances with a relatively wide carbonnitrogen ratio, such as alfalfa meal; these substances are usually acted upon first of all by fungi and only later by bacteria. The fungi rapidly break down the complex carbohydrates and cause a narrowing of the carbon-nitrogen ratio. This leads to an abundant liberation of $\mathrm{CO}_{2}$ but not of ammonia, since the proteins are decomposed to a limited extent and all the ammonia is reassimilated. The synthesized fungus mycelium is richer in nitrogen than the alfalfa and the fungi are efficient utilizers of the available energy. The bacteria first of all break down the proteins and liberate large quantities of ammonia as a waste product. Due to the limited utilization of the celluloses and to 
the low nitrogen content of the bacteria, only a small amount of the ammonia is reassimilated. This is the reason why bacteria produce small amounts of $\mathrm{CO}_{2}$ while considerable quantities of ammonia may accumulate. The amount of ammonia and of nitrate produced and accumulated in the soil will, therefore, depend upon the carbonnitrogen ratio of the organic matter added. The influence of microorganisms upon the carbon-nitrogen ratio of the soil itself is discussed elsewhere (p. 702).

Influence of straw and plant residues upon the growth of cultivated plants. Higher cultivated plants may have to compete with microorganisms for the available plant food, especially the nitrogen. When

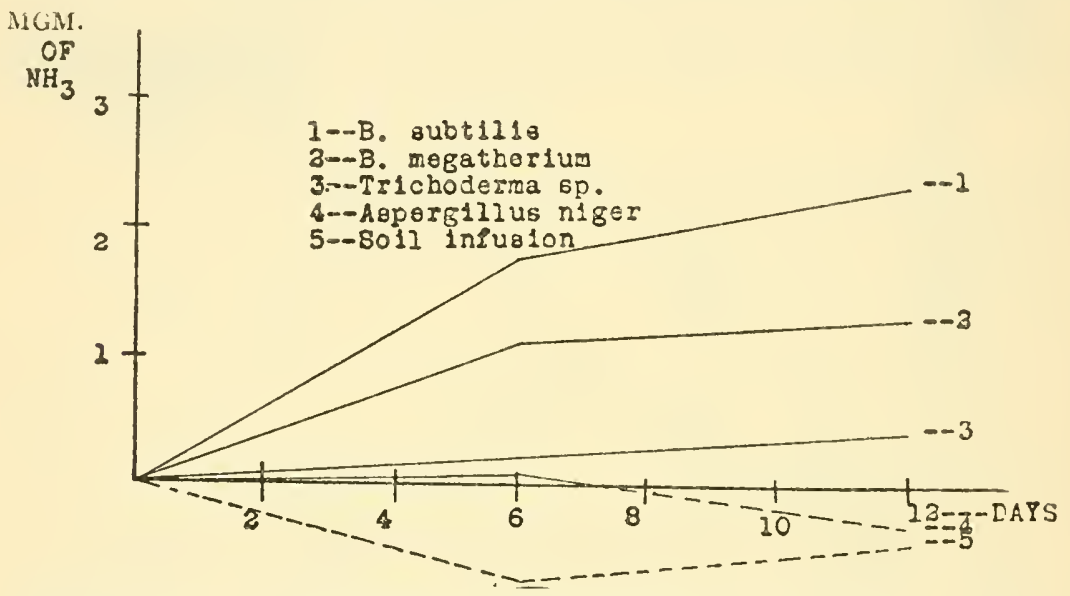

FIG. 33. Rate of decomposition of alfalfa meal by pure cultures of microorganisms and by the mixed soil flora, as indicated by the accumulation of ammonia (from Neller).

large amounts of green manure or straw are plowed under and a crop is planted soon afterwards, distinct injury to the crop may set in. This injury is largely a phenomenon of nitrogen starvation. Krüger and Schneidewind ${ }^{13}$ submitted definite evidence that the addition of cellulose to the soil stimulates the development of various soil organisms which reduce the soil nitrates and prevent the plants from obtaining sufficient nitrogen for their growth. The fact that leguminous plants

${ }^{13}$ Trrüger, W., and Schneidewind, W. Ursache und Bedeutung der Salpeterzersetzung im Boden. Landw. Jahrb., 23: 217-252. 1899; Zersetzungen und Umsetzungen von Stickstoff verbindungen im Boden durch niedere Organismen und ihr Einfluss auf das Wachstum der Pflanzen. Landw. Jahrb., 30: 633-649. 1901. 
grew readily in soil in the presence of materials rich in cellulose, since they are independent of the soil nitrogen, and the fact that no ill effects were observed in partially sterilized soil served to prove the above theory. Pfeiffer and Lemmermann ${ }^{14}$ pointed out that the injurious effect of straw upon plant growth was due not to denitrification but to the development of organisms which assimilated the nitrates and used the nitrogen for the synthesis of microbial protoplasm. It was later found ${ }^{15}$ that substances like hay and sugar caused a harmful effect the first year and a beneficial effect the second year; i.e. the application of materials rich in carbohydrate depressed crop growth when applied just previous to planting but stimulated crop growth when a considerable period elapsed. ${ }^{16}$ According to Rahn, ${ }^{17}$ easily assimilable carbon compounds are present in the soil only in minute quantities; ammonia and nitrate can, therefore, accumulate as a result of a gradual decomposition of the soil organic matter. The addition of straw and other plant substances rich in available carbon (energy) brings about an increase in the development of microorganisms as a result of which a nitrogen minimum may occur. This will last as long as easily decomposable carbon compounds are still left. The nitrogen minimum appears more quickly and lasts longer in nitrogen-poor than in nitrogen-rich soils. During this condition, the plants cannot obtain any nitrogen from the soil. The addition of available nitrogen overcomes the harmful results. The depressing effects upon plant growth following the application of straw has been reported by a number of other investigators. ${ }^{18}$ The results of Kellerman and Wright ${ }^{19}$ on the nutri-

14 Pfeiffer, Th., and Lemmermann, O. Denitrifikation und Stallmistwirkung. Landw. Ver. Stat., 54: 386-462. 1900.

${ }^{15}$ Bredemann, G. Untersuchungen über das Bakterien-Impfpräparat "Heyl's Concentrated Nitrogen Producer." Landw. Jahrb., 43: 669-694. 1912.

${ }^{16}$ Hutchinson, H. B. The influence of plant residues on nitrogen fixation and on losses of nitrate in the soil. Jour. Agr. Sci., 9: 92-111. 1918.

${ }^{17}$ Rahn, O. Die schädliche Wirkung der Strohdüngung und desen Verhütung. Zeitschr. Tech. Biol., 7: 172-186. 1919.

${ }^{18}$ Albrecht, W. A. Nitrate accumulation under straw mulch. Soil Sci., 14: 299-305. 1922; 20: 253-265; Hill, H. H. The effect of green manuring on soil nitrates under greenhouse conditions. Virginia Agr. Exp. Sta. Tech. Bul. 6. 1915; Murray, T. J. The effect of straw on the biological soil processes. Soil Sci., 12: 233-260. 1921; Scott, H. The influence of wheat straw on the accumulation of nitrate in the soil. Jour. Amer. Soc. Agron., 13: 233-258. 1921; Martin, T. I. Effect of straw on accumulation of nitrates and crop growth. Soil Sci., 20: 159-164. 1925.

${ }^{19}$ Kellerman, K. F., and Wright, R. C. Relation of bacterial transformations 
tion of seedlings and the results of Barthel and Bengtsson ${ }^{20}$ on the influence of manure upon cellulose decomposition definitely indicate that we are not dealing here with an injury of the process of nitrification but with the actual assimilation of the nitrate by the soil fungi and bacteria that use the celluloses as sources of energy. Collison and Conn ${ }^{21}$ concluded that two separate harmful factors are associated with the influence of straw and other plant residues upon plant growth: (1) a toxic chemical agent which acts upon the plants immediately after germination, the effect not being pronounced in soils; (2) a biological factor as a result of the competition between soil microorganisms and plants for the available nitrogen. The results of Viljoen and Fred ${ }^{22}$ on the effect of wood and wood pulp upon the growth of oats

TABLE 51

Influence of difierent kinds of wood on the growth of oats and red clover

\begin{tabular}{|c|c|c|c|}
\hline \multirow{2}{*}{ TREATMENT } & \multirow{2}{*}{$\begin{array}{l}\text { YIELD OF } \\
\text { OATS, } \\
\text { AVERAGE }\end{array}$} & \multicolumn{2}{|c|}{$\begin{array}{c}\text { YIELD OF RED } \\
\text { CLOVER, AVERAGE }\end{array}$} \\
\hline & & $\begin{array}{c}\text { Uninocu- } \\
\text { lated }\end{array}$ & $\begin{array}{l}\text { Inocu- } \\
\text { lated }\end{array}$ \\
\hline & grams & grams & grams \\
\hline None . . . . . . . . . . & 26.6 & 27.5 & 44.0 \\
\hline 1.5 per cent coarse wood.. & 18.3 & 26.5 & 37.3 \\
\hline 3.0 per cent coarse wood..... & 14.8 & 21.5 & 43.0 \\
\hline 3.0 per cent fine wood $\ldots \ldots \ldots \ldots \ldots \ldots$ & 21.0 & 24.5 & 41.5 \\
\hline 3.0 per cent wood burned and ash used...... & 27.5 & 60.0 & 56.0 \\
\hline
\end{tabular}

and clover demonstrated definitely that the injurious effects are due to a lack of available nitrogen (table 51).

A study of the decomposition of two natural organic materials, varying in nitrogen content, indicates that the decomposition of the material of a lower nitrogen content, like timothy residues, is extended

of soil nitrogen to nutrition of citrous plants. Jour. Agr. Res., 2: 101-113. 1914.

${ }^{20}$ Barthel, C., and Bengtsson, N. Action of stable manure in the decomposition of cellulose in tilled soil. Soil Sci., 18: 185-200. 1924; Idem., 1926 (p. 448); also Anderson, 1926 (p. 451).

${ }^{21}$ Collison, R. C., and Conn, H. J. The effect of straw on plant growth. N. Y. (Geneva) Agr. Exp. Sta. Tech. Bul. 114. 1925.

${ }^{22}$ Viljoen, J. A., and Fred, E. B. The effect of different kinds of wood and wood pulp on plant growth. Soil Sci., 17: 199-208. 1924. 
over a longer period of time than that of an organic material containing more nitrogen, like clover residues. The more rapid decomposition of the latter is accompanied by a more rapid increase in the number of microorganisms concerned in the process followed by a more rapid drop. The removal of nitrate from the soil solution will, therefore, not be as prolonged in the case of clover as in the case of timothy residues; this tends to explain the slight depression of the nitrate content of the soil as a result of addition of clover or other leguminous materials than that following the addition of timothy or other plant residues low in nitrogen. ${ }^{23}$

${ }^{23}$ Wilson, B. D., and Wilson, J. K. An explanation for the relative effects of timothy and clover residues in the soil on nitrate depression. N. Y. (Cornell) Agr. Exp. Sta., Mem. 95. 1925. 


\section{CHAPTER XX}

\section{Oxidation Processes in the Soll-Nitrate Formation}

Oxidation-reduction phenomena. Oxidation-reduction processes have commonly been interpreted in terms of oxygen; "oxidation" designated a process whereby oxygen was added to a substance or hydrogen was removed; "reduction" was applied to reactions involving the removal of oxygen or addition of hydrogen. However, in certain processes of oxidation-reduction no oxygen or hydrogen participate, as in the following reaction:

$$
\mathrm{FeCl}_{2}+\mathrm{Cl} \rightleftarrows \mathrm{Fe} \mathrm{Cl}_{3}
$$

Clark and associates ${ }^{1}$ were, therefore, led to consider these processes in the light of addition or withdrawal of electrons. Taking the oxiclation and reduction of iron, the following reactions may be given:

$$
\begin{aligned}
& 2 \mathrm{Fe}^{+++}+\mathrm{H}_{2} \rightleftarrows 2 \mathrm{Fe}^{++}+2 \mathrm{H}^{+} \\
& 2 \mathrm{Fe}^{+++}+2 \mathrm{O} \rightleftarrows 2 \mathrm{Fe}^{++}+\mathrm{O}_{2} \\
& \mathrm{Fe}^{+++}+\mathrm{e} \rightleftarrows \mathrm{Fe}^{++}
\end{aligned}
$$

When the reaction proceeds from left to right, reduction is taking place; when it proceeds from right to left, oxidation is taking place. In the presence of methylene blue, nitrate or any other substance capable of acting as hydrogen acceptors, oxidation may take place even in the absence of atmospheric oxygen; this enables certain bacteria to live anaerobically. Processes of oxidation can thus be considered either as (1) aerobic processes, in which atmospheric oxygen acts as the hydrogen acceptor or the oxidizing agent and (2) anaerobic processes, in which organic or inorganic compounds act as the hydrogen acceptors, both processes resulting in the liberation of energy.

In addition to the action of unactivated molecular oxygen as a hydrogen acceptor, there are at least three ways in which activation of oxygen can occur: (1), by means of iron, which acts as oxygen carrier; ${ }^{2}(2)$ by

1 Clark, W. M., et al. Studies on oxidation-reduction. Public Health Reports, 38: 443, 666, 933, 1669; 39: 381, 804. 1924.

${ }^{2}$ Warburg, O. Über Eisen, den sauerstoffübertragenden Bestandteil des Atmungsferments. Biochem. Ztschr., 152: 479-494. 1924. 
the action of the sulfhydryl group; $;^{3}$ (3) by substances which are capable of peroxide formation. ${ }^{4}$

The oxygen liberated in synthetic processes is consumed directly for the liberation of energy as in the formation of amino acids from organic acids and ammonia, which is the first step in protein synthesis by heterotrophic microorganisms:

$$
\begin{gathered}
2 \mathrm{CH}_{3} \cdot \mathrm{CO} \cdot \mathrm{COOH}+2 \mathrm{NH}_{3}=2 \mathrm{CH}_{3} \cdot \mathrm{CH} \cdot \mathrm{NH}_{2} \cdot \mathrm{COOH}+\mathrm{O}_{2} \\
1 / 6\left(\mathrm{C}_{6} \mathrm{H}_{12} \mathrm{O}_{6}\right)+\mathrm{O}_{2} \rightarrow \mathrm{CO}_{2}+\mathrm{H}_{2} \mathrm{O}
\end{gathered}
$$

The oxygen in the $\mathrm{CO}_{2}$ molecule that has thus become liberated is not derived from free gas but from a molecule capable of reduction by glucose, a phenomenon distinctly different from that involving oxygen occurring in an external medium. ${ }^{5}$ In considering oxidation as the activation of hydrogen, atomic oxygen will be formed if the hydrogen of water is activated. In the presence of a substance, such as methylene blue or nitrates, which readily absorbs hydrogen, oxidation becomes possible as a result of the reduction of the active hydrogen. For example, acetic acid bacteria oxidize alcohol in the absence of oxygen but in the presence of methylene blue.

$$
\begin{aligned}
\mathrm{CH}_{3} \mathrm{CH}_{2} \mathrm{OH} & =\mathrm{CH}_{3} \mathrm{COH}+2 \mathrm{H}^{+} \\
2 \mathrm{H}^{+} & +\mathrm{O} \rightarrow \mathrm{H}_{2} \mathrm{O}
\end{aligned}
$$

The rôle of oxygen consists in binding the hydrogen and its place can be taken by other hydrogen acceptors. The acetaldehyde is changed by the Cannizzaro reaction to alcohol and acetic acid, this process being accompanied by the liberation of energy:

$$
2 \mathrm{CH}_{3} \mathrm{COH}+\mathrm{H}_{2} \mathrm{O} \rightarrow \mathrm{CH}_{3} \cdot \mathrm{COOH}+\mathrm{CH}_{3} \cdot \mathrm{CH}_{2} \mathrm{OH}
$$

The phenomena of oxidation and reduction by microorganisms are brought about in most instances by means of specific enzymes of the oxidase-peroxidase nature on the one hand and reductase or perhydridase nature on the other.

The oxidation-reduction intensities of biological systems can be

${ }^{3}$ Hopkins. Biochem. Jour., 19: 798. 1925.

- See Quastel, J. H. Dehydrogenations produced by resting bacteria. IV. A theory of the mechanism of oxidations and reductions in vivo. Biochem. Jour., 20 : 166-194. 1926.

- Aubel, E., and Wurmser, R. Sur l'utilisation de l'énergie libérée par les oxydations. Compt. Rend. Acad. Sci., 179: 848-851. 1924. 
determined colorimetrically by the use of indigo-sulfonate or other appropriate indicators, or by means of an electrode of a noble metal. By immersing two electrodes in two liquids of different oxidation potential connected with a siphon, a current is formed and oxidation will occur in the solution about one electrode and reduction in the solution about the other. The intensity factor can thus be measured. ${ }^{6}$ There is a relation between the hydrogen-ion concentration and the oxidation-reduction potential of the cell. ${ }^{7}$

Oxidation processes in the soil. According to the older conception, oxidation of inorganic and organic compounds in the soil consists in the intake of oxygen and the transformation of the soil compounds into higher oxidized forms. According to the newer conceptions, it consists in the change of a substance from a higher potential to a substance of a lower potential, with the liberation of energy. Although some of the oxidation processes in the soil may be purely chemical in nature or may be carried on by plant roots and their enzymes, ${ }^{8}$ the predominant rôle of oxidation in the soil is played by microorganisms.

Liebig $^{9}$ recognized that proper oxidation is essential for the decomposition of plant and animal residues added to the soil. Mulder ${ }^{10}$ called attention to the fact that oxidation as well as reduction processes take place in the soil at the same time, with a certain equilibrium established between the two. Oxidation processes usually lead to the complete decomposition of organic substances (mineralization) in the soil (so-called "decay"), the oxidation of ammonium salts to nitrites and the latter to nitrates, the oxidation of elementary sulfur and sulfur compounds to sulfates, and the oxidation of hydrogen, methane, and other substances produced by processes of incomplete oxidation or reduction. Oxidation processes may be looked upon as beneficial processes in the soil. Reduction processes may often become harmful, since, with incomplete oxidation, substances may be formed which are directly injurious to plant growth. It is sufficient to indicate that the reduced forms of nitrates (nitrites), of sulfates (sulfites) and of phosphates (phosphites) are toxic to plant growth.

${ }^{6}$ Gillespie, K. J. Reduction potentials of bacterial cultures and of waterlogged soils. Soil Sci., 9: 199-216. 1920.

${ }^{7}$ Needham, J., and Needham, D. M. Hydrogen-ion concentration and the oxidation-reduction potential of the cell interior; a micro-injection study. Proc. Roy. Soc. B, 98: 259-286. 1925.

${ }^{8}$ Schreiner, O., and Reed, H. S. The rôle of oxidation in soil fertility. Bur. Soils, U. S. Dept. Agr. Bul. 56. 1909.

${ }^{9}$ Liebig, J. Chemie in ihrer Anwendung auf Agrikultur. 4 Aufl., 1842.

${ }^{10}$ Mulder. Die Chemie der Ackerkrume 1. 1863, Tr. by Müller. Berlin. 
Deherain and Demoussy ${ }^{11}$ demonstrated that, in the process of oxidation of organic matter, oxygen is always taken up and carbon dioxide set free. They distinguished between microbial and chemical oxidation. Microbial oxidation is most active at normal temperatures and is favored by increased temperatures, $65^{\circ}$ being the maximum; the quantities of oxygen absorbed and $\mathrm{CO}_{2}$ produced are found to differ with the soil type, moisture, aeration. The volume of $\mathrm{CO}_{2}$ produced is usually smaller than that of oxygen absorbed. Chemical oxidation is low at normal temperatures and increases with temperature elevation, reaching a maximum at $110^{\circ}$. The $\mathrm{CO}_{2}$ produced chemically often exceeds the oxygen absorbed. Russell ${ }^{12}$ found that oxidation increases with an increase in the fertility of the soil. The rate of oxidation increased with temperature, amount of water (up to a certain optimum) and amount of $\mathrm{CaCO}_{3}$. Heating of soil to $100^{\circ} \mathrm{C}$. or treatment with volatile antisepties, which were subsequently removed, brought about a great increase in the oxygen absorbed.

Schreiner and Sullivan ${ }^{13}$ used a solution of aloin ( 0.125 per cent) for the study of soil oxidation, the change in color being taken as an index of oxidation. As determined by this method, oxidation in soil was found to be non-enzymatic in nature and was considered a result of interaction between inorganic constituents and certain types of organic matter. The addition of salts of $\mathrm{Mn}, \mathrm{Fe}, \mathrm{Al}, \mathrm{Ca}$ and $\mathrm{Mg}$ increased this type of oxidation. Factors decreasing oxidation in soils were found to bring about conditions which decrease soil productivity and vice versa.

Oxidation of organic matter and the formation of nitrates are among the most important oxidation processes in the soil. The evolution of $\mathrm{CO}_{2}$ is usually taken as an index of the first (p. 681).

Source of nitrates in the soil. The decomposition of proteins and of other nitrogenous organic substances leads to the formation and often the accumulation of ammonia in the soil. Under favorable conditions, this is rapidly oxidized to nitrites and then to nitrates. Under certain conditions, when the nitrifying bacteria are killed, as

${ }^{11}$ Dehérain, P. P., and Demoussy, E. Sur l'oxydation de la matière organique du sol. Ann. Agron., 22: 305-337. 1896.

${ }_{12}$ Russell, E. J. Oxidation in soils, and its connection with fertility. Jour. Agr. Sci., 1: 261-279. 1905; Darbishire and Russell, 1903 (p. 752).

${ }^{13}$ Schreiner, O., and Sullivan, M. X. Studies in soil oxidation. Bur. Soils, U. S. Dept. Agr. Bul. 73. 1910; Schreiner, O., and Reed, H. S. The rôle of oxidation in soil fertility. Ibid., Bul. 56. 1909. 
in the partial sterilization of soil, or when conditions do not favor nitrification, as with excessive soil acidity, ammonia may accumulate in the soil.

The intense accumulation of nitrates in places where large quantities of organic matter are allowed to decompose was explained by the chemists of the earlier part of the nineteenth century to be a result of chemical processes. Davy ${ }^{14}$ expressed the opinion that nitrates are formed at the expense of the ammonia of the soil and atmospheric oxygen; Liebig demonstrated that atmospheric nitrogen takes no part at all in the process of nitrification.

The oxidation of ammonia to nitrate can be accomplished by chemical means, especially at high temperatures and in the presence of catalysts, ${ }^{15}$ as in the case of the electrolytic oxidation of ammonia in the presence of copper oxyhydrate. ${ }^{16}$ Ammonia can be oxidized to nitrate to a limited extent in an atmosphere saturated with ammonia and in the presence of ferric hydrate. ${ }^{17}$ Ammonia is also oxidized to nitrite by ultra-violet radiation. ${ }^{18}$ According to Weith and Weber, ${ }^{18}$ hydrogen peroxide and ammonia react with each other giving rise to nitrous acid. The interaction between ozone and ammonia to give ammonium nitrate has been known for several decades:

$$
\begin{aligned}
\left(\mathrm{NH}_{3}\right)_{2}+4\left(\mathrm{O}_{3}\right) & \rightarrow \mathrm{NH}_{4} \mathrm{NO}_{2}+\mathrm{H}_{2} \mathrm{O}_{2}+4\left(\mathrm{O}_{2}\right) \\
\mathrm{NH}_{4} \mathrm{NO}_{2}+\mathrm{H}_{2} \mathrm{O}_{2} & \rightarrow \mathrm{NH}_{4} \mathrm{NO}_{3}+\mathrm{H}_{2} \mathrm{O}
\end{aligned}
$$

The quantities of nitrite and nitrate formed by chemical agencies are insignificant and of little importance in the soil. In the soil,

14 Davy, H. Elements of agricultural chemistry. 1814, p. 308.

${ }^{15}$ Sestini, F. Bildung von salpetriger Säure und Nitrifikation als chemischer Prozess im Kulturboden. Landw. Vers. Sta., 60: 103-112. 1904; Mooser, W. Biologisch-chemische Vorgänge im Erdboden. Beiträge zur Stickstofffrage. Landw. Vers. Sta., 75: 53-106. 1911.

${ }^{16}$ Traube, W., and Biltz, A. Die Gewinnung von Nitriten und Nitraten durch elektrolytische Oxydation des Ammoniaks bei Gegenwart von Kupferhydroxyd. Ber. deut. chem. Gesell., 39: 166-178. 1906.

${ }^{17}$ Russell, E. J., and Smith, N. On the question whether nitrites or nitrates are produced by non-bacterial processes in the soil. Jour. Agr. Sci., 1: 444-453. 1906 .

${ }^{18}$ Berthelot, D., and Gaudechon, H. La nitrification par les rayons ultraviolets. Compt. Rend. Acad. Sci., 152: 522-524. 1911.

${ }^{10}$ Weith, W., and Weber, A. Ueber Bildung von Salpetrigsauren Ammoniak aus Wasser und N. Ber. deut. chem. Gesell., 7: 1745-1749. 1874. 
nitrification is entirely biological in nature, as established by Schloesing and Müntz, ${ }^{20}$ Warington ${ }^{21}$ and others.

Mechanism of ammonia oxidation. Various reactions have been suggested to explain the mechanism of oxidation of ammonia to nitrite by the nitrite forming bacteria. The following two reactions are most probable:

$$
\begin{aligned}
& 2 \mathrm{NH}_{3}+3 \mathrm{O}_{2} \rightarrow 2 \mathrm{HNO}_{2}+2 \mathrm{H}_{2} \mathrm{O} \\
& 2 \mathrm{NH}_{3}+3 \mathrm{O}_{2} \rightarrow \mathrm{N}_{2} \mathrm{O}_{3}+3 \mathrm{H}_{2} \mathrm{O}
\end{aligned}
$$

Godlewski ${ }^{22}$ found that the ratio between the oxygen consumed in the process and the nitrogen changed from the ammonia to the nitrite stage is 3 , or $\mathrm{R}=\frac{\mathrm{O}_{2}}{\mathrm{~N}_{2}}=3$. However, Schloesing ${ }^{23}$ recorded previously that this ratio varies from 4.57 to 5.57 . The difference between these results may be due to the fact that Schloesing made his determinations in the soil as a medium while Godlewski carried out his studies in solution. In the first instance, some of the oxygen was no doubt consumed for other oxidation processes, in addition to nitrate formation. Meyerhof ${ }^{24}$ used the theoretical value of $R=3$ for the calculation, from the amount of oxygen consumed, of the quantity of nitrogen oxidized from ammonia to nitrite. In a careful study of the gaseous exchange in the reaction of oxidation of ammonia to nitrite, Bonazzi ${ }^{25}$ demonstrated that the average value of $R$ is $2.89 \pm 0.08$, which is very close to 3.0 , thus justifying the above equations.

The presence of the carbonate is essential both as a source of $\mathrm{CO}_{2}$ (although the organism can also use free $\mathrm{CO}_{2}$ present in the atmosphere), and for keeping the medium properly buffered, preventing it from becoming acid. Nitrites are formed also in an atmos-

${ }^{20}$ Schloesing, Th., and Müntz, A. Sur la nitrification par les ferments organisés. Compt. Rend. Acad. Sci., 84: 301. 1877; 85: 1018. 1877; 86: 892 . 1878; 89: 891, 1074. 1879.

${ }^{21}$ Warington, R. On nitrification. Jour. Chem. Soc., 33: 44-51. 1878; 35: $429-456$.

${ }^{22}$ Godlewski, K. Über die Nitrifikation des Ammoniaks und die Kohlenstoffquellen bei der Ernährung der nitrifizierenden Fermente. Centrbl. Bakt. II, 2: 458-462. 1896.

${ }^{23}$ Schloesing, Th. Sur la nitrification de l'ammoniaque. Compt. Rend., 109: 423-428, 883-887. 1885.

${ }^{24}$ Meyerhof, 1916 (p. 390).

${ }^{25}$ Bonazzi, A. On nitrification. V. The mechanism of ammonia oxidation. Jour. Bact., 8: 343-363. 1923. 
phere free from $\mathrm{CO}_{2}$ (but containing $\mathrm{CO}_{2}$ in the medium), although at a slower rate. The cells of the organism are strongly catalytic and are capable of liberating oxygen from a peroxide. Ferric hydrate has a stimulating effect upon the oxidation of ammonia to nitrate. ${ }^{26}$ Since iron was found in active cultures partly in a ferrous state, Bonazzi suggested that it acts as a carrier of oxygen, thereby hastening the oxidation process; iron fulfills in these cultures the functions of the peroxide, due to its mechanism of auto-oxidation resulting in a combination with oxygen, while the cells liberate the oxygen thus bound.

$$
\begin{aligned}
& \mathrm{Fe}^{\prime \prime}+\mathrm{O} \rightarrow \mathrm{Fe}^{\prime \prime \prime} \cdot \mathrm{O} \\
& \mathrm{Fe}^{\prime \prime \prime} \cdot \mathrm{O}+\text { peroxidase }+\mathrm{NH}_{3} \rightarrow \mathrm{HNO}_{2}+\text { peroxidase }+\mathrm{Fe}^{\prime \prime} .
\end{aligned}
$$

In $100 \mathrm{cc}$. of medium and at $35^{\circ}, 20 \mathrm{mgm}$. of nitrogen in the form of ammonium sulfate can be oxidized in 6 hours. Nitrite formation comes to a standstill, when the solution contains about 1.5 to 2.0 per cent $\mathrm{NO}_{2}$. The concentration of the substrate which is most favorable for the oxidation process lies at $0.005 \mathrm{M} \mathrm{NH}_{4}$, while with a tenth molar solution of ammonia oxidation is nil.

The more recent theories tend to indicate that the oxidation of ammonia to nitrous acid goes through the hydroxylamine and hyponitrous acid stages. ${ }^{26 a}$

$$
\begin{aligned}
& \underbrace{\mathrm{N}_{-\mathrm{H}}^{\mathrm{H}}}_{\mathrm{OH}}+\mathrm{O} \rightarrow \underset{\text { Hydroxylamine }}{\mathrm{N}} \underbrace{\mathrm{H}}_{\mathrm{OH}}+\mathrm{H}_{2} \mathrm{O} \\
& \mathrm{N} \smile_{\mathrm{OH}}^{\stackrel{\mathrm{H}}{H}}+\mathrm{O} \rightarrow \mathrm{N} \ll_{\mathrm{O}}^{\mathrm{H}}, \mathrm{N} \ll_{\mathrm{O}}^{\mathrm{H}}+\mathrm{H}_{2} \mathrm{O} \rightarrow \mathrm{N} \underset{\mathrm{OH}}{\stackrel{\mathrm{OH}}{\mathrm{O}}} \\
& \mathrm{N}=\stackrel{\mathrm{OH}}{-} \underset{\mathrm{OH}}{\mathrm{H}}+\mathrm{O} \rightarrow \mathrm{N} \mathbb{O}_{\mathrm{OH}}^{\mathrm{O}}
\end{aligned}
$$

Mechanism of nitrite oxidation. The oxidation of nitrite to nitrate takes place according to the following reaction:

$$
\mathrm{NaNO}_{2}+\frac{1}{2}\left(\mathrm{O}_{2}\right)=\mathrm{NaNO}_{3}
$$

This was demonstrated to hold true by measuring the nitrite and oxygen consumption. With optimum concentration of the nutrients and

${ }^{26}$ Ashby, 1907 (p. 394).

26 Kluyver, A. J., and Donker, H. J. L. Die Einheit in der Biochemie. Chem. d. Zelle u. Gewebe., 13: 134-190. 1926. 
proper aeration of the culture, the nitrate forming organisms, in liquid culture, may oxidize 4 to 5 grams $\mathrm{NaNO}_{2}$ per liter in 24 hours.

According to Miyake, ${ }^{27}$ nitrification in the soil obeys the law of autocatalysis; i.e., the reaction is at first slow, then becomes more rapid and finally comes to a standstill, as a result of accumulation of nitrates. The relation between nitrite oxidation and concentration of substrate is given in figure 18, which shows a rapid increase in oxidation with an increase in nitrite concentration up to 0.05 per cent. An optimum is reached with 0.1 per cent of substrate, with a slow decrease to 0.3 per cent. This is followed by a gradual drop, so that in a 4 per cent solution of nitrite, oxidation is only 26 per cent of the optimum. A detailed discussion of the oxidation process, especially from the point of view of growth and respiration is given elsewhere (p. 388).

Nitrate formation from inorganic salts and from organic nitrogenous compounds. Schloesing ${ }^{28}$ compared the formation of nitrates from various ammonium salts added to the soil and found that the following relative amounts of nitrogen (in milligrams) are nitrified per day:

$$
\mathrm{NH}_{4} \mathrm{Cl}-3.4,\left(\mathrm{NH}_{4}\right)_{2} \mathrm{SO}_{4}-9.0,\left(\mathrm{NH}_{4}\right)_{2} \mathrm{CO}_{3}-4.0
$$

Ammonium salts of organic acids are also nitrified rapidly. ${ }^{29}$

It was thought at first that organic matter can be nitrified directly. However, Müntz ${ }^{30}$ has shown that organic matter has to be decomposed first and ammonia liberated, before nitrates can be formed. Omeliansky ${ }^{31}$ later obtained negative results also for urea, asparagine, methylamine, dimethylamine and egg-albumin, so that he concluded that all forms of organic nitrogen have to be transformed first into ammonia before they can be nitrified. The same was found to hold true for calcium cyanamide. ${ }^{32}$ When the processes of nitrate formation from ammo-

${ }^{27}$ Miyake, K. On the nature of ammonification and nitrification. Soil Sci., 2: 481-492. 1916; Miyake, K., and Soma, S. Jour. Biochem. Tokio, 1: 123-9. 1922 .

${ }^{28}$ Schloesing, 1885 (p. 525).

${ }^{29}$ Boullanger, E., and Massol, L. Études sur les microbes nitrificateurs. Ann. Inst. Pasteur., 18: 181-196. 1904; Löhnis, F., and Blobel, S. Die Ursachen der Wirkungsunterschiede von Schwefelsaurem Ammoniak und Chilesalpeter. Fühlings landw. Ztg., 57: 385-402. 1908.

${ }^{30} \mathrm{Müntz}$, A. Sur la décomposition des engrais organiques dans le sol. Compt. Rend. Acad. Sci., 110: 1206-1209. 1890.

s Omelianski, W. Über die Nitrifikation des organischen Stickstoffes. Centrbl. Bakt. II, 5: 473-490. 1899; 9: 63-65. 1902.

${ }^{32}$ de Grazia, S. Sulla nitrificazione della cianamide di calcio in diversi tipi di terreno. Staz. sper. agr. ital. Modena, 41: 241-257. 1908. 
nium salts and from amino acids are compared, the latter is found to take place more slowly. ${ }^{33}$ This is probably due to the fact that the amino-acids have to be changed first to ammonia and also to the fact that some of the nitrogen will be stored away in the microbial cells which use the carbon of the amino compounds as a source of energy.

According to Barthel and Bengtsson ${ }^{34}$ only the ammonia (and the urea, which is rapidly transformed into ammonia) of stable manure is readily nitrified; the other part of the nitrogen, present in the manure in the form of complex proteins, nitrifies only very slowly since it has to be decomposed first by various microorganisms, with the liberation of ammonia. Nitrite bacteria find conditions in stable manure very favorable for their development so long as aeration is favorable and the manure is not saturated with urine. ${ }^{35}$ Deep layers as well as compact manure contain only few nitrifying bacteria, since conditions are not very favorable for their development, under anaerobic or semianaerobic conditions. The nitrite bacteria cannot develop in urine, probably because of the presence of some injurious substances and the high concentration of the soluble organic matter; they develop readily in the solid portion of the manure. The free ammonia, especially in a medium of a high alkalinity, is also injurious to the nitrate-forming bacteria.

Influence of reaction on nitrate formation. The optimum reaction for the respiration of the nitrite-forming bacteria was found ${ }^{36}$ to be at $\mathrm{pH}$ 8.4 to 8.8 , with limiting reactions at $\mathrm{pH} 7.6$ and 9.3. The optimum reaction for the respiration of the nitrate-forming bacteria was found to be at $\mathrm{pH} 8.3$ to 9.3 and the limits at $\mathrm{pH} 5.6$ and 10.3. The presence of $\mathrm{NaHCO}_{3}$, which acts as buffer at $\mathrm{pH} 8.4$, is, therefore, beneficial to the activities of these organisms, as shown in figure 30 . This is true, however, only for the respiration of the organisms but not for their growth.

The optimum reaction for the growth of the nitrite bacteria is at $\mathrm{pH} 7.8$, with a minimum at $\mathrm{pH} 7.0$ and maximum at $\mathrm{pH} 8.6$; for nitrate

${ }^{33}$ Batham, H. N. Nitrification in soils. Soil Sci., 20: 337-351. 1925.

${ }^{34}$ Barthel, Chr., and Bengtsson, N. The nitrification of stable manure nitrogen in cultivated soils. Medd. Centralanst. Försökov. Jordbruksomradet, No. 211, 1920; also 1926 (p. 448).

${ }^{35}$ Niklewski, B. Über die Bedingungen der Nitrifikation im Stallmist. Centrbl. Bakt. II, 26: 388-442. 1910; Diminution du taux de l'azote dans le fumier sous l'influence des bactéries nitrifiantes. Bull. Soc. Chim. biol., 6: 491-500. 1923.

${ }^{36}$ Meyerhof, 1916 (p. 390). 
bacteria the optimum is at 7.1 with limiting reactions at 6.5 and 7.8 . The kind of buffer used is of importance. ${ }^{37}$ According to Gerretsen, ${ }^{33}$ the limiting acid reaction is at $\mathrm{pH} 3.9$ to 4.5 , depending on the origin of the nitrifying bacteria; those isolated from acid soils are better adapted to acid conditions. The limiting alkali reaction was found to be at $\mathrm{pH} 8.9$ to 9.0 . Meek and Lipman ${ }^{39}$ demonstrated that the limiting reactions for the nitrite and nitrate-forming bacteria may depend on the reaction of the soil from which they were isolated. By gradual adaptation, the organisms can be made to grow at reactions beyond their acid and alkaline range so that nitrate formation was even obtained at $\mathrm{pH}$ 13.0.

When ammonium sulfate is used as a source of nitrogen for nitrate formation and the reaction of the soil is acid to begin with, there will be an increase in acidity in the absence of sufficient buffer or base, as a result of formation of nitric acid from the oxidation of the ammonia and the accumulation of the residual sulfuric acid. Nitrate accumulation will proceed until the reaction of the soil has reached a $\mathrm{pH}$ of about 4.0. The amount of nitrate formed under these conditions depends upon the initial reaction of the soil and its buffer and base content; the higher the buffer and base content of the soil, the larger will be the amount of nitrate formed for a certain change of reaction..$^{40}$ The continuous use of ammonium sulfate as a fertilizer without the addition of lime will, therefore, lead to a gradual increase in soil acidity. However, nitrates may be found even in very acid soils. This was explained by Hall and associates ${ }^{41}$ as due to the fact that, under acid conditions, nitrate formation takes place in films surrounding the small isolated particles of $\mathrm{CaCO}_{3}$. The addition of $\mathrm{CaCO}_{3}$ has, therefore, a decided stimulating effect on nitrate formation, particularly in acid soils. ${ }^{42}$

${ }^{37}$ Gaarder and Hagem, 1920-1923 (p. 77).

${ }^{38}$ Gerretsen, 1921 (p. 736).

${ }^{39}$ Meek, C. S., and Lipman, C. B. The relation of the reaction and salt concentration of the medium to nitrifying bacteria. Jour. Gen. Physiol., 5: 195-204. 1922.

${ }^{40}$ Barthel and Bengtsson, 1920 (p. 528); Waksman, S. A. Microbiological analysis of soils as an index of soil fertility. V. Methods for the study of nitrification. Soil Sci., 15: 241-260. 1923.

${ }^{41}$ Hall, A. D., Miller, N. H. J., and Gimingham, C. T. Nitrification in acid soils. Proc. Roy. Soc. B., 80: 196-212. 1908.

${ }^{42}$ Fischer, H. Versuche über Stickstoffumsetzung in verschiedenen Böden. Landw. Jahrb., 41: 755-822. 1911; Vogel, J. Ammoniak und Salpeterassimilation durch Mikroorganismen. Centrbl. Bakt. II, 32: 169-179. 1911; Lemmer- 
In alkaline soils which are deficient in humus, $\mathrm{CaCO}_{3}$ may have the opposite effect since it tends to liberate from ammonium salts free ammonia, which retards nitrification.

Lime does not stimulate the activities of the nitrifying bacteria ${ }^{43}$ so much as it serves as a base for neutralizing the acid formed from the oxidation of the ammonium salt. Nitrate formation takes place readily in peat and muck soils ${ }^{44}$ if the reaction is not too acid and if the soil is properly inoculated with the organisms. Acid peat soils do not generally offer a favorable medium for the development of the nitrate forming bacteria. When lime is added, these organisms become

TABLE 52

Influence of application of lime upon nitrogen content and nitrification of a muck soil

\begin{tabular}{|c|c|c|c|c|c|}
\hline \multirow[b]{2}{*}{ APPLICATION OF LIME } & \multirow{2}{*}{$\begin{array}{l}\text { NITROGEN } \\
\text { CONTENT OF } \\
\text { SOIL }\end{array}$} & \multicolumn{2}{|c|}{ NITRATE FORMATION } & \multicolumn{2}{|c|}{ REACTION } \\
\hline & & $\begin{array}{c}\text { Original } \\
\text { soil }\end{array}$ & $\begin{array}{l}\text { Incu- } \\
\text { bated } \\
\text { soil }\end{array}$ & $\begin{array}{c}\text { Original } \\
\text { soil }\end{array}$ & $\begin{array}{l}\text { Incu- } \\
\text { bated } \\
\text { soil }\end{array}$ \\
\hline & per cent & $\begin{array}{l}\text { parts per } \\
\text { million }\end{array}$ & $\begin{array}{l}\text { parts per } \\
\text { million }\end{array}$ & $p H$ & $p H$ \\
\hline None...................... & 1.120 & 28 & 114 & 3.67 & 3.56 \\
\hline Different forms of lime, 1 ton. . & 1.203 & 38 & 142 & 4.15 & 3.80 \\
\hline Different forms of lime, 2 tons.. & 1.151 & 37 & 162 & 4.37 & 4.24 \\
\hline Different forms of lime, 3 tons.. & 1.108 & 35 & 178 & 5.02 & 4.80 \\
\hline Different forms of lime, 4 tons.. & 1.054 & 37 & 205 & 5.46 & 5.24 \\
\hline Fertilizer.$\ldots \ldots \ldots \ldots \ldots \ldots$ & 1.114 & 30 & 59 & 3.88 & 3.48 \\
\hline Fertilizer + limestone, 1 ton... & 1.165 & 35 & 151 & 4.06 & 3.85 \\
\hline Fertilizer + limestone, 2 tons. . & 1.133 & 35 & 130 & 4.70 & 4.32 \\
\hline Fertilizer + limestone, 3 tons. . & 1.016 & 40 & 189 & 5.40 & 4.93 \\
\hline Fertilizer + limestone, 4 tons. & 1.046 & 35 & 173 & 6.13 & 5.44 \\
\hline
\end{tabular}

mann, O., Fischer, H., and Husek, B. Über den Einfluss verschiedener Basen auf die Umwandlung von Ammoniakstickstoff und Nitratstickstoff. Landw. Vers. Sta., 70: 317-342. 1909; Fred, E. B. A study of the formation of nitrates in various types of Virginia soils. Centrbl. Bakt. II, 39: 455-463. 1913; Miller, F. Über den Einflusz des Kalkes auf die Bodenbakterien. Ztschr. Gärungsphysiol., 4: 194-206. 1914; White, J. W. Nitrification in relation to the reaction of the soil. Ann. Rpt. Penn. Agr. Exp. Sta. 1913-14, 70-84.

${ }^{4}$ Stephenson, R. F. Nitrification in acid soils. Iowa Agr. Exp. Sta. Res. Bul. 58. 1920; Temple, J. C. Nitrification in acid or non-basic soils. Ga. Agr. Exp. Sta. Bul. 103.1914.

${ }^{44}$ Arnd, Th. Beitrag zur Kenntnis der Mikrobiologie unkultivierter und kultivierter Hochmoore. Centrbl. Bakt. II, 45: 554-574. 1916: Úber die Entstehungsweise salpeter und salpetrigsaurer Salze in Moorböden. Landw. Jahrb., 51: 297-328. 1918. 
very active, leading often to a rapid diminution of available nitrogen, ${ }^{45}$ as shown in table 52.46

Influence of organic matter upon nitrate formation. It has been pointed out that small amounts of soluble organic matter are found to retard the activities of nitrite and nitrate forming bacteria. Glucose, which is so important for the activities of the majority of microorganisms, is injurious in concentrations of 0.025 to 0.05 per cent. In the soil, however, the organisms can stand high concentrations of organic matter. ${ }^{47}$ Müntz and Lainé ${ }^{48}$ concluded that organic matter or humus in the soil may even be distinctly favorable to the activities of the nitrifying organisms. The greater the organic content of the soil, the more abundant is its bacterial flora and the more rapid will be the process of nitrification taking place. It was later found ${ }^{49}$ that, even in solution, impure cultures may be favored by soil extracts. According to Barthel, ${ }^{50}$ the easily soluble organic substances must be mineralized in the soil before nitrate formation takes place, if no injurious effect is to occur (figure 38). Difficultly soluble organic substances have little effect on the process.

Influence of salts upon nitrate formation. Winogradsky ${ }^{51}$ observed that ammonium salt had a distinctly injurious action upon nitrateforming bacteria; this action was found to be due not to the salt itself but to free ammonia. ${ }^{52}$ At as low a concentration as $0.001 \mathrm{~N}$ of am-

${ }^{45}$ Arnd, Th. Über schädliche Stickstoffumsetzungen in Hochmoorböden als Folge der Wirkung starker Kalkgaben. Landw. Jahrb., 47: 372-442. 1914; 49: 191-213. 1916; Tulin, A. F. The injurious action of high doses of lime on podsol soils, in connection with the nature of the biological processes in them (Russian). Trans. Institute Fertilizers No. 26, 1925.

${ }^{46}$ Willis, L. G. Nitrification and acidity in the muck soils of North Carolina. Tech. Bul. 24, N. C. Agr. Exp. Sta. 1923.

${ }^{47}$ Stevens, F. L., and Withers, W. A. Studies in soil bacteriology. IV. The inhibition of nitrification by organic matter, compared in soils and in solutions. Centrbl. Bakt. II, 27: 169-186. 1910.

${ }^{48}$ Müntz, A., and Lainé, E. Rôle de la matière organique dans la nitrification. Compt. Rend. Acad. Sci., 142: 430-435. 1906.

${ }^{49}$ Coleman, 1908 (p. 391); Mazé.-Compt. Rend. Acad. Sci., 152: 1625. 1911; Fremlin.-Jour. Hyg., 14: 149. 1914; Wright, 1916 (p. 552); Barthel.-Centrbl. Bakt. II, 49: 382. 1919; Greaves and Carter.-Jour. Agr. Res., 6: 889. 1916; Makrinow, J.-Centrbl. Bakt. II, 24: 415. 1919; Lòhnis and Green, 1914 (p. 579).

${ }^{50}$ Barthel, C. Die Einwirkung organischer Stoffe auf die Nitrifikation und Denitrifikation im Ackerboden. Ztschr. Gärungsphysiol., 4: 11-43. 1914.

${ }^{61}$ Winogradsky, 1890 (p. 389).

${ }^{62}$ Meyerhof, 1916 (p. 390). 
monia, at a $\mathrm{pH} 9.5$, the injury to nitrate-formation was equal to 70 per cent. Most inorganic alkali salts have only a slightly injurious effect, usually only at a concentration greater than $0.3 \mathrm{~N}$; alkali earths are more injurious, $0.1 \mathrm{~N}$ causing an injury of 60 per cent (p. 394). The injurious effect of cations of alkali salts depends to a large extent on the $\mathrm{OH}$ concentration. Meek and $\operatorname{Lipman}^{53}$ found that nitrification takes place in solution in the presence of 10,000 parts per million of $\mathrm{NaCl}(0.1 N)$, but not in higher concentrations. $\mathrm{Na}_{2} \mathrm{SO}_{4}$ was not injurious even in concentrations of 30,000 parts per million $(0.42 \mathrm{~N})$. $\mathrm{Na}_{2} \mathrm{CO}_{3}$ was found to be most injurious. ${ }^{54}$ However, the nature and amount of the nitrogen source were found to modify the injurious effect of the salt. ${ }^{55}$ The ratio of the calcium to magnesium is not of great importance to the activities of the nitrate-forming bacteria, but the total concentration of magnesium in solution and its relations to the concentration of the other constituents are of great importance. ${ }^{56}$

According to Greaves and associates ${ }^{57}$ chlorides, nitrates, sulfates and carbonates of $\mathrm{Na}, \mathrm{K}, \mathrm{Ca}, \mathrm{Mg}, \mathrm{Mn}$ and $\mathrm{Fe}$ exert a toxic effect upon nitrate-formation in the soil, depending on the specific salt and not on the electro-negative ion. The quantity of a salt which can be applied to a soil without decreasing the nitrate-nitrogen accumulation in the soil varies with the salt. In the soil under investigation, the order of decreasing toxicity was found to be as follows: $\mathrm{Na}_{2} \mathrm{SO}_{4}, \mathrm{Na}_{2} \mathrm{CO}_{3}$, $\mathrm{CaCO}_{3}, \mathrm{~K}_{2} \mathrm{SO}_{4}, \mathrm{~K}_{2} \mathrm{CO}_{3}, \mathrm{Fe}\left(\mathrm{NO}_{3}\right)_{3}, \mathrm{NaNO}_{3}, \mathrm{MgSO}_{4}, \mathrm{Fe}_{2}\left(\mathrm{SO}_{4}\right)_{3}, \mathrm{Ca}\left(\mathrm{NO}_{3}\right)_{2}$, $\mathrm{KNO}_{3}, \mathrm{KCl}, \mathrm{Mg}\left(\mathrm{NO}_{3}\right)_{2}, \mathrm{MnCO}_{3}, \mathrm{MnCl}_{2}, \mathrm{MnSO}_{4}, \mathrm{Fe}_{2}\left(\mathrm{CO}_{3}\right)_{3}, \mathrm{MgCl}_{2}$, $\mathrm{Mn}\left(\mathrm{NO}_{3}\right)_{2}, \mathrm{FeCl}_{3}, \mathrm{MgCO}_{3}, \mathrm{NaCl}, \mathrm{CaCl}_{2}$ and $\mathrm{CaSO}_{4}$. Those compounds which become toxic in lower concentrations are not necessarily most toxic in higher concentrations, as the toxicity of some salts increases more rapidly than the toxicity of others. The common alkali salts are very toxic, including $\mathrm{CaCl}_{2}, \mathrm{Na}_{2} \mathrm{SO}_{4}, \mathrm{Na}_{2} \mathrm{CO}_{3}$, and the less common $\mathrm{Ca}\left(\mathrm{NO}_{3}\right)_{2}$. All the salts, except $\mathrm{Na}_{2} \mathrm{SO}_{4}, \mathrm{Na}_{2} \mathrm{CO}_{3}, \mathrm{CaCO}_{3}, \mathrm{~K}_{2} \mathrm{SO}_{4}, \mathrm{~K}_{2} \mathrm{CO}_{3}$ and $\mathrm{Fe}\left(\mathrm{NO}_{3}\right)_{3}$, act as stimulants in some concentrations; the amount of stimulation depends on the salt, $\mathrm{CaSO}_{4}$ and $\mathrm{CaCl}_{2}$ being most efficient.

${ }^{53}$ Meek and Lipman, 1922 (p. 529).

${ }^{54}$ Lipman, C. B. Toxic effects of "alkali salts" in soils on soil bacteria. II. Nitrification. Centrbl. Bakt. II, 33: 305-313. 1912.

${ }^{55}$ Kelley, W. P. Nitrification in semi-arid soils. Jour. Agr. Res., 7: 417437. 1916.

${ }^{86}$ Kelley, W. P. The lime-magnesia ratio: II. The effects of calcium and magnesium carbonates on nitrification. Centrbl. Bakt. II, 42: 577-582. 1914.

${ }^{87}$ Greaves, J. B., Carter, E. G., and Goldthorpe, H. C. Influence of salts on the nitric-nitrogen accumulation in the soil. Jour. Agr. Res., 16: 107-135. 1919. 
A marked antagonism was found ${ }^{58}$ to exist between the anions of $\mathrm{Na}_{2} \mathrm{CO}_{3}, \mathrm{Na}_{2} \mathrm{SO}_{4}$ and $\mathrm{NaCl}$ in respect to nitrification in soils. Combination of salts, each of which is toxic, may not only bring about normal nitrification but may even stimulate it. 0.2 per cent $\mathrm{NaCl}$ is antagonized by 0.05 per cent $\mathrm{Na}_{2} \mathrm{SO}_{4}$ or 0.025 per cent $\mathrm{Na}_{2} \mathrm{CO}_{3} ; 0.35$ per cent $\mathrm{Na}_{2} \mathrm{SO}_{4}$ is antagonized by 0.15 per cent $\mathrm{NaCl}$ or 0.02 per cent

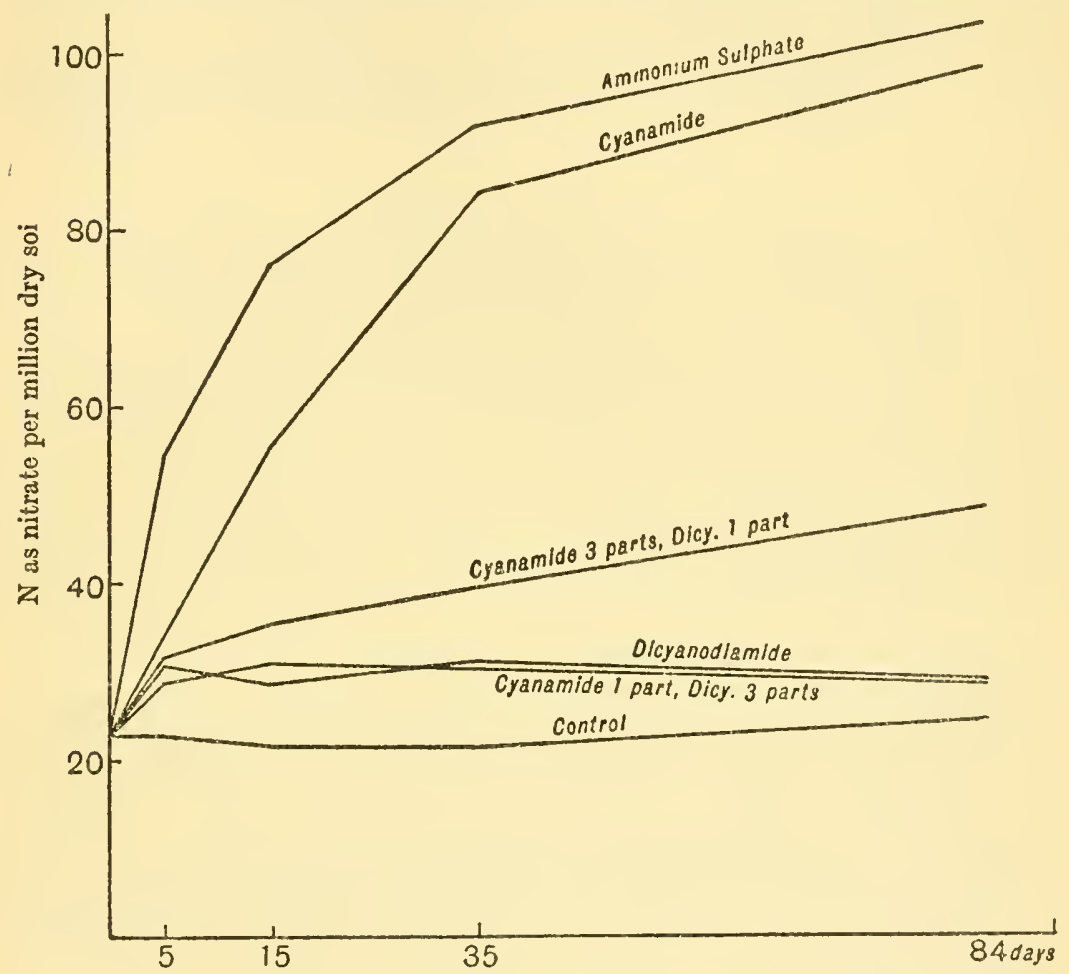

FIG. 34. Influence of dicyanodiamide upon nitrate production in the soil (from Cowie).

$\mathrm{Na}_{2} \mathrm{CO}_{3} ; 0.05$ per cent $\mathrm{Na}_{2} \mathrm{CO}_{3}$ is antagonized by 0.4 per cent $\mathrm{Na}_{2} \mathrm{SO}_{4}$ or 0.2 per cent $\mathrm{NaCl}$. These results, however, need to be interpreted in terms of physiological processes.

${ }^{68}$ Lipman, C. B., and Burgess, P. S. Antagonism between anions as affecting soil bacteria. II. Nitrification. Centrbl. Bakt. II, 41: 430-414. 1913; Plant World, 17: 295. 1914. 
It has been claimed that manganese ${ }^{59}$ and arsenic ${ }^{60}$ exert a stimulating effect upon nitrate formation. Montanari ${ }^{61}$ could not confirm this so far as arsenic is concerned. Heavy metals inhibit nitrate formation according to their protein-precipitating properties, $\mathrm{Hg}$ and $\mathrm{Ag}$ salts being most injurious. Copper, zine, iron and lead may exert a stimulating effect. ${ }^{62}$ Ashby ${ }^{63}$ found that, in the presence of iron hydroxide, nitrification takes place even in the absence of carbonates; the catalytic effect of iron is very important in the growth and respiration of the organisms. The injurious influence of dicyanodiamide upon the activities of the nitrate forming bacteria is illustrated in figure 34 .

Influence of soil gases upon nitrate formation. A liberal supply of oxygen was found ${ }^{64}$ to be very favorable to nitrate formation. The mere stirring of the soil was found to greatly stimulate the process; this stimulating effect was looked upon ${ }^{65}$ as due to better aeration (fig. 35). It is known, however, that nitrate formation takes place as rapidly in compact clay soils as in coarser grained soils, when the available water is the same in both cases. ${ }^{66}$ This would tend to indicate $^{67}$ that the amount of oxygen necessary for nitrate formation need not be abundant, so long as it is sufficient for the normal respiration of the organisms and the moisture supply is favorable. The optimum

${ }^{59}$ Olaru, D. A. Rôle du manganèse en agriculture. Son influence sur quelques microbes du sol. Paris. Baillères. 1920.

${ }^{60}$ Greaves, J. E. Some factors influencing ammonification and nitrification in soils. The influence of arsenic. Centrbl. Bakt. II, 39: 542-560. 1913; Biochem. Bul. 3: 2. 1913.

${ }^{61}$ Montanari, C. Azione degli elementi oligodinamici sui batteri della nitrificazione. II. Staz. sper. agr. ital. Modena, 50: 69-72. 1917.

${ }^{62}$ Lipman, C. B., Burgess, P. S. The effects of copper, zinc, iron and lead salts on ammonification and nitrification in soils. Univ. Cal. Publ. Agr. Sci., 1: 127-139. 1914 .

${ }^{63}$ Ashby, 1907 (p. 394).

${ }^{64}$ Warington, R. Lectures on investigations at the Rothamsted Experimental Station. Exp. Sta. Rec., 3: 894-903. 1892.

${ }^{65}$ King, F. H., and Whitson, A. R. Development and distribution of nitrates and other soluble salts in cultivated soils. Wisconsin Agr. Exp. Sta. Bul. 85 . 1901; Bul. 93. 1902.

${ }^{66}$ Schloesing, Th., Jr. Contribution à l'étude de la nitrification dans les sols. Compt. Rend. Acad. Sci., 125: 824-827. 1897; Fischer, H. Versuche über Stickstoffumsetzung in verschiedenen Boden. Landw. Jahrb., 41: 755-822. 1911.

${ }^{67}$ Gainey, P., and Metzler, L. F. Some factors affecting nitrate-nitrogen accumulation in soil. Jour. Agr. Res., 11: 43-64. 1917. 
concentration of oxygen for nitrate formation was found ${ }^{68}$ to be 35 per cent. Similar observations were made for the influence of $\mathrm{CO}_{2}$ concentration. ${ }^{69}$ Some believed that a supply of this gas is very important both for the nitrite and nitrate forming organisms. Owen, ${ }^{70}$ however, found that $\mathrm{CO}_{2}$ (above a certain concentration) has no effect on nitrate formation in the soil. In view of the fact that the $\mathrm{CO}_{2}$ is used by the organism for the building up of its cells chemosynthetically, its presence is necessary for growth. But since the organism produces only a limited amount of growth, only small amounts of $\mathrm{CO}_{2}$ are required

Parts per

million of

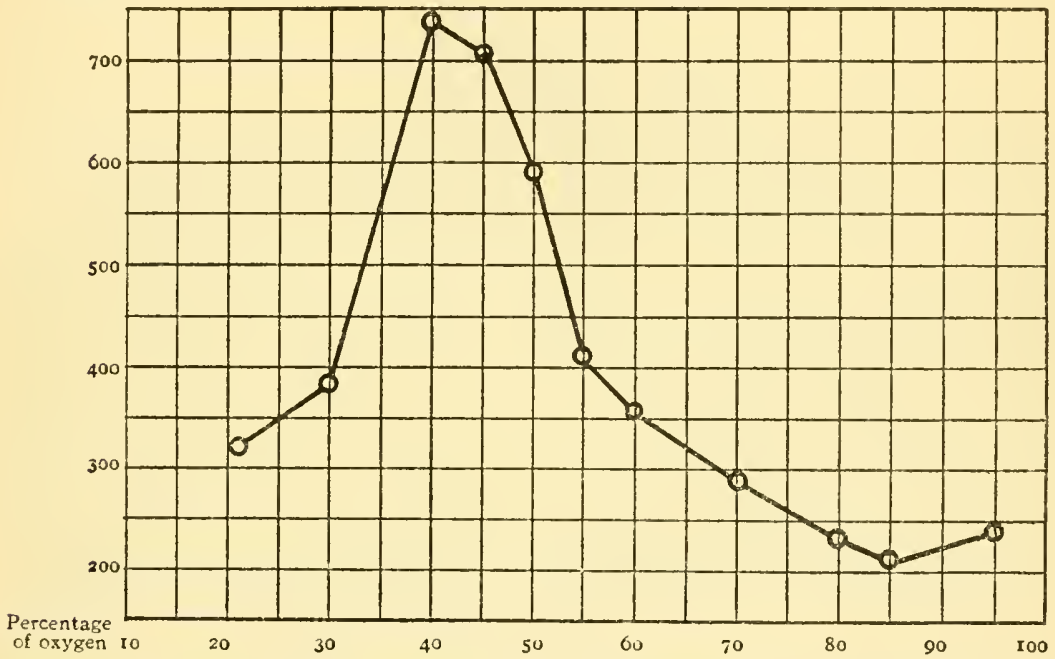

FIG. 35. Influence of oxygen tension upon nitrate formation in the soil (from Plummer).

even for the maximum nitrification. Larger amounts seem to act merely as an inert gas. In general, while only small amounts of $\mathrm{CO}_{2}$ are required, an excess of oxygen is essential and a lack of this gas will produce anaerobic conditions which will lead to nitrate reduction until all the nitrates are destroyed.

${ }^{68}$ Plummer, J. K. Some effects of oxygen and carbon dioxide on nitrification and ammonification in soils. N. Y. (Cornell) Univ. Agr. Exp. Sta. Bul. 384. 1916.

${ }^{69}$ Coleman, 1908 (p. 391).

70 Owen, W. L. Effect of carbonates upon nitrification. Georgia Agr. Exp. Sta. Bul. 81. 1908. 
Toluol, in strength of $0.1 \mathrm{cc}$. per 100 grams of soil, and $\mathrm{CS}_{2}$, in strength of less than $1 \mathrm{cc}$. per 100 grams of soil, do not exert any appreciable effect upon nitrate formation. ${ }^{71}$ Larger quantities (5 to 10 times) exert a temporary retarding effect; as a matter of fact, when these substances are used for partial sterilization of soil nitrate forming bacteria are killed, and it takes a long time before the soil becomes inoculated again.

Nitrate formation in solution and in soil. Stevens and Withers ${ }^{72}$ were the first to call attention to the fact that nitrate formation in solution inoculated with a certain amount of soil is not the same as

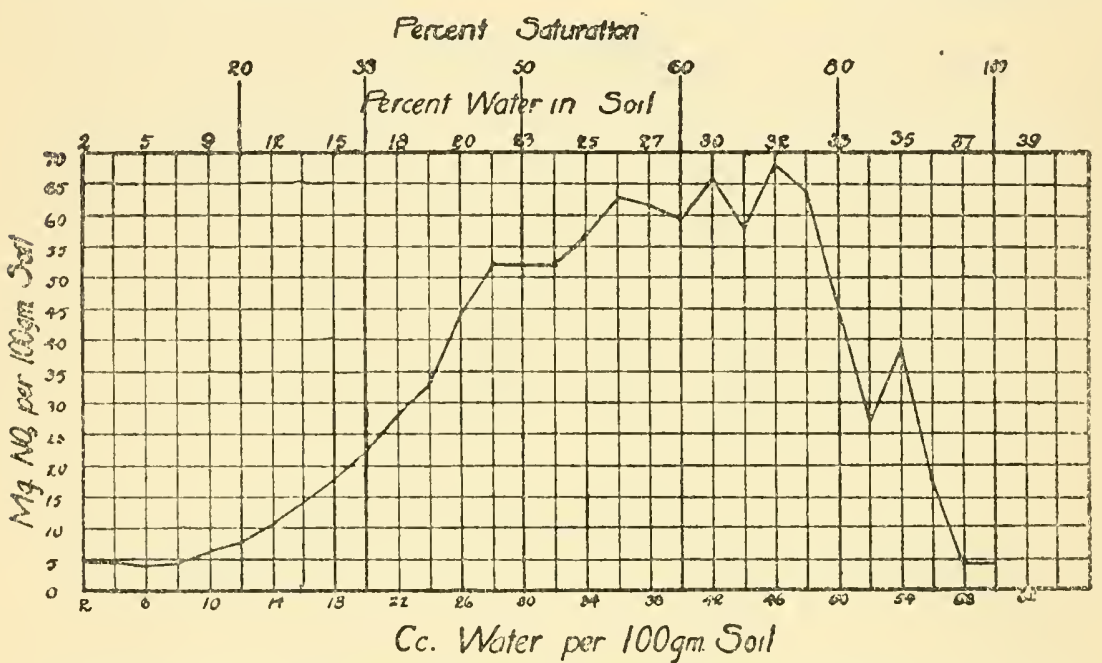

Fig. 36. Influence of moisture content upon nitrate production in the soil (from Gainey).

nitrate formation in the soil itself. Nitrates are formed in the soil in the upper layers, 90 per cent of the process being carried out in the upper 40 to $50 \mathrm{~cm} .^{73}$ This is due to the need of oxygen for the activities

${ }^{71}$ Gainey, P. L. Effect of $\mathrm{CS}_{2}$ and toluol upon nitrification. Centrbl. Bakt. II, 39: 584-595. 1914.

${ }^{72}$ Stevens, F. L., and Withers, W. A. Studies in soil bacteriology. I. Nitrification in soils and in solutions. Centrbl. Bakt. II, 23: 355-373. 1909; 34: 187-203. 1912.

${ }^{73}$ Koch, A. Versuche über die Salpeterbildung im Ackerboden. Jour. Landw., 59: 293-315. 1911; MacBeth, I. G., and Smith, N. R. The influence of irrigation and crop production on soil nitrification. Centrbl. Bakt. II, 40: 24-51. 1914. 
of the organisms. Even nitrate formation in solution is greatly stimulated by aeration. ${ }^{74}$

Deherain ${ }^{75}$ found that when the moisture content of the soil is 5 per cent the process of nitrate formation is very slight but it becomes appreciable with 10 per cent moisture and reaches a maximum with 15 to 20 per cent. Schloesing and Müntz ${ }^{76}$ reported that nitrate formation in soil is at a maximum with the highest moisture content which will not saturate the soil. When the soil approaches the saturation

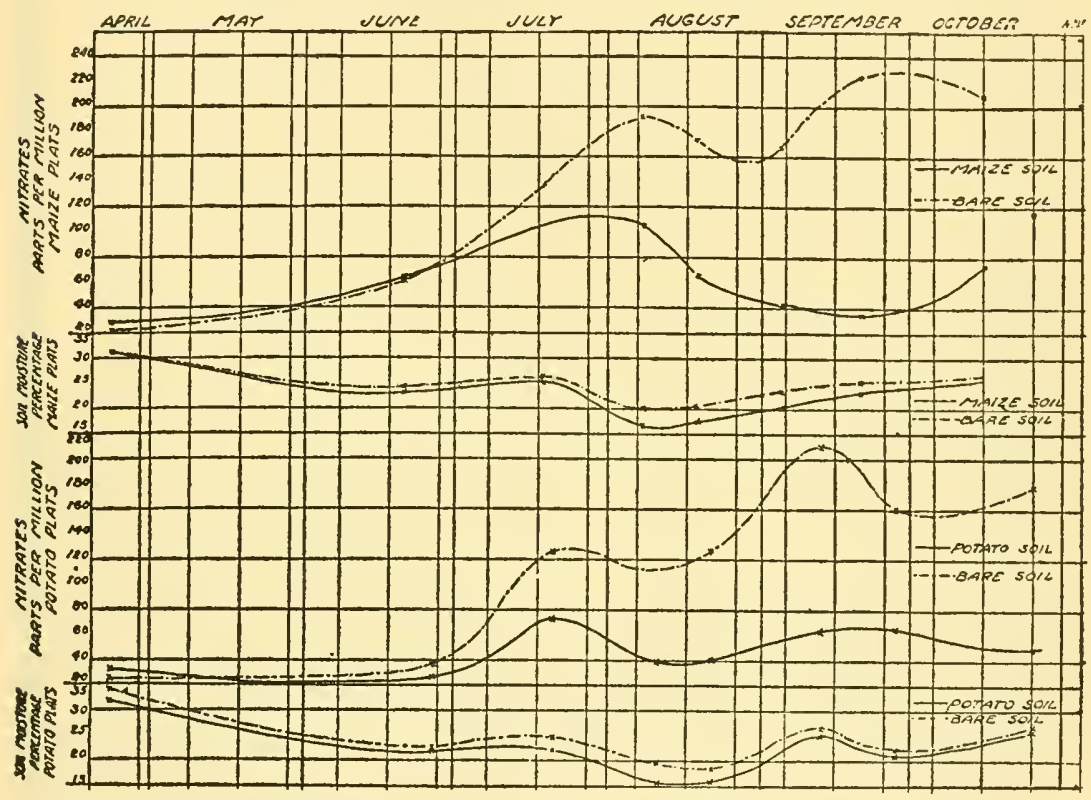

FIG. 37. Influence of crop upon nitrate content of the soil (after Lyon and Bizzell).

point, the process of nitrate formation is greatly reduced and may disappear completely ${ }^{77}$ (figure 36 ). The nature of the nitrogen source was found to be important in this connection; the nitrogen in the

${ }^{76}$ Barthel, Chr. Bodenbakteriologische Untersuchungen. Centrbl. Bakt. II, 25: 108-125. 1909.

${ }^{75}$ Dehérain, 1902 (p. 793).

${ }^{76}$ Schloesing, Th., and Müntz, A. Recherches sur la nitrification. Compt. Rend. Acad. Sci., 89: 1075. 1879.

${ }_{77}$ Traaen, A. E. Úber den Einflusz der Feuchtigkeit auf die Stickstoffumsetzungen im Erdboden. Centrbl. Bakt. II, 45: 119-135. 1916. 
form of ammonium sulfate and cottonseed meal change into nitrates more rapidly in arid soils, while dried blood and the soil's own nitrogen change into nitrates with greater vigor in humid soils. ${ }^{78}$

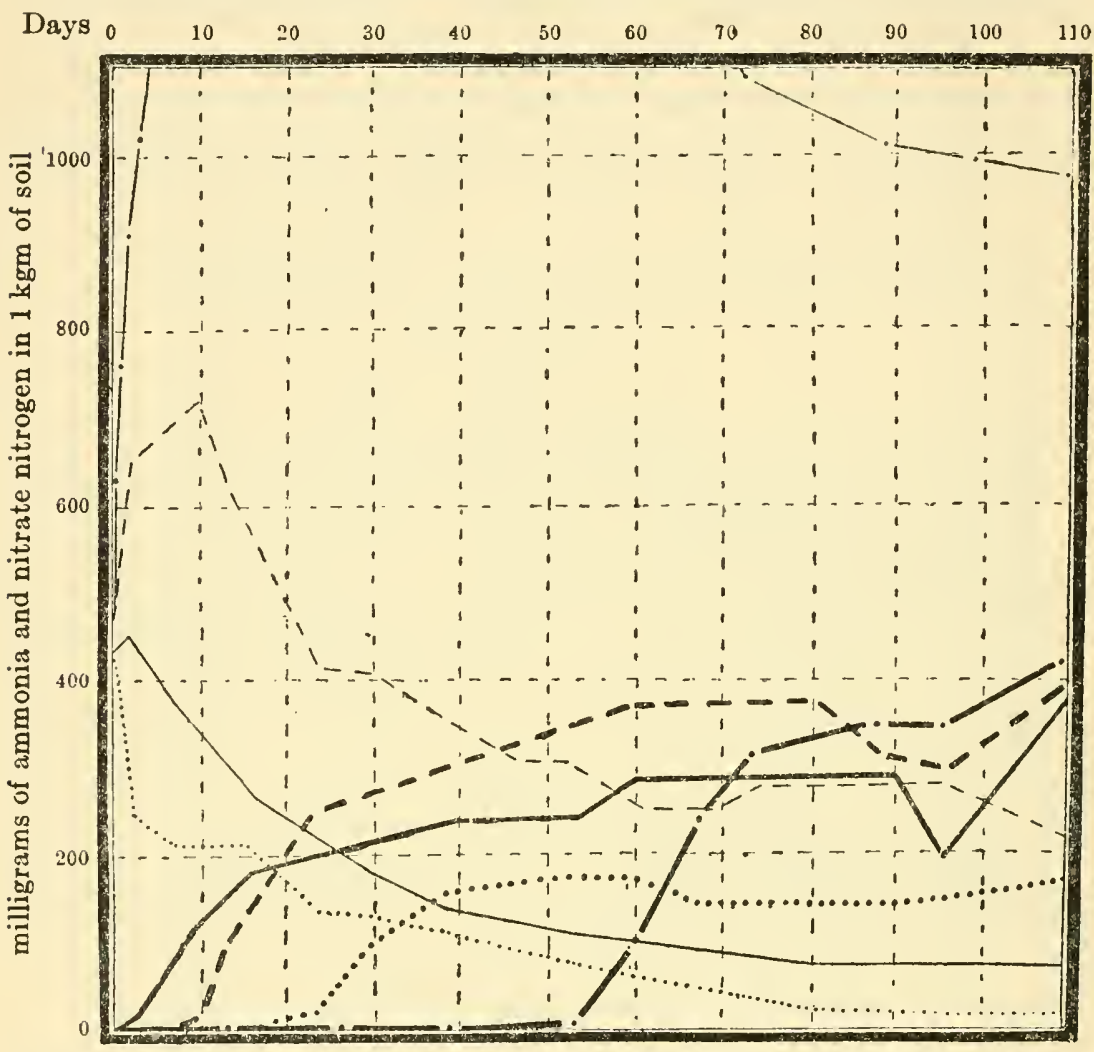

FIG. 39. Influence of organic matter upon the formation of nitrate in the soil: $a$, soil receiving 0.2 per cent ammonium sulfate, - nitrate $\mathrm{N},-$ ammonia $\mathrm{N}$; $b$, soil receiving 0.25 per cent peptone,- - nitrate $\mathrm{N},-$ - ammonia $\mathrm{N}$; $c$, soil receiving 1 per cent peptone, - - - nitrate nitrogen, - - - ammonia $\mathrm{N}$; $d$, soil receiving 1 per cent dextrose $\ldots .$. nitrate $\mathrm{N}, \ldots \ldots$ ammonia $\mathrm{N}$ (after Barthel and de Rossi).

Abundant nitrate formation and even extensive accumulation may take place in semi-arid soils. ${ }^{79}$ The amount and application of irriga-

${ }^{78}$ Lipman, C. B., Burgess, P. S., and Klein, M. A. Comparison of nitrifying powers of some humid and some arid soils. Jour. Agr. Res., 7: 47-82. 1916.

${ }^{79}$ Stewart, R. The intensity of nitrification in arid soils. Centrbl. Bakt. II, 36: 477-490. 1913; Sackett, W. G. The nitrifying capacity of certain Colo- 
tion water has an appreciable influence upon the process of nitrate formation in arid and semi-arid soils. ${ }^{80}$

Air drying has a favorable effect upon the formation of nitrates in the soil; this effect is noticeable even after spreading out the soil for twenty-four hours and then remoistening. ${ }^{81}$ Freezing of the soil in winter was also found to improve the nitrifying power of the soil. ${ }^{82}$ According to Müntz and Gaudechon, ${ }^{83}$ maximum nitrifying activities take place in spring (March 28 to April 25).

Conditions which tend to promote nitrate formation in the soil are: ${ }^{84}$ (1) temperature of $37.5^{\circ} \mathrm{C}$., (2) an abundant supply of air (oxygen), (3) proper moisture supply, (4) a favorable reaction ( $\mathrm{pH}$ greater than 4.6), (5) presence of carbonates or other buffering agents, and (6) absence of large quantities of soluble organic matter in the soil. The nature of the crop grown also influences the nitrate content of the soil, as shown in figures 37 and 38 .

Further information on the influence of soil treatment upon nitrate formation in the soil and on the correlation between nitrate formation and other microbiological activities in the soil is given elsewhere (p. 715). The formation of nitrates from organic and inorganic nitrogenous fertilizers can be used as an index of the availability of the nitrogen for the growth of higher plants. ${ }^{85}$

rado soils. Colo. Agr. Exp. Sta. Bul. 193. 1914; Science, 42: 452. 1914; Headden, W. P. The excessive quantities of nitrates in certain Colorado soils. Jour. Ind. Engin. Chem,, 6: 586-590. 1914; also Col. Agr. Exp. Sta. Bul. 155, 160, 178, 179, 183, 184, 186, 193; Kelley, 1916 (p. 532); Stewart, R., and Greaves, J. E. The production and movement of nitric nitrogen in soil. Centrbl. Bakt. II, 34: 115-147. 1912.

${ }^{80}$ McBeth and Smith, 1914 (p. 536).

${ }^{81}$ Buddin, W. Note on the increased nitrate content of a soil subjected to temporary drying in the laboratory. Jour. Agr. Sci., 6: 452-455. 1914.

${ }^{82}$ Lyon, T. L., and Bizzell, J. A. Some relations of certain higher plants to the formation of nitrates in soils. N. Y. (Cornell) Univ. Agr. Exp. Sta. Mem. 1. 1913.

${ }^{83}$ Müntz, A., and Gaudechon, H. Le réveil de la terre. Compt. Rend. Acad. Sci., 154: 163-8. 1912.

84 Owen, 1908 (p. 535).

${ }_{85}$ Withers, W. A., and Fraps, G. S. The rate of nitrification of some fertilizers. Jour. Amer. Chem. Soc., 23: 318-326. 1901; also Ibid., 28: 213-233. 1906 ; Lipman, C. B. Some observations on the present status of the subject of the availability of nitrogen in fertilizers. Jour. Ind. Engin. Chem., 9: 189. 1917: Cal. Agr. Exp. Sta. Bul. 260. 1915; Lipman, J. G., Brown, P. E., and Owen, I. L. Relative availability of nitrogenous materials as measured by nitrification. N. J. Agr. Exp. Sta., 31st Ann. Rept., 152-155. 1910. 
Oxidation of sulfur and other minerals in the soil. The cycle of sulfur transformation in the soil is treated in detail elsewhere (p. 600). It is sufficient to indicate here that, when elementary sulfur is added to the soil, it is oxidized to a limited extent chemically and to a much greater extent biologically. A large number of organisms seem to be capable, in the presence of various organic substances, of oxidizing small amounts of sulfur, with the formation of various compounds. Certain specific groups of bacteria seem to be most active in the process, since these organisms utilize the sulfur as a source of energy. This is true also of sulfides; the speed of oxidation of these depends on their solubility. Hydrogen sulfide and alkali sulfides are oxidized very readily and rapidly; alkali earth sulfides are oxidized more slowly; while the biological oxidation of iron sulfide (iron pyrites) has not yet been demonstrated.

A detailed study of the oxidation and reduction of arsenic compounds by microorganisms has been made by Van Zyl. ${ }^{86}$

Oxidation of organic compounds in the soil. Attention has been called previously to the fact that various organic compounds are formed in the soil as a result of the activities of microorganisms. These may become toxic to the growth of higher plants unless further oxidized. Conditions favoring oxidation processes stimulate the decomposition of these substances and make conditions in the soil more favorable for the growth of higher plants.

Various oxidation processes are also essential for the liberation of a sufficient amount of energy for the activities of microorganisms. The maximum energy is liberated by organic substances only when they are completely oxidized. Oxidation of amino acids and oxidation of purine bases are important soil processes, especially in respect to the formation of ammonia. 87

Iron plays an important part as a catalytic agent in the oxidation of various substances. In the auto-oxidation of cysteine, an intermediate cysteine-iron complex is formed which is auto-oxidizable; this process is inhibited by HCN. ${ }^{88}$

${ }^{86}$ Van Zyl, J. P. Union S. Africa Dept. Agr. Repts. Div. Vet. Ed. and Res. 9-10: 727-808. 1923 (Exp. Sta. Recd., 82: 178).

${ }^{87}$ Dakin, 1922 (p. 483).

${ }^{88}$ Warburg, O., and Sakuma, S. Pflüg. arch. ges. Physiol., 200: 203. 1923; Sakuma, S. Uber die sogenannte Autooxydation des Cysteins. Biochem. Ztschr., 142: 68-78. 1923; Harrison, D. G. The catalytic action of traces of iron on the oxidation of cysteine and glutathione. Biochem. Jour., 18: 10091022. 1924 . 
The oxidation of hydrogen, methane and carbon monoxide, resulting from the incomplete decomposition of organic matter is treated in detail elsewhere (p. 403). Oxidation processes, which depend upon the presence of substances which act as hydrogen donators and hydrogen acceptors are also treated elsewhere (p. 414). 


\section{CHAPTER XXI}

\section{Reduction Processes in the Soll-Nitrate Reduction}

Reduction processes in the sail. Just as aerobic conditions in the soil favor oxidation processes, so do anaerobic conditions (exclusion of free oxygen) favor processes of reduction. Either organic or inorganic compounds may be formed, as a result of these processes, depending upon the constituents of the medium. ${ }^{1}$ It is not necessary for the soil to be saturated with water for the conditions to be anaerobic. Winogradsky ${ }^{2}$ demonstrated, by the development of anaerobic nitrogenfixing bacteria (see p. 783), that when the soil contains water equivalent to only about 40 per cent of its moisture-holding capacity, anaerobic bacteria find conditions favorable for their development up to the surface of the soil.

A soil possessing a reducing power will form naphthol-blue from a mixture of para-nitroso-dimethylaniline and $\alpha$-naphthol but will not readily oxidize easily oxidizable substances, such as aloin. ${ }^{3}$ Other indicators, like p-nitromalachite green which is reduced to p-amino malachite green, ${ }^{4}$ can also be used to determine the oxidation-reduction potential of the soil. Reduction phenomena are also characterized by the reduction of inorganic salts rich in oxygen, especially nitrates and sulfates. In the absence of atmospheric oxygen, the organic matter of the soil is broken down with the formation of hydrogen which, in statu nascendi, brings about the reduction of the salts rich in oxygen. Formation of $\mathrm{H}_{2} \mathrm{~S}$ is thus a secondary phenomenon. Under aerobic conditions, however, the formation of $\mathrm{H}_{2} \mathrm{~S}$ is primary since it results in the decomposition of proteins. Bact. coli, for example, decomposes glucose

${ }^{1}$ Van Wolzogen Kühr, C. A. Biochemical reduction processes in the soil. Arch. Suikerind, Nederlandsch. Indie, 23: 501-511. 1915.

2 Winogradsky, S. Sur l'étude de l'anaérobiose dans la terre arable. Compt. Rend. Acad. Sci., 179: 861. 1924.

${ }^{3}$ Sullivan, M. X. Reduction processes in plant and soil. Science, 39: 958. 1914.

${ }^{4}$ Felton, L. D. A new indicator for testing reducing power of bacteria. Jour. Inf. Dis., 34: 414-419. 1924. 
under anaerobic conditions, with the formation of pyruvic acid and hydrogen. ${ }^{5}$

$$
\mathrm{C}_{6} \mathrm{H}_{12} \mathrm{O}_{6}=2 \mathrm{CH}_{3} \cdot \mathrm{CO} \cdot \mathrm{COOH}+2 \mathrm{H}_{2}+12 \mathrm{Cal} \text {. }
$$

Nitrates and sulfates can act as the hydrogen acceptors and are reduced to nitrites, sulfides, etc.

Reducing conditions in the soil have usually been recognized either by the absence of oxidation or by the presence of specific reducing substances, as ferrous carbonate; soils acquire these conditions when waterlogged for a few days. The $\mathrm{H}_{2} \mathrm{~S}$ formed from the reduction of sulfates combines with iron to form insoluble iron sulfide. The ferrous compounds themselves act as reducing agents. The very presence of these compounds indicates the intense reducing power of the soil.

Bacterial cultures themselves are normally reducing. ${ }^{6}$ Processes of reduction require sources of energy to enable the organisms to carry on their activities. In most cases, however, these are obtained from various organic compounds. ${ }^{7}$ The autotrophic bacteria, for example, use the energy obtained by chemosynthetic processes for the reduction of $\mathrm{CO}_{2}$. Various organic compounds may be reduced under anaerobic conditions, especially in connection with oxidation of other substances which result in the liberation of energy. The reducing power of bacteria has commonly been determined by the use of certain organic substances, especially dyes, and of certain inorganic substances, such as nitrates and sulfates, acting as hydrogen acceptors. The hydrogen obtained from the decomposition of organic matter is used by the bacteria for the reduction of the $\mathrm{dye}^{8}$ or the nitrate. In some cases aldehydes or purine bases (hypoxanthine, xanthine, adenine) are required as hydrogen donators. ${ }^{9}$

Transformation of nitrates by microorganisms. The disappearance of nitrates in the soil as a result of activities of microorganisms may be

- Aubel, E., and Salabartan, J. Mécanisme de la production d'hydrogène aux dépens du glucose par le bacille coli. Compt. Rend. Acad. Sci., 180: 11831186, 1784-1787. 1925.

6 Rubner, M. Reduktionswirkungen bei Bakterien. Arch. Hyg., 16: 62. 1893.

${ }^{7}$ Beijerinck, M. W. Phénomènes de réduction produits par les microbes. Arch. Sci. Ex. Nat. Neerl. (II), 9: 131-157. 1904.

${ }^{8}$ Carapelle, E. Utber die Reduktionerscheinungen bei Bakterien. Centrbl. Bakt. I, Orig., 47: 545-559. 1908.

- Dixon, M., and Thurlow, S. Studies on xanthine oxidase. III. The reduction of nitrates. Biochem. Jour., 18: 989-992. 1924. 
due to three groups of phenomena: (1) direct utilization of nitrates by microorganisms as sources of nitrogen, in the presence of sufficient energy material, (2) reduction of nitrogen to nitrites and ammonia in the process of the nitrate assimilation, (3) utilization of nitrates as sources of oxygen (nitrates as hydrogen acceptors). In the last process oxygen is used by the organism for the oxidation of carbon compounds or inorganic substances, such as sulfur. The energy thus derived is used for the reduction of the nitrate to the nitrite, free nitrogen gas, oxides of nitrogen or the ammonia stage. The formation of nitrogen gas from nitrate may be so rapid under favorable conditions that the gas can actually serve as a measure of the amount of nitrate reduced.

The disappearance of nitrates in the soil due to the various processes of nitrate reduction and nitrate assimilation has often been referred to as "denitrification." However, the reduction of nitrates to nitrites and ammonia as well as their assimilation by microorganisms does not involve any losses of nitrogen, but merely indicates that the nitrates are for the moment taken out of circulation and transferred into forms from which nitrate can be again produced. The nitrates may even completely disappear without involving any loss of nitrogen, as in the case of their assimilation by fungi and various bacteria in the presence of available energy. ${ }^{10,11}$ The term denitrification (or complete denitrification) should designate the complete reduction of nitrates to atmospheric nitrogen and oxides of nitrogen, while the other processes involving disappearance of nitrates may be referred to as nitrate reduction and nitrate assimilation.

Nitrate assimilation. Large numbers of microorganisms, including bacteria, actinomyces, fungi and algae are capable of utilizing 'nitrates as a source of nitrogen. In the presence of a sufficient source of available energy, the microorganisms rapidly assimilate the nitrate nitrogen and transform it into proteins. The nature of the organism, the amount and nature of energy source, as well as the environmental conditions, influence the amount of nitrate thus assimilated.

'The fungi readily utilize nitrate-nitrogen, although often not to such an extent as ammonia nitrogen. For every 30 to 40 units of carbohydrate decomposed, certain fungi assimilate one part of nitrogen. The nitrate is usually first reduced to ammonia before it is assimilated. Only certain groups of bacteria (so-called "nitrate" bacteria) are capable of utilizing this source of nitrogen. The actinomyces assimi-

${ }^{10}$ Vogel, J. Ammoniak und Salpeterassimilation durch Mikroorganismen. Centrbl. Bakt. II, 32: 169-179. 1912.

11 Bierema, 1909 (p. 486). 
late nitrate readily, but usually reduce it first to nitrites; carbon sources favoring growth also favor nitrate reduction; when nitrite is the sole source of nitrogen, particularly in low concentrations $(0.01$ to 0.05 per cent), it is assimilated very readily as such, but when present in the nitrate form it is first reduced to nitrites and then assimilated. The reduction of nitrate by microorganisms is usually accompanied by an increase in alkalinity of the medium, due to the fact that the reduced anion is assimilated and the cation is left. The amount of nitratenitrogen converted into microbial protoplasm will thus depend upon the nature of the organisms active in the process as well as upon the environmental conditions. Seiser and Walz ${ }^{12}$ demonstrated that a pure culture of a bacterium (Bact. putidum) assimilated, under anaerobic conditions, about ten per cent of the nitrate nitrogen in the medium, but, under aerobic conditions, nearly thirty-three per cent of the nitrogen was assimilated, due to the greater utilization of the energy (citric acid), under aerobic conditions.

Utilization of nitrates by microorganisms as sources of oxygen. Certain bacteria are capable of reducing nitrates to nitrites, ammonia, and atmospheric nitrogen or oxides of nitrogen. Goppelsröder ${ }^{13}$ was the first to observe that nitrates are reduced in the soil to nitrites. This was attributed by Meusel ${ }^{14}$ to the action of bacteria. As already mentioned, microorganisms can utilize nitrates as sources of oxygen in the presence of inorganic or organic substances which serve as sources of energy (or as hydrogen donators). In the absence of free oxygen but in the presence of nitrate, various aerobic organisms are capable of existing anaerobically. Some organisms bring about complete denitrification; others reduce the nitrate to the nitrite stage only, with a smaller amount of oxygen becoming thereby available.

$$
2 \mathrm{HNO}_{3}=2 \mathrm{HNO}_{2}+\mathrm{O}_{2}(-36.6 \mathrm{Cal} \text {. })
$$

If we assume that one molecule of oxygen can liberate 112 Calories, when carbohydrates are used as a source of energy (with complete oxidation to $\mathrm{H}_{2} \mathrm{O}$ and $\mathrm{CO}_{2}$ ) a net gain in the above reaction is obtained:

$$
112-36.6=75.4 \text { Cal } \text {. }
$$

12 Seiser, A., and Walz, L. Stickstoffumsatz bei der Denitrifikation. Arch. Hyg., 95: 189-208. 1925.

${ }^{13}$ Goppelsröder, F. Beiträge zum Studium der Salpeterbildungen. Poggensdorf's Annallen., 115: 125. 1862.

14 Meusel, E. Nitritbildung durch Bakterien. Ber. deut. chem. Gesell., 8: $1214,1653$. 
When the nitrate is reduced to atmospheric nitrogen,

$$
2 \mathrm{HNO}_{2}=\mathrm{N}_{2}+1 \frac{1}{2} \mathrm{O}_{2}+\mathrm{H}_{2} \mathrm{O}(+6.8 \text { Cal. })
$$

The second reaction gives, therefore, a net gain of

$$
1 \frac{1}{2} \times 112+6.8=174.8 \mathrm{Cal} \text {. }
$$

In the reduction of nitrate to ammonia, the following reaction takes place: ${ }^{15}$

$$
\mathrm{HNO}_{3}+\mathrm{H}_{2} \mathrm{O}=\mathrm{NH}_{3}+2 \mathrm{O}_{2}
$$

The more complete the reduction of the nitrate, the more oxygen becomes available and, therefore, the greater is the amount of carbohydrate that can be oxidized and the greater is the gain in energy.

In some cases two organisms may participate in the same process, as in the decomposition of cellulose; one organism reduces the nitrate in the absence of atmospheric oxygen, and the other decomposes the cellulose. The second organism supplies energy to the first and utilizes the oxygen liberated by the first. ${ }^{16}$ Sulfur and thiosulfate may also be used under anaerobic conditions as a source of energy, with nitrate as a source of oxygen. This was first demonstrated by Beijerinck, ${ }^{17}$ who assumed that two organisms are concerned in the process, one reducing the nitrate and the other oxidizing the sulfur chemosynthetically. But he ${ }^{18}$ later demonstrated that only one organism carries out the complete reaction:

$$
6 \mathrm{KNO}_{3}+5 \mathrm{~S}+2 \mathrm{CaCO}_{3}=3 \mathrm{~K}_{2} \mathrm{SO}_{4}+2 \mathrm{CaSO}_{4}+2 \mathrm{CO}_{2}+3 \mathrm{~N}_{2}
$$

About 1 Calorie is produced per gram of nitrate reduced. When a mixture of sulfur (10 per cent), calcium carbonate and $\mathrm{KNO}_{3}$ solution (up to 10 per cent) is inoculated with soil, spontaneous and intense gas production takes place, accompanied by slime formation. The gas consists of nitrogen and $\mathrm{CO}_{2}$. In the absence of organic matter and with sulfur as the only source of energy, carbon dioxide of the atmosphere is

${ }^{15}$ Warburg, O., and Negelein, E. Utber die Reduktion der Salpetersäure in grünen Zellen. Biochem. Ztsschr., 110: 66-115. 1920.

${ }^{16}$ Groenewege, 1920 (p. 436).

${ }^{17}$ Beijerinck, 1904 (p. 84).

${ }_{18}$ Beijerinck, M. W., and Minkman, D. C. J. Bildung und Verbrauch von Stickstoffoxydul durch Bakterien. Centrbl. Bakt. II, 25: 30-63. 1910. 
utilized for the synthesis of the microbial protoplasm. The soil was believed to act as a catalyzer which hastens the process since, on consecutive transfer, the activities of the organism are weakened.

According to Beijerinck ${ }^{19}$ the organisms concerned in the process may occur in two physiologically different modifications, which are hereditarily constant when the feeding conditions remain unchanged. One, an autotrophic form which is adapted to inorganic media (sulfur- or thiosulfate-carbonate-nitrate) and which shows chemosynthesis; the other, an heterotrophic form, requires organic food. The heterotrophic forms preserve the power of denitrification with organic food.

Trautwein ${ }^{20}$ also demonstrated that some soil organisms are capable of oxidizing thiosulfate under aerobic conditions in the absence of nitrate;

TABLE 53

Influence of nitrate upon the decomposition of sucrose in (4 per cent) nutrient bouillon, under anaerobic conditions ${ }^{23}$

\begin{tabular}{|c|c|c|c|c|}
\hline & \multicolumn{2}{|c|}{ BACT. IACTIB AEROGENES } & \multicolumn{2}{|c|}{$\begin{array}{l}\text { PNEUMOBACILLUS OF } \\
\text { FRIEDLANDER }\end{array}$} \\
\hline & $\begin{array}{l}\text { Nitrate } \\
\text { present }\end{array}$ & Nitrate absent & $\begin{array}{l}\text { Nitrate } \\
\text { present }\end{array}$ & Nitrate absent \\
\hline & $c c$. & $c c$. & $c c$. & $c c$. \\
\hline Volume of gas produced.... & 628.4 & 1715.15 & 548.9 & 1118.9 \\
\hline $\mathrm{CO}_{2}$ per 100 of gas ......... & 57.6 & 64.7 & 69.3 & 62.9 \\
\hline $\mathrm{H}_{2}$ per $100 \ldots \ldots \ldots \ldots$ & 0 & 33.4 & 0 & 35.0 \\
\hline NO per $100 \ldots \ldots \ldots \ldots \ldots$ & 6.7 & 0 & 1.2 & 0 \\
\hline $\mathrm{N}_{2} \mathrm{O}$ per $100 \ldots \ldots \ldots \ldots$ & 2.3 & 0 & 0 & 0 \\
\hline $\mathrm{N}_{2}$ per $100 \ldots \ldots \ldots \ldots$ & 23.4 & - & 29.5 & - \\
\hline
\end{tabular}

growth and autotrophic respiration took place anaerobically only when nitrate was present as a source of oxygen.

Nitrate reduction can be brought about readily by a number of soil bacteria, under anaerobic conditions, when carbon sources are available as source of energy. ${ }^{21}$ Nitrates enable many facultative anaerobes to develop under anaerobic conditions, using sources of carbon which could otherwise not be utilized.22

${ }^{19}$ Beijerinck, M. W. Chemosynthesis at denitrification with sulfur as source of energy. K. Acad. Wetenschappen. Amsterdam, 22: Nos. 9 and 10. 1920.

${ }^{20}$ Trautwein, 1924 (p. 88).

${ }^{21}$ Van Iterson, G. Anhäufungsversuche mit denitrifizierenden Bakterien. Centrbl. Bakt. II, 12: 106-115. 1904.

${ }^{22}$ Ritter, G. Beiträge zur Physiologie der fakultativ anaeroben Bakterien. Centrbl. Bakt. II, 20: 21-38. 1908. 
According to Mazé, ${ }^{23}$ nitrate reduction is caused by the hydrogen produced by anaerobic bacteria; however, not all hydrogen-forming organisms are capable of reducing nitrate, as in the case of butyric acid bacteria. Table 53 illustrates the rôle of nitrate in the decomposition of carbohydrate ( 4 per cent sucrose) under anaerobic conditions and in a nutrient bouillon; a much greater decomposition of the sugar and an abundant formation of hydrogen in the absence of nitrate points to a distinct difference in the mechanism of the decomposition of the substrate.

Reduction of nitrates to gaseous nitragen and oxides of nitrogen. The reduction of nitrates to atmospheric nitrogen always goes through the nitrite stage. The following reaction was at first suggested ${ }^{24}$ to explain the complete reduction of the nitrate molecule:

$$
5 \mathrm{C}_{6} \mathrm{H}_{12} \mathrm{O}_{6}+24 \mathrm{KNO}_{3}=24 \mathrm{KHCO}_{3}+6 \mathrm{CO}_{2}+18 \mathrm{H}_{2} \mathrm{O}+12 \mathrm{~N}_{2}
$$

The carbohydrates or organic acids of the media are decomposed with the formation of carbon dioxide and nascent hydrogen; ${ }^{25}$ the nitrate is then used by the organism as the hydrogen acceptor, which results in the reduction of the nitrate. The theories concerning the nitrate reduction current about 1910 illustrate the reactions involved as follows:

$$
\begin{aligned}
& 2 \mathrm{KNO}_{3}+\mathrm{C}=2 \mathrm{KNO}_{2}+\mathrm{CO}_{2} \\
& 4 \mathrm{KNO}_{2}+3 \mathrm{C}=2 \mathrm{~N}_{2}+2 \mathrm{~K}_{2} \mathrm{CO}_{3}+\mathrm{CO}_{2}
\end{aligned}
$$

$\mathrm{C}$ designates the carbon source. In view of the fact that oxides of nitrogen are always produced in the complete reduction of the nitrate the above reactions had to be modified $:^{26}$

$$
\begin{aligned}
& 2 \mathrm{KNO}_{3}+\mathrm{C}=2 \mathrm{KNO}_{2}+\mathrm{CO}_{2} \\
& 2 \mathrm{KNO}_{2}+\mathrm{C}=\mathrm{N}_{2} \mathrm{O}+\mathrm{K}_{2} \mathrm{CO}_{3} \\
& 2 \mathrm{~N}_{2} \mathrm{O}+\mathrm{C}=2 \mathrm{~N}_{2}+\mathrm{CO}_{2}
\end{aligned}
$$

An abundant formation of $\mathrm{N}_{2} \mathrm{O}$ takes place at a high nitrate concentration of the medium and at a high temperature. The above reactions are altogether hypothetical and are not based upon sufficient experi-

${ }^{23}$ Mazé, 1911 (p. 182).

${ }^{24}$ Gayon and Dupetit, 1882 (p. 181); Dehérain, P. P., and Maquenne, L. Compt. Rend. Acad. Sci., 95: 691. 1882.

${ }^{25}$ Stoklasa, J., and Vitek, E. Beiträge zur Erkenntnis des Einflusses verschiedener Kohlenhydrate und organischer Säuren auf die Metamorphose des Nitrats durch Bakterien. Centrbl. Bakt. II, 14: 102-118, 183-205. 1905.

${ }^{26}$ Beijerinck and Minkman, 1910 (p. 546). 
mental evidence. However, the more recent ideas concerning the processes involved in the reduction of nitrates can be best presented as follows: $: 26$

$$
\text { }
$$

To explain the formation of hydroxylamine and ammonia, in the reduction of nitrates, by the above theories, the following reactions may be suggested:

$$
\begin{aligned}
& \begin{array}{l}
\mathrm{N}-\mathrm{OH}+2 \mathrm{H} \\
\begin{array}{l}
\mathrm{N}-\mathrm{OH}+2 \mathrm{H} \\
\mathrm{H}
\end{array}
\end{array} \rightarrow 2 \mathrm{H}_{2} \mathrm{NOH} \\
& \mathrm{H}_{2} \mathrm{NOH}+2 \mathrm{H} \rightarrow \mathrm{NH}_{3}+\mathrm{H}_{2} \mathrm{O}
\end{aligned}
$$

With the exception of the organisms capable of oxidizing sulfur and the Bac. amylobacter group, all denitrifying bacteria reduce nitrate to nitrogen gas and $\mathrm{N}_{2} \mathrm{O}$, in varying proportions, Bac. nitroxus being particularly active in the process. A 5 to 12 per cent solution of nitrate inoculated with soil gives, at $20^{\circ}$ to $37^{\circ}$, a current of gas which is eighty per cent $\mathrm{N}_{2} \mathrm{O}$. Various other denitrifying bacteria, like Bact. pyocyaneum and Bact. stutzeri, give in solutions of nitrate (particularly $\mathrm{NH}_{4} \mathrm{NO}_{3}$ ) a gas rich in $\mathrm{N}_{2} \mathrm{O}$. Out of one hundred cultures of bacteria tested by Maassen, ${ }^{27}$ thirty-one were found capable of reducing nitrate

${ }^{26} 6$ Kluyver and Donker, 1926 (p. 526); Blom, J. Studier over Nitrat, Nitrit og Hydroxylamin. N. J. F. Kongr. Oslo. 1926; Joss, E. J. The action of metals on nitric acid. Jour. Phys. Chem., 30: 1222-1275. 1926.

${ }^{27}$ Maassen, 1901 (p. 181). 
to nitrite; the latter is then reduced to atmospheric nitrogen and NO. This process was rather slow and independent of the oxygen supply. Tacke ${ }^{28}$ found that thirty-eight per cent of the gas mixture formed during the process of nitrate reduction by bacteria may consist of $\mathrm{N}_{2} \mathrm{O}$. The formation of nitric oxide in the reduction of nitrates has also been demonstrated by other investigators. ${ }^{29}$

The free nitrogen may, of course, be a result of the chemical interaction of the oxides of nitrogen with ammonia:

$$
\mathrm{NH}_{4} \mathrm{NO}_{2}=\mathrm{N}_{2}+2 \mathrm{H}_{2} \mathrm{O}
$$

Formation of nitrogen gas from organic compounds. To make the study of formation of nitrogen gas in microbiological reactions complete, attention should be called to the possibility of its formation in the decomposition of organic compounds, especially as a result of rapid oxidation of ammonia which is formed from those compounds:

$$
\begin{aligned}
& 4 \mathrm{NH}_{3}+3 \mathrm{O}_{2}=6 \mathrm{H}_{2} \mathrm{O}+2 \mathrm{~N}_{2} \\
& 2 \mathrm{NH}_{3}+3 \mathrm{H}_{2} \mathrm{O}_{2}=6 \mathrm{H}_{2} \mathrm{O}+\mathrm{N}_{2}
\end{aligned}
$$

These two processes may play an important part causing a loss of nitrogen in the decomposition of manure..$^{30}$ Nitrogen gas may also be formed by the interaction of nitrites with amino compounds; both of these may be formed in the decomposition of organic matter rich in nitrogen accompanied by the incomplete liberation of ammonia.

$$
-\mathrm{CH}_{2} \cdot \mathrm{NH}_{2}+\mathrm{HNO}_{2}=-\mathrm{CH}_{2} \cdot \mathrm{OH}+\mathrm{H}_{2} \mathrm{O}+\mathrm{N}_{2}
$$

Denitrification in the soil. Denitrification takes place in an entirely different manner in soil than in solution. ${ }^{31}$ In solution and in the presence

28 Tacke, 1888 (p. 184).

${ }^{29}$ Lebedeff, A. J. Über die Bildung des Stickoxyds bei dem durch Bac. hartlebii eingeleiteten Denitrifikationprozess. Ber. deut. bot. Gesell., 29: 327329. 1911; Suzuki, S. Über die Entstehung der Stickoxyde im Denitrifikationsprozess. Centrbl. Bakt. II, 31: 27-49. 1911; see also Acklin, O. Zur Biochemie des Bacterium pyocyaneum. Ein Beitrag zur Frage seines Stoffwechsels und dessen Beziehungen zur intramolecularen Atmung. Biochem. Ztschr., 164: 312-370. 1925.

${ }^{30}$ Pfeiffer, Th., Franke, F., Götze, C., and Thurmann, H. Beiträge zur Frage über die bei den Fäulnis stickstoffhaltiger organischer Substanzen eintretenden Umsetzungen. Landw. Vers. Sta., 48: 189-245. 1897; Street, J. P. A review of the investigations concerning denitrification. N. J. Agr. Exp. Sta. 14th Ann. Rept.: 183-210. 1901; Lohnis, 1910, p. 488 (p. xiii).

${ }^{31}$ Koch, A., and Pettit, H. Über den verschiedenen Verlauf der Denitrifikation im Boden und in Flüssigkeiten. Centrbl. Bakt. II, 26: 335-345. 1910. 
of the proper organic substances the bacteria may liberate practically all the nitrogen present in the nitrate form as free nitrogen gas, while in moderately moist soil only protein may be formed out of the nitrate. But if the soil is very moist and nitrates are present, denitrifying bacteria behave as in solution and liberate considerable quantities of free nitrogen gas. The minimum moisture content at which the complete reduction of nitrate may occur may depend upon the nature of the soil. Oelsner ${ }^{32}$ found that it takes place in soils containing 40 per cent moisture even when no additional carbon has been added. This is especially true of rice fields ${ }^{33}$ and of peat soils. ${ }^{34}$ The loss of available nitrogen as a result of liming acid peat soil was ascribed ${ }^{35}$ to the reduction of nitrate to nitrite and to atmospheric nitrogen. A decrease in aeration leads to an increase in denitrification; cultivation alone could not prevent the loss of nitrogen. The use of disinfectants for the destruction of the denitrifying bacteria in the soil is often recommended.

Denitrification is found to be at an optimum at $27^{\circ}$ to $30^{\circ}$. However, it takes place abundantly in the soil even in the coldest seasons of the year when the temperature of the soil at a depth of 0.2 to 0.3 meters is about zero. ${ }^{36}$ The optimum reaction for denitrification is at $\mathrm{pH} 7.0$ to 8.2 ; the process is greatly retarded at $\mathrm{pH} 5.2$ to 5.8 and 8.2 to $9.0 .{ }^{37}$

The denitrifying bacteria (except the forms which obtain their energy from the oxidation of sulfur) require organic matter for their metabolism and are, therefore, favored by an addition of available organic matter. Various mono- and di-basic organic acids (except oxalic) can be utilized as sources of carbon. ${ }^{38}$ Glucose is one of the best sources of energy. Fresh straw is utilized to a more limited extent and composted straw

32 Oelsner, A. Über Nitratereduktion in nassem Ackerboden ohne Zusatz von Energiematerial. Centrbl. Bakt. II, 48: 210-221. 1918.

${ }^{33}$ Daikuhara, G., and Imaseki, T. Bul. Imp. Centrl. Agr. Exp. Sta. Japan, 1: 7. 1907 .

${ }^{34}$ Ritter, 1912 (p. 790); see also Lemmermann, O., and Wichers, J. L. Verlauf der Denitrifikation in Boden bei verschiedenem Wassergehalt. Centrbl. Bakt. II, 41: 608-625. 1914.

${ }^{35}$ Arnd, 1914-1916 (p. 531).

${ }^{36}$ Barthel, 1909 (p. 537).

${ }^{37}$ Zacharova, T. M. The influence of soil reaction upon denitrification, in connection with liming of soil (Russian). Institute of Fertilizers, Moskau. No. 29. 1925.

${ }^{38}$ Jensen, 1897 (p. 180); Salzmann, P. Chemisch-physiologische Untersuchungen über die Lebendauer zweier denitrifizierender Bakterien und der Streptothrix chromogena. Diss. Konigsberg. 1902. 
even less so, ${ }^{39}$ due probably to a slow availability of the more insoluble constituents, since cellulose is not used to any extent as a source of energy by these organisms. ${ }^{40}$ A combination of an available source of energy and anaerobic conditions in the soil (either brought about by high moisture content or replacement of oxygen by hydrogen and $\mathrm{CO}_{2}$ ) leads to most active denitrification. An increased nitrate content of a soil favoring conditions of complete denitrification will favor the process further. The addition of large quantities of straw manure and green manure ${ }^{41}$ has, therefore, an important influence upon the disappearance of nitrates, both through transformation into protein and reduction to nitrites, ammonia and nitrogen gas. It has been found that even difficultly decomposable organic substances may also have a favorable influence upon denitrification in the soil. ${ }^{42}$

The fact that denitrifying bacteria are favored by an alkaline reaction and are injured by acids suggests the use of substances which would make the soil reaction acid. However, the final reaction should not be acid enough so as to injure the activities of useful bacteria, like the nitrifying organisms. Applications of acid phosphate were found to be useful in the preservation of the manure by neutralizing the ammonia; this brings about a change in reaction and tends, therefore, to lessen denitrification. Of the various nitrates, salts of alkalies and alkali earths are readily denitrified; the reduction of $\mathrm{Al}\left(\mathrm{NO}_{3}\right)_{3}$ is doubtful. ${ }^{43}$ Iron, manganese, thorium, ythrium and silver nitrates give negative results, due to the toxic action of the cations. Ethyl nitrate is reduced, but not nitro-methane. The same bacteria that reduce nitrates were found capable of reducing potassium chlorate, arsenate and potassium ferricyanide.

Importance of nitrate reduction in the soil. Gayon and Dupetit and Dehérain and Maquenne established in 1882 that there are bacteria in the soil capable of reducing nitrates to atmospheric nitrogen and oxides

${ }^{39}$ Caron, H. V. Untersuchungen über die Physiologie denitrifizierender Bakterien. Centrbl. Bakt. II, 33: 62-116. 1912.

${ }^{40}$ Wright, C. R. The influence of certain organic materials upon the transformation of soil nitrogen. Centrbl. Bakt. II, 46: 74-79, 1916; Albrecht, 19221926 (p. 517).

${ }^{41}$ Ferguson, M., and Fred, E. B. Denitrification: the effect of fresh and wellrotted manure on plant growth. Va. Agr. Exp. Sta. Rep. 1908, 134-149.

${ }^{42}$ Nolte, O. Über Denitrifikation bei Gegenwart von schwerzersetzlichen organischen Substanzen. Centrbl. Bakt. II, 49: 182-184. 1919.

${ }^{43}$ Ampola, G., and Ulpiani, C. Sull'azione riduttrice dei batteri denitrificanti. Gazz. chim. ital. Rome, 29, pt. 1: 49-72. 1899; 34, pt. 2: 301-315. 1904. 
of nitrogen. Lawes, Gilbert and Warington pointed out the same year that considerable quantities of nitrogen may be given off when a soil receives heavy applications of manure and is saturated with water or is improperly aerated. Breal ${ }^{44}$ announced in 1892 that many substances of organic origin, especially straw, can serve as sources of energy which would enable the bacteria to liberate atmospheric nitrogen from nitrates. This is seen from table 54, where 2 grams of straw and sodium nitrate were added to $400 \mathrm{cc}$. of water. Breal emphasized the conclusion that denitrification is not of any importance in normal soils, but may become so in humus-rich forest soils. In 1895 Wagner ${ }^{45}$ reported that the addition of manure to liquid cultures containing nitrates greatly increased denitrification; this observation led him to the conclusion that the same process takes place in the soil. He found confirmation in this in field experiments where organic nitrogen and nitrates were added simulta-

TABLE 54

Influence of straw upon denitrification in solution

\begin{tabular}{|c|c|}
\hline & MILLIGRAMS \\
\hline Nitrogen content of straw . . . . . . . . . . . . . & 9.7 \\
\hline Nitrogen content of nitrate added... & 26.0 \\
\hline Total nitrogen added . . . . . . . . . & 35.7 \\
\hline Nitrogen found at end of experiment. . . . . . . . . . . . . & 27.1 \\
\hline Nitrogen lost into the atmosphere $\ldots \ldots \ldots \ldots \ldots \ldots \ldots \ldots$ & 8.6 \\
\hline
\end{tabular}

neously before the crop was planted. Wagner declared, on the basis of these experiments, that denitrification may take place extensively in cultivated soils; the application of manure (cow or horse) to the soil was believed to be often not only unprofitable but even harmful; this was believed to be due to the fact that manure carries microorganisms which destroy the nitrates in the soil, not only added as such, but even those formed by the nitrifying bacteria.

These, as well as similar other investigations, created the impression that when nitrates are added to the soil denitrification sets in and may cause an injurious action by causing the transformation of the nitrate into gaseous nitrogen. It was soon found that these results were greatly

${ }^{44}$ Bréal. Compt. Rend. Acad. Sci., 114: 681-683. 1892; Ann. Agron., 18: 181; 22: 32; Dehérain, 1902 (p. 793).

${ }_{45}$ Wagner, P. Die geringe Ausnutzung des Stallmiststickstoffs und ihre Ursachen. Deut. landw. Presse, 22: 98. 1895; see also 1897 (p. 185). 
exaggerated. ${ }^{46}$ Losses of nitrogen were found possible only when considerable amounts of organic matter are added together with the nitrate, but this is not commonly done. Pfeiffer and Lemmermann ${ }^{47}$ demonstrated that very little actual denitrification takes place in the soil as a result of addition of manure. The lack of nitrogen often observed is due to other causes rather than to the actual loss of nitrogen. Nitrate reduction sets in when the soil is saturated with water. Only in the presence of a great abundance of organic manures is there any fear of loss of nitrate-nitrogen from the soil in a gaseous form. ${ }^{48}$

Great losses of nitrogen may take place in a humid, hot climate ${ }^{49}$ the rate of loss was found to be much increased by liming; bare fallows in rainy season were found to be especially wasteful because of the leaching of nitrates in drainage waters. There is little danger from denitrification in normal soils. ${ }^{50}$ The partial reduction of nitrates to nitrites and ammonia, which is more extensive and carried out by larger numbers of microorganisms does not involve any actual losses of nitrogen. The nitrates may completely disappear from the medium without any actual loss of nitrogen. ${ }^{51}$ The products formed from the nitrates (nitrites and ammonia) can be further acted upon by nitrifying bacteria; the part of the nitrate assimilated by microorganisms is merely stored away in the soil in an organic form. ${ }^{52}$

${ }^{46}$ Burri, R., Herfeldt, E., and Stutzer, A. Bakteriologisch-chemisehe Forschungen über die Ursachen der Stickstoffverluste in fäulenden organischen Stoffe, insbesondere im Stallmist und in der Jauche. Jour. Landw., 42: 329-384. 1894.

${ }^{47}$ Pfeiffer, Th., and Lemmermann, O. Über Denitrifikationsvorgänge. Landw. Vers. Sta., 50: 115-142. 1898; Lemmermann and Wichers, 1914 (p. 551 ).

48 Stoklasa, J. Treten Stickstoffverluste im Boden ein bei Düngung mit Chilisalpeter? Centrbl. Bakt. II, 17: 27-33. 1906; Fischer, H. Versuche über Stickstoffumsetzung in verschiedenen Böden. Landw. Jahrb., 41: 755822. 1911.

${ }^{49}$ Meggitt, A. A. Studies of an acid soil in Assam. II. Mem. Dept. Agr. India, 7: 31-53. 1923 .

${ }^{50}$ Voorhees, E. B. Investigations relative to the use of nitrogenous materials. N. J. Agr. Exp. Sta. Rpts., 12: 97-119. 1899; 13: 88-110. 1900; 14: 144-154, 183-211. 1901; 15: 133. 1902; 16: 148. 1903; 17: 191. 1904.

${ }^{51}$ Lemmermann, O. Kritisehe Studien über Denitrifikationsvorgänge. (Habilitationssehrift), Jena, 1900.

${ }^{52}$ Gerlach and Vogel. Ueber eiweissbildende Bakterien. Centrbl. Bakt. II, 7: 609-623. 1901; Ueber Nitrifikation und Denitrifikation in der Ackererde. Centrbl. Bakt. II, 13: 706-715. 1904; Löhnis, F. Beiträge zur Kenntnis der Stickstoffbakterien. Ibid., 14: 582-604, 713-723. 1905. 
Attention must be called here to the fact that many of the studies on denitrification were carried out in solution and not in soil. It is known that in very wet soils and in liquids which do not have a ready access to oxygen the bacteria utilize the oxygen from the nitrate molecule for oxidation purposes, while this does not occur in the presence of sufficient oxygen as in well aerated soils.

The original suggestion of Winogradsky that the introduction of large quantities of manure favors denitrification while preventing nitrification has been proved erroneous. Both processes may take place side by sicle. The losses of nitrogen in the manure compost were found ${ }^{53}$ to be due largely to the presence of nitrate forming bacteria. When these bacteria are eliminated or conditions are made unfavorable for their action the losses are considerably reduced. The presence of the bacteria resulted in an increase in the loss of nitrogen from 6.28 to 23.75 per cent in the case of cow manure and from 0.73 to 11.66 per cent in the case of horse manure. ${ }^{54}$

It is often observed that the addition of large quantities of undecomposed organic matter to the soil particularly rich in carbohydrates and poor in nitrogen injures crop growth. This is not due to denitrification, to which it has often been ascribed, but to the fact that, in the presence of an excess of available organic matter, the fungi, actinomyces, and various heterotrophic bacteria synthesize an extensive protoplasm. For this purpose, they assimilate the nitrates and ammonium compounds present in the soil and thus compete with higher plants.

The conclusion may be reached that the phenomenon of denitrification is of no economic significance in well aerated, not too moist soils, in the presence of moderate amounts of organic matter or nitrate. However, in the case of soils kept under water for some time, as rice soils, the addition of nitrates may even prove injurious due to the formation of toxic nitrite..$^{55}$ The injury by denitrification in peat soils has been mentioned above.

Reduction of other oxygen-rich compounds in the soil. Among the various inorganic, oxygen-rich compounds which can be readily reduced

${ }^{53}$ Niklewski, 1923 (p. 499); Smirnow, V. G. Rôle of nitrifying bacteria in the process of decomposition of manure. Zhur. Opit. Agron., 16: 329-386, 1915.

${ }^{54}$ A detailed review of the subject is given by Löhnis, 1910 (p. xiii); see also Russell and Richards. Jour. Agr. Sci., 8: 495-563, 1917.

${ }_{55}$ Nagaoka, M. Effect of nitrate of soda on paddy soils. Bul. Coll. Agr. Tokyo, 6: No. 3. 1904; Kelley, W. P. The assimilation of nitrogen by rice. Hawaii Agr. Exp. Sta. Bul. 24. 1911. 
by microorganisms, the following may be mentioned in addition to nitrates and nitrites: sulfates, ${ }^{56}$ sulfur, sulfites, selenates, selenites, tellurates and phosphates. $\mathrm{H}_{2} \mathrm{~S}$ is formed not only from sulfates but also from elementary sulfur, sulfites and polythionates. ${ }^{57}$ The reduction of selenium compounds, ${ }^{58}$ including selenious acid ${ }^{59}$ and various salts as well as tellurium salts, to their elements has been demonstrated for a number of bacteria ${ }^{60}$ and fungi. The amount of reduction was found ${ }^{61}$ to be proportional to the growth of the organisms. Selenic acid is reduced in two stages, first to selenious acid and then to free selenium. ${ }^{62}$

The reduction of arsenic to arsine is carried out by Pen. brevicaule, an organism found in the soil, ${ }^{63}$ as well as by certain other organisms. Various bacteria are also capable of reducing organic ${ }^{64}$ and inorganic phosphorus compounds. According to Rudakov, ${ }^{65}$ mineral phosphates are reduced, under anaerobic conditions, to phosphites $\left(\mathrm{H}_{3} \mathrm{PO}_{3}\right)$ and hypophosphites $\left(\mathrm{H}_{3} \mathrm{PO}_{2}\right)$ as well as to phosphene. Pure cultures were obtained of a bacterium capable of bringing about the reduction of the phosphate. Different soils varied in their capacity of bringing about this reduction. The addition of $\mathrm{KNO}_{3}$ and $\mathrm{MgSO}_{4}$ to the medium led to a

${ }^{56}$ Saltet, R. H. Uber Reduktion von Sulfaten in Brackwasser durch Bakterien. Centrbl. Bakt. II, 6: 648-695. 1900; van Delden, A. Beitrag zur Kenntnis des Sulfatreduktion durch Bakterien. Centrbl. Bakt. II, 11: 81-94, 113-119. 1903; Kochmann, R. Über Schwefelwasserstoff-bildung aus Sulfaten durch Faeces. Biochem. Ztschr., 112: 255.1920.

${ }^{67}$ A detailed study of sulfate reduction in the soil is given elsewhere (p. 610).

${ }^{58}$ First reported by Japha, A. Experimenta nomulla de vi selenii in organisnum animalem. Diss. Halle. 1842.

${ }^{69}$ Chabrié, C., and Lapicoque, I. Sur l'action physiologique de l'acide sélénieux. Compt. Rend. Acad. Sci., 110: 152. 1890.

${ }^{60}$ Scheurlen, E. Die Verwendung der selenigen und tellurigen Säure in der Bakteriologie. Ztschr. Hyg., 33: 135-136. 1900.

${ }^{61}$ Klett, A. Zur Kenntnis der reduzierenden Eigenschaften der Bakterien. Ztschr. Hyg., 33: 137. 1900.

${ }^{62}$ Levine, V. E. The reducing properties of microorganisms with special reference to selenium compounds. Jour. Bact., 10: 217-264. 1925.

${ }^{63}$ Gosio, B. Azione di alcune muffe sui composti fissi d'arsenico. Riv. d'igiene, 3: 201. 1892; Abel, R., and Buttenberg, J. Über die Einwirkung von Schimmelpilzen auf Arsen und seine Verbindungen. Ztschr. Hyg., 32: 449. 1899 .

${ }^{64}$ Barrenscheen, H. K., and Beckh-Widmenstetter, H. A. Über bakterielle Reduktion organisch-gebundenen Phosphorsäure. Biochem. Ztschr., 140: 279283. 1923 .

${ }^{65}$ Rudakov, K. I. The biological reduction of mineral phosphates (Russian). Viestnik Bact. Agron. Sta., 26: 171-188. 1926. 
diminution of the reduction of phosphate, since the activities of the reducing microorganisms were directed towards the more readily reducable compounds. Carbon compounds were used as sources of energy:

$$
\begin{aligned}
& 2 \mathrm{H}_{3} \mathrm{PO}_{4}+\mathrm{C}=2 \mathrm{H}_{3} \mathrm{PO}_{3}+\mathrm{CO}_{2} \\
& 2 \mathrm{H}_{3} \mathrm{PO}_{3}+\mathrm{C}=\mathrm{H}_{3} \mathrm{PO}_{2}+\mathrm{CO}_{2} \\
& \mathrm{H}_{3} \mathrm{PO}_{2}+\mathrm{C}=\mathrm{PH}_{3}+\mathrm{CO}_{2}
\end{aligned}
$$

The reduction of various organic compounds in the soil, under anaerobic conditions, is very common, as pointed out previously. 


\section{CHAPTER XXII}

\section{Fixation of Atmospheric Nitrogen by Microorganisms}

Attention has been called to the fact that fixation of nitrogen in the soil is carried on largely by bacteria. The most active representatives of the non-symbiotic nitrogen-fixing luacteria are Azotobacter and Clostridium (Bac. amylobacter) groups, while the symbiotic nitrogen fixing bacteria are so far represented by one group, the Bact. radicicola. The great majority of investigations on the activities of the non-symbiotic bacteria, particularly on the energy utilization, mechanism of nitrogen fixation, and influence of various environmental conditions upon this process have been carried out with species of Azotobacter. The same principles may or may not apply to the Cl. pastorianum, Bac. asterosporus and the other bacteria capable of fixing nitrogen non-symbiotically. Special emphasis should be laid on the difference in the mechanism of energy utilization, nitrogen fixation and general principles of growth between the aerobic and anacrobic bacteria. The first decompose most of the sugar to carbon dioxide and water and utilize, therefore, a large amount of the energy that can be made available from the decomposition of carbohydrates; the anaerobic organisms break down the sugar largely to organic (butyric) acids and gases, and utilize only a small part of the energy (see p. 412). The difference in growth and nitrogen fixation between the aerobic and anaerobic bacteria is further emphasized by the difference in the influence of oxygen tension and resistance towards acidity and alkalinity.

Non-symbiotic fixation of nitrogen. Berthelot ${ }^{1}$ was the first to recognize that the fixation of atmospheric nitrogen leading to an increase in the supply of combined nitrogen in the soil is due to the action of microorganisms. When the soil was heated to $100^{\circ}$, the property was lost. By placing $50 \mathrm{kgm}$. of soil in pots, having a surface of $1500 \mathrm{sq} . \mathrm{cm}$. and a perforated bottom, and allowing the pots to remain exposed to weather for seven months, he found an increase of 12.73 grams of nitrogen, tak-

${ }^{1}$ Berthelot, M. Nouvelles recherches sur la fixation de l'azote atmosphérique par les microbes. Compt. Rend. Acad. Sci., 101: 775. 1885; 115: 569-574. 637, 737. 1892; Chimie végétale et agricole. Paris, Masson et Cie. 1899. 
ing into consideration the combined nitrogen brought down by the rainfall and the nitrates washed out by the water. These results were confirmed in a series of other experiments by Berthelot as well as by a number of other writers. ${ }^{2}$ Although Berthelot did not succeed in isolating any organisms, he found that the bacteria require combined carbon and hydrogen and enough combined nitrogen to promote their initial growth, and that, when the amount of combined nitrogen available is increased, the bacteria prefer to use this combined nitrogen rather than to fix atmospheric nitrogen. Berthelot demonstrated conclusively that in bare soil, free from vegetation, bacteria exist which are capable of fixing atmospheric nitrogen; these organisms, he found, act best at temperatures of $10^{\circ}$ to $40^{\circ} \mathrm{C}$., in the presence of sufficient oxygen and with an optimum amount of moisture (from 2-3 to 12-15 per cent).

This work led to the important contributions of Winogradsky and Beijerinck, as pointed out above. Winogradsky ${ }^{3}$ carefully freed the nutrient solutions from all traces of nitrogen and used only mineral salts with 4 per cent glucose as a source of energy. He obtained a gain of $24.68 \mathrm{mgm}$. and $28.87 \mathrm{mgm}$. of nitrogen per liter of medium, after 15 and 20 days' incubation. A slight addition of ammonium salt or nitrate stimulated the growth and butyric acid fermentation of the organism, but not nitrogen fixation. When more than 0.6 gram ammonia or nitrate nitrogen were added per 100 grams of sugar, nitrogen-fixation ceased entirely; in other words, 6 parts of combined nitrogen for 1000 parts of sugar is just sufficient to prevent any fixation of gaseous nitrogen. In the absence of combined nitrogen, 2.4 to $3 \mathrm{mgm}$. of nitrogen were fixed by the organism for every gram of glucose supplied. As a result of this evidence it was concluded that growth and nitrogen fixation are two distinctly separate phenomena; the nitrogen fixing bacteria grow as other organisms do in the presence of available energy and combined nitrogen, but, in the absence of combined nitrogen and in the presence of available energy, they are able to obtain their nitrogen from the atmosphere.

At first Azotobacter was considered to be the most active nitrogenfixing organism, since it fixed as much as 15 to $20 \mathrm{mgm}$. of nitrogen per gram of sugar, while the $C l$. pastorianum fixed only 2 to $3 \mathrm{mgm}$. of nitro-

2 For detailed review of earlier literature consult Voorhees and Lipman, 1907 (p. 491); Koch, A. Lafar's Handb. techn. Mykol., 3: 1. 1907; Löhnis, 1910 (p. xiii); Omeliansky, Wr. L. Monogr. 5 Russian Acad. Sci., Petrograd. 1923.

${ }^{3}$ Winogradsky, S. 1893 (p. 107). 
gen for the same amount of sugar. However, more recent work ${ }^{4}$ tends to show that $\mathrm{Cl}$. pastornanum is more abundant and more universally distributed in the soil; also that it actually fixes far more nitrogen when the $\mathrm{CO}_{2}$ formed is considered as the real index of energy consumption. ${ }^{5}$ The activities of these two groups of organisms do not exclude, however, one another; this has been brought out by Omeliansky, who demonstrated that, by "symbiosis" or "commensalism" in reference to the oxygen tension, even larger quantities of nitrogen are fixed.

Gainey ${ }^{6}$ compared the nitrogen fixing capacity of a large number of soils in which Azotobacter was present or absent. A total of 418 soils were examined, of which 199 contained Azotobacter and 219 did not. The presence of Azotobacter was noted by pellicle formation and microscopic examination of a culture prepared by inoculating some soil into $50 \mathrm{cc}$. of a medium consisting of:

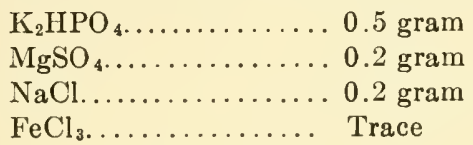

$\mathrm{CaCl}_{2} \ldots \ldots \ldots$ Trace

Mannite........... 20 grams

Distilled water...... $1000 \mathrm{cc}$.

This was neutralized to phenolphthalein by means of sodium hydroxide solution. A small quantity of sterile $\mathrm{CaCO}_{3}$ was added to each flask before inoculation in order to insure sufficient base for the neutralization of the organic acids formed.

The average amount of nitrogen fixed, in $50 \mathrm{cc}$. mineral solution containing 2 per cent mannite, in three weeks by 367 soils was $6.36 \mathrm{mgm}$.; 174 soils containing Azotobacter fixed an average of $8.30 \mathrm{mgm}$. of nitrogen and 193 soils not containing Azotobacter fixed only $4.61 \mathrm{mgm}$. Thus the quantity of nitrogen fixed by other microorganisms in the soil is practically one-half of that fixed when Azotobacter is present. The amounts of nitrogen fixed by pure cultures of the other bacteria is usually not greater than 1 to $2 \mathrm{mgm}$. per 1 gram of sugar consumed, although, in some cases, larger quantities were reported. These differences in amounts of nitrogen fixed are undoubtedly due to the efficiency

4 Pringsheim, 1908 (p. 564); Omeliansky, 1923 (p. 559); 'Truffaut, G., and Bezssonoff, N. Sur la prédominance de l'activité des fixateurs anaérobies d'azote dans le sol. Compt. Rend. Acad. Sci., 181: 165-167. 1925.

5 Bonazzi, A. The mineralization of atmospheric nitrogen by biological means. IVth. Intern. Soil. Sci. Conf. IIIB, No. 8, Rome. 1924, 42 p.

- Gainey, P. L. Influence of the absolute reaction of a soil upon its Azotobacter flora and nitrogen-fixing ability. Jour. Agr. Res., 24: 907-938. 1923. 
with which the different organisms use the available energy, as will be shown later.

Sources of energy. The process of nitrogen fixation is an endothermic reaction, which necessitates a large supply of energy for the organisms concerned. This energy is derived primarily from carbohydrates and allied compounds as well as from salts of organic acids. Glucose,

TABLE 55

Nitrogen fixed per gram of energy material

\begin{tabular}{|c|c|c|c|c|}
\hline \multirow{3}{*}{ SUBSTANCE ADDED } & \multicolumn{4}{|c|}{ RESULTS } \\
\hline & \multicolumn{2}{|c|}{ Löhnis and Pillai10 } & \multirow{2}{*}{ Krainsky ${ }^{11}$} & \multirow{2}{*}{$\begin{array}{l}\text { Hoffmann and } \\
\text { Hammer }{ }^{12}\end{array}$} \\
\hline & $\mathrm{No} \mathrm{CaCO}_{3}$ & $\mathrm{CaCO}_{3}$ added & & \\
\hline & mgm. & mgm. & $m g m$. & $m g m$. \\
\hline Mannite................. & 9.96 & 9.40 & 5.70 & 14.40 \\
\hline 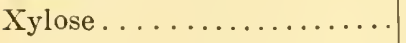 & 9.40 & 9.54 & $\ldots$ & 4.55 \\
\hline Lactose . . . . . . . . . . . . & 8.80 & 9.12 & 0.80 & 7.20 \\
\hline Laevulase . . . . . . . . . . & 8.80 & 8.52 & 5.55 & 10.30 \\
\hline 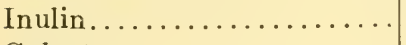 & 8.58 & 7.72 & 5.80 & 10.85 \\
\hline Galactose............... & 7.44 & 7.86 & 0.67 & 7.35 \\
\hline Maltose................ & 7.86 & 7.44 & 2.80 & \\
\hline Arabinose .............. & 7.34 & 7.62 & 0.60 & 10.00 \\
\hline Dextrin ................ & 7.58 & 7.18 & 1.20 & 13.40 \\
\hline Sucrose............... & 5.90 & 8.60 & 0 & 11.70 \\
\hline Glucose.$\ldots \ldots \ldots \ldots \ldots$ & 4.36 & 4.62 & 1.35 & 8.95 \\
\hline 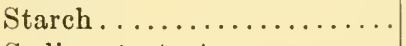 & 3.50 & 3.36 & 0.40 & $\ldots$ \\
\hline Sodium tartrate......... & 2.82 & 5.06 & $\ldots$ & $\ldots$ \\
\hline Glycerol. . . . . . . . . . & 1.68 & 4.78 & 2.40 & 5.05 \\
\hline Sodium succinate. . . . . . & 282 & 2.96 & & \\
\hline Calcium lactate.......... & 2.22 & 2.49 & & \\
\hline Sodium citrate........... & 1.00 & 1.42 & & \\
\hline Sodium proprionate....... & 0.96 & 1.10 & & \\
\hline Potassium oxalate...$\ldots \ldots$ & 0.26 & 0.12 & & \\
\hline Calcium butyrate.......... & 0.16 & 0.02 & & \\
\hline Humus . . . . ........... & -1.10 & -0.96 & & \\
\hline
\end{tabular}

mannite and other simple carbohydrates and alcohols form the most available sources of energy for nitrogen-fixing bacteria. It has been found that polysaccharides, like celluloses, can also serve as valuable sources of energy if they are first partially broken down by cellulose decomposing organisms. ${ }^{7}$ However, these results need still further con-

${ }^{7}$ McBeth, I. G. Cellulose as a source of energy for nitrogen-fixation. U. S. Dept. Agr. Bur. Pl. Ind. Circ. 131: 25-34. 1913; Pringsheim, 1906-1912 (p. 110); 
firmation; this is especially important since the bulk of the energy material commonly added to the soil consists of celluloses and pentosans. It is claimed that the latter can be used as a source of energy by nitrogen-fixing bacteria. ${ }^{8}$

Table 55 contains a summary of the results obtained by different investigators concerning the relative availability of different sources of energy for nitrogen fixation; the results are rather variable and point to the unreliability of such criteria, which are subject to numerous influences. By using different periods of incubation, media of different composition and different soils for inoculation (difference in mixed flora), a different series of results would be obtained.

As to the availability of natural organic materials as sources of energy for nitrogen fixing organisms, table 56 shows the amounts of nitrogen fixed for 100 grams of carbon by $A z$. chroococcum, as determined by

TABLE 56

Nitrogen fixed by Az. chroococcum for 100 grams of carbon

\begin{tabular}{|c|c|c|c|}
\hline & $\begin{array}{l}\text { MILLI- } \\
\text { GRAMS }\end{array}$ & & $\begin{array}{l}\text { MILLI- } \\
\text { GRAMS }\end{array}$ \\
\hline Pine needles. & 57.3 & Plant roots and stubble..... & 596.8 \\
\hline Oakleaves ............ & 126.9 & Lupines . . . . . . . . . . . . . . . . & 711.5 \\
\hline Maple leaves. & 89.5 & Alfalfa.... & 319.5 \\
\hline Wheat straw ... & 325.4 & Clover.................. & 1237.9 \\
\hline Corn stover .... & 280.3 & Glucose ................. & 1456.5 \\
\hline
\end{tabular}

Dvorak. ${ }^{9}$ He used a medium containing 1 gram $\mathrm{K}_{2} \mathrm{HPO}_{4}$ and 1 gram $\mathrm{CaCO}_{3}$ in 1 liter of tap water; 10 grams of organic matter and 250 ec. of medium were placed in liter flasks, which were then sterilized and inoculated.

The favorable action of the last four substances preceding glucose is

Bottomley, W. B. The assimilation of nitrogen by certain nitrogen-fixing bacteria in the soil. Proc. Roy. Soc. B., 82: 627-629. 1910; 85: 466. 1912; Koch, A. Über Luftstickstoffbindung im Boden mit Hilfe von Zellulose als Energiemateria'. Centrbl. Bakt. II, 27: 1-7. 1910; 31: 567-570. 1912; Stoklasa, J. Beitrag zur Kenntnis der chemischen Vorgänge bei der Assimilation des elementaren Stickstoffs durch Azotobacter und Radiobacter. Centrbl. Bakt., II, 21: 4\$4-509, 620-632. 1908.

${ }^{8}$ Stranák, Fr. Zur Assimilation des Luftstickstoffes durch im Boden freilebenden Mikroorganismen. Zeitschr. Zuckerind. Bihmen 33: 599. 1909; (Centrbl. Bakt. II, 25: 320. 1909).

- Dvořák, 1912 (p. 428). 
due to at least two factors: (1) the abundance of monosaccharides or readily hydrolyzable hemicelluloses in the leguminous plants and fresh materials; (2) the legumes were used fresh and might have exerted, therefore, a more stimulating effect upon the assimilating capacity of the cells, whereas the other substances were all used in a dry condition. Substances especially rich in lignin are not good sources of energy for the activities of the nitrogen fixing organisms.

The amount of nitrogen fixed depends not orily upon the nature of the energy source, but also on the presence of available nitrogen, minerals, reaction and other environmental conditions, as wtll as upon the specific organisms. ${ }^{10-12}$ Some species utilize more readily one source of energy than another. The amount of nitrogen fixed depends upon the energy value of the particular compound as well as the nature of its decomposition. Lipman ${ }^{13}$ recorded an increase in the amount of nitrogen fixed with an increase in molecular weight of fatty acids, in the form of solium salts, namely, acetic, propionic, butyric; the next member of the homologous series (valerianic acid) presented a poor source of carbon; the sodium salts of succinic and citric acids were not utilized at all. Mockeridge $^{14}$ obtained $6.08 \mathrm{mgm}$. of nitrogen fixed with butyric acid and 1.47 mgm. with formic acid as sources of energy. There wasnearly a cor stant ratio between the amount of nitrogen fixed and heat of combustion of the fatty acicts; the heat of combustion of butyric acid is 5.96 calories per gram and of formic acid 1.37 calories. Benzene derivatives and most glucosides seem to be unsuitable as sources of energy for Azotobacter. ${ }^{1 ;}$

The amount of nitrogen fixed is usually calculated per unit of carbon source (sugar) consumed. This does not, however, give a true picture of the process. As pointed out above, some organisms (Azotobacter) break down the sugar chiefly to carbon dioxide and water; others $(\mathrm{Cl}$.

${ }^{10}$ Löhnis, F., and Pillai, N. K. Über Stickstoff-fixierende Bakterien. Centrbl. Bakt. II, 20: 781-800. 1908. A nutrient solution was inoculated with $10 \mathrm{gm}$. of soil and incubated for 10 days.

${ }^{11}$ Krainsky, A. Azotobacter chroococcum und seine Wirkung im Boden. Zhur. Opit. Agron., 9: 6S9. 1908; (Centrbl. Bakt. II, 20: 725-736. 1908).

12 Hoffmann, C., and Hammer, R. W. Some factors concèrned in the fixation of nitrogen by Azotobacter. Wis. Agr. Exp. Sta. Res. Bul. 12. 1910; Centrbl. Bakt. II, 28: 127-139. 1910. Pure cultures used in Ashby's solution containing 1 per cent sugar and incubated 30 days.

${ }^{13}$ Lipman, 1903 (p. 115), p. 217; 1904 (p. 112), p. 237.

${ }^{14}$ Mockeridge, F. A. Some organic matter as culture media for Azotobacter. Biochem. Jour., 9: 272-283. 1915; also Ann. Bot., 26: 871-857. 1912.

${ }_{15}^{15}$ Greaves, J. E. Azofication. Soil Sci., 6: 163-217. 1918. 
pastorianum) produce largely organic acids. Different amounts of energy are thus made available for the organisms (see p. 412). The amount of nitrogen fixed should, therefore, be calculated on the basis of energy utilized and not on the basis of sugar consumed. By comparing two strains of Clostridia, one anaerobic and the other aerobic, Pringsheim $^{16}$ reported that the difference in the amount of nitrogen fixed per unit of sugar consumed is due to the relative amounts of acids and gases formed. The anaerobic organism produced 45 per cent acid and 55 per cent gas out of the sugar consumed. The aerobic strain produced only 33 per cent acid and 67 per cent gas because of the more complete decomposition of the organic matter; this strain fixed, therefore, more nitrogen. The ratio between the sugar changed into gas and the nitrogen fixed was nearly the same for both organisms, namely, 23 and 21 . The differences in the consumption of sugar by the different organisms cannot serve, therefore, as criteria. Azotobacter fixes as much as 3 to $20 \mathrm{mgm}$. of nitrogen per gram of sugar consumed, while $C l$. pastorianum fixes a maximum of 2 to $3 \mathrm{mgm}$. nitrogen for the same amount of sugar. However, when the actual energy liberated is compared, the latter organism may be found to be more efficient.

Chemistry and decomposition of carbohydrates. 'The anaerobic nitrogen-fixing bacteria decompose carbohydrates and their derivatives with the formation of various acids, chiefly butyric and acetic, and various gases. One liter of medium containing forty grams of glucose inoculated with the anaerobic organism and placed in a nitrogen atmosphere showed a gain of $53.6 \mathrm{mgm}$. of nitrogen in 20 days. All the sugar disappeared, giving rise to 3.714 grams acetic acid, 14.164 grams $n$-butyric acid, $\frac{1}{3}$ cc. alcohol, chiefly iso-butyl, and traces of lactic acid. The amount of acids as well as the relation of the gases $\left(\mathrm{CO}_{2}: \mathrm{H}_{2}\right)$ were found to vary in the different experiments. ${ }^{17}$ The gases were found to make up 55 to 67 per cent of the sugar decomposed and to consist of 49 per cent carbon dioxide and of 51 per cent hydrogen. ${ }^{18}$

Azotobacter decomposes carbohydrates, higher alcohols and organic acids, without the formation of considerable amounts of intermediary products, such as various organic acids; $\mathrm{CO}_{2}$ is the only gas formed; the reaction of the medium does not become more acid, but may even

${ }^{16}$ Pringsheim, H. Über die Verwendbarkeit verschiedener Energiequellen zur Assimilation des Luftstickstoffes und die Verbreitung stickstoffbindenden Bakterien auf der Erde. Centrbl. Bakt. II, 20: 248-256. 1908.

${ }^{17}$ Winogradsky, 1893 (p. 107).

18 Omeliansky, 1923 (p. 559). 
become more alkaline because of the utilization of the organic acids present as sources of energy. ${ }^{19}$ Some aerobic bacteria may produce ethyl alchohol and acetic acid out of the sugar, in the process of nitrogen fixation. ${ }^{20}$

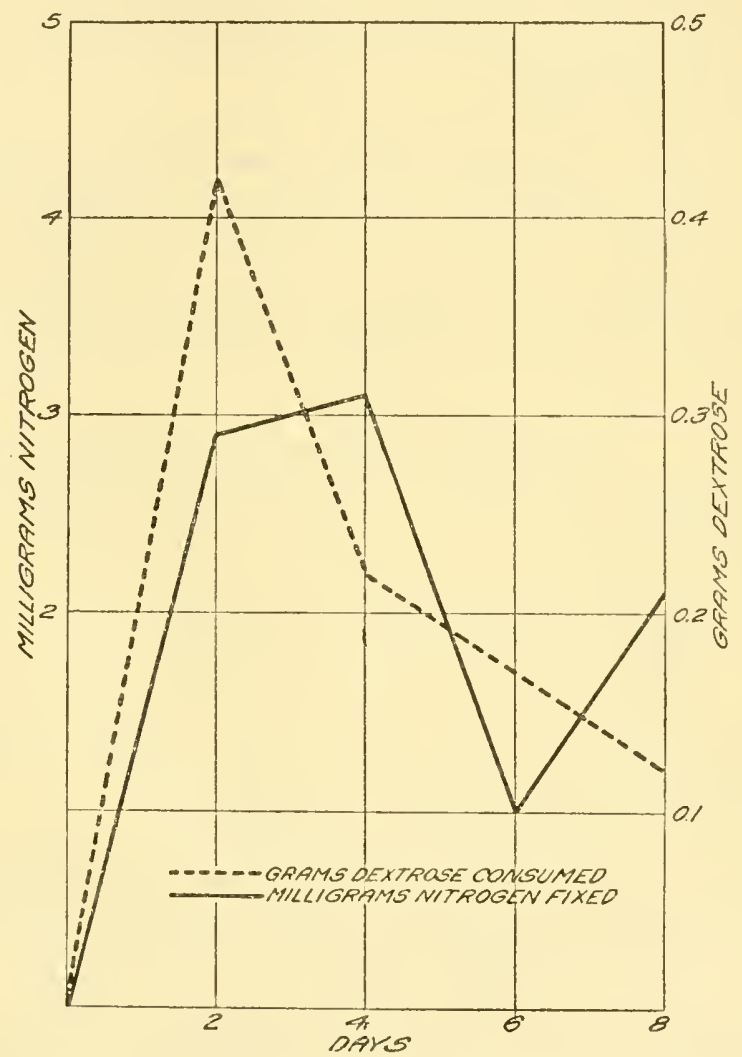

FIG. 39. Rate of decomposition of glucose and fixation of nitrogen by Azotobacter (after Hunter).

The maximum formation of carbon dioxide by Azotobacter takes place within the fourth to tenth day of growth. ${ }^{21}$ Active $\mathrm{CO}_{2}$ production

${ }^{19}$ Prazmowski, 1912 (p. 114); Omeliansky, W. L., and Ssewerowa, O. P. Die Pigmentbildung in Kulturen des Azotobacter chroococcum. Centrbl. Bakt. II, 29: 643-650. 1911.

20 Truffaut, G., and Bezssonoff, N. Une nouvelle bactérie du sol, le Bacillus truffauti, fixateur aérobie d'azote atmosphérique. La Science du sol., 2: 3-16. 1923.

${ }^{21}$ Stoklasa, 1908 (p. 562). 
may last up to 21 to 24 days of growth and is then followed by a decrease to 32 to 39 days. ${ }^{22}$ In old cultures, the most active $\mathrm{CO}_{2}$ evolution may be observed even later (on the thirty-sixth day of growth). When aeration is increased, the maximum evolution of $\mathrm{CO}_{2}$ takes place at a much earlier period, namely, between the sixth and ninth days. The curves shown in figure 39 were obtained by growing $A z$. chroococcum in a glucose medium free from nitrogen.

The differences in the products formed by the different nitrogen fixing bacteria from the carbohydrate used as a source of energy account to a large extent for the difference in the amounts of nitrogen fixed. One gram of glucose liberates 3.7 Calories when oxidized completely to $\mathrm{CO}_{2}$ and water; it liberates only 0.08 Calorie when changed into butyric acid and 0.19 Calorie when changed to acetic acid under anaerobic conditions. The energy made available to Azotobacter, from the same amount of sugar decomposed, may be forty-six times as much as to Cl. pastorianum. The fixation of nitrogen consumes a large amount of energy; the greater the amount of energy liberated the greater will be the amount of nitrogen fixed. 'The organism that will be able to utilize a larger amount of energy from the same amount of substrate will, therefore, be able to fix larger quantities of nitrogen, even if it is not more efficient. This accounts for the statements made ${ }^{23}$ that $\mathrm{Cl}$. pastorianum is actually a more energetic nitrogen "fixing" organism than Azotobacter; this holds true of course only when the energy made available in the process is used as a basis for comparison.

Respiration and nitrogen-fixation. The utilization of energy enables the organism to obtain the nitrogen necessary for the synthesis of its protoplasm from the atmosphere. The amount of nitrogen fixed and the efficiency of the process depend on a series of physical, chemical, and biological factors including temperature, composition and concentration of medium, aeration, age and development of culture, and racial peculiarities. $^{24}$ The nature and concentration of the energy source and presence or absence of combined nitrogen are of special importance. The actual quantity of cell substance formed per unit of sugar consumed

${ }^{22}$ Krainsky, A. B. Fixation of free nitrogen in the soil by Azotobacter chroococcum, its physiological properties and activities in the soil (Russian). Zhur. Opit. Agron., 9: 689, 749. 1908; Univ. Izv. Kiev, 52: 1-58, 59-131, 133-1S2. 1912.

${ }^{23}$ Bonazzi, 1924 (p. 560).

${ }^{24}$ Omeliansky, W. L. On the relation between nitrogen-fixation and utilization of non-nitrogenous organic matter by nitrogen-fixing bacteria (Russian). Arch. Sci. Biol. Petrograd, 18: No. 4. 1914. 
was found to vary at different stages of growth of the nitrogen-fixing organism. Bonazzi ${ }^{25}$ differentiated between the "ferment power" or first stage in the growth of the organism, when nitrogen assimilation is at a maximum, and the second or "maintenance" phase. During this maintenance stage the carbohydrate complexes are actually reworked, partially burned to liberate energy, partially utilized in the building of cellular substance, and partially secreted into the medium in the form of soluble by-products, as shown in table 57. In this table, $S$ represents the sugar consumed; $c$, the mass of cellular substance at work during the period, and $t$, the time of incubation. During the early periods of growth, a unit of cellular substance could utilize in a unit of time 5.45 units of sugar; after an incubation period of 30 days, a unit of cellular substance utilized in a unit of time only 0.28 unit of sugar (fig. 40). Not

TABLE 57

Ferment power of Azotobacter chroococcum

\begin{tabular}{c|c}
\hline INcuBation & 8:c.t \\
\hline days & \\
4 & 5.45 \\
5 & 1.83 \\
9 & 0.82 \\
23 & 0.29 \\
30 & 0.28 \\
\hline
\end{tabular}

the sugar itself, but the products of its decomposition form the true sources of energy for Azotobacter.

The fixation process is usually most efficient in the earlier stages of growth coinciding with the period of greatest cell multiplication and sugar utilization. It was found, ${ }^{26}$ for example, that 70 to $80 \mathrm{mgm}$. of nitrogen are fixed by Azotobacter per gram of glucose decomposed on the second and third day of growth, and only 5 to $8 \mathrm{mgm}$. on the eighth day. Although the total amount of nitrogen fixed during the first five days is small, the process is most economical. In the following 3 to 5 days' periods, the process becomes less and less economical. In the latter stages a larger part of the energy is utilized for respiration only. A definite correlation is thus found between the processes of

${ }^{25}$ Bonazzi, A. Studies on Azotobacter chroococcum Beij. Jour. Bact., 6: 331-369. 1921.

${ }^{26}$ Koch, A., and Seydel, S. Versuche über den Verlauf der Stickstoffbindung durch Azotobacter. Centrbl. Bakt. II, 31: 570-577. 1912. 
assimilation and dissimilation taking place in the cell and bringing about its development. The rate of growth is more rapid at the early periods and, since nitrogen fixation is a function of the growth of the organism,

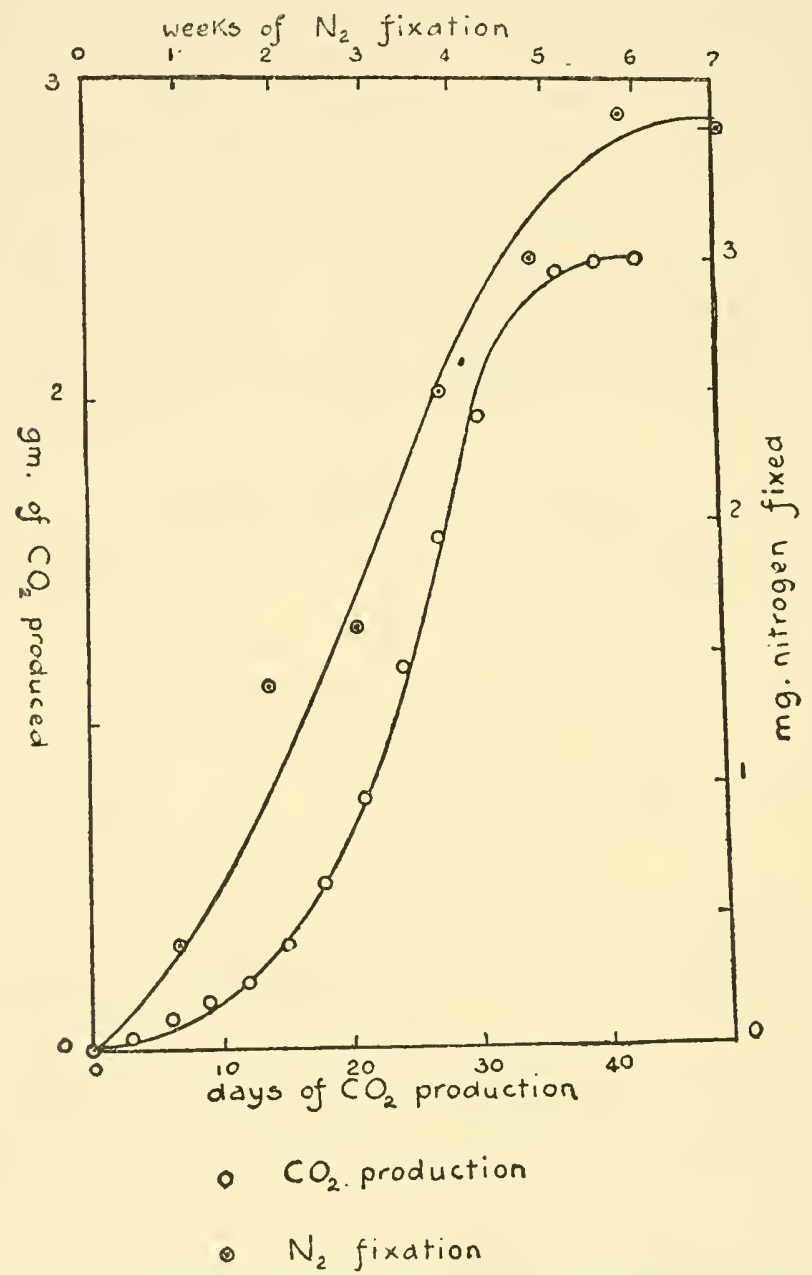

FIG. 40. Rate of nitrogen fixation and energy consumption (after Krainsky and Bonazzi).

it will be most active in the early periods; later, however, a great deal of the energy is spent for sustenance of the cells without further growth. ${ }^{27}$

${ }^{27}$ Hunter, O. W. Stimulating the growth of Azotobacter by aeration. Jour. Agr. Res., 23: 665-677. 1923. 
On increasing the concentration of the energy source in the medium, there is an increase in the amount of nitrogen fixed, but the process is less economical, i.e., less nitrogen is fixed per unit of carbon utilized. When the mannite contents of the medium are $0.5,1$ and 5 per cent, the corresponding amounts of nitrogen fixed are 11.4, 8.2 and $7.45 \mathrm{mgm}$. per gram of mannite oxidized. ${ }^{2 s}$ The following amounts of nitrogen were reported ${ }^{29}$ fixed per gram of mannite in different concentrations of the latter:

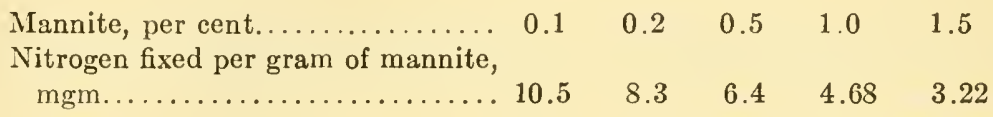

The more dilute the concentration of the energy source, the greater is the nitrogen-fixing efficiency of the organisms. This probably accounts for the very efficient energy utilization by the nitrogen-fixing bacteria in the surface layers of the soil.30 The amount of nitrogen fixed also depends on the presence of minerals, especially phosphates, of certain stimulating substances and upon the nature of the medium. Nearly ten times as much nitrogen was fixed per unit of sugar consumed in sand as in solution. ${ }^{31} \mathrm{Cl}$. pastorianum fixed $4.56 \mathrm{mgm}$. nitrogen per gram of sugar consumed in a 0.5 per cent glucose solution and $1.93 \mathrm{mgm}$. in a 3.0 per cent sugar solution. ${ }^{32}$

These considerations account for the great variability in the amounts of nitrogen fixed (from 1.2 to $17 \mathrm{mgm}$.) per gram of sugar consumed by crude and pure cultures of bacteria, as determined by various investigators. ${ }^{33}$

The maximum amount of nitrogen fixed by non-symbiotic bacteria in the soil was reported as $10 \mathrm{mgm}$. for one gram of nutrient consumed. ${ }^{34}$

${ }^{28}$ Hoffmann and Hammer, 1910 (p. 563).

${ }^{29}$ Lipman, 1903 (p. 115).

${ }^{30}$ Omeliansky, 1923 (p. 559).

${ }^{31}$ Krainsky, A. V. Über die Stickstoffanreicherung des Bodens. Centrbl. Bakt. II, 26: 231-235. 1910.

32 Omeliansky, 1923 (p. 559); Pringsheim, 1908 (p. 564); Truffaut, G., and Bezssonoff, N. Sur les variations d'énergie du Clostridium pastorianum comme fixateur d'azote. Compt. Rend. Acad. Sci., 175: 868-870. 1921; Influence de la concentration en sucre des milieux sur l'activité des bactéries fixatrices d'azote. Ibid., 177: 619-652. 1923.

${ }^{33}$ Omeliansky, W. Sur la physiologie et la biologie des bactéries fixant l'azote. Arch. Sci. Biol. Petrograd, 19: 162-208. 1915.

${ }^{34}$ Remy, Th. Untersuchungen über die Stickstoffsammlungsvorgänge in ihrer Beziehung zum Bodenklima. Centrbl. Bakt. II, 22: 561-651. 1909. 
Thus for every kilogram of nitrogen fixed, the soil loses about $100 \mathrm{kgm}$. of energy material. If $1 \mathrm{kgm}$. of material is equivalent to 4000 Calories, $1 \mathrm{kgm}$. of nitrogen fixed requires an energy consumption of 464 kilowatt hours, greatly in excess of that used in chemical processes (about 46 to 48 kilowatt hours). Such a large expenditure of energy is due to the fact that not all the energy is used by the organism for nitrogen fixation, but a part of the energy is utilized for life activities and for the synthesis of proteins of a high molecular weight. At most only one-half of the energy liberated by nitrogen-fixing bacteria is used for nitrogen fixation and one-half for metabolic processes and cell activities. ${ }^{35}$ We must also consider the fact that not all the energy is made available to the nitrogen-fixing bacteria, since the nutrient is not completely broken down to $\mathrm{CO}_{2}$ and water, but a part is left in the form of intermediate compounds.

The amount of available energy actually utilized by Azotobacter for the fixation of atmospheric nitrogen was calculated ${ }^{36}$ as one per cent, assuming that all the sugar is used up and converted into $\mathrm{CO}_{2}$ and water.

Protein synthesis by Azotobacter. Azotobacter was reported ${ }^{37}$ to contain 10.45 per cent total nitrogen, of which 6.39 per cent was non-basic $\mathrm{N}, 2.76$ per cent basic $\mathrm{N}$, and 0.98 per cent ammonia $\mathrm{N}$. In young cultures the nitrogen was believed to be present largely in a soluble form which is not precipitated by phosphotungstic acid; as the culture grows older, the material becomes more insoluble. When cultivated in liquid media Azotobacter was found ${ }^{38}$ to contain 11.3 per cent nitrogen and 8.6 per cent ash of which 58 to 62.35 per cent was phosphoric acid; the nitrogen and the phosphorus were present in the cells chiefly in the form of nucleo-proteins and lecithin. Both the nitrogen and the phosphorus content increase with the age of the cell.

When the nitrogen-fixing organism is grown on solid media, such as an agar surface, and all the growth collected and dried, a much smaller relative amount of nitrogen is found, amounting to not more than 2 to 3 per cent of the dry weight of the cells. ${ }^{33}$ The protein content of Azoto-

${ }^{35}$ Christiansen-Weniger, F. Der Energiebedarf der Stickstoffbindung durch die Knöllchenbakterien im Vergleich zu anderen Stickstoffbindungsmöglichkeiten und erste Versuche zur Ermittlung desselben. Centrbl. Bakt. II, 58: 41-66. 1923.

${ }^{36}$ Linhart, G. A. The free energy of biological processes. Jour. Gen. Physiol., 2: 247-251. 1919.

37 Lipman, 1904-1905 (p. 112).

38 Stoklasa, 1908 (p. 562).

${ }^{39}$ Hoffmann and Hammer, p. (563). 
coccum was found ${ }^{45}$ to secrete soluble nitrogen compounds only after death; Az. agile and $A z$. vinelandii, however, readily secrete soluble nitrogenous compounds during active growth.

The nitrogen synthesized by Azotobacter is utilized by higher plants. This is accomplished either by the secretion of a substance which has a favorable influence upon plant growth, ${ }^{46}$ or through the autolysis of the dead Azotobacter cells. The proteins of the Azotobacter cells are not completely broken down by the soil bacteria and are not readily acted upon by proteolytic enzymes. ${ }^{47}$ Remy, ${ }^{48}$ however, considered the microbial proteins readily available for plant growth.

Chemistry of process of non-symbiotic nitrogen-fixation. Due to its position in the periodic system, nitrogen shows a strong affinity for the electropositive elements and only a slight affinity for the electronegative elements. The combination of nitrogen and hydrogen is exothermic so that

$$
\mathrm{N}_{2}+3 \mathrm{H}_{2} \rightleftarrows 2 \mathrm{NH}_{3}+24.0 \text { Cal. }
$$

At ordinary temperatures, 90 per cent of the nitrogen is found as $\mathrm{NH}_{3}$. With increasing temperatures, the anmonia breaks up more and more. The combination of nitrogen with oxygen is endothermic:

$$
\mathrm{N}_{2}+\mathrm{O}_{2}=2 \mathrm{NO}-43.2 \mathrm{Cal} \text {. }
$$

The oxidation of nitrogen, therefore, requires large quantities of energy and must be carried out at a high temperature so as to obtain the necessary reaction velocity and favorable equilibrium between $\mathrm{N}_{2}$ $+\mathrm{O}_{2} \rightleftarrows 2 \mathrm{NO}$, which amounts to 5 per cent at $3200^{\circ}$ and 10 per cent at $4200^{\circ}$. With an increase in temperature the molecular nitrogen changes to atomic $\left(\mathrm{N}_{2} \rightleftarrows 2 \mathrm{~N}\right)$ and brings about an increase of contact between the reacting molecules. In the presence of catalyzers, the reactions are brought about at lower temperatures. The bacteria depend primarily on catalyzers. Winogradsky ${ }^{49}$ believed that, in the case of the anaerobic Clostridium, the bacterial plasma produces ammonia out of the nitrogen

${ }^{45}$ Molér, T. Ein Beitrag zur Kenntnis der Entbindung des durch Azotobakte fixierten Stickstoffes. Botan. Notiser, 4: 163-178. 1915; (Centrbl. Bakt. II 47: 635. 1917).

${ }^{46}$ Kayser, E. Influence de la matière azotée élaborée par l'Azotobacter sur le ferment alcoolique. Compt. Rend. Acad. Sci., 172: 1539-1541. 1921.

${ }^{47}$ Bonazzi, 1924 (p. 560).

${ }^{48}$ Remy, 1909 (p. 569).

${ }^{49}$ Winogradsky, 1893-1895 (p. 107). 
gas and nascent hydrogen with which it comes into contact. The hydrogen is formed in the butyric acid fermentation of the organism. The ammonia is immediately assimilated and is converted into protein. ${ }^{50}$ The actual assimilation of the nitrogen may take place according to the following reactions: ${ }^{51}$

$$
\begin{aligned}
2 \mathrm{NH}_{3}+2 \mathrm{CO}_{2}+\mathrm{H}_{2} \mathrm{O} \rightarrow \underset{\text { formamide }}{2 \mathrm{H} \cdot \mathrm{CO} \cdot \mathrm{NH}_{2}+\mathrm{H}_{2} \mathrm{O}+\mathrm{O}_{2}} \\
2 \mathrm{H} \cdot \mathrm{CO} \cdot \mathrm{NH}_{2}+\mathrm{H}_{2} \mathrm{O} \rightarrow \underset{\mathrm{CO} \cdot \mathrm{NH}_{2}}{\mathrm{COONH}}+\mathrm{H}_{2} \rightarrow \underset{\mathrm{CH}_{2} \cdot \mathrm{NH}_{2}}{\mathrm{COO} \cdot \mathrm{NH}_{4}+\frac{1}{2}\left(\mathrm{O}_{2}\right) .}
\end{aligned}
$$

It has also been suggested ${ }^{52}$ that the fixation of nitrogen by Azotobacter takes place by reduction by means of hydrogen with the formation of cyanides as intermediary products. Wieland ${ }^{53}$ considered that the action of the hydrogen acceptors formed in the cells of nitrogen-fixing bacteria does not depend upon oxygen for hydration, but upon the molecular nitrogen with which it forms ammonia, perhaps through the hydrazine stage in a manner similar to the Haber synthesis.

The fixation of nitrogen by an oxidation process, similar to nitrogen-fixation in moist air through the oxidation of organic matter, has also been suggested. ${ }^{54}$ The nitrogen is believed to be first oxidized to $\mathrm{N}_{2} \mathrm{O}_{3}$ with iron hydrate as a catalyst; the nitrous acid may then be assimilated by the organism. ${ }^{55}$ It has also been suggested ${ }^{56}$ that ammonium nitrite is first synthesized. However, neither nitrate nor

${ }^{50}$ Kostytschew, S., and Ryskaltshouk, A. Les produits de la fixation de l'azote atmosphérique par l'Azotobacter agile. Compt. Rend. Acad. Sci., 180: 2070-2072. 1925; Ztschr. physiol. Chem., 154: 1-17. 1926.

1 1 Loeb, W. Über das Verhalten des Formamids unter der Wirkung der stillen Entladung. Ein Beitrag zur Frage der Stickstoff-Assimilation. Ber. deut. chem. Gesell., 46: 684-697. 1913.

52 Stoklasa, 1908 (p. 562).

${ }^{53}$ Wieland, H. Über den Verlauf der Oxydationsvorgänge. Ber. deut. chem. Gesell., 55: 3639-3648. 1922.

${ }^{54}$ Gautier, A., and Drouin, R. Recherches sur la fixation de l'azote par les sols et les végétaux. Compt. Rend. Acad. Sci., 106: 754-757, S63, 944, 1174, 1232, 1605. 18S8; 113: \$20-825. 1891; also Berthelot, 1892 (p. 558).

${ }_{55}$ Bonnema, A. Gibt es Bakterien, die den freien $\mathrm{N}$ assimilieren oder ist dies ein chemischer Prozesz? Chem. Ztg., 27: 148. 1903; Centrbl. Bakt. II, 10: 598-602. 1903.

${ }^{66}$ Czapek, F. Der Stickstoff im Stoffwechsel der Pflanze. Ergeb. Physiol. I, 2: 638-672. 1903; Heinze, B. Centrbl. Bakt. II, 12: 364. 1904. 
nitrite could be found in the cells of Azotobacter. ${ }^{57}$ Loew and $\mathrm{AzO}^{58}$ considered the reaction of nitrogen-fixation by Azotobacter to take place as follows:

$$
\mathrm{N}_{2}+2 \mathrm{H}_{2} \mathrm{O}=\mathrm{NH}_{4} \mathrm{NO}_{2}
$$

The ammonium nitrite is reduced to ammonia which will interact with the decomposition products of carbohydrates to give amino acids. ${ }^{59}$

$$
\begin{aligned}
& \mathrm{CH}_{3} \cdot \mathrm{CO} \cdot \mathrm{COOH}+\mathrm{NH}_{3}=\mathrm{CH}_{3} \cdot \mathrm{CHN} \cdot \mathrm{COOH}+\mathrm{H}_{2} \mathrm{O} \\
& \text { pyruvic acid } \\
& \mathrm{CH}_{3} \cdot \mathrm{CHN} \cdot \mathrm{COOH}+\mathrm{H}_{2}=\mathrm{CH}_{3} \cdot \mathrm{CHNH}_{2} \cdot \mathrm{COOH} \\
& \text { alanine } \\
& \mathrm{CHO} \cdot \mathrm{COOH}+\mathrm{NH}_{3}=\mathrm{H} \cdot \mathrm{CNH} \cdot \mathrm{COOH}+\mathrm{H}_{2} \mathrm{O} \\
& \text { glyoxylic acid } \\
& \mathrm{HCNH} \cdot \mathrm{COOH}+\mathrm{H}_{2}=\mathrm{CH}_{2} \cdot \mathrm{NH}_{2} \cdot \mathrm{COOH} \\
& \text { glycocoll }
\end{aligned}
$$

By the process of condensation, the amino acids are built upinto proteins. Beijerinck and van Delden ${ }^{60}$ originally thought that the nitrogen is first fixed in the form of an inorganic soluble compound which goes into solution. No soluble inorganic nitrogen compounds could be demonstrated in pure cultures, but in crude cultures the proteins may again be hydrolyzed into soluble forms of nitrogen. It was suggested, ${ }^{61}$ therefore, that the nitrogen is attached to the nitrogen-free organic compounds which are then changed to proteins. Soluble organic nitrogen compounds were found, ${ }^{62}$ however, not only in the filtrate of a phosphotungstic acid precipitate of a dead Azotobacter culture, but also after the culture was filtered through a Chamberland filter. It was suggested $^{63}$ that Azotobacter forms, in its early stage of development, a complex consisting of sugar and nitrate which is similar to the sugarphosphoric acid complex which takes an active part in alcoholic fermen-

${ }^{57}$ Kellerman, F., and Smith, N. R. The absence of nitrate formation in cultures of Azotobacter. Centrbl. Bakt. II, 40: 479. 1914.

${ }^{58}$ Loew and Aso. On changes of availability of nitrogen in soils. II. I3:1ll. Coll. Agr., Tokyo, 7: No. 5 (Centrbl. Bakt. II, 22: 452. 1909).

${ }^{59}$ Lipman, 1904-5 (p. 112).

${ }^{60}$ Beijerinck and van Delden, 1902 (p. 105).

${ }^{61}$ Gerlach and Vogel, 1903 (p. 379).

6. Lipman, 1903 (p. 115).

${ }^{63}$ Bonazzi, 1921 (p. 567). 
tation. That complex is later used partly for energy and partly for synthesis of protoplasm. It was actually demonstrated ${ }^{64}$ that a large percentage of the total nitrogen fixed in the first few days of growth of Azotobacter consists of amino acid nitrogen. This proves that the elementary nitrogen goes through the simple organic forms before it is changed into protein. It also tends to prove that nitrogen is fixed by combination with hydrogen and not with oxygen, thus insuring much greater economy of energy.

Influence of available nitrogen compounds upon nitrogen fixation. The nitrogen fixing bacteria do not depend entirely upon atmospheric nitrogen for their need, but are capable of utilizing combined nitrogen present in the medium. This is a direct result of the distinct difference in growth and nitrogen-fixation pointed out above. Nitrates are readily utilized by Azotobacter as sources of nitrogen ${ }^{65}$ accordingly the presence of nitrates in the medium inhibits the fixation of atmospheric nitrogen. Ammonium sulfate and peptone are also available nitrogen compounds ${ }^{66}$

The injurious action of the nitrate upon the fixation of nitrogen was considered to be due either to $(a)$ a direct toxic action of the salt upon the growth of the organism, $(b)$ stimulation by nitrate of other organisms in a mixed culture which are antagonistic to Azotobacter, and $(c)$ competition by such organisms with Azotobacter for the energy supply.

By taking the number of organisms developing and the nitrogen fixed in the nitrate-free cultures as 100 , it was found ${ }^{67}$ that the addition of 50 mgm. of $\mathrm{NaNO}_{3}$ brought about an inerease in the number of organisms from 100 to 3150 , while the nitrogen fixed was increased 342 per cent in sterilized soil and 500 per cent in unsterilized soil. The presence of nitrate was thus found to stimulate greatly the multiplication of the Azotobacter organism, while it reduced its physiological efficiency. Bonazzi, ${ }^{68}$ therefore, suggested that $A z$. chroococcum may fix nitrogen in the

${ }^{64}$ Waynick, D. D., and Woodhouse. By what steps does Azotobacter fix nitrogen? Cal. Agr. Exp. Sta. Ann. Rpt. 1918-19, p. 62-63.

${ }^{65}$ Lipman, 1903 (p. 115); Pringsheim, H. Zur Stickstoffassimilation in Gegenwart von Saltpeter. Centrbl. Bakt. II, 40: 21-24. 1914; Hanzawa, J. Einigc Beobachtungen über Stickstoffbindung durch Azotobacter in stickstoffarmen und in stickstoffreichen Substanzen. Centrbl. Bakt. II, 41: 573-576. 1913.

${ }^{66}$ Krainsky, 1908-1912 (p. 566); Prazmowski, A. Azotobacter-Studien. II. Physiologie und Biologie. Bull. Intern. Acad. Sci. Cracovie, Math. Nat. Cl. Sc. B, No. 7: 855-950. 1912 .

${ }^{67}$ Hills, T. L. Influence of nitrates on nitrogen assimilating bacteria. Jour. Agr. Res., 12: 183-230. 1918.

${ }^{68}$ Bonazzi, 1921 (p. 567). 
absence of such fixed nitrogen and act as a "denitrifying" organism in the presence of nitrates. Except in high concentrations, however, the nitrogen of humus does not seem to exert any injurious influence upon nitrogen-fixation. This is probably due to the fact that its availability is only limited. As a matter of fact, it is even claimed ${ }^{69}$ that the soil organic compounds can be used as sources of energy by nitrogen-fixing bacteria. These results, however, need confirmation and elucidation.

Influence of salts upon nitrogen fixation. In addition to an energy source, the presence of certain minerals in minimum concentrations is important for the activities of the nitrogen-fixing bacteria. Azotobacter was found ${ }^{70}$ to prefer soils containing calcium salts and races of the organism isolated from those soils were more active than those isolated from unlimed soils. Calcium was looked upon as serving a double purpose: (1) directly for metabolism (in the form of soluble phosphates, as the oxide, carbonate, and in the form of salts of organic and inorganic acids) and (2) for the purpose of neutralizing the acids formed in the metabolism (in the form of oxide, hydroxide or carbonate). Certain calcium salts, especially tricalcium phosphate and the chloride, cannot be utilized. ${ }^{71}$ Magnesium salts cannot take the place of calcium. ${ }^{72}$ The primary importance of calcium is due, however, not to its direct nutrient quality but chiefly to its buffering properties, and it may serve to some extent as a catalytic agent. ${ }^{73}$

According to Ashby, ${ }^{74}$ magnesium carbonate is very favorable for the development of Azotobacter in solution; its presence discourages also the development of foreign organisms, probably due to their supression by the magnesium.

Potassium salts favor the development of Azotobacter, the minimum

${ }^{69}$ Lipman, C. B., and Teakle, L. J. H. The fixation of nitrogen by Azotobacter in a displaced solution and in soil residue therefrom. Soil Sci., 19: 99-103. 1925.

70 Krzemieniewski, 1908 (p. 579).

${ }^{71}$ Christensen, H. R. Utber das Vorkommen und die Verbreitung des Azotobacter chroococcum in verschiedenen Böden. Centrbl. Bakt. II, 17: 109-119. 1907; 19: 735-6. 1917.

${ }^{72}$ Fischer, H. Ein Beitrag zur Kenntnis der Lebensbedingungen von stickstoffsammelnden Bakterien. Centrbl. Bakt. II, 14: 33-34. 1905; 15: 235-236. 1906.

${ }^{73}$ Vogel, J. Untersuchungen über das Kalibedürfnis von Azotobacter. Centrbl. Bakt. II, 32: 411-442. 1912; Krzemieniewska, H. Zur Ernährung des Azotobakters. Bul. Intern. Acad. Sci. Cracovie, Cl. Sci. Math. Nat. No. 5: 445-448. 1908.

74 Ashby, 1907 (p. 113). 
quantity of this element corresponding to that of calcium. A minimum of $0.38 \mathrm{mgm}$. K, $0.36 \mathrm{mgm}$. Ca and $0.35 \mathrm{mgm}$. Mg was required by Azotobacter for every gram of sugar decomposed. When nitrogenfixation takes place in the soil, the addition of small amounts of potassium is without any effect. ${ }^{75}$ In higher concentrations, potassium salts, as a rule, become more toxic than sodium salts. The latter do not seem to be indispensable for the growth of Azotobacter, although the addition of three per cent of $\mathrm{NaCl}$ does not injure the development of the organism. There are claims in the literature ${ }^{76}$ however, that alkalies, and particularly alkali carbonates, are injurious to nitrogen-fixation; the action of $\mathrm{NaCl}$ becomes apparent only when 0.5 to 0.6 part are present in 100 grams of dry soil. $\mathrm{Na}_{2} \mathrm{SO}_{4}$ becomes injurious at 0.25 per cent concentration, while 0.4 to 0.5 per cent of $\mathrm{Na}_{2} \mathrm{CO}_{3}$ inhibits growth of the nitrogen-fixing organisms completely.

Phosphorus compounds greatly accelerate the activities of the nitrogen-fixing organisms, since they play an important rôle in the metabolism of Azotobacter, ${ }^{77}$ which requires large quantities of the mineral for the synthesis of its cells. The organism utilizes particularly well those soluble phosphates which do not tend to make the soil reaction acid, as in the case of the di- and tri-sodium and potassium phosphates and di-calcium phosphates. The presence of mono-basic-phosphates which serve as buffers and tend to make the reaction of the medium more acid than the minimum for the growth of Azotobacter is not favorable. The difficultly soluble tri-basic calcium, iron and aluminum salts are available only according to the degree of their solubility. In the presence of an excess of available energy a definite relation is found to exist between the growth of Azotobacter and the phosphorus content of the soil. ${ }^{78}$ It was suggested that information can be obtained on the presence of available plant food in the soil by determining the food requirements of bacteria. When a mannite solution free from phosphorus yields a good growth of Azotobacter, after inoculation with soil, it may be assumed that the soil is not deficient in phosphorus

${ }^{75}$ Greaves, J. E., Carter, E. G., and Lund, Y. Influence of salts on azofication in soil. Soil Sci., 13: 481-499. 1922.

${ }^{76}$ Lipman, C. B., and Sharp, L. T. The effects of alkali salts in soils on soil bacteria. III. Nitrogen fixation. Centrbl. Bakt. II, 35: 647-655. 1912. Sce also Greaves, Carter and Lund, 1922.

${ }^{77}$ Dzierzbicki, A. Beiträge zur Bodenbakteriologie. Bul. Intcrn. Acad. Sci. Cracovie, B. 1910, 21-66. 
so far as its availability to crops is concerned. Stoklasa ${ }^{78}$ found that 5.0 to $5.7 \mathrm{mgm}$. of atmospheric nitrogen are fixed for every $\mathrm{mgm}$. of phosphorus used. The minimum need of phosphorus is $2.46 \mathrm{mgm}$. of $\mathrm{P}$ (or $5.46 \mathrm{mgm} . \mathrm{P}_{2} \mathrm{O}_{5}$ ) for every gram of glucose. Sulfur in the form of sulfates is essential for the growth of Azotobacter. ${ }^{79}$

Iron, in the form of its salts, has a definitely favorable influence upon the development of Azotobacter, by playing a part in its metabolism and exerting a favorable influence through its colloidal condition. When iron sulfate was added to the medium the amount of nitrogen fixed per gram of mannite was increased from 2.23 to $10.3 \mathrm{mgm} .{ }^{80}$ It has been suggested that the colloidal iron absorbs the nitrogen and oxygen of the air and thus brings them into more intimate contact with the cells of Azotobacter. In the presence of organic colloids, only small quantities of iron are effective. The favorable influence of soil infusion upon nitrogen fixation by Azotobacter has been found ${ }^{81}$ to be due chiefly to their content of iron and partly to silicic acid. Inorganic colloids like the oxides of aluminum, iron and colloidal silicic acid greatly stimulate nitrogen-fixation by $A z$. chroococcum. ${ }^{82}$ After inserting a strip of paper into the medium, Azotobacter grows exclusively in contact with the paper. This led Söhngen to conclude that microbial life in the soil takes place chiefly upon the colloids. The colloid is believed to absorb the nitrogen and oxygen thus making them more readily available to the organism. Iron has the same stimulating effect upon nitrogen-fixation as "humus" substances do, but much larger quantities of the inorganic colloid are required when it is present alone as when it is used together with the organic colloid. The iron is most active in the form of an organic compound. ${ }^{81}$

${ }^{78}$ Stoklasa, J. Biochemischer Kreislauf des Phosphat Ions im Boden. Centrbl. Bakt. II, 29: 385-419. 1911; Christensen, H. R. Studien über den Einflusz der Bodenbeschaffenheit auf das Bakterienleben und dem Stoffumsatz im Erdboden. Centrbl. Bakt. II, 43: 1-166. 1915; also Soil Sci., 15: 329-360. 1923; Greaves, 1918 (p. 563).

${ }^{79}$ See also Koch, A. Ernährung der Pflanzen durch frei im Boden lebende stickstoffsammelnde Bakterien. Ber. deut. landw. Gesell., 22: 117-121. 1907; Jour. Landw., 55: 355-416. 1907.

${ }^{80}$ Rösing, G. Zusammenfassung der Ergebnisse von Untersuchungen über die Stickstoffsammlung von Azolobacter chroococcum. Centrbl. Bakt. II, 33: 618-623. 1912.

81 Reny, Th., and Rösing, G. Über die biologische Reizwirkung natürlicher Humusstoffe. Centrbl. Bakt. II, 30: 349-3S4. 1911.

82 Söhngen, N. L. Einflusz von Kolloiden auf mikrobiologische Prozesse. Centrbl. Bakt. II, 38: 621-647. 1913. 
Some salts may act directly as stimulants to nitrogen-fixing bacteria. The optimum concentration of manganese for nitrogen-fixation by Azotobacter chroococcum in mannite solution was found to be ${ }^{83} 1$ to 2 $\mathrm{mgm}$. per 100 gram of medium; further increases diminished nitrogenfixation. One part of manganese per million parts of soil was the optimum for Bac. amylobacter. The addition of small amounts of arsenic (10 parts per million) exerted a stimulating effect upon nitrogen-fixation in the soil and upon the more economic utilization of energy by Azotobacter. ${ }^{84}$ Aluminum has been looked upon ${ }^{85}$ both as a stimulant and as a retarding agent.

Uranium salts exert a decided stimulating effect upon Azotobacter. ${ }^{86}$ The maximum amount of nitrogen fixed and maximum growth take place in the yellow or green rays; the least, in violet light. The maximum amount of nitrogen per gram of sugar decomposed is fixed in blue light; the least, in yellow light.

Influence of organic matter upon nitrogen fixation. The favorable influence of soluble soil organic matter, or so-called "humus," on nitrogen-fixation was known for a long time; ${ }^{87}$ however, it was recognized that the nature of this action depends on the source of the organic matter. It was at first suggested that some of the constituents of the soil organic matter are used by Azotobacter as a source of energy. ${ }^{88}$ Löhnis and Green, ${ }^{89}$ however, working with various species of Azotobacter in mannite solution, found that the amount of nitrogen fixed in three weeks in $100 \mathrm{cc}$. of solution was $5.6 \mathrm{mgm}$.; the addition of green manure increased it to $8.0 \mathrm{mgm}$., fresh stable manure to $9.8 \mathrm{mgm}$., and fresh straw to $10.0 \mathrm{mgm}$. When these substances were previously decom-

${ }^{83}$ Olaru, D. A. Rôle du manganèse en agriculture. Son influence sur quelques microbes du sol. Paris, Baillères. 1920.

${ }^{84}$ Greaves, J. E. Stimulating influence of arsenic upon the nitrogen-fixing organisms in the soil. Jour. Agr. Res., 6: 389-416. 1916.

${ }^{85}$ Kaserer, H. Zur Kenntnis des Mineralstoffbedarfs von Azotobacter. Ber. deut. bot. Gesell., 28: 208-262. 1910.

${ }^{86}$ Kayser, E. Influence des radiations lumineuses sur l'Azotobacter. Compt. Rend. Acad. Sci., 171: 969-971. 1920; 172: 183-185, 491-493, 1133-1134. 1921; Ann. Inst. Nat. Agron. (2), 16: 11-43. 1922.

${ }^{87}$ Krzemieniewski, S. Untersuchungen über Azotobacter chroococcum Beij. Bull. Int. Acad. Sci. Cracovie, Cl, Sci. Math. Nat., No. 9: 929-1051. 1908. ${ }^{88}$ Remy, 1909 (p. 569).

${ }^{80}$ Löhnis, F., and Green, H. H. Uber die Entstehung und die Zersetzung von Humus, sowie über dessen Einwirkung auf Stickstoff-Assimilation. Centrbl. Bakt. II, 41: 52-60. 1914. 
posed, the fixation of nitrogen was even greater. By increasing the amount of stable manure added up to three per cent, there was $^{90}$ a great increase in nitrogen-fixation. The stimulating effect is probably caused by the increase in available energy, due to the introduction of straw and its derivatives, and by the colloidal content of the material. A further increase in organic content may bring about a depression unless the soil is well aerated and contains sufficient $\mathrm{CaCO}_{3}$. The various plant residues, such as roots, leaves and stems will react similarly. Manure is also a carrier of various nitrogen-fixing organisms..$^{91}$

The possible favorable influence of growth-promoting substances (vitamins, auximones) upon Azotobacter is still a subject of discussion..$^{92}$

The beneficial action of humus is frequently ascribed to its inorganic constituents, particularly aluminum and silicic acid. This is confirmed by the fact that the so-called artificial humus has no such effect, while the source of the natural humus influences the degree of its beneficial action. The claim that the action of the humus is due to its inorganic constituents has been further substantiated by the fact that purified humates do not possess the stimulating effect. ${ }^{93}$ The rôle of the colloid is probably chiefly due to its catalytic action and its protective action against poisons; ${ }^{94}$ the protective action of the colloid has also been ascribed to the distribution of the phosphorus and to the buffering effect upon the reaction of the medium.

${ }^{90}$ Hanzawa, 1913 (p. 575).

91 Tottingham, W. E. The increase of nitrogen in fermenting manures. Jour. Biol. Chem., 24: 221-225. 1916; Fulmer, H. L., and Fred, E. B. Nitrogenassimilating organisms in manure. Jour. Bact., 2: 422-434. 1917.

92 Bottomley, W. B. Some accessory factors in plant growth and nutrition. Proc. Roy. Soc. B., 82:627. 1910; 85: 466. 1912; 88: 237-247. 1914; 89: 102 . 1915; The significance of certain food substances for plant growth. Ann. Bot., 28: 531-540. 1914 ; Mockeridge, F. A. Some effects of organic growth promoting substances (auximones) on the soil organisms concerned in the nitrogen cycle. Proc. Roy. Soc. B., 89: 508-533. 1915; Biochem. Jour., 19: 272-283. 1915; Allen, E. R. Some conditions affecting the growth and activities of Azotobacter chroococcum. Ann. Mo. Bot. Gard., 6: 1-44. 1919; Itano, A. Physiological study of $A$ zotobacter chroococcum. I. Influence of vitamine B (?) and nucleic acid on Azotobacter. Jour. Bact., 8: 483-486. 1923; Hunter, O. W. Production of a growth promoting substance by Azotobacter. Jour. Agr. Res., 23: 825830. 1923.

${ }_{93}$ Kaserer, H. Über die biologische Reizwirkung natïrlicher Humusstoffe. Centrbl. Bakt. II, 31: 577-578. 1912.

${ }_{94}$ Voicu, J. Influence de l'humus sur la sensibilité de l'Azotobacter chroococcum vis-à-vis du bore. Compt. Rend. Acad. Sci., 175: 317-319. 1922. 
According to Voicu, ${ }^{94}$ organic matter will influence the sensitiveness of Azotobacter to poisons such as boron. Urea, glycocoll, formamide and allantoin depress nitrogen-fixation; this was attributed, ${ }^{95}$ not to a direct toxicity but to the fact that those substances furnish an available nitrogen source. Among the substances acting injuriously upon nitrogen-fixing organisms, we find caffeine, alloxan, betaine, trimethyl-amine, legumin, cinnamic acid, aspartic acid, hippuric acid, creatine, creatinine, xanthine and hypoxanthine. The first two have a stimulating effect in dilute solutions.

Infiuence of reaction upon the growth of non-symbiotic nitrogen-fixing bacteria. Lime exerts such a favorable influence upon the activities of Azotobacter in the soil that Christensen ${ }^{96}$ suggested using the presence of this organism as an index of the lime requirement of the soil. When the reaction of the soil is more acid than $\mathrm{pH} 5.7$, Azotobacter is absent and the soil needs lime; when the $\mathrm{pH}$ of the soil is above 7.4, the soil does not need any lime. But when the pH of the soil is between 5.8 and 7.3 , an Azotobacter test is made. A definite weight of soil ( 5 or 10 grams) is added to a definite amount of mannite solution free from calcium carbonate $(50$ or $100 \mathrm{cc}$.); the flasks are sterilized, inoculated with a fresh culture of Azotobacter and incubated. 'The greater the lime or buffer content of the particular soil, the more abundant will be the growth of Azotobacter. The amount of pellicle development is an index of the buffer action of the soil and can yield information on its lime requirements. Out of 100 soils used, the Azotobacter test for the lime requirement of soils agreed in 90 per cent of the cases with the known soil condition, while the ammonium chloride and litmus tests agreed only in 50 and 40 per cent of cases respectively. The amount of $\mathrm{CaCO}_{3}$ which should be added to the soil, to obtain maximum nitrogen fixation, varies with the soil. This is due to differences in the buffer content of soils, in addition to differences of the initial reaction. Soils of a different buffer content, even of the same initial reaction, will require different quantities

${ }_{95}$ Reed, H. S., and Williams, B. The effect of some organic soil constituents upon nitrogen-fixation by Azotobacter. Va. Agr. Exp. Sta. Tech. Bul., 4: 81-95. 1915; Walton, J. H. Azotobacter and nitrogen-fixation in Indian soil. Mem. Dept. Agr. India. Bact. Ser., 1: 97-112. 1915.

${ }^{96}$ Christensen, 1907 (p. 576); 1915 (p. 578); Experiments in methods for determining the reaction of soils. Soil Sci., 11: 115-178. 1917; Untersuchungen über einige neuere Methoden zur Bestimmung der Reaktion und des Kalkbedürfnisses des Erdbodens. Intern. Mitt. Bodenk., 13: 111-146. 1923; Christensen, H. R., and Larsen, O. II. Untersuchungen über Methoden zur Bestimmung des Kalkbedürfnisses des Bodens. Centrbl. Bakt. II, 29: 347-380. 1911. 
of lime to bring them to the same optimum reaction. Azotobacter is capable of existing in many soils which contain none or only mere traces of $\mathrm{CaCO}_{3}$ and also in some soils reacting acid by the ordinary test. ${ }^{97}$ A reaction equivalent to about $\mathrm{pH} 6.0$ is found to be, in most cases, the limiting acid reaction for Azotobacter. The optimum reaction for nitrogen fixation by Azotobacter in pure culture seems to be closely associated with the optimum reaction for growth. Different strains of Azotobacter may vary in their sensitiveness to the limiting acid reactions, the minimum for growth having been reported to be in some cases pH 6.6 to 6.8. ${ }^{98}$ The optimum reaction for the development of Azotobacter is $\mathrm{pH}$ 7.0 to 7.8 , while the limiting alkaline reaction was reported to be $\mathrm{pH}$ 8.8. ${ }^{99}$ Different species of Azotobacter may vary, however, also in their behavior to the optimum reaction. ${ }^{100}$

\begin{tabular}{|c|c|c|}
\hline AZOTOBACTER BPECIES & оРтIMUM $\mathrm{pH}$ & Limiting $\mathrm{pH}$ \\
\hline 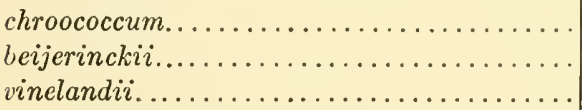 & $\begin{array}{l}7.45-7.60 \\
6.65-6.75 \\
7.50-7.70\end{array}$ & $\begin{array}{l}5.80 \\
5.80 \\
5.90\end{array}$ \\
\hline
\end{tabular}

The fixation of nitrogen in soils of a greater acidity than the limiting reaction for Azotobacter ( $\mathrm{pH}$ less than 6.0) is due to the activities of Bac. amylobacter ( $\mathrm{Cl}$. pastorianum), which has its optimum at $\mathrm{pH} 6.9$ to 7.3, but can still grow at an acidity greater than $\mathrm{pH} 5.7 .{ }^{101}$ As a matter of fact growth of this organism can be obtained at $\mathrm{pH}$ 5.0. Other nitrogen-fixing forms, like Bact. aerogenes and Radiobacter, can also grow at a higher acidity than Azotobacter. The nitrogen fixed under these conditions is much less than that fixed in soils supporting an Azotobacter flora. Figures 41 and 42 show the correlation between the hydrogen-ion concentration and nitrogen fixation by Azotobacter. ${ }^{102}$

Calcium carbonate stimulates nitrogen fixation and is never toxic to

${ }_{97}$ Gainey, P. L. Soil reaction and the growth of Azotobacter. Science, N. S., 48: 139-140. 1922; Jour. Agr. Res., 14: 265-271. 1918.

${ }^{98}$ Fred, E. B., and Davenport, A. Influence of reaction on nitrogen-assimilating bacteria. Jour. Agr. Res., 14: 317-336. 1918.

${ }_{99}$ Johnson, H. W., and Lipman, C. B. The effect of reaction on the fixation of nitrogen by Azotobacter. Univ. Cal. Publ. Agr. Sci., 4: 397-405. 1922.

100 Yamagato and Itano, 1923 (p. 117).

101 Dorner, 1924 (p. 165).

${ }_{102}$ Gainey, P. L., and Batchelor, H. W. The influence of hydrogen-ion concentration on the growth and fixation of nitrogen by cultures of Azotobacter. Jour. Agr. Res., 24: 759-768. 1923. 
Az. chroococcum at a concentration of 2 per cent in mannite solution. ${ }^{103}$ Magnesium carbonate is very toxic above 0.1 to 0.2 per cent. Calcium exerts a protective influence against the injurious effect of magnesium.

Influence of moisture and temperalure upon nitrogen-fixation. Nitrogen-fixing bacteria are able to resist drying for a long period of time, depending upon the nature of the medium. The soil contains substances which exert a protective influence upon bacteria subjected to desiccation; the bacteria will resist desiccation longer in a rich clay soil than in sand, probably because of the colloidal content of the clay. ${ }^{104}$

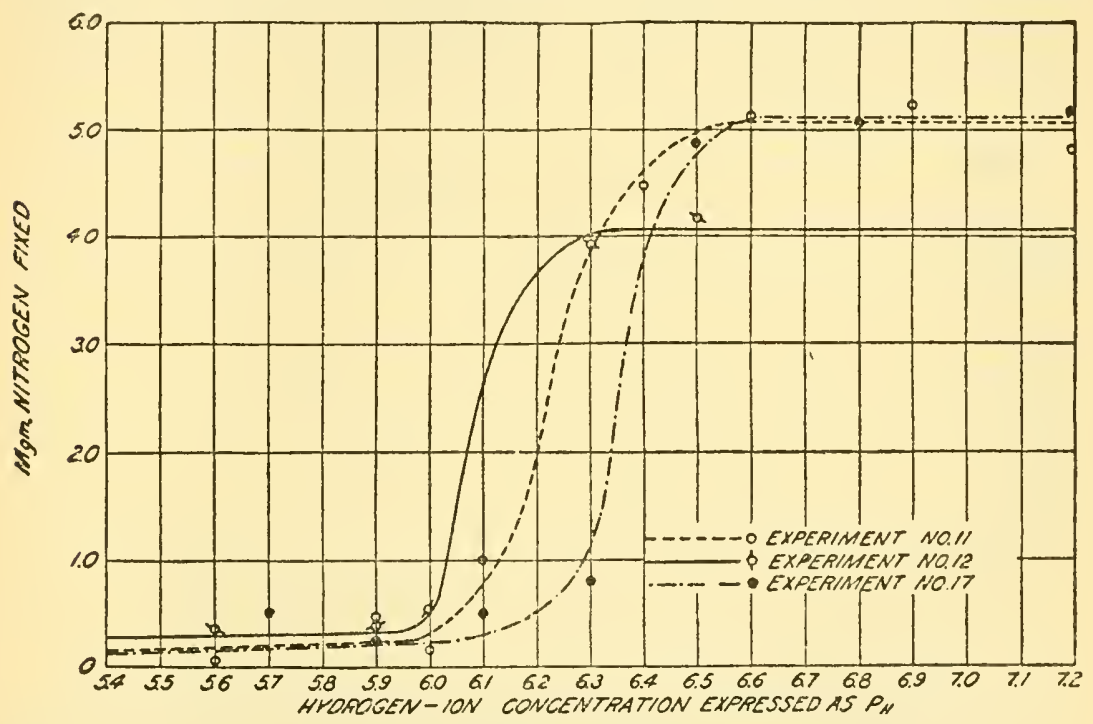

FIG. 41. Influence of reaction of medium upon nitrogen-fixation by Azotobacter (from Gainey and Batchelor).

Soils air-dried for five to twenty years and kept in stoppered museum bottles were found to contain ${ }^{105}$ viable nitrogen-fixing bacteria. Nitrogen-fixation takes place in the soil when its moisture content is only 2

${ }^{103}$ Lipman, C. B., and Burgess, P. S. The protective action against magnesium carbonate of calcium carbonate for Azotobacter chroococcum. Jour. Agr. Sci., 6: 484-494. 1914; Gainey, P. L. On the use of calcium carbonate in nitrogen fixation experiments. Jour. Agr. Res., 24: 185-190. 1923.

${ }^{104}$ Giltner, W., and Langworth, H. V. Some factors influencing the longevity of soil microorganisms subjected to desiccation with special reference to soil solution. Jour. Agr. Res., 5: 927-942. 1916.

${ }^{105}$ Lipman, C. B., and Burgess, P. S. Studies on nitrogen-fixation and Azotobacter forms in soils of foreign countries. Centrbl. Bakt. II, 44: 481-511. 1915. 
to 15 per cent. ${ }^{106}$ Soil with a higher content of organic matter will have higher moisture optima. An excess of water may stop the action of Azotobacter but may stimulate the action of the anaerobic bacteria.

Using a loam soil with a maximum moisture holding capacity of 27.4 per cent, Traaen ${ }^{107}$ observed a fixation of $1.9 \mathrm{mgm}$. of nitrogen in 100 grams of soil with 5 to 10 per cent moisture, $13.2 \mathrm{mgm}$. with 17.5 per cent moisture, $16.6 \mathrm{mgm}$. with 25 per cent moisture, and $15.5 \mathrm{mgm}$. with 30 per cent moisture. At a temperature of $13^{\circ} \mathrm{C}$., the amounts of nitrogen fixed were less, with a similar maximum. With the higher moisture contents, the anaerobic organisms play an important part in the fixation of nitrogen. Two maxima for nitrogen-fixation in relation

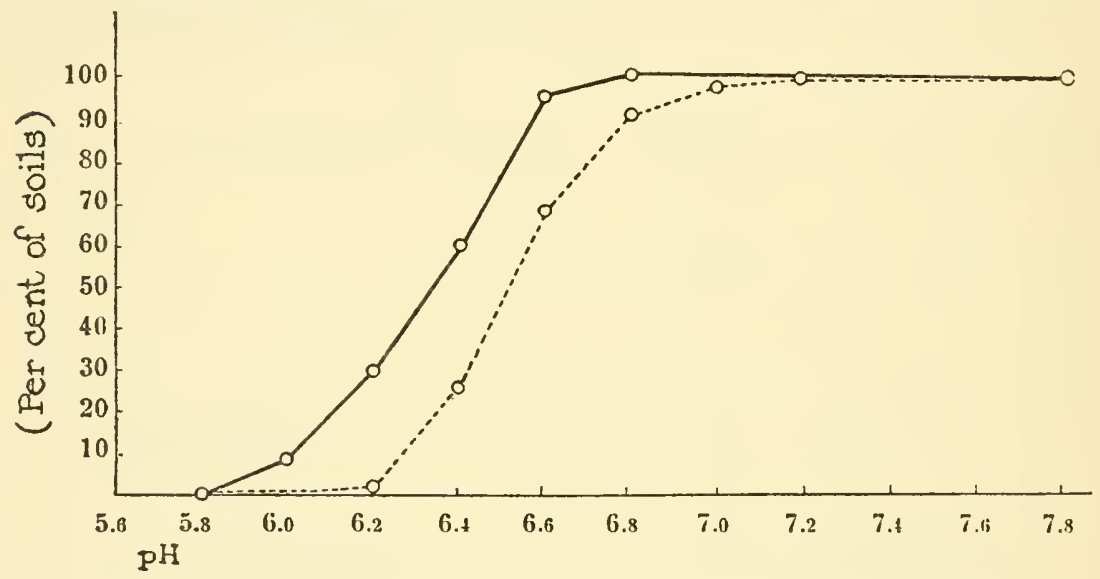

FIG. 42. A correlation between soil reaction and the presence of Azotobacter: - positive test; ------- abundant growth of Azotobacter (from Christensen).

to the water content of the soil are frequently recorded, depending on whether the conditions are favorable to the action of aerobic or anaerobie bacteria. ${ }^{108}$

The optimum temperature for the activities of nitrogen-fixing bacteria

${ }^{106}$ Krainsky, 1908 (p. 566).

${ }_{107}$ Traaen, A. E. Über den Einflusz der Feuchtigkeit auf die Stickstoffunsetzungen im Erdboden. Centrbl. Bakt. II, 45: 119-135. 1916.

${ }^{108}$ Lipman, C. B., and Sharp, L. T. Effect of moisture content of a sandy soil on its nitrogen-fixing powers. Bot. Gaz., 59: 402-406. 1915; Greaves, J. E., and Carter, E. G. Influence of barnyard manure and water upon the bacterial activities of the soil. Jour. Agr. Res., 6: 889-926. 1916; also 9: 293-341. 1917. 
lies at $28^{\circ} \mathrm{C} .\left(25^{\circ}\right.$ to $\left.30^{\circ}\right)$, with limits between $9^{\circ}$ and $33^{\circ} \mathrm{C} .{ }^{109} \quad \mathrm{Koch}^{110}$ obtained fixation of 3,11 , and $15.5 \mathrm{mgm}$. of nitrogen in 100 grams of soil at $7^{\circ}, 15,^{\circ}$ and $24^{\circ}$ respectively. The maximum temperature for Azotobacter is ${ }^{111} 55^{\circ}$ to $60^{\circ}$ and the minimum near zero. The organism can withstand heating at $45^{\circ}$ to $50^{\circ} \mathrm{C}$. for 15 minutes, but is destroyed in 30 minutes. The optimum temperature for the growth of $\mathrm{Cl}$. pastorianum is $20^{\circ}$ to $25^{\circ}$, according to Winogradsky, and $28^{\circ}$ to $30^{\circ}$, according to Bredemann. ${ }^{112}$ At $30^{\circ}$ to $35^{\circ}$, the action of the organismis retarded..$^{11^{\circ}}$ The organism can withstand a temperature of $75^{\circ}$ for even 5 hours or more; the spores can be preserved in a dry state for 20 years without losing their power of germination and nitrogen fixation.

Soil cultivation and nitrogen-fixation. It has been generally observed ${ }^{114}$ that fallowing leads to an increase in nitrogen-fixation, probably due to better aeration and moisture conditions. According to Hiltner, ${ }^{115}$ non-symbiotic nitrogen-fixation is stimulated by growing plant roots; the higher plants use up the available nitrogen in the soil and thus create a nitrogen-hunger for the non-symbiotic nitrogen-fixing bacteria. The plants supply the bacteria with available energy, in the form of rotting roots hairs, root tips, etc. Plant roots may also create a better physical environment for the nitrogen fixing organisms. In view of the fact that different cultural methods are used for the growth of different crops, the influence of the crops upon nitrogen-fixation will vary. A much higher nitrogen-fixing power was found ${ }^{116}$ in cultivated than in virgin soils; the fallowed soils show more nitrogen fixed than the cropped soils. Importance of non-symbiotic nitrogen-fixation in the soil. It should

${ }^{109}$ Krrzemieniewski, 1908 (p. 579); Löhnis and Westermann, 1908 (p. 115).

${ }^{110}$ Kioch, A. Ernährung der Pflanzen durch frei im Boden lebende stickstoffsammelnde Bakterien. Ber. deut. landw. Gesell., 22: 117-121. 1907.

111 Jones, 1913 (p. 114).

112 Bredemann, 1909 (p. 111).

${ }^{113}$ Omeliansky, W. L. Sur la physiologie et la biologie des bactéries fixant l'azote. Arch. Sci. Biol. Petrograd, 19: 209-228. 1915.

${ }^{114}$ Heinze, B. Über die Stickstoffassimilation durch niedere Organismen Landw. Jahrb., 35: 889-910 1906.

${ }_{115}$ Hiltner, L. Ueber neuere Erfahrungen und Probleme auf dem Gebiete der Bodenbakteriologie und unter besonderer Berücksichtigung der Gründüngung und Brache. Arb. deut. landw. Ges. H. 98: 59-78. 1904 (Centrbl. Bakt. II, 14: 46-48. 1904).

${ }_{116}$ Greaves, J. E. A study of the bacterial activities of virgin and cultivated soils. Centrbl. Bakt. II, 41: 444-459. 1914; Reed, H. S., and Williams, B. Nitrogen-fixation and nitrification in various soil types. Va. Agr. Exp. Sta. Tech. Bul., 3: 59-80. 1915. 
not be assumed that the addition of available carbohydrates to various soils is always sufficient to induce non-symbiotic fixation of nitrogen. In the presence of available nitrogen in the soil, the addition of carbohydrates stimulates the development of various fungi and bacteria which use the added source of energy and transform the available nitrogen into microbial protein. In the presence of available nitrogen, the nonsymbiotic nitrogen-fixing bacteria will act upon the carbohydrates like the other heterotrophic bacteria, merely synthesizing proteins. Only in the absence of available nitrogen is there a probability of nitrogen fixation by non-symbiotic bacteria. But even when fixation of nitrogen takes place the process is usually a slow one in normal soils; in many cases, the actual amount of nitrogen fixed falls within the probable error for the determination of total nitrogen. There are undisputed claims in the literature that very porous soils of a moderately high water content can fix small amounts of nitrogen under sterile conditions. ${ }^{117}$ There is still more definite evidence that appreciable quantities of nitrogen can be fixed both in the laboratory and in the field by non-symbiotic bacteria, when there is sufficient available energy. ${ }^{118}$ Remy found that considerable nitrogen fixation takes place as long as provision is made for the neutralization of the acids formed and a proper source of energy is present. The nitrogen fixed by the bacteria becomes a proper source of nitrogen for higher plants; it becomes available slowly, although not less so than the most active organic fertilizers. It has been suggested $^{119}$ that the great economy with which the nitrogen fixing bacteria use the organic matter in the soil is due to their symbiotic action with algae. There is no doubt that the nitrogen content of sand or soil may be appreciably increased by the activity of Azotobacter, if sufficient energy is supplied.119 About $6 \mathrm{mgm}$. of nitrogen were fixed per 1 gram of plant residue, under laboratory experiments, and up to $9 \mathrm{mgm}$. in pot

117 Warmbold, H. Untersuchungen über die Biologie stickstoffbindender Bakterien. Landw. Jahrb., 35: 1-123. 1906. Centrbl. Bakt. II, 20: 121-126. 1907.

${ }_{118}$ Koch, A., Litzendorff, J., Krull, F., and Alves, A. Die Stickstoffanreichung des Bodens durch freilebende Bakterien und ihre Bedeutung für die Pflanzenernährung. Jour. Landw., 55: 355-416. 1907; 57: 269-286. 1909; Remy, Th. Untersuchungen über die Stickstoffsammlungsvorgänge in ihrer Beziehung zum Bodenklima. Centrbl. Bakt. II, 22: 561-651. 1909; Löhnis, F. Centrbl. Bakt., 15: 361. 1905; Schneidewind. Ibid., 21: 437. 1908; H. Fischer. Ibid., 22: 654.1909 .

${ }^{119}$ Krainsky, $\Lambda$. Über die Stickstoffanreicherung des Bodens. Centrbl. Bakt. II, 26: 231-235. 1910. 
experiments. ${ }^{120}$ Anong the most important conditions required for non-symbiotic nitrogen fixation are: (1) a proper supply of energy material, (2) sufficient $\mathrm{CaCO}_{3}$ to neutralize soil acidity and improve the physical condition of the soil, (3) available phosphorus, (4) proper temperature, and (5) aeration of the soil. According to statements usually made in the texts and found at Rothamsted and other stations, non-symbiotic nitrogen-fixing bacteria add, under favorable conditions, 15 to 40 pounds of available nitrogen to each acre of soil yearly and

TABLE 58

Influence of sugar upon crop yield and nitrogen content of crop

\begin{tabular}{|c|c|c|c|c|c|}
\hline \multirow{2}{*}{\multicolumn{2}{|c|}{ YEAR }} & \multirow{2}{*}{ CONTROL } & \multicolumn{3}{|c|}{$\begin{array}{l}\text { GRAMS OF DRY SUBSTANCE FER POT FOR } \\
\text { 3-YEAR PERIOD }\end{array}$} \\
\hline & & & $\begin{array}{c}\text { Glucose, } \\
360 \text { grams }\end{array}$ & $\begin{array}{l}\text { Cane sugar, } \\
360 \text { grams }\end{array}$ & $\begin{array}{l}\text { Cane sugar, } \\
720 \text { grams }\end{array}$ \\
\hline & $1905-07$ & 91.3 & 111.6 & 113.2 & 157.6 \\
\hline & $1908-10$ & 51.2 & 78.5 & 77.6 & 91.8 \\
\hline & $1911-13$ & 76.1 & 79.8 & 85.6 & 89.9 \\
\hline & $1914-16$ & 63.6 & 65.9 & 68.6 & 67.4 \\
\hline & $1917-19$ & 73.0 & 80.9 & 75.6 & 69.6 \\
\hline & $1920-22$ & 65.3 & 64.0 & 72.6 & 66.3 \\
\hline \multirow{2}{*}{\multicolumn{2}{|c|}{$\begin{array}{l}\text { Total . . . . . . . . . } \\
\text { Excess over control. }\end{array}$}} & 420.5 & 480.7 & 492.2 & 542.6 \\
\hline & & $\ldots$ & 60.2 & 72.7 & 122.1 \\
\hline & & & \multicolumn{3}{|c|}{ MILLIGRAMS OF NITROGEN IN CROP } \\
\hline & $1905-07$ & 765 & 984 & 982 & 1476 \\
\hline & $1908-10$ & 519 & 785 & 808 & 883 \\
\hline & $1911-13$ & 616 & 634 & 670 & 739 \\
\hline & $1914-16$ & 463 & 613 & 540 & 548 \\
\hline \multirow{2}{*}{\multicolumn{2}{|c|}{$\begin{array}{l}\text { Total . . . . . . . . . . . . . . } \\
\text { Excess over control...... }\end{array}$}} & 2363 & 2916 & 3000 & 3640 \\
\hline & & $\ldots$ & 553 & 637 & 1283 \\
\hline
\end{tabular}

usually not more than 10 pounds. In view of the fact that the energy added to the soil is not direetly available to the nitrogen-fixing bacteria, that small amounts of available nitrogen are always present in the soil and that the error in the laboratory determination of total nitrogen by the Kjeldahl method is greater than the possible amount of nitrogen fixed by non-symbiotic bacteria, we are still unable to decide the ques-

${ }^{120}$ Hutchinson, H. B. The influence of plant residues on nitrogen-fixation and on losses of nitrate in the soil. Jour. Agr. Sci., 9: 92-111. 1918. 
tion definitely. Until our methods are more aceurate, the question cannot be answered in a positive way. It has been stated ${ }^{121}$ that the apparent gain of nitrogen in the soil is often due to drifting dust and plant residues or to soil variability.

Certainly the field results of $\mathrm{A}$. Koch ${ }^{122}$ do not speak for any nitrogen fixation in the soil, following the addition of celluloses and even straw. Positive fixation was obtained only when soluble sugars were added, as seen from table 58.

By determining the amount of nitrogen fixed in the soil per gram of sugar added, it was found that although 720 grams of cane sugar had been added per pot of soil and $9.75 \mathrm{mgm}$. of nitrogen has been fixed per gram of sugar added, the plants utilized only $1.78 \mathrm{mgm}$. of nitrogen per gram of sugar added. The larger part remained in the soil in a eomplex

TABLE 59

Influence of cellulose upon crop yield

\begin{tabular}{|c|c|c|c|c|}
\hline \multirow{2}{*}{ YEARS } & \multirow{2}{*}{ CONTROL } & \multicolumn{3}{|c|}{ GRAMS OF DRY SUBSTANCES PER POT FOR 3-YEAR PERIOD } \\
\hline & & 120 grams paper & $\begin{array}{c}120 \text { grams paper } \\
+ \text { manure infusion }\end{array}$ & $\begin{array}{l}\text { Manure infusion } \\
\text { alone }\end{array}$ \\
\hline $1911-13$ & 68.3 & 12.8 & 17.9 & 67.0 \\
\hline $1914-16$ & 60.0 & 81.7 & 87.3 & 62.8 \\
\hline $1917-19$ & 66.0 & 77.4 & 82.8 & 69.9 \\
\hline $1920-21$ & 65.2 & 71.1 & 72.8 & 67.0 \\
\hline Total ....... & 259.5 & 243.0 & 260.8 & 266.7 \\
\hline
\end{tabular}

form not readily utilized. The addition of cellulose exerted a decided injurious effect upon erop yield due to eompetition for the available nitrogen between the microorganisms and the plants. The following years the nitrogen is made available again; however, one cannot speak here of any nitrogen fixation. Similar results were obtained with straw.

\section{SYMBIOTIC NITROGEN FIXATION}

Relation between the bacteria and the host plant. "Virulence" in conneetion with nodule bacteria has been defined as the ability of the organism to penetrate into the root tissues of the host plant, to multiply there,

${ }^{121}$ Hopkins, C. Soil fertility and permanent agriculture. Gin \& Co., New York. 1910.

${ }_{122}$ Rippel, A. Versuche aus dem Nachlasz von Alfred Koch. Jour. Landw., 72: 17-52. 1924. 
and to cause a certain benefit or injury. Various attempts have been made to study this physiological property by vegetation experiments. It was found ${ }^{123}$ that the activities (including the ability of fixing nitrogen) of the bacteria that have already penetrated into the plants increase with an increase in the amount of nitrogen available to the plants. Hiltner ${ }^{124}$ observed an increased growth of leguminous plants (peas) when grown continuously upon the same soil; he ascribed this not only to an increase in the number of bacteria causing inoculation, but also to an increase in the virulence of the bacteria, similar to an increase in virulence of a pathogenic organism when passed through several animals. Assuming that the nodule bacteria increase in virulence by repeated symbiosis with plants, Hiltner planted peas repeatedly on the same soil, which was sufficiently provided with minerals; he found an increase in the infection by the organism from the first to the fourth generation, a period without change then followed, and finally the continued growth of peas gradually led to a diminution in plant growth.

On the basis of these results Hiltner proposed the "immunity" theory, according to which substances are formed by the bacteria within the nodules which immunize the plant against further invasion of bacteria. The organism (1) may not get into the plant, (2) it may gain admission, but without producing nodules because of the greater resistance of the plant, (3) it may enter the plant and produce nodules but without fixing any nitrogen, (4) it may fix nitrogen which is assimilated by the plant, (5) the bacterium may become more efficient than the plant, which is then injured, or (6) the bacterium itself may even be killed. According to the "immunity" theory, active nodules impart to the plant an immunity against bacteria of lower or equal virulence than those already found in the plant; only bacteria of higher virulence are capable of penetrating into the plant. The above theory was not confirmed by subsequent investigations. Nodules were found to be transient on biennial and perennial legumes, depending somewhat on the climatic conditions; i.e., there are two crops of nodules in biennial legumes, one each year, while there are many crops on perennial legumes such as alfalfa. When a fresh culture is added to a leguminous plant growing on agar and having already formed nodules, more nodules are formed on the new roots that have grown since the first inoculation. Under

${ }^{123}$ Remy, Th. Ueber die Steigerung des Stiekstoffsammlungs-Vermögens der Hülsenfrüchte durch bakterielle Hilfsmittel. Deut. landw. Presse, 29: 31-32, 37-38, 46-47. 1902.

${ }^{124}$ Hiltner, 1904 (p. 128). 
these conditions, one cannot speak of plant immunity against further invasion by bacteria. ${ }^{125}$

The "equilibrium" theory proposed by Süchting, 126 as an explanation for the mutual relationship between the leguminous plant and noduleforming bacteria, is more plausible and has many facts to support it. A state of equilibrium was considered to exist between the attacking power of the bacteria and resisting power of the plant, due perhaps to the fact that the bacteria produce a toxin and the plants an antitoxin. The degree of equilibrium determines the extent of nodule formation, the plant becoming immunized by an antibody and not by a substance produced by the bacteria and the nitrogen supply being regulated by the production of the antibody. When the leguminous plants are grown in soil containing plenty of nitrates, their resisting power to the infection of the bacteria is greater than when grown on nitrogen free media. The bacteria may vary in virulence, depending on the media in which they are grown. Increasing virulence was also found to be directly correlated with a shortening of the vegetation period of the plant.

The nitrogen is fixed by the bacteria present within the nodules and is made available for the growth of the host plants by the autolysis of these nodules, or through the production of a bacteriophage by the plant, or perhaps as a result of the action of enzymes produced by the plant. The plant obtains its carbon from the $\mathrm{CO}_{2}$ of the atmosphere by photosynthetic processes; a part of the carbohydrates thus synthesized is transferred to the roots and used by the bacteria as a source of energy. This enables the microorganism to fix atmospheric nitrogen much more efficiently than it can ever do in artificial media, or even more efficiently than any non-symbiotic nitrogen fixing organism.

Wunschik ${ }^{127}$ based his idea of the relation between the bacterium and the host plant on the statement of Beijerinck that "when living plant cells have to derive help from another organism, an equilibrium between the growth of both must be reached." The equilibrium is in this case between the vegetative energy of the plant and of the nodule forming organism. Wunschik differentiated between the vegetative energy, or ability to penetrate into the roots of the plant, and nitrogen-fixing capacity of the organism. The vegetative energy of the bacteria results in the removal from the host plant of a part of its nutrients, thus causing

125 Whiting, A. L.: Ill. Agr. Exp. Sta., Bul. 179. 1915.

${ }^{126}$ Süchting, H. Kritische Studien über die Knöllchenbakterien. Centrbl. Bakt. II, 11: 377-388, 417-441, 496-520. 1904.

127 Wunschik, 1.925 (p. 139). 
injury; the nitrogen-fixation by the bacterium is beneficial to the plant and is, to a certain extent, correlated with the vegetative energy of the bacterium. This stimulates the growth energy of the plants. The equilibrium established is between the growth energy of the plant, which enables it to utilize the nitrogen made available by the bacterium, and the vegetative energy of the bacterium. When this stage is reached, the growth of the plant continues uninterrupted. The vegetative energy of the nodule bacteria is increased by repeated physiological adaptation to the host plant, namely by repeated passage through the host plant.

Chemistry of nitrogen-fixation by symbiotic bacteria. In the presence of an abundance of available nitrogen in the soil, the leguminous plants utilize that nitrogen and do not depend on the activities of the bacteria. $^{128}$ Alkali nitrates in concentrations of 1:10,000 and ammonium salts in 1:2,000 repress nodule formation. ${ }^{129}$ The addition of 5 mgm. nitrogen as $\mathrm{KNO}_{3}$ per liter of medium was sufficient to prevent the penetration of the bacteria into the roots of the plants in water cultures; this action was much less in sand and hardly obtained in soil. In some cases small amounts of nitrogenous substances were found to stimulate plant growth and nodule formation. ${ }^{130}$

The average amount of nitrogen fixed by a good crop of a legume, under favorable conditions, may be taken as 200 pounds per acre. If the energy need of the organisms is 100 parts of carbohydrate for every part of nitrogen fixed, as in the ease of the non-symbiotic bacteria, the symbiotic bacteria would require 20,000 pounds of carbohydrate per acre for the fixation of the favorable amount of nitrogen. This would have to be supplied by the growing plant which is hardly imaginable since it would amount to two to four times as much as the total crop itself. We must assume that the organism uses the energy supplied by the plant much more efficiently than the non-symbiotic bacteria or that the process of nitrogen-fixation by the legume bacteria is exothermic. ${ }^{131}$ In the second case, the energy liberated is so small that it would hardly be sufficient to cover the need of the bacteria for metabo-

${ }^{128}$ Wohltmann and Bergené. Die Knöllchen-Bakterien in ihrer Abhängigkeit von Boden und Düngung. Jour. Landw., 50: 377-395. 1902.

${ }^{129}$ Marchal, E. Influence des sels minéraux nutritifs sur la production des nodosités chez le pois. Compt. Rend. Acad. Sci., 133: 1032-1033. 1901.

${ }^{130}$ Hiltner, L. Über die Ursachen, welche die Grösse, Zahl, Stellung und Wirkung der Wurzelknöllchen der Leguminosen bedingen. Arb. biol. Anst, K. Ges. Amt., 11: 177-222. 1900.

${ }^{131}$ Christiansen-Weniger, 1923 (p. 570). 
lism alone. It was, therefore, suggested ${ }^{131}$ that the organism actually utilizes the energy derived from the exothermic nitrogen fixation for metabolic processes.

Of the three possible processes by which the nitrogen can be fixed, namely, $(a)$ reduction, $(b)$ oxidation and (c) direct union with organic compounds, the first is the most plausible, especially in view of the fact that a great many microorganisms assimilate the nitrogen in the form of ammonia. Whiting 132 could not demonstrate any ammonia, nitrites or nitrates within the plants; his work tends to confirm the direct organic combination theory. Some evidence was previously obtained ${ }^{133}$ on the direct union of the free nitrogen with some organic compound inside the bacterial cell; this compound was believed ${ }^{134}$ to be glycogen and carbamic acid as the first product of combination.

Once the nitrogen has been fixed in the bacterial cells, it may be transferred to the host when the bacterial cells (so-called bacteroids) are decomposed and the contents absorbed by the plants, ${ }^{135}$ or when the nitrogen has been secreted by the bacterial cells in a form which the plant then utilizes. ${ }^{136}$ This removal of the products of bacterial growth by the plant was believed to stimulate further nitrogen fixation. The composition of the nitrogenous substance of the bacterial secretions is still unknown, except that it is believed to be protein-like in nature.

The formation of a bacteriophage in the nodules of the leguminous plants has been established. ${ }^{137}$ This bacteriophage dissolves the bacteria and thus makes their contents available to the plant. It was found not only in the nodules but also in the roots and stems of the plants, and not in the leaves, also in garden and field soils, but not in prairie soils. The bacteriophage is specific in its lytic action and attacks only those bacteria which form the nodules in the roots of the specific plants. The bacteriophage can resist, according to species, a temperature of $60^{\circ}$

${ }^{132}$ Whiting, A. L., and Schoonover, W. R. Nitrogen fixation by cowpeas and nodule bacteria. Soil Sci., 10: 411-420. 1920.

${ }^{133}$ Gerlach and Vogel, 1903 (p. 379).

${ }^{134}$ Heinze, B. Ưber die Stickstoffassimilation durch niedere Organismen. Landw. Jahrb., 35: S89-910. 1906.

135 Nobbe and Hiltner, 1900 (p. 127).

${ }^{136}$ Golding, J. The importance of the removal of the products of growth in the assimilation of nitrogen by the organisms of the root nodules of leguminous plants. Jour. Agr. Sci., 1: 59-64. 1905.

${ }^{137}$ Gerretsen, F. C., Gryns, A., Sack, J., and Söhngen, N. L. Das Vorkommen eines Bakteriophagen in den Wurzelknöllchen der Leguminosen. Centrbl. Bakt. II, 60: 311-316. 1923. 
to $65^{\circ} \mathrm{C}$., for fifteen minutes. It withstands drying and passes through a thin collodium membrane; it also resists ultra-violet light eight times as much as the corresponding bacteria. To obtain the bacteriophage, fresh nodules, previously sterilized on the surface, are ground up and are placed in a nutrient medium. After 5 days, the turbid solution is filtered through a Chamberland filter and a few cubic centimeters of the clear filtrate is added to a fresh medium previously inoculated with a corresponding pure culture of the nodule organism. This is repeated after 10 days, diminishing every time the amount of liquid used for infection. This results in an accumulation of the bacteriophage in the culture, and if a few cubic centimeters of such a culture are added to a culture of Bact. radicicola, the turbid culture of the latter will become transparent due to the dissolution of the bacteria. When some of the bacteriophage is placed upon an agar slant and a culture of the nodule organism is then inoculated, the latter will grow only where the bacteriophage was absent.

It is also possible that the plant produces bacteriolytic enzymes, which hydrolize the bacterial cell liberating the available nitrogen. The bacterium itself seems to produce a cellulose-dissolving enzyme, by means of which it enters the root hairs of the host plant, dissolving the cell wall;138 however, this still needs confirmation. The presence of oxidase in the slime of various nodule bacteria has also been demonstrated. ${ }^{139}$

Production of gum by the nodule bacteria. In artificial cultures, Bact. radicicola produces a gum which goes partly into solution and is partly held by the zoogleal masses of the organism. This gum is precipitated by alcohol, acetone, concentrated solutions of ammonium sulfate, magnesium sulfate or ammoniacal lead acetate. It does not reduce Fehling's solution, but, on heating with a dilute solution of sulfuric acid ( 2 per cent) at $120^{\circ} \mathrm{C}$. for one hour, reducing sugars are formed, indicating that it is of a hemicellulose nature. It contains no protein or other forms of nitrogen. The gum is formed with various sources of energy in the medium, such as cane sugar, glycerol, or legume extract, ${ }^{140}$ and

${ }^{138}$ Hiltner, L. Über die Bakteroiden der Leguminoseknöllchen und ihre willkürliche Erzeugung ausserhalb der Wirtspflanzen. Centrbl. Bakt. II, 6: 273-281. 1900.

${ }^{139}$ Fred, E. B. A physiological study of the legume bacteria. Va. Agr. Exp. Sta. Ann. Rpt. 1911-1912, 145-173.

${ }^{140}$ Buchanan, R. E. The gum produced by Bacillus radicicola. Centrbl. Bakt. II, 22: 371-396. 1909; Greig-Smith, R. The slime or gum of Rhizobium leguminosarum. Centrbl. Bakt. II, 30: 552-556. 1911; Fred, 1911-12. 
should be considered as a synthesized product. The bacteria of the monotrichcus type do not produce as much gum as those of the peritrichous type. ${ }^{141}$ Different strains of the same organism vary greatly in the amount of gum formed. ${ }^{142}$ A further study of the nature of this substance and its rôle in the fixation of nitrogen is desirable.

Influence of reaction on the growth of Bact. radicicola and nodule formation. Symbiotic nitrogen-fixing bacteria have limiting reactions which are not so sharply defined, however, as in the case of Azotobacter and Clostridium. Mazé ${ }^{143}$ was the first to call attention to the fact that there are acid resistant and acid sensitive types of nodule baeteria. A sharp line of demarcation was obtained between the reaction permitting growth and the one entirely preventing it. ${ }^{144}$ The nodule bacteria were divided, according to their sensitiveness towards acidity, into five groups:
1. Alfalfa and sweet clover................ limg $p$
2. Garden pea, field pea and vetch.................... 4.7
3. Red clover and common beans....................... 4.2
4. Soybeans and velvet beans......................... 3.3
5. Lupines.................................... 3.15

Of the nodule bacteria, the alfalfa organism is most sensitive to aciclity and the lupine organism the most resistant to acidity. It was suggested that a correlation exists between the aeid resistance of bacteria and acid resistance of higher plants. The eritical reaction values for nodule formation are $\mathrm{pH} 4.0$ and 9.0 to 10.0 , with an optimum at about $\mathrm{pH} 7.0$; this optimum may be higher or lower depending on the legume. Different biological types of alfalfa and soybean organisms may vary in their limiting reactions. ${ }^{145}$ In the case of the soybean organism one strain was found to have its acid limit at $\mathrm{pH} 4.0$ to 4.5 and the other at 4.5 to 5.0. The optimum was found to be at pH 4.8 to 6.5 , depending also on strains; the alkali limit was not so sharp.

Germination of alfalfa seed in the soil is practically the same at reactions ranging from $\mathrm{pH} 4.5$ to 7.0 ; it is greatly reduced, however, at $\mathrm{pH}$

${ }^{141}$ Burrill and Hansen, 1917 (p. 126).

142 Wright, 1925 (p. 127).

${ }^{143}$ Mazé, M. Les microbes des nodosités des légumineuses. Ann. Inst. Past., 13: $145-185.1899$.

${ }^{144}$ Fred and Davenport, 1918 (p. 582).

${ }^{145}$ Stevens, 1925 (p. 135); Wright, 1925 (p. 127). 
less than 4.5.146 Alfalfa yields were found to show an increase with an increase in the $\mathrm{pH}$ value of the soil from 3.8 to 7.0. The plants experience difficulty in becoming established in soil with low $\mathrm{pH}$ values, but, after becoming established, they make an excellent growth at as low a $\mathrm{pH}$ as 3.8. With increasing hydrogen-ion concentrations (decrease of $\mathrm{pH}$ ), nodule formation is decreased. According to Bryan, ${ }^{147}$ alfalfa organisms do not survive a greater acidity than $\mathrm{pH} 5.0$, red clover organisms $\mathrm{pH} 4.5$ to 4.7 and soybean organisms $\mathrm{pH} 3.5$ to 3.9. The optimum growth for all strains of the alfalfa organism was found to be at $\mathrm{pH} 7.0$, with a limiting acid reaction at $\mathrm{pH}$ 5.5. ${ }^{145}$

Nodule formation and nitrogen fixation. When leguminous plants are grown on soil properly limed, containing the necessary amount of minerals, and inoculated with the proper organism, considerable nitrogen is found in the plant. Most of this nitrogen comes from the atmosphere. The presence of nitrates in the soil will retard and may even prevent, if present in sufficient quantities, nodule formation by the plant. ${ }^{148}$ The injurious influence of nitrate upon nodule formation is due largely to the fact that it offers a source of available nitrogen to the plant; it may also have a specific action upon the plant juice. But other nitrogen compounds, such as ammonium salts or ammonia-producing substances, may also reduce or even inhibit nodule formation. ${ }^{149}$ This is probably due to the direct assimilation of the combined nitrogen by the plants rather than to any inhibition of bacteria from penetrating into the roots. Carbonaceous substances, such as carbohydrates, certain organic acids and alkaloids stimulate nodule production in the soil. However, appreciable amounts of nitrogen will be fixed even in the presence of considerable quantities of available nitrogen, including nitrates, in the soil..$^{150}$

The mechanism of nitrogen fixation by the plant was a subject of early

${ }^{146}$ Joffe, J. S. The influence of soil reaction on the growth of alfalfa. Soil Sci., 10: 301-307. 1920.

147 Bryan, O. C. Effect of acid soils on nodule forming bacteria. Soil Sci., 15: $37-40.1923$.

148 Strowd, W. H. H. The relation of nitrates to nodule production. Soil Sci., 10: 343-356. 1920.

149 Wilson, J. K. Physiological studies of Bacillus radicicola of soybean (Soja $\max$ Piper) and of factors influencing nodule production. N. Y. (Cornell) Agr. Exp. Sta. Res. Bul. 386. 1917.

${ }_{150}$ Albrecht, W. A. Symbiotic nitrogen fixation as influenced by the nitrogen in the soil. Soil Sci., 9: 275-319. 1920. 
controversy. It was shown conclusively ${ }^{151}$ that leguminous plants (cowpea and soybean) fix atmospheric nitrogen through their roots and not through their leaves, as it had been assumed in some cases. In the earlier part of the growth of the plant, the roots contain the larger part of the nitrogen while, at the time of harvest, 74 per cent of the nitrogen of cowpeas and soybeans was found in the tops. The fixation of the nitrogen takes place in the early stages of growth of the seedling, sometimes within fourteen days.

A study of the composition of leguminous plants ${ }^{152}$ established the presence of various amino acicls and amides. Inoculation was found to increase the protein content of the plant, often without even increasing the crop yield.

TABIE 60

Influence of inoculation and fertilization upon yield, alkaloid and nitrogen contcne of Lupinus angustifolius

\begin{tabular}{|c|c|c|c|c|c|}
\hline \multirow{2}{*}{ TREATMENT } & \multicolumn{3}{|c|}{ YIELD OF GRAIN } & \multicolumn{2}{|c|}{ YIELD OF STRAW } \\
\hline & Weight & $\begin{array}{l}\text { Alkaloid } \\
\text { content }\end{array}$ & $\begin{array}{c}\text { Nitrogen } \\
\text { content }\end{array}$ & Weight & $\begin{array}{l}\text { Nitrogen } \\
\text { content }\end{array}$ \\
\hline Sterile, uninoculated . . . . . . . . . & 100 & 100 & 100 & 100 & 100 \\
\hline Sterile, inoculated (average of two & & & & & \\
\hline good preparations) $\ldots \ldots \ldots \ldots$ & 244 & 1648 & 554 & 119 & 266 \\
\hline Sterile, fertilized with $\left(\mathrm{NH}_{4}\right)_{2} \mathrm{SO}_{4} \ldots$ & 186 & 558 & 229 & 111 & 113 \\
\hline Sterile, fertilized with $\mathrm{NaNO}_{3} \ldots$ & 200 & 678 & 236 & 113 & 103 \\
\hline Unsterilized, uninoculated . ... & 151 & 738 & 300 & 56 & 66 \\
\hline Unsterilized, inoculated . . . & 144 & 577 & 277 & 59 & 81 \\
\hline
\end{tabular}

The formation of branching forms, or bacteroids, in the nodule is due largely to specific nutrition, especially to the presence of alkaloids. Plants depending largely upon the bacteria for their nitrogen show a high alkaloid content; plants which obtain their nitrogen from inorganic nitrogenous compounds, especially lupines, are poor in alkaloids. ${ }^{153}$

Table 60 shows that inoculation resulted in a large increase in the nitrogen content of the plant, but this is accompanied by a still larger increase in its alkaloid content. When sterile plants obtain their

161 Whiting, 1915 (p. 590).

${ }_{152}$ Schulze, E. Ueber den Umsatz der Eiweissstoffe in der lebenden Pflanze. Ztschr. physiol. Chem., 24: 18-114. 1895; 30: 241-312; 48: 387, 396. 1906.

${ }_{153}$ Weber, E. Über den Einflusz der Stickstoffernährung auf den Bitterstoffgehalt der Lupine. Inaug. Diss. Leipzig. 1920. 
nitrogen from $\left(\mathrm{NH}_{4}\right)_{2} \mathrm{SO}_{4}$ or $\mathrm{NaNO}_{3}$, not only is the alkaloid content lower, but the nitrogen content of the plant decreases accordingly.

Influence of environmental conditions upon the growth, of symbiotic nitrogen-fixing bacteria. The limiting temperatures for the growth of nodule bacteria are $3^{\circ}$ and $46^{\circ} \mathrm{C}$.; the thermal death point is at $60^{\circ}$ to $62^{\circ}$; the optimum varies between $18^{\circ}$ and $26^{\circ} .{ }^{154}$ Bact. radicicola is not injured by diffused sunlight and can readily withstand direct sunlight. Drying injures the organism, ${ }^{155}$ but does not destroy it completely even after two years. ${ }^{156}$ The numbers of Bact. radicicola are greatly diminished as a result of direct and rapid drying, as determined by the plate method; however, the number of cells that actually remain alive is much greater than the number germinating on the plate. ${ }^{157}$ In the soil it may persist for at least several years, even in the absence of the host plant..$^{158}$

Importance of symbiotic-nitrogen fixation in the soil. In the case of non-symbiotic nitrogen fixation, the evidence as to actual amount of nitrogen fixed under field conditions is still of doubtful value; however, in the case of symbiotic fixation of nitrogen, the evidence is undisputed. The amount of nitrogen added to the soil by the bacteria depends upon the relative abundance of available nitrogen in the particular soil, both in inorganic and organic forms. The poorer the soil is in available nitrogen (for the growth of the leguminous plants) and the richer it is in lime, available phosphorus and potash, the greater will be the gain in nitrogen. In addition to this, the kind of legume and seasonal condrtions affect the amount of nitrogen fixed. The maximum amount of nitrogen was found to be fixed a little before, or just at blossoming time.

Warington ${ }^{159}$ pointed out in 1891 that an approximate increase of 350 pounds of nitrogen per acre may be obtained as a result of the growth of inoculated legumes (clover). Since then, extensive data have been secured, all of which point to definite increases in soil nitrogen due to the

${ }_{154}$ Zipfel, H. Beiträge zur Morphologie und Biologie der Knöllchenbakterien der Leguminosen. Centrbl. Bakt. II, 32: 97-137. 1912.

${ }^{155}$ Chester, F. B. The effect of desiccation on root tubercle bacteria. Del. Agr. Exp. Sta. Bul. 78. 1907.

${ }^{156}$ Ball, O. M. A contribution to the life history of Bacillus (Ps.) radicocola Beij. Centrbl. Bakt. II, 23: 47-59. 1909.

${ }^{157}$ Duggar, B. M., and Prucha, M. J. The behavior of Pseudomonas radicicola in the soil. Centrbl. Bakt. II, 34: 67. 1912.

${ }^{158}$ Lipman and Fowler, 1915 (p. 129).

159 Warington, $\mathrm{R}$. The circumstances which determine the rise and fall of nitrogenous matter in the soil. U. S. Dept. Agr. Off. Exp. Sta. Bul. 8, 22-41. 1892 . 
growth of leguminous plants in the presence of the proper bacteria. Poor soils are usually found to give larger gains than rich soils. Soils to which lime and phosphorus compounds have been added show greater increases in combined nitrogen than soils where those minerals were lacking. Inoculated soils give better results than uninoculated, particularly if the legume in question or the related forms have not been grown previously on the same soil. Hiltner, ${ }^{160}$ for example, obtained an increase of 1.7 to 31 times the yield for lupines and 15-80 times for serradella as a result of inoculation with the proper organism. On the average, there may be a gain of 50 to 100 pounds of nitrogen per acre of soil due to the growth of legumes. Lipman and Blair ${ }^{161}$ found a gain of 54 pounds annually over a period of seven years from the growth of legumes in rotation with corn, potatoes, oats and rye in cylinders.

According to Hopkins, ${ }^{162}$ a 3 -ton crop of cowpea hay adds 86 pounds of nitrogen per acre, a 25-bushel crop of soybeans with $2 \frac{1}{4}$ tons of straw adds 106 pounds, a 4-ton clover crop adds 106 pounds and a 4-ton alfalfa crop adds 132 pounds. At least two-thirds of the nitrogen in legumes grown on normally productive soils is obtained from the air. Under optimum conditions and on a relatively poor soil as much as 400 pounds of nitrogen may be added per acre per year. ${ }^{163}$ The net yearly gain per acre from the growth of clover on a light sandy soil was found to be 50 pounds of nitrogen. ${ }^{164}$ From 120 to $250 \mathrm{mgm}$. of nitrogen are fixed per plant of red clover and alfalfa..$^{165}$ If the tops are removed, the nitrogen content of the soil may not be increased, since the amount fixed may be just sufficient to fulfill the need of the tops. In the case of perennial legumes, like alfalfa, there may not be an actual increase in soil nitrogen, as compared with uncultivated soils, although the nitrogen is higher than in the same soils upon which grains are grown. ${ }^{166}$

160 Hiltner, 1904 (p. 128).

${ }^{161}$ Lipman, J. G., and Blair, A. W. Cylinder experiments relative to the utilization and accumulation of nitrogen. N. J. Agr. Exp. Sta. Bul. 289. 1916. 1904.

${ }^{162}$ Hopkins, C. Nitrogen bacteria and legumes. Ill. Agr. Exp. Sta. Bul. 94.

${ }^{163}$ Wheeler, H. J. Cooperative experiments in alfalfa culture. R. 1. Agr. Exp. Sta. Bul. 152. 1912.

${ }_{164}$ Shutt, F. T. Nitrogen enrichment of soils. Experiment Farms Rpt., Ottawa. 1912, 144-146.

${ }^{165}$ Brown, P. E., and Stallings, J. H. Inoculated legumes as nitrogenous fertilizers. Soil Sci., 12: 365-407. 1921.

${ }^{168}$ Swanson, C. O., and Latshaw, W. L. Effect of alfalfa on the fertility elements of the soil in comparison with grain crops. Soil Sci., 8: 1-39. 1919. 
Associative action of legumes and non-legumes. When non-leguminous plants are grown together with legumes, the former will obtain from the soil a larger quantity of nitrogen; this has been known since earlier times and has been pointed out by La Flize ${ }^{167}$ in 1892 . It was later confirmed by other investigators. By placing a small unglazed porous pot in which a non-leguminous plant was growing, inside of a large glazed pot, in which a legume was growing, Lipman ${ }^{168}$ observed a favorable influence of the legume upon the non-leguminous crop; he ascribed this to the diffusion of the nitrogen fixed, from the legume to the non-legume. Lyon and Bizzell ${ }^{169}$ found that timothy grown alone contained 12.75 per cent protein and, when grown together with alfalfa, 15.56 per cent. The same was true of oats when grown together with peas; the non-legume contained a greater amount of nitrogen when grown with the legume than when grown alone.

${ }^{167}$ La Flize, S. Expériences sur Légumineuses. Ann. Sci. Agron., 1: 174178. 1892.

${ }_{168}$ Lipman, J. G. A method for the study of soil fertility problems. Jour. Agr. Sci., 3: 297-300. 1909: The associative growth of legumes and non-legumes. N. J. Agr. Exp. Sta. Bul. 253. 1912.

${ }^{169}$ Lyon, T. L., and Bizzell, J. A. Availability of soil nitrogen in relation to the basicity of the soil and to the growth of legumes. Jour. Ind. Engin. Chem. 2: 313-315, 1910; also N. Y. (Cornell) Univ. Agr. Exp. Sta. Bul. 294. 1911. 


\section{CHAPTER XXIII}

\section{Transformation of Sulfur by Microorganisms}

Sources of sulfur in the soil and processes of transformation. In addition to carbon and nitrogen, there are a number of elements which are of prime importance in the growth of plants and microorganisms. We need mention only sulfur, phosphorus, potassium, iron, calcium and magnesium. 'The transformation of sulfur by microorganisms will be discussed at this point not because this element is more important than the others, but because, next to carbon and nitrogen and except for oxygen and hydrogen, it can be used by certain organisms for energy purposes and is required by the majority of organisms for structural purposes. Certain forms of sulfur may also be used as sources of oxygen under anaerobic conditions. Sulfur is more similar to nitrogen than any other element in the many transformations that it enters and in the types of microorganisms which produce these transformations. One finds in the sulfur cycle apparent duplications of the processes associated with the nitrogen cycle.

Sulfur occurs in the soil and may be introduced there in the form of organic and inorganic compounds. The latter comprise elementary sulfur, sulfides and sulfates. The organic matter added to the soil contains from 0.1 to 0.5 per cent of sulfur, as shown in table $61 .{ }^{1}$

The sulfur is present in the plant, chiefly in the cystine group of the protein molecule. When large quantities of sulfates are present in the soil, the plant may also contain sulfur in the form of sulfate. Certain plants contain various volatile sulfur compounds, including certain glucosides, such as sinigrin

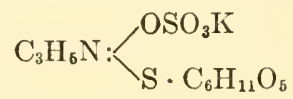

which is decomposed in the soil to mustard oil $\left(\mathrm{C}_{3} \mathrm{H}_{5} \mathrm{NCS}\right)$, glucose and potassium acid sulfate. ${ }^{2}$

${ }^{1}$ Hart, E. B., and Peterson, W. H. Sulphur requirements of farm crops in relation to the soil and air supply. Wis. Agr. Exp. Sta. Res. Bul. 14. 1911.

${ }^{2}$ Peterson, IV. H. Forms of sulfur in plant materials and their variation with the soil supply. Jour. Amer. Chem. Soc., 36: 1290-1300. 1914. 
The amount of sulfur brought down yearly by rainfall may be as much as 45 pounds per acre. ${ }^{3}$ The sulfur content of the soil varies from 0.01 to 0.09 per cent, the upper 6 to 7 inches of soil usually containing 250 to 1000 pounds of sulfur per acre. ${ }^{4}$ According to Kossowitsch, ${ }^{5}$ the average sulfur content of the upper $30 \mathrm{~cm}$. of soil is 0.1 per cent $\mathrm{SO}_{3}$, while that of the following $70 \mathrm{~cm}$. is 0.025 per cent $\mathrm{SO}_{3}$. One-half this amount is sufficient for 285 cereal crops or 70 alfalfa crops (cereal grains containing 0.29 to 0.45 per cent $\mathrm{SO}_{3}$; straw, 0.26 to 0.55 per cent $\mathrm{SO}_{3}$; alfalfa hay, 0.50 per cent $\mathrm{SO}_{3}$ ). Considerable quantities of sulfur are also brought down by rainfall; this amounts to 1.93 to $14.17 \mathrm{mgm} . \mathrm{SO}_{3}$ per liter, or about 10 pounds per acre (Kossowitsch). The quantity is considerably higher near large cities. Drainage waters

TABLE 61

Sulfur content of various organic materials

\begin{tabular}{|c|c|}
\hline MATERIAL & SULFUR \\
\hline & per cent \\
\hline Alfalfa hay ............... & 0.287 \\
\hline 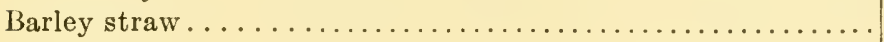 & 0.147 \\
\hline 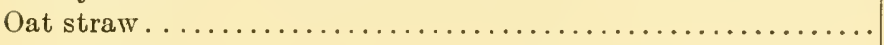 & 0.207 \\
\hline 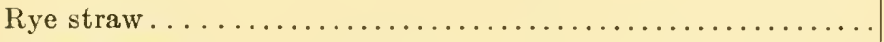 & 0.049 \\
\hline 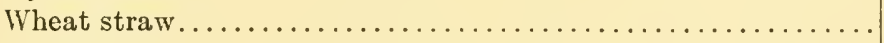 & 0.140 \\
\hline 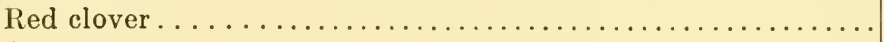 & 0.164 \\
\hline 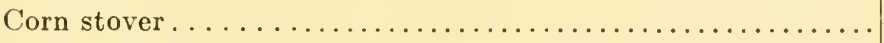 & 0.120 \\
\hline 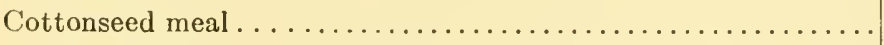 & 0.487 \\
\hline 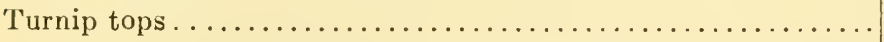 & 0.900 \\
\hline
\end{tabular}

are richer in $\mathrm{SO}_{3}$ than rainfall; the concentration depending on climate, topography, type of soil, fertilization, etc. Sulfur is also added to the soil in the form of gypsum, superphosphates and elementary sulfur in artificial fertilizers.

3 Johnson, E. M. Analyses of rainfall from a protected and an exposed gage for sulfur, nitrate nitrogen, and ammonia. Jour. Amer. Soc. Agron., 17: 589591. 1925.

4 Woodward, J. Sulphur as a factor in soil fertility. Bot. Gaz., 73: 81-109. 1922; Olson, G. A., and St. John, J. L. An investigation of sulfur as a plant food. Wash. Agr. Exp. Sta. Bul. 165. 1921; Joffe, J. S. The rôle of sulfur in agriculture. N. J. Agr. Exp. Sta. Bul, 374. 1922.

- Kossowitsch, P. C. On the cycle of sulfur and chlorine in the soil and on the importance of this process in the life of soils and in the plant world (Russian). Zhur. Opit. Agron., 14: 181-218. 1913. 
The sulfur does not remain long in the form in which it is introduced. It undergoes in the soil a series of reactions involving the activities of a number of microorganisms, the nature of which depends on the nature of the compound containing the sulfur. If it is introduced into the soil in the form of an organic substance, the organic matter is first decomposed by various heterotrophic bacteria, fungi and actinomyces and the sulfur bearing fraction is liberated. This is either assimilated by microorganisms or it is decomposed by various bacteria, and the sulfur is finally liberated as $\mathrm{H}_{2} \mathrm{~S}$. The part of the sulfur utilized by the microorganisms for the synthesis of microbial protein has to be decomposed again before the sulfur is liberated and made available for higher plants. The $\mathrm{H}_{2} \mathrm{~S}$ is oxidized by autotrophic and facultative autotrophic bacteria to sulfur and then to sulfuric acid, which combines with the soil bases to give sulfates. The latter are either assimilated by higher plants or microorganisms and again transformed into proteins or reduced to $\mathrm{H}_{2} \mathrm{~S}$ by specific reducing bacteria under anaerobic conditions. The $\mathrm{H}_{2} \mathrm{~S}$ is of course again oxidized.

When unoxidized or partially oxidized inorganic forms of sulfur, such as thiosulfates, sulfides, including hydrogen sulfide, and elementary sulfur, are added to the soil they are at first oxidized, if the soil aeration and moisture are favorable. These substances may originate from the decomposition of organic matter in the soil, in sulfur springs, in river and sea waters, from the reduction of sulfates, from volcanic eruptions, from the burning of coal or sulfide ore smelters. The oxidation of sulfur may be both chemical and biological in nature resulting in the formation of sulfates. When soil conditions favor anaerobiosis, as in soils saturated with water, or when sufficient aeration is lacking, the sulfates as well as the elementary sulfur may be reduced to sulfides. Sulfates may be leached out from the soil into lakes and seas, where they are reduced by other microorganisms to hydrogen sulfide.

The transformation of sulfur in the soil may thus be summarized under four headings: (1) oxidation, (2) reduction, (3) synthesis (into proteins), and (4) decomposition of proteins and protein derivatives containing sulfur.

The nature of oxidation of sulfur and its compounds in the soil. The question of the chemical or biological oxidation of sulfur has been the subject of various investigations. There is no doubt that some quantities of sulfur, particularly in a finely divided or colloidal state, as well as small amounts of $\mathrm{H}_{2} \mathrm{~S}$ and sulfides, may be oxidized by chemi- 
cal agencies, especially in the presence of proper catalysts. The oxidation of thiosulfate to tetrathionate and even to sulfate can be carried out by means of inorganic catalysts, the iodine ion and peroxide being sufficient for the first reaction and molybdic acid and a peroxide for the second $:^{6}$

$$
\begin{gathered}
2 \mathrm{~S}_{2} \mathrm{O}_{3}=+\mathrm{H}_{2} \mathrm{O}_{2} \stackrel{\mathrm{I}^{-}}{\rightarrow} \mathrm{S}_{4} \mathrm{O}_{6}=+2 \mathrm{OH}^{+} \\
\mathrm{S}_{2} \mathrm{O}_{3}+4 \mathrm{H}_{2} \mathrm{O}_{2} \stackrel{\mathrm{Na}_{2} \mathrm{MoO}_{4}}{\longrightarrow} 2 \mathrm{SO}_{4}=+2 \mathrm{H}^{+}+3 \mathrm{H}_{2} \mathrm{O}
\end{gathered}
$$

The purely chemical theory of the process of sulfur oxidation has been suggested. ${ }^{7}$ With quartz sand containing iron oxide, as the medium for the transformation of the sulfur used in the form of milk of sulfur or in the colloidal form, the quantities given in table 62 were oxidized. The oxidation of sulfides which took place very rapidly,

TABLE 62

\begin{tabular}{|c|c|c|}
\hline KIND OF SOIL & RHOMBIC SULFUR & MILK OF SULFUR \\
\hline & mgm. & mgm. \\
\hline Quartz sand............... & 3.69 & 44.64 \\
\hline Sandy soil. . . . . . . . . . . & 3.81 & 144.22 \\
\hline 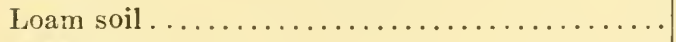 & 16.45 & 227.58 \\
\hline Meadow soil . . . . . . . . . . . . . . . . & 10.92 & 284.02 \\
\hline
\end{tabular}

Formation of $\mathrm{SO}_{4}$ from $200 \mathrm{mgm}$. of $\mathrm{S}$ in 100 grams of soil in six weeks

especially in the case of the more soluble forms, was believed to go through the sulfur stage, as shown by the following reactions:

$$
\begin{aligned}
& \mathrm{Fe}_{2} \mathrm{O}_{3}+3 \mathrm{H}_{2} \mathrm{~S}=\mathrm{Fe}_{2} \mathrm{~S}_{2}+\mathrm{S}+3 \mathrm{H}_{2} \mathrm{O} \\
& \mathrm{Fe}_{2} \mathrm{~S}_{2}+\mathrm{S}+30+3 \mathrm{H}_{2} \mathrm{O}=\mathrm{Fe}_{2} \mathrm{O}_{3} \cdot 3 \mathrm{H}_{2} \mathrm{O}+3 \mathrm{~S}
\end{aligned}
$$

'The elementary colloidal sulfur was rapidly oxidized to sulfate; the rhombic sulfur, only very slightly. Kappen and Quensell themselves have brought forth data to demonstrate that considerably larger quantities of sulfur are oxidized in unsterile than in sterile soils. When active sulfur oxidizing organisms are present, it is easy to demonstrate that this process is primarily biological in nature.

${ }^{6}$ Abel, E. Über katalytische Reaktionsauslese. Ztschr. Elektrochem., 18: 705. $1912 ; 19: 480.1913$.

${ }^{7}$ Kappen, H., and Quensell, E. Über die T'mwandlungen von Schwefel und Schwefelverbindungen im Ackerboden, ein Beitrag zur Kenntnis des SchwefelKreislaufes. Landw. Vers. Stat., 86: 1-34. 1915. 
MacIntire, Gray and Shaw ${ }^{8}$ have also attempted to prove that sulfur is oxidized chemically in the soil, but considerably more sulfur was found to be oxidized under unsterile than under sterile conditions. A careful comparison of the chemical and biological oxidation of sulfur led to the conclusion that the process is chiefly biological in nature. ${ }^{9}$ Of the various compounds, the soluble sulfides and especially $\mathrm{K}_{2} \mathrm{~S}$ and $\mathrm{CaS}$ are rapidly oxidized in the soil by chemical agencies. ${ }^{10}$

Elementary sulfur and various sulfides are, however, oxidized in the soil more actively by microorganisms. It was thought originally that this process is limited to certain specific groups of bacteria which are capable of utilizing the energy obtained in the process of oxidation for chemosynthetic purposes. We are coming more and more to recognize that the property of slow oxidation of sulfur or of incompletely oxidized sulfur compounds, such as sulfides, is probably widely distributed among microorganisms. Not only various common heterotrophic soil bacteria (Bac. mycoides, Bact. fuorescens) are capable of oxidizing small amounts of elementary sulfur, in nutrient solutions containing organic nitrogen and sources of energy (glycerol), ${ }^{11}$ but also various common soil fungi and even actinomyces are reported as oxidizing small amounts of sulfur in artificial media and in soil. ${ }^{12}$ Pen. luteum seems to be particularly active in this connection. However, neither the oxidation of sulfur by chemical agencies nor its transformation by heterotrophic microorganisms can compare with the rapidity with which sulfur is oxidized, when used as a source of energy by autotrophic bacteria. The mechanism of assimilation of elementary sulfur by heterotrophic microorganisms is still unknown. It may be

${ }^{8}$ MacIntire, W. H., Gray, F. J., and Shaw, W. M. The non-biological oxidation of sulfur in quartz media. Jour. Ind. Eng. Chem., 13: 310-313. 1921.

${ }^{9}$ Boullanger, E., and Dujardin, M. Mécanisme de l'action fertilisante du soufre. Compt. Rend. Acad. Sci., 155: 327-329. 1912; Brioux, Ch., and Guerbet, M. L'action fertilisante du soufre. Son évolution dans le sol. Ann. Sci. Agr. (4), 2: 384-396. 1913; Évolution du soufre dans le sol; étude sur son oxydation. Compt. Rend. Acad. Sci., 156: 1476. 1913; Demolon, M. A. Recherches sur l'action fertilisante du soufre. Compt. Rend. Acad. Sci., 156: 725-72S. 1913.

${ }^{10}$ Brown, P. E., and Kellogg, E. H. The determination of the sulfofying power of soils. Jour. Biol. Chem., 21: 73-89. 1915.

${ }_{11}$ Demolon, A. Sur le pouvoir sulfoxydant des sols. Compt. Rend. Acad. Sci., 173: 1408-1410. 1921.

${ }_{12}$ Abbott, E. V. The occurrence and action of fungi in soils. Soil Sci., 16: 207-216. 1923; Rippel, A. Úber einige Fragen der Oxydation des elementaren Schwefels. Centrbl. Bakt. II, 62: 290-295. 1924; Guittonneau, 1926 (p. 609). 
reduced by means of an enzyme, as in the case of yeasts, ${ }^{13}$ to hydrogen sulfide and the latter assimilated and utilized for protein synthesis. The mechanism of autotrophic oxidation of sulfur has been studied in detail and is well known.

In considering the process of sulfur oxidation by autotrophic bacteria, we must differentiate carefully between the nature of the organism and the sources of sulfur. Of the different groups that have been enumerated as capable of oxidizing sulfur and its compounds (p. 79), only the Thiobacillus group is found in normal soils. The presence of larger forms belonging to the unbranched types, accumulating sulfur within their cells, is possible only in muds or in soils kept under anaerobic conditions, where the formation of hydrogen sulfide takes place.

The Thiobacillus group is present abundantly in all soils but the most active forms are found in soils receiving applications of sulfur as a fertilizer, either in organic (sewage, etc.) or inorganic forms. This is due either to their direct introduction into the soil or to a response due to the addition of the specific nutrient. It was shown, for example, that soils receiving stable manure or green manure were capable of oxidizing sulfur more rapidly than the untreated soils poor in organic matter. By increasing soil aeration and keeping the moisture content at 50 per cent of the moisture holding capacity, favorable conditions are created for the oxidation of sulfur in the soil.

Oxidation of sulfur in the soil may be followed by (1) an increase in acidity as expressed by a change in the $\mathrm{pH}$; (2) an increase in the amount of sulfates in the soil; (3) the disappearance of elementary sulfur. The last condition can be determined by extracting the residual sulfur from the soil with acetone. ${ }^{14}$

Oxidation of sulfur by microorganisms. The biological oxidation of sulfur has been studied in detail by Winogradsky. ${ }^{15}$ As a source of sulfur $\mathrm{H}_{2} \mathrm{~S}$ was used or conditions were made favorable for its production.

The reactions involved in the process were presented as follows:

$$
\begin{aligned}
& 2 \mathrm{H}_{2} \mathrm{~S}+\mathrm{O}_{2}=2 \mathrm{H}_{2} \mathrm{O}+\mathrm{S}_{2} \\
& \mathrm{~S}_{2}+3 \mathrm{O}_{2}+2 \mathrm{H}_{2} \mathrm{O}=2 \mathrm{H}_{2} \mathrm{SO}_{4} \\
& \mathrm{H}_{2} \mathrm{SO}_{4}+\mathrm{CaCO}_{3}=\mathrm{CaSO}_{4}+\mathrm{H}_{2} \mathrm{O}+\mathrm{CO}_{2}
\end{aligned}
$$

${ }^{13}$ Morison, C. B. The production of hydrogen sulphide by yeast. Science, 60: 482-483. 1924 .

${ }^{14}$ Simon, R. H., and Schollenberger, C. J. The acetone method of extracting sulfur from soil. Soil Sci., 20: 393-396. 1925.

15 Winogradsky, 1887 (p. 80 ). 
Elementary sulfur was formed as an intermediary product and was actually demonstrated in the cells of the bacteria (Beggiatoa and Thiothrix). Some organisms like Thiobacillus thiooxidans oxidize the $\mathrm{H}_{2} \mathrm{~S}$ directly to sulfuric acid without forming elementary sulfur, while others, like Thiobacillus thioparus, liberate free sulfur outside of their cells.

Thiosulfate is oxidized by microorganisms, according to the following group of reactions, depending on the organism taking part in the process:

$$
3 \mathrm{Na}_{2} \mathrm{~S}_{2} \mathrm{O}_{3}+2 \frac{1}{2} \mathrm{O}_{2}=2 \mathrm{Na}_{2} \mathrm{SO}_{4}+\mathrm{Na}_{2} \mathrm{~S}_{4} \mathrm{O}_{6}
$$

Free sulfur was found to be liberated in the process; Nathanson ${ }^{16}$ considered this to be due to the interaction of the $\mathrm{Na}_{2} \mathrm{~S}_{4} \mathrm{O}_{6}$ and $\mathrm{Na}_{2} \mathrm{~S}_{2} \mathrm{O}_{3}$. However, according to Beijerinck, ${ }^{17}$ the reaction actually takes place as follows:

$$
\mathrm{Na}_{2} \mathrm{~S}_{2} \mathrm{O}_{3}+\mathrm{O}=\mathrm{Na}_{2} \mathrm{SO}_{4}+\mathrm{S}
$$

TABLE 63

\begin{tabular}{|c|c|c|c|c|c|c|c|}
\hline \multirow{2}{*}{ INCUBATION } & \multirow{2}{*}{$\begin{array}{l}\text { AMOUNT OF } \\
\text { CULTURE } \\
\text { IN FLASE }\end{array}$} & \multicolumn{2}{|c|}{ CONTROL FLASK } & \multicolumn{2}{|c|}{ INOCULATED FLASKS } & \multirow{2}{*}{$\begin{array}{l}\text { ELEMEN- } \\
\text { TARY } \\
\text { SULFUR } \\
\text { DISAP- } \\
\text { PEARED }\end{array}$} & \multirow{2}{*}{$\begin{array}{c}\text { INCREABE } \\
\text { IN } \\
\text { SULFATE }\end{array}$} \\
\hline & & Sulfur & Sulfate* & Sulfur & Sulfate & & \\
\hline days & $c c$. & $m g m$. of $S$ & $m g m$. of $\mathrm{S}$ & mgm. of $S$ & $m g m$. of $S$ & $m g m$. of $S$ & $m g m$. of $S$ \\
\hline 15 & 100 & 1,001 & 86.4 & 788 & 302.1 & 213 & 215.7 \\
\hline 30 & 100 & 992 & 90.5 & 735 & 354.0 & 257 & 263.5 \\
\hline 15 & 300 & 3,002 & 112.2 & 2,496 & 633.0 & 506 & 520.8 \\
\hline 30 & 300 & 2,997 & 126.5 & 1,974 & $1,168.0$ & 1,023 & $1,041.5$ \\
\hline
\end{tabular}

Oxidation of elementary sulfur to sulfuric acid by Thiobacillus thiooxidans

* Milligrams of soluble sulfates as sulfur in flask; averages of 3 flasks are given; the concentration of sulfates in the small flasks was greater, due to the fact that, in these, a medium containing $2 \mathrm{gm}$. $\left(\mathrm{NH}_{4}\right)_{2} \mathrm{SO}_{4}$ and $0.5 \mathrm{gm} . \mathrm{MgSO}_{4}$ per liter was used.

It was believed that the sulfur was separated in the process of direct oxidation. However, the precipitation of the sulfur is probably caused by some secondary reaction. Trautwein ${ }^{18}$ suggested that the oxidation of the thiosulfate by the organism that he isolated takes place according to the following reaction:

$$
7 \mathrm{Na}_{2} \mathrm{~S}_{2} \mathrm{O}_{3}+8 \frac{1}{2} \mathrm{O}_{2}=4 \mathrm{Na}_{2} \mathrm{~S}_{2} \mathrm{O}_{6}+\mathrm{Na}_{2} \mathrm{~S}_{4} \mathrm{O}_{6}+2 \mathrm{Na}_{2} \mathrm{SO}_{4}
$$

No sulfur was precipitated, the reaction did not become acid. Th. thiooxidans oxidizes thiosulfate directly to sulfate as follows: ${ }^{19}$

$$
\mathrm{Na}_{2} \mathrm{~S}_{2} \mathrm{O}_{3}+2 \mathrm{O}_{2}+\mathrm{H}_{2} \mathrm{O}=\mathrm{Na}_{2} \mathrm{SO}_{4}+\mathrm{H}_{2} \mathrm{SO}_{4}
$$

${ }^{16}$ Nathanson, 1902 (p. 84). These reactions have been discussed in detail elsewhere, in reference to energy utilization.

${ }^{17}$ Beijerinck, 1904 (p. 84).

${ }_{18}$ Trautwein, 1921 (p. 87).

19 Waksman, S. A., and Starkey, R. L. On the growth and respiration of sulfur-oxidizing bacteria. Jour. Gen. Physiol., 5: 285-310. 1923. 
Elementary sulfur is oxidized to sulfuric acid:

$$
2 \mathrm{~S}+3 \mathrm{O}_{2}+2 \mathrm{H}_{2} \mathrm{O}=2 \mathrm{H}_{2} \mathrm{SO},
$$

The sulfur is oxidized quantitatively without any intermediary reactions taking place (table 63).

In the presence of tricalcium phosphate, the sulfuric acid interacts giving first di-calcium phosphate, then mono-calcium phosphate and finally phosphoric acid (figs. 43, 44):

$$
\begin{aligned}
& \mathrm{Ca}_{3}\left(\mathrm{PO}_{4}\right)_{2}+\mathrm{H}_{2} \mathrm{SO}_{4}+2 \mathrm{H}_{2} \mathrm{O}=\mathrm{Ca}_{2}\left(\mathrm{HPO}_{4}\right)_{2}+\mathrm{CaSO}_{4} \cdot 2 \mathrm{H}_{2} \mathrm{O} \\
& \mathrm{Ca}_{2}\left(\mathrm{HPO}_{4}\right)_{2}+\mathrm{H}_{2} \mathrm{SO}_{4}+2 \mathrm{H}_{2} \mathrm{O}=\mathrm{Ca}_{2}\left(\mathrm{H}_{2} \mathrm{PO}_{4}\right)_{2}+\mathrm{CaSO}_{4} \cdot 2 \mathrm{H}_{2} \mathrm{O} \\
& \mathrm{Ca}\left(\mathrm{H}_{2} \mathrm{PO}_{4}\right)_{2}+\mathrm{H}_{2} \mathrm{SO}_{4}+2 \mathrm{H}_{2} \mathrm{O}=2 \mathrm{H}_{3} \mathrm{PO}_{4}+\mathrm{CaSO}_{4} \cdot 2 \mathrm{H}_{2} \mathrm{O}
\end{aligned}
$$

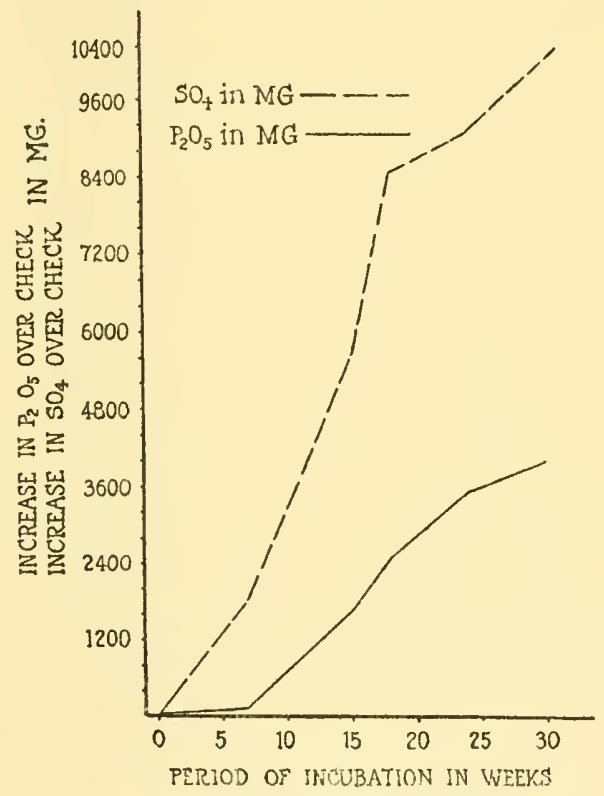

FIG. 43. Course of accumulation of citrate-soluble $\mathrm{P}_{2} \mathrm{O}_{5}$ and $\mathrm{SO}_{4}$ in composts of soil-rock phosphate and sulfur (from Lipman, McLean and Lint).

When the sulfur is oxidized by the denitrifying organism, the reaction may take place as follows:

$$
5 \mathrm{~S}+6 \mathrm{KNO}_{3}+2 \mathrm{CaCO}_{3}=3 \mathrm{~K}_{2} \mathrm{SO}_{4}+2 \mathrm{CaSO}_{4}+2 \mathrm{CO}_{2}+3 \mathrm{~N}_{2}
$$

or

$5 \mathrm{Na}_{2} \mathrm{~S}_{2} \mathrm{O}_{3}+8 \mathrm{KNO}_{3}+2 \mathrm{NaHCO}_{3}=6 \mathrm{Na}_{2} \mathrm{SO}_{4}+4 \mathrm{~K}_{2} \mathrm{SO}_{4}+2 \mathrm{CO}_{2}+4 \mathrm{~N}_{2}+\mathrm{II}_{2} \mathrm{O}$ 


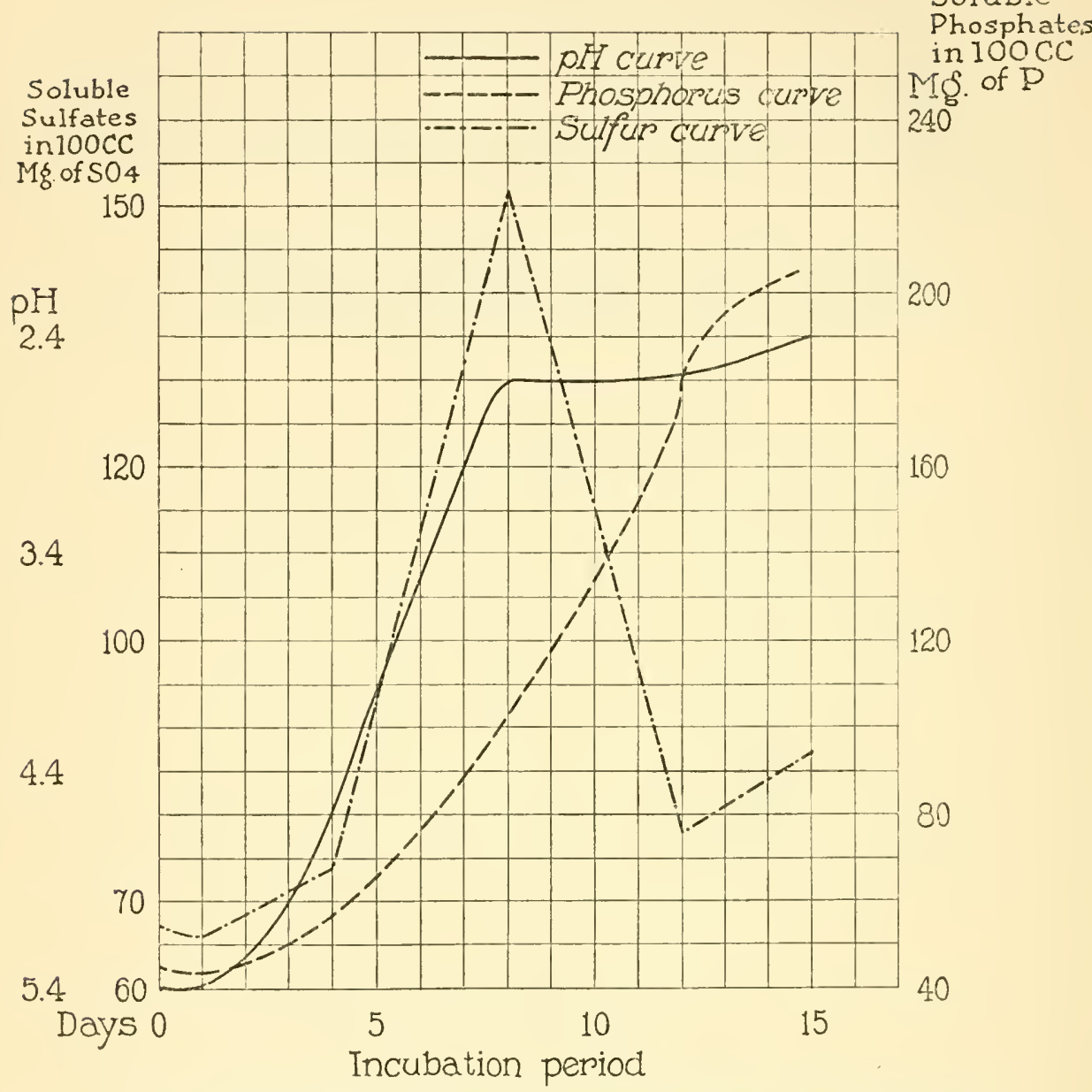

FIG. 44. Course of sulfur oxidation and transformation of insoluble phosphate into soluble forms by Th. thiooxidans in liquid media (from Waksman and Joffe).

The addition of $\mathrm{CaCO}_{3}$ frequently stimulates sulfur oxidation in the soil;20 it also prevents the injurious effect of sulfur oxidation upon the

${ }^{20}$ Brown, H. D. Sulfofication in pure and mixed cultures with special reference to sulphate production, hydrogen-ion concentration and nitrification. Jour. Amer. Soc. Agron., 15: 350-352. 1923. 
nitrifying bacteria. The influence of sulfates, elementary sulfur, and reaction upon the oxidation of sulfur by $T h$. thiooxidans is shown in figures 45 and 46 . According to Guittonneau, ${ }^{21}$ the oxidation of elementary sulfur in the soil may be carried out by two different organisms, one of which oxidizes the sulfur (S) to hyposulfite $\left(\mathrm{S}_{2} \mathrm{O}_{2}\right)$ and the other oxidizes the hyposulfite to sulfate $\left(\mathrm{SO}_{3}\right)$. An outside source of energy, either in the form of organic acids, carbohydrates or

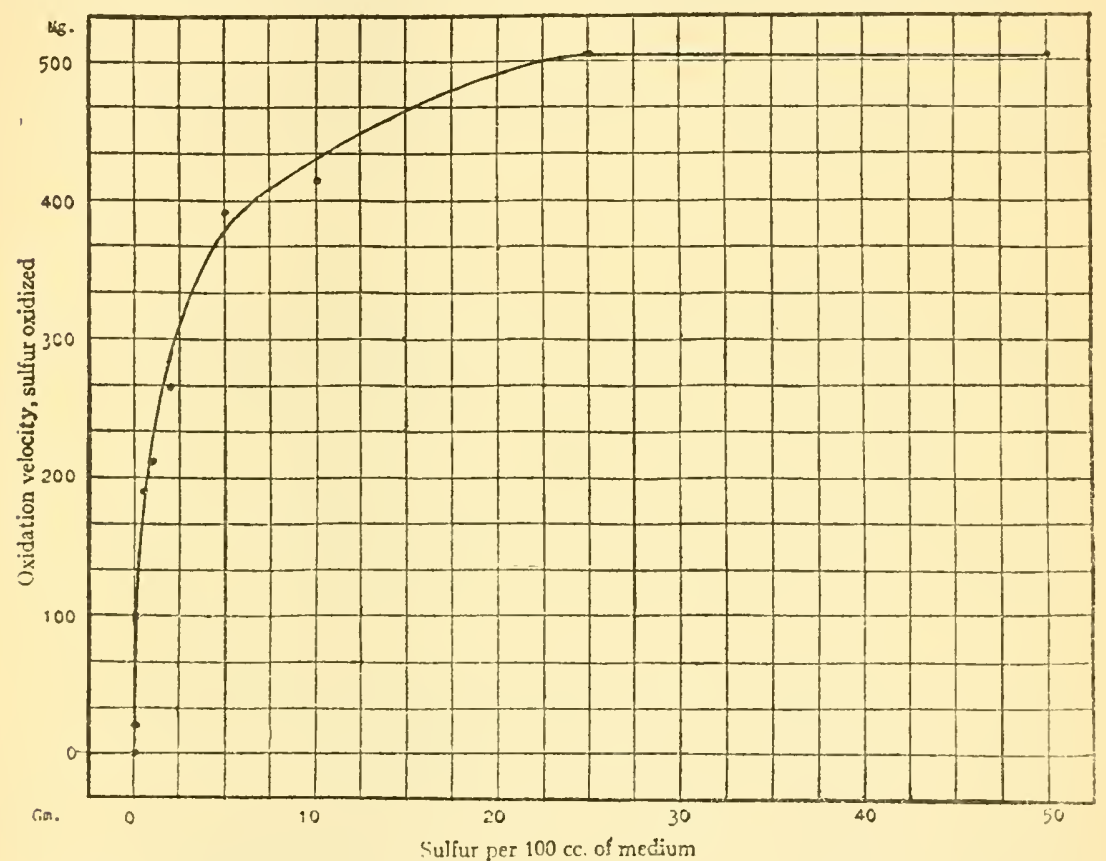

FIG. 45. Influence of sulfur content of medium upon the oxidation velocity of sulfur by Th. thiooxidans (from Waksman and Starkey).

amino acids, is required. The rapidity of the process depends on the nature of the carbon source and the active organisms.

It has been suggested ${ }^{22}$ that different sulfides are acted upon by different groups of organisms. Among the iron sulfides, markazite and ferrous sulfide are oxidized more readily than pyrite.

${ }^{21}$ Guittonneau, G. Sur la formation d'hyposulfites aux dépens du soufre par les microorganismes du sol. Compt. Rend. Acad. Sci., 180: 1142-1144. 1925; 181: 261-262. 1925; 182: 661-663. 1926.

${ }^{22}$ Gubin, B. M. On the oxidation of sulfur and sulfides by soil bacteria (Russian). Viestnik Bakt. Agron. Sta., 24: 52-74. 1926. 
Reduction of sulfur and its compounds. When sulfur is added to the soil in an elementary form it is subject to reduction processes, especially when it comes in contact with the living protoplasm of bacteria, fungi, or yeasts; ${ }^{23}$ thiosulfates, tetrathionates and pentathionates are also subject to reduction processes, with the formation of $\mathrm{H}_{2} \mathrm{~S}$. Rey-

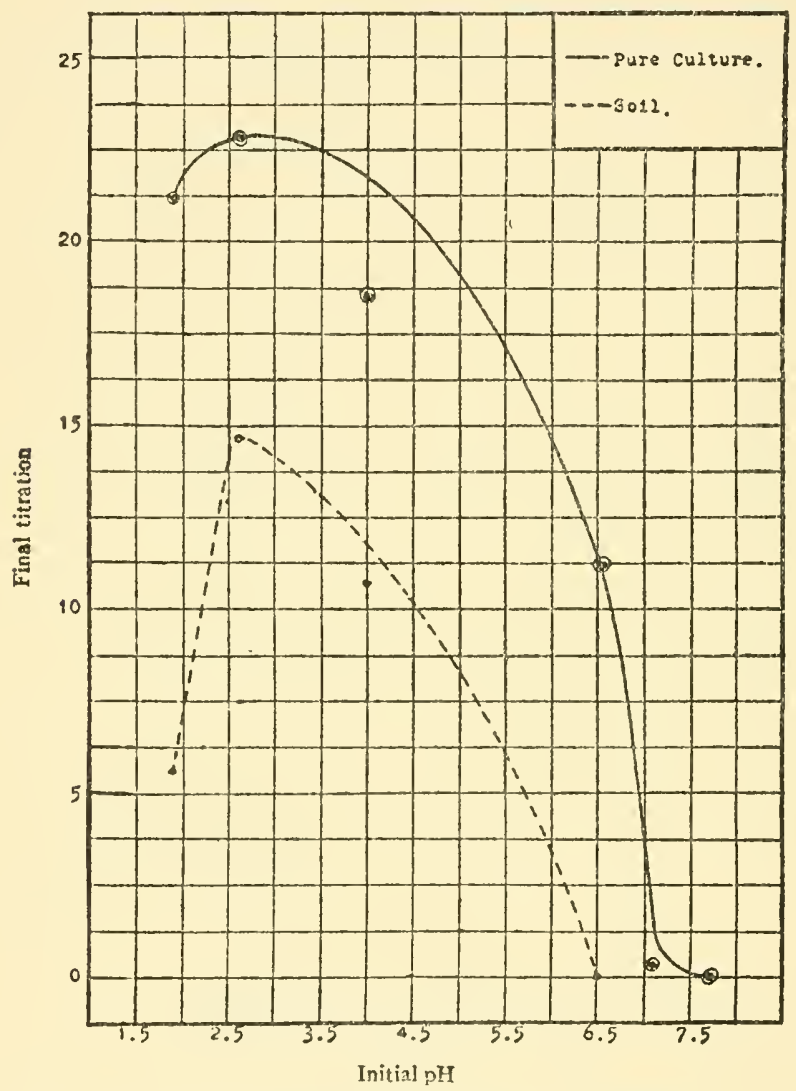

FIG. 46. Influence of hydrogen-ion concentration of medium upon sulfur oxidation by Th. thiooxidans (from Waksman and Starkey).

Pailhade ${ }^{24}$ suggested that this process is enzymatic in nature. When sulfates are added to the soil, they are either assimilated by the plants

${ }^{23}$ Rubner, M. Über den Modus der Schwefelwasserstoff bildung bei Bakterien. Arch. Hyg., 16: 53-72. 1893.

${ }^{24}$ Rey-Pailhade, J. de. Études sur les propiétés chimiques de l'extrait alcoolique de levure de bière; formation de l'acide carbonique et absorption d'oxygène. Compt. Rend. Acad. Sci., 118: 201-203. 1894. 
and microorganisms and transformed into proteins, or are gradually washed out in the drainage waters, or are reduced under anaerobic conditions. This phenomenon was explained ${ }^{25}$ as due to the production of nascent hydrogen by the microbes. It was suggested ${ }^{26}$ that the oxygen of the sulfate obtained in the reduction process is used for the oxidation of organic matter.

$$
3 \mathrm{CaSO}_{4}+2 \mathrm{C}_{3} \mathrm{H}_{5} \mathrm{O}_{3} \mathrm{Na}=3 \mathrm{CaCO}_{3}+\mathrm{Na}_{2} \mathrm{CO}_{3}+2 \mathrm{H}_{2} \mathrm{O}+2 \mathrm{CO}_{2}+3 \mathrm{H}_{2} \mathrm{~S}
$$

This process is exothermic, resulting in the liberation of a small amount of energy. The sulfate is usually first reduced to the sulfide which is then transformed into hydrogen sulfide, according to the reaction:

$$
\mathrm{CaS}+\mathrm{CO}_{2}+\mathrm{H}_{2} \mathrm{O}=\mathrm{CaCO}_{3}+\mathrm{H}_{2} \mathrm{~S}
$$

The organisms concerned in this process are described elsewhere (p. 188). The Microspira desulfuricans is not very sensitive to the products of its metabolism, and can withstand as much as $246 \mathrm{mgm}$. of $\mathrm{H}_{2} \mathrm{~S}$ per liter of medium. The use of sulfates as a source of oxygen is limited to a closely related group of organisms, of which only three have been described, including a thermophilic form isolated by Elion (Vibria thermodesulfuricans). ${ }^{27}$ Both sulfate and thiosulfate can be used as a source of oxygen and salts of organic acids as well as other compounds as sources of carbon.

In crude cultures, the $\mathrm{H}_{2} \mathrm{~S}$ formed from the reduction of sulfate in the presence of organic matter and in contact with oxygen is again oxidized by the sulfur-oxidizing bacteria. In curative muds and certain lakes there is an increase in the $\mathrm{H}_{2} \mathrm{~S}$ content with depth, starting from none at the surface and reaching a concentration of $30 \mathrm{mgm}$. at a depth of 25 to 30 meters. The hydrogen sulfide formed in the lower layers of the mud is oxidized to sulfate on reaching the surface; the latter is then again reduced when reaching the lower layers. ${ }^{28}$

${ }^{25}$ Petri, R., and Maassen, A. Beiträge zur Biologie der krankheitserregenden Bakterien inbesondere über die Bildung von Schwefelwasserstoff durch dieselben unter vornehmlicher Berücksichtigung des Schweinerothlaufs. Arb. K. Gesund. Amt., 8: 318, 490. 1893.

${ }^{26}$ Beijerinck and VanDelden, 1904 (p. 188).

${ }^{27}$ Elion, L. A thermophilic sulfate-reducing bacterium. Centrbl. Bakt. II, II, 63: 58-67. 1924 .

${ }^{28}$ A detailed review of this subject is given by Nadson, G. On the hydrogen sulfide fermentation in the Veissovo-Salt lake and the part played by the microorganisms in the formation of black mud. 1903; St. Petersburg (Russian); and Düggeli, 1919 (p. 82). 
The presence of sulfur-reducing bacteria in deep layers of earth has been demonstrated by Wolzogen Kühr ${ }^{29}$ who found them at depths of 6 to 35 meters. One can readily imagine that processes, similar to those taking place in muds, may also occur in the soil. The requirements for sulfate-reduction by Microspira desulfuricans are (1) absence of free oxygen, (2) presence of organic compounds as sources of energy, (3) presence of sulfate as a source of oxygen, and (4) presence of essential inorganic elements in available forms. The following reactions will then take place:

$$
\begin{aligned}
4 \mathrm{C}_{3} \mathrm{H}_{6} \mathrm{O}_{3}+\mathrm{H}_{2} \mathrm{SO}_{4} & =4 \mathrm{C}_{2} \mathrm{H}_{4} \mathrm{O}_{2}+\mathrm{H}_{2} \mathrm{~S}+4 \mathrm{CO}_{2}+4 \mathrm{H}_{2} \\
\mathrm{C}_{2} \mathrm{H}_{4} \mathrm{O}_{2}+\mathrm{H}_{2} \mathrm{SO}_{4} & =2 \mathrm{CO}_{2}+\mathrm{H}_{2} \mathrm{~S}+2 \mathrm{H}_{2} \mathrm{O}
\end{aligned}
$$

or

$$
4 \mathrm{C}_{3} \mathrm{H}_{6} \mathrm{O}_{3}+2 \mathrm{H}_{2} \mathrm{SO}_{4}=3 \mathrm{C}_{2} \mathrm{H}_{4} \mathrm{O}_{2}+2 \mathrm{H}_{2} \mathrm{~S}+6 \mathrm{CO}_{2}+4 \mathrm{H}_{2}+2 \mathrm{H}_{2} \mathrm{O}
$$

Certain actinomyces are also capable of reducing sulfates to hydrogen sulfide. ${ }^{30}$

Formation of $\mathrm{H}_{2} \mathrm{~S}$ in the decomposition of organic matter. It has been pointed out elsewhere that a large number of bacteria, including aerobic and anaerobic forms, are capable of forming hydrogen sulfide and other volatile sulfur compounds in the decomposition of organic matter containing sulfur. Proteins 'may contain as much as 1.5 per cent of sulfur; on hydrolysis, sulfur is liberated from them partly in the form of $\mathrm{H}_{2} \mathrm{~S}$. This process is carried out by a large number of bacteria, especially certain obligate (Bac. putrificus, Bac. sporogenes) and facultative (Bact. coli, Bact. vulgare, Staph. pyogenes aureus) anaerobes.

The formation of $\mathrm{H}_{2} \mathrm{~S}$ can be tested by the use of a piece of bibulous paper saturated with lead acetate to which a little glycerol has been added. The paper is suspended in the upper part of the container over the growing culture; it will at first become brown, then black. To determine the numbers of organisms in the soil capable of forming $\mathrm{H}_{2} \mathrm{~S}$ from a specific organic material, it is sufficient to incorporate some lead acetate into an agar medium; the formation of a dark color will indicate the ability of the organism to produce $\mathrm{H}_{2} \mathrm{~S}^{31}$

The differences in the amounts of $\mathrm{H}_{2} \mathrm{~S}$ formed by various organisms

${ }^{29}$ von Wolzogen Kühr, C. A. H. Occurrence of sulfate-reduction in the deep layers of the earth. Proc. Roy. Soc. Amsterdam, 25: 188-198, 1922. (Chem. Abstr., 17: 47).

${ }^{30}$ Sawjalow, 1913 (p. 189).

${ }^{31}$ Burnet, E., and Weissenbach, R. J. Valeur des renseignements fournis par la culture en gelose à l'acetate de plomb, pour la différenciation des bacilles typhique, paratyphique A et paratyphique B. Compt. Rend. Soc. Biol., 78: 565-568. 1915. 
are quantitative rather than qualitative in nature,32 they are largely determined by the nature of the medium and oxygen tension. According to Rubner, ${ }^{33}$ Bact. vulgare formed $33 \mathrm{mgm}$. of $\mathrm{H}_{2} \mathrm{~S}$ under anaerobic conditions, and only 4 to $5 \mathrm{mgm}$. under aerobic conditions in one liter of peptone-free bouillon. Quantitatively, the $\mathrm{H}_{2} \mathrm{~S}$ is determined by the difference in the total sulfur content of the medium. ${ }^{34}$ The gases formed may be absorbed in standard iodine solution from which the sulfide is determined by titration with thiosulfate. When organic sulfur compounds are decomposed by the agency of microorganisms, most of the sulfur may be assimilated and resynthesized, as shown by Rubner for Bact. vulgare grown in a liter of bouillon:

\begin{tabular}{|c|c|c|c|}
\hline & $\begin{array}{l}\text { BEFORE THE } \\
\text { EXPERIMENT }\end{array}$ & $\begin{array}{l}\text { AT THE END } \\
\text { OF THE } \\
\text { EXPERIMENT }\end{array}$ & DIFFERENCE \\
\hline Sulfate S.. & $\begin{array}{r}m g m . \\
6.1\end{array}$ & $\begin{array}{r}m g m . \\
1.5\end{array}$ & $\begin{array}{l}m g m . \\
-4.6\end{array}$ \\
\hline 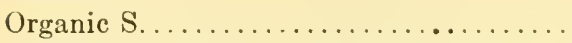 & 52.8 & 28.1 & -24.7 \\
\hline Iron precipitated $\mathrm{S}$, in the bacterial cells. & 1.2 & 25.3 & +24.1 \\
\hline
\end{tabular}

The loss of $5.2 \mathrm{mgm}$. is due to the formation of $\mathrm{H}_{2} \mathrm{~S}$, while the larger portion of the organic sulfur is transformed into microbial protoplasm.

When proteins and' other sulfur bearing organic materials are added to the soil they are hydrolized by the activities of microorganisms into the various constituent groups and the sulfur-bearing amino acid, cystine or di-cystine, or di- $\beta$-thio- $\alpha$-amino-propionic acid liberated.<smiles>NC(CSSC[C@H](N)C(=O)O)C(=O)O</smiles>

Cystine

${ }^{32} \mathrm{~A}$ detailed study of the organisms concerned in the formation of $\mathrm{H}_{2} \mathrm{~S}$ from various sulfur compounds is recorded by Sasaki, T., and Otsuka, I. Experimentelle Untersuchungen über die Schwefelwasserstoffentwicklung der Bakterien aus Cystin und sonstigen Schwefelverbindungen. Biochem. Ztschr., 39: 20S215. 1912; Myers, J. T. The production of hydrogen sulfide by bacteria. Jour. Bact., 5: 231-252. 1920.

${ }^{33}$ Rubner, M. Die Wandlungen des Schwefels im Stoffwechsel. Arch. Hyg. 16: $78-100.1893$.

${ }^{34}$ See Almy, L. H. A method for the estimation of hydrogen sulfide in proteinaceous food products. Jour. Amer. Chem. Soc., 47: 13S1-1390. 1925. 
Another source of sulfur in an organic form is bile which contains taurine.<smiles>CCCC(=O)O</smiles>

These substances are decomposed in the soil or in culture media by microorganisms. The sulfur is liberated as $\mathrm{H}_{2} \mathrm{~S}$ or in the form of mercaptans, ${ }^{35}$ depending on the organisms and environmental conditions, especially oxygen supply. The production of mercaptan from l-cystine by Ract. vulgare is not affected by the presence of glucose, lactose and glycerol. Bact. vulgare and B. coli are also capable of forming $\mathrm{H}_{2} \mathrm{~S}$ and ethyl sulfide from $l$-cystine, independent of the presence of the carbon sources just named. Mercaptans, either the ethyl or methyl form $\left(\mathrm{C}_{2} \mathrm{H}_{5} \cdot \mathrm{HS}\right.$ or $\left.\mathrm{CH}_{3} \cdot \mathrm{HS}\right)$ often accompany $\mathrm{H}_{2} \mathrm{~S}$ as a decomposition product of proteins under anaerobic conditions. These are often produced in mere traces. A definite parallelism has been found between the influence of carbohydrates on bacterial multiplication and on the production of $\mathrm{H}_{2} \mathrm{~S}$ from proteins. The rate of formation of $\mathrm{H}_{2} \mathrm{~S}$ even increases in the presence of glucose, although the formation of amino-nitrogen remains stationary. ${ }^{3 t}$

Taurine is very resistant to the action of microorganisms. ${ }^{37}$

Influence of sulfur oxidation upon the transformation of minerals in the soil. The acid produced from the oxidation of elementary sulfur by microorganisms can be utilized (1) as a solvent for such difficultly soluble minerals, as phosphorus in rock phosphate, potassium in glauconite, or green-sand marl; (2) for the neutralization of excess base in alkaline soils; (3) for the control of certain plant diseases.

When a compost of soil, sulfur and insoluble calcium phosphate is made, the sulfuric acid formed from the oxidation of the sulfur acts upon the phosphate and makes it soluble. By composting 100 grams of soil, 5 grams of flowers of sulfur and 15 grams ground rock phosphate, 85 per cent of the phosphate is made available after a period of 30 weeks. $^{38} \mathrm{~A}$ compost consisting of 100 parts of soil, 120 parts of sulfur and 400 parts of rock phosphate is the most economical com-

${ }_{35}$ Petri and Maassen, 1893 (p. 611); Kondo, M. Über die Bildung des Mercaptans aus l-Cystin durch Bakterien. Biochem. Ztschr., 136: 198-202. 1922.

${ }^{36}$ Heap, H., and Cadness, B. H. E. The influence of carbohydrates on $\mathrm{H}_{2} \mathrm{~S}$ production by Bacillus aertrycke (Mutton). Jour. Hyg., 23: 77-93. 1924.

${ }^{37}$ Sasaki and Otsuka, 1912 (p. 613).

${ }^{38}$ Lipman, J. G., McLean, H. C., and Lint, H. C. Sulfur oxidation in soils and its effect on the availability of mineral phosphates. Soil Sci., 2: 499-538. 1916. 
bination for the production of phosphoric acid.39 However, for the maximum transformation of the phosphate, a compost of equal amounts of sulfur and phosphate and a large amount of soil is required. When the compost is inoculated, the reaction takes place much more rapidly. Abundant aeration and optimum moisture offer favorable conditions; small amounts of ferrous and aluminum sulfates exert a stimulating effect. The uncomposted mixture cannot be added as such to the soil since the phosphate will not become soluble under soil conditions. The reaction of the soil would have to be made acid, before the transformation would take place.

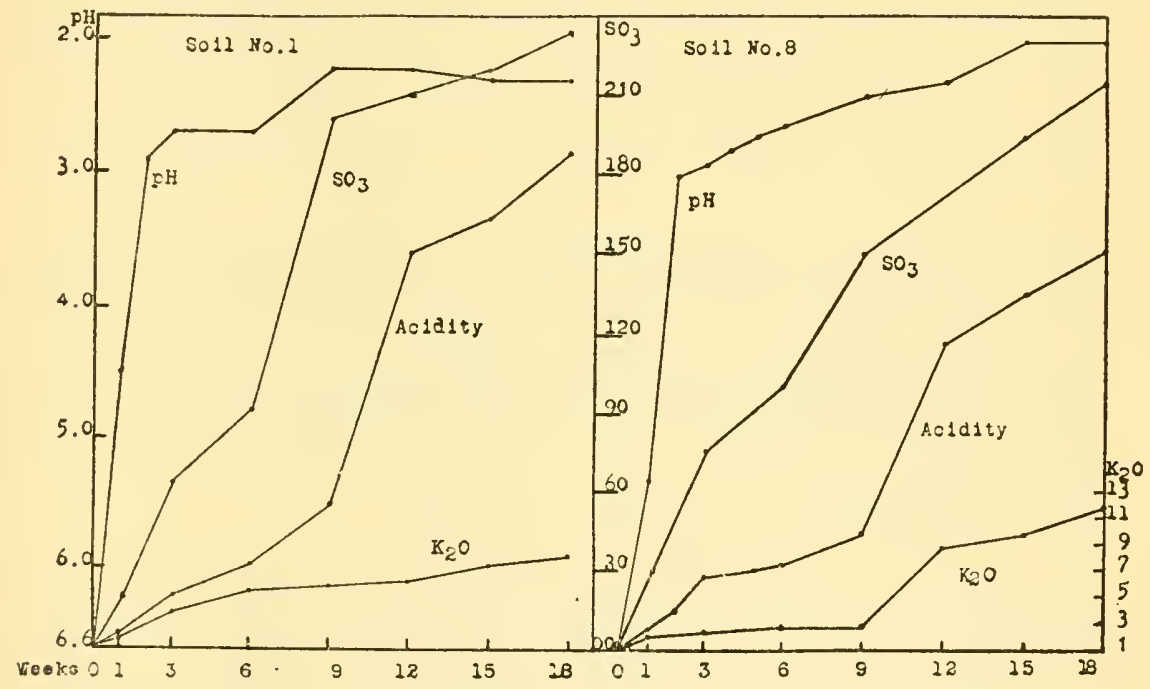

FIG. 47. Relation between sulfur oxidation and water-soluble potassium in composts containing sulfur and greensand marl (from Rudolfs).

The same reactions take place in sterile liquid media inoculated with a pure culture of $T h$. thiooxidans. By adding 1 gram of powdered sulfur and one gram of chemically pure tri-calcium phosphate to 100 cc. of a synthetic solution, sterilizing and inoculating with a pure culture of the organism, the following curves are obtained (fig. 44) ${ }^{40}$

Composts prepared from greensand and sulfur will allow the liberation of small amounts of potassium at $\mathrm{pH} 2.7$ to 2.3 (fig. 47); this

${ }^{39}$ McLean, H. C. The oxidation of sulfur by microorganisms in its relation to the availability of phosphates. Soil Sci., 5: 251-290. 1918.

${ }^{40}$ Waksman, S. A., and Joffe, J. S. The chemistry of the oxidation of sulfur by microorganisms to sulfuric acid and transformation of insoluble phosphates into soluble forms. Jour. Biol. Chem., 50: 35-45. 1922. 
potassium when introduced into the soil is readily assimilated by plants. ${ }^{41}$

Another interesting process in which the oxidation of sulfur may be utilized is the neutralization of the alkalinity of black alkali soils. In view of the fact that the alkalinity of such soils is due not only to the presence of sodium carbonate but to the fact that sodium forms the saturating base in the zeolitic silicates, large quantities of sulfur have to be applied before any marked effect is observed. The sulfur is readily oxidized and the sulfuric acid changes the carbonates to bicarbonates and then to sulfates. However, when insufficient amounts of sulfur are used, the zeolitic sodium will soon form fresh carbonates and the reaction of the soil will again become markedly alkaline. The acid not only neutralizes the carbonates, but coagulates the colloids, thus making the soil more permeable and allowing leaching to take place. $^{42}$

An increase in the acidity of the soil which results from the application of sulfur can be utilized for the control of organisms which cause plant diseases, such as Act. scabies causing potato scab. However, an increased acidity may prove injurious to microorganisms whose activities are essential for the normal biochemical soil processes, such as the bacteria concerned in the process of nitrification, etc. ${ }^{43}$ The practical application of sulfur must, therefore, always be accompanied by a careful study of the reaction of the soil.

${ }^{41}$ Rudolfs, W. Sulfur oxidation in inoculated and uninoculated greensand mixtures and its relation to the availability of potassium. Soil Sci., 14: 307319. 1922 .

42 This process was studied in detail by Hibbard, P. L. Sulfur for neutralizing alkali soil. Soil Sci., 11: 385-387. 1921; Rudolfs, IV. Sulfur oxidation in "Black alkali"' soils. Soil Sci., 13: 215-229. 1922; Joffe, J. S., and McLean, H. C. Alkali soil investigations. Soil Sci., 17: 395-409. 1924; 18: 13-30, 133-149, 237251. 1924.

${ }^{43}$ The influence of sulfur oxidation upon microbiological activities in the soil is discussed in detail by Vogel, J. Die Einwirkung von Schwefel auf die bakteriellen Leistungen des Bodens. CentrbI. Bakt. II, 40: 60-83. 1914. 
PART D

SOIL MICROBIOLOGICAL PROCLSSES AND SOIL FER'TILITY

... la terre végétale est regardée comme un support actif, une chose vivante . . . .-M. Berthelot 



\section{CHAPTER XXIV}

\section{The Soll as a Medium for the Growth and Activities of Microorganisms}

To be able to understand the processes resulting in the soil from the activities of microorganisms, we must understand the nature of the medium, the soil, in which these organisms live, act and reproduce.

The soil as a culture medium. The soil is a complex system consisting of (a) mineral particles formed as a result of mechanical and chemical decomposition of the various mineral constituents of native rocks; (b) organic matter of plant, animal and microbial origin, in the process of decomposition or resisting further decomposition; (c) compounds formed as a result of interaction of substances produced in the decomposition of organic matter with materials resulting from the disintegration of the inorganic soil complexes; $(d)$ soil moisture, containing in solution $\mathrm{CO}_{2}$, oxygen and other gases, and various organic compounds and inorganic salts; and finally (e) soil atmosphere.

The soil is regarded ${ }^{1}$ as a mineral framework, the particles of which are coated with a jelly-like layer of organic and inorganic materials present in a colloidal condition, the soil solution being present partly in the colloidal layer and partly in a free condition. The microbial population of the soil lives largely in the colloidal layer and partly in the soil solution. The activities of the microorganisms living in the soil as a medium are affected by the nature of the different ingredients of the medium and by the various conditions influencing them.

The complex medium supplies to the various organisms inhabiting it the necessary nutrients, of an organic and inorganic nature, consisting of the elements oxygen, hydrogen, carbon, nitrogen, phosphorus, sulfur, potassium, magnesium, calcium and iron; and, to a less extent, chlorine, silicon, sodium, aluminum and manganese. The availability

${ }^{1}$ Page, H. J. The part played by organic matter in the soil system. Trans. Faraday Soc., 17: 272-287. 1922. Bouyoucos recently called attention to the fact that the colloids in the soil do not exist entirely as a coating around the soil grains, but are also independent components; sand particles may not be covered with colloidal gel (Soil Sci., 21: 431-488. 1926.) 
of these nutrients as well as their utilization will be greatly influenced not only by the (1) physical and chemical composition of the solid part of the soil, but also by the (2) composition of the soil atmosphere, (3) composition of the soil solution, (4) reaction of the soil and (5) soil temperature. When any one of these factors is changed there is a correlated change in the biological composition of the soil; i.e., any modification in the physical, chemical or physico-chemical conditions of the soil will greatly affect the biological flora and its activities. ${ }^{2}$ We possess only fragmentary information concerning the biological responses to modifications of these soil conditions.

Soil composition and microbiological activities. The solid, liquid, and gaseous phases of the soil infuence individually and collectively the distribution and activities of microorganisms. The mineral framework is of prime importance. It is made up of (1) mineral matter derived from the disintegration of rock materials; (2) calcium carbonate, calcium phosphate, and organic matter deposited in the soil by the various marine organisms during soil formation; and (3) the mineral substances (zeolites) present in a colloidal state. The organic soil constituents contributing to the soil as a medium for the growth of microorganisms are (1) undecomposed plant and animal resilues of recent origin; (2) various intermediary substances, various more or less inert constituents of the original organic matter added to the soil, and final products of decomposition of plant and animal substances; and (3) the various dead and living cells of microorganisms and the products resulting from their decomposition.

The mineral framework influences the activities of microorganisms by modifying the mechanical condition of the medium, by forming substances (such as the zeolitic silicates) which, either themselves or by interaction with certain of the organic compounds, form the colloidal film in which most of the microbial transformations take place, by offering direct mineral nutrients to the microorganisms, and by combining with various products of the metabolism of microorganisms, such as the organic and inorganic acids.

The inorganic as well as the organic soil colloids give to the soil such desirable properties as its capacity for absorption and retention of water and bases and its buffering action, which ragulates changes in

${ }^{2}$ Lantsch, K. Bacillus amylobacter A. M. et Bred. und seine Beziehungen zu den Kolloiden. Centrbl. Bakt. II, 54: 1-12. 1921; König, J., and Hasenbäumer, J. Die Bedeutung neuer Bodenforschungen für die Landwirtschaft. Landw. Jahrb., 55: 185-252. 1920. 
reaction. They may also exert a direct influence upon the distribution and nature of action of microorganisms in the soil.

The organic matter of the soil gives to it a brown to black color. The higher moisture holding capacity of the soil is due to a large extent to a higher content of organic matter. Carbon is present in the soil chiefly in the various organic substances collectively termed "humus" and in the form of carbonates. The nitrogen is present in the soil in the form of complex proteins and their derivatives ${ }^{3}$ as well as other complex nitrogenous compounds largely derived from the cells of microorganisms inhabiting the soil; only about one per cent of the nitrogen of the soil is present there as ammonia and nitrates. The various minerals required by the microorganisms for their activities are present partly in the mineral framework, partly in the organic and inorganic soil colloids, partly in the soil solution, and partly in a precipitated form.

The soil moisture ${ }^{4}$ is combined with the colloidal materials, forming the liquid phase of the complex, and is also in a free state. The amount of moisture that a soil can hold varies with the size of these particles and will be low in the coarse sandy soils and greater in the fine clay and especially in the peat soils, which consist largely of organic matter in a colloidal state. The minimum and optimum amounts of moisture for the activities of microorganisms will depend upon the nature of the soil and its colloidal content. Using the evolution of $\mathrm{CO}_{2}$ from glucose as an index of the activities of microorganisms, Van Suchtelen ${ }^{5}$ found that when a loam soil contained only 4.4 per cent moisture, the activities were at a standstill. When the moisture was increased to 6 per cent, $19 \mathrm{mgm}$. of $\mathrm{CO}_{2}$ were formed, and with 15 per cent moisture, 208 mgm. were formed. Similar results were obtained when the number of bacteria developing on the plate was used as an index of microbiological activities. ${ }^{6}$ Optimum moisture conditions, for the activities of many soil microorganisms, are reached when about half the pore space

${ }^{3}$ Jodidi, S. L. The chemical nature of the organic nitrogen in the soil. Iowa Agr. Exp. Sta. Res. Bul. 1. 1911; Potter, R. S., and Snyder, R. S. Jour. Agr. Res., 6: 61. 1916.

${ }^{4}$ Soil sampling as well as moisture determination is discussed in detail by E. Heine. Die Praktische Bodenuntersuchung. Bornträger, Berlin, 1911; and J. Stoklasa. Methoden zur biochemischen Untersuchung des Bodens. Abderhald. Handb. biochem. Arbeitsmeth. 5, Pt. 2, 843-910. 1925.

- Van Suchtelen, 1910 (p. 684).

- Engberding, 1909 (p. 14). 
of the soil is filled with water. In the case of light sandy soils this condition obtains when the water content is about 8 to 10 per cent of its weight and, in heavy silt or clay soils, when the water content is 16 to 20 per cent or more. As the soil dries out the activities of the organisms are gradually reduced; the larger forms, like the fungi, suffer most while the smaller and more resistant forms, like the actinomyces and spores of bacteria, ${ }^{7}$ suffer least. Excessive moisture may prove unfavorable to aerobic microorganisms by limiting the supply of oxygen, while anaerobic bacteria are favored

Since the microorganisms live largely upon the colloidal film surrounding the inorganic soil particles, the lower the colloidal content of a soil the smaller is the amount of water necessary to bring it into a condition favorable for the activities of microorganisms. An excess above the optimum amount of moisture will prove injurious to the activities of the aerobic organisms. The heavier the soil, the higher must be the water content to bring about equal decomposition of organic nitrogenous substances. Using the liberation of ammonia and nitrate from horn meal as an index of the activities of microorganisms, Münter ${ }^{8}$ demonstrated (table 64) that in a sandy soil decomposition did not vary within the moisture range of 6 to 18 per cent (decreasing at greater moisture contents). The rapidity of decomposition reached its highest point during the first three weeks in the sandy soil. In a loam soil, decomposition was twice as great at 16 per cent moisture as at 8 per cent, and was constant between 16 and 24 per cent. The influence of the moisture content was still more marked in a clay soil. Only 0.63 per cent of the material was decomposed in three weeks at 8 per cent moisture, while at 18 and 28 per cent moisture and in the same period of time, 30.80 and 36.36 per cent of the material was decomposed respectively. After twelve weeks, 13.35, 63.21 and 57.94 per cent of the material was decomposed at the respective moisture contents.

The effect of moisture is also shown in the composition of the soil flora and the nature of the processes occurring in the soil will consequently be materially affected. The decomposition of cellulose can readily illustrate this phenomenon. In the presence of sufficient available nitrogen and minerals, cellulose is decomposed at a medium mois-

${ }^{7}$ Hoffmann, C. Relation of soil bacteria to evaporation. Wis. Agr. Exp. Sta. Res. Bul. 23. 1912.

${ }^{8}$ Münter, F. Untersuchungen über chemische und bakteriologische Umsetzungen im Boden. Landw. Jahrb., 55: 62-138. 1920. 
ture content by filamentous fungi and aerobic bacteria; at a low moisture content, by filamentous fungi and actinomyces; when the soil is saturated with water, anaerobic bacteria are largely concerned with the decomposition of the cellulose. When sugar is added to the soil and the development of microorganisms is followed by direct microscopic examination, Azotobacter is found to develop under aerobic and Bac. amylobacter under anaerobic conditions. The latter condition

TABLE 64

Influence of moisture upon the formation of ammonia and nitrate (from horn meal) in different soils

\begin{tabular}{|c|c|c|c|}
\hline BOIL TYPE & MOISTURE CONTENT & $\begin{array}{l}\text { PERIOD OF } \\
\text { INCUBATION }\end{array}$ & $\begin{array}{l}\text { AMMONIA AND } \\
\text { NITRATE NITROGEN }\end{array}$ \\
\hline \multirow{7}{*}{ Sand . . } & per cent & weeks & per cent \\
\hline & 6 & 3 & 45.7 \\
\hline & & 12 & 60.2 \\
\hline & 12 & 3 & 42.4 \\
\hline & & 12 & 55.5 \\
\hline & 18 & 3 & 38.5 \\
\hline & & 12 & 55.0 \\
\hline \multirow{6}{*}{ Loam. } & 8 & 3 & 18.9 \\
\hline & & 12 & 49.7 \\
\hline & 16 & 3 & 45.5 \\
\hline & & 12 & 53.9 \\
\hline & 24 & 3 & 39.5 \\
\hline & & 12 & 39.0 \\
\hline \multirow{6}{*}{ Clay. } & 8 & 3 & 0.6 \\
\hline & & 12 & 154 \\
\hline & 18 & 3 & 29.1 \\
\hline & & 12 & 54.9 \\
\hline & 28 & 3 & 36.9 \\
\hline & & 12 & 24.2 \\
\hline
\end{tabular}

may be reached below the surface even when the moisture content of the soil is only 40 per cent of saturation. ${ }^{9}$

The influence of moisture upon the activities of bacteria is due to two factors: ${ }^{10}$ (1) penetration of atmospheric oxygen through the medium;

${ }^{9}$ Winogradsky, 1924 (p. 542).

${ }^{10}$ Rahn, O. Die Bakterientätigkeit im Boden als Funktion der Nahrungskonzentration und der unlöslichen organischen Substanz. Centrbl. Bakt. II, 38: 484-494. 1913; Bacterial activity in soil as a function of the grain-size and moisture content. Nich. Agr. Exp. Sta. Tech. Bul. 16. 1912. 
(2) rapidity of diffusion of nutrients. A high moisture content is more favorable for bacteria, but it diminishes aeration; when the soil is saturated with water, oxygen can penetrate only by solution, which is too slow for the development of aerobic organisms. When the moisture content of the soil is diminished, aeration increases. The larger the inorganic soil particles the greater are the possibilities for aeration. The smaller the inorganic soil particles, the greater is the amount of moisture required for the activities of microorganisms and the less is the soil aerated.

TABLE 65

Comparative mineral composition of surface soil and of lithosphere

\begin{tabular}{|c|c|c|}
\hline COMPOUNDS & $\begin{array}{l}\text { AMERICAN SURFACE } \\
\text { SOILS }\end{array}$ & LITHOSPHERE \\
\hline & per cent & per cent \\
\hline 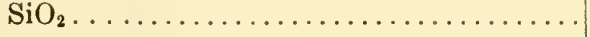 & 84.67 & 59.77 \\
\hline 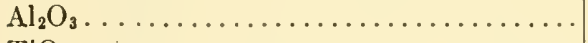 & 6.73 & 14.89 \\
\hline 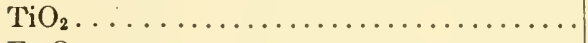 & 0.66 & 0.77 \\
\hline 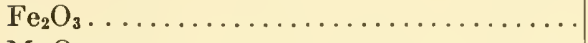 & 2.53 & 6.25 \\
\hline 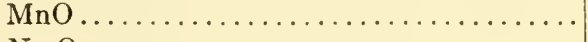 & 0.06 & 0.09 \\
\hline $\mathrm{Na}_{2} \mathrm{O} \ldots \ldots \ldots \ldots \ldots \ldots \ldots \ldots \ldots \ldots \ldots \ldots \ldots$ & 0.49 & 3.25 \\
\hline 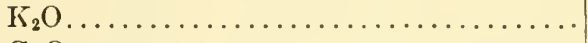 & 1.03 & 2.98 \\
\hline 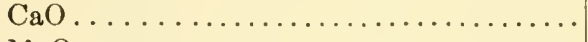 & 0.40 & 4.86 \\
\hline 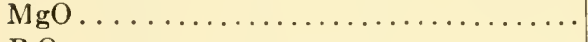 & 0.27 & 3.74 \\
\hline $\mathbf{P}_{2} \mathrm{O}_{5} \ldots \ldots \ldots \ldots \ldots$ & 0.09 & 0.28 \\
\hline 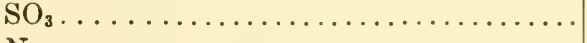 & 0.09 & 0.28 \\
\hline $\mathrm{N}_{2} \ldots \ldots \ldots \ldots \ldots \ldots \ldots \ldots \ldots \ldots \ldots \ldots \ldots \ldots \ldots \ldots \ldots$ & 0.07 & $\cdots$ \\
\hline Organic matter $\ldots \ldots \ldots \ldots \ldots \ldots \ldots$ & 2.61 & $\cdots$ \\
\hline 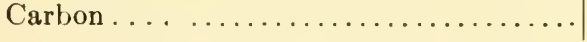 & 1.51 & 0.03 \\
\hline
\end{tabular}

Aeration of the soil or the diffusion of the soil gases greatly influence the activities of microorganisms. Oxygen is needed for oxidation processes, $\mathrm{CO}_{2}$ for the activities of autotrophic bacteria, and nitrogen for the nitrogen-fixing organisms. ${ }^{11}$ Oxidation favors the activities of nitrate-forming and nitrogen-fixing bacteria, fungi, actinomyces, and other organisms which bring about the decomposition of organic matter. The processes of decomposition may be so rapid in well aerated soils that farmers must resort to rolling, marling and manuring in order to maintain the proper supply of organic matter in the soil. In heavy fine-grained soils with insufficient aeration, the decomposition of or-

In Russell, E. J., and Appleyard, A. The composition of the soil atmosphere. Jour. Agr. Sci., 7: 1-4.9. 1915; 8: 385-417. 1917. 
ganic matter may be too slow and the farmer may use drainage, tillage, liming and manuring to intensify aeration. Insufficient aeration favors reduction processes.

The mineral composition of the soil. While nitrogen and, to a large extent, sulfur are present in the soil almost entirely in organic form and the carbon utilized by the heterotrophic organisms is also of complex organic nature, the other elements are largely or entirely of inorganic origin. Phosphorus exists in the soil as apatite $\left(\mathrm{Ca}_{5}\left(\mathrm{PO}_{4}\right)_{3} \cdot \mathrm{Cl}\right.$ or $\left.\mathrm{Ca}_{5}\left(\mathrm{PO}_{4}\right)_{3} \cdot \mathrm{F}\right)$, calcium phosphate $\left(\mathrm{Ca}_{3}\left(\mathrm{PO}_{4}\right)_{2}\right)$, iron and aluminum phosphates, as well as in various organic combinations. Potassium occurs in the soil in orthoclase and microcline feldspar $\left(\mathrm{KAlSi}_{3} \mathrm{O}_{8}\right)$, in muscovite mica $\left(\mathrm{KH}_{2} \mathrm{Al}_{3} \mathrm{Si}_{2} \mathrm{O}_{12}\right)$ and in hydrated and non-hydrated aluminum silicates and to a less extent in organic combination. Calcium exists in the soil in various minerals such as calcite, plagioclase, feldspar, hornblende and augite, and in absorbed compounds with kaolinite, etc.

Table 65 shows the composition of some typical American soils compared with the composition of the lithosphere. ${ }^{12}$

It is only seldom that the mineral constituents become limiting factors to the development of microorganisms in normal soils. These minerals influence the activities of the organisms by modifying the soil reaction, the concentration of the soil solution and by serving as direct nutrients and in some cases even as sources of energy.

The physico-chemical rôle of organic matter in the soil. Organic matter plays a manifold rôle in the soil. Most soil microorganisms find in it their source of energy and other nutrients. Its influence on soil texture is of especial importance. Organic matter helps to loosen a clay soil and add body to a sandy soil. It is best to apply only undecomposed organic matter to heavy soils, since the large quantities of $\mathrm{CO}_{2}$ produced in the process of decomposition tend to make the heavy soil porous. However, it is best to subject the organic matter first to partial decomposition before applying it to sandy soils, so as not to make the soil too open. The colloidal "humus" seems to have a cementing effect upon the coarser soil particles. It also exerts a protective effect upon clay, so that greater concentrations of electrolytes are required for its flocculation.

${ }^{12}$ Robinson, W. O. The inorganic constituents of some important American soils. U. S. Dept. Agr. Bul. 122. 1914. Methods of ehemieal and mechanical soil analysis are diseussed by Russell and others (see list of texts). 
Due to its large capacity for absorbing water, the soil organic matter causes a swelling of the soil when wetted. The influences of successive drying, moistening and freezing modify the nature of the organic matter and make it more available to the activities of microorganisms with the production of larger amounts of $\mathrm{CO}_{2}$ and nitrate. When a soil is well cultivated, the formation of spaces allows a rapid development of the fungi, actinomyces and aerobic heterotrophic bacteria. These decompose the organic matter, use the available oxygen, and form $\mathrm{CO}_{2}$ as one of the chief products. The gases formed produce a certain pressure which brings about a further extension of the spaces between the soil particles and create a condition referred to in German as "Bodengare," or puffing up of the soil similar to the rising of bread. An improved tilth results. This condition is favored by fertilizing the soil with stable or green manure, by liming the soil and by thorough cultivation. The colloidal organic matter increases the water holding capacity of the soil and helps to warm up the soil more rapidly, due to a decrease in the evaporation of water, to better drainage and absorption of the radiant heat of the sun. The organic colloids exert a definite buffer effect upon the reaction of the soil solution; $;^{13}$ they also regulate the composition and concentration of the solution.

Colloidal condition of soils ${ }^{14}$ and microbiological activities. Colloids are characterized by a group of reactions which were believed originally to differentiate them sharply from crystalloids, and especially by the fact that they show no marked tendency to diffuse in solutions or to pass through semi-permeable membranes. With the advance of our knowledge on colloids, it has been found that no sharp line of demarcation can be drawn between them and crystalloids. Both conditions depend on the method of preparation, including the nature of the sol-

${ }^{13}$ Oden, Sven. The application of physico-chemical methods to the study of humus. Trans. Faraday Soc., 17: 28\$-294. 1922.

${ }_{14}$ The following texts give an excellent discussion of the subject of colloids. Ostwald, Wo. Colloid chemistry (Tr. Fischer). 1916; Zsigmondy, R. Kolloidehemie. 5th Ed. Spamer. Leipzig. 1925; Taylor, W. W. Chemistry of colloids. 3d. Ed. New York. 1915; Freundlich, H. Kapillarchemie. 2d Ed. Leipzig. 1922; Ehrenberg, P. Die Bodenkolloide. Steinkopff. Leipzig. 2d Ed. 1922; Bechhold, H. Colloids in biology and medicine (Tr. J. G. M. Bullowa). Van Nostrand Co. New York. 1919; Burton, E. F. The physical properties of colloidal solutions. Longmans. 2d Ed. 1921; Casuto, L. Der kolloidale Zustand der Materie. Steinkopff. 1913; Wiegner, G. Boden und Bodenbildung in kolloidchemischer Betrachtung. T. Steinkopff. 3rd Ed. Dresden. 1924; Bogue, R. H. The theory and application of colloidal behavior. 2 vols., McGraw-Hill. New York. 1924. 
vent employed. We speak now of colloidal systems rather than of colloidal substances. Colloidal systems are not stable. Colloids are also characterized by extended surfaces which allows them to absorb water and dissolved substances from a solution. The attraction for water is both chemical and physical. Heat of wetting is characteristic of the soil colloids. An active soil colloid may be changed to an inactive one by changing its physical condition (ignition) and also to some extent by changing its chemical condition. ${ }^{15}$

Soil colloids consist largely of silica, alumina, iron oxides and organic matter. ${ }^{16}$ The natural organic matter added to the soil consists largely of colloidal substances (proteins, celluloses, starches, lignins). When these substances are acted upon by microorganisms, they are partly transformed, either directly or through a series of stages, into crystalloids, and partly into new colloids, namely the soil organic matter (p. 630). The clay portion of the soil is in itself colloidal in nature.

Colloids are usually separated from crystalloids by dialysis, ultrafiltration, and centrifuging. The osmotic pressure of colloidal solution is small, due to the large molecular weight; diffusion is, therefore, also small; the lowering of the freezing point is almost negligible. When the colloids are transformed by microorganisms into crystalloids, the molecular weight is decreased with a corresponding increase in osmotic pressure, diffusion and lowering of freezing point. A study of the chemical properties of the proteins as organic colloids led to the conclusion ${ }^{17}$ that the theory of amphoteric colloids is in its general features identical with the theory of inorganic metal hydroxides.

The colloidal properties of soil which are of special importance in the growth of microorganisms in the soil as a culture medium are (1) the absorption of substances from solution and their concentration upon the surface of the colloid, including substances used as nutrients by microorganisms and those which may be injurious to their activities; (2) ability to absorb water in large amounts; (3) flocculation and deflocculation phenomena of colloids themselves and of bacterial cells considered as colloids; (4) the "sol" and "gel" states of the colloids; (5) modification of soil conditions, such as reaction.

${ }_{15}$ Anderson, M. S. The heat of wetting of soil colloids. Jour. Agr. Res., 28: 927-936. 1924; Bouyoucos, G. J. The chief factors which influence the heat of wetting of soil colloids. Soil Sci., 19: 477-4S3. 1925.

${ }^{16}$ Robinson, W. O., and Holmes, R. S. The chemical composition of soil colloids. U. S. Dept. Agr. Bul. 1311. 1924.

${ }_{17}$ Loeb, J. Proteins and the thcory of colloidal behavior. McGraw-Hill. New York. 1922. 
Colloids are coagulated, or flocculated, by means of electrolytes; the univalent ions have a less intensive effect than the bivalent and the latter less than the trivalent. Clay is an electro-negative colloid and can be flocculated by positively charged ions; at a certain point it is deflocculated by the negatively charged hydroxyl ion. This deflocculation may be due to the lessened solubility of the di- and tri-valent cations in the soil rather than to the direct effect of the hydrogen-ion concentration. ${ }^{18}$ Of particular importance is the action of calcium in flocculating colloids. Sodium salts, notably sodium carbonate, serve to deflocculate the soil colloids, although a sufficient concentration of sodium ions may even cause flocculation. The flocculation of soil particles is similar to the flocculation of suspensoid sols and is amenable to the isoelectric theory, except in the case of lime. ${ }^{19}$ Soil organic matter has a protective effect on the flocculation of clay. ${ }^{20}$

Calcium carrying a double positive charge precipitates the negative soil colloids, bringing about a change in the plastic properties of the soil. The soil structure is thus changed entirely; the resistance to penetration of moisture is reduced, an increase in pore space is brought about, and there is an increase in the water holding capacity of the soil. This improves the physical condition of the soil as a medium for the activities of microorganisms. Drying of the soil also causes a precipitation of colloids, but the change produced in the colloidal soil is reversible. The change produced by lime is not reversible.

The soil organic compounds contain reversible and irreversible colloids. The addition of lime brings about an increase in the watersoluble carbon compounds of the soil which favorably influences bacterial activities (in addition to favorable effect of reaction). This leads to a greater decomposition of the soil organic matter with the formation of $\mathrm{CO}_{2}, \mathrm{NH}_{3}$, nitrates and soluble phosphates. Thus the application of lime leads to a neutralization of the soil acids, an in-

${ }^{18}$ Dayhuff, W. C., and Hoagland, D. R. The electrical charge on a soil colloid as influenced by hydrogen-ion concentration and by different salts. Soil Sci., 18: 401-408. 1924.

${ }^{19}$ Comber, N. M. The mechanism of flocculation in soils. Trans. Faraday Soc., 17: 349. 1922; Jour. Agr. Sci., 10: 425-436. 1920; Mattson, S. E. Die Beziehungen zwischen Ausflockung, Adsorption, and Teilchenladung mit besonderer Berïcksichtigung der Hydroxylionen. Inaug. Diss. Breslau. 1922; Kolloid Chem. Beihefte, 14: 227-313. 1922.

20 Wolkoff, M. I. Studies on soil colloids. I. Flocculation of soil colloidal solutions. Soil Sci., 1: 5S5-601. 1916; Oden, Sven. Die Koagulation der Tone und die Schutzwirkung der Humussäure. Jour. Landw., 67: 177-208. 1919. 
crease in the decomposition of the soil organic matter, greater liberation of $\mathrm{CO}_{2}$, mineralization of the organic matter, absorption of bases and increase in colloidal matter. ${ }^{21}$

Van Bemmelen ${ }^{22}$ was the first to show that soil organic matter (humus) plays an important part in the absorption of both basic and acid radicals from the soil solution; this process of absorption was found to be similar in nature to that of an artificial calcium-aluminum silicate. However, different forms of absorption in the soil are often recognized :23 (1) biological absorption or the assimilation of the anions or cations by microorganisms; (2) mechanical absorption, or the mere mechanical retention of particles suspended in water; (3) physical, or surface adsorption, which may be positive or negative, depending on the fact as to whether the substance decreases or increases the surface tension of the dispersion medium; (4) physico-chemical, or adsorption in the narrow sense, which consists in the exchange of bases between the added salt and the zeolitic or alumino-silicate (and humic) complex of the soil; and finally (5) chemical absorption, or the chemical interaction between two substances giving difficultly soluble compounds, as in the formation of ealcium phosphate from the carbonate and soluble phosphate. Certain investigators, however, do not take the view that any sharp differentiation exists between chemical and physical reactions, which may all be due to electrical forces differing only in degree; this applies especially to the exchange of bases in the soil.

In proportion to their total mass, colloids exhibit a remarkable power of adsorption because of the large surface that they possess. Adsorption increases with the concentration of the solute. The absorption of ammonia by soils or by calcium silicates (permutite) from a solution of an ammonium salt follows the laws of adsorption. ${ }^{24}$ The same was found to hold true for the adsorption of other bases. Of the acids, the phosphates alone are absorbed, or rather precipitated on interaction

${ }^{21}$ Thaer, W. Der Einflusz von Kalk und Humus auf die mechanische, physikalische und chemische Beschaffenheit von Ton-, Lehm- und Sandboden. Gijttingen. 1910 (Centrhl. Bakt. II, 32: 271-274. 1912).

${ }^{22}$ van Bemmelen, J. M. Die Absorptionsverbindungen und das Absorptionsvermögen der Ackererde. Landw. Vers. Sta., 35: 69-136. 18ss; Die Absorption. Dresen. Steinkopff. 1910.

${ }^{23}$ Gedroiz, K. K. On the absorptive power of soils. Zhur. Opit. Agron., 19: 269-322. 1918; Leningrad. 1922.

${ }_{24}$ Wiegner, G. Zum Basenaustaush in der Ackererde. Jour. Landw., 60: $111-150,197-222.1912$. 
with the soil bases $(\mathrm{Ca}, \mathrm{Mg})$. When bases are absorbed by the soil, they displace an equivalent amount of another base which is combined in the soil either with the inorganic zeolites or with the organic compounds.

The adsorption of dyes by soils, which depends upon the surface of the soil, has been used for the estimation of colloids of the soil by assuming that only the colloids in the soil take part in this process. ${ }^{25}$

Colloids play an important part in making the soil a favorable medium for the growth of mieroorganisms, by absorbing the soluble fertilizing elements added to or produced in the soil and by their buffering properties in preventing rapid changes of the soil reaction. The growth of bacteria was found ${ }^{26}$ to be a function of the soil surface; in culture media colloidal silicic acid and its compounds, as well as colloidal ferric and aluminum hydrates and humus stimulate nitrogen fixation by Azotobacter, possibly by absorbing nitrogen gas. A colloid (like soil extract, gelatin, etc.) quickly shortens the period necessary for germination of the spores of Bac. amylobacter A. M. and Bred. in a nutrient solution. ${ }^{27}$ In the presence of 0.25 to 1.0 per cent gelatin, the period of incubation, from inoculation to beginning of fermentation, was reduced from fifty-one days in a nutrient solution free from colloids to three days. In the presence of a colloid, a clear zone is found to surround the spores; this zone is absent in a suspension of spores in a colloid-free solution. The shortening of the period necessary for spore germination depends on the dispersion of the eolloid and is explained chiefly by adsorption phenomena. ${ }^{28}$

${ }^{25} \mathrm{~A}$ detailed discussion of the subject of absorption is found in the following papers. Whitney, M., and Cameron, F. The chemistry of the soil as related to crop production. U. S. Dept. Agr. Bur. of Soils, Bul. 22. 1903; Bul. 23. 1904; Cameron, 1911 (p. xiv), p. 61; Wiegner, G. Die Festlegung des Stickstoffs durch sogenannte Zeolithe. Jour. Landw., 61: 11-56. 1913; Prescott, J. The phenomenon of absorption in its relation to soils. Jour. Agr. Sci., 8: 110-130. 1916; Gedroiz, 1922 (p. 629); Fischer, E. A. The phenomena of absorption in soils: a critical discussion of the hypotheses put forward. Trans. Farady Soc., 17: 305-316. 1922; Mattson, 1922 (p. 62S).

${ }^{26}$ Söhngen, N. L. Einflusz von Kolloiden auf mikrobiologische Prozesse. Centrbl. Bakt. II, 38: 621-647. 1913.

${ }^{27}$ Lantzsch, 1921 (p. 620).

${ }^{28}$ Further information on the influence of colloids upon the activities of microorganisms is given by Plotho, O. Der Einflusz kolloidaler Metallösungen aui niedere Organismen und seine Ursachen. Biochem. Ztschr., 110: 33. 1920; Schade, H. Die Kolloide als Träger der Lebenserscheinungen. Die Naturw., 9: 89-92. 1921. 
Bacteria are adsorbed by various colloids ${ }^{29}$ as well as by sand. ${ }^{30}$ Since soils contain an abundance of substances in a colloidal condition, it is but natural to expect a marked influence upon the bacteria. The following method can be used for the study of this phenomenon. ${ }^{31}$ One cubic centimeter of a bacterial culture is added to 9 cc. of water and the mixture placed in a flask containing 5 grams of soil. After shaking for one minute, the soil is allowed to settle for ten minutes. The number of bacteria is then determined in the suspension both by plating and by direct microscopic examination. It was found that pure sand has little adsorptive action. Some bacteria, like Bac. mycoides, Bact. prodigiosum and Staph. pyogenes, are adsorbed rapidly and completely (80 to 98 per cent); other bacteria, like Bact. coli, are only weakly adsorbed (10 to 20 per cent). Adsorption of the bacteria was found to lead to a diminution not only in numbers but also in their chemical activities. Decomposition of organic matter in the soil seems to be carried out largely by the unadsorbed bacteria, probably due to the lower oxygen tension upon the soil colloidal particles. Adsorption does not diminish the action of anaerobic bacteria upon organic matter in the soil.

The absorption of inorganic materials by microorganisms is quite marked, ${ }^{32}$ some bacteria and fungi possessing a greater absorptive power than higher plants per unit of cells. ${ }^{33}$

Soil solution. The water present in the soil and added through rainfall dissolves some of the soil constituents. If the soil conditions were stable the solution would soon become saturated. Constant evaporation, rainfall, change in weather conditions, development of

${ }^{29}$ Eisenberg, P. Ueber spezifische Adsorption von Bakterien. Centrbl. Bakt. I, Orig., 81 : 72-104. 1918.

${ }^{30}$ Frey, W., and Erismann, H. Beiträge zur Theorie der Bakterienfiltration. Centrbl. Bakt. I, 88: 306-336. 1922.

${ }^{31}$ Dianowa, E. W., and Woroshilowa, A. A. The adsorption of bacteria by soils and its influence upon microbiological activities (Russian). NautchnoAgron. Zhur. No. 10. 1925; Chudiakow, N. N. Centrbl. Bakt. II, 68: 345-358. 1926.

32 Beijerinck, M. W. Utber die Absorptionserscheinung bei den Mikroben. Centrbl. Bakt. II, 29: 161-166. 1911; Stoklasa, J. Über die biologische Absorption der Böden. Chem. Ztg., 35: 1425. 1911; Labes, R. Über die fc̈rdernde Wirkung von Kohlensuspensionen und anderen Körpern mit groszer Oberflächenentwicklung, etc. Biochem., Ztschr. 130: 1-13. 1922.

${ }^{33}$ Beard, E., and Cramer, W. Surface tension and fermentation action. Proc. Roy. Soc. B., 88: 575. 1915; 98: 584. 1915. 
acids by microorganisms, absorption of inorganic elements by higher plants, and many other changing conditions, cause an unceasing fluctuation in the composition and concentration of the soil solution. The osmotic pressure of the soil solution varies ${ }^{34}$ from 0.1 to 1 atmosphere in most soils to 4.5 to 16.5 atmospheres in soils with low moisture content. In normal soils, the concentration of the soil solution ranges between 0.1 and 1 atmosphere, depending on the rainfall, fertilization and plant growth..$^{35}$

The soil solution contains calcium nitrate and bicarbonates, some organic matter, $\mathrm{Na}, \mathrm{Mg}, \mathrm{Si}, \mathrm{Cl}, \mathrm{SO}_{4}$, small amounts of $\mathrm{K}$, and traces of ammonia and phosphates. The following constituents were found in a soil solution obtained by the soil pressure method ${ }^{36}$ (table 66).

It is from this solution that the microorganisms obtain a large part of their food and in it they leave their waste products. The colloidal

TABLE 66

Composition of soil solution

\begin{tabular}{|c|c|c|c|c|c|}
\hline \multirow{2}{*}{ NATURE OF SOIL } & \multirow{2}{*}{$\begin{array}{l}\text { MOISTURE IN } \\
\text { SOIL }\end{array}$} & \multicolumn{4}{|c|}{ PARTS PER MILLION OF SOIL SOLUTION } \\
\hline & & $\mathbf{K}$ & $\mathrm{PO}_{4}$ & $\mathrm{Ca}$ & $\mathrm{N}$ \\
\hline Fine sand $\ldots \ldots \ldots \ldots \ldots \ldots$ & 29.74 & 24.1 & 5.2 & 30.6 & 3.1 \\
\hline Losm. . . . . . . . . . . . . . . . . & 37.80 & 71.1 & 12.2 & 68.2 & 3.2 \\
\hline Clay ...... & 24.50 & 44.8 & 4.6 & 42.9 & 6.1 \\
\hline 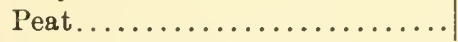 & 132.90 & 50.1 & 2.5 & 183.8 & 17.1 \\
\hline
\end{tabular}

nature of the soil has an important bearing upon the nature of the soil solution. The rates of solubility, decomposition of organic matter, carbon dioxide production, nitrification, absorption of the soluble constituents by plants, microorganisms and soil particles, all have an important bearing upon the nature and concentration of the soil solution. At a given moisture content, the rate of formation of soluble material increases with the temperature. ${ }^{37}$ At higher temperatures,

${ }^{34}$ Bouyoucos, G. J., and McCool, M. M. The freezing point method as a new means of measuring the concentration of the soil solution directly in the soil. Mich. Agr. Exp. Sta. Tech. Bul. 24. 1915; 27, 1916; 31. 1910.

${ }^{35}$ Hoagland, D. R. The freezing point method as an index of variations in the soil solution due to season and crop growth. Jour. Agr. Res., 12: 369-395. 1918.

${ }^{36}$ Morgan, J. F. The soil solution obtained by the oil pressure method. Soil Sci., 3: 531-545. 1917.

${ }^{37} \mathrm{McCool}, \mathrm{M}$. M., and Whiting, L. C. Some studies on the rate of formation of soluble substances in several organic soils. Soil Sci., 11: 233-247. 1921. 
optimum moisture conditions tend to bring greater amounts of material into solution than are found under saturated water conditions; with lower temperatures, the opposite effect was observed. Below two feet, the muck soils are very inactive, the ability of producing soluble materials decreasing regularly from the surface to the water level, indicating that aeration greatly influences this process.

A definite correlation was found ${ }^{38}$ between bacterial activities in the soil and the thickness of the moisture film. The optimum thickness of the film in the case of Bac. mycoides was found to be between 20 and 40 microns. This film was obtained in sand of $1 \mathrm{~mm}$. diameter at a moisture content of about 10 per cent. In arable soils with a grain size not more than $0.1 \mathrm{~mm}$., it would require more than 50 per cent of moisture to produce the optimum film thickness.

Lowering of the freezing point and conductivity of the soil ${ }^{39}$ can also be used as indices of changes in the composition of the soil solution. Pantanelli ${ }^{40}$ suggested the use of electrolytic conductivity of soils for studying the course of solubilization of soil constituents by microorganisms; this was found, in most cases, to vary with the bacterial content of the soil.

It is doubtful whether the actual concentration of the soil solution can be determined by the electrical bridge, since in most of these measurements an excess of water is added.

Soil reaction and microbiological activities. The nature and quantity of substances present in the soil in a colloidal condition, which act as buffers or are capable of combining with acids and bases, the nature and amount of bases present in the soil either in an absorbed condition or in the form of carbonates, influence the reaction of the soil, the medium in which the microorganisms live and act. Soil acidity may be due either to free organic and inorganic acids, which liberate hydrogenions, or to a non-saturation of the soil organic and inorganic complexes with bases, which results in a replacement of the base by hydrogen. ${ }^{41}$

${ }^{38}$ Rahn, 1913 (p. 623).

${ }^{39}$ Davis, R. O. E., and Bryan, H. The eleetrical bridge for the determination of soluble salts in soils. U. S. Dept. Agr. Bur. Soils, Bul. 61. 1910; König, J., Hasenbäumer, J., and Glenk, K. Über die Anwendung der Dialyse und die Bestimmung der Oxydationskraft für die Beurteilung des Bodens. Landw. Vers. Sta., 80: 491-534. 1913.

${ }^{40}$ Pantanelli, E. Elektrolytische Bestimmung der biologischen Bodenaufsehlieszung. Centrbl. Bakt. II, 42: 439-443. 1915.

${ }^{41}$ Gedroiz, K. K. Soils unsaturated with bases. Method of determining in soils the hydrogen present in an absorbed eondition. Soil requirement of lime 
When neutral salts are added to a soil, the cations are adsorbed, replacing the hydrogen ions, thus making the soil even more acid. ${ }^{42}$ It has also been suggested ${ }^{43}$ that acidity in well aerated soils is due to the hydrolysis of silicates; the bases are removed by plants or soil water, while the acid silicates are left behind.

Definite concentrations of free hydrogen-ions have actually been demonstrated in soils, and have been measured electrometrically ${ }^{44}$ and colorimetrically. ${ }^{45} \quad \mathrm{~A} \mathrm{pH}$ of 3.7 is the extreme value obtained for mineral acid soils, while values of $\mathrm{pH} 3.2$ have been reported for peat soils; $\mathrm{pH} 9.7$ to 10.0 were reported for alkaline soils (containing free sodium carbonate); fertile soils usually give a range of $\mathrm{pH}$ values of 6.0 to 7.5.

Soils are usually well buffered over considerable ranges of hydrogenion concentrations. ${ }^{46}$ By adding acid or base to a soil and titrating the resulting hydrogen-ion concentrations, a linear titration curve is

as a neutralizing agent (Russian). Zhur. Opit. Agron., 22: 3-27. 1924; see also Hissink, D. J., and Van der Spek, J. The acidity of the soil. Verslag. Land. Onderzoek, Rijksland., 27: 146-161. 1922 (Chem. Abstr., 16: 4293).

${ }^{42}$ Cameron, F. K. The soil solution. Easton, Pa. 1911; Kappen, H. Zu den Ursachen der Azidität der durch Ionenaustausch sauren Boden. Landw. Vers. Sta., 89: 39-80. 1916; 96: 277-307. 1920; Wrangell, M. Phosphorsäureaufnahme und Bodenreaktion. Landw. Vers. Sta., 96: 209-255. 1920; Harris, J. E. Soil acidity. Mich. Agr. Exp. Sta., Tech. Bul. 19. 1914; Jour. Phys. Chem., 18: 355. 1914.

${ }^{43}$ Truog, E. Cause and nature of soil acidity with special regard to colloids and adsorption. Jour. physik. Chem., 20: 457-4S4. 1916.

${ }^{44}$ Sharp, L. T., and Hoagland, D. R. Acidity and adsorption in soils as measured by the hydrogen electrode. Jour. Agr. Res., 7: 123-145. 1916; Soil Sci., 7: 196-200. 1919.

45 Gillespie, L. The reaction of soil and measurement of hydrogen-ion concentration. Jour. Wash. Acad. Sci., 6: 7-16. 1916; Soil Sci., 4: 313-319. 1917. An excellent theoretical discussion of the hydrogen-ion concentration of soils and culture media, methods for determination and applications to microbiological processes is given by L. Michaelis, Die Wasserstoffionenkonzentration. Berlin. 1922 ; Clark, 1922 (p.371). The use of the quinhydrone electrode for determining the soil reaction is discussed in detail by H. Christensen and S. T. Jensen, Untersuchungen bezüglich der zur Bestimmung der Bodenreaktion benutzten elektrometrischen Methoden. Intern. Mitt. Bodenk., 14: 1-26. 1924; and Baver, L. D. The use of the quinhydrone electrode for measuring the hydrogen-ion concentration of soils. Soil Sci., 21: 167-180. 1926.

${ }^{46}$ Charlton, J. The buffer action of some Burma soils. Mem. Dept. Agr. India, 7: 101-121. 1924; Jensen, S. T. Om bestemmelse af jordens stodpudevirkning. 177 Ber. Statens Forsogs. i. Plantenk, 1924; Arrhenius, O. Clay as an ampholyte. Jour. Amer. Chem. Soc., 44: 521-524. 1922; see also various papers in the Trans. second Comm. of the Intern. Soc. Soil Sci. Groningen. 1926. 
obtained which can serve as an index of the buffer content of the soil. The slopes of the curve vary with different soils according to their buffer content. It has been suggested ${ }^{47}$ that, although there may be no correlation between the reaction of an acid soil and crop growth, there is a definite correlation between the latter and the buffer content of the soil.

The concentration of carbon dioxide is of great importance in such a system of measurement, especially when a relatively poorly buffered soil extract is used. The actual soil solution surrounding the absorbing membrane of the plant roots may be slightly acid, although the soil suspension gives an electrometric measure of pH 7.0 and above. Titratible acidity has much wider ranges of variation due to difference in buffer content. A peat or clay soil may have the same hydrogen-ion

\section{TABLE 67}

Influence of different ritrogenous fertilizers upon the reaction of the soil $100 \mathrm{mgm}$. nitrogen added to 100 grams of soil

\begin{tabular}{|c|c|c|c|}
\hline INCUBATION & $\begin{array}{c}\text { UREA } \\
220 \text { MGM. }\end{array}$ & $\begin{array}{c}\left(\mathrm{NH}_{4}\right)_{2} \mathrm{SO}_{4} \\
500 \mathrm{MGM} .\end{array}$ & $\begin{array}{r}\mathrm{NaNO}_{3} \\
660 \mathrm{MGM}\end{array}$ \\
\hline & $p H$ & $p H$ & $p H$ \\
\hline Start............ & 6.45 & 6.45 & 6.45 \\
\hline 2 days $\ldots \ldots \ldots \ldots$. & 7.60 & 6.90 & 6.85 \\
\hline 35 days $\ldots \ldots$. & 6.25 & 6.20 & 6.80 \\
\hline 50 days $\ldots \ldots \ldots \ldots \ldots \ldots$ & 5.70 & 5.40 & 6.60 \\
\hline 76 days $\ldots \ldots \ldots \ldots \ldots$ & 5.35 & 5.10 & 6.55 \\
\hline
\end{tabular}

concentration as a sandy soil, but the titration (or lime requirement) of the first two soils will be much higher due to the greater buffer content.

When nitrogen-poor organic matter is added to the soil in the form of green manure or plant stubble, the first stage in the decomposition results in the formation of various organic acids, particularly in the absence of free calcium carbonate. ${ }^{48}$ If aeration, temperature and reaction favor a further decomposition of the organic acids thus formed, there may be a change in reaction to alkalinity, due to the formation

${ }^{47}$ Arrhenius, O. The potential acidity of soils. Soil Sci., 14: 223-232. 1922. A possible correlation between the fertility of rice soils and their titration curves. Ibid., 21-26.

${ }^{43}$ Charpentier, 1921 (p. 431). 
of $\mathrm{CO}_{2}$ and carbonates. ${ }^{49}$ The reaction of the soil as a result of application of fertilizer may change, according to the nature of the biological transformation of the fertilizer. Urea, for example, causes the soil reaction first to become alkaline because of the formation of ammonia and then acid because of the oxidation of the ammonia to nitric acid, as shown in table 67.50

The soil reaction is also influenced by the moisture content of the soil, application of fertilizers, green manures, stable manures, plants grown and other factors. ${ }^{51}$

The reaction of the soil has a definite influence upon the activities of various microorganisms $\mathrm{s}^{52}$ and upon the very distribution of the microflora and microfauna in the soil. An acid soil favors the development of fungi and is distinctly injurious to development of certain groups of bacteria, like Azotobacter, which has a limiting reaction at $\mathrm{pH}$ 6.0. Nitrifying bacteria are limited in their activities to a maximum acid range of $\mathrm{pH} 4.0$ to 4.6 ; Bact. radicicola has its limiting acid reaction at $\mathrm{pH} 3.4$ and $\mathrm{pH}$ 6.0. Actinomyces are inbibited in growth by reactions more acid than $\mathrm{pH} 4.8$; this fact is utilized for the control of Act. scabies causing potato scab in the soil. The application of lime to an acid soil has a favorable influence upon the bacteriological

${ }^{49}$ Coville, F. V. The formation of leafmold. Simithsonian Report for 1913: 333-343. 1914; Ayers, S. H., and Rupp, P. Simultaneous acid and alkali bacterial fermentations from dextrose and the salts of organic acids respectively. Jour. Inf. Dis., 23: 188-216. 1924.

${ }^{50}$ Brioux, Ch. Influence de l'urée employée comme engrais, sur la réaction du sol. Compt. Rend. Acad. Sci., 179: 914-917. 1924.

${ }^{51}$ Plummer, J. K. Studies in soil reaction as indicated by the hydrogen electrode. Jour. Agr. Res., 12: 19. 1918; Knight, H. G. Acidity and alkalinity of soils. Jour. Ind. Engin. Chem., 12: 559. 1920; Hardy, F. Soil sourness-its meaning and significance. West Indian Bul. 19: 37-85. 1921; Salter, R. M., and Morgan, M. F. Factors affecting soil reaction. I. The soil-water ratio. Jour. Phys. Chem., 27: 117-140. 1923; Fischer, E. A. Studies on soil reaction. Jour. Agr. Sci., 11: 19-44. 1921; Sci. Progr., 16: 408. 1922; Connor, S. D. Soil acidity as affected by moisture conditions in the soil. Jour. Agr. Res., 15: 321. 1918; Morse, F. W. Effect of fertilizers on hydrogen-ion concentration in soils. Jour. Ind. Engin. Chem., 10: 125. 1918; Atkins, W. R. G. Some factors affecting the hydrogen-ion concentration of the soil and its relation to plant distribution. Sci. Proc. Roy. Dublin Soc., 16: 369-413, 414-426, 429-434. 1922; Kappen, H., and Zapfe, M. Über Wasserstoffionenkonzentrationen in Auszügen von Moorböden und von moor- und rohhumusbildenden Pflanzen. Landw. Vers. Sta., 90: 321-374. 1917.

${ }^{52}$ Adam, A. Über die Bedeutung der Eigenwasserstoffzahl (des H-Ionen optimum) der Bakterien. Centrbl. Bakt. I, 87: 481-486. 1922. 
TABLE 68

Optimum and limiting reactions for the activities of microorganisms

\begin{tabular}{|c|c|c|c|c|}
\hline ORGANISMS & $\begin{array}{c}\text { ACID } \\
\text { MAXIMUM }\end{array}$ & OPTIMUM & $\begin{array}{c}\text { ALKALI } \\
\text { MAXIMUM }\end{array}$ & AUTHOR \\
\hline & $p H$ & $p H$ & $p H$ & \\
\hline Nitrosomonas... & 3.9 & $7.7-7.9$ & 9.7 & $\begin{array}{c}\text { Gaarder and } \\
\text { Hagem }\end{array}$ \\
\hline Nitrobacter.............. & 3.9 & $6.8-7.3$ & 13.0 & Meek and Lipman \\
\hline Nitrification in soils ....... & 3.5 & $6.5-7.5$ & $>11.9$ & $\begin{array}{l}\text { Gerretsen, Waks- } \\
\text { man }\end{array}$ \\
\hline Thiobacillus denitrificans.... & 5.0 & $7.0-9.0$ & 10.75 & Trautwein \\
\hline Th. thiooxidans........... & $1.0>$ & $2.0-4.0$ & $6.0(?)$ & $\begin{array}{l}\text { Waksman and } \\
\text { Starkey }\end{array}$ \\
\hline Bac. pycnoticus. & 5.2 & $6.8-8.7$ & 9.2 & Ruhland \\
\hline Bac, amylobacter. & $5.7>$ & $6.9-7.3$ & & Dorner \\
\hline Azotobacter..... & $5.6-6.0$ & $6.5-7.8$ & $8.8-9.2$ & $\begin{array}{l}\text { Gainey, Johnson } \\
\text { and Lipman, } \\
\text { Yamagato and } \\
\text { Itano, Stapp }\end{array}$ \\
\hline $\begin{array}{l}\text { Bact. radicicola of } \\
\text { Medicago and Melilotus... } \\
\text { Pisum and Vicia.......... }\end{array}$ & $\begin{array}{l}5.0 \\
4.8\end{array}$ & & & \\
\hline $\begin{array}{l}\text { Trifolium and Phaseolus.. } \\
\text { Soja } \ldots \ldots \ldots \ldots \ldots \ldots \ldots \\
\text { Lupinus } \ldots \ldots \ldots \ldots \ldots\end{array}$ & $\left.\begin{array}{l}4.3 \\
3.4 \\
3.2\end{array}\right\}$ & & 11.0 & $\begin{array}{l}\text { Fred and Daven- } \\
\text { port, Fred and } \\
\text { Loomis, Bryan }\end{array}$ \\
\hline Bact. coli................ & 4.4 & 6.5 & 7.8 & Dernby \\
\hline Bact. vulgare. . . . . . . . . . & 4.4 & 6.5 & 8.4 & Dernby \\
\hline Bact. pyocyaneurn......... & 5.6 & 6.8 & 8.0 & Dernby \\
\hline Bact. stutzeri............. & 6.1 & $7.0-8.2$ & $9.6-9.8$ & Zacharowa \\
\hline Bac, subtilis.............. & 4.2 & $7.5-8.5$ & 9.4 & Itano \\
\hline Bac. putrificus............. & 5.8 & 6.8 & 8.5 & Dernby \\
\hline Act. scabies............... & $4.8-5.0$ & $6.5-7.5$ & 8.7 & Gillespie, Waksman \\
\hline Mucor glomerula ........... & $3.2-3.4$ & & $8.7-9.2)$ & \\
\hline Asp. terricola............ & $1.6-1.8$ & & $9.0-9.3$ & Johnson \\
\hline Pen. italicum............ & $1.6-1.8$ & & $9.1-9.3$ & Jonnson \\
\hline Fus. oxysporum.......... & $1.8-2.0$ & & $9.2-11.1$ & \\
\hline Asp. niger. . . . . . . . . & 1.2 & $1.7-7.7$ & & $\begin{array}{l}\text { Terroine and } \\
\text { Wurmser }\end{array}$ \\
\hline Gibberella saubinetii. . ..... & 3.0 & $4.8-9.4$ & 11.7 & MacInnes \\
\hline $\begin{array}{l}\text { Spore germination of fungi.. } \\
\text { Protozoa: }\end{array}$ & $1.5-2.5$ & $3.0-4.0$ & & Webl) \\
\hline $\left.\begin{array}{l}\text { Paramoccium } \\
\text { Colpidium }\end{array}\right\}$ & $3.3-3.9$ & $7.0-7.4$ & 9.0 & Cutler and Crump \\
\hline
\end{tabular}


activities; the growth of microorganisms may even be stimulated more than that of higher plants grown upon the soil. ${ }^{53}$

Acids affect the activities of microorganisms not merely by creating a favorable or unfavorable hydrogen-ion concentration, but also through the undissociated part of the molecule. ${ }^{54}$

The optimum and limiting reactions of some typical soil organisms are indicated in table 68.

The soil atmosphere. The soil atmosphere is a mixture of gases which change constantly in composition, chiefly because of biological activities and also to some extent because of chemical processes. The composition of this atmosphere depends upon the amount and nature of the organic matter and upon environmental conditions. During dry seasons, when oxidation of the organic matter is low, the soil gases are rich in oxygen and poor in $\mathrm{CO}_{2}$. Soon after heavy rains, the oxygen content rapidly diminishes and the $\mathrm{CO}_{2}$ content increases because of the active oxidation of the soil organic matter. The nitrogen content of the atmosphere of aerated soils does not vary appreciably and is not affected either by the assimilation of nitrogen by bacteria or by its liberation from the decomposition of the nitrogen compounds of the soil. In rice soils, which are kept under water, a large part of the nitrogen may be derived from the soil organic matter. For collecting and analyzing the soil gases, the apparatus shown in figure 58 may be employed.

The amount of carbon dioxide in fallow land is smaller than in soil which is vegetated. The atmosphere of soil freshly treated with farm manure or green manure contains a high proportion of $\mathrm{CO}_{2}$ and a low proportion of oxygen. ${ }^{543}$ The actual $\mathrm{CO}_{2}$ content of the soil atmosphere thus depends upon a number of factors, including (1) $\mathrm{CO}_{2}$ production in the soil from the decomposition of organic matter and interaction between carbonates and acids; (2) diffusion of the $\mathrm{CO}_{2}$ in the soil atmosphere; (3) assimilation of $\mathrm{CO}_{2}$ by plants. ${ }^{55}$ A large part of the

${ }^{53}$ Brown, P. E. Some bacteriological effects of liming. Centrbl. Bakt. II, 34: 148-172. 1912; 35: 234-248. 1912; Waksman, 1922 (p. 712).

${ }^{54}$ Hall, I. W., and Fraser, A. D. The action of dilute acids upon bacterial growth in optimum hydrogen-ion concentration. Jour. Pathol. Bact., 25: 19-25. 1922.

${ }^{542}$ Attention need only be called here to the early contribution of Boussingault and Lewy. Mémoire sur la composition de l'air confiné dans la terre végétale. Am. Chim. Phys. (3 ser.). 37. 1853.

${ }_{55}$ Romell, L. G. Die Bodenventilation als ökologischer Faktor. Meddel. fran Statens Skogsförsoks. H. 19. 1922; Lundegardh, H. Der Kreislauf der Kohlensäure in der Natur. G. Fischer, Jena. 1924. 
$\mathrm{CO}_{2}$ is present in the soil solution. Diffusion of $\mathrm{CO}_{2}$ into the atmosphere and of oxygen into the soil is very rapid at a depth of six inches, ${ }^{56}$ as shown in table 69 .

The soil atmosphere shows much greater fluctuations in composition than atmospheric air. On the average, the soil air was found ${ }^{57}$ to contain 0.25 per cent $\mathrm{CO}_{2}$ and 20.6 per cent oxygen. From November to May the curves for $\mathrm{CO}_{2}$ follow closely those of the soil temperature; from May to November they follow rainfall and to a less extent the soil temperature curves. The favorable effect of rainfall is believed to be due ${ }^{58}$ to the dissolved oxygen brought down.

While the decomposition of green manure in normal soils leads to the formation of carbon dioxide, the gases formed under anaerobic

TABLE 69

Composition of gas in variously treated soils

\begin{tabular}{|c|c|c|c|c|c|}
\hline & \multicolumn{5}{|c|}{ AVERAGES OF SEVERAL DETERMINATIONS, IN PER CENT } \\
\hline & \multicolumn{2}{|c|}{ Fallow land } & \multirow{2}{*}{$\begin{array}{l}\text { Gases near } \\
\text { roots } \\
\text { of corn }\end{array}$} & \multirow{2}{*}{$\begin{array}{c}\text { Green } \\
\text { manured } \\
\text { land }\end{array}$} & \multirow{2}{*}{$\begin{array}{c}\text { Swamp } \\
\text { rice land }\end{array}$} \\
\hline & $\begin{array}{c}\text { Before } \\
\text { rainfall }\end{array}$ & $\begin{array}{c}\text { After } \\
\text { rainfall }\end{array}$ & & & \\
\hline Nitrogen . . . . . . . . . . & 78.05 & 78.83 & 80.15 & 79.18 & 85.59 \\
\hline Oxygen ............... & 20.40 & 19.26 & 9.00 & 7.71 & 0.54 \\
\hline Carbon dioxide... & 0.58 & 0.95 & 9.11 & 12.03 & 4.42 \\
\hline Hydrogen ............ & None & None & 0.73 & 0.07 & 6.42 \\
\hline Methane.............. & None & None & None & None & 2.81 \\
\hline 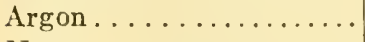 & 0.977 & 0.955 & 1.010 & 1.003 & 0.893 \\
\hline$\frac{N}{A} \cdots \cdots$ & 80.0 & 82.5 & 79.5 & 78.8 & 95.7 \\
\hline
\end{tabular}

conditions, as in swamp rice soils, are largely methane, a small amount of nitrogen, carbon dioxide, and hydrogen. ${ }^{59}$

An increase in atmospheric pressure brings about first an increase

${ }^{66}$ Leather, J. W. Soil gases. Mem. Dept. Agr. India, Chem. Ser., 4: 85134. 1915.

${ }^{57}$ Russell, E. J., and Appleyard, A. The atmosphere of the soil; its composition and the cause of variation. Jour. Agr. Sci., 7: 1. 1915.

${ }^{58}$ See also Potter, R. S., and Snyder, R. S. Carbon dioxide production in soils and carbon and nitrogen changes in soils variously treated. Iowa Agr. Exp. Sta. Res. Bul. 39. 1916.

${ }^{69}$ Harrison, W. H., and Aiyer, P. A. S. The gases of swamp rice soils, their composition and relationship to the crop. Mem. Dept. Agr. India, Chem. Ser., 3: 65-106. 1913. 
in the activities of certain microorganisms, such as the autotrophic bacteria, and then a slackening. ${ }^{60}$

The $\mathrm{CO}_{2}$ of the soil atmosphere was found ${ }^{61}$ to be a more important source of carbon for the growth of plants than the $\mathrm{CO}_{2}$ of the air. Plants thus depend entirely upon the activities of the microorganisms in the soil for their $\mathrm{CO}_{2}$, which is liberated largely as a result of the decomposition of the soil organic matter.

Soil temperature. Soil temperature is affected by climate, season of year, chemical and mechanical composition of soil, topography, and soil treatment. In the spring of the year, fine-grained soils containing a large amount of water warm up more slowly than coarse-grained soils containing a relatively small amount of moisture. The heat conductance of the specific soil constituents is of importance as well as the cultivation of the soil which influences the rate of evaporation. In general, sandy soils and sandy loams warm up more quickly in spring than heavy clay and clay loam soils; microbial activities are, therefore, sooner accelerated in the spring in the first types of soil than in the second. ${ }^{62}$

The colloidal condition of the soil and the soil organic matter are modified in the temperate climates by the action of frost during the winter, so that, when the soil finally warms up in the spring and loses the excess moisture, a rise in biological activities takes place. ${ }^{63}$ In the summer months there is a drop to normal which is undoubtedly due to the fact that the available energy has been largely used up and the soil may lack in sufficient moisture. In the autumn there is another rise in biological activities which is probably due to the addition of plant residues. The drop in winter is due to low temperature. Bacterial activities are not, however, entirely suspended at low temperatures. The activities of some of the most important soil organisms become marked at temperatures above $10^{\circ} \mathrm{C}$. with an optimum at $25^{\circ}$. A detailed study of the influence of temperature upon the biological activities in the soil is given elsewhere (p. 774).

${ }^{60}$ Berghaus, W. H. Über die Wirkung der Kohlensiure, des Sauerstoffs und des Wasserstoffs auf Bakterien bei verschiedenen Druckhöhen. Areh. Hyg., 62: 172-200. 1907; Chlopin, G. W., and Tammann, G. Einflusz hoher Drueke auf Mikroorganismen. Ztsehr. Hyg., 45: 171-204. 1903.

${ }^{61}$ Lundegardh, H. Klima und Boden. Fischer, Jena. 1925.

${ }^{62}$ Lipman, J. G. Mierobiology of soil. In Marshall's Mierobiology. 3d Ed. 345-427. 1921.

${ }^{63}$ Müntz, A., and Gaudechon, H. Le réveil de la terre. Ann. Sci. Agron. (4), 2: 1-15. 1913. 
Grouth of microorganisms in soil in pure and mixed culture. There is no method available for sterilizing the soil without changing its physical and ehemical properties. The common method used at present for sterilizing the soil consists in heating it in flowing steam for thirty minutes on seven consecutive days, ${ }^{64}$ or at high pressure (15 pounds) for two hours. Both of these treatments eause a decided change in the physical and chemical condition of the soil which results in an increase in the available organic matter in the soil. Sterile soil forms an excellent medium for the development of various bacteria and other microorganisms. ${ }^{65}$ A number of soil organisms, such as Azotobacter or Bac. amylobacter, will regain their vigor of fixing nitrogen, when cultivated in sterile soil. ${ }^{66}$

However, from processes carried out by pure eultures of microorganisms grown in sterile soil we cannot determine what actually occurs in normal soils. Not only is the nature and the composition of the culture medium completely changed by sterilization of soil, but the various antagonistic and associative influences which are active in normal soils are eliminated. This can be readily illustrated by the following instances. An organism belonging to the Bac. mesentericus group was found ${ }^{67}$ capable of dissolving and clarifying cultures of Bact. coli, Staphylococcus, and other bacteria, a phenomenon which may not take place in pure culture. The inhibitive effects of filamentous fungi, especially of ascomycetes, on the growth of mieroorganisms has been commonly observed ${ }^{68}$ this may be due to exhaustion of nutrients or formation of some toxic products during growth. ${ }^{69}$ Various symbiotic processes take place in the soil, such as the symbiosis between the chlorophyll-bearing algae and the nitrogen fixing Azotobacter, between the anaerobic $\mathrm{Cl}$. pastorianum and the aerobic Azotobacter, between Azotobacter and cellulose-decomposing bacteria. Then we have proc-

${ }^{64}$ Eekelmann, E. Über Bakterien, welehe die fraktionierte Sterilization lebend überdauern. Centrbl. Bakt. II, 48: 140-178. 1918.

${ }^{65}$ Barthel, C. Kulturen von Mikroorganismen in sterilisierter Erde. Centrbl. Bakt, II, 48: 340-349. 1918.

${ }^{66}$ Bredemann, 1909 (p. 111).

${ }^{67}$ Kimmelstiel, P. Über eine biologische Eigenschaft eines Wurzelbazillus. Centrbl. Bakt. I, Orig. 89: 113-115. 1922.

${ }^{68}$ Porter, C. L. Concerning the charaeters of certain fungi as exhibited in their growth in the presence of other fungi. Amer. Jour. Bot., 11: 168-188. 1924.

${ }^{69}$ Liesegang, R. Gegenseitige Waehstumshemmung bei Pilzkulturen. Centrbl. Bakt. II, 51: 85-86. 1920. 
esses which depend upon the activities of other microorganisms: the nitrite-forming bacteria depend upon the heterotrophic bacteria and fungi for ammonia, the nitrate bacteria depend upon the nitrite formers for nitrite, the sulfur bacteria depend upon the heterotrophic organisins for the decomposition of the proteins and liberation of the $\mathrm{H}_{2} \mathrm{~S}$.

The soil population. In the complex medium of the soil and under the influence of various physical, chemical and environmental conditions, soil microorganisms carry on their activities, not as individual forms or even as groups, but as a soil population. The most common soil bacteria, including the heterotrophic spore-formers (Bac. cereus, Bac. mycoides, Bac. mesentericus, etc.) and the non-spore formers (Bact. fluorescens, Bact. caudatum, Bact. radiobacter, etc.), the nitrogen-fixing Azotobacter and $\mathrm{Cl}$. pastorianum, the nitrifying bacteria, etc., are of universal occurrence, limited only by specific soil conditions, such as reaction. They are reported from all soils, from East and West, North ${ }^{70}$ and South. The most common soil protozoa, including the amoebae, flagellates and ciliates, are also universally distributed in the soil. ${ }^{71}$ The common soil fungi, including species of Zygorhynchus, Trichoderma, Penicillium, etc., have also been isolated from various soils coming from different parts of the world. ${ }^{72}$ The same is true of algae and other soil microorganisms.

As a result of soil conditions this population shows quantitative, rather than qualitative differences. Excessive moisture, for example, stimulates the development of anaerobic bacteria ${ }^{73}$ but inhibits the development of aerobic forms like Azotobacter and fungi. Excessive acidity and a high content of organic matter rich in carbohydrates greatly stimulate the development of fungi. Applications of lime and the addition of organic matter rich in protein stimulate the development of bacteria and actinomyces.

We are thus fully justified in speaking of a soil population and may even accept the idea of an Edaphon as suggested by Francé, ${ }^{74}$ although his conclusion that the edaphon is an indicator of soil fertility may not be fully justified. ${ }^{75}$ The composition and activities of the soil popula-

70 Barthel, Chr. Recherches baetériologiques sur le sol et sur les matières fécales des animaux polaires du Groenland Septentrional. Saertr. Meddl. Gronland., 64. 1922.

${ }^{71}$ Sandon, 1924-1927 (p. 329).

72 Waksman, 1917 (p. 237).

${ }^{73}$ Winogradsky, 1924 (p. 542).

${ }^{7}$ Francé, R. H. Das Fidaphon, Stuttgart. 1921.

${ }^{75}$ Fischer, H. Cibt es ein Edaphon? Int. Mitt. Bodenk., 13:192-200. 1923. 
tion is controlled by the nature of the soil and other environmental conditions. The magnitude of the population is especially controlled by the supply of available energy. It may be controlled qualitatively by the nature of the available energy.

Very little is known concerning the rôle of the rhizosphere, or the subterraneous part of the plant system, in controlling this population. The concept of this system and its possible influence upon the soil population was first introduced by Hiltner. ${ }^{76}$ It is known (p. 792) that plants actually secrete carbohydrates and phosphatides. ${ }^{77}$ The sloughed off portions of the root caps, the root hairs, etc., may influence greatly the nature of the population developing in their neighborhood. The nature of the gases formed by the plants also influences the nature of the organisms developing in the particular locality. A certain soil decomposes cellulose with varying rapidity according to the kind of plants which have been growing in it; also, the nature of the organisms taking part in the decomposition of the cellulose varies with the plants grown in the soil. ${ }^{78}$ Further studies in this direction are much needed.

${ }^{76}$ Hiltner, 1904 (p. 128).

${ }^{77}$ Hansteen Cranner, B. Zur Biochemie und Physiologie der Grenzschichten lebender Pflanzenzellen. Meld. Norges. Landbruks., 2. 1922.

${ }^{78}$ Rokitzkaia, A. Aerobic fermentation of cellulose under the influence of soilmicroflora in the root-zone of plants. Jour. Sci. Inst. Amelior. Leningrad., 13: 168-208. 1926. 


\section{CHAPTER XXV}

\section{Transformation of Minerals in the Soll}

Nature of mineral transformation by microorganisms. Among the mineral elements of plant food which are subject directly or indirectly to the action of microorganisms, the following may be included: phosphorus, sulfur, potassium, calcium, magnesium, iron, sodium, manganese, also chlorine, aluminum, zinc and silicon. The transformation of the elements and compounds of carbon, nitrogen, hydrogen and oxygen, both in organic and inorganic combinations, are considered in detail elsewhere. The above minerals are transformed in the soil by different processes:

1. Mineral elements (S, Fe, Mn, etc.) or their inorganic compounds may be used by certain bacteria as sources of energy.

2. Certain salts (nitrates, sulfates, etc.), rich in oxygen, may be used, under conditions favoring anaerobiosis, as sources of oxygen. This usually leads to the reforming of substances which have been acted upon in the processes of oxidation.

3 . The transformation of minerals present in the soil in the form of complex organic compounds. When the bodies of plants, animals and microorganisms are decomposed or mineralized by the soil microorganisms, a part of the minerals is liberated in the form of inorganic compounds and a part may be reassimilated.

4. The assimilation of minerals by microorganisms. In the presence of available energy, simple inorganic salts are converted into complex organic compounds; this is especially true of phosphates, potassium salts and sulfates and leads to a temporary removal of the soluble salts. Most of these materials are again made available upon the death and decomposition of the microbial cells, as described in the third process.

5. The indirect transformation of minerals in the soil by products of the metabolism of microorganisms. The action of carbon dioxide, organic and inorganic acids upon carbonates, phosphates and silicates is largely due to the change in the $\mathrm{H}^{+}$or the $\mathrm{OH}^{-}$concentrations of the soil. This is even true of the interaction between insoluble phosphates and the "humic acids."'

Phosphates, sulfates and salts of potassium, calcium and magnesium (iron salts in smaller amounts), are the most important compounds in

1 Baumann and Gully, Mitt. K. Bayr. Moork. 4: 31-156, 1910; Niklas, N. Untersuchungen über den Einflusz von Humusstoffen auf die Verwitterung der Silikate. Diss. München 1912. 
the metabolism of all microorganisms. Large quantities of these are taken from the soil solution and synthesized into microbial protoplasm. Notwithstanding the fact that in the decomposition of plant residues and animal manures, phosphates and potassium salts are quite soluble, Krawkow ${ }^{2}$ found that when organic matter is decomposed in the soil by microorganisms, calcium and magnesium are less soluble. The decomposition and synthesis of organic matter in the soil takes place constantly and leads to constant changes in the amount of available minerals in the soil. It has been suggested ${ }^{3}$ that fungi take a more active part in the decomposition of mineral soil constituents than root secretions of higher plants. A great many bacteria also play important rôles in the process. The fungi and algae as well as other groups of microorganisms store away considerable quantities of soluble minerals in the form of microbial protoplasm due to the extensive growth of the organisins in the presence of available energy. ${ }^{4}$

Decomposition of rocks and rock constituents by microorganisms. Not only the mineral constituents of normal soils but rocks as well may undergo disintegration and degradation through the action of microorganisms. Autotrophic bacteria obtain their carbon from the carbon dioxide of the atmosphere and their energy from inorganic substances of the soil or ammonia formed by electrical discharges and rainfall; algae utilize the photosynthetic energy of the sun. The various inorganic and organic acids formed by these organisms exert solvent action upon the rocks.

The chemosynthetic assimilation of $\mathrm{CO}_{2}$, fixation of nitrogen, and denitrification are considered ${ }^{5}$ as the three most primitive activities of microorganisms in the development of life upon this planet. It has been demonstrated ${ }^{6}$ that various algae, particularly the Cyanophyceae, exert a corroding effect upon stones. Diatoms transform alumi-

${ }^{2} \mathrm{Krawkow}, \mathrm{S}$. The processes of interaction of the soluble products of decomposition of organic matter with the soil constituents. Zhur. Opit. Agron., 9: 569-624. 1908; 10: 1-34. 1909.

${ }^{3}$ Kunze, F. Über Säuereausscheidung bei Wurzeln und Pilzhyphen und ihre Bedeutung. Jahrb. wiss. Bot., 42: 357-391. 1906.

${ }^{4}$ Pantanelli, 1915 (p. 633).

' Fischer, H. Physiologische Leistungen primitivster Organismen in ihrer stammesgeschichtlichen Bedeutung. Centrbl. Bakt. II, 55: 1-5. 1921.

${ }^{6}$ Jensen, P. R. Über Steinkorrosion an den Ufern von Furesö. Intern. Rev. ges. Hydrob. Hydrogr. Leipzig, 2. 1909; Roux, M. Recherches biologiques sur le lac d'Annecy. Ann. biol. lacustre., 2. 1907. 
num silicates into hydrated aluminum oxide. ${ }^{7} \quad$ Müntz $^{8}$ suggested in 1890 that bacteria are concerned in rock decomposition, their action being confined not only to the surface but often entering into the depth of the rock mass; nitrifying organisms were always demonstrated in decomposed rocks. Other investigators ${ }^{9}$ also suggested that bacteria are possible agents in the decomposition of rocks.

Certain bacteria were found ${ }^{10}$ capable of deriving their necessary mineral nutrients from feldspars, bringing considerable quantities of undecomposed orthoclase into solution, probably by means of the carbon dioxide which is formed. The action of a number of bacteria, including $B$. extorquens, nitrate-forming and butyric acid organisms, as well as yeasts, upon twelve different silicates and upon apatite was investigated. The bacteria were able, by means of their products of respiration, to dissolve considerable amounts of pulverized silicates; the formation of organic acids by Bac. amylobacter markedly influenced the solubility of silicates. The intensity of contact of the organism with the mineral to be acted upon was found to be of even greater importance than the other agents of solubility. Thus, $B$. extorquens, which produced only carbon dioxide but which formed a close and firm envelope around the mineral particles, had the strongest solvent action. Yeasts which do not form as close a contact, although they produce more carbon dioxide, brought about less solubility. Nitrite forming bacteria, as a result of the production of a strong inorganic acid $\left(\mathrm{HNO}_{2}\right)$, caused a considerable solubility of the silicates. Minerals rich in alkaline earths were most readily acted upon. Apatite dissolves only to a limited extent in carbonic acid and only those bacteria which produce organic acids can bring about a considerable solubility. The chemical constituents of the minerals were found ${ }^{10}$ in the filtrates of the bacterial cultures, especially in case of $B$. extorquens. The alkalies came into solution first, followed by the alkaline earths and iron; silicic acid and aluminum oxide came into solution last.

${ }^{7}$ Vernadsky, W. J. Sur le problème de la décomposition du kaolin par les organismes. Compt. Rend. Acad. Sci., 175: 450-452. 1922; see also Stoklasa, J. Úber die Verbreitung des Aluminums in der Natur. G. Fischer, Jena. 1922.

${ }^{8} \mathrm{Müntz}, \mathrm{A}$. Chimie agricole. Sur la décomposition des roches et la formation de la terre arable. Compt. Rend. Acad. Sci., 110: 1370-1372. 1890.

- Merrill, G. P. Disintegration of the granite rocks of the District of Columbia. Bul. Geol. Soc. Am., 6: 321-332. 1895.

${ }^{10}$ Bassalik, K. Úber Silikatzersetzung durch Bodenbakterien. Ztschr. Gärungsphysiol., 2: 1-32. 1912; 3: 15-42. 1913. 
Kamamura ${ }^{11}$ described an organism, Volcanothrix silicophila, found in the volcanic material in Japan at an altitude of 6600 feet, which formed a zoogloeal mass, the ash of which contained 8.873 per cent silica.

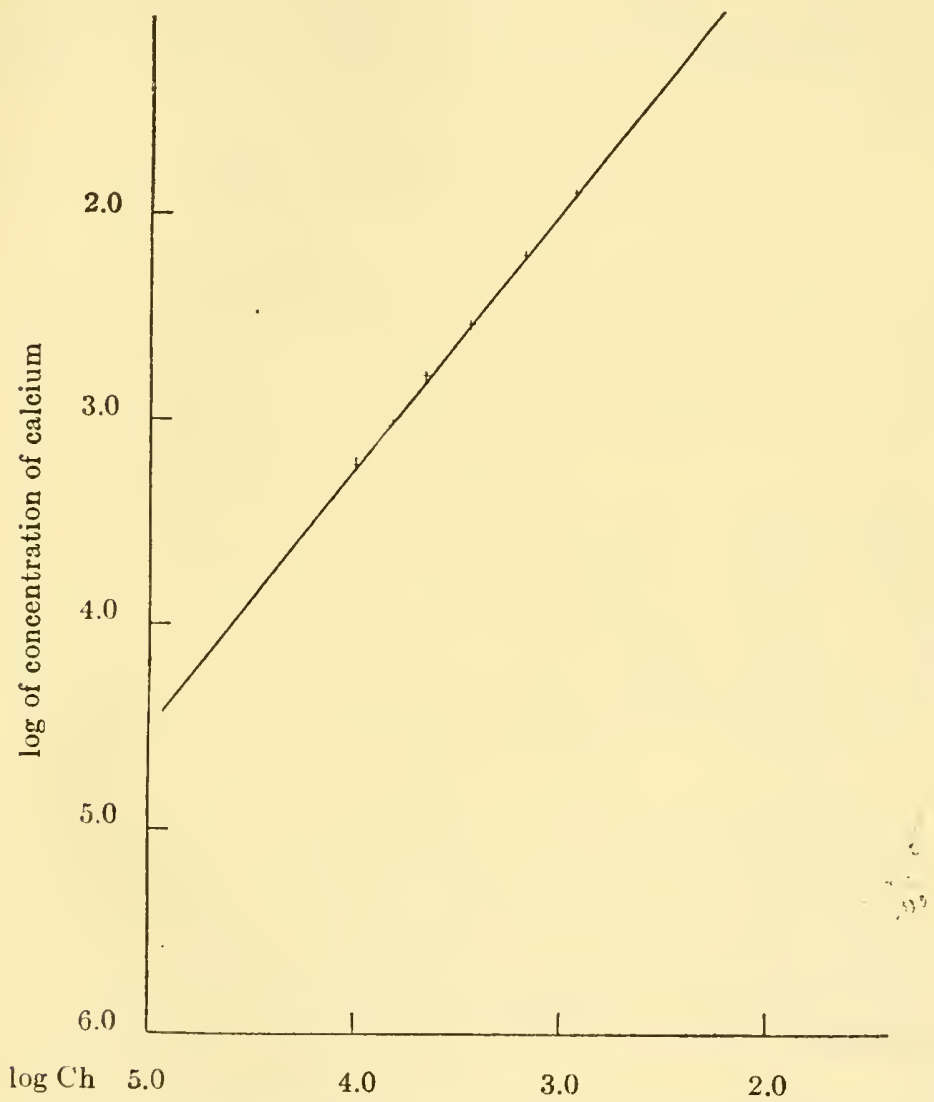

FIG. 48. Influence of sulfuric acid upon the solubility of ealcium silicate (from Wright).

The presence of bacteria was also found to increase the etching power of the roots of plants. ${ }^{12}$

A certain relationship exists between the hydrogen-ions produced by

${ }^{11}$ Kamamura (cited by Wright, 1922 (p. 648)).

${ }^{12}$ Fred, E. B., and Haas, A. R. C. The etching of marble by roots in the presence of bacteria. Jour. Gen. Physiol., 1: 631-638. 1919. 
bacteria and the amount of bases brought into solution from the mineral, since the magnitude of the effect of bacterial end-products upon a mineral depends upon the equilibrium established. ${ }^{13}$ It was suggested that the action of bacterial end-products, acid in nature, upon minerals is explainable as a chemical reaction. Figures 48 and 49 show the action of mineral acids and bacterial cultures upon some typical sili-

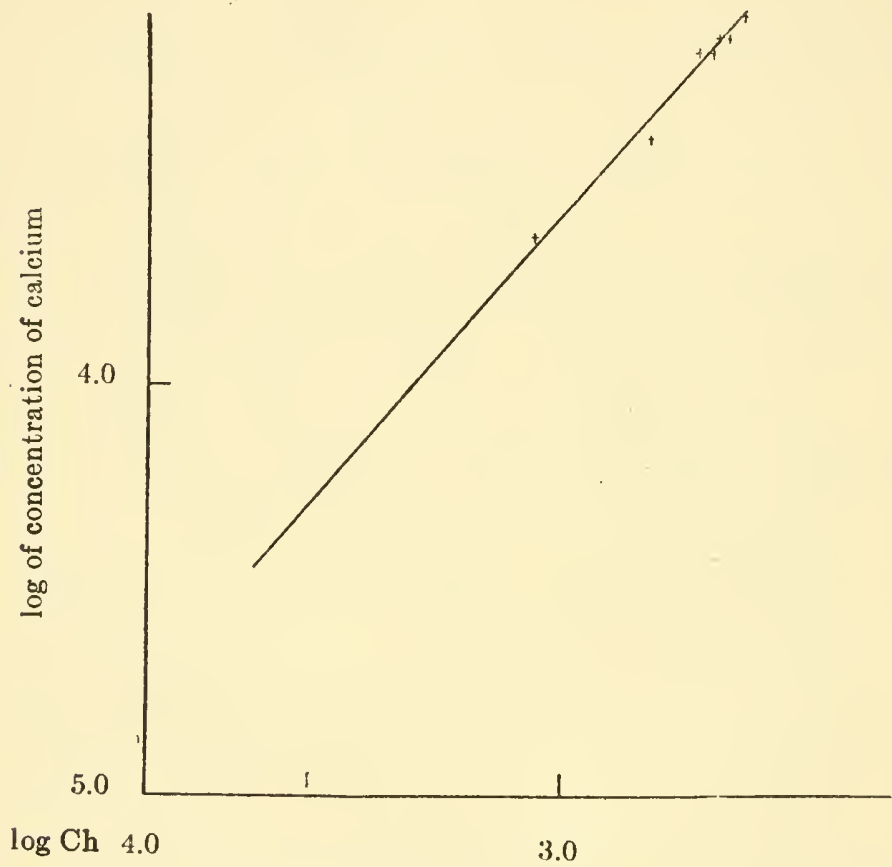

FIG. 49. Influence of B. lactis acidi upon the solubility of orthoclase (from Wright).

cates. The numbers along the ordinates represent the logarithms of the hydrogen-ion concentration, or $\log \mathrm{Ch}$. Those along the abscissac measure the logarithm of the concentrations, or $\log$ of $\mathrm{Ca}$, of $\mathrm{Mg}$, of Fe or $\mathrm{K}$.

${ }^{13}$ Wright, D. Equilibrium studies with certain acids and minerals and their probable relation to the decomposition of minerals by bacteria. Univ. Cal. Publ. Agr. Sci., 4: 247-337. 1922. 
Definite information is available on the transformation of a few of the more important mineral elements by microorganisms; some of the rarer elements, such as $\mathrm{Ni}$ and $\mathrm{Co},{ }^{14}$ exist in the soil in small quantities and probably play a rôle in the activities of microorganisms. A detailed study of the transformation of sulfur in nature is given elsewhere (p. 600).

Nature of phosphorus compounds in the soil. Phosphorus undergoes various changes in the soil as a result of activities of microorganisms. When organic matter is mineralized, the phosphorus is liberated in the form of inorganic salts; the latter may be reassimilated by the same or by other microorganisms and synthesized into microbial protoplasm, especially in the presence of available energy. Insoluble inorganic phosphates may be made soluble, as a result of the action of the products of metabolism of microorganisms, including carbon dioxide and the various organic and inorganic acids. Phosphorus compounds may also be reduced by microorganisms. ${ }^{15}$

Phosphorus is present in normal soils in the form of inorganic and organic compounds. The inorganic compounds include mono-, di-, tri-, and tetra-phosphates of potassium, sodium, calcium, magnesium, aluminum, iron and manganese. The organic compounds comprise the phosphorus of plant and animal residues and that in the living or deacl protoplasm of microorganisms: these include various compounds, such as nucleic acids, ${ }^{16}$ lecithin ${ }^{17}$ and phytin. ${ }^{18}$ Phosphorus is usually added to the soil in the form of superphosphates, insoluble tri- and tetracalcium phosphates, and organic forms, both in plant residues and in organic fertilizers. When soluble phosphates, such as superphosphate, are added to the soil, they interact with the hydroxides, carbonates, silicates and tri-phosphates of calcium, magnesium, iron and aluminum to give insoluble precipitated phosphates. Superphosphates were found to change, in the presence of sufficient $\mathrm{CaCO}_{3}$ in the soil, into

${ }^{14}$ Bertrand, G., and Mokradnatz, M. Sur la présence simultanée du nickel et du cobalt dans la terre arable. Ann. Sci. Agron. 1921, 179-182.

${ }^{15}$ Rudakov. Viestnik Bakteriol. Agron. Sta. Moskau. No. 26. 1926.

${ }_{16}$ Shorey, E. Nucleic acid in soils. Science N. S., 35:390. 1911; Biochem. Bull., 1: 104. 1911; Some organic soil constituents. U. S. Dept. Agr., Bur. Soils, Bul. 8S. 1913.

${ }^{17}$ Stoklasa, J. Biochemischer Kreislauf des Phosphat-Ions im Boden. Centrbl. Bakt. II, 29: 385-519. 1911.

18 Auten, J. T. Organic phosphorus of soils. Soil Sci., 16: 281-294. 1923; see also Aso, K. On organic compounds of phosphorus in soils. Bul. Coll. Agr. Tokyo Imp. Univ., 6: 277-294. 1904. 
insoluble phosphates, within 50 to 60 days. Normal soils contain 0.025 to 0.3 per cent of phosphorus, very little of which is soluble in pure water, but quite appreciable quantities are soluble in water containing carbon dioxide. In fertile soils, the phosphorus is present partly in the form of organic phosphorus compounds. ${ }^{18}$ A part or even all the organic phosphorus found in the soil may be in the form of bodies of microorganisms. ${ }^{19}$ The total phosphorus brought into the soil by a two ton crop of green manure (including roots) may amount to 20 to 50 pounds $\mathrm{P}_{2} \mathrm{O}_{5}$ per acre. The $\mathrm{P}_{2} \mathrm{O}_{5}$ content of straw is 0.15 to 0.30 per cent, of clover and timothy hay 0.50 to 0.55 per cent, of fresh horse manure (without straw) 0.34 , cow manure 0.21 , sheep manure 0.40 , chicken manure 0.83 per cent. ${ }^{20}$

The following analysis of the dry matter of a few typical bacteria show that these organisms can store away considerable quantities of phosphorus, ${ }^{17}$ (table 70). Seventy-nine to 81 per cent of this phosphorus was found to be in the form of nucleic acid and 7.6 to 8.6 per cent as lecithin. The ash of yeasts may consist of 60 per cent $\mathrm{P}_{2} \mathrm{O}_{5}$. The ash of fungi, however, contains a lower concentration of phosphorus than yeasts and bacteria, depending largely on the phosphoric acid content of the medium. A more or less constant nitrogenphosphorus ratio $\left(\mathrm{N}: \mathrm{P}_{2} \mathrm{O}_{5}=4.2 \%: 2.0 \%\right)$ was found ${ }^{21}$ in the dry mycelium of Asp. niger. A similar ratio is found in the cells of other organisms and in the soil organic matter, pointing to a definite $\mathrm{c} / \mathrm{p}$ (organic) ratio in the soil.

The presence of phosphorus is so important for the growth of microorganisms that a direct correlation has been found between the amount of available phosphate in the medium and the growth, mannite decomposition and nitrogen fixation by Azotobacter (see p. 577).

Decomposition of organic phosphorus compounds by microorganisms. A large number of microorganisms including various heterotrophic bacteria, fungi and actinomyces, are capable of decomposing organic phosphorus compounds.

Lecithin contains 9.39 per cent $\mathrm{P}_{2} \mathrm{O}_{5}, 1.6$ per cent $\mathrm{N}$ and 65.36 per cent C. It contains two fatty acid radicils, usually palmitic and stearic or oleic, which are rather poor sources of carbon for microorganisms.

${ }^{19}$ Gortner, R. A., and Shaw, W. M. The organic matter in the soil. V. Some data on humus-phosphoric acid. Soil Sci., 3: 99-111. 1916.

20 Thorne, 1914 (p. 429).

21 Schmücke, R. Der Phosphorstoffwechsel einiger Pilze, mit besonderer Berücksichtigung von Aspergillus niger. Biochem. Ztschr., 153: 372-423. 1924. 
In the presence of available carbon and nitrogen sources, microorganisms will rapidly break down the lecithin and liberate the phosphorus. A transformation of 66 per cent of the lecithin phosphorus into soluble phospliate by different bacteria, in 60 days at $28^{\circ}$ to $30^{\circ} \mathrm{C}$, has been reported $; 1^{17}$ the rest of the phosphorus was reassimilated by the bacteria.

Phytin is an hexaphosphate, occurring abundantly in vegetable tissues, especially in seeds or grains.22 It contains (as phytic acid, $\mathrm{C}_{6} \mathrm{H}_{24} \mathrm{O}_{27} \mathrm{P}_{6}$ ) about 26 per cent phosphorus. It is acted upon by fungi and bacteria by means of an enzyme, phytase, ${ }^{23}$ with the transformation of the phosphorus into the inorganic form.

Nucleo-proteins contain 7 to 9 per cent phosphorus and 13 to 14 per cent nitrogen. The resulting products of their decomposition are phosphoric acid, a sugar, purine and pyrimicine bases. ${ }^{24}$ The nucleic acids are broken down by various soil microorgansims, both in the presence

TABLE 70

Phosphorus and potassium content of some typical soil bacteria

\begin{tabular}{|c|c|c|c|}
\hline & $\mathrm{ASH}$ & TOTAL $\mathrm{P}_{2} \mathrm{O}_{5}$ & TOTAL $\mathrm{K}_{2} \mathrm{O}$ \\
\hline & per cent & per cent & per cent \\
\hline Az. chroococcum. . & $8.2-8.6$ & $4.93-5.2$ & $2.41-2.65$ \\
\hline 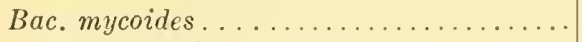 & 7.5 & 4.07 & 2.27 \\
\hline Bact. fluorescens liquefaciens........... & 6.48 & 5.32 & 0.83 \\
\hline
\end{tabular}

and absence of other nitrogen sources. Koch and Oelsner ${ }^{24}$ found that, in addition to some common soil organisms, a special group of bacteria (genus Nucleobacter) is specifically concerned in the decomposition of nucleins, through the nucleic acid stage, into phosphoric acid.

${ }^{22}$ Anderson, R. J. Phytin and phosphoric acid esters of inosite. N. Y. (Geneva) Agr. Exp. Sta. Tech. Bul. 19. 1912; The organic phosphoric acid of cottonseed meal. Ibid., Bul. 25. 1912.

${ }^{23}$ Dox, A. W., and Golden, R. Phytase in lower fungi. Jour. Biol. Chem., 10: 183-186. 1911; Plimmer, R. H. A. The metabolism of organic phosphorus compounds. Their hydrolysis by the action of enzymes. Biochem. Jour., 7: 43-71. 1913; Egorov, MI. A. Über das Verhalten von Schimmelpilzen (A. niger und P. glaucum) zum Phytin. Ztschr. physiol. Chem., 82: 231-242. 1912.

${ }^{24}$ Iwanoff, N. Nuclease, forkommend in Schimmelpilzen. Ztschr. Gärungsphysiol., 1: 60. 1912; also Ztschr. physiol. Chem., 39: 31-43. 1903; Schittenhelm, A., and Schroeter, F. Über die Spaltung der Hefenukleinsaure durch Bakterien. Ztschr. physiol. Chem., 39: 203-207. 1903; 40: 62-69. 1903; 41: 283-292. 1903; 57: 21-27. 1908; Koch, A., and Oelsner, A. Über Nucleoproteidspaltende Bakterien und ihre Bedeutung für die Erschliesung des PhosphorKaptials im Ackerboden. Biochem. Ztschr., 134: 76-96. 1922. 
In addition to these compounds, other organic phosphorus compounds, such as that of wheat bran (inosite mono-phosphate $-\mathrm{C}_{6} \mathrm{H}_{13} \mathrm{O}_{9} \mathrm{P}$ ) are added to the soil, in considerable quantities. Their decomposition is probably similar to that of phytin.

Transformation of insoluble tri-calcium phosphates into soluble forms by microorganisms. Insoluble tri-calcium phosphates may be brought into solution by microorganisms in three different ways: (1) by the direct metabolism of microorganisms, perhaps through the formation of some enzyme or interaction with some synthesized substance, (2) by the action of carbon dioxide as well as various organic acids produced by soil microorganisms, (3) by the action of inorganic acids formed in the metabolism of the autotrophic nitrifying and sulfur oxidizing bacteria.

Soil microorganisms were found capable of rendering insoluble tricalcium phosphate soluble when it is present in culture media as the only source of phosphorus. Attempts have been made to explain this by a direct metabolism of the organism, involving the formation of specific enzymes. It has also been suggested ${ }^{25}$ that various fungi may directly assimilate the phosphorus from the tri-calcium phosphate: $A s p$. niger, Pen. brevicaule, Pen. glaucum assimilated, in 60 days at $22^{\circ} \mathrm{C}$., one-fifth to one-third of the phosphate present as $\mathrm{Ca}_{3}\left(\mathrm{PO}_{4}\right)_{2}$ in liquid culture media. When the mycelium of the organisms is further decomposed by soil bacteria and fungi, the phosphorus goes into solution in an available form.

Out of twenty-five bacteria isolated from the soil, twelve had a definite solvent action on rock phosphate, bone, pure tri-calcium phosphate, di-calcium phosphate and calcium carbonate, when supplied with some form of sugar in the nutrient medium. ${ }^{26}$ Both the acid formed by the bacteria and the carbon dioxide were found to be factors exerting the solvent action. The solubility of phosphates is influenced by the nature of carbon and nitrogen sources for the growth of microorganisms; ${ }^{27}$ disaccharides are better sources of carbon than mono-

${ }^{25}$ de Grazia, S., Gerza, U. Sull intervento dei microorganismi nella utilizzazione dei fosfati insolubili del suolo da parte delle piante superiori. Ann. R. Sta. Chein. Agr. Sper. Roma (II), 2. 1908; 3. 1909.

${ }^{20}$ Sackett, IV. G., Patten, A. J., and Brown, C. W. The solvent action of soil bacteria upon the insoluble phosphates of raw bone meal and natural raw rock phosphate. Centrbl. Bakt. II, 20: 688-703. 1909.

27 Perotti, R. Über den biochemischen Kreislauf der Phosphosïure im Ackerboden. Centrbl. Bakt. II, 25: 409-419. 1909. 
saccharides and ammonium salts are better sources of nitrogen than other nitrogenous substances. The soluble bases (especially Ca) prevent the solubility of phosphates; iron oxide influences the process least. This would seem to indicate definitely that this process is rather secondary in nature and depends upon the action of the products of carbon and nitrogen metabolism upon the insoluble phosphate.

The production of soluble phosphates was reported ${ }^{28}$ to be associated with the vital function of microorganisms. However, the existence of specific enzymes capable of bringing into solution insoluble phosphates has been questioned by Bazarevski, ${ }^{29}$ who submitted evidence to show that this process is chiefly a result of acid production by microorganisms. Fven if the organism does not form any acid in the medium, a part of the phosphate may be assimilated by it, either by the action of carbon rlioxide or as a result of basic exchange between the soluble products formed and certain soil constituents. The continuous removal of the soluble phosphate by the growing organism and its synthesis into organic matter may sometimes bring about appreciable transformation. The greatest amount of dissolution of the phosphate has been obtained with ammonium salts and the least with nitrate; this substantiates the claim that the acids formed in the metabolism of the organisms, rather than any enzymatic phenomena, are responsible for the process. In the case of ammonium salts, the organisms remove the ammonium as a source of nitrogen, leaving the $\mathrm{SO}_{4}$ in the medium, while in the case of the nitrate, the acid-ion is removed and the alkaline is left. ${ }^{36}$

The growing organism is capable of forming large quantities of carbon dioxide and often appreciable quantities of organic acids, both under aerobic and anaerobic conditions. One gram of bacterial cells produces 0.25 to $0.5 \mathrm{mgm}$. of $\mathrm{CO}_{2}$ in twenty-four hours and 1 gram of fungus mycelium produces 0.13 to $0.18 \mathrm{mgm}$. $\mathrm{CO}_{2}$. As much as 6000 pounds of $\mathrm{CO}_{2}$ may be given off in 200 days by one acre of normal soil, on a $2,000,000$ pounds basis. The soil atmosphere may contain 0.6

${ }_{28}$ Pozerski, E., and Levy, M. M. Sur l'exretion de composés phosphor's par les microbes. Compt. Rend. Soc. Biol., 87: 1157-1159. 1922.

${ }^{29}$ Bazarevski, S. On the question of mobilization of phosphoric acid in the soil by the agency of microorganisms (Russian). Moskau. 1916.

${ }^{30}$ Haselhoff, E. Untersuchungen über die Zersetzung bodenbildender Gesteine. Landw. Vers. Sta., 70:53-143. 1909; Stålström, A. Beitrag zur Kenntnis der Einwirkung steriler und in Gärung befindlicher organischer Stoffe auf die Löslichkeit der Phosphorsäure des Tricalciumphosphats. Centrbl. Bakt. II, 11: 724-732. 1904. 
to 3.8 per cent of $\mathrm{CO}_{2}$. Czapek ${ }^{31}$ ascribed the most important rôle in bringing the soil minerals into solution to carbon dioxide.

Carbon dioxide interacts with the different phosphates in the following manner:

$$
\begin{aligned}
& \mathrm{Ca}_{3}\left(\mathrm{PO}_{4}\right)_{2}+4 \mathrm{H}_{2} \mathrm{O}+4 \mathrm{CO}_{2}=\mathrm{Ca}\left(\mathrm{H}_{2} \mathrm{PO}_{4}\right)_{2} \cdot \mathrm{H}_{2} \mathrm{O}+2 \mathrm{Ca}\left(\mathrm{HCO}_{3}\right)_{2} \\
& 2\left(\mathrm{CaHPO}_{4} \cdot 2 \mathrm{H}_{2} \mathrm{O}\right)+2 \mathrm{CO}_{2}=\mathrm{Ca}\left(\mathrm{H}_{2} \mathrm{PO}_{4}\right)_{2} \cdot \mathrm{H}_{2} \mathrm{O}+\mathrm{Ca}\left(\mathrm{HCO}_{3}\right)_{2}+\mathrm{H}_{2} \mathrm{O} \\
& \mathrm{Ca}_{4} \mathrm{P}_{2} \mathrm{O}_{9}+5 \mathrm{H}_{2} \mathrm{O}+6 \mathrm{CO}_{2}=\mathrm{Ca}\left(\mathrm{H}_{2} \mathrm{PO}_{4}\right)_{2}+3 \mathrm{Ca}\left(\mathrm{HCO}_{3}\right)_{2}
\end{aligned}
$$

One kilogram of soil containing 0.13 per cent $\mathrm{P}_{2} \mathrm{O}_{5}$, when extracted for twenty-five days with distilled water (five repeated extractions of five days each), yielded 0.002 gram $\mathrm{P}_{2} \mathrm{O}_{5}$, while 0.0055 grams $\mathrm{P}_{2} \mathrm{O}_{5}$ was extracted in the same period by water containing carbon dioxide. ${ }^{32}$

\begin{tabular}{|c|c|c|c|c|c|}
\hline PHOSPHATE & $\begin{array}{c}\mathrm{P}_{\mathrm{A}} \mathrm{O}_{5} \\
\text { CONTENT }\end{array}$ & $\begin{array}{l}\text { SOLUBLE EN } \\
0.5 \text { PER CENT } \\
\text { ACETIC ACID }\end{array}$ & $\begin{array}{c}\text { SOLUBLE IN } \\
0.5 \text { PERCENT } \\
\text { FORMIC } \\
\text { ACID }\end{array}$ & $\begin{array}{l}\text { SOLUBLE IN } \\
\mathrm{CO}_{2} \text { WATER }\end{array}$ & $\begin{array}{l}\text { DISSOLVED } \\
\text { AND ASSIMI- } \\
\text { LATED BY } \\
\text { AZ. CHROO- } \\
\text { COCCUM }\end{array}$ \\
\hline & per cent & per cent & per eent & per cent & per cent \\
\hline Di-calcium . . . . . . & 41.0 & 97.13 & 99.54 & 45.79 & 32.41 \\
\hline Tri-calcium ............ & 41.0 & 73.83 & 90.90 & 25.01 & 24.89 \\
\hline Mono-differi........... & 47.0 & 19.58 & 29.35 & 27.44 & 40.94 \\
\hline Tri-ferri ...... & 38.0 & 8.13 & 16.00 & 7.87 & 9.05 \\
\hline Tri-aluminum.... & 44.0 & 22.09 & 93.79 & & 10.71 \\
\hline Florida rock . . . . . . & 36.0 & 16.31 & 54.04 & & 18.57 \\
\hline Steamed bone meal. & 21.0 & 62.25 & 67.65 & & \\
\hline Dry granitic soil ........ & 0.103 & 7.76 & 6.79 & 4.85 & 49.02 \\
\hline Dry basalt soil ......... & 0.180 & 7.22 & 8.33 & 5.50 & 50.27 \\
\hline
\end{tabular}

TABLE 71

Solubility of different phosphates

The various organic acids (butyric, lactic, acetic, propionic, formic, valerianic, gluconic, citric, oxalic, fumaric, etc.) formed by soil organisms interact with the phosphates, carbonates and silicates present in the soil, to give lactates, acetates, butyrates, citrates, etc. These are usually further decomposed by different microorganisms to carbon dioxide and carbonates. Table 71 shows the amounts of various phosphates made soluble when extracted by dilute solutions of organic acids (for 500 hours), by water saturated with carbon dioxide and by the growth of Azotobacter chroococcum, the particular phosphate being the only source of phosphorus in the medium.

\footnotetext{
${ }^{31}$ Czapek, 1920-1921 (p. xv).

32 Stoklasa, 1911 (p. 649).
} 
In the case of the bone meal, the solubility of the phosphate was found to depend on the fineness of division, amount and composition of fat and nitrogen in the keratin and collagen. The decomposition of organic matter in the soil is thus found to influence to a large extent the process of rendering insoluble soil phosphorus available. ${ }^{33}$ The presence of calcium carbonate represses the solubility of the phosphate.

The activities of the soil microorganisms, however, do not always result in an increase of soluble phosphates, but may often even lead to an actual diminution. ${ }^{34}$ This takes place especially when a large amount of energy bearing materials is added to the soil without a corresponding addition of soluble phosphates. The available energy stimulates the activities of various soil microorganisms, the synthe-

TABLE 72

Influence of soil sterilization upon the activities of microorganisms and transformation of phosphorus

\begin{tabular}{|c|c|c|c|c|c|}
\hline \multirow{2}{*}{ SOIL TREATMENT } & \multicolumn{2}{|c|}{$\mathrm{CO}_{2}$ FORMATION } & \multirow{2}{*}{\begin{tabular}{|c} 
NITRATE \\
FORMATION \\
IN 100 GRAMS \\
OF SOIL
\end{tabular}} & \multirow{2}{*}{$\begin{array}{c}\text { SOLUBLE } \\
\text { PHOSPHATE }\end{array}$} & \multirow{2}{*}{$\begin{array}{l}\text { NUABERS OF } \\
\text { BACTERIA } \\
\text { PER GRAM }\end{array}$} \\
\hline & 30 days & 60 days & & & \\
\hline & $m g m$. & mgm. & $\begin{array}{c}m g m . \text { of } \\
\mathrm{N}_{2} \mathrm{O}_{5}\end{array}$ & $\begin{array}{c}\text { per cent } \\
\mathrm{P}_{2} \mathrm{O}_{5}\end{array}$ & millions \\
\hline Sterile soil.............. & 0.281 & 0.418 & 48.3 & 0.0060 & \\
\hline $\begin{array}{l}\text { Sterile soil inoculated with } \\
\text { fresh soil suspension ......... }\end{array}$ & 7.636 & 10.854 & 114.0 & 0.0040 & $22.8-26.7$ \\
\hline Non-sterilized soil . . . . . . & 2.962 & 4.640 & 12.3 & $\begin{array}{l}0.0014^{*} \\
0.0018\end{array}$ & $3.2-5.8$ \\
\hline
\end{tabular}

* Upper figure found at beginning, lower at end of experiment.

sizing processes of which result in a disappearance of the soluble phosphates in the soil. The actual amount of available phosphorus in the soil was found to be a result of the sum total of the activities of the microbial soil population which includes acid formation, secondary reactions, and the synthesizing activities. Soil sterilized in the autoclave was reinoculated with pure cultures of bacteria or with soil sus-

${ }^{33}$ Kröber, E. Ưber das Löslichwerden der Phosphorsäure aus wasserunlöslichen Verbindungen unter der Einwirkung von Bakterien und Hefen. Jour. Landw., 57: 5-80. 1909; see also Koch, A., and Kröber, E. Fühlings landw. Ztg., $55: 225-235.1906$.

${ }^{34}$ Sewerin, S. A. Die Mobilisierung der Phosphorsïure des Bodens unter dem Einflusz der Lebenstätigkeit der Bakterien. Centrbl. Bakt. II, 28: 561580. 1910; 32: 498-520. 1912; Viestnik Bakteriol.-Agron. Stan. (Russian), No. 21: 53-83. 1914. 
pensions, and, after a certain period of incubation, the anounts of carbon dioxide formed from 1,100 gm. of soil and the phosphorus brought into solution were determined, ${ }^{34}$ as shown in table 72 .

On inoculating sterilized soil with pure cultures of bacteria, Sewerin obtained a gain of 14 per cent of $\mathrm{P}_{2} \mathrm{O}_{5}$ soluble in acetic acid for Azotobacter + Bacterium sp.; a gain of 12.9 per cent for Bac. mesentericus vulgatus; a gain of 8.0 per cent for Bact. radicicola + Azotobacter; a loss of 5.8 per cent for Bact. fuorescens liquefaciens; and a loss of 12.6 per cent for unsterilized soil. No correlation was found between the bacterial population of the soil and the soluble $\mathrm{P}_{2} \mathrm{O}_{5}$, and none between the latter and the energy of decomposition of the soil organic matter.

When manure is added to the soil, the rapidly growing bacteria cause a definite decrease in the water-soluble phosphorus of the manure, and transform it into organic phosphorus. This is eventually released in an available form as a result of the action of the bacteria on the dead microbial cells, after the available energy had been used up..$^{35}$ The addition of green manure and stable manure to citrus soils in California was found to bring about a measurable increase in solubilty of phosphorus, calcium, magnesium and iron. ${ }^{36}$

The addition of carbohydrates to the soil brings about an increase in the number of microorganisms and a diminution in the amount of phosphoric acid soluble in 2 per cent acetic acid. ${ }^{37}$ The amount of soluble phosphate in the soil was found to depend not so muchupon the numbers of microorganisms as upon their kind. As to the influence of season of year, an increase in soluble phosphate is usually found in the spring and fall and a decrease in the summer as a result of the activities of microorganisms.

The amount of available phosphorus in the soil will thus depend on the total phosphorus in the soil, nature of the phosphorus compounds, soil reaction, presence of available energy and nitrogen, and kind of microorganisms. A bacteriological method for determining the amount of available phosphorus in the soil is described elsewhere (p. 577).

Transformation of insoluble phosphates by inorganic and organic acids formed by microorganisms. Inorganic acids are formed in the soil by

${ }^{35}$ Tottingham, W. E., and Hoffmann, C. Nature of changes in the solubility and availability of phosphorus in fermenting mixtures. Wis. Agr. Exp. Sta. Res. Bul., 29: 273-321. 1913.

${ }^{36}$ Jensen, C. A. Effect of decomposing organic matter on the solubility of certain inorganic constituents of the soil. Jour. Agr. Res., 9: 253-268. 1917.

${ }^{37}$ Bazarevski, 1916 (p. 653). 
the nitrite-forming, nitrate-forming, and sulfur-oxidizing bacteria. The continued oxidation in normal soils of ammonium salts to nitrous and nitric acids results in the formation of appreciable quantities of these acids, 132 parts of ammonium sulfate giving, on complete oxidation, 126 parts of nitric and 196 parts of sulfuric acids. Even organic compounds rich in nitrogen, like urea, finally lead to a high acidity.

$$
\mathrm{CO}\left(\mathrm{NH}_{2}\right)_{2}+2 \mathrm{H}_{2} \mathrm{O} \rightarrow\left(\mathrm{NH}_{4}\right)_{2} \mathrm{CO}_{3}+4 \mathrm{O}_{2} \rightarrow 2 \mathrm{HNO}_{3}+\mathrm{CO}_{2}+3 \mathrm{H}_{2} \mathrm{O}
$$

The acids may, under proper conditions of reaction, interact with the tri-calcium phosphate added to the soil and make it soluble.

$$
\begin{aligned}
& \mathrm{Ca}_{3}\left(\mathrm{PO}_{4}\right)_{2}+2 \mathrm{HNO}_{2}=2 \mathrm{CaHPO}+\mathrm{Ca}\left(\mathrm{NO}_{2}\right)_{2} \\
& \mathrm{Ca}_{3}\left(\mathrm{PO}_{4}\right)_{2}+4 \mathrm{HNO}_{2}=\mathrm{Ca}\left(\mathrm{H}_{2} \mathrm{PO}_{4}\right)_{2}+2 \mathrm{Ca}\left(\mathrm{NO}_{2}\right)_{2} \\
& \mathrm{Ca}_{3}\left(\mathrm{PO}_{4}\right)_{2}+\mathrm{H}_{2} \mathrm{SO}_{4}=2 \mathrm{CaHPO}_{4}+\mathrm{CaSO}_{4}
\end{aligned}
$$

Theoretically 188 parts of nitrous acid mixed with 310 parts of pure rock phosphate should give 234 parts of acid phosphate and 264 parts of calcium nitrite. As the average of thirteen tests in liquid culture, Hopkins and Whiting ${ }^{38}$ found that 115 parts of phosphorus and 211 parts of calcium were made water soluble for every 56 parts of nitrogen oxidized by the nitrite forming bacteria. No further increase was obtained from the action of the nitrate bacteria, since the oxidation of the nitrite to nitrate does not bring about any further increase in acidity.

However, the reactions taking place in the soil are not similar to those observed in liquid cultures, due to the fact that the nitrous acid combines in the soil with calcium and magnesium carbonate and salts of organic acids liberating rather weak organic acids, as shown in table $73 .^{39}$

The acids resulting from the activities of the bacteria neutralize the carbonate in preference to the tri-calcium phosphate in the soil. When considerable acidity is produced, as in the presence of ammonium sulfate, some phosphate goes into solution. But the degree of acidity necessary for the transformation of the tri-calcium phosphate into soluble phosphates is so high (p. 659) that it may become distinctly injurious to crop growth. The amount of phosphate that goes into solution, as a result of the activities of the nitrifying bacteria is, there-

${ }^{38}$ Hopkins, C. G., and Whiting, A. L. Soil bacteria and phosphates. Ill. Agr. Exp. Sta. Bul. 190. 1916.

${ }^{39}$ Kelley, W. P. Effect of nitrifying bacteria on the solubility of tricalcium phosphate. Jour. Agr. Res., 12: 671-683. 1918. 
fore, very limited. Nitrification of organic nitrogenous compounds like dried blood does not increase the amount of citrate-soluble phosphate when rock phosphate is added to the soil. The nitrification of ammonium sulfate in normal soils does not have any appreciable effect upon the solubility of rock phosphate. However, the concentration of the watersoluble calcium is increased in both instances, due largely to the action of the acid upon the calcium present in the soil in the form of silicates. ${ }^{40}$

TABLE 73

Effect of nitrification on the solubility of tricalcium phosphate in soil*

\begin{tabular}{|c|c|c|c|c|c|c|c|c|c|}
\hline \multirow[b]{2}{*}{ MATERIALS ADDED } & \multicolumn{3}{|c|}{ AFTER 28 DAYS } & \multicolumn{3}{|c|}{ AFTER 57 DAYS } & \multicolumn{3}{|c|}{ AFTER 157 DAYS } \\
\hline & $\begin{array}{l}z \\
b \\
i \\
z\end{array}$ & రొ & مْ & $\begin{array}{l}z \\
\vdots \\
0 \\
z \\
z\end{array}$ & లో & ○్ & $\begin{array}{l}z \\
1 \\
0 \\
z \\
z\end{array}$ & లో & ○ึ \\
\hline & p.p.m. & p.p.m. & p.p.m. & p.p.m. & p.p.m. & p.p.m. & p.p.m. & p.p.m. & p.p.m. \\
\hline $\mathrm{CaCO}_{3} \ldots$ & 22.0 & $\begin{array}{l}40.0 \\
56.5\end{array}$ & \begin{tabular}{|l|}
10.1 \\
11.9
\end{tabular} \mid & $\begin{array}{l}20.0 \\
29.0\end{array}$ & $\begin{array}{l}50.0 \\
70.8\end{array}$ & $\begin{array}{l}11.0 \\
13.2\end{array}$ & & & \\
\hline $\mathrm{Ca}_{3}\left(\mathrm{PO}_{4}\right)_{2} \ldots \ldots \ldots \ldots \ldots$ & 21.0 & 53.5 & 24.2 & 28.0 & 58.8 & 25.0 & & & \\
\hline $\mathrm{CaCO}_{3}+\mathrm{Ca}_{3}\left(\mathrm{PO}_{4}\right)_{2} \ldots \ldots \ldots$ & 22.0 & 59.1 & 17.3 & 28.0 & 70.1 & 22.4 & & & $\ldots \ldots$ \\
\hline$\left(\mathrm{NH}_{4}\right)_{2} \mathrm{SO}_{4} \ldots \ldots \ldots \ldots \ldots$ & 98.0 & 219.4 & 18.5 & 99.0 & 225.4 & 19.4 & 114.0 & 232.1 & 8.0 \\
\hline$\left(\mathrm{NH}_{4}\right)_{2} \mathrm{SO}_{4}+\mathrm{CaCO}_{3} \ldots \ldots \ldots$ & 97.0 & 254.4 & 18.5 & 98.0 & 270.5 & 7.4 & & & ... \\
\hline$\left(\mathrm{NH}_{4}\right)_{2} \mathrm{SO}_{4}+\mathrm{Ca}_{3}\left(\mathrm{PO}_{4}\right)_{2} \ldots$ & 99.0 & 217.7 & 52.1 & 99.0 & 229.6 & 38.0 & 111.0 & 218.4 & 30.0 \\
\hline$\left(\mathrm{NH}_{4}\right)_{2} \mathrm{SO}_{4}+\mathrm{CaCO}_{3}+$ & & & & & & & & & \\
\hline $\mathrm{Ca}_{3}\left(\mathrm{PO}_{4}\right)_{2} \ldots \ldots \ldots \ldots$ & 100.0 & 253.4 & 26.6 & 101.0 & 230.4 & 13.9 & & & \\
\hline Dried blood........ & 91.0 & 107.7 & 9.7 & 90.0 & 113.9 & 10.0 & 94.0 & 116.4 & 5.7 \\
\hline Dried blood $+\mathrm{CaCO}_{3} \ldots \ldots$ & 89.0 & 107.2 & 9.8 & 90.0 & 140.2 & 11.5 & & & . \\
\hline Dried blood $+\mathrm{Ca}_{3}\left(\mathrm{PO}_{4}\right)_{2} \ldots$ & 82.0 & 111.7 & 24.3 & 88.0 & 117.7 & 22.2 & & $\cdots \cdots$ & .. \\
\hline Dried blood $+\mathrm{CaCO}_{3}+$ & & & & & & & & & \\
\hline $\mathrm{Ca}_{3}\left(\mathrm{PO}_{4}\right)_{2} \ldots \ldots \ldots \ldots$ & 81.0 & 118.2 & 19.5 & 87.5 & $\mid 138.1$ & 18.3 & & & \\
\hline
\end{tabular}

* The ammonium sulfate was added at the rate of 0.01 gram of nitrogen per 100 grams of soil; an equal quantity of nitrogen was added in the form of dried blood; tri-calcium phosphate -0.10 gram and calcium carbonate -0.25 gram per 100 grams of soil.

The transformation of rock phosphate into soluble forms by sulfuric acid formed from the oxidation of sulfur by microorganisms is very similar to its transformation by the nitrous acid. In pure culture or in composts, the transformation of the phosphate is rapid and almost complete. In the soil, the sulfuric acid tends to transform the calcium

${ }^{40}$ Ames, J. W. Solvent action of nitrification and sulfofication. Ohio Agr. Exp. Sta. Bul. 351. 1921. 
and magnesium carbonates, the silicates and salts of organic acids, in preference to the phosphate. The reaction of the medium has to be distinctly acid ( $\mathrm{pH}$ 3.0) for the phosphate to become soluble. Such acidity is injurious to plant growth. Figure 50 shows the correlation

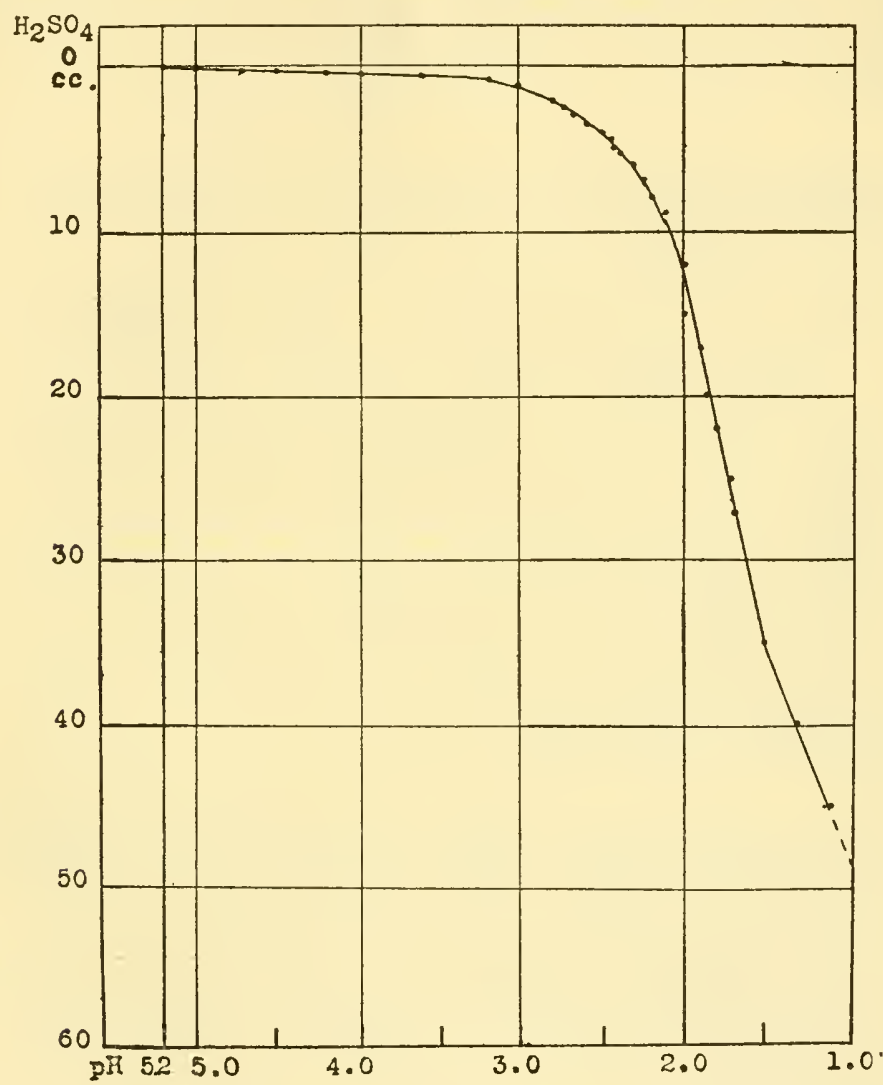

FIG. 50. Hydrogen-ion concentration at which rock phosphate becomes available (from Rudolfs).

between soil reaction and transformation of tri-calcium phosphate. ${ }^{41}$ When rock phosphate is used in place of tri-calcium phosphate, the reactions involved are more complicated, since it contains aluminum

${ }^{41}$ Rudolfs, W. Influence of sulfur oxidation upon growth of soybeans and its effect on bacterial flora of soil. Soil Sci., 14: 247-262. 1922 . 
and iron phosphates in addition to calcium as shown by the following analysis of Florida rock:

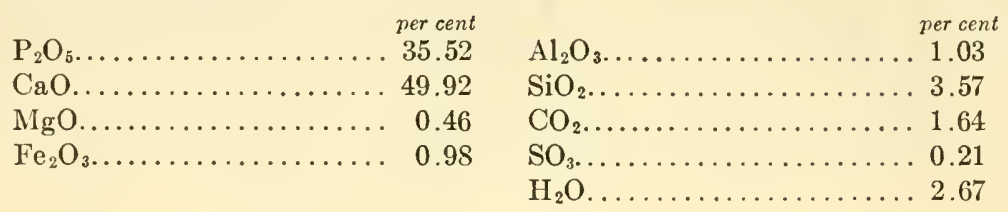

The reactions involved in the conversion of the rock phosphate (insoluble tricalcium phosphate) into soluble forms (di- and monocalcium phosphate and phosphoric acid) by means of acid belongs to the type of reactions of heterogeneous systems. The rock phosphate minerals have no definite composition and the products formed are not always the same. The following factors control the reaction:42 (1) concentration of the reacting mass; (2) temperature of the reacting medium; (3) the amount of contact of the reacting substances; (4) the speed of diffusion of the reacting substances; and (5) catalytic agents. In addition to these, other factors are of importance, including the chemical composition and the physical properties of the solid phase. These have a tremendous influence on the speed of the reaction and they are the least known, since the chemical makeup of the rock phosphate is still obscure.

Schloesing ${ }^{43}$ showed in 1898 that the quantity of phosphoric acid dissolved in normal soils is a result of an equilibrium of very complex chemical processes tending, on the one hand, to take this acid out of solution and, on the other, to bring it into solution. It may only be added that these chemical processes are brought about by the activities of microorganisms, and whatever will influence these activities will also influence the amount of phosphorus available in the soil at any given time.

Transformation of potassium in the soil by microorganisms. Potassium is present in the soil in the form of organic compounds and in the form of various zeolitic and non-zeolitic silicates. The potassium added to the soil is either in a soluble inorganic form, an insoluble inorganic form (marl), or an insoluble organic form (manures). The $\mathrm{K}_{2} \mathrm{O}$ content of fresh manure ranges from 0.288 to 0.504 per cent. ${ }^{44}$ The ash

42 Kazakov, A. V. Moskau Inst. Agron., 9: 21-45, 57-68. 1913.

${ }^{43}$ Schloesing fils, Th. Êtude sur l'acide phosphorique dissout par les eaux du sol. Compt. Rend. Acad. Sci., July 25, 1898.

${ }_{44}$ Thorne, 1914 (p. 429). 
content of bacterial cells contains 4.0 to 25.6 per cent $\mathrm{K}_{2} \mathrm{O}$ and of fungus mycelium 8.7 to 39.5 per cent. The activities of bacteria may lead to an increase in the available potassium, as in the decomposition of organic matter by microorganisms and in the formation of acids which liberate potassium from zeolites. Microbial activities may also lead to a decrease of the available potassium through processes of assimilation and transformation into organic materials. Orthoclase, for example, may interact with acids formed by microorganisms or with the calcium bicarbonate formed from insoluble calcium phosphate by the action of carbon dioxide, to give, in both cases, soluble potassium salts:

$$
\begin{aligned}
& \mathrm{Al}_{2} \mathrm{O}_{3} \cdot \mathrm{K}_{2} \mathrm{O} \cdot 6 \mathrm{SiO}_{2}+4 \mathrm{H}_{2} \mathrm{SO}_{4}=\mathrm{Al}_{2}\left(\mathrm{SO}_{4}\right)_{3}+\mathrm{K}_{2} \mathrm{SO}_{4}+6 \mathrm{SiO}_{2}+4 \mathrm{H}_{2} \mathrm{O} \\
& \mathrm{Al}_{2} \mathrm{O}_{3} \cdot \mathrm{K}_{2} \mathrm{O} \cdot 6 \mathrm{SiO}_{2}+\mathrm{Ca}\left(\mathrm{HCO}_{3}\right)_{2}=\mathrm{Al}_{2} \mathrm{O}_{3} \cdot \mathrm{CaO} \cdot 6 \mathrm{SiO}_{2}+2 \mathrm{KHCO}_{3}
\end{aligned}
$$

The process of replacement of basic ions in the zeolitic part of the soil is of common occurrence, the hydrogen ion acting also as a base. The solubility of the potassium, often ascribed to the action of acids, may be due merely to the replacement of the potassium in the zeolitic complexes by the calcium or magnesium salts of organic or inorganic acids added to the soil. However, when feldspar, glauconite or other silicates rich in potassium are composted with substances which result in the formation of acid (e.g., sulfur), a great deal of the potassium may go into solution (p. 615).

By composting greensand, sulfur, manure and soil, 9.1 to 41.3 per cent of the total initial potassium present can be made soluble. ${ }^{45}$ The results of Wright cited previously on the action of organic acids upon silicates containing potassium tend to confirm this assumption. This process will take place only very slowly in normal soils. According to Ames, ${ }^{4}$ the liberation of potassium in the soil is brought about by the salts formed rather than by the direct action of acidity on insoluble potassium compounds, although he found that both nitrification of organic and inorganic nitrogen compounds and oxidation of sulfur in the soil increased the amount of water-soluble potassium.

The available potassium compounds are also readily assimilated by the heterotrophic bacteria and fungi and stored away in their

45 McCall, A. G., and Smith, A. M. Effect of manure-sulfur composts upon the availability of the potassium of greensand. Jour. Agr. Res., 19: 239-256. 1920; also Jour. Assoc. Offic, Agr. Chem., 5: 133-136. 1921.

${ }^{46}$ Ames, 1921 (p. 658). 
mycelium. ${ }^{47}$ When this is decomposed the potassium again becomes available. However, only a part of the free potassium salt remains in the soil as such; it also replaces some of the zeolitic bases, such as Ca, $\mathrm{Mg}$, Na. The available potassium in the soil at any given time depends not only on the total content of this element in the soil, but also on the form in which it is present in the soil, the degree of saturation of zeolitic compounds, soil reaction, available organic matter and activities of various groups of microorganisms.

The method outlined on page 577 for determining the available phosphorus in the soil can also be utilized for determining the available potassium; ${ }^{48} 30 \mathrm{cc}$. of water containing 2.5 grams glucose, 1 gram $\mathrm{Na}_{2} \mathrm{HPO}_{4}$ and 0.05 gram $\mathrm{MgCl}_{2}$, is added to 100 grams of air-dry soil. The mixture is sterilized and inoculated with Azotobacter. The amount of nitrogen fixed, under these conditions, is an index of the available potassium (allowing that Azotobacter cells contain about 2.5 per cent $\mathrm{K}_{2} \mathrm{O}$ and 10 per cent nitrogen). Stoklasa thus studied a fertile soil with a total of 0.093 per cent $\mathrm{K}_{2} \mathrm{O}$, of which 27.4 per cent was available; a soil of medium fertility with a total of 0.27 per cent $\mathrm{K}_{2} \mathrm{O}$, of which 5.46 per cent was available, and a poor forest soil with a total of 0.137 per cent $\mathrm{K}_{2} \mathrm{O}$ of which only 2.18 per cent available.

Transformation of calcium in the soil. In normal soils, calcium forms the chief base with which the soil zeolites and the organic complexes are saturated. If an alkali salt is added to the soil, the base is absorbed and an equivalent amount of calcium is replaced. The activities of the microorganisms will affect the transformation of calcium in the soil in various ways. (1) Calcium salts, particularly calcium carbonate, may be precipitated in the soil, ${ }^{49}$ as a result of the interaction of the soluble calcium salts (of organic acids or nitrates) with carbonic acid produced by the decomposition of organic matter.

(2) Calcium carbonate may be made soluble, as a result of activities of microorganisms

${ }^{47}$ Kyropoulos. Über die Festlegung von Kali durch Bodenbakterien. Ztschr. Gärungrsphysiol., 5: 161. 1915.

48 St.oklasa, 1925 (p. 621).

${ }^{49}$ Gimingham, C. T. The formation of calcium carbonate in the soil by bacteria. Jour. Agr. Sci., 4: 145-149. 1911; Drew, G. H. On the precipitation of calcium carbonate by marine bacteria and on the action of denitrifying bacteria in tropical and temperate seas. Carnegie Inst. Washington, Dept. Marine Biology, Papers from Tortugas Labor, 5: 7-45. 1914; Kellermann, K. F., and Smith, N. R. Bacterial precipitation of calcium carbonate. Jour. Wash. Acad. Sci., 4: 400-402. 1914. 
in a manner similar to that of the phosphates. The calcium is made soluble much more easily than the phosphate, since organic and inorganic acids interact very readily with calcium carbonate and silicates in the soil with the formation of soluble calcium compounds.

Nadson ${ }^{50}$ found that soil bacteria may bring about the formation of calcium carbonate by means of ammonium carbonate which is formed in the decomposition of organic matter:

$$
\mathrm{CaSO}_{4}+\left(\mathrm{NH}_{4}\right)_{2} \mathrm{CO}_{3}=\mathrm{CaCO}_{3}+\left(\mathrm{NH}_{4}\right)_{2} \mathrm{SO}_{4}
$$

The formation of calcium carbonate was also observed in the decomposition of organic compounds containing calcium. Nadson even reported the formation of dolomite, or a mixture of calcium and magnesium carbonates, in media containing bacterial mixtures or a pure culture of Bact. vulgare. According to Molisch, ${ }^{51}$ various bacteria, yeasts and actinomyces are capable of causing the precipitation of calcium salts; but his use of the term "calcium bacteria" is not justified.

Kellerman and Smith" ${ }^{49}$ suggested that calcium carbonate precipitation takes place in any of the following ways: (1) Nitrates are reduced to nitrites and ammonia; the ammonia unites with $\mathrm{CO}_{2}$ to form $\left(\mathrm{NH}_{4}\right)_{2} \mathrm{CO}_{3}$ which reacts with $\mathrm{CaSO}_{4}$ to form $\mathrm{CaCO}_{3}$. (2) Ammonia itself may act upon calcium bicarbonate and precipitate $\mathrm{CaCO}_{3}$ :

$$
\mathrm{Ca}\left(\mathrm{HCO}_{3}\right)_{2}+2 \mathrm{NH}_{4} \mathrm{OH}=\mathrm{CaCO}_{3}+\left(\mathrm{NH}_{4}\right)_{2} \mathrm{CO}_{3}+2 \mathrm{H}_{2} \mathrm{O}
$$

(3) The bacteria utilize organic acids as source of energy; the calcium, with which the organic acids were combined in the form of salts, is thus liberated and reacts with the free $\mathrm{CO}_{2}$ to give precipitated $\mathrm{CaCO}_{3}$.

The dissolution of calcium in the soil, whether present in the form of carbonates or as an absorbed base, is brought about by the various organic and inorganic acids formed by the activities of microorganisms. The calcium thus dissolved is either removed by the plant or is lost in drainage waters. The washing out of the calcium from the soil is sometimes so great that some soils of calcareous origin are practically

50 Nadson, G. Mikroorganismi kak geologitscheskie dieisteli. St. Petersburg. 1903.

51 Molisch, H. Über Kalkbakterien und andere kalkfällende Pilze. Centrbl. Bakt. II, 65: 130-139. 1925. 
free from lime. ${ }^{52}$ The following reactions are involved in these processes:

1. $\mathrm{CaCO}_{3}+\left(\mathrm{NH}_{4}\right)_{2} \mathrm{SO}_{4}=\mathrm{CaSO}_{4}+\left(\mathrm{NH}_{4}\right)_{2} \mathrm{CO}_{3}$

2. $\left(\mathrm{NH}_{4}\right)_{2} \mathrm{SO}_{4}+4 \mathrm{O}_{2}=2 \mathrm{H} \mathrm{NO}_{3}+\mathrm{H}_{2} \mathrm{SO}_{4}+2 \mathrm{H}_{2} \mathrm{O}$

$\mathrm{CaCO}_{3}+\mathrm{H}_{2} \mathrm{SO}_{4}=\mathrm{CaSO}_{4}+\mathrm{H}_{2} \mathrm{O}+\mathrm{CO}_{2}$

$\mathrm{CaCO}_{3}+2 \mathrm{HNO}_{3}=\mathrm{Ca}\left(\mathrm{NO}_{3}\right)_{2}+\mathrm{H}_{2} \mathrm{O}+\mathrm{CO}_{2}$

3. $\mathrm{Ca}\left(\mathrm{H}_{2} \mathrm{PO}_{4}\right)_{2}+\mathrm{CaCO}_{3}=2 \mathrm{CaHPO}_{4}+\mathrm{H}_{2} \mathrm{O}+\mathrm{CO}_{2}$

4. $\mathrm{CaCO}_{3}+\mathrm{CO}_{2}+\mathrm{H}_{2} \mathrm{O}=\mathrm{Ca}\left(\mathrm{HCO}_{3}\right)_{2}$

The use of fertilizers which are directly acid or which lead to the formation of acids in the soil, such as ammonium sulfate, superphosphate and sulfur, leads to a depletion of the calcium content of the soil.

Calcium is also used directly as a nutrient by various microorganisms and small amounts of it may be assimilated. However, its chief value lies in the neutralization of organic and inorganic acids in the soil and in replacing injurious soil bases (sodium in alkaline soils), thus producing a medium more favorable for the growth of plants and microorganisms. Calcium salts also neutralize to some extent the injurious action of soluble magnesium salts, as shown by various studies ${ }^{53}$ on the influence of the lime-magnesia ratio upon crop growth. This ratio is not of great importance in bacterial action but the concentration of magnesium in solution and its relation to the concentration of the other constituents are of great importance..$^{54}$

The amount of available calcium in the soil can be determined by adding 5 to 10 grams of soil to 50 or $100 \mathrm{cc}$. of mannite solution free from calcium, inoculating with Azotobacter and determining the relative amount of growth. ${ }^{55}$

Transformation of magnesium in the soil. Next to calcium magnesium is the most common base in humid soils with which the zeolites and humates are saturated. Magnesium is also introduced in considerable quantities into the soil in the various inorganic materials (dolomitic limestone, rock phosphate) and in the organic matter added to the soil.

52 Hall, A. D., and Miller, N. H. J. Effect of plant growth and of manures upon the retention of bases by the soil. Proc. Roy. Soc. (London), B., 77: 1-32. 1905.

${ }^{53}$ Lemmermann, O., Einecke, A., und Fischer, H. Untersuchungen über die Wirkung eines verschiedenen Verhältnisses von Kalk und Magnesia in einigen Böden auf höhere Pflanzen und Mikroorganismen. Landw. Jahrb., 40: 173254. 1911. Kelley, W. P. The lime-magnesia ratio. Centrbl. Bakt. II, 42: $519-526,577-582.1915$.

${ }^{54}$ See Greaves, J. E., and Carter, E. G. The action of some common soil amendments. Soil Sci., 7: 121-160. 1919.

55 Christensen, 1923 (p. 730). 
In the metabolism of bacteria and especially of fungi, magnesium may form a more important mineral nutrient than calcium. The transformation of magnesium in the soil is very similar to that of calcium, although Ames $^{56}$ found that magnesium compounds are less resistant than calcium salts to the action of nitric and sulfuric acids formed in the processes of nitrification and sulfur oxidation.

Transformation of manganese in the soil. Beijerinck ${ }^{57}$ described several fungi and bacteria which are capable of oxidizing manganese carbonate to oxides of manganese, using cellulose or other carbohydrates as sources of energy. It has been further shown ${ }^{58}$ that, in alkaline media, manganese salts are changed to manganese hydroxide, which is then oxidized by atmospheric oxygen to $\mathrm{MnO}_{2}$. Microorganisms also oxidize manganese salts of organic acids to manganese carbonate. Manganic compounds may also be reduced to manganous compounds by biological processes.

$$
\begin{aligned}
& \mathrm{MnO}_{2}+2 \mathrm{H}_{2} \mathrm{~S}=\mathrm{MnS}+2 \mathrm{H}_{2} \mathrm{O}+\mathrm{S} \\
& \mathrm{MnSO}_{4}+2 \mathrm{C}+2 \mathrm{H}_{2} \mathrm{O}=2 \mathrm{H}_{2} \mathrm{CO}_{3}+\mathrm{MnS} \\
& \mathrm{MnS}+\mathrm{H}_{2} \mathrm{CO}_{3}=\mathrm{H}_{2} \mathrm{~S}+\mathrm{MnCO}_{3} \\
& \mathrm{MnS}+2 \mathrm{O}_{2}=2 \mathrm{MnSO}_{4}
\end{aligned}
$$

This process was utilized for the determination of the number of cellulose decomposing bacteria in the soil. Filter paper saturated with $\mathrm{MnSO}_{4}$ solution is placed in a $\mathrm{KMnO}_{4}$ solution. The $\mathrm{MnO}_{2}$ formed turns the paper black. The paper is then placed in petri dishes, sterilized and moistened with a solution of inorganic salts in tap water. When this is inoculated with cellulose decomposing organisms, the oxyand fatty acids formed from the decomposing cellulose reduce the manganese dioxide giving clear zones on the paper.

When sulfur is oxidized in the soil, considerable quantities of manganese may go into solution, especially in soils rich in this element. The utilization of certain manganese compounds as sources of energy by some of the iron bacteria has been pointed out elsewhere (p. 59). Small quantities of manganese seem to act as a stimulant for various organisms, ${ }^{59}$ and especially for the nitrogen-fixing bacteria. ${ }^{60}$

${ }^{56}$ Ames, 1921 (p. 658).

${ }^{57}$ Beijerinck, M. W. Oxydation des Mangancarbonats durch Bakterien und Schimmelpilze. Folia Microb., 2: 123-135. 1913.

${ }^{58}$ Söhngen, N. L. Umwandlungen von Manganverbindungen unter dem Einflusz mikrobiologischer Prozesse. Centrbl. Bakt. II, 40: 545-554. 1914.

${ }^{59}$ Pietruszczynski, Z. The influence of manganese on the nitrification of ammonia. Rocz. Nauk Rolnicz., 9: 235-287. 1923.

${ }^{60}$ Olaru, 1920 (p. 534). 
Transformation of zinc. Certain microorganisms are capable of oxidizing zine sulfide (blende) to zinc sulfate. The transformation is favored by the presence of sulfur. ${ }^{61}$ Sulfur oxidizing bacteria can bring about the dissolution of natural silicates and carbonates of zinc by the sulfuric acid formed from the oxidation of the sulfur. Traces of zine will greatly increase the growth of various organisms, especially fungi. ${ }^{62}$

Transformation of iron. A detailed discussion of the transformation of iron by specific bacteria is found elsewhere. Most of the so-called iron bacteria seem to be able to exist heterotrophically or without iron as a source of energy. ${ }^{63}$ The precipitation of iron salts seems to be merely a physiological phenomenon accompanying the activities of various bacteria growing in media rich in iron salts. Iron hydroxide and basic ferric salts are precipitated when organic iron compounds and inorganic salts of iron are added to the soil. The precipitation occurs also without the interaction of microorganisms but is much less. In addition to bacteria, some algae, fungi and protozoa are also capable of bringing about precipitation of iron in the form of ferric hydroxide, basic ferric salts, and ferrous sulfide. Indirectly, microorganisms may be of importance in depositing ferrous carbonate and ferrous silicate. ${ }^{64}$ Microorganisms also play an important part in the transformation of the insoluble iron compounds into soluble forms by means of the carbon dioxide as well as organic acids formed in the metabolism of the organisms. Small quantities of iron added to nutrient media have a catalytic effect upon the activities of various microorganisms. This is especially true of various autotrophic processes, such as oxidation of hydrogen and sulfur. The precipitation of small amounts of iron as a result of sterilization of an alkaline medium containing phosphate has been shown to stop the development of various organisms, such as the hydrogen bacteria.

Transformation of aluminum in the soil. Aluminum forms one of the most abundant elements in the soil, especially in clay soils, where it occurs in combination with silicates and with organic substances. It

${ }^{61}$ Rudolfs, W., and Hellbronner, A. Oxidation of zine sulfide by microorganisms. Soil Sci., 14: 459-464. 1922; also Compt. Rend. Acad. Sci., 174: 1378-1380. 1922.

${ }^{62}$ Steinberg, R. A. A study of some factors in the chemical stimulation of the growth of Aspergillus niger. Amer. Jour. Bot., 6: 330-372. 1919; Butkewitsch, W., and Orlow, W. G. Zur Frage nach den "Okonomischen Koeffizienten" bei Aspergillus niger. Biochem. Ztschr., 132: 556-565. 1922.

${ }^{63}$ Some exceptions are noted by Lieske, 1911 (p. 95).

${ }^{64}$ A detailed study of these processes is given by Harder, 1919 (p. 93). 
may even form definite compounds with some of the constituents of the soil organic matter. ${ }^{65}$ 'The transformation of organie and inorganic substanees in the soil by mieroorganisms affects direetly or indirectly the solubility and condition of aluminum in the soil; the oxidation of sulfur in the soil brings into solution considerable quantities of alu-

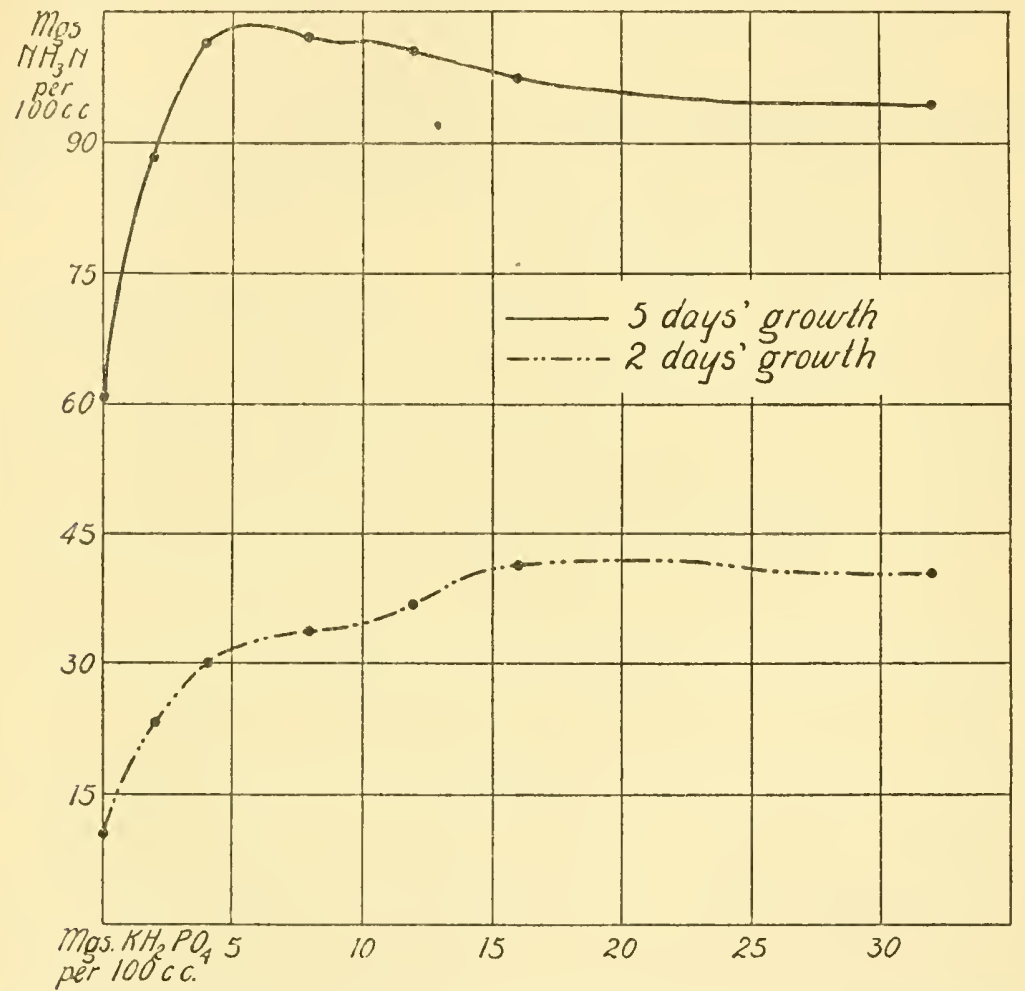

FIG. 51. Influence of $\mathrm{KH}_{2} \mathrm{PO}_{4}$ on the formation of ammonia from peptone by bacteria (from Fred and Hart).

minum, the same is true of the formation of nitrous and nitric acids from ammonia in soils defieient in bases. ${ }^{66}$

Rôle of minerals in bacterial metabolism. The various minerals studied here are more or less essential to the metabolism of mieroorganisms

${ }^{65}$ Niklas, 1912 (p. 644); Ostwald, W., and Steiner, A. Beiträge zur Kolloidchemie von Humussäure und Torf. Kolloidchem. Beih., 21: 97-170. 1925; Waksman, 1926 (p. 447).

${ }^{68}$ Further information on the transformation of aluminum in the soil is given by Stoklasa, 1922 (p. 646). 
(fig. 51). Although microorganisms require small amounts of minerals, they are capable of developing in media having considerable concentrations of the various salts. ${ }^{67}$ Investigators frequently differentiate between fixed and free salts, in regard to their influence upon bacteria. ${ }^{68}$ The presence of various minerals in the soil is essential not only to the nutrition of microorganisms, but also for the purpose of neutralizing unfavorable reactions, which result from the activities of various organisms. The soil bases, including iron and aluminum hydrates ${ }^{69}$ are especially important in this respect. The maintenance of a proper reaction in the soil is very essential for the activities of such important organisms as nitrate-forming, ${ }^{70}$ nitrogen fixing and various cellulose decomposing bacteria. ${ }^{71}$

Microorganisms thus play a manifold part in the transformation of minerals in the soil. The activities of these organisms which result in a change of the minerals from one chemical state into another may be classified as follows: (1) Heterotrophic energy utilization of microorganisms leads to a mineralization of the soil organic matter or to the liberation of minerals from their combination with organic compounds. (2) A part of the minerals thus liberated or added to the soil in the form of inorganic fertilizers may be reassimilated by various soil organisms and thus changed from a soluble into an insoluble condition. (3) The autotrophic bacteria, utilizing minerals as sources of energy, bring about a change in the chemical nature of the minerals in question. (4) The interaction between insoluble minerals in the soil with the products formed by the activities of microorganisms, especially organic and inorganic acids, results in an increase in solubility of these minerals.

The stimulating effect of small amounts of various mincrals, such as zinc, iron and copper, upon the activities of various specific organisms, and of arsenic upon certain soil processes in general has already been noted. The action of arsenic is probably of the nature of partial sterilization of soil. $^{72}$

${ }^{67}$ Sperlich, A. Über Salztoleranz bezw. Halophilie von Bakterien der Luft, der Erde und des Wassers. Centrbl. Bakt. II, 34: 406-430. 1912.

${ }^{68}$ Guillemin, M., and Larson, W. P. The relation between the fixed and frce salts of bacteria. Jour. Inf. Dis., 31: 349-355. 1922.

${ }^{69}$ Whiting, A. L. Inorganic substances, especially aluminum, in relation to the activities of soil organisms. Jour. Amer. Soc. Agron., 15: 277-289. 1923.

${ }^{70}$ Ashby, 1907 (p. 394).

71 Further information on the influence of minerals and salts upon bacteria and their activities in the soil is given by Greaves, J. E. and Carter, E. G. The action of some common soil amendments. Soil Sci., 7: 121-160. 1919.

${ }^{72}$ Greaves, J. E. Stimulating influence of arsenic upon the nitrogen-fixing organisms of the soil. Jour. Agr. Res., 6: 389-416. 1916. 


\section{CHAPTER XXVI}

\section{Transformation of Organic Matter in the Soll}

Nature of soil organic matter. The organic matter of the soil comprises a great mass of substances of plant, animal, and microbiological origin. Some of these substances are undecomposed and include the living or recently dead roots of plants and microorganisms, others are ingredients of the original organic matter resistant to decomposition, others are intermediary substances formed from the original constituents of the organic matter, and the remainder are products synthesized by the activities of the soil microorganisms. Soil organic matter is, therefore, complex in composition and varies according to the original materials, extent of their decomposition, environmental conditions under which the processes of decomposition are taking place, and the organisms concerned in these processes.

The natural materials which contribute chiefly to the formation of the soil organic matter are plant roots, branches, stems, leaves, plant seeds, dead bodies of all sorts of plants and animals, manures, and the bodies of microorganisms. These natural organic substances consist of proteins and other nitrogenous compounds, of carbohydrates (celluloses, hemicelluloses, compound celluloses, starches, pectins, di- and monosaccharides, glucosides) and their derivatives, of fats, waxes, lignins, tannins, resins, alkaloids and mineral matter. However, these various constituents of the original organic matter are found in the soil only to a limited extent. Most of the organic materials actually found in the soil consist of substances more or less resistant to decomposition and, to a less extent, of materials undergoing decomposition. Quantitatively and qualitatively, this organic matter depends upon the activities of the soil microorganisms, which are in their turn influenced by environmental soil conditions including moisture, aeration, soil reaction, and presence of available nitrogen and mineral elements.

The average content of organic matter in the soils of the United States is 2.06 per cent and of the subsoils 0.83 per cent. Very little is known concerning the chemical composition of this organic matter, although a large number of chemical substances have been isolated from the soil. 
Carbon makes up over 50 per cent of the elements in this organic matter. The ratio of soil nitrogen to soil carbon is in the case of most cultivated soils more or less constant, about 1 to 10 , as shown later.

Total organic matter in the soil is measured by ignition, or by multiplying the total carbon found in the soil by 1.75 . The carbon is determined either (1) by dry combustion, (2) by the bomb method, or (3) by wet combustion, using a mixture of chromic and sulfuric acid or of $\mathrm{KMnO}_{4}$ and sulfuric acid. ${ }^{1}$ The carbon dioxide is absorbed either in a weighed $\mathrm{KOH}$ or soda-lime tube or in standard alkali solution. ${ }^{2}$ The available organic matter may be determined by oxidation with $\mathrm{KMnO}_{4}{ }^{3}$ or with 6 per cent $\mathrm{H}_{2} \mathrm{O}_{2}{ }^{4}$ A fraction of the soil organic matter known as "humus" or "humic acid," which comprises 50 to 80 per cent of the total soil organic matter, is frequently determined separately, by extracting the soil with alkalies, as shown later. The amount and nature of the organic matter in the soil varies with the kind of soil, type of vegetation, methods of fertilization and the numerous environmental conditions. ${ }^{5}$

Various attempts have been made to isolate definite chemical compounds from the soil organic matter. Without going into a detailed review of this extensive subject, it is sufficient to say that although the existence of a number of complexes in the soil has been established, it is still a question whether many of these have not been obtained as a result of the treatment of the soil with chemical reagents. By treating the soil with alkali solutions $\left(\mathrm{NH}_{4} \mathrm{OH}, \mathrm{NaOH}, \mathrm{KOH}\right)$, the organic matter can be divided into several distinct fractions: (1) a part insoluble in the alkali solutions, which includes some of the undecomposed natural organic material; (2) a part soluble in alkalies and precipitated by an excess of hydrochloric acid; (3) a part soluble in alkalies but not

${ }^{1}$ Gehring, A. Beitrag zur Klärung der Düngewirkung organischer Substanzen. Centrbl. Bakt. II, 57: 241-271. 1922; White, J. W., and Holben, F. J. Perfection of chromic acid method for determining organic carbon. Jour. Ind. Eng. Chem., 17: 83-85. 1925.

2 Waksman and Starkey, 1923 (p. 401).

${ }^{3}$ Robinson, C. S., Winter, O. B., and Miller, D. J. Studies on the availability of organic nitrogenous compounds. J. Ind. Engin. Chem., 13: 933-936. 1921; König, 1926 (p. 676) Fallot, B. Humus et humification, sur une méthode de dosage de l'humus dans les terres. Chimie et Ind. 2: 873-874, 1924.

${ }^{4}$ Robinson, G. W., and Jones, J. O. A method for determining the degree of humification of soil organic matter. Jour. Agr. Sci., 15: 26-29. 1925.

${ }^{5}$ Lipman, C. B., and Waynick, D. D. A detailed study of effects of climate on important properties of soils. Soil Sci., 1:5-48. 1916. 
precipitated by an excess of acid. ${ }^{6}$ The second group has commonly been known as "humus" or "humic acid," and has been frequently further subdivided into a number of fractions by the use of various solvents, as the alcohol soluble fraction ("hymetomelanic acid" of Hoppe-Seyler) and the alcohol insoluble fraction ("humic acid" of Oden).

By special manipulations, various definite chemical substances have been isolated from one or another of the above fractions. Some of these substances are not characteristic of soil organic matter but are constituents of the original materials added to the soil, while some are products of the cell substance, synthesized by the soil microorganisms. Among these isolated substances are those found by Schreiner and Shorey, ${ }^{8}$ namely pentosans, arginine $\left(\mathrm{C}_{6} \mathrm{H}_{14} \mathrm{O}_{2} \mathrm{~N}_{4}\right)$, histidine $\left(\mathrm{C}_{6} \mathrm{H}_{9} \mathrm{O}_{2} \mathrm{~N}_{3}\right)$, cytosine $\left(\mathrm{C}_{4} \mathrm{H}_{5} \cdot \mathrm{ON}_{3} \cdot \mathrm{H}_{2} \mathrm{O}\right)$, hypoxanthine $\left(\mathrm{C}_{5} \mathrm{H}_{4} \mathrm{ON}_{4}\right)$, xanthine $\left(\mathrm{C}_{5} \mathrm{H}_{4} \mathrm{O}_{2} \mathrm{~N}\right)$, picoline carboxylic acid $\left(\mathrm{C}_{7} \mathrm{H}_{7} \mathrm{O}_{2} \mathrm{~N}\right)$, dihydroxystearic acid $\left(\mathrm{C}_{18} \mathrm{H}_{36} \mathrm{O}_{4}\right)$ (found also in fungus mycelium), paraffinic acid $\left(\mathrm{C}_{24} \mathrm{H}_{48} \mathrm{O}_{2}\right)$, lignoceric acid $\left(\mathrm{C}_{24} \mathrm{H}_{48} \mathrm{O}_{12}\right)$, agroceric acid $\left(\mathrm{C}_{21} \mathrm{H}_{42} \mathrm{O}_{3}\right)$, agrosterol $\left(\mathrm{C}_{26}\right.$ $\left.\mathrm{H}_{44} \mathrm{O} \cdot \mathrm{H}_{2} \mathrm{O}\right)$, phytosterol $\left(\mathrm{C}_{26} \mathrm{H}_{44} \mathrm{O} \cdot \mathrm{H}_{2} \mathrm{O}\right)$, glycerides, resin acids and resin esters. Some of these may become toxic to plants and microorganisms and have been held responsible by some investigators for the injurious influence of straw upon plant growth. ${ }^{9}$ Some of the resins, pigments and other substances frequently found among the constituents of the plants added to the soil may be more or less detrimental to the germination of seed..$^{10}$

Various aldehydes, ${ }^{11}$ nitrogenous compounds, ${ }^{12}$ fats, waxes, and cholestcrols ${ }^{13}$ are commonly found in the soil. The organic matter of peat and muck soils may contain 3.3 to 6.2 per cent of fats and waxes, ${ }^{13}$

${ }^{6}$ Waksman, S. A. What is humus? Proc. Nat. Acad. Sci., 11: 463-468. 1925.

${ }^{7}$ Oden, S. Die Huminsäuren. Kolloid Chem. Beihefte, 11: 75-260. 1919.

${ }^{8}$ Schreiner, O., and Shorey, E. C. Chemical nature of soil organic matter. Bur. of Soils, U. S. Dept. Agr. Bul. 74. 1910.

${ }^{9}$ Collison, R. C. The presence of certain organic compounds in plants and their relation to the growth of other plants. Jour. Amer. Soc. Agr., 17: 58-68. 1925.

${ }^{10}$ Sigmund, IV. Über die Einwirkung von Stoffwechsel-Endprodukten auf die Pflanzen. IV. Einwirkung N-freier pflanzlicher Stoffwechsel-Endprodukte auf die Keimung von Samen: Harze, Farbstoffe. Biochem. Ztschr., 154: 399422. 1924.

${ }_{11}$ Skinner, J. J. Soil aldehydes. Jour. Frankl. Inst., 186: 165. 1918.

${ }_{12}$ Lathrop, 1917 (p. 474).

${ }^{13}$ Ramann, E. Dic von Postlisehen Arbeiten über Schlamm, Moor, Torf, und Humus. Landw. Jahrb., 17: 405-420. 1888. 
mineral soils may contain as much as 0.154 per cent wax and 0.03 per cent fat. ${ }^{14}$ The high content of wax is due to its accumulation in the soil, since it is not readily decomposed by microorganisms. The socalled soil "humus" may contain 10 per cent of material soluble in ether and in alcohol (dihydroxystearic-, oxystearic-, lignoceric, and other acids), in the case of virgin soils rich in organic matter, and as much as 42 to 50 per cent of ether and alcohol soluble substances in the case of soils poor in organic matter. ${ }^{15}$

The nitrogen of the soil organic matter is made up of complexes which give, on hydrolysis, amino acids and acid amides. ${ }^{16}$ By boiling the soil with hydrochloric acid, 75.8 per cent of the soil nitrogen was extracted in the form of these compounds, while boiling water alone extracted only 2.92 to 9.96 per cent of the total soil nitrogen. The amino acids and acid amides do not exist in the soil in a free state but in combination, probably as constituents of the cells of microorganisms, modified or unmodified by secondary processes of decomposition. When the soil "humus" is obtained from the alkali extract by precipitation with an excess of hydrochloric acid and is carefully washed with acid and water, it is found to contain about 3 per cent nitrogen. The nature of this nitrogen has been the subject of considerable controversy; some ${ }^{17}$ have claimed that it is an extraneous material (as protein nitrogen) and can be separated from the non-nitrogenous "humic acids," while others ${ }^{18}$ have claimed that it forms an important constituent of the soil "humus" or "humic acids."

Various organic acids, such as formic, acetic, butyric and propionic, as well as alcohols, are often found in the soil, especially when the soil is kept under anaerobic conditions. These substances do not remain in the soil as such for a long time, but are used, under favorable conditions,

${ }^{14}$ Reinitzer, 1900 (p. 266). See also Fraps, G. S., and Rather, J. B. The ether extract and the chloroform extract of soils. Texas Agr. Exp. Sta. Tech. Bul. 155. 1913.

${ }_{15}$ Piettre, M. Recherches, au moyen de la pyridine, des matières humiques et des matières grasses du sol. Compt. Rend. Acad. Sci., 176: 1329-1336. 1923.

${ }^{16}$ Jodidi, S. L. Organic nitrogenous compounds in peat soils. Tech. Bul. 4, Mich. Agr. Exp. Sta. 1909; The ehemical nature of the organic nitrogen in the soil. Iowa Agr. Exp. Sta. Res. Bul. 1. 1911; Jour. Amer. Chem. Soc., 32: 396. 1910; 33: 1226. 1911; 34: 94. 1912.

${ }_{17}$ Detmer, W. Die natiurlichen Humuskörper des Bodens und ihre landwirtschaftliche Bedeutung. Landw. Vers. Sta., 14: 248-300. 1871; Oden, 1919 (p. 671).

${ }^{18}$ Eggertz, C. G. Studier och undersökninger öf ver mullämnen i aker-och mossjord. Diss. Lund. Centrbl. Agrik. Chem., 18: 75-80. 1888. 
as sources of energy by various microorganisms. Even different aldehydes and other compounds toxic to plant growth are decomposed in the soil, under favorable conditions. ${ }^{19}$

Some of these numerous compounds may be present in the soil in very low concentrations or as mere traces, or may be absent altogether. Most of them are probably formed in the processes of extraction of these materials from the soil and are not present in normal soil. The very nature of the larger part of the soil organic matter, which is commonly referred to as "humus" and which is only very slowly decomposed in the soil is still little understood, notwithstanding the extensive literature dealing with this subject, as shown later. To be able to understand the nature of the soil organic matter, it is essential to know the processes of decomposition of the various constituents of the natural organic materials added to the soil. Without a knowledge of these transformations, the phenomena leading to a change from the organic substances of plant or animal origin to a group of complex bodies in the soil, very resistant to decomposition, can never be explained.

Decomposition of organic matter added to the soil. When a complex natural organic material is added to the soil, it is acted upon by various groups of microorganisms, including the fungi, actinomyces and bacteria. There is no doubt that some of the protozoa and the various worms and insects present in the soil ingest the organic materials, utilizing their various constituents as nutrients thereby causing various physical and chemical changes, the extent of which depends upon the nature of the organism and the environmental conditions. As a result of these activities, a number of the constituents of the organic tissues are broken down by processes of hydrolysis, oxidation, reduction, and condensation. These processes make available the locked up energy, which is utilized by the microorganisms for their activities of mineralizing the organic matter and liberating the inorganic compounds of nitrogen, phosphorus, potassium, magnesium, etc. in forms available for plant growth.

The composition of plants varies at different stages of growth. Green plants are rich in soluble sugars and soluble nitrogenous compounds; ${ }^{20}$

${ }^{19}$ Gardner, W. A. The decomposition of salicylic aldehyde by soil organisms. Science N. S., 60: 503; also p. 390. 1924; Robbins, W. J. The cause of the disappearance of cumarin, vanilin, pyridine and quinoline in soil. Ibid. $44: 894-895 . \quad 1916$.

${ }_{20}$ Bogdanov, S. The culture of buckwheat. Selsk. Khoz. i. Liesovod., 193: 227-271. 1899 (Exp. Sta. Reed., 11: 724); Singleton, G. H. Nitrogen availability studies on crops harvested at different stages of growth. N. J. Agr. Exp. Sta. Bul. 421. 1925. 
mature plants are rich in pentosans, celluloses and lignins. This is true also of leaves. ${ }^{21}$ It is natural, therefore, to find ${ }^{22}$ that green plants decompose much more readily than mature plants and that the nitrogen in the former is changed much more rapidly into nitrates than the nitrogen of mature plants, due to differences in the relative composition, in the rates of decomposition and in the nature of the organisms bringing these processes about.

A part of the organic matter, consisting of monosaccharides, pentosans, hexosans, and of the proteins and their derivatives, is completely decomposed, with the formation of $\mathrm{CO}_{2}, \mathrm{H}_{2} \mathrm{O}, \mathrm{NH}_{3}$ and various minerals, under aerobic conditions; $\mathrm{CH}_{4}$ and $\mathrm{H}_{2}$ are also formed under anaerobic conditions. A part of the materials decomposed is reassimilated by the organisms and synthesized into microbial protoplasm; under aerobic conditions this amounts to as much as 20 to 40 per cent of the decomposed materials. A part of the original materials is left in the form of intermediate products, due either to the greater resistance of these to the action of the specific microorganisms, or to the formation, under certain conditions such as excessive moisture and excessive acidity, of products which hinder further development of the organisms. A part of the original organic matter, consisting largely of fats, waxes, tannins, resins, and lignins, is left undecomposed. This mass of undecomposed, partially decomposed and transformed materials makes up the soil organic matter, which is being modified constantly. A large part of this organic matter is soluble in alkalies and is commonly referred to as "humus" or the "humified" fraction of the organic matter.

The chemical ingredients of the organic matter added to the soil are decomposed at various rates and to varying degrees. Of the non-nitrogenous substances, the mono-saccharides are the first to disappear; these are followed by the starches and pectins and then by the celluloses and pentosans. The lignins, fats and waxes are decomposed only very slowly. The more ripe and mature the original plant from which the organic matter is derived, the greater is the degree of its lignification and the more slowly does the lignified portion decompose. The pentosans

${ }^{21}$ Fricke, K. Beiträge zur Kenntnis der Bestandteile einiger Laubholzblätter. Ztschr. physiol. Chem., 143: 272-289. 1925.

${ }^{22}$ Martin, T. I. Decomposition of green manures at different stages of growth. N. Y. (Cornell) Agr. Exp. Sta. Bul. 406. 1921, 139-169; Whiting, A. L., and Schoonover, W. R. The comparative rate of decomposition of green and cured clover tops in soil. Soil Sci., 9: 137-149. 1920. 
disappear more rapidly than the celluloses, as has been observed in the numerous studies on the composting of manure. It is sufficient to cite the results obtained ${ }^{22 a}$ in composting horse manure at $35^{\circ}$ to $37^{\circ} \mathrm{C}$., under various conditions:

Percentage loss of material

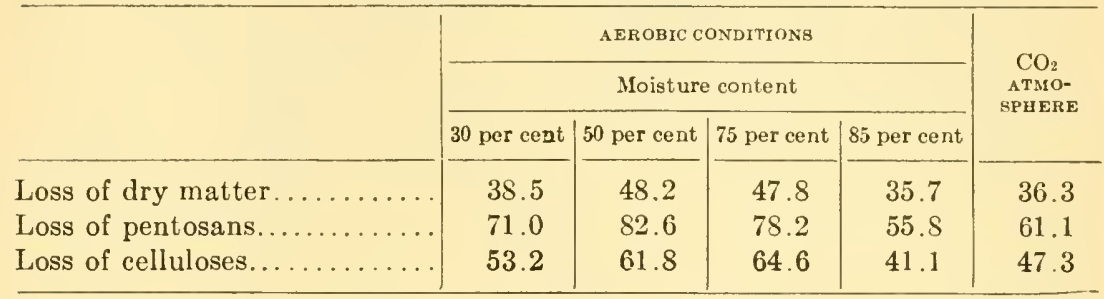

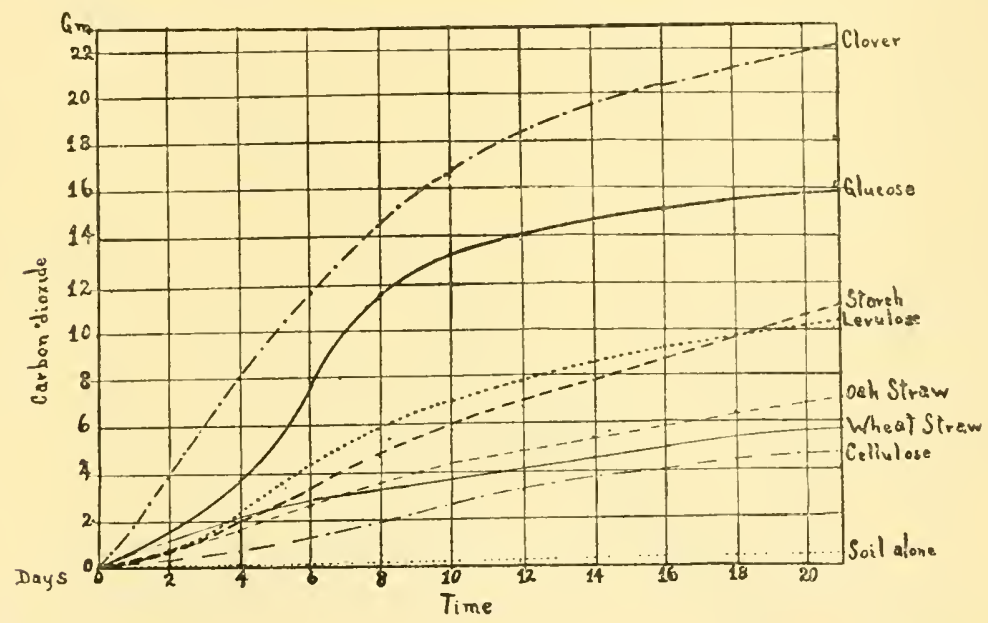

Fig. 52. Course of decomposition of different organic materials in the soil, as indicated by the evolution of carbon dioxide (after Dvorak).

The protcin content of the manure increased as a result of composting. Another result of the composting of natural organic materials, or of their decomposition in the soil, is an increase in the carbon content of the residual material, due to the fact that the pentosans and celluloses with a low carbon content ( 42 to 44 per cent) disappear and the liginins

${ }^{22 a}$ Jegorow, M. Report of commission on decomposition of manure for 1910 (Russian). Moskau Agr. Inst., 17: 1-59. 1911. 
(as well as the synthesized cell substance) with a high carbon content accumulate. ${ }^{2 \mathrm{~b}}$

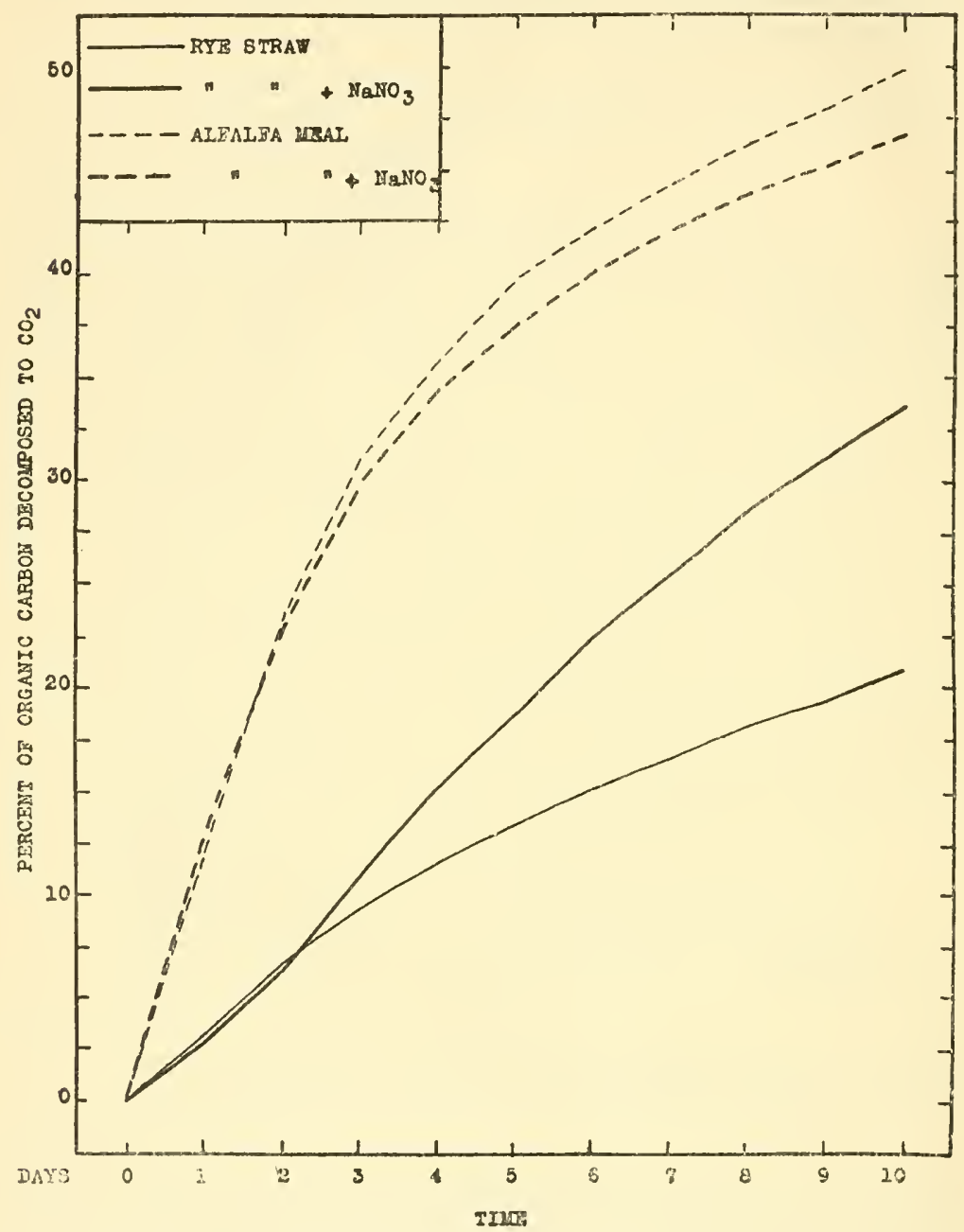

FIG. 53. Effect of nitrate upon the course of decomposition of rye straw and alfalfa meal (from Starkey).

The proteins introduced into the soil with the organic matter are first hydrolyzed to amino acids; some of the amino acids are more rapidly

${ }^{22 b}$ König, J. Die Formgebilde der Zellmembran und ihr Verhalten bei der Zersetzung derselben. Biochem. Ztschr., 171: 261-276. 1926. 
and completely decomposed than others. As a result of incomplete oxidation, substances may be formed which are more resistant than the original materials. In view of the fact, however, that constant synthesis of microbial protoplasm takes place, it is often difficult to establish how much of the protein has been decomposed and how much has been resynthesized. The nature and extent of decomposition depend largely

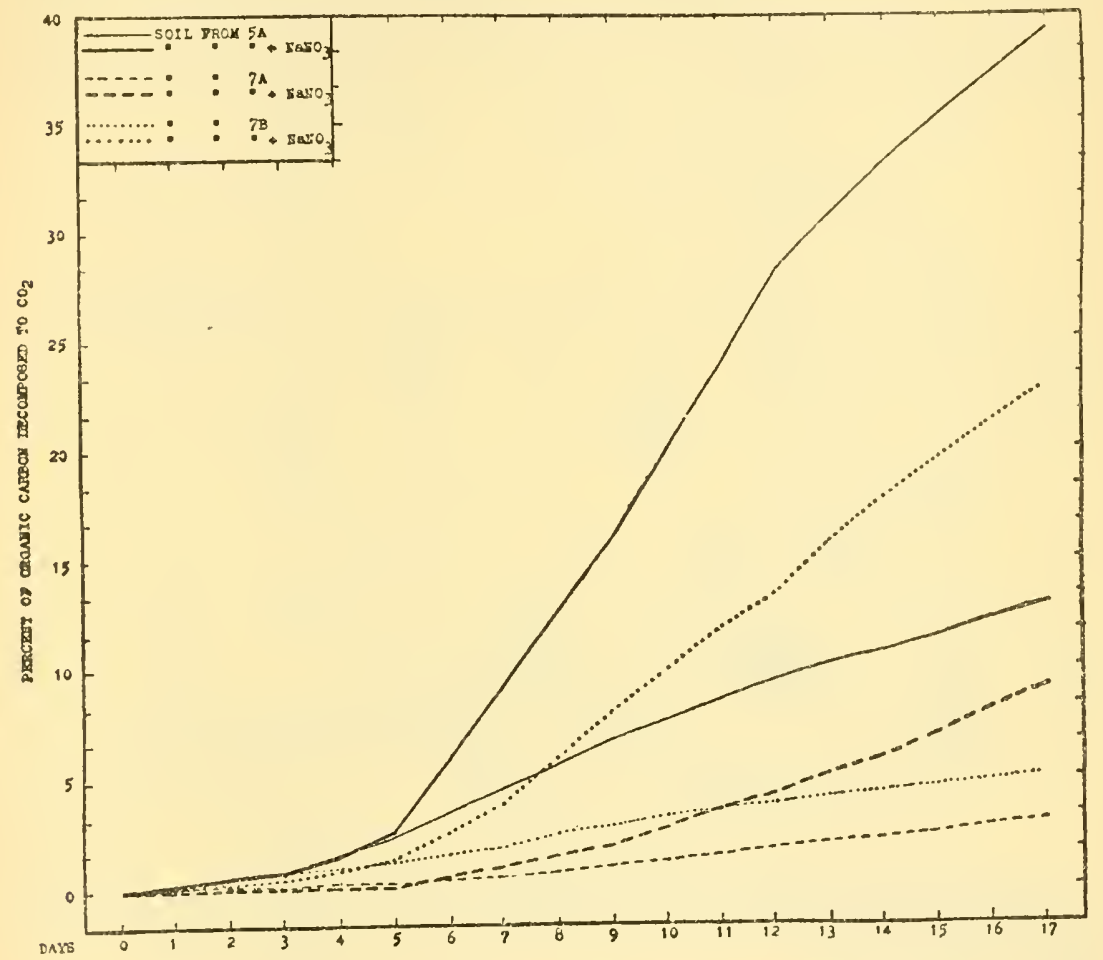

FIG. 54. Effect of nitrate upon the course of decomposition of cellulose in soils of different fertility (from Starkey).

on the organisms concerned, which in their turn are influenced by the environmental conditions. Under aerobic conditions, especially in aerated and acid soils, the fungi are active. Fungi attack the organic material rapidly, especially in the presence of sufficient available nitrogen, and synthesize large quantities of mycelium; this is of course later decomposed by the bacteria, with the result that the nitrogen is liberated again as ammonia and rapidly changed to nitrate. The bacteria and 
actinomyces, which develop in the less acid aerated soils, also attack the proteins readily, liberating ammonia even before all the carbohydrates have been decomposed, a process unimaginable for fungi. Bacteria leave a larger amount of the material in the form of intermediate products, including the various organic acids.

The extent of decomposition of carbohydrates by microorganisms is found to depend not only on the nature of the organism, but also on the nature and amount of available nitrogen. For every unit of carbon decomposed as a source of energy, a certain amount of nitrogen

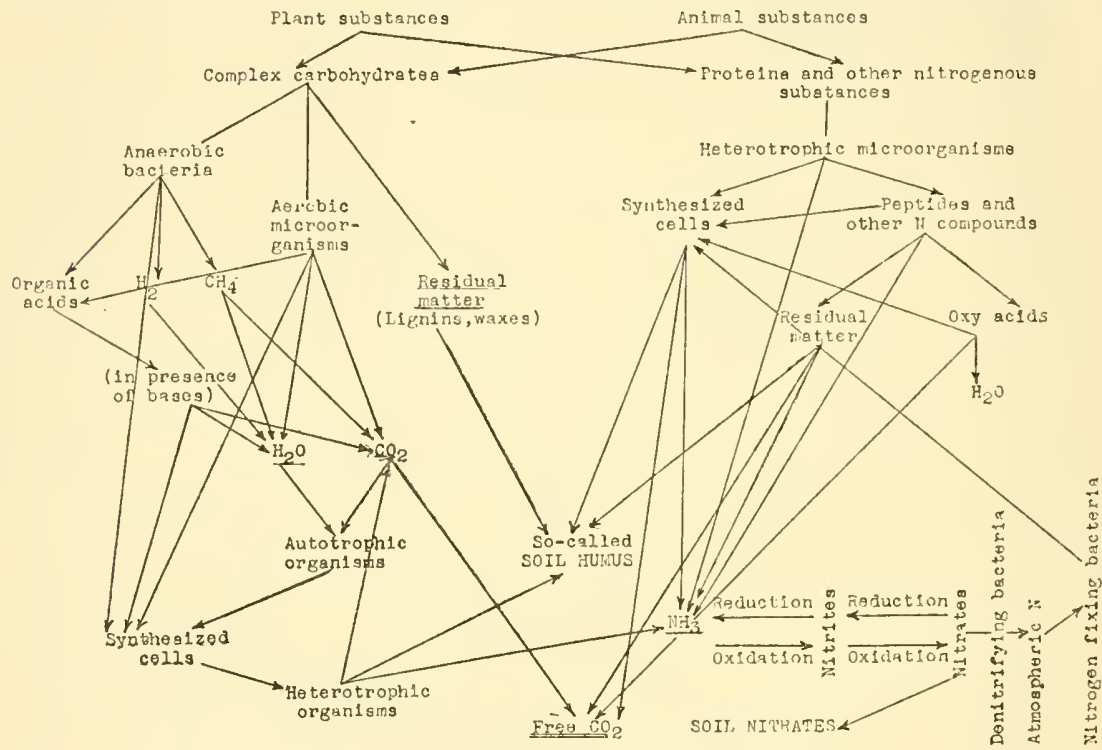

FIG. 55. Decomposition of organic matter in the soil by microorganisms (original.)

is assimilated, whether the latter is present in the form of proteins, simple protein degradation products or inorganic salts. In this respect the fungi differ distinctly from the bacteria. Fungi assimilate a great deal of the earbon decomposed and, although their nitrogen requirement is less than that of bacteria, the total amount of nitrogen assimilated is much greater because of the comparatively much smaller amount of protoplasm synthesized by the bacteria.

A schematic presentation of the decomposition of carbohydrates and proteins, the two most important constituents of natural organic matter, with the formation of some intermediate and some final products is 
given in figure 55, while the transformation of a typical protein in the soil is given in figure $56 .^{23}$

The decomposition of organic matter in the soil can be traced by determining one or more of the products of the reaction, at a definite set of environmental conditions, and with a definite knowledge of the

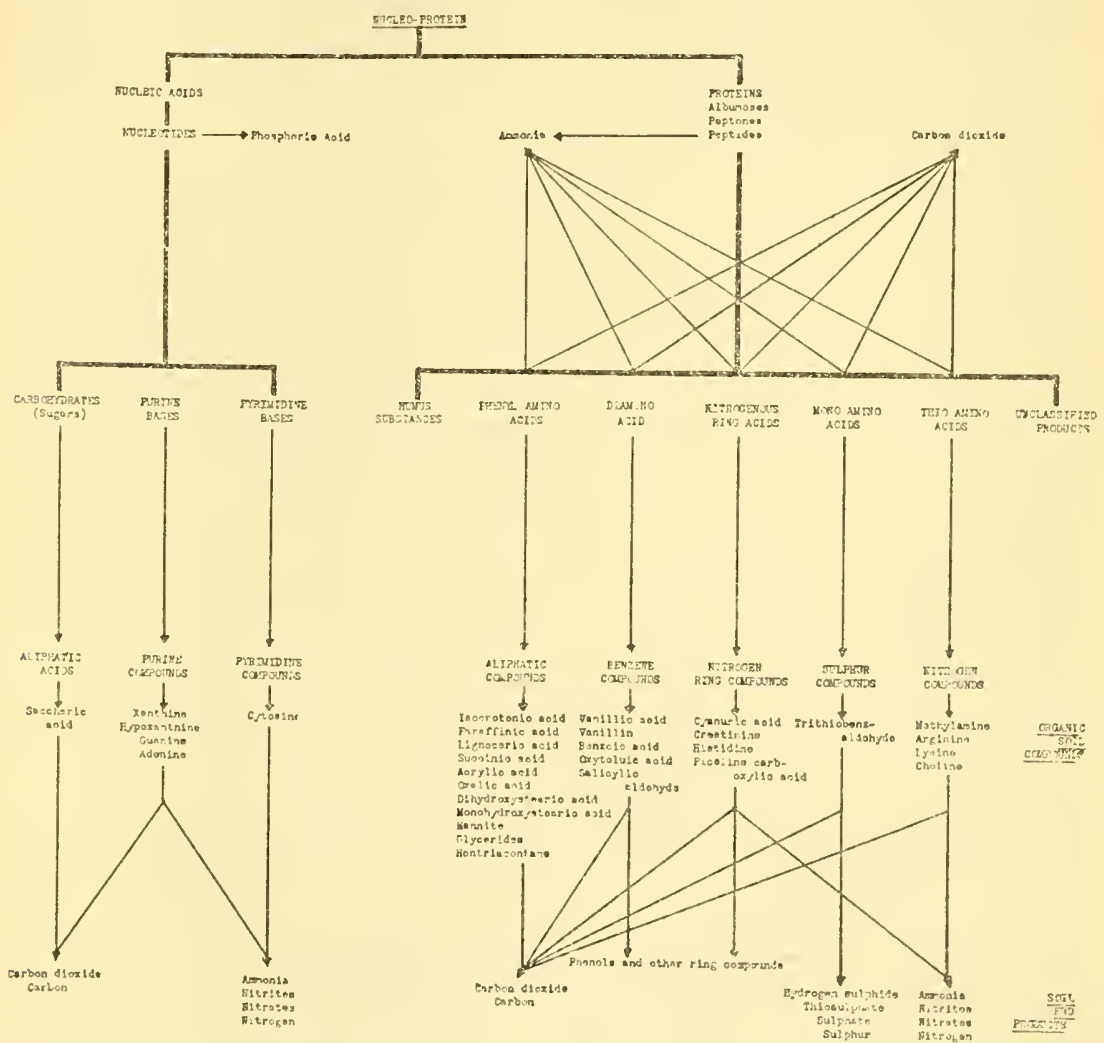

FIG. 56. Decomposition of a complex protein in the soil by microorganisms (Schreiner).

nature of the organisms which are active. These methods can be classified into three groups. (1) Methods which are based upon measuring the amount of total original organic matter decomposed or only of one or more of its constituents, such as cellulose or pentosan. (2) Those methods which are based upon measuring the accumulation of one of

${ }^{23}$ Schreiner, O. Changes in character, condition and amount of soil organic matter. Jour. Amer. Soc. Igron., 18: 115-126. 1926. 
the final products of the reaction: viz., carbon dioxide, ammonia or nitrate. These are the easiest and most reliable methods; carbon dioxide is the end product of energy utilization and respiration of microorganisms; $\mathrm{NH}_{3}$ is the product of the nitrogen metabolism of microorganisms; since some or all of the ammonia is rapidly oxidized in the soil to nitrates, both ammonia and nitrates should be determined in the latter case. (3) Methods for measuring the formation or accumulation of the less readily decomposable organic materials in the soil, namely the so-called "humus" and the related compounds.

Decomposition of the various constituents of the organic matter added to the soil. In view of the fact that the most important constituents of natural organic materials added to the soil are the celluloses, pentosans, lignins, proteins and their derivatives, fats, waxes, and the lower saccharides, the quantitative determination of these substances is sufficient to indicate the course of transformation of the organic matter added. The methods for making these determinations are described in another chapter. However, these methods have to be modified for certain of the complex natural organic materials, such as straw, corn stover, and forest products. Organic matter or the soil containing it is dried to constant weight, extracted with ether to remove the fats, waxes and resins. The material is then treated with cold and hot water to remove the protein degradation products, the sugars and starches. This is followed by alkali extraction ( 2 to 5 per cent $\mathrm{NaOH}$, for forty-eight hours in the cold or for thirty minutes at 15 pounds pressure), which removes the lignins, proteins, and, in the case of soil, the humus-like substances. The pentosans are determined in 1 gram of organic matter or in an aliquot portion of soil by distilling with 12 per cent hydrochloric acid, until a pink color is no longer given with aniline acetate paper, then precipitating as phloroglucide. The cellulose can be determined ${ }^{24}$ by treating a separate portion of the soil (20 grams) at $98^{\circ}$ to $100^{\circ} \mathrm{C}$. in flowing steam for 72 hours (for straw and manure) or 192 hours (for sawdust and moss) with $100 \mathrm{cc}$. of a solution which contains 80 grams $\mathrm{NaHSO}_{3}$ and $200 \mathrm{cc}$. normal $\mathrm{HCl}$ per liter, in flasks with patent rubber clamp stoppers; the material is filtered through hardened filter paper, then washed with water till colorless, dried at $50^{\circ} \mathrm{C}$, and extracted with Schweizer's reagent, then precipitating the cellulose with hydrochloric acid, washing and drying as usual. Instead of this procedure, the soil containing the organic material may be extracted with ether, water, 2 per cent $\mathrm{NaOH}$

${ }^{24}$ Bengtsson, N. Bestämming av inkrusterad cellulosa i jord. Meddl. f. Centralanst. försöksv. jordbruks. Bakt. Avd. No. 37. 1925. 
solution, at 15 pounds pressure for 30 minutes, and boiled with 2 per cent $\mathrm{H}_{2} \mathrm{SO}_{4}$ solution, washed and dried and extracted with Schweizer's reagent.

These methods permit one to observe the processes of decomposition of the various constituents of natural organic substances added to soil or to sand media, the rapidity with which each is decomposed, and the nature of the constituents which contribute to the formation of the complex mass of soil organic matter or "humus." But when, in addition to the original organic substances, the end products of decomposition are also measured, a clearer picture is obtained of the mechanism of transformation of organic matter in the soil. In view of the fact that these can frequently be measured, as in the case of the evolution of $\mathrm{CO}_{2}$, without disturbing the soil in which decomposition is taking place, they are especially important.

Erolution of carbon dioxide as an index of decomposition of organic matter in the soil. In determining the power of the soil to decompose organic matter as indicated by the evolution of $\mathrm{CO}_{2}$, the terms "oxidative capacity," "carbon dioxide producing capacity," "respiratory capacity of soils" are often used. They all designate the decomposition of organic matter in the soil by microorganisms, whereby energy is liberated. However, carbon dioxide may be formed without the liberation of energy, as in the decomposition of pyruvic acid:

$$
\underset{\text { pyruvic acid }}{\mathrm{CH}_{3} \cdot \mathrm{CO} \cdot \mathrm{COOH}} \rightarrow \underset{\text { acetaldehyde }}{\mathrm{CH}_{3} \cdot \mathrm{COH}}+\mathrm{CO}_{2}
$$

On the other hand, energy may be liberated without the formation of carbon dioxide, as in the case of the anaerobic fermentations of sugars.

$$
\begin{array}{lc}
\mathrm{C}_{6} \mathrm{H}_{12} \mathrm{O}_{6}=2 & \mathrm{CH}_{3} \cdot \mathrm{CHOH} \cdot \mathrm{COOH} \\
\text { Glucose } & \text { Lactic acid } \\
\mathrm{C}_{6} \mathrm{H}_{12} \mathrm{O}_{6}= & 3 \mathrm{CH}_{3} \cdot \mathrm{COOH} \\
\text { Acetic acid }
\end{array}
$$

Some $\mathrm{CO}_{2}$ undoubtedly also originates in normal soils from carbonates interacting with organic or mineral acids formed by biological agencies.

The absorption of oxygen can be only a partial index of energy transformation, since some energy is liberated without the intervention of free oxygen, as in the case of anacrobic decomposition of organic matter. A more accurate index of energy transformation would be the calorific changes in the soil (the liberation of heat) as a result of the activities of microorganisms..$^{25}$

${ }^{25}$ Van Suchetelen, 1923 (p. 425). 
A detailed study of the carbon dioxide content of the soil atmosphere is given elsewhere (p. 640). A discussion of the evolution of $\mathrm{CO}_{2}$ in the soil as an index of the availability of the soil organic matter is also discussed elsewhere (p. 717). It is sufficient to point out here that the evolution of $\mathrm{CO}_{2}$ from the soil and its content in the soil atmosphere depend upon a number of other factors outside of the actual carbon content of the soil. Kissling and Fleischer, ${ }^{26}$ as far back as 1891, used $\mathrm{CO}_{2}$ production of peat soils as an index of the rapidity of decomposition going on in the soil. The addition of sand was found to stimulate oxidation greatly, while temperature was found to be one of the most important factors. As a measure of oxidation taking place in the soil, Dehérain and Demoussy ${ }^{27}$ used the amount of $\mathrm{CO}_{2}$ present in the atmosphere of a closed 100-cc. tube containing the soil. The tube of soil was kept at constant temperature for a certain period of time. They demonstrated that the production of carbon dioxide in basic soil (1) is due almost wholly to bacteria; (2) it increases with temperature to about $65^{\circ} \mathrm{C}$., then decreases, and at higher temperatures $\left(90^{\circ} \mathrm{C}\right.$.) increases again; (3) it increases with the amount of water present up to a certain point and then decreases, the optimum amount varying with the soil; and finally (4) it is greatly influenced by the state of division of the soil and aeration. Sterile soil produces small amounts of carbon dioxicle, but, when reinoculated with soil extract, it forms twenty-five times as much $\mathrm{CO}_{2}{ }^{28}$ Sterilized and inoculated soil gives two to five times as much carbon dioxide as unsterilized and inoculated soil.

When manure is treated with disinfectants (thymol, phenol, $\mathrm{HgCl}_{2}$ ), little $\mathrm{CO}_{2}$ is produced; this proves that the process of decomposition of organic matter in the rotting of manure and the evolution of carbon dioxide are biological in nature. Since microorganisms are influenced in their activities by the temperature and moisture content of the medium, one would expect that a change in temperature and moisture, within certain limits, influences the evolution of $\mathrm{CO}_{2}$. Decomposition of the organic matter was found to vary roughly with the amount of oxygen available, although some $\mathrm{CO}_{2}$ is formed in the complete absence

${ }^{26}$ Kissling, R., and Fleischer, M. Die Bodenluft in besandeten und nicht besandeten Hochmoor und Niederungsmoorböden. Landw. Jahrb., 20: 876889. 1891 .

${ }^{27}$ Dehérain, P. P., and Demoussy, E. Sur l'oxydation de la matière organique du sol. Ann. Agron., 22: 305-337. 1896.

${ }^{28}$ Sewerin, S. A. Die Mobilisierung der Phosphorsäuren des Bodens unter dem Einflusz der Lebenstätigkeit der Bakterien. Centrbl. Bakt. II, 13:616; 28: 561 . $1910 ; 32: 498.1912$. 
of oxygen. ${ }^{29}$ Under anaerobic conditions, the organic matter is not decomposed completely and a large part of the energy is left in the form of intermediary products; the amount of $\mathrm{CO}_{2}$ liberated is small and cannot serve as good an index of decomposition as under aerobic conditions. When the amount of oxygen absorbed is used as an index of oxidation in soil, the rate of absorption is found to increase with the temperature, the amount of water (up to a certain point), and the amount of calcium carbonate; oxygen absorption is favored by conditions obtaining in the surface soil as opposed to those in the subsoil. ${ }^{30}$

When a soil is air-dried and then moistened, or when it is partially sterilized by means of heat or chemicals, there follows a decided increase in microbiological activities, resulting in the liberation of greater amounts of $\mathrm{CO}_{2}$. When undecomposed organic matter is added to the soil, it is decomposed with a rapidity depending not only on the nature of the substance added, but also upon the presence of available nitrogen, soil reaction, moisture, aeration, etc. The amount of $\mathrm{CO}_{2}$ produced from the decomposition of a certain organic substance depends also upon the nature of the organisms which are concerned in the process; different organisms attack the same substance, but yield different products.

The nature and composition of the organic material added to the soil greatly influence the type of organism developing and the mechanism of the process of decomposition. Glucose decomposes in the soil very rapidly. The absence of available nitrogen does not become a limiting factor, since nitrogen-fixing organisms can use glucose as a source or energy and develop readily when large amounts of it are added to the soil. One per cent of glucose is rapidly decomposed in forty-eight hours. The decomposition of cellulose, however, is carried out by certain specific bacteria and fungi, which require an available source of nitrogen; the amount of the latter in the soil will, therefore, become the limiting factor in the decomposition of cellulose. Natural organic substances, which are poor in nitrogen, like cereal straws, corn stover, wood products, contain various water soluble substances. They decompose more rapidly than pure cellulose, but here also the nitrogen soon becomes the limiting factor. In the decomposition of natural organic substances, the monosaccharides and starches are decomposed first, followed by the pentosans, celluloses, pectins, and proteins; the strongly resistant carbonaceous residue (consisting largely of lignins and

29 Wollny, 1897 (p. 477).

${ }^{30}$ Russell, E. J. Oxidation in soils and its connection with fertility. Jour. Agr. Sci., 1: 261-279. 1905. 
waxes) is decomposed only very slowly.31 Organic matter containing sufficient nitrogen, like ground leguminous plants, cotton seed meal, dried blood, and fungus protoplasm, decompose even more rapidly; the nitrogen, sooner or later, depending on its concentration, becomes liberated as ammonia. Substances rich in proteins decompose at an entirely different rate than those composed principally of carbohydrates. Materials rich in oxygen and low in carbon decompose more quickly than those rich in carbon and poor in oxygen. ${ }^{32}$ The following amounts of various organic substances, on a per cent basis, were decomposed in 21 days, as indicated by the carbon dioxide, using 10 grams of material per 100 grams of soil:

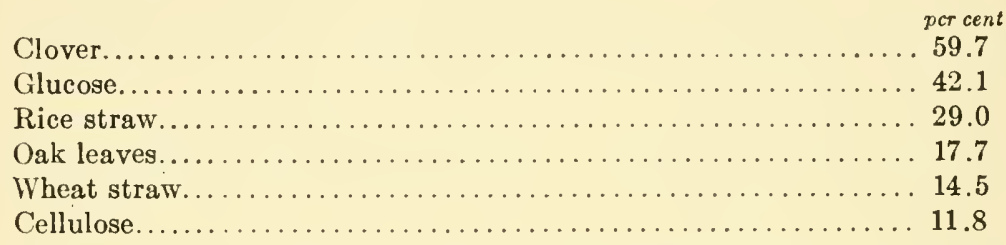

Similar results were obtained ${ }^{33}$ when the decomposition of 0.5 per cent organic matter in the soil was studied. The addition of available nitrogen $\left(\mathrm{NaNO}_{3}\right)$ to a nitrogen poor substance, like straw, stimulates its decomposition but not that of a substance containing sufficient nitrogen, like alfalfa meal (fig. 53). The influence of available nitrogen upon the composition of a nitrogen-poor substance, like cellulose, depends also upon the nature of the soil, as shown in figure 54, where the stimulating effect was greatest in a well manured, fertile soil (5A), least in an unmanured, poor soil (7A), and medium in an unfertilized but limed soil (7B).

These results confirm the earlier observations that the $\mathrm{CO}_{2}$ content of the soil rises and falls with the amount of organic matter present and that the addition of manure to the soil stimulates the evolution of carbon dioxide. Fresh manure stimulates this evolution more than old decomposed manure, because of the introduction of both available energy and available nitrogen. Grinding of peat increases its rate of decomposition.

${ }^{31}$ Van Suchtelen, F. H. H. Ưber die Messung der Lebenstätigkeit der aerobiotischen Bakterien im Boden durch die Kohlensïureproduktion. Centrbl. Bakt. II, 28: 45-89. 1910.

${ }^{32}$ Dvorak, 1912 (p. 428).

${ }^{83}$ Starkey, R. L. Some observations on the decomposition of organic matter in soils. Soil Sci., 17: 293-314. 1924. 
It was suggested ${ }^{34}$ that $\mathrm{CO}_{2}$ formation in soil, whether treated with organic matter or not, does not proceed in accordance with the growth law of bacteria. Under aerobic and constant environmental conditions, it proceeds in accordance with the equation

$$
x=a k t^{m}
$$

in which $x$ is the quantity of $\mathrm{CO}_{2}$ produced in time $t, a$ is the initial $\mathrm{CO}_{2}$ content of the soil, and $k$ and $m$ are constants. However, as experiments with peat and other soils have shown, the $\mathrm{CO}_{2}$ formation in the soil is not always necessarily parallel to the concentration of carbon.

As to the method used for measuring the evolution of carbon dioxide, at first the air freed from $\mathrm{CO}_{2}$ was passed through the soil placed in a container, and the $\mathrm{CO}_{2}$ in the outgoing air measured. ${ }^{35}$ This method was later modified so that air, previously feed from $\mathrm{CO}_{2}$, was passed continuously over the surface of the soil in containers. Under these conditions the soil more nearly approaches normal, since constant aeration greatly accelerates microbiological activities. ${ }^{36}$

Formation of ammonia (and nitrate) as an index of decomposition of organic matter in the soil. Nitrogen is present in the complex organic substances largely in the form of proteins. In the process of decomposition, these are first hydrolized to proteoses, peptones and poly-

${ }^{34}$ Lemmermann, O., and Weissmann, H. Z. Pflanzenernähr. u. Düng., 2B: 387-395. 1924.

${ }^{36}$ Pettenkofer, M. Ueber eine Methode die Kohlensäure in der atmosphärischen Luft zu bestimmen. Chem. Soc. Trans., 10: 292. 1858; Peterson, P. Ueber den Einfluss des Mergels auf die Bildung von Kohlensäure und Salpetersäure im Ackerboden. Landw. Vers. Sta., 13: 155-175. 1870; Wollny, 1897 (p. 477); Stoklasa and Ernest, 1905 (p. 34); Lemmermann, K., Fischer, H., and Fresenius, L. Untersuchungen über die Zersetzung der Kohlenstoff verbindungen verschiedener organischer Substanzen im Boden, speciell unter dem Einfluss von Kalk. Landw. Jahrb., 41:217-256. 1911; Klein, M. A. Studies in the drying of soils. Jour. Amer. Soc. Agr., 7: 49. 1915; Gainey, P. L. Parallel formation of carbon dioxide, ammonia and nitrate in the soil. Soil Sci., 7: 293-311. 1919.

${ }^{36}$ Fred, E. B., and Hart, E. B. The comparative effect of phosphates and sulfates on soil bacteria. Wis. Agr. Exp. Sta. Res. Bul. 35. 1915; Fraps, G. S. Oxidation of organic matter in soils. Texas Agr. Exp. Sta. Bul. 181. 1915; Potter, R. S., and Snyder, R. S. Carbon dioxide production in soils and carbon and nitrogen changes in soil variously treated. Iowa Agr. Exp. Sta. Res. Bul. 39. 1916: Merkle, F. G. The decomposition of organic matter in soils. Jour. Amer. Soc. Agron., 10: 281-302. 1918: Neller, J. R. Studies on the correlation between the production of $\mathrm{CO}_{2}$ and the accumulation of ammonia by soil organisms. Soil Sci., 5: 225-239. 1918; Waksman and Starkey, 1923 (p. 739). 
peptides, and finally to amino acids and acid amides. The latter, when used completely or incompletely as sources of carbon by microorganisms, liberate ammonia. This is oxidized in normal aerated soil to nitrites and then to nitrates. ${ }^{37}$

Some amino acids are probably split off in the first stages of protein hydrolysis. Some ammonia is also formed long before all of the protein is changed to amino acids; some of the latter are decomposed very readily, while others are more resistant. The amino acids may be directly assimilated by microorganisms or they may form condensation products with carbohydrates. Ammonia and nitrates are the final steps in the transformation of nitrogen in the decomposition of proteins; their determination can serve as a good index of the course of decomposition of simple and complex organic nitrogenous compounds in the soil. In the case of some soils rich in organic matter, as in the fertile prairie soils, the transformation of the ammonia into nitrate goes on less rapidly than the formation of ammonia, hence the latter may accumulate. ${ }^{37 a}$ In the presence of carbohydrates or other carbon compounds, serving as sources of energy for microorganisms, the ammonia and nitrate are rapidly changed again to proteins.

The nitrogen in stable manure is about evenly divided between the urea and ammonia nitrogen, on the one hand, and protein or complex organic nitrogen, on the other. When manure is composted or added to the soil, the urea and ammonia nitrogen readily changes to nitrate. The second part of the nitrogen has to be first liberated as ammonia and may again be reassimilated by microorganisms in the presence of considerable quantities of straw. Only after the excess of available carbohydrates has been decomposed, is the ammonia liberated and changed to nitrate. ${ }^{38}$

The sum total of ammonia and nitrate formed as a result of decomposition of a certain organic substance added to the soil can be used as an

${ }^{37}$ A detailed study of the decomposition of nitrogenous substances in the soil is given by Lathrop, 1917 (p. 474); in forest soil by Süchting, H. Der Abbau der organischen Stickstoffverbindungen des Waldhumus durch biologische Vorgänge. Ztschr. Pflanzernähr. Düngung., 1: 113-154. 1922; Chemical nature of soil organic nitrogen is discussed by Jodidi, S. L. The chemical nature of the organic nitrogen in the soil. Iowa Agr. Exp. Sta. Res. Bul. 1. 1911.

37 Wyatt, F. A., Ward, A. S., and Newton, J. D. Nitrate production under field conditions in soils of Central Alberta. Sci. Agr., 7: 1-24. 1926.

38 Bright, J. W., and Conn, H. J. Ammonification of manure in soil. N. Y. Agr. Exp. Sta., Tech. Bul. 67. 1919. 
index of the availability of the nitrogen in the particular material, especially in respect to the particular soil. ${ }^{39}$ Different organic substances decompose with different rapidity. ${ }^{40}$

Attempts have been made to differentiate between the fertility of different soils on the basis of the ammonia formed by a given quantity of soil from a given amount of protein, either in solution or in soil. When dried blood, cottonseed meal, urea or other organic material with a high nitrogen content and, therefore, with a narrow $\mathrm{C}: \mathrm{N}$ ratio is added to normal soils, a large amount of nitrogen will accumulate as ammonia. A number of investigations ("ammonification studies") have been devoted to measuring this ammonia formed from an excess of protein material in different soils. The solution method was at first suggested. ${ }^{41}$ A 0.5 to 5.0 per cent sterile peptone solution was inoculated with a quantity of soil (usually 0.5 to 10 grams per 50 to $100 \mathrm{cc}$. of solution), incubated for 2 to 8 days, then the ammonia was determined by distilling the solution with $\mathrm{MgO}$. Certain differences were obtained in the amount of ammonia formed in various soils. It was soon found, ${ }^{42}$ however, that these differences may be due more to the difference in the quantity of minerals introduced with the various soils rather than to the differences in the kind or activity of the soil flora. It was then suggested ${ }^{43}$ to use a soil extract peptone solution, but this medium also shows variations as a result of differences in the composition of the extract obtained from the various soils. Since the peptone is so rapidly decomposed in solution and since all soils contain large numbers of bacteria capable of forming ammonia from peptone, very little difference is obtained between different soils.

These limitations of the solution method led to the introduction of the soil method (beaker or tumbler method). ${ }^{44}$ The method consists in

${ }^{30}$ Lipman, J. G. Bacteriological methods for determining the available nitrogen in fertilizers. Jour. Indus. Engin. Chem., 2: 146-148. 1910.

10 Löhnis, F., and Green, H. H. Über die Entstehung und die Zersetzung von Humus, sowie über dessen Einwirkung auf die Stickstoff Assimilation. Centrl)l. Bakt. II, 40: 52-60. 1914.

${ }^{41}$ Remy, 1902 (p. 710).

${ }^{4}$ Fischer, H. Ưber die physiologische Wirkung von Bodenauszügen. Centrbl. Bakt. II, 24: 62-74. 1909; Versuche über Stickstoffumsetzung in verschiedenen Boden. Landw. Jahrb., 41: 755-\$22. 1911.

${ }^{43}$ Löhnis, F. Zur Methodik der bakteriologischen Bodenuntersuchung. Centrbl. Bakt. II, 12: 262-267, 448-463. 1904; 14: 1-9. 1905.

4 Vogel. Beiträge zur Methodik der bakteriologischen Bodenuntersuchung. Centrbl. Bakt. II, 27: 593-605. 1910; Lipman, J. G. Chemical and bacteriological factors in the ammonification of soil nitrogen. N. J. Agr. Exp. Sta. 27th Ann. Rpt. 1906, 119-187. 
adding a small amount of a certain organic substance (usually 1 per cent) rich in nitrogen, such as hoof meal, cottonseed meal, dried blood, or a pure protein, such as casein, to 100 grams of fresh soil, placing the mixture in a tumbler in the presence of sufficient water and incubating for 7 to 10 days; the ammonia formed is then determined. Even with this method, the differences obtained between the formation of ammonia in different soils were found ${ }^{45}$ to be due to a number of causes other than the microbial flora of the soil. This becomes selfevident when we consider the following factors: (1) a large number of soil organisms are capable of decomposing proteins with the formation of ammonia; (2) the amount of ammonia formed depends also upon the nature of the carbon of the organic matter added to the soil in the form of nitrogenous and non-nitrogenous substance; (3) a part of the ammonia changes into nitrates, depending upon the physico-chemical, chemical and biological condition of the soil; (4) the amount of ammonia that a soil can hold depends upon its initial reaction, nature of absorbed bases and buffer content.

However, according to some investigators ${ }^{46}$ no necessary fundamental difference exists between bacteriological processes in soil and solution media. Among the important factors in soil and in solution, the nature, quantity, and distribution of substrate, aeration, diffusion, absorption, destruction or evaporation of metabolic products, reaction of the medium, temperature and duration of experiment are all of importance. Ammonia accumulation can be readily used as an index of the activities of pure cultures of microorganisms or of the complex soil flora upon proteins or different organic materials.

The course of ammonia accumulation and the course of $\mathrm{CO}_{2}$ production from the same nitrogenous organic substance added to the soil were found $^{47}$ to run parallel, tending to indicate that both can be taken as indices of the rapidity of decomposition of organic matter in the soil. However, when the curves of $\mathrm{NH}_{3}$ accumulation from dried blood and $\mathrm{CO}_{2}$ evolution from another organic substance, like soy bean meal, were compared, even in the same soil, no parallelism at all was observed. ${ }^{43}$

45 Temple, J. C. The value of the ammonification test. Ga. Agr. Exp. Sta. Bul. 126. 1919.

${ }^{46}$ Löhnis, F., and Green, H. H. Methods in soil bacteriology. VII. Ammonification and nitrification in soil and solution. Centrbl. Bakt. II, 40: 457-479 1914.

${ }^{47}$ Gainey, 1919 (p. 685).

48 Neller, 1918 (p. 685). 
This is due to the fact that different organic substances are attacked at different rates even by the same groups of microorganisms. The addition of these different organic substances to the soil may stimulate the development of different groups of organisms, with the result that there is no basis for comparison between the decomposition of two different substances, even in the same soil, when two different indices of decomposition of organic matter $\left(\mathrm{CO}_{2}\right.$ and $\mathrm{NH}_{3}$ evolution) are employed. It was found ${ }^{49}$ that, for a certain amount of organic nitrogen, in the form of soy bean cake and herring cake, changed to ammonia, twice as much organic matter is changed to $\mathrm{CO}_{2}$ in an acid soil as in a loam soil. By comparing two sources of organic matter, it was found that 1.5 times as much is changed to $\mathrm{CO}_{2}$ in herring cake as in soy bean cake. The mechanical soil conditions influence markedly the relation between ammonia, nitrate and carbon dioxide production. ${ }^{50}$ A detailed study of the influence of straw upon utilization of nitrogen by plants is discussed in detail elsewhere (p. 516). ${ }^{51}$

Formation of "humus" as an index of decomposition of organic matier in the soil. The term "humus" has commonly been applied to a heterogeneous mass of organic matter occurring in soils in different proportions. Not only did the methods of its determination vary, but the mere conception of it remained unclear. An alkaline solution, usually 4 per cent $\mathrm{NH}_{4} \mathrm{OH}$ or 2 to 4 per cent $\mathrm{NaOH}$ is commonly used to extract the soil. In some cases, an aliquot portion of the ammoniacal solution is evaporated to dryness and weighed, then ignited and weighed again; the loss in weight is calculated as "humus." In other instances, the alkaline solution is precipitated with hydrochloric acid and this precipitate is taken to be "humus;" this preparation is often referred to as "humic acid." Crandeau's ${ }^{52}$ original method consisted in leaching the soil first with a dilute acid to set the "humus" free from its combination

${ }^{49}$ Miyake, K., and Nakamura, K. On the effect of calcium oxide and calcium carbonate upon the decomposition of soybean cake and herring cake in two different soils. Jour. Biochem. Tokyo., 3: 27-54. 1923.

${ }^{\text {so }}$ Carpenter, P. H., and Rose, A. K. Ammonia, nitrate and $\mathrm{CO}_{2}$ production in relation to the best mechanical soil conditions. Indian Tea Assoc. Sci. Dept. Quart. Jour. 1921, p. 103.

${ }^{5} 1$ See also May, F. V. Über den Einflusz von Stroh auf die Ausnïtzung organischgebundenen Düngerstickstoffes. Mitt. Wien Hochschule f. Bodenkultur., 2: $433-454$. 1913-14.

${ }^{52}$ Grandeau, L. Recherches sur le rôle des matières organiques du sol dans les phénomènes de la nutrition des végétaux. Compt. Rend. Acad. Sci., 74: 988-991. 1872. 
with alkaline earths ("humates"), removing the excess of acid by washing with water, then adding ammonia to the soil and allowing this to stand a few hours; this results in a dark brown solution of the "humus" or "matière noire." An aliquot portion of this solution was used for the determination of the "humus." This method served as a basis for all modern methods, with various modifications.

Some investigators differentiated between the total alkaline solution and the hydrochloric acid precipitate. Schreiner and Shorey, ${ }^{53}$ for example, referred to a 2 per cent $\mathrm{NaOH}$ solution as the "humus" extract and to the precipitate obtained by adding acid to this solution as "humic acid." However, it has been shown ${ }^{54}$ that not only does a 4 per cent sodium hydroxide solution not extract the same quantity and quality of substances as a 4 per cent ammonium hydroxide solution, but that the very "humus" extract of soils is not a typical soil product. It was also shown that the organic matter extracted by an alkaline solution consists of a black pigment, which contains a relatively small proportion of the nitrogen, and of colorless substances. It was frequently concluded, therefore, that the determination of "humus" by alkaline extraction is wholly without scientific justification. Other methods for determining "humus" in the soil are based upon the color of the alkaline extract, ${ }^{55}$ or upon extraction of the soil with pyridine. ${ }^{56}$ However, none of these methods were found to be free from criticism.

When a soil is treated with an equal volume of 5 per cent solution of sodium hydroxide (or 2 consecutive portions of 2.5 per cent solution), either for 48 hours in the cold or for 30 minutes at 15 pounds pressure, a dark extract is obtained; an equal volume of water is added immediately to the mixture of soil and alkali and the solution filtered through paper; the soil is again treated with an equal volume of 2 per ceut $\mathrm{NaOH}$ solution and the second filtrate and the washings of the soil with distilled water are added to the first. The combined solution ( $\mathrm{I}$ ) is treated with warm hydrochloric acid $(1: 1)$ until a floceulant precipitate is formed, adding a few cc. of acid in excess and shaking the flask. The precipitate $(\alpha)$ is filtered

63 Schreiner, O., and Shorey, E. C. The isolation of harmful organic substances from soils. U. S. Dept. Agr. Bur. Soils Bul. 53. 1909.

"Gortner, R. A. The organic matter of the soil. I. Some data on humus, humus carbon, and humus nitrogen. Soil Sci., 2: 395-441; 539-54S. 1916.

b Eden, T. A note on the colorimetric estimation of humic matter in mineral soils. Jour. Agr. Sci., 14:469-472. 1924; Oden, 1919 (p. 671); A detailed review of the investigations dealing with the origin and nature of "humus" in the soil is given by Baumann and Gully, 1910 (p. 644); Oden, 1919 (p. 671); and Waksman, 1926 (p. 447).

" Piettre, 1923 (p. 672); Page, H. J. The part played by organic matter in the soil system. Trans. Faraday Soc., 17: 272-287. 1921. 
through a weighed Gooch crucible or filter paper; a brown to yellow brown solution (II) is obtained. The precipitate is washed with dilute acid, then with distilled water, dried and weighed; this precipitate or fraction $\alpha$ of the soil organic matter is equivalent to the portion commonly referred to as "humus" or "humic acid." When properly washed with acid, the $\alpha$ fraction contains only 1 to 4 per cent ash and about 3.0 to 3.5 per cent nitrogen. The filtrate (II) from this fraction is then treated with 5 per cent $\mathrm{NaOH}$ solution, until the reaction reaches approximately $\mathrm{pH} 4.8$. At this point a heavy precipitate (fraction $\beta$ ) is formed. This is filtered off; the solution (III) should be straw to yellowish colored; if the solution is brownish, more alkali or acid solution should be added to adjust to the proper reaction and the precipitate is filtered off and added to the rest of fraction $\beta$. This precipitate $(\beta)$ is well washed with distilled water, dried to constant weight and then ashed. This fraction is found to contain about 40 to 60 per cent ash and about 1 per cent of nitrogen. It consists of either a chemical or physical complex of aluminum hydroxide and organic materials. These two fractions contain 60 to 80 per cent of the soil organic matter (the undecomposed part is left in the soil and a part is left in the final solution III). The amounts of these two fractions vary with the soil and its treatment and can serve as an index of the amount and nature of the organic matter in the soil. ${ }^{55}$

\section{Nature of soil "humus." Since the chemical nature of "humus"} is not known and the very methods for measuring it are not exact, there is little wonder that a number of theories have been suggested to explain the formation of this more or less stable substance or group of substances in the soil. It was at first supposed that "humus" is derived chiefly from carbohydrates. ${ }^{56} \quad$ Even at present various theories are frequently suggested to explain how celluloses may change, through the oxy-cellulose stage, into "humic acids." 1889, Hoppe-Seyler suggested that cellulose decomposition does not contribute to the formation of "humus" under anaerobic conditions. Cellulose was found to be decomposed completely to $\mathrm{CO}_{2}$ and $\mathrm{CH}_{4}$, according to the following tentative reactions:

$$
\mathrm{C}_{6} \mathrm{H}_{12} \mathrm{O}_{6}=3 \mathrm{CO}_{2}+3 \mathrm{CH}_{4}
$$

The greater the amount of oxygen, the less methane and the more carbon dioxide was formed. The direct sources of "humus" in the soil are looked for among the lignins, proteins, tannins, chlorophyll, pigments, certain fats, and resins. The celluloses, hemi-celluloses, monoand di-saccharides, glucosides, organic acids and various alcohols do not appear to form "humus" directly. ${ }^{58}$ The protoplasm of fungi

57 Marcusson. Zur Kenntnis der Huminsïuren. Ztschr. angew. Chem., 31: 237-238; 34: 437; Ber. deut. Chẹm. Gesell., 54: 542. 1918-1921.

58 Trusov, A. G. Contributions to the study of soil humus. I. Processes of formation of "humic acid." Materials on the study of Russian soils. XXVIXXVII. 1-210. 1917. 
and probably also of bacteria can serve as a source of "humus" in the soil; all organic substances utilized by microorganisms for nutrients can thus become indirect sources of "humus." Typical black "humus" was found to be formed only as a result of the participation of a group of substances: lignin, protein, pigments and tannins; a mixture of lignin and the latter alone, when acted upon for a considerable period of time, may suffice. Celluloses are decomposed completely by soil fungi without the direct formation of humus-like substances, except through the synthesized microbial protoplasm..$^{59} \quad$ Grave doubts were expressed ${ }^{60}$ as to whether a specific humification of plant material takes place in the soil, since the so-called humus extract of soils and peats is not a typical soil product formed in the soil by the action of microorganisms, but similar extracts can be obtained from unchanged vegetable material, i.e., the "humus" found in the soil was believed to depend entirely on the process of extraction employed.

The formation of "humus" in the soil is thus found to be due either to chemical or microbiological agencies. The different theories explaining this phenomenon can be summarized as follows:

1. "Humus" is formed from the interaction of carbohydrates with amino acids or polypeptides, formed from the decomposition of plant proteins. $^{61}$ Proteins were frequently considered ${ }^{62}$ to be the most important sources of humus in the soil. Certain amino acids, like tryptophane, may be concerned in the reaction which produces black insoluble humin, but this reaction cannot take place without the presence of some as yet unidentified component of the protein molecule. ${ }^{63}$

2. "Humus" is a result of oxidation of benzene ring compounds. ${ }^{64}$ The oxidation of quinone, hydroquinone and phenol results in the for-

${ }^{59}$ Waksman and Heukelekian, 1924 (p. 443); 1925 (p. 443).

${ }^{60}$ Gortner, 1916 (p. 690).

${ }^{61}$ Maillard, L. C. La formation de matière humique sans l'oxygène d'atmosphère. Compt. Rend. Acad. Sci., 154: 66. 1912; 155: 1554-1556. 1912; 156: 1159. 1913; Genèse des matières protéiques et des matières humiques. Paris. 1913.

${ }^{62}$ Benni. Über die Entstehung des Humus. Diss. Gieszen. 1896. Suzuki. Ref. Centrbl. Agr. Chemie., 37: 347. 1908.

${ }^{63}$ Gortner, R. I., and Norris, E. R. The origin of the humin formed by the acid hydrolysis of proteins. Jour. Amer. Chem. Soc., 37: 1613. 1915; also 39: 24. 1917; 42: 821, 632, 2378. 1920; 45: 550. 1923; Jour. Biol. Chem., 26: 127. 1916.

${ }^{64}$ Eller, W., and Koch, K. Synthetische Darstellung von Huminsäuren. Ber. deut. Chem. Gesell., 53: 1469-1476. 1920; Ann. Chim. phys., 431: 133, 162, 177. 1923. 
mation of acids similar to natural humic acid, of the formula $\left(\mathrm{C}_{6} \mathrm{H}_{4} \mathrm{O}_{3}\right)_{\mathrm{x}}$. These compounds may condense with amino acids to give "humus;" 65 the black coloration produced by Bac. mesentericus niger in nutrient media containing a carbohydrate was found to be due to components of the benzene series closely related to o- and p-dihydroxybenzenes which apparently form condensation products with the amino acids. Similar results were obtained for bacteria and fungi. ${ }^{66}$

3. "Humus" is formed from the polymerization of furfural, the latter being produced when acids are acting upon carbohydrates. ${ }^{67} \mathrm{~A}$ dark colored substance containing 75.1 per cent carbon results on heating furfural or oxy-methyl furfural with hydrochloric acid.68 A similar compound was demonstrated in rotting straw and in the soil, but not in the decomposition of cellulose by bacteria. ${ }^{69}$ These three theories can account only for a very small amount of "humus" in the soil. It must be kept in mind that very strong mineral acids are not found in normal soils and amino acids are not liberated in a free state to any considerable cxtent. Even the benzene ring compounds, which are not present in great abundance in natural organic substances, are decomposed by certain soil microorganisms.

4. The formation of "humus" from lignins. ${ }^{70}$ Lignins are present in amounts ranging from 10 to 40 per cent in natural organic matter. ${ }^{71}$ While the constituent celluloses, pentosans, and proteins are decomposed by microorganisms, more or less rapidly, when natural organic matter is added to the soil, the fats, waxes and lignins are acted upon only very slowly, and gradually accumulate in the soil.

5. The rôle of microorganisms, especially by synthesizing fresh cell

${ }^{65}$ Muschel, A. Zur Chemie der Schwarzfärbung kohlenhydrathaltiger Nährböden durch den Bac. mesentericus var. niger. Biochem. Ztschr., 131: 570-590. 1922.

${ }^{66}$ Perrier, A. Recherches sur la fermentation de quelques composés de la série cyclique et sur la formation de la matière noire de l'humus. Ann. Sci. Agron (4), 2: 321-350. 1913.

${ }^{67}$ Roxas, M. L. The reaction between amino-acids and earbohydrates as a probable cause of humin formation. Jour. Biol. Chem., 27: 71-93. 1916.

${ }^{68}$ Marcusson, J. Die Synthese der Humine und Huminsäuren. Ber. deut. Chem. Gesell., 54: 542-545. 1921.

${ }^{69}$ Beckley, V. A. The formation of humus. Jour. Agr. Sci., 11: 69-77. 1921.

${ }^{70}$ Fischer, F. Was lehrt die Chemie über die Entstehung und die chemische Struktur der Kohle. Die Naturwiss., 9: 955-965. 1921; Schrauth, W. Utber die chemische Struktur der Kohle. Brennstoffchemie., 4: 161-164. 1923.

${ }^{71}$ Ritter, G. J. Distribution of lignin in wood. Jour. Ind. Engin. Chem., 17: 1194.1925. 
substance, in the formation of "humus."72 The black pigment of $A z o t$. chroococcum is insoluble in chemical reagents but can be extracted by boiling with strong $\mathrm{NaOH}$ solutions, thus also contributing to the soil "humus." The same is true of a large number of fungi. ${ }^{73}$

To demonstrate the probable rôle of different groups of microorganisms in the formation of soil "humus," it is sufficient to cite the ideas of Falck $^{74}$ on the origin of "humus" in forest soils. Several processes of transformation of organic matter leading to various types of "humus" formation are differentiated:

1. Mycocriny. This is the complete decomposition of organic matter by fungi, whereby the raw materials (broad leaves, pine needles, roots, branches) added every year to the soil are readily decomposed and there is no increased accumulation of "humus." The filamentous fungi and the higher or mushroom fungi (represented in the soil to a large extent also by the mycorrhiza fungi) can decompose the organic matter to the end, without forming any intermediate dark, humus-like substances. The carbon is either assimilated or given off as $\mathrm{CO}_{2}$, the nitrogen and minerals are largely transformed into fungus protoplasm; the latter forms an excellent forest fertilizer, since it is readily decomposed further. The woody and crude fibrous substances may be thereby destroyed or corroded. In destruction, the cellulose is decomposed completely to $\mathrm{CO}_{2}$ through the organic acid stage, more or less resistant to decomposition. The residual substances are soluble in ammonia. In corrosion, the lignin crust is first attacked (by Merulius and other Basidiomycetes), then the cellulose (or both at the same time) is decomposed almost completely.

2. Anthracriny. This is the process of decomposition of organic matter inter-

72 Müller, P. E. Die natürlichen Humusformen. Berlin. 1887. Kostytschew, M. Ann. Agron., 17: 17-38. 1891; Köning, C. J. Beiträge zur Kenntnis des Lebens der Humuspilze und der chemischen Vorgänge bei der Humusbildung. Archiv. Neerland. Sci. Exact. Nat. (2), 9: 34-107. 1904; Beijerinck, M. W. Utber Chinonbildung durch Streptothrix chromogenus und Lebensweise dieses Mikroben. Centrbl. Bakt. II, 6: 2-12. 1900; Wehmer, C. Zum Abbau der Holzsubstanz durch Pilze. Ber. deut. chem. Gesell., 48: 130-134. 1915; Waksman, 1926.

${ }^{73}$ Rippel, A., and Ludwig, O. Die Schwarzfärbung von Azotobacter chroococcum Beij. als Melaninbildung. Centrbl. Bakt. II, 64: 161-166. 1925; Further information on the formation of "humus" in the soil is given by Löhnis, 1910 (p. xiii); Heinze, B. Humusbildung und Humuszersetzung im Ackerboden. Centrbl. Bakt. II, 26: 682-3. 1910; Bottomley, W. B. Formation of humic bodies from organic substances. Biochem. Jour., 9: 260-268. 1915; Mïller and Hansendorf. Humusstudien. Ztschr. Forst. u. Jagdwessen., 53: 789-\$40. 1921; Waksman, S. A. On the nature and origin of the soil organic matter or soil "humus." I. Introductory and historical. Soil Sci., 22: 123-162. 1926.

${ }^{74}$ Falck, R. Mykologische Untersuchungen und Berichte. Gebr. Gotthelft. Cassel., 2: 1923. 
rupted by lower invertebrates and bacteria. In this process, the fungi begin the decomposition of the organic matter, but cannot bring it to completion. Larvae of various insects and various lower invertebrates devour the mycelium and the complex cells of the original organic matter covered with mycelium and produce a dark mass of "humus." 'This is then attacked by bacteria, the activities of which result in the formation of nitrates. The process of "humus" formation thus consists here of three distinct biological stages: (a) growth of fungi, which attack the organic matter in a preparatory manner and only to a certain extent: $(b)$ activities of insect larvae and worms, which break down the organic matter, surrounded with the fungus mycelium, and prepare it for the following stage; $(c)$ "humification" proper, the bacteria beginning their action probably in the body of the larvae and then continuing outside. The nitrogen is changed to ammonia and then to nitrate and the ash content of the residue is increased, while appreciable quantities of $\mathrm{CO}_{2}$ are produced. A muck soil results. A good forest soil consists of four layers: (1) an upper layer of unchanged residues, heavier in the autumn when the leaves have fallen; (2) a fungus layer especially active in spring and early summer; (3) a true humus layer consisting of dark-colored insect excreta, mixed with decomposed and powdered leaf residue rich in bacteria and animals; and (4) the first layer of mineral soil, containing extractives of the upper layer washed down by rain water. In the case of $\mathrm{My}$ cocriny predominating, there is no dark muck layer, the unchanged mineral soil following soon after the fungus layer. In some cases, the fungus layer is at a minimum and the muck layer is more extensive. In the second layer the plant residues are all surrounded with the fungus mycelium (the abundance of the fungi under these conditions cannot be determined by the plate method, since the mycelium extends throughout the soil, representing one individual. Only the spores are counted by the plate method, which does not give a fair idea of the abundance of growth and the nature of the population. For such studies the direct microscopic method should be used). The fourth layer is ramified with the roots of trees, which may also penetrate into layers two and three. The two processes of decomposition of organic matter result in a constant evolution of carbon dioxide and later in a continuous formation of nitrate. The first is rapid at the start and then retarded; the second is at first slow, then gradually more rapid. Nitrate is used up in the forest soil as soon as formed; in beaker studies in the laboratory it accumulates only from layer 3.

3. Peat formation. When fungus development is lacking or is insufficient, the undecomposed leaves gradually accumulate on the surface of the soil. The material can be "humified" and broken up and can also pass through the bodies of animals. The chemical processes of peat formation are still unknown; ${ }^{75}$ it takes place when organic matter is decomposing in the presence of an excess of water; it consists chiefly in the preservation of the carbon, in the splitting off of water and the darkening of the material. The sugars, celluloses and the various other constituents are rapidly decomposed, while the lignins, fats and waxes are fully preserved, since the anaerobic and acid conditions do not allow the development of organisms which are capable of decomposing these substances.

${ }^{75}$ For a full discussion of nature of humification process, see H. J. Page. Fuel. 1923, August. 232. 
The solubility of the organic matter and the ease with which it can decompose decrease with an advance of this process. The further advanced the process of peat formation, the more resistant the materials become to the attack of microorganisms. When peat soils are brought under cultivation, they are at first drained, and if lime is lacking (high-peat or low-lime soils) they are limed, so as to produce favorable conditions for the development of the actinomyces and certain bacteria which are able to decompose the "humus" complexes and liberate the nitrogen in an available form. Since the constant washing of these soils results in the removal of the soluble minerals, the decomposition processes and especially the growth of higher plants are usually favored by the addition of phosphates and potassium salts. Inoculation of a newly drained (and limed if necessary) peat soil with a rich garden soil is essential, so as to introduce the organisms active in the processes of decomposition of organic matter and nitrate formation.

Factors influencing the different processes of transformation of organic matter in the soil are (1) temperature (low temperature favors peat formation; thorough aeration and high soil temperature favor fungus development); (2) physical and chemical soil conditions (excessive moisture favors peat formation, low moisture and soil acidity with proper aeration and temperature favor fungus development, high lime content favors the processes of decomposition by neutralizing the acids formed by the fungi); (3) abundance of spores, and (4) the nature of plant products (thick needles are decomposed less readily than loose leaves, old needles are decomposed with greater difficulty than young ones).

The various forms of "humus formation" are not distinct but may be followed one by another, depending on the soil conditions. Forest trees also thrive well in soils in which the process of decomposition is incomplete, due to the interaction of mycorrhiza fungi, usually the ectotrophic types. ${ }^{75 a}$

Chemistry and classification of humus compounds. While some investigators consicler all the soil organic matter as "humus," others designate by that name only that part of the soil organic matter which is soluble in a solution of an alkali. Still others designate by "humus" only that part of the organic matter which is precipitated from the alkaline solution on acidification; this substance, insoluble in acids and soluble in alkalies, was first regarded as an acid ("humic acid").

The decomposition of plant residues under aerobic or anaerobic conditions was considered to yield different groups of substances, to which different names and formulae were assigned:

${ }^{758}$ A detailed study of the nature of organic matter and nitrate formation in forest soils has been recently made by Hesselman, H. Studien ïber die Humusdecke des Nadelwaldes, ihre Eigenschaften und deren Abhängigkeit vom Waldbau. Meddel. Statens Skagsfors., 22: No. 5. 1926. 
Substances formed under aerobic condiditions :

Substances formed under anaerobic conditions:
Por (modern formula) Portion insoluble (modern formula)
alkali-Ulmic acid- $\mathrm{C}_{40} \mathrm{H}_{28} \mathrm{O}_{12}$ in alkali-Ulmin- $\mathrm{C}_{40} \mathrm{H}_{32} \mathrm{O}_{14}$

Portion soluble in alkali-Humic acid- $\mathrm{C}_{40} \mathrm{H}_{36} \mathrm{O}_{15}$ (modern formula)

Portion insoluble in alkali-Humin- $-\mathrm{C}_{4} \mathrm{H}_{24} \mathrm{O}_{12}$ (modern formula)

The ulmic bodies (in the brown humus) were considered as the first products of decomposition of the plant material in the soil and as occurring with the absorption of oxygen, evolution of $\mathrm{CO}_{2}$, and elimination of water. The humic bodies (in the black humus) were considered as the second stage in the decomposition of the plant material. The formation of apocrenic acid $\left(\mathrm{C}_{24} \mathrm{H}_{12} \mathrm{O}_{12}\right)$ and crenic acid $\left(\mathrm{C}_{2}{ }_{4} \mathrm{H}_{24} \mathrm{O}_{16}\right)$ were considered as the third stage in the decomposition of organic matter in the soil. These acids were not precipitated on acidification of the alkaline solution. Crenic acid was a colorless substance and, on exposure to the air, was oxidized to apocrenic acid: the former could be obtained from the latter by reduction with zinc and $\mathrm{HCl}$. The nitrogen was considered to be present in the soil humus in the form of ammonium or related compounds, since most of it was given off as ammonia on boiling with potassium hydroxide. All these theories and formulae were based of course on mere speculation and not on experimental evidence.

On the other hand, the physical chemist considered that the organic matter of the soil is not present there in the form of "humic acids" and "humates," or definite chemical compounds of calcium and magnesium, but in the form of complex colloidal systems which form adsorption compounds with the various cations present in the soil. The colloidal nature of "humus" was first recognized by Van Bemmelen" in connection with his studies on the absorptive properties of soils. "Humic acid" is a hydrosol and can be flocculated by concentrated electrolytes, especially polyvalent cations (calcium). Similar to silicic acid, it is electronegative, but the charge can be reversed by certain electrolytes. Freezing causes the flocculation of "humus" in soils. "Humus" is capable of absorbing large quantities of water and swelling up. It also absorbs nutrient minerals in the soil, particularly bases. The exact

${ }^{76}$ Mulder, J. J. Die Chemie der Ackerkrume., 1: 308. 1863; Hoppe-Seyler, F. Uber Huminsubstanzen, ihre Entstehung und ihre Eigenschaften. Ztschr. physiol. Chem., 13: 66-121. 1889; Hermann, R. Untersuchungen über den Moder. Jour. prakt. Chem., 22: 65-81; 23: 375-386; 25: 189-206. 1841-1842; Van Bemmelen, J. M. Die Absorptionsverbindungen und das Absorptionsvermögen der Ackererde. Landw. Versuchst., 35: 69-136. 1888; Die Absorption, 81-144. Dresden. 1910. 
nature of combination of the bases with the soil "humus" is insufficiently understood, some considering them to form definite chemical compounds and some as forming absorption complexes. ${ }^{77}$

In general the fractionating of the soil organic matter can be repreented by the following scheme: $:^{78}$

\section{Soil}
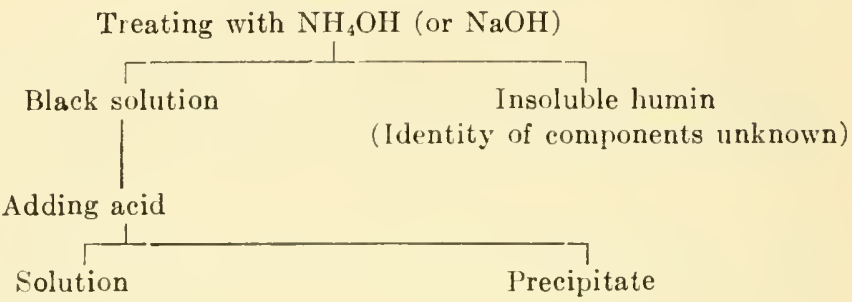

(Mulder's apocrenic acid or

Oden's fulvic acid)

(Contains dihydroxystearic acid, xanthine, hypoxanthine, cytosine, histidine, arginine, pentosan)

\section{Solution}

(Hoppe-Seyler's hymetomelanic acid)

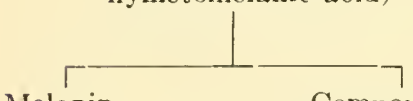

Melanin
Compounds obtained by Sichreiner and Shorey

(Humus)

Dissolving in alcohol

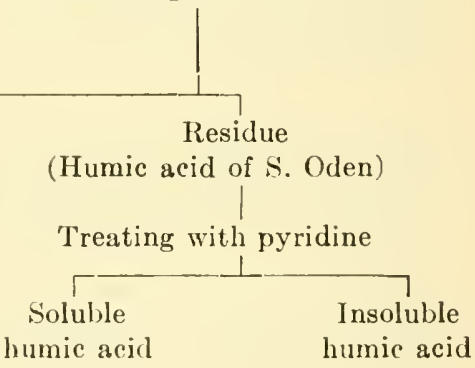

Oden ${ }^{79}$ submitted some evidence to indicate that "humic acid" is a definite chemical compound, with three or four replaceable hydrogens, forming salts with alkalies and being electrically conductive. $\mathrm{He}$ believes with earlier investigator's that the nitrogen is present in this "humic acid" as an impurity, since the content of nitrogen does not fit into the particular chemical formula. However, other investigators ${ }^{80}$

${ }^{77}$ Gedroiz, K. K. The absorbing capacity of the soil and the zeolitic bases of the soil. Zhur. Opit. Agron., 17: 472-527. 1916; Contributions to our knowledge of the absorptive capacity of soils. Ibid., 19: 269-322. 1918; 20: 31-58. 1919.

78 Beckley, 1921 (p. 693).

70 Oden, 1919 (p. 671).

Bo Schmuck, A. The organic substances of the soil. Trans. Kuban Agr. Inst. (Russian), I, No. 2·1-92. 1923. 
consider "humus" to be a nitrogen containing substance of an acid type, the acidity due partly to adsorption by the colloidal "humic acid" and partly to the presence of carboxyl groups. The salts of "humic acid" are not considered as true salts formed in stoichiometric proportions, but as complicated chemical and adsorption compounds. The nitrogen containing part of the "humic acid" is protein in nature and gives hydrolytic products as proteins do; these proteins are at least partly of microbial origin. The "humic acid" contains benzene ring compounds with hydroxyl groups in the form of side chains. "Humic acid" contains about 62 per cent carbon, 3.2 per cent nitrogen, and 4.2 per cent hydrogen, calculated on an ash-free basis. These and more recent ${ }^{81}$ investigations point definitely to the lignins as the mother substances of these so-called "humic acids." In addition to the lignins, the cell substance synthesized by microorganisms is another source of the soil "humus." A complex mixture of these accompanied by various decomposed and partly decomposed constituents of plant and microbial origin form the soil organic matter or soil "humus." Some of these constituents are amphoteric in nature and increase the buffer content of the soil. The mycelium of fungi, for example, has an isoelectric point at pH 4.9 to $5.5 .{ }^{82}$

Soil organic matter and the activities of microorganisms. Organic matter influences the growth and activities of microorganisms in the soil by forming a more favorable physical and chemical environment and by offering a source of energy and other nutrients. The different constituents of the organic matter and the degree of their decomposition influence to a large extent the nature of the organisms which are capable of developing.

The favorable influence of small amounts of soil extract upon the activities of various bacteria, like Azotobacter, led to various assumptions that we are dealing with certain vitamines (auximones). ${ }^{83}$ It was also suggested that the favorable influence of organic matter upon the growth of various microorganisms is due to the chemical improvement of the medium. Others ${ }^{84}$ consider soil "humus" as a reservoir of nutrients required by the soil organisms.

81 Waksman, 1926 (p. 694).

${ }^{82}$ Robbins, W. J. Isoelectric points for the mycelium of fungi. Jour. Gen. Physiol., 6: 259-271. 1924; Jour. Agr. Res., 31: 385-399. 1925.

${ }^{83}$ Bottomley, 1915 (p. 580); Mockeridge, 1915 (p. 580).

${ }^{84}$ Kaserer, H. Einige neue Gesichtspunkte über die Rolle des Humus in der Ackererde. Inter. Mitt. Bodenk., 1: 367-375. 1911. 
However, more careful studies have established the fact that soil "humus" cannot serve as an available source of energy for the great majority of soil microorganisms. Hoppe-Seyler ${ }^{85}$ believed that "humic" substances afford a habitat and substrate for the soil bacteria, fungi, algae and lower animals, but that "humus" itself cannot offer any food to plants, or animals and cannot be decomposed by bacteria. The very fact that "humus" may accumulate in the soil indicates the low availability of these compounds as sources of energy for microorganisms. One could hardly expect that sources of available energy should exist in the soil in great abundance in the presence of the various microorganisms and not be attacked. The low availability of the soil organic matter as a source of carbon is further confirmed by the fact that the addition of a small amount of available nitrogen, such as $\mathrm{NaNO}_{3}$ or $\left(\mathrm{NH}_{4}\right)_{2} \mathrm{SO}_{4}$, does not greatly stimulate decomposition of the organic matter, as indicated by the evolution of carbon dioxide, except in soils with a wide carbon-nitrogen ratio. The nitrogen part of the soil organic matter seems to be more available for the activities of microorganisms than the carbon part. On adding available energy, even in the form of celluloses, various organisms are enabled to use some of the soil nitrogen. This has been also clearly demonstrated by various investigators, ${ }^{86}$ who cultivated fungi using purified "humus" as the only source of nitrogen; the "humus" could not be utilized, however, as a source of carbon. The various claims put forth that "humus" can be used as a source of energy for nitrogen fixing bacteria, as well as for fungi and urea bacteria still need confirmation. ${ }^{87}$ Warmbold $^{88}$ demonstrated previously that

${ }^{85}$ Hoppe-Seyler, F. Utber Huminsubstanzen, ihre Entstehung und ihre Eigenschaften. Ztschr. physiol. Chem., 13: 66-121. 1889.

${ }^{86}$ Reinitzer, F. Über die Eignung der Huminsubstanzen zur Ernährung von Pilzen. Bot. Ztg., 58: 59-73. 1900; Nikitinsky, J. Über die Zersetzung der Huminsäure durch physikalisch chemische Agentien und durch Mikroorganismen. Jahrb. wiss. Bot., 37: 365-420. 1902.

${ }^{87} \mathrm{It}$ is sufficient to cite the work of Robertson, R. A., Irvine, J. C., and Dobson, M. E. A eontribution to ehemistry and physiological action of the humic acids. Bioehem. Jour., 2: 458-480. 1907; Christensen, H. Utber Ureumspaltung. Centrbl. Bakt. II, 24: 130. 1909; Krrzemieniewski, 1908 (p. 579); Pringsheim, 1908-1912 (p. 564). The same is true of the results of Lipman and Teakle, on the use of displaced soil solution and residual soil as sources of energy by Azotobacter; Lipman, C. B., and Teakle, L. J. H. The fixation of nitrogen by Azotobacter in a displaced solution and in soil residue therefrom. Soil Sei., 19: 99-103. 1925.

${ }^{88}$ Warmbold, H. Untersuchungen über die Biologie stickstoffbindender Bakterien. Landw. Jahrb., 35: 1-123. 1906. 
"humus" cannot serve as a source of energy for nitrogen-fixing bacteria. Even crude "humic acids" (extracted with $\mathrm{NaOH}$ and precipitated with $\mathrm{HCl}$ ) cannot be used as nutrients by the majority of microorganisms, but may stimulate the activities of various organisms in a physicochemical way as accompanying mineral impur t'es wil do. ${ }^{89}$

It is true, however, that "humus" does decompose in well aerated and limed soils and that it does not accumulate under these conditions. The exact nature of the organisms concerned in these processes and the processes themselves still await investigation.

When the soil is heated, treated with antiseptics, or air dried, its organic matter decomposes more readily than in the untreated soil. As a matter of fact the amount of $\mathrm{CO}_{2}$ formed from sterilized soil inoculated with a suspension of bacteria or fungi may run parallel to the availability of the organic matter in the soil. König and Hasenbäumer ${ }^{90}$ determined the amount of $\mathrm{CO}_{2}$ evolved from 500 grams of soil in seven weeks, after the soil was sterilized and inoculated with pure cultures of some microorganisms.

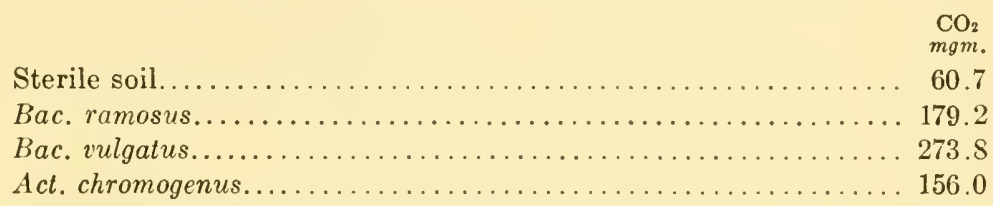

The evolution of $\mathrm{CO}_{2}$ by a pure culture of an organism from the soil itself, to which no fresh organic matter has been added, varies not only with the organism but with the amount and availability of the organic matter in the soil. Trichoderma was found ${ }^{91}$ to produce in eight days, from 100 grams of sterile sandy loam manured with cow manure each year, $124.1 \mathrm{mgm} . \mathrm{CO}_{2}$, while only $37.4 \mathrm{mgm}$. were produced from the same quantity of the corresponding unfertilized soil. These quantities are much larger than those obtained by König and Hasenbäumer because of the difference in composition of soil used and the greater activity of the fungus over the bacteria. The fact that a soil kept at an optimum moisture and temperature will give off a constant stream of $\mathrm{CO}_{2}$ indicates that the soil organic matter is constantly decomposing, truly at a low

${ }^{89}$ Ritter, G. A. Einige Versuche betrefend die physiologische Bedeutung der Humusstoffe des Bodens. Intern. Mitt. Boden., 2: 301-311. 1912. Centrbl. Bakt. II, 34: 577-666. 1912.

${ }^{90}$ König and Hasenbäumer, 1920 (p. 620).

${ }^{11}$ Waksman and Starkey, 1924 (p. 723). 
rate, but very definitely. Among the various soil organisms, certain actinomyces and various non-spore forming bacteria and cocci seem to be especially capable of attacking the soil "humus." 92

Carbon-nitrogen ratio in the soil. According to Agafonoff, ${ }^{93}$ there is a definite equilibrium between the accumulation of organic matter and its decomposition in the soil. But there is no doubt that by constant addition of fresh organic matter, in the form of green manure or stable manure, the supply of soil organic matter can be increased, especially so under conditions which do not favor soil aeration and in the absence of sufficient bases. There is another equilibrium between the carbon and nitrogen of the soil. Analyses of numerous soils with different contents of organic matter, reveal a constant ratio between these two elements, this ratio varying in normal soils within narrow limits. Just what this ratio will be in any soil in an undisturbed condition depends on a number of factors, such as the physical and chemical conditions of the soil, which may cause the unequal development of the different groups of microorganisms.

The ratio of $\mathrm{C}$ to $\mathrm{N}$ in the soil has been variously estimated as between $8: 1$ and $12: 1$; the ratio becomes narrower in the subsoil. Hutin ${ }^{94}$ was among the first to report that the average ratio between the carbon and nitrogen of soil organic matter (or "humus") is 11.4. Similar results have been reported by other investigators. ${ }^{95}$

This ratio varies also with the type of soil, ${ }^{96}$ as shown in figure 57 . Although the first foot of soil in dry land agriculture contains 2.24 per cent organic matter and the second foot 1.62 per cent, the $\mathrm{C}: \mathrm{N}$ is, in both cases, $11 .{ }^{97}$ It was suggested ${ }^{98}$ that the activities of microorganisms play an important rôle in establishing this definite relationship in the soil between the two most important elements. In decomposing

${ }_{92}$ Nikitinsky, 1902 (p. 700); Winogradsky, 1924 (p. 10).

${ }^{93}$ Agafonoff, V. Sur la limite d'accumulation de l'humus dans les sols à propos des observations des sols de la Nièvre. Compt. Rend. Acad. Sci., 177: 828-830. 1923.

${ }_{94}^{4}$ Hutin, A. Chein. Centrbl. II, 174. 1913.

${ }^{96}$ Sievers, F. J. The maintenance of organic matter in soils. Science N. S., 58: 78-79. 1923; Sievers, F. J., and Holtz, H. F. The silt loam soils of eastern Washington and their management. Wash. Agr. Exp. Sta. Bul. 166.1922 ; Bul. 176. 1923.

${ }^{96}$ Brown, P. E., and O'Neil, A. M. The color of soils in relation to organic matter content. Iowa Agr. Exp. Sta. Res. Bul. 75. 1923.

${ }^{97}$ Jones, J. S., and Gates, W. W. The problem of soil organic matter and nitrogen in dry-land agriculture. Jour. Amer. Soc. Agron., 16: 721-730. 1924.

98 Waksman, 1926 (p. 694). 


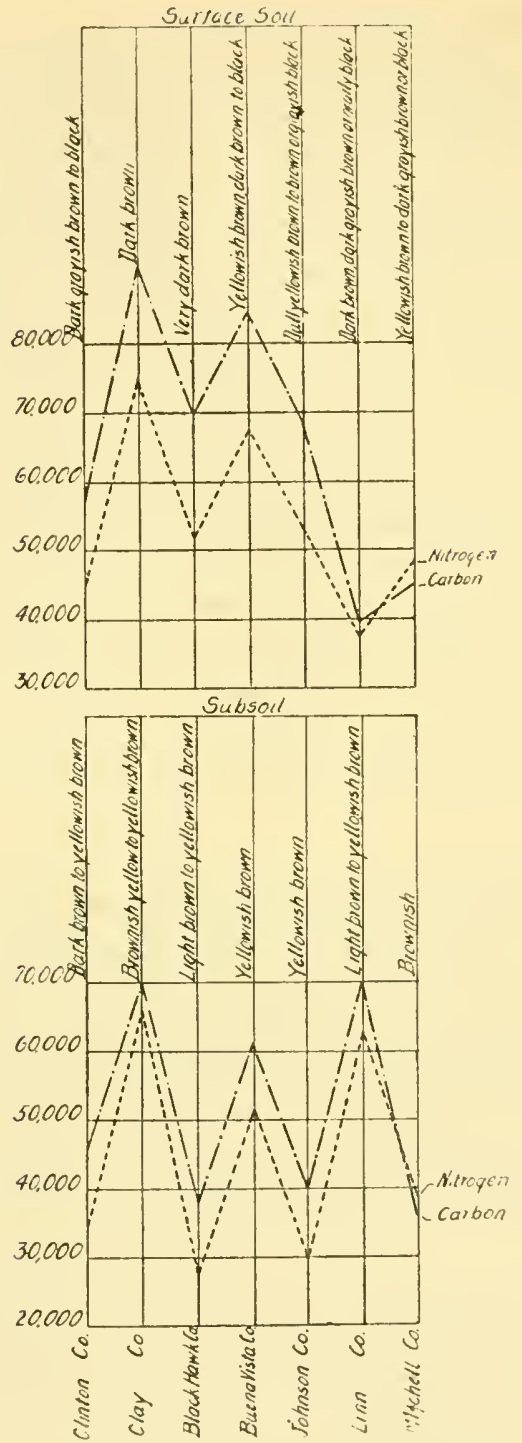

FIG. 57. Carbon and nitrogen content of Carrington silt loam (Brown and O'Neil).

the organic matter as an available source of energy, soil microorganisms may assimilate as much as 10 to 40 per cent of the carbon of the original material and convert it into microbial protoplasm. The latter contains 
about 5 to 10 per cent of nitrogen and about 45 per cent of carbon. This necessitates the assimilation of considerable quantities of available nitrogen by microorganisms, with the result that the nitrogen is converted from an available into an unavailable form. In other words. for every 100 units of organic matter decomposed, from 0.5 to 4.0 units of nitrogen may be assimilated. If the organic matter contains 0.5 per cent nitrogen, as in the case of straw, additional available nitrogen has to be provided, 1 to 2 parts of nitrogen for every 100 parts of organic matter, before the latter can be completely decomposed. If the organic matter, like clover or alfalfa, contains 1.5 to 2.5 per cent nitrogen, no additional nitrogen is required for its complete decomposition by fungi, but over a period of a few months no nitrogen will be liberated as $\mathrm{NH}_{3}$. However, if the organic matter contains more than $2 \frac{1}{2}$ per cent nitrogen, some of it will be liberated as ammonia and the amount will depend on the actual nitrogen content. Very little will be formed in the early period from alfalfa which contains about 3 per cent nitrogen; more will be formed from linseed meal, cottonseed meal and similar substances which contain 4 to 8 per cent of nitrogen. Large amounts of nitrogen will be liberated from dried blood which contains 11 to 13 per cent nitrogen.

The bacteria and actinomyces are much less economical in energy utilization than the fungi and, although their nitrogen content is higher (9-13 per cent), the total amount of nitrogen assimilated and stored away is less than in the case of the fungi. An organic substance, like alfalfa, can, therefore, liberate more available nitrogen when it is decomposed by bacteria or actinomyces than when it is decomposed by fungi. Conditions favoring the activities of bacteria and destructive to fungi, such as liming an acid soil or treating a soil with volatile antiseptics, tend toward a liberation of available nitrogen, as will be shown in detail elsewhere.

The equilibrium between the carbon and nitrogen, which becomes established in the soil is, therefore, a result of three processes resulting from the activities of microorganisms: (1) the complete decomposition of most of the organic material, including most of the carbohydrates, proteins, etc.; (2) the resistance of some materials as lignins to decomposition; (3) the synthesizing activities of microorganisms.

If fresh organic matter is added to a soil with a wide carbon-nitrogen ratio, the microorganisms which attack it reduce the ratio, by liberating part of the carbon as $\mathrm{CO}_{2}$ and assimilating part of it into the microbial cells. The products formed depend largely on the amount of available 
nitrogen and energy and on the organisms concerned. If the organic matter added to the soil is of a narrow carbon-nitrogen ratio, the same processes will take place, with a tendency for the ratio to become wider. A part of the nitrogen, depending on its original concentration, is liberated as ammonia. When the carbon-nitrogen ratio of the soil is wider than normal, the soil is not in a condition to support active plant growth and nitrogen starvation will be observed as long as the excess of carbon lasts, since the microorganisms using the carbon as a source of energy will assimilate every trace of available nitrogen that would otherwise be utilized by the higher plants. In the case of a soil with a constant carbon-nitrogen ratio, the activities of the microorganisms are in a condition of a more or less unstable microbiological equilibrium: only small amounts of energy are utilized, resulting in the liberation of corresponding amounts of ammonia, which are later transformed into nitrates. The amount of ammonia (and nitrate) liberated in a soil under normal conditions depends on the amount and kind of organic matter in the soil as well as on the environmental conditions. However, the addition of fresh organic matter with a $\mathrm{C}: \mathrm{N}$ ratio of $10: 1$ will also stimulate the activities of microorganisms, which bring about a liberation of $\mathrm{CO}_{2}$ and a parallel formation of ammonia.

The inhibitive effect of a wide $\mathrm{C}: \mathrm{N}$ ratio is not exerted upon legumes, which do not rely upon fixed nitrogen for their requirements of this element, as shown elsewhere.

It is known that growing plants like maize and wheat have a depressive influence upon the nitrate accumulation in the soil. It was suggested $^{99}$ that the roots of the growing plants liberate organic matter much of which is non-nitrogenous; this favors the development of nitrate-consuming organisms in the soil, with the subsequent transformation of the nitrates into other nitrogenous substances. The composition of the organic matter liberated (or made available) by the living and decomposing plant roots has a potent influence upon the activity of the nitrate consuming organisms. The amounts of nitrate nitrogen recovered by leaching, when different roots and dried blood are added to the soil, were found to vary directly with the percentage of nitrogen in these substances (by comparing the decomposition of organic matter added, in quantities sufficient to contain 0.6 gram of nitrogen, to 28 pounds of soil and incubating three months). There was about the same

${ }^{99}$ Lyon, T. L., Bizzell, J. A., and Wilson, B. D. Depressive influence of certain higher plants on the accumulation of nitrates in soil. Jour. Amer. Soc. Agron., 15: 457-466. 1923. 
amount of nitrate formed in the control soil and in the soil to which clover was added. This shows that about 2 per cent of nitrogen was sufficient to allow the microorganisms to utilize the available energy in the fresh organic matter; the greater the amount of organic matter added, the less is the amount of nitrate found and the more of it is used up by the microorganisms. In soil treated with dried blood (any other source of organic matter containing more than 2 per cent nitrogen could have been used), the amount of nitrate found was greater than in the

TABLE 74

Relation of nitrogen content of various plant roots to nitrogen in leachings from soil in which they were decomposed

\begin{tabular}{|c|c|c|c|}
\hline MATERIAL USED & NITROGEN & $\begin{array}{c}\text { WEIGHT OF MATERIAL } \\
\text { ADDED }\end{array}$ & $\begin{array}{c}\text { TOTAL NITRATE } \\
\text { NITROGEN } \\
\text { IN LEACHINGS }\end{array}$ \\
\hline & per cent & grams & $m g m$. \\
\hline Control soil .............. & $\ldots$ & $\ldots \ldots$ & 946.6 \\
\hline Oat roots $\ldots \ldots \ldots \ldots \ldots \ldots$ & 0.45 & 133.3 & 207.3 \\
\hline Timothy roots ........... & 0.62 & 96.8 & 398.4 \\
\hline Maize roots........ & 0.79 & 75.9 & 510.6 \\
\hline Clover roots..... . & 1.71 & 35.1 & 924.4 \\
\hline Dried blood.......... & 10.71 & 5.6 & 1751.1 \\
\hline
\end{tabular}

TABLE 75

Milligrams of nitrate nitrogen per 100 grams of dry soil

\begin{tabular}{|c|c|c|c|c|c|c|c|}
\hline \multirow{2}{*}{$\begin{array}{c}\text { ORGANIC MATTER ADDED } \\
(0.3-0.6 \text { PER CENT })\end{array}$} & \multirow{2}{*}{ AT START } & \multicolumn{6}{|c|}{ AFTER, WEEKS } \\
\hline & & 12 & 20 & 24 & 28 & 32 & 40 \\
\hline None... . . . . . . . & 0.59 & 0.74 & 0.55 & 1.25 & 1.50 & 3.51 & 2.65 \\
\hline Paper.......... & 0.59 & 0 & 0 & Trace & Trace & 0.20 & 1.29 \\
\hline Straw......... & 0.59 & 0 & 0 & 1.81 & 2.20 & 3.18 & 3.70 \\
\hline Clover........ & 0.59 & 1.22 & 2.01 & 2.40 & 2.00 & 3.62 & 3.82 \\
\hline
\end{tabular}

control. The actual amount of nitrate produced was regulated by the per cent of nitrogen contained in the organic matter. The higher the nitrogen content, all other factors being alike, the greater will be the amount of nitrate formed.

The nitrogen fixed by the microorganisms in their cells will sooner or later become available, when these cells begin to decompose, as seen in table 75.100

100 Hill, H. H. The effect of green manuring on soil nitrates under greenhouse conditions. Virginia Agr. Exp. Sta. Tech. Bul. 6. 1915. 
These results point to the practical conclusion that, whenever a readily available source of nitrogen is wanted immediately, substances containing less than 2 per cent of nitrogen cannot be profitably used. The greater the nitrogen content of a material, the greater is its value as an immediate source of nitrogen. Whenever substances with a nitrogen content of less than 2 per cent are added to the soil just before a crop is planted, some inorganic nitrogen fertilizers, like $\mathrm{NaNO}_{3},\left(\mathrm{NH}_{4}\right)_{2} \mathrm{SO}_{4}$, urea, should also be added, otherwise the growing plants may experience nitrogen starvation.

Hilgard ${ }^{101}$ suggested that soil in which the nitrogen content of "humus" (as determined by the Grandeau method) was only 2 per cent, the application of available nitrogen was essential or the soil is nitrogenhungry; the presence of 3 per cent nitrogen in "humus" was sufficient to cover the need; a greater content of nitrogen ( 5 per cent) indicated an abundance of this element. However, as pointed out previously, the amount and nature of "humus" obtained from a soil depends upon the method used. ${ }^{102}$

${ }^{101}$ Hilgard, E. W. Zur Erkennung des Düngebedürfnisses der Böden für Stickstoff. Deut. landw. Presse., 22: 490. 1595.

${ }^{102}$ The carbon and nitrogen ratio of peat materials is discussed in detail by Dachnorski; the bog flora and vegetation by Transeau; the microorganisms living in peat soils by Ritter, Arnd and Christensen; in forest soils by Migula and Schultz; Dachnorrski, A. P. The chemical examination of various peat materials by means of foodstuff analysis. Jour. Agr. Res., 29: 69-84. 1924; Transeau, E. N. The bogs and bog flora of the Huron River Valley. Bot. Gaz., 40: 351375, 418-418. 1905; 41: 17-42. 1906; Ritter, G. A. Beiträge zur Kenntnis der niederen pflanzlichen Organismen, besonders der Bakterien, von Hoch- und Niderungsmooren, in floristischer, morphologischer und physiologischer Beziehung. Centrbl. Bakt. II, 34: 577-666. 1912: Arnd, Th. Beiträge zur Kenntnis der Mikrobiologie unkultivierter und kultvierter Hochmoore. Centrbl. Bakt. II, 45: 554-574. 1916; Landw. Jahrb., 49: 191-214. 1916; 51: 297-328. 1917; Christensen, R. Mikrobiologische Untersuchungen von Hoch-und Niederungsmoortorf. Centrbl. Bakt. II, 37: 414-431. 1913; Migula, W. Ủber die Tätigkeit der Bakterien im Waldboden. Forstwissensch. Zentrbl., 35: 161-169. 1913; Schulz, K. Die Verbreitung der Bakterien im Waldboden. Inaug. Diss. Jena. 1913; (Centrbl. Bakt. II, 41: 277). 


\section{CHAPTER XXYII}

\section{Microbiological Analysis of Soll as an Index of Soil Fertility}

Soil fertility and microbiological activities. The measure of soil fertility is the crop itself. This is influenced by the physical and chemical conditions of the soil, such as texture, moisture content, aeration and presence of nutrient elements essential for plant growth. The availability of these nutrients is variously affected by the activities of the soil microorganisms. By modifying the soil, as by manuring, liming, cultivation, etc., the activities of the microorganisms are modified, which is followed by a modification of the availability of plant nutrients. In addition to the beneficial microorganisms, the soil harbors various plant parasites, which are greatly influenced by the treatment of the soil.

The very occurrence and abundance of various specific organisms can be modified by soil treatment. By keeping the soil well aerated and properly limed, in the presence of sufficient available energy, we stimulate the development of Azotobacter, nitrifying bacteria, and most strains of Bact. radicicola. When a soil is more acid than $\mathrm{pH} 6.0$ and when it is not properly aerated, due to excess of moisture or compactness, Azotobacter is inactive, but the Bac. amylobacter predominates and may take an active part in the process of nitrogen fixation in the soil. By adding an abundance of organic matter, low in nitrogen, to the soil, as well as by adding fertilizers which tend to make the soil reaction acid, the development of fungi is favored, over and above that of bacteria and actinomyces. Fungi rapidly decompose the organic matter, assimilating the available nitrogen compounds in the soil for the synthesis of their mycelium; this nitrogen is liberated again only when the fungi are decomposed by bacteria. Nitrification and denitrification, decomposition of proteins with the liberation of ammonia, or utilization of the latter by microorganisms with the building up of proteins, reduction of the supply of available nitrates in the soil, sulfate reduction or oxidation of sulfur to sulfates, are among the phenomena which can thus be controlled by soil management.

By heating the soil or by treating it with various disinfectants, the 
physico-chemical condition of the soil and its flora and fauna are affected in such a manner as to bring about increased activities of certain groups of microorganisms, accompanied by a greater decomposition of the soil organic matter; this results in the liberation of nitrogen in an available form and in increased crop growth. Whether growth of cultivated plants in the so-called "sick" or "exhausted" soils is due to the development of parasitic fungi or of organisms competing with the bacteria for the plant food, or of organisms actually destroying the bacteria, or whether this is due to the formation of toxic substances by microorganisms in the soil, there is no doubt that, by modifying the microbial flora and fauna and their activities, through heat or treatment with antiseptics, more favorable conditions for plant growth will result.

In considering the soil microflora as a whole, can a group of methods be suggested, which would supply the information necessary for an understanding of the various processes carried on by microorganisms in the soil, so as to obtain an insight into the actual or potential fertility of the particular soil? The methods for measuring the biological activities of the soil should be quantitative, both for the study of numbers of all or of certain specific types of microorganisms and for measuring the physiological activities of the microorganisms, both in the soil as a whole and under specifically controlled laboratory conditions. However, since soil fertility is affected, aside from the biological activities, also by the physical and chemical soil conditions, nature of crop, weather, etc., the results should not be expected to represent a mathematical function of crop productivity of a given soil. The results obtained from the study of one group of soils may not necessarily apply to other soils, under different climatic, topographic and other conditions. The mechanical composition, reaction, presence of free salts, as well as the physico-chemical condition of the soil, are of great importance in this connection. ${ }^{1}$

Methods for determining the microbiological condition of the soil. According to Niklewski, ${ }^{2}$ the value of microbiological methods for soil characterization is largely due to the fact that we are able to determine the properties of a soil more exactly than by ordinary methods of chemistry and physics. Christensen ${ }^{3}$ also states that the microbiologi-

${ }^{1}$ See Lühnis, F. Ziele und Wege der bakteriologischen Bodenforschung. Landw. Jahrb., 42: 751-765. 1912.

2 Niklewski, 1912 (р. 726).

${ }^{3}$ Christensen, 1915 (p. 578). 
cal condition of the soil, consisting of a knowledge of the qualitative and quantitative composition of its microflora and microfauna, can be considered as an expression of its complex chemical and physical condition.

Chester ${ }^{4}$ was the first to suggest a formula for determining the coefficient of "zymotic efficiency," which would express the results of a quantitative-qualitative bacteriological analysis of soil. "Zymotic efficiency" was looked upon as a compound involving a number of factors, capable of individual expression. Large numbers of bacteria combined with great activity would show a high zymotic efficiency, while low efficiency would mean small numbers and low activity. The lack of proper bacteriological methods, combined with an insufficient knowledge of the various groups of soil organisms prevented Chester and those following soon after from developing this idea.

Following the work of Chester, the study of soil microbiological activities was divided along two main lines: (1) an intensive study of numbers and types of microorganisms occurring in the soil, and (2) a study of the chemical changes taking place when a small amount of soil is added to sterile or unsterile solutions of definite composition, or when a definite chemical substance is added to a definite amount of soil and the transformations taking place are determined, after a definite period of incubation. ${ }^{5}$ The principle of the original solution method consisted in inoculating various solutions, the composition of which depended upon the transformation under consideration, with comparatively large amounts of soil and determining, at the end of a definite period of incubation, the chemical change that has taken place. When a 1 per cent peptone solution is inoculated with ten per cent of soil, and the ammonia formed determined after 4 to 8 days incubation at $20^{\circ} \mathrm{C}$., a correlation could be demonstrated between the amount of ammonia thus formed and the productivity of certain soils. Löhnis laid down two considerations which could be observed in carrying on these experiments:

1. The course of various transformations should be demonstrated quantitatively. 2. The composition of the soil solutions should be of such a nature that

${ }^{4}$ Chester, F. D. Study of the predominating bacteria in a soil sample. Del. Agr. Exp. Sta. Rpt., 14: 52-66. 1903; Bul. 65. 1904.

${ }^{5}$ Remy, Th. Bodenbakteriologische Studien. Centrbl. Bakt. II, 8: 657, 699, 728, 761. 1902; Landw. Jahrb. Erganzb., 4: 31. 1906; Ehrenberg, P. Die bakterielle Bodenuntersuchung in ihrer Bedeutung für die Feststellung der 
the transformations take place within a definite length of time, these should not be too rapid, so that the original differences, due to bacterial activities, should not become obliterated. On the other hand, definite transformations should take place at least within one month.

The soil method was soon substituted ${ }^{6}$ for the solution method, for the biochemical soil investigations. Here, the substance is added to a certain amount of soil, well mixed and kept at optimum moisture and temperature, for a certain period, at the end of which the chemical change produced is determined.

NUMBERS OF MICROORGANISMS IN THE SOIL

The direct microscopic method has not as yet been sufficiently developed so that it cannot be used readily for determining the total numbers of microorganisms in the soil. So far we have to depend on the plate methods with all its numerous limitations for the information on the relative abundance of microorganisms. The variability of the soil, methods of sampling, preparation of media and plates, and other details for determining the number of microorganisms have been recorded in detail elsewhere (p. 12). Synthetic media should be employed for the soil bacteria and actinomyces, using 8 to 10 plates for each soil sample and taking at least 4 or 5 composite samples from each field or plot. The fungi should be determined on the same samples of soil, using a different acid medium and a dilution of 1:100 or thereabouts of that employed for the determination of bacteria.

Treatment of soil which brings about differences in fertility also results in decided differences not only of the total number of microorganisms in the soil, but also of the relation between the different groups of organisms. The system of cropping and the nature of the crop grown

Bodenfruchtbarkeit. Landw. Jahrb., 33: 1-139. 1904; Löhnis, F. Untersuchungen über den Verlauf der Stickstoffumsetzungen in der Ackererde. Mitt. landw. Inst. Leipzig, H 7: 1-103. 1905.

${ }^{6}$ Stevens, F. L., and Withers, W. A. Studies in soil bacteriology. Centrbl. Bakt. II, 23: 355-373, 776-7S5. 1909; 25: 64-80. 1910; Lemmermann, O., Fischer, H., Kappen, H., and Blanck, E. Bakteriologischchemische Untersuchungen. Landw. Jahrb., 38: 319. 1909; Koch, A., and Petit. Uber den verschiedenen Verlauf der Denitrifikation im Boden und in Flüssigkeiten. Centrbl. Bakt. II, 26: 335-345. 1910; Vogel. Beiträge zur Methodik der bakteriologischen Bodenuntersuchung. Centrbl. Bakt. II, 27: 593-605. 1910; Lipman, J. G., and Brown, P. E. Experiments on ammonia and nitrate formation in soils. Centrbl. Bakt. II, 26: 590-632. 1910. 
are of importance in this connection. Engberding, ${ }^{7}$ however, found that whenever a difference was observed as due to cropping, it could be accounted for by the difference in the moisture content of the soil. The addition of organic matter to the soil, either in the form of stable manure, green manure and plant stubble, is known to have a decided stimulating effect upon the number of microorganisms. After most of the available energy materials have been decomposed the numbers begin to fall again, so that in a few months the level of the control may be reached. Soluble inorganic nitrogen salts and minerals also exert a stimulating effect upon the numbers of microorganisms.

The correlation between the numbers of microorganisms in the soil and soil fertility has met, on the one hand, with a certain amount of criticism, but, on the other hand, has yielded some very interesting results in the hands of a number of investigators. Löhnis ${ }^{7 a}$ did not consider the determination of numbers of microorganisms in the soil as bearing upon soil fertility processes. Certain other investigators ${ }^{8}$ could not find any correlation between soil fertility and results obtained by physiological methods (ammonification, nitrification).

On the other hand, a great deal of confidence was placed ${ }^{9}$ in the determination of the numbers of microorganisms in the soil by the plate method, with the idea of correlating these results with soil fertility. It was believed that an insight into some of the differences in the productivity of different soils could thus be obtained. A definite correlation was found to exist ${ }^{10}$ between crop yield, oxidizing power of soil, nitrate production and numbers, but not between crop yield and mnmonia accumulation. It was concluded that the determination of numbers of microorganisms in the soil by the plate method, allowing for the variability of the methods used and of the soil, can serve as a

${ }^{7}$ Engberding, 1909 (p. 14).

7a Löhnis, F. Landw. Jahrb. 42: 751-765. 1926.

${ }^{8}$ Maassen and Behn. Zur Kenntnis der bakteriologischen Bodenuntersuchungen. Arb. Biol. Reichsanst. Land u. Forstw., 11: 399-505. 1923.

${ }_{9}^{9}$ Fischer, H. Besitzen wir eine brauchbare Methode der bakteriologischen Bodenuntersuchung? Centrbl. Bakt. II, 23: 144-159. 1909.

${ }^{10}$ Neller, J. R. The oxidizing power of soil from limed and unlimed plots and its relation to other factors. Soil Sci., 10: 29-39. 1920; Noyes, H. A., and Conner, S. D. Nitrates, nitrification and bacterial contents of five typical soils as affected by lime, fertilizer, crops and moisture. Jour. Agr. Res., 16: 27-42. 1919; Waksman, S. A. Microbiological analysis of soil as an index of soil fertility. III. Influence of fertilization upon numbers of microorganisms in the soil. Soil Sci., 14: 321-346. 1922. 


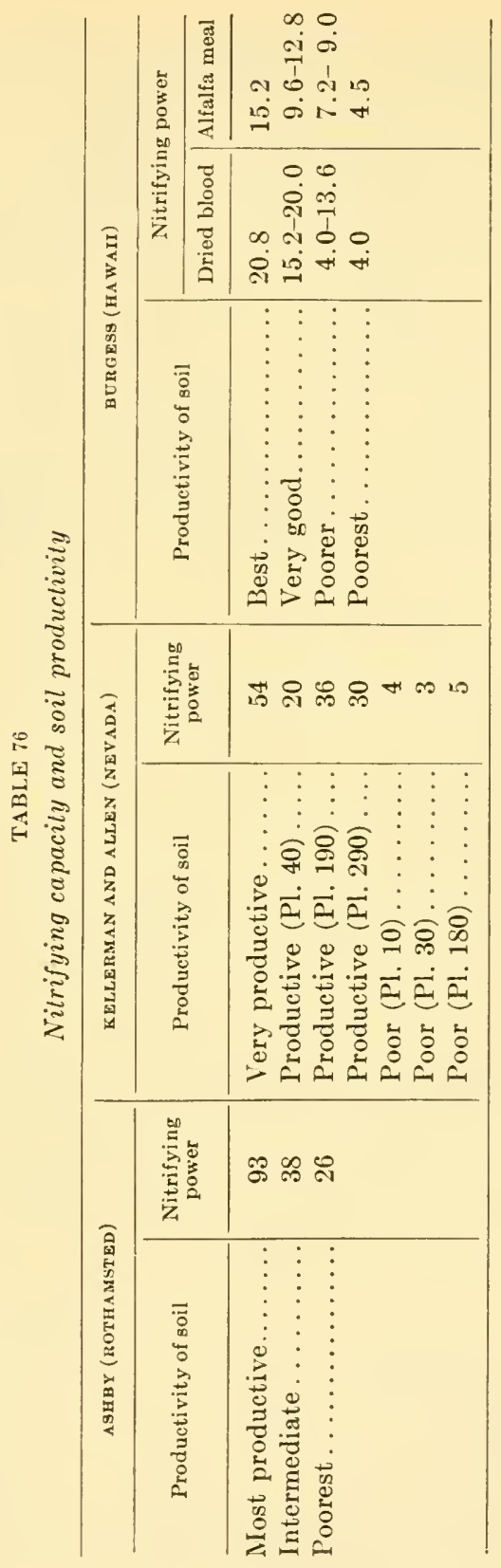


function for measuring the bacteriological condition of the soil and potential crop production, or soil fertility. The relative numbers of bacteria, actinomyces and fungi can further indicate the chemical condition of the soil, such as soil reaction, degree of decomposition of organic matter, etc. A comparison between the crop yields of a series of plots, fertilized in the same manner for a number of years, in which definite differences in fertility have been established, with bacterial numbers, is given in figure 62 .

The plots recorded in figure 62 have been fertilized as follows:

The A plots were unlimed, the B plots limed, receiving two tons of ground limestone per acre every five years; plots 4 and 19 received minerals only (640 pounds acid phosphate and 320 pounds potassium chloride per acre); plot 5 received manure (32 tons per acre) and minerals; plot 7, no fertilizer; plot 9, sodium nitrate (320 pounds per acre) and minerals; plot 18, manure, minerals and sodium nitrate.

The addition of lime was found to have a more stimulating effect upon the numbers of microorganisms than upon crop yield. It brought about, in the particular plots, a change in reaction from one below the acid limit for the development of Azotobacter and not very favorable for the development of actinomyces to a reaction very favorable for the development of both groups of organisms. This, combined with the redistribution of the various groups of soil organisms, as a result of liming, may account for the lack of perfect parallelism between the unlimed and limed soils in regard to numbers and crop yields.

Let us compare two plots, each $\frac{1}{20}$ of an acre in size. Plot 9A received yearly applications of 320 pounds of sodium nitrate per acre, 640 pounds of acid phosphate and $320 \mathrm{lbs}$. of potassium chloride. Plot $11 \mathrm{~B}$ received an equivalent amount of ammonium sulfate and the same minerals; two tons of lime were also applied every five years. The following results were obtained:

\begin{tabular}{|c|c|c|}
\hline & PLOT 9A & PLOT 11B \\
\hline Total bacteria and actinomyces. & $10,113,000$ & $9,500,000$ \\
\hline Actinomyces, per cent......... & 25 & 265 \\
\hline Fungi (on acid medium)............ & 46,450 & 39,100 \\
\hline Reaction of soil, pH....... & 5.5 & 5.8 \\
\hline Total crop yield, pounds... & 50,488 & 53,826 \\
\hline
\end{tabular}




\section{NITRIFYING CAPACITY OF THE SOIL}

\section{Several methods are available for the study of nitrification:}

1. Solution or sand method. A standard sterile solution containing a certain amount of ammonium sulfate and $\mathrm{CaCO}_{3}$ or $\mathrm{MgCO}_{3}$ as a base, in addition to the necessary minerals, is placed in a series of flasks and inoculated with 10 per cent of the soil to be tested. The flasks are incubated at $25^{\circ}$ to $30^{\circ} \mathrm{C}$. for thirty days and the nitrates formed are determined by the phenol-disulfonic acid method. The results obtained by this method supply information as to the presence or absence of nitrifying bacteria, influence of stimulating substances present in the soil, ete. The solution method may be replaced by the sand method. One hundred-gram portions of pure washed sand, containing $210 \mathrm{mgm} . \mathrm{CaCO}_{3}$ are placed in $250 \mathrm{cc}$. Erlenmeyer flasks; $15 \mathrm{cc}$. portions of a mineral solution (2 grams $\mathrm{K}_{2} \mathrm{HPO}_{4}, 1$ gram $\mathrm{MgSO}_{4}, 0.4$ gram $\mathrm{FeSO}_{4}$ in $1000 \mathrm{cc}$. of water) are then added to each flask. The flasks are plugged and sterilized in the autoclave for 1 hour; 5 cc. portions of a sterile aqueous solution containing $30 \mathrm{mgm}$. of nitrogen, in the form of ammonium sulfate, are added after sterilization; these are inoculated with 10 grams of soil and incubated for 30 days at $28^{\circ}$ to $30^{\circ} \mathrm{C}$. The nitrates are then determined.

2. Nitrification of the soil's own nitrogen. This consists in incubating, for 30 days at $25^{\circ}$ to $25^{\circ} \mathrm{C}$., 100 -gram portions of the soil to be tested. The soil is placed in covered tumblers and contains the optimum amount of water (50 to 60 per cent of saturation). The results obtained by this method indicate the condition of the forms of nitrogen present in the soil and the rapidity with which these are transformed into nitrate nitrogen.

3. Nitrification of ammonium sulfate. Thirty milligrams of nitrogen in the form of ammonium sulfate are added to 100 -gram portions of soil, which are placed in tumblers or flasks and kept at optimum moisture for 30 days at $25^{\circ}$ to $28^{\circ} \mathrm{C}$. The nitrates formed supply information on the buffer content of the soil and on the maximum nitrate accumulation when no basic substances or buffering agents are added. Initial and final hydrogen-ion concentrations of the soil should be determined.

4. Thirty milligrams of nitrogen as ammonium sulfate and $210 \mathrm{mgm} . \mathrm{CaCO}_{3}$ are added to the soil. The lime should be well mixed with the soil before the ammoninm sulfate is added. This amount of carbonate is equivalent to an addition of the theoretical amount of base necessary for the complete neutralization of all the nitric and sulfuric acids formed from the complete oxidation of the $30 \mathrm{mgm}$. of nitrogen, in the form of ammonium sulfate. The results obtained by this method are more indicative of the nitrifying condition of the soil than any of the other methods, since nitrification is tested here with the reaction factor eliminated. Further work may, however, lead to a modification of this method. Initial and final hydrogen-ion concentration should always be determined.

5. Nitrification of organic nitrogenous materials. One-quarter per cent of organic matter with a high nitrogen content (10 to 12 per cent), such as dried blood, or 0.5 to 1.0 per cent of organic materials of a low nitrogen content (cottonseed meal, soy bean meal, alfalfa meal) should be employed. Nitrates are 
determined at the end of 15 and 30 days incubation at $25^{\circ}$ to $28^{\circ} \mathrm{C}$. The nitrate content of the original soil should always be determined. ${ }^{11}$

At first the solution method, with or without soil extract, was used ${ }^{12}$ for measuring the nitrifying power of the soil. This method was later found ${ }^{13}$ entirely unreliable and the use of the soil method was suggested. Löhnis and Green ${ }^{14}$ called attention to the fact that many of the known critical factors in solution studies on nitrification were ignored by those who have criticized them severely.

A definite correlation between the nitrifying power of a soil and its crop productivity has been observed by various investigators. ${ }^{15}$ In some cases a correlation was found to exist between the nitrogen content of the soils and their nitrifying powers, ${ }^{16}$ as shown in figures 61 and 62 .

Some investigators reported that the nitrifying power of a soil may or may not correlate with its crop producing power and that continuous cropping, especially without fertilization, was found to reduce the nitrifying power of the soil. ${ }^{17}$ While nitrification is a valuable and essential asset in fertility, it probably does not, under normal conditions, become a limiting factor in productivity. ${ }^{18}$ This is suggested on the

"Waksman, S. A. Microbiological analysis of soils as an index of soil fertility. V. Methods for the study of nitrification. Soil Sci., 15: 241-260. 1923.

12 Remy, 1902 (p. 710); Löhnis, 1904 (p. 687); Gutzeit, E. Einwirkung des Hederichs auf die Nitrifikation der Ackererde. Centrbl. Bakt. II, 16: 353381. 1906; Buhlert and Fickendey. Zur Methodik der bakteriologischen Bodenuntersuchung. Centrbl. Bakt. II, 16: 399-405. 1906.

"Stevens, F. L., and Withers, W. A. Studies in soil bacteriology. I. Nitrification in soils and in solutions. Centrbl. Bakt. II, 23: 355-373. 1909.

14 Löhnis and Green, 1914 (p. 688).

15 Gainey, P. L. The significance of nitrification as a factor in soil fertility. Soil Sci., 3: 399-416. 1917; Lipman, C. B. The nitrifying power of soils as indices to their fertility. Proc. Soc. Prom. Agr. Sci. 35th Ann. Med. 1914, 33-39; Cal. Agr. Exp. Sta. Bul. 260, 107-127: Given, G. B. Bacteriology of the general fertilizer plots. Penn. Agr. Exp. Sta. Rpt. 1912-13, 204-206; Brown, P. E. Bacteriological studies of field soils. Centrbl. Bakt. II, 35: 234-272. 1912; Jour. Agr. Res., 5: 855-869. 1916; Burgess, P. S. Can we predict probable fertility from soil biological data? Soil Sci., 6: 449-462. 1918; Ashby, S. F. The comparative nitrifying power of soils. Trans. Chem. Soc., 85: 1158-1170. 1904; Kellerman, K. F., and Allen, E. R. Bacteriological studies of the soil of the Truckee-Carson Irrigation Project. U. S. Dept. Agr., Bur. Pl. Industry, Bul. 211. 1911; Waksman, S. A. Microbiological analysis of soil as an index of soil fertility. VI. Nitrification. Soil Sci., 16: 55-67. 1923.

${ }^{16}$ Fraps, G. S. Nitrification studies. Science, 42: 68. 1916.

${ }^{17}$ Allen, E. R., and Bonazzi, A. On nitrification. Ohio Agr. Exp. Sta. Tech. Bul. 7. 1915.

18 Gainey, 1917 (p. 534). 
basis of the fact that all normal cultivated soils contain active nitrifying organisms, which transform ammonia into nitrate.

There are other cases on record where the nitrate and ammonia formation in the soil and bacterial numbers are not correlated. When fresh organic matter, particularly of non-nitrogenous nature, is added to the soil, there is a rapid increase in the number of microorganisms. This is not accompanied by an immediate increase in the amount of ammonia or nitrate in the soil, but rather by a decrease, due to the fact that the microorganisms use up the available nitrogen compounds in the process of growth and multiplication. Russell and Appleyard also observed that the curve for nitrate always lags behind that of bacterial numbers. Also as a result of partial sterilization of soil, the bacterial numbers greatly increase without any corresponding increase in nitrates; the ammonia increases but not necessarily in proportion to the numbers. The lack of correlation between certain bacterial processes, such as nitrogen changes, and soil fertility may be due to the fact that, in these cases, the latter is limited by some factor other than the nitrogen supply, such as moisture, temperature, aeration.

Whenever plant growth is limited by the supply of compounds produced by bacterial activities, the relationship between bacterial numbers and activities and plant growth is definite. Otherwise it may be accidental or it may not exist at all.

\section{CARBON DIOXIDE EVOLUTION}

The carbon dioxide produced by microorganisms from the decomposition of organic matter has both a chemical and physical action upon the soil. It renders certain insoluble soil minerals soluble and it imparts to the soil, after spring plowing and cultivation, a condition of ripeness ("Crare" in German). An increased carbon dioxide production also stimulates plant growth. Since all heterotrophic aerobic microbiological processes are accompanied by the production of carbon dioxide, this can be readily taken as an index of the microbiological activities in the soil. After harvesting a crop of rye, oats, clover or alfalfa, considerable amounts of organic matter are left in the soil, so that the quantities of carbon dioxide formed, as a result of the decomposition of these residues in the soil, are quite appreciable. The larger part of the organic matter is decomposed in the first few days, the rate of decomposition soon falling off.

In 1905 Russell $^{19}$ pointed out that soil oxidation, when measured

19 Russell, 1905 (p. 683). 
by the amount of oxygen absorbed, varied with fertility and suggested using the former as a measure of the latter. Oxidation was influenced by soil temperature and moisture and content of calcium carbonate. Stoklasa and Ernest ${ }^{20}$ placed $1-\mathrm{kgm}$. portions of sieved soil in a glass

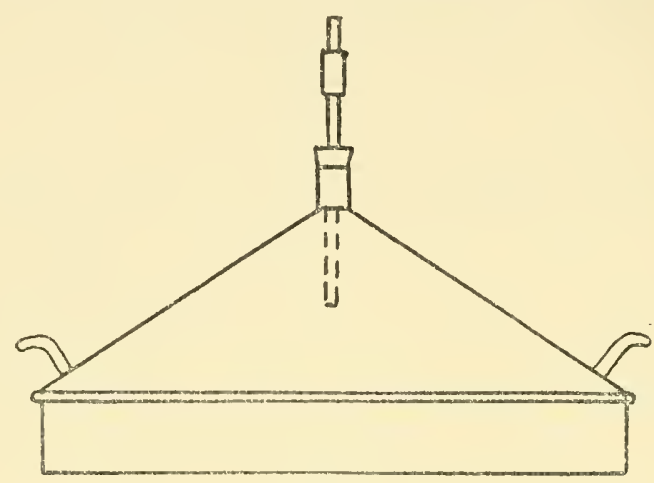

$1(a)$

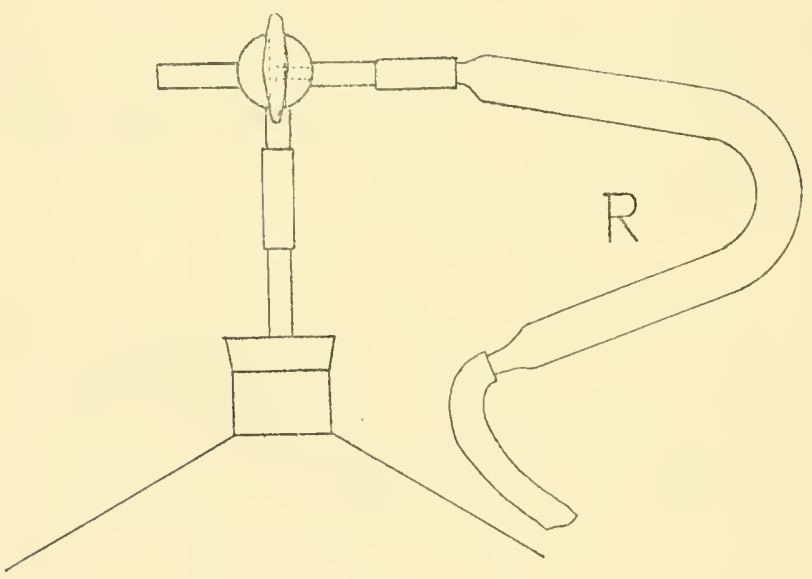

$1(b)$

FIg. 58. Apparatus for determining the $\mathrm{CO}_{2}$-production in field soil: $a$, Zinc bell, in side view; $b$, arrangement for taking sample $(R=$ Reeipient) (from Lundegardh).

${ }^{20}$ Stoklasa, J., and Ernest, A. Über den Ursprung, die Menge und die Bedeutung des Kohlendioxyds im Boden. Centrbl. Bakt. II, 14: 723-736; Ztsehr. Zuekerind. Böhmen., 31: 291-401. 1911; Stoklasa, J. Methoden zur Bestimmung der Atmungsintensität der Jakterien im Boden. Ztschr. Landw. Versuehst. Oesterreieh., 14. 1911, 1243-1279; also Chem. Ztg., 46: 681-683. 1922. 
cylinder through which a current of air was passing at the rate of 10 liters in 24 hours; for the study of anaerobic activities they substituted hydrogen for air. They suggested that the determination of carbon dioxide evolved by a soil under given conditions of moisture, temperature and time, can furnish a reliable and an accurate method for the

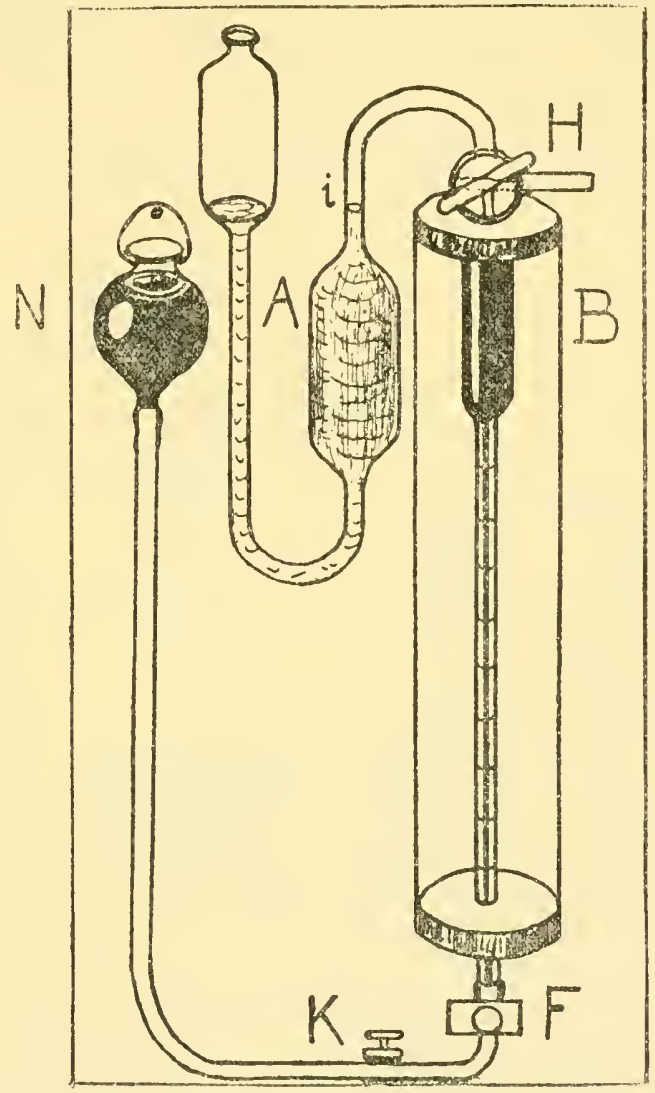

Fic. 59. Gas analysis apparatus: $B$, gas burette; $H$, three way stop cock; $A$, potash apparatus (30 per cent $\mathrm{KOH}) ; i$, index; $N$, mercury vessel; $F$, fine adjustment (from Lundegardh).

detcrmination of bacterial activities in the soil. The presence of organic matter and the temperature were found to be of greatest importance in the production of carbon dioxide. Evolution of carbon dioxide was found to occur most abundantly in neutral or slightly alkaline soil abundantly supplied with air and readily assimilable plant nutrients; 
it was also found to run parallel with nitrification. Rahn ${ }^{21}$ used sugar solutions containing $\mathrm{CaCO}_{3}$, so that he measured not only $\mathrm{CO}_{2}$ formed by bacteria but also that produced from the interaction of the organic acids formed with the $\mathrm{CaCO}_{3}$. Drying of soil was found to exert a decidedly favorable influence.

Van Suchtelen ${ }^{22}$ placed upon the bottom of a jar pure sand and upon it $6 \mathrm{kgm}$. of soil. Through this he passed air, usually 16 liters in 24 hours. The intensity of $\mathrm{CO}_{2}$ production was found to be much greater in the beginning of the experiment but it decreased rapidly after a short time. Carbon dioxide was measured until a definite intensity

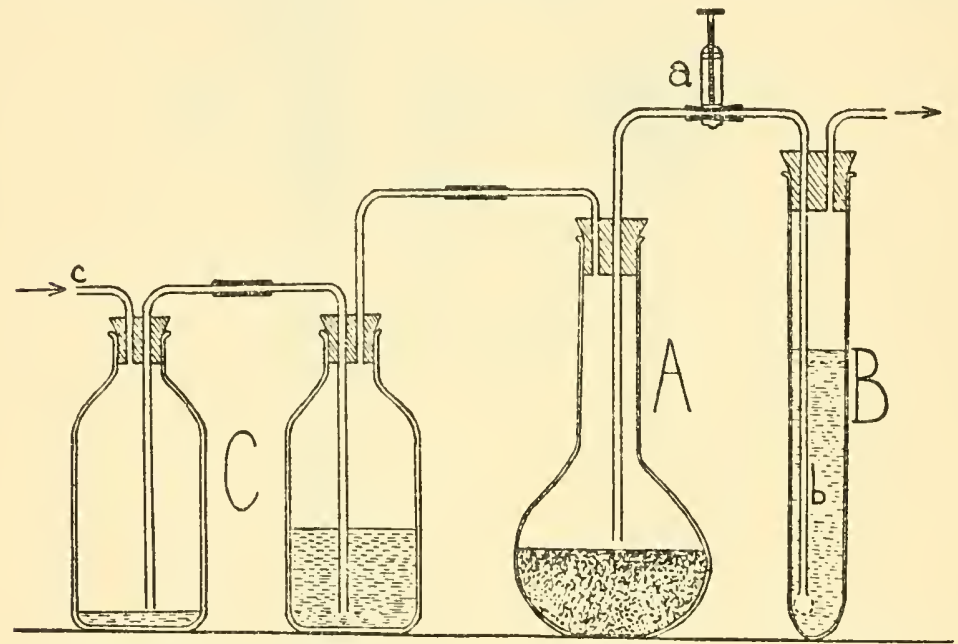

Fia. 60. Method for determining the ability of soil to decompose organic matter (from Waksman and Starkey).

has been attained. The average production of carbon dioxide in a unit of time was used as a measure. It was concluded that the comparison of the carbon dioxide production of different soils furnishes a better means for the estimation of their relative bacterial activities than the bacterial content. Soil cultivation was found to have a favorable influence upon the carbon dioxide evolution, well sieved

${ }^{21}$ Rahn, O. Bakteriologische Untersuchungen über das Trocknen des Bodens. Centrbl. Bakt. II, 20: 38-61.

${ }^{22}$ Van Suchtelen, F. H. H. Ubber die Messung der Lebenstätigkeit der äerobiotischen Bakterien im Boden durch die Kohlensäureproduktion. Centrbl. Bakt. II, 28: 45-89. 1910. 
soils producing 177 per cent as much $\mathrm{CO}_{2}$ as unsieved soils. An increase in aeration brought about an increase in $\mathrm{CO}_{2}$ production in soil to which organic matter had been or had not been added. Moisture was found to be one of the most important factors. The influence of salts upon the evolution of carbon dioxide is seen from the following table. $\mathrm{CS}_{2}$ was found to serve first as a check and then as a stimulant upon carbon dioxide production.

TABLE 77

$\mathrm{CO}_{2}$ formed in 5 days, at $10^{\circ}$ to $12^{\circ} \mathrm{C}$., from $6 \mathrm{kgm}$. of soil, with and without different salts

\begin{tabular}{|c|c|}
\hline TREATMENT & $\begin{array}{c}\text { MILLIGRAMS OF } \\
\mathrm{CO}_{2}\end{array}$ \\
\hline Soil alone......... & 145 \\
\hline Soil +90 grams $\mathrm{MgSO}_{4} \ldots \ldots \ldots \ldots \ldots$ & 408 \\
\hline 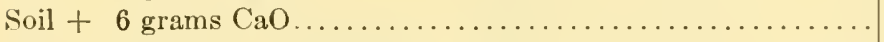 & 62 \\
\hline 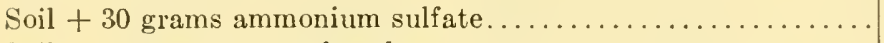 & 864 \\
\hline Soil +6 grams superphosphate $\ldots \ldots \ldots \ldots \ldots \ldots \ldots$ & 306 \\
\hline
\end{tabular}

TABLE 78

$N$ umbers of bacteria and evolution of $\mathrm{CO}_{2}$ in different soil types

\begin{tabular}{|c|c|c|c|}
\hline & \multicolumn{3}{|c|}{ SOIL TYPE } \\
\hline & Sandy soil & Loam & Clay \\
\hline Bacterial numbers . . . . . . . . . . . . & $8,300,000$ & $9,800,000$ & $11,900,000$ \\
\hline $\begin{array}{l}\text { Milligrams of } \mathrm{CO}_{2} \text { produced in } 24 \text { hours, no } \\
\text { glucose added. } \ldots \ldots \ldots \ldots \ldots \ldots \ldots \ldots\end{array}$ & 96 & 109 & 111 \\
\hline $\begin{array}{l}\text { Milligrams of } \mathrm{CO}_{2} \text { produced in } 3 \frac{1}{2} \text { days, no } \\
\text { glucose added } \ldots \ldots \ldots \ldots \ldots \ldots \ldots \ldots \ldots\end{array}$ & 193 & 188 & 434 \\
\hline $\begin{array}{l}\text { Milligrams of } \mathrm{CO}_{2} \text { produced in } 3 \frac{1}{2} \text { days, } 0.1 \\
\text { per cent glucose added................. }\end{array}$ & 3179 & 3730 & 3660 \\
\hline
\end{tabular}

By using $\mathrm{CO}_{2}$ as an index, it was found that similar soils behave the same under similar conditions. When glucose is added, the abundant production of $\mathrm{CO}_{2}$ tends to obliterate any differences, hence the briefest possible period (12 hours) should be used in this connection. A certain parallelism was obtained between the numbers of bacteria and the evolution of carbon dioxide in different soils, as shown in table 78 .

The curves for bacterial numbers, nitrate content and carbon dioxide in the soil air were found ${ }^{23}$ to be sufficiently similar to justify the view

${ }^{23}$ Russell, E. J., and Appleyard, A. The atmosphere of the soil: its composition and the cause of variation. Jour. Agr. Sci., 7: 1. 1915. 
that all these phenomena are related. A rise in bacterial numbers was accompanied by a rise in the $\mathrm{CO}_{2}$ in the soil air, and somewhat later by a rise in the nitrate content. The rate of decomposition of organic matter in the soil was, therefore, looked upon as a function of bacterial activity. It was further demonstrated ${ }^{24}$ that the principal factors affecting carbon dioxide production are, in order of importance, temperature, moisture, dissolved oxygen and the growing crop.

In all the investigations up to 1915, the air was either drawn through the soil, thus greatly accelerating microbiological activities, or intermittenly over the soil. Potter and Snyder ${ }^{25}$ found that field results can be most closely duplicated in laboratory studies when the air is passed continuously over the soil. The amount of air passing over the soil in the laboratory does not affect materially the amount of $\mathrm{CO}_{2}$ evolved. When the soil is placed under optimum laboratory conditions, the initial rise in carbon dioxide formation is soon followed by a drop, which becomes nearly a straight line. Klein ${ }^{26}$ also found that the amount of $\mathrm{CO}_{2}$ given off by the soil when brought into the laboratory and the proper amount of moisture added is considerable for a short period. He attributed this phenomenon to the previous drying of the soil which made the soil a better medium, both physically and chemically, for the growth of bacteria. This is no doubt correct, since when normally moist soil is used no such rapid drop is observed. Previous drying of the soil alters its colloidal condition to the extent of increasing the rate of oxidation. Because of this, rainfall may increase the carbon dioxide formation in field soils, due to the increase in moisture content more favorable for biological activities rather than for the reason of oxygen brought down by the rain, as suggested by some investigators. It was found, by the use of this method, that manure stimulated $\mathrm{CO}_{2}$ production while sodium nitrate and ammonium sulfate did not. $\mathrm{CaCO}_{3}$ did not indicate at first any increase of $\mathrm{CO}_{2}$ as a result of the decomposition of the organic matter (the abundant formation of $\mathrm{CO}_{2}$ when $\mathrm{CaCO}_{3}$ is added to an acid soil is due to chemical interaction between the carbonate and the buffering sub-

${ }^{24}$ Russell, E. J., and Appleyard, A. The influence of soil conditions on the decomposition of organic matter in the soil. Jour. Agr. Sci., 8: 385-417. 1917.

${ }^{25}$ Potter, R. S., and Snyder, R. S. Carbon dioxide production in soils and earbon and nitrogen changes in soils variously treated. Iowa Agr. Exp. Sta. Res. Bul. 39. 1916.

${ }^{26}$ Klein, M. A. Studies in the drying of soils. Jour. Amer. Soc. Agron., 7: 49. 1915. 
stances of the soil). After prolonged incubation, following the addition of $\mathrm{CaCO}_{3}$, a definite favorable effect was evidenced.

A marked correlation between crop yield, nitrate accumulation and bacterial numbers, but not between crop yield and ammonia accumulation, is shown in figure 61 where the bacterial activities of limed and unlimed soils are compared. ${ }^{27}$ The soil $(1 \mathrm{kgm}$.) may be placed in a pot which is then covered with a bell-jar using the suction apparatus described elsewhere.

One can differentiate between the formation of $\mathrm{CO}_{2}$ in untreated soil and the formation of $\mathrm{CO}_{2}$ from glucose or other available crganic matter

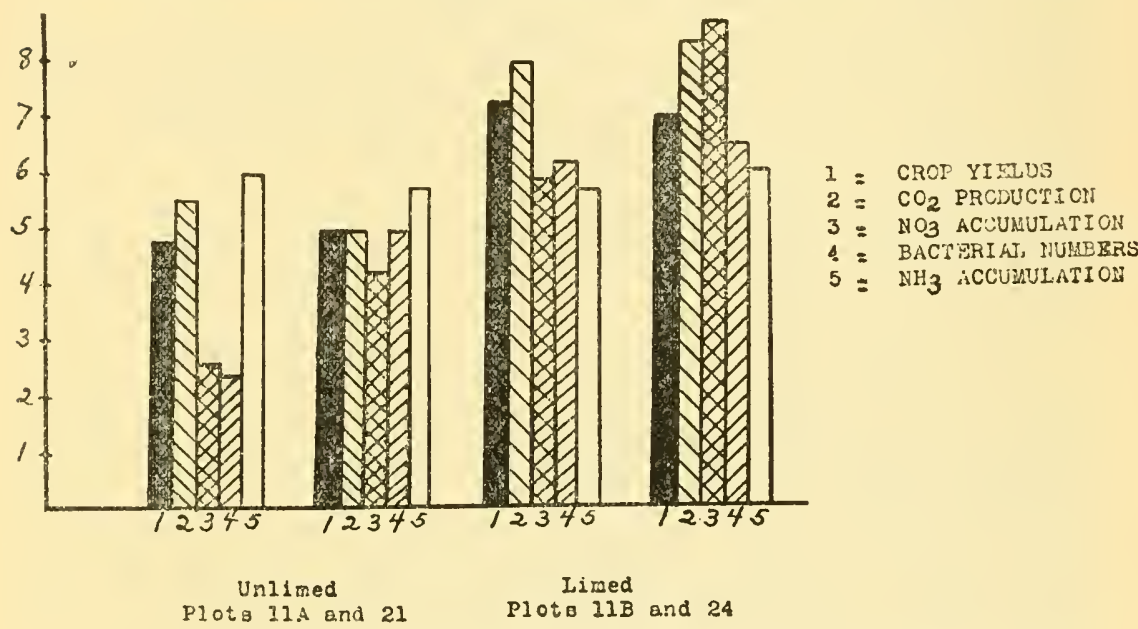

FIG. 61. The correlation between crop yields, $\mathrm{CO}_{2}$-producing power of the soil, bacterial numbers, $\mathrm{NH}_{3}$ and $\mathrm{NO}_{3}$ accumulation in soil from limed and unlimed plots (from Neller).

added to the soil. ${ }^{28}$ In the first instance, a definite amount of soil is placed under optimum conditions of moisture and temperature and the amount of $\mathrm{CO}_{2}$ formed in a definite period of time is measured. This was found (Stoklasa) to depend upon (1) the number and kind of microorganisms present, (2) the amount of organic matter in the soil, (3) the composition of this organic matter and the degree of its decom-

27 Neller, 1920 (p. 712).

28 Waksman, S. A., and Starkey, R. I. Microbiological analysis of soils as an index of soil fertility. VII. Carbon dioxide evolution. Soil Sci., 17: 141161. 1924 . 
position, (4) soil aeration, (5) moisture content, (6) physical condition of the soil, (7) chemical composition (altered by fertilization), (8) soil reaction and (9) kinds of plants grown. The $\mathrm{CO}_{2}$ thus determined is a measure of the rapidity with which the soil organic matter itself decomposes under the influence of the sum total of microbiological complexes. It can be determined in three different ways:

1. One-kilogram portions of fresh soil from a composite sample taken to a depth of $6 \frac{1}{2}$ inches and put through a $3 \mathrm{~mm}$. sieve are placed in pots. Enough water is then added to bring the moisture content of the soil to the optimum. The pots of soil are then placed in the respirator and the amount of $\mathrm{CO}_{2}$ evolved in fourteen days is determined at various intervals.

2. One kilogram portions of air-dried, sieved soil, taken to a definite depth, are placed in proper containers; the necessary amount of water is added and the $\mathrm{CO}_{2}$ evolved in 24 hours is determined. By this method, Stoklasa ${ }^{29}$ found that an infertile soil, poor in organic matter, produced 8 to $14 \mathrm{mgm} . \mathrm{CO}_{2}$, while a good beet soil produced 56 to $68 \mathrm{mgm}$.

3. One hundred-gram portions of fresh soil, prepared as in the first method, are placed in 300-ce. flasks with long necks ( $\mathrm{A}$ in figure 60). Cotton plugs are placed in the necks of the flasks and in the glass connections. After the proper amount of water is added ( 50 per cent of total moisture holding capacity), the flasks are sterilized for 1 to $1 \frac{1}{2}$ hours, on two consecutive days, at 15 pounds pressure. The soils are then inoculated with a cuiture of Trichoderma which was found to be one of the most active groups of soil fungi decomposing celluloses, proteins, pectins and other complex organic substances; a suspension of fresh cow manure may also be used for inoculation. The flasks are then connected with the $\mathrm{Ba}(\mathrm{OH})_{2}$ tubes in the respirator and the amount of $\mathrm{CO}_{2}$ evolved is determined for 12 to 14 days. By this method, two soils, one, fertile and rich in organic matter, and another, infertile and poor in organic matter, were found to produce 124.08 and $37.40 \mathrm{mgm}$. of $\mathrm{CO}_{2}$ respectively, in eight days.

The decomposition of fresh organic matter added to the soil can be determined by a group of methods, which differ chiefly in the nature of the organic matter used. A few substances have been commonly employed:

1. Glucose. This substance is very readily decomposed in the soil; an excess of the material, as well as a long period of incubation, may obliterate finer differences in the activities of the microorganisms in the different soils. It is best to add $500 \mathrm{mgm}$. of glucose to 100 grams of soil and determine the $\mathrm{CO}_{2}$ evolved every 6 or 12 hours for a period of 49 to 72 hours. The resulting curves bring out distinctly the differences in the microbiological activities of the different soils. Since glucose is used very readily as a source of energy not only

${ }^{29}$ Stoklasa, J. Le rôle de l'acide carbonique degagé par les microorganismes dans l'amélioration des terres culturales arables pour obtenir le meilleur rendement. Compt. Rend. Agr. France, 8: 594-596. 1922. 
by the soil fungi and actinomyces, but also by the great majority of heterotrophic soil bacteria, including the nitrogen-fixing organisms, its rate of decomposition is very rapid. It is especially rapid when conditions are favorable for the latter group of organisms, which make them independent of a supply of available nitrogen.

2. Cellulose. The decomposition of cellulose in the soil is based upon the establishment of a nitrogen minimum. One gram of cellulose, in the form of ground filter paper, is added to 100 grams of soil and the $\mathrm{CO}_{2}$ evolved is determined; this indicates not only the ability of soil to form $\mathrm{CO}_{2}$ from cellulose, but also the amount of available nitrogen and phosphate present in the soil. This is due to the fact that the cellulose is decomposed in the soil (with the exception of alkaline or partially sterilized soils) to a large extent by fungi. These rapidly growing organisms consume a great deal of nitrogen in the synthesis of their mycelium, and the nitrogen soon becomes a limiting factor; therefore, the greater the amount of available nitrogen in the soil the larger will be the quantity of cellulose decomposed. The distinctive differences in the curves of $\mathrm{CO}_{2}$ evolution from glucose and cellulose have been pointed out elsewhere (p. 675). In addition to glucose and ccllulose, other substances, like straw, alfalfa meal and dried blood, may be used in the study of decomposition of organic matter in the soil. Cellulose may also be used together with sufficient nitrogen in the form of inorganic salts.

\section{CELLULOSE DECOMPOSING CAPACITY OF THE SOIL}

Christensen ${ }^{30}$ was the first to suggest that the cellulose decomposing power of a soil may serve as an index of soil fertility. A definite amount. of the soil to be investigated was placed in Erlenmeyer flasks so as to cover four-fifths of the bottom of the flasks. Water was added from a pipette to the uncovered part of the bottom of the flask. A few strips of filter paper were then pressed upon the soil, the latter being kept moist during the period of incubation. Between 9 to 93 days were required for the complete decomposition of the paper. The physical condition of the soil and its reaction did not influence greatly the cellulose decomposing capacity of a particular soil.s1 The presence of available minerals, primarily phosphates, as well as available nitrogen were found to be of first importance, and, in some cases, the microbial flora; i.e., the phenomenon of cellulose decomposition is influenced by the chemical and microbiological soil conditions. The amount of cellulose decomposed was governed by the available nitrogen and phosphates in the soil. Only in the case of certain peat soils, did the

${ }^{30}$ Christensen, H. R. Ein Verfahren zur Bestimmung der zellulosezersetzenden Fähigkeit des Erdbodens. Centrbl. Bakt. II, 27: 449-451. 1910.

${ }^{31}$ Christensen, H. R. Studien über den Einflusz der Bodenbeschaffenheit auf das Bakterienleben und den Stoffumsatz im Erdboden. Centrbl. Bakt. II, 43: 1-166. 1915. 
inoculation of the soil with cellulose deccmposing bacteria have any effect.

Mütterlein ${ }^{32}$ suggested placing one or two pieces of filter paper of a uniform weight (10 grams) at various depths of soil, then, after 2 to 3 weeks, removing the paper from the soil and weighing the residue; the loss in weight of the paper was taken as an index of the cellulosedecomposing capacity of the soil.

Niklewski ${ }^{33}$ added cellulose to the soil and measured the carbon dioxide produced by a soil thus treated. In addition to cellulose, 1 gram $\mathrm{K}_{2} \mathrm{HPO}_{4}, 1$ gram $\mathrm{MgSO}_{4}, 8$ grams $\mathrm{CaCO}_{3}$, and $\left(\mathrm{NH}_{4}\right)_{2} \mathrm{SO}_{4}$ were added to $8 \mathrm{kgm}$. of soil. He found that the decomposition of cellulose is chiefly controlled by the presence of available nitrogen in the soil. The greater the amount of cellulose added or present in the soil, the quicker does the nitrogen need set in. Nitrogen fixing organisms were thought to play only a secondary rôle in normal soils, since cellulose is very slowly decomposed in normal soils without the addition of available nitrogen. This would not be the case if nitrogen-fixing organisms were active, as when glucose is added. When only 0.125 per cent cellulose was added to a loess soil, containing 0.15 per cent nitrogen, a nitrogen need could be observed. 'The greater the amount of cellulose added, the greater was the evolution of $\mathrm{CO}_{2}$ up to a certain concentration, 1.5 per cent giving at first less $\mathrm{CO}_{2}$ than 1.0 per cent cellulose. When the available nitrogen is exhausted, the curve soon falls to a certain level depending upon the rapidity of decomposition of the nitrogenous substances in the soil and the rate with which the nitrogen becomes available. The addition of 0.0125 per cent ammonium sulfate greatly stimulated cellulose decomposition; this amounted to about 1 gram of $\left(\mathrm{NH}_{4}\right)_{2} \mathrm{SO}_{4}$ in the case of soil, and 2 grams of the ammonium salt in the case of sand, for every 10 grams of cellulose. Larger amounts of nitrogen acted injuriously; this injurious action may be later overcome.

On comparing the evolution of carbon dioxide, with and without the addition of a nitrogen salt, Niklewski suggested calculating the available nitrogen in the soil from the amount of cellulose decomposed, as indicated by the evolution of $\mathrm{CO}_{2}$. In the case of loess soil, with a total of 0.150 per cent nitrogen, 0.040 per cent nitrogen was found to

${ }^{32}$ Mütterlein, C. Studien über die Zersetzung der Zellulose im Düngen und im Boden. Inaug. Diss., Leipzig. 1913.

${ }^{33}$ Niklewski, B. Bodennakteriologische Beobachtungen als Mittel zur Beurteilung von Boden. Centrbl. Bakt., II, 32: 209-217. 1912. 
be active, while in the case of a sandy soil with a total of 0.015 per cent, all the nitrogen was active, or could be made readily available.

One per cent of cellulose, in the form of finely divided or ground filter paper, is added to soil sieved through a 2-mm. sieve. After carefully mixing the paper with the soil the proper amount of moisture is added. At the end of the incubation period, the soil is air dried and the amount of cellulose left undecomposed determined by extracting with Schweizer's reagent (see p. 431). Stable manure was found to have a decided effect upon cellulose decomposition in the soil, especially when the moisture content is satisfactory. The influence of reaction is not of great importance in cellulose decomposition and lime serves merely in adjusting the reaction. The favorable influence of manure is due to the nutrients present, especially the nitrogen. The greater the amount of nutrients (nitrogen and minerals) present in the manure, the greater is its favorable influence. The poorer the soil is, the greater is the influence of the manure. When ammonium sulfate and manure containing the same amount of nitrogen were added to the soil, the stimulating effect upon cellulose decomposition was found to be the same. ${ }^{34}$

These facts, namely that the cellulose decomposing power of a soil depends more upon the physical and chemical conditions of the soil, especially the available nitrogen, rather than upon a specific microbial flora can be readily explained when the activities of microorganisms concerned in cellulose decomposition in the soil are considered.

As pointed out above, cellulose is decomposed in normal soils largely by various fungi and aerobic bacteria. Only in soils saturated with water do the anaerobic bacteria become active in cellulose decomposition. The ratio between the amount of cellulose decomposed and the amount of nitrogen assimilated is about $30: 1$ in the case of fungi and aerobic bacteria; however, in the soil, when the cells of microorganisms freshly synthesized are constantly decomposed by other organisms, the ratio is 50-60:1. In other words, for every unit of nitrogen that can become available in the soil in a definite period of time, about 50 to 60 units of cellulose will be decomposed. If one gram of cellulose in the form of ground filter paper were added to 100 grams of soil, then

${ }^{34}$ Charpentier, C. A. G. Studien über den Einflusz des Rindvieh und Pferdestallmistes auf die Zersetzung der Zellulose in der Ackererde. Inaug. Diss. Helsingfors. 1921; Barthel, Chr., and Bengtsson, N. Bidrag till fragen om Stallgödselns verkningssätt vid cellulosasönderdelningen. I. Akerjorden. Meddl. No. 248, Centralaust. Forsoksv. Jordbrucks. Bakt. Avdel. No. 29. 
incubated at optimum temperature and moisture conditions for 30 or 60 days, and the amount of cellulose decomposed in that period of time were found to be $400 \mathrm{mgm}$., this would inclicate that about 7 to $8 \mathrm{mgm}$. of nitrogen had become available in that period of time.

TABLE 79

Influence of $\mathrm{NaNO}_{3}$ upon the decomposition of cellulose, in the presence of $\mathrm{CaCO}_{3}$ and minerals

\begin{tabular}{|c|c|c|c|c|c|}
\hline \multirow{2}{*}{ BOIL NUMBER } & \multirow{2}{*}{$\begin{array}{c}\mathrm{NaNO}_{3} \text { A DDED } \\
\text { TO } 100 \text { GRAMS OF } \\
\text { SOIL }\end{array}$} & \multicolumn{3}{|c|}{ EVOLUTION OF $\mathrm{CO}_{2}$ IN 14 DAYS } & \multirow{2}{*}{$\begin{array}{c}\text { CELLULOSE } \\
\text { DECOMPOSED IN } \\
100 \text { GRAMS OF } \\
\text { SOIL }\end{array}$} \\
\hline & & $\begin{array}{c}\text { Soil }+ \\
\text { cellulose }\end{array}$ & Soil alone & $\begin{array}{l}\text { Due to } \\
\text { addition of } \\
\text { cellulose }\end{array}$ & \\
\hline $5 \mathrm{~A}$ & $\begin{array}{c}m g m . \\
0\end{array}$ & $\begin{array}{c}m g m . \\
544.50\end{array}$ & $\begin{array}{l}m g m . \\
75.50\end{array}$ & $\begin{array}{c}m g m . \\
469.00\end{array}$ & $\begin{array}{c}m g m . \\
387\end{array}$ \\
\hline $5 \mathrm{~A}$ & 25 & 778.25 & 75.50 & 702.75 & 567 \\
\hline $5 \mathrm{~A}$ & 50 & 817.30 & 75.50 & 741.80 & 680 \\
\hline $7 \mathrm{~A}$ & 0 & 364.10 & 88.60 & 275.50 & 222 \\
\hline $7 \mathrm{~A}$ & 25 & 526.35 & 88.60 & 437.75 & 437 \\
\hline $7 \mathrm{~A}$ & 50 & 684.20 & 88.60 & 595.60 & 557 \\
\hline
\end{tabular}

TABLE 80

Influence of different forms of nitrogen upon the decomposition of cellulose in soil ${ }^{34}$ (1 per cent filter paper added to 1 kilogram of soil)

\begin{tabular}{|c|c|c|c|}
\hline \multirow{2}{*}{ NITROGEN SOURCE } & \multicolumn{3}{|c|}{ CELLCLOSE LEFT, PER CENT } \\
\hline & At start & $\begin{array}{l}\text { After } 2 \\
\text { months }\end{array}$ & $\begin{array}{c}\text { After } 4 \\
\text { months }\end{array}$ \\
\hline Control. . . . . . . . . . . . . . . . & 0.87 & 0.53 & 0.48 \\
\hline $16 \mathrm{mgm}$. nitrogen, as manure (10 grams). & 0.80 & 0.51 & 0.31 \\
\hline $32 \mathrm{mgm}$. nitrogen, as manure (20 grams). & 0.85 & 0.38 & 0.24 \\
\hline $64 \mathrm{mgm}$. nitrogen, as manure (40 grams). & 0.80 & 0.27 & 0.18 \\
\hline $32 \mathrm{mgm}$. nitrogen, as $\left(\mathrm{NH}_{4}\right)_{2} \mathrm{SO}_{4} \ldots \ldots \ldots$ & 0.85 & 0.35 & 0.26 \\
\hline $16 \mathrm{mgm}$. nitrogen, as $\mathrm{NH}_{4} \mathrm{NO}_{3} \ldots$ & 0.83 & 0.34 & 0.27 \\
\hline $32 \mathrm{mgm}$. nitrogen, as $\mathrm{NH}_{4} \mathrm{NO}_{3} \ldots$ & 0.81 & 0.22 & 0.13 \\
\hline
\end{tabular}

Tables 79 and 80 bring out the influence of nitrogen in different forms upon the decomposition of cellulose in the soil.

To measure the cellulose-decomposing power of the soil, three methods are recommended. ${ }^{35}$

${ }^{35}$ Waksman, S. A., and Heukelekian, O. Microbiological analysis of soil as an index of soil fertility. VIII. Decomposition of cellulose. Soil Sci., 17: 275-291. 1924. 
1. One gram of finely cut or well ground filter paper is well mixed with 100 grams of fresh sieved soil. This is placed in a tumbler, brought to optimum moisture, covered, and incubated for 42 days, at $25^{\circ}$ to $28^{\circ} \mathrm{C}$. with frequent additions of water to keep at optimum moisture. The amount of residual cellulose is determined by the method of Charpentier in the soil which is first air dried. The residual cellulose is then subtracted from the amount of cellulose originally present in the soil, which is determined by extracting 20 grams of the original soil to which $200 \mathrm{mgm}$. of the paper has been added. The amount of cellulose actually decomposed in the soil is thus obtained.

2. One gram of well ground filter paper and $100 \mathrm{mgm}$. of sodium nitrate are added to 100 grams of soil. The mass is then well mixed and placed in a tumbler, brought to optimum moisture, covered, and incubated for 15 days. The amount of cellulose decomposed is determined as in the case of the first method.

3. One hundred grams of soil, $200 \mathrm{mgm}$. of $\mathrm{CaCO}_{3}, 50 \mathrm{mgm} . \mathrm{K}_{2} \mathrm{HPO}_{4}, 25 \mathrm{mgm}$. $\mathrm{MgSO}_{4}$, with and without one gram of ground dry filter paper are mixed in tumblers. These are placed in a respiratory apparatus and the amount of $\mathrm{CO}_{2}$ given off in fourteen days is determined. The excess of $\mathrm{CO}_{2}$ produced in the soil containing the cellulose over that produced in the soil containing the minerals only, and the amount of cellulose decomposed will serve as an index of the cellulose decomposing power and, ipse facto, of the available nitrogen in the soil. For every milligram of nitrogen that is available in the soil or that can become available in the given period of time, about $50 \mathrm{mgm}$. of cellulose are decomposed.

\section{NITROGEN-FIXING AND MANNITE DECOMPOSING CAPACITY OF THE SOIL}

The principle of the various methods used for the study of nitrogen fixation can be summarized as follows. A readily available source of energy, chiefly mannite or glucose, is added to the soil or to a solution inoculated with soil; the amount of available nitrogen in the soil is very limited, so that the fungi and heterotrophic non-nitrogen fixing bacteria, which would otherwise be capable of consuming the mannite or glucose, cannot do that extensively. The amount of glucose or mannite commonly used in the laboratory studies ( 1 to 2 per cent) is in great excess, so that the amount of available nitrogen is far from sufficient for supplying the requirements of the non-nitrogen fixing organisms. The bacteria, which are capable of obtaining nitrogen from the gaseous form, can readily utilize mannite or glucose as sources of energy. It has been shown elsewhere (p. 444) that the addition of celluloses and cellulose-rich substances to the soil greatly stimulates the development of fungi, especially in the presence of available nitrogen. The addition of glucose to the soil does not affect greatly the development of these organisms, but brings about an abundant multiplication of bacteria, especially the nitrogen-fixing forms.

In the presence of an available source of energy, the nitrogen-fixing 
bacteria may become limited in their development by the lack of sufficient available phosphorus in the soil or in the medium. Since Azotobacter cells may contain as much as 2 to 5 per cent $\mathrm{P}_{2} \mathrm{O}_{5}$, the rapid development of this and other nitrogen-fixing bacteria, which produce an extensive growth in the presence of an excess of available energy, may be limited by the presence of this mineral. For every unit of nitrogen fixed or assimilated by Azotobacter and synthesized into microbial protein about half a unit of available phosphorus $\left(\mathrm{P}_{2} \mathrm{O}_{5}\right)$ is required. The amount of phosphorus present in an available form can be calculated from the amount of nitrogen fixed. The latter may then become merely an index of the available phosphorus in the soil.

Four methods may be suggested ${ }^{36}$ for measuring the nitrogen-fixing and mannite decomposing power of a soil:

1. The solution method consists of adding 1 or 5 grams of soil to 50 or $100 \mathrm{cc}$. of a standard mannite solution (20 grams mannite, 0.2 gram $\mathrm{MgSO}_{4} \cdot 7 \mathrm{H}_{2} \mathrm{O}, 0.2 \mathrm{gram}$ $\mathrm{K}_{2} \mathrm{HPO}_{4}, 0.2$ gram NaCl, 5.0 grams $\mathrm{CaCO}_{3}$, in 1000 cc. distilled water and made neutral to phenolphthalein), incubating for 7 to 28 days, then determining the increase in total nitrogen above the control (original solution + original soil analyzed immediately for total nitrogen). This serves as an index of the activities of the nitrogen-fixing flora of the soil and thus also, to some extent, of the microbiological condition of the soil.

2. The snil method consists of adding 1 or 2 grams of mannite to 100 grams of fresh sieved soil, bringing the latter to optimum moisture, incubating for 28 days, and determining the increase of nitrogen in the treated soil over the untreated soil, incubated under similar conditions.

3. The pure culture method ${ }^{37}$ consists of adding 10 grams of the particular soil to 100 cc. of a 2 per cent mannite solution, free from available phosphates, sterilizing and inoculating with a vigorous culture of Azotobacter. After incubating for 20 to 30 days, the increase in total nitrogen is determined. This can serve as an index of the available phosphate in the soil. This method can also be modified by adding to the above mineral solution, free from phosphorus, 10 per cent of soil and estimating, from the amount of Azotobacter growth or from the actual increase in total nitrogen, the amount of available phosphate in the soil. In view of the fact that the majority of field soils contain only small quantities of available phosphate, increasing quantities $\left(0.0005\right.$ to 0.005 gram $\left.\mathrm{K}_{2} \mathrm{HPO}_{4}\right)$ can be added to a series of flasks, which are then inoculated with the soil.

4. The determination of residual mannite (or rather soluble organic matter in the soil). ${ }^{38}$ This consists of adding 2 per eent of mannite to air dry soil,

${ }^{36}$ Waksman, S. A., and Karunaker, N. Microbiological analysis of soil as an index of soil fertility. IX. Nitrogen fixation and mannite decomposition. Soil Sci , 17: 379-393. 1924.

37 Niklewski, 1912 (p. 726); Stoklasa, 1925 (p. 621); Christensen, 1915 (p. 578).

${ }^{38}$ Christensen, H. R. Influence of soil conditions on bacterial life and changes in the soil. II. Ability of soil to break down mannite. Soil Sci., 15: 329-360, 361-365. 1923. 
bringing to optimum moisture, incubating, and determining the residual mannite every five days by oxidation with $\mathrm{KMnO}_{4}$. This method can serve as an index of the activities of the nitrogen fixing flora of the soil, as well as of the amount of phosphorus available.

The method of determination of soluble organic matter in the soil is carried out as follows. Five grams of soil is withdrawn and allowed to air-dry; the airdry soil is then weighed again and extracted for two hours, with occasional shaking, with $200 \mathrm{cc}$. of water. The extract is filtered through paper and $10 \mathrm{cc}$., or an amount equivalent to $0.25 \mathrm{gram}$ of soil, is placed in a 400 -cc. beaker with $50 \mathrm{cc}$. of $0.05 \mathrm{~N}$ potassium permanganate solution and $3 \mathrm{cc}$. of dilute $(6: 100)$ sulfuric acid. The beaker is placed in boiling water for twenty minutes, $50 \mathrm{cc}$. of $0.05 \mathrm{~N}$ oxalic acid is then added and the solution is titrated with $0.02 \mathrm{~N}$ potassium permanganate solution. The number of cubic centimeters of the latter expresses the amount of organic matter (residual mannite + soluble soil organic matter).

TABLE 81

Nitrogen fixed in $100 \mathrm{cc}$. of mannite solution +10 grams of soil

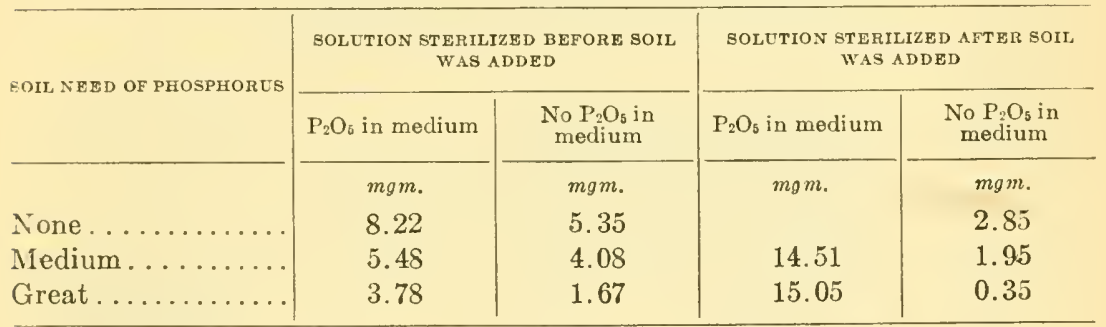

A definite correlation was found to exist between nitrogen fixation in mannite solution and soil fertility.39 A certain correlation was also reported ${ }^{40}$ between crop productivity of a soil and its ability of fixing nitrogen, when mannite is added to it (soil method). By adding a definite amount of soil (10 grams) to a mannite solution, free from phosphates, then inoculating with a culture of Azotobacter and determining the amount of nitrogen fixed, after a definite period of incubation, an approximate index of the presence or absence of available phosphorus in the soil can be obtained, ${ }^{41}$ as shown in table 81.

${ }^{39}$ Löhnis, F., and Pillai, N. K. Über stickstofffixierende Bakterien. III. Beitrag zur Methodik der bakteriologischen Bodenuntersuchung. Centrbl. Bakt. II, 20: 781-795; Green, H. Investigation into the nitrogen metabolism of soil. Centrbl. Bakt. II, 41 : 577-608. 1914; Burgess, 1918 (p. 716).

${ }_{40}$ Brown, P. E. Bacterial activities and crop production. Iowa Agr. Exp.

Sta. Res. Bul. 25. 1915.

${ }^{41}$ Niklewski, 1912 (p. 726). 
The available phosphorus in the soil may be calculated from the amount of nitrogen fixed. To 100 grams of soil, $30 \mathrm{cc}$. of water containing 2.5 grams of glucose, 0.2 gram $\mathrm{K}_{2} \mathrm{SO}_{4}$ and 0.05 gram of $\mathrm{MgCl}_{2}$ were added. The soil was then sterilized and inoculated with Azotobacter. After 21 days incubation, the total nitrogen and phosphoric acid were determined in the soil. The following process was used for calculating the amount of available phosphorus. One hundred grams of soil contained 0.164 gram nitrogen in the inoculated and 0.110 gram in the uninoculated soil. The amount of nitrogen fixed was, therefore, 0.054 gram. Since Azotobacter cells contain 10 per cent nitrogen and 5 per cent $\mathrm{P}_{2} \mathrm{O}_{5}, 0.027$ gram of the latter was made available in the given quantity of soil. The total $\mathrm{P}_{2} \mathrm{O}_{5}$ in 100 grams of soil was 0.103 gram, hence about 26 per cent of this phosphorus is readily available. ${ }^{42}$ A very fertile soil containing 0.084 per cent $\mathrm{P}_{2} \mathrm{O}_{5}$ has shown 48.8 per cent of it utilizable; a soil of medium fertility contained 26.21 per cent utilizable $\mathrm{P}_{2} \mathrm{O}_{5}$, and a poor forest soil only 11.66 per cent of the $\mathrm{P}_{2} \mathrm{O}_{5}$ utilizable.

There is no doubt that all agricultural soils can be made to fix nitrogen when an excess of an available source of energy is added. However, the reaction of the soil, which favors the development of specific nitrogen fixing organisms, is of great importance in this respect, as pointed out above. The presence of available phosphorus in the soil and the soil reaction influencing the development of specific nitrogen-fixing bacteria, are the two factors controlling the amount of nitrogen fixed and mannite decomposed.

Winogradsky ${ }^{43}$ recently suggested several new methods for determining the nitrogen-fixing capacity of the soil, the results serving in a way as a measure of the fertility of the soil.

1. A silica gel plate, $9 \mathrm{~cm}$. in diameter, is inoculated with a few grains of soil. In the presence of Azotobacter, the soil will be surrounded, after 48 hours, with the colonies of the organism. The relative abundance of the colonies will indicate the biological activities of the soil.

2. One-half gram of mannite is added to $50 \mathrm{grams}$ of soil, which is incubated for 48 hours. The soil is then examined microscopically and the abundance of nitrogen-fixing bacteria serves as an index of the activity of the soil.

3. Five parts of fresh soil are added to 100 parts of starch and the mixture kneaded with sufficient water and placed in a Petri dish; an excess of water is avoided. After $4 S$ hours incubation, minute colonies will be formed on the

\footnotetext{
42 Stoklasa, 1911 (p. 649).

${ }^{43}$ Winogradsky, 1925 (p. 11).
} 


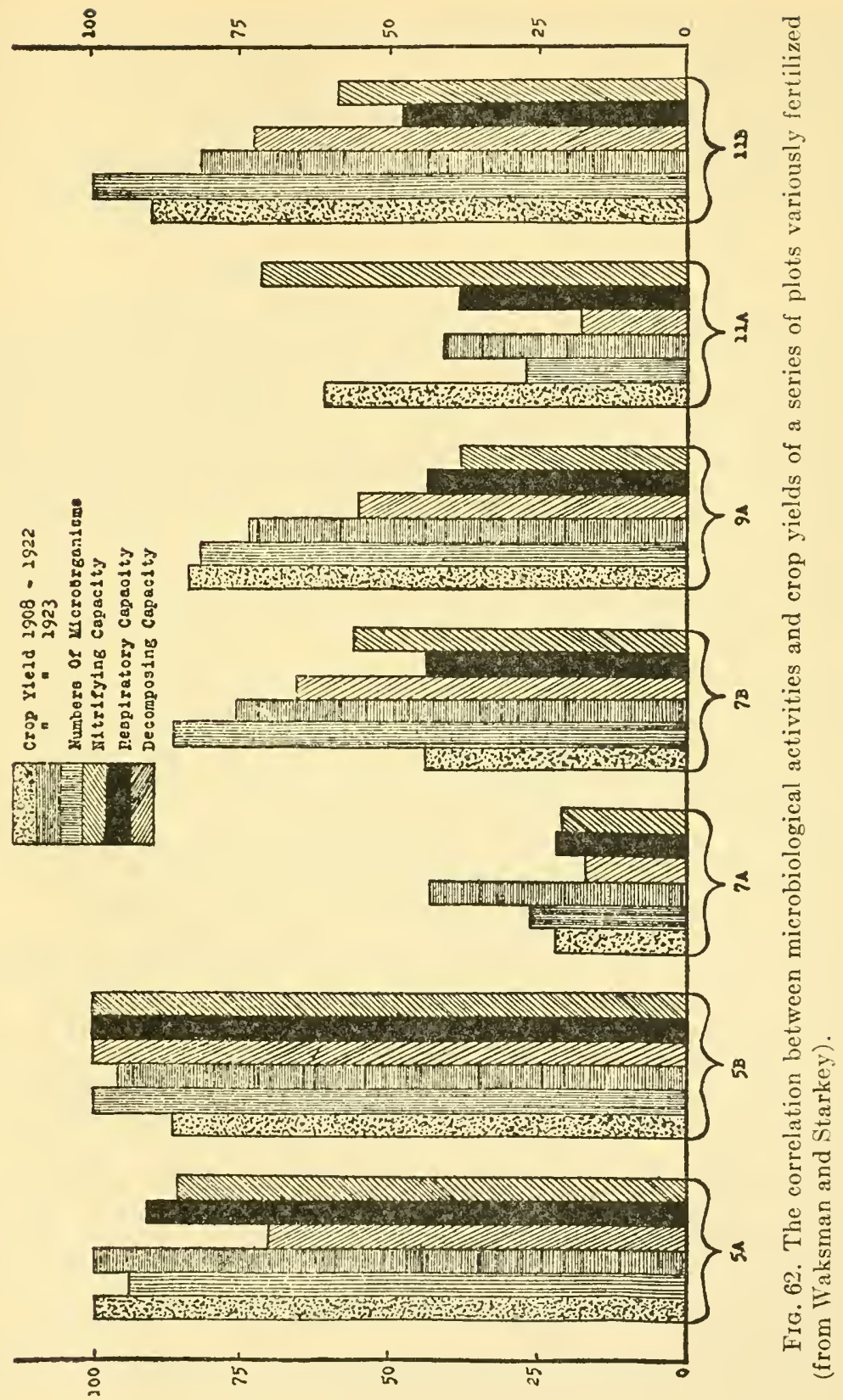


surface of the mixture; the abundance of the colonies serves as an index of the activity of the soil.

4 and 5. A large silica-gel plate, containing 2 grams of mannite is inoculated with 1 gram of soil. After 48 hours incubation, the number of colonies on the plate is determined; after 5 days incubation, the contents of the plate are analyzed for total nitrogen. An active soil will show 2,000 to 3,000 colonies per 1 gram of soil and will fix $20 \mathrm{mgm}$. of nitrogen for the 2 grams of mannite.

THE CATALYTIC ACTION OF SOIL

The catalytic action, or the catalytic power, of a soil is its ability to produce oxygen from hydrogen peroxide; this has often been found to be an index of the fertility of the soil. This action can be determined by adding 5 grams of soil to 20 or $40 \mathrm{cc}$. of a 1.5 or 3 per cent solution of $\mathrm{H}_{2} \mathrm{O}_{2}$ and collecting the oxygen liberated; a 100 cc. gas-measuring tube filled with a dilute solution of $\mathrm{NaOH}$ or $\mathrm{KOH}$ and inverted into a bath of the same solution is used for collecting the gas. The soil is usually placed in a large test tube or in a 300-cc. Erlenmeyer flask and may be suspended in a little water, before adding the peroxide. One portion of soil is used untreated and another portion is previously sterilized in the autoclave so as to determine the rôle of the living organisms in the process; a third portion of soil may be ignited and then used in the test, so as to determine the rôle of the organic matter in the process of $\mathrm{H}_{2} \mathrm{O}_{2}$ decomposition. The period of incubation is usually 5 to 60 minutes and the temperature $17^{\circ}$ to $37^{\circ} \mathrm{C}$. An increase in concentration of substrate, temperature and period of incubation will all lead to an increase in the amount of oxygen liberated.

König ${ }^{44}$ found that the decomposition of $\mathrm{H}_{2} \mathrm{O}_{2}$ by soil was due chiefly to the enzyme catalase produced by the soil microorganisms and plant materials, and to some extent to the inorganic part of the soil and to organic colloids. On sterilizing the soil by heat or treatment with chloroform, iodine, mercury bichloride and especially hydrocyanic acid, the liberation of oxygen was greatly diminished. The catalytic action was found to be further increased by a similar action of manganic oxide, iron and aluminum oxides. The formation of oxygen by heated soils was ascribed to the increase in alkalinity due to the formation of $\mathrm{CaO}$ from $\mathrm{CaCO}_{3}$. When heated soil is moistened and allowed to remain one day in a desiccator filled with $\mathrm{CO}_{2}$, its catalytic power is greatly diminished. König found a

${ }^{44}$ König, J., Coppenrath, E., and Hasenbäumer, J. Beziehungen zwischen den Eigenschaften des Bodens und der Nährstoffaufnahme durch die Pflanzen. Landw. Vers. Sta., 66: 401-461. 1907; 53: 472-476. 1906. 
direct correlation between the humus content of the soil and its catalytic power. According to May and Gile, ${ }^{45}$ the catalytic action of a soil is a rough measure of the combined quantity of bacteria and organic matter present. Surface soils were found ${ }^{46}$ to be more active than subsoils, more fertile soils are more active than infertile ones.

Since inorganic soil constituents are also capable of liberating oxygen from $\mathrm{H}_{2} \mathrm{O}_{2}$, Chouchack ${ }^{47}$ used the difference between the oxygen formed by normal soil and that formed by the same amount of sterilized soil as an index of the biological activities. By treating the soil with phosphates, potassium and nitrogen salts, then determining the increase in catalytic action, reliable information can be obtained on the practical value of such treatments. Osuga, ${ }^{43}$ however, confirmed the previous observations of König and associates that ferric oxide, manganese oxide and humus show marked catalytic action. He suggested that these substances may be the main constituents which react with the $\mathrm{H}_{2} \mathrm{O}_{2}$. Bacterial effect in soil catalysis was believed to be small. In this respect, he confirmed the earlier observations of Kappen ${ }^{49}$ that the catalytic action of the soil is due largely to the colloidal complexes of the soil.

The catalytic action of the soil is thus found ${ }^{50}$ to be due to the inorganic constituents of the soil; to certain organic soil compounds, such as benzol derivatives, and to the action of catalase formed by microorganisms in the soil. Although a correlation exists between the catalytic action of the soil and the numbers of soil microorganisms as well as soil productivity, the phenomenon is very complex and cannot

"May, D. W., and Gile, P. L. The catalase of soils. Porto Rico Agr. Exp. Sta. Circ. 9. 1909.

${ }^{46}$ Sullivan, M. X., and Reid, F. R. Studies in soil catalysis. Bur. of Soils. U. S. Dept. Agr. Bul. 86. 1912.

${ }^{47}$ Chouchack, D. L'analyse du sol par les bactéries. Compt. Rend. Acad. Sci., 178: 1842-4, 2001-2. 1924.

${ }^{48}$ Osuga, C. On the catalytic action of soil. Ber. Ohara. Inst. Agr. Invest. Kuraschiki., 2: 197-218. 1922.

${ }^{49}$ Kappen, H. Die katalytische Kraft des Ackerbodens. Fühling's landw. Ztg., 62: 377-392. 1913; see also Smolik, L. Hydrogen-peroxide catalase of marsh soils. Proc. Intern. Soc. Soil Sci., 1: 6-21. 1925; A detailed review of the occurrence and action of catalase in general is given by Morgulis, S. Die Katalase. Ergebn. Physiol., 23: 308-367. 1924.

${ }^{50}$ Waksman, S. A., and Dubos, R. Microbiological analysis of soils as an index of soil fertility. X. The catalytic power of the soil. Soil Sci., 22: 407-422. 1926. 
be used as a simple method of cletermining soil productivity, unless the various factors are determined individually.

\section{OXIDIZING AND REDUCING POWER OF THE SOIL}

Oxidation consists in the addition of oxygen or subtraction of hydrogen, the oxygen can be obtained either directly from the atmosphere or from a peroxide (see p. 520). Soil fertility and the rate of oxidation were found ${ }^{51}$ to be influenced by the same factors and to the same extent, so that it was suggested that the latter could be used as a measure of the former. Oxidation was found to be greater in fertile than in unfertile soils, in surface soil than in subsoil. The oxidizing power of soils can be determined ${ }^{52}$ by shaking 5 grams of soil with $10 \mathrm{cc}$. of an alcoholic solution of gum guaiac and then allowing the soil to settle. The formation of a blue color indicates the degree of oxidation. When the blue color fades, it can be brought back by the addition of $0.5 \mathrm{cc}$. of a 2 per cent $\mathrm{H}_{2} \mathrm{O}_{2}$ solution. Another method of testing oxidation in soils consists in shaking 20 grams of soil with $50 \mathrm{cc}$. of 0.125 per cent aqueous solution of aloin for one hour; the soil is allowed to settle or the solution is centrifuged (if turbid, $50 \mathrm{cc}$. of 95 per cent alcohol is added to flocculate the soil and extract the oxidized aloin); the clear solution is poured off and the depth of color is determined by a colorimeter. It was found that soils known to be productive had a strong oxidizing power, and that the poorer soils had little or no oxidizing power; factors favoring oxidation also favor soil productivity. However, agreement has not been obtained in all cases.

Gerretsen ${ }^{53}$ used, as an index of the oxidizing power of soils, the amount of iodine liberated when 100 grams of soil are treated with a dilute solution of potassium iodide acidified with sulfuric acid. The method was carried out as follows. Two grams of soil were ground in a mortar, then washed into an Erlenmeyer flask with water; 5 cc. of a 1 per cent solution of potassium iodide and 6 drops of a $1: 1$ solution of sulfuric acid were then adcled to the soil suspension. After five minutes, the suspension was centrifuged, filtered and titrated with $0.01 \mathrm{~N} \mathrm{Na}_{2} \mathrm{~S}_{2} \mathrm{O}_{3}$. When the moisture content of the soil is known, the oxidizing power of 100 grams of dry soil can be calculated. It was found that rich soils had

51 Russell, 1905 (p. 683).

62 Schreiner, O., and Sullivan, M. X. Studies in soil oxidation. Bur. of Soils, U. S. Dept. Agr. Bul. 73. 1910.

${ }^{53}$ Gerretsen, F. C. Het oxydeerend vermogen van den bodem in verband met het uitzuren. Meddl. Proefsta. Java. Suikerind., 5: 317-331. 1915; Meddel. Proefsta. Java. Suik. No. 3. 1921. 
a high iodine (or HI) value; poor soils had a low value. These results were not confirmed, however, by Honing ${ }^{54}$ for soils of Deli, due to large quantities of organic matter present and to the irregular distribution of the ferric iron.

The oxidation of sulfur in the soil, the reduction of nitrates (denitrification) and formation of ammonia from proteins are often used for comparing the microbiological condition of different soils, but the value of these methods in throwing light upon the soil microbiological processes is often questioned.

${ }^{64}$ Honing, J. A. The oxidizing power of some soils in Deli, Sumatra. Bul. Deli Proefsta, No. 8. 1917; Bul. Agr. Intel., 8: 838. 1917. 


\section{CHAPTER XXVIII}

\section{Soil Microbiological Equilibrium}

INELUENCE OF AIR DRYING AND PARTIAL STERILIZATION UPON THE ACTIVITIES OF MICROORGANISMS IN THE SOIL

Microbiological equilibrium in the soil. The large numbers of microorganisms harbored in the soil vary greatly morphologically and physiologically. Conditions favoring the activities of one group of organisms may be distinctly injurious to others. An acid reaction, for example, may be favorable to the development of fungi but inhibitory to a number of bacteria and actinomyces. The presence of an excess of lime will favor bacteria, including nitrogen-fixing, nitrifying and other groups, but may depress the development of fungi. Aeration has a favorable influence upon some organisms but not upon others. The very metabolism of some organisms depends upon the activities of others which provide the substrate for them, as in the case of ammonia forming, nitrite and nitrate bacteria, etc.

The soil flora is so complex and the resulting activities are so various that one group of processes can hardly be separated from another and studied by itself. The addition to the soil of nitrogen compounds, carbon compounds, or minerals does not only stimulate the activities of one or more groups of organisms, but may bring about a series of changes in the soil, the resultant or the end of which is hard to foresee. Not only are the various organisms affected in different ways by different soil treatment, but they themselves exert stimulating or injurious influences upon the activities of one another. Some aerobic organisms, for example, use up the excess of oxygen, and thus create in the soil conditions favorable for the activities of the anaerobic forms and, ipse facto, unfavorable for the activities of other aerobic organisms. Some break down complex carbon compounds, like the celluloses, making the energy available for other forms, like the nitrogen-fixing organisms; others may compete with the latter for this available energy in the presence of available nitrogen. Some break down the complex nitrogenous substances liberating the ammonia, which can be utilized by higher plants or can serve as a substrate for nitrifying bac- 
teria; others use up the ammonia for the building up of microbial protoplasm. Some produce soluble substances as intermediary or byproducts of metabolism, which are either distinctly beneficial and stimulating to other organisms, or distinctly injurious. The soil also harbors a number of fungi, actinomyces and bacteria which are causative agents of plant diseases, although they may be able to live in the soil saprophytically.

When a soil is left undisturbed for a long period of time the numbers and activities of the various groups of organisms come to a condition which may be termed unstable equilibrium. This equilibrium is not static but dynamic, in a chemical sense, especially under field conditions. Sunshine and rain, freezing and thawing, plowing and cultivating, fertilizing and manuring and a host of other factors which affect the soil will bring about a change in this equilibrium. If the numbers of bacteria and protozoa are determined daily for a period of time, constant fluctuations are found. ${ }^{1}$ The same is true of the numbers of fungi, nitrate and carbon dioxide content of the soil.

However, when a soil is kept under constant optimum conditions and undisturbed, the daily variability is very small and there is a constant gradual diminution in the numbers and activities of the microorganisms, as shown ${ }^{2}$ in figure 63 . This figure indicates that the rapid rise of the numbers of bacteria and evolution of carbon dioxide, as a result of moistening of an air-dry soil, was followed by a gradual drop for about 200 days, when the drop became hardly perceptible but was still present. The soil was kept in pots and the soluble products, resulting from the decomposition of the organic matter in the soil, were not removed by drainage, nor by growing plants, nor by any microorganisms, since no fresh sources of energy were added. For this reason nitrates continued to accumulate. This equilibrium in microbiological activities is not due to a lack of nitrogen, but to a lack of available energy. $\operatorname{Rahn}^{3}$ found that the addition of straw to such a soil will result in a rapid increase in the growth and development of microorganisms, lasting as long as the available energy does and followed again by a decline. The same increase in the activities

${ }^{1}$ Cutler, et al., 1923 (p. 32).

2 Waksman, S. A., and Starkey, R. L. Partial sterilization of soil, microbiological activities and soil fertility. Soil Sci., 16: 137-156, 247-268, 343-357. 1923.

'Rahn, O. Die schädliche Wirkung der Strohdïngung und deren Verhütung. Ztschr. techn. Biol., 7: 172-186. 1919. 
of microorganisms can also be obtained, however, by treatment of soil with various volatile antiseptics, heating the soil or even merely drying it. The resulting activities are similar to those following the addition of a fresh supply of energy, as shown in the following pages.

Influence of air-drying of soil upon the microbiological equilibrium. 'The favorable effect of drying of soil upon the growth of higher plants has been reported from various sourees. ${ }^{4}$ This effect was first attributed to the improvement in the physical condition of the soil, especially in

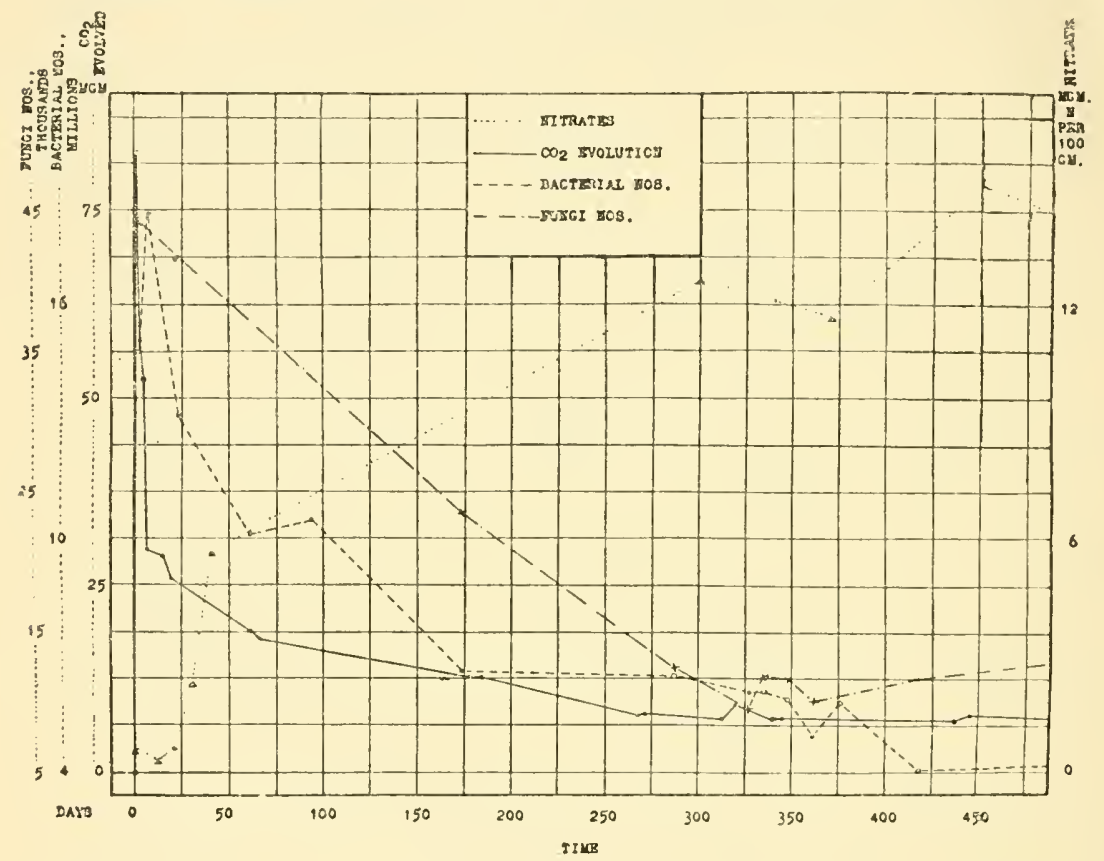

FIg. 63. Course of biological activities in undisturbed soil (from Waksman and Starkey).

case of fine grained soils, then it was aseribed to some chemical change in the soil as a result of drying. The number's and activities of microorganisms are found to be markedly influenced by the drying of the soil. When one part of the same soil is allowed to remain moist and the other part is air dried for some time and then moistened, a rise in the numbers of bacteria and an increase in the evolution of carbon

${ }^{4}$ Lebedjantzev, A. N. Drying of soil, as one of the natural factors in maintaining soil fertility. Soil Sei., 18: 419-447. 1924. 
dioxide and in the accumulation of nitrates is found to take place in the second soil. The rise in the numbers and activities of microorganisms is soon followed by a rapid fall until they approach those of the control soil. When the formation of acid in glucose solution and anmonia in urea and peptone solutions were used as indices, an air-dried soil was about 20 per cent more active than the corresponding
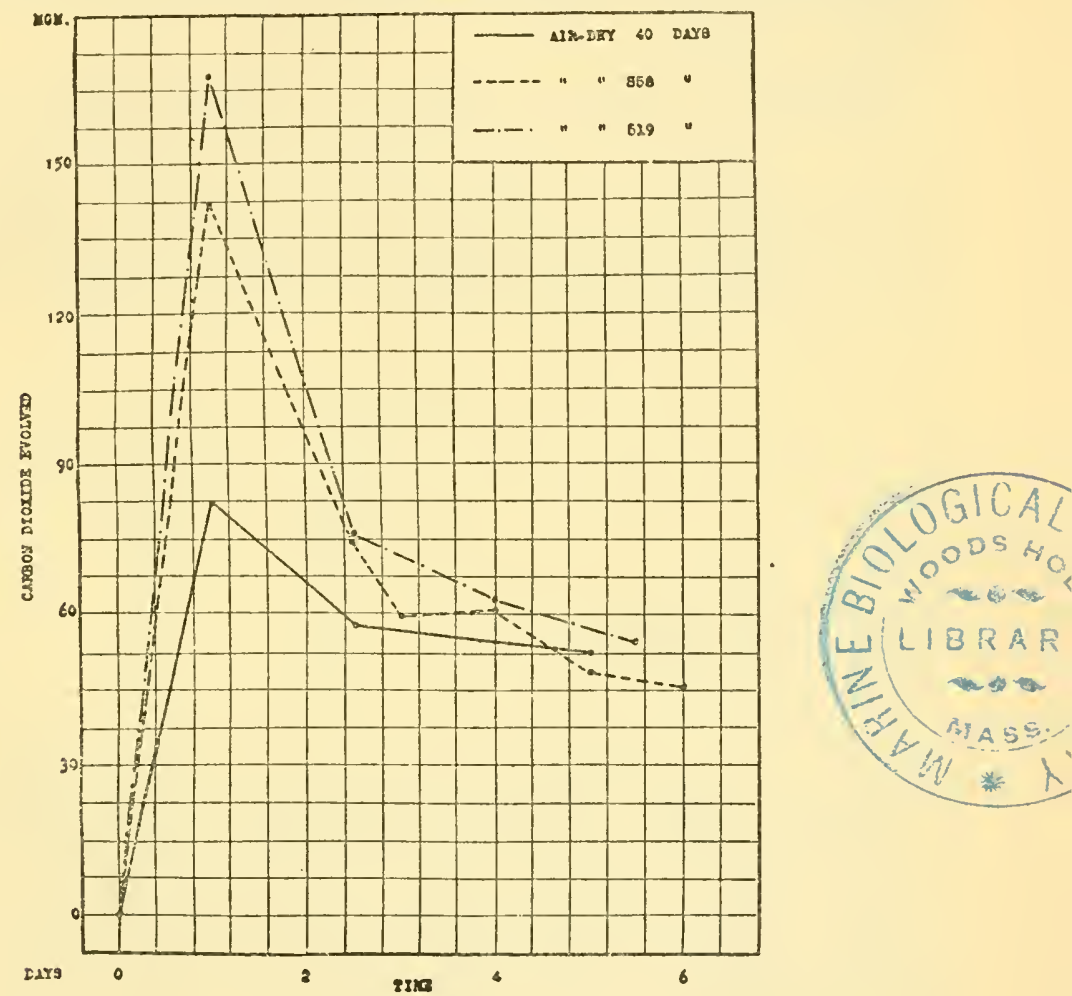

Frg. 64. Influence of length of air-drying of soil upon its biological activities, as indicated by the evolution of $\mathrm{CO}_{2}$ (from Waksman and Starkey).

moist soil. ${ }^{5}$ Different soils behave differently in this respect, heavy soils showing greater differences than light soils; the difference was particularly noticeable in garden soils. The bacteriological methods of analysis were found very unsatisfactory and Rahn, therefore, ascribed the beneficial effect of drying to the degree of solubility of minerals.

'Rahn, O. Bakteriologische Untersuchung über das Trocknen des Bodens. Centrbl. Bakt. II, 20: 38-61. 1908. 
Soils dried gradually become more active than soils dried rapidly; ${ }^{6} \mathrm{com}-$ plete drying results also in a greater stimulus than moderate drying. Ritter suggested that this favorable influence of drying might be due to a selective action upon the species of soil microorganisms. The greater the period of time during which the soil is air dried, the more are the activities of microorganisms stimulated, as indicated by numbers of bacteria, evolution of carbon dioxide and increase in available nitrogen (fig. 64).

Drying of soil results in a decrease in bacterial numbers of 40 to 70 per cent, followed by a rapid increase, when the soil is moistened. ${ }^{7}$ When a soil kept in pots becomes unfavorable for the growth of leguminous plants, it may be restored to normal condition by drying. The protozoa (cysts) are not destroyed as a result of drying,,$^{8,9}$ neither are the fungi and actinomyces affected to any large extent.

TABLE 82

Increase in total soluble salts due to drying

\begin{tabular}{|c|c|c|c|}
\hline SOIL LAYER & $\begin{array}{c}\text { INCREASE DUE } \\
\text { TO OVEN-DHYINO } \\
\text { WET SOIL }\end{array}$ & $\begin{array}{l}\text { INCREASE DUD } \\
\text { TO AIR-DRYINO } \\
\text { WET BOIL }\end{array}$ & $\begin{array}{l}\text { INCREASE DUD } \\
\text { TO OVEN-DRYINO } \\
\text { AIR-DHY SOIL }\end{array}$ \\
\hline & per cent & per cent & per cent \\
\hline Surface, 0 to 8 inches ........... & 60 & 23 & 50 \\
\hline Subsurface, 12 to 20 inches.. & 62 & 74 & 59 \\
\hline Subsoil, 20 to 40 inches..... & 200 & 94 & 104 \\
\hline
\end{tabular}

König and associates ${ }^{10}$ found that all soils except clays show a small but definite increase in dialyzable materials, when heated under diminished pressure. This is due to a change in the colloidal condition of the soil, which causes the adsorbed materials to become soluble. Air-drying of soil, under natural conditions, also causes a partial destruction of the colloidal state, and, therefore, an increase in the solubility of the nutrients held by the colloids. The influence

${ }^{6}$ Ritter, G. Das Trocknen der Erden. Centrbl. Bakt. II, 33: 116-143. 1912.

${ }^{7}$ Heinze, B. Bakteriologische Versuche. Landw. Jahrb., 65: 139-184. 1920.

${ }^{8}$ Goodey, T. Investigations on protozoa in relation to the factor limiting bacterial activity in soil. Proc. Roy. Soc. B., 88: 437-456. 1915.

${ }^{9}$ Greig-Smith, R. Contributions to our knowledge of soil fertility. XII. The action of toluene upon the soil protozoa. Proc. Linn. Soc. N. S. Wales, 39: 839-850. 1914.

${ }^{10}$ König, J., Hasenbäumer, J., and Glenk, K. Ưber die Anwendung der Dialyse und die Bestimmung der Oxydationskraft für die Beurteilung des Bodens. Landw. Vers. Sta., 79-80: 491-534. 1913. 
of repeated wetting and drying of soil in increasing plant growth is believed to be due to this phenomenon. Air drying of soil very markedly increases the amount of water soluble substances especially the inorganic soil constituents ${ }^{1,12}$ (table 82 ).

The cultivation of the soil has in itself a stimulating effect upon the bacterial activities; this is, however, negligible in comparison with the effect of drying. Proper aeration supplies the oxygen necessary for bacterial activities, and brings about more fundamental changes influencing these activities. This is particularly true when cultivation of soil is accompanied by air drying.

Influence of caustic lime upon soil processes. Caustic lime (about 0.5 per cent) has had a recognized value as an antiseptic. When applied to the soil, even in the presence of large quantities of $\mathrm{CaCO}_{3}$, $\mathrm{CaO}$ was found to disturb or even destroy the state of equilibrium normally existing between the micro-flora and micro-fauna of the soil. ${ }^{13}$ The action of $\mathrm{CaO}$ is intermediate between the action of antiseptics and changes induced by high temperatures. Its action seems to consist in bringing about a greater decomposition of the organic nitrogen constituents of the soil. The numbers of bacteria are at first depressed but later on they rise. ${ }^{14,15}$ Many bacteria and the larger protozoa are destroyed. The numbers of bacteria remain depressed until the excess of the calcium oxide is transformed into carbonate when active bacterial multiplication takes place. The action of lime depends, of course, upon the character of the soil, each soil neutralizing a definite amount before the phenomenon of partial sterilization becomes evident; when there is no further absorption of lime, the free alkali begins to function as a disinfectant. This is the reason why $\mathrm{CaCO}_{3}$ does not produce the same effect.

Partial sterilization of soil. Russell and Hutchinson ${ }^{16}$ demonstrated that partial sterilization of soil (heating to $60^{\circ} \mathrm{C}$. or treatment with

"Kelley, W. P. Ammonification and nitrification in Hawaiian soils. Hawaii Agr. Exp. Sta. Bul. 37, 1915.

${ }^{12}$ Gustafson, A. F. The effect of drying soils on the water-soluble constituents. Soil Sci., 13: 173-213. 1922.

${ }^{13}$ Hutchinson, H. B. The partial sterilization of the soil by means of caustic lime. Jour. Agr. Sci., 5: 320. 1913; 6: 302. 1914.

${ }^{14}$ Fischer, H. Über den Einfluss des Kalkes auf die Bakterien eines Bodens. Landw. Versuchsta., 70: 335-342. 1909.

${ }^{16}$ Miller, F. Uber den Einflusz des Kalkes auf die Bodenbakterien. 7tschr. Gärungsphysiol., 4: 194-206. 1914.

${ }^{16}$ Russell and Hutchinson, 1909-1913 (p. 311). 
volatile antiseptics) increased the rate of oxidation in the soil, as well as the numbers of bacteria. Similar observations for bacterial numbers were made previously (1901) by Hiltner and Störmer ${ }^{17}$ who treated the soil with $\mathrm{CS}_{2}$. Russell and Hutchinson also found that the high numbers in partially sterilized soil rose for a time even higher if a little fresh untreated soil was added to the partially sterilized soil; later, however, the numbers in the soil reinoculated with fresh scil fell.

Partial sterilization of soil can be accomplished by heating the soil or by treating it with various antiseptics. By the use of heat (steam or dry heat) the soil can be partially or completely sterilized, depending on the temperature and length of treatment. To sterilize the soil completely, it must be subjected to steam pressure for two hours at 15 pounds, or for one hour, on seven consecutive days, in flowing steam. Temperatures less than $100^{\circ} \mathrm{C}$. only destroy certain groups of microorganisms; at $60^{\circ}$ to $65^{\circ}$, for example, living protozoa, particularly the large forms, and fungus mycelium and spores ${ }^{18}$ as well as vegetative cells of various bacteria are destroyed. To partially sterilize a soil is to treat it in such a manner as to destroy certain groups of organisms and leave others uninjured. Soil partially or completely sterilized by heat becomes a favorable medium for the growth of certain groups of fungi and bacteria.

A large number of antiseptics bring about true partial sterilization with the following results: $:^{19,20}$

\footnotetext{
a. An initial decrease in the number of bacteria followed by a large sustained rise.

$b$. The destruction of the protozoa and nitrifying organisms.

c. An initial increase of ammonia followed by a considerable increase in the rate of ammonia formation and consequently of soil productivity.

$d$. No increase in the dose of the antiseptic causes any change in the results obtained, once true partial sterilization has set in.

$e$. The complete or almost complete destruction of the soil fungi, ${ }^{21}$ of soil nematodes and other soil infesting worms and insects. ${ }^{22}$
}

${ }^{17}$ Hiltner and Störmer, 1903 (p. 12).

18 Thom and Ayers, Jour. Agr. Res., 6: 153-166. 1916.

19 Buddin, W. Partial sterilization of soil by volatile and non-volatile antiseptics. Jour. Agr. Sci., 6: 417-451. 1914.

${ }^{20}$ Russell, E. J. The recent work at Rothamsted on the partial sterilization of soil. Intern. Inst. Agr., Bur. Agr. Int. Pl. Dis., 8. 1917, No. 5.

${ }^{21}$ Waksman and Starkey, 1923 (p. 739).

${ }^{22}$ Russell, E. J. The partial sterilization of soils. Jour. Roy. Hort. Soc., 55: $236-246.1920$. 
True partial sterilization has been obtained only with the easily volatile or removable antiseptics. Non-removable substances have a lasting effect upon the flora, stimulating only a few species, without bringing about, however, a considerable gain in ammonia or nitrate. Larger doses of these chemicals may even suppress microbiological activities. ${ }^{19}$ The influence of the concentration of the antiseptic is given in table 83.

It is sufficient to mention, among the volatile antiseptics, toluol, carbon bisulfide and chloroform. Concentrations of 1 to 4 per cent of the disinfectant are allowed to act upon the soil for 12 to 48 hours; the soil is then aerated so that the disinfectant may evaporate. Among the non-volatile antiseptics, it is sufficient to mention phenol, cresol

TABLE 83

Influence of toluene upon soil microorganisms and their activities

\begin{tabular}{|c|c|c|c|c|c|c|}
\hline \multirow{2}{*}{$\begin{array}{l}\text { TOLUENE ADDED PER KILOGRAM } \\
\text { OF DRY BOIL }\end{array}$} & \multicolumn{3}{|c|}{$\begin{array}{l}\text { BACTERIA PRESENT, MLLIONS } \\
\text { PER GRAM OF DRY SOIL }\end{array}$} & \multicolumn{2}{|c|}{$\begin{array}{l}\text { AMMONIA + NITRATE, } \\
\text { PAATS PER } \\
\text { MILLION OF DRY SOIL }\end{array}$} & \multirow{2}{*}{$\begin{array}{c}\text { EFFECT } \\
\text { ON } \\
\text { PROTOZO }\end{array}$} \\
\hline & Start & 34 days & 51 days & Start & 30 days & \\
\hline Untreated $=0$ gram $\ldots$ & 22.0 & 16.0 & 18.0 & 24.0 & 43.0 & $\mathrm{CAF}^{*}$ \\
\hline$M / 200=0.46$ gram.. & 16.0 & 22.5 & 18.5 & 26.5 & 50.0 & $\mathrm{CF}$ \\
\hline$M / 100=0.92 \mathrm{gram}$. & 8.5 & 76.0 & 92.0 & 28.5 & 56.0 & $\mathrm{~F}$ \\
\hline $\mathrm{M} / 50=1.84$ grams. & 7.0 & 87.0 & 94.0 & 29.0 & 63.0 & (F) \\
\hline $\mathrm{M} / 10=9.2 \mathrm{grams} .$. & 8.0 & 95.0 & 87.0 & 29.5 & 65.0 & 0 \\
\hline $\mathrm{M} / 5=18.4$ grams.. & 8.0 & 77.0 & 90.0 & 29.5 & 66.0 & 0 \\
\hline$M=92.0$ grams $\ldots$. & 7.0 & 90.0 & 86.0 & 30.0 & 66.0 & 0 \\
\hline
\end{tabular}

$* \mathrm{C}=$ ciliates $\mathrm{A}=$ amoebae $; \mathrm{F}=$ flagellates.

$(11 / 10)$, cresyllic acid, calcium oxide, various metallic salts, like arsenic compounds. Some of these, like the phenols, are decomposed in course of time by various bacteria; $\mathrm{CaO}$ is soon carbonated; others, like the arsenic oxide, may persist for some time in the soil. The intensity of partial sterilization shades off gradually from the powerful non-volatile antiseptics, through cresol $(\mathrm{m} / 50)$ and formaldehyde, to the more or less potent volatile antiseptics, until finally a hardly noticeable effect is obtained, as in the case of merely spreading out the soil in a thin layer. ${ }^{19}$

The use of heat as an agent of partial sterilization. Franke ${ }^{23}$ observed

${ }^{23}$ Franke, B. Ueber den Einfluss, welchen das Sterilisieren des Erdbodens auf die Pflanzenentwicklung ausübt. Ber. deut. bot. gesell. Generalsammlungsheft., 6: $87-97.1888$. 
that heating of soil increased the solubility of the mineral constituents and organic matter in the soil, and soil productivity. Krüger and Schneidewind ${ }^{24}$ also suggested that the favorable effect of heat is due to the increase in the solubility of soil minerals, as shown in the following summary:

Yield of mustard, in grams per pot

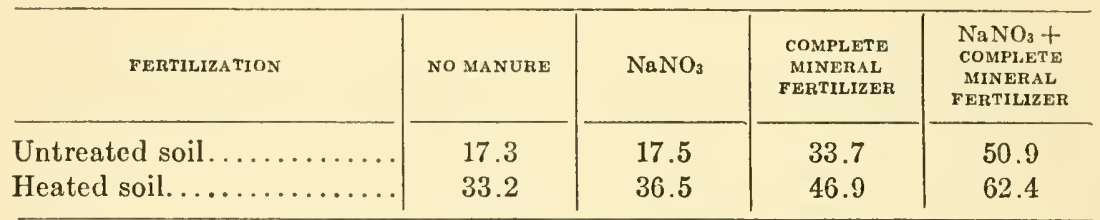

It was later found that heating of soil brings about a decided change in its microbial population, as pointed out above. On subsequent remoistening of the soil, the greatest increase in the numbers of microorganisms is shown by the non-spore forming bacteria; the actinomyces increase only slowly, while the fungi and protozoa destroyed by the treatment reappear only later. The fungi once introduced make a very rapid growth on soil sterilized by heat. ${ }^{25}$ Sterilization by heat results also in the destruction of the nitrifying bacteria; it brings about a decided increase in the amount of ammonia accumulated in the soil, due to a greater decomposition of the soil organic matter by the microorganisms. ${ }^{26}$ This accounts for the increased fertility of the soil and beneficial influence upon plant growth which results from the steaming of the soil. ${ }^{27}$

Fischer ${ }^{28}$ observed that when a soil is sterilized by means of steam and reinoculated with bacteria, a great increase in biological activities results; this can be determined by the increase in numbers and by the production of carbon dioxide. After some time (three weeks), the bacterial numbers still remain at a high level while the production of carbon dioxide

${ }^{24}$ Krüger, W., and Schneidewind, W. Ursache und Bedeutung der Salpeterzersetzung im Boden. Landw. Jahrb., 28: 277-252. 1899.

25 This phenomenon is readily observed also in field soils, which became subject to considerable heat for one reason or another: Tokugawa, Y., and Emoto, Y. Über einem kurz nach der letzten Feuerbrust plötzlich entwickelten Schimmelpilz. Japanese Jour. Bot., 2: 175-188. 1924.

${ }^{26}$ Russell and Hutchinson, 1909 (p. 311).

${ }^{27}$ Elveden, V. A contribution to the investigation into the results of partial sterilization of soil by heat. Jour. Agr. Sci., 11: 197-210. 1921.

${ }^{28}$ Fischer, H. Versuche über Bakterienwachstum in steriliziertem Boden. Centrbl. Bakt. II, 22: 671-675. 1909. 
rapidly diminishes. Fischer suggested, therefore, that after a period of decided activities the bacteria become rather inactive although they still show increased numbers; they go into "resting" forms, which possess a low respiratory power, but are capable of developing on the plate into colonies. The rapid increase of bacteria was not found to be accompanied by a similar increase of fungi. The increase in bacterial activities was considered to be not so much a result of the nutrients coming into solution during sterilization, but as a result of the

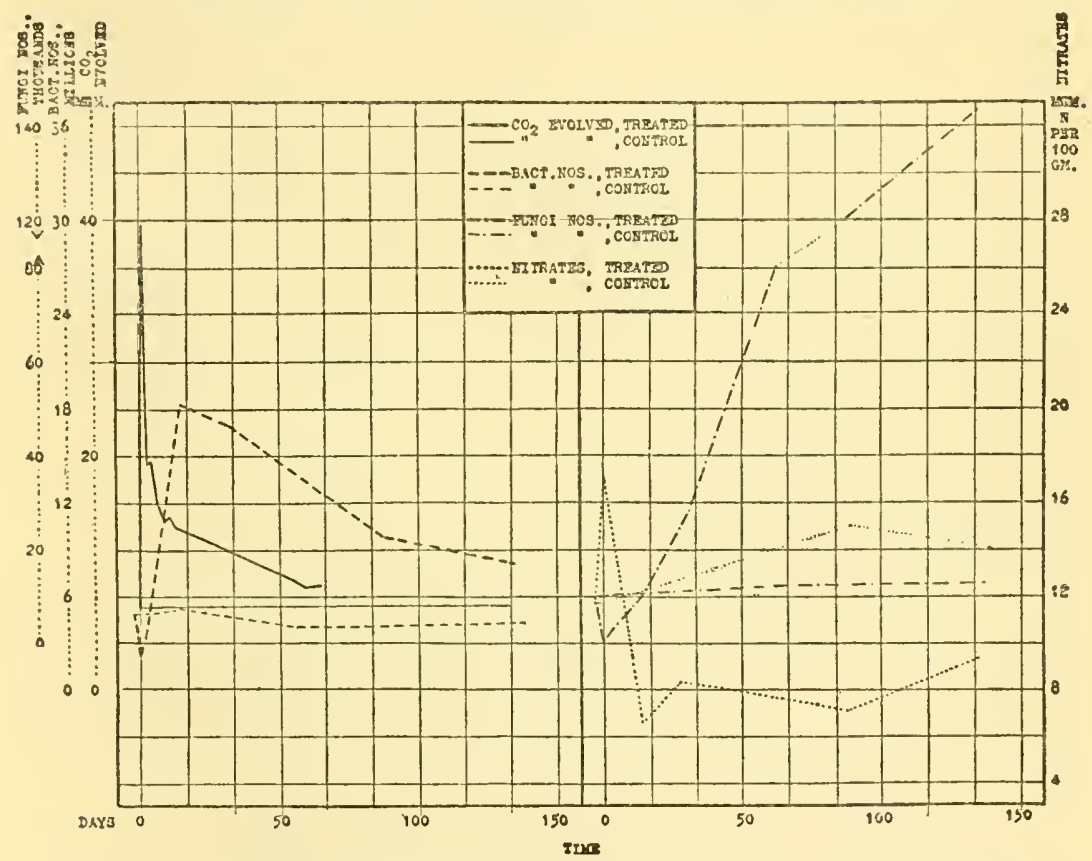

FIG. 65. Influence of heating of soil upon the numbers and activities of its population (from Waksman and Starkey).

decomposition of the bodies of microorganisms in the soil. The increased numbers of bacteria bring about an increase in the decomposition of the soil constituents, both of organic and inorganic nature.

Heating of peat soil, at $100^{\circ}$ for fifteen minutes, was found ${ }^{29}$ to stimulate greatly the biological activities, when the evolution of carbon dioxide (from 200 grams of soil) was used as an index of these activities.

${ }^{29}$ Demolon, A., and Boischot, P. Sur l'activité des phénomènes biologiques dans la tourbe. Compt. Rend. Acad. Sci., 177: 282-284. 1923. 
This favorable influence of heating was found to be due not to the destruction of toxins or protozoa, but to a chemical modification of the peat. A stimulative effect of steam treatment of soil upon the numbers of bacteria in the soil has also been observed. ${ }^{30}$ The results of heating $\left(65^{\circ} \mathrm{C}\right.$. for one hour) of a soil upon the numbers of fungi and bacteria, evolution of carbon dioxide and accumulation of available nitrogen (ammonia + nitrates) are given in figure 65 . Heating a soil even to low temperatures seems to improve it as a medium for bacterial growth. It is interesting to mention, in this connection, the change brought about by heat in the physical and chemical condition of the soil. While treatment of soil at temperatures lower than $100^{\circ} \mathrm{C}$. rendered the soil more fertile, temperatures higher than $100^{\circ}$ rendered it less fertile. ${ }^{31}$ The lower temperatures bring about an increase in the soluble organic matter ${ }^{32}$ in the soil; treatment of soil at higher temperatures (especially above $100^{\circ} \mathrm{C}$.) results in the formation of substances toxic to the growth of higher plants: among those guanine, arginine, dihydroxystearic acid have been recorded. There is also an increase in acidity, or rather ability of soil to neutralize bases. ${ }^{33}$ The toxic substances are unstable, gradually disappearing in the course of time, if the soil is kept moist and aerated. This is probably due to oxidation and other activities of microorganisms.

The increase in soluble organic matter, as a result of heating, varies directly with the temperature to which the soil is subjected, particularly in the case of carbohydrates. It has also been observed that heating of soil brings about a greater solubility of the phosphorus and nitrogen compounds in the soil. ${ }^{34,35}$ Similar results were obtained by a number

${ }^{30}$ Osmun, A. V. A comparison of the numbers of bacteria in sterilized and unsterilized soils. Mass. Agr. Exp. Sta. Rpt. 1905, 146-148.

${ }^{31}$ Pickering, S. U. The activities of heat and antiseptics on soils. Jour. Agr. Sci., 3: 32-54, 258-276. 1910.

32 Schreiner, O., and Lathrop, E. C. The chemistry of steam heated soils. U. S. Dept. Agr. Bur. Soils Bul. 89. 1912; Jour. Amer. Chem. Soc., 34: 11421159. 1912 .

${ }^{33}$ Robinson, R. H. Concerning the effect of heat on the reaction between limewater and acid soils. Soil Sci., 9: 151-157. 1920.

${ }^{34}$ Liebscher, G. Welche Kulturpflanzen vermehren den Stickstoff vorrat der Wirtschaft. II. Die Stickstoffsammlung der Kulturpflanzen. Deut. Landw. Presse., 20: 975-976. 1893.

${ }^{35}$ Krüger, W., and Schneidewind, W. Ursache und Bedeutung der Salpeterzersetzung im Boden. Landw. Jahrb., 28: 217-252. 1899. 
of other investigators. ${ }^{36-39}$ Bouyoucos ${ }^{40}$ and Wilson ${ }^{41}$ found an increase in the concentration of the soil solution as a result of heating of soil, using the freezing point method. This increase is greater in soils rich in organic matter than in mineral soils. Heat also effects a flocculation of the soil colloids, thus changing the physical condition of the soil.

The increase in the soluble matter and the changes in the microbiological population of the soil brought about by heating result in an increase in the numbers of bacteria; these in their turn decompose more organic matter, which results in a greater liberation of available nitrogen. This favors the growth of plants. ${ }^{42}$

Influence of volatile antiseptics upon bacterial activities in the soil. Volatile antiseptics, especially carbon bisulfide, were first applied to soils and plants for the destruction of insect and fungus pests. As far back as 1870 the observation was made that this disinfectant has a stimulating effect upon plant growth. Girard ${ }^{43}$ used $\mathrm{CS}_{2}$ to clear a piece of sugar-beet ground badly infested with nematodes and observed marked increases in the succeeding crops as a result of the treatment.

36 Whitney, M., and Cameron, F. K. The chemistry of the soil as related to crop production. U. S. Dept. Agr., Bur. Soils, Bul. 22, 1-71.

${ }^{37}$ Lyon, T. L., and Bizzell, J. A. Effect of steam sterilization on the watersoluble matter in soil. N. Y. (Cornell) Agr. Exp. Sta. Bul. 275. 1910; Bul. 326. 1913.

${ }^{38}$ Seaver, J. F., and Clark, F. D. Changes brought about by heating of soils and relation to the growth of Pyronema and other fungi. Mycologia, 2: 109124. 1910; Biocehm. Bul. 1: 413-427. 1912.

${ }^{39}$ Gustafson, 1922 (p. 743).

${ }^{10}$ Bouyoucos, G. The freezing point method as a new means of measuring the concentration of the soil solution directly in the soil. Mich. Agr. Exp. Sta. Tech. Bul. 24. 1915.

41 Wilson, A. Changes in soils brought by heat. Proc. Roy. Dublin Soc. N. S., 38: 513. 1915.

${ }_{42}$ The favorable influence of heating of soil at temperatures less than $100^{\circ}$ uron erop growth has been studied in detail by Russell, E. J., and Petherbridge, F. R. On the growth of plants in partially sterilized soils. Jour. Agr. Sci., 5: 245-287. 1913; The practice of burning soils is described by Mann, H. H., Joshi, N. V., and Kanitkar, N. V. The "rab" system of rice cultivation in Western India. Mem. Dept. Agr. India, Chem. Ser., 2: 141-192. 1912; Kelley, W. P., and McGeorge, W. The effect of heat on Hawaiian soils. Hawaii Agr. Exp. Sta. Bul. 30. 1913; Demolon, A. The partial sterilization of peat. Intern. Rev. Sci. Pract. Agr., 3: 431. 1924 (Chem. Abstr., 20: 1878).

${ }^{43}$ Girard, A. Recherches sur l'augmentation des récoltes par l'injection dans le sol du sulfure de carbone à doses massives. Bul. Soc. Nat. Agr. France, 54: 356-363. 1894. 
In 1894 Oberlin ${ }^{44}$ applied $\mathrm{CS}_{2}$ for the destruction of Phylloxera and noticed that the productiveness of the soil was greatly increased. He suggested, therefore, that soil sickness can be corrected by the applieation of the disinfectant and ascribed this favorable influence to the destruction of injurious microorganisms. This favorable effect of the disinfectant was ascribed to the direct stimulation of young plants. ${ }^{45,46}$

Nobbe and Richter ${ }^{47}$ obtained a definite increase in erop yield by treatment of soil with ether, chloroform or benzene. It was soon found that the stimulating effect applies to all soils and all plants. ${ }^{43}$ The antiseptics, like carbon bisulfide, carbon tetrachloride, toluol,

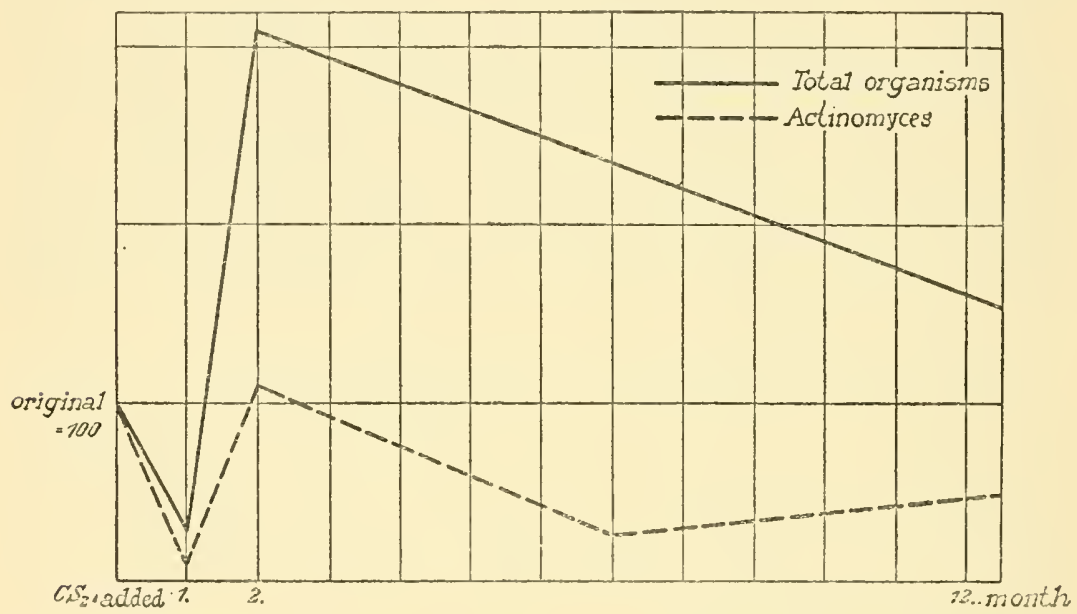

FIG. 66. Influence of $\mathrm{CS}_{2}$ upon the numbers of bacteria and actinomyces in the soil (from Hiltner and Störmer).

benzol, phenol, eresol, are in themselves directly poisonous to plants when added to water cultures. They were found to exert a deciced

${ }^{44}$ Oberlin. Bodenmüdigkeit und Sehwefelkohlenstoff. Mainz. 1894.

${ }^{45} \mathrm{Koch}, \mathrm{A}$. Untersuchungen über die Ursachen der Bodenmüdigkeit. Arb. deut. landw. Gesell. H., 40. 1899, 44 p.

${ }^{46}$ Egorov, M. A. On the influence of earbon bisulfide upon soils and plants (Russian). Zhur. Opit. Agron., 9: 34-95. 1908.

${ }^{47}$ Nobbe, F., and Riehter, L. Über die Behandlung des Bodens mit Äther, Schwefelkohlenstoff, Chloroform, Benzol und Wasserstoffsuperoxyd und deren Wirkung auf das Wachstum der Pflanzen. Landw. Vers. Sta., 60: 433-44S. 1904.

${ }^{48}$ Störmer, K. Über die Wirkung des Schwefelkohlenstoffs und ähnlicher Stoffe auf den Boden. Jahresb. ver. angew. Bot. for 1907, 5: 113-131. 1908; Centrbl. Bakt. II, 20: 2\$2-28s. 1908. 
stimulating effect when added to the soil some time before the crop is planted. This was attributed ${ }^{49}$ to a changed bacterial population. A bacterial flora of $9 \frac{1}{2}$ millions per gram, as determined by the plate method, was depressed by the addition of the disinfectant (fig. 66); it soon increased rapidly, reaching, within a month after the evaporation of the disinfectant, 50 millions; the numbers then slowly fell but remained above the original number. The normal flora of the soil consisted of 75 per cent non-liquefying bacteria, 20 per cent actinomyces and 5 per cent gelatin liquefying forms. As a result of treatment with carbon bisulfide, the non-liquefying organisms were greatly increased, while the actinomyces were reduced and did not return to the original proportion for at least two years. The denitrifying bacteria were completely destroyed, while the pectin-fermenting organisms were reduced. As a result of these studies, Hiltner and Störmer came to the following conclusions:

1. By destroying the existing bacterial equilibrium in the soil, carbon bisulfide opens the way for an entirely new bacterial development. This is achieved through the unequal retardation in the growth of the different groups of bacteria. Hence certain groups become disproportionately prominent, while others are almost entirely suppressed.

2. The rapid increase in the numbers of the bacteria is followed by a more intense transformation of plant food substances. Decomposition and fixation processes result in an accumulation of readily available nitrogen compounds utilized by the crops. Hence the action of carbon bisulfide is in the nature of nitrogen action.

3. The initial suppression of the nitrifying species becomes of advantage in that the nitrogen compounds, simplified by other species, are prevented from being rapidly changed into nitrates and being leached out of the soil.

4. The more or less permanent suppression of the denitrifying organisms must be regarded as an additional factor favoring plant growth. ${ }^{60}$

Van Suchtelen ${ }^{51}$ found that $\mathrm{CS}_{2}$ stimulates the decomposition of organic matter, as indicated by the $\mathrm{CO}_{2}$ production; $12 \mathrm{kgm}$. of soil

${ }^{49}$ Hiltner and Störmer, 1903 (p. 12); Hiltner, L. Über neuere Ergebnisse und Probleme auf dem Gebiete der landwirtschaftlichen Bakteriologie. Jahresb. Angew. Bot., 5: 200-222. 1907; Centrbl. Bakt. II, 38: 228. 1912; Störmer, 1907 (p. 750).

${ }^{50}$ The observations of Hiltner and Störmer were confirmed by Moritz, J., and Scherpe, R. Über die Bodenbehandlung mit Schwefelkohlenstoffe und ihre Einwirkung auf das Pflanzenwachstum. Arb. K. Gesundhsamt. Biol. Abt., 4: 123-156. 1904; also Arb. K. Biol. Anst. Land. Forstw., 7: 353-425. 1909; Centrbl. Bakt. II, 13: 573.

${ }_{61}$ Van Suchtelen, 1910 (p. 720). 
+ 6 grams glucose gave 7,215 milligrams of $\mathrm{CO}_{2}$ in nineteen days when treated with 170 grams of $\mathrm{CS}_{2}$, while the untreated soil gave 5,991 milligrams. Soil treated with heat or volatile antiseptics has a much greater oxidizing power, as indicated by the oxygen absorption by the soil. ${ }^{52}$

Störmer suggested that the disinfectants kill the larger soil organisms, such as worms, insects, fungi, algae, protozoa; these are then decomposed by the surviving bacteria with the formation of ammonia. Bacterial development and ammonia accumulation are a result of this decomposition. The total increase in ammonia nitrogen over the untreated soil is not more than 3 to $4 \mathrm{mgm}$. of nitrogen per 100 grams of soil; this quantity can be readily derived from the decomposed organisms. Garden soils may be very rich in nematodes which often do great damage to the crop. ${ }^{53}$ These nematodes are destroyed by the disinfectant. Among the injurious bacteria, which may also be destroyed, are the nitrate and sulfate reducing forms.

According to Stoklasa, ${ }^{54}$ the increase in soil fertility due to treatment with $\mathrm{CS}_{2}$, chloroform, benzol, or ether is due to the destruction of a definite number of soil microorganisms; the surviving bacteria readily break down the dead organisms, liberating phosphate and other ions, which now become available for plant growth. It is to be noted that among the organisms which develop in great abundance in partially sterilized soils Clostridium pastorianum, the anaerobic nitrogen-fixing organism, occupies a prominent place, occurring as 100,000 or more per gram of soil. ${ }^{55}$

It thus became evident that the treatment of soil with antiseptics is equivalent to nitrogen fertilization. It was suggested ${ }^{56}$ that partial sterilization of soil renders a number of undecomposed plant residues, such as pectins and pentosans, more soluble; these are used as sources

52 Darbishire, F. V., and Russell, E. J. Oxidation in soils and its relation to productiveness. II. The influence of partial sterilization. Jour. Agr. Sci., 2: 305-326. 1908.

${ }^{53}$ Emmerich, R. W., Graf zu Leiningen, and Loew, "O. Utber Bodensāuberung. Centrbl. Bakt. II, 29: 668. 1911; 31: 466-477. 1911.

${ }^{54}$ Stoklasa, 1911 (p. 649).

${ }^{56}$ Truffaut, G., and Bezssonoff, N. Influence de la stérilisation partielle sur la composition de la flore microbienne du sol. Compt. Rend. Acad. Sci., 170: 1278-9. 1920; 171: 268-270. 1920；172: 1319-1323. 1921.

${ }^{56}$ Heinze, B. Einiges über den Schwefelkohlenstoff, dessen Wirkung auf niedere pflanzliche Organismen, sowie seine Bedeutung für die Fruchtbarkeit des Bodens. Centrbl. Bakt. II, 16: 329-357. 1906; 18: 56, 246, 462, 624, 790. 1907; Landw. Jahrb., 36: 418. 1907. 
of energy by nitrogen-fixing bacteria; the subsequently more intense transformation of the bacterial proteids and of other nitrogenous organic substances into amino- and ammonium compounds places an abundant and uniform supply of soluble nitrogen compounds at the disposal of the plant.

TABLE 84

Influence of $\mathrm{CS}_{2}$ upon the development of bacteria in the soil ${ }^{58}$

\begin{tabular}{c|r|r|r|r}
\hline TIME & CONTROL SOIL & 2 PER CENT CS & $\begin{array}{r}\text { 2 PER CENT CS } 2, \\
\text { EVAPORATED }\end{array}$ & $\begin{array}{r}\text { 2 PER CENT CS } \\
\text { EVAPORATED }+ \\
\text { 5 PER CENT FRESH } \\
\text { SOIL }\end{array}$ \\
\cline { 1 - 3 } days & & & & \\
1 & $11,496,000$ & $1,965,000$ & $2,260,000$ & $2,358,000$ \\
3 & $22,010,000$ & $23,975,000$ & $8,254,000$ & $12,480,000$ \\
5 & $20,635,000$ & $25,253,000$ & $27,416,000$ & $95,499,000$ \\
9 & $14,739,000$ & $36,651,000$ & $61,904,000$ & $\ldots \ldots \ldots$ \\
13 & $16,115,000$ & $90,473,000$ & $98,850,000$ & $80,420,000$ \\
21 & $19,508,000$ & $60,149,000$ & $71,257,000$ & $52,495,000$ \\
25 & $18,272,000$ & $68,276,000$ & $86,483,000$ & $64,570,000$ \\
29 & $15,346,000$ & $90,645,000$ & $84,272,000$ & $38,495,000$ \\
60 & $12,372,000$ & $58,101,000$ & $60,000,000$ & $30,000,000$ \\
\hline
\end{tabular}

TABLE 85

Numbers of bacteria in untreated and partially sterilized soils ${ }^{63}$

\begin{tabular}{|c|c|c|c|c|c|}
\hline & \multirow[t]{2}{*}{ AT START } & $\begin{array}{l}\text { END OF FIRST } \\
\text { PERIOD }\end{array}$ & $\begin{array}{l}\text { END OF SECOND } \\
\text { PERIOD }\end{array}$ & $\begin{array}{c}\text { END OF THIRD } \\
\text { PERIOD }\end{array}$ & \multirow[t]{2}{*}{$\begin{array}{l}\text { END OF FOURTH } \\
\text { PERIOD }\end{array}$} \\
\hline & & 16 days & 30 days & 74 days & \\
\hline Untreated..... & 27 millions & 10 millions & 10 millions & 45 millions & \\
\hline \multirow[t]{2}{*}{$\mathrm{CS}_{2} \ldots \ldots \ldots \ldots$} & \multirow[t]{2}{*}{2 millions } & 17 millions & 53 millions & 121 millions & \\
\hline & & 15 days & 110 days & 170 days & 200 days \\
\hline \multirow{3}{*}{$\begin{array}{l}\text { Untreated..... } \\
65^{\circ} \mathrm{C} \ldots \ldots \ldots\end{array}$} & \multirow{3}{*}{$\begin{array}{l}13 \text { millions } \\
13 \text { millions }\end{array}$} & 9 millions & 4 millions & 9 millions & 12 millions \\
\hline & & 21 millions & 37 millions & 45 millions & 60 millions \\
\hline & & 40 days & 100 days & 160 days & 500 days \\
\hline \multirow{2}{*}{$\begin{array}{l}\text { Untreated ..... } \\
\text { Toluene ...... }\end{array}$} & \multirow{2}{*}{$\begin{array}{r}11 \text { millions } \\
2 \text { millions }\end{array}$} & 16 millions & 9 millions & 13 millions & 6 millions \\
\hline & & 43 millions & 41 millions & 43 millions & 18 millions \\
\hline
\end{tabular}

The original idea of $\mathrm{Koch}^{57}$ that increased crop growth due to the application of the disinfectant is a result of a direct stimulation of the plant by traces of the disinfectant or its decomposition products

67 Koch, 1899 (p. 750). 
found various adherents. Fred ${ }^{58}$ found that proper concentrations of ether, $\mathrm{CS}_{2}$ and $\mathrm{CuSO}_{4}$ have a stimulative effect upon the growth of lower microorganisms; even nitrification, which was at first decreased, was later stimulated. $\mathrm{CS}_{2}$, in dilute solutions, was found to stimulate growth of plants, including that of fungi..$^{59}$ According to Hüne, ${ }^{60}$ small doses of poisons may be directly stimulative to bacterial development.

The influence of antiseptics upon the development of microorganisms in the soil, namely those that can be determined by the plate method, is brought out by tables 84 and 85 . A large increase in soluble nitrogen, as a result of treatment with $\mathrm{CS}_{2}$, is found both in the inoculated

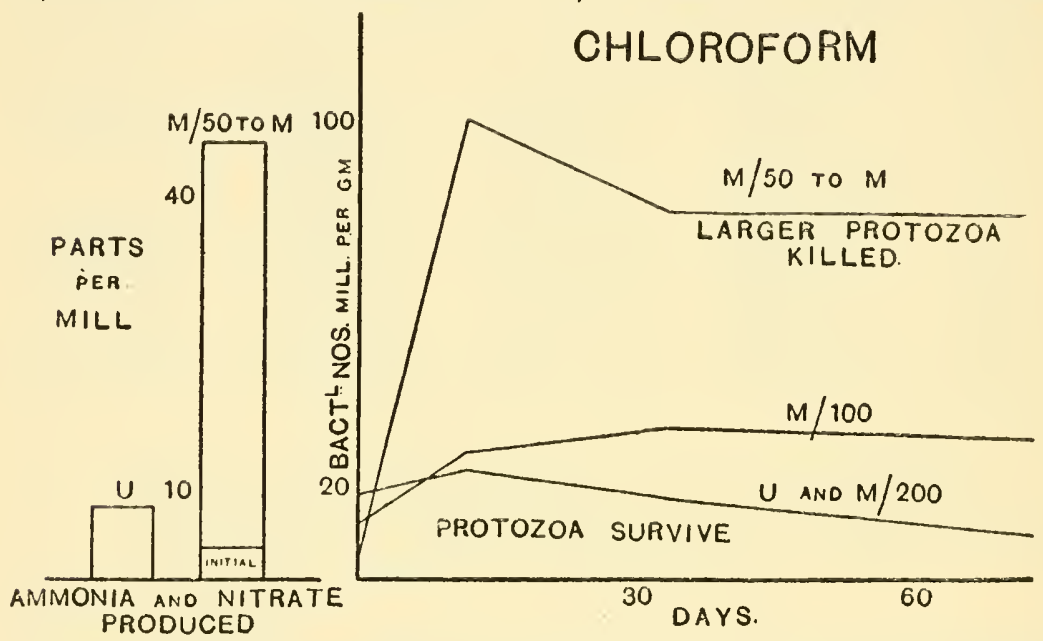

Fig. 67. Influence of different amounts of chloroform upon the bacteria, protozoa and available nitrogen in the soil (from Buddin).

and uninoculated soils. The ammonia content of the soil was found to follow the curve of bacterial growth and later giving rise to nitrates. $\mathrm{CS}_{2}$ did not act alike on all soils and toward all crops.

Russell and associates (figs. 67 and 68 ) attempted to correlate the de-

${ }^{88}$ Fred, E. B. Über die Beschleunigung der Lebenstïtigkeit höherer und niederer Pflanzen durch kleine Giftmengen. Centrbl. Bakt. II, 31: 185-245. 1912.

${ }^{59}$ Oldenbusch, C. Stimulation of plants by $\mathrm{CS}_{2}$. Bull. Torrey. Bot. Club., 49: 375-390. 1922 .

${ }^{80} \mathrm{Hüne}$, Dr. Die begünstigende Reizwirkung kleinster Mengen von Bakteriengiften auf die Bakterienvermehrung. Centrbl. Bakt. I, Orig., 48: 135140. 1907. 
struction of protozoa following partial sterilization with the increase in the numbers of bacteria and their activities and subsequently soil
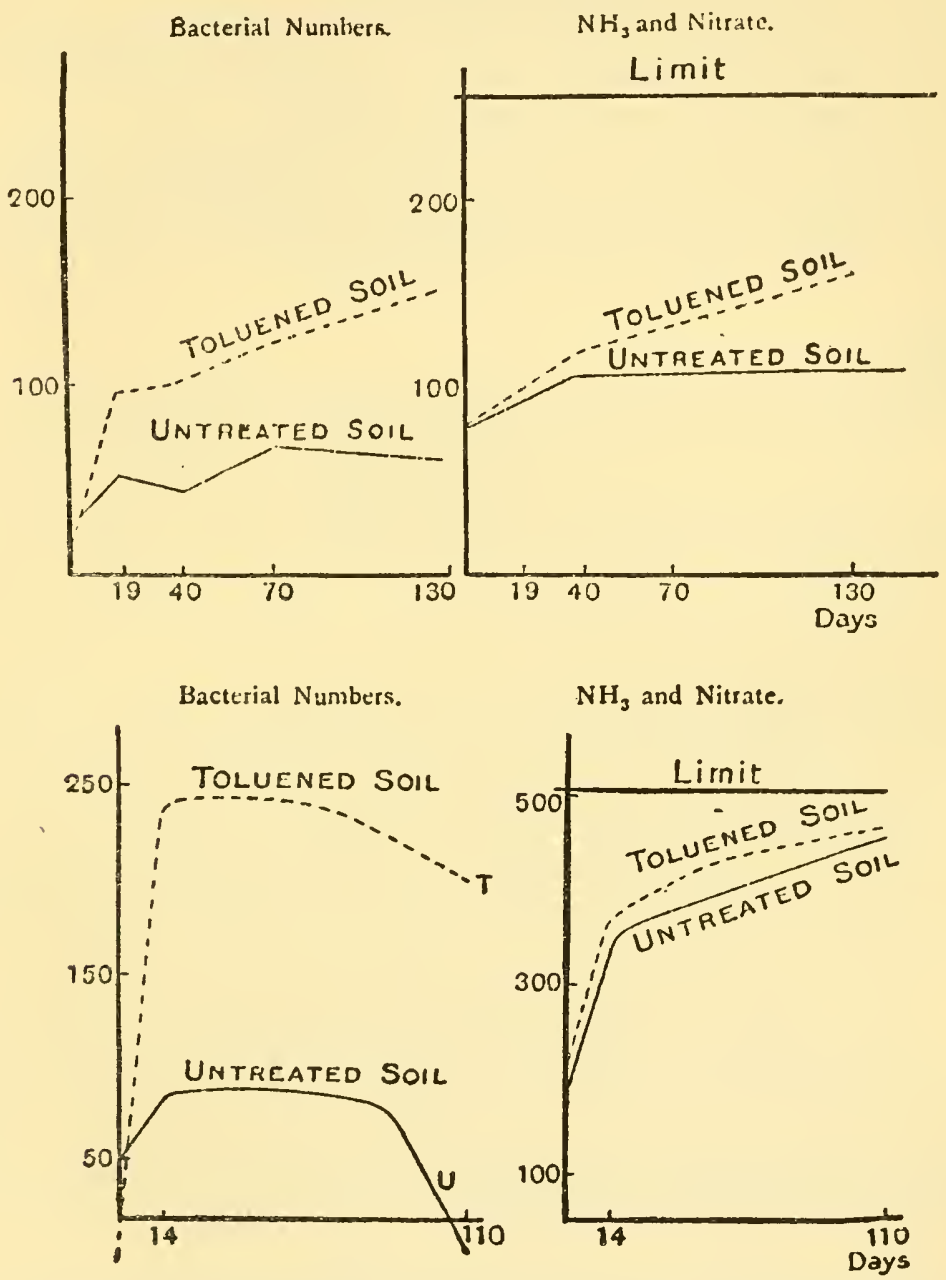

Fig. 68. Influenee of toluene upon numbers of bacteria and available nitrogen (ammonia and nitrate) formed in the soil; upper figures from a soil in which small amounts of available nitrogen were initially present; lower figures from a soil in which large amounts of available nitrogen were initially present (after Russell).

fertility. They suggested that the protozoa are responsible for lieeping down bacterial numbers in an untreated soil and, therefore, affect 
adversely the production of plant food. The partial sterilization of the soil results in the destruction of protozoa, thus removing the agent injurious to normal bacterial development.

The various theories and hypotheses that have been proposed in explanation of the favorable influence of partial sterilization of soil upon its fertility can be summarized as follows:

1. Direct stimulation theory. Plant roots and microorganisms may be stimulated directly by small quantities of antiseptics $;{ }^{61}$ it has been suggested ${ }^{62}$ that the latter are used directly as a nutrient by microorganisms.

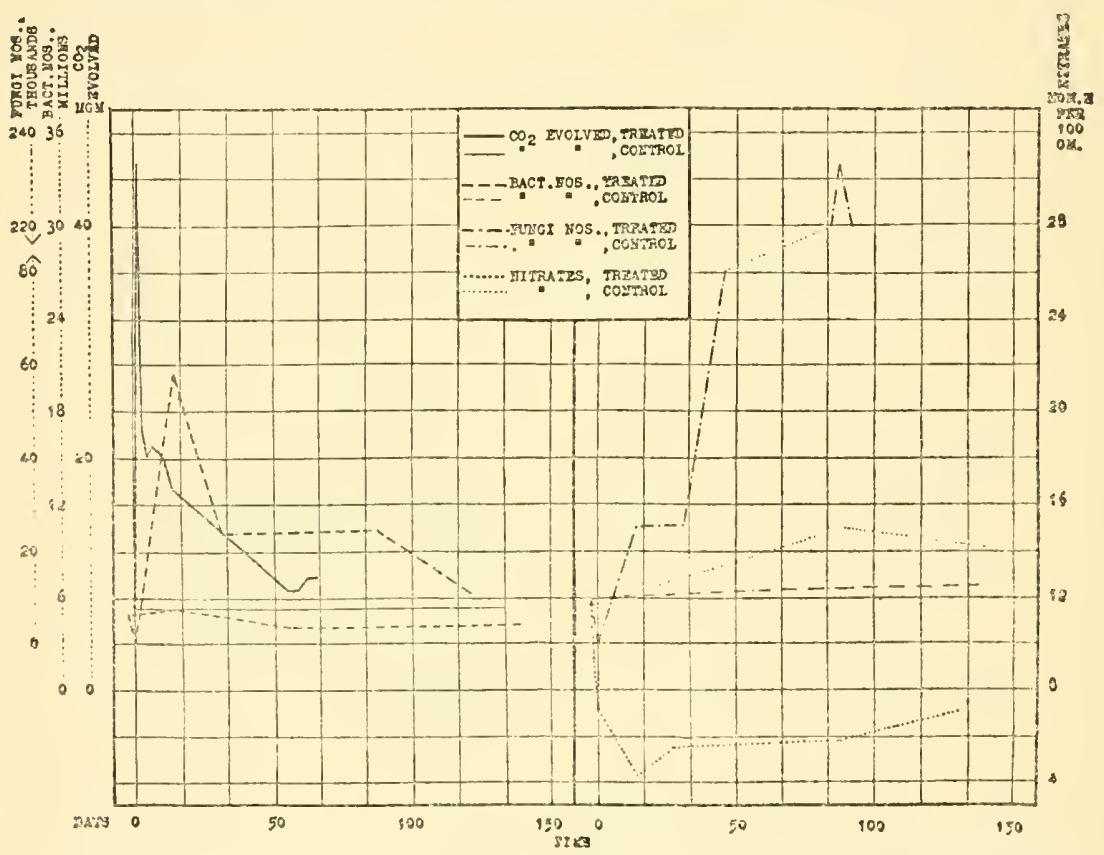

FIG. 69. Influence of $\mathrm{CS}_{2}$ upon the numbers and activities of microorganisms in the soil (from Waksman and Starkey).

2. Indirect stimulation of bacteria. The organic matter in the soil may be modified in such a manner, as a result of partial sterilization, as to make it more

${ }^{61}$ Maassen, A., and Behn, H. Das Verhalten der Bakterien, insbesondere der Bodenbakterien gegenüber dem Schwefelkohlenstoff, und die Beeinfluszung des Pflanzenwachstums durch eine Schwefelkohlenstoffbehandlung des Bodens. Mitt. K. Biol. Anst. Land. u. Forstwirt., 12: 285-338. 1924.

${ }_{62}$ Matthews, A. Partial sterilization of soil by antiseptics. Jour. Agr. Sci., $14: 1-5.1924$. 
available for bacterial action; this may be due either to the removal of the fats, to greater solubility of carbohydrates, nitrogen compounds, or phosphates; to the killing of worms, nematodes, protozoa, algae, fungi, which are then decomposed by the bacteria; or to all these combined.

3. Microbiological balance or equilibrium. Partial sterilization produces a change in the balance between the bacterial flora and the other groups of organisms, such as the fungi and actinomyces.

4. The protozoa are responsible for the limitation of bacteria in the soil; their removal by partial sterilization leads to increased bacterial development, greater decomposition of organic matter and, therefore, improved soil fertility.

5. Toxin theory. The soil is believed to contain toxins of biological origin. Partial sterilization of soil leads to their destruction, hence to improved fertility.

6. Destruction of fungi and bacteria which are causative agents of plant diseases. The repeated growth, year after year, of the same crop leads to an accumulation of fungi and insects injurious to the particular crop. Partial sterilization of soil brings about the destruction of these pests.

7. Increased nitrogen-fixation. Partial sterilization of soil is believed to render a greater amount of energy available to the nitrogen-fixing bacteria. Koch, however, maintains that nitrogen fixation by bacteria is decreased by partial sterilization.

Only three of these theories need be discussed at greater length.

Protozoan theory. The "protozoan theory of soil fertility" advanced by Russell and Hutchinson ${ }^{63}$ has met with severe criticisms. According to this theory, the number of bacteria found in the soil, at any given time, is not merely a function of environmental soil conditions, but depends on the interrelationship between the bacteria and the protozoa; partial sterilization does not bring about an improvement in the bacterial flora but makes the soil a better medium for the growth of bacteria, by eliminating the detrimental factor.

It was suggested ${ }^{64}$ that the destruction of spores of disease producing fungi and bacteria have more to do with the final increase in productiveness of heated soils than either the destruction of bacteria-loving protozoa or the increase in soluble plant food. The increase in ammonia formation in partially sterilized soils was believed to be due to fungi. ${ }^{65}$

${ }^{63}$ Russell and Hutchinson, 1909-1912 (p. 311).

${ }^{64}$ Bolley, H. L. Interpretation of results in experiments upon cereal cropping methods after soil sterilization. Science, 33: 229-234. 1911; also 32: 529-541. 1910; 38: 48-50, 249-259. 1913; N. D. Agr. Exp. Sta. Bul. 107. 1913; Jachschewski, A. On the causes which determine infertility of the soil and loss of crops. Khoziastvo, Z. 1912, 1103-1108 (Intern. Inst. Agr. Bul. Bur. Agr. Inst. Pl. Dis., 3: 2528).

${ }^{65}$ Kopeloff, N., and Coleman, D. A review of investigations in soil protozoa and soil sterilization. Soil Sci., 3: 197-269. 1917. 
The fact that fungi grow readily on soils subjected to dry or moist heat ${ }^{66}$ would tend to add further weight to this idea. The abundant

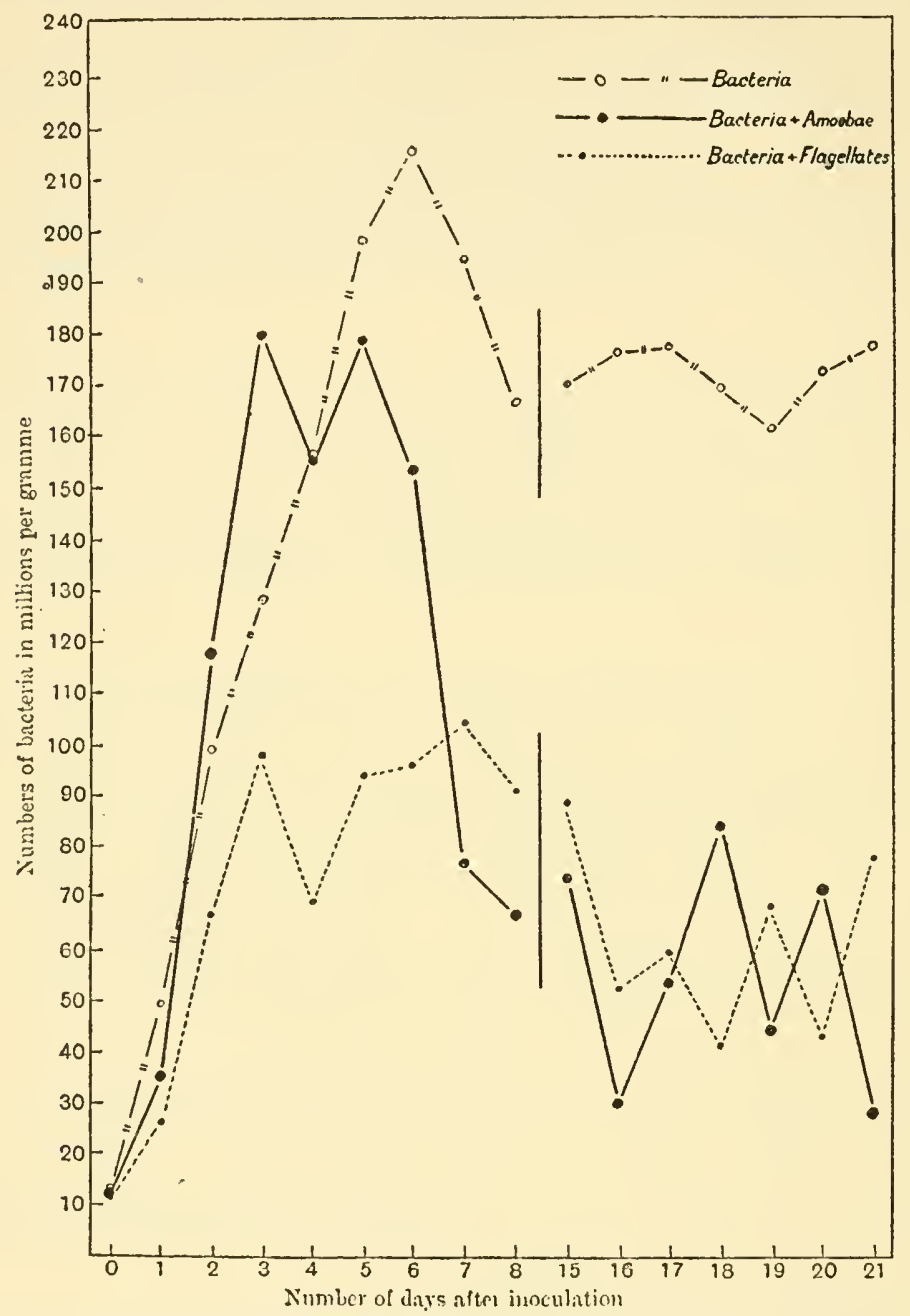

FIG. 70. Action of protozoa upon the development of bacteria (from Cutler)

growth of fungi in soils treated with disinfectants, after a certain period has elapsed, is also quite marked. Figures 70 and 71 show that ${ }^{66}$ Seaver and Clark, 1912 (p. 749). 
the inoculation of soil with protozoa may lead to a decided depression in the numbers of bacteria; ${ }^{67}$ however, so far no definite proof has been submitted that the introduction of protozoa actually depresses biochemical processes in the soil important to soil fertility; the meagre

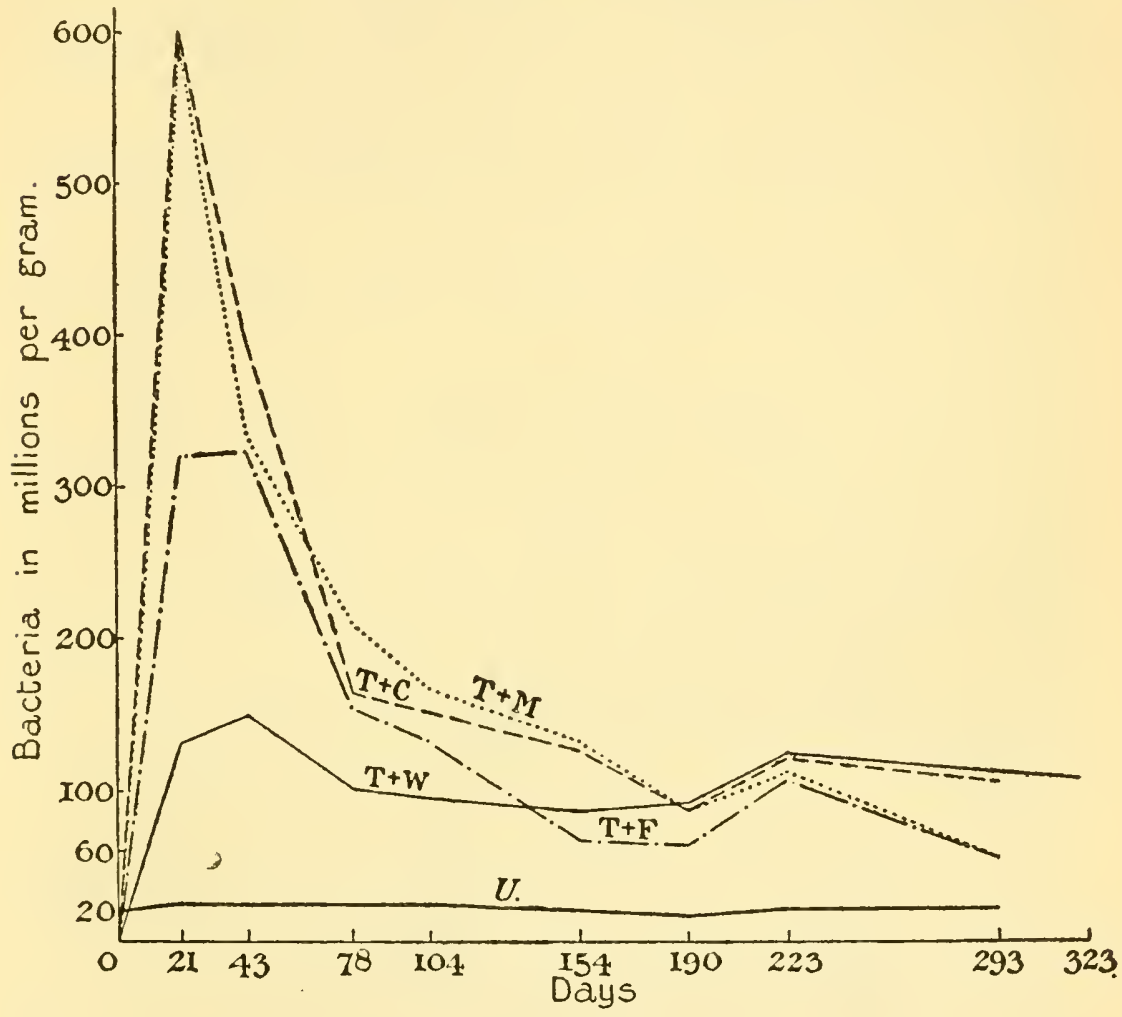

FIG. 71. Influence of protozoa upon the development of bacteria: $U=$ uninoculated; $T+W=$ toluene treated soil plus distilled water; $T+F=$ toluened soil plus hay-infusion, filtered through a Berkfeld filter; $T+C=$ toluened soil plus ciliates in hay-infusion; $T+M=$ toluened soil plus mixed culture of protozoa and bacteria in hay-infusion (from Goodey).

results available seem to point to the contrary, as shown elsewhere (p. 338).

Agricere and Bacteriotoxin theories. The results of Schreiner, Shorey and their associates seemed to indicate that the soil harbors certain

${ }^{67}$ Cutler, 1923 (p. 32). 
substances (dihydroxy-stearic acid, etc.) which are distinctly injurious to crop growth. Livingston ${ }^{68}$ regards the general hypothesis that unproductiveness of agricultural soils as due frequently to soil toxins as well established and generally accepted.

According to Greig-Smith, ${ }^{69}$ no one phenomenon can explain the cause of the enhanced fertility of soils treated with volatile antiseptics. Bacteria growing in any culture medium produce injurious or toxic products, which check and inhibit their further growth. These toxins may be in the nature of lysins, acids, accumulated by-products, etc. Soil extract filtered through porcelain was found to have a destructive influence upon Bact. prodigiosum, while the same extract heated and treated by sunlight or allowed to stand in aqueous solution stimulated bacterial growth.

Greig-Smith considered that, in addition to the toxic substances, the soil contains a mixture of fatty substances (agricere) derived from plant material. These fats are not readily acted upon by microorganisms and finally cover and inpregnate the residual organic matter. Volatile antiseptics, being fat solvents, dissolve the agricere, which is either carried toward the surface of the soil or is segregated upon the points and angles of the individual soil particles. This was believed to be the cause of the favorable influence of the action of antiseptics upon bacterial growth and activities. When the soil fats are removed or segregated, the soluble matter diffuses out more readily from the soil particles and serves as a source of food for microorganisms. ${ }^{70}$

Treatment with volatile antiseptics was found to induce an increased growth of bacteria in soils in which the protozoa have been destroyed by moist or dry heat at $65^{\circ}$ to $75^{\circ} \mathrm{C}$. It was suggested, therefore, that two factors influence bacterial activities in the soil, one of which is a bacteriotoxin and which is destroyed by heat, and the other a soil fat or wax, which is dissolved by volatile antiseptics. According to Hutchinson, ${ }^{70 a}$ the formation of toxic substances depends upon the existence of anaerobic conditions due to water logging; when organic

${ }^{68}$ Livingston, B. E. Palladin's Plant Physiology. 1st Ed. 1918, p. 93.

${ }^{69}$ Greig-Smith, R. The agricere and the bacteriotoxins of the soil. Centrbl. Bakt. I., 34: 224-226. 1912; Proc. Linn. Soc. N. S. Wales., 36: 679-699. 1911.

${ }^{70}$ Greig-Smith, R. Contributions to our knowledge of soil fertility. Proc. Linn. Soc. N. S. Wales, 35: 808-822. 1910; 36: 679-699. 1911; 37: 238-243, 655672. 1912; 38: 725-746. 1913; 39: 839-850. 1914; 40: 631-645, 724-733. 1915; 42: 162-166. 1917; 43: 142-190. 1918.

${ }^{70 a}$ Hutchinson, C. M. Causes of infertility in soils in relation to bacterial action. Agr. Jour. India, 21: 125-133. 1926. 
matter is decomposed under these conditions, waxes and slimes are formed which coat the soil particle tending to block up its pores, thus interfering with aeration and drainage and protecting the organic particles from the further action of the bacteria. Greig-Smith admitter that protozoa may play a part in checking the multiplication of bacteria in the soil, but they were not believed to be alone responsible for this limitation. These results on the formation of a bacteriotoxin in the soil were not confirmed by other investigators. ${ }^{71}$ However, certain metabolic products are formed by at least some soil microorganisms, which are either toxic to themselves or to other organisms. The removal, destruction or modification of these products may bring about an increased activity of the microorganisms concerned.

Treatment of soil by heat or antiseptics results in a number of very complex processes, which cannot be explained by a protozoan theory, toxin theory, presence of soil waxes, etc., although all of these may play a certain part in limiting bacterial development. A series of changes are brought about which lead to an increase in the soluble soil organic matter, ${ }^{72}$ and to a modification of the concentration of the soil solution and of the soil reaction. The physical condition (permeability, capillarity, cohesion, surface tension) of the soil is also modified by the treatment, particularly the colloidal properties of the soil. ${ }^{72}$ Quantities of toluol and $\mathrm{CS}_{2}$, insufficient to modify the number and types of protozoa in the soil, were found ${ }^{73}$ to exert a stimulative effect upon bacterial activities in the soil.

Destruction of selective groups of organisms. Different soil organisms are not affected alike by disinfectants. ${ }^{74}$ Some are injured but not completely destroyed. The degree of injury also depends upon the concentration and length of action of the disinfectant, on the soil moisture and aeration conditions. The gelatin liquefying bacteria (mostly spore-formers) are not affected at all or to only a very limited extent, while the actinomyces may be considerably reduced; the same is true of other aerobic, especially non-spore-forming bacteria. When

${ }^{71}$ Hutchinson, H. B., and Thaysen, A. C. The non-persistence of bacteriotoxins in soil. Jour. Agr. Sci., 9: 43-62. 1918.

72 Pickering, 1910, (p. 748).

${ }_{72 a}$ Taylor, E. McK., and Burns, A. C. The effect of the summer fallow upon soil protozoa in Egypt. Egypt. Min. Agr. Tech. Sei. Serv. Bul. 52. 1924.

${ }^{73}$ Gainey, P. L. The effect of toluol and carbon bisulfide upon the microflora and fauna of the soil. Mo. Bot. Gard. Ann. Rpt., 23: 147-169. 1912.

${ }^{74}$ Hiltner and Störmer, 1903 (p. 12). 
the disinfectant is evaporated, there is a rapid increase in the non-liquefying forms; the activity of the actinomyces and gelatin liquefying bacteria lags very much behind. After the maximum of bacterial activities is attained, a gradual decrease follows and within about a year the flora of the treated soil has reached the level of the untreated soil.

The most active bacteria, after partial sterilization, were found ${ }^{75}$ to be Bac. butyricus, Bac. mycoides, Bac.megatherium, Bac. arborescens, Microc. ochraceus luteus and, to a less extent, Bact. fluorescens liquefaciens.

Various other investigators found ${ }^{76}$ actinomyces to be decidedly injured by treatment with $\mathrm{CS}_{2}$; the Bac. mycoides group was less affected, the spore formers being especially resistant. Legume bacteria (peas) and denitrifying bacteria (B. stutzeri) are rapidly killed, within two and a half hours; Bact. coli, Bact. prodigiosum, Bact. vulgare, Micr. ureae survive four hours. Staphylococci are very resistant, surviving forty-eight hours. Az. chroococcum survives in moist soil impregnated with fumes of $\mathrm{CS}_{2}$ for forty-eight hours, but it is destroyed after a longer treatment. The vegetative forms are destroyed in twentyfour hours, but the spores survive. A comparison of the influence of antiseptics upon bacteria and protozoa brought out the fact that smaller doses are required to kill the organisms in solution than in soil. ${ }^{77}$ The actual concentration of the antiseptic required to destroy amoebae in the soil is so large as to become unapplicable for purposes of partial sterilization, which has as its aim the destruction of the protozoa. Even 60 per cent $\mathrm{CS}_{2}$ did not kill the cysts of amoebae in the soil; the same was true of 15 per cent ether, 6 per cent chloroform, 25 per cent $\mathrm{CaO}, 30$ parts per thousand of chlorine water, less than 15 per cent toluol and 5 per cent CaS. Bacterial spores were found to be more resistant to the antiseptic than the cysts of amoebae. Active amoebae have a lower resistance than non-spore-forming bacteria, but the latter are more readily destroyed than cysts of amoebae. The data clid not justify any claim for an equilibrium between the numbers of amoebae and bacteria in the soil, the fluctuations of the numbers of

${ }^{75}$ Truffaut and Bezssonoff, 1920-21 (p. 37); Compt. Rend. Acad. Agr. France, 4: 1049-1057, 1030-103S. 1918.

${ }^{76}$ Maassen and Behn, 1924 (p. 756).

${ }^{77}$ Sewertzoff, L. B. The effect of some antiseptics on soil amoeboe in partially sterilized soils. Centrbl. Bakt. II, 65: 278-291. 1925; Ibid I. Or., 92: 151-158. 1924. 
amoebae and bacteria being due more to the successive drying and moistening of the test soil than to the action of amoebae on the bacteria.

Various plant pathogenic fungi, particularly organisms like Fusarium, Phytophthora, Melanospora, Rhizoctonia, Neocosmopora vasinfecta, Cladosporium scabies, Sclerotinia, Synchytrium, spores of rusts and smuts, are readily destroyed by volatile antiseptics, such as toluol, carbon bisulfide, or by heat. ${ }^{78}$ A soil containing over 100,000 fungi (spores and pieces of mycelium) per gram becomes practically free from fungi after treatment with steam or volatile antiseptics. Partial sterilization of soil can thus correct the condition of soil sickness caused by the development of certain specific plant pathogens. ${ }^{79}$

Hiltner $^{80}$ used a logical process of reasoning for demonstrating the destruction of fungi and actinomyces by antiseptics. When straw is applied to soil, the available nitrogen is stored away by the micrcorganisms to the detriment of higher plants. When the soil is treated with carbon bisulfide, during or after the addition of straw, the injurious influence is not observed. This is due to the fact that, with straw fertilization, the soil nitrogen is stored away chiefly by fungi and actinomyces. The disinfectant brings about an appreciable reduction in the number of these organisms, thus leaving the soil nitrogen available for higher plants. The favorable influence of $\mathrm{CS}_{2}$ is due not merely to the destruction of the organisms directly injurious to higher plants but also to the destruction of those which have a passive effect by storing away the soil nitrogen. Parasitic nematodes, such as Heterodera radicicola and various other worms, are also killed by heating the soil to $60^{\circ}$ to $90^{\circ} \mathrm{C}$. or by volatile antiseptics like $\mathrm{CS}_{2}$.

In view of the fact that actinomyces grow only very slowly and that the injurious factor in the soil is apparently something which is slowly growing, for an infection with 5 per cent of raw soil only begins to show a limiting action upon the fortieth day, Greig-Smith suggested that actinomyces are the limiting factor for bacterial activities. Not all the disinfectants, however, injure the actinomyces alike.

Interrelationships of microorganisms in the soil. If the soil could be

${ }^{78}$ Pathogenic fungi in soil and their treatment are described elsewhere; see P. Waget. Stérilization et désinfection du sol. La Revue d. prod. chimiques., 22: 655. 1920; 4: 115. 1921; 6: 183. 1921 .

${ }^{79}$ Kaserer, H. Versuche über Bodenmüdigkeit, besonders Leinmüdigkeit. Mitt. Wien. Hochschule f. Bodenkultur., 2: 375-410. 1913-14; Russell, E. J., and Petherbridge, F. R. Partial sterilization of soil for glasshouse work. Jour. Board Agr., 19. 1913, No. 10.

${ }^{80}$ Hiltner, 1908 (p. 41). 
imagined in an undisturbed condition, even for a very brief period of time, when the moisture content, aeration and temperature are not changed appreciably, one could speak of a condition of equilibrium. A microbiological equilibrium is distinctly different from that of a chemical reaction; in the latter, equilibrium is reached when the reaction goes both ways at an equal rate. A microbiological equilibrium in the soil may occur when the changes in the numbers and activities of the various groups of organisms are constant, possibly when as many new cells are formed in a given period as are destroyed in that time. An ideal condition of equilibrium may never be reached under field conditions more than for a few brief seconds. Under carefully controlled laboratory conditions, an equilibrium can be readily demonstrated, although it takes a long period of time before it is established.

When a soil is brought into the laboratory and kept at constant optimum moisture and temperature, there is at first a rise in the number of microorganisms, particularly if the soil has been partially or fully air dried before being placed in the incubator. The numbers of microorganisms and the rate of their activities, using the carbon dioxide production of the soil as an index, rise at first, soon drop rapidly and then more slowly, until the rate of change in the numbers and activities becomes constant.

But even under soil conditions, one may speak roughly of a certain equilibrium which becomes established between various groups of microorganisms, in the competition for the available energy, as shown by Hiltner and Störmer. The quantitative and qualitative composition of the soil flora and fauna were found to depend on the amount of energy and nitrogen available as well as the forms in which these are present in the soil. Any modification in the amount and form of energy and nitrogen brings about a modification not only in the number but also in the kind of microorganisms developing in the soil. Such modifications are brought about either by introducing fresh energy and nitrogen materials, air drying and cultivating of soil, partial sterilization, growth of plants, etc. These modifications can be looked upon as resulting in a shift in the condition of equilibrium.

The differences in the energy and nitrogen metabolism of the various soil microorganisms combined with their relative resistance to the action of disinfectants and their rates of multiplication are the basic factors governing the phenomenon of soil microbiological equilibrium.

The fungi consume a large amount of the available energy for structural purposes. They produce, therefore, large quantities of carbon 
dioxide and consume a great deal of nitrogen which they transform into microbial protein. They multiply rapidly when large quantities of energy material, like undecomposed organic matter, are added to the soil. They are also less resistant to the action of heat and antiseptics, but multiply very rapidly when reintroduced into partially sterilized soils. In such a case, the fungi, together with the bacteria, contribute the large amount of carbon dioxide formed, but they use up, for structural purposes, a part of the available nitrogen, which otherwise would remain in the soil as ammonia or nitrates.

The actinomyces develop very slowly in the soil, but are more resistant to the action of antiseptics like toluene and air drying of soil. When the soil is kept under uniform conditions and the flora gradually comes to an equilibrium, there is generally an increase in the proportion of actinomyces. When the equilibrium is shifted either by air drying of soil, volatile antiseptics, heat, etc., the actual number of actinomyces may actually diminish only slightly, but after the disinfectant is removed, or when moisture is added to the air dry soil, the actinomyces regain their previous numbers only very slowly. In comparison with the rapid increase of the bacteria, they diminish rapidly so that, two years after treatment with carbon bisulfide, they have not fully regained their former numbers. They do not use up much available nitrogen unless an available source of energy is introduced, but a number of them produce substances distinctly toxic to certain bacteria and fungi.

The bacteria are such an heterogeneous group of organisms that their activities cannot be classified together. The spore formers are very resistant to the treatments that result in partial sterilization of soil and may develop abundantly afterwards. The non-spore-forming bacteria are very sensitive to the treatment and are much diminished in numbers as a result of partial sterilization of soil; but soon afterwards they begin to multiply very rapidly and may bring up the numbers to hundreds of millions per gram. They use very little of the energy for structural purposes, and, therefore, consume only very little of the ammonia liberated from the decomposition of the proteins. The ammonia can thus accumulate in the soil, unless the fungi are reintroduced. The temporary suppression of the nitrifying bacteria tends to intensify the accumulation of the ammonia.

The soil protozoa probably also play some part in this group of processes. At least some of the protozoa consume bacteria as food, perhaps even large numbers of them; their selective feeding may affect only certain groups of bacteria. They may thus store away consider- 
able quantities of energy in their bodies. Their direct rôle in definite soil processes has not been established as yet, although some information seems to point to the fact that by removing the old bacterial cells, they may even exert a beneficial effect. The possibility that some protozoa exist as saprophytes in the soil, taking perhaps a part in the decomposition of the soil organic matter, is not exclucled.

We may conclude in the words of Miège ${ }^{81}$ that disinfection of soil still presents too many obscurities and uncertainties. It is certain that it cannot be presented as a panacea capable of remedying the ills from which agriculture suffers. A detailed review of the subject of soil disinfection, from theoretical and practical viewpoints, is given elsewhere. ${ }^{82}$

81 Miège, E. Les nouvelles théories de la fertilization des terres. Compt. Rend. Soc. Nat. Agr. France. March, 1914; also Compt. Rend. Acad. Sci., 164: 362-365. 1917.

${ }^{82}$ Vogt, E. Methoden der Schädlingsbekïmpfung. III. Bodendesinfektion. Centrbl. Bakt. II, 61: 323-356. 1924. 


\section{CHAPTER XXIX}

Influence of Envinonmental Conditions, Soll Treatment and Plant Growtit upon Microorganisus and Their

\section{Activities IN THE Soll}

When a soil is kept at the same moisture and temperature for a considerable period of time the microorganisms are found to reach in that soil a certain eondition of equilibrium, as pointed out elsewhere (p. 740). Winogradsky found that a change in the physical, ehemical and physico-chemieal condition of the soil brings about a change in the soil flora and fauna. The nature of the change depends upon the treatment. The addition of organic matter stimulates the development of certain specific groups capable of decomposing this partieular organic substance. A change in the soil reaction brought about by liming, by addition of sulfur or of ammoniuin salts favors the development of organisms more adapted to that soil reaction. An exeessive rainfall or reduction of pore space by mechanical means modifies the composition of the soil atmosphere and stimulates the development of anacrobic organisms in preference to aerobes. Changes in temperature and aeration also lead to ehanges in the quantitative and qualitative relationships of the soil population.

Whether we accept the idea of Winogradsky conccrning an autochtonous or native soil flora or not, one thing is certain that a soil, under a given set of conditions, can liberate a definite amount of energy, which is sufficient for the aetivities of a definite number of microorganisms, the qualitative composition of the population depending upon the soil conditions. Any change in these conditions will modify the population both quantitatively and qualitatively. The changes in the soil population may take place from day to day and even from hour to hour, under field conditions. ${ }^{1}$ Samples of soil taken at long intervals of time may not give, therefore, a true picture of the actual soil population and its changes in the soil. It is important to study the soil flora and fauna at frequent intervals and establish the interrelationships

' Cutler, D. W., and Crump, L. M. Daily periodicity in numbers of active soil flagellates. Ann. Appl. Biol., 7: 11-24. 1920; Cutler et al., 1923 (p. 32). 
between the different members of the population and between the latter and the environmental conditions.

Influence of organic matter upon the soil population. The addition of organic matter to the soil results in an increase in the numbers of various groups of soil microorganisms, of which some are directly concerned in the process of decomposition and some utilize the products formed by the first or attack the living or dead cells of those organisms themselves. Differences in the physical and chemical nature of the soil lead to the development of different groups of microorganisms as a result of addition of the same organic substance. The composition of the organic matter is of prime importance in this connection, modifying largely the nature of the organisms which develop in preference to others. The addition of soluble sugars to the soil brings about an extensive development of bacteria, primarily nitrogenfixing forms, such as Azotobacter, under aerobic conditions, and Clostridium under anaerobic conditions. The addition of substances rich in celluloses and poor in proteins, like cereal straw, stimulates largely the development of fungi; these decompose the celluloses and synthesize an extensive mycelium. This mycelium is immediately attacked by a large number of bacteria and actinomyces, leading to the formation of various products in addition to the synthesized cells of these microorganisms, which in their turn along with the residual products of the organic matter and the fungus mycelium, serve as food for protozoa and other invertebrate animals. One group of organisms carries on a certain process and then gives way to another group, which carries on the process further; both may be active at the same time. The activities of these organisms lead to a gradual increase in the carbon content of the residual organic matter, which has become changed into a colloidal mass more or less constant in composition and less readily available as a source of energy. Finally those microorganisms (largely the minute non-spore forming bacteria), which require only a small amount of energy and nutrients, continue to act in the colloidal film surrounding the soil particles, slowly breaking down the residual lignins and the resistant synthesized materials of a protein nature.

Engberding 2 found that the addition of 2 per cent cane sugar to a soil brought about an increase of 1000 to 1500 per cent in the number of bacteria developing upon Heyden agar; 0.5 per cent glucose brought about an increase of only 300 to 400 per cent. This increase was soon

${ }^{2}$ Engberding, 1909 (p. 14). 
followed by a decrease and in some cases there were no more bacteria in the treated soils than in the control soils after two and one-half months. The addition of glucose to the soil increases the number of bacteria but diminishes the number of fungi, both in the presence and absence of available nitrogen salts. ${ }^{3}$ It was suggested that this may be due to the formation of a dry pellicle of sugar on the surface of the soil preventing the admission of oxygen. Cellulose, however, greatly favors the development of fungi and also favorably influences the development of bacteria, especially in the presence of ammonium salts.

By direct microscopic examination, it can be demonstrated ${ }^{4}$ that the addition of glucose or mannite to the soil brings about a rapid development of nitrogen-fixing bacteria; starch stimulates the development of actinomyces, the addition of cellulose brings about an extensive development of fungi, the addition of dried blood leads to an abundant growth of spore forming bacteria. These results indicate that bacteria are favored primarily by lower carbohydrates and protein-rich substances, while the fungi and actinomyces are increased to a greater extent by celluloses and other polysaccharides and natural organic substances, especially those of a non-protein nature. The greater' stimulative effect of sugars upon bacteria than upon fungi and actinomyces is due to several factors:

1. The majority of bacteria prefer glucose to higher carbohydrates and their derivatives, while many fungi readily decompose celluloses, pentosans, etc.; many actinomyces are capable of attacking the lignins in the natural organic materials.

2. Bacteria generally require much less nitrogen for the synthesis of their cells per unit of glucose decomposed than do the fungi, which produce an abundant mycelium requiring considerable nitrogen.

3. Among the bacteria, the nitrogen-fixing forms readily utilize sugars as sources of energy without requiring any combined nitrogen.

The addition of glucose, in the presence of even a small amount of available nitrogen will, therefore, greatly stimulate the development of rapidly growing bacteria and may not affect at all the development of fungi, which require a large amount of available nitrogen, or of actinomyces, which develop only very slowly.

The stimulative effect of celluloses upon the development of fungi in the soil is especially marked under aerobic conditions and in the presence of available nitrogen. An extensive bacterial development

${ }^{3}$ Bazarevski, 1916 (p. 653).

${ }^{4}$ Winogradsky, 1924 (p. 10). 
may take place as a result of addition of celluloses to the soil. However, the true cellulose-decomposing bacteria are usually not determined, since they do not develop (as Spirochaeta cytophaga) on the ordinary plate. The actual increase in bacterial numbers resulting from addition of celluloses, as shown by the ordinary plate, may be a result of development of bacteria feeding upon synthesized or intermediary products, which result from the activities of fungi and aerobic cellulose decomposing bacteria. Under anaerobic conditions, however, it is the bacteria which are greatly stimulated by the addition of celluloses. Pure cellulose may even depress the development of bacteria which develop on the ordinary plate. ${ }^{5}$ Straw, however, stimulates the development of bacteria due to the presence of soluble carbohydrates and proteins.

The stimulative effect of proteins upon the development of sporeforming and non-spore forming bacteria has been recorded by a number of observers. Urea stimulates the development of various bacteria, especially certain non-spore forming rods.

Natural organic matter, like straw, plant stubble and green manures, as well as stable manures or organic fertilizers, consist of a number of various substances. The addition of this organic matter to the soil will stimulate the development of various groups of organisms. ${ }^{6}$ The greater the protein content of the organic materials added to the soil, the greater is the development of bacteria in preference to the fungi, as shown in table 86 .

It has been shown elsewhere (p. 517) that the addition of organic matter of a wide carbon-nitrogen ratio to the soil leads to a considerable reduction of the nitrate nitrogen, which results in a harmful effect upon plant growth. However, the following year a beneficial effect may be noted, ${ }^{7}$ due to the subsequent decomposition of the synthesized protoplasm. In some cases it has been claimed ${ }^{8}$ that the depressing effect of a straw mulch upon nitrate formation in the soil is due to the checked evaporation of the soil moisture which lowers the tempera-

${ }^{5}$ Hill, H. H. The effect of green manuring on soil nitrates under greenhouse conditions. Va. Polyt. Inst. Agr. Exp. Sta. Tech. Bul. 6, 121-153. 1915.

${ }^{6}$ Waksman, S. A., and Starkey, R. L. Influence of organic matter upon the development of fungi, actinomycetes and bacteria in the soil. Soil Sci., 17: 373-378. 1924.

${ }^{7}$ Bredemann, G. Untersuchungen über das Bakterien-Impfpräparat "Heyls concentrated nitrogen producer" (Composite Farmogerm). Landw. Jahrb., 43: 669-694. 1913.

${ }^{8}$ Albrecht, W. A., and Uhland, R. E. Nitrate accumulation under the straw mulch. Soil Sci., 20: 253-268. 1925. 
ture, prevents the normal air exchange, and creates an unfavorable environment for the formation of nitrates. No attempt, however, has been made to correlate these results with the microbiological activities of the vast soil population, outside of the nitrate-forming bacteria.

Influence of stable manure. The introduction of stable manure affects chiefly the following physical, chemical and biological conditions of the soil:

1. Soil temperature. The amount of temperature change depends upon the kind and amount of manure added. ${ }^{9}$ The addition of 25 tons of manure per acre may give an average increase of five degrees Centigrade in the temperature of the soil. ${ }^{10}$

TABLE 86

Influence of various substances upon the development of fungi and bacteria (including actinomyces) in a poor soil

\begin{tabular}{|c|c|c|c|}
\hline TREATMENT & INCUBATION & FUNGI & BACTERIA \\
\hline & days & & \\
\hline Untreated . . . . . . . . . . . . . & & 115,700 & $3,860,000$ \\
\hline 0.5 per cent glucose $\ldots \ldots \ldots \ldots \ldots \ldots$ & 2 & 82,000 & $22,200,000$ \\
\hline Cellulose, 1 per cent. ............ & 17 & 160,000 & $3,600,000$ \\
\hline Cellulose, 1 per cent +0.1 per cent & & & \\
\hline $\mathrm{NaNO}_{3} \ldots \ldots \ldots \ldots \ldots \ldots \ldots \ldots$ & 17 & $4,800,000$ & $4,800,000$ \\
\hline Straw, 1 per cent. . . . . . . . . . & 10 & 600,000 & $25,200,000$ \\
\hline Dried blood, 1 per cent. . . . . . & 12 & $1,438,300$ & $473,900,000$ \\
\hline
\end{tabular}

2. Soil moisture. A higher moisture holding capacity of the soil results from the addition of manure because of the accumulation of the soil organic matter. This affects bacterial activities favorably. ${ }^{11,12}$

3. Soil atmosphere. The rapid decomposition of manure added to the soil results in the formation of large quantities of $\mathrm{CO}_{2}$, which will tend to improve the physical condition of the soil giving it a crumbly appearance.

9 Wagner, F. Uber den Einflusz der Düngung mit organischen Substanzen auf die Bodentemperatur. Forsch. Agr. Phys., 5: 373-402. 1882 (Centrbl. Agr. Chem., 12: 150. 1883).

${ }_{10}$ Troop, J. The relation of barn manures to soil temperature. Ind. Agr. Exp. Sta. 8th Ann. Rpt., 18-19. 1895.

11 Engberding. D. Vergleichende Untersuchungen über die Bakterienzahl im Ackerboden in ihrer Abhängigkeit von äusseren Einflüssen. Centrbl. Bakt. II, 23: 569-642. 1909.

${ }^{12}$ King, W. E., and Doryland, C. J. T. The influence of depth of cultivation upon soil bacteria and their activities. Kans. Agr. Exp. Sta., Bul. 161, 211-242. 1909. 
4. Reaction and buffer content of the soil. The decomposition of available nitrogenous substances (in the liquid part of the urine) leading to the formation of ammonia and nitric acid, on the one hand, and the decomposition of the carbohydrates which may lead to formation of some organic acids, on the other, are important in this connection. The buffering properties of the residual "humus" are considerable.

5. The introduction of large quantities of readily available energy, as well as of nitrogen and minerals, will in itself greatly stimulate bacterial activities.

6. Finally the introduction of large quantities of living bacteria in the manure may result in a change of the qualitative composition of the soil flora and fauna.

A number of observations have been made concerning the increase in the numbers of bacteria in the soil as a result of addition of manure. The number of bacteria present in the soil was found ${ }^{13}$ to depend not only upon the manure added but also upon the cultural methods and crop grown. Fallowing of a soil leads to a decrease in numbers of bacteria as compared with the untreated soil, while manuring and fallowing lead to a decided increase. ${ }^{14}$ Chester $^{15}$ stated in 1898 that "the greater the organic matter or humus in the soil the greater, pari passu, is the number of bacteria."

The increase in bacterial numbers in the soil as a result of the addition of stable manure has been explained as due to the introduction of large numbers of bacteria with the manure; or due to the introduction of readily decomposable organic matter which stimulates bacterial activities. The fertilizing effect of the manure, aside from the quantities of fertilizer constituents contained within them, was believed to be due merely to the bacterial content of the manure. ${ }^{16,17}$ Frequent small applications of manure rather than large applications made at longer intervals were, therefore, recommended. The bacteria introduced into the soil, with small quantities of manure, were believed ${ }^{18}$ to be valuable in bringing about a more rapid decomposition of a green manure crop.

${ }^{13}$ Caron, A. Landwirtschaftlich-Bakteriologische Probleme. Landw. Vers. Sta., 45: 401-418. 1895 .

${ }^{14}$ Hiltner and Störmer, 1903 (p. 12).

${ }^{16}$ Chester, F. D. Soil bacteria and their relation to agriculture. Del. Agr. Exp. Sta. Bul. 40. 1898; The microbiological analysis of soils. Ibid. Bul. 65, 1904

${ }^{16}$ Hellström, P. On the effect of animal manures on marsh soils. (Exp. Sta. Rec., 11: 627. 1900.)

${ }^{17}$ Stoklasa, J. Über die Wirkung des Stallmistes. Chem. Centrbl. Jahrg., 78: (N. F. 11): 1702. 1907; also Stoklasa and Ernest, 1905 (p. 34).

${ }^{18}$ Lipman, J. G., MeLean, H. C., et al. The influence of mechanical composition of the soil on the availability of nitrate of soda and dried blood. N. J. Agr. Exp. Sta. Bul. 268. 1914. 
By comparing the influence of manure with inorganic fertilizers, Temple ${ }^{19}$ found that the addition of sodium nitrate to the soil increased the number of bacteria from $6,500,000$ to $8,480,000$; the addition of a complete mineral fertilizer increased these numbers to $11,540,000$, while stable manure brought about an increase to $23,310,000$, on the average of several determinations. This inerease continues over a considerable period. However, when the manure was previously sterilized, before addling it to the soil, the increase in the numbers of bacteria was even greater than in the case of unsterilized manure. Temple suggested, therefore, that the inerease in the numbers of bacteria as a result of addition of manure is due to the addition of the organic matter (available energy) rather than to the aetual introduction

TABLE 87

Influence of cow manure (10 tons per acre) upon the number of bacteria per gram of dry soil (1 gm. of manure contained 625,000,000 bacteria)

\begin{tabular}{c|r|r} 
DATE OF INCUBATION & No MANURE & MANURE \\
\hline days & & \\
2 & $2,227,000$ & $2,227,000$ \\
6 & $3,780,000$ & $6,000,000$ \\
13 & $6,540,000$ & $13,600,000$ \\
20 & $6,750,000$ & $11,690,000$ \\
28 & $7,700,000$ & $24,200,000$ \\
33 & $3,630,000$ & $6,330,000$ \\
40 & $4,270,000$ & $6,330,000$ \\
90 & $3,800,000$ & $7,850,000$ \\
\hline
\end{tabular}

of bacteria, as suggested by other investigators. A direct relationship between the organic matter added to the soil and the bacterial count was also observed. ${ }^{20}$ The work of Charpentier and Barthel (p. 450) on the decomposition of pure cellulose in the soil tends to confirm the observations that the fertilizing effect of manure is due entirely to its nitrogen and minerals and not to the bacteria introduced. No greater increase in the numbers of bacteria from the addition of stable manure with green manure to the soil was obtained than from the

${ }_{19}$ Temple, J. The influence of stall manure upon the bacterial flora of the soil. Ga. Agr. Exp. Sta. Bul. 95. 1911; Centrbl. Bakt. II, 34: 204-223. 1912.

${ }^{20}$ Briscoe, C. F., and Harned, H. H. Bacteriological effects of green manure. Miss. Agr. Exp. Sta. Bul. 168, 20 p. 1915. 
green manure itself. ${ }^{21}$ The kind of manure greatly influences the change in microbial activities. ${ }^{22}$

A close correlation was found between the bacterial numbers, ammonifying power, nitrifying power and crop production of a soil receiving no manure, 5 tons and 15 tons of manure per acre. ${ }^{23}$ The maximum activities were obtained from the addition of the largest amounts of manure; the increase from 20 inches of irrigation water was also most marked in soil receiving the largest quantity of manure. Table 88 shows that the addition of manure to the soil results in an immediate rapid increase in the numbers of microorganisms which reaches the maximum in a few days, and is soon followed by a precipitous decrease due to the rapid exhaustion of the available organic matter.

TABLE 88

Influence of manure on the development of bacteria in the soil as determined by the plate method ${ }^{23 a}$

(5 parts of manure per 100 parts of soil)

\begin{tabular}{c|c||c|c}
\hline INCUBATION & $\begin{array}{c}\text { TOTAL NUMBER OF } \\
\text { ORGANISMS }\end{array}$ & $\begin{array}{c}\text { TOTAL NUMBER OF } \\
\text { ORGANISMS }\end{array}$ \\
\cline { 1 - 3 } days & & days & \\
2 & $60,000,000$ & 21 & $50,000,000$ \\
3 & $80,000,000$ & 24 & $55,000,000$ \\
4 & $125,000,000$ & 29 & $85,000,000$ \\
6 & $235,000,000$ & 38 & $45,000,000$ \\
9 & $45,000,000$ & 58 & $95,000,000$ \\
13 & $43,000,000$ & 94 & $18,000,000$ \\
16 & $35,000,000$ & 123 & $20,000,000$ \\
\hline
\end{tabular}

Influence of temperature. Soil microorganisms are often divided in respect to temperature, into three groups:

1. Thermophilic, or those which require a high temperature for their development, usually $45^{\circ}$ to $65^{\circ} \mathrm{C}$.

${ }^{21}$ Lemmermanu, O., and Einecke, A. Utber die Wirkung einer Beigabe von Stalldünger zur Gründüngung. Mitt. deut. Landw. Gesell., 29 (Stück 52): 702-704. 1914.

${ }^{22}$ Emmerich, R., Graf zu Leiningen, W., and Loew, O. Uther schädliche Bakterientätigkeit im Boden und über Bodensäuberung. Centrbl. Bakt. Abt.. II, 29: 668-6S3. 1911.

${ }^{23}$ Greaves, J. E., and Carter, E. G. Influence of barnyard manure and water upon bacterial activities of the soil. Jour. Agr. Res., 6: 889-926. 1916; also 9: 293-341. 1917.

${ }^{238}$ Bright and Conn, 1919 (p. 41). 
2. Psychrophilic, or those which grow best at low temperatures (below $10^{\circ} \mathrm{C}$.).

3. Mesophilic, or those which grow best at $10^{\circ}$ to $45^{\circ} \mathrm{C}$.

Attention has already been called to certain processes carried on by thermophilic bacteria and fungi, notably the decomposition of cellulose (p. 439). It is doubtful whether any specific group of "psychrophilic" bacteria exists in the soil, these organisms being more "psychrotolerant." The presence of "thermophilic" groups of organisms is more definite, although a large number of these are probably also only "thermotolerant." Most of the thermophilic microorganisms have their optimum at 50 to $70^{\circ} \mathrm{C}$. with a minimum at $30^{\circ}$ to $40^{\circ}$ and a maximum at $70^{\circ}$ to $74^{\circ} \mathrm{C}$. Krohn even isolated bacteria having an optimum at $54^{\circ}$ and a maximum at $89^{\circ} \mathrm{C}$. The question of heating of hay called forth considerable discussion. Miehe found that by inoculating hay with a mixture of Bact. coli and Bac. calfactor or Oidium lactis and Bac. calfactor, heating of hay to $70^{\circ} \mathrm{C}$. could be brought about. At that temperature, chemical processes take place in the hay which lead to the formation of substances which ignite on contact with air. The biological nature of the process was denied by some investigators, who ascribed the phenomenon to the action of oxidative and reducing enzymes. ${ }^{23 b}$

Higher temperatures usually never become limiting factors in the activities of microorganisms in the soil, except in very hot climates, where only the surface layer may be affected. The destructive action in this case may be due more to the lack of moisture at the surface of the soil. Most microorganisms are able to withstand dryng and this process exerts a decided stimulating effect upon the organisms after the soil is remoistened, as shown elsewhere. The thermophilic bacteria are not only able to withstand high temperatures $\left(65^{\circ}\right.$ to $75^{\circ} \mathrm{C}$.), but they may take an active part in various processes of great importance in the soil (p. 157).

It is not necessarily essential for the soil to be heated up to $45^{\circ}$ to $50^{\circ} \mathrm{C}$., before these organisms become active. They act in the soil even at lower temperatures, but to a more limited extent. The peculiar ability of these organisms to grow at such high temperatures is due to their adaptation to environment. The temperature optimum of soil bacteria depends upon the soil from which they were isolated,

asb Tschirch, A. Die Lokalisation der chemischen Arbeit in der Pflanze. Mitt. Naturf. Gesell. Bern., 138-152. 1917; Laupper, G. Die neuesten Ergebnisse der Heubrandforschung. Landw. Jahrb. Schweiz., 34: 1-54. 1920. 
bacteria isolated from soils of colder climates being capable of growing at lower temperatures than bacteria isolated from soils of warm climates. $^{24}$

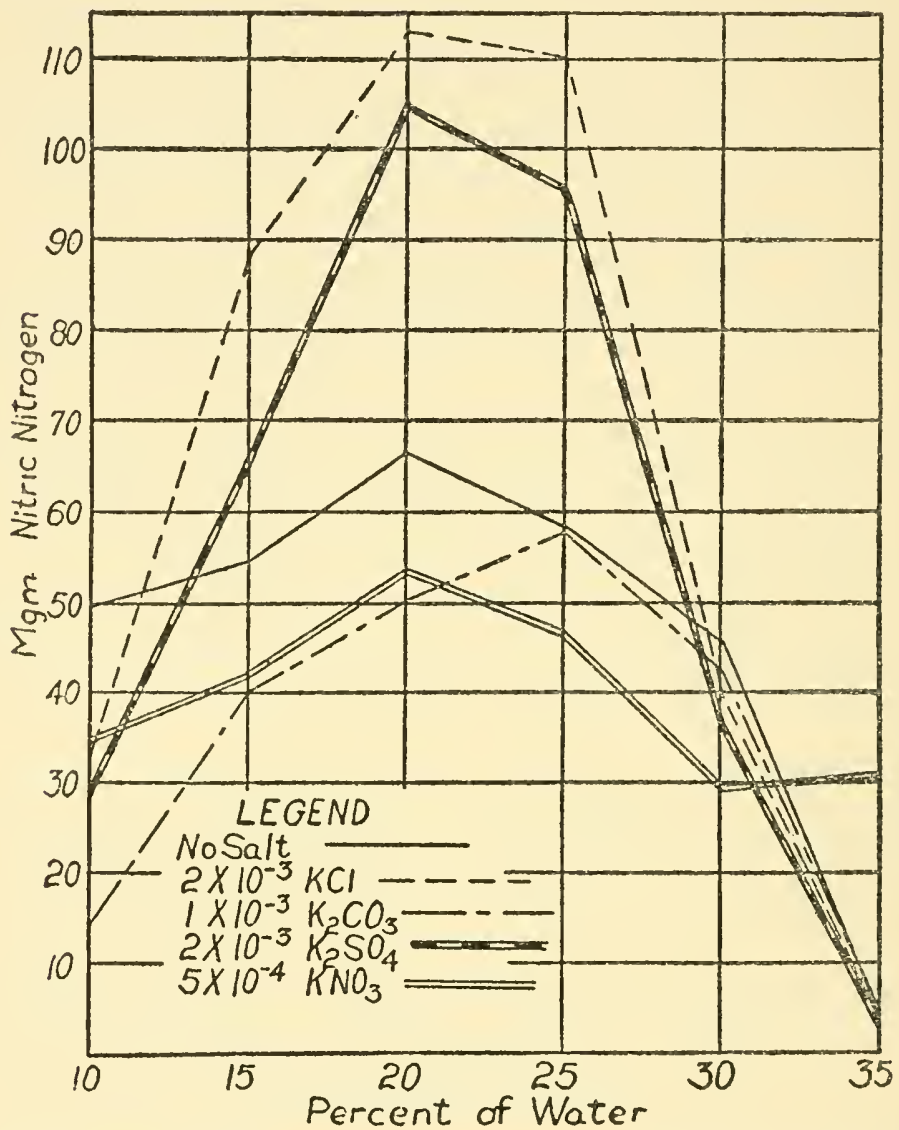

F1G. 72. Influence of moisture and potassium salts upon nitrate accumulation in the soil (from Greaves and Carter).

Ammonia formation takes place between $15^{\circ}$ and $60^{\circ} \mathrm{C}$., the thermophilic organisms being very active in this respect. Nitrification takes place at $15^{\circ}$ to $40^{\circ} \mathrm{C}$., the optimum being at $35^{\circ}$ or a little higher (fig.

${ }^{24}$ Mischustin, E. The analysis of temperature conditions of bacterial processes in the soil in connection with the adaptation of bacteria to climate. Potchvoviedienie., 20: 43-67. 1925. 
73). Nitrate reduction takes place at $15^{\circ}$ to $40^{\circ}$, with an optimum at $25^{\circ}$ to $30^{\circ}$; the same is true of aerobic and anaerobic nitrogen-fixation. ${ }^{25}$

Ordinary soil bacteria can withstand very low temperatures, even $40^{\circ} \mathrm{C}$. below zero. ${ }^{26}$ The action of frost upon the soil flora may be compared to that of partial sterilization. Prucha, ${ }^{27}$ for example, demonstrated that Bact. typhosum added to ice cream, kept constantly frozen, at first increases in numbers (due to the breaking up of the bacterial lumps), then gradually diminishes, but will no the completely destroyed, cven when the ice cream is frozen for over two years; when the ice cream is allowed to thaw out, an increase in numbers takes place. Freezing of soil or even very low temperatures may bring about a change in the balance of soil microorganisms; this may be followed by a great increase in numbers, especially of those organisms which develop on the plate. This increase may be due both to the breaking up of the clumps of bacteria and to an actual multiplication when the soil is warmed up again. Freezing of soil causes the coagulation of soil colloids; ${ }^{28,29}$ heating of soil also modifies its physical conditions. Grinding ${ }^{30}$ of soil particles also exerts an important influence upon the numbers and activities of soil microorganisms. ${ }^{31}$

One may compare the soil flora found in very cold climates with that of temperate zones. Omeliansky ${ }^{32}$ examined the soil obtained from the frozen ground of Northern Siberia $\left(72^{\circ} 15^{\prime}\right.$ latitude and $142^{\circ}$ longitude East) and found the microflora to consist of spore forming and

${ }^{25}$ Panganiban, E. H. Temperature as a factor in nitrogen changes in the soil. Jour. Amer. Soc. Agron., 17: 1-31. 1925.

${ }^{26}$ Harder, 1916 (p. 33).

${ }^{27}$ Prucha, M. J., and Brannon, J. M. Viability of Bacterium typhosum in ice cream. Jour. Bact., 11: 27-30. 1926.

${ }^{28}$ Czermak, W. Ein Beitrag zur Erkenntnis der Veränderungen der sog. physikalischen Bodeneigenschaften durch Frost, Hitze, und die Beigabe einiger Salze. Landw. Vers. Sta., 76: 75-116. 1912.

${ }^{29}$ Nolte, O., and Hahn, E. Die Wirkung des Frostes auf den Boden. Jour. Landw., 65: 75-81. 1917.

${ }^{30}$ Fred, E. B. Effect of grinding soil on the number of microorganisms. Science, 44: 282. 1916.

${ }^{31}$ Further information on the influence of low temperatures upon soil bacteria is given by Smith, E. F. Das Verhalten von Mikroorganismen gegen niedere Temperaturen. Centrbl. Bakt. II, 33: 335. 1912; Keith, S. C. Factors influencing the survival of bacteria at temperatures in the vicinity of the freezing point of water. Science, 37: 877. 1913.

${ }_{32}$ Omeliansky, V. L. Etude bactériologique du mammouth de Sanga Jourah et du sol adjacent. Arch. Sci. Biol. St. Petersburg, 16: No. 4. 1911. 
non-spore forming bacteria, sarcina, actinomyces and fungi commonly associated with processes of decomposition of organic matter. How-

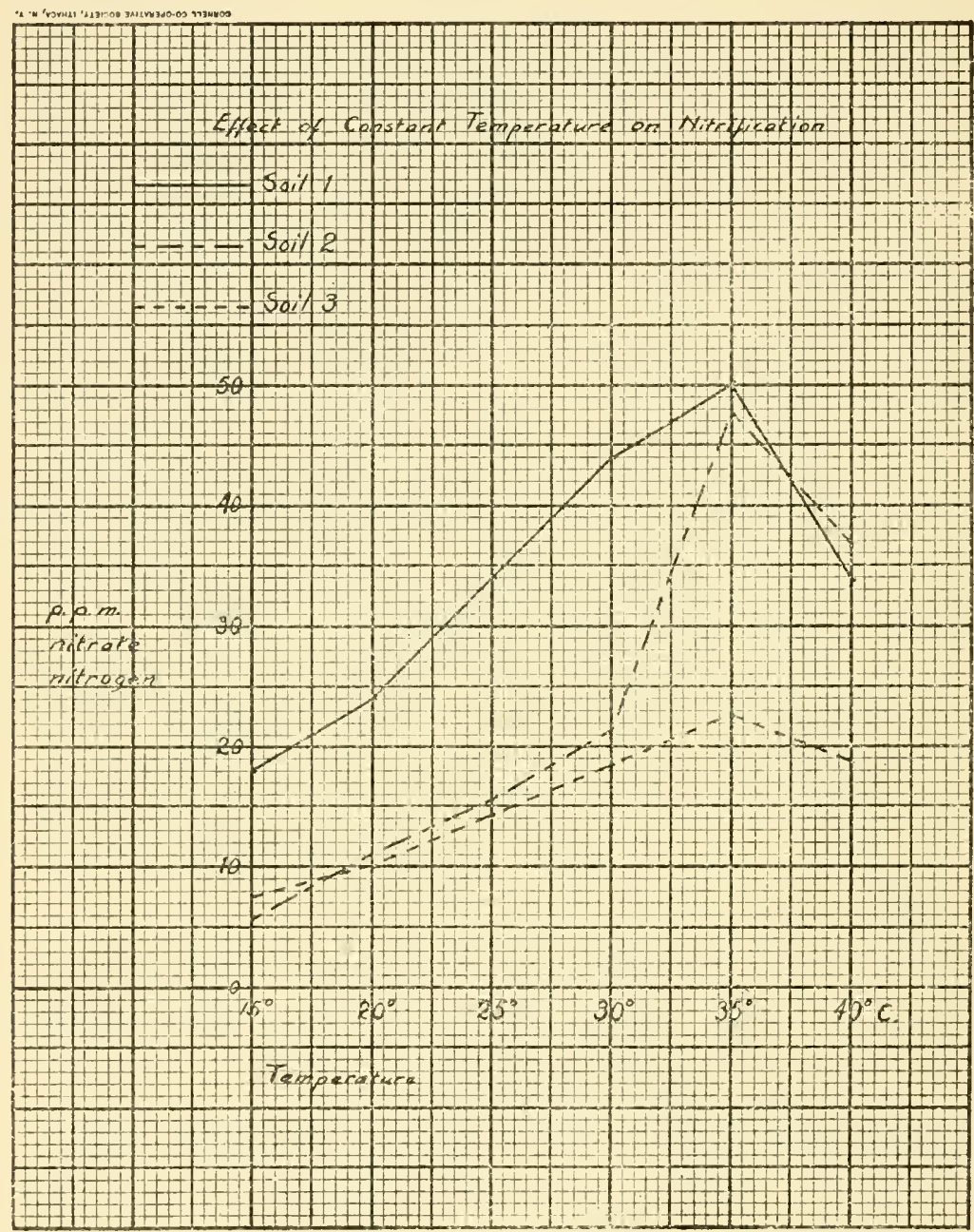

Fia. 73. Influence of temperature upon nitrification in the soil (from Panganiban).

ever, nitrifying, denitrifying, nitrogen-fixing, cellulose decomposing and pathogenic bacteria were absent. A careful study of the flora of the soil of northern Greenland and of the island of Disko near Cape 
York has been made by Barthel, ${ }^{33}$ who found, in addition to various aerobic and anaerobic, spore-forming and non-spore forming bacteria, also actinomyces and fungi (Mucors, Torulae). Nitrifying bacteria were present only in three out of fourteen soils of Disko, while Azotobacter was absent in all; Bac. amylobacter could not be demonstrated, although its presence originally was not excluded; Azotobacter and protozoa were found in the Greenland soils.

Various investigations have been made concerning the temperature relations of fungi, especially in relation to fruit rot in storage. The great majority of these fungi grow at $4.5^{\circ} \mathrm{C}$. and even develop slowly at $0^{\circ} \mathrm{C} .{ }^{34}$ The minimum temperatures of germination of fungi vary from $1^{\circ} \mathrm{C}$., for Monilia fructigena and Pen. digitatum, to $6^{\circ}$ to $9^{\circ}$ for Cephalothecium roseum..$^{35}$ Spores of Alternaria, Botrytis, Pen. expansum and Sclerotinia germinate slowly at zero; the spores of Ceph. roseum, Fusarium radicicola and others failed to germinate at zero but germinated slowly at $5^{\circ} \mathrm{C} .{ }^{36}$ Some fungi, like Pen. expansum, after starting growth at ordinary temperatures, were able to continue growth at zero. The rate of growth increases with rise in temperature up to a certain limit, being a direct function of $\left(t-t^{\circ}\right)$, where $t$ is the particular temperature and $t^{\circ}$ is the minimum temperature. ${ }^{37}$

It is of interest to call attention, in this connection, to the changes in the numbers and activities of microorganisms in the soil with the season of the year, due to changes in soil temperature and moisture, and introduction of available organic matter, soil aeration, etc. Russell and Appleyard ${ }^{38}$ found that there is very little activity in the soil during the winter months (November to March). Below $5^{\circ} \mathrm{C}$., the changes taking place in the soil are very slow; above that temperature, bacterial numbers, $\mathrm{CO}_{2}$ production, and nitrate accumulation all

${ }^{3}$ Barthel, 1922 (p. 149).

${ }^{34}$ Schneider-Orelli, O. Versuche über die Wachstumsbedingungen und Verbreitung der Fäulnispilze des Lagerobstes. Centrbl. Bakt. II, 32: 161-169. 1912.

${ }^{35}$ Ames, A. The temperature relations of some fungi causing storage rots. Phytopathol., 11: 19.1915.

${ }^{36}$ Brooks, C., and Cooley, J. S. Temperature relations of apple-rot fungi. Jour. Agr. Res., 8: 139-164. 1917.

${ }^{37}$ Brown, $W$. On the germination and growth of fungi at various temperatures and in various concentrations of oxygen and of carbon dioxide. Ann. Bot., 36: 257-283. 1922.

${ }^{38}$ Russell, E. J., and Appleyard, A. The influence of soil conditions on the decomposition of organic matter in the soil. Jour. Agr. Sci., 8: 385-417. 1917. 
increase, the curves agreeing closely with the temperature curve. Under favorable temperature conditions, rainfall becomes the limiting factor as well as the oxygen brought down by the rain. In general they have observed a period of spring activity, summer sluggishness, autumn activity, followed by winter inertness. Woitkiewicz ${ }^{39}$ also found bacterial numbers to be highest in spring and lowest in winter; the ratios of nitrogen-fixation in solution, in the seasons of winter,

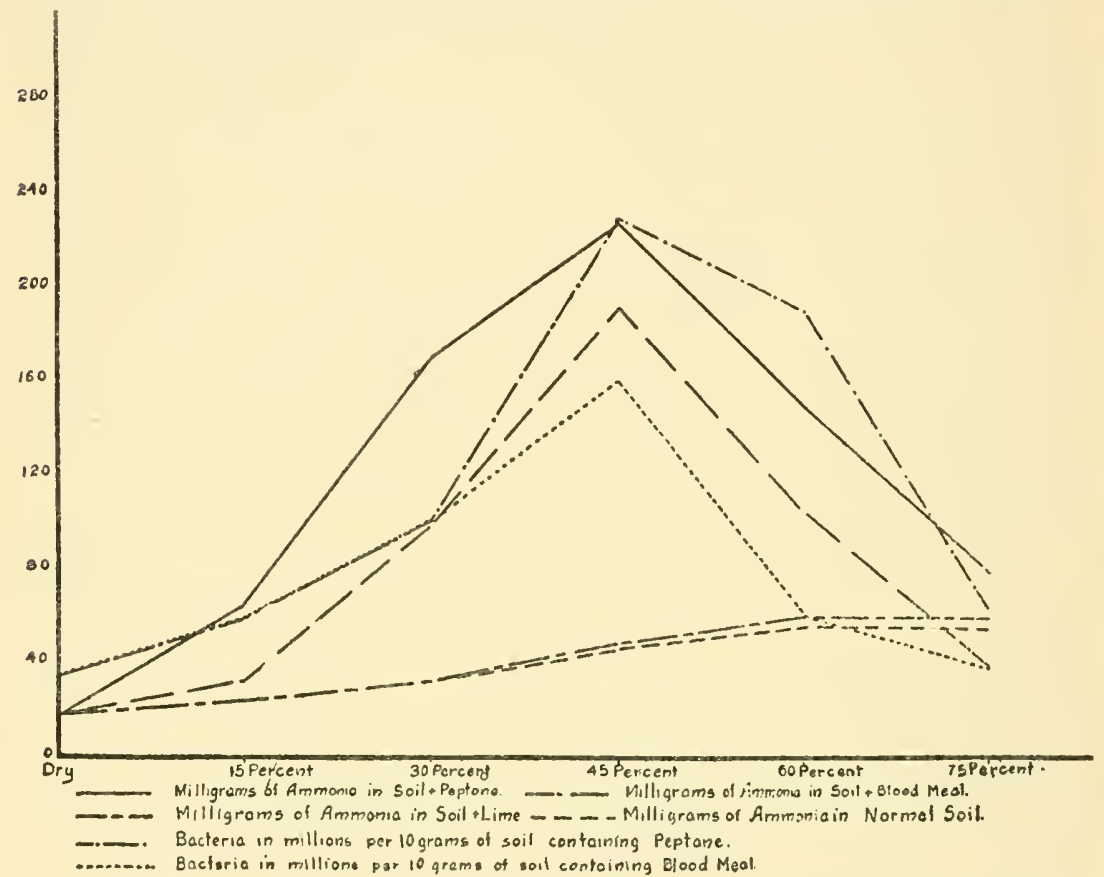

Fig. 74. Influence of moisture content of an Oregon soil upon ammonia formation and bacterial development from peptone and blood meal, 75 per cent moisture being that of full saturation (from Beckwith, Vass and Robinson).

spring, summer, and fall were as $1: 2: 2 \frac{2}{3}: 3$. This may be due to the greater abundance of available energy in the fall of the year. Denitrification was highest in fall and lowest in spring. By the use of the Remy method, it was ${ }^{40}$ found that the urea-decomposing, nitrifying, and

${ }^{39}$ Woitkiewicz, A. Beiträge zur bakteriologischen Bodenuntersuchungen. Centrbl. Bakt. II, 42: 254-261. 1914.

${ }^{40}$ Löhnis, F., and Sahaschnikoff, A. Uber die Zersetzung von Kalkstickstoff und Stickstoffkalk. Centrbl. Bakt. II, 20: 322-332. 1908. 
nitrogen-fixing powers of the soil reached a maximum in the spring, a minimum in summer and a maximum again in autumn. Similar results were obtained in the study of the influence of season of year on ammonia formation from peptone in solution. ${ }^{41}$ Maximum nitrifying power of the soil was found in spring. ${ }^{42}$ Lemmermann and Wichers, ${ }^{43}$ however, found that the season of year, outside of influence of temperature and other physical weathering conditions, has no appreciable influence on nitrification. The seasonal course of ammonia and nitrate formation, with all other factors alike, were found ${ }^{44}$ to be influenced primarily by the temperature course. The season of year, independent of temperature and other physical conditions, had no influence at all; the maximum activity is found in the spring and is due to outer influences, primarily change in temperature, but is independent of inner causes.

Influence of moisture. Some bacteria, like the nitrifying organisms, are very sensitive to drying, while others, like Azotobacter, can resist drying for a long period of time. The addition of moisture to a soil, which contains less water than is the optimum for biological activities, brings about an increase in numbers and activities of microorganisms. Most active nitrification takes place when the soil is allowed to become partially dry between the applications of water; ${ }^{45}$ a direct relationship was observed between the speed of nitrification and the moisture content of fallow soil. Every soil has an optimum for nitrification; higher or lower amounts of moisture reduce this optimum. Nitrification was found ${ }^{46}$ to be at its highest when the soil contains moisture

${ }^{41}$ Moll, R. Beiträge zur Biochemie des Bodens. Diss. Leipzig. 1909.

${ }^{42}$ Müntz, A., and Gaudechon, H. Le réveil de la terre. Compt. Rend. Acad. Sci., 1.54: 163-168. 1912; see also Lumière, A. Le rythme saisonnier et le réveil de la terre. Rev. Gen. Bot., 33: 545-557. 1921; Nitrate content of soil at different seasons of the year has been studied by Jensen, C. A. Seasonal nitrification as influenced by crops and tillage. U. S. Dept. Agr. Bur. Pl. Ind. Bul. 173. 1910; Leather, J. W. Water requirements of crops in India. Mem. Dept. Agr. India, Chem. ser., 1: 133-184. 1910; 205-281; 2: 63-140. 1912.

${ }^{43}$ Lemmermann, O., and Wichers, L. Über den periodischen Einflusz der Jahreszeit auf den Verlauf der Nitrifikation. Centrbl. Bakt. II, 63: 33-43. 1920.

${ }^{44}$ Schönbrunn, B. Ưber den zeitlichen Verlauf der Nitrifikation, unter besonderer Berüchsichtigung der Frage nach dem periodischen Einflusz der Jahreszeit. Centrbl. Bakt. II, 56: 545-565. 1922.

${ }^{45}$ Dehérain, P. P. Sur la production des nitrates dans la terre arable. Ann. Agron., 13: 241-261. 1887; also 22: 515-523. 1896.

${ }^{46}$ Fraps, G. S. The production of active nitrogen in the soil. Texas Agr. Exp. Sta. Bul. 106. 1908. 
equivalent to 55.6 per cent of its water-holding capacity. Excessive quantities of water were found to be much more injurious than too small quantities, due to the fact that in the first case soil conditions become anaerobic and denitrification sets in. The water requirements of the microorganisms vary considerably with the soil. Maximum nitrification in a loam soil occurred with 16 per cent water; by reducing the water content to 10 per cent or increasing to 26 per cent, nitrification was greatly retarded..$^{47}$

A definite favorable influence of increased moisture upon bacterial numbers was recorded. ${ }^{48}$ Moisture content of the soil was found ${ }^{49}$ to have a greater influence upon bacterial numbers than the temperature. By increasing the moisture content of the soil from 6.5 to 14 per cent, there was an increase in bacterial numbers from 10 to 16.4 millions per gram. By raising the moisture content of the soil from 6 to

TABLE 89

Influence of moisture upon the evolution of $\mathrm{CO}_{2}$ from different soils

\begin{tabular}{c|c||c|c}
\hline MOISTURE & $\begin{array}{c}\mathrm{CO}_{2} \text { EVOLUTION FROM } \\
\text { LOAM SOIL }\end{array}$ & $\begin{array}{c}\text { MOISTURE } \\
\text { per cent }\end{array}$ & $\begin{array}{c}\text { EvOLUTION FROM } \\
\text { HUMUS SOIL }\end{array}$ \\
\cline { 1 - 2 } 2.59 & 100 & per cent & \\
5.75 & 397 & 2.43 & 100 \\
8.49 & 554 & 5.43 & 207 \\
13.75 & 767 & 7.90 & 329 \\
& 12.68 & 254 \\
\hline
\end{tabular}

15 per cent, van Suchtelen obtained an increase in $\mathrm{CO}_{2}$ production from 19 to $208 \mathrm{mgm}$., which led him to conclude that the latter was a more sensitive method for studying changes in microbiological activities than determining numbers, as is shown elsewhere. Sixty to eighty per cent of the total water holding capacity of the soil is an optimum for bacterial activities. ${ }^{50}$ Excessive soil moisture reduces both the numbers of soil microorganisms and their activities. ${ }^{51}$ A definite relation between moisture content of different soils and bacterial activities

${ }^{47}$ Coleman, I. C. Untersuchungen über Nitrifikation. Centrbl. Bakt. II, 20: 401-420, 4S4-513. 1908 .

${ }^{48}$ Fischer, H., Lemmermann, A., Kappen, H., and Blanck, E. Bakteriologischchemische Untersuchungen. Landw. Jahrb., 38: 319-364. 1909.

${ }^{49}$ Engberding, 1909 (p. 771).

50 Löhnis, F. Untersuchungen äber den Verlauf der Stickstoffumsetzungen in der Ackererde. Mitt. landw. Inst. Leipzig, 7: 1-105. 1905.

b1 King and Doryland, 1909 (p. 771). 
has been demonstrated. ${ }^{52}$ At the lower limits of moisture, less water is required to start nitrification in sand than in clay soils; at the higher limits of moisture, less water is required to stop nitrification in sand than in clay. The optimum for the two soils varies; a rise above the optimum is more injurious than an equal fall below the optimum. Table 89 gives the results obtained ${ }^{53}$ on the influence of moisture upon the decomposition of organic matter in the soil as measured by $\mathrm{CO}_{2}$ production.

The nature of the soil is also found to be an important factor in modifying the influence of moisture upon microbiological activities in the soil, as shown in table 89 and in the following summary:54

\begin{tabular}{|c|c|c|c|}
\hline SOIL TYPE & $\begin{array}{l}\text { CARBON } \\
\text { CONTENT OF } \\
\text { SOIL }\end{array}$ & $\begin{array}{l}\mathrm{CO}_{2} \text { PRODUCED } \\
\text { IN } 24 \text { HODRS, } \\
\text { BY } 1 \text { KGM. OF } \\
\text { FRESH SOIL }\end{array}$ & $\begin{array}{l}\mathrm{CO}_{2} \text { PRODUCED } \\
\text { IN } 24 \text { HOURS } \\
\text { BY } 1 \text { KGM. OF } \\
\text { SOIL, BTERI- } \\
\text { LIZED AND } \\
\text { INOCULATED }\end{array}$ \\
\hline & per cent & mgm. & mgm. \\
\hline Tenacious clay soil............. & 1.68 & 8.2 & 14.0 \\
\hline 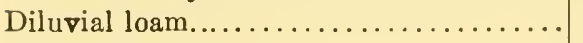 & 2.12 & 14.6 & 27.8 \\
\hline 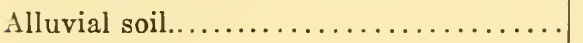 & 1.73 & 36.6 & 59.8 \\
\hline
\end{tabular}

Winogradsky ${ }^{55}$ found that, in the case of a soil with a moisture holding capacity of 48 per cent, 15 per cent moisture favored the development of aerobic bacteria to a depth of $23 \mathrm{~cm}$.; 19 per cent moisture to $18 \mathrm{~cm}$.; 21 per cent moisture caused the anaerobic bacteria to develop a few centimeters below the surface, while 24 per cent moisture and above made the soil decidedly favorable for anaerobic bacteria. Nitrogen fixation was found ${ }^{56}$ to be at a maximum near the point of saturation; even higher nitrogen fixation was recorded under anaerobic than under aerobic conditions. ${ }^{57}$ In some cases two maxima were recorded ${ }^{58,59}$ for

${ }^{2} 2$ Patterson, J. W., and Scott, P. R. The influence of soil moisture upon nitrification. Jour. Dept. Agr. Victoria, 10: 275-282. 1912.

${ }^{63}$ König, J., and Hasenbäumer, J. Die Bedeutung neuer Bodenforschungen für die Landwirtschaft. Landw. Jahrb., 55: 185-252. 1920.

${ }^{54}$ Stoklasa, 1926 (p. XIII).

55 Winogradsky, 1924 (p. 542).

${ }^{56}$ Traaen, A. E. Utber den Einflusz der Feuchtigkeit auf die Stickstoffumsetzungen im Erdboden. Centrbl. Bakt. II, 45: 119-135. 1916.

${ }^{67}$ Panganiban, 1925 (p. 777).

${ }^{88}$ Greaves and Carter, 1917 (p. 774).

${ }^{\circ}$ Lipman, C. B., and Sharp, L. T. Effect of moisture content of a sandy soil on its nitrogen fixing power. Bot. Gaz., 59: 402-406. 1915. 
nitrogen fixation, one under aerobic and the other under anaerobic conditions.

Ammonia formation from proteins was found ${ }^{60}$ to be at an optimum when the soil contained water equivalent to 60 per cent of its total moisture holding capacity. The formation of ammonia may also be very intensive even in saturated soils. ${ }^{61,62}$ This is due to active decomposition of proteins by anaerobic bacteria. The mechanism of ammonia formation is different of course under aerobic and anaerobic conditions. ${ }^{63}$

In arid regions, the application of irrigation water has ${ }^{64}$ a definite beneficial effect upon the number of organisms in fallow soils and upon the ammonifying and nitrifying capacities of both fallow and cropped soils. These activities result in an increase in soluble nitrogen. An excess of water may result in the washing out of the nitrates from the soil.

Greaves and Carter, ${ }^{60}$ using the Briggs formula for the moisture equivalent and the wilting and hygroscopic coefficients, found that the following equations represent the water requirements for maximum bacterial activities:

$$
\begin{aligned}
& M_{a m}=0.6 c=0.942 e+12.6=1.74 w+12.6=2.55 h+12.6 \\
& M_{n}=1.55 c=0.8525 e+11.55=1.472 w+11.55=2.163 h+11.55 \\
& M_{n f}=0.7 c=1.049 e+14.7=1.947 w+1.47=2.848 h+14.7
\end{aligned}
$$

$c=$ moisture capacity as defined by Hillgard, $w=$ wilting coefficient, $e=$ the moisture equivalent, $h=$ the hygroscopic coefficient, $a m=$ ammonification, $n=$ nitrification, $n f=$ nitrogen fixation:

Influence of soil cultivation. Cultivation tends to conserve the soil moisture at a time of the year when it is most needed; it brings about a better aeration of the soil, it influences the soil temperature and

${ }^{60}$ Greaves, J. E., and Carter, E. G. Influence of moisture on the bacterial activities of the soil. Soil Sci., 10: 361-387. 1920; 13: 251-270. 1922.

${ }^{61}$ Lipman, J. G., and Brown, P. E. Report of the soil ehemist and bacteriologists. 29th Ann. Rpt., N. J. Agr. Exp. Sta. 105-115. 1908.

${ }_{62}$ Murray, T. J. The oxygen requirements of biological soil processes. Jour. Bact., 1: 547-614. 1916.

${ }^{63}$ See also Münter, F., and Robson, W. P. Über den Einflusz der Böden und des Wassergehaltes auf die Stickstoffumsetzungen. Centrbl. Bakt. II, 39: 419-440. 1916; Rahn, O. Bacterial activities in soil as a function of grain size and moisture content. Mich. Agr. Exp. Sta. Bul. 16. 1912; Centrbl. Bakt. II, 35: 429-465. 1912; 38: 484. 1913.

6r Prescott, J. A. A note on the Sheraqi soils of Egypt. Jour. Agr. Sci., 10: 177-181. 1920. 
tends to improve the physical condition of the soil; it brings about a rapid drying of the surface layer of the soil and, when moistened by rainfall, bacterial activities are stimulated. Prolonged drought brings about similar results in a still more pronounced way. ${ }^{64}$ Greater numbers of microorganisms were found in cultivated than in uncultivated soils. ${ }^{65,66}$ The efficiency of the soil for nitrate production is increased by cultivation and acration. ${ }^{67}$

The following quantities of aerobic bacteria (growing on the common plate) were recorded ${ }^{68}$ in 1 gram of moist soil:

Raw peat, undrained........................ 138,500

Drained, but not cultivated...................... 200,300

Freshly cultivated, treated with lime and sand.......... 6,900,400

Cultivated for some time, limed, manured............. 6,224,500

Same, fallowed............................. $7,801,600$

In comparing the bacteria in soils from under corn and under alfalfa, greater numbers of organisms were found ${ }^{69}$ to be present in the first three feet of corn soil than in the same layer of alfalfa soil; this is probably due to better aeration of the corn soil brought about by the soil treatment.

The number of organisms in cultivated soils may be twice as large as in corresponding virgin soils, and higher in wheat land than in alfalfa land. ${ }^{70}$ Nitrification and nitrogen-fixation were also twice as active in land under cultivation. The beneficial effect of summer fallowing and disking was believed to be due, in part at least, to increased available plant food in cultivated soil, brought about by increased bacterial activities.

Fallowing has a favorable influence on nitrate formation and rapidity of clecomposition of the organic matter in the soil. ${ }^{71}$ Caron's results

${ }^{85}$ Caron, 1895 (p. 772).

${ }^{86}$ Houston, 1898 (p. 14).

${ }^{67}$ Lyon, T. L. Intertillage of crops and formation of nitrates in soils. Jour. Amer. Soc. Agron., 14: 97-109. 1922.

${ }^{68}$ Fabricius, O., and von Feilitzen, H. Über den Gehalt an Bakterien in jungfräulichem und kultiviertem Hochmoorboden auf dem Versuchsfelde des Schwedischen Moorkulturvereins bei Flahult. Centrbl. Bakt. II, 14: 161-168. 1905.

69 Waite, H. H., and Squires, D. H. A comparative study of the bacterial content of soils from fields of corn and alfalfa. Nebr. Agr. Exp. Sta., 24th Ann. Rpt., 160-177. 1911.

${ }^{70}$ Greaves, J. E. A study of bacterial activities in virgin and cultivated soils. Centrbl. Bakt. II, 41: 444-459. 1914.

${ }^{71}$ Ehrenberg, P. Ưber den Stickstoffhaushalt des Ackerbodens. Fühlings landw. Ztg., 58: 241-246. 1909. 
point to a stimulating effect of fallowing upon bacterial numbers, but those of Hiltner and Störmer do not. An increase in the numbers of bacteria followed later by a decrease in numbers, as a result of fallowing, has also been reported. ${ }^{72}$ Several times as much carbon dioxide was found ${ }^{73}$ in fallowed land than in corresponding land left under grass; however, in soils poor in inorganic matter carbon dioxide may soon become lower in the fallowed soil. Nitrate formation ${ }^{74}$ and

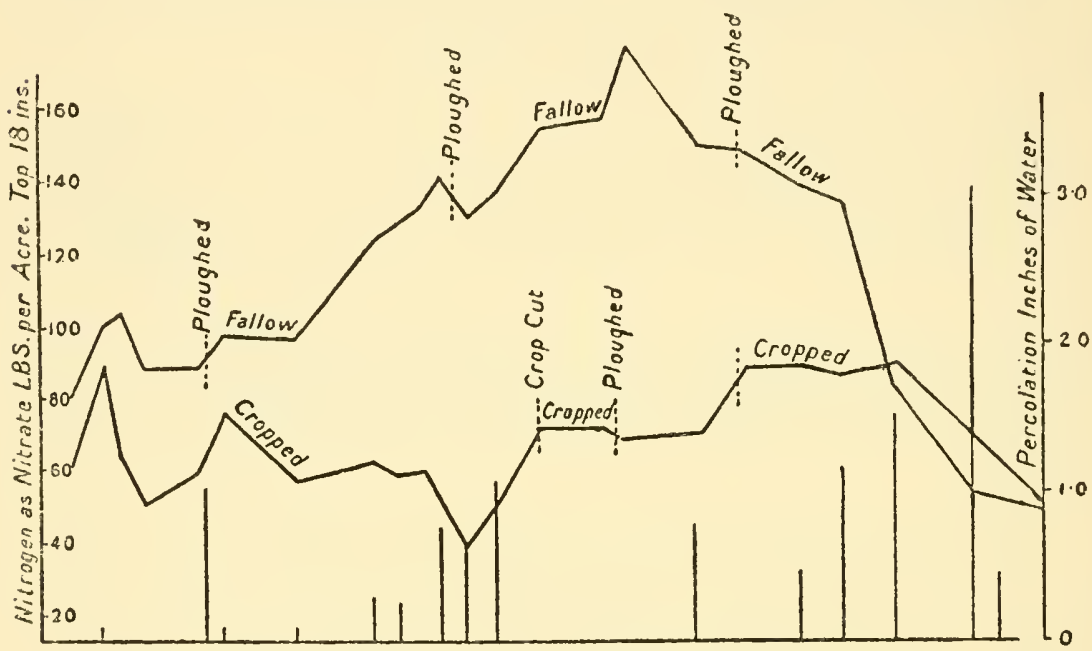

Apr. I May. June. J July. I Aug. I Sep. I Oct. I Nov. I Dec.

FIG. 75. Influence of cropping and fallowing upon nitrate aceumulation at different seasons of the year in the soil (after Russell).

nitrogen-fixation are favorably influenced by cultivation and fallowing. It has been observed at an early date ${ }^{75}$ that fallowing makes the soil

72 Krïger, W., and Heinze, B. Untersuchungen über das Wesen der Brache. L andw. Jahrb., 36: 383-423. 1907; A detailed study of the influence of fallowing upon plant growth and bacterial activities has been made by Makkus, W. Die Braehe, ihre Physiologie, Formen, Zweck, Bedeutung und Verbreitung einst and jetzt. Eine kritische Studie. Landw. Jahrb., 47: 673-718. 1914; Pfeiffer, Th. Einflusz der Brache bezw. der Stallmistd üngung auf die Ernteerträge und den Stickstoffhaushalt im Boden. Landw. Vers. Sta., 98: 187-222. 1921.

${ }^{73}$ Wollny, 1897 (p. 477).

${ }^{i 4}$ Dehérain, 1896 (p. 781).

${ }^{75}$ Boussingault, J. B. De la terre végétale, considérée dans ses effets sur la végétation. Compt. Rend. Aesd. Sei., 48: 303-318. 1859. 
poorer in carbon but richer in nitrogen, due to the greater liberation of carbon dioxide and perhaps to increased nitrogen fixation.

The nature of the crop rotation also influences the activities of microorganisms in the soil; a soil under a four year rotation, while the fourth crop was still on the land or before the cycle was completed for the first time, gave increased number of organisms over that of the soil under continuous cropping. ${ }^{76}$ Soil under continuous corn and wheat contained relatively low numbers of bacteria, in comparison with the timothy and rotation plots. ${ }^{77}$

Influence of salt concentration upon the activities of microorganisms in the soil. The addition of mineral nutritive elements to the soil influences the activities of microorganisms in the soil in various ways. (1) It stimulates the growth of higher plants, thus leading to an increase in crop residues, greater supply of available energy and, there-

TABLE 90

Influence of soil treatment upon the numbers of microorganisms in the soil

\begin{tabular}{|c|c|}
\hline TREATMENT OF SOIL & $\begin{array}{c}\text { AVERAGE NUMBER } \\
\text { OF BACTERIA PER } \\
\text { ORAM }\end{array}$ \\
\hline 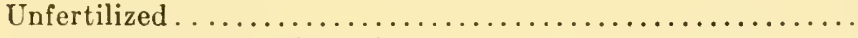 & $8,860,000$ \\
\hline Complete fertilizer with dried blood nitrogen.......... & $10,210,000$ \\
\hline Complete fertilizer with ammonium sulfate nitrogen.... & $5,130,000$ \\
\hline Stable manure and lime $\ldots \ldots \ldots \ldots \ldots \ldots \ldots$ & $14,750,000$ \\
\hline Lime alone . . . . . . . . . . . . . . . . . . & $10,150,000$ \\
\hline
\end{tabular}

fore, an increase in microbial activities. (2) In the presence of an excess of available energy, the mineral elements are often limitin. factors in the activities of microorganisms; this is true especiany of nitrogen, phosphorus, potassium, calcium and magnesium. (3) It tends to produce a more favorable balance in the concentration of the soil solution and colloidal condition of the soil, for these activities. However, an increase in the concentration of salts, as in the case of saline and alkali soils, tends to injure these activities, although most soil microorganisms are capable of withstanding high concentrations of salts.

${ }^{76}$ Brown, P. E. Bacteriological studies of field soils. II. The effect of continuous cropping and various rotations. Iowa Agr. Exp. Sta., Res. Bul. 6. 1912.

${ }^{77}$ Gainey, P. L., and Gibbs, W. M. Bacteriological studies of a soil subjected to different systems of cropping for twenty-five years. Jour. Agr. Res., 6: 953-975. 1916. 
In addition to data recorded elsewhere (p. 733) concerning the influence of fertilization upon the activities of microorganisms, the following results obtained by Given in Pennsylvania may be reported here (table 90$).{ }^{78}$

Similar results were obtained by other investigators for other soils. Phosphoric acid has a favorable influence upon the development of Azotobacter. ${ }^{79}$. The growth of this organism is in a certain way proportional to the easily soluble phosphates in the soil. ${ }^{80}$ It was suggested $^{81}$ that the amount of nitrogen fixed in a phosphorus-free mannite solution, to which a definite amount of soil is added, can be used as an index of the available phosphorus in the soil. The addition of available phosphates to the soil may bring about a large increase in the number of soil bacteria and in the decomposition of organic matter, as measured by the formation of ammonia and carbon dioxide; sulfates were found to exert only a limited effect. ${ }^{82}$ The possibility that the increased crop production resulting from the application of phosphates to the soil is due, in part at least, to the stimulation of bacterial activities was, therefore, suggested. The addition of $\mathrm{NaNO}_{3}$ $\left(\mathrm{NH}_{4}\right)_{2} \mathrm{SO}_{4}, \mathrm{~K}_{2} \mathrm{SO}_{4}, \mathrm{MgSO}_{4}$ to the soil has only a small stimulating effect upon the numbers of bacteria. ${ }^{83}$

The continuous applications of large quantities of artificial fertilizers may injure certain groups of bacteria, particularly the nitrate forming organisms, which may be overcome by the nitrite formers. ${ }^{84}$ Many bacteria and fungi can readily withstand high concentrations of salts, varying from 5 to 15 per cent of sodium chloride, depending on the nature of the salt and the type of the organism. The influence of

${ }^{78}$ Cited by Frear, W. Sour soils and liming. Pa. Dept. Agr. Bul. 261. 1915.

${ }^{79}$ Heinze, B. Über die Stickstoffassimilation durch niedere Organismen. Landw. Jahrb., 35: 889-910. 1906; Wilfarth, H., and Wimmer, G. Über den Einfluss der Mineraldüngung auf die Stickstoffbindung durch niedere Organismen im Boden. Landw. Vers. Sta., 67: 27-50. 1907.

${ }^{80}$ Lipman, J. G. Bacteriological indications of the mineral requirements of soils. N. J. Agr. Exp. Sta. Ann. Rpt., 19: 177-187. 1906.

${ }^{81}$ Christensen, 1923 (p. 730); Stoklasa, 1925 (p. 621).

${ }^{82}$ Fred, E. B., and Hart, E. B. The effect of phosphates and sulfates on soil bacteria. Wis. Agr. Exp. Sta. Res. Bul. 35. 1915; Centrbl. Bakt. II, 45: 379. 1916.

${ }^{83}$ Engberding, 1909 (p. 771).

${ }^{84}$ Aberson, Y. H. A contribution to the knowledge of the so-called physiological acid and alkaline salts, and their importance for the explanation of the sickness of the soil. Meddel. v. de Rijks Hoogere Hand Tuinen Boschborowschool., 11: 1-93. 1916 (Physiol. Abstr., 1: 509. 1917). 
alkali salts upon bacterial activities in the soil received special consideration. ${ }^{85}$ The chlorides are usually the most toxic salts, followed by the nitrates, sulfates and carbonates. The nitrifying organisms are more susceptible than the ammonia forming forms. There is a definite antagonism between various ions. ${ }^{86}$ However, the nature of the organism and the process used as an index of the antagonistic action is of great importance. In suitable concentrations salts of arsenic, ${ }^{87}$ copper, ${ }^{88}$ lead, zinc, and iron, stimulate the activities of the nitrifying and other bacteria. The action depends on the nature of the salt, type of soil and nature of organism. Other investigators ${ }^{89}$ recorded, however, that $\mathrm{As}_{2} \mathrm{O}_{3}$ in itself does not stimulate bacterial growth.

The organisms that decompose proteins with the formation of ammonia are apparently ${ }^{90}$ more resistant to the action of salts than are the higher plants. Nitrates are toxic to bacteria in definite concentrations, the limits depending on the organism and the medium; ;1 this is true both of various autotrophic bacteria, independent of the ability of the organisms to assimilate nitrate nitrogen. The activities of the majority of heterotrophic organisms are favorably influenced by small amounts of nitrate, due to the fact that it serves as a good source of nitrogen.

Influence of calcium oxide and carbonates of calcium and magnesium. The influence of calcium oxide and calcium carbonate on the bacterial numbers and their activities depends on the change produced in the

${ }^{86}$ Lipman, C. B. Toxic effects of alkali salts in soils on soil bacteria. Centrbl. Bakt. II, 32: 55-64. 1912; 33: 305-313, 647-655. 1912. Greaves, J. E. The influence of salts on the bacterial activities of the soil. Soil Sci., 2: 443-480. 1916; Jour. Agr. Res., 16: 107-135. 1919; Kelley, W. P. Nitrification in semiarid soils. I. Jour. Agr. Res., 7: 417-437. 1916.

${ }^{86}$ Lipman, C. B. Bot. Gaz., 48: 106. 1909; Centrbl. Bakt. II, 41: 430-44i. 1914; also Greaves, J. E. Soil Sci., 10: 77-102. 1920; Szücs, J. Experimentalle Beiträge zu einer Theorie der antagonistischen Ionenwirkung. Jahrb. wiss. Bot., 52: 85-142. 1912.

${ }^{87}$ Greaves, J. E., and Carter, E. G. Influence of sodium arsenite on microflora of soil. Bot. Gaz., 77: 63-72. 1924; Centrbl. Bakt. II, 39: 542-560. 1913; 42: 244-254. 1914; Jour. Agr. Res., 6: 389-416. 1913.

${ }^{88}$ Lipman, C. B., and Burgess, P. S. Univ. Cal. Publ. Agr. Sci., 1: 127-139. 1914.

${ }^{89}$ Cobet, R., and van der Reis, V. Über den Einflusz der arsenigen Säure auf das Bakterienwachstum. Biochem. Ztschr., 129: 73-88. 1922.

${ }^{90}$ Greaves, 1916-1919.

${ }^{91}$ Böttger, H. Über die Giftwirkungen der Nitrate auf niedere Organismen. Centrbl. Bakt. II, 54: 220-261. 1921. 
soil reaction. In the case of acid soils, there is a decided stimulating effect as a result of application of lime, due also to a change in the physical condition of the soil which results in making it a more favorable medium for the growth of bacteria.

Ramann and associates ${ }^{92}$ have shown in 1899 that bacteria predominate in alkaline and neutral soils, while in acid soils, fungi are more predominant and may be even greatly in excess of the bacteria, especially in acid peat soils. Treatment of soil with fertilizers, such as ammonium sulfate, acid phosphate, sulfur, which tend to leave the soil reaction acid, will tend to increase the number of fungi in the soil and decrease the number of bacteria, especially when there is not sufficient lime to neutralize the acid. A definite increase in the number of bacteria, as a result of addition of lime to acid soils, has been observed repeatedly. ${ }^{93}$ It was concluded that small applications of $\mathrm{CaCO}_{3}$ to acid soils are more effective, as a rule, than large applications in stimulating bacterial activities; the stimulating effect was obtained, however, only after the neutral point has been reached, as shown by the Veitch method. This is not necessarily true for all soils, since in the case of some acid soils a decided stimulating effect of lime upon the numbers of bacteria is found even if the $\mathrm{pH}$ is not above 6.3. Peat soils, which are usually acid in reaction, are characterized by a high content of fungi and low content of actinomyces;94 among the bacteria, the butyric acid organisms predominate.

$\mathrm{MgCO}_{3}$ exerts a similar effect. The addition of $\mathrm{CaO}$ and $\mathrm{MgO}$ resulted in a reduction in the carbon dioxide formation until the oxides were all carbonated; then there was an increase, as in the case of the carbonates. $\mathrm{CaSO}_{4}$ seems to have no appreciable influence on bacterial activities in the soil. ${ }^{948}$ When 0.5 gram $\mathrm{CaO}$ and 0.75 gram of

${ }_{92}^{2}$ Ramann, E., Remele, E., Schellhorn, and Krause, M. Anzahl und Bedeutung der niederen Organismen in Wald- und Moosböden. Ztschr. Forst. u. Jagdwes., 31: 577-606. 1899.

${ }^{93}$ Fischer, H. Uber den Einflusz des Kalkes auf die Bakterien eines Bodens. Landw. Vers. Sta., 70: 335. 1909; Bear, F. E. A correlation between bacterial activity and lime requirement of soils. Soil Sci., 4: 433-462. 1917; Hutchinson, H. B., and McLennan, K. Studies in the lime requirements of certain soils. Jour. Agr. Sci., 7: 75-105. 1915.

${ }^{94}$ Ritter, G. A. Beiträge zur Kenntnis der niederen pflanzlichen Organismen, besonders der Bakterien, von Hoch- und Niederungsmooren, in floristischer, morphologischer und physiologischer Beziehung. Centrbl. Bakt. II, 34: 577666. 1912.

${ }_{94 a}$ See also Cubbon, M. H. Calcium sulfate as a soil amendment. Cornell Univ. Agr. Exp. Sta. Mem. 97. 1926. 
hay were added to $1 \mathrm{kgm}$. of soil, the soil receiving $\mathrm{CaO}$ produced, in 18 days, $380 \mathrm{mgm} . \mathrm{CO}_{2}$ less than the unlimed soil (theoretical amount necessary to carbonate the $\mathrm{CaO}$ is $390 \mathrm{mgm}$.). After that period, the $\mathrm{CaO}$ treated soil began to give increased amounts of $\mathrm{CO}_{2} \cdot{ }^{95}$ The addition of lime to the soil increases the decomposition of the organic matter added to the soil, whether this is determined by the evolution of carbon dioxide, formation of "humus," or formation of nitrates. The increase in the decomposition of the soil organic matter as a result of addition of lime depends on the nature of the soil and the change in reaction brought about rather than upon the nature of the organic matter added..$^{96}$

As to the influence of liming upon the decomposition of organic matter in the soil, the following results may be cited: ${ }^{97}$

Influence of $\mathrm{CaCO}_{3}$ on evolution of $\mathrm{CO}_{2}$ from soil

\begin{tabular}{c|c}
\hline $\mathrm{CaCO}_{3}$ added & $\mathrm{CO}_{2}$ EVOLVED PER DAY \\
\hline percent & mgm. \\
0 & 181.3 \\
0.04 & 223.6 \\
0.10 & 308.4 \\
0.20 & 416.4 \\
0.40 & 455.4 \\
\hline
\end{tabular}

The addition of an excess of calcium carbonate may be detrimenta to certain bacterial activities as shown by Wollny for the decomposition of organic matter, and by Lipman and associates ${ }^{98}$ for ammonia formation. In many cases, however, beneficial results may be obtained. ${ }^{99}$ An excess of calcium oxide may exert a sterilizing effect

${ }^{95}$ Lemmermann, O., Aso, K., Fischer, H., and Fresinius, L. Untersuchungen ïber die Zersetzung der Kohlenstoff verbindungen verschiedener organischer Substanzen im Boden, speziell unter den Einfluss von Kalk. Landw. Jahrb., 41: 217-256. 1911.

${ }^{96}$ Miyake and Nakamura, 1923 (p. 689); White, J. W., and Holben, F. J. Residual effects of forty years continuous manurial treatments. II. Effect of caustic lime on soil treated with barnyard manure. Soil Sci., 20:313-327. 1925.

97 König and Hasenbäumer, 1920 (p. 783).

${ }^{88}$ Lipman, J. G., Brown, P. E., and Owen, I. L. Experiments on ammonia and nitrate formation in soils. Centrbl. Bakt. II, 30: 156-181. 1911.

${ }^{\circ}$ Peck, S. S. Hawaiian Sugar Planter's Chem. Bul. 34. 1911; Greaves, J. E. The influence of salts on the bacterial activities of the soil. Soil Sci., 2: 443-480. 1916; Fulmer, H. L. Influence of carbonates of magnesium and calcium on bacteria of certain Wisconsin soils. Jour. Agr. Res., 12: 463-504. 1918; Further in- 
upon the soil, as pointed out elsewhere (p. 743). Magnesium carbonate becomes toxic in large amounts, although in small quantities it may be more effective than calcium carbonate. ${ }^{100}$

Some microorganisms do not grow in the soil when the acidity is greater than a certain maximum. Of particular interest in this connection is the occurrence and development of Azotobacter in the soil. The presence of this organism can be used as an index of the lime requirement of the particular soil. ${ }^{101}$ When the reaction of the soil is less than pH 5.7 (no Azotobacter present), the soil needs lime; when the $\mathrm{pH}$ is above 7.4, the soil does not need any lime. But when the $\mathrm{pH}$ of the soil is between 5.8 and 7.3, an Azotobacter test is made. A definite weight of soil ( 5 or 10 grams) is added to a definite amount of mannite solution, free from calcium carbonate ( 50 or $100 \mathrm{cc}$.), and the flashs are sterilized; these are then inoculated with a fresh culture of Azotobacter and incubated. The amount of pellicle development is an index of the buffer action of the soil and can yield information on its lime requirement. When lime is added to an acid soil in which Azotobacter is lacking, it will not take very long before this organism will appear. When a culture of Azotobacter is added to soils in which it is lacking or not abundant, it will survive only in those soils in which the reaction is above $\mathrm{pH}$ 6.0. The whole question of influence of reaction upon the growth of microorganisms is discussed in detail elsewhere (p. 637).

Influence of growing plants upon soil microorganisms and their activities. The growing plants exert various influences upon the activities of the microorganisms in the soil:

1. They excrete soluble substances which offer a favorable medium for the activities of microorganisms. ${ }^{102}$ Under sterile conditions,

formation on the influence of calcium upon the activities of microorganisms is given by Miller. Über den Einflusz des Kalkes auf Bodenbakterien. Ztschr. Gärungsphysiol., 4: 194. 1914; Plummer, J. H. The effects of liming on the availability of soil potassium, phosphorus and sulfur. Jour. Amer. Soc. Agron., 13: $162-171.1921$.

${ }^{100}$ Lipman, J. G., and Brown, P. E. N. J. Agr. Exp. Sta. 28th Ann. Rpt., 141-204, 1907.

101 Christensen, H. R. Untersuchungen über einige neuere Methoden zur Bestimmung der Reaktion und des Kalkbedürfnisses des Erdbodens. Intern. Mitt. Bodend., 13: 111-146. 1923.

102 Wilson, J. K. 'The nature and reaction of water from hydathodes. Cornell Univ. Agr. Exp. Sta. Mem., 65. 1923; also Lyon, T. L., and Wilson, J. K. Ibid. Mem. 40. 1921. 
plants secrete formic, oxalic and malic acids, as well as reducing and non-reducing sugars. ${ }^{103}$ Plant roots also secrete phosphatides and stimulate the development of various soil fungi. ${ }^{104}$

2. They supply energy and nitrogen sources for the microorganisms through their residues, in the form of dead roots, root cap cells, etc.

3 . They remove the various soluble materials from the soil through their roots, especially the nitrates. This changes the composition of the soil solution and modifies the activities of microorganisms.

4. They excrete carbon dioxide into the soil, which, in addition to that produced by the microorganisms, will tend to change the reaction of the soil, increase the solubility of certain inorganic soil constituents and change the composition of the soil atmosphere.

5. They remove the moisture from the soil, exerting an injurious influence upon the growth of microorganisms. ${ }^{105}$ The importance of this influence was, however, minimized by Lyon and associates. ${ }^{106}$

6. Plant roots modify the structure of the soil and produce a medium more favorable for the development of microorganisms. ${ }^{107}$ The removal of nitrates from the soil, leaving the bases behind in the form of carbonates, ${ }^{108}$ would come under the third group of phenomena; this may affect the activities of microorganisms favorably.

The influence of growing plants upon bacterial activities may be expressed in terms of (1) numbers of microorganisms, (2) nitrate accumulation or nitrifying capacity of the soil, (3) oxidizing power of the soil as expressed either in terms of oxygen absorption or carbon dioxide production, (4) other biological activities. It is most difficult to letermine the influence of the growing plant upon the numbers of

${ }^{103}$ Czapek, F. Zur Lehre von der Wurzelausscheidungen. Jahrb. wiss. Bot., 29: 321-390. 1896; Mazé, P. Recherches sur la physiologie végétale. Ann. Inst. Past., 25: 705-738. 1911; Schulov, I. C. Investigations on the physiology of nutrition of higher plants (Russian). Moskau. 1913.

${ }^{104}$ Melin, E. Die Phosphatiden als ökologischer Faktor im Boden. Svensk. Bot. Tidskr., 18: 460-464. 1924.

${ }^{105}$ Dehérain, P. P. Drainage des terres nues. Traité de Chimie Agricole., 586-587. 1902.

${ }^{106}$ Lyon, T. L., Heinicke, A. J., and Wilson, B. D. The relation of soil moisture and nitrates to the effects of sod on apple trees. Cornell Univ. Agr. Exp. Sta. Mem.63. 1923; Mem. 91. 1925.

${ }^{107}$ Berkmann, M. Untersuchungen über den Einflusz der Pflanzewurzeln auf die Struktur des Bodens. Intern. Mitt. Bodenk., 3: 1-49. 1913.

${ }^{108}$ Hall, A. D., and Miller, N. H. J. The effects of plant growth and of manures upon the retention of bases by the soil. Proc. Roy. Soc., 7B, 1-32. 1905; (Exp. Sta. Recd., 27: 124. 1912.). 
microorganisms, due to many variables involved in a study of this kind and the fact that the results are very difficult of duplication; it is also difficult to differentiate between the direct influence of the growing plant and the influence of the plant products.

A larger number of organisms was found ${ }^{109}$ under clover than under grain crops, one gram of clover soil containing seven to eight millions of microorganisms, barley soil, five to six millions, and soil growing sugar beets, one to two millions. Higher numbers of bacteria were found in soil under cowpeas than in fallow land. ${ }^{110}$ Wilson ${ }^{111}$ placed 300 -gram portions of soil in large test tubes; these were plugged with cotton and sterilized. Some were inoculated with sterile corn and some not. A few of the tubes with and without corn were inoculated with a nitrate reducing organism, a few with $B$. radicicola, and a few left uninoculated. After 25 to 75 days incubation, the numbers of bacteria were determined in the various soils. About three times as many bacteria were found in the planted soil than in the unplanted soil, irrespective of the organism and of the nitrate added to the soil. Soils adjacent to the roots of various plants were found to contain, in 27 out of 32 soils, a higher bacterial content than the soil at some distance away from the roots. ${ }^{112}$ A particular plant continuously grown in a soil leaves residues which will occasion a change in the chemical composition of the soil; these in turn influence the bacterial flora. Certain plant species will favor certain types of bacteria and inhibit others and thus disturb the bacterial equilibrium in the soil. The new flora thus established produces a specific change in the composition of the soil which affect subsequent plant growth, favoring some plant species and retarding others. This is true not only in case of favorable organisms, but also of plant pathogens; the continuous growth of a single plant, such as wheat, flax, clover, etc., will bring about the development of fungi pathogenic to this plant, making the soil "sick" for the particular plant.

A number of contributions are devoted to the subject of influence ${ }^{109}$ Caron, 1895 (p. 772); Stoklasa and Ernest, 1905 (p. 34).

110 Lechair, C. A. The influence of the growth of cowpeas upon some physical, chemical and biological properties of soil. Jour. Agr. Res., 5: 439-448. 1916.

111 Wilson, J. K., and Lyon, T. L. The growth of certain microorganisms in planted and in unplanted soil. Cornell Univ. Agr. Exp. Sta. Mem. 103, 1926.

112 Hoffmann, C. A contribution to the subject of the factors concerned in soil productivity. Kansas Univ. Science Bul. 9: 81-99. 1914. 
of growing plants on nitrification in soil. Lawes, Gilbert and Warington ${ }^{113}$ were among the first to note that nitrogen of unmanured land nitrifies with greater difficulty than nitrogen of land that has yielded large crops. More than twice as much nitrate nitrogen was formed, including the nitrogen in the crop and soil nitrate, in the plot growing oats, than in the corresponding bare plot.114 Certain plants, like maize, may, during the most active periods of growth, stimulate the

TABLE 91

Influence of plant upon the numbers of bacteria and evolution of $\mathrm{CO}_{2}$

\begin{tabular}{|c|c|c|c|}
\hline PLANT & $\begin{array}{c}\text { BACTERIA PER } \\
1 \text { ORAM OF SOIL }\end{array}$ & SOIL REACTION & $\begin{array}{l}\text { MILLIGRAMS OF CO } \\
\text { PRODUCED BY } \\
1 \text { KGM. OF BOIL IN } \\
24 \text { HOCRS } \triangle T \text { T } 20^{\circ} \mathrm{C} \text {. }\end{array}$ \\
\hline & millions & $p H$ & \\
\hline Triticum vulgare . . . . . . . & 49 & 6.75 & 69.4 \\
\hline Secale cereale $\ldots \ldots \ldots \ldots \ldots$ & 42 & 6.44 & 68.2 \\
\hline Avena sativa .......... & 45 & 6.42 & 79.0 \\
\hline Beta vulgaris . . . . . . . . . & 78 & 6.89 & 74.3 \\
\hline Medicago sativa...... & 120 & 6.89 & 86.8 \\
\hline Trifolium pratense ........ & $\ldots$ & 6.66 & 82.4 \\
\hline
\end{tabular}

TABLE 92

Evolution of $\mathrm{CO}_{2}$ from $1 \mathrm{kgm}$. portions of different soils in 24 hours at $20^{\circ} \mathrm{C}$. and $\$ 5$ per cent moisture

\begin{tabular}{|c|c|c|c|c|c|}
\hline \multirow{3}{*}{ SOIL TREATMENT } & \multicolumn{5}{|c|}{ SOIL DEPTH } \\
\hline & $10-20 \mathrm{~cm}$ & $20-30 \mathrm{~cm}$ & $30-50 \mathrm{~cm}$. & $50-80 \mathrm{~cm}$ & $80-100 \mathrm{~cm}$. \\
\hline & \multicolumn{5}{|c|}{ Milligrams of $\mathrm{CO}_{2}$ given off } \\
\hline Pasture.... & 16.5 & 19.4 & 9.8 & 3.3 & 2.2 \\
\hline Wheat....... & 47.0 & 49.7 & 28.5 & 6.6 & 4.3 \\
\hline Alfalfa........... & 60.6 & 62.8 & 42.2 & 16.3 & 3.7 \\
\hline Sugar beets . . . . . . . . . & 56.4 & 58.2 & 36.4 & 8.3 & 4.8 \\
\hline
\end{tabular}

formation of nitrates; cluring the latter periods of growth, when the roots cease to grow and begin to undergo decomposition, the same plants may exert a depressing effect. ${ }^{115}$ This depressive influence was

${ }^{113}$ Lawes, J. B., Gilbert, J. H., and Warington, R. Nitrogen as nitric acid in the soils and subsoils at Rothamsted. Jour. Roy. Agr. Soc., 19: 331-367. 1883.

114 King, F. H., and Whitson, A. R. Development and distribution of nitrates in cultivated soils. Wis. Agr. Exp. Sta. Bul. 93. 1902.

${ }^{115}$ Lyon, T. L., and Bizzell, J. A. Some relations of certain higher plants to the formation of nitrates in soils. Cornell Univ. Agr. Exp. Sta. Mem., 1. 1913; Jour. Frankl. Inst., 171: 1-16. 1911. 
later explained ${ }^{116}$ by the fact that plant secretions and root residues are sources of energy for the soil organisms. The nature of the crop is of importance in this connection, due to the difference between the absorptive power of the plant and the carbon-nitrogen ratio of the

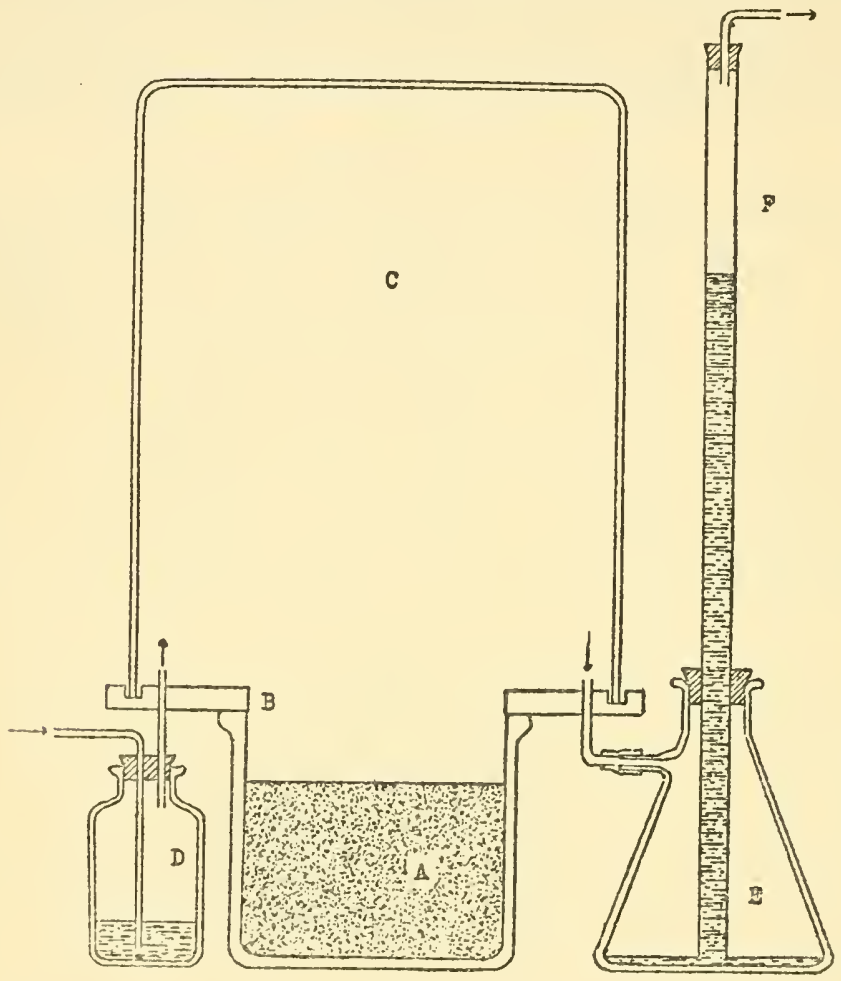

FIG. 76. Diagram representing a seetion through one of the units of the apparatus used in determining the carbon dioxide evolved from the soil cultures (from Neller).

plant residues. Nitrate production was found ${ }^{117}$ to be higher under a cultivated crop, such as corn and potatoes, than under an uncultivated

116 Lyon, Bizzell and Wilson, 1923 (p. 705).

117 Jensen, C. A. Seasonal nitrification as influenced by crops and tillage. U. S. Dept. Agr. Bur. Pl. Ind. Bul. 173. 1910; Ladd, E. F. Humus and soil nitrogen. N. D. Agr. Exp. Sta. Bul. 47, 685-721. 1901; Lyon, T. I.., and Bizzell, J. A. The formation of nitrate in a soil following the growth of red clover and timothy. Soil Sei., 9: 53-54. 1920. 
crop, such as wheat, rye, or timothy; this is particularly true of soils rich in organic matter, and may be due to the more frequent cultivation of the soil, on which the former crops are grown. An alfalfa or clover soil kept fallow for two years was found ${ }^{118}$ to nitrify dried blood more rapidily than a timothy soil similarly treated. McBeth and Smith ${ }^{119}$

TABLE 93

Effect of buckwheat and of field peas upon the oxidation processes in a loam soil

\begin{tabular}{|c|c|c|c|c|c|c|c|}
\hline & \multirow{2}{*}{$\mid$\begin{tabular}{|c|} 
INTER- \\
VALS \\
BE- \\
TWEEN \\
TITRA- \\
TIONS
\end{tabular}} & \multicolumn{2}{|c|}{ BUCKWHEAT } & \multicolumn{2}{|c|}{$\begin{array}{c}\text { CHECK } \\
\text { (NO PLANTS) }\end{array}$} & \multicolumn{2}{|c|}{ FIELD PBAa } \\
\hline & & Jar 1 & Jar 2 & Jar 3 & Jar 4 & Jar 5 & Jar 0 \\
\hline \multirow{9}{*}{$\mathrm{CO}_{2}$ withdrawn from system.... } & days & $m g m$. & $m \diamond m$. & $m g m$. & $m g m$. & mom. & mom. \\
\hline & $0-3$ & 88.9 & 85.0 & 81.7 & 74.6 & 112.3 & 112.3 \\
\hline & $4-5$ & 23.9 & 15.8 & 46.5 & 34.2 & 55.1 & 47.6 \\
\hline & $6-7$ & 76.7 & 61.1 & 33.0 & 38.9 & 25.1 & 38.0 \\
\hline & $8-10$ & 39.7 & 6.5 & 32.0 & 21.7 & 37.3 & 33.7 \\
\hline & $11-13$ & 49.0 & 21.8 & 58.3 & 58.1 & 55.0 & 36.8 \\
\hline & $14-18$ & 79.6 & 40.0 & 41.4 & 46.8 & 7.9 & 10.5 \\
\hline & $19-23$ & 44.4 & 46.0 & 69.3 & 43.0 & 22.0 & 62.1 \\
\hline & $24-32$ & 27.0 & 20.1 & 121.0 & 79.7 & 22.1 & 15.8 \\
\hline 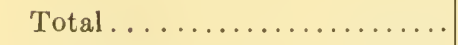 & & 429.2 & 296.3 & 483.2 & 397.0 & 336.8 & 356.8 \\
\hline Dry weight of crop............ & & 786.8 & 842.8 & & & 1032.5 & 1024.6 \\
\hline 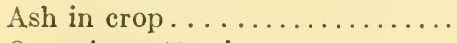 & & 347.0 & 367.0 & & & 317.9 & 405.2 \\
\hline Organic matter in crop......... & & 439.8 & 475.8 & & & 714.6 & 619.4 \\
\hline Organic matter in seedlings..... & & 92.7 & 92.7 & & & 416.7 & 416.7 \\
\hline $\begin{array}{l}\text { Organic matter produced during } \\
\text { experiment } \ldots \ldots \ldots \ldots \ldots \ldots\end{array}$ & & 347.1 & 383.1 & & & 297.9 & 202.7 \\
\hline $\begin{array}{l}\mathrm{CO}_{2} \text { fixed by plants during experi- } \\
\text { ment } \ldots \ldots \ldots \ldots \ldots \ldots \ldots\end{array}$ & & 561.3 & 619.5 & & & 418.7 & 327.8 \\
\hline Total $\mathrm{CO}_{2}$ obtained from soil.... & & 990.5 & 915.5 & 483.2 & 397.0 & 818.5 & 684.6 \\
\hline $\begin{array}{l}\text { Average } \mathrm{CO}_{2} \text { obtained from soil. } \\
\text { Average increase over check... }\end{array}$ & & $\begin{array}{r}953 . \\
116 . \\
\text { ce }\end{array}$ & $\begin{array}{l}\text { mgm. } \\
5 \text { per } \\
\text { nt }\end{array}$ & 440.1 & mgm. & $\begin{array}{c}751.6 \\
70.8 \\
\text { cen }\end{array}$ & $\begin{array}{l}\text { mgm. } \\
\text { per } \\
\text { at }\end{array}$ \\
\hline
\end{tabular}

concluded that the nitrifying power of a cropped and irrigated soil was higher than that of one which was not cropped. There was no

${ }^{118}$ Lyon, T. L., and Bizzell, J. A. The influence of alfalfa and timothy on the production of nitrates in soils. Centrbl. Bakt. II, 37: 161-167. 1913.

119 MeBeth, I. G., and Smith, N. R. The influence of irrigation and crop production on soil nitrification. Centrbl. Bakt. II, 40: 24-51. 1914. 
increase in the nitrifying power of a semi arid soil, upon which legumes have previously grown; it was suggested that a growing crop may have a different influence upon nitrate formation in different soils. ${ }^{120}$

TABLE 94

Effect of the second crop of wheat and of soybeans upon the oxidation processes in sand cultures

\begin{tabular}{|c|c|c|c|c|c|c|c|}
\hline & \multirow{2}{*}{\begin{tabular}{|} 
INTER- \\
VALS \\
BE- \\
TWEEN \\
TTRAA- \\
TIONS
\end{tabular}} & \multicolumn{2}{|c|}{ WHEAT } & \multicolumn{2}{|c|}{$\begin{array}{c}\text { CHECK } \\
\text { (NO PLANTS) }\end{array}$} & \multicolumn{2}{|c|}{ SOYBEANS } \\
\hline & & Jar 7 & Jar 8 & Jar 9 & Jar 10 & Jar 11 & Jar 12 \\
\hline $\mathrm{CO}_{3}$ removed from system. & $\begin{array}{c}\text { days } \\
0-3 \\
4-6 \\
7-9 \\
10-12 \\
13-14 \\
15 \\
16-19 \\
20-24\end{array}$ & \begin{tabular}{|r|}
\multicolumn{1}{c}{ mom. } \\
191.1 \\
187.0 \\
108.9 \\
129.7 \\
40.6 \\
84.7 \\
48.0 \\
21.8
\end{tabular} & $\begin{array}{r}m g m . \\
191.1 \\
187.0 \\
170.0 \\
143.4 \\
43.8 \\
99.4 \\
75.0 \\
50.5\end{array}$ & \begin{tabular}{|r|}
\multicolumn{1}{|c|}{$m g m}$. \\
191.1 \\
175.5 \\
178.0 \\
83.0 \\
68.1 \\
165.1 \\
108.1 \\
326.3
\end{tabular} & $\begin{array}{r}\text { mgm. } \\
181.1 \\
187.0 \\
97.1 \\
109.2 \\
51.0 \\
107.0 \\
116.0 \\
349.0\end{array}$ & $\begin{array}{r}\text { mgm. } \\
191.1 \\
187.0 \\
89.4 \\
135.2 \\
65.5 \\
95.9 \\
36.8\end{array}$ & \begin{tabular}{|r}
\multicolumn{1}{l}{$m g m}$. \\
182.1 \\
187.0 \\
167.0 \\
94.2 \\
55.0 \\
123.0 \\
24.9 \\
43.4
\end{tabular} \\
\hline 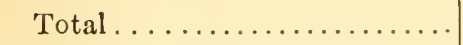 & & 811.8 & 960.4 & 1295.3 & 1098.3 & 780.9 & 876.6 \\
\hline 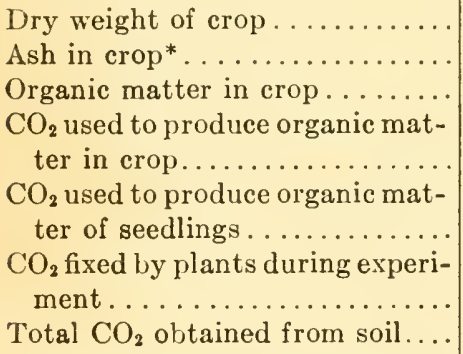 & & $\begin{array}{r}1280.8 \\
220.0 \\
1080.8 \\
1747.4 \\
26.9 \\
1702.8 \\
2514.4\end{array}$ & $\begin{array}{r}2756.5 \\
1916.0 \\
840.5 \\
1359.1 \\
26.9 \\
1332.2 \\
2292.6\end{array}$ & 1295.3 & & $\begin{array}{r}1442.5 \\
394.0 \\
1048.5 \\
1695.4 \\
69.5 \\
\\
1625.9 \\
2406.8\end{array}$ & $\begin{array}{r}1523.6 \\
424.2 \\
1099.4 \\
\\
1783.9 \\
69.5 \\
\\
1714.4 \\
2591.0\end{array}$ \\
\hline $\begin{array}{l}\text { Average } \mathrm{CO}_{2} \text { obtained from soil. } \\
\text { Average increase over check... }\end{array}$ & & $\begin{array}{r}2403.6 \\
100.9 \\
\text { cen }\end{array}$ & $\begin{array}{l}\text { mgm. } \\
\text { per } \\
\text { t }\end{array}$ & 1196.8 & mgm. & $\begin{array}{r}2498.9 \\
108.8 \\
\text { cen }\end{array}$ & $\begin{array}{l}\text { mgm. } \\
8 \text { per } \\
\text { nt }\end{array}$ \\
\hline
\end{tabular}

* Including also the soil grains which adhered to roots.

The growing crop may have a depressive effect upon the nitrate content of the soil (not necessarily nitrate-producing capacity of the

${ }^{120}$ Kellerman, K. F., and Wright, R. C. Mutual influence of certain crops in relation to nitrogen. Jour. Amer. Soc. Agr., 6: 201-210. 1914. 


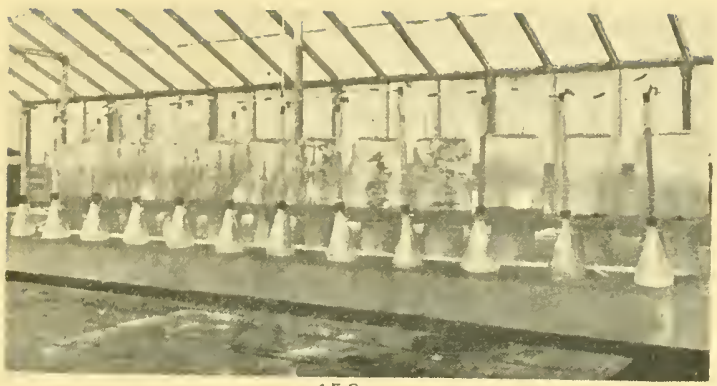

153

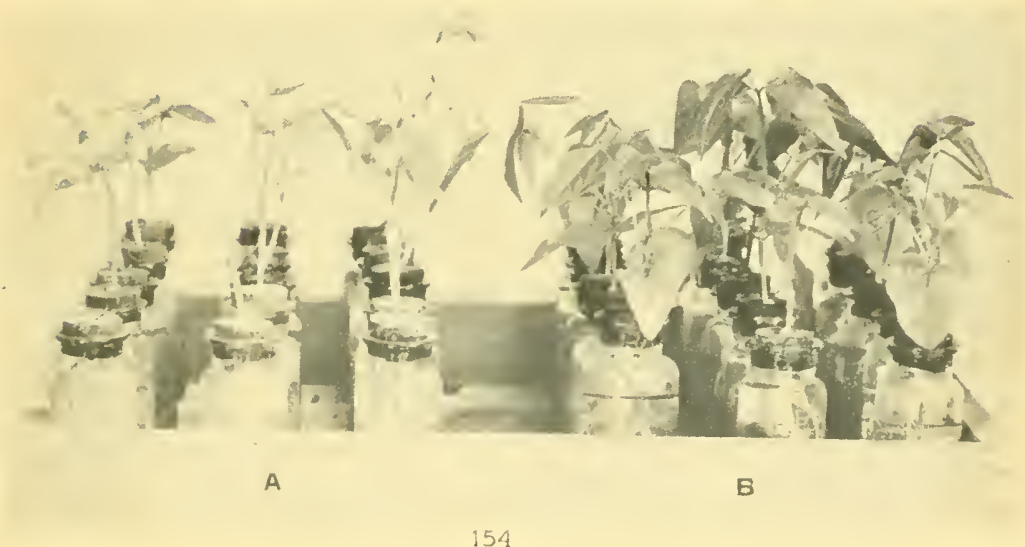

153. A view of the front or outlet side of the apparatus used to determine the influence of plants upon the oxidation activities in the soil. Twelve barium hydroxide towers were used for recovering carbon dioxide from air removed while soda lime in the long horizontal tube, lying on the table, freed the indrawn air from carbon dioxide. The six central jars contain barley and soybean plants (from Neller).

154. Influence of inoculation upon the growth of soy beans in sterilized water. $A$, Uninoculated; $B$, inoculated (from Garman and Didlake). 

soil). ${ }^{121}$ It was suggested ${ }^{122}$ that the lower nitrate formation in cropped land may be due to the adverse effect of the crop upon bacterial activities or to some process of destruction of nitrates, at work in the cropped soil which does not take place in the fallow soil. ${ }^{123}$ The stimulative effect of the growing crop upon the activities of heterotrophic organisms (including decomposition of organic matter) and the injurious effect upon nitrate accumulation explain one another since one process is the cause of the other, the heterotrophic organisms, using the available energy of the fresh organic material of a wide carbon-nitrogen ratio, consume some of the nitrate.

The growing crop brings about an increase in the carbon dioxide content of the atmosphere, as indicated by the fact that the carbon dioxide content in a cropped soil is much greater than in a corresponding bare soil. ${ }^{124}$ The excess of carbon dioxide was ascribed to the respiratory activity of the plants rather than to the decompoition of the root particles from the crop growing in the soil. This is in line with the previous observations of Barakov ${ }^{125}$ that plants produce much greater quantities of carbon dioxide in the soil than do the bacteria; maximum carbon dioxide production was found to coincide with the maximum life activity of the plant. Leather ${ }^{126}$ also found greater quantities of carbon dioxide in the neighborhood of roots of crops than in fallow land.

Neller ${ }^{127}$ obtained quantitative measurements of the total carbon dioxide liberated from oxidation processes taking place in the soil during plant growth (fig. 76 , no. 153, Pl. XIX); much more rapid

${ }^{121}$ Voorhees, E. B., Lipman, J. G., and Brown, P. E. Some chemical and bacteriological effects of liming. N. J. Agr. Exp. Sta. Bul. 210. 1907.

${ }^{122}$ Russell, E. J. The nature and amount of fluctuations in nitrate contents of arable soils. Jour. Agr. Sci., 6: 18-57. 1914; also Ibid., 7: 1-45. 1915.

${ }^{123}$ Burd, J. S. Water extracts of soils as criteria of their crop producing power. Jour. Agr. Res., 12: 297-310 (301). 1918.

${ }^{124}$ Russell and Appleyard, 1915 (p. 721); Turpin, H. W. The carbon dioxide of the soil air. Cornell Univ. Agr. Exp. Sta. Mem., 32: 319-362. 1920.

${ }^{125}$ Barakov, P. The carbon dioxide content of soils during different stages of growth of plants. Zhur. Opit. Agron., 11: 321-342. 1910.

${ }^{126}$ Leather, J. W. Soil Gases. Mem. Dept. Agr. India, Chem. Series, 4: 85-132. 1915; see also Bizzell, J. A., and Lyon, T. L. The effect of certain factors on the carbon dioxide content of soil air. Jour. Amer. Soc. Agron., 10: 97-112. 1918.

${ }^{127}$ Neller, J. R. The influence of growing plants upon oxidation processes in the soil. Soil Sci., 13: 139-159. 1922. 
oxidation was found to occur in a soil in which plants were growing than in the corresponding uncropped soil kept under the same conditions of moisture, aeration, temperature, etc. The growing roots were found to exert a direct influence upon the decomposition of organic matter in the soil. This will, of course, also bring about a greater liberation of available plant nutrients and thus stimulate further plant growth. A symbiotic relationship between the growing plant and the oxidizing organisms in the soil was, therefore, suggested. Further information on the influence of nature of crop upon the numbers of bacteria and evolution of $\mathrm{CO}_{2}$ from soil is given in tables ${ }^{91,92,128} 93$ and $94 . .^{127}$

It is of interest to note here that the harmful effect of grass upon the growth of trees so commonly observed has been found ${ }^{129}$ to be due to the fact that the surface roots of the trees are deprived of combined nitrogen; by producing a soil atmosphere rich in $\mathrm{CO}_{2}$, the grass causes the surface roots to grow down and thus suffer from lack of oxygen; there was no evidence of the formation of a toxin by the grass.

Berthelot ${ }^{130}$ recorded less nitrogen fixed by non-symbiotic organisms in eropped than in uncropped soil. Heinze, ${ }^{131}$ however, found that fallowing increased the nitrogen-fixing capacity of the soil. Definite information on this problem is difficult to obtain since our methods are not sensitive enough to detect a minute increase in the total nitrogen of the soil. In the case of leguminous plants, which offer a favorable substrate for the growth of the different froms of $B$. radicicola, the death of the plant and the decomposition of the roots lead to an increase in the numbers of the nodule organisms in the soil.

${ }^{128}$ Stoklasa, J. Die modernen Ziele der biochemischen Forschung des Bodens. Chemie d. Zelle u. Gewebe, 12: 22-44. 1924.

${ }^{129}$ Howard, A. The effect of grass on trees. Proc. Roy. Soc., 97B: 234-321. 1925.

130 Berthelot, $1 S S 8$ (p. 104).

${ }^{131}$ Heinze, B. Bodenbakteriologische Untersuehungen. Landw. Jahrb. 39, Erganzungbd., 3: 314-343. 1910. 


\section{CHAPTER XXX}

Soll as a Habitat for Microorganisms Causing Plant and Animal Diseases

The majority of soil microorganisms carry on in the soil processes which are of prime importance to the growth of higher plants. Sometimes the microorganisms compete with higher plants for specific nutrients; some of them may also produce substances which are directly injurious to higher plants. In addition to the injury which saprophytic soil microorganisms may cause to plants by carrying on certain physiological processes, the soil harbors organisms directly parasitic to plants or animals.

Influcnce of saprophytic soil microorganisms upon plant growth. Microorganisms take part in four soil processes which directly affect the growth of higher plants. (1) They decompose the soil organic matter and liberate the nitrogen and minerals necessary for the growth of higher plants. They also produce considerable quantities of $\mathrm{CO}_{2}$, which is essential for the growth of plants. (2) They oxidize and otherwise transform the various minerals introduced into the soil (ammonium salts, sulfur, etc.), or formed from the decomposition of the organic matter (as $\mathrm{NH}_{3}, \mathrm{H}_{2} \mathrm{~S}$, etc.), into forms readily available to plants. They synthesize organic matter from inorganic compounds and thus compete with higher plants for the available nitrogen and minerals. This process may become useful in the absence of a growing crop, since the soluble materials are prevented from being leached out. (4) They reduce, under proper conditions, various oxidized substances like sulfates and nitrates to substances which may be directly toxic to higher plants.

The growth of the extensive group of leguminous plants is directly affected by the symbiotic bacteria, so much so that these plants become almost independent of the soil nitrogen and, therefore, of all processes affecting the available nitrogen in the soil. The growth of a large number of trees and other plants depends to a large extent upon the fungi forming mycorrhiza on their roots, as shown clsewhere. Whatever the nature of the phenomenon, whether it is a case of symbiosis or of mutual parasitism, there is no doubt that the fungi favor in some way 
the growth of the plants, both in the case of ectotrophic and endotrophic forms.

Microorganisms affect the growth of higher plants not only directly, but also indirectly. The formation of carbon dioxide and various organic acids brings about a greater solubility of the soil minerals, particularly the carbonates and phosphates, as well as to some extent the zeolitic materials. To this we must add, of course, the action of inorganic acids, namely nitrous, nitric and sulfuric, which result directly from the activities of microorganisms. The favorable influence of bacteria upon the activities of the roots of plants, by increasing their etching power, may also be referred to here. ${ }^{1}$ The favorable influence of legumes upon non-leguminous plants has also been noted above. ${ }^{2}$

When seeds are planted immediately after turning under a green manure crop, the seedlings may be injured. As a result of the decomposition of the green manure, numerous fungi develop, some of which are destructive to the seedlings, especially in the case of oil seeds. The rapid evolution of $\mathrm{CO}_{2}$ and utilization of oxygen produce conditions unfavorable to oxidation, which is essential for the seeds in the process of germination. However, when seeds are planted two weeks after the addition of the green manure, no serious injury is caused to their germination. ${ }^{3} \quad$ An attempt was made to explain unproductiveness of soils not by a lack of proper nutrients but by the presence of substances actually injurious to plant growth ${ }^{4}$ these substances were presumably formed in the soil partly at least as a result of activities of microorganisms. The hypothesis that protozoa are concerned in the destruction of bacteria and, therefore, bring about the formation of "sick" and unproductive soils, as well as other biological theories which attempt to explain this phenomenon, have been discussed above.

1 Fred and Hass, 1919 (p. 617).

${ }^{2}$ See also Koch, A. Die Pflanzennährstoffe des Bodens unter dem Einflusz der Bakterien. Chem. Ztg., 36: 726. 1911; Koch, A. Utber die Einwirkung des Laub-und Nadelwaldes auf den Boden und die ihn bewohnenden Pflanzen. Centrbl. Bakt. II, 41: 545-572. 1913; Gibbs, W. M., and Werkman, C. H. Effect of tree products on bacteriological activities in soil. I. Ammonification and nitrification. Soil Sci., 13: 303-322. 1922; Bondorff, A. The use of microorganisms for the determination of the content in the soil of plant food available for higher plants. Den. Kgl. Verteriner. Z. Lanbohojsholes aarskrift. 191S, 339-362 (Physiol. Abstr., 6: 137).

${ }^{3}$ Fred, E. B. Relation of green manures to the failure of certain seedlings. Jour. Agr. Res., б: 1161-1176. 1916.

${ }^{4}$ Schreiner, O., and Reed, H. S. Some factors infuencing soil fertility. U. S. Dept. Agr. Bur. of Soils, Bul. 40. 1907. 
In other words a soil condition may be brought about, commonly referred to as "sickness," which may not be a result of the activities of microorganisms directly pathogenic to plants, but which is due to certain processes brought about by saprophytic soil microorganisms.

Saprophytism and parasitism ainong soil microorganisms. Parasitism is a form of nutrition whereby an organism obtains its nutrients from the tissues or cells of another living organism. Symbiosis or mutual parasitism takcs place when the host plant obtains nutrients from the invading organism. Parasitism is a matter of degree in the case of a number of microorganisms (especially fungi) found in the soil. Some organisms are strictly parasitic and are brought into the soil by the growing plant, by wind or other agencies. They cannot grow in the soil, but remain there alive and capable of causing the disease only for a short time; this is true of most smuts and certain bacteria among plant pathogens; Bact. typhosum is a case of an animal pathogen. Some organisms continue to live in the soil a season or more but, in the absence of the host plant, they soon die out. They may, however, be able to attack a number of hosts and thus become more or less permanent in the soil, until all the host plants are completely removed; this is true of the club root organism, Plasmodiophora brassicae; (3) Some organisms are able to grow saprophytically in the soil for many years and become parasitic when the specific host plant is introduced. In this group there are various species of Fusaria ( $F$. oxysporum, $F$. radicicola, $F$. lini, etc.), Act. scabies, certain Rhizoctonia (Rh. solani), and many other plant pathogens. Bac. tetani, Bac. anthracis, Bac. botulinus, numerous gas gangrene types as Bac. welchii, and Act. bovis are instances of organisms capable of causing animal diseases, which may find a more or less permanent habitat in the soil. Finally we find organisms primarily saprophytic in nature and abundantly distributed in the soil. They are capable, however, of causing diseases of the growing plant or various storage rots, when conditions become favorable. This group includes $R h$. nigricans, certain species of Fusarium, Penicillium, etc. ${ }^{5}$

In the interaction of plants and microorganisms, various gradations between strict parasitism and strict symbiosis are found, with mutual parasitism as an intermediary phenomenon. ${ }^{6}$ Mycorrhiza formation

"See Strong, R. P. The relationship of certain "free-living" and saprophytic microorganisms to disease. Science N. S., 61: 97-107. 1925.

- Bernard, N. L'évolution dans la symbiose. Ann. Sci. Nat. Bot. 9 me Ser., 1909, 9; Caullery, M. La symbiose chez les animaux. Bull. Inst. Past., 19: 569-583, 617-627. 1921. 
by fungi fills in the gap between parasitism and symbiosis. Some of the inycorrhiza are probably more symbiotic; others are often looked upon as parasitic in nature; still others first attack the plant and then are digested by the plant juices. In the last instance we have a case of balanced parasitism; the root-tubercles of Arbutus unedo are caused by a fungus first ectotrophic, then endotrophic; the digestion of the fungus by the root tubercles confers immunity upon the root system as a whole. ${ }^{7}$ On the other hand we find cases, like the infection of the thallus of the liverwort Pellia epiphylla with a species of Phoma, ${ }^{8}$ where the fungus kills the protoplasmic contents of the infected cells. Since the plant can be grown without the fungus, the relationship is largely parasitic. The mycorrhiza of forest trees may be classed between these extremes.

The relation of the soil organisms to the plant can thus be arranged schematically as follows:

Obligate parasitism $\rightarrow$ Parasitism combined $\rightarrow$ Largely parasitic, $\rightarrow$ (certain bacteria, smuts, etc.) with soil saprophytism (Fusaria, Rhizoctonia) although plants may derive some benefit (certain mycorrhiza)

$\rightarrow$ Balanced parasitism $\rightarrow$ Symbiosis (legume $\rightarrow$ Saprophytic microorgan(certain mycorrhiza) bacteria and leguminous plants, Pavetta indica and other plants with gallforming bacteria, lichen-formations, etc.)

The problem of host selection and host specialization has been studied carefully in the case of plant infesting nematodes. ${ }^{9}$ The chief species of these organisms attack a large number of host plants. However, different populations of a nema species may prefer different host plants; when different host plants are growing in a given soil area the soil nemas will attack the one preferred, leaving the others unattacked even though they are favored host plants of the particular species. If peas or oats are grown on a soil for a number of successive years, Heterodera schachtii becomes so adapted to this host that it will attack this plant in the

${ }^{7}$ Rivett, M. F. The root tubercles in Arbutus Unedo. Ann. Bot., 38: 661677. 1924 .

${ }^{8}$ Ridler, 1922-1923 (p. 277).

${ }^{9}$ Steiner, G. The problem of host selection and host specialization of certain plant infesting nemas and its application in the study of nemic pests. Phytopathol., 15: 499-534. 1925. 
presence of a number of other plants, which may not be attacked at all. This observation was first made by Liebscher. ${ }^{10}$ Nemas are capable of locating their host plants at considerable distances, moving even against the water-flow. ${ }^{11}$ The nemas are even capable of distinguishing closely related plant species. This was explained by the fact that although different species of plant-parasitic nemas feed on a wide range of host plants, a given population of one species will, if possible, always attack first the kind of host plants that its ancestors lived on. If this host plant is not available, host plants of near relationship (taxonomical, chemical) are sought and attacked. If the ancestors of a given population lived on a number of host plants for many generations, the population is polyphagous. If the ancestors of a population lived for many generations on a single species or variety of plant, their descendants will always attack that host plant and, only in exceptional cases, other plants, unless the host is absent; such a population is monophagous.

The growing plants seem to produce some root secretions which are carried by the soil water and act as stimuli upon the nemas. The latter perceive the stimuli by means of a special sense organ (amphid). The nema then moves towards the points of higher concentration of the stimulating fluid until the host plant is reached.

A detailed review of the relation between parasite and host plant, especially in respect to rusts, is given elsewhere. ${ }^{12}$

Animal and plant diseases caused by bacteria that may be found in the soil. A number of bacteria capable of causing various animal diseases have been isolated from the soil, where they find a natural habitat or persist only for longer or shorter periods of time. It is sufficient to mention that Bac. anthracis (Pasteur, Koch), Bac. tetani (Nicolaier, Sanfelice), Bac. chauvoei (Arloing, Pellegrino), Bact. pestis (Jersin), Bact. typhi (Macé) will persist in the soil for many months or even years. Pathogenic bacteria were often found to be actually capable of leveloping in the soil. Pasteur showed that earthworms can spread

10 Liebscher, G. Beobachtungen über das Auftreten eines Nematoden an Erbsen. Jour. Landw. 40: 357-368. 1892.

11 Baunacke, 1922 (p. 344).

12 Zimmermann. Sammelreferate über die Beziehungen zwischen Parasit und Wirtspflanze. Centrbl. Bakt., II, 65: 311-418. 1925.

${ }_{13}$ Prausnik, W. Die Hygiene des Bodens. Handb. der Hygiene (Rubner usw.), 1: 520-562. 1911 (Int. Mitt. Bodenk., 4: 239); Bail, O., and Breinl, F. Versuche über das seitliche Verdringen von Verunreinigungen im Boden. Arch. Hyg., 82: H. I. 1914. 
anthrax organisms through the soil and even isolated the organism from the intestines of the worms. The soil may thus become a carrier of human disease, as demonstrated in the case of $V$. cholerce and Bact. typhosum. ${ }^{13}$ Bac. botulinus is commonly found in the soil; the presence of this organism has been demonstrated not only for soils infested with the organism, but also for various virgin mountain and forest soils. ${ }^{14}$

Bac. tetani appears to be also universally distributed in the soil, especially in soils fertilized with animal manures and subject to the dust of the streets. Nicolaier ${ }^{15}$ demonstrated the presence of this organism in over fifty per cent of the soils examined. It was even suggested ${ }^{16}$ that the organism develops in rotting straw or manure, taking a part in processes of decomposition. The presence of this organism in the soil has also been ascribed to its presence in fecal secretions due to its (levelopment in the intestine.

The soil harbors various bacteria capable of causing plant diseases; these include Bact. tumefaciens, Bact. solanacearum and Bac. phytophthorus. ${ }^{17}$ It has long been known ${ }^{18}$ that the mosaic disease of tobacco is caused by a filterable virus and this has since been found true of a large number of similar plant diseases of the type known as infectious chlorosis. The nature of this virus is problematical. It has been held that in some cases the virus may persist in the soil but this remains as a question deserving further critical study.

Plant diseases caused by fungi found in the soil. Numerous fungi capable of causing plant diseases find their natural or temporary habitat in the soil. Such fungi have been isolated not only from cultivated soils where they might have been introduced, but also from virgin soils or from soils on which the particular host plant has never been grown before. Fungi, like $F$. radicicola and Rhizoctonia solani known to be parasitic on the Irish potato, were isolated from Idaho soils never cropped

${ }^{14}$ Meyer, K. F., and Dubovsky, B. J. The distribution of the spores of $B$. botulinus in California. Jour. Inf. Dis., 31: 41-55. 1923; also 56-58, 59-94. 95-99, 100-109.

${ }_{15}$ Nicolaier, A. Beiträge zur Aetiologie des Wundstarrkrampfen. Inaug. Diss. Göttingen. 1S85; (Baumgart. Jahresber., 2: 270-272. 1S86).

${ }^{16}$ Vincent, H. Le bacille du tétanos se multiplie-t-il dans le tube digestif des animaux? Compt. Rend. Soc. Biol., 65: 12-14. 1908.

${ }_{17}$ Smith, E. F. An introduction to bacterial diseases of plants. Sanders Co., Philadelphia, 1920.

${ }_{18}$ Beijerinck, M. W. Ueber ein Contagrium vivium fluidum als Ursache der Fleckenkrankheit der Tabaksblïtter. Centrbl. Bakt., II, 5: 27. 1899. 
with potatoes as well as from virgin desert lands. ${ }^{19}$ Disease-free seed planted on new lands yielded a diseased product. Land previously planted to alfalfa, clover or grain is better adapted to the production of disease-free potatoes than virgin land. Various species of Phytophthora may persist in the soil for considerable periods of time and can stand the low winter temperatures without much injury; they can also resist some desiccation. Ph. infestans can live saprophytically in the soil, growing on old, partially decomposed plants. Their pathogenicity is not diminished by living in the soil. ${ }^{20} \mathrm{~A}$ number of these and other organisms are facultative parasites, in other words, they are capable of growing in the soil in the absence of the host plant. The spores of Sclerotinia trifoliorum, for example, were found ${ }^{21}$ to give rise to a mycelium which is at first saprophytic and then becomes facultatively parasitic. The spores appear to germinate on vegetable residues in the soil; the mycelium spreads over the soil at a rate which depends on the environmental conditions. These plant pathogenic fungi comprise several distinct groups:

1. Various damping off fungi, ineluding Pythium debaryanum, Sclerotinia libertiana, Phoma solani, Sclerotium rolfsii, Rhizoctonia solani (Corticium vagum), species of Fusarium and Colletotrichum. ${ }^{22}$

2. Root rots as well as other root infections comprising a number of fungi, such as Rh. solani and other species of Rhizoctonia. ${ }^{23}$ The constant culture of wheat on the same soil will bring about a condition of "wheat sickness." This is not a question of soil infertility or the formation of toxins detrimental to wheat, but is due to the introduction of fungi which eause various wheat diseases, by blighting, rotting and destroying the roots. These fungi are capable of persisting in the soil, living on the decomposing straw. In this group are species of Macrosporium, Alternaria, Helminthosporium, Fusarium and Colletotrichum.

3. Wilts. Fusarium oxysporum has been isolated as a soil saprophyte. ${ }^{24}$

${ }^{19}$ Pratt, O. A. Soil fungi in relation to diseases of the Irish potato in Southern Idaho. Jour. Agr. Res., 13: 73-100. 1918.

${ }^{20}$ Bruyn, H. L. G. de. The saprophytie life of Phytophthora in the soil. Medd. Landbou. Wageningen., 24. 1922; The overwintering of Phytophthora infestans (Mont.) DeBy. Phytopath., 16: 121-146. 1926.

21 Wadham, S. M. Observations on clover rot (Sclerotinia trifoliorum Eriks). New Phytol., 24: 50-56. 1925.

${ }^{22}$ Hartley, C. Damping-off in forest nurseries. U. S. Dept. Agr. Bul. 934. 1921.

${ }^{23}$ Bolley, H. L. Wheat: soil troubles and seed deterioration. N. D. Agr. Exp. Sta. Bul. 107. 1913; Beckwith, T. D. Root and culm infections of wheat by soil fungi in North Dakota. Phytopathol., 1: 169. 1911.

${ }^{24}$ Goss, R. W. Relation of environment and other factors to potato wilt eaused by Fusarium oxysporum. Nebraska Agr. Exp. Sta. Res. Bul. 23. 1923. 
This organism may cause a potato wilt disease. F.lycopersicum can also live as a saprophyte in the soil, upon the dead stems of the wilted tomato plants and on the soil organic matter; it can live in the soil several years retaining its virulence, even without the host plant. ${ }^{25}$ The same is true of $F$. conglutinans and $F$.lini. $F$. hypcroxysporum and $F$. batatatis, causing the stem-rot of sweet potato, may also be generally disseminated in the soil; also other pathogenic Fusaria. ${ }^{26}$

Among the other plant pathogenic fungi which can find their habitat in the soil, we may include different species of Rhizoctonia. ${ }^{27}$ Rh. solani, for example, is abundant in cultivated land, where it lives on dead organic matter in the soil. When a proper host is introduced, the organisms may become active parasites, as in the damping-off of carnation cuttings, stem-rot and potato diseases; they can also attack a variety of weeds. $R h$. solani attacks as many as 165 species of plants. Spongospora subterranea causes powdery scab of potatoes. Thielavia basicola causes root rot of tobacco, legumes and many other plants. Synchitrium endobioticum produces the wart disease of the potato and its spores may remain in the soil for two to eight years. ${ }^{28}$ Asterocystis radicis attacks flax. Urophlyctis alfalfae produces swellings on the roots of alfalfa. Aphanomyces lacvis causes "Wurzelbrand" on beets. Pythiacystis citrophthora causes the brown rot of the lemon. Ozonium omnivorum produces root rot on cotton and alfalfa. Sclerotium rolfsii can propagate itself by mycelium in the soil, forming sclerotia under unfavorable conditions. Rosellinia necatrix and Melanospor $a^{29}$ must also be mentioned. Cercospora personata is capable of multiplying in the soil saprophytically, preserving its virulence for eleven years. ${ }^{30}$ Various smuts are of ten found in the soil and may persist there for long periods of time; however, the extent to which rusts may persist in the soil has not been established yet. ${ }^{31}$

Cabbage and tomato sick soils may show as many as forty thousand colonies (on plate) of the parasitic organisms per gram of soil. ${ }^{32}$ On land showing much root rot of corn, Fusarium moniliforme and a Cephalosporium have frequently been found. Trichoderma köningi and $\mathrm{Tr}$. lignorum, two of the most common saprophytic soil fungi, are the causcs of storage rots of sweet potato; the former is also associated with the

${ }_{25}$ Scott, 1924 (p. 811).

${ }^{26}$ Harter, L. L., and Field, E. C. The stem-rot of sweet potato (Ipomea batatus). Phytopathol., 4: 279-304. 1914.

${ }_{27}$ Peltier, G. L. Parasitic Rhizoctonias in America. Ill. Agr. Exp. Sta. Bul. 189. 1916.

28 Schander and Richter. Über den Nachweis von Dauersporen von Chrysophlyctis endobiotica Schill. (Kartoffekrebs) in der den Kartoffeln anhaftenden Erde. Centrbl. Bakt., II, 58: 454-461. 1923.

29 Delacroix and Maublanc. Maladies parasitaires des plantes cultivées. Bailliere Ed.

${ }^{30}$ Miège, E. Le désinfection du sol. Paris. 1918.

${ }^{31}$ Klebahn, cited by Waget, P. Stérilization et disinfection du sol. Rev. Prod. Chim., No. 22. 1920, 655; No. 4. 1921, 115; No. 6, 183.

${ }^{32}$ Manns, T. F. Soil bacteriology. Del. Agr. Exp. Sta. Bul. 133, 35-36. 1922. 
so-called "ring rot." 33 The common soil organism Rhizopus nigricans is the cause of soft rot of sweet potatoes.

Plant and animal diseases caused by species of actinomyces. Several plant pathogenic actinomyces have been found in the soil, including Act. scabies, the organism causing the common scab disease of potatoes and sugar beet.

On comparing a large number of organisms isolated from scabby potatoes, we can readily recognize that we are dealing here not with one species, but with a whole group which can be readily subdivided into several sub-groups, not only on the basis of physiological characteristics, but also on the basis of morphology. As a matter of fact, as many as 30 species of actinomyces have been described,,$^{34}$ which are supposed to be causative agents of potato scab, the type of lesion being influenced by the species.

The formation of pox on sweet potatoes may be due, to some extent at least, to an actinomyces ${ }^{35}$ found in the soil.

The causative agents of human and animal actinomycotic diseases are often claimed to be brought about by soil organisms or forms harbored upon plants. ${ }^{36}$ Klinger $^{37}$ called attention to the fact that the aerobic actinomyces commonly found on grasses and in straw infusions (also in soil) have never been isolated by him in any actinomycotic case. Only anaerobic forms were obtained from the latter; these develop on most media at temperatures above $30^{\circ} \mathrm{C}$, and only seldom were cultures obtained which make a scant growth under aerobic conditions. Mixed infections consisting of anaerobes growing at body temperature together with aerobes are often obtained. We have to do here with species which have adapted themselves to a symbiosis with warm blooded animals, and which have almost nothing in common with aerobic saprophytes. However, there is no doubt that some aerobic actinomyces are capable of causing infections of men and animals.

The actinomyces capable of causing plant diseases, such as potato

${ }^{33}$ Cook, M. T., and Taubenhaus, J. J. Trichoderma köningi the cause of a disease of sweet potatoes. Phytopathol., 1: 184-1S9. 1911.

${ }^{34}$ Wollenweber, H. W. Der Kartoffelschorf. Arb. Forsch. Inst. Kartoffelbau. H. 2. 1920; Millard, W. A., and Burr, S. Ann. Appl. Biol. 13: 580-644. 1926. 35 Taubenhaus, J. J. Pox, or pit (soil rot), of the sweet potatoes. Jour. Agr. Res., 13: 437-450. 1918.

${ }^{36}$ Odermatt, W. Aetiologisches zur Aktinomykoseerkrankung. Schweiz. Med. Wochnschr., 50: 26-28. 1920.

${ }^{37}$ Klinger, R. Zur Oetiologie der Aktinomykose. Centrbl. Bakt., I, Or., 85: 357-359. 1921. 
and sugar-beet scab, are true soil organisms. Application of lime, which produces a favorable reaction, and of barnyard manure favor the development of scab. The addition of acid fertilizers (acid phosphate) or fertilizers which make the soil reaction acid (sulfur, ammonium salts) tends to decrease the development of scab, as shown elsewhere (p. 301). According to Millard ${ }^{38}$ sufficiently jiberal dressings of green manure added to the soil will inhibit the disease; this is probably due to the temporary increase in soil acidity, as a result of the decomposition of the organic matter by the soil fungi, and to an increase in soil moisture (scab is much more prevalent in dry seasons; actinomyces are much less active in very moist soils).

Sanford ${ }^{39}$ suggested that the soil reaction may not be the important factor in controlling the development of potato scab in the soil. Moisture was found to be directly or indirectly the main factor, a high moisture content controlling the disease, while abundant scab is formed in dry soils. The development of scab is influenced also by the temperature of the soil, the optimum for scab being $22^{\circ} \mathrm{C} .4^{40}$

Plant and animal diseases caused by invertebrate animals found in the soil. Among the animal pests present in the soil, we find protozoa, nematodes and other worms, crustaceans, myriapods and insects. Among the nematodes, we find Heterodera schachtii causing the disease of mangels, Tylenchus tritici ${ }^{41}$ of wheat, Heterodera radicicola causing swellings or knots on roots of tomatoes, cucumbers, etc. ${ }^{42}$ Tylenchus dipsae (syn. devastatrix) causing the root knot on oats, tulip root, clover (one form of clover sickness), and Aphelenchus olesistus causing leaf blight.

Relation of soil environment to plant infection. The soil environment, including temperature, moisture, reaction and composition, has an important controlling influence upon all plant parasites found in the soil, whether they are obligate parasitic or can also exist in the soil facultatively. These soil environmental factors may determine not

${ }^{38}$ Millard, W. A. Common scab of potatoes. Ann. Appl. Biol., 9: 156-164. $1922 ; 10: 70-88.1923$.

3) Sanford, G. B. The relation of soil moisture to the development of common scab of potato. Phytopathol., 13: 231-236. 1923.

40 Jones, L. R., McKinney, H. H., and Fellows, H. The influence of soil temperature on potato scal). Wis. Agr. Exp. Sta. Res. Bul. 63. 1922.

${ }^{41}$ Guénaud, C. Zoologie agricole et Entomologie et Parasitologie agricole. Bailliere Ed.

${ }^{42}$ Bessey, E. Root-knot and its control. U. S. Dept. Agr., Bur. Pl. Ind. Bul. 217. 1911 . 
only the geographical distribution of the disease, but also its seasonal severity. ${ }^{43}$

The case of onion smut illustrates the possible importance of a specific factor of soil environment in determining the possible geographical range of soil parasites. This smut is a persistent soil born fungus, Urocystis cepulae, which is each year distributed throughout the United States on smutty onion sets. It infects the seedling onions only at low temperatures, being totally inhibited at the higher soil temperatures, $28^{\circ} \mathrm{C}$. or above. As a result, although established in all the northern onion districts where onion seed is planted in cool soil in spring, it is unknown in the southern states, Texas and Louisiana, where the seed is planted in the autumn when soil temperature is so high as to inhibit infection. Different soil born parasites are affected very differently by environmental factors. Thus high soil temperatures stimulate the development of the Fusarium "yellows" disease of the cabbage and low temperatures inhibit it. By contrast the Thielavia root rot of tobacco is checked in warm soils and is seriously injurious only in cool soils. Jones further points out this seasonal contrast by citing evidence from two successive summers of which the one, 1915, was very cool, with a mid-summer soil temperature averaging about $5{ }^{\circ} \mathrm{C}$. lower than that of the succeeding summer. In the cool summer the Thielavia root rot of tobacco was unusually severe whereas the cabbage remained relatively free from disease. The succeeding year with its warm mid-summer period brought disaster to the cabbage crop because of the yellows disease, whereas the tobacco was free from root rot even on old "tobacco sick" soils. In general high soil temperatures favor the vascular Fusarium diseases, including flax wilt, $F$. lini, ${ }^{44}$ tomato wilt, $F$. lycopersici, ${ }^{45}$ and cabbage yellows, $F$. conglutinans. ${ }^{46}$ High

${ }^{4}$ Jones, L. R. The relation of environment to disease in plants. Amer. Jour. Bot., 11: 601-609. 1924; Soil temperature as a factor in phytopathology. Plant world, 20 : 229-237. 1917; Experimental work on the relation of soil temperature to disease in plants. Trans. Wis. Acad. Sci., XX: 433. 1922.

${ }_{44}$ Tisdale, W. H. Relation of soil temperature to infection of flax by Fusarium lini. Phytopathol., 6: 412. 1916.

45 Scott, I. T. The influence of hydrogen ion concentration on the growth of Fusarium lycopersici and on tomato wilt. Missouri Agr. Exp. Sta. Res. Bul. 64. 1924 .

${ }^{46}$ Gilman, J. C. Cabbage yellows and the relation of temperature to its occurrence. Ann. Mo. Bot. Gard., 3: 25-84. 1916; Tisdale, W. B. Influence of soil temperature and soil moisture upon the Fusarium disease in cabbage seedlings. Jour. Agr. Res., 24: 55-86. 1923. 
temperature $\left(25-27^{\circ}\right)$ also favors Sclerotium rolfsii and certain other plant pathogenic fungi.

On the other hand, not only the onion smut as noted earlier, but certain grain smuts are favored by low soil temperatures, e.g., the stinking sinut of wheat, Tilletia tritici, thrives at 9-12 ${ }^{\circ}$ according to some, ${ }^{47}$ and even at $5^{\circ}$ to $10^{\circ}$, according to others. ${ }^{4 s}$ Rhizoctonia solani, which may attack potato and many other plants, is aggressive only at relatively low temperatures. ${ }^{49}$ Of the two fungi capable of causing tomato wilt or "sleepy disease," Verticillium albo-atrum operates only at a low soil temperature $\left(21-23^{\circ}\right)$ whereas Fusarium wilt as already noted is a high temperature disease $\left(28-29^{\circ}\right) . .^{50}$

Soil moisture also exerts a potent influence on many plant parasites. As previously noted, Sanford found dry soils favorable and wet soils inhibitory to potato scab. More often soil fungi, especially of the "damping off" types, are favored by high moisture; wet soils, even to the saturation point, favor the club root parasite of cabbage, Plasmodiophora brassicae. ${ }^{51}$ Spongospora subterranea (powdery scab) develops best in periods of damp, rainy, and cloudy weather and is favored by poor drainage. ${ }^{52}$

Hungerford recorded that there is a definite relation between the amount of moisture in the soil at seeding time and the amount of bunt or stinking smut which occurs in the resulting crop of wheat; the drier the soil at seeding time the less will be the amount of infection. When the soil is moist and cultivated frequently, the spores of Tilletia tritici rapidly lose their power of infection.

Of course in all such cases more than one variable factor is concerned. In the case of both cabbage club root and potato scab, it has long been known that soil reaction influences their occurrence. The above cited investigations, as well as the fact that high soil temperature, $22^{\circ}$ or

${ }^{47}$ Hungerford, C. W. The relation of soil moisture and soil temperature to bunt infection in wheat. Phytopathol., 12: 337-352. 1922.

${ }^{48}$ Faris, J. A. Factors influencing the infection of wheat by Tilletia tritici and Tilletia laevis. Mycologia, 16: 259-282. 1924.

${ }^{49}$ Richards, B. L. Pathogenicity of Corticium vagum on the potato as affected by soil temperature. Jour. Agr. Res., 21: 459-482. 1921.

${ }^{50}$ Bewley, W. F. Sleepy disease of the tomato. Ann. Appl. Biol., 9: 116134. 1922; Jour. Ministry Agr., Great Britain, 30: 430-457. 1923.

${ }^{51}$ Monteith, J. Relation of soil temperature and soil moisture to infection by Plasmodiophora brassicae. Jour. Agr. Res., 28: 549-561. 1924.

${ }_{52}$ Mclhus, J. E., Rosenbaum, J., and Schultz, E. S. Sponjospora subterranea and Phoma tuberosa on the Irish potato. Jour. Agr. Res., 7: 213-254. 1916. 
above, favors potato $\mathrm{scab},{ }^{53}$ all point to the conclusion that when these potential parasites are present in the soil the occurrence and severity of the disease must be interpreted as a resultant of several variable environmental factors operating simultaneously.

The amount of organic matter present in the soil also influences plant infection, since it offers a source of energy for the saprophytic existence of the organisms. Thielavia basicola cannot infect the host plant in pure sand, but can do so in the presence of organic matter, which allows the mycelium to exist for some time. ${ }^{54}$ Clay soils are more favorable to infestation than sandy soils. ${ }^{55}$ The decay of the underground portion of the pea plant is largely due to four fungi $5^{56}$ Fusarium martii var. pisi, Pythium debaryanum, Corticium vagum and a species of Aphanomyces. The Fusarium is not disseminated by the seed, but spreads through the soil and is especially favored by a high content of organic matter. Ozonium omnivorum Shear, the cotton and alfalfa root rot, spreads through the soil radially with a growth similar to fairy rings; it is favored by heavy soils, humid weather and dense cover crops. ${ }^{57,58}$ The influence of soil and manure on plant diseases has been recorded elsewhere, ${ }^{59}$ as well as the influence of soil nutrients and soil structure upon plant infection. ${ }^{60}$

Influence of reaction upon the growth of plant pathogenic organisms in the soil. Some plant pathogenic organisms are readily affected by certain hydrogen-ion concentrations of the soil which are not injurious

${ }^{53}$ McKinney, H. H. Influence of soil temperature and moisture on infection of wheat seedlings by Helminthosporium sativum. Jour. Agr. Res., 26: 195-218. 1923.

${ }^{54}$ Massee, C. E. A disease of sweet peas, asters, and other plants. Roy. Gard. Kew. Bul. Misc. Inform. No. 1. 1912, 44-52.

${ }^{56}$ Johnson, J., and Hardman, R. E. Influence of "soil environment on the root-rot of tobacco. Jour. Agr. Res., 17: 44-52. 1919.

${ }^{56}$ Jones, F. R. Stem and root rot of peas in the United States caused by species of F'usarium. Jour. Agr. Res., 26: 459-476. 1923.

${ }^{57}$ Duggar, B. M. The Texas root rot fungus and its conidial stage. Ann. Mo. Bot. Gard., 3: 11-23. 1916.

${ }^{58}$ King, C. J. Habits of the cotton root-rot fungus. Jour. Agr. Res., 26:405418. 1923.

${ }^{69}$ Ehrenberg, P. Der Einfluss des Bodens und der Düngung auf Pflanzenkrankheiten. Fühlings Landw. Ztg. 1917, 130-132; 1919, 401-412.

${ }^{60}$ Levine, M. Studies on plant cancers. III. The nature of the soil as a determining factor in the health of the beet, Beta vulgaris, and its relation to the size and weight of the crown gall produced by inoculation with Bacterium tumefaciens. Amer. Jour. Bot., 8: 507-525. 1921. 
to the growth of the host plant, as in the case of potato seab ${ }^{61,62}$ and wheat seab. ${ }^{63,64}$ Some organisms have a certain acid minimum or alkali maximum which permit methods of control. Act. scabies and most other actinomyces, for example, not do thrive well at pH less than 4.8; Plasm. brassicae is inhibited by an alkali reaction ${ }^{65}$ obtained by the addition of lime. Bact. solanacearum eauses serious infection in acid soils, but selclom in neutral or alkaline soils. ${ }^{66} \quad F$. lycopersici causes minimum infection at pH 6.4 to 7.0 (Scott); it has both an acid and an alkaline maximum.

Method of control. 'To combat disease producing organisms, one has to know not only the life history of the pathogen, but frequently, as in the ease of nemas, the host history of the organism. In this case crops susceptible to the particular species, but not the particular population, may be employed.

The saturation of soil with formaldehyde to prevent spreading of disease has often been practiced. In addition to formaldehyde, various other soil fungicides and volatile antiseptics, like $\mathrm{CS}_{2}$ and toluol, have been frequently employed for the destruction of the plant pathogenic fungi. ${ }^{67,68} \quad \mathrm{CS}_{2}$ can be used with success against a number of fungi, such as Dematophora necatrix, Rhizoctonia, Synchitrium ${ }^{69}$ etc. Miège ${ }^{70}$ obtained the best results with toluene in controlling Sclcrotinia libertiana,

${ }^{61}$ Gillespie, L. J. The growth of the potato scal organism at various hydrogen-ion concentrations as related to the comparative freedom of acid soils from the potato scab. Phytopathol., 8: 257-269. 1918; Gillespie, L. J., and Hurst, L. A. Hydrogen-ion concentration-soil type-common potato scab. Soil Sci., 6: 219-236. 1918.

${ }^{62}$ Waksman, S. A. The influence of soil reaction upon the growth of actinomyces causing potato scab. Soil Sci., 14: 61-79. 1922.

${ }^{63}$ Hopkins, R. F. The hydrogen-ion concentration in its rclation to wheat scab. Amer. Jour. Bot., 9: 159-179. 1922.

${ }^{64}$ McInnes, J. The growth of wheat scab organism in relation to hydrogenion concentration. Phytopathol., 12: 290-294. 1922.

${ }^{65}$ Atkins, W. R. G. Hydrogen-ion concentration and elub root. Sci. Proc. Roy. Dubl. Soc. N. S., 16: 369-413. 1922.

${ }^{66}$ Arrhenius, O. A factor influencing the growth of tobacco wilt discase. Ark. Bot., 18: No. 1. 1922.

${ }^{67}$ Halsted, B. D. Soil fungicides for potato and turnip diseases. N. J. Agr. Exp. Sta., Sp. Bul. S. 1900.

68 Johnson, J. The control of damping off disease in plant beds. Wis. $A$ gr. Exp. Sta. Res. Bul. 31, 29-61. 1914.

${ }^{69}$ Gimingham, C. T., and Spinks, G. T. Soil sterilization. Jour. Bat. and West and South Cont. Soc. 14, 126-130. 1920.

${ }^{70}$ Miège, 1917 (p. 766). 
and Fusarium lycopersici. ${ }^{71}$ When soil is steamed, the fungi are readily destroyed; but once a parasitic organism like Pythium debaryanum is introduced, it will readily develop in the treated soil and may even cause a larger amount of infection. This parasitic activity can be decreased by inoculating the treated soil with various saprophytic fungi. Treatment of soil with a disinfecting agent followed by inoculation with saprophytic fungi may prove to be most efficient in increasing the value of the treatment. ${ }^{72}$

In general the methods of control consist, on the one hand, of crop rotation, seed treatment and selection of resistant varieties, on the other hand, of soil sterilization by heat or by chemicals, change in soil reaction, or other chemical treatment. For the sterilization of grcenhouse soil, the following temperatures are required: ${ }^{73}$

\begin{tabular}{|c|c|c|}
\hline \multirow{2}{*}{ INFECTING ORGANISM } & \multicolumn{2}{|c|}{ TEMPERATURE OF CONTROL } \\
\hline & 18 hours & Few minutes \\
\hline & ${ }^{\circ} \mathrm{C}$. & ${ }^{\circ} \mathrm{C}$. \\
\hline Nematodes............... & 40 & 60 \\
\hline 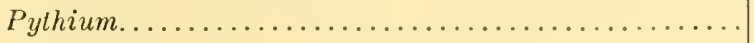 & & 60 \\
\hline 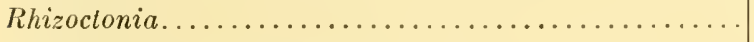 & & 80 \\
\hline 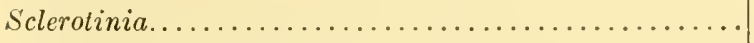 & & 80 \\
\hline 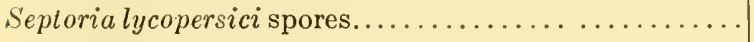 & & 55 \\
\hline 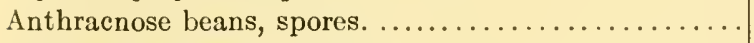 & & 48 \\
\hline 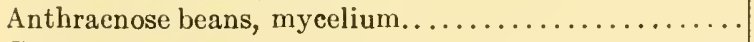 & & 65 \\
\hline 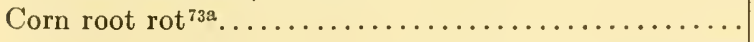 & & 65 \\
\hline
\end{tabular}

Further information on the steam disinfection of soil is given elsewhere. ${ }^{74}$

${ }^{71}$ See Foex, E. Protection of seeds and young plants against diseases by soil sterilization. Jour. Soc. Natl. Horticult., France, 4, Ser. 22: 242-254. 1921.

${ }^{72}$ Hartley, C. Damping off in forest nurseries. U. S. Dept. Agr. Prof. Paper Bul. 934. 1921.

${ }^{7}$ Brown, H. D., Baldwin, I. L., and Conner, S. D. Greenhouse soil sterilization. Purdue Univ. Agr. Exp. Sta. Bul. 266. 1922.

${ }_{73 \mathrm{a}}$ Valleau, W. D., Karraker, P. E., and Johnson, E. M. Corn root rot-a soil-borne disease. Jour. Agr. Res., 33: 453-476. 1926.

${ }^{74}$ Hunt, N. R., O'Donnell, F. G., and Marshall, R. P. Steam and chemical soil disinfection with special reference to potato wart. Jour. Agr. Res., 31: 301-363. 1925; Beinhart, E. G. Steam sterilization of seed-beds for tobaceo and other crops. U. S. Dept. Agr. Farm. Bul. 996. 191s; Byers, L. P., and Gilbert, IV. W. Soil disinfection with hot water to control the root-knot nematode and parasitic soil fungi. U. S. Dept. Agr. Bul. 818. 1920. 
For the control of potato scab, sulfur is used with success. Care must be exercised, however, in using the proper amounts, so as not to make the soil too acid. Sweet potato scurf and pox of sweet potatoes can also be checked by the application of sulfur. Organisms like Pythium (damping off of seedlings) and Spongospora subterranea are intolerant to acid, while the myxomycete Plasmodiophora brassicae (finger and toe disease) is kept in check by addition of lime. 


\section{CHAPTER XXXI}

\section{Soll Inoculation}

Beneficial and injurious microbiological processes in the soil. The growth of higher cultivated plants is usually taken as a criterion in determining whether a certain microorganism or a certain microbiological process is beneficial or injurious. But a careful study of these processes and the organisms concerned can hardly justify such a strict division in all cases. Some, like the nitrogen-fixing, the nitrifying and the sulfur oxidizing bacteria, the various organisms decomposing celluloses and proteins, are no doubt beneficial to the growth of higher plants. Plant pathogenic fungi, like the various Fusaria, Rhizoctonia, Pythium, etc., may, no doubt, become injurious, when environmental conditions are favorable. We may even call denitrifying and sulfur reducing bacteria harmful, although their action is indirect and depends entirely upon the soil conditions.

However, as pointed out above, some organisms may carry on processes in the soil which are both injurious and beneficial to the growth of higher plants; a certain process may be beneficial at one time and injurious at another. The question becomes then merely relative. A fungus, like Trichoderma or Asp. fumigatus, decomposes cellulose rapidly and is no doubt beneficial, but it also synthesizes considerable protoplasm and stores away large amounts of nitrogen and it becomes, therefore, temporarily injurious to higher plants. When a protein is decomposed by fungi, smaller amounts of ammonia are liberated than when it is decomposed by bacteria. When the protein is added, an acid soil favors the development of fungi, while a neutral or alkaline soil favor the development of bacteria.

Facts like these as well as the conditions which may favor the development of the different groups of soil microorganisms and the presence or absence in the soil of the particular organism in question, must be known before we can make use of the principle of soil inoculation. This consists not merely in the introduction of useful organisms which may be lacking, but also in making soil conditions favorable for the biological processes useful to the growth of higher plants. 
Introduction of certain useful microorganisms into the soil. Among the useful microorganisms, which we may want to introduce into the soil are: (1) organisms, which carry on important processes beneficial to a specific plant or to plant growth as a whole; (2) strains more vigorous than those already found in the soil; (3) organisms which destroy or injure the development of organisms directly injurious to higher plants. It is not merely sufficient to introduce the beneficial organisms, but the soil conditions should be made favorable for the development of these organisms.

So far as our present knowledge of the soil biological processes is concerned, the microorganisms which may be lacking in the soil, or whose activities in the soil are to be stimulated are as follows: (1) symbiotic and non-symbiotic nitrogen fixing bacteria; (2) sulfur-oxidizing bacteria; (3) nitrifying bacteria, and (4) microorganisms capable of vigorous decomposition of the soil organic matter. The favorable influence of small quantities of manure added to the soil is ascribed by some investigators to the inoculating power of various bacteria present in the manure, these organisms presumably decomposing the soil organic matter more vigorously than the native flora. However, this favorable action is probably due not to the organisms, but rather to the presence in the manure of certain inorganic substances, such as available nitrogen and phosphates, which stimulate the growth of higher plants or of certain soil organisms. Most of the bacteria capable of decomposing starches and celluloses in the intestinal tract of animals are specific inhabitants of the tract and are not found in great abundance outside of the animal. ${ }^{1}$ Among the organisms which may directly destroy or otherwise eliminate the activities of soil organisms directly injurious to higher plants, the following may be mentioned: (1) the predacious nematodes, like Mononchus, which destroy the injurious nematodes, like Heterodera or Tylenchus; (2) saprophytic fungi which may act as a check to the development of pathogenic fungi.

Among the soil conditions, which may have to be modified, so as to stinulate the development of organisms whose activities in the soil are favorable to the growth of higher plants, the following may be included: (1) a proper carbon-nitrogen ratio of the soil; (2) a favorable soil reaction and presence of sufficient bases; (3) presence of inorganic nutri-

${ }^{1}$ Henneberg, W. Untersuchungen über die Darmflora des Menschen mit besonderer Berücksichtigung der jodophilen Bakterien im Menschen- und Tierdarm sowie im Kompostdünger. Centrbl. Bakt., II, 55: 242-281. 1922. 
ents, especially phosphates and potassium salts; (4) soil moisture and acration. In addition to these, certain specific treatments may prove to be useful for the control of specific microorganisms, as presence of available carbohydrates for the stimulation of non-symbiotic nitrogen fixation; a certain reaction, for the control of specific plant diseases; soil sterilization, for the improvement of the physical and chemical conditions of the soil and the elimination of certain injurious microorganisms.

When the soil is to be inoculated with certain microorganisms, one may choose between the use of (1) soil, in which the desired crop has been grown successfully; (2) pure cultures, or artificially prepared mixed cultures; (3) specific vigorous strains, which are more active than those already present in the soil.

Legume inoculation. ${ }^{2}$ The first inoculation test on record is the experiment carried out in 1887 at the Bremen Experiment Station. It was found that a good stand of clover was obtained on newly drained heath or swamp soils inoculated with old soil in which clover was grown, provided the swamp soil was limed properly. In comparing the use of soil, in which the specific legume was grown, with pure cultures, for inoculation purposes, it is of ten found that soil gives better results. Hiltner ${ }^{3}$ suggested that this may be due to the fact that, when the seed germinates, certain toxic substances pass out from the embryo which seem to be toxic to the bacteria ; this danger can be obviated by inoculating the soil directly rather than the seed.

Atwater and Woods ${ }^{4}$ were among the first in America to show the favorable effect of inoculation on the growth and nitrogen content of alfalfa and peas. The gain in nitrogen was proportional to the number of nodules on the roots. Warington ${ }^{5}$ soon demonstrated that the growth of properly inoculated legumes resulted in an increase in the nitrogen content of the soil; part of a wheat field sceded to clover contained 0.156 per cent nitrogen and only 0.142 per cent was found in

${ }^{2}$ A detailed review of the earlier literature on legume inoculation is given by K. F. Kellerman. The present status of soil inoculation. Centrbl. Bakt., II, 34: 42-50. 1912 .

${ }^{3}$ Hiltner, L. Über die Impfung der Leguminosen mit Reinkulturen. Deut. landw. Presse, 29: 15, 119. 1902.

${ }^{4}$ Atwater, W. O., and Woods, C. D. The aequisition of atmospheric nitrogen by plants. Storrs Agr. Exp. Sta. Rpt. 18s9-90, 11-51.

5 Warington, R. The circumstances which determine the rise and fall of the nitrogenous matter in the soil. U. S. Dept. of Agr. Off. Exp. Sta. Bul. 8, 22-41. 1891. 
the part of a field seeded to barley. The nitrogen content of inoculated plants was found to be much higher than that of uninoculated plants, Nobbe and Richter ${ }^{6}$ reporting 4.29 per cent of nitrogen for the first as against 1.85 per cent for the second. These results were soon confirmed by a number of workers in Europe and in America, as shown later.

In 1896 Nobbe $^{7}$ suggested the use of pure cultures of $B$. radicicola for the inoculation of leguminous plants. A product placed on the market consisted at first of $B$. radicicola grown on gelatin. However, gelatin was found to be an unsuitable medium for the growth of this organism. It was then replaced by a liquid medium, namely a 2 per cent peptone solution or skimmed milk, ${ }^{8}$ and later by agar media. In 1902 the use of cotton cultures was introduced. ${ }^{9}$ Cotton was placed in a liquid culture of bacteria, then dried and placed in packages. This was accompanied by two packages of nutrient substances, the first containing sugar, $\mathrm{K}_{2} \mathrm{HPO}_{4}$ and $\mathrm{MgSO}_{4}$, and the second ammonium phosphate. Before using, the cotton was placed in boiled water and the contents of the first package were added. After 24 hours at $20^{\circ}$, the contents of the second package were added and the culture allowed to incubate; this culture was then used for moistening the seed or for inoculation of a small amount of soil which was then spread over the field. Usually mixtures of the various legume bacteria were employed. The result proved to be unsatisfactory, due to the fact that the bacteria could not withstand the process of drying on cotton. ${ }^{10}$

Various other preparations, consisting of liquid, semiliquid or solid cultures were soon introduced. However, the early beneficial results

' Nobbe, F., and Richter, L. Über den Einfluss des im Kulturboden vorhandenen assimilierbaren Stickstoffs und die Aktion der Knöllchenbakterien. Landw. Vers. Sta., 59: 167-174. 1903.

${ }^{7}$ Nobbe, F. Einige neue Beobachtungen, betreffend die Bodenimpfung mit rein kultivierten Knöllchenbakterien für die Leguminosenkultur. Bot. Centrbl., 68: 171-173. 1896.

${ }^{8}$ Hiltner, L., and Störmer, K. Arb. K. Gesundsamt. Biol. Abt. 3. 1903, 151.

9 Moore, G. T. Bacteria and the nitrogen problem. U. S. Dept. Agr. Yearbook 1902-1903, 333-342; Soil inoculation for legumes; with reports upon successful use of artificial cultures by practical farmers. U. S. Dept. Agr., Bur. PI. Ind. Bul. 71. 1905.

${ }^{10}$ Simon, J. Die Wiederstandsfähigkeit der Wurzelbakterien der Leguminosen und ihre Bedeutung für die Bodenimpfung. Jahresb. ver. angew. Bot. 1907. 
secured with these pure cultures by Nobbe and others ${ }^{11}$ were not confirmed by investigators both in America ${ }^{12}$ and in Europe,${ }^{13}$ who found soil to be superior to artificial cultures for inoculation purpose. The inoculating value of some of these earlier preparations has been compared critically with the inoculating value of soil on which the particular legumes were grown. ${ }^{14}$

Use of soil for inoculation of legumes. Nodule production on plants is a result of chance contact; a large number of nodule-forming bacteria must, therefore, be present in the soil so that maximum nodule formation may take place. After the first experiments on the inoculation of legumes, it was found that certain crops, like clover, peas and beans, did not benefit from inoculation; others, like alfalfa and soybeans, could not be grown successfully without inoculation of the soil with some soil in which these crops had been grown previously. It became a common practice to top dress fresh soil with some old soil for these crops. In most cases 300 to 500 pounds of soil, taken from the upper 6 inches of a field where the particular legume had been grown successfully, was spread over each acre of soil and disked or harrowed in before the planting of the seed. It was found ${ }^{15}$ that soils once inoculated for soybeans and red clover did not need to be reinoculated when these crops were again grown in the four-year rotation. Dry soil stored for thirty months was as good for purposes of inoculation as fresh soil from the field. Further studies ${ }^{16}$ have shown that there is a considerable improvement in the growth of peas in an acid silt loam, in which peas had grown eleven years previously, as a result of inoculation with artificial cultures. An acid soil may lead to a disappearance of certain nodule bacteria, the destruction of the bacteria running parallel with increasing acidity. The nodule bacteria survived for fifteen years in soils which were limed,

\footnotetext{
${ }^{11}$ Edwards, S. F., and Barlow, B. Legume bacteria. Ont. Dept. Agr. Bul. 164. 1908.

${ }^{12}$ Stevens, F. L., and Temple, J. C. The efficiency of pure culture inoculation for legumes. N. C. Agr. Exp. Sta. 30th Ann. Rept., 48-57. 1908.

${ }^{13}$ Barthel, C. Culture experiments with bacterial inoculations of lupine and alfalfa. Meddel. Centralanst. Försöksv. Jordbruk., 95. 1914; K. Landbr. Akad. Handb. o. tdskr., 53: 251-280. 1914.

${ }^{14}$ Feilitzen, H. V. Nitro-Bacterine, Nitragin oder Impferde? Centrbl. Bakt. II, 23: 374-378. 1909.

${ }^{15}$ Albrecht, W. A. Viable legume bacteria in sun dried soil. Jour. Amer. Soc. Agron., 14: 49-51. 1922; Mo. Agr. Exp. Sta. Bul. 197. 1922.

${ }^{16}$ Whiting, A. L. The relation of inoculation to quality and yield of peas. Jour. Amer. Soc. Agr., 17: 474-487. 1925.
} 
but corresponding unlimed soils showed a deficiency of bacteria even when the host plant had been grown a year previously. Artificial inoculation of such a soil was found ${ }^{17}$ to lead to a considerable increase in nodule formation.

The use of large quantities of soil for purposes of inoculation involves great expense and trouble in transportation and handling, aside from the introduction, with the old soil, of weed seeds and injurious microorganisms, such as the fungi causing various wilts and nematodes. This led again to the use of pure cultures. More reliable cultures are now produced, both on artificial media and in sterile soils, as a result of the increased knowledge on the cultivation of the organisms. ${ }^{18}$

Commercial cultures and their preparation. The commercial preparations of nodule bacteria commonly found on the market are in the form of liquid, agar, or soil and peat cultures. The historical process of development of the artificial culture of these bacteria is as follows: Gelatin $\rightarrow$ cotton $\rightarrow$ liquid $\rightarrow$ agar $\rightarrow$ organic $\rightarrow$ inorganic material. ${ }^{19}$

Two media are used at the United States Department of Agriculture, for the preparation of the legume cultures. One is a soil extract medium, made from 10 $\mathrm{kgm}$. of field soil, 40 grams $\mathrm{CaO}$ and 100 liters of tap water. Ten grams of eane sugar and 0.5 gram $\mathrm{K}_{2} \mathrm{HPO}_{4}$ are added for each liter of the extract. The reaction is adjusted to slight acidity to prevent the precipitation of the phosphate. The other medium is a modification of Ashby's medium for aerobic nitrogen assimilating organisms:

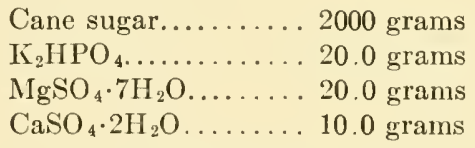

$\mathrm{NaCl} \ldots \ldots \ldots . .20 .0$ grams

Calcium carbonate... 100 grams

Tap water......... 100 grams

The organism is grown in square bottles containing about $200 \mathrm{ce}$. of medium, which is the quantity used for one bushel of seed. The cultures are not kept for more than a month and their efficiency is tested by inoculating plants grown in sand cultures.

${ }_{17}$ Wilson, J. K. Effeet on nodulation of supplementing the legume baeteria of the soil with artificial cultures. Jour. Amer. Soc. Agron., 18: 2S0-294. 1926.

${ }_{18}$ The movement of legume baeteria in the soil is discussed by Frazier, W. C., and Fred, E. B. Movement of legume bacteria in soil. Soil Sei., 14: 29-35. 1922. The application of inoculated soil to legume seed by Arny, A. C., and MeGinnis, F. W. Method of applying inoculated soil to the seed of leguminous erops. Jour. Amer. Soc. Agron., 13: 259-303. 1921. A comparative study between the inoculating power of artifieial cultures with inoculated soil has been made by v. Feilitzen, 1909 (p. 821) and Teisler, E. Azotogen, Nitragin oder Naturimpferde? Centrbl. Bakt. II, 34: 50-56. 1912; also Kühn, A. Ibid., 30: 548. 1911.

19 Rural New Yorker, April 20, 1915. 
As an agar medium, the following ${ }^{20}$ may be employed:

\begin{tabular}{|c|c|}
\hline Mannite............. & 10.0 grams \\
\hline $\mathrm{K}_{2} \mathrm{HPO}_{4}$. & 0.5 gram \\
\hline $\mathrm{NaCl} \ldots . . .$. & 0.2 gram \\
\hline $\mathrm{MgSO}_{4} \cdot 7 \mathrm{H}_{2} \mathrm{O} \ldots \ldots$ & $0.2 \mathrm{gram}$ \\
\hline $\mathrm{CaSO}_{4} \cdot 2 \mathrm{H}_{2} \mathrm{O} \ldots \ldots$ & $0.1 \mathrm{gram}$ \\
\hline
\end{tabular}

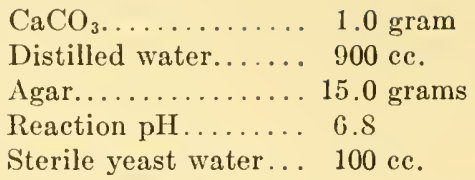

The liquefied agar is allowed to solidify in the form of slants on the broad side of the flat square bottles; the solidified agar is then inoculated with a few drops of a vigorous liquid culture or a suspension of a solid culture in distilled water. The bottles are incubated at $28^{\circ}$. Each culture is sufficient for the inoculation of one acre. For the preparation of large quantities of medium, the following method may be employed: ${ }^{21}$ 175 grams of agar are dissolved in $3000 \mathrm{cc}$. of water, by placing it in the autoclave at 10 to 15 pounds pressure; 2.25 pounds hard wood ashes are boiled in $1000 \mathrm{cc}$. of water and filtered; 0.5 gram $\mathrm{KH}_{2} \mathrm{PO}_{4}, 0.5 \mathrm{gram}$ $\mathrm{MgSO}_{4}, 0.5$ gram $\mathrm{NaCl}, 0.25$ gram $\mathrm{CaSO}_{4} .2 \mathrm{H}_{2} \mathrm{O}$ and 6.25 grams $\mathrm{CaCO}_{3}$ are placed in $1000 \mathrm{cc}$. of hot water. The three solutions are mixed and 87.5 grams saccharose and 12.5 grams mannite are added. The medium is placed in 1.5 ounce bottles and sterilized at 10 pounds. The bottles are then inoculated with $2 \mathrm{cc}$. of a culture of the desired organism, incubated seven days, and then distributed.

The use of good fertile soil, which has been previously sterilized, for the cultivation of Bact. radicicola was found ${ }^{22}$ to give very good results both for the propagation of the organism and as a culture for distribution. The growth of the nodule-organism on nitrogen-rich media does not destroy the infecting power of the organism. ${ }^{23}$ A sandy soil to which some decomposed organic matter is added is air dried, then placed in ten pots and sterilized for two hours at $100^{\circ} \mathrm{C}$. Water is then added to the pots to bring the soil to optimum moisture and the soil inoculated with a suspension of the culture in Ashby's solution. A few cc. are used for inoculating each pot. Soil cultures last much longer than

${ }^{20}$ Fred, E. B., Peterson, W. H., and Davenport, A. Fermentation characteristics of certain pentose-destroying bacteria. Jour. Biol. Chem., 42: 175. 1920.

${ }^{21}$ Harrison, F. C. Nitro-cultures and their commercial application. Trans. Roy. Soc. Canada, Ser. 3, 9: 219. 1915.

${ }_{22}$ Simon, J. Mitt. Öhon. Gesell. Sachsen., 13: 1-27. 1905; Kühn, A. Azotogen, Nitragin und Impferde. Centrbl. Bakt. II, 30: 545-552. 1911; Temple, J. C. Studies of Bacillus radicicola. Ga. Agr. Exp. Bul. 120. 1916.

${ }_{23}$ Prucha, M. r. Physiological studies of Bacillus radicicola of Canada field pea. Cornell Lniv. Agr. Exp. Sta., Mem. 5. 1915. 
agar cultures. Each pot weighing about 680 grams can be used to inoculate one bushel of seed or one acre of land (Wilson). Peat cultures of the nodule bacteria are also being used quite extensively. ${ }^{24}$

To test cultures of legume bacteria for the abundance and vitality of the particular organism, two methods are used:

1. The culture is diluted to $1: 10,000$ or $1: 100,000$, then $1 \mathrm{cc}$. of the final dilution is added to $9 \mathrm{cc}$. of agar medium (Temple used a medium consisting of 10 grams sucrose, 1 gram $\mathrm{KH}_{2} \mathrm{PO}_{4}, 15$ grams agar, $1000 \mathrm{cc}$. tap water, $\mathrm{pH}=$ about 6.5 to 7.0 ) and plates prepared. These are incubated for 6 to 7 days at $25^{\circ} \mathrm{C}$.; the number of viable bacteria, as well as abundance of contaminations, can then be determined. It is frequently difficult to differentiate on the plate between Radiobacter and Bact. radicicola ${ }^{25}$ and it is also impossible to learn which particular groups of the organism are present in the soil.

2. 'To identify the strain, direct inoculation tests must be employed. Either bottles with sterilized sand containing 20 per cent moisture or tall cylinders containing sterile 0.75 per cent agar media must be used. The seeds are sterilized by treatment for fifteen minutes with 0.1 per cent corrosive sublimate, 1 per cent formaldehyde or 5 per cent hypochlorite, then rinsed in sterile water and germinated on moist filter paper in a moist chamber. The sprouted seeds are then removed with sterile forceps, dipped in the inoculating material and dropped upon the substrate, in which they are expected to grow. Controls should always be employed. The formation of nodules is an index of the activity of the culture. The purity of culture can also be tested on sterilized potato, upon which nodule bacteria do not grow (some give some growth in 4 weeks), while common contaminations and Bact. radiobacter produce a growth in 5 to 7 days at $28^{\circ} \mathrm{C} .{ }^{26}$

Bact. radicicola multiplies very rapidly in sterile soil and the development of the organism is greatly diminished when the sterile soil is mixed with non-sterile soil, indicating that normal soil is not a very favorable medium for their development. ${ }^{27}$

Biological types of legume bacteria. It has been pointed above that,

${ }^{24}$ Earp-Thomas, G. H. Peat as a carrier for bacteria. Jour. Amer. Peat Soc., 15: 18-23. 1922.

${ }^{25}$ Joshi, N. V. Studies on the root nodule organism of the leguminous plants. India Dept. Agr. Mem. Bact. Ser., 1: 219-276. 1920.

${ }^{26}$ Löhnis and Hansen, 1921 (p. 126).

${ }^{27}$ Duggar, B. M., and Prucha, M. J. The behavior of Pseudomonas radicicola in the soil. Centrbl. Bakt. II, 34:67. 1912. 
although so far all the bacteria capable of inoculating leguminous plants are classified under one species Bact. radicicola or Rhiz. leguminosarum, different morphological, serological, and cultural differences are found between the forms inoculating different plants. Morphologically they are differentiated by the formation of peritrichous or monotrichous flagellation. Serologically and culturally they are differentiated into a number of groups (3 to 11), the different representatives of each group being capable of cross-inoculation. However, even one type of plant may be inoculated by strains of the organism which possess certain distinct differences.

It was found $\mathrm{d}^{28}$ that (1) different strains of bacteria used in inoculating soybeans differ in their nitrogen-fixing efficiency; (2) different strains of bacteria used for soybean inoculation differ in their power of producing nodules on the roots of the plants, as shown by actual count both as to number and size of nodules; (3) different varieties of beans differ in their relative "susceptibility" of inoculation; (4) the efficiency of nitrogen fixation varies with the soil composition and reaction. There is no difference in the morphology of the strains, but physiologically they may be different. This raises anew the question of the value of inoculation of soil, already inoculated, with vigorous strains of the organism.

Importance of legume inoculation. The effect of inoculation upon the growth of legumes depends to a large extent upon the physical and chemical soil conditions, such as aeration, temperature, moisture, soil composition, reaction, etc.

The effect of legume inoculation was found to consist in increasing the percentage of nitrogen in the tops and roots of the plants and the percentage of ash (excluding phosphorus) in the tops. ${ }^{29}$ Inoculation alone increased ${ }^{30}$ the yield of clover and alfalfa on a Colby silt loam 15.6 per cent; lime and inoculation gave an increase in yield of 49.7 per cent and in nitrogen content of 52.3 per cent. The addition of phosphorus and potassium to this soil did not give any large increase in yield. However, in the case of a poor soil, inoculation and lime, as well as applications of phosphorus and potassium, gave marked increases in crop yield; inoculation alone nearly doubled the crop yield, while

28 Wright, 1925 (p. 127).

${ }^{29}$ Arny, A. C., and Thatcher, R. W. The effect of different methods of inoculation on the yield and protein content of alfalfa and sweet clover. Jour. Amer. Soc. Agron., 7: 172-185. 1915; 9: 127-137. 1917.

${ }^{30}$ Graul, E. B., and Fred, E. B. The value of lime and inoculation for alfalfa and clover on acid soils. Wis. Agr. Exp. Sta., Res. Bul. 54. 1922. 
$\mathrm{CaCO}_{3}$, in addition to inoculation, brought about an increase in yield of 182.8 per cent. Inoculation usually increased the percentage of nitrogen in the roots. Alfalfa showed an average gain of 87.5 pounds of nitrogen on a poor soil and only 41.3 pounds on a rich soil; soybeans properly inoculated fixed about 108 pounds of nitrogen in an acid soil and about 129 pounds when half enough lime needed to neutralize the soil acidity was added.

The use of pure cultures affords a quick and easy method for introducing the bacteria which enable the leguminous plants to obtain nitrogen from the atmosphere. Fresh inoculation of soil with specific nodule bacteria may be of direct benefit to the crop, even if the same plant has been grown previously. ${ }^{31}$ This is due to the fact that the organisms present in the soil itself may not be as vigorous as freshly introduced cultures and the small expense involved by fresh inoculation may be fully compensated by the more vigorous growth of the plants.

Nobbe and Richter found that in some cases 93 to 96 per cent of the nitrogen in vetch was obtained from the atmosphere. The addition of available nitrogen to the soil brought about a decrease in the amount of nitrogen fixed. A fixation of 92 per cent of nitrogen in the alfalfa plants as a result of inoculation was recorded. ${ }^{32}$ Others ${ }^{33}$ obtained a fixation of 15 pounds of nitrogen for alfalfa with soil as an inoculum and 35 pounds when a commercial culture was used for inoculation. In cylinder experiments with various legumes turned under as green manures, in a rotation of corn, potatoes, oats and rye, a gain of 54 pounds of nitrogen annually over a period of seven years, as a result of inoculation, was reported. ${ }^{34}$

Clover was found to contain at maturity an average of 27 per cent of its nitrogen in the roots; 46 per cent of the total nitrogen of alfalfa was also found in the roots. ${ }^{35}$

The nitrogen content of clover and especially of alfalfa inoculated with the proper bacteria is greatly increased as a result of inoculation.

${ }^{31}$ Fred, E. B., and Bryan, O. C. The effect of nodule bacteria on the yield and nitrogen content of canning peas. Soil Sci., 14: 413-415. 1922.

${ }^{32}$ Alway, F. J., and Pinckney, R. M. The nitrogen content of inoculated and uninoculated alfalfa plants. Neb. Agr. Exp. Sta. 25th Ann. Rpt. 1912, 56.

${ }^{33}$ Lipman, J. G. Tests of commercial cultures for soil inoculation. N. J. Agr. Exp. Sta. Bul. 227. 1910.

${ }^{34}$ Lipman, J. G., and Blair, A. W. The yield and nitrogen content of soybeans as affected by inoculation. Soil Sci., 1: 579. 1916.

${ }^{36}$ Brown, P. E., and Stalling, J. H. Inoculated legumes as nitrogenous fertilizers. Soil Sci., 12: 365-307. 1921. 
In some soils the increase was 171.2 per cent greater than that of the untreated control. On adding 2.5 tons of $\mathrm{CaCO}_{3}$ per acre in addition to inoculation, the increased crop yield was 310.7 per cent more than the control. Inoculation also increased the nitrogen percentage in the roots and vines. ${ }^{36}$ In case of soybeans an average increase of 100

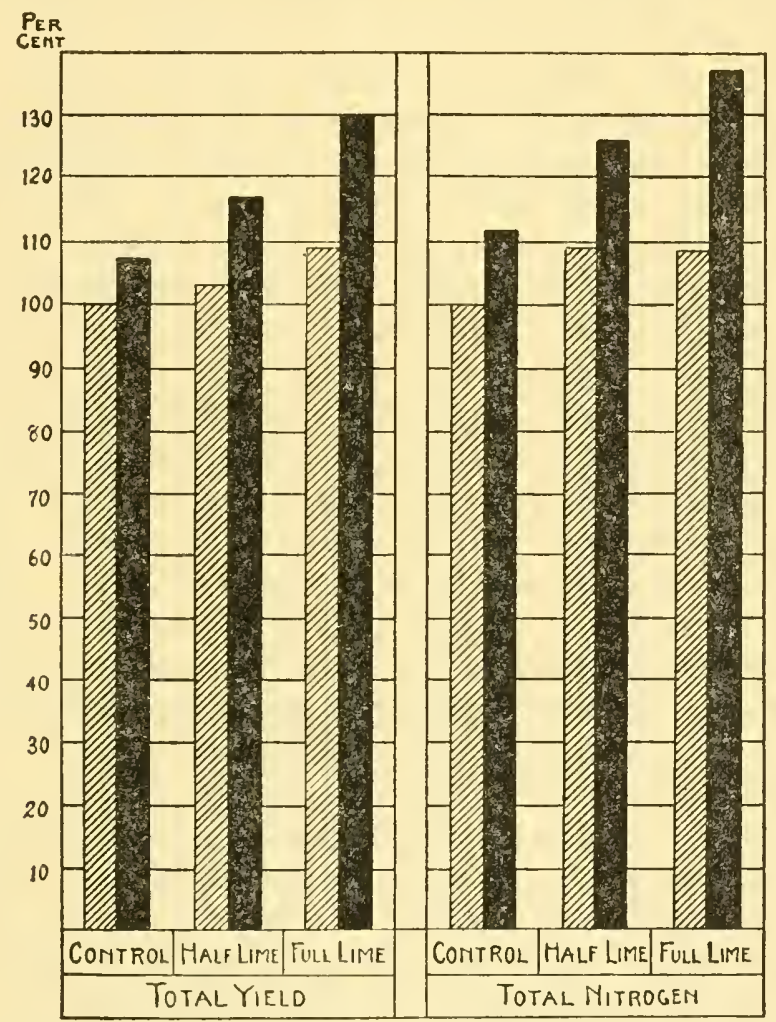

F1G. 77. Influence of inoculation and liming upon the growth and nitrogen content of alfalfa: checked columns denote uninoculated and dark columns inoculated soil (from Fred and Graul).

pounds of nitrogen per acre from inoculation, in pot experiments, and 24 pounds in field experiments is recorded. Inoculation increased the

${ }^{36}$ Graul and Fred, 1922 (p. 825); Fred, E. B. The fixation of atmospheric nitrogen by inoculated soybeans. Soil Sci., 11: 469-477. 1921; Whiting, A. L., Fred, E. B., and Stevens, J. W. Inoculation increases yield and quality of peas for canning. Wis. Agr. Exp. Sta Bul. 372. 1925. 
yield of soybeans 1787 pounds per acre, or more than threefold; it also resulted in a net gain of nitrogen of 57 pounds per acre, 87 per cent of which was in the tops. The residue left after the crop has been removed, also benefits the succeeding crop. An average increase in the total nitrogen content of the crop, as a result of inoculation, is given as 122 pounds per acre for American soil, and 200 pounds per acre for German soil.

Inoculation of non-leguminous plants with nodule bacteria. Various attempts have been made to inoculate nodule bacteria upon non-leguminous plants, with variable success. Burrill and Hansen, ${ }^{37}$ basing their conclusions on their own observations and reports of other investigators, reported the results to be absolutely negative. Blunck, ${ }^{38}$ however, reported positive results. He grew the organisms first on a synthetic medium, then added to the medium an extract of the roots of the non-leguminous plant, then grew the organism on the sterile dead root of the plant, and finally on the living root. By this process of gradual adaptation, Blunck claims to have obtained positive results. However, in view of the fact that these results have not yet been confirmed, nor has Blunck himself brought further evidence to substantiate his hypothesis, we must consider the results as doubtful. Various other claims to discoveries of cultures of symbiotic nitrogen-fixing bacteria adapted to non-leguminous plants are usually found to be worthless on careful study. As far as our present information is concerned, nonlegumes cannot yet be inoculated with benéficial results. ${ }^{39}$

Inoculation of soil with non-symbiotic nitrogen fixing bacteria. It has long been known that a soil is capable of moderating in some way the losses of nitrogen due to removal in crop, drainage, etc. From various practical observations, it has been established that one hectare of soil of Central Europe is capable of fixing between 10 to 60 kilograms of nitrogen per year, independent of the leguminous plants. ${ }^{40}$ The most abundant and most active of the non-symbiotic nitrogen fixing organisms are the species of Azotobacter and Bac. amylobacter. As pointed out elsewhere, the most important factors influencing the activity of

${ }^{37}$ Burrill and Hänsen, 1917 (p. 126).

${ }^{38}$ Blunck, G. Die Anpassung der Knöllchenbakterien an Nichtleguminosen. Centrbl. Bakt. II, 51: 87-90. 1920.

${ }^{39}$ Kordes, H. Kritische Besprechung der Frage "Impfung der Nichtleguminosen." Ztschr. Pflanzenenähr. u. Düng., 4B: 382-394. 1925.

${ }^{40}$ Omeliansky, V. L. On the application of non-symbiotic nitrogen-fixing bacteria for soil fertilization. Russian Jour. Microb., 2: 125-139. 1915. 
the nitrogen-fixing bacteria in the soil are (1) the degree of activity of the specific organisms; (2) amount of available carbohydrates and other carbon compounds in the soil, which could serve as source of energy for nitrogen-fixation; (3) presence of mineral substances, especially calcium, phosphates, potassium, iron, etc.; (4) proper soil aeration favoring the activity of aerobic forms and not injuring the development of anaerobes (together with the aerobes); (5) presence of sufficient water; (6) proper soil temperature; and (7) favorable soil reaction, etc. These factors have been considered in detail elsewhere. It is sufficient to emphasize here that, in addition to the presence of vigorous nitrogen fixing bacteria, the soil must be in a proper physical and chemical condition, before nitrogen-fixation will take place. If soil conditions are made favorable, the nitrogen fixing bacteria will develop rapidly, since they are present in sufficient abundance in all soils. In acid soils, no infection with Azotobacter is apt to occur soon after the reaction is corrected. ${ }^{41}$ It is also important to emphasize that a sufficient amount of energy is required for nitrogen fixation to take place, i.e., for every pound of nitrogen fixed by the non-symbiotic bacteria, about 100 pounds of available carbohydrate or other carbon compounds are consumed.

However, when natural organic substances, such as straw and various plant residues, green manure, etc. are added to the soil, they are first of all attacked by the numerous saprophytic soil microorganisms, especially the fungi, which break them down rapidly with the liberation of carbon dioxide as the final product. In assimilating the available carbon compounds, the fungi and other microorganisms require available nitrogen to build up their body proteins, about 2 to 5 parts of nitrogen for every 100 parts of carbon available. This nitrogen is obtained from the available nitrogen in the soil, to the detriment of the growing plants, unless it is also introduced into the soil, as in stable manure. The fungi and other saprophytic organisms will stop growing when the available nitrogen is exhausted. It is then when the nitrogen-fixing bacteria become active. In the presence of some available carbohydrate or its derivatives, such as the various organic acids, and in the absence of available nitrogen, they may fix the nitrogen of the atmosphere. After all the available carbohydrate has been used up or transformed into unavailable forms, the fungus mycelium and bacterial cells, including those of the nitrogen-fixing bacteria, begin to be decomposed by the

4t Remy and Rösing, 1911 (p. 578); Gainey, 1925 (p. 832). 
various soil microorganisms, especially the bacteria and actinomyces, with the result that the nitrogen is becoming available for higher plants.

It is this group of phenomena which brought about confusion in an attempt to explain why the addition of available carbohydrates at first lowers crop yield, ${ }^{42}$ and why favorable results are obtained one year after the application of carbohydrates, as shown in the following summary:

\begin{tabular}{|c|c|c|c|c|c|}
\hline \multirow{2}{*}{ CARBOHYDRATE } & \multicolumn{2}{|c|}{ CROP YIELD, DRY MATTER } & \multirow{2}{*}{$\begin{array}{l}\text { TOTAL } \\
\text { NITROGEN IN } \\
\text { CROP }\end{array}$} & \multirow{2}{*}{$\begin{array}{l}\text { NITROOEN IN } \\
\text { SOIL, SPRING } \\
\text { OF } 1906\end{array}$} & \multirow{2}{*}{ Nitrate $N$} \\
\hline & Oats, 1905 & Beets, 1906 & & & \\
\hline percent & & & grams & per cent & p.p.m. \\
\hline None & 100.0 & 100.0 & 0.5914 & 0.093 & 10 \\
\hline Glucose, 2 & 32.8 & 186.0 & 0.6814 & 0.105 & 17 \\
\hline Sucrose, 2 & 33.3 & 179.0 & 0.6800 & 0.105 & 15 \\
\hline Sucrose, 4 & 37.7 & 283.0 & 1.0092 & 0.119 & 37 \\
\hline
\end{tabular}

In various studies no effect has been noted as a result of application of carbohydrates and, in some cases, even an injurious effect has been observed. This may be clue to the variability of the method for cletermining the total nitrogen. The following example may be taken as an illustration: The addition of five tons of a pure carbohydrate (on a water-free basis), whether in the form of straw, hay, plant stubble, green manure, etc., is quite a large amount to add per acre of soil. Even assuming that such a quantity is added and that it is all utilized by the nitrogen-fixing bacteria as a source of energy (which is again doubtful), the maximum amount of nitrogen fixed under these conditions would be 0.5 part of nitrogen for every 100 parts of carbohydrate, or 50 pounds of nitrogen per acre. If the soil contains only 0.1 per cent nitrogen, this will form only about $2 \frac{1}{2}$ per cent of the nitrogen content of the soil, i.e., less than the error involved in the method for determining nitrogen. By using $5 \mathrm{gm}$. of soil for total nitrogen determination, the difference will be only $\frac{1}{8}$ of a milligram. Those familiar with the method know how easily such an error is obtained.

The question of soil reaction has been also discussed in detail else-

${ }^{42}$ Krüger, W., and Schneidewind, W. Ursache und Bedeutung der SalpeterZersetzung im Boden. Landw. Jahrb., 29: 747-770. 1900; Gerlach, M., and Vogel, I. Versuche mit stickstoffbindenden Bakterien. Centrbl. Bakt. II, 9: 817, S80. 1902; 10: 636-643. 1903; Lipman, J. G. Soil inoculations with Azotobacter beijerincki. N. J. Agr. Exp. Sta. 21 Ann. Rep. 1908, 144-147.

${ }^{43}$ Koch, Litzendorff, Krrull and Alves, 1907-1909 (p. 586). 
where. No introduction of Azotobacter will help to establish this organism in the soil and bring about increased nitrogen fixation in an acid soil with a pH less than 6.0. However, the addition of lime to change the $\mathrm{pH}$ to above 6.0 will by itself bring about a development of an active nitrogen fixing flora, of course if other conditions are favorable. Good results from inoculation may be obtained in the case of freshly drained swamps, in which Azotobacter would be absent. ${ }^{44}$ But the reaction of the soil must first be adjusted by the use of lime.

All attempts to inoculate normal soils with Azotobacter and other non-symbiotic nitrogen-fixing organisms failed on repeated study. From Caron's "alinit" 45 in 1895 to Bottomley's" "bacterized peat," all attempts to exploit commercially the nitrogen-fixing capacity of Azotobacter and other bacteria failed. ${ }^{47}$ The soil itself harbors sufficient organisms which become active when conditions and nutrients are favorable, as shown by Gainey for Azotobacter. Hiltner ${ }^{48}$ claimed to have obtained good results from inoculation of sugar beets with bacteria; just what these bacteria do in the soil, has not been determined. The U-cultures of Kühn, ${ }^{49}$ which are also used as an all-crop inoculant, have been found worthless by Barthel. ${ }^{50}$

Ehrenberg ${ }^{51}$ compared soil inoculation with symbiotic and non-symbiotic nitrogen-fixing bacteria, with the following conclusions:

1. On comparing the abundance of the various bacteria living in the soil, hardly any change takes place as a result of artificial inoculation, since the bacteria

${ }^{44}$ Stoklasa, J. Deut landw. Presse 1908, No. 25-27; Stranak, Fr. Zur Assimilation des Luftstickstoffes durch im Boden freilebenden Mikroorganismen. Centrbl. Bakt. II, 25: 320-321. 1909.

45 Caron, A. Landwirtsehaftlich-bakteriologische Probleme. Landw. Vers. Sta., 45: 401-418. 1S95; see also Stoklasa, J. Biologische Studien über Alinit. Centrbl. Bakt. II, 4: 39-41, 7S-86, 119-130, 284-289, 507-513, 535-540. 1898; Deut. landw. Presse, 35: 274, 286-297. 1908; Heinze, B. Über die Beziehungen der sog. Alinit bakterien (Bac. ellenbachiensis Caron) zu dem Bac. megatherium deBary bezw. zu den Heubacillen (B. subtilis Cohn). Centrbl. Bakt. II, 8: $391,417,449,513,545,609,663.1902$.

${ }^{46}$ Bottomley, W. B. Rpt. Brit. Assn. Adv. Sci. 1911, 607-608.

${ }^{47}$ Russell, E. J. Report on humogen. Jour. Bd. Agr. (London), 24: 11-20. 1917.

${ }^{48}$ Hiltner, L. Über die Impfung der Futter und Zuckerrüben. Mitt. Deut. Landw. Gesell., 26: 243. 1921; Engelmann, E. Mitt. deut. Landw. Gesell., 37: 560. 1922 .

${ }^{49}$ Kühn. Deut. Landw. Presse, 44: 467. 1917.

${ }^{50}$ Barthel, Chr. Försök med Dr. A. Kühns U-Kulturer. Meddl. No. 184, Centralanst. f. forsoksv. jordbruks. 1919; Deut. Landw. Presse, 50: 192. 1920.

51 Ehrenberg, P. Theoretische Hinweise zur Frage der Wirkung einer Boden- 
from the commercial preparations rapidly succumb. The legume bacteria have the opportunity of penetrating the roots of the leguminous plants, whereby they are protected from competition with other bacteria. The protection is afforded also when the leguminous plants are dead since the nodules do not decompose so readily.

2. Although soil bacteria fix appreciable quantities of nitrogen under laboratory conditions and a definite success may be obtained on inoculating soil with such bacteria, the use of rather expensive substances like mannite or sugar make it rather prohibitive. The growth of algae was found to offer only questionable hopes. ${ }^{52}$

Soil inoculation with autotrophic bacteria. A number of organisms causing plant diseases can be affected in their growth by a proper control of the soil reaction; this is especially true of those that are very sensitive to acidity, as in the case of diseases caused by actinomyces (potato scab, etc.). The addition of sulfur to the soil is used as a means of increasing the acidity of the soil to a point at which the development of the disease-producing organism is checked. But before this can take place, the sulfur has to be oxidized to sulfuric acid by proper bacteria. All soils contain organisms capable of oxidizing elementary sulfur; these may carry on the oxidation only very slowly, especially in certain soils. When strong sulfur oxidizing organisms are added, the oxidation of the sulfur may be hastened appreciably. This led to the development of a commercial product, which consists of sulfur inoculated with a crude culture of Thiobacillus thiooxidans. It still remains to be proved, however, how long the culture will survive on the dry sulfur and how efficient it may be, in comparison with the organisms present in ordinary soils.

The inoculation of soil with nitrifying bacteria, especially in case of freshly drained swamps may also be of direct benefit.

Inoculation of soil with heterotrophic, non-nitrogen-fixing microorganisms. Attention has already been called to Caron's first attempt to prepare a bacterial culture $\left(\right.$ alinit $^{53}$ ) for soil inoculation, with the idea of stimulating the decomposition of organic matter in the soil. Although

impfung mit freilebenden stickstoffsammelnden Bakterien. Fühl. landw. Ztg., 69: 161-166. 1920; Centrbl. Bakt. II, 53: 409. 1921.

62 Further information on the inoculation of soil with Azotobacter is given by Emerson, P. Soil inoculation with Azotobacter. Iowa Agr. Exp. Sta. Res. Bul. 45. 1918; Omeliansky, 1923 (p. 559); Brown, P. E., and Hart, W. J. Soil inoculation with Azotobacter. Jour. Amer. Soc. Agr., 17:456-473. 1925; Gainey, P. L. Inoculating soil with Azotobacter. Soil Sci., 20: 73-86. 1925.

${ }^{63}$ Complete literature on alinit is given by Heinzc, 1902 (p. 831 ). 
the first attempts were unsuccessful, references are still found in recent literature concerning the use of similar preparations. It is claimed ${ }^{54}$ that $B$. ellenbachensis $\alpha$ and alinit-bacillus $\alpha$ will allow luxuriant growth of grain crops without the addition of nitrogenousfertilizers. Various other preparations (A. Kühn's U-cultures, All-crop Inoculant, Inoculin) have been placed on the market for the inoculation of cultivated plants other than legumes. The results have so far proved negative.

It still remains to be seen whether the inoculation of soil with strong cellulose-decomposing bacteria can stimulate the processes of decomposition of organic matter in the soil.

We need also mention here again the results of Hartley ${ }^{55}$ showing that soils partially sterilized by means of heat or volatile antiseptics will benefit by the inoculation with saprophytic fungi. These fungi develop rapidly in the soil and thus prevent development of parasitic fungi causing the damping off of forest seedlings. If a soil is infested with injurious nematodes, it may be benefited by inoculation with predatory nematodes. ${ }^{56}$

${ }^{54}$ Daude. Impfung von Feldern mit Bakterien. Blätt. Zuckerrüben., 25: 156. 1919; 26: 30, 45, 176. 1919; Centrbl. Bakt. II, 53: 408. 1921.

${ }^{55}$ Hartley, 1921 (p. 000).

${ }^{50}$ Steiner and Heinley, 1925 (p. 347). 


\section{CHAPTER XXXII}

History of Soll Microbiology, its Past, Present, and Future

"The history of a science is not merely a chronicle of discovery, but a study of the relation of methods and ideas in progress and the application of the conceptions thus gained to guide us in present and future work."-Henderson.

Every science, especially every biological science, goes through, in the course of its development, a series of stages which can be briefly summarized as follows:

1. Ecological stage, including description and classification. Here we are largely interested with the description of the organisms, their morphology and taxonomy.

2. Physiological stage, or a study of the activities of the organisms in question.

3. Experimental stage, whereby changes in the physiology of the organisms are studied, as a result of experimental conditions.

4. Mathematical stage, when formulae are developed to express in exact language the mechanism of the physiological processes.

Finally, we find that every science, when it reaches a certain stage of development, branches off into several new sciences.

The age of a science is definitely indicated by the stage in which it is in. Soil microbiology is only a science in the maling; but, while it has not left as yet the ecological stage and the very methods of study are still undergoing active change, it has already reached the stage when expressions are found for a correlation between the activities of the microorganisms and the environmental conditions. This science includes not only a study of soil microorganisms and their activities under experimental conditions, but also the resultant phenomena of the sum total of their activities in the soil. The fact that numerous groups of organisms, the activities of which may be supplementary or antagonistic, exist in a very complex medium, the soil, under very complex environmental conditions, tends to complicate the subject still further. The science of soil microbiology is also beginning to branch off into soil mycology, algology, protozoology, nematology, etc., as well as soil biochemistry. 
Beginnings of soil microbiology. Each science has its roots and antecedents in the past and each is developed out of the materials of the past. This is true particularly of soil microbiology, which has developed directly from the empirical practices in agriculture and as a result of the advances made by the science of bacteriology; it owes a great deal to the older sciences, botany and its daughter science mycology, zoology and its offspring protozoology, chemistry, physics, and especially these sciences as applied to soil processes.

Among the empirical practices, we need mention (1) the beneficial influence of the growth of legumes upon subsequent crops, (2) the composting of manure or various farm wastes, (3) the burning of the upper layer of soil to insure better crops, (4) the addition of fertile soil to soil newly prepared from bogs. The progress of physics resulted in the development of the microscope and balances. The progress of chemistry resulted in a knowledge of the chemical composition of matter, a better understanding of the composition of complex proteins and carbohydrates, and in the development of various methods used in organic and inorganic analysis. The development of physical chemistry resulted in the progress of our understanding of the nature of colloids and surface phenomena, of the hydrogen-ion concentration of the medium, oxidation and reduction processes. All have contributed to the development of soil microbiology. The study of the microorganisms themselves clates back to the work of Kircher and Leeuvenhoek (1683), who made the first observations on the bacteria, followed by the investigations of O. G. Müller (Animalcula infusoria, 1786), Ehrenberg' ${ }^{1}$ and T. Schwann. ${ }^{2}$ The last demonstrated that yeast was a living organism. The science of botany has contributed to a better knowledge of the morphology and physiology of fungi and algae. The science of zoology advanced our understanding of the protozoa, nematodes and other invertebrates found in the soil, especially in respect to their nutrition and relation to the other members of the soil population. - Bacteriology, beginning with the work of Pasteur on microorganisms as chemical agents, has been one of the most fruitful fields in stimulating the development of soil microbiology. Both the medical and agricultural bacteriologists have made important contributions. It is sufficient to mention the methods of pure culture study of bacteria, finally leading to a differentiation of microorganisms on a physiological basis; the plate method for counting and isolating bacteria; the introduction of selective enrich-

${ }^{1}$ Ehrenberg. Die Infusionstierchen als vollkommene Organismen. 1839.

'Schwann, T. Gilbert's Ann. Phys. u. Chemie., 51: 1837. 
ment and specific culture media, the anaerobic methods, etc., all of which were necessary steps in the development of the science. The development of media proceeded from the complex organic media, introduced by R. Koch, to the special inorganic media such as silica jelly, introduced by Winogradsky, and synthetic media introduced by Beijerinck. These artificial media finally led to the use of the soil itself as a culture medium for the growth and activities of microorganisms. Any modification of the physical or chemical condition of this medium, either as a result of addition of nutrients or stimulants, or as a result of change of environmental conditions, leads to a change in the numbers and activities of the microorganisms.

Three distinct biological processes had been clearly outlined and partly understood by the middle of last century: (1) Decomposition of organic matter. This was known to give rise to humus which was believed to be one of the fundamental principles in soil fertility. Some investigators (Liebig, 1840) considered humus only as an intermediary product and not as a plant food; organic matter was believed to decompose slowly by chemical oxidation ("eremacausis"). The work of Schloesing, Wollny and others finally led to a better understanding of the process. (2) Nitrification. The accumulation of nitrates in the soil as a result of decomposition of organic matter was known in 17 th and 18th centuries, but only Boussingault connected this process with soil fertility. (3) Nitrogen fixation. The use of legumes for enrichment of the soil was known to the ancient Romans. Berthelot was the first to suggest that nitrogen fixation may be accomplished also by non-symbiotic bacteria. The isolation of the organisms concerned both in nitrification and nitrogen fixation took place only at the close of last century.

Soil microbiology as an independent science. Three definite and often distinct conceptions are included in the science of soil microbiology, namely: (1) a knowledge of the organisms occurring in the soil, their numbers, types and relationships; (2) the biochemical activities of these organisms, under laboratory conditions and in pure culture; (3) the rôle of these activities in the soil processes and their application to agriculture. Any advance in the science of botany, zoology, or bacteriology, which throws light upon the nature of organisms which occur in the soil, such as the development of new methods, a better system of classification in bacteriology, the rôle of bacteria in the nutrition of protozoa, the question of the physiology and classification of filamentous fungi, the rôle of mycorrhiza in plant nutrition, etc. can be considered 
as contributing to the advance of soil microbiology. Any discovery in the field of chemistry or physics, which has a bearing upon soil formation, composition and processes, upon the chemistry of plant cells, as well as any new methods of analysis, are of direct importance to the development of soil microbiology.

It is argued, however (Winogradsky), that, while a great deal of information has accumulated on the methods of isolation and cultivation of certain organisms present in the soil, while a great many organisms have been isolated and described, while the biochemical activities of a number of these organisms are known, there is still lacking the science of soil microbiology proper, or the applied science.

The beginnings of soil microbiology as an independent science date back to the sixth and seventh decades of the last century. There are two outstanding names in soil chemistry and bacteriology, whose theories were far from agreeing, but whose researches have dovetailed to give origin to the science; namely, those of Liebig (1S40) and Pasteur (1860). Liebig's theories of soil fertility fell short because he did not recognize the activities of microorganisms. Pasteur's work was not concerned directly with soil microorganisms, but his bacteriological investigations in general, and specifically the study of the various fermentations including that of urea and butyric acid, pointed the way to a new development.

It remained for the practical agriculturist to combine the efforts of the chemist and bacteriologist and call attention to the importance of microorganisms in soil fertility. Kette $^{3}$ (1865) deserves the credit for being the first to recognize this fact. He advanced the fermentation theory, in which he stated that the importance of the addition of stable manure to the soil consisted in the fact that it cannot be replaced by nitrogen compounds and minerals as well as by purely vegetable matter, because the latter lack "a true vibrion fermentation." His views have found ardent adherents, as can be recognized from the work of Rosenberg-Lipinsky, ${ }^{4}$ who stated that "milliards of lower animals per acre are born every moment and die after a few days, sometimes after a few hours, serving others as food." The birth, or rather awakening, of medical bacteriology in the carly part of the ninth decade of last century was also accompanied by a rapid development in soil bacteriology. The work of Koch on the gelatin plate method, of

${ }^{3}$ Kette, W. Die Fermentationstheorie gegenüber der Humus-Mineral und Stickstofftheorie. 2 Aufl. 1865.

${ }^{4}$ Rosenberg-Lipinsky. Der praktische Ackerbau. 3 Aufl., 2: 27.1869. 
Hellriegel and Wilfarth on the nodule bacteria and fixation of nitrogen by leguminous plants; the work of Frank and Beijerinck on the isolation of the organisms and their cultivation in pure culture, and finally the work of Winogradsky on the autotrophic bacteria were the contributions which transformed the science from its preparatory into the building period.

With the introduction by Robert Koch, in 1881, of the gelatin plate for the study of bacteria, a stimulus was given to the systematic study of soil microorganisms, although the earliest bacteriologists were medical men and were more interested in public health and hygiene than in soil processes. They limited themselves entirely to a study of the numbers of bacteria and fungi in various soil layers, that would develop on the gelatin plate. Any organism that did not develop on the plate was not considered to be of importance. The occurrence of specific organisms was studied chiefly from the point of view of finding out whether the soil contained pathogenic organisms. Here may be mentioned, in addition to Koch, Fränkel in Germany and Houston in England.

Of biochemical processes in the soil, the first to attract universal attention, as said before, were those of nitrification and nitrogen-fixation. Pasteur suggested in 1862 that nitrification is a bacterial process and Schlösing and Müntz definitely proved that in 1877. This was soon followed by the work of Warington, who in a series of splendid contributions, beginning with 1878, established some of the most fundamental principles of the process of nitrification in the soil, outside of actual isolation of the organisms concerned. This was accomplished in 1890 , by Winogradsky. In reference to nitrogen-fixation, universal attention was first centered upon the symbiotic process. Boussingault emphasized in 1838 that the favorable action of legumes upon the soil is due to their power of fixing atmospheric nitrogen. Frank demonstrated in 1879 that the nodules on the roots of the plants are formed as a result of inoculation with microorganisms. This was definitely demonstrated in 1886 by Hellriegel and Wilfarth. The organism Bact. radicicola was isolated and described by Beijerinck in 1888. The non-symbiotic nitrogen-fixing bacteria were isolated in 1893 by Winogradsky (Clostridium) and in 1901 by Beijerinck (Azotobacter).

The names of Winogradsky and Beijerinck stand for the most fundamental work that has been done in building up the science of soil microbiology. While Winogradsky limited himself to the study of autotrophic and the anaerobic nitrogen-fixing organisms, Beijerinck's 
contributions are distributed throughout the whole field of soil microbiology. His studies embraced symbiotic and non-symbiotic nitrogen-fixing bacteria, sulfur-oxidizing bacteria, nitrate and sulfate reducing bacteria, actinomyces, algae, etc. The bulk of Winogradsky's work was limited, but the quality is of the highest, it stands for the most classical work in the science of soil microbiology.

The study of decomposition of nitrogenous organic compounds in the soil is closely connected with the names of Pasteur (1863), Müntz and Coudon (1893) and Marchal (1893), who pointed out that various bacteria and fungi are capable of breaking down proteins with the rapid formation of ammonia. Here belongs the work of Gayon and Dupetit (1881) on nitrate reduction, of Deherrain (1886) on the decomposition of farmyard manure, and Wollny (1897) who studied organic matter as a whole. The beginning of the study of cellulose decomposition by bacteria is closely connected with the name of Omeliansky, but neither the organisms nor the chemistry of the process were completely understood for a long time. Attention should also be called in this connection of the important contribution of Ferdinand Cohn to the classification and description of a number of heterotrophic soil bacteria, followed by the work of A. Meyer and his associates on the spore-forming bacteria of the soil, as well as by Chester and others. The name of one other man should be mentioned here, that of Caron (1895); he was neither a chemist nor a bacteriologist, but a practical agriculturist who contributed a great deal to the stimulation of the theoretical and practical interest in the subject of soil microbiology. Caron demonstrated that any soil treatment which leads to an increase in the number of microorganisms also leads to an increase in crop productivity; fallowing of a heavy soil can be used in place of green manure. Although the practical agriculturists, by pointing out the great importance of microorganisms in soil processes and, therefore, in agriculture, often aroused great interest in the soil processes, the influence was frequently not far reaching. The practical men expected that soil microbiology would revolutionize agriculture just as medical bacteriology revolutionized medicine, but this did not materialize. Where this influence was strongest, especially in Germany and in the United States, some people came to believe that, outside of legume inoculation, there is nothing to the whole science of soil microbiology. This attitude toward a science which lies at the very roots of all soil economy and will no doubt influence, in the future, the whole agricultural practice, could result only from a lack of sufficient knowledge concerning the problems under consideration. 
The soil is a medium, more or less colloidal in nature, containing a great mass of microscopic forms of life. These produce various physical and chemical changes in the soil which are of greatest importance to the growth of higher plants. The pathologist can study the action of his organisms in vivo; the microbiologist working on fermentation processes can sterilize his medium, without altering its composition greatly, and inoculate it with a pure culture of the organism concerned; the soil microbiologist, however, has great difficulties in attempting to learn just what the particular organisin does in the soil. When the soil is sterilized, it is no longer, biologically and chemically, a normal soil. In a pure culture, free from stimulating and competing influences of other microorganisms, an organism may manifest certain activities which would not take place in the soil, or vice versa. It is even possible that, in pure culture, different races develop from those present originally in the soil and it is quite probable that the biochemical action is often quite different. As a matter of fact, a very large number of soil organisms develop upon artificial media only with great difficulty and are often repressed there by other organisms which may be only occasional visitors in the soil.

Recent advances of the science. During the first decade of the present century, the methods used in the study of soil biological processes have undergone various modifications. Some investigators centered their attention upon the study of the metabolism of specific soil microorganisms, especially the mechanism of transformation of organic or inorganic substances as bearing upon soil processes. This was determined either by adding a small amount of soil to a sterile solution containing the specific substance, then measuring the change that took place after a definite period of incubation; or by adding the specific substance to the soil, keeping it at optimum moisture and temperature for a definite length of time, and then measuring the change. In most of these studies, the organisms responsible for the change were not considered at all. In the study of protein decomposition, ammonia was usually taken as an index, without eonsidering the fact that the process can be carried on by numerous types of organisms and various associations and combinations, each resulting in a different amount of ammonia accumulating. In the study of nitrogen fixation, the fact was usually left out of consideration that different organisms are active at different reactions and, therefore, different amounts of nitrogen are fixed under laboratory conditions, which may or may not hold true in the field. In the study of nitrification, the fact that the addition 
of large amounts of ammonium salts will soon result in a reaction (the degree depending on the buffer content of the soil) injurious to nitrification, while the addition of a large quantity of organic nitrogenous material may result in the formation of such large amounts of ammonia that the nitrifying bacteria will be injured, were usually left out of consideration. These investigators, often referred to as the physiological group, consisted of practical men, often insufficiently interested in microbiology, but primarily interested in the phenomena resulting from soil processes rather than in the organisms active in the soil itself. The first representatives of this group are Remy and Löhnis, later followed also by various workers in Germany, J. G. Lipman, Brown, Greaves, C. B. Lipman, and others in America, with Perotti in Italy, Christensen in Denmark, and others contributing more to one or another phase of the subject.

The other group of investigators, often referred to as the botanical group, were more interested in knowing how many bacteria there are in the soil, what these bacteria are, and if physiological groups were studied, they wanted to know the numerical relation of one group to another. Hiltner and Störmer (1902) were the strongest advocates of this method of attack, followed by H. Fischer in Germany, Chester, H. J. Conn and others in this country, etc. In addition to these two groups of investigators interested in soil biological processes chiefly from the standpoint of the soil, a number of botanists, zoologists, general microbiologists, and chemists continued to make definite contributions to the science of soil microbiology, either by the study of one more group of soil organisms, including the soil bacteria (A. Meyer and associates, Ford et al.), fungi (Hagem, Lendner, Dale, Waksman, etc.), algae (Chodat, Bristol, Esmarch, etc.), actinomyces (Krainsky, Conn, Waksman, Drechsler), protozoa (Wolff, Goodey, Cutler et al.) and invertebrate animals (Cobb, Micoletzky), or by the study of one chemical process in the soil and the organisms concerned, such as cellulose decomposition (Kellerman and associates, Barthel, Pringsheim, etc.), nitrogen fixation (Omeliansky, Bredemann, J. G. Lipman, Christensen, Gainey, Winogradsky, etc.), evolution of $\mathrm{CO}_{2}$ (J. Russell, Stoklasa, van Suchtelen, Neller, etc.).

The more outstanding recent contributions to the science of soil microbiology deal with microorganisms non-bacterial in nature. It is sufficient to mention the work of Russell and his associates on the occurrence of protozoa in the soil and on the phenomenon of partial sterilization; the occurrence and activities of algae, fungi, actinomyces and nematodes in the soil. It is also important to call attention to 
the development of methods for the direct examination of microorganisms in the soil by $\mathrm{H}$. J. Conn and recently by Winogradsky. We possess now also a better understanding of the organisms concerned in the oxidation of sulfur in the soil (Lipman and associates), while the rôle of microorganisms in the decomposition of cellulose and other polysaccharides in the soil (Hutchinson and Clayton, Fred, etc.) has been made clearer; a knowledge of the controlling influence of soil reaction upon the distribution and activities of soil microorganisms has influenced certain practices; the same is true of our increased knowledge of legume cultivation and inoculation (Hiltner, Whiting, etc.), of the use of green cover crops, fallowing and soil cultivation.

Present outstanding problems in soil microbiology. The science of soil microbiology is in its mere infancy. New contributions open up broader and broader vistas, rich in reward both to the investigator and to practical men. The soil is the basis of all agricultural practice. The population of the soil makes the soil what it is and not a mass of debris containing all the elements necessary for plant growth in an unavailable form; sooner or later a study of this population will be recognized to be of most importance in the future advance of agriculture.

We possess at the present time considerable information on the organisms inhabiting the soil and on the chemical processes of many of these organisms, under controlled laboratory conditions; but little is known of the processes carried on in the soil itself, by the numberless representatives of the soil flora and fauna. The transformation of organic matter, the availability of the mineral elements, the fixation and transformation of nitrogen, the best means for the preservation of the nitrogen already present in the soil or manure, these are a few of the processes which depend largely upon the activities of microorganisms and which control the growth of cultivated plants. Some of the outstanding problems in the science may be suggested here:

1. Microscopic and cultural methods in soil microbiology, especially those which tend to indicate the organisms active in the soil under field conditions and their, rôle in the transformations taking place in the soil.

2. The soil population, nature, extent and activities; the complexity of the population with its various associative and antagonistic influences. It is especially desirable to know what rôle the animal population, such as protozoa and nematodes, play in soil processes and how they influence bacterial activities, also the interrelation between the fungi and the bacteria and the rôle of actinomyces in the soil. 
3. Transformation of organic matter in the soil, both as to the chemical processes involved and organisms concernerl, also the rôle of these transformations in soil fertility.

4. The energy balance in the soil as well as the balance between the soil constituents, largely the carbon and nitrogen.

5. A better understanding of the rôle of cultivated higher plants in soil transformations and the influence that they exert upon the activities of soil microorganisms.

6. Methods of modifying the soil population and its activities with a better understanding of the processes of partial sterilization, application of lime and fertilizing materials, soil inoculation, as well as soil fallowing.

7. The physical, chemical, and physico-chemical condition of the soil (reaction, buffer content, moisture holding capacity, temperature) and the occurrence and activities of soil microorganisms.

These as well as a host of other problems to which attention has been called in the previous pages will not only throw light upon the different phases of soil microbiology, little understood at the present time, but will place the science where it should be, namely in the front rank of agricultural sciences.

Depending as he does upon the contributions of the protozoologist, mycologist, bacteriologist, nematologist, etc., for a better understanding of the organisms inhabiting the soil and their activities, the soil microbiologist is in a position to correlate the sum total of the knowledge gained from these investigations and throw light upon the chemical processes in the soil. The soil physicist and the soil chemist do and will contribute definitely to the understanding of the nature of the medium in which these organisms act and of the soil solution, which receives, on the one hand, the waste products of their activities and which supplies nutrients to the plants and frequently to the microorganisms. It is to the development of the science of soil microbiology as much as to any other science that we must look for the proper understanding of the soil as to its ability to supply the nutrients necessary for the growth of higher plants. ${ }^{5}$

${ }^{5}$ Further information on the history and development of soil mierobiology is found in the following papers and books: Fischer, 1909 (p. 712); Löhnis, 1910 (p. xiii); Löhnis, F. Ergebnisse amerikanischer, britischer und französicher Arbeiten auf dem Gebiete der landwirtschaftlichen Bakteriologie aus den Jahren 1915 bis 1920. Centrbl. Bakt. II, 54: 273-307. 1921; Winogradsky, S. La méthode directe dans l'étude microbiologique du sol. Chimie et Industrie., 11: No. 2. 1924; Waksman, S. A. Soil microbiology in 1924; an attempt at an analysis and a synthesis. Soil Sci., 19: 201-249. 1925. 



\section{INDEX OF AUTHORS}

\section{A}

Abderhalden, E., xiii, xvi, 269

Abel, E، 603

Abel, R., xiii, 556

Aberson, G., 185

Aberson, Y. H., 788

Abbott, E. V., 270, 604

Ackermann, D., 485

Acklin, O., 550

Adametz, 28, 237

Adam, A., 636

Adams, C. C! 358,360

Adams, G. O., 509

Aelyy, J., 185

Afanassiewa, M., 244, 417

Agafonoff, V., 702

Aichberger, R. V., 353

Aikman, C. M., xiv

Aiyer, C. V. R., 489

Aiyer, P. A.S., 96, 97, 99, 234, 639

Albrecht, W. A., 517, 552, 595, 770, 821

Albus, IV. B., 374

Alexeiev, A. G., 317, 340

Alilaire, E., 378

Allen, E. J., 221

Allen, E. $R_{r}, 580,716$

Allison, F. E., 49, 326, 328, 329

Allison, R. V., 333

Allison, V. C., 178

Almy, I. H., 613

Alves, A., 586, 830

Alway, F. J., 826

Ambroz, A., 156, 158, 188

Ames, A., 779

Ames, J. W., 658, 661, 665

Ampola, G., 185, 186, 187, 552

Amster, 322

Anderson, B. G., 178

Anderson, H. IW, 250

Anderson, J. A., 451, 518
Anderson, G. M., 361

Anderson, M.S., 627

Anderson, R. J., 651

Ankersmit, P., 166

Appel, O., 264

Appleyard, A., 624, 639, 721, 722, 779, 799

Arinstein, B., 468

Arnaud, A., 418

Arnd, Th., 530, 531, 551, 707

Arndt, A, 320

Arny, A. C., 822, 825

Arrhenius, O.. 352, 634, 635, 814

Arrhenius, S., 418

Artari, A., 230

Arzberger, E. G., 138

Ashby, S. F., 113, 117, 394, 526, 534, $576,668,716$

Ashe, I. H., 467

Aso, K., 450, 574, 649, 791

Atkins, W. R. Gi, 359, 636, 814

Atwater, W. O., 124, 819

Aubel, E., 415, 467, 507, 521, 543

Auten, J. T., 649

Ayers, S. H., 245, 636

B

Baas-Becking, L. G. M., 357, 397

Baeh, 464

Bach, $M_{\iota}, 244$

Baehmann, F., 163, 164

Bail, O., 805

Bainbridge, F. A., 478

Baker, F. G. C., xi

Bal, D. V., 338

Baldwin, I. L., 815

Ball, O. M., 129, 597

Barakov, P., 799

Barlyer, M. A., 55, 167, 220, 246

Barlow, B., 127, 128, 821 
Barlow, P., 26

Barnard, J. E., xiii, 55

Barrenscheen, H. К., 556

Barthel, Chr., 104, 130, 131, 149, 154, $448,498,518,528,529,531,537,551$, $641,642,727,779,821,831$

Bassalik, K., 646

Bassu, E., 162

Batchelor, H. W., 497, 582

Batham, H. N., 528

Baumann, 644, 690

Baumgärtel, T., xii

Baunacke, IV., 344, 348, 350, 805

Bavendamm, W., 82

Baver, L. D., 634

Baylis, H. A., xii

Bayliss, W. M., xvi

Bazarevski, S. V., 154, 653, 656, 769

Bear, F. E., 790

Beard, E., 631

Beauverie, J., 58

Bechhold, H., xvii, 626

Beckh-Wirlmenstetter, H. A., 556

Beckley, V. A., 693, 698

Beckmann, E., 456, 807

Beckwith, T. D., 259, 496

Beers, C. D., 315

Behn, 712, 756, 762

Behrens, J., 203, 242, 264, 266, 466

Beijerinck, M. W., v, 70, 76, 84, 87, $98,103,104,105,112,115,119,121$, $125,160,171,183,187,188,203,204$, $207,217,219,222,299,304,319,383$, $385,391,399,447,484,543,546,547$, $548,571,574,606,611,631,665$, 694, 806

Beiling, R., 412

Beinhart, E. G., 815

Van Bemmelen, J. M., 629, 697

Benecke, W., xii, 221, 489

Bengtsson, N., 432, 448, 497, 518, 528, $529,680,727$

Benni, 692

Benoist, S., 431

Bergey, D. H., x, 136, 158, 289, 309

Berestneff, N. MI., 300

Bergene, 591

Berghaus, W. H., 640
Berhauer, K., 467

Berkhout, C. N., 238

Berkmann, M., 793

Berliner, E., 349

Berman, N., 475, 478

Bernard, N., 272, 276, 803

Berry, R. A., 427

Berthelot, D., 524

Berthelot, M., 104, 415, 558, 573, 800

Bertrand, G., 431, 435, 448, 649

Bessey, E., 810

Besson, A., xiii, 167

Bevan, E. J., 431

Bewley, W. F., 131, 812

Bezssonoff, N., 37, 110, 121, 560, 565, $569,752,762$

Bialosuknia, W., 137

Bierema, S., 187, 212, 486, 502, 544

Biernacky, IV., 455

Bierry, H., 454

Biltz, A., 524

Binder, K., 170

Biourge, $\mathrm{Ph}$, 238

Birchard, F. J., 473

Bizzell, J. A., 539, 599, 705, 749, 795, 796, 797, 799

Bjorkman, C. B., 456

Blair, A. W., 375, 448, 501, 511, 598, 826

Blakeslee, A. F., 246

Blanck, E., 260, 353, 711, 782

Blau, O., 148, 156

Blaxall, F. R., 156, 201, 440

Blobel, S., 527

Blochwitz, A., 242

Blom, J., 549

Blunck, G., 828

Bodine, J. H., 325

Bogdanov, S., 673

Bogue, R. H., 626

Boischot, P., 747

Bojanowsky, R., 195

Bokorny, Th., 230

Bolley, H. L., 757, 807

Bonazzi, A., 66, 71, 73, 114, 396, 22 ', $560,566,567,572,574,575,716$

Bondorff, K. A., 121, 802

Bonnema, A., 573

Bonnet, R., 410, 415 
Bornebusch, C. H., 117

Botkin, S., 171

Böttger, H., 789

Bottomley, W. B., 138, 562, 580, 694, 699,831

Boulet, V., 283

Boulanger, E., 65, 394, 527, 604

Boussingault, J. B., 106, 122, 638, 786

Bouyoucos, G. J., 371, 619, 627, 632, 749

Brannon, J. M., 777

Brasch, W., 485

Bréal, E., 184, 337, 553

Bredemann, G., 108, 109, 110, 111, 121, $172,203,517,585,641,770$

Breed, R. S., 9, 22, 57, 182, 288

Brefeld, O., x, 241

Breinl, F., 805

Breitschneider, 123

Brenchley, W. E., xv

Brenner, W., 91, 117, 241, 269, 503

Brew, J. D., 9

Brierley, W. B., 239, 259

Bright, J. W. , 41, 491, 500, 686, 774

Brioux, Ch., 604, 636

Briscoe, C. F., 773

Bristol-Roach, M. B., 50, 218, 221, 224, $225,231,233$

Brizi, U., 234

Broadhurst, J., 58

Brooks, C., 779

Brooks, S., 244

Brown, C. W., 652

Brown, H. D., 91, 608, 815

Brown, P. E., xiv, 15, 32, 33, 35, 43, $112,539,598,604,638,702,711,716$, $731,779,785,787,791,792,799,826$, 832

Brown, W., 244

Brussoff, A., 94

Bruyn, H. L. G. de, 807

Bruyn, W. K. H. de, 328

Bryan, H., 633

Bryan, O. C., 128, 595, 826

Buchanan, R. E., x, xii, 58, 131, 373, 593

Buchanan, R. M., 170

Buchner, H., 170

Buckle, P., 356

Buckman, H. C., xv
Buddin, W., 539, 744

Buhlert, 716

Burd, J. S., 799

Burgeff, H., 276

Burgess, P. S., xiii, 116, 491, 533, 534, $538,583,716,731,789$

Burke, V., 134

Burkey, L., 134

Burnet, E., 612

Burns, A. C., 761

Burr, S., 306, 809

Burri, R., 55, 115, 161, 162, 167, 170, 185,554

Burrill, T. J., 125, 126, 135, 139, 156, 594,828

Burton, E. F., 626

Busch, K., 349

Busse, W., 247

Buswell, 311

Buttenberg, J., 556

Butkewitsch, Wl., 262, 467, 494, 503, 666

Butler, E. J., 238, 247

Bütschli, O., xi, 312

Butterfield, C. T., 322, 336

Byars, L. P., 349, 815

\section{C}

Cadness, B. H. E., 614

Calkins, G. N., xi, 312, 336

Cameron, A. E., 356, 357, 361

Cameron, F. K., xiv, 630, 634, 749

Carbone, D., 204

Carapelle, E., 543

Carey, C., 196

Caron, A., 34, 104, 772, 785, 794, 831

Caron, H. V., 181, 552

Carpenter, P. H., 689

Carter, E. G., 531, 532, 577, 584, 664, $668,774,783,784,789$

Carter, N., 230

Cash, J., xi, 331

Casuto, L., 626

Cauda, A., 328

Caullery, M., 803

Chabrie, C., 556

Chalmers, C. H., 199, 455

Chalmot, G. de, 453 
Chambers, C. O., 270

Chambers, R., 56

Chambers, W. H., 373

Chandler, A. C., 345

Chapman, A. C., xi

Chapman, C. W., 371

Charaire, 316

Charlton, J., 634

Charpentier, C. A. G., 431, 449, 450, 635, 727

Charpentier, P. G., 232

Charrin, A., 418

Chatton, 320

Chen, C. C., 155

Chester, F. D., x, 35, 103, 143, 150, $491,597,710,772$

Chivers, A. H., 238, 251

Chlopin, G. W., 640

Chodat, R., x, 220, 221, 230

Cholodny, N., 94, 385

Chouchack, D., 735

Christensen, H. R., 116, 186, 209, $449,576,578,581,634,664,700,707$, $709,725,730,788,792$

Christiansen-Weniger, F., 570, 591

Christoph, H., 277

Chudiakow, N. N., xii, 161, 631

Chukevitch, J., 166

Church, M. B., 238, 241, 744

Churchman, 165

Cingolani, M., 186, 214

Clark, F. D., 749, 758

Clark, H. W., 509

Clark, W. M., xvii, 18, 164, 371, 520, 634

Clarke, F. W2, xiv

Claypole, E., 289

Clayton, I., 120, 195, 439, 448

Clegg, M.'T., 299

Clements, F. E., x, xv

Cleveland, L. R., 316, 339

Colbb, N. A., 343, 346, 348, 349

Colset, R., 789

Cohen, B., 164

Cohen, E., xvii

Cohnheim, O., xvi

Cohn, $F_{\text {" }}, 80$

Cohn, R., 436

Coleman, D. A., 269, 320, 328, 757
Coleman, L. C., 391, 531, 535, 782

Colin, $\mathrm{H}_{2}, 461$

Collins, F. S., 230

Collison, R. C., 500, 518, 671

Comber, N. M., 628

Compton, A., 448

Conn, H. J., xii, $6,7,10,15,23,27$, $32,40,41,56,142,149,150,152,182$, $240,288,290,304,309,491,500,518$, 686, 774

Conn, H. W., xii, 333, 335

Connor, S. D., 636, 712, 815

Conrad, C. M., 460

Cook, M., 167

Cook, M. T., 243, 809

Cook, R. C., 15, 495

Cooley, J. S., 244, 779

Coppa, A., 328

Coppenrath, E., 734

Coudon, H., 267, 480, 490

Coupin, H., x, xi

Coville, F. V., 636

Cowie, G. A., 488

Cramer, 80, 378, 380, 382, 455

Cramer, IV., 631

Crisafulli, G., 212

Crozier, W. J., 418

Cross, C. F., 431

Crump, L. M., 32, 49, 50, 318, 321, 326, $328,329,336,767$

Cubbon, M. H., 790

Cunningham, A., 45, 320, 327, 336

Curtis, R. E., 40, 290, 304, 309

Cutler, D. W., 32, 46, 47, 50, 318, 321, $326,327,328,329,336,337,338,739$, 759,767

Cutright, C. R., 359

Czapek, F., xv, 269, 270, 379, 419, 424, $459,502,573,654,793$

Czermak, W., 777

Dachnowski, A. P., 707

Dack, G. M., 174

Daikuhara, G., 551

Dakin, H. D., 481, 483, 540

Dale, D., 314 
Dale, E., 237, 259

Damon, S. R., 176

Dangeard, P. A., 230

Darbishire, F. V., 523, 752

Darwin, C., 352

Daszewska, 238, 265

Daude, 833

Davenport, A., 76, 127, 132, 582, 594, 823

Davenport, C. B., xviii, 26,

Davis, A. R., 270, 281

Davis, J. J., 362

Davis, R. O. E., 633

Davison, W. C., xvii

Davy, H., 122, 183, 524

Dayhuff, IV. C., 628

DeBary, A., x, 264

Debord, J. J., 476

Dehérain, P. P., 183, 445, 523, 537, $548,553,682,781,786,793$

Delacroix, 808

DeMIan, J. G., xii

Demolon, A., 604, 747, 749

Demoussy, E., 523, 682

Dernby, K.. G., 301

Derx, H. G., 464

Detemar, K., 277

Detmer, W., 672

Deusch, 508

Devaux, H, 460

Dianowa, E. W., 631

Didlake, M., 135

Dicm, K., 355, 357

Dietzell, B. E., 183

Dimo, N. A, 363

Dischendorfer, O., 431

Distaso, A., 172, 199

Dixon, M., 543

Dmochowski, R., 432

Dobson, M. E., 700

Doerell, E. G., xiii

Doflein, F., xi, 312, 323, 325

Donker, H. J. L., 173, 526, 549

Dorner, W., 111, 164, 165, 166, 175, 582

Dorseh, R., 185

Doryland, C. J. T., 35, 69, 506, 771, 782

Dotterer, W. D., 22

Dox, A. W., 382, 651

Dozier, C. C॰, 171, 176
Drechsler, C., 288

Drew, G. H., 662

Drouin, R., 234, 573

Dubaquié, 463

Dubos, R., 735

Dubovsky, B. J., 174, 806

Duclaux, E., xiii

Dufort, 208

Dufrenoy, J., 283

Düggeli, M., 30, 39, 77, 82, 85, 110, 175, 611

Duggar, B. M., 270, 281, 597, 813, 824

Dujardin, M., 604

Dukes, C. E., 382

Dupetit, G., 181, 183, 185, 548

Dupont, C., 156

Dvorak, J., 428, 562, 684

Dzierzbicki, A., 577

E

Earp-Thomas, G. H., 824

Eckelmann, E., 150, 641

Ecker, E. E. , 212

Edgerton, C. W., 257

Eden, T., 690

Edmondson, C. H., 312, 331, 333, 335

Edwards, S. F., 821

Effront, J., xvi

Eggertz, C. G., 672

Egorov, M. A., 651, 750

Ehrenberg, A., 184

Ehrenberg, C. G., 92, 222, 329, 835

Ehrenberg, P., xiv, 268, 480, 498, 626, $710,785,813,831$

Ehringhaus, A., xiii

Ehrlich, F., 242, 429, 481, 482, 483

Ehrlich, R., xiii

Eichwald, E., xvii

Eijkman, C., 464

Einecke, A., 664, 774

Eisenberg, P., 631

Elion, L., 189, 611

Ellenberger, W., 436

Eller, W., 692

Ellinger, A., 485

Ellis, D., xii, 93, 94

Elveden, V., 746 
Emerson, F. V., xiv

Emerson, P., 832

Emich, xii

Emmerich, R. W., 752, 774

Emmerling, O., 502

Emoto, Y., 746

Engberding, D., 14, 21, 621, 712, 768, $771,782,788$

Engelmann, E., 831

Engler, A., x, xi, 230, 252

Enlows, E. M. A., 59

Epstein, A., 199

Erismann, H., 631

Ernest, A., 34, 429, 685, 718, 772, 794

Esmarch, F., 218, 222

Esselen, G. J., 456

Esten, W. M., 30

Estienne, V., 461

Euler, A. C., 431

Euler, H., xvi

Eyre, J. W. H., xiv

\section{F}

Faber, F. C., 105, 140

Fabricius, O., 785

Falck, R., 467, 694

Fallot, B., 670

Fantham, H. B., 329

Faris, J. A., 812

Fawcett, E. H., 129

Fearon, W. B., 487

Fehrs, 311

Feiber, W. A., 176

von Feilitzen, H., 785, 821, 822

Fellers, C. R., 49, 326, 328, 329

Fellows, H., 810

Felton, L. D., 542

Fierguson, M., 552

Fermi, C., 162

Fernandes, J. F. S. A., 288

Feuilletau, 328

Fickendey, 716

Field, E. C., 808

Findlay, A., xvii

Fine, M. S., 315, 318

Fischer, A., xii, 247

Fischer, E., x, 435, 472
Fischer, E. A., 630, 636

Fischer, F., 459, 693

Fischer, H., 13, 15, 105, 118, 121, 232, $251,260,450,529,530,534,554,576$, $586,664,685,687,711,712,743,746$, $782,790,791,843$

Fischer, Her, 642, 644

Fischer, R. A., xviii, 26, 46

Fleischer, M., 682

Floess, R., 26

Flügge, C., x, 149, 476

Fodor, A., xvii

Foex, E., 815

Fol, J. G., 298

Folin, O., 475

Folpmers, T., 489

Folsom, J. W., 362

Ford, W. W., 143

Forti, 230

Foulerton, A. G. R., 300

Fousek, A., 40, 302, 309, 441, 493

Fowler, G. J., xvi,

Fowler, L. W., 120, 129, 597

Fraendel, C., 171

Francé, 225, 642

Frank, B., 124, 126, 231, 271, 280

Franke, B., 745

Franke, F., 550

Frä,nkel, C., 1.2, 20, 34

Frankland, 64, 181

Fraps, G.S., xiv, 539, 672, 685, 716, 781

Fraser, A. D., 638

Fray, W. W., 316, 319

Frazier, W. C., 822

Frear, W., 788

Fred, E. B., xiii, xiv, 15, 76, 120, 121, $127,131,132,133,136,157,186,202$, $222,242,378,379,417,440,452$, $454,518,530,552,580,582,593,594$, $647,685,754,777,788,802,822,823$, $825,826,827$

Fremlin, 531

Fresenius, L., 450, 685, 791

Freudenreich, E. V., 110, 119

Freundlich, H., xvii, 626

Frey, W., 631

Fricke, K., 674

Friebes, V., 204 
Fries, K. A., 10

Fritsch, F. E., 222, 234

Froehlich, H., 261

Fuchs, W., 458

Fuhrmann, F., xiii, 169

Fulmer, H. L., 121, 580, 791

Furman, N. H., xvii

\section{G}

Gaarder, T., 77, 529

Gage, S. D., 491

Gage, S. H., xiv

Gainey, P. L., 116, 496, 534, 536, 560, $582,583,685,688,716,761,787,829$, 832

Gallaud, I., 272

Galle, E., 98

Gardner, W. A., 673

Garino, E., 186, 187

Garman, H., 135

Gates, W. W., 702

Gaudechon, H., 524, 539, 610, 781

Gaümann, E., $x$

Gautier, A., 234, 573

Gayon, U., 181, 183, 185, 548

Gedroiz, K. K., 629, 630, 633, 698

Gehring, A., 87, 188, 670

Geilinger, H., 176, 210

Georgevitsch, 105

Gerard, E., 211

Gerlach, M., 119, 183, 379, 508, 554, $574,592,830$

Gerretsen, F. C., 188, 529, 592, 736

Gerza, U., $6 j 2$

Gescher, N., 199

Ghosh, E., 331

Giaja, J., 454

Gibbs, H. D., 164

Gibbs, W. M., 66, 497, 787, 802

Gicklehorn, J., 83

Giesecke, F., 353

Gilbert, 300

Gilbert, J. H., 106, 122, 124, 795

Gilbert, W. W., 815

Gile, P. L., 735

Gillespie, L. J., 18, 301, 522, 634, 814

Gilman, J. C., 811
Giltay, E., 185

Giltner, W., xiv, 583

Gimmingham, C. T., 268, 529, 662, 814

Girard, A., 749

Given, G. B., 716

Glenk., K., 633, 742

Glinka, K. D., xiv

Globig, 155, 300

Goddard, H. M., 238, 259, 270

Godlewski, K., 525

Golden, R., 651

Golding, J., 592

Goldthorpe, H. C., 532

Goodey, T., 323, 325, 326, 32s, 337, $338,349,742$

Goodfrey, G. H., 345

Goppelsröder, F., 545

Gordon, G. E., 320

Gordon, J., 163

Gortner, R. A., 452, 650, 690, 692

Gosio, B., 556

Goss, R. W., 807

Gottheil, O., 143, 148

Götze, C., 550

Gozony, L., 319

Grafe, V., 382, 462

Gran, H. H., 455

Grandeau, L., 689

Grassheim, K., 417

Graul, E. B., \$25, 827

Gray, F. J., 604

Gray, P. H. H., 199, 455

Grazia, S. de, 527, 652

Greaves, J. E., xiii, 36, 117, 179, 531, $532,534,539,563,577,578,579,584$, $585,661,663,774,783,784,785,789$

Greef, R., 329

Green, H. H., 531, 579, 687, 688, 716, 731

Greenfield, M., 155

Gregory, W., 222

Greig-Smith, R., 37, 465, 593, 742, 760

Griddle, N., 359

Griffith, B. M., 82

Grint esco, J., 221, 230

Groenewege, J., 117, 20J, 421, 46, 441, 448,546

Grohmann, G., 101

Gruber, Th., 29 
Gryns, A., 592

Guarnieri, G., 203

Gubin, B. M., 609

Guénaud, C., 810

Guerbet, M., 604

Guggenheim, M., 178

Guillemin, M., 668

Guillermond, A., xi, 250

Guittonneau, G., 299, 493, 604, 609

Gully, 644, 690

Gustafson, A. F., 743, 749

Gustafson, F. G., 412

Gutzeit, E., 716

\section{H}

Haas, A. R. C., 647, 802

Haas, P., xvi

Hagem, O., 77, 237, 247, 266, 268, 269, 503

Hager, H., xiv

Hägglund, $\mathrm{F}$., 456

Hahn, E., 777

Hahn, J., xv

Haines, F. M., 222

Hall, A. D., xiv, 268, 529, 664, 793

Hall, I. C., 164, 165, 174

Hall, I. W., 638

Halsted, B. D., 814

Halversen, IV. V., 33, 43

Hamilton, C. C., 359

Hammer, R. W., 563, 569, 570

Handschin, E., 358

Hansen, E. C., 251

Hansen, R., 125, 126, 132, 135, 136, $139,594,824,828$

Hansendorf, 694

Hansteen Craner, B., 643

Hanzawa, J., 119, 238, 575, 580

Harder, E. C., 93, 402, 666

Harder, E. G., 33, 777

Harding, H. A., 56

Hardman, R. E., 813

Hardy, F., 636

Hargitt, G. T., 316, 319, 323

Harned, H. H., 773

Harring, H. K., 351

Harris, J. E., 634
Harrison, D. G., 540

Harrison, F. C., 823

Harrison, W. H., 96, 99, 234, 639

Harrison, F. C., 127, 128

Hart, E. B., 600, 685, 788

Hart, W. J., 832

Harter, L. L., 418, 461, 808

Hartleb, R., 77, 105

Hartley, C., 807, 815, 833

Hartmann, M., xvi, 323

Hartig, 263

Harz, C. O., 288

Haselhoff, E., 110, 653

Hasenbäumer, J., 620, 633, 701, 734, $742,783,791$

Hastings, E. G., xiii

Hata, S., 163

Hatschek, E., xvii

Hauman, L., 203, 242

Hayes, W. P., 362

Headden, W. P., 539

Headlee, T. J., 361

Heap, H., 614

Hecker, F., 55

Hedin, G., xvii

Heiden, E^, xv

Heimberger, H. V., 352

Heine, E., 621

Heinemann, P. G., xiv

Heinicke, A. J., 793

Heinley, H., 347, 833

Heinze, B:, 121, 232, 446, 573, 585, 592, $694,742,752,786,788,800,831,832$

Hellbronner, А., 666

Heller, E., 265

Heller, H. H., 164, 172

Hellriegel, H., 124

Hellström, P., 449, 772

Helz, G. E., 136

Henneberg, W., xi, 818

Henrici, A. T., 58, 251, 291

Henry, T. A., xvi

Hensen, V., 352

Herfeldt, E., 554

Hérissey, H., 454

Hesse, R., 360

Hesselman, H., 696

Heraeus, W., 63 
Hermann, R., 697

Heukelekian, H., 261, 266, 443, 451, 692,728

Heurck, H. J., xi, 230

Heuser, E., 427, 431

Hewlett, R. T., xiv

Heymons, R., 353

Hibbard, P. L., 616

Hibbard, R. P., 371

Hibbert, H., 431

Hibler, E. V., 167, 172

Hilgard, E. W., xv, 707

Hilgermann, 349

Hill, H. H., 517, 706, 770

Hill, T. G., xvi

Hill, T. L., 339

Hills, T. L., 575

Hiltner, L., 12, 21, 41, 47, 125, 127, $128,129,134,138,150,337,585,589$, 591, 592, 593, 59S, 643, 744, 751, 761, $763,772,819,820,831$

Hinkle, S. F., xiv

Hinze, G., 82

Hirschler, A., 505

Hirsch, P., 178

Hiss, P. H., xii,

Hissink, D. J., 634

Hoagland, D. R., 371, 628, 632, 634

Höber, R., xvi

Hoering, P., xv

Höflich, C., 186

Hoffmann, C., 39, 158, 563, 569, 570, $571,622,656,794$

Hoffmann, F., 30

Holben, F. J., 670, 791

Holderer, M., 435

Holker, J., 167

Holmes, R. S., 627

Holthaus, K., 357

Holtz, H. F., 702

Holzmüller, K., 143, 149

Honcamp, F., xv

Honing, J. A., 737

Hopfe, A., 199, 265

Hopkins, C. G., xv, 521, 5ss, 598, 657

Hopkins, R. F., 814

Hoppe-Seyler, F., 433, 446, 697, 700

Horowitz, A., 181
Hort, E. C., 55, 169

Hösslin, A., 194

Houston, A. C., 14, 142, 154, 173, 785

Howard, A., 800

Huber, B., 275

Hubert, E. F., 459

Hucker, G. J., 153

Hüne, 754

Hungerford, C. IV., 812

Hunt, N. R., 815

Huntemüller, O., 336

Hunter, O. IV., 568, 571, 580

Hunter, W. D., 362

Hurst, L. A., 814

Husek, B., 530

Husz, H., 303, 464

Hutchinson, C. M., 117, 121, 760

Hutchinson, H. B., 120, 131, 195, 311, $439,448,502,517,587,743,746,757$, 761,790

Hutin, A., 702

Hüttermann, IV., 30

Hyslop, J. A., 362

Imaseki, 'T., 551

Imms, A. D., 356

Irvine, J. C., 700

Itano, A., 117, 476, 580, 582

van Iterson, 186, 195, 200, 264, 266, 433,547

Iwanoff, N. L., 3S1, 651

\section{J}

Jachschewski, A., 757

Jacobsen, A., 481, 483

Jacobsen, H. C., \&5, 217, 399

Jacquot, R., 410, 415

Janke, A., xiii, 407

Janse, J. M., 272

Japha, A., 556

Jeannert, J., 478

Jegen, G., 354

Jegorow, M., 675

Jegunow, M., 83

Jellinek, K., xvii

Jensen, C. A., 656, 781, 796 
Jensen, C. N., 237, 259

Jensen, H., 180, 181, 186, 187, 551

Jensen, O., 59, 297, 421

Jensen, P. R., 645

Jensen, S. T., 634

Jodidi, S. L., 501, 513, 621, 672, 686

Joffe J. S., 10, 89, 595, 601, 615, 616

Johnson, E. M., 601, 815

Johnson, H. W., 262, 582

Johnson, J., 813, 814

Jollyman, W. H., 180

Jones, C. B., 300

Jones, D. H., 114, 116, 118, 585

Jones, F. R., 128, 275, 813

Jones, J. O., 670

Jones, J. S., 702

Jones, J. W., 178

Jones, L. R., 203, 461, 810, 811

Jordan, E. O., xii

Jörgensen, A., xi

Joshi, N. V., 749, 824

Jost, L., xv

Jungano, M., 172

K

Kadisch, E. 164

Kahn, M. C., 176

Kamamura, 647

Kanitkar, N. V., 749

Kanitz, A., 418

Kappen, H., 260, 267, 603, 634, 636, 711, 735, 782

Karraker, P. E, 815

Karrer, J. L, , 217, 224

Karrer, P., 190, 431

Karunaker, N., 730

Kaserer, H., 97, 98, 403, 579, 580, 699, 763

Kauffman, C. H., 276

Kayser, E., xiii, 572, 579

Kazakov, A. V., 660

Keil, F., 81, 398

Keith, S. C., 777

Kellerman, K. F., 126, 129, 138, 193, $197,435,436,439,444,517,574,662$, $716,798,819$

Kelley, W. P., 512, 532, 539, 555, 657, $664,743,749,789$
Kellogg, E، H., 604

Kendall, A. I., xii, 167, 505

Kette, W., 837

Khouvine, Y., 193, 438

Killer, J., 45, 320

Kimmelstiel, P., 641

King, C. J., 813

King, F. H., 122, 534, 795

King, W. E., 35, 771, 782

Kissling, R., 682

Kitasato, S., 165

Kiuyma, B., 467

Klaeser, M., 148, 181

Klason, 456

Klebahn, 809

Klebs, G., 333

Klein, A., 9, 173

Klein, G., 88

Klein, M. A., 538, 685, 722

Klett, A., 556

Klimmer, M., 135

Klinger, R., 809

Klöcker, A., xi, 251

Klott, C., 137

Kluyver, A. J., 526, 549

Knight, H. G., 636

Knudson, L., 281

Köber, L., XV

Koch, A., xiv, 159, 447, 443, 536, 550, $559,562,567,578,535,536,651,655$, $711,750,753,802,830$.

Koch, G.P., 45, 326

Koch, K., 692

Koch, R., 12, 838

Kochmann, R., 556

Koffman, M., 314

Kofoid, C A., 325

Kohl, F. G., xi, 250

Kohswitz, H. G., 353

Kolkwitz, R., xv, 82

Kolle, W., xii

Kolthoff, I. M., xvii

Kondo, M., 614

König, J., 429, 430, 478, 620, 633, 670, $676,701,734,742,783,791$

Köning, C. J., 237, 259, 263, 234, 265, 634

Koorders, S. H., 139

Kopeloff, N., 320, 328, 757 
Kordes, H., 828

Koser, S. A., 153

Kosin, N. I., 436

Kossowicz, A., xiii, 212, 267, 270, 503

Kossowitsch, P., 232, 601

Kostytschew, P., 361

Kostytschew, S., xv, 183, 244, 417, 573

Kosyachenko, I. S., 267

Krrainsky, A., 40, 288, 297, 309, 442, $563,566,569,575,584,586$

Kramer, E., 383

Kraus, R., xiv

Krause, M., 353, 790

Krawkow, S., 645

Kröber, E., 453, 655

Krohn, V., 158

Kroulik, A., 157, 202, 440

Krüger, F., 310

Krüger, R., 135

Krüger, W., 105, 232, 516, 746, 748, 786,830

Krull, F., 586, 830

Krumwiede, C., xii, 58

Kruse, W., xii, 183, 378, 389, 410, 415, 424

de Kruyff, E., 157, 251, 464

Krzemieniewski, H., 159, 576

Krzemieniewski, S., 159, 576, 579, 585, 700

Kühl, H., 181

Kühn, A., 319, 333, 822, 823, 831

Künnmann, $\mathrm{O}, 187$

Kuntze, W., 32, 187

Kunze, F., 645

Kürsteiner, J., 162, 169

Kürsteiner, R., 30

Kusano, S., 284

Küster, E., xiv, 241

Kyropoulos, 662

\section{L}

Labes, R., 631

Lachmann, 124

Lachner-Sandoval, V., 288

Ladd, E. F., 796

Lafar, F., xiii, 241

La Flize, S., 599
Lainé, E., 66, 531

Langeron, M., xiv

Langwell, H., 202, 439

Langworth, H. V., 583

Lantsch, K., 98, 169, 298, 620, 630

Lapicoque, L., 556

Larsen, O. H., 581

Larson, W. P., 668

Lathrop, E. C., 257, 453, 474, 479, 501, $502,503,671,6866748$

Latshaw, W. L., 598

Laubach, C. A., 143

Laubenheimer, xiv

Laupper, G., 775

Laurent, E., 125, 133, 181

Lavialle, P., 489

Lawes, J. B., 106, 122, 124, 795

Lawrence, J. S., 143

Leather, J. W., 639, 781, 799

Lebedeff, A. F., 98, 101, 403, 550

Lebedjantzev, A. N., 740

Lebour, M. V., 359

Lechair, C. A., 794

Lee, A. B., xiv, 323

Lehmann, F., 456

Lehmann, K. B., x, 56, 289

Leidy, J., 331

Leiningen, Graf zu, 752, 774

Lemmermann, E., xi, 333

Lemmermann, O., 251, 260, 450, 501, $517,530,551,554,664,685,711,774$, 781,791

Lendner, A., 237, 247

Lennep, R. V., 163

Lentz, O., 167

Leonard, L. T., 129, 137, 362

Lesser, 194

Levene, P. A., 475

Levine, M., 813

Levine, V. E., 556

Levy, M. M., 653

Lewin, K. R., 43, 318, 324, 326, 328, 329

Lewis, G. N., xvii, 386

Lewis, W.C., McC., xvii

Lewt, 638

Lex, R., 211

Lichtenstein, S., 199

Liebert, F., 212, 488 
Liebig, J., 522, 837

Liebscher, G., 748, 805

Liesche, D., 456

Liesegang, R., 641

Lieske, R., 86, 95, 18s, 28s, 297, 398, $399,402,666$

Limburger, A., SS

Lindau, G. K., x, xi i, 252

Lindner, A., xi

Linhart, G. A., 419, 570

Lint, H. C., \&8, 320, 328, 614

Lipman, C. B., 36, 77, 106, 116, 120, $129,179,491,529,532,533,534,538$, $539,576,577,582,583,584,597,670$, $700,716,783,789$

Lipman, J. G., xiii, xiv, 15, 88, 89, 92, $112,115,119,125,375,448,479,480$, $491,501,511,539,559,563,569,570$, $574,575,598,599,614,640,687,711$, $772,784,788,791,792,799,826,830$

Lissauer, M., 29

Lister, A., xi

Littauer, F., 207

Litzendorff, J., 586, \$30

Livingston, B. E., 760

Lochhead, A. G., 34, 41, 196, 199, 435 Loeb, J., xvi, 627

Loeb, IV., 573

Loew, O., 381, 390, 574, 752, 774

Löhnis, F., xiii, xiv, 13, 28, 30, 32, 36, $55,56,94,98,114,115,119,120,126$, $135,179,196,199,207,209,211,320$, $327,435,479,489,491,501,527,531$, $554,555,559,563,579,585,586,687$, $688,694,709,711,712,716,731,780$, $782, \$ 24,843$

Lomanitz, S., 379, 491, 513

Long, 311

Lotka, A. J., xvii

Löwi, E., 169

Ludwig, O., 694

Lumière, A., 781

Lund, Y., 577

Lundegardh, H., xv, 412, 638, 640 Lwoff, A., 317

Lymn, A., 202, 439

Lyon, T. L., xv, 539, 599, 705, 749, 785, $792,793,794,795,796,797,799$
M

Maassen, A., 171, 181, 182, 185, 187, $549,611,614,712,756,762$

MacBride, T. H., xi

MacDougal, D. T., 275, 281

Macé, E., xiv, 293, 309, 493

Macfayden, A., 156, 201, 440

MacIntire, W. H., 604

Mackenzie, W. A., 26

Magdeburg, P., 225

Magistris, H., 382

Magrou, J., 273, 281

Maillard, L. C., 692

Makkus, W., 786

Makrinov, I. A., 71, 203, 531

Malone, R. H., 55

Malpighi, 123

Mameli, E., 106

de Man, J. G., 346, 348, 349

Mann, H. H., 749

Manns, T. F., 808

Maplestone, P. A., xii

Maquenne, L., 183, 548

Marchal, E., 182, 267, 480, 490, 591

Marcinowski, K., 349

Marcusson, J., 446, 691, 693

Marino, F., 167

Marshall, C. E., xiii

Marshall, R. P., 815

Martelly, 492

Martin, C. H., 48, 318, 324, 328, 329

Martin, T. L., 517, 674

Mason, C. J., 30

Massee, C. E., 813

Massol, L., 65, 394, 527

Mast, S. O., 315

M'Atee, W. L., 358

Mathews, A. P., xvi

Matthews, A., 756

Mattson, S. E., 628, 630

Matz, F., 185

Matzuschita, T., x, 29

Maublane, 808

May, D. W., 735

May, F. V., 689

Mayer, A., xv, 381 
Mazé, P., 103, 169, 182, 378, 531, 54S, 594,793

McBeth, I. G., 197, 263, 265, 435, 536, $539,561,797$

McCall, A. G., 661

MeClendon, J. F., xvii

McColoch, J. W., 360, 362

McConnell, IV. R., 362

McC.ool, M. M., 371, 632

MeDougal, W. B., 283

McGeorge, W., 749

MeGinnis, F. W., 822

MeInnes, J., $\$ 14$

McKinney, H. H., 810,813

McLean, H. C., S8, 259, 267, 375, 44S, $494,501,511,614,615,616,772$

McLennan, E. I., 272

McLennan, K., 790

McLeod, J. M., 163

Medes, G., xvii

Medical Research Committee, 174

Meek, C. S., 529, 532

Meggitt, A., 554

Mehta, M. M., 457

Melhus, J. E., $\$ 12$

Melin, E., 5, 274, 276, 27S, 279, 281, 793

Meller, R., 375

Mello, F., $28 s$

Mellor, W. J., xviii

Mendel, L. B., 30

Menzel, R., 350

Merker, E., 195

Merkle, F. G, 685

Merrill, E. D., $28 s$

Merrill, G. P., xv, 646

Metzler, L. F., 534

Meusel, E., 545

Meyer, K. F., 174, 806

Meyerhof, O., 385, 390, 413, 417, 525, 528,531

Michaelis, L., 634

Michaelsen, WV., 351

Mieoletzky, H., xii, 347, 349

Niehe, H., 105, 139, 140, 156, 300, 440

Miège, E., 766, 808, 814

Migula, W., $x, 67,157,707$

Millard, IV. A., 36, 306, \$09, 810

Miller, D. J., 670
Miller, F., 530, 743, 792

Miller, N. H., 268, 502, 529, 664, 793

Minchin, E. A., xi, 312, 337

Minkmann, D. C. J., 187, 546, 548

Miquel, P., 206, 207, 221

Mischustin, E., 157, 776

Mitscherlieh, E. A., xv, 190, 432

Miyake, K., 375, 479, 495, 527, 689, 791

Miyoshi, M., 460

Moekeridge, F. A., 377, 563, 580

Moeller, A., 158

Mokradnatz, M., 649

Molér, T., 339, 572

Molisch, H., 83, 94, 385, 39S, 663

Moll, R., 781

Mollard, M., 106

Möller, A., 275, 281

Molliard, M., 262

Montanari, C., 534

Monteith, J., 812

Moore, B., 233

Moore, G. T., 126, 217, 224, 230, 236, $\$ 20$

Mooser, W., 524

Morgan, J. F., 632

Morgan, M. F., 636

Morgulis, S., 735

Morison, C. B., 605

Morris, H., 342, 347, 352, 357, 380

Morris, J. L., 212

Morse, F. W., 636

Mouton, H., 316

Mulder, J. J., 522, 697

Müller, A., 125

Mïller, C., S0

Mïller, K. O., 269

Müller, O. G., 835

Müller, P. E., 332, 337, 694

Müller, P. 'T., 45

Müller-Thurgau, H., 251

Mulvania, 114

Mumford, E. M., 96

Munk, M., 293

Münter, F., 297, 298, 302, 309, 622, 784

Munro, J. H. M., 63

Müntz, A., 62, 66, 267, 480, 490, 525, $527,531,537,539,610,646,7 \mathrm{SI}$

Münz, E., 97, 406

Murdoch, F. C., 116 
Murray, J. A., xv

Murray, T. J., 153, 155, 179, 517, 784

Muschel, A., 693

Musgrave, W. E., 299

Mütterlein, C., 434, 446, 726

Myers, F. J., 351

Myers, J. T., 613

\section{$\mathrm{N}$}

Nabokich, A. J., 98, 403

Nadson, G. A., 82, 83, 189, 269, 611, 663

Nagaoka, M., 555

Nakamura, K., 689, 791

Nakano, H., 232

Namyslowski, B., 248

Nasir, S. M., 315, 338

Naslund, C., 301

Nathanson, A., 84, 399, 424, 606

Nawiasky, P., 212, 481, 502

Needham, 522

Negelein, E., 412, 421, 546

Nègre, L., 156

Neide, E., 143, 148

Neidig, R. E., 382, 497

Neller, J. R., 263, 514, 685, 688, 712, 723, 799

Nelson, E. W., 221

Nencki, M., 477, 484

Neresheiner, E., 354

Nernst, W., xvii

Neuberg, C., 407, 436, 468, 485

Neukirch, H., 293, 302

Newcombe, F. C., 454

Newmann, R. O., $\mathrm{x}, 56,288$

Newton, J. D., 686

Nicolaier, A., 806

Nicolle, M., 378

Nikitinsky, J., 266, 700, 702

Niklas, N., 644, 667

Niklewski, B., 98, 99, 188 385, 403, $499,528,555,709,726,730,731$

Nikolsky, M., 378

Noack, K., 202, 300, 418

Nobbe, F., 125, 127, 129, 133, 134, 592, 750,820

Noble, W., 174
Nolte, O., xv, 552, 777

Norris, E. R., 692

Norris, R. V., 489

Norton, J. F., xvii, xviii

Northrop, J. H., 467

Nortrup-Wyant, Z., 21, 169

Novy, F. G., 171, 177

Nowikoff, M., 328

Noyes, H. A., 21, 712

Oberlin, 750

Oden, S., 626, 628, 671, 672, 690, 698

Odermatt, W., 809

O'Donnell, F. G., 815

Oehler, R., 319, 320, 322, 328

Oelsner, A., 551, 651

Ogata, M., 167

Olaru, D. A., 534, 579, 665

Oldenbusch, C., 754

Olig, A., 478, 490

Olson, G. A., 601

Oltmanns, Fr., xi

Omeliansky, W. L., xii, 66, 68, 71, 82, $96,108,109,110,113,118,121,170$, $191,199,393,433,437,445,527,560$, 564, 565, 566, 569, 571, 585, 777, 828, 832

O'Neil, A. M., 702

Oppenheimer, C., xvi

Oprescu, V., 156

Orlow, W. G., 666

Orr, M. V., 140

Orskov, J., 287, 288

Osborn, H., 362

Osborne, T. B., 30, 472

Osmun, A. V., 748

Osterhaut, W. J. V., 412

Ostwald, Wo., 626, 667

Osuga, C., 735

Otsuka, I., 613, 614

Otto, H., 265, 454, 459, 460

Oudemans, C. A. J. A., 237, 259

Owen, I. L., 375, 448, 501, 511, 539, 791

Owen, W. L., 535, 539 
$\mathrm{P}$

Page, H. J., 233, 619, 690, 695

Pakes, W. C. C., 180

Palladin, V. I., xv

Panganiban, E. H., 179, 777, 783

Pantanelli, E., 633, 645

Park, W. H., xii

Parker, W. L., 178

Parks, 387

Pascher, A., xi, 333

Pasteur, L., 62, 160, 206, 385, 412, 837

Patten, A. J., 652

Patterson, J. W., 783

Peck, S. S., 791

Peklo, J., 270, 275, 310

Peltier, G. L., 808

Penard, E., 331

Pennington, L. H., 276

Perey, J. F., 333

Perotti, R., 211, 489, 652

Perrier, A., 693

Pervier, N. C., 452

Peter, M., 97, 204, 408, 465

Peters, L., 247

Peters, R. A., 317, 321

Petersen, J. B., 223

Peterson, E. G., 174

Peterson, W. H., 127, 157, 202, 242, $378,379,417,440,452,454,600,823$

Peterson, P., 685

Petherbridge, F. R., 749, 763

Petit, P., 415, 711

Petri, R. J., 171, 611, 614

Pettenkofer, M., 685

Pettit, H., 550

Peyronel, B., 257, 274, 277

Pfeffer, W., xv, 270

Pfeiffer, Th., 517, 550, 554, 786

Philip, J. C., xvii

Phillips, R. L., 316

Pickering, S. U., 748, 761

Piemeisel, H. L., 262, 282

Pietruszczynski, Z., 665

Piettre, M., 239, 672, 690

Pillai, N. K., 120, 563, 731

Pinckney, R. M., $\$ 26$

Pistchimuka, P., 492
Plimmer, R. H. A., 651

Plinius, 122

Plotho, O. V., 388, 630

Plummer, J. K., 535, 636, 792

Poche, F., 331

Polk, M., 299

Pollacci, G., 106

Popoff, L., 432

Porter, C. L., 269, 641

Potter, R. S., 263, 450, 485, 497, 621, $639,685,722$

Povah, A. H. W., 238

Pozerski, E., 653

Powell, IV. J., 453, 456

Prantl, K., 252

Pratt, O. A., 257, 259, 807

Prausnik, W., 805

Prazmovski, A., 114, 125, 565, 575

Prescott, J., 630, 784

Pribram, E., 169, 241

Pringsheim, E. G., 218, 220, 221, 232, $241,244,318,377$

Pringsheim, H., 54, 110, 120, 121, 157, $190,199,202,427,431,434,435,440$, $446,447,455,458,462,560,561,564$, $569,575,700$

Proskauer, B., 12, 34

Prowazek, S. V., xiv, 323

Prucha, M. J., 133, 597, 777, 823, 824

Pucher, G. IW., 453

Puchner, H., xv

Pugh, E., 106, 122

Purdy, IV. C., 322

Puriewitsch, K., 269, 411

Puschkarew, B. M., 317

Q

Quastel, H., 163, 414, 469, 521

Quensell, E., 603

$\mathrm{R}$

Rabinowitsch, L., 156

Raciborski, M. I., 269

Radais, 289

Rahn, O., 45, 47, 56, 374, 465, 517, 623, $633,720,739,741,784$

Raistrick, H., 483 
Ramann, E., xv, 237, 359, 671, 790

Randall, M., xpii, 386

Rao, K. A., 139, 140

Rassow, B., 456

Rathbun, A. E., 259, 260

Rather, J. B., 672

Raulin, J., 380, 415

Ravendamm, W., 173, 203

Rayner, M. C., 272, 274, 277, 281, 283

Razoomov, A. S., 37

Reed, H. S., 502, 522, 581, 585, 802

Reid, F. R., 735

Reimers, J., 34

Reinitzer, F., 266, 672, 700

Reinke, J., 105, 232

Reisinger, E., 345

Remelé, E., 352, 790

Remy, Th., 23, 32, 569, 572, 578, 579, $586,589,687,710,716,829$

Rettger, L. F., 155, 368, 475, 478, 482

Reuter, C., 381

Rexhausen, L., 281

Rey-Pailhade, J., 610

Riccardo, S., 110, 117

Rice, J. L., 143

Richards, B. L., $\$ 12$

Richards, E. R., 499, 555

Richardson, A. C., 171

Richardson, H., 354

Richter, 808

Richter, A. A., 10

Richter, L., 133, 750, 820

Richter, O., 54, 219, 231

Richters, F., 354

Rideal, E. K., 376

Ridler, W. F. F., 277, 804

Riefenstahl, R., 429

Rippel, A., 190, 270, 588, 604, 694

Ritter, G., 269, 547, 701, 707, 742, 790

Ritter, G. J., 457, 693

Ritzema-Bas, J., 349

Rivas, D., 165

Rivett, M. F., 274, 804

Robbins, W. J., 673, 699

Robbins, WV. IV., 217, 224

Roberts, J. W., 246

Robertson, R. A., 700

Robertson, T. B., xvi, 320, 374
Rolsinson, C. S., 670

Robinson, G. W., 670

Robinson, R. H., 493, 496, 748

Robinson, W. O., 625, 627

Robson, W. P., 784

Rochaix, 208

Rockwell, G. E., 368

Roehm, H. R., 177

Rogers, L. A., 58

Rakitzkaia, A., 643

Roman, 432

Rommel, L. G., 276, 638

Rona, P., 269, 417

Root, F. M., 315

Rose, A. K., 689

Rosenbaum, J., 812

Rosenberg-Lipinsky, A., 329, 837

Rösing, G., 578, 829

Ross, R., 328

Rossi, G., 5, 203

Rossi, G. de, xiii, 130, 381

Rothe, 268

Roux, J., 335

Roux, Mr, 645

Roxas, M. L., 693

Rubentschik, L., 211

Rubner, M., 409, 419, 543, 610, 613

Rubner, N., 463

Rudakov, K. I., 556, 649

Rudan, B., 459

Rudolfs, WV., 616, 659, 666

Ruhland, W., 101, 406

Rullmann, W., 94, 303

Rupp, P., 636

Ruschmann, G., 120, 173, 203

Russell, E. J., xiii, xv, 311, 353, 499, $523,524,555,624,639,683,717,721$, $722,736,743,744,746,749,752,757$, $763,779,799,831$

Russell, H. L., xiii

Ryan, M., 167

Ryskaltshouk, A., 573

\section{$\mathrm{S}$}

Saluaschnikoff, A., 780

Saccardo, P. A., $x$

Sack, J., 77, 199, 592 
Sackett, W. G., 652

Sakuma, S., 540

Salabartan, J., 543

Salter, R. M., 636

Saltet, R. H., 556

Salzmann, P., 297, 551

Sames, T., 156

Sandon, H., 32, 49, 315, 32S, 329, 333, 642

Sanford, G. B., 299, 810

Sangiorgi, G., 328

Sano, K., 304

Sasaki, T., 613, 614

Saussure, Th. de, 98

Savageau, 2S9

Sawyalow, IV., 1S9, 612

Scales, F. M., 197, 263, 265, 297

Schade, H., 630

Schatz, 276

Schaeffer, A. A., xii, 312,320

Schander, sos

Schardinger, F., 462

Scheffelt, E., 328

Schellenberg, H. C., 264, 266, 443, 454, 460

Schellhorn, 352, 790

Schenkel, R., 464

Scherpe, R., 751

Scheunert, A., 434

Scheurlen, E., 556

Schikhorra, 264

Schillinger, A., 156

Shirokikh, J., 186

Schittenhelm, A., 651

Schloesing, Th., 62, 156, 179, 525, 527, 534,537

Schloesing fils, Th., 125, 660

Schmid, E., 129, 134

Schmidt, D., 382

Schmidt, E. G., 242, 379, 417, 454

Schmidt, E. IV., $44 \mathrm{~s}$

Schmuck, A., 69s

Schmücke, R., 650

Schneider, A., xiv

Schneider-Orelli, O., 779

Schneidewind, IV., 105, 232, 516, 5S6, $746,748,830$

Schnellmann, II., 213

Schoen, M., 469
Schoenflies, A., xviii

Schollenberger, C. J., 605

Schönbein, C. F., 181

Schönbrunn, B., 7\$1

Schoonover, W. R., 592, 674

Schorger, A. W., xvi, 456, $45 \mathrm{~s}$

Schorler, B., 93

Schrader, H., 458

Schramm, J. R., 219, 232

Schrauth, IV., 693

Schreiner, O., 463, 502, 522, 523, 671, $679,690,736,748,802$

Schroeder, H., 98

Schroeter, F., 651

Schulov, I. C., 793

Schultz, E. S., $\$ 12$

Sehultz, L., 123

Schulz, K., 707

Schulze, E., 596

Schwalbe, H., 456, 458

Schwann, T., 835

Scott, H., 517

Scott, I. 'T., S0s, 811

Scott, R. P., 783

Sears, H. J., 476

Seaver, J. F., 749, $75 \mathrm{~S}$

Seguin, P., 175

Seidenschwartz, I., 34 S

Seiser, A., 545

Seliber, G., 464

Sen Gupta, N. N., 466

Senior, J. K., 467

Senn, G., 333

Sestini, F., 211, 524

Sewerin, S. A., 154, 176, 1S6, 1ST, 491, 655,682

Severtzoff, L. B., 317, 319, 762

Seydel, S., 417, 567

Shanz, H. L., 262, 282

Sharp, L. T., 179, 577, 5S4, 634, 783

Shaw, C., 344

Shaw, H. B., 348

Shaw, IV. M., 604, 650

Shearer, C., 419

Shelford, V. E., 358

Sheriakoff, C. 1)., 238, 257

Sherman, J. M., 45, 47, 326, 374 
Shibata, K., 138, 281, 464

Shorey, E. C., 453, 463, 474, 502, 649, 671,690

Shouten, S. L., 55

Shunk, I. V., 132

Shutt, F. T., 598

Sieben, H., xiv

Sieber, H. O., 571

Sierp, 464

Sievers, F. J., 702

Sigmond, W., 671

Simon, J., 135, 820, 823

Simon, R. H., 605

Skar, O., 10

Skinner, C. E., 153, 155, 190, 195, 261, 266,444

Skinner, J. J., 502, 671

Skraup, Z. H., 430

Smirnow, V. G., 555

Smith, A. M., 661

Smith, E. F., xiii, 126, 777, 806

Smith, G., 317

Smith, G. H., 58

Smith, J. H., 30, 244, 501

Smith, N., 524

Smith, N. R., 18, 56, 114, 197, 536, 539, $574,662,797$

Smith, R. E., 32, 35

Smolik, L., 735

Snow, L. M., 36

Snyder, R. S., 263, 450, 485, 497, 621, $639,685,722$

Söhngen, N. L., 96, 97, 158, 204, 207, $209,298,406,408,409,488,578,592$ 630,665

Solounskoff, M., 108, 110

Soma, S., 527

Sopp, J. O., 238

Sörensen, S. P. L., 475

Soule, M. H., 177

Souza, G., 239

Speakman, H. B., 462, 468

Spear, E. B., xvii

Sperlich, 668

Sperry, J. A., 478

Spieckermann, A., 242, 478

Spinks, G. T., 814
Spratt, E. R., 139

Squires, D. H., 785

Sseverowa, O. P., 113, 565

Stahl, E., 273, 280

Stalström, A., 653

Stallings, J. H., 826

Stapp, C., 120, 125, 145, 213, 571

Starkey, R. L., 251, 263, 268, 399, 400, $401,606,670,684,685,701,723,739$, 744,770

Statkewitsh, P., 45

Stearn, 382

Steinberg, R. A., 666

Steinecke, F., 235

Steiner, A., 667

Steiner, G., 346, 347, 804, 833

Stephenson, M., 414, 464

Stephenson, R. E., 530

Stevens, J. W., 135, 137, 594, 827

Stevens, F. L., 69, 531, 536, 711, 716, 821

Stewart, R., 538, 539

St. John, J. L., 601

Stockhausen, 54

Stoddard, J. L., 167

Stokes, A. C., 335

Stoklasa, J., xiii, 29, 34, 104, 114, 155, $181,183,381,444,548,554,562,570$, $573,578,621,631,649,654,662,667$, $685,718,724,730,732,752,772,783$, $788,800,831$

Stolc, A., 316

Störmer, K., 12, 21, 47, 97, 134, 150, $204,302,744,750,751,772,820$

Stranak, Fr., 562, 831

Street, J. P., 550

Strong, R. P., S03

Strowd, W. H. H., 595

Stutzer, A., 77, 105, 131, 185, 554

van Suchtelen, F. H. H., 425, 621, 681, $684,720,751$

Süchting, H., 590, 686

Sullivan, M. X., 523, 542, 735, 736

Supniewski, J., 368, 468, 485

Suzuki, S., 550

Swanson, C. O., 598

Szücs, J., 789 
Tacke, B., 184, 550

Tahara, M., 138

Takahashi, R., 259

Takenouchi, M., 167

Tammann, G., 640

Tangl, F., 386

Tanner, F. W., xiii, 174, 250

Tappeiner, H., 432

Tarassoff, B., 497

Tartar, H. V., 493

Taubenhaus, J. J., 809

Tausson, W. O., 465

Tausz, J., 97, 204, 408, 465

Taylor, E., 329

Taylor, E. M., 761

Taylor, J. K., 106

Taylor, M. W., 257, 259

Taylor, W. W., xvii, 626

Teakle, L. J. H., 576, 700

Teisler, E., 822

Temple, J. C., 69, 530, 688, 773, 821, 823

Ternetz, C., 270, 281

Terroine, E. F., 408, 410, 415

Thaer, W., 629

Thatcher, R. W., xvi, 825

Thaysen, A. C., 460, 761

Thom, C., 238, 245, 257, 744

Thomas, IV. A., 361

Thompson, M., 352, 357

Thomson, D., 329

Thorne, C. E., 429, 470, 650, 660

Thornton, H. J., 15, 26, 317, 466

Thurlow, S., 543

Thurmann, H., 550

van Tieghem, P. E. L., 191, 212

Tilden, J. E., xi, 230

Tischutkin, N., 219

Tisdale, 128, 811

'Tissier, H., 492

Tokugawa, Y., 746

Tollens, B., 427, 432

de Toni, G. C., xi, 230

Topley, W. W. C., 55

Tottingham, W. E., 580, 656

Traube, W., 524
Traaen, A. E., 179, 238, 265, 537, 584, 783

Transeau, E. N., 707

Trautwein, K., 87, 88, 385, 399, 421, 547, 606

Treherne, R. C., 362

Treub, M., 234

Troop, J., 771

Truffaut, G., 37, 110, 121, 560, 565, $569,752,762$

Truog, E., 634

Trusov, A. G., 691

Tschirch, A., 775

Tsikilinsky, P., 156

Tsujitani, J., 319

Tswetkowa, E., 183

Tubeuf, C. V., 243, 460

Tulin, A. F., 531

Turner, C. F., 362

Turpin, H. W., 799

Ucke, A., 175

Uhland, R. E., 770

Uhlenhuth, P., xiv

Ulpiani, C., 185, 211, 214, 489, 552

Ulrich, P., 247

\section{V}

Vahlkampf, 314

Valleau, W. D., 815

Valley, G., 368

Van Delden, A., 98, 105, 115, 121, 183, 188, 203, 204, 556, 571, 574, 611

Vanderleck, J., 33

Van der Reis, V., 789

Van der Spek, J., 634

Van Douwe, C., 354

Van Hulst, J. H., 452, 454

Van Slyke, D. D., 473, 475

Van Slyke, L. L., xv

Van't Hoff, J. H. 372

Van Zyl, J. P., 540

Varro, 122

Vass, A. F., 33, 496

Veillon, A., 169, 176 
Vernadsky, W. J., 646

Verworn, M., xvi

Vestal, A. G., 358

Viehoever, A. B., 208, 209

Vierling, K., 158

Viljoen, J. A., 156, 202, 440, 518

Ville, 122

Vincent, G., 410, 415

Vincent, H., 806

Vismanath, B., 489

Vitek, E., 183, 548

Vogel, J., 119, 130, 134, 183, 184, 379, $529,544,554,574,576,616,687,711$, \$30

Vogt, E., 766

Voigt, E., 21

Voorhees, E. B., 125, 479, 4S0, 491, $554,559,799$

Voicu, J., 580

Vouk, V., 462

IV

Wade, H. W., 2SS

Wadham, S. M., S07

Waget, P., 763

Wagner, F., 771

Wagner, P., 185, 553

Wagner, R., 205

Wailes, C. H., 331

Waite, H. H., 7 S5

Waksman, S. A., xvii, 15, 19, 20, 26, $40,43,47,85,89,90,92,116,181$, $190,195,196,237,240,259,261,263$, $266,267,288,290,297,298,299,301$, $304,309,326,376,379,400,401,443$, $444,447,451,459,476,491,493,495$, $509,513,606,615,638,642,670,671$, $685,690,692,694,699,701,702,712$, $716,723,728,730,735,739,770,814$, \$43

Walters, E. H., 474, 479

Walton, J. H., 581

Walz, L., 545

Wann, F. B., 221

Warburg, O., 412, 421, 520, 540, 546

Ward, H., xii

Ward, H. M., 219, 640
Ward, M., 124

Warington, R., xv, 63, 67, 396, 525, 534, 597, 795, $\$ 19$

Warmbold, H., 586, 700

Warner, E. A., 487

Washburn, E. W., xvii

Wasielewski, T. V., 319

Waynick, D. D., 575, 670

Webb, R. W., 262

Weber, A., 524

Weber, E., 596

Weber, G. G. A., 33

Webster, T. A., 233

Wehmer, C., 238, 694

Weigert, xiii

Weimer, J. L., 418, 461

Weinberg, M., 175

Weinzirl, J., 244

Weis, F., 117

Weissenbach, R. J., 612

Weissenberg, H., 180

Weissenberg, R., 349

Weissmann, H., 501, 685

Weith, W., 524

Werkman, C. H., 802

West, G. S., xi, 82, 230

Westermann, T., 115, 585

Westling, R., $23 \mathrm{~S}$

Wettstein, F., 216, 268

Wettstein, R., $\mathrm{x}$

Weyl, Th., 165

Weyland, H., 282

Wheeler, H. J., xv, 598

Whetham, M. D., 414, 464

Whipple, G. C., xii

White, J. W., 530, 670

Whiting, A. L., 136, 590, 592, 596, $657,668,674,821, \$ 27$

Whiting, L. C., 632

Whitney, M., 630, 749

Whitson, A. R., 534, 795

Whittaker, H., 453, 456

Whittles, C. L., 7, 22

Wiechowski, W., 486

Wiegner, G., 626, 629, 630

Wieland, H., 573

Wiesner, J. V., xvii

Wiley, H. W., xv 
Wilfarth, H., 124, 78s

Wilhelmy, L., 372

Williams, A. W., xii

Williams, B., 5\&1, 585

Willis, L. G., 531

Hillows, R. S., xvii

Willstïtter, R., 456

Wilson, A., 749

Wilson, B. D., 519, 705, 793

Wilson, C. W., 325

Wilson, G. S., 55

Wilson, G. W., 259, 267, 494

Wilson, J. K., 129, 132, 519, 595, 792, 794, 796, 822

Vimmer, G., 788

Windish, F., 407

Winogradsky, S., v, 7, 8, 10, 11, 19, 55, $61,62,64,65,66,68,71,72,74,76$, $80,92,93,104,107,113,121,143,152$, $204,389,397,531,542,559,564,572$, $605,623,642,702,732,769,783,843$

Winslow, C. E. A., x, 58

Winter, O. B., 670

Winterstein, E., 381

Wislouch, C. N., 82, 831

Withers, W. A., 531, 536, 539, 711, 716

Wohlgemuth, J., xvii

Wohltmann, F., 591

Woitkiewicz, A., 780

Wolcott, R. H., 355

Wolff, K., 181

Wrolff, M., 328, 329

Wolkoff, M. I., 628

Wollenweber, H. W., 304, 809

Wollny, E., 353, 477, 683, 786, 839

Wolzogen Kühr, C. A. H., 340, 542, 612

Woodhouse, 575

Woodruff, L. L., 318

Woods, C. D., 124, 819

Woodward, J., 601

Worden, S., 18
Woronin, M., 124

Woroshilowa, A. A, 631

Wrangell, M., 634

Wright, C. R., 517, 531, 552

Wright, D., 647, 648

Wright, R. C., 798

Wright, IV. H., 127, 132, 137, 594, 825

Wiilker, G., 348

Wund, M., 148, 162

Wunschik, H., 138, 590

Wurmser, R., 40S, 415, 521

Wyatt, F. A., 686

\section{Y}

Yabusoe, M., 412

Yakimoff, M. L., 328

Yamagata, U., 117, 582

Yamazaki, E., 487

Yoshimura, K., 213

Young, C. C., 155

Youngburg, G., 453

Younge, C. M., 434

\section{Z}

Zacharowa, T. M., 186, 551

Zapfe, M., 636

Zeichmeister, L., 456

Zemplen, G., 435

Zérèn, S., 328

Ziemiecka, J., 117

Zikes, H., 94

Zimmermann, 805

Zimmermann, A., 139

'Zipfel, H., 131, 134, 597

Zolkiewicz, A. I., 269

Zopf, W., x, 380

Zschenderlein, A., 456

Zsigmondy, R., xvii, 626

Zumstein, 317 



\section{INDEX OF SUBJECTS}

A

Absidia, 248, 258, 275

Acacia, nodule bacteria of, 135, 136

Acanthocystis aculeata, 331

Acarina, 355, 357, 358

Accumulative culture method, 54

Acetaldehyde, 439, 467, 469

Acetic acid, as a source of energy, 407

formation of, by bacteria, 178, 411, 414,440

Achnanthes, 227

Achromatium, 79, 82, 83

Acid soils, occurrence of algae in, 223

Acidity of soil and development of actinomyces, $42,301,810$

Acids and solubilization of phosphates, 656-660

formation of, in soil, $437-439,635,672$

formation of, from monosaccharides, 466

organic, utilization of, by fungi, 242

Acremoniella, 255

Acrochordonoposita, 345

Acrostalagmus, 254, 258

Actinolaimus, 349

Actinomonas, 333

Actinomycetes (see Actinomyces)

Actinomyces, 285-310, 490, 514, 636 ammonia formation by, 493

causing plant and animal diseases, 809

cellulose decomposition by, 441

classification of, 306

description of, 285

importance of, in soil, 309

nitrogen fixation by, 105

occurrence of, in manure, 30

occurrence of, in soil, 39, 259, 260

reduction of nitrates by, 181

thermophilic forms, 157
Actinomyces alboflavus, 309

albosporeus, 309

albus, 305, 307

alni, 310

annulatus, 305

aureus, 307, 309

bobili, 307

bovis, 803

californicus, 307

cellulosae, 444

chromogenus, 305, 701

citreus, 308

diastaticus, 308

erythreus, 308

exfoliatus, 308

flavovirens, 308

flavus, 307

fradii, 309

gelaticus, 308

griseolus, 308

griseus, 308

halstedii, 305, 309

lavendulae, 307

lipmanii, 308

melanocyclus, 442

melanosporeus, 442

myricae, 138

niger, 305

olivaceus, 308

olivochromogenus, 306

pelogenes, 189

pheochromogenus, 307, 309

poolensis, 308

purpeochromogenus, 307

reliculi, 295, 307

reticulus-ruber, 307

roseus, 308

ruber, 307

rutgersensis, 308, 309

scabies, 299, 301, 306, 616, 637, 803, 814 
Actinomyces sulfureus, 305

tricolor, 304

verne, 305,307

violaceus, 300

violaceus-caesari, 308

violaceus-ruber, 304, 307, 309, 444

viridochromogenus, 307, 309, 379, 444

Actinophrys sol, 331

Actinopoda, 331

Adaptation of nodule bacteria to host plant, $13 \mathrm{~S}$

Adenine in soil, 479

Adenoplea, 345

Adineta, 351

Adsorption, in soil, 629-630

of bacteria, 631

Aerobacter aerogenes, 212

Aerobic bacteria, 4, 112, 141, 145

utilization of energy by, 410

Aerophile bacteria, 160

Agar plate method, for counting bacteria, 13

for counting protozoa, 45

for isolation of algae, 219

Agar tubes, deep, use of, in the isola-

tion of anaerobic bacteria, 164, 168

Agaricus, 243, 261

Agricere, in soil, 465

theory of soil fertility, 759-761

Agriotes, 356, 358

Agroceric acid, 671

Agrosterol in soil, 671

Air-drying of soil, influence of, on activities of microorganisms, 539, $740-743$

Alaimus, 350

Albumin agar, 16

Alcohol, formation by microorganisms, $412,413,440$.

oxidation of, by bacteria, 99

utilization by fungi, 242

Aldehydes in soil, 671

Alfalfa, nodule formation by, 136

Algae, in soil, 3, 50, 215-235

composition of, 378

corroding action of, 645

cultivation of, 218

distribution of, in soil, 222
Algae, isolation of, in pure culture, 221

nitrogen fixation by, 105, 121, 232-233 rôle of, in the soil, 234

Algal fungi (sce Phycomycetes)

Alinit preparation, 105, 831

Aliphatic hydrocarbons, decomposition of, 465

Alkali soils, neutralization by sulfur oxidation, 616

occurrence of algae in, 224

Alkaline pyrogallol solution, 170

Alkaloids, content of, in leguminous plants, 596

use of, in stimulation of bacteroid formation, 131

Allantoin, formation of, in the decomposition of uric acid, 212,486

Allantion tachyploon, 333

Allocoelae, 345

Allogromia fluvialis, 332

Allolobophora, 352

Alnus, bacteria in, 105, 138

Aloin, as indicator of oxidation in soil, 523

Alsike clover, nodule bacteria of, 136 Alternaria, 244, 256, 258, 265, 779, 807 Aluminum, transformation of, in soil, 666

Amanita, 276, 278

Amblyosporium, 253

Amides, decomposition of, 485

Amines, formation by bacteria, 178

Amino acids, as sources of energy, 419

formation of, in synthetic processes, 424

Amino nitrogen, as index of protein decomposition, 476

Ammonia formation, as index of protein decomposition, 475, 501, 695

as influenced by presence of nonnitrogenous organic substances, 504

by bacteria, 178,499

by fungi, $266,376,493$

chemistry of, 480

from different organic materials, 511,512

in the reduction of nitrates, 182 
Ammonia formation, rate of, 375,495 , 688

factors influencing, 688-689

methods of determination, 497

Ammonia oxidation, by chemical agencies, 524

mechanism of, 525

Ammonification studies, 687 (see also A,mmonia-formation)

Ammonium salts, nitrification of, 715 Amoeba, 331, 332, 337

Amoebae, in soil, 2, 47, 315, 326, 328 cultivation of, 319

Amoebida, 331

Amorpha, nodule formation by, 137

Amphicarpa, nodule formation by, 137

Amphileptus, 335

Amylobacter group of bacteria, 106 (see Bac. amylobacter)

Amylomyces boidin, 462

Amystidae, 355

Anabaena, in soil, 217, 224, 227

in the roots of cycads, 138, 302

Anachaeta, 354

Anacystis, 226

Anaerobic bacteria, 4, 141, 160-179

classification of, 172

cultivation of, 169

decomposing celluloses, 166,437

decomposing pectins, 203

facultative, 160

isolation of, 164

nitrogen-fixing, 107

numbers of, in soil, 38,175

obligate, 163

physiology of, 176

Anaerobic conditions in soil, 164 utilization of energy, 412

Aniline dyes, use of, in the separation of soil bacteria, 166

Anguillula, 350

Animal diseases caused by, actinomyces in soil, 809

bacteria found in the soil, 805

Animal ecology, 341

Anisonema, 334

Ankistrodesmus, 228

Annelida in soil, 341, 351, 354, 359
Anorgoxydants, 61

Anthracnose of beans in soil, 815

Anthracriny, 694

Antiseptics, volatile, influence of, on bacterial activities, 744-745 749 759

Aphanethece, 226

A phanocapsa, 226

Aphanomyces, 247, S08, 813

A phelenchus, 348, 349, 810

Apocrenic acid, 697, 698

Arachnida, 354, 355, 357, 359

Arachnis, nodule formation by, 136 Arbutus unedo, mycorrhiza formation by, 274, 804

Arcella, 332

Arcellidae, 332

Archiboreoiulus, 355

Archionchus, 350

Archivortex, 345

Ardisia, bacteria in, 105, 139

Areinida, 355, 357

Arid soils, distribution of bacteria in, 36

Arginine in soil, 479, 671

Armillaria, 276, 284

Arsenic compounds, oxidation of, 540 reduction of, $303,540,556$

infiuence of, on bacterial activities, 534,668

Arthobotrys, 255

Arthropoda in soil, $341,354,359$

Ascomycetes, 3, 249, 250, 259, 277

Asparaginate agar, 16

Aspergillaceae, 242, 267

Aspergillus, in soil, $3,238,245,251,253$, $258,259,260,265,443,459$

flavus, 454, 465

fumigatus, 444, 454, 495, $\$ 17$

fuscus, 444

glaucus, 444

niger, 243, 244, 380, 382, 411, 415, $416,417,454,462,464,467,494$,

$503,511,514,637,650,652$

oryzae, $261,454,462$

repens, 454

terricola, 261, 490, 637

wentii, 444 
Aspidisca, 336

Associative action of bacteria in the reduction of nitrate, 186

Associative growth of legumes and non-legumes, 599

Assulina, 332

Astasia, 334

Asterocystis radicis, 278, 808

Atmosphere of soil, 638

Atmospheric nitrogen, fixation of, 103

Aulosira, 227

Autocatalytic reaction in the growth of microorganisms, 320, 373-376, 527

Autochtonous microflora of soil, 10, 151

Autotrophic bacteria, in soil, 4, 59, 61-102, 369

classification of, 388

Autotrophic protozoa, 315, 316

Auximones, 580, 699

Azo:obacter, 59, 105, 106, 110, 111, 112-122, 138, 164, 447, 559, 560, 563, 564, 565, 575, 579, 581, 594, $623,630,637,641,642,656,662$, 699, 708, 779, $82 \mathrm{~S}$

agile, 105, 114, 117, 118, 572

beijerinckii, 115, 117, 118, $5 \mathrm{~S} 2$

chroococcum, 105, 107, 112, 114, 116, $117,118,119,155,183,441,562$, 566, 567, 572, 575, 578, 579, 582, $654,694,762$

vinelandii, 115, 116, 117, 118, 572, 582

vitreum, 115, 117

Azotobacter, as food for amoebae, 319 composition of, 381, 570,571

energy utilization by, 419, 561, 569

fixation of nitrogen by, in presence of protozoa, 338

life cycles of, 117

nitrogen-fixation by, 560, 567

numbers of, in soil, 37

occurrence in soil, 10, 11, 117

physiology of, 119

protein synthesis by, 570

species, description of, 114
B

Bacillariaceae, 215, 225

Bacillariales, 227, 230

Bacilli in soil, 11

Bacillus, 58

acetoethyslicum, 467

adhaerens, 144

aerogenes capsulatus, 173

agri, 144, 150

albolactus, 144

alvei, 146

amylobacter, 37, 59, 104, 106, 107,

$110,146,161,162,164,167,172$,

$173,175,178,191,203,204,447$,

$462,549,558,579,582,623,630$,

$637,641,646,708,779,828$ (see also

Clostridium pastorianum)

amylocyme, 172

anthracis, 146, 803, 805

arborescens, 490, 762

asterosporus, 105, 120, 144, 146, 149,

$162,203,383,558$

aterrimus, 143

azophile, 121

bifermentans, 174, 492

botulinus, 174, 803, 806

brevis, 145, 150

butyricus, 172, 762

calfactor, 157, 441, 775

capri, 146, 213

carotarum, 146, 149, 214

carotovorus, 203, 461

cellulosae dissolvens, 173, 194, 203

centrosporus, 145

cereus, 10, 27, 142, 144, 145, 149, 150,

$382,444,462,491,500,642$

cereus, var. fluorescens, 144, 150

chauvoei, 161, 174, 805

circulans, 145

cobayae, 146, 213

cohaereus, 144, 146, 149, 150

comesii, 203

danicus, 120

ellenbachensis, 104, 141, 146, 149, 833

enteritidis sporogenes, 173

felsineus, 173, 178, 203, 204 
Bacillus ferrugineus, 195

favigena, 455

foliicola, 140

fossicularum, 193

fusiformis, 118, 145, 146, 149, 150, 162

globigii, 143

gracilis putidus, 492

granulobacter pectinovorum, 462, 468

graveolus, 146, 149

guano, 147, 213

histolyticus, 174

hollandicus, 147, 214

hydrogenes, 101, 404

janthinus, 490

kramerii, 203

lacticola, 147

lactis, 147, 162

lactis niger, 144

laterosporus, 145

luteus, 147

macerans, 203

malabarensis, 120, 149

megatherium, 10, 104, 120, 142, 145,

$147,149,150,181,208,507,515,762$ mesentericus, 120,142,143, 149, 150,

$155,203,212,462,641,642$

mesentericus var. flavus, 144, 150

mesentericus fuscus, 143

mesentcricus niger, 143, 693

mesentericus panis viscosus, 144

mesentericus rubcr, 143, 150

mesentericus vulgatus, 143, 183, 490, 656

methanicus, 96, 100, 406

methanigenes, 193

musculi, 147, 213

mycoides, 105, 142, 144, 145, 147,

$149,150,155,162,182,208,490$,

$491,507,508,604,631,633,642$,

762

niger, 144

nitroxus, 187, 549

oedematis maligni, 174

oligocarbophilus, 98

orthobutylicus, 109, 172

oxalaticus, 147

panis, 144

parvus, 147
Bacillus pastorianus, 173

perfringens, 173, 209, 492

pestifer, 181

petasites, 145, 147, 149, 150

phytophthorus, 806

prausnitzii, 144

probatus, 147, 208, 209, 210

pseudotetanicus, 145

pseudotetanicus var. aerobius, 145

pumilus, 118, 147, 149

putrificus, 111, 174, 175, 209, 490, $492,612,637$

pycnoticus, 100, 101, 637

radicicola (see Bact. radicicola)

ramosus, 181, 701

ramosus liquefaciens, 144

robustus, 147

ruminatus, 145, 149

schirokikhi, 187

silvaticus, 147

simplex, 144, 147, 149, 150, 162

sphaericus, 147

sporogenes, 173, 174, 178, 492, 612

subtilis, 96,142, 143,148, 149, 150,

$162,164,182,183,203,205,368$,

$382,383,418,462,478,489,490$,

506, 507, 508, 514, 637

subtilis-viscosus, 143

ieres, 144, 148

tetani in soil, 148, 161, 174, 803, 805, 806

thiogenes, 82

tostus, 148

tumescens, 148, 149, 491

ureae, 208

vulgatus, 143, 149, 150, 182, 184, 212, $444,507,701$

welchii, 173, 178, 803

Bacteria, composition of, 378

decomposing celluloses, 190, 195, 200, 201

fixing atmospheric nitrogen, 103

in leaves of plants, 139

in roots of legumes, 122

in roots of non-leguminous plants, 138

life cycles of, 57

numbers of, in soil, 28-29 
Bacteria, numbers of, in manure, 2931

oxidizing carbon compounds, 96

oxidizing hydrogen and its compounds, 98

oxidizing iron compounds, 92

oxidizing nitrogen compounds, 62

oxidizing sulfur and its compounds, 78

reducing nitrates to nitrites, 180

reducing nitrates to ammonia, 182 reducing nitrates to nitrogen gas, 183 requiring combined nitrogen, 141

Bacteriaceae, 58, 78

Bacterio-chlorin, 83

Bacteriophage in nodules of leguminous plants, 592

Bacterio-purpurin, 83

Bacteriotoxin theory, 759

Bacteriotoxins in soil, 859

Bacterium, 58

acidi lactici, 30, 155, 648

acidi urici, 212

aerogenes, 59, 119, 126, 153, 155, 382, 582

aliphaticum, 204, 465

aliphaticum liquefaciens, 204, 465

anthracoides, 155

bovista, 82

calco-aceticum, 212

caudatum, 153, 154, 642

cellaresolvens, 201

centropunclatum, 187

cloacae, 155

coli, 153, 154, 155, 157, 163, 182, 184, 186, 209, 319, 440, 320, 382, 419, $492,542,612,614,631,637,641,762$, 775

denitrificans, 88, 185, 186, 187

denitrificans agilis, 186, 187

denitrofluorescens, 186

erythrogenes, 209, 211, 212, 488

extorquens, 646

filiformis aerobius, 492

fimi, 444

fluorescens, 27, 30, 107, 151, 154, 182, $186,203,205,209,320,323,379$,

$464,491,492,500,514,604,642$
Bacterium fluorescens liquefaciens, 97, 155, 186, 209, 212, 465, 490, 656, 762 fluorescens putidum, 490

freudenreichii, 212

fulvum, 155, 187

güntheri, 30

hartlebii, 186, 187

herbicola, 30, 182

hexacarbovorum, 97

kirchneri, 211

hünnemanni, 187

lactis viscosum, 118, 120, 126, 154

leguminosarum, 126

lipolyticum, 204, 464

nitrovorum, 187

ochraceum, 154, 155

odoratum, 212

opalescens, 201

parvulum, 500

pestis, 805

pneumoniae, 59, 120, 126, 155

porticensis, 182, 187

praepollens, 186, 187

prodigiosum, 120, 154, 163, 171, 182, 184, 209, 212, 383, 464, 490, 631, 760

proteus (see Bact.vulgare)

punctatum, 154, 155

putidum, 118, 155, 182, 545

pyocyaneum, 97, 182, 186, 204, 212,

$368,418,464,467,468,485,549,637$

radicicola, 39, 120, 122-138, 139, $383,558,593,597,637,656,708,818$,

823,824

colony formation, 130

isolation of, from nodules, 128

isolation of, from soil, 129

media for cultivation of, 126

morphology and life cycles, 130

motility of, 132

nitrogen fixation by, 592, 597

nodule formation by, 128

nomenclature, 125

numbers of, in soil, 129

physiology of, 133

specific differentiation of, 134

stages of development, 125

staining of, 132 
Bacterium radiobacter, $119,120,126$, 447,642

solanacearum, 806, 814

stutzeri, 186, 187, 204, 212, 549, 637, 762

tumefacier 806

typhi, 805

typhosum, 777, 803, 806

ulpiani, 187

umbilicatum, 154

ureas, 209, 211

violaceum, 154

viscosum, 201

vulgare, 121, 154, 155, 163, 181, 182, 184, 209, 212, 368, 485, 489, 490, $492,507,508,612,613,614,637$, 663,762

vulpinus, 186

zopfii, 154

Bacterized peat, 831

Bacteroids, 126, 130, 140

Bactridium butyricum, 161

Balantiophorus, 335

Baptisia tinctoria, nodule formation by, 136

Barber pipette method, for isolation of actinomyces, 305

for isolation of algae, 218,220

for isolation of bacteria, 55

for isolation of protozoa, 320

for isolation of spores of 'fungi, 246

Basidiomycetes in soil, 3, 243, 257, $260,277,278,282,459$

Bastiana, 350

Beaker method, 687

Beetles in soil, 361

Beggiatoa, 79, 80, 81, 100, 397, 398, 606

Benzene ring compounds, as a source of humus in soil, 692

decomposition of, by bacteria, 204, 465

Benzoic acid, formation from hippuric acid, 212

Benzol, oxidation of, 97, 205

Bersem clover, nodule bacteria of, 136

Betaine, 486

Bibionidae, 358

Biochemical activities of algae, 230
Biomyxa vagans, 331

Biotypes in nodule bacteria, 137, 824

Bispora, 256

Black locust, nodule bacteria of, 137

Black medick, nodule bacteria of, 136

Blaniulus, 355

Blepharisma, 336

Blue-green algae (see Cyanophyceae)

Bodo, 330, 333

Boletus, 257, 276, 278

Boron, influence of, on Azotobacter, 581

Botrydium, 229

Botryos porium, 229, 253

Botrytis, 3, 244, 254, 258, 264, 266, 779

Brachydesmus, 355

Braconidae, 361

Broad bean, nodule bacteria of, 136

Buffer content of soil, 635

Bumilleria, 225, 229

Bunonema, 347, 350

Bur clover, nodule bacteria of, 136

Butyl alcohol, formation of, by bacteria, 178

Butyric acid bacteria, 106, 108, 155, 172,175

in manure, 30

numbers of, in soil, 38

Butyric acid, formation of, by bacteria, $178,204,412,439$

\section{C}

Caconema radicicola, 348,349

Caffeine, use of, for stimulation of bacteroid formation, 131

Calcium, accumulation of, by bacteria, 663

as a bacterial nutrient, 664

influence of, on biological activities in soil, 689 (see also Lime)

cyanamide, decomposition of, 211

influence of, on nitrogen-fixation, 576

oxide as an agent of partial sterilization, 743

transformation of, in soil, 662-664

Callidina, 351

Calluna vulgaris, mycorrhiza formation by, $276,277,281,283$

Calothrix, 227 
Campascus, 332

Canada field pea, nodule bacteria of, 136

Canthocamptus, 355

Carabidae, 356, 361

Carbohydrates, decomposition of, by microorganisms, 409, 564, 678

influence of, on protein decomposition, 511

utilization of, by nitrogen-fixing bacteria, 561

Carbon bisulfide, influence of, on biological activities in soil, 749, 754, 762

Carbon dioxide, content of soil atmosphere, 640,682

evolution, $376,445,515,621,681-685$, 688-689, 701, 720, 721

and energy utilization, 425, 566

as an index of biological activities in soil, $717-725$

Carbon monoxide as a source of energy for bacteria, 59, 98, 407

Carbon-nitrogen ratio, in medium, as affected by different groups of organisms, 513

in soil, 509, 510, 702-707

of organic matter, 514, 687, 704, 770

Carbon, oxidation of, by bacteria, 98 sources for bacteria, 368

transformation by microorganisms, 504

utilization of, by actinomyces, 296

utilization of, by fungi, 242

Carboxydomonas oligocarbophila, 98

Cardinal points for growth and spore formation of obligate anaerobic bacteria, 162

Carotin in algae, 215

Carrots as reducing agents, 171

Carychium, 359

Cassia, nodule bacteria of, 135, 136

Casuarina, nodule formation by, 139

Catalase formation by anaerobic bacteria, 163

Catalytic action of soil, 734-736

Ceanothus, nodule formation by, 105, 138,139
Cellulase, 435,436

Cellulose agar medium, 197, 297

Cellulose as a source of energy, 297, 448

for nitrogen-fixing bacteria, 447

Celluloses, chemistry of, 427-432

Cellulose decomposing bacteria, 27, $38,60,154,175,190,448$

decomposing capacity of soil, 725 decomposition and $\mathrm{CO}_{2}$ evolution, 725

decomposition and nitrogen assimilation, 727

decomposition by aerobic bacteria, 195-200, 434, 439

decomposition by anaerobic bacteria, $166,173,190-195,432,437$

decomposition by denitrifying bacteria, 188, 200-201, 441

decomposition by herbivorous animals, 434

decomposition by thermophilic bacteria, 173, 201-203, 435-436, 439441,445

decomposition by actinomyces, 441 decomposition by fungi, 242, 263, 443-444

decomposition by protozoa and other invertebrate animals in manure, 444

decomposition in soil, importance of, 446,683

decomposition, influence of soil conditions on, 448

Cellulose, determination of, 431

influence of on soil microorganisms, 769

preparation of, 197

Centricae, 227

Centropyxis, 332

Cephalobus, 347, 350

Cephalosporium, 253, 258, 277, 808

Cephalothamnion, 334

Cephalothccium roseum, 244, 490, 779

Cercobodo, 333

Cercomonas, 330, 333, 337

Cercospora personata, 808

Cerotoma, 362

Chactocladiaceae, 249 
Chaetocladium, 249

Chaetomella, 257

Chaetomium, 3, 238, 250, 251, 258, 260, 264

Chaetonatus, 351

Chamaesiphonaceae, 226

Chamaesiphon, 226

Chambers apparatus for isolation of bacteria, 56

Charophyta, 230

Chemical activities of microorganisms, 369

agents, influence of, on protozoa, 325

composition of the microbial cell, 377

Chilodon, 335

Chilomonas, 334

Chilopoda, 355, 357

Chinon, action of, on bacteria, 165

Chironomidae, 358

Chitin in the microbial cell, 382, 489

Chitinase, 489

Chlamydomonas, 211, 228, 233, 334

Chlamydophrys, 332

Chlorella, 228, 232, 233

Chlorochytrium, 228

Chlorococcum, 224, 225, 228, 233

Chloroform as an agent of partial sterilization of soil, 754

Chlorogonium, 217, 334

Chlorophyceae, 3, 215, 220, 224, 225, 228

Chlorophyll in algae, 215

Choenia, 335

Cholesterols in soil, 671

Choline in soil, 479, 485

Chordata in soil, 342

Chordeuma, 355

Chromatium cuculliferum, 83

Chroococcaceae, 226

Chroococcus, 226

Chrysamoeba, 334

Chrysomonadinae, 334

Ciliciopodium, 256

Ciliates, in soil, $3,48-49,314,328,335$ cultivation of, 319

Citric acid, 410

Citrate-glycerin agar, 291, 306

Cladomonas, 334

Cladophora, 224, 228
Cladosporium, 155, 256, 253, 264, 265, 278,763

Cladothrix, 287, 288

Classification, of actinomyces, 294-296 of anaerobic bacteria, 172

of autotrophic bacteria, 388

of soil animals, 341

of soil bacteria, 58-60, 141, 143, 151

of soil protozoa, 313,329

Clathrulina elegans, 249, 331

Clostenema, 334

Clostridium, 59, 106, 107, 110, 115, 178, 204, 594

americanum, 110, 172, 447

butyricum, 161, 173

pastorianum, 37, 104, 108, 109, 110, $111,112,120,166,172,173,558$, $559,560,564,566,569,641,642$,

752 (see also Bacillus amylobacter) thermocellum, 173, 194, 195, 202, 203

Clover, composition of, $42 \mathrm{~s}$

Club-root of cabbage, 236

Coccaceae, 58

Cocci in soil, 11, 141, 154

Coccomyxa, 228

Coccospora, 252

Codosiga botrytis, 333

Coelhelminthes in soil, 342,488

Cohnistreptothrix, 294

Coleoptera, 356, 357, 358

Coleps, 335

Collembola, 356, 357, 358, 361

Colletotrichum, 807

Colloidal condition of soils, 33, 626 nature of soil humus, 697

Colloids, influence of, on the growth of microorganisms, 578, 622, 627, 630 properties of, $627-631$

Colon group of bacteria in the soil, 155 (see also Bact. coli)

Colony isolation, 167

Colpoda, 324, 330, 335

Colpidium, 317, 318, 321, 335, 338, 637

Colponema, 333

Commensalism, 560

Commercial cultures of nodule bacteria, 822 
Composition, chemical, of the microbial cell, 377

of vegetable organic matter, 427

Composts, of greensand and sulf ur, 661 of sulfur and phosphate, 614

Conductivity of soil, 633

Condylostoma, 336

Conidiophorae, 249

Conifers, mycorrhiza formation by, 272

Conjugatae, 229

Control of plant diseases, 814

Copepoda in soil, 342,354

Coprinus, 243

Coriaria, nodules of, 105, 138

Corn cobs and fodder, composition of, 428

Corn root rot, temperature of control, 815

Corticium vagum, 807,813

Cortinarius, 276, 278

Corycia, 332

Corynebacteria, 289

Corythion, 332

Coscinodiscus, 227

Cothurnia, 336

Cow clover, nodule bacteria of, 136

Cowpea, nodule bacteria of, 136

Craspedosoma, 355

Creatinine in soil, 479

Crenic acid, 697

Crenothrix, 93

Cresol, decomposition of, 205, 465

Crimson clover, nodule bacteria of, 136

Cropping of soil, influence of, on micro-

biological activities, 712,800

Cross-inoculation of nodule bacteria, 134

Cruciferae, mycorrhiza formation by, 273

Crude fibre, 429

Crustacea in soil, $342,354,357$

Cryptoglena, 334

Cryptomonadaceae, 215

Cryptomonadinae, 334

Cryptomonas, 334

Cultivation, of algae, 221 of soil, influence of, on biological activities, $743,784-787$
Cultivation, of soil, influence of, on nitrogen-fixation, 585

of soil, influence of, on numbers of microorganisms, 40

Cultural methods for study of soil bacteria, 11, 12

Culture media for counting soil bacteria, 13-19

Cunninghamella, 249, 444, 454

Curculionidae, 361

Cutins, 460

Cutworms in soil, 362

Cyanamide, decomposition of, by bacteria, 211, 487, 488

decomposition of, by fungi, 267

Cyanophyceae, 3, 215, 220, 223, 224, $225,226,230,645$

Cyanuric acid in soil, 479

Cyatholaimus, 349

Cyathomonas, 334

Cycas, nodule formation by, 138, 139

Cyclidium, 335

Cyclotella, 227

Cylindrocystis, 228

Cylindroiulus, 355

Cylindrospermum, 217, 227

Cymbella, 227

Cyperaceae, mycorrhiza formation by, 273

Cystine, 600, 613, 614

Cystococcus, 231

Cysts of protozoa, 46-50, 316, 325

Cytase, 454

Cytosine in soil, 479, 671

Czapek's solution, 243, 291

$\mathrm{D}$

Dactylococcus, 228

Dalea alopecuroides, nodule bacteria of, 137

Damping-off fungi in soil, 807

Deaminization, 473

Death of microorganisms, 372

Decarboxylation, 482

Decay, 477, 522

Decomposition, of manure, 496

of organic matter in soil, 500,680 
Dcep colony procedure in isolation of bacteria, 168

Deflocculating agent in preparation of soil suspension, 22

Dematiaceae, 3, 255, 267, 443

Demalium, 244, 256

Dematophora, 264, '814

Denitrification, 180, 544, 550

Denitrifying bacteria, $60,180,185$ cellulose decomposition by, 441 numbers of, in soil, $37,3 \mathrm{~s}$

Depths of soil, and distribution of actinomyces, 40

and distribution of bacteria, 34-36 and distribution of fungi, 259

and distribution of protozoa, 48-49

Desiccation of bacteria, 583

Desmidium, 228

Desmodium canescens, nodule bacteria of, 136

Desmobacteriaceae, 78

Dextrans in the microbial cell, 383

Diaschiza, 351

Diatoms, occurrence of, in soil, 223, 227,645

Dicoccum, 256

Dicyanodiamide, decomposition by bacteria, $48 S$

influence of, on nitrate formation, 533

Diflugia, 332

Difflugidae, 332

Difugiella, 332

Dihydroxystearic acid in soil, 463, 671

Dileptus, 335

Dilution method for counting protozoa in the soil, $45-47$

for determining numbers of soil bacteria, 13, 27

in the isolation of soil bacteria, 55, 167

Dilutions of soil in preparation of plates, 18, 21-23

Dimastigamoeba grubcri, 330, 337

Dinoflagellata, 215, 230, 335

Dinomonas, 333

Diplogaster, 347, 349

Diplophrys, 332

Diplopoda, 355, 357
Diptera, 356, 357, 358

Direct method of isolation, of nitriteforming bacteria, 71

of soil bacteria, 55

Direct microscopic methods for study of soil bacteria, 7-11

Discomyces, 287,288

Discomycetes, 251

Discorea macroura, bacteria in, 140

Disinfectants (see Antiseptics)

Distigma, 334

Distribution of bacteria in soil, 34-36

Dorylaimus, 346, 345, 349

Drying, influence of, on actinomyces, 299

of soil and increase of soluble salts, 742

Dydymopsis, 278

Dyer's greenwood, nodule bacteria of, 136

Dyes, as indicators of oxidation-reduction potential, 542

influence of, on the growth of actinomyces, 302

\section{E}

Earthworms, as carriers of pathogenic bacteria, $805-\$ 06$

occurrence of, in soil, 3, 342, 351-353

Economic coefficient, 417

Ectotrophic mycorrhiza, 271, 280, 281

Edaphon, 642

Egg-albumin agar, 16

Eisenia, 352

Elateridae, 361

Eleagnus, nodule formation by, 138, 139

Enchytraeids in soil, 342,353

Enhytraeus, 354

Enchelys, 335

Endogone, 277

Endotrophic mycorrhiza, 140, 271, 280

Energy, of ionization, 387

liberation in microbiological processes, 422

-nitrogen ratio, 506

Energy source for non-symbiotic nitrogen fixation, 561-553, 569 
Energy transformation in the metabolism of microorganisms, 384-426 transformation in the soil, 425 utilization by autotrophic bacteria, 384,387

utilization by heterotrophic bacteria, 384,704

utilization by nitrogen-fixing bacteria, 566

utilization, efficiency of, 415

Enrichment culture method, 54, 215

Environmental conditions, influence of, on symbiotic nitrogen fixation, 597

Entosiphon, 334

Enzymes of microorganisms, 371, 436

Eparidaceae, mycorrhiza formation by, 271

Epicoccum, 257

Epistylis, 336

Equilibrium, between carbon and nitrogen in soil, 702, 704

microbiological, in soil, 6, 738-740, $757,764,767$

theory of symbiotic nitrogen fixation, 590

Ericaceae, mycorrhiza formation by, $271,272,273,276,281,283$

Errors in plate counts of numbers of microorganisms, 24

Erythrosine stain for soil bacteria, 8 Ethyl alcohol, formation of, by bacteria, 178

Euasci, 251

Euastrum, 229

Eubacteria, 58, 78, 92

Euglena, 315, 317, 334

Euglenaceae, 215

Euglypha, 332

Euglyphidae, 332

Eumycetes, 236, 246

Euplotes, 336

Eutreptia, 334

Eutylenchus, 350

Evolution in plants, 273

Exhausted soils, 709
F

Facultative anaerobic bacteria, 160 autotrophic bacteria, 59, 96, 101, 399

Fairy rings, 262, 293

Fat-splitting bacteria, 204

Fat utilization, by actinomyces, 297 by fungi, 242

Fats in soil, 463, 671

Fauna of soil, 341-363

Feces as a source of bacteria in soil, 29,176

Feldspars, decomposition of, by bacteria, 646

Fenugreek, nodule bacteria of, 136

Fermentation, 385, 413

Fementation of nitrates (see Denitrification)

Ferrous sulfate, as reducing agent, 171

Fertilizers, influence of, on biological activities in soil, 733,788

influence of, on soil reaction, 635

Filamentous fungi (see Fungi)

Fixation of nitrogen, 103, 558

Fixative agents, 323

Flagellata, 215, 230, 313

Flagella staining, 132

Flagellates in soil, 3, 47-50, 326, 328

Flagellation of nodule bacteria, 132

Flatworms, 341, 345

Fleming's solution, 346

Fluctuation of bacteria in soil, 32

Flukes in soil, 341, 345

Fluorescent bacteria in the soil, 154

Forest soils, formation of humus in, 694

occurrence of algae in, 224

Formaldehyde as intermediary product in $\mathrm{CO}_{2}$ assimilation, 403

Formic acid, formation of by bacteria, 414,440

Formicidae, 358

Fragillaria, 227

Fredericia, 354

Free energy, 386

Free-living nematodes in soil, 348 
Freezing of soil, influence of on bacterial activities, 777

Frozen soil, numbers of bacteria in, 32

Fulvic acid, 698

Fumaric acid, formation of, by bacteria, 414

decomposition of, 469

Fumigants of soil, 362

Fungi, activities of fungi in soil, 260 ammonia formation by, 266, 493

carbon and nitrogen assimilation by, 413

causing plant diseases, 806

cellulose decomposition by, 238, $260,263,443$

composition of, 379

cultivation of, 241

decomposing uric acid, 212

decomposition of organic matter by, 708

destruction of, by partial sterilization of soil, 757, 763

germination of spores and reaction of medium, 637

influence of reaction on, 237, 239, 262,637

isolation of, 237,245

media for isolation and cultivation, 19, 239-244

methods of studying soil fungi, 239 mycelium of, in soil, 11, 42

mycorrhiza fungi, 238

nitrogen-fixation by, 105, 235, 270

nitrogen utilization by, 267

numbers of, in soil, 42-44, 237

occurrence of, in soil, $3,27,236,259$

reduction of nitrates by, 181

relation of, to plant diseases, 806

spores of, in soil, 42

thermophilic, 157

Fungi imperfecti, 252, 259

Fungus agar medium, 19

mycelium in soil, 11, 268

Furfural as a source of humus, 693

Fusarium, 155, 238, 257, 258, 259, 260,

$264,265,278,443,444,763,807$

batatatis, 808

bullatum, 261
Fusarium conglutinans, 808, 811

hyperoxysporium, 808

lini, 803, 808, 811

lycopersici, 808, 811, 814, 815

martii ver. pisi, 813

moniliforme, $80 \mathrm{~s}$

oxysporum, 261, 637, 803, 807

radicicola, 244, 779, 803, $\$ 06$

vasinfectum, 264

G

Galactans in the microbial cell, $3 S 3$

Gallionella, 93, 94

Garden bean, nodule bacteria of, 136

Gas illuminating, utilization of, by bacteria, 97

Gas,indifferent, for air replacement, 171

Gases of soil, composition of, 639

influence of, on nitrate formation, 534

Gasteromycetes, 275, 276

Gastrodia elata, 284

Gastropods in soil, 342, 359

Gastrostyla, 336

Gelatin liquef ying bacteria, 14, 151, 153

Gelatin media, 16, 291, 306

Genista tinctoria, nodule bacteria of, 136

Gentian-violet, inhibitive action of, on the growth of acrobic bacteria, 165

Geocentrophora, 345

Geomyces, 254

Geotrichum, 252

Geophilis, 355

Geophilomorph, 355

Gephyramoeba delicatula, 331

Gibberella saubinetii, 637

Glaucoma, 335

Glenodinium, 335

Gliocladium, 253

Gloeococcus, 228

Glococopsa, 226

Gloeocystis, 228

Glomeris, 355

Gluconic acid, 410

Glucose, as a reducing agent, 171

decomposition of, in suil, 683, 725 
Glucose, influence of, on ammonia formation from proteins, 503 influence of, on development of microorganisms, 769

Glucose agar, 291, 306

Glucosides, decomposition of, 466

Glucuronic acid, 410

Glycerides in soil, 67

Glycine, nodule bacteria of, 130, 134, 137

Glycocoll, as a source of energy, 411 formation from hippuric acid, 212

Gonatobotrys, 254

Gongrosira, 228

Gonidia formation by bacteria, 57

Gonostomum, 336

Gramineae, mycorrhiza formation by, 274

Granulobacter, 95, 105, 106, 109, 119, $120,178,204$

pectinovorum, 73,110

saccharobutyricum, 172

Graphium, 256

Grass-green algae (see Chlorophyceae)

Grass lands, insect fauna in, 356

Green manure, influence of, on seed germination, 802

Greensand-sulfur compost, 661

Gromia, 332

Gromiidae, 332

Growth, of microorganisms, 372

promoting substances, influence of, on nitrogen fixation, 580

Grubs in soil, 361

Grumilea, nodule formation by, 139 Guanidin, decomposition of, by bacteria, 214, 486

Guanin, decomposition of, by bacteria, 214,486

Gum formation by bacteria, 439, 593

Gums and their decomposition, 460

Cyysum block media, for isolation of nitrite-forming bacteria, 71

\section{$\mathrm{H}$}

Habrotrocha, 351

Hairy vetch, nodule bacteria of, 136 Halteria, 336
Hantzschia, 224, 225, 226

Hapalosiphon, 227

Harpacticidae, 354, 355

Hartmanella hyalina, 330, 331

Hay, composition of, 428

infusion medium, 318

Heat as an agent of partial sterilization, 744, 745-749

Heat, destruction of fungi by, 244 formation of, in microbiological processes, 425

Heat, of dilution, 387

of reaction, 387

of solution, 387

Heating of soil, for separation of bacteria, 166

influence of on biological activities, 742

Heleopera, 332

Heliozoa, 331

Helix, 359

Helodrillus, 352

Hemicelluloses, chemistry of, 452 decomposition of, by microorganisms, 166,454

Helminthosporium, 256, 807

Hemiptera, $35 \mathrm{~s}$

Heterodera, 344, 348, 350, 818 radicicola, $348,350,763,810$ schachtii, 348, 349, 804, 810

Heterokontae, 229

Heteromita, 330, 333

Heteronema, 334

Heterotricha, 335

Heterotrophic bacteria, 4, 59, 141, 369 anaerobic, 60 classification of, 141

non-spore forming, 150 spore-forming, 142

Heterotrophic protozoa, 315

Heterotrophic utilization of energy, $40 \mathrm{~s}$

Hexamitus, 334

Hibernation of insects in soil, 359

Hippuric acid, 206, 212 decomposition of, by bacteria, 212, 487

Histidine in soil, 479, 671 
History of soil microbiology, $\$ 34$

Hodotermes, 363

Hog peanut, nodule bacteria of, 137

Holophrya, 335

Hol otricha, 335

Holozoic protozoa, 315

Hoplolaimus, 348

Hormodendrum, 265

Humic acids in soil, 671, 696-697, 698-699

Humid soils, distribution of bacteria in, 34

Humification, 695

Humin, 697, 698

Humus compounds, chemistry of and classification, $671,696-699$

Humus, decomposition of, 151, 298, 310,449

formation of, in soil, 309, 447, 460, 681, 689-691, 692-696

influence of, on nitrogen fixation, 580 nature of, 691-696, 707

rôle of, in soil processes, 629

Hyalopus, 253

Hyalosphenia, 332

Hyalotheca, 229

Hydrocarbons, decomposition of, by bacteria, 159, 204, 465

Hydrogen bacteria, 59, 403

Hydrogen, energy utilization in the oxidation of, 403

Hydrogen formation, by bacteria, 177 in the decomposition of cellulose by bacteria, $193,437,440$

Hydrogen oxidation by bacteria, 98,99 , 188

Hydrogen-ion concentration (see Reaction)

Hydrogen peroxide, decomposition of in soil, 734

Hydrogen sulfide formation, in the decomposition of organic matter, 612,613

in the reduction of sulfates, 602

Hydrogen sulfide, oxidation of, 78, 605

Hydrogenomonas, 99, 188, 403

Hydrolytic decomposition of proteins, 473,481
Hydroxylamine, 526

Hymenomycetes, 257, 275, 276, 278, 459

Hymenoptera, 356, 357, $35 \mathrm{~s}$

Hymetomelanic acid, 671, 698

Hypheothrix, 226

Hyphomycetes, 3, 250, 252, 265, 276, 289

Hypochnus, 278

Hypotricha, 336

Hypoxanthine in soil, 479, 671

\section{I}

Ichneumonidae, 361

Immunity theory and nodule formation, 128,589

Incubation of plates, 23

India-ink method of isolating bacteria, 55,101

Indigo-carmin as reducing agent, 170

Inf usoria, 314, 335

Inoculation, cross, of nodule bacteria, 136

Inoculation of soil with non-symbiotic bacteria, 105

Inoculation, principles of, 817-833

Insects in soil, 3, 50, 342, 356, 359

Insecticides, 362

Interpretation of results of plate counts, 24-27

Inulin, decomposition of, 462

Invertebrate fauna of soil, causing plant and animal diseases, 810 economic importance of, 360 occurrence of, 341-363

rôle of, in soil, 360

Invigoration of nitrogen-fixing bacteria, 111

Iota, 349

Iron, as a catalytic agent, 540

as a reducing agent, 170 accumulation by bacteria, 94

bacteria, 59, 92-96, 402-403

compounds, energy utilization in the oxidation of, 402

influence of, on the growth of Azotobacter, 578

precipitation of, 402

transformation of, in soil, 666

Ironus, 348, 349 
Irrigation, influence of, on biological activities in soil, 784

Isocystis, 226

Isolation, of algae (impure cultures) from soil, 216

of algae (pure cultures) from soil, 216 of bacteria from nodules, 128

of nodule bacteria from the soil, 129

of protozoa, 320

Isonchus, 349

Isopoda in soil, 342

Isopods, 354, 355, 357

\section{$\mathrm{J}$}

Julus, 355

Jumping beetles, 361

June bugs in soil, 361

\section{$\mathrm{K}$}

Karteria, 217

Kirchnerella, 233

Koch's postulates as applied to study of soil bacteria, 6

Kraussia, bacteria in, 105

I

Lacrymaria, 335

Lactarius, 278

Lactic acid, formation of, by bacteria, $178,410,412,414,440$

Lamellibranchiata, 359

Larvae of insects in soil, 359

Lathyrus, nodule bacteria of, 134, 135,136

Law of ehance in counting bacteria, 24

Lead plant, nodule bacteria of, 137

Leaf glands, bacteria in, 140

Leaves, composition of, 428 decomposition of, 684 nodule formation in, 139

Lecithine, decomposition of, 485, 650

Lecythium, 332

Legume inoculation, 819

Leguminosae, mycorrhiza formation by, 274,275

Lembus, 335

Lens, nodule bacteria of, 135, 136 Lepidoptera, 356, 358
Leptomyxa, 331

Leptothrix, 93, 287, 288, 402 ochracea $93,95,100$ trichogenes, 93

Lespedeza, nodule bacteria of, 136

Leucine as a source of energy, 411

Levulans, decomposition of, 461 synthesis of, by bacteria, 383

Life cycles, of bacteria, $57,117,130$ of protozoa, 324

Lignins, and their decomposition, 298, $429,455-460$

as a source of humus in soil, 693

Ligno-celluloses, 429, 455

Lignoceric acid in soil, 671, 672

Lima bean, nodule bacteria of, 136

Limax amoebae, 330

Lime, influence of, on biological activities, 530, 714, 743, 789 - requirement of soil, as determined by growth of Azotobacter, 581

Limicolae in soil, 342,353

Limonite, deposition of, 235

Linyphia, 355

Lionotus, 335

Lipoids in the microbial cell, 392

Lithobius, 355

Lithosphere, composition of, 624

Lolium temulentum, mycorrhiza formation by, 272

Loxophyllum, 335

Lumbricus, 352

Lupinus, composition of, 428, 596 nodule bacteria of, $130,134,135,137$

Luzerne, composition of, 428

Lyngbya, 226

Lysine in soil, 479

\section{M}

Macro-actinomyces, 309

Macrobiotus, 354

Macrosporium, 256, 807

Magnesium carbonate-gypsum block, 71

Magnesium, influence of, on biological activities in soil, 576,789

transformation of, in soil, 664-665

Malate-glycerin agar, 291, 306 
Mallomonas, 334

Manganese, as a source of energy, 59 salts, oxidation of, 93 stimulating action of, 665 transformation of, in soil, 665

Mannite decomposing capacity of soil, 729

inedium, 112, 113

Manure, as a carrier of bacteria, $772-773$

cellulose decomposing bacteria in, 434

composting of, 675

decomposition of, 444, 682

fertilizing action of, 773

influence of, on biological activities in soil, 771

influence of, on cellulose decomposition, 727, 728

influence of, on numbers of actinomyces in soil, 41

nitrogen transformation in the rotting of, 498, 686

numbers of bacteria in, 29-31

Marmots, in soil, 342

Marsh soils, occurrence of algae in, 224

Mastigamoeba, 333

Mastigella, 333

Mastigophora, 312, 313, 333

Nathematical interpretation of results of plate counts of numbers of microorganisms, 24-27

Meat extract-peptone agar, 14

Media, for counting bacteria, 13-16 for counting fungi, 19

for cultivation of soil actinomyces, 291,306

for cultivation of soil algae, 221

for cultivation of soil fungi, 241-243

for cultivation of soil protozoa, 317

for differentiation of actinomyces, 306

for isolation of algae, 218

for isolation of cellulose decomposing bacteria, 191, 195, 196, 193

for isolation of denitrifying bacteria, 185

for isolation of iron bacteria, 95
Media, for isolation of mycorrhiza fungi, 279

for isolation of nitrate-forming bacteria, 74-75

for isolation of nitrite-forming bacteria, 64-72

for isolation of nitrogen-fixing bacteria, 107, 112

for isolation of nodule bacteria, 127

for isolation of urea bacteria, 207

for isolation of uric acid bacteria, 213

for isolation of sulfur oxidizing bacteria, 84-90

Medicago, nodule bacteria of, 130, 134, 135,136

Melanconiales, 257

Melanin, 698

Melanconium, 257

Melanospora, 763, 808

Melilotus, nodule bacteria of, 130, 135, 136

Mclolontha, 356

Melosira, 227

Menoidium, 334

Mercaptans, formation of, by bacteria, 178,614

Mermithidae, 350

Merulius, 243, 257, 460

Mesophilic bacteria, 775

Mesolaenium, 229

Metabolism as a whole, 367

Metals, heavy, influence of, on nitrate formation, 534

Metapides, 336

Methane bacteria, 59, 96-98, 406

Methane formation, by bacteria, $17 \bar{T}$, 437

by cellulose decomposing bacteria, 193

in the decomposition of manure, 445

Methanomonas methanica, 96, 100, 406

Methods, of counting protozoa in the soil, 45

of cultivation of soil fungi, 241

of demonstration of mycorrhiza formation, 279

of demonstration of occurrence and abundance of fungi in the soil, 239 
Methods, of determination of ammonia in soil, 497

of determination of numbers of microorganisms in the soil, 6

of isolation of anaerobic bacteria from soil, 164

of isolation of soil algae, 218

of studying actinomyces, 291

of studying animal population, 342 of studying cellulose decomposition, 443

of studying soil microorganisms, 6

Metopus, 336

Mice in soil, 342

Micro-actinomyces, 309

Microaerophile bacteria, 160

Microbial activities in the soil, proof of, 5-6

Microbial cell, chemical composition of, 377

Microbiological condition of soil, methods of determination, 709

Micrococcus, 58, 118, 153, 208

cytophagus, 195

melanocyclus, 195

nitrosus, 73

ochraceus luteus, 762

paraffinae, 204

pyogenes, 1\$2, 208, 209, 212

selenicus, 91

ureae, 208, 209, 212, 762

ureae liquefaciens, 208

Microcoleus, 220, 226

Microcystis, 226

Microgromia, 332

Micromonospora, 295

Microorganisms, and partial sterilization of soil, 763-766

rôle of, in humus formation, 693

Microscopic counts compared with plate counts, 27

methods for study of soil bacteria, 7-11

methods for study of soil fungi, 240

study of actinomyces, 291

Microsiphonales, 287

Microspira aestuarii, 189

agar-liquefaciens, 199
Microspira desulfuricans, 188, 611, 612

Microspora, 228

Milk, growth of actinomyces on, 298

Milnesium, 354

Mineral composition, of microbial cells, 380,625

of plants, 429

Mineral requirements, of algae, 231

of Azotobacter, 571

of fungi, 242,260

Mineral transformation in soil, 614, 644-668

Mineralization of organic matter, 522

Minerals, rôle of, in bacterial metabolism, 368, 667-668

Mites in soil, 342

Mixed and pure cultures in the study of soil organisms, 641

Modification of nitrate-forming bacteria by culture, 76

Modification of nodule bacteria, 134

Moisture, influence of, on bacterial numbers in soil, 34

influence of, on biological activities in soil, 621-624, 781-784

influence of, on nitrogen-fixation, 583 influence of, on plant parasites, 812

Moisture film, 633

Molds (see Fungi)

Moles in soil, 342

Molluses in soil, 342, 357, 359

Monas, \$2, 334

Monilia, 3, 238, 252, 265, 779 sitophila, 495

Moniliaceae, 267

Moniliopsis, 278

Monocilia, 228

Monohystera, 346, 347, 350

Mononchus, 346, 348, 349, 350, 818

Nonosiga, 333

Monosaccharides, decomposition of, by microorganisms, 466

Monosporium, 254, 260, 265

Moraria, 355

Morphological characters of bacteria, 57

Morphology, of anaerobic nitrogen fixing bacteria, 108

of Azotobacter, 117 
Morphology, of Bact. radicicola, 130 of nitrite-forming bacteria, 72

Mortierellaceae, 249

Mosaic virus in soil, 806

Moss protonema in soil, 215, 225

Mougeotia, 229

Mucedinaceae, 252, 289

Mucilages, 460

Мucor, 3, 238, 243, 244, 248, 258, 259, $278,444,459$

amylomyces, 379

glomerula, 260, 637

hiemalis, 495

pusillus, 244

ramannianus, 275

stolonifer, 266

Mucoraceae, 247, 248, 249, 267

Mucorales, 239, 241, 243, 244, 247, $260,266,268,275$

Mucorineae, 3, 246

Mucuna utilis, nodule bacteria of, 136

Mycelial filaments in the soil, 239

Myceliphthora, 252

Mycelium of actinomyces, 287, 293

Mycelium radicis alrovirens, 278, 279

Mycetophilidae, 358

Mycobacteria, 59, 15S, 204, 205, 2S6, 465

Mycobaclerium album, 465

lacticola, 97

paraffinae, 465

phlei, 97, 782

rubiacearum, 140

rubrum, 465

Mycoderma, 155

Mycocriny, 694

Mycodextrans, 460

Mycogalactans, 460

Mycogone, 255, 264, 265

Mycomycetes, 277, 278

Mycorrhiza formation, 270, 803

fungi, 236, 270-284

rôle of, in plant nutrition, 280

Myriapods in soil, $342,355,357,361,362$

Myrica, nodule formation by, 105,

138,139

Myxobacteria, 59, 159

Myxomycetes, 236

Myxophyceae (see Cyanophyceae)

\section{$\mathrm{N}$}

Näegleria gruberi, 325, 330, 331

Naphthalene, decomposition of, 466

Nassula, 335

Navicula, 224, 227

Nebela, 332

Nematodes, in soil, 3, 341, 345-351, $357,358,804$

destruction of, in partial sterilization, 763

methods of determination, 343

temperature of control, 815

Nematogonium, 254

Nemathelminthes in soil, 341

Neocosmopora, 763

Nessler's reagent, 67

Nitrate "fermentation," 183, 185

formation as index of nitrogen availability, 539

formation as influenced by plant residues, 706

formation in soil and in solution, 536

-forming bacteria, $59,62,68,74,151$

-reducing bacteria, 174, 180

reduction in nature, 103,552

reduction and cellulose decomposition, 200

Nitrates, assimilation of, 269, 544

as sources of oxygen, 420,545

influence of, on cellulose decomposition, 728

influence of, on nitrate-forming bacteria, 394

influence of, on nitrogen fixation, 133,575

reduction of, and energy utilization, 420,546

reduction of, by actinomyces, 293, 302

reduction of, by Azotobacter, 576 reduction of, to ammonia, 182

reduction of, to atmospheric nitrogen 183,548

reduction of, to nitrites, 180

source of, in soil, 523

transformation of, by microorganisms, 543 
Nitrification, $62,527,637,836$

as influenced by carbon-nitrogen ratio of soil, 509

methods of studying, 715

Nitrifying bacteria, numbers of, in soil, $37,38,77$

isolation of, from soil, 63,68

limiting and optimum reaction of, 77 occurrence of, in soil, 67,77

Nitrifying capacity of soil as index of soil fertility, 713, 715-717

Nitrite formation, from inorganic and organic substances, 527

in the reduction of nitrates, 298

Nitrite-forming bacteria, 59, 62, 151

Nitrite oxidation, mechanism of, 526

Nitrite utilization by actinomyces, 298-299

Nitrobacter, 74, 75, 79, 100, 400, 637 growth of, on organic media, 76

Nitrogen compounds, assimilation of, by algae, 234

assimilation of, by bacteria, 368 as sources of energy for autotrophic bacteria, 62,389

decomposition of, in presence of nonnitrogenous, 505

decomposition of, in organic matter, 705

in leachings, as influenced by plant residues, 706

in manure, 498

influence of, on plant growth, 502 non-protein nitrogen, decomposition of, 485

utilization of by bacteria and fungi, 502

Nitrogen fixation, and respiration, 566 as influenced by partial sterilization of soil, 757

by algae, 105,231

by algae, in symbiosis with Azotobacter, 120, 232

by anaerobic bacteria, 109, 179

by higher plants, 106

by mycorrhiza fungi, 281

by nodule bacteria, 103, 122-140

by soil fungi, 105, 207
Nitrogen fixation, chemistry of process, 572

chemical fixation in soil, 103

in nature, 103

in soil, 560

influence of available nitrogen on, 575

influence of organic matter on, 579

non-symbiotic, 104, 111，558

non-symbiotic, importance of in soil, 585-588

symbiotic, 106, 122, 588

Nitrogen-fixing bacteria, 5,27

aerobic, 59, 106, 112, 558 (see also Azotobacter)

anaerobic, 59, 106, 107, 166, 175, 558 (sce also Bac. amylobacter and Clostridium)

numbers of, in soil, 37,38

symbiotic, 59

Nitrogen-fixing capacity of soil, 729-734

Nitrogen gas, formation of in decomposition of organic matter, 183

formation of, in nitrate reduction, $183,184,550$

losses of, in soil, 554

Nitrogen, oxides of, formation by bacteria, 178, 184, 549

transformation by microorganisins, 504

transformation in the rotting of manure, 498

transformation in the decomposition of organic matter in the soil, 500

Nitrogen utilization, by actinomyces, 298

by algae, 231

by fungi, 267

Nitrogenous substances, decomposition of, by fungi, 266

Nitromicrobium, 77

Nitrosococcus, $72,73,74,79,100$

Nitrosomonads, 8

Nitrosomonas, 72, 79, 100, 400, 637

europea, 72

javanensis, 73,95

Nitschia, 224, 227

Nocardia, 287, 288, 402 
Noctuidae, 361

Nodularia, 224, 225, 226

Nodule bacteria, groups of, 136 nitrogen fixation by, 122-140, 595

Nodule formation, by actinomyces, 310 by leguminous plants, 124, 128 by non-leguminous plants, 138 in leaves of plants, 105

Non-leguminous plants, inoculation of with nodule bacteria, 828

Non-spore forming bacteria, 4, 10, $60,141,150,153,209$

Non-symbiotic nitrogen fixation, chemistry of, 572

Nostoc, 220, 224, 225, 227

Nostococcaceae, 217, 223, 226

Nuclearia, 331

Nucleic acids, 474, 479, 651

Nucleobacter, 651

Nucleo-proteins, decomposition of, 651

Numbers of actinomyces in the soil, 39-42

of anaerobic bacteria in soil, 38

of anaerobic nitrogen fixing bacteria in soil, 110

of bacteria at different depths of soil, 34-36

of bacteria in different seasons of year, 31-34

of bacteria in manure, 29

of microorganisms in the soil, 3-50 of microorganisms in soil as an index of soil fertility, 711

of nitrifying bacteria in soil, 38

of nodule bacteria in soil, 129

of fungi in the soil, 42-44

of physiological groups of bacteria, 36

of protozoa in the soil, $45-50$

Nutrition of protozoa, 315

\section{$\mathrm{O}$}

Obligate anaerobic bacteria, 160-163 parasitism, 804

relation between mycorrhiza and host plant, 283

Occurrence of heterotrophic bacteria in soil, 145, 153
Occurrence, of microorganisms in the soil, 3-5

of trophic and encysted protozoa in soil, 325, 329

Odor production by actinomyces, 303

Oedocephalum, 253

Oedothorax, 355

Oidium, 3, 252, 287, 288, 289, 441, 775

Oicomonas, 318, 330, 334

Oligochaeta, 342, 351, 353, 357, 358

Oligonitrophilic bacteria, 104

Oligotricha, 336

Omnivagous nematodes, 346

Onobrychis sativa, nodule bacteria of, 135

Onychodromus, 336

Oomycetes, 247, 275

Oospora, 252, 287, 28s, 289

Orange-liquefying bacteria in soil, 27

Orcheomyces, 276

Orchidaceae, mycorrhiza formation by, $271,276,277,283$

Organic acids, decomposition of, 468

Organic matter, decomposition of, by actinomyces. 309

decomposition of, by mycorrhiza fungi, 282

decomposition of, in manure, 498 decomposition of, in soil, 500, 510, $673-681$

influence of, on activities of microorganisms, 699

influence of, on autotrophic bacteria, 61

influence of, on nitrification, 531 influence of, on nitrite and nitrateforming bacteria, 395,528

influence of, on nitrogen fixation, $\mathbf{5 7 9}$ influence of, on oxidation processes, 523,540

influence of, on soil population, 768 nature of, 669

rôle of, in soil processes, 625

transformation of, in soil, 669-707

utilization of, by algae, 231

Organic media for the cultivation of algae, 222

nitrogen, nitrification of, 715 
Oribatidae, 355

Ornithopus, nodule bacteria of, 134, 135,137

Orobus tuberosus, mycorrhiza formation by, 274

Orthoptera, 358

Oscillaloria, 220, 224, 226

Oscillatoriaceae, 223, 226

Osmotic pressure in the growth of microorganisms, 370

Oxalic acid, formation by microorganisms, 212, 410

Oxidase, 521

Oxidation processes in the soil, 520-541, $717-720$

Oxidation-reduction phenomena, 163, 385,520

Oxidative deaminization, 483

Oxidizing power of soil, 736

Oxygen absorption, by soil organisms, 163

from atmosphere, 170

Oxygen, influence of, on the growth of anaerobic bacteria, 169

limit for the growth of bacteria, 161 removal in the cultivation of anaerobic bacteria, 169

requirement of actinomyces, 299

requirement of protozoa, 314

supply of, in the growth of algae, 234 tension, in the growth of bacteria, 160,170

tension, influence of, on nitrate formation, 535

Oxytricha, 336

Ozonium, 257, s08, 813

\section{$\mathrm{P}$}

Pachybasium, 254

Palmitic acid, 411

Pamphagus, 332

Pandorina, 334

Pantostomatinae, 333

Paraffinbacterium, 204

Paraffin oil, decomposition of, by bacteria, 204, 465

Paraffin, oxidation of, 97, 204
Paraffinic acid in soil, 671

Paramoecium, 314, 317, 318, 319, 335, 637

Parasitic fungi in soil, 709

nematodes in soil, 348

Parasitism among soil microorganisms, 803,804

of mycorrhiza, 283

Partial sterilization of soil, 743-749

Partridge pea, nodule bacteria of, 136

Pasture lands, insect fauna in, 356

Pavetla, nodule formation in leaves of, $105,106,139,804$

Peanut, nodule bacteria of, 136

Peat, bacteria in, 785

Peat formation, 695

Pectins, 428, 446, 460

Pectin-decomposing bacteria in soil, $38,175,203$

Pectinobacter amylophilum, 203

Pectins, utilization of, by fungi, 242

Pecto-celluloses, 429

Pellia epiphylla, mycorrhiza formation by, 277,804

Penicillium, 3, 238, 244, 251, 253, 258, $259,260,265,275,418,443,444$, $454,465,642,803$

brevicaule, 303, 556, 652

chrysogenum, 495

expansum, 244, 382, 779

glaucum, 380, 382, 417, 652

intricatum, 495

italicum, 261, 637

luteum, 270, 604

variabile, 261

Penium, 229

Pennatae, 227

Pentosans, decomposition of, by microorganisms, 446

determination of, 453

occurrence of, 452

Peptone-decomposing bacteria in soil, 37

Peranema, 334

Perhydridase, 521

Peritricha, 336

Peronosporales, 247

Peroxidase, 521

Petalomonas, 334 
Petroleum, oxidation of, by bacteria, 97,201

Phacus, 334

Phaeophyceae, 230

Phalansterium, 333

Phaseolus, nodule bacteria of, 134, $135,136,137$

Phenol, oxidation of, by bacteria, 205, 465

\section{Philodina, 351}

Phoma, 270, 276, 277, 281, 804, 807

Phormidium, 224, 225, 226

Phosphate-sulfur composts, 614

Phosphates, solubilization of, as a result of direct bacterial action, 614,652

solubilization of, as a result of interaction with acids formed by microorganisms, 656-660

influence of, on nitrogen-fixation, 57 . reduction of, in soil, 556

Phosphatides, synthesis of, by microorganisms, 382

Phosphorus compounds in soil, 625, 649

content of bacteria, 650,651

organic in soil, decomposition of, $650-652$

requirements of soil, as indicated by growth of Azotobacter, 577, 730, 731

transformation in soil, 650-660

Photosynthetic utilization of energy, 4

Phycomycetes, 247, 265, 2`5, 277

Phyllomitus, 333

Phyllomonas, 333

Phryganella, 332

Phycobacteria, 59

Phycocyanin, 215

Phycomycetes, 3, 259

Physiological activities as a basis of bacterial classification, 57

Physiological groups of bacteria, numbers of, in soil, 36

Physiology of anaerobic bacteria, 110, 176

Physomonas, 334

Phytin, decomposition of, 651
Phytoflagellata, 315, 335

Phytomonadinae, 334

Phytophthora, 247, 763, 807

Phytosterol in soil, 671

Picoline carboxylic acid in soil, 671

Pigment formation by microorganisms, 303,439

Pilobolaceae, 249

Pine needles, composition of, 428

Pinnularia, 227

Piptocephalis, 249

Pisum, nodule bacteria of, 130, 134, 135,136

Placocysta, 332

Plagiotricha, 336

Planarians, 345

Planobacillus nitrofigens, 121

Planococcus, 58

Planostreptococcus, 58

Planosarcina, 58, 208

ureae, 208

Plant composition at different stages of growth, 673

diseases caused by actinomyces, 809 diseases caused by bacteria found in the soil, 806

diseases caused by fungi found in the soil, 806-809

growth and nitrogenous decomposition products, 501

growth and saprophytic soil organisms, 801

growth, influence of, on microbiological activities in soil, 705, 792-800

infection as influenced by soil environment, 810

infection, as influenced by soil reaction, 813

nutrition, rôle of mycorrhiza in, 282 parasitic nematodes, 804-805

residues, decomposition of, by fungi, 266

residues, influence of, upon plant growth, 516

secretions, 643,692

Plants, non-leguminous, nitrogen-fixation by, 106

forming mycorrhiza, 273-275 
Plasmodiophora brassicae, 236, 803, $812,814,816$

Plasmodium formation, 236

Plasmoptic mycorrhiza, 277

Plastic equivalent, 417

Plate counts compared with microscopic counts, 27

Plate method, for determining numbers of soil bacteria, 13

for isolation of bacteria, 55

Plates, preparation of, 21

Plathelminthes, 341, 345

Plectoascineae, 251

Plectonema, 225, 227

Plectridium, 173, 178, 204

pectinovorum, 173

Plcctus, 346, 349, 350

Pleurococcus, 228, 234

Pleuronema, 335

Pleurotaenium, 229

Pleurotricha, 336

Podocarpus, nodule formation by, 13S, 139

Poisons, influence of, on actinomyces, 302

Poisson series, 26

Polydesmus, 355

Polypodiaceae, mycorrhiza formation by, 273

Polypseudopodius, 334

Polytoma, 334

Porrhomma, 355

Potassium, available, 662

in soil, 625

influence of, on nitrogen fixation, 577

transformation of, in soil, 615, 660-662

Potato as reducing agent, 171

Potato scab, 301, 616

Potato wart, 236

Potatoes, symbiosis with mycorrhiza fungi, 274

Primitive activities of microorganisms, 645

Prismatolaimus, 350

Probable error in bacterial counts, 26

Proleptomonas, 333

Proof of microbial activities in soil, 5

Prorhynchus, 345
Prorodon, 335

Protein content of natural organic materials, 470

decomposition of, $299,475,480,679$

hydrolysis, 473

physical and chemical properties of, 470

synthesis by Azotobacter, 570

synthesis, in soil, 479

Protein decomposing bacteria, numbers of, in soil, 38, 175

Protein-forming bacteria, 183

Proteins of microorganisms, decomposition of, 268

Proteolytic bacteria, 154, 166

Proteomyxa, 331

Protoasci, 250

Protococcus, 234

Proteus vulgaris (see Bact. vulgare)

Protoderma, 228

Protomastiginae, 333

Protosiphon, 228, 233

Protozoa, 311-340

autotrophic forms, 315,316

classification of soil protozoa, 313, 329

cysts of, in soil, 45

heterotrophic forms, 315

importance of, in soil, 336

influence of, on nitrogen fixation, 338

isolation of pure cultures, 320

life history of, 324

media for cultivation of, 317

methods of determination of numbers, 45

morphology of , 311-314

numbers of, in the soil, 45-50, 327

occurrence of trophic forms and cysts

in soil, 3, 325, 329

physiology of, 314

reproduction of, 312

staining of, 323

Protozoan theory of soil fertility, 757

Prowazekia, 333

Pseudococcus, 362

Pseudochlamys, 332

Pseudodifflugia, 332 
Pseudomonas, 58

caudatus (see Bact.caudatum)

fluorescens (see Bact.fluorescens)

radicicola (see Bact.radicicola)

Pseudomycorrhiza, 278

Psilocybe, 257

Psychrophilic bacteria, 775

Pulmonata, 357

Punctiform bacteria in soil, 151, 153

Pure culture study, 53, 641

Purification of anaerobic bacteria, 165

Purple bacteria, 79, 83

Putrefaction, 175, 477

Pyrenomycetes, 275

Pyrenomycetineae, 251

Pyrocatechin, action of, on bacteria, 165,167

oxidation of, by bacteria, 205

Pyrogallic acid, use of, in the isolation of anaerobic bacteria, 170

Pyruvic acid, 414, 439, 469, 574, 681

Pythiacystis, 808

Pythium, 238, 247, 807, 813, 815, 816

\section{Q}

Quadrula, 332

\section{R}

Radiation, influence of, on actinomyces, 299

Radiobacter group of bacteria, 59, $106,112,212,582$

Raisin agar, 18

Raphidiophrys, 331

Raphidium, 228

Ray fungi, 288 (see Actinomyces)

Reaction, influence of, on actinomyces, $301,636,637$

influence of, on anaerobic nitrogenfixing bacteria, 111, 637

influence of, on denitrification, 551 influence of, on growth of anaerobic bacteria, 176

influence of, on growth of fungi, 244, 262,637

influence of, on hydrogen bacteria, 102,637
Reaction, influence of, on nitrate formation, 528, 637

influence of, on nitrate-reducing bacteria, 186

influence of, on nitrogen-fixation, 581,595

influence of, on nodule bacteria, 133,637

influence of, on plant pathogenic fungi, 813

influence of, on potato scab, 809

influence of, on protozoa, 314, 637

limiting and optimum for growth of Azotobacter, 582, 637, 792

limiting and optimum for growth of Bact. radicicola, 594, 636, 637 limiting and optimum for growth of nitrifying bacteria, $66,77,637$ limiting and optimum for growth of sulfur-oxidizing bacteria, 90, 91, 400,637

Reaction, of media, 118

of soil, 633-638

of soil, as influenced by cellulose decomposition, 451

Reaction velocity, 372

Red clover, nodule bacteria of, 136 Reducing power of soil, 736

Reductase, 521

Reduction of nitrates to atmospheric nitrogen, 183

of nitrates to ammonia, 182

of nitrates to nitrites, 180

of sulfates by bacteria, 556,610

Reduction processes in soil, 522, 542-557

Reductive deaminization, 483

Resin acids and esters in soil, 671

Respiration and nitrogen-fixation, 566 coefficient, 417

equivalent, 417

of nitrate-forming bacteria, 392

Rhabditis, 347, 349, 350

Rhabdolaimus, 350

Rhadocoelae, 345

Rhizobium, numbers of, in soil, 37,39 leguminosarum, 126, 825 (see Bact. radicicola) 
Rhizobium leguminosum, 136 radicicolum, 136

Rhizoctonia, 257, 276, 277, 278, 279, $763,807,814,815$, solani, 257, 277, 803, 806, 807, S08, 812

Rhizomyxa, 278

Rhizopoda, 313, 331

Rhizopus, 3, 238, 247, 258, 259, 266, 454, 461

arrhizus, 247

nigricans. 247, 495, 803, 809

nodosus, 247

Rhizosphere, 155, 643

Rhodobacteria, 59

Rhodomonas, 334

Rhodophyceae, 230

Rhopalomyces, 253

Rhynchota, 358

River flukes, 345

Rivularia, 227

Rivulariaceae, 227

Robinia, nodule bacteria of, 137

Robertus, 355

Rocks, decomposition of, by microorganisms, 645

Root-knot nematode, 348

Root-rots in soil, 807

Rose-bengal stain for soil bacteria, 9

Rosellinia necatrix, 808

Rotatoria (see Rotifers)

Rotifers, occurrence of, in soil, 3,342 , 351

Roundworms in soil, 341

Rubiaceae, nodule formation in leaves of, 139

Russula, 257, 276, 278

Rusts, 763, 808

\section{S}

Saccharolytic bacteria, 166, 172

Saccharomyces, 251

Saccharomycopsis, 251

Sainouron, 333

Salpingoeca, 333

Salt concentration, influence of, on

biological activities in soil, 301,787

Saltpeter beds, 62
Salts, influence of, on nitrification, 531 influence of, on nitrogen fixation, 576

Sampling of soil, 19

Saprolegniales, 247

Saprophytism among soil microorganisms, 803

Sarcina, 58, 154

flava, 154

lutca, 490, 491, 507, 508

Sarcodina, 313, 331

Scarabaeidae, 361

Scarlet runner bean, nodule bacteria of, 137

Scenedesmus, 228

Schinzia leguminosarum, 126

Schizomycetes, 236

Schizophyceae (see Cyanophyccae)

Schizophyllum, 355

Schweitzer's reagent, 431

Sclerotia, 257

Sclerolinia, 264, 763, 779, 807, 814, 815

Sclerotium, 257 rolfsii, 807, 809, 812

Scytoncma, 224, 227

Scytonemaceae, 227

Seasons of the year, influence of, on biological activities, 40, 779-781 influence of, on numbers of bacteria, 31-34

Seed germination, rôle of fungi in, 280

Seeds of plants as carriers of bacteria, 106

Segmented worms, 342

Selective culture method, 54

destruction of microorganisms in partial sterilization, 761

media, use of, in separation of bacteria, 166

media, use of, in feeding of protozoa, 317

Selenates, reduction of, 303,556

Selenium, oxidation of, 91

Separation of anaerobic bacteria, 160

Septoria, 815

Seradella, nodule bacteria of, 137

Serological method of differentiation of nodule bacteria, 134, 137

Sick soils, 326, 709, 794, s0s 
Siderocapsa, 93

Sideromonas, 93

Silica gel media, 68, 166, 196, 220

plates for isolation of Azotobacter, 113

Silicates, decomposition of, by bacteria, 646

Single-cell cultures, isolation of, 55, 169

Single-spore cultures, 245

Sinigrin, 600

Slime molds, 236

Slime of bacteria, 460

Slow growing bacteria, 153

Smuts in soil, 763, 808

Sodium formate, action of, on bacteria, 165,171

pyrogallate, use of, in the cultivation of anaerobic bacteria, 167,170

sulfide as reducing agent, 171

sulfite as reducing agent, 171

sulphindigotate, action of, on bacteria, 165

Soil, as a medium for growth of microorganisms, 619

atmosphere, 638-640

colloidal condition of, 622,626

composition of, 619,620

energy transformation in, 425

environments, relation to plant infection, 810

extract agar, 15

extract gelatin, 17

fertility and microbiological activities, 708

gases, 626

humus, nature of, 669

inoculation, principles of, 817-833

inoculation, with non-symbiotic bacteria, 105

oxidation processes in, 522

population, 642

reaction and microbiological activities, 633-638

sampling, 19-21

solution, 631-633

sterilization, 641

temperature, 640

use of, for legume inoculation, 821
Soil, variability, 20

Soja (see Glycine)

Solanaceae, mycorrhiza formation by, 275

Solid media for isolation of nitrite forming bacteria, 68

Solution method, 710

Solvent action of algae, 235

Sordaria, 251

Soy bean, nodule bacteria of, 137

Spathidium, 335

Specific differentiation of actinomyces, 290

Sphaeronema, 257

Sphaeropsidales, 257, 276

Sphenoderia, 332

Sphenomonas, 334

Spicaria, 254

Spirillaceae, 58

Spirillum, 58, 82, 83, 141

Spirochaeta, 58

cytophaga, 195, 196, 203, 368, 439, 770

Spiromonas, 334

Spitonema, 334

Spirophyllum, 93, 94, 95, 100, 402

Spirostomum, 336

Spondylomorum, 217

Spongomonas, 334

Spongospora subterranea, 808, 812, 815

Sporangiophorae, 247

Spore-forming bacteria, $10,60,141$, 142, 143, 209

Spores of fungi, germination of, 246

Sporogenous hyphae of actinomyces, 294

Sporormia, 251

Sporozoa, 314

Sporotrichum, 3, 254, 264, 265

Spring vetch, nodule bacteria of, 136

Stachobotrys, 255, 264

Staining, of flagella, 132

of nitrite-forming bacteria, 74

of protozoa, 323

Standard loop for counting protozoa, 45

Staphyinidae, 358

Staphylococcus, 612, 631, 641

Starch agar, 39, 291 
Starch, as a source of energy, 561

decomposition of, 461

Starch-zinc iodide reagent, 67

Staurastrum, 229

Steam, as an agent of partial sterilization, 746,748

Stemphylium, 256, 258, 260, 265, 490

Sterilization of soil, 641 and solubilization of minerals, 655

Stichococcus, 224, 229, 233

Stichotricha, 336

Stigonema, 224, 227

Stigonemaceae, 227

Stilbaceae, 3, 256

Stimulation of bacteria by antiseptics, 756

Straw, bacteria in, 30

composition of, 428

decomposition in soil, 684, 704

influence of, upon the growth of plants, 516

Streptococcus, 58

pyogenes, 208

Streptothrix, 287, 288

Strombidium, 336

Strophostyles, nodule formation by, 135,137

Stubble, composition of, 428

Stylonychia, 336

Stysanus, 257

Sugar-beet nematode, 348

Sulfate-reducing bacteria, 174, 188

Sulfate reduction, 185-189, 556

Sulfates, as sources of oxygen for anaerobic bacteria, 420

reduction of, by bacteria, 610-612 reduction of, and energy utilization, 420

Sulfide bacteria, 79, 398

Sulfides, oxidation of, 604

Sulfur bacteria, 59, 78-91, 399

Sulfur, chemical oxidation of, 603,604 energy utilization in the oxidation of, 397

liberation in decomposition of proteins, 602, 612

oxidation of, by autotrophic bacteria, 605-609
Sulfur, oxidation of, by heterotrophic organisms, 604

oxidation of, in soil, 540, 602, 605 presence of, in plants and in soil, 601 reduction of, 610

sources of, in soil, 600

transformation of, by microorganisms, 600-616

use of, for control of soil-born diseases, 816,832

Sulfur-phosphate composts, 88, 614

Sulfuric acid, formation of, by bacteria, 90, 608

Summer bacteria, 32

Sweet pea, nodule bacteria of, 136

Symbiosis, between bacteria and leguminous plants, 122-140, 804

between bacteria and non-leguminous plants, 105

Symbiotic action, between Azotobacter and other bacteria, 121, 560, 641

between Azotobacter and algae, 121, 232

in cellulose decomposition, 201

in mycorrhiza, 230

Symbiotic nitrogen fixation, chemistry of, 591

Symphyla, 355, 357

Symplastic stage in bacterial development, 57

Syncephalis, 249

Syncephalastrum, 249

Synchitrium, 236, 763, 809, 814

Synechoccus, 226

Synedra, 227

Synsporium, 255

Synthetic agar, 16

Systematic position of actinomyces, 287

\section{$\mathrm{T}$}

Tachinidae, 356

Tap water gelatin, 16

Tardigrada, 342,354

Tarsonemidae, 355

Tartaric acid as a source of energy, 411

Taurine, 614

Tellurates, reduction of, 303,556 
Temperature, influence of, on actinomyces, 299

influence of, on bacterial numbers, 32 influence of, on biological activities in soil, 774

influence of, on energy utilization, 419

influence of, on fungi, 244

influence of, on nitrate formation, 539,776

influence of, on nitrogen fixation, 583

influence of, on oxidation processes in soil, 523

influence of, on period of incubation of plates, 23

influence of, on protozoa, 314, 320, 327

of soil and biological activities, 640 of soil and plant diseases, 811

Temperature, selective use of, in the separation of soil bacteria, 166

Teratoce phalus, 350

Termites in soil, 339,363

Terricolae, 342, 351

Testacea, 332

Testacella, 359

Testaceous rhizopods, 315

Tetmemorus, 229

Tetracoccus, 154

Tetramitus, 334

Thamnidium, 258

Thamnidiaceae, 249

Thecamoebae in soil, 49, 326, 328

Thermoascus, 418

Thermophilic actinomyces, 300

bacteria, 155-158, 774, 775

anaerobic bacteria, 166,176

cellulose-decomposing bacteria, 157, 439-441

denitrifying bacteria, 157, 188

nitrogen-fixing bacteria, 157

occurrence of, bacteria, 156

Thielavia basicola, 808, 811

Thiobacillus, 78, 151, 605

denitrificans, $79,86,87,100,188$, $398,399,400,637$

thiooxidans, 79, 89, 90, 91, 92, 100, $399,400,401,606,609,615,637,832$
Thiobacillus thioparus, 79, 85, 86, 91, $92,100,395,399,606$

Thiobacteria, 59

Thiobacteriales, 78

Thiobacterium, 83

Thionic acid bacteria, 79, 88, 398

Thiophysa volutans, 82

Thioploca, 80

Thiospirillum, 79, 82

Thiosulfate, chemical oxidation of, 603 oxidation of, by sulfur bacteria, 84 , 18S, 606

media for sulfur bacteria, 84

Thiothrix, 79, 80, 81, 100, 397, 398, 606

Thiovulum, 79, 82

Thread-forming bacteria, 79, 80

Thysanoptera, 358

Thysanura, 358

Tick trefoil, nodule bacteria of, 136

Ticks in soil, 342

Tilachlidium, 256

Tilletia tritici, 812

Tipula, 356

Tipulidae, 361

Tissues as reducing agents, 171

Toluol, as an agent of partial sterilization of soil, 753,755

influence of, on nitrate formation, 536

oxidation of, by bacteria, 97,205

Tolypothrix, 227

Torula ammoniacale, 206, 251, 255

Toxin theory of partial sterilization of soil, 760

Trachelomonas, 334

Trailing wild bean, nodule bacteria of, 137

Trematoda in soil, 341,345

Tribonema, 229

Tri-calcium phosphate (see Phosphate)

Trichocera, 358

Trichocladium, 264

Trichoderma, 3, 253, 258, 259, 260, 265, $443,514,642,701,817$

koningi, 250, 259, 260, 267, 379, 495, 808

lignorum, 808

Tricholoma, 276, 278

Trichothecium, 255, 258, 459 
Trifolium, nodule bacteria of, 130 , $134,135,136$

Trigonella, nodule bacteria of, 135,136

Trilobus, 350

Trimethylamine in soil, 479

Trinema, 332

Triphaena, 358

Tripyla, 348, 350, 358

Trochalworms in soil, 342

Trochelminthes in soil, 342

Trochilia, 335

Trochiscia, 224, 225, 228

Trombidiidae, 355

Trophic protozoa in the soil, 47,326

Tuber formation and plant evolution, 273

Tuberculareaceae, 3,257

Tumbler method, 687

Turbellaria in soil, 341,345

Tylenchorhynchus, 348

Tylenchus, 348, 349, 350, 810, 818

Tylopharynx, 350

Tyroglyphidae, 355

Tyrosine, decomposition of, 484

\section{$\mathrm{U}$}

Ulmic acid, 697

Ulmin, 697

Ulothrix, 225, 228

Ultramicroscopic organisms in the soil, 5

Ur eolus, 334

Urea as a source of nitrogen, 299

Urea bacteria, 27, 60, 151, 202-211

anaerobic, 176,210

classification of, 208

influence of oxygen tension on, 210 isolation of, 207

numbers of, in soil, 37, 38, 207

Urea, formation of, in the decomposition of proteins, 299

formation of, in the decomposition of uric acid, 212,486

decomposition of, $206,486,487$

nitrate agar, 16

Uredinales, 257

Uric acid, 206, 211, 486, 487

bacteria, 60,211
Urine, bacteria in, 30

Urobacillus, 208, 488

Urobacterium, 209

Urococcus, 208

Urocystis, 811

Uroleptus, 336

Uronema, 335

Urophlyctis alfalfae in soil, 808

Urosarcina, 208

Urostyla, 336

Urotricha, 335

Ustilaginales, 257

Utilization quotient, 416

\section{V}

Vacuum, use in the cultivation os bacteria, 170

Vaginicola, 336

Vampyrella laterita, 331

Variability, of actinomyces, 304 of bacteria in soil, 20

Vaucheria, 228

Vegetable organic matter, composition of, 427

Velvet bean, nodule bacteria of, 136

Vertebrates in soil, $31,342,362$

Verticillium, 254, 258, 260, 265, 278, 812

Vibrio cholerae, 806 denitrificans, 187

thermo-desulfuricans, 189, 611

Vibrion septique, occurrence of, in soils, 173

Vicia, nodule bacteria of, 130, 134, 135,136

Vigna, nodule bacteria of, 135, 136

Vinca minor, mycorrhiza formation by, 277

Virulence of nodule bacteria, 588

Volcanolhrix silicophila, 647

Vorticella, 336

\section{W}

Washed agar media, 70

Water blanks for counting bacteria, 19

Waxes, decomposition of, 463

Waxes in soil, 463, 671

Wheat nematode, 348

Wheel animalcules in soil, 342 
White clover, nodule bacteria of, 136

White sweet clover, nodule bacteria of, 136

Wild indigo, nodule bacteria of, 136

Willia, 251

Wilts in soil, 807

Winter bacteria, 32

Wireworms, 361

Wood residues, influence of, upon plant growth, 518

Wood's clover, nodule bacteria of, 137

Worms in soil, 50, 341

\section{$\mathrm{X}$}

Xanthine in soil, 479,671

Xanthophyll in algae, 215

Xylol, oxidation of, by bacteria, 97,205

\section{Y}

Yeast, as a reducing agent, 171 in soil, 3,11
Yeast, reduction of nitrates by, 181

Yellow sweet clover, nodule bacteria of, 137

Yellow trefoil, nodule bacteria of, 137 Yellows, as influenced by soil environment, 811

\section{Z}

Zigzag clover, nodule bacteria of, 136 Zinc, transformation of, in soil, 666

Zooglea formation by nitrite-forming bacteria, 73

Zygodesmus, 255

Zygogonium, 229

Zygomycetes, 3, 247

Zygorhynchus, 248, 258, 259, 275, 642 mölleri, 260, 275, 379, 444 vuilleminii, 495

Zygospore, isolation of, 246

Zymotic efficiency, 710 




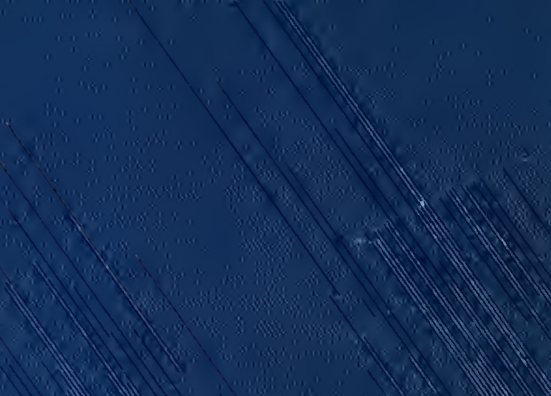
느는

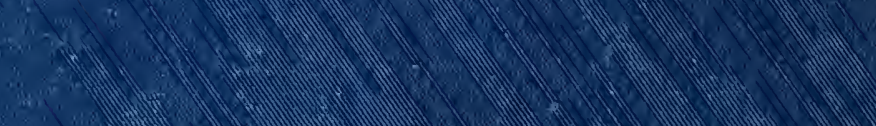
s. 1

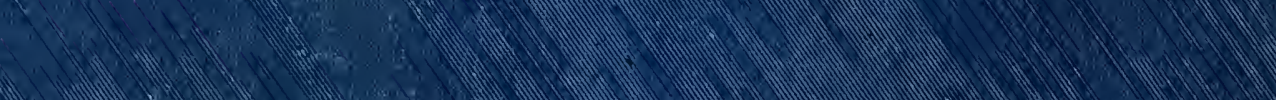
1.

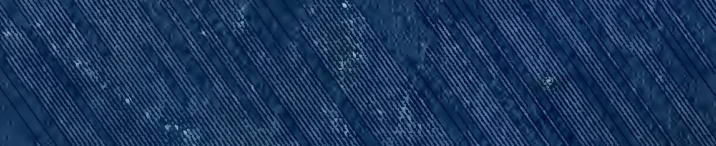

, 1 )

3.

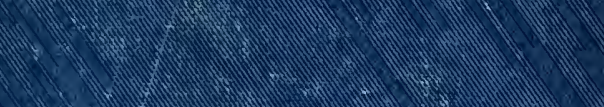
$1 \ldots \ldots \ldots m \ldots$

15) 1 -

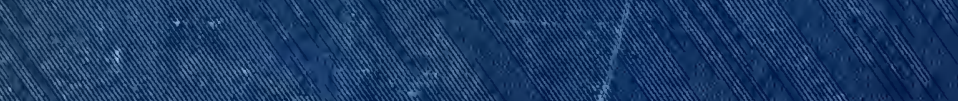
-1)

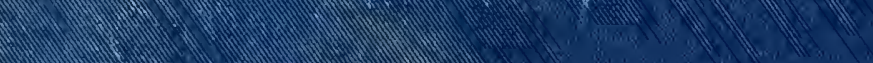
$16+1 / 6)$ $\frac{1}{6}+\frac{1}{2}+\frac{1}{2}$ H. HOH 